\title{
The petrology and genesis of silicic magmas in the Kermadec arc
}

\author{
Simon James Barker
}

A thesis submitted in fulfilment for the degree of Masters of Science in Geology, Victoria University of Wellington, October 2010 


\section{Abstract}

Recent work has shown that silicic volcanism can be abundant in intra-oceanic subduction settings, and is often associated with large explosive caldera-forming eruptions. Several major petrogenetic questions arise over the origin and eruption of large amounts of silicic magma at these relatively simple subduction settings. This study has investigated the geochemistry of pyroclasts collected from four volcanoes along the Kermadec arc, a young ( $<2$ Myr) oceanic subduction zone in the southwest Pacific. Raoul, Macauley and a newly discovered volcano (here informally named 'New volcano') in the northern Kermadec arc, and Healy volcano in the southern Kermadec arc have all erupted dacitic to rhyolitic pumice within the last $10 \mathrm{kyr}$. For Raoul, New volcano and Healy, whole rock major element compositions fall with a limited compositional range. In contrast, pumice dredged from around Macauley caldera covers a wide compositional range indicating that there have been multiple silicic eruptions, not just the Sandy Bay Tephra exposed on Macauley Island. Distinctive crystal populations in both pumice samples and plutonic xenoliths suggest that many of the crystals did not grow in the evolved magmas, but were mixed in from other sources including gabbros and tonalites. Such open system mixing is ubiquitous in magmas from the four Kermadec volcanoes studied here. Silicic magmas, co-eruptive mafic enclaves and previously erupted basalts show sub-parallel REE patterns, and crystal composition and zonation suggests that mafic and silicic magmas have a strong genetic affiliation. Examination of whole rock, glass and mineral chemistry reveals that evolved magmas can be generated at each volcano through $60-75 \%$ crystal fractionation of a basaltic parent. These findings are not consistent with silicic magma generation via crustal anatexis, as previously suggested for the Kermadec arc. Although crystallisation is the dominant process driving melt evolution in the Kermadec volcanoes, the magmatic systems are open to contributions from both newly arriving melts and wholly crystalline plutonic bodies. Such processes occur in variable proportions between magma batches, and are largely reflected by small scale chemical variations between eruption units. Larger scale chemical trends reflect the position of the volcanoes along the arc, which in turn may reflect structural changes in the subduction zone and variations in sediment influx. 


\section{Table of contents}

Title page.

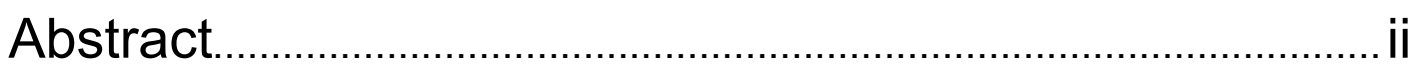

Table of contents

List of figures................................................................................ vii

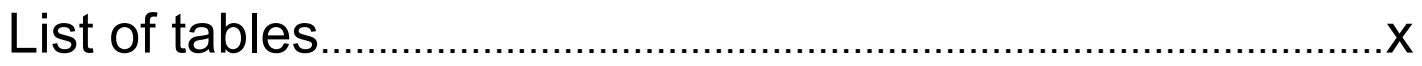

Acknowledgements.......................................................................

Chapter 1: Introduction ..................................................................

Chapter 2: Geological setting......................................................13

Chapter 3: Analytical techniques...................................................27

Chapter 4: Results......................................................................5

Chapter 5: Discussion......................................................................125

Chapter 6: Conclusion ................................................................... 157

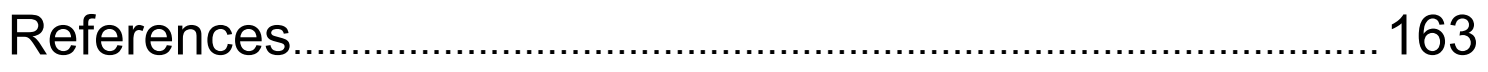

Supplementary information.......................................................... 177

Appendix A: Sample information .................................................. 179

Appendix B: Whole rock major element data.........................187

Appendix C: Whole rock trace element data...........................193

Appendix D: Whole rock $\mathrm{Pb}$ isotope data ................................. 199

Appendix E: Glass major element data .....................................201

Appendix F: Mineral major element data.................................. 209

Appendix G: Mineral trace element data...................................383 


\section{CHAPTER 1: INTRODUCTION}

1.1 Silicic magmas in an ocean-arc setting................................ 2

1.1.1 Petrogenesis of silicic magmas in oceanic arcs....................2

1.1.2 Silicic volcanism in the Kermadec arc.................................. 6

1.2 How to construct large magma bodies................................... 7

1.2.1 Magma crystallisation and evolution..................................... 8

1.2.2 Silicic magma chambers................................................... 9

1.3 Research objectives........................................................... 11

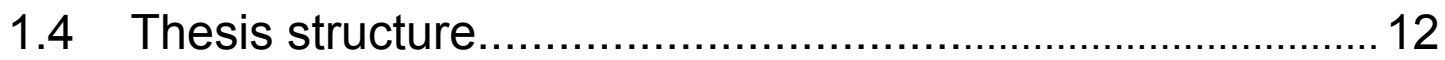

\section{CHAPTER 2: GEOLOGICAL SETTING}

2.1 Regional overview............................................................. 14

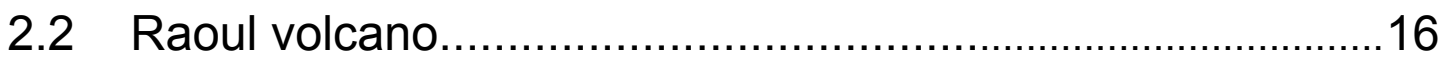

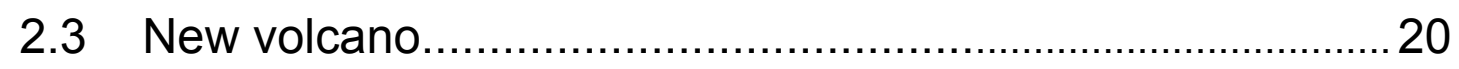

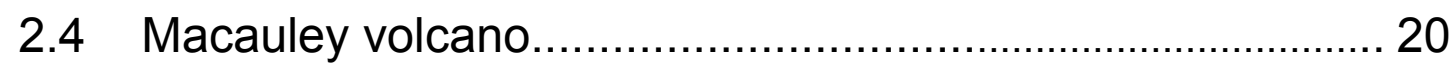

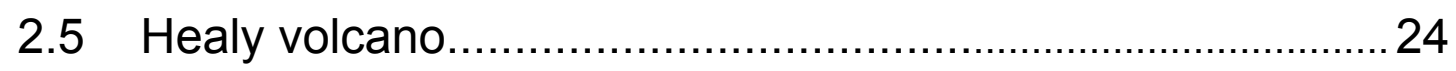

\section{CHAPTER 3: ANALYTICAL TECHNIQUES}

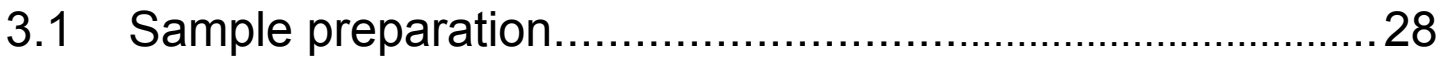

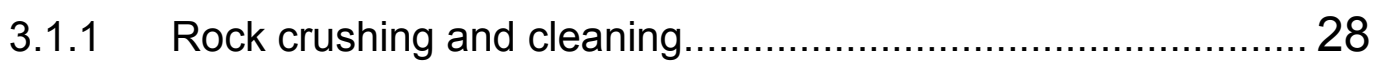

3.1.2 Mineral separation and preparation...................................... 29

3.2 Whole rock major element analysis........................................30

3.2.1 X-ray fluorescence spectrometry........................................... 30

3.2.2 Accuracy and precision of XRF.......................................... 31

3.3 Whole rock trace element and $\mathrm{Pb}$ isotope analysis............. 31

3.3.1 Laboratory protocol............................................................... 31

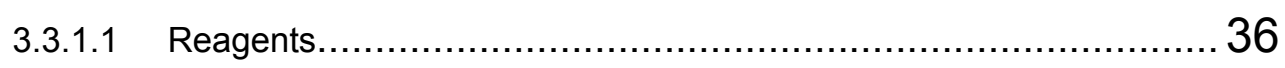

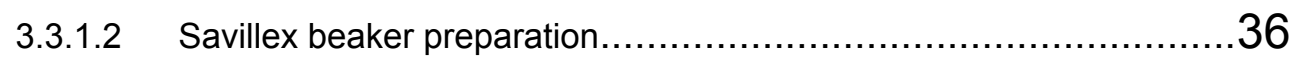

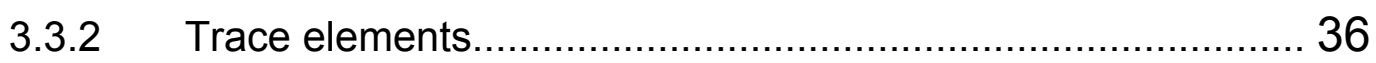

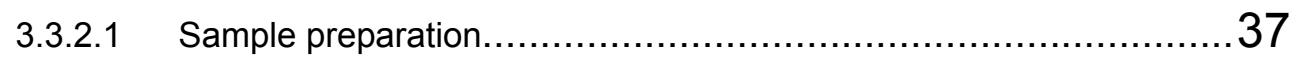

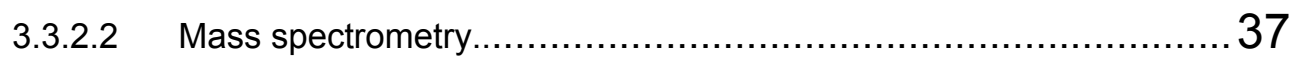


3.3.2.3 Raw data processing and concentration calculations....................39

3.3.2.4 Accuracy and precision of solution ICP-MS analysis................. 40

3.3.3 $\mathrm{Pb}$ isotopes................................................................ 43

3.3.3.1 Sample preparation.......................................................43

3.3.3.2 Pb separation......................................................... 47

3.3.3.3 $\mathrm{Pb}$ isotope analysis.......................................................... 47

3.3.3.4 MC-ICP-MS Accuracy and precision of $\mathrm{Pb}$ isotope analysis............. 49

3.4 Mineral/glass major element analysis................................. 49

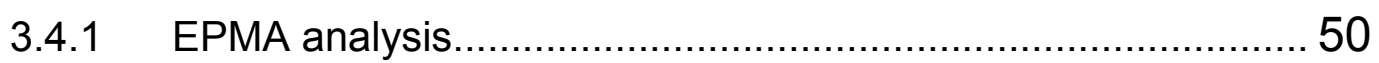

3.4.2 Mineral/glass major element precision and accuracy..............51

3.5 Mineral/glass trace element analysis................................. 51

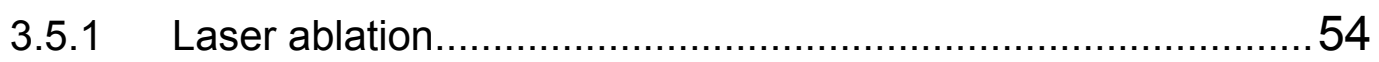

3.5.2 Raw data processing ...................................................... 54

3.5.3 Mineral trace element precision and accuracy...................... 56

\section{CHAPTER 4: RESULTS}

4.1 Sample selection and pumice types....................................58

4.1.1 Raoul samples........................................................ 58

4.1.2 Macauley samples...................................................59

4.1.3 Healy samples................................................................. 61

4.1.4 New volcano samples........................................... 63

4.1.5 Overall variations in major element chemistry......................65

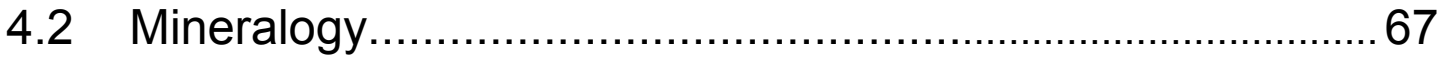

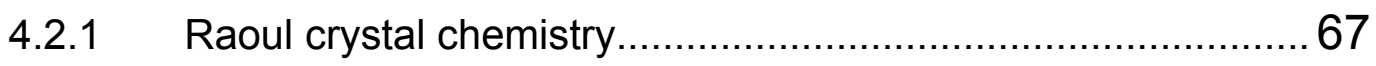

4.2.2 Plutonic xenoliths from the Matatirohia deposit.....................73

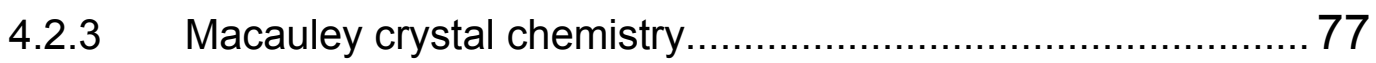

4.2.4 Plutonic xenoliths in the Sandy Bay Tephra.........................83

4.2.5 Healy crystal chemistry .............................................. 83

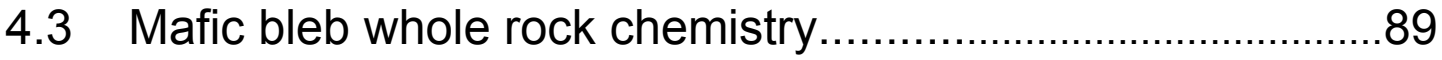

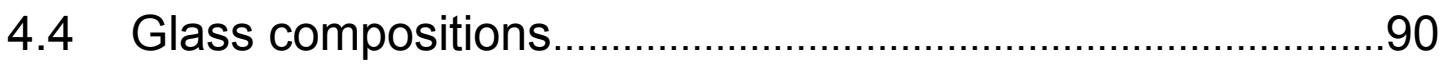

4.5 Whole rock trace element and isotope data..........................96 
4.5.1 Whole rock trace element variations...................................... 96

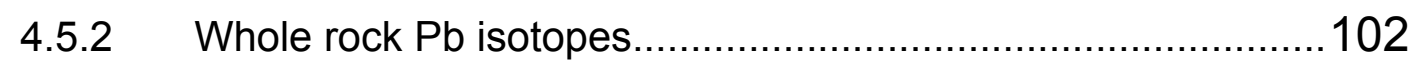

4.6 Mineral trace element data.................................................. 104

4.6.1 Clinopyroxene trace elements.................................................. 104

4.6.2 Plagioclase trace elements................................................. 111

4.6.3 Amphibole trace elements..................................................114

4.7 Intensive parameters and equilibrium calculations.............. 117

4.7.1 Fe-Ti oxide thermo-oxybarometry...................................... 117

4.7.2 Amphibole thermobarometry and hydrometry........................ 119

4.7.3 Mineral-liquid and two-pyroxene equilibrium and thermometry

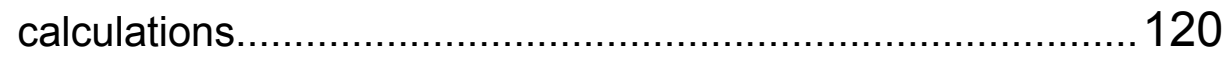

\section{CHAPTER 5: DISCUSSION}

5.1 Magmatic conditions: clues from the crystals........................126

5.1.1 Origins of the observed crystal assemblages.........................126

5.1.2 Compositional zoning: diverse magmatic conditions................131

5.1.3 Calculated equilibrium liquids from mafic xenocrysts...............133

5.2 Petrogenesis of silicic magma in the Kermadec arc..............135

5.2.1 The dominant process: fractional crystallisation or crustal

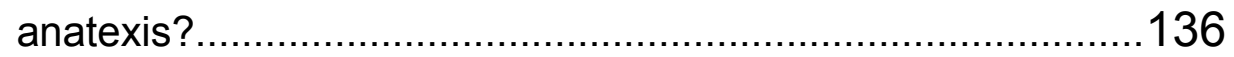

5.2.2 Fractional crystallisation: problems and solutions................... 141

5.3 Implications for Kermadec silicic volcanoes.......................... 147

5.3.1 Magmatic systems of the Kermadec volcanoes....................... 147

5.3.2 Implications for worldwide oceanic arc settings...................... 151

5.4 Along-arc variations in magma chemistry............................ 153

\section{CHAPTER 6: CONCLUSIONS}

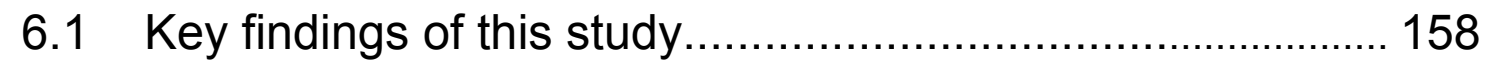

6.2 Suggestions for future work ........................................ 160

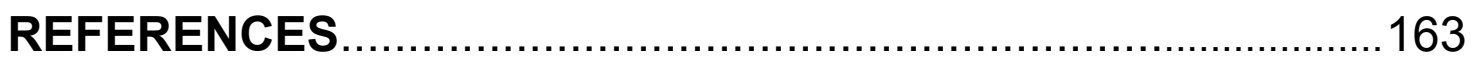




\section{List of figures}

\section{CHAPTER 1: INTRODUCTION}

1.01 Model cross section of an oceanic subduction zone including a flow diagram demonstrating how to generate silicic melts from mantle derived basaltic magma.............................................. 3

1.02 Histogram of rock types erupted from the Kermadec arc.....7

1.03 Schematic diagram of a silicic magma chamber 10

\section{CHAPTER 2: GEOLOGICAL SETTING}

2.01 Tectonic setting of the Tonga-Kermadec arc........................ 15

2.02 Map of Raoul Island and its features...................................17

2.03 Bathymetric map of Raoul volcano and New volcano...........21

2.04 Bathymetric map of Macauley volcano.....................................23

2.05 Bathymetric map of Healy volcano.......................................... 25

\section{CHAPTER 3: ANALYTICAL TECHNIQUES}

3.01 Accuracy of solution ICP-MS analysis............................... 40

3.02 $\mathrm{Pb}$ isotope variations in step-leaching experiment................ 46

3.03 Schematic diagram of $\mathrm{Pb}$ separation procedure .................... 48

\section{CHAPTER 4: RESULTS}

4.01 Raoul whole rock major element variation diagrams............60 60

4.02 Macauley whole rock major element variation diagrams.... 62

4.03 Healy whole rock major element variation diagrams.............64

4.04 Major element variation diagrams for all samples.................66

4.05 Images of representative crystal types from Raoul............... 68

4.06 Images of mafic blebs and crystal clusters from Raoul........ 69

4.07 Compositions of crystals from Raoul eruptive units...............70 
4.08 Lithic types found in the Matatirohia deposit............................ 74

4.09 Compositions of crystals from Raoul xenolith fragments..... 76

4.10 Images of plagioclase crystals from Raoul xenoliths............ 76

4.11 Images of representative crystal types from Macauley........ 78

4.12 Images of mafic blebs and crystal clusters from Macauley. 79

4.13 Images of plutonic lithics from the Sandy Bay Tephra..........79

4.14 Compositions of crystals from Macauley samples.................81

4.15 Images of representative crystal types from Healy................85

4.16 Images of mafic blebs and crystal clusters from Healy........ 86

4.17 Compositions of crystals from Healy samples........................ 87

4.18 Major element variation diagrams of Raoul glass................. 92

4.19 Major element variation diagrams of Macauley glass........... 93

4.20 Major element variation diagrams of Healy glass.................. 94

4.21 Whole rock trace element variations for all four volcanoes..97

4.22 Multi-element diagrams comparing all four volcanoes..........99

4.23 Rare Earth element diagrams comparing all four volcanoes.

4.24 $\mathrm{Pb}$ isotopic compositions of samples from all four volcanoes

4.25 Rare Earth element diagrams of clinopyroxenes. 105

4.26 Clinopyroxene trace element variations in Raoul samples...106

4.27 Images of strongly zoned clinopyroxene from Raoul............ 108

4.28 Clinopyroxene trace element variations in Macauley samples.

4.29 Clinopyroxene trace element variations in Healy samples...110

4.30 Plagioclase trace element variations in Raoul samples....... 112

4.31 Plagioclase trace element variations in Macauley samples

4.32 Plagioclase trace element variations in Healy samples

4.33 Amphibole REE and trace element variations in Healy samples.

4.34 Intensive parameters calculated for samples from Healy and Macauley volcanoes 


\section{CHAPTER 5: DISCUSSION}

5.01 Major element variation diagrams of Raoul mafic blebs compared with previously published whole rock data.

5.02 Calculated liquid REE compositions from clinopyroxene xenocrysts compared with whole rock compositions.

5.03 REE patterns calculated by fractional crystallisation models

5.04 Variation diagrams of $\mathrm{La}$ and $\mathrm{Yb}$ versus $\mathrm{SiO}_{2}$ for all four volcanoes.

5.05 Schematic illustration of the Raoul magmatic system 148

5.06 Stacked frequency histograms comparing the compositional range of eruptive material from worldwide oceanic arc settings

5.07 Schematic cross section of the northern and southern sections of the Kermadec arc.

5.08 Variation diagram of $\mathrm{Nb} / \mathrm{Zr}$ versus $(\mathrm{La} / \mathrm{Sm})_{\mathrm{N}}$ highlighting the differences in mantle depletion along-arc. 156 


\section{List of tables}

\section{CHAPTER 2: GEOLOGICAL SETTING}

2.01 Stratigraphy of Raoul Island.

\section{CHAPTER 3: ANALYTICAL TECHNIQUES}

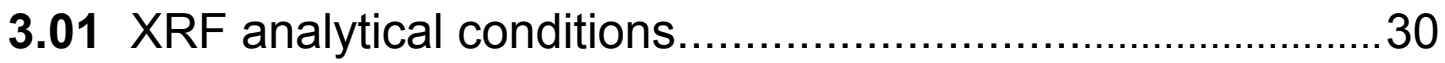

3.02 Precision and accuracy of XRF standard WS-E...................32

3.03 Precision and accuracy of XRF standard G-94 …................ 33

3.04 Repeated measurements of samples analysed by XRF..... 34

3.05 ICP-MS instrumental and analytical conditions...................... 38

3.06 Precision and accuracy of ICP-MS standard BCR-2 .............41

3.07 Precision of ICP-MS standard JR-1 ….............................42

3.08 Repeated analyses of samples by solution ICP-MS............ 44

3.09 Accuracy of MC-ICP-MS standard JB-2 ….......................... 49

3.10 List of standards used for WDS calibration............................. 50

3.11 Precision and accuracy of EPMA clinopyroxene analysis....52

3.12 Precision and accuracy of EPMA orthopyroxene analysis...52

3.13 Precision and accuracy of EPMA plagioclase analysis........ 52

3.14 Precision and accuracy of EPMA olivine analysis................ 52

3.15 Precision and accuracy of EPMA amphibole analysis.........52

3.16 Precision and accuracy of EPMA Fe-Ti oxide analysis........ 53

3.17 Precision and accuracy of EPMA glass analysis................... 53

3.18 LA-ICP-MS instrumental and analytical conditions................55

\section{CHAPTER 4: RESULTS}

4.01 Whole rock major element composition of mafic blebs........ 90

4.02 Calculated temperatures for Kermadec magmas using a range of thermometers 
4.03 Variations in thermometry calculations with changing pressure and water inputs.

\section{APPENDIX A: SAMPLE INFORMATION}

A.1 Sample details and descriptions.

180

\section{APPENDIX B: WHOLE ROCK MAJOR ELEMENT DATA}

B.1 Whole rock major element data. 188

\section{APPENDIX C: WHOLE ROCK TRACE ELEMENT DATA}

C.1 Whole rock trace element data 194

\section{APPENDIX D: WHOLE ROCK Pb ISOTOPE DATA}

D.1 Whole rock $\mathrm{Pb}$ isotope data. 200

\section{APPENDIX E: GLASS MAJOR ELEMENT DATA}

E.1 Glass major element data. 202

\section{APPENDIX F: MINERAL MAJOR ELEMENT DATA}

F.1 Clinopyroxene major element data........................................ 212

F.2 Orthopyroxene major element data............................................ 261

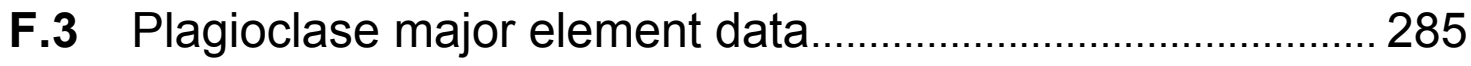

F.4 Olivine major element data..................................................... 342

F.5 Amphibole major element data................................................. 357

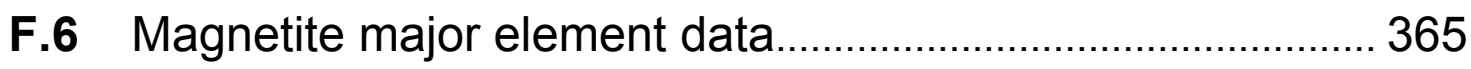

F.7 IImenite major element data .............................................. 379 


\section{APPENDIX G: MINERAL TRACE ELEMENT DATA}

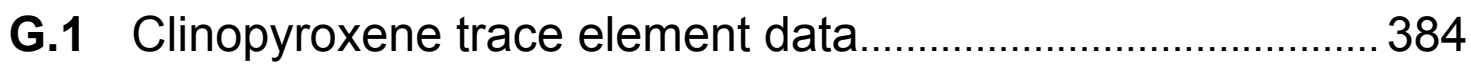

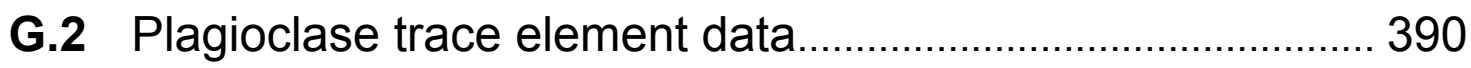

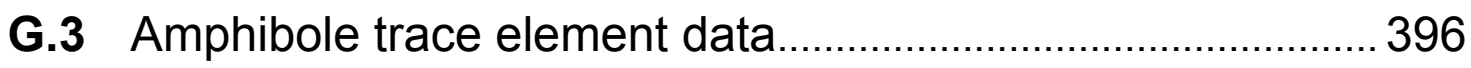




\section{Acknowledgements}

Firstly, I would like to thank my supervisors Prof. Colin Wilson and Prof. Joel Baker for all of their support, I am very grateful for all of the time and effort that you have both dedicated over the past year and a half. Colin, thank you for offering me the opportunity to work on the Kermadecs project, this work would not have been possible without your encouragement, enthusiasm and extra strong coffee. Your passion for volcanology and top quality research is truly inspiring. Joel, thank you for being so welcoming to the whole Auckland crew and for creating such an excellent research environment, I look forward to getting back onto the squash court and back down to the coast for some more summer fishing. I also would like to give special thanks to Richard Wysoczanski for all his advice and support, particularly towards the end of this project. Your comments and willingness to help both Melissa and I has been invaluable, and is greatly appreciated. Marc Alban Millet is also thanked for all of his technical support in the chem lab. Frenchie, your attention to detail and advice was vital for the analytical side of this thesis.

This research was funded by a Marsden grant awarded to Prof. Colin Wilson. Samples were collected by Colin Wilson, Melissa Rotella, Darren Gravely; Max Borella and Mike Rosenburg on R.V. Tangaroa voyages NZAPLUME III (2004) and TAN07/06 (2007). The following people are thanked for their assistance during this project: Stewart Bush for thin section making; John Watson for XRF analysis (Open University) and rock crushing; Stephen Brown for XRF analysis (Canterbury); Kevin Mackay for supplying the ArcGIS files (twice, actually); Andrew Rae for technical support with ArcGIS; John Creech for technical support with microprobe work; Kate Saunders for help with diffusion work and REE pattern modeling and Monica Handler for technical support in the chemistry lab and with $\mathrm{Pb}$ isotope work. Many thanks to the many people in the VGP group who provided valuable discussions and suggestions for this project (usually over a beer or two) including: Aidan Allan, George Cooper, Dave Murphy, Julie Vry, Michael Gazley, Sophie Barton, Sarah Martin, Chelsea Tutt, Alexa Van Eaton.

Thank you to my parents Stephen and Maryrose for your love, support and advice, which always brings be back down to Earth. Philip, thank you for your advice and encouragement, both in life and in champagne selection. And lastly, thank you Melissa for all your love and support, I can't explain in words what you have given me. 


\section{CHAPTER 1: \\ Introduction}




\subsection{Silicic magmas in an ocean arc setting}

The eruption of silicic magma (defined as $>63 \% \mathrm{SiO}_{2}$ for the purposes of this study) is a prominent feature of many continental arc systems. For example, $>90 \%$ of all the magma erupted from the Taupo Volcanic Zone (TVZ) over the past 1.6 Myr has been rhyolitic in composition (Wilson et al., 1995). The genesis of silicic magmas in such settings has often been attributed to a variety of processes, including interaction with the crust by either partial melting of crustal material (e.g. Saito et al., 2007) and/or through fractional crystallisation processes along with assimilation of crustal rocks (e.g. DePaolo, 1981; Graham et al., 1995; Price et al., 2005). In general, continental arc settings provide a complex physical and thermal filter through which rising magmas must ascend. With the crust acting as a density trap, magmas can stall, and undergo differentiation and modification (e.g. Hildreth, 1981). In contrast, the crust in oceanic arc settings is generally thinner, mafic in composition, and rising magmas have less opportunity to stall and differentiate. However, recent work has shown that volcanism involving silicic magma can also be abundant in intra-oceanic subduction settings, and is often associated with large explosive caldera forming eruptions. (Devine, 1995; Lloyd et al., 1996; Worthington et al., 1999; Smith et al., 2003a,b, 2006; Leat et al., 2003; Wade et al., 2005; Shukuno et al., 2006; Vogel et al., 2006a; Wright et al., 2006; Graham et al., 2008; Tani et al., 2008; Tamura et al., 2009). In a relatively simple oceanic subduction setting, the origin and eruption of large amounts of silicic magma presents several major questions from both petrogenetic and volcanological perspectives.

\subsubsection{Petrogenesis of silicic magmas in oceanic arcs}

In oceanic subduction zones, flux melting of the mantle wedge is triggered by dehydration processes in the subducted oceanic lithosphere that is inferred to generate primitive arc magma (Figure 1.01A), which has a bulk composition approximating high-Mg basalt (see Tatsumi and Eggins, (1995) for a summary). As this melt ascends into the overlying oceanic lithosphere it becomes neutrally buoyant, typically around the base of the crust, providing a starting composition from which a spectrum of magmas can be generated (Sisson and Grove, 1993; Grove et al., 2003; Greene et al., 2006). In particular, it has been established that two contrasting end-member processes could potentially generate silicic magmas in intra-oceanic arc settings. One process is of prolonged magmatic differentiation through fractional crystallisation of a high-Mg 


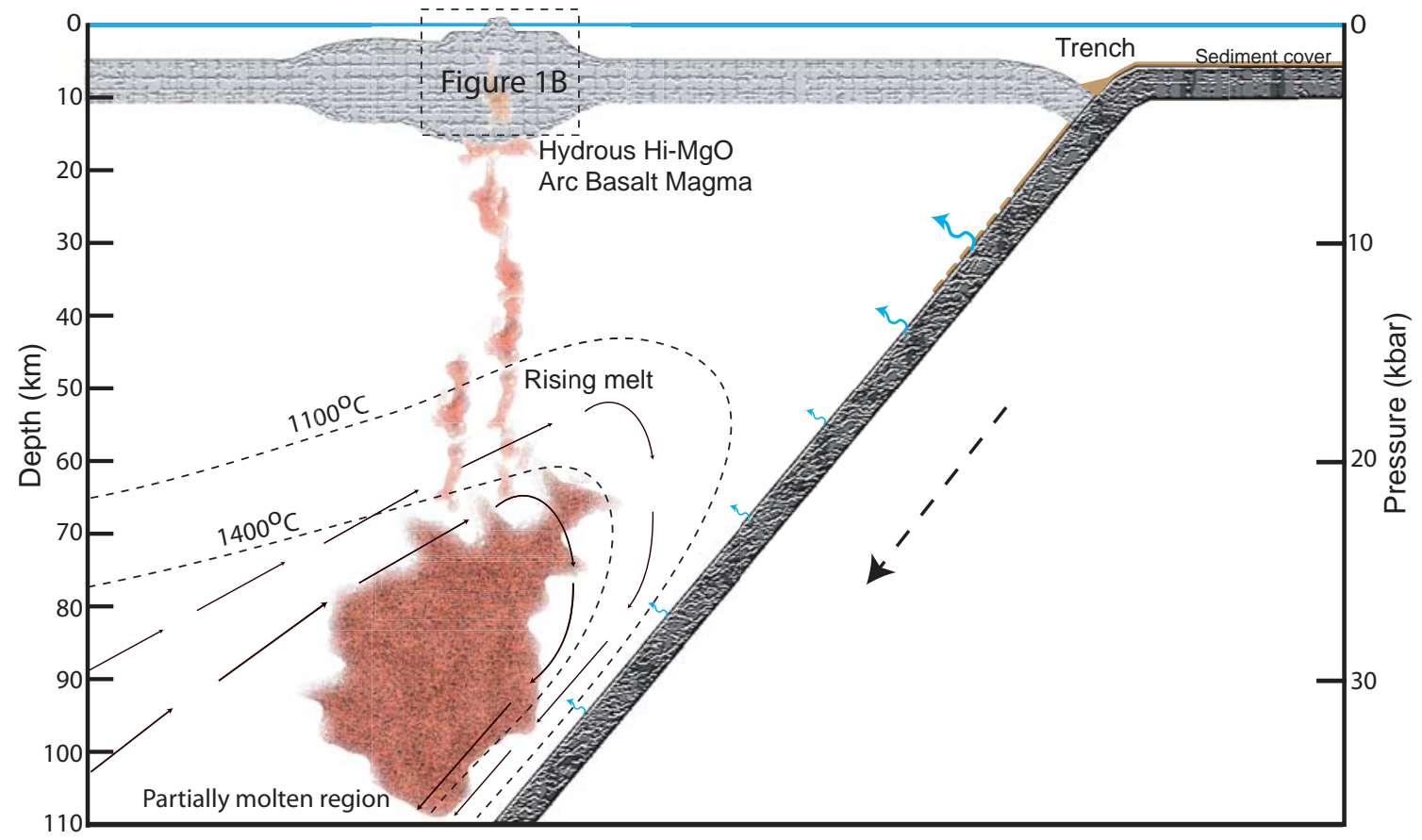

B

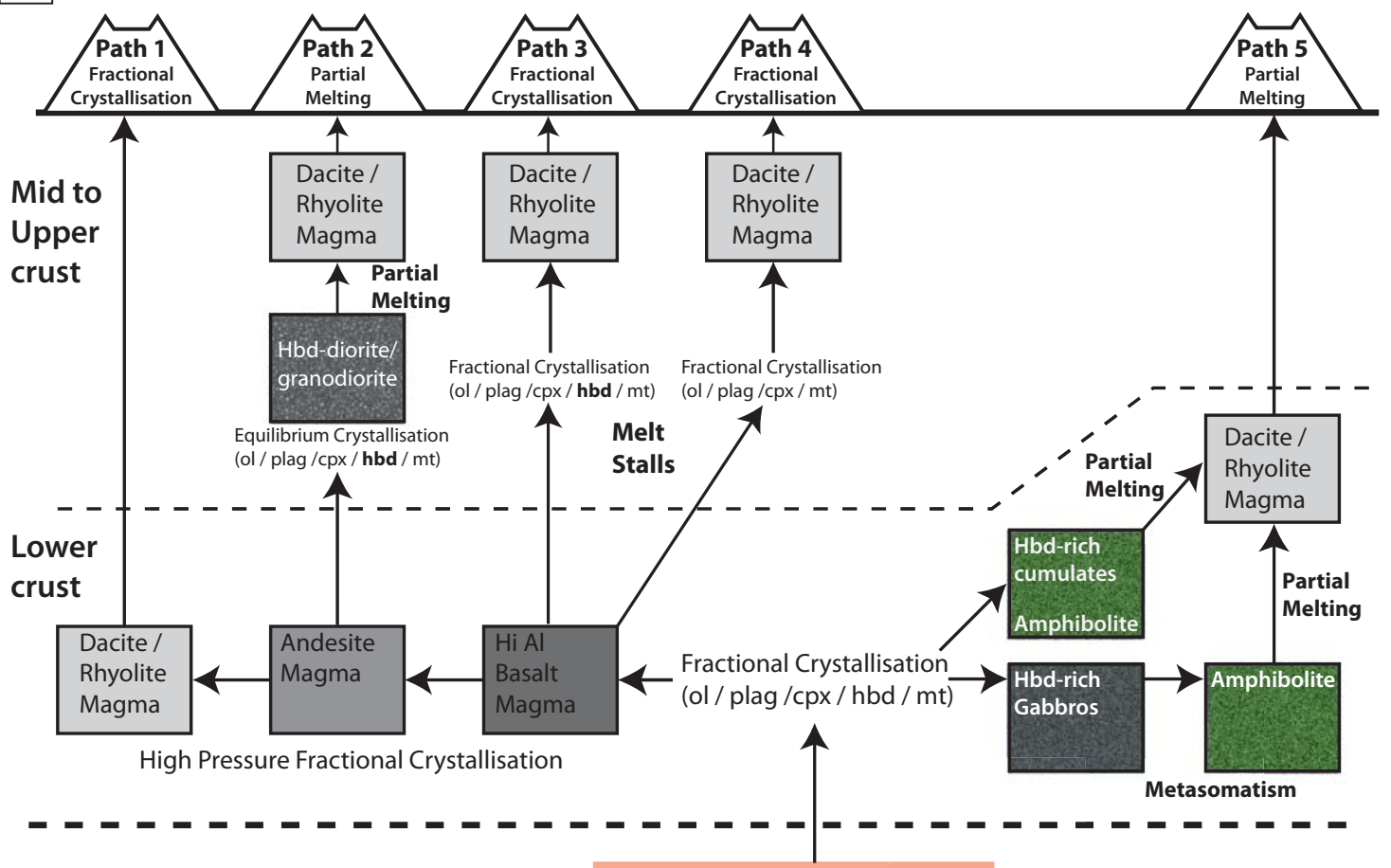

Mantle

Hydrous Hi-MgO

Arc Basalt Magma

Figure 1.01. A) Model cross section of an oceanic subduction zone showing some of the processes that could lead to the generation of subduction zone magmas. Dehydration of minerals in the subducted peridotite, ocean crust and overlying sediments provide water to the overlying mantle wedge over a broad range of depths, indicated by blue arrows. Isotherms indicate the temperature distribution in the wedge overlying the slab (modified from Schmidt and Poli, 1998). B) Schematic flow diagram demonstrating the five possible end-member pathways to generate a silicic melt from an original mantle derived basaltic magma in an intra-oceanic arc setting ( modified from Brophy, 2008). Abbreviations for mineral phases are: ol = olivine; plag = plagioclase; $c p x=$ clinopyroxene; $h b d=$ hornblende; $\mathrm{mt}=$ magnetite . 
basalt primary magma. The other is where the overlying oceanic arc crust is underplated by newly arrived mafic magma and partial melting or melt extraction occurs from previously emplaced mantle-derived intrusions (anatexis).

To illustrate the different processes proposed to generate evolved dacite-rhyolite magmas in an ocean arc setting, Brophy (2008) summarized five potential end-member pathways. All of these pathways start with a mantle derived high $\mathrm{MgO}$ island arc basalt magma that ponds in the lower crust and undergoes high pressure fractional crystallisation (Figure 1.01B). In paths 1, 3 and 4 fractional crystallisation is the dominant process which modifies the melt and can take place at various levels within the oceanic crust (e.g. Sisson and Grove 1993; Devine 1995; Pearce et al., 1995; Grove et al., 2003; Sisson et al., 2005; Wade et al., 2005; Haase et al., 2006). Due to the effects of increasing pressure on hornblende crystallisation temperature (Grove et al., 2003), hornblende fractionation may occur early in the crystallisation path (path 4). In contrast to fractional crystallisation, paths 2 and 5 demonstrate how partial melting of amphibole-bearing intrusions can generate silicic melts. In path 2 the magma undergoes high pressure fractional crystallisation to yield hydrous andesitic magmas which ascend to and stall within the mid to upper crust, crystallising (or partially crystallising) to form a plutonic body of hornblende-rich diorite to granodiorite. Melt extraction, or partial melting of intermediate hornblende-rich rocks by heat transfer from other mantle derived melts, can generate dacite-rhyolite composition magmas (e.g. Tamura and Tatsumi, 2002; Vogel et al., 2004; Shukuno et al., 2006; Tamura et al., 2009). In path 5 high pressure melting of lower crustal mafic amphibolite produces dacite to rhyolite composition magmas (e.g. Leat et al., 2003; Smith et al., 2003a,b, 2006, 2010; Vogel et al., 2006b; Deering et al., 2007). The amphibolites may have originated from either magmatic cumulates generated by high pressure crystallisation of high $\mathrm{MgO}$ basalts (e.g. Greene et al., 2006), or from previously solidified gabbroic magmas that have undergone metasomatism (e.g. Smith et al., 2003a,b, 2006, 2010). Such a scenario of lower crustal melting usually requires a thermal evolution of the oceanic crust through crustal thickening and underplating by fresh mantle-derived melts.

Despite multiple studies which have investigated rhyolite and dacite magmas in diverse oceanic arc settings, the specific details and significance of the two contrasting end-member processes described above are still a matter of considerable interest and debate (Pearce et al., 1995; Tamura and Tatsumi, 2002; Leat et al., 2003; Smith et al., 2003a,b, 2006; Wade et al., 2005; Haase et al., 2006). Much of the problem lies in the ambiguous nature of the petrological and geochemical data which is utilised to 
distinguish crustal melting versus extreme fractional crystallisation in oceanic arcs. In continental arcs, evolved crustal rocks usually have major element, trace element and isotopic signatures that are significantly different to those of mantle derived magmas. Melting of the crustal material in continental arcs (as either contaminant or a primary mechanism to generate a melt) can therefore usually be identified through a crustal signature in the erupted rocks (e.g. elevated ${ }^{87} \mathrm{Sr} /{ }^{86} \mathrm{Sr}$ ratios: Hildreth and Moorbath, 1988). In contrast, the dominant lithologies that make up the lower crust in oceanic arcs are thought to comprise mainly mafic cumulates, gabbros and possibly amphibolite, with chemical and isotopic properties that are very similar to the mantle derived melts from which they originated (Greene et al., 2006). This has made discrimination of crustal melting versus fractional crystallisation in ocean arc settings difficult, and multiple studies of the same arc system have proposed contrasting views (e.g. South Sandwich arc: Pearce et al., 1995 versus Leat et al., 2003; Kermadec arc: Smith et al., 2003a, 2006 versus Haase et al., 2006).

Many studies have suggested that fractional crystallisation alone cannot explain the whole-rock chemical diversity of silicic magmas in oceanic arcs when compared to contemporaneous basaltic or andesitic magmas, and have therefore adopted models of lower to middle crust amphibolite melting for the genesis of silicic melts (e.g. Tamura and Tatsumi 2002; Leat et al., 2003; Smith et al., 2003a,b, 2006, 2010; Vogel et al., 2004; Shukuno et al., 2006). It is important to consider that magmatic systems are subject to open system processes which may have significant effects on the final composition of an erupted magma. It is unlikely that any given magma will move far from its source without some degree of contamination or compositional modification through the addition of material. Contamination of a magma body through assimilation of surrounding (country rock) material may involve a complete spectrum of processes from partial to complete melting of adjacent country rock (e.g. Reiners et al., 1995; Bohrson and Spera, 2001; Thompson et al., 2002), to the physical fragmentation and bulk assimilation of country rocks or xenoliths (e.g. Tindle and Pearce, 1981). Magma mixing may also serve to dramatically change the composition of individual magma bodies (Sparks et al., 1977; Woods and Cowan, 2009), and may or may not be directly observable in the final product erupted at the volcano. Deciphering a single petrogenetic mechanism from a final eruptive product may prove to be very difficult as original geochemical indicators may become overprinted by a complex range of second-stage processes. 


\subsubsection{Silicic volcanism in the Kermadec arc}

The Kermadec arc in the southwest Pacific is a classic example of a relatively young (Quaternary) oceanic arc system (Smith and Price, 2006; Mortimer et al., 2010). Eruptive deposits on small subaerial portions of much larger, mainly submarine volcanoes along the arc indicate that silicic volcanism has occurred along the arc (Brothers and Searle, 1970; Ewart et al., 1977; Lloyd and Nathan, 1981; Smith et al., 1988, 2003a, 2006; Lloyd et al., 1996). It was not until detailed bathymetric mapping of the arc was carried out (Wright, 1994, 1996, 1997, Wright and Gamble, 1999; Wright et al., 2002, 2003, 2006) and sampling of submarine volcanoes recovered large amounts of silicic material (Gamble et al., 1993a; Wright and Gamble, 1999; Haase et al., 2002, 2006; Wright et al., 2003, 2006), that it was recognised that silicic volcanism is quite common and relatively widely distributed along the arc. Like other ocean arc systems (e.g. Izu-Bonin: Tamura and Tatsumi, 2002; South-Sandwich: Leat et al., 2003) erupted magma compositions show a bimodal distribution, with andesitic magmas being relatively minor in volume (Figure 1.02: Wright et al., 2006). The eruption of silicic magmas along the arc has often been associated with caldera collapse and large pyroclastic deposits, suggesting that silicic magma is generated and erupted in large, explosive caldera forming events (Lloyd and Nathan, 1981; Smith et al., 1988, 2003a, 2006; Lloyd et al., 1996; Worthington et al., 1999; Wright and Gamble, 1999; Wright et al., 2003, 2006).

Recent work on the geochemistry of various Kermadec volcanoes has produced contrasting views regarding the genesis of silicic magmas. Smith et al. (2003a,b, 2006, 2010) studied two subaerial volcanoes (Raoul and Macauley, also studied for this thesis) in the northern Kermadec arc and concluded that the silicic magmas erupted there could not be generated through fractional crystallisation of a single basaltic magma. Smith et al. (op. cit.) stated that fractional crystallisation failed to completely explain the observed compositions and variations of the silicic rocks, the compositional gap between basaltic and silicic rocks, the volume of magma erupted and its aphyric nature. Instead, they suggested silicic melts are generated through crustal anatexis, with underplating and dehydration partial melting of lower crustal amphibolite to generate distinctive magma batches. These authors also proposed that the eruption of silicic magmas only occurs in the modern Kermadec arc, inferring that the arc is in an adolescent stage of evolution in which the lower crust has been primed to the appropriate thickness and heat flow to melt. In turn, once the lower crust has undergone 


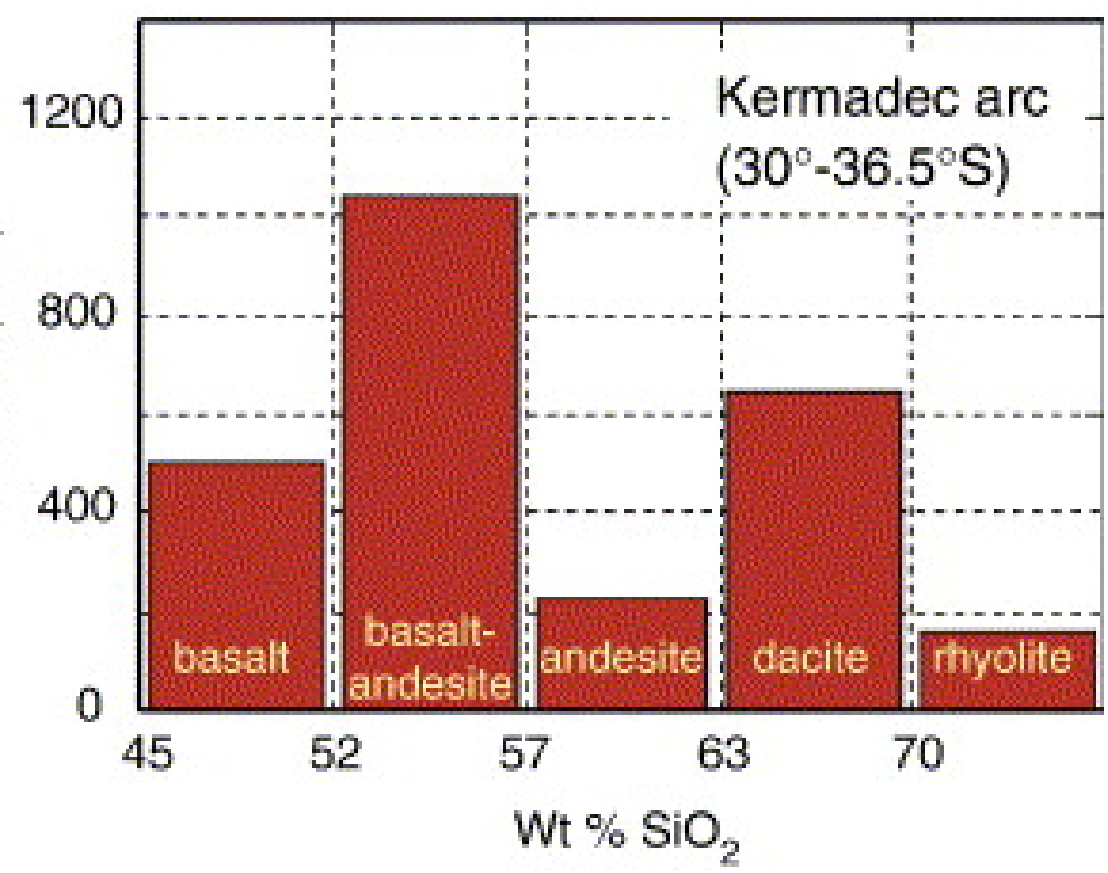

Figure 1.02. Volume weighted $\left(\mathrm{km}^{3}\right)$ histogram of rock types erupted from the $30-36.5^{\circ} \mathrm{S}$ sector of the Kermadec arc (from Wright et al., 2006).

sufficient melt extraction the source may become anhydrous granulite and silicic volcanism will cease. In contrast to this model of crustal anatexis, Haase et al. (2006) suggested that dacite eruptives from Brothers volcano in the southern Kermadec arc were produced by extreme fractional crystallisation of a basaltic parent. In addition, Saunders et al. (2010) used rare earth element (REE) modelling to show silicic melts from Healy volcano in the southern Kermadec arc could be generated through fractional crystallisation. The generation of silicic melts in the Kermadec arc thus remains an open question. Is it a case where one process of silicic magma generation dominates over the other, or does the process vary depending upon the given set of tectonic-magmatic conditions?

\subsection{How to construct large silicic magma bodies}

The presence of large calderas in the Kermadec arc suggests that significant amounts of silicic magma is generated, stored and then erupted in large scale events (e.g. Lloyd et al., 1996; Worthington et al., 1999; Smith et al., 2003b, 2006; Wright et al., 2006; Tani et al., 2008). How large magma bodies are formed beneath such volcanoes requires an understanding of both: a) the transport and evolution of magma through the crust and b) the structure and behaviour of magma chambers. 


\subsubsection{Magma crystallisation and evolution}

One of the most important processes in magmatic systems that can greatly affect both the chemical and rheological properties of magma is crystallisation. The dynamics of magma crystallisation has been studied through experimental petrology (e.g. Hammer, 2008), and through field observations of chemical zonation in solidified Hawaiian lava lakes (e.g. Wright and Okamura, 1977; Helz and Thornber, 1987; Cashman and Marsh, 1988), uplifted exposed crustal sections (Barboza and Bergantz, 2000; Greene et al., 2006) and in exposed plutonic bodies which represent exhumed (fossil) magma chambers (e.g. Miller and Miller, 2002; Marsh, 2004). An important concept developed from such observations is the formation of solidification fronts (Marsh, 1996), which consist of a partially crystalline front separating the molten hot interior of a magma body from the solid surroundings. The growth and erosion of solidification fronts during the transport and storage of magmas plays a major role in magmatic evolution, and may help explain chemical variations in erupted magmas and their associated crystal cargo.

As the degree of crystallinity increases in a magma, either by advancement of the solidification front with time as the magma cools (e.g. Marsh, 1988) or through decompression-induced crystallisation (e.g. Sisson and Grove, 1993; Moore and Carmichael, 1998; Annen et al., 2006; Brophy, 2009), the viscosity and behaviour of the magma body undergoes significant changes (Marsh, 1988, 1996; Vigneresse et al., 1996). Once the crystallinity of a magma reaches a critical threshold ( $>50-60$ vol. $\%$ : Marsh, 1988; Vigneresse et al., 1996), the viscosity increases dramatically and the magma becomes a rigid interlocking network of crystals containing interstitial residual melt. If the magma is allowed to cool further, it will completely crystallise to form a plutonic body (Bachmann et al., 2007). Crystal rich melts, however, may stay partially molten for long periods of time as rates of thermal loss to surrounding rock are slow (Koyaguchi and Kaneko, 1999), and the arrival of new melts can provide both new magma and thermal energy (Murphy et al., 2000; Bachmann et al., 2002).

One of the difficulties in explaining how large silicic magma bodies form through fractional crystallisation by crystal settling (e.g. Bowen, 1928; Martin and Nokes, 1988) is the fact that melt-crystal separation efficiency will decline with increasing melt viscosity, dramatically increasing the amount of time required, and the size of a magma reservoir required to form an evolved silicic melt (Hawkesworth et al., 2000; Eichelberger et al., 2006). Extraction of a liquid from a crystal rich melt overcomes many of these volumetric and time constraints, and has been proposed as the 
dominating process for the formation of high viscosity, generally crystal poor silicic magmas over crystal settling (e.g. Bachmann and Bergantz, 2004; Hildreth, 2004; Eichelberger et al., 2006; Bachmann et al., 2007). In a partially crystallised magma where the magma is rigid but permeability is still high enough that melt can be extracted, separation of liquid from the crystal network may occur. Several mechanisms have been proposed for this, including forceful expulsion of the interstitial melt through either compaction or deformation (e.g. Vigneresse et al., 1996), by solidification front instabilities (Marsh, 1996), or by gas-driven filter pressing (Sisson and Bacon, 1999).

\subsubsection{Silicic magma chambers}

A common feature of continental magmatic systems used to help explain the storage, generation and eruption of large amounts of silicic magma is the crystal mush model (Bachmann and Bergantz, 2004, 2008a; Hildreth, 2004; Glazner et al., 2004; Wilson et al., 2006; Hildreth and Wilson, 2007; Lipman, 2007; Girard and Stix, 2009). The crystal mush model is largely based on links between plutons and volcanic systems including field relationships, temporal-compositional relationships and geophysical observations (Bachmann and Bergantz, 2004; Hildreth, 2004; Marsh, 2004; Bachmann et al., 2007; Lees, 2007). A crystal mush zone consists of rigid or semi-rigid magma comprising a framework of touching crystals and interstitial melt, which can best be described as a rigid sponge (Hildreth, 2004). The formation of crystal mush zones in the upper crust has been proposed as the driving force behind large long-lived silicic systems (e.g. Hildreth, 2004; Wilson et al., 2006; Hildreth and Wilson, 2007), providing sufficient quantities of melt required for even the largest eruptions.

The presence of multiple crystal populations in silicic eruptive units that cannot be derived solely from a single source, along with complex crystal zoning, provides evidence for the recycling of crystals from progenitor melts and/or the remobilization of crystal mush (Davidson et al., 2001, 2007; Bachmann and Bergantz, 2004, 2008a; Charlier et al., 2005; Jerram and Martin, 2008). Convective overturn, along with magma recharge events, may provide heat and new material to different parts of the crystal mush zone, greatly affecting the chemical zonation and overall stability of the magmatic system. Modern concepts of silicic magmatic systems must therefore incorporate not only the molten eruptible material, but also the zones within, around and beneath the magma chamber (termed the magma reservoir: Hildreth and Wilson, 2007; Bachmann and Bergantz, 2008a) (Figure 1.03). The final eruptive sequence can be complicated by 


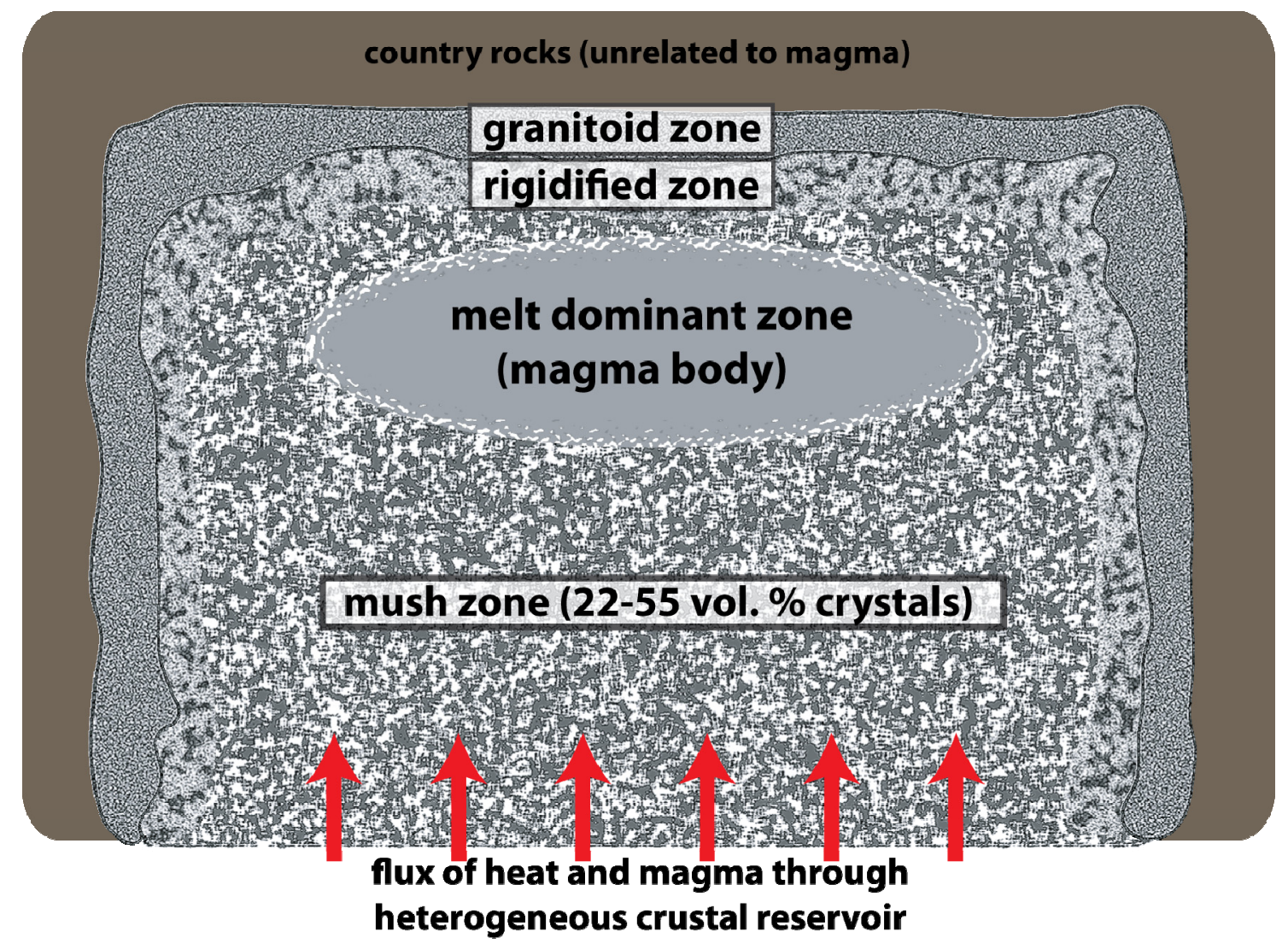

Figure 1.03. Schematic diagram illustrating the zones within, around and beneath a silicic magma chamber. The granitoid zone represents a thick crystallised rind which separates the magma chamber (the areas where melt is present), and remains physically and chemically linked to the melt-bearing zones. Within the melt-bearing zone is a zone of concentrated liquid (the melt dominant zone), which would be partly or completely tapped during a typical eruption. The mush region supplies melt and suspended crystals to the magma body. The region below the mush zone further includes the chamber's feeder zone and the heterogeneous crustal column (consisting of dikes, melt rich pods, and permeable mush zones: Marsh, 2004) from which recharge batches intermittently add to the overlying chamber. The magma system (not fully sketched) would still further include partially molten supply domains in underlying crust and mantle. Modified from Hildreth and Wilson (2007).

the range of constantly changing variables such as magma recharge rate, the amount of mixing between melts and/or mush zones, the amount of wall rock assimilation and the amount/type of crystals which are incorporated into the eruptible melt.

The crystal mush model has been widely applied to large silicic magmatic systems in continental settings, but its possible role in ocean arc settings is largely unexplored. Given the fact that there is generally less vertical room in oceanic crust for magmas to stall and crystallise, and the composition of the crust is generally more primitive, it may be expected that crystal mush regions are less likely to form. The movement and evolution of magma through the crust, however, is not only dependent on the thickness and composition of the crust, but many other factors including the rate of magma input from the mantle (Takada, 1994; Geist et al., 1995; Annen et al., 2006), the local tectonic stress regime (Takada, 1994; Hughes and Mahood, 2008), the rate of 
decompression and crystallisation (Moore and Carmichael, 1998; Annen et al., 2006; Brophy, 2009), and the interaction of new magma with previously emplaced (and possibly crystallised) magmas (Marsh 1988, 2004). Given the right set of conditions, is it possible that crystal mush regions could play a part in the sub-volcanic oceanic arc crust, and help explain the formation of silicic rocks in a simple tectonic setting?

\subsection{Research objectives}

As summarised in the previous sections, the processes involved in the formation of silicic magmas in intra-oceanic arcs are a matter of considerable interest and debate. In particular, recent work on the Kermadec arc has sparked debate as to the mechanism of silicic magma generation along the arc (Smith et al., 2003a,b, 2006, 2010; Haase et al., 2006). In this thesis, samples from four volcanoes along the Kermadec arc have been investigated: Raoul, 'New volcano' (an un-named volcano newly discovered just SW of Raoul), Macauley and Healy, to develop a better understanding of how silicic magmas are generated, stored and erupted in a young intra-oceanic arc setting.

This research has utilised the following techniques:

1) Whole rock major element, trace element and isotopic chemistry on eruptive products collected from the four volcanoes. A comparison and contrast of products from within (i.e. between individual eruptions where they can be distinguished) and between different volcanoes has been carried out to identify any chemical trends or similarities (or lack thereof). These chemical and isotopic data are also compared to previously published work from the three named volcanoes where such data are available.

2) Major and trace element chemistry on crystals from representative eruptive products to determine the pre-eruptive conditions and evolution of the magmatic systems below each volcano. In particular, crystal zones and different crystal populations are used to identify the different magma sources and processes which may have contributed to the magmatic diversity.

3) The major element chemistry of glasses from representative pumice samples to compare with whole rock major element chemistry, and investigate the effects of magma mixing and/or assimilation. 


\subsection{Thesis structure}

This thesis is presented in six chapters.

Chapter 1) Introduction: An overview of silicic volcanism in oceanic arcs, how silicic magmas are stored and erupted, and a general introduction to the objectives of this thesis.

Chapter 2) Geological Setting: A background to the Kermadec arc and the four volcanoes which are investigated in this thesis. The details of sample collection are also given to provide constraints on exactly what material was analysed in this study.

Chapter 3) Analytical Techniques: A description of the methods used to obtain the geochemical data in this thesis. This also includes a complete presentation of analytical standards which are used to constrain the accuracy and precision of each technique.

Chapter 4) Results: Presents key results obtained from this study. As several different types of geochemical data have been obtained, this section is split into several sections according to data type.

Chapter 5) Discussion: An interpretation of the results, relating them to various magmatic processes. A comparison is made with previous work on the Kermadec volcanoes and on other similar studies on worldwide oceanic arcs.

Chapter 6) Conclusions: A summary of the key findings of this study and recommendations for future work not covered in this thesis.

References: A complete list of all the references cited in this thesis. The reference style used in this thesis follows that of the Journal of Petrology.

Supplementary Information: A series of seven appendices (labelled A-G) including all chemical and isotopic data collected in this project, as well as a list of sample details. 


$$
\text { CHAPTER 2: }
$$

\section{Geological Setting}




\subsection{Regional overview}

Associated with Pacific-Australian intra-oceanic plate convergence along the TongaKermadec subduction system, the Tonga-Kermadec arc is a chain of volcanoes that stretch ca. $2500 \mathrm{~km}$ northeast from the North Island of New Zealand (Figure 2.01). The current Tonga-Kermadec subduction zone is a relatively young system which stabilised around $2 \mathrm{Ma}$ (Mortimer et al., 2010), with evidence for an older arc system represented by the Colville-Lau Ridge system, which runs parallel to the west of the active TongaKermadec ridge (Figure 2.01). Relative convergent rates along the Tonga-Kermadec subduction system increase northwards with distance from the Pacific-Australian pole of rotation (Wallace et al., 2009). More rapid convergence occurs at the northernmost part of the Tongan subduction system with considerably slower subduction occurring towards the southern Kermadec arc (Figure 2.01) where the trench shallows and there is a transition into the Hikurangi Trough and the continental subduction system (Gamble et al., 1993a). Subduction of the Pacific Plate into the Tonga-Kermadec trench is accompanied by eastward rollback of the trench axis, accommodated as back-arc spreading and rifting in the Lau Basin and Havre Trough (Wright, 1993; Delteil et al., 2002; Ruellan et al., 2003; Todd et al., 2010; Wysoczanski et al., 2010). As one of the youngest examples of an intra-oceanic arc system on Earth, the Tonga-Kermadec arc has been a key location for testing new ideas on magmatic and tectonic processes in the subduction zone factory (for a review see Smith and Price, 2006).

The intersection of the prominent Louisville Ridge of seamounts with the Tonga-Kermadec Trench at $25.6^{\circ} \mathrm{S}$ separates the Tonga and Kermadec segments of the arc system (Figure 2.01). The ca. $1200 \mathrm{~km}$ Kermadec portion of the arc which is the focus of this study, consists dominantly of submarine volcanoes, with only the volcanoes Raoul, Macauley, Curtis and L'Esperance, between ca. $29^{\circ}$ and $31^{\circ} \mathrm{S}$, being partially emergent. Detailed bathymetric surveys and multibeam mapping has shown that there is considerable variation in volcano-tectonic structure along the length of the Kermadec arc (Wright, 1997; Wright et al., 2006). Steepening of the subducting slab towards the north (Reyners, 1989) causes a decrease in the distance from the arc front to trench from ca. $300 \mathrm{~km}$ at $37^{\circ} \mathrm{S}$ to ca. $185 \mathrm{~km}$ at $32^{\circ} \mathrm{S}$, north of which a near constant separation is maintained (Wright, 1997). The ridge between $37^{\circ} \mathrm{S}$ to $32^{\circ} \mathrm{S}$ is also relatively narrow, with the active volcanic front located to the west. In contrast, the ridge from $32^{\circ} \mathrm{S}$ to $25.6^{\circ} \mathrm{S}$ is wider with the active volcanic front on or near the ridge crest. The nature of the material being subducted also changes significantly along the 


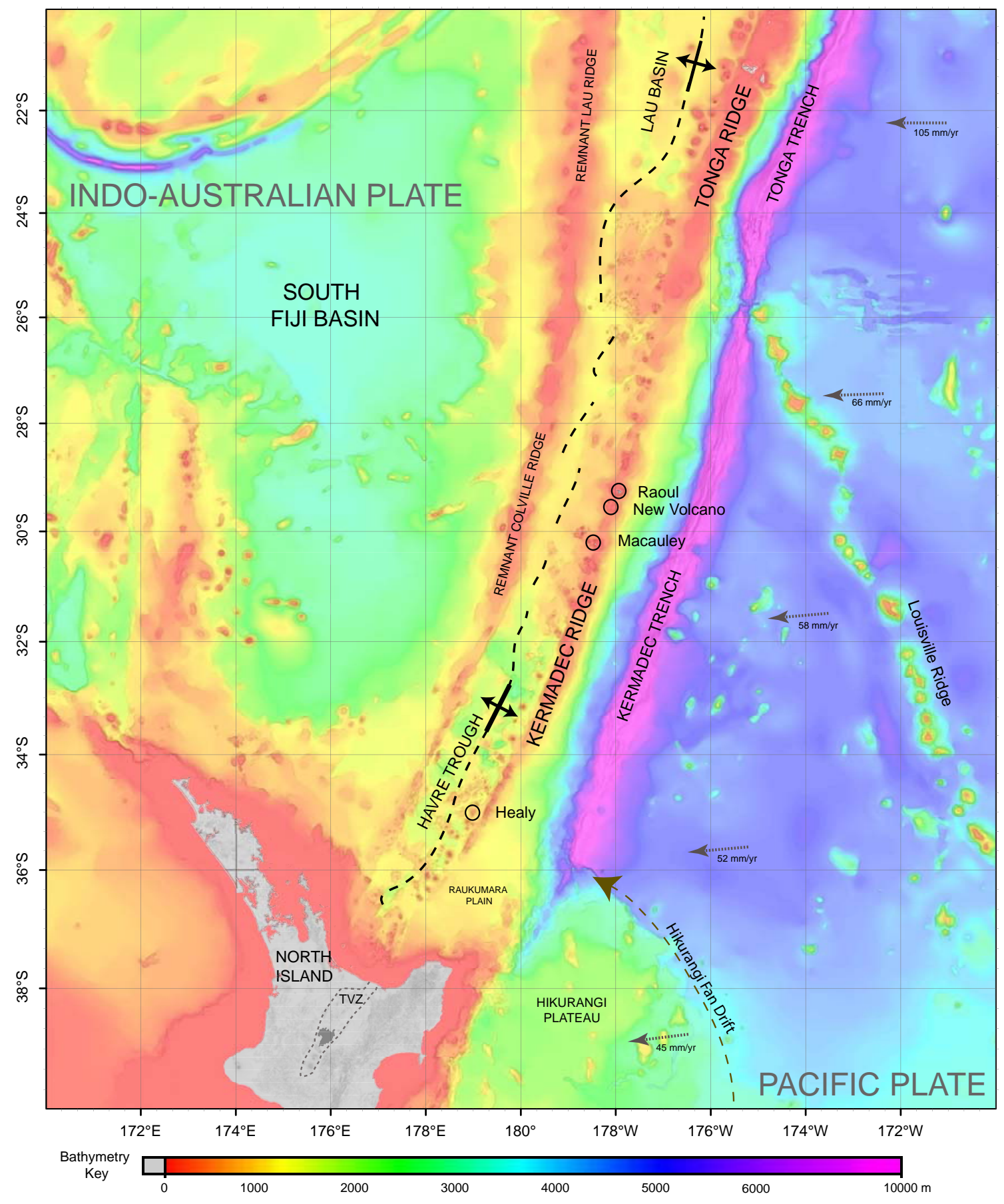

Figure 2.01. Regional tectonic setting of the Tonga-Kermadec arc system. Relative Pacific-Australian plate motions (mm/yr) shown by arrows are from Wallace et al. (2009) after DeMets et al. (1994). Spreading axis marked by black dashed line in the Havre Trough and Lau Basin is from Wysoczanski et al. (2010). Modern Taupo Volcanic Zone (TVZ) outline is taken from Wilson et al. (1995). The direction of sediment drift ('Hukurangi Fan Drift') is taken from Carter et al. (1996). The four volcanoes investigated in this study are marked by open circles. 
length of the Kermadec arc (Castillo et al., 2009). The southern Kermadec trench is closer to the New Zealand landmass with considerably more sediment input from the Hikurangi fan drift (Carter et al., 1996), reflected in the isotopic characteristics of the arc and back-arc lavas (Gamble et al., 1996; Haase et al., 2002; Todd et al., 2010).

Despite being an intra-oceanic arc setting, silicic volcanism $\left(\mathrm{SiO}_{2}>63\right.$ wt. \%) is surprisingly common in the young records of many Kermadec volcanoes (Lloyd and Nathan, 1981; Lloyd et al., 1996; Worthington et al., 1999; Smith et al., 2003a, 2006, 2010; Wright et al., 2006; Graham et al., 2008). Silicic magmas have been estimated to contribute ca. $30 \%$ by volume of the erupted products south of ca. $30^{\circ} \mathrm{S}$ (Figure 1.02), and tend to be restricted to areas of higher-standing thickened arc crust (Wright et al., 2006). The 2004 and 2007 research voyages of the R.V. Tangaroa (NZAPLUME III and TAN0706, respectively) along the Kermadec arc sampled the eruptive products of the four volcanoes investigated in this thesis. Three of these volcanoes; Healy, Macauley and Raoul (Figure 2.01), have erupted similar silicic magmas within the last $10 \mathrm{kyr}$, generating large explosive eruptions and associated with caldera collapse (Lloyd and Nathan, 1981; Smith et al., 1988, 2003a, 2006; Lloyd et al., 1996; Worthington et al., 1999; Wright et al., 2003, 2006). In addition, dredged silicic pumice of unknown age but exceptional freshness was also recovered from a fourth unnamed volcano, just southwest of Raoul Island, that is referred to here as 'New volcano'. These four volcanoes present a unique opportunity to study silicic magmatism in an ocean arc setting as they vary in position along the arc, not only permitting investigation into the petrogenesis of silicic magmas, but also allowing comparisons to be made in the geochemical variability of silicic magmas over a significant length of the Kermadec arc (Figure 2.01). A brief summary of each volcano follows and a full sample list, along with descriptions of each sample is presented in Appendix A.

\subsection{Raoul volcano}

Raoul volcano is the northernmost of the emergent volcanoes in the Kermadec arc (Figure 2.01). Its $30 \mathrm{~km}^{2}$ subaerial expression, Raoul Island, is only a small portion of a much larger $>200 \mathrm{~km}^{3}$ volcano which rises $900 \mathrm{~m}$ from its base on the Kermadec ridge (Lloyd and Nathan, 1981; Worthington et al., 1999; Smith et al., 2003b). Raoul Island incorporates two adjacent collapse structures, Raoul and Denham calderas (Figure 2.02) which are both slightly elongated in a NE-SW direction, perpendicular to the extension axis in the Kermadec Arc (Worthington et al., 1999; Campbell et al., 2007). Raoul 


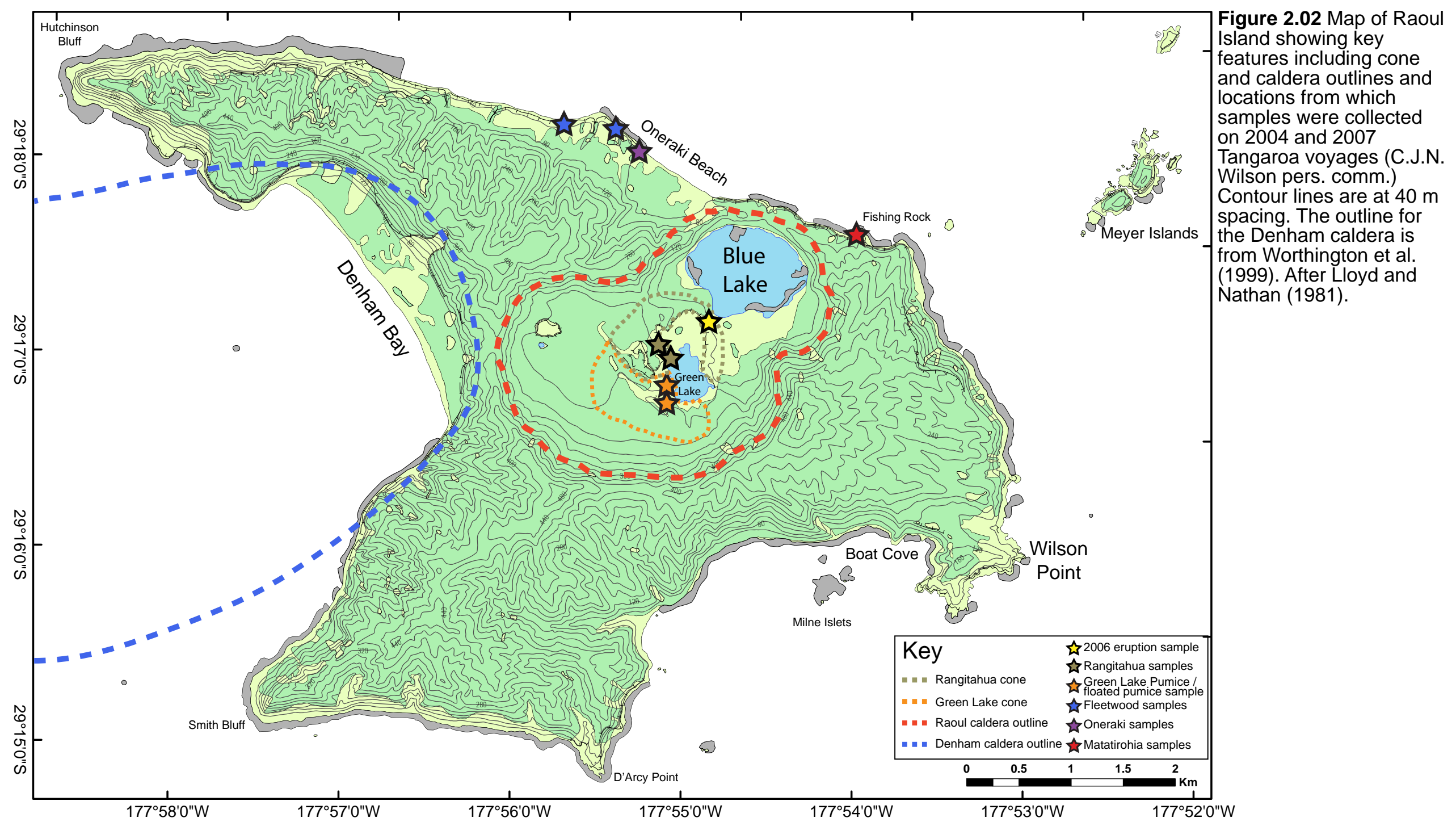


caldera is approximately $3 \times 2 \mathrm{~km}$ in size, occupies the central part of the island and contains the Blue Lake, Green Lake and Tui Lake craters (Figure 2.02). The dominantly submarine Denham Caldera abuts the western margin of Raoul Island, and occupies approximately $6.5 \times 4 \mathrm{~km}$ and has a depth of $>300 \mathrm{~m}$ (Figure 2.02: Worthington et al., 1999). Although the subaerial edifice of Raoul volcano was formed by early eruptions of predominantly basaltic and basaltic andesite magmas, the last 4000 yrs have produced mainly dacitic eruptions associated with caldera collapse (Lloyd and Nathan, 1981; Smith et al., 2006). Raoul volcanic stratigraphy was described by Lloyd and Nathan (1981) and is summarized in Table 2.01.

The Matatirohia and Oneraki eruptions dated at 3700 and $3150{ }^{14} \mathrm{C}$ years ago, respectively, represent the first silicic eruptions preserved within the eruptive stratigraphy of Raoul Island (although a tonalite beach boulder from Matatirohia eruption lithic-rich breccias has been dated at 1.25 $\pm 0.06 \mathrm{Ma}$ : Mortimer et al., 2010). These eruptions are thought to have formed the modern day outline of Raoul caldera (Figure 2.02: Lloyd and Nathan, 1981), and although volume estimates have not been carried out, the eruptions are associated with widespread pumice fall deposits and lithicrich pyroclastic density current (pdc) deposits. The largest silicic deposit represented on Raoul Island is from the Fleetwood eruption $2200{ }^{14} \mathrm{C}$ years ago (Lloyd and Nathan, 1981). Worthington et al. (1999) speculated that the Denham caldera was formed during this event, and estimated a minimum erupted magma volume of $8-16 \mathrm{~km}^{3}$ on the basis of caldera reconstruction. Eruptive products from these three large, sheet-forming (subplinian to plinian) fall deposits of these eruptions were collected from coastal exposures around Raoul Island (Figure 2.02), and are included in this study. Subsequent silicic eruptions from Raoul have been smaller in volume, and predominantly consist of bedded pumice fall deposits (Lloyd and Nathan, 1981; Smith et al., 2006). The Green Lake Pumice $\left(1400{ }^{14} \mathrm{C}\right.$ years ago) and the Rangitahua $\left(370{ }^{14} \mathrm{C}\right.$ years ago $)$ eruptions produced pumiceous dacite deposits, almost entirely confined within the Raoul caldera (Figure 2.02). Samples from these two eruptions were collected, along with a newly discovered unit consisting of floated pumice blocks incorporated in lake sediments below the Green Lake Pumice deposit (C.J.N. Wilson, pers. comm.).

Eruptive activity following the Rangitahua eruption is dominated by phreatomagmatic explosions within the modern day Raoul caldera (Table 2.01), and small eruptions which built short-lived islands in Denham caldera (Healy et al., 1965; Lloyd and Nathan, 1981; Worthington et al., 1999). Graaf (2006) found a juvenile component in the 1964 eruption breccias within Raoul caldera (indicated by its fresh 
Table 2.01. Stratigraphy of Raoul Island modified from Worthington et al. (1999) after Lloyd and Nathan (1981) and C.J.N. Wilson (pers. comm.). The underlined and bold eruption names are those studied in this thesis.

\begin{tabular}{|c|c|c|c|}
\hline Formation & $\begin{array}{c}\text { Age } \\
\left({ }^{14} \mathrm{C} \mathrm{ka}\right)\end{array}$ & $\begin{array}{l}\text { Vent } \\
\text { Location }\end{array}$ & Eruption Description \\
\hline \multicolumn{4}{|l|}{ Ngaio Group } \\
\hline 2006 Breccia & & Raoul caldera & Phreatomagmatic \\
\hline 1964 Breccia & & Raoul caldera & Phreatomagmatic \\
\hline 1870 Breccia & & Raoul caldera & Phreatomagmatic \\
\hline Smith Breccia & 0.19 & Raoul caldera & Phreatic \\
\hline Tui Breccia & $(0.28)$ & Raoul caldera & Phreatic \\
\hline Sentinel & 0.28 & Denham caldera & Small pumiceous dacite \\
\hline Rangitahua & 0.37 & Raoul caldera & $\begin{array}{l}\text { Small pumiceous dacite, initial phreatic activity, } \\
\text { pyroclastic cone }\end{array}$ \\
\hline Meyer & $(0.5)$ & Meyer Islands & Small scoriaceous basaltic andesite \\
\hline $\begin{array}{l}\text { Expedition } \\
\text { Breccia }\end{array}$ & 1.1 & Raoul caldera & Phreatic \\
\hline $\begin{array}{l}\text { Pukekohu } \\
\text { Breccia }\end{array}$ & $(1.25)$ & Raoul caldera & Phreatic \\
\hline \multicolumn{4}{|r|}{ 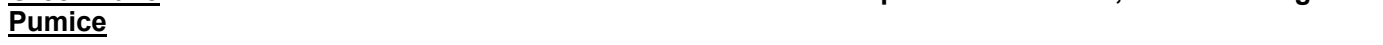 } \\
\hline Floated Pumice & $>1.4$ & Raoul caldera & $\begin{array}{l}\text { Dacite pumice in lake sediments, floated from crater } \\
\text { lake dome }\end{array}$ \\
\hline Rayner & $(1.55)$ & Raoul caldera & Small pumiceous dacite \\
\hline Judith & $(1.85)$ & Raoul caldera & Medium scoriaceous basaltic andesite \\
\hline Bell & $(2.05)$ & Denham caldera & Small pumiceous dacite \\
\hline Fleetwood & 2.2 & $\begin{array}{l}\text { Denham } \\
\text { caldera }\end{array}$ & $\begin{array}{l}\text { Voluminous pumiceous dacite, fall deposits, } \\
\text { pyroclastic flows }\end{array}$ \\
\hline Oneraki & 3.15 & Raoul caldera & $\begin{array}{l}\text { Large pumiceous dacite, fall deposits, pyroclastic } \\
\text { flows }\end{array}$ \\
\hline Matatirohia & 3.7 & Raoul caldera & $\begin{array}{l}\text { Large pumiceous dacite, fall deposits, pyroclastic } \\
\text { flows }\end{array}$ \\
\hline \multicolumn{2}{|c|}{ Older Formations } & \multicolumn{2}{|l|}{ Description } \\
\hline Moumoukai & $(4-10)$ & \multicolumn{2}{|c|}{$\begin{array}{l}\text { Basaltic andesite flows and pyroclastic deposits. Formed a strato-cone near } \\
\text { Raoul caldera }\end{array}$} \\
\hline Hutchison & $(50-100)$ & \multicolumn{2}{|c|}{$\begin{array}{l}\text { Basaltic andesite flows, debris flows, fall and pyroclastic flow deposits. Built a } \\
\text { strato-cone near the present site of Denham caldera }\end{array}$} \\
\hline D’Arcy & $(100-200)$ & \multicolumn{2}{|c|}{ Basalt and basaltic andesite flows with inter-bedded pyroclastic deposits. } \\
\hline Boat Cove & $600-1400$ & \multicolumn{2}{|c|}{$\begin{array}{l}\text { Pillow basalt, hyaloclasite and calcareous sediments. Possibly formed } \\
\text { stratocones. }\end{array}$} \\
\hline
\end{tabular}

Ages for Ngaio Group tephras determined by ${ }^{14} \mathrm{C}$ age dating and for Boat Cove Formation using K-Ar age dating (Lloyd and Nathan, 1981). Ngaio Group ages in brackets were determined allowing for palaeosol thickness between known ${ }^{14} \mathrm{C}$ age determinations (Lloyd and Nathan, 1981). 
appearance, prismatic jointing and chilled margins), suggesting that the 1964 eruption was triggered by a magma intrusion at shallow levels. A smaller, but similar style eruption occurred in 2006, forming breccia deposits dominated by lake sediment and recycled material from previous eruption deposits (C.J.N. Wilson, pers. comm.). A single pumice clast from the 2006 eruption deposits that is inferred to represent juvenile magma on the basis of its exceptionally fresh appearance (C.J.N. Wilson, pers. comm.), was collected in 2007 and is included in this study.

\subsection{New volcano}

EM300 multibeam mapping of the submarine area around Raoul Island was carried out during the TAN0706 voyage (Figure 2.03A). This mapping indentifed two previously unknown calderas to the northwest and southwest of Raoul Island. The northwestern volcano has a caldera diameter of ca. $4 \mathrm{~km}$ with a $1000 \mathrm{~m}$ high caldera wall. The southwestern volcano has a caldera diameter of ca. $4 \mathrm{~km}$, with a caldera floor depth of ca. $1200 \mathrm{~m}$ and caldera walls reaching ca. $500 \mathrm{~m}$ high (Figure 2.03A,B). Rock dredging of the northwestern caldera recovered no analysable material, but dredging of the southwestern caldera volcano recovered a large suite of fresh pumice clasts, some of which were analysed for this study. The pristine morphology of the southwestern volcano and extremely fresh glassy appearance of the recovered pumice suggests that it has been a site of recent volcanism, comparable in age to other materials analysed here. No formal name has been given to this eruptive centre and it is informally labelled 'New volcano' for the purpose of this study.

\subsection{Macauley volcano}

Macauley Island is the second largest island of the Kermadec group, located ca. $100 \mathrm{~km}$ southwest of Raoul Island (Figure 2.01). Macauley Island is the $3 \mathrm{~km}^{2}$ emergent portion of the much larger submarine Macauley volcano, which spans ca. $380 \mathrm{~km}^{2}$ at the $900 \mathrm{~m}$ isobath (Lloyd et al., 1996). The steep cliff sections of Macauley Island rise to a height of $>200 \mathrm{~m}$ above sea-level, providing a partial record of the eruptive history of the volcano, described by Brothers and Martin (1970) and reviewed by Lloyd et al. (1996). The oldest rocks observed on Macauley Island are the North Cliff ' $a$ ' $\bar{a}$ lava flows and the Boulder Beach Formation basaltic tephra deposits. Lloyd et al. (1996) interpreted these basaltic formations and a series of younger Annexation Basalt lavas as recording the building of a larger, now mostly destroyed, subaerial basaltic shield volcano. The 

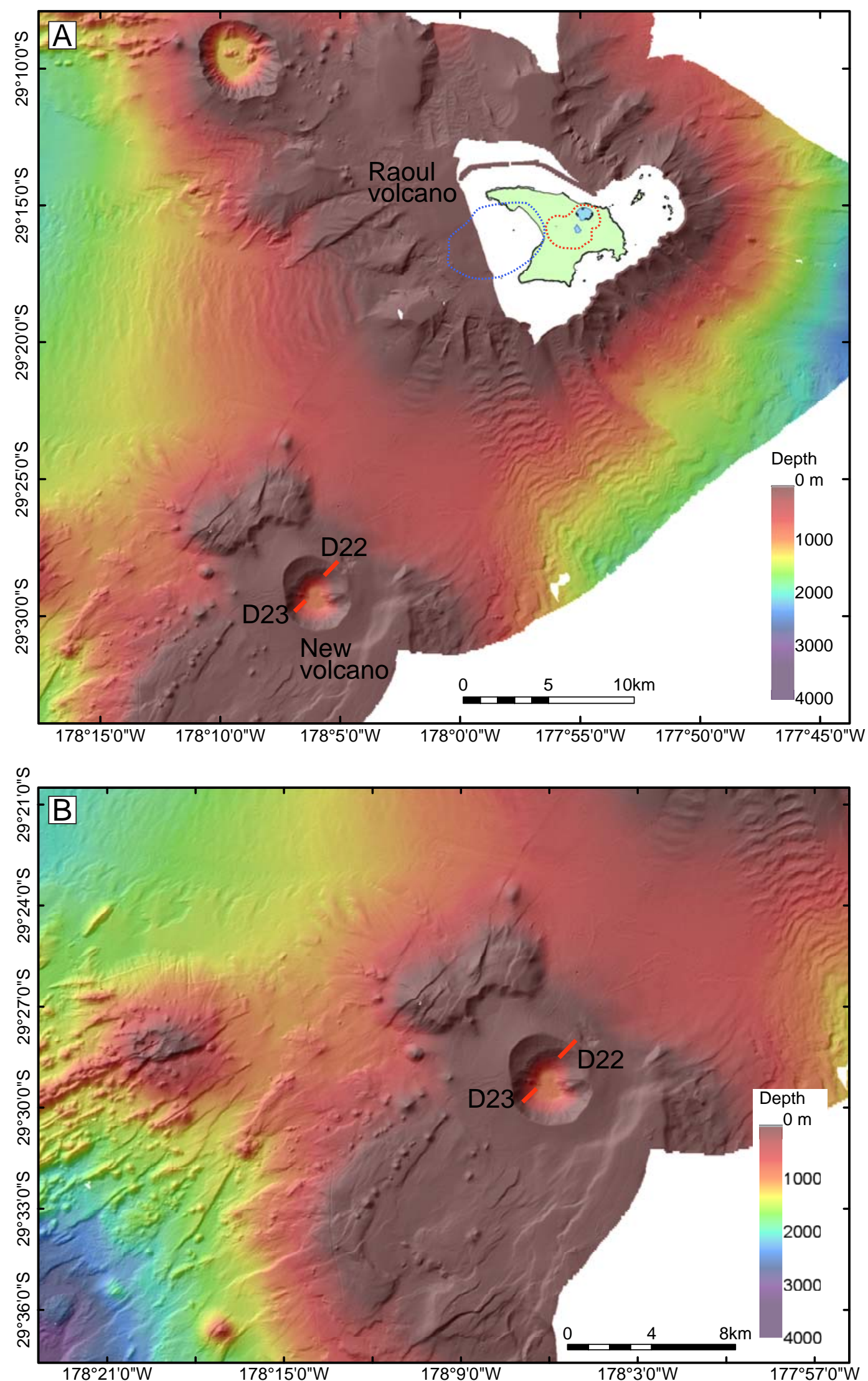

Figure 2.03. Bathymetry around Raoul volcano and New volcano based on EM300 multibeam mapping. A. Map showing the extent of the Raoul edifice, and its proximity to two newly discovered submarine volcanoes found during the 2007 Tangaroa voyage. The caldera to the southwest of Raoul has been termed New volcano for the purpose of this study. Raoul Island is shown with the same features as Figure 2.2. B. Map of New volcano showing the extent of the caldera, and the surrounding edifice. The location of dredge hauls from the 2007 Tangaroa voyage are shown by red lines and labelled by dredge number. Only dredge hauls which recovered the material analysed in this study are shown. A complete list of the samples are presented in Appendix A. Data from the National Institute of Water and Atmosphere (NIWA). 
Annexation Lavas are exposed mainly on the island shore platform, and are covered by thick deposits of the Sandy Bay Tephra (SBT), a pale grey, poorly sorted, dacite pumice deposit (Lloyd et al., 1996; Smith et al., 2003a). The SBT is up to $100 \mathrm{~m}$ thick in the southern cliffs of Macauley Island but thins northwards to ca. $15 \mathrm{~m}$ on the upper parts of the Annexation lava shield (Lloyd et al., 1996). The youngest eruptive units on Macauley Island reflect a renewal of basaltic volcanism, with a composite tephra and lava cone at the western end of the island (Mount Haszard). Lava flows associated with this activity (Cascade Lavas) extend southwards over a small area covering the SBT, and pyroclastic fall deposits (Haszard Tephras) mantle the upper slopes of the island.

Immediately northwest of Macauley Island there is a large, roughly circular submarine depression ca. $11 \times 8 \mathrm{~km}$ in size, with maximum depth of ca. $1.1 \mathrm{~km}$ (Figure 2.04). This is interpreted to be the caldera into which part of the Macauley volcano subsided during the voluminous eruption of the SBT at $6310{ }^{14} \mathrm{C}$ years ago (Lloyd et al., 1996; Smith et al., 2003a). The topographic rim of the Macauley caldera is at an average water depth of ca. $500 \mathrm{~m}$. It deepens to a depth of $750 \mathrm{~m}$ in the southeast then shallows to $<100 \mathrm{~m}$ as the eastern walls meet Macauley Island (Wright et al., 2006). EM300 multibeam mapping of the seafloor around Macauley (Figure 2.04) indicates that to the east of the caldera the pre-caldera edifice controls the submarine dispersal of clastic material, which has been channelled to the north, east and south. The southwest caldera flanks comprise a series of concentric ridges ca. $100 \mathrm{~m}$ high (Figure 2.04). Seismic reflection data (Wright et al., 2006) indicates these ridges are the surface of acoustically transparent units, which thin away from the caldera and are interpreted to be mega bedforms associated with eruptive SBT density flows and some penecontemporaneous edifice failure. Mapping has also revealed that the caldera rim is capped by $>30$ small vent cones which have erupted dacite lavas both into the caldera and down the outer-rim flanks (Wright et al., 2006; Campbell et al., 2007). Small cones are also scattered over the seafloor to the northwest of the caldera, over Lloyd dome and throughout the Lloyd vent field (Campbell et al., 2007), along with a single hydrothermally active cone (Macauley cone), located on the caldera floor ca. $2 \mathrm{~km}$ northwest of Macauley Island (Figure 2.04).

The size of the Sandy Bay eruption is unknown, with estimates of erupted volume of pyroclastic material ranging over an order of magnitude. The largest estimate of $100 \mathrm{~km}^{3}$ of pyroclastic material (Latter et al., 1992) is based on caldera reconstruction assuming the caldera was formed entirely by the Sandy Bay event. This is a maximum estimate, and an eruption of this size would be one of the largest 


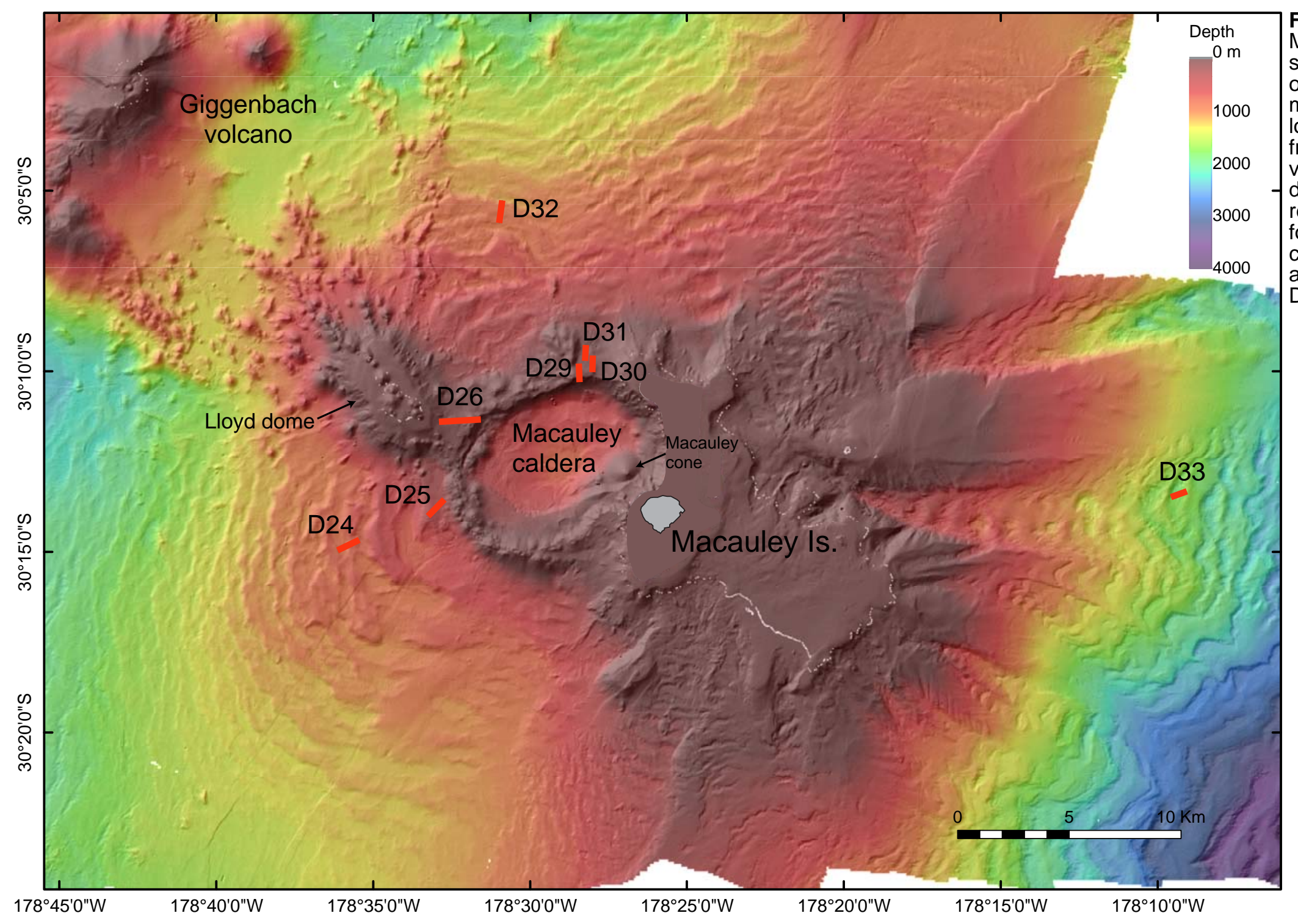

Figure 2.04. Bathymetry of Macauley volcano and the surrounding seafloor based on EM300 multibeam mapping, showing the locations of dredge hauls from the 2007 Tangaroa voyage TAN0706. Only dredge hauls which

recovered material analysed

for this study are shown. A

complete list of the samples

are presented in Appendix A.

Data courtesy of NIWA. 
Holocene eruptions worldwide. Exposed deposits of the SBT on Macauley Island have a total volume of $0.1-0.2 \mathrm{~km}^{3}$, but this represents only a small portion of the dispersal area. More conservative minimum estimates of $1-5 \mathrm{~km}^{3}$ were proposed by Lloyd et al. (1996). Pumice clasts used in this study were collected from the Sandy Bay Tephra at several locations along the cliff faces on Macauley Island during a two day shore landing during the TAN0706 voyage. Submarine samples were collected by dredging around the submarine caldera on the same voyage (Figure 2.04). The dredges recovered abundant suites of fresh white to brown pumice, as well as several blocky lava fragments from around the caldera rim (see Appendix A for sample details).

\subsection{Healy volcano}

The submarine Healy volcano, in the southern Kermadec arc, is a ca. 15 x $7 \mathrm{~km}$ sized composite volcanic complex consisting of a central edifice, and a large caldera on the northeastern, mid-lower flank (Figure 2.05). The caldera is roughly circular (2.0-2.5 km in diameter), with a smooth flat floor at water depths of ca. $1700 \mathrm{~m}$. The caldera rim rises only $250-400 \mathrm{~m}$ above the caldera floor, with inner caldera slopes typically inclined at $15-20^{\circ}$, which locally increase to $25^{\circ}$ at the southwest margin (Wright and Gamble, 1999). A cone structure which rises to a water depth of $1150 \mathrm{~m}$ forms the central edifice, with a small caldera $(1.3 \mathrm{~km}$ in diameter with $50-100 \mathrm{~m}$ high caldera walls) sited on the upper southwestern flank (Figure 2.05). Sidescan imagery and dredge sampling show that the outer flanks of the volcanic complex, caldera floor and walls, and the main edifice are mantled with pumice which is distributed over at least 50 $\mathrm{km}^{2}$ (Wright and Gamble, 1999; Wright, 2001; Wright et al., 2003). Extensive reconnaissance work on the Healy edifice and caldera by Wright and Gamble (1999), including photographic data, reveals the ubiquitous distribution of pyroclastic blocks and lapilli. Samples collected from dredging almost invariably recover highly vesicular rhyodacite pumice with whole rock $\mathrm{SiO}_{2}$ values ranging from 69-72 wt. \% (Wright and Gamble, 1999, Wright et al., 2003).

Although Healy volcano is mantled with rhyodacite pumice, its eruptive history is not well constrained due to the surficial nature of seafloor dredge sampling. Wright et al. (2003) suggested that a large single eruption would have produced on the order of $10-15 \mathrm{~km}^{3}$ of pyroclastic material, based on pre-caldera edifice reconstruction. Surface pumice rafts generated in such an eruption were also suggested to be a correlative of the sea rafted Loisels pumice deposits found in some New Zealand Holocene beach 


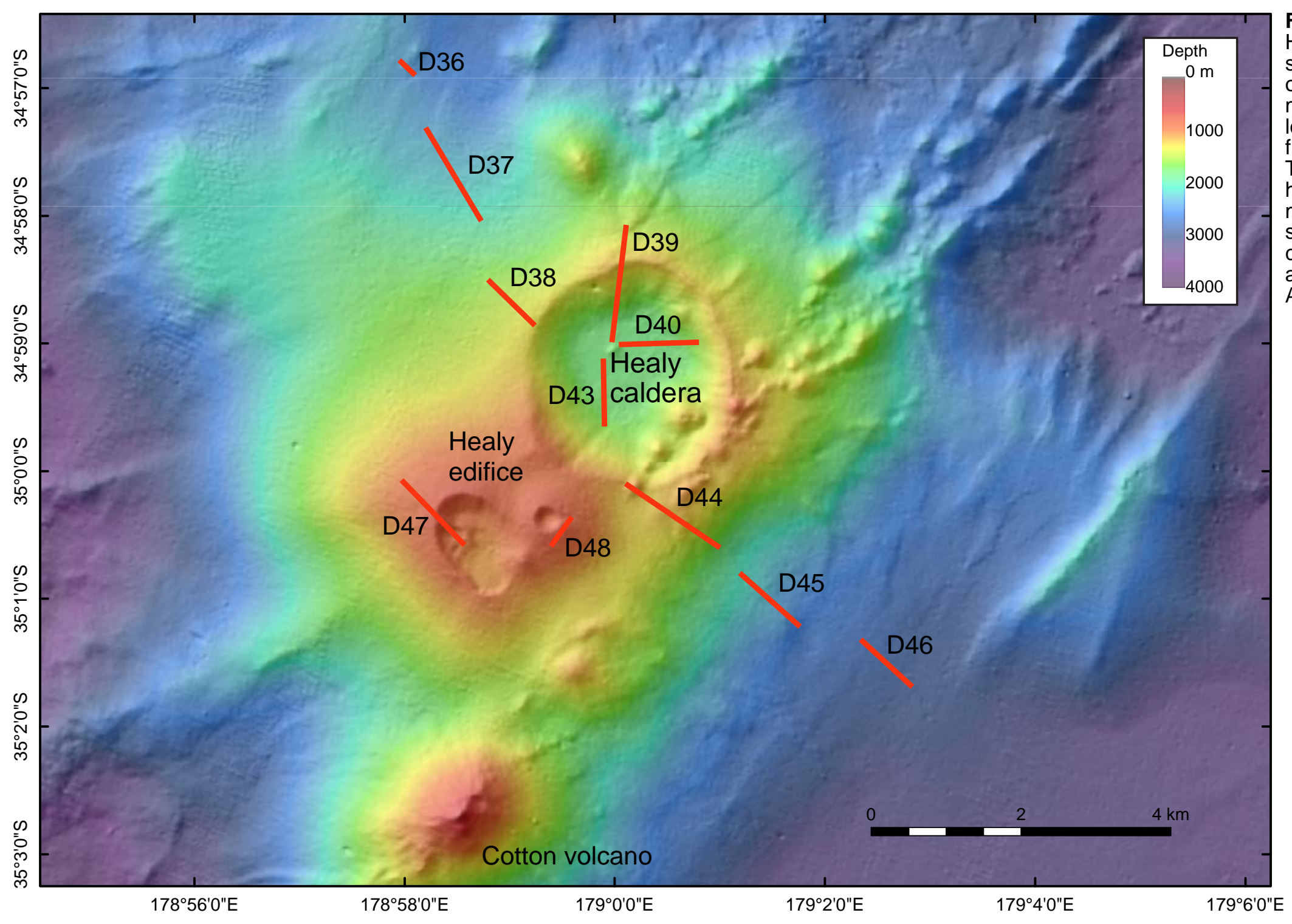

Figure 2.05. Bathymetry of Healy volcano and the

surrounding seafloor based n EM300 multibeam

mapping, showing the

ocations of dredge hauls

from the Tangaroa voyage

TAN0706. Only dredge

hauls which recovered

material analysed for this

study are shown. A

complete list of the samples

are presented in Appendix

A. Data courtesy of NIWA.

$179^{\circ} 0^{\prime} O^{\prime \prime} \mathrm{E}$

$179^{\circ} 2^{\prime} \mathrm{O}^{\prime \prime E}$

$179^{\circ} 4^{\prime} 0^{\prime \prime} \mathrm{E}$

$179^{\circ} 6^{\prime} 0^{\prime \prime E}$ 
sequences dated at ca. $590 \pm 80{ }^{14}$ C years B.P. (McFadgen, 1994; Shane et al., 1998; Wright et al., 2003). Material from Healy volcano was collected during the 2007 TAN0706 voyage by submarine dredging inside the caldera, and down the central edifice flanks on both the northwestern and southeastern sides of the volcano (Figure 2.05). All dredge hauls recovered abundant white to dark grey pumice, and large representative pumice samples from each dredge haul were chosen for this study (see Appendix A for sample details). 


\section{CHAPTER 3: \\ Analytical \\ Techniques}




\subsection{Sample preparation}

\subsubsection{Rock crushing and cleaning}

As many of the rock samples were collected from the seafloor or from coastal cliffs exposed to sea spray, salt and sediment contamination was an important consideration for obtaining material suitable for chemical analysis. Crystals of sodium chloride precipitated from sea water can crucially contaminate samples, effecting the accuracy and reproducibility of chemical analysis (Tani et al. 2003). This is especially the case for porous samples such as pumice in which salt can penetrate deeply into the rock through connected vesicles. To remove contamination from salt water, each sample was put through a series of meticulous preparation procedures to ensure that only clean material was used in chemical analysis.

Prior to crushing, samples were soaked in deionised water for at least $24 \mathrm{hr}$, then dried in an oven at $105^{\circ} \mathrm{C}$ for $12 \mathrm{hr}$. Samples with remaining visible surface sediment were repeatedly scrubbed with a nylon brush and cleaned in an ultrasonic bath. Once samples were dry, any weathered or altered surfaces were cut away. The majority of samples were large enough that all surface material could be removed regardless of condition, ensuring that only the freshest core material was selected for crushing. The remaining sample was coarsely crushed in a Rocklabs Boyd crusher, to chips $<15 \mathrm{~mm}$ in size. The Boyd crusher was repeatedly cleaned and dried with compressed air between samples. The crushed rock was picked to remove remaining altered material and sieved to remove any material less than $\sim 2 \mathrm{~mm}$, as smaller material would be lost in later cleaning stages. The removal of large xenoliths was also important during this step, as many samples contained large mafic inclusions (see sample descriptions: Appendix A).

To remove salt contamination from sea water, the coarsely crushed samples were soaked in distilled water and then boiled in Milli-Q (ultra-clean water with resistivity $>18.2 \mathrm{M} \Omega$ ). The boiling process is very effective in cleaning pumice as water vapour penetrates deep into vesicles, completely cleaning and sinking pumice chips (Tani et al., 2003). After boiling, the water was discarded and replaced with fresh Milli $\mathrm{Q}$, and any remaining floating pumice was removed. This boiling procedure was repeated until either the conductivity of the water matched that of distilled water (0.5-3 $\mu \mathrm{s} / \mathrm{cm}$ ), or until a solution of silver nitrate added to the boiling water stopped precipitating silver chloride. Submarine pumice samples usually required 10-15 cycles of boiling until all salt had been removed. 
After each sample had been cleaned and coarsely crushed, up to $120 \mathrm{~g}$ of sample was extracted for further crushing required for whole rock analysis. Coarse chips $(<15$ $\mathrm{mm}$ ) were reduced to 1-2 $\mathrm{mm}$ size in a hardened steel jaw crusher. Large initial sample sizes reduce the effects of heterogeneity in whole rock analysis. From this size fraction, approximately $30 \mathrm{~g}$ of each rock was reduced to powder (ca. $75 \mu \mathrm{m}$ ) in an agate Tema swing mill for whole rock major and trace element analysis.

\subsubsection{Mineral separation and preparation}

Minerals were extracted from the fine $(<2 \mathrm{~mm})$ material produced from the Boyd crusher during coarse crushing. The splitting action of the slowly rotating steel plates in the Boyd crusher allowed crystals to fall out of the splitting pumice without being fragmented, which is a common problem encountered during impact splitting. When further sample was required, coarse, cleaned pumice chips were reduced to $<2 \mathrm{~mm}$ in size by hand using an agate mortar and pestle, although this technique did not result in such pristine crystal extraction. Fine material was then repeatedly ultrasonically rinsed in distilled water to remove any ash adhering to the crystals and then dried in an oven at $60^{\circ} \mathrm{C}$.

Individual minerals, small mafic blebs and crystal clusters were handpicked under a binocular microscope, depending on their size and preservation. Crystals were grouped by type and size and mounted on double sided tape with the a-axis perpendicular to the tape. Elemental diffusion rates often vary between crystallographic axis orientations (e.g. Costa and Dungan, 2005). Therefore, where crystal axes could be distinguished, individual minerals were aligned with their c-axis parallel to allow direct comparison between crystal zones from different samples. Crystals were set in Epotech ${ }^{\circledR}$ epoxy resin to form a $32 \mathrm{~mm}$ disk, which was then subsequently polished down to expose the interior of the crystals. Once crystals were exposed to an appropriate depth, final polishing was carried out using $3 \mu \mathrm{m}$ and $1 \mu \mathrm{m}$ diamond paste and colloidal silica to produce a high quality polish for back-scattered electron imaging. 


\subsection{Whole rock major element analysis}

\subsubsection{X-ray fluorescence spectrometry}

The majority of whole rock major element analyses were carried out using an $\mathrm{ARL}^{\circledR}$ $8420+$ dual goniometer wavelength dispersive X-ray fluorescence (XRF) spectrometer at the Open University, Milton Keynes, United Kingdom. Major elements were determined by the analysis of fused lithium metaborate glass discs following the methods of Ramsey et al. (1995). A single batch of 20 samples were analysed using a Philips ${ }^{\circledR}$ PW2400 XRF spectrometer at the University of Canterbury, New Zealand, using similar methods. Glass disks were formed by mixing 1 part by weight $(0.70 \mathrm{~g})$ of rock powder (dried at $110^{\circ} \mathrm{C}$ ) with 5 parts by weight of dried lithium metaborate flux and fusing in a muffle furnace for 15 minutes at $1100^{\circ} \mathrm{C}$ in $95 \% \mathrm{Pt}-5 \% \mathrm{Au}$ crucibles. Loss-on-ignition (LOI) measurements were undertaken on dried rock powders by heating in a pre-ignited aluminium crucible to $1000^{\circ} \mathrm{C}$ for $1 \mathrm{hr}$ and recording percentage weight loss. The analytical conditions and count times used for the determination of each element by XRF analysis are detailed in Table 3.01.

Table 3.01. Conditions for major element determination by XRF (from Ramsey et al., 1995).

\begin{tabular}{|c|c|c|c|c|c|c|}
\hline \multicolumn{3}{|c|}{ Element data } & \multicolumn{4}{|c|}{ Analytical conditions } \\
\hline element & $\begin{array}{l}\text { X-ray } \\
\text { line }\end{array}$ & wavelength $(\AA)$ & count time (s) & crystal & detector & collimator \\
\hline $\mathrm{Na}$ & $\mathrm{K}_{\alpha}$ & 11.910 & 40 & AX06 & fpc & coarse \\
\hline $\mathrm{Mg}$ & $\mathrm{K}_{\alpha}$ & 9.890 & 25 & AX06 & $\mathrm{fpc}$ & coarse \\
\hline $\mathrm{Al}$ & $\mathrm{K}_{\alpha}$ & 8.340 & 20 & PET & $\mathrm{fpc}$ & coarse \\
\hline $\mathrm{Si}$ & $\mathrm{K}_{\alpha}$ & 7.126 & 30 & PET & fpc & coarse \\
\hline$P$ & $\mathrm{~K}_{\alpha}$ & 6.158 & 30 & Ge111 & fpc & fine \\
\hline$S$ & $\mathrm{~K}_{\alpha}$ & 5.373 & 20 & Ge111 & $\mathrm{fpc}$ & fine \\
\hline K & $\mathrm{K}_{\alpha}$ & 3.742 & 15 & LiF200 & fpc & fine \\
\hline $\mathrm{Ca}$ & $\mathrm{K}_{\alpha}$ & 3.359 & 15 & LiF200 & $\mathrm{fpc}$ & fine \\
\hline $\mathrm{Ti}$ & $\mathrm{K}_{\alpha}$ & 2.750 & 20 & LiF200 & $\mathrm{fpc}$ & fine \\
\hline $\mathrm{Mn}$ & $\mathrm{K}_{\alpha}$ & 2.130 & 15 & LiF200 & fpc & fine \\
\hline $\mathrm{Fe}$ & $\mathrm{K}_{\alpha}$ & 1.937 & 15 & LiF200 & $\mathrm{fpc}$ & fine \\
\hline
\end{tabular}

$\mathrm{fpc}=$ flow proportional counter. X-ray tube operated at 40kV / $60 \mathrm{~mA}$. 


\subsubsection{Accuracy and precision of XRF}

A total of 106 samples were analysed by XRF in five separate batches of 20-25 samples. To assess the accuracy and reproducibility of these analysis, two internal standards were run at the beginning and end of each batch. Whin Sill Dolerite (WS-E) was used as an internal standard as it is a well constrained international rock standard (Table 3.02). G94 (micro-granite) is less constrained as a standard, but was also used as its composition more closely matches the analysed samples (Table 3.03). Approximate 2 standard deviation (SD) analytical precisions determined by 10 replicate analyses of the same standards for elements are generally $<1-3$ relative \% (Table 3.02 and 3.03). Average values from each standard presented in Table 3.02 and Table 3.03 also closely agree with recommended values (within 1-2\% offset), indicating that the XRF analysis had a high degree of accuracy. As some pumice clasts had a large amount of fresh material available, several hundred grams of rock chips could be extracted. Large sample sizes allowed multiple batches of the same whole-rock sample to be powdered and sent for repeated analyses. As shown in Table 3.04, repeat analyses of separate powders from the same rock samples show excellent reproducibility, with only two samples (D38/PC03, RI06/P12) showing a slightly wider range in values between separate batches. As separate batches were split from coarsely crushed rock, variations between these batches are most likely due to textural heterogeneities in the pumice sample (e.g. zones with higher crystal or xenolith proportions). Repeated analysis of the same sample powders analysed using the two different XRF spectrometers also shows excellent reproducibility (Table 3.04).

\subsection{Whole rock trace element and $\mathrm{Pb}$ isotope analysis}

\subsubsection{Laboratory protocol}

Samples selected for trace element and isotopic analyses were processed in the ultraclean geochemistry laboratory facility at Victoria University of Wellington. The ultraclean chemical separation laboratory is positively pressured with air filtered to Class 100, and equipped with four PicoTrace Class 10 laminar flow workstations to minimise the risk of contamination. 
Table 3.02. XRF precision and accuracy for the internal standard WS-E (Whin Sill / Belford Dolerite)

\begin{tabular}{|c|c|c|c|c|c|c|c|c|c|c|c|c|c|c|}
\hline XRF Batch & $1 \mathrm{a}$ & $1 \mathrm{~b}$ & $2 a$ & $2 b$ & $3 a$ & $3 b$ & $4 a$ & $4 b$ & $5 a$ & $5 b$ & 2sd (\%) & Average & Accepted & $\%$ offset \\
\hline $\mathrm{SiO}_{2}$ & 51.50 & 51.46 & 51.47 & 51.57 & 51.46 & 51.54 & 51.49 & 51.44 & 51.43 & 51.48 & 0.17 & 51.48 & 51.62 & -0.3 \\
\hline $\mathrm{TiO}_{2}$ & 2.44 & 2.44 & 2.45 & 2.44 & 2.45 & 2.45 & 2.45 & 2.45 & 2.47 & 2.46 & 0.74 & 2.45 & 2.45 & +0.1 \\
\hline $\mathrm{Al}_{2} \mathrm{O}_{3}$ & 14.01 & 14.00 & 13.99 & 14.03 & 13.99 & 14.02 & 14.04 & 14.10 & 14.10 & 14.12 & 0.70 & 14.04 & 13.92 & +0.1 \\
\hline $\mathrm{Fe}_{2} \mathrm{O}_{3}$ & 13.34 & 13.35 & 13.34 & 13.32 & 13.35 & 13.33 & 13.35 & 13.35 & 13.34 & 13.33 & 0.18 & 13.34 & 13.38 & -0.3 \\
\hline $\mathrm{MnO}$ & 0.169 & 0.172 & 0.170 & 0.167 & 0.170 & 0.168 & 0.168 & 0.172 & 0.171 & 0.168 & 2.19 & 0.169 & 0.173 & -2.0 \\
\hline $\mathrm{MgO}$ & 5.63 & 5.61 & 5.61 & 5.56 & 5.62 & 5.59 & 5.60 & 5.61 & 5.60 & 5.59 & 0.71 & 5.60 & 5.61 & -0.1 \\
\hline $\mathrm{CaO}$ & 9.14 & 9.15 & 9.15 & 9.14 & 9.19 & 9.14 & 9.11 & 9.10 & 9.12 & 9.09 & 0.66 & 9.13 & 9.04 & +1.0 \\
\hline $\mathrm{Na}_{2} \mathrm{O}$ & 2.47 & 2.49 & 2.49 & 2.48 & 2.46 & 2.44 & 2.46 & 2.45 & 2.45 & 2.44 & 1.51 & 2.46 & 2.49 & -1.3 \\
\hline $\mathrm{K}_{2} \mathrm{O}$ & 1.002 & 1.014 & 1.014 & 1.006 & 1.007 & 1.013 & 1.020 & 1.018 & 1.023 & 1.015 & 1.31 & 1.013 & 1.010 & +0.3 \\
\hline $\mathrm{P}_{2} \mathrm{O}_{5}$ & 0.302 & 0.308 & 0.304 & 0.301 & 0.302 & 0.304 & 0.309 & 0.307 & 0.307 & 0.305 & 1.74 & 0.305 & 0.305 & -0.3 \\
\hline Sum & 100.15 & 100.19 & 100.17 & 100.25 & 100.14 & 100.16 & 100.08 & 100.19 & 100.25 & 99.96 & 0.17 & 100.15 & 99.85 & 0.3 \\
\hline LOI & 0.85 & 0.85 & 0.85 & 0.85 & 0.85 & 0.85 & 0.85 & 0.85 & 0.85 & 0.85 & 0.00 & 0.85 & 0.85 & 0.0 \\
\hline
\end{tabular}

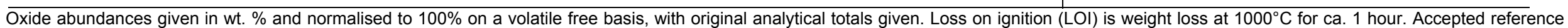
values are from Govindaraju et al. (1994) with the exception of $\mathrm{SiO}_{2}, \mathrm{TiO}_{2}$ and $\mathrm{Fe}_{2} \mathrm{O}_{3}$, which are from Thompson et al. (2000). 
Table 3.03. XRF precision and accuracy for internal standard G94 (Threlkeld microgranite)

\begin{tabular}{|c|c|c|c|c|c|c|c|c|c|c|c|c|c|c|}
\hline XRF Batch & $1 a$ & $1 b$ & $2 a$ & $2 b$ & $3 a$ & $3 b$ & $4 a$ & $4 b$ & $5 a$ & $5 b$ & $2 \sigma(\%)$ & Average & Accepted & $\%$ offset \\
\hline $\mathrm{SiO}_{2}$ & 71.15 & 71.16 & 71.14 & 71.24 & 71.19 & 71.23 & 71.21 & 71.24 & 71.19 & 71.23 & 0.10 & 71.20 & 71.26 & -0.1 \\
\hline $\mathrm{TiO}_{2}$ & 0.324 & 0.318 & 0.325 & 0.323 & 0.321 & 0.322 & 0.324 & 0.325 & 0.317 & 0.316 & 2.16 & 0.322 & 0.320 & +0.6 \\
\hline $\mathrm{Al}_{2} \mathrm{O}_{3}$ & 14.94 & 14.94 & 14.93 & 14.91 & 14.88 & 14.92 & 14.88 & 14.90 & 14.94 & 14.94 & 0.31 & 14.92 & 14.93 & -0.1 \\
\hline $\mathrm{Fe}_{2} \mathrm{O}_{3}$ & 3.11 & 3.10 & 3.10 & 3.10 & 3.10 & 3.11 & 3.11 & 3.10 & 3.11 & 3.11 & 0.25 & 3.10 & 3.11 & -0.1 \\
\hline $\mathrm{MnO}$ & 0.078 & 0.076 & 0.078 & 0.076 & 0.078 & 0.079 & 0.078 & 0.076 & 0.075 & 0.075 & 3.56 & 0.077 & 0.076 & +0.6 \\
\hline $\mathrm{MgO}$ & 1.074 & 1.078 & 1.076 & 1.066 & 1.096 & 1.073 & 1.096 & 1.082 & 1.082 & 1.065 & 1.99 & 1.079 & 1.060 & +1.8 \\
\hline $\mathrm{CaO}$ & 1.401 & 1.407 & 1.403 & 1.385 & 1.399 & 1.400 & 1.398 & 1.399 & 1.391 & 1.380 & 1.20 & 1.396 & 1.365 & +2.3 \\
\hline $\mathrm{Na}_{2} \mathrm{O}$ & 4.70 & 4.72 & 4.73 & 4.70 & 4.72 & 4.66 & 4.70 & 4.68 & 4.69 & 4.70 & 0.86 & 4.70 & 4.69 & +0.2 \\
\hline $\mathrm{K}_{2} \mathrm{O}$ & 3.05 & 3.04 & 3.05 & 3.03 & 3.05 & 3.05 & 3.03 & 3.02 & 3.04 & 3.02 & 0.87 & 3.04 & 3.02 & +0.7 \\
\hline $\mathrm{P}_{2} \mathrm{O}_{5}$ & 0.169 & 0.167 & 0.167 & 0.168 & 0.169 & 0.173 & 0.175 & 0.171 & 0.172 & 0.173 & 3.17 & 0.170 & 0.168 & +1.4 \\
\hline Sum & 100.27 & 100.03 & 100.09 & 100.10 & 100.21 & 100.14 & 100.17 & 100.03 & 100.05 & 100.00 & 0.17 & 100.11 & 100.12 & -0.0 \\
\hline LOI & 1.97 & 1.97 & 1.97 & 1.97 & 1.97 & 1.97 & 1.97 & 1.97 & 1.97 & 1.97 & 0.00 & 1.97 & 1.97 & 0.0 \\
\hline
\end{tabular}

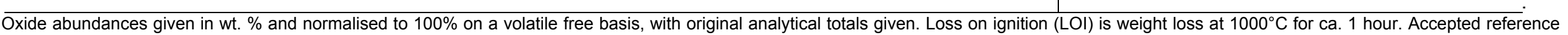
values are from Thompson et al. (1996) with the exception of $\mathrm{Na}_{2} \mathrm{O}$, which is recommended from the consistent long-term average value obtained by repeated standard analysis at the Open University XRF laboratory. 
Table 3.04. Repeated analyses on samples analysed in this study by XRF

\begin{tabular}{|c|c|c|c|c|c|c|c|c|c|c|c|c|c|c|c|}
\hline Sample & RI03_PC09 & & Offset & RI06_PC12 & & Offset & RI12_PC19 & & Offset & RI18_PC05 & & Offset & RI19_PC01 & & Offset \\
\hline Run & 1 & 2 & $\%$ & 1 & 2 & $\%$ & $\begin{array}{l}- \\
\end{array}$ & 2 & $\%$ & $\begin{array}{l}- \\
-\end{array}$ & 2 & $\%$ & 1 & 2 & $\%$ \\
\hline $\mathrm{SiO}_{2}$ & 66.69 & 66.58 & 0.2 & 68.24 & 67.93 & 0.5 & 67.97 & 68.04 & -0.1 & 69.34 & 69.33 & 0.0 & 66.46 & 66.44 & 0. \\
\hline $\mathrm{TiO}_{2}$ & 0.661 & 0.671 & -1.4 & 0.487 & 0.499 & -2.5 & 0.583 & 0.574 & 1.6 & 0.597 & 0.605 & -1.3 & 0.663 & 0.667 & -0 . \\
\hline $\mathrm{Al}_{2} \mathrm{O}_{3}$ & 14.59 & 14.64 & -0.3 & 14.65 & 14.72 & -0.5 & 14.71 & 14.70 & 0.0 & 14.10 & 14.11 & -0.1 & 14.69 & 14.69 & 0 \\
\hline $\mathrm{Fe}_{2} \mathrm{O}_{3}$ & 6.32 & 6.32 & 0.0 & 5.48 & 5.54 & -1.1 & 5.39 & 5.41 & -0.5 & 5.27 & 5.27 & -0.1 & 6.40 & 6.36 & 0 . \\
\hline $\mathrm{MnO}$ & 0.189 & 0.184 & 2.5 & 0.159 & 0.162 & -1.6 & 0.159 & 0.156 & 2.1 & 0.163 & 0.162 & 0.5 & 0.186 & 0.187 & -0 \\
\hline $\mathrm{MgO}$ & 1.625 & 1.636 & -0.7 & 1.333 & 1.425 & -6.9 & 1.368 & 1.358 & 0.7 & 1.133 & 1.129 & 0.4 & 1.626 & 1.638 & -0 \\
\hline $\mathrm{CaO}$ & 5.70 & 5.77 & -1.3 & 5.43 & 5.57 & -2.5 & 5.23 & 5.12 & 2.2 & 4.71 & 4.71 & -0.1 & 5.64 & 5.72 & -1 \\
\hline $\mathrm{Na}_{2} \mathrm{O}$ & 3.54 & 3.53 & 0.4 & 3.53 & 3.48 & 1.4 & 3.80 & 3.83 & -0.7 & 3.93 & 3.92 & 0.3 & 3.66 & 3.63 & \\
\hline $\mathrm{K}_{2} \mathrm{O}$ & 0.531 & 0.529 & 0.3 & 0.578 & 0.566 & 2.0 & 0.645 & 0.654 & -1.5 & 0.618 & 0.612 & 1.0 & 0.531 & 0.520 & \\
\hline $\mathrm{P}_{2} \mathrm{O}_{5}$ & 0.141 & 0.136 & 3.4 & 0.113 & 0.113 & -0.1 & 0.151 & 0.157 & -4.0 & 0.147 & 0.151 & -2.2 & 0.142 & 0.140 & \\
\hline Total & 100.08 & 99.70 & 0.4 & 99.15 & 99.80 & -0.7 & 100.06 & 100.00 & 0.1 & 99.90 & 100.21 & -0.3 & 100.14 & 100.08 & \\
\hline LOI & 1.14 & 1.21 & & 1.14 & 1.13 & & 1.60 & 1.65 & & 1.40 & 1.56 & & 0.33 & 0.37 & \\
\hline
\end{tabular}

Oxide abundances given in wt. \% and normalised to $100 \%$ on a volatile free basis, with original analytical totals and LOI given. Phil denotes samples re-analysed using the Canterbury XRF.

Table 3.04. Continued

\begin{tabular}{|c|c|c|c|c|c|c|c|c|c|c|c|c|c|c|c|}
\hline Sample & D22_PC03 & & Offset & D23_PC02 & & Offset & D38_PC03 & & Offset & D39_PC05 & & Offset & D43_PC02 & & Offset \\
\hline Run & 1 & 2 (Phil) & $\%$ & 1 & 2 & $\%$ & 1 & 2 & $\%$ & 1 & 2 (Phil) & $\%$ & 1 & 2 & $\%$ \\
\hline $\mathrm{SiO}_{2}$ & 73.84 & 73.95 & -0.1 & 74.16 & 74.30 & -0.2 & 69.59 & 70.08 & -0.7 & 71.64 & 72.47 & -1.2 & 71.23 & 71.09 & 0.2 \\
\hline $\mathrm{TiO}_{2}$ & 0.406 & 0.407 & -0.3 & 0.399 & 0.390 & 2.3 & 0.487 & 0.480 & 1.4 & 0.405 & 0.390 & 3.8 & 0.472 & 0.478 & -1.3 \\
\hline $\mathrm{Al}_{2} \mathrm{O}_{3}$ & 13.78 & 13.71 & 0.5 & 13.69 & 13.61 & 0.6 & 14.62 & 14.42 & 1.4 & 13.81 & 13.97 & -1.2 & 14.22 & 14.27 & -0.3 \\
\hline $\mathrm{Fe}_{2} \mathrm{O}_{3}$ & 2.70 & 2.68 & 0.8 & 2.58 & 2.54 & 1.5 & 3.74 & 3.65 & 2.2 & 2.77 & 2.71 & 2.3 & 3.37 & 3.42 & -1.3 \\
\hline $\mathrm{MnO}$ & 0.123 & 0.123 & 0.1 & 0.121 & 0.121 & 0.0 & 0.122 & 0.119 & 2.7 & 0.111 & 0.110 & 0.7 & 0.116 & 0.115 & 0.5 \\
\hline $\mathrm{MgO}$ & 0.668 & 0.677 & -1.4 & 0.699 & 0.632 & 9.6 & 1.247 & 1.213 & 2.7 & 0.609 & 0.580 & 4.8 & 0.906 & 0.908 & -0.3 \\
\hline $\mathrm{CaO}$ & 3.74 & 3.69 & 1.4 & 3.62 & 3.65 & -0.9 & 3.70 & 3.53 & 4.8 & 2.51 & 2.44 & 2.7 & 2.99 & 3.05 & -1.8 \\
\hline $\mathrm{Na}_{2} \mathrm{O}$ & 3.98 & 4.00 & -0.5 & 3.97 & 4.01 & -1.1 & 4.88 & 4.86 & 0.4 & 4.93 & 5.17 & -4.8 & 5.01 & 4.99 & 0.3 \\
\hline $\mathrm{K}_{2} \mathrm{O}$ & 0.664 & 0.667 & -0.4 & 0.671 & 0.661 & 1.5 & 1.503 & 1.537 & -2.2 & 1.729 & 1.680 & 2.8 & 1.579 & 1.574 & 0.3 \\
\hline $\mathrm{P}_{2} \mathrm{O}_{5}$ & 0.096 & 0.098 & -2.2 & 0.095 & 0.091 & 4.5 & 0.106 & 0.104 & 2.3 & 0.073 & 0.070 & 3.8 & 0.104 & 0.106 & -2.6 \\
\hline Total & 100.16 & 100.46 & -0.3 & 101.71 & 101.34 & 0.4 & 100.33 & 100.65 & -0.3 & 98.59 & 99.57 & -1.0 & 99.91 & 99.80 & 0.1 \\
\hline LOI & 3.43 & 3.39 & & 3.48 & 2.99 & & 1.50 & 1.49 & & 1.11 & -0.07 & & 1.45 & 1.41 & \\
\hline
\end{tabular}


Table 3.04. Continued

\begin{tabular}{|l|rrrr|rrrrr|}
\hline Sample & D29_PC02 & & & Max offset & D29_PC03 & & & Max offset \\
Run & 1 & 2 & 3 & $\%$ & 1 & 2 & 3 & 4 & $\%$ \\
\hline $\mathrm{SiO}_{2}$ & 72.37 & 72.36 & 72.35 & 0.0 & 72.22 & 72.29 & 72.30 & 72.40 & 0.2 \\
$\mathrm{TiO}_{2}$ & 0.435 & 0.445 & 0.440 & 2.4 & 0.442 & 0.442 & 0.439 & 0.447 & 1.8 \\
$\mathrm{Al}_{2} \mathrm{O}_{3}$ & 12.78 & 12.81 & 12.78 & 0.3 & 12.78 & 12.83 & 12.80 & 12.75 & 0.6 \\
$\mathrm{Fe}_{2} \mathrm{O}_{3}$ & 4.62 & 4.62 & 4.63 & 0.1 & 4.65 & 4.63 & 4.64 & 4.63 & 0.4 \\
$\mathrm{MnO}$ & 0.124 & 0.129 & 0.125 & 3.2 & 0.127 & 0.126 & 0.126 & 0.126 & 1.3 \\
$\mathrm{MgO}$ & 0.488 & 0.494 & 0.491 & 1.3 & 0.503 & 0.500 & 0.493 & 0.494 & 2.0 \\
$\mathrm{CaO}$ & 2.53 & 2.50 & 2.47 & 2.3 & 2.52 & 2.53 & 2.55 & 2.48 & 2.7 \\
$\mathrm{Na}_{2} \mathrm{O}$ & 4.75 & 4.72 & 4.79 & 1.4 & 4.83 & 4.76 & 4.72 & 4.76 & 2.2 \\
$\mathrm{~K}_{2} \mathrm{O}$ & 1.827 & 1.829 & 1.850 & 1.3 & 1.850 & 1.820 & 1.842 & 1.837 & 1.6 \\
$\mathrm{P}_{2} \mathrm{O}_{5}$ & 0.076 & 0.076 & 0.077 & 1.2 & 0.077 & 0.076 & 0.079 & 0.076 & 4.3 \\
$\mathrm{Total}$ & 99.74 & 100.38 & 100.49 & 0.7 & 100.07 & 100.07 & 100.00 & 100.36 & 0.4 \\
$\mathrm{LOI}$ & 1.11 & 1.22 & 1.22 & & 1.63 & 1.43 & 1.64 & 1.52 & \\
\hline
\end{tabular}




\subsubsection{Reagents}

All water used for laboratory work in this study was filtered Millipore ${ }^{\circledR} \mathrm{H}_{2} \mathrm{O}$ (Milli-Q), with a measured resistivity of $>18.2 \mathrm{M} \Omega$. Only SeaStar ${ }^{\mathrm{TM}}$ (SS) grade ultra-pure acids (all key metals $<10 \mathrm{ppt}$ ) were used for trace element and $\mathrm{Pb}$ isotope sample preparation. Other acids used in final stages of beaker preparation were analytical reagent (AR) grade acids, distilled to produce sub-boiled (SB) distilled acids. Acid dilutions were made with Milli-Q water and their molarities were checked using a density meter.

\subsubsection{Savillex beaker preparation}

Prior to sample preparation, Savillex screw-top teflon beakers were subjected to a series of procedures to ensure the beakers were completely clean and free of contaminants. Firstly, used beakers were thoroughly rinsed and wiped down with methanol and soaked in $6 \mathrm{M} \mathrm{HCl}$ for a minimum of $24 \mathrm{hr}$ on a hotplate at $120^{\circ} \mathrm{C}$. They were then rinsed three times with Milli-Q and soaked in $7 \mathrm{M} \mathrm{HNO}_{3}$ on a hotplate for a further 24 hours. Following these steps, beakers were rinsed in Milli-Q. For the final cleaning steps, the beakers were filled with 4-5 mL of 6-7M SB $\mathrm{HNO}_{3}$, sealed and refluxed on a hotplate for a minimum of $24 \mathrm{hr}$. The refluxed acid was then discarded and the beakers were

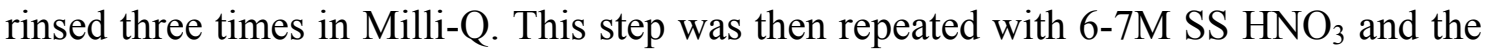
beakers were then dried. For $\mathrm{Pb}$ isotopes, this step was repeated with $6 \mathrm{M} \mathrm{SS} \mathrm{HCl}$ and the beakers were stored in acid until immediately prior to use.

\subsubsection{Trace elements}

Whole rock trace element analysis was carried out by solution inductively coupled plasma mass spectrometry (ICP-MS), using methods similar to Eggins et al. (1997). Eggins et al. (1997) outlined the benefits of internal doping techniques in solution ICPMS, where samples are spiked with a known concentration of enriched isotopes to correct for complex mass-dependent changes in sensitivity encountered during ICP-MS analysis. However, new generation ICP-MS instruments have improved stability across the mass spectrum. Therefore in this study ${ }^{43} \mathrm{Ca}$ was used for an internal correction, as $\mathrm{CaO}$ concentrations of sample powders had previously been determined to $\pm 1 \%$ by XRF. This method also allows any major changes or inconsistencies in results which 
may be caused by sample loss during sample preparation to be monitored and corrected for.

\subsubsection{Sample preparation}

All sample powders used in solution ICP-MS were extracted from the same batch of rock powder that was used for XRF major element chemistry and isotopic analysis. Approximately $50 \mathrm{mg}$ of rock powder was weighed on a high precision balance to \pm $0.0001 \mathrm{~g}$ in pre-cleaned $23 \mathrm{~mL}$ Savillex screw-top teflon beakers. Samples and international reference materials were dissolved by conventional digestion methods using ca. $2 \mathrm{~mL}$ concentrated hydrofluoric acid (29 M HF) and ca. $0.5 \mathrm{~mL} \mathrm{HNO}_{3}(16 \mathrm{M}$ $\mathrm{HNO}_{3}$ ) in sealed Savillex beakers heated on a hotplate to $120^{\circ} \mathrm{C}$ for 3-4 days to ensure complete digestion. Once the sample was completely digested, the solution was evaporated to incipient dryness (not overly dry to avoid sample loss and formation of insoluble fluoride), refluxed twice in ca. $2 \mathrm{~mL}$ of concentrated $\mathrm{HNO}_{3}$ for 1-2 days and taken again to incipient dryness. The sample cake was then refluxed in ca. $5 \mathrm{~mL}$ of $6 \mathrm{M}$ $\mathrm{HCl}$ overnight and the solution was checked to make sure the sample had completely dissolved. The $\mathrm{HCl}$ was evaporated and the sample cake was taken up again in ca. $2 \mathrm{~mL}$ of concentrated $\mathrm{HNO}_{3}$ for two days. The sample was once again evaporated and then taken up in $9 \mathrm{~mL}$ of $1 \mathrm{M} \mathrm{HNO}_{3}$ to reflux for a further 2-3 days to form a final solution, which was run through a centrifuge at $2000 \mathrm{rpm}$ for ca. 5 minutes, to make sure the sample was in fully solution and no solids remained. The final solution was carefully transferred into pre-cleaned $10 \mathrm{~mL}$ polyethylene centrifuge-tubes and precisely weighed on a high precision balance $( \pm 0.0001 \mathrm{~g})$ ensuring all drops were removed from the beaker. To form a dilution of the sample, a $60 \mu \mathrm{L}$ aliquot was transferred and precisely weighed into another clean $10 \mathrm{~mL}$ c-tube (centrifuge-tube), which was topped up with ca. $6 \mathrm{~mL}$ of $1 \% \mathrm{HNO}_{3}$ and weighed again so a final dilution of the sample could be accurately calculated.

\subsubsection{Mass spectrometry}

Sample dilutions were analysed for trace element concentrations using an Agilent 7500CS ICP-MS at Victoria University of Wellington (VUW), New Zealand. Analytical conditions during analysis are outlined in Table 3.05. Sample solutions were introduced through a peristaltic pump, which draws the sample up through to a 
Table 3.05. ICP-MS instrumental and analytical conditions

\begin{tabular}{|c|c|}
\hline ICP-MS & \\
\hline ICP-MS system & Agilent $7500 \mathrm{CS}$ \\
\hline Acquisition mode & Peak hopping \\
\hline Detection mode & Pulse and analog (mostly pulse) \\
\hline Standards and calibration & \\
\hline Calibration/bracketing standard & BHVO-2 \\
\hline Secondary standards & BCR-2 (basalt) and JR-1 (rhyolite) \\
\hline Analysis method & \\
\hline Background acquisition & 60 seconds \\
\hline Sample/standard acquisition & 180 seconds \\
\hline Washout times & 1st washout 30 seconds \\
\hline & 2nd washout 120 seconds \\
\hline Measured isotopes and integration times: & $\begin{array}{l}\text { 3rd washout } 120 \text { seconds } \\
10 \mathrm{~ms}:{ }^{7} \mathrm{Li},{ }^{11} \mathrm{~B},{ }^{24} \mathrm{Mg},{ }^{43} \mathrm{Ca},{ }^{45} \mathrm{Sc},{ }^{47} \mathrm{Ti},{ }^{51} \mathrm{~V},{ }^{53} \mathrm{Cr}, \\
{ }^{60} \mathrm{Ni},{ }^{63} \mathrm{Cu},{ }^{66} \mathrm{Zn},{ }^{71} \mathrm{Ga},{ }^{86} \mathrm{Sr},{ }^{89} \mathrm{Y},{ }^{90} \mathrm{Zr},{ }^{93} \mathrm{Nb}, \\
{ }^{137} \mathrm{Ba},{ }^{139} \mathrm{La},{ }^{140} \mathrm{Ce},{ }^{141} \mathrm{Pr},{ }^{146} \mathrm{Nd} \\
20 \mathrm{~ms}:{ }^{85} \mathrm{Rb},{ }^{141} \mathrm{Pr},{ }^{147} \mathrm{Sm},{ }^{157} \mathrm{Gd},{ }^{163} \mathrm{Dy} \\
50 \mathrm{~ms}:{ }^{95} \mathrm{Mo},{ }^{133} \mathrm{Cs},{ }^{151} \mathrm{Eu},{ }^{153} \mathrm{Eu},{ }^{159} \mathrm{~Tb},{ }^{165} \mathrm{Ho}, \\
{ }^{166} \mathrm{Er},{ }^{169} \mathrm{Tm},{ }^{172} \mathrm{Yb},{ }^{175} \mathrm{Lu},{ }^{178} \mathrm{Hf},{ }^{181} \mathrm{Ta},{ }^{182} \mathrm{~W}, \\
{ }^{208} \mathrm{~Pb} .{ }^{232} \mathrm{Th} .{ }^{238} \mathrm{U}\end{array}$ \\
\hline Tuning & \\
\hline Tuning standards & $\begin{array}{l}\text { Agilent } 10 \text { ppb standard diluted to } 1 \mathrm{ppb}(\mathrm{Li}, \mathrm{Co}, \\
\mathrm{Y}, \mathrm{Ce}, \mathrm{TI})\end{array}$ \\
\hline Monitored isotopes during tuning & ${ }^{7} \mathrm{Li},{ }^{89} \mathrm{Y},{ }^{140} \mathrm{Ce},{ }^{205} \mathrm{TI}(\% \mathrm{RSD}<5 \%)$ \\
\hline Calibration standard & BHVO-2 \\
\hline Monitored isotopes during calibration & $\begin{array}{l}{ }^{43} \mathrm{Ca},{ }^{60} \mathrm{Ni},{ }^{86} \mathrm{Sr},{ }^{89} \mathrm{Y},{ }^{137} \mathrm{Ba},{ }^{140} \mathrm{Ce},{ }^{208} \mathrm{~Pb},{ }^{232} \mathrm{Th} \\
\text { (\% RSD always <5\%) }\end{array}$ \\
\hline Background & $\begin{array}{l}{ }^{43} \mathrm{Ca}<2000 \mathrm{cps} \text { or }<0.1 \% \text { of BHVO-2 cps } \\
\text { other elements }<1 \% \text { with most }<0.5 \% \text {, } \\
\text { exceptions are Sc and Mo }(<5 \%) \text { and } \mathrm{TI}(<10 \%)\end{array}$ \\
\hline Oxides & $\mathrm{CeO}^{+} / \mathrm{Ce}^{+} 1 \mathrm{ppb}$ solution $<1.5 \%$ \\
\hline Carrier gas (Ar) & 1.07-1.13 L/min \\
\hline Make up gas (Ar) & $0 \mathrm{~L} / \mathrm{min}$ \\
\hline RF Power & $1500 \mathrm{~W}$ \\
\hline RF matching & $1.68-1.75 \mathrm{~V}$ \\
\hline Sample depth & $7 \mathrm{~mm}$ \\
\hline
\end{tabular}


nebuliser. The ICP-MS was tuned using an Agilent $10 \mathrm{ppb}$ multielement standard diluted to $1 \mathrm{ppb}$, where instrumental conditions such as torch position and carrier/makeup gas flow were adjusted to achieve the lowest relative standard deviation (RSD) and to optimise sensitivity (Table 3.05). This step was then repeated for the calibration standard, BHVO-2. Oxide generation was monitored using measured $\mathrm{CeO}^{+} / \mathrm{Ce}^{+}$ratios $(<1.5 \%)$. To assess the quality of the data, multiple isotopes from some elements (e.g. ${ }^{90} \mathrm{Zr}$ and ${ }^{91} \mathrm{Zr}$ ) were included in the analysis, generally producing concentrations within $\pm 0.5 \%$. Prior to analysis pulse/analog (P/A) factors were measured on all relevant elements to ensure that the ICP-MS correctly performs the adjustment when switching between pulse (low concentration) and analog (high concentration) counting modes. This $\mathrm{P} / \mathrm{A}$ switching is required if an element has a high enough concentration which results in a count rate $>1 \times 10^{6}$ counts per second.

Each sample solution was measured for a total time of $180 \mathrm{~s}$. Following sample analyses, the ICP-MS was washed out in 3 consecutive rinse cycles in $1 \% \mathrm{SS}^{\mathrm{HNO}} 3$ (Table 3.05). As concentrations were calculated by sample-standard bracketing, samples were typically run in a looping sequence starting with the primary standard (BHVO-2), followed by 2 samples, a secondary standard (BCR-2 or JR-1), 2 more samples, and finishing back on the primary standard. Total procedural blanks for solution ICP-MS were within background count levels on all measured elements.

\subsubsection{Raw data processing and concentration calculations}

Abundances of individual trace elements were calculated relative to a bracketing standard (BHVO-2), which was analysed under identical conditions throughout the analysis sessions. Background count rates were measured for $60 \mathrm{~s}$ prior to analysis of each sample on the secondary washout analytical blank, and the mean background of this was subtracted from the count rates measured during sample analysis. The adjusted count rates for each sample was then converted into a concentration based on the bracketing standard values using the following relationship:

1) Sample $C_{i}=\left(\right.$ Sample $_{C P S} /$ BHVO $\left._{C P S}\right) \times\left(\right.$ Sample $_{\text {Dil }} /$ BHVO $\left._{\text {Dil }}\right) \times$ ref. value.

2) Sample $\mathrm{C}_{\mathrm{i}}(\mathrm{Ca}$ corrected $)=$ eq. (1) $\mathrm{x}\left(\mathrm{C}_{\mathrm{ca}} \mathrm{XRF} / \mathrm{C}_{\mathrm{ca}} \mathrm{ICP}-\mathrm{MS}\right)$. 
$\mathrm{C}_{\mathrm{i}}$ and $\mathrm{C}_{\mathrm{Ca}}$ are the concentrations of isotope $\mathrm{x}$ or $\mathrm{Ca}$, respectively, and $\mathrm{X}_{\mathrm{Dil}}$ is the concentration of material in the dilution aliquots. The reference values for BHVO-2 were compiled from Georem preferred values (http://georem.mpch-mainz.gwdg.de/). Only samples which had $<5 \%$ deviation of $\mathrm{C}_{\mathrm{ca}}$ ICP-MS from $\mathrm{C}_{\mathrm{ca}} \mathrm{XRF}$ were accepted for this study. Higher or lower values than this suggest that material may have been lost or added during sample preparation.

\subsubsection{Accuracy and precision of solution ICP-MS trace element analysis}

Secondary standards were run at regular intervals across each analysis session to assess the accuracy and precision of solution ICP-MS analysis. Two international rock standards were used as secondary standards in this study, BCR-2 (Basalt, Columbia River) and JR-1 (Japanese Rhyolite). BCR-2 was chosen as it is relatively well documented standard, which has been measured over a wide range of laboratories using modern analytical equipment. JR-1 is not as well documented, but its bulk composition is more similar to the majority of samples which have been analysed in this study. Trace element data obtained from repeated analyses of these standards are shown in Tables 3.06 and 3.07. Approximate $2 \mathrm{SD}$ analytical precisions found by 13 replicate analyses of the BCR-2 standard are generally $<5 \%$ for most trace elements. Exceptions to this are $\mathrm{Zn} \pm 8.5 \%, \mathrm{Cu} \pm 8.8 \%, \mathrm{Cs} \pm 13.1 \%, \mathrm{~Pb} \pm 13.7 \%, \mathrm{Ta} \pm 15.6 \%$ and $\mathrm{Mo} \pm 43.4 \%$. The

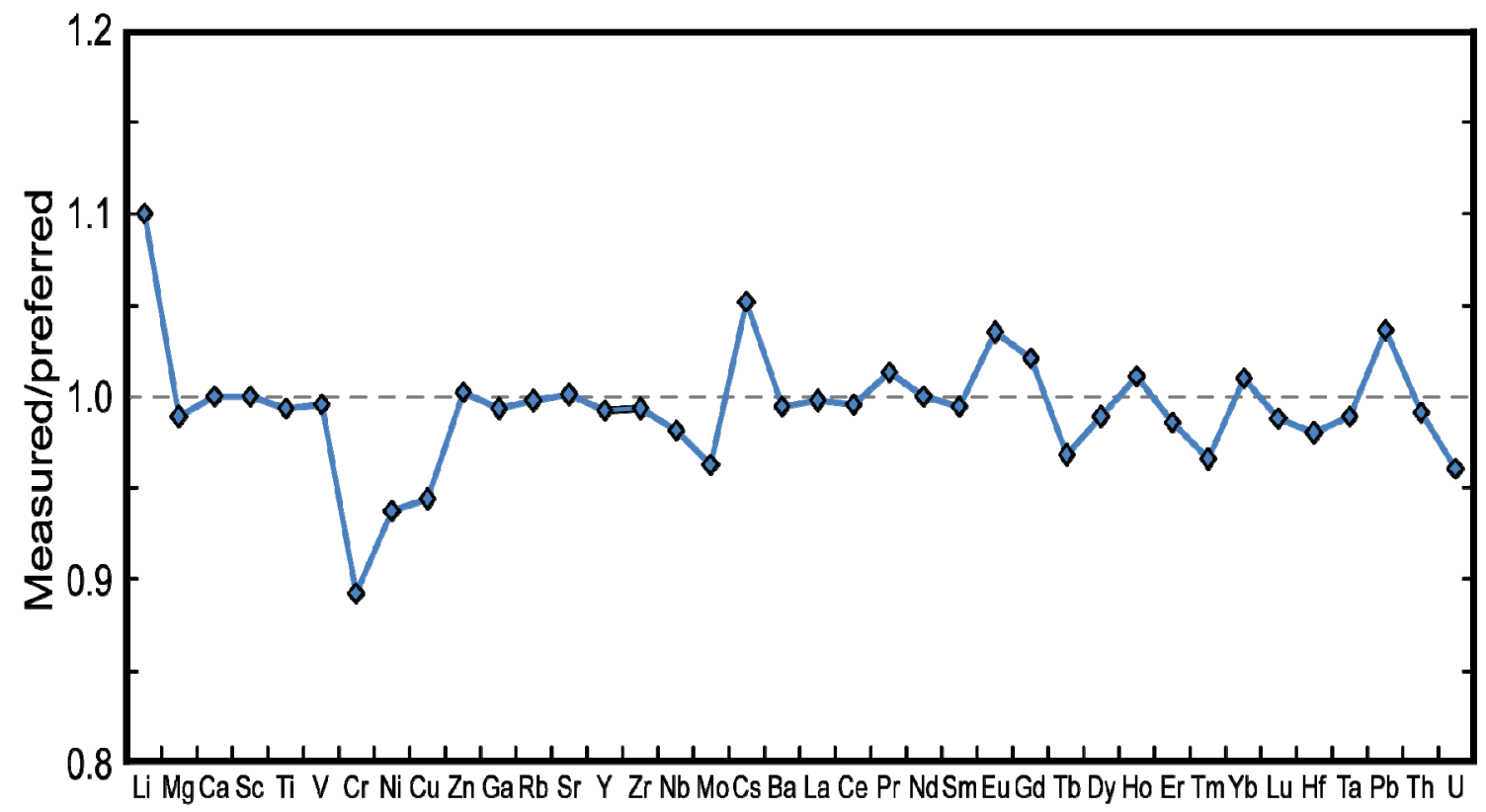

Figure 3.01. Line Graph showing the accuracy of ICP-MS analysis of BCR-2 standard over the range of trace elements measured. Values normalised to BCR-2 reference values from the Georem website (http://georem.mpch-mainz.gwdg.de/) 
Table 3.06. Accuracy and precision of solution ICP-MS trace element analysis: Standard BCR-2.

\begin{tabular}{|c|c|c|c|c|c|c|c|c|c|c|c|c|c|c|c|c|c|c|}
\hline Run & A1 & A2 & A3 & B1 & B2 & B3 & C1 & D1 & E1 & E2 & E3 & F1 & $\mathrm{F} 2$ & Average & $\pm(2 \sigma)$ & $2 \sigma \%$ & Ref. value & $\%$ offset \\
\hline $\mathrm{Li}$ & 9.91 & 9.95 & 9.87 & 9.57 & 9.91 & 9.89 & 9.86 & 10.27 & 9.99 & 9.96 & 9.63 & 9.82 & 10.12 & 9.90 & 0.36 & 3.6 & 9 & 10.0 \\
\hline MgO wt.\% & 3.53 & 3.57 & 3.51 & 3.49 & 3.55 & 3.57 & 3.57 & 3.61 & 3.58 & 3.56 & 3.52 & 3.51 & 3.56 & 3.55 & 0.07 & 1.9 & 3.59 & -1.2 \\
\hline $\mathrm{Sc}$ & 32.9 & 33.2 & 32.3 & 33.4 & 33.3 & 33.5 & 33.2 & 33.0 & 32.7 & 33.0 & 32.8 & 32.7 & 33.0 & 33.0 & 0.7 & 2.0 & 33 & 0.0 \\
\hline $\mathrm{TiO}_{2}$ wt.\% & 2.22 & 2.25 & 2.25 & 2.25 & 2.23 & 2.25 & 2.25 & 2.25 & 2.27 & 2.26 & 2.28 & 2.23 & 2.22 & 2.25 & 0.04 & 1.6 & 2.26 & -0.6 \\
\hline V & 417 & 419 & 413 & 418 & 417 & 414 & 410 & 415 & 412 & 416 & 415 & 405 & 414 & 414 & 7.16 & 1.7 & 416 & -0.4 \\
\hline $\mathrm{Cr}$ & 14.2 & 14.5 & 14.3 & 14.2 & 14.0 & 14.4 & 14.2 & 14.0 & 14.5 & 14.5 & 14.3 & 14.2 & 14.4 & 14.3 & 0.3 & 2.4 & 16 & -10.8 \\
\hline $\mathrm{Ni}$ & 12.3 & 12.4 & 12.2 & 12.0 & 12.0 & 12.0 & 11.8 & 12.1 & 12.4 & 12.2 & 12.3 & 12.2 & 12.5 & 12.2 & 0.4 & 3.3 & 13 & -6.3 \\
\hline $\mathrm{Cu}$ & 21.1 & 21.0 & 20.8 & 20.8 & 20.2 & 19.4 & 19.1 & 18.9 & 18.9 & 18.9 & 19.1 & 19.8 & 19.7 & 19.8 & 1.7 & 8.8 & 21 & -5.7 \\
\hline $\mathrm{Zn}$ & 117 & 119 & 118 & 132 & 131 & 132 & 131 & 130 & 129 & 129 & 130 & 127 & 130 & 127 & 11 & 8.5 & 127 & 0.2 \\
\hline $\mathrm{Ga}$ & 22.7 & 23.3 & 22.7 & 22.9 & 22.6 & 22.8 & 22.6 & 22.6 & 23.2 & 23.0 & 23.2 & 22.6 & 22.7 & 22.8 & 0.5 & 2.2 & 23.0 & -0.7 \\
\hline $\mathrm{Rb}$ & 46.8 & 46.9 & 46.7 & 47.4 & 46.9 & 47.1 & 46.8 & 46.6 & 46.6 & 46.8 & 46.8 & 46.3 & 46.3 & 46.8 & 0.6 & 1.2 & 46.9 & -0.3 \\
\hline $\mathrm{Sr}$ & 343 & 344 & 339 & 341 & 337 & 340 & 338 & 342 & 336 & 343 & 341 & 340 & 339 & 340 & 5 & 1.4 & 340 & 0.1 \\
\hline Y & 35.8 & 36.1 & 35.8 & 36.1 & 35.9 & 35.8 & 35.5 & 35.6 & 35.6 & 35.8 & 36.0 & 35.1 & 35.5 & 35.7 & 0.6 & 1.6 & 36 & -0.8 \\
\hline $\mathrm{Zr}$ & 187 & 190 & 188 & 190 & 188 & 188 & 187 & 186 & 186 & 188 & 189 & 187 & 187 & 188 & 3 & 1.5 & 189 & -0.7 \\
\hline $\mathrm{Nb}$ & 12.1 & 12.3 & 12.1 & 12.3 & 12.2 & 12.2 & 12.3 & 12.6 & 12.7 & 12.9 & 13.0 & 12.1 & 12.0 & 12.4 & 0.6 & 4.9 & 12.6 & -1.9 \\
\hline Mo & 293 & 299 & 294 & 230 & 228 & 230 & 227 & 179 & 177 & 178 & 182 & 304 & 305 & 241 & 104 & 43.4 & 250 & -3.8 \\
\hline Cs & 1.23 & 1.26 & 1.23 & 1.19 & 1.18 & 1.21 & 1.17 & 1.05 & 1.05 & 1.05 & 1.07 & 1.18 & 1.17 & 1.16 & 0.15 & 13.1 & 1.1 & 5.2 \\
\hline $\mathrm{Ba}$ & 665 & 685 & 676 & 689 & 672 & 678 & 664 & 670 & 667 & 687 & 680 & 658 & 665 & 673 & 20 & 3.0 & 677 & -0.5 \\
\hline La & 24.9 & 25.3 & 25.1 & 25.5 & 25.1 & 25.1 & 25.1 & 24.7 & 25.2 & 25.4 & 25.2 & 24.5 & 24.7 & 25.0 & 0.6 & 2.3 & 25.12 & -0.3 \\
\hline $\mathrm{Ce}$ & 52.6 & 53.8 & 52.6 & 54.0 & 52.5 & 53.3 & 52.4 & 53.3 & 52.4 & 53.2 & 53.3 & 51.7 & 52.5 & 52.9 & 1.3 & 2.5 & 53.13 & -0.5 \\
\hline $\operatorname{Pr}$ & 6.80 & 6.94 & 6.85 & 7.00 & 6.85 & 6.88 & 6.81 & 6.79 & 6.83 & 6.81 & 6.91 & 6.71 & 6.78 & 6.84 & 0.15 & 2.2 & 6.76 & 1.3 \\
\hline $\mathrm{Nd}$ & 28.7 & 29.4 & 29.5 & 29.1 & 28.6 & 28.9 & 28.4 & 28.7 & 28.6 & 28.4 & 28.5 & 28.4 & 28.3 & 28.7 & 0.8 & 2.7 & 28.7 & 0.0 \\
\hline Sm & 6.50 & 6.63 & 6.50 & 6.65 & 6.56 & 6.72 & 6.46 & 6.45 & 6.46 & 6.57 & 6.51 & 6.46 & 6.59 & 6.54 & 0.17 & 2.6 & 6.58 & -0.6 \\
\hline Eu & 2.01 & 2.05 & 2.02 & 2.05 & 1.99 & 2.01 & 1.98 & 2.01 & 1.99 & 2.03 & 2.01 & 2.00 & 2.02 & 2.01 & 0.04 & 2.1 & 1.944 & 3.5 \\
\hline $\mathrm{Gd}$ & 6.77 & 6.97 & 7.07 & 6.98 & 6.80 & 6.83 & 6.87 & 6.77 & 6.85 & 6.84 & 6.78 & 6.82 & 6.95 & 6.87 & 0.19 & 2.7 & 6.73 & 2.1 \\
\hline $\mathrm{Tb}$ & 1.04 & 1.05 & 1.04 & 1.05 & 1.03 & 1.04 & 1.04 & 1.02 & 1.03 & 1.03 & 1.03 & 1.02 & 1.03 & 1.04 & 0.02 & 2.0 & 1.07 & -3.3 \\
\hline Dy & 6.32 & 6.44 & 6.35 & 6.47 & 6.37 & 6.40 & 6.41 & 6.28 & 6.27 & 6.47 & 6.39 & 6.22 & 6.36 & 6.37 & 0.15 & 2.4 & 6.44 & -1.1 \\
\hline Ho & 1.30 & 1.31 & 1.30 & 1.32 & 1.27 & 1.31 & 1.29 & 1.27 & 1.28 & 1.31 & 1.30 & 1.27 & 1.29 & 1.29 & 0.03 & 2.5 & 1.28 & 1.1 \\
\hline Er & 3.67 & 3.69 & 3.68 & 3.73 & 3.60 & 3.66 & 3.65 & 3.63 & 3.63 & 3.71 & 3.68 & 3.61 & 3.62 & 3.66 & 0.08 & 2.1 & 3.71 & -1.4 \\
\hline $\mathrm{Tm}$ & 0.518 & 0.528 & 0.528 & 0.533 & 0.523 & 0.520 & 0.521 & 0.512 & 0.518 & 0.532 & 0.514 & 0.515 & 0.516 & 0.521 & 0.014 & 2.6 & 0.54 & -3.5 \\
\hline $\mathrm{Yb}$ & 3.37 & 3.42 & 3.39 & 3.45 & 3.32 & 3.37 & 3.38 & 3.32 & 3.33 & 3.43 & 3.34 & 3.39 & 3.34 & 3.37 & 0.08 & 2.5 & 3.34 & 1.0 \\
\hline Lu & 0.498 & 0.499 & 0.491 & 0.511 & 0.492 & 0.501 & 0.489 & 0.487 & 0.481 & 0.494 & 0.496 & 0.487 & 0.485 & 0.493 & 0.016 & 3.2 & 0.50 & -1.2 \\
\hline $\mathrm{Hf}$ & 4.82 & 4.87 & 4.85 & 4.99 & 4.85 & 4.84 & 4.77 & 4.63 & 4.72 & 4.76 & 4.81 & 4.75 & 4.74 & 4.80 & 0.17 & 3.6 & 4.90 & -2.0 \\
\hline Ta & 0.753 & 0.766 & 0.759 & 0.786 & 0.755 & 0.767 & 0.768 & 0.845 & 0.887 & 0.893 & 0.924 & 0.755 & 0.758 & 0.801 & 0.125 & 15.6 & 0.81 & -1.1 \\
\hline $\mathrm{Pb}$ & 10.2 & 10.7 & 10.4 & 12.5 & 11.9 & 12.1 & 11.6 & 11.7 & 11.8 & 12.0 & 12.1 & 10.6 & 10.5 & 11.4 & 1.6 & 13.7 & 11.0 & 3.7 \\
\hline Th & 5.92 & 6.12 & 5.99 & 6.29 & 5.70 & 5.77 & 5.79 & 5.76 & 5.56 & 5.58 & 5.83 & 5.82 & 5.87 & 5.85 & 0.40 & 6.9 & 5.90 & -0.9 \\
\hline U & 1.64 & 1.66 & 1.62 & 1.70 & 1.58 & 1.65 & 1.61 & 1.59 & 1.57 & 1.64 & 1.65 & 1.60 & 1.58 & 1.62 & 0.08 & 4.6 & 1.69 & -3.9 \\
\hline
\end{tabular}

values from Georem website (http://georem.mpch-mainz.gwdg.de/). 
Table 3.07. Precision of solution ICP-MS trace element analysis: Standard JR-1

\begin{tabular}{|c|c|c|c|c|c|c|c|c|c|c|c|c|}
\hline Run & A1 & A2 & B1 & B2 & B3 & B4 & C1 & C2 & C3 & Average & $\pm(2 \sigma)$ & $2 \sigma \%$ \\
\hline $\mathrm{Li}$ & 63.8 & 65.5 & 64.8 & 62.9 & 65.3 & 63.5 & 64.4 & 67.1 & 64.0 & 64.6 & 2.5 & 3.9 \\
\hline $\mathrm{MgO}$ wt. \% & 0.115 & 0.115 & 0.107 & 0.108 & 0.109 & 0.105 & 0.116 & 0.118 & 0.109 & 0.111 & 0.009 & 8.4 \\
\hline Sc & 4.79 & 4.9 & 4.6 & 4.7 & 4.8 & 4.6 & 4.6 & 4.7 & 4.7 & 4.7 & 0.2 & 3.6 \\
\hline $\mathrm{TiO}_{2}$ wt. $\%$ & 0.095 & 0.096 & 0.096 & 0.095 & 0.096 & 0.098 & 0.097 & 0.098 & 0.096 & 0.096 & 0.002 & 1.9 \\
\hline V & 5.25 & 5.26 & 5.07 & 5.10 & 5.21 & 5.34 & 4.97 & 5.01 & 5.15 & 5.15 & 0.25 & 4.9 \\
\hline $\mathrm{Cr}$ & 0.91 & 0.90 & 1.02 & 1.10 & 1.09 & 1.06 & 1.02 & 1.06 & 1.07 & 1.02 & 0.14 & 13.9 \\
\hline $\mathrm{Ni}$ & 0.495 & 0.495 & 0.521 & 0.520 & 0.453 & 0.532 & 0.537 & 0.555 & 0.511 & 0.513 & 0.060 & 11.6 \\
\hline $\mathrm{Cu}$ & 3.10 & 3.15 & 2.87 & 2.89 & 2.96 & 2.91 & 2.96 & 3.07 & 2.93 & 2.98 & 0.20 & 6.7 \\
\hline $\mathrm{Zn}$ & 21.0 & 22.7 & 26.0 & 25.0 & 24.6 & 25.8 & 23.9 & 24.6 & 24.8 & 24.3 & 3.1 & 12.9 \\
\hline $\mathrm{Ga}$ & 16.4 & 16.9 & 16.0 & 15.9 & 16.1 & 17.1 & 16.3 & 17.1 & 16.3 & 16.5 & 0.9 & 5.7 \\
\hline $\mathrm{Rb}$ & 233 & 240 & 223 & 224 & 226 & 238 & 229 & 235 & 229 & 231 & 12 & 5.2 \\
\hline $\mathrm{Sr}$ & 26.5 & 27.1 & 25.5 & 25.7 & 25.7 & 27.4 & 26.5 & 26.5 & 26.4 & 26.4 & 1.3 & 4.9 \\
\hline Y & 40.4 & 41.2 & 38.9 & 38.6 & 39.3 & 41.3 & 40.1 & 40.8 & 39.8 & 40.1 & 2.0 & 4.9 \\
\hline $\mathrm{Zr}$ & 87.6 & 89.4 & 85.2 & 84.8 & 85.1 & 89.5 & 84.1 & 84.6 & 85.9 & 86.3 & 4.2 & 4.8 \\
\hline $\mathrm{Nb}$ & 14.2 & 14.6 & 13.9 & 13.8 & 14.0 & 14.8 & 14.4 & 14.7 & 14.2 & 14.3 & 0.7 & 4.9 \\
\hline Mo & 3.17 & 3.27 & 2.45 & 2.45 & 2.48 & 2.62 & 1.94 & 1.94 & 2.37 & 2.52 & 0.92 & 36.6 \\
\hline Cs & 19.9 & 20.4 & 18.9 & 18.7 & 19.3 & 20.3 & 17.0 & 16.9 & 18.8 & 18.9 & 2.5 & 13.4 \\
\hline $\mathrm{Ba}$ & 43.5 & 45.5 & 42.5 & 42.9 & 43.4 & 45.2 & 43.0 & 44.2 & 43.6 & 43.8 & 2.0 & 4.6 \\
\hline La & 18.4 & 19.2 & 17.7 & 17.7 & 18.3 & 18.8 & 18.0 & 18.3 & 18.2 & 18.3 & 0.9 & 5.1 \\
\hline $\mathrm{Ce}$ & 44.3 & 45.6 & 42.0 & 42.4 & 42.6 & 44.5 & 42.8 & 44.4 & 43.1 & 43.5 & 2.4 & 5.5 \\
\hline $\operatorname{Pr}$ & 5.59 & 5.84 & 5.37 & 5.39 & 5.50 & 5.72 & 5.54 & 5.66 & 5.54 & 5.57 & 0.30 & 5.4 \\
\hline $\mathrm{Nd}$ & 22.4 & 23.1 & 21.1 & 21.1 & 21.4 & 22.3 & 21.7 & 22.5 & 21.6 & 21.9 & 1.4 & 6.4 \\
\hline $\mathrm{Sm}$ & 5.41 & 5.71 & 5.17 & 5.18 & 5.36 & 5.43 & 5.31 & 5.45 & 5.32 & 5.37 & 0.32 & 6.0 \\
\hline Eu & 0.262 & 0.275 & 0.251 & 0.248 & 0.254 & 0.263 & 0.256 & 0.262 & 0.255 & 0.258 & 0.016 & 6.1 \\
\hline Gd & 5.42 & 5.65 & 5.25 & 5.19 & 5.42 & 5.43 & 5.51 & 5.44 & 5.39 & 5.41 & 0.27 & 5.0 \\
\hline $\mathrm{Tb}$ & 0.902 & 0.953 & 0.868 & 0.873 & 0.897 & 0.920 & 0.917 & 0.906 & 0.902 & 0.904 & 0.051 & 5.6 \\
\hline Dy & 5.89 & 6.15 & 5.65 & 5.75 & 5.79 & 6.08 & 5.90 & 5.96 & 5.88 & 5.89 & 0.31 & 5.3 \\
\hline Ho & 1.26 & 1.30 & 1.20 & 1.21 & 1.23 & 1.29 & 1.24 & 1.25 & 1.24 & 1.25 & 0.06 & 5.2 \\
\hline Er & 3.87 & 4.03 & 3.70 & 3.71 & 3.80 & 3.94 & 3.86 & 3.90 & 3.83 & 3.85 & 0.21 & 5.4 \\
\hline Tm & 0.622 & 0.640 & 0.594 & 0.596 & 0.607 & 0.624 & 0.610 & 0.617 & 0.609 & 0.613 & 0.029 & 4.7 \\
\hline $\mathrm{Yb}$ & 4.39 & 4.55 & 4.18 & 4.22 & 4.29 & 4.43 & 4.33 & 4.37 & 4.32 & 4.34 & 0.22 & 5.1 \\
\hline Lu & 0.656 & 0.680 & 0.625 & 0.635 & 0.644 & 0.666 & 0.659 & 0.658 & 0.651 & 0.652 & 0.033 & 5.0 \\
\hline $\mathrm{Hf}$ & 4.33 & 4.51 & 4.15 & 4.10 & 4.23 & 4.36 & 4.07 & 3.99 & 4.19 & 4.21 & 0.32 & 7.7 \\
\hline $\mathrm{Ta}$ & 1.55 & 1.59 & 1.47 & 1.45 & 1.50 & 1.57 & 1.41 & 1.44 & 1.48 & 1.50 & 0.12 & 8.3 \\
\hline $\mathrm{Pb}$ & 17.9 & 18.5 & 19.7 & 19.3 & 19.9 & 20.8 & 20.4 & 20.3 & 20.1 & 19.7 & 1.9 & 9.6 \\
\hline Th & 25.5 & 25.9 & 23.6 & 23.0 & 24.0 & 24.5 & 23.5 & 24.0 & 23.8 & 24.2 & 1.9 & 7.9 \\
\hline U & 7.92 & 8.21 & 7.59 & 7.47 & 7.77 & 8.10 & 7.87 & 7.96 & 7.80 & 7.86 & 0.46 & 5.8 \\
\hline
\end{tabular}

Values have been normalised to $\mathrm{CaO}$. All concentrations in ppm, unless otherwise stated. Letters represent individual digestions, numbers are repeated analysis of the same digestion. As this standard is poorly constrained, no reference values are show, and it has only been used to assess reproducibility. 
majority of BCR-2 trace elements are accurate to $\leq 5 \%$ (most are $<1 \%$ ), apart from Li, $\mathrm{Cr}$ and Ni, which are $\leq 10 \%$ (Table 3.04, Figure 3.01). As reference values for JR-1 are poorly constrained, only the reproducibility of repeated analyses have been determined (Table 3.07). Approximate 2 SD analytical precisions found by 9 replicate analyses of the JR-1 standard are $<5-10 \%$ for most trace elements. Offsets calculated from duplicate analysis on sample solutions also generally vary by $<5 \%$ (mostly $<1-2 \%$ : Table 3.08).

\subsection{3 $\mathrm{Pb}$ isotopes}

Isotope analysis was carried out on the same rock powders that were used for whole rock major and trace element analysis. As the Kermadec samples investigated in this study have previously been exposed to seawater and other common forms of contamination, they were put through a step-leaching procedures to remove any anthropogenic contaminants.

\subsubsection{Sample preparation}

Approximately $500 \mathrm{mg}$ of rock powder was carefully added and precisely weighed in pre-cleaned (Pb-standard) $23 \mathrm{~mL}$ Savillex screw-top teflon beakers. Acid leaching was then conducted on all samples to remove any anthropogenic $\mathrm{Pb}$ contamination. The amount of time and strength of acid required to achieve this step was initially determined by carrying out a series of leaching steps on a single sample (Figure 3.02). For this experiment, a single sample was step leached (partially dissolved) in $5 \mathrm{~mL}$ of different molarity acids, either at room temperature, or on a hotplate at $120^{\circ} \mathrm{C}$ for $1 \mathrm{hr}$. At the end of each stage, the sample was centrifuged at $2000 \mathrm{rpm}$ for $5 \mathrm{~min}$ and the acid leachate was extracted by pipette out into a separate Pb-cleaned beaker for further preparation and individual analysis for its $\mathrm{Pb}$ isotope composition. In between each leaching step, the sample was rinsed 3 times in Milli-Q to remove any traces of the previous acid leachate. As shown in Figure 3.02, weaker acids at room temperature did not fully remove the anthropogenic $\mathrm{Pb}$ and the leachates fall along a mixing trend between the final composition of the rock and the composition of the contaminating $\mathrm{Pb}$. When the sample was leached on a hotplate at $120{ }^{\circ} \mathrm{C}$, however, the acids removed considerably more anthropogenic $\mathrm{Pb}$, and the resulting leachates have a $\mathrm{Pb}$ isotope composition more similar to that of the rock sample. From this experiment, it was 
Table 3.08. Duplicate trace element analysis on samples analysed in this study by solution ICP-MS

\begin{tabular}{|c|c|c|c|c|c|c|c|c|c|c|c|c|c|c|c|}
\hline & RI03_PC03 & & & RI12_PC08 & & & RI12_PC18 & & & RI18_PC05 & & & RI26_PC01 & & \\
\hline Run & 1 & $2^{*}$ & $\%$ offset & 1 & 2 & $\%$ offset & 1 & $2^{*}$ & $\%$ offset & 1 & 2 & $\%$ offset & 1 & 2 & $\%$ offset \\
\hline $\mathrm{Li}$ & 8.28 & 8.01 & 3.3 & 10.10 & 9.98 & 1.2 & 10.93 & 10.72 & 1.9 & 11.96 & 12.02 & -0.5 & 10.72 & 10.80 & -0.8 \\
\hline MgO wt. \% & 1.66 & 1.63 & 2.0 & 1.37 & 1.36 & 0.6 & 1.54 & 1.50 & 2.0 & 1.15 & 1.16 & -0.3 & 1.32 & 1.33 & -0.4 \\
\hline Sc & 25.8 & 25.1 & 2.8 & 20.9 & 20.7 & 1.1 & 23.2 & 23.2 & 0.1 & 21.8 & 21.8 & -0.4 & 22.8 & 22.7 & 0.1 \\
\hline $\mathrm{TiO}_{2}$ wt. $\%$ & 0.659 & 0.656 & 0.5 & 0.577 & 0.586 & -1.4 & 0.635 & 0.634 & 0.2 & 0.605 & 0.615 & -1.7 & 0.597 & 0.597 & -0.1 \\
\hline V & 57.3 & 54.9 & 4.3 & 32.9 & 33.1 & -0.6 & 38.4 & 38.6 & -0.3 & 19.9 & 20.5 & -3.4 & 41.5 & 41.1 & 1.0 \\
\hline $\mathrm{Cr}$ & 2.02 & 2.01 & 0.6 & 1.34 & 1.40 & -4.5 & 2.64 & 2.83 & -7.1 & 1.10 & 1.20 & -8.9 & 3.43 & 3.32 & 3.2 \\
\hline $\mathrm{Ni}$ & 1.15 & 1.03 & 10.2 & 0.99 & 0.97 & 1.9 & 1.20 & 1.28 & -7.3 & 0.77 & 0.71 & 8.5 & 1.68 & 1.66 & 1.3 \\
\hline $\mathrm{Cu}$ & 14.3 & 12.9 & 9.9 & 10.5 & 10.4 & 1.7 & 13.4 & 13.1 & 2.1 & 8.6 & 8.8 & -2.1 & 11.0 & 10.5 & 4.9 \\
\hline$Z n$ & 107 & 110 & -2.6 & 78 & 78 & 0.5 & 85 & 97 & -13.8 & 81 & 83 & -3.2 & 87 & 88 & -1.9 \\
\hline $\mathrm{Ga}$ & 16.8 & 16.3 & 2.5 & 16.1 & 16.0 & 1.0 & 17.5 & 17.1 & 2.4 & 15.5 & 15.8 & -2.2 & 15.6 & 15.4 & 1.6 \\
\hline $\mathrm{Rb}$ & 7.96 & 7.63 & 4.2 & 10.03 & 9.94 & 0.9 & 10.54 & 10.53 & 0.1 & 9.21 & 9.61 & -4.3 & 9.62 & 9.52 & 1.1 \\
\hline $\mathrm{Sr}$ & 182 & 176 & 3.6 & 193 & 191 & 1.1 & 206 & 203 & 1.8 & 172 & 178 & -3.8 & 164 & 162 & 1.0 \\
\hline Y & 37.8 & 36.1 & 4.6 & 37.4 & 37.1 & 0.6 & 39.7 & 39.2 & 1.5 & 39.6 & 41.3 & -4.3 & 38.6 & 37.8 & 2.3 \\
\hline $\mathrm{Zr}$ & 65.0 & 62.7 & 3.5 & 75.1 & 73.9 & 1.6 & 80.0 & 78.6 & 1.7 & 70.9 & 73.3 & -3.4 & 71.6 & 70.2 & 1.9 \\
\hline $\mathrm{Nb}$ & 0.536 & 0.497 & 7.2 & 0.708 & 0.693 & 2.2 & 0.760 & 0.741 & 2.5 & 0.589 & 0.612 & -3.9 & 0.658 & 0.644 & 2.1 \\
\hline Mo & 2.50 & 1.93 & 23.0 & 2.52 & 2.47 & 1.9 & 2.76 & 2.14 & 22.4 & 2.53 & 2.61 & -3.3 & 2.02 & 1.98 & 2.0 \\
\hline Cs & 0.660 & 0.635 & 3.9 & 0.741 & 0.727 & 1.8 & 0.793 & 0.769 & 3.1 & 0.792 & 0.807 & -1.9 & 0.818 & 0.815 & 0.4 \\
\hline $\mathrm{Ba}$ & 197 & 188 & 4.3 & 220 & 219 & 0.6 & 235 & 234 & 0.6 & 208 & 213 & -2.6 & 204 & 201 & 1.4 \\
\hline La & 3.40 & 3.25 & 4.3 & 4.80 & 4.74 & 1.4 & 5.09 & 5.03 & 1.2 & 3.85 & 3.97 & -3.2 & 4.31 & 4.18 & 3.0 \\
\hline $\mathrm{Ce}$ & 9.76 & 9.31 & 4.6 & 13.07 & 12.91 & 1.3 & 13.90 & 13.67 & 1.7 & 10.81 & 11.27 & -4.2 & 11.76 & 11.67 & 0.7 \\
\hline $\mathrm{Pr}$ & 1.70 & 1.64 & 3.6 & 2.18 & 2.17 & 0.5 & 2.31 & 2.29 & 1.2 & 1.90 & 1.97 & -3.3 & 1.99 & 1.97 & 1.2 \\
\hline $\mathrm{Nd}$ & 9.42 & 9.11 & 3.3 & 11.57 & 11.46 & 1.0 & 12.27 & 12.12 & 1.3 & 10.46 & 10.88 & -4.0 & 10.70 & 10.56 & 1.3 \\
\hline $\mathrm{Sm}$ & 3.44 & 3.31 & 3.7 & 3.88 & 3.73 & 3.9 & 4.06 & 3.96 & 2.7 & 3.68 & 3.80 & -3.5 & 3.73 & 3.58 & 4.1 \\
\hline $\mathrm{Eu}$ & 1.22 & 1.16 & 5.0 & 1.27 & 1.24 & 2.3 & 1.34 & 1.30 & 2.6 & 1.24 & 1.27 & -2.4 & 1.19 & 1.15 & 3.5 \\
\hline$G d$ & 4.57 & 4.43 & 3.0 & 4.87 & 4.79 & 1.7 & 5.14 & 5.07 & 1.3 & 4.81 & 5.15 & -7.0 & 4.90 & 4.75 & 3.1 \\
\hline $\mathrm{Tb}$ & 0.855 & 0.812 & 5.1 & 0.878 & 0.850 & 3.2 & 0.923 & 0.905 & 1.9 & 0.912 & 0.942 & -3.3 & 0.885 & 0.856 & 3.2 \\
\hline Dy & 6.04 & 5.82 & 3.5 & 6.10 & 5.97 & 2.1 & 6.46 & 6.29 & 2.7 & 6.41 & 6.53 & -1.9 & 6.20 & 6.01 & 2.9 \\
\hline $\mathrm{Ho}$ & 1.35 & 1.30 & 3.6 & 1.34 & 1.32 & 1.6 & 1.42 & 1.40 & 1.9 & 1.42 & 1.46 & -2.9 & 1.37 & 1.34 & 2.0 \\
\hline Er & 4.02 & 3.89 & 3.2 & 4.10 & 3.99 & 2.8 & 4.25 & 4.20 & 1.2 & 4.32 & 4.44 & -2.6 & 4.13 & 4.07 & 1.3 \\
\hline $\mathrm{Tm}$ & 0.612 & 0.577 & 5.7 & 0.613 & 0.608 & 1.0 & 0.648 & 0.645 & 0.5 & 0.660 & 0.677 & -2.5 & 0.620 & 0.608 & 1.8 \\
\hline $\mathrm{Yb}$ & 4.14 & 3.96 & 4.4 & 4.17 & 4.10 & 1.9 & 4.43 & 4.31 & 2.6 & 4.52 & 4.57 & -1.0 & 4.19 & 4.17 & 0.5 \\
\hline Lu & 0.629 & 0.598 & 5.0 & 0.630 & 0.618 & 2.0 & 0.665 & 0.663 & 0.2 & 0.680 & 0.684 & -0.6 & 0.639 & 0.632 & 1.2 \\
\hline $\mathrm{Hf}$ & 2.21 & 2.10 & 4.9 & 2.49 & 2.45 & 1.7 & 2.62 & 2.60 & 0.8 & 2.45 & 2.47 & -0.9 & 2.39 & 2.37 & 0.8 \\
\hline $\mathrm{Ta}$ & 0.0406 & 0.0377 & 7.1 & 0.0535 & 0.0502 & 6.2 & 0.0555 & 0.0556 & -0.2 & 0.0482 & 0.0464 & 3.6 & 0.0485 & 0.0467 & 3.8 \\
\hline $\mathrm{Pb}$ & 12.8 & 14.5 & -12.5 & 3.33 & 3.27 & 1.7 & 4.60 & 5.17 & -12.4 & 3.41 & 3.47 & -1.8 & 4.44 & 4.44 & -0.2 \\
\hline Th & 0.447 & 0.431 & 3.6 & 0.684 & 0.658 & 3.7 & 0.703 & 0.707 & -0.5 & 0.510 & 0.518 & -1.6 & 0.580 & 0.572 & 1.3 \\
\hline$U$ & 0.204 & 0.197 & 3.2 & 0.267 & 0.257 & 3.7 & 0.284 & 0.279 & 1.9 & 0.223 & 0.226 & -1.0 & 0.231 & 0.232 & -0.3 \\
\hline
\end{tabular}

All values normalised to $\mathrm{CaO}$. Concentrations in ppm unless otherwise stated. ${ }^{*}$ denotes samples which were re-run from separate digestions, otherwise samples were re-run on the same dilution. 
Table 3.08. Continued

\begin{tabular}{|c|c|c|c|c|c|c|c|c|c|c|c|c|}
\hline & D33_PC01 & & & D23_PC02 & & & D38_PC06 & & & D47_PC02 & & \\
\hline Run & 1 & 2 & $\%$ offset & 1 & $2^{*}$ & $\%$ offset & 1 & 2 & $\%$ offset & 1 & 2 & $\%$ offset \\
\hline$\overline{\mathrm{Li}}$ & 11.25 & 11.02 & 2.0 & 9.69 & 9.34 & 3.6 & 14.47 & 14.82 & -2.4 & 15.42 & 15.56 & -0.9 \\
\hline MgO wt. \% & 1.20 & 1.18 & 1.1 & 0.69 & 0.66 & 4.9 & 1.23 & 1.27 & -3.2 & 0.86 & 0.87 & -1.8 \\
\hline Sc & 16.0 & 16.0 & -0.1 & 16.7 & 16.9 & -1.2 & 12.3 & 12.6 & -3.0 & 10.4 & 10.5 & -0.3 \\
\hline $\mathrm{TiO}_{2}$ wt. \% & 0.576 & 0.571 & 0.9 & 0.382 & 0.389 & -1.8 & 0.483 & 0.496 & -2.7 & 0.524 & 0.527 & -0.5 \\
\hline V & 37.5 & 37.6 & -0.2 & 12.7 & 13.1 & -2.8 & 50.8 & 51.0 & -0.3 & 16.3 & 16.2 & 0.7 \\
\hline $\mathrm{Cr}$ & 3.06 & 3.04 & 0.5 & 0.90 & 0.94 & -3.9 & 6.66 & 6.75 & -1.4 & 1.78 & 1.71 & 3.7 \\
\hline $\mathrm{Ni}$ & 1.26 & 1.21 & 3.7 & 1.41 & 1.35 & 4.6 & 3.27 & 3.37 & -2.9 & 0.69 & 0.64 & 6.2 \\
\hline $\mathrm{Cu}$ & 34.6 & 34.3 & 1.1 & 8.3 & 8.5 & -2.4 & 20.2 & 20.2 & 0.0 & 7.0 & 6.9 & 2.1 \\
\hline $\mathrm{Zn}$ & 79 & 80 & -0.9 & 78 & 79 & -2.5 & 51 & 52 & -0.7 & 69 & 67 & 2.1 \\
\hline Ga & 16.1 & 15.9 & 1.1 & 14.7 & 15.2 & -3.3 & 16.3 & 16.5 & -1.5 & 16.3 & 16.3 & -0.3 \\
\hline $\mathrm{Rb}$ & 23.19 & 22.95 & 1.1 & 10.39 & 10.61 & -2.1 & 24.30 & 24.65 & -1.4 & 26.18 & 25.99 & 0.7 \\
\hline $\mathrm{Sr}$ & 216 & 214 & 0.8 & 169 & 175 & -3.8 & 218 & 220 & -0.7 & 247 & 243 & 1.7 \\
\hline Y & 35.1 & 34.5 & 1.6 & 38.6 & 40.0 & -3.6 & 38.4 & 38.8 & -1.2 & 40.2 & 39.7 & 1.3 \\
\hline $\mathrm{Zr}$ & 109.4 & 108.3 & 1.0 & 82.9 & 85.7 & -3.3 & 160.6 & 162.5 & -1.2 & 162.8 & 160.1 & 1.7 \\
\hline $\mathrm{Nb}$ & 1.143 & 1.148 & -0.5 & 0.725 & 0.753 & -3.8 & 2.964 & 2.996 & -1.1 & 2.983 & 2.977 & 0.2 \\
\hline Mo & 1.49 & 1.48 & 0.6 & 1.86 & 1.91 & -2.6 & 1.62 & 1.65 & -2.0 & 1.35 & 1.32 & 1.6 \\
\hline Cs & 1.276 & 1.252 & 1.9 & 0.841 & 0.856 & -1.8 & 0.720 & 0.732 & -1.6 & 0.716 & 0.718 & -0.3 \\
\hline $\mathrm{Ba}$ & 424 & 422 & 0.3 & 231 & 231 & 0.1 & 778 & 788 & -1.2 & 833 & 825 & 0.9 \\
\hline La & 8.36 & 8.33 & 0.4 & 5.11 & 5.23 & -2.2 & 13.08 & 13.04 & 0.3 & 13.75 & 13.70 & 0.4 \\
\hline $\mathrm{Ce}$ & 20.62 & 20.68 & -0.3 & 13.59 & 13.81 & -1.6 & 30.09 & 29.97 & 0.4 & 32.06 & 31.26 & 2.5 \\
\hline $\mathrm{Pr}$ & 3.11 & 3.07 & 1.4 & 2.21 & 2.24 & -1.4 & 4.25 & 4.27 & -0.3 & 4.49 & 4.43 & 1.2 \\
\hline $\mathrm{Nd}$ & 14.86 & 14.91 & -0.3 & 11.46 & 11.72 & -2.2 & 19.06 & 18.93 & 0.7 & 20.13 & 20.21 & -0.4 \\
\hline $\mathrm{Sm}$ & 4.16 & 4.18 & -0.4 & 3.75 & 3.75 & 0.0 & 4.89 & 4.91 & -0.4 & 5.17 & 5.10 & 1.4 \\
\hline Eu & 1.27 & 1.27 & -0.1 & 1.20 & 1.23 & -2.3 & 1.43 & 1.44 & -0.3 & 1.56 & 1.53 & 1.8 \\
\hline Gd & 4.88 & 4.76 & 2.5 & 4.86 & 4.83 & 0.4 & 5.44 & 5.43 & 0.3 & 5.70 & 5.66 & 0.6 \\
\hline $\mathrm{Tb}$ & 0.828 & 0.824 & 0.5 & 0.878 & 0.886 & -0.9 & 0.912 & 0.926 & -1.5 & 0.961 & 0.942 & 2.0 \\
\hline Dy & 5.65 & 5.57 & 1.4 & 6.17 & 6.27 & -1.7 & 6.10 & 6.16 & -0.9 & 6.37 & 6.38 & -0.1 \\
\hline Ho & 1.22 & 1.23 & -0.4 & 1.37 & 1.40 & -2.2 & 1.34 & 1.32 & 1.2 & 1.37 & 1.38 & -0.7 \\
\hline $\mathrm{Er}$ & 3.72 & 3.69 & 0.8 & 4.14 & 4.24 & -2.4 & 4.06 & 4.08 & -0.4 & 4.15 & 4.17 & -0.5 \\
\hline $\mathrm{Tm}$ & 0.569 & 0.555 & 2.5 & 0.634 & 0.641 & -1.2 & 0.621 & 0.634 & -2.2 & 0.637 & 0.629 & 1.2 \\
\hline $\mathrm{Yb}$ & 3.88 & 3.81 & 1.8 & 4.37 & 4.40 & -0.7 & 4.31 & 4.32 & -0.3 & 4.40 & 4.32 & 1.8 \\
\hline Lu & 0.581 & 0.579 & 0.2 & 0.665 & 0.682 & -2.6 & 0.666 & 0.659 & 1.0 & 0.661 & 0.663 & -0.3 \\
\hline $\mathrm{Hf}$ & 3.23 & 3.20 & 0.9 & 2.64 & 2.73 & -3.1 & 4.34 & 4.34 & 0.0 & 4.24 & 4.24 & 0.1 \\
\hline Тa & 0.0814 & 0.0817 & -0.4 & 0.0544 & 0.0552 & -1.5 & 0.1966 & 0.1978 & -0.6 & 0.1961 & 0.1966 & -0.3 \\
\hline $\mathrm{Pb}$ & 6.49 & 6.49 & 0.1 & 3.72 & 3.77 & -1.3 & 3.75 & 3.81 & -1.5 & 4.43 & 4.48 & -1.1 \\
\hline Th & 1.663 & 1.635 & 1.7 & 0.822 & 0.857 & -4.3 & 2.354 & 2.352 & 0.1 & 2.429 & 2.472 & -1.8 \\
\hline U & 0.557 & 0.555 & 0.5 & 0.294 & 0.293 & 0.1 & 0.707 & 0.692 & 2.2 & 0.722 & 0.732 & -1.4 \\
\hline
\end{tabular}



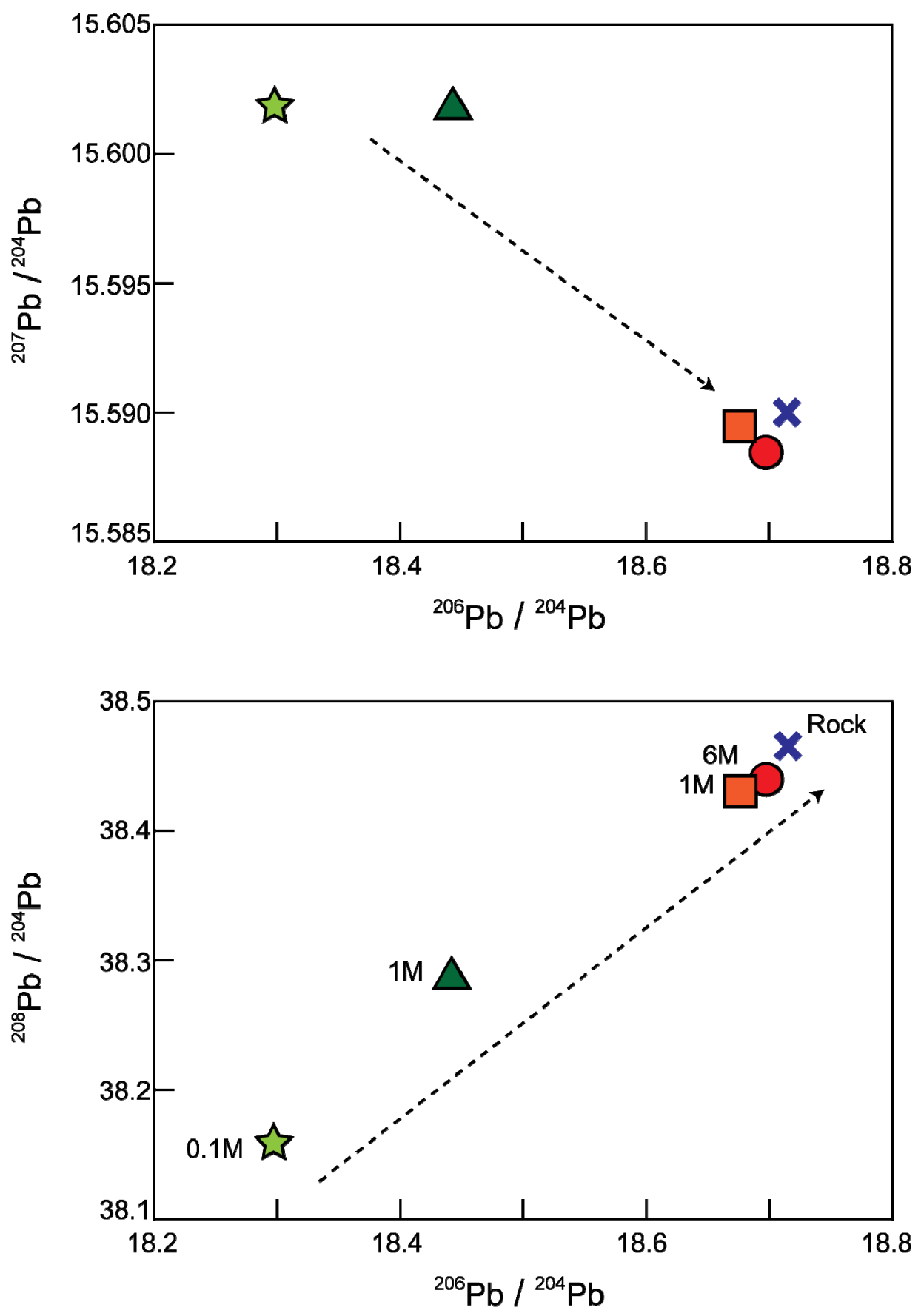

Figure 3.02. $\mathrm{Pb}$ isotope compositions of leachate and a single rock sample from the stepleaching experiment. Each different filled symbol represents the composition of the acid leachate removed after 1 hour, either at room temperature (green symbols) or on a hotplate at $120^{\circ} \mathrm{C}$ (orange-red symbols). The dark blue cross is the final composition measured from rock sample D25_PC01. All acids used in this experiment were SeaStar ultra-pure $\mathrm{HCl} .2 \sigma$ uncertainty is smaller than the size of the symbols (see Table 3.09).

calculated that samples required ca. 2 hours of leaching in a single cycle of $1 \mathrm{M} \mathrm{HCl}$ acid at $120^{\circ} \mathrm{C}$ to removed anthropogenic $\mathrm{Pb}$ prior to digestion. Standard JB-2 was the only sample which did not go through this leaching process.

Following the acid leaching procedure, samples were rinsed in Milli-Q and then refluxed on a hotplate in $1 \mathrm{~mL}$ of $29 \mathrm{M} \mathrm{HF}$ with $0.2 \mathrm{~mL}$ of $16 \mathrm{M} \mathrm{HNO}_{3}$ for $2-3$ days to 
ensure complete digestion. Samples were then evaporated, and re-dissolved in $1 \mathrm{~mL}$ of $16 \mathrm{M} \mathrm{HNO}_{3}$. This step was repeated twice to nitrify the samples. Following these steps, the samples were re-dissolved on a hotplate in $3 \mathrm{~mL}$ of $0.8 \mathrm{M} \mathrm{HBr}$ for at least 24 hours to equilibrate the solution in bromide form. Following evaporation, the sample was then once again dissolved in ca. $1.5 \mathrm{~mL}$ of $0.8 \mathrm{M} \mathrm{HBr}$, ready for $\mathrm{Pb}$ separation.

\subsubsection{Pb separation}

$\mathrm{Pb}$ was separated from the bromide solution by a double pass through AG1-X8 anion exchange resin. This was done by converting $1 \mathrm{~mL}$ pipette tips into columns by inserting polypropylene frits into the end of the pipette tip. These columns were then soaked in $2 \mathrm{M} \mathrm{HCl}$ for a minimum of 1 week and rinsed at least 3 times in Milli-Q prior to use. Samples were centrifuged at $2000 \mathrm{rpm}$ for 5 minutes to separate the solids from the $1.5 \mathrm{~mL}$ solution. The procedure for $\mathrm{Pb}$ separation from the bromide solution by loading anion exchange resin into the base of the columns is shown in steps 1-6 in Figure 3.03. The $\mathrm{Pb}$ cut resulting from this separation process was then dissolved twice in $16 \mathrm{M} \mathrm{HNO}_{3}$, evaporated and re-dissolved twice in $1.5 \mathrm{~mL}$ of $0.8 \mathrm{M} \mathrm{HBr}$ for a second pass through the $\mathrm{Pb}$ columns, repeating the $\mathrm{Pb}$ separation process. The double pass through the $\mathrm{Pb}$ columns reduces the amount of other matrix elements in the final solution, which could cause analytical artefacts during analysis. Following $\mathrm{Pb}$ separation, the solution was evaporated and then re-dissolved in $2 \mathrm{~mL}$ of $0.5 \% \mathrm{HNO}_{3}$ for analysis.

\subsubsection{Pb isotope analysis}

Samples were analysed for $\mathrm{Pb}$ isotopic compositions using a Nu-Plasma multi-collector inductively coupled plasma mass spectrometer (MC-ICP-MS) at VUW, coupled to a desolvating nebuliser system (DSN-100). The machine was tuned using a $30 \mathrm{ppb}$ solution of $\mathrm{Pb}$ standard NBS-981, by adjusting instrumental conditions including torch position, nebuliser gas flow and voltage across each lens to optimise analytical sensitivity to $\sim 8 \mathrm{~V}$ for ${ }^{208} \mathrm{~Pb}$. Each sample was diluted to $8 \pm 2 \mathrm{~V}$ for ${ }^{208} \mathrm{~Pb}$ with $0.5 \%$ $\mathrm{HNO}_{3}$ in acid-cleaned micro-centrifuge tubes. $\mathrm{Pb}$ isotope measurements were corrected for instrumental mass bias and drift by sample-standard bracketing using standard NBS981. The background was recorded by deflecting the ion beam for 2 mins and automatically deducted from sample measurements. Isotope measurements were 

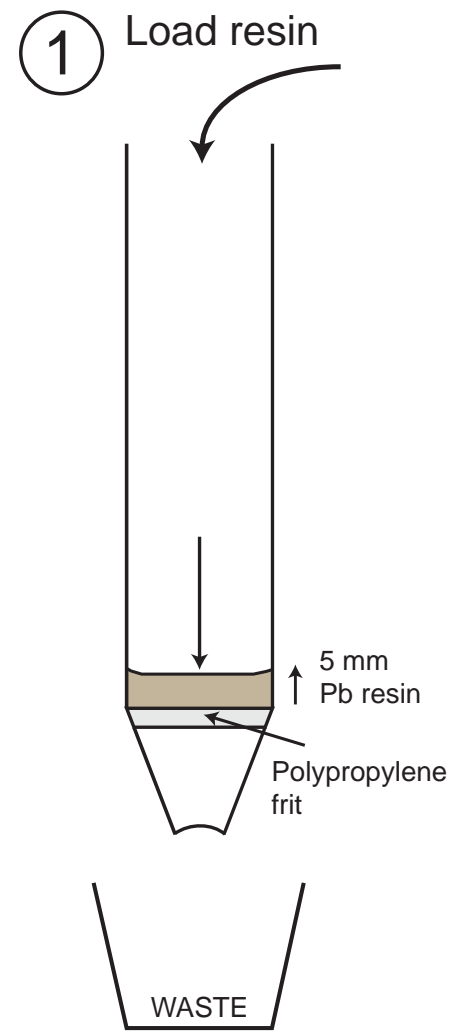

(4)

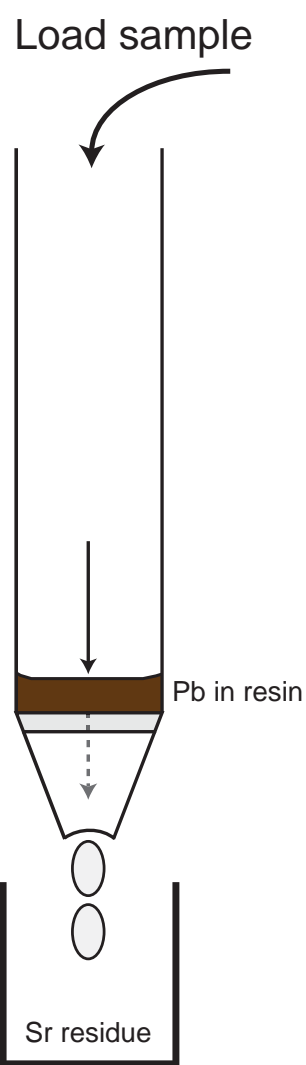

(2)

Clean resin

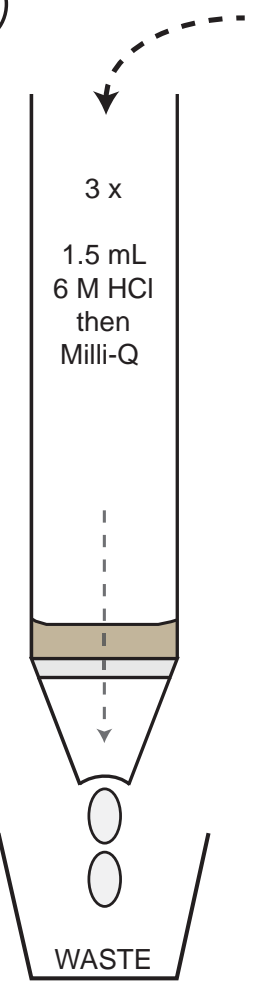

(5)

Flush $\mathrm{Sr}$

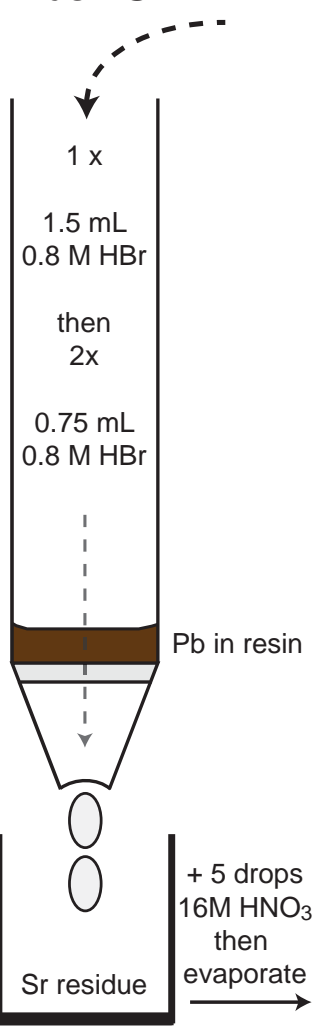

(3)

Equilibrate resin

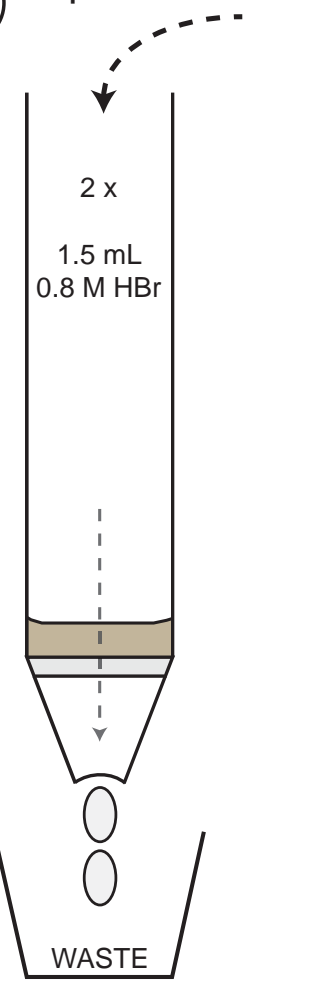

(6)

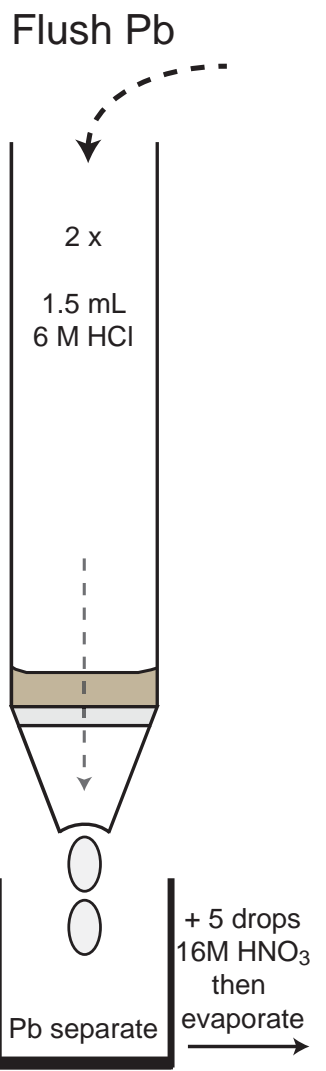

Figure 3.03. Schematic diagram showing the steps in the procedure used to separate $\mathrm{Pb}$ from digested rock samples using anion exchange resin. AG1-X8 resin was used to extract $\mathrm{Pb}$ from solution. This procedure was repeated twice on all samples. 
recorded in $5 \mathrm{~s}$ intervals over a total of 50 integrations (2 blocks of 25). Standard error calculated from the range of values measured over these 50 integrations is presented for each sample in Appendix D, along with the average value for each isotope. Total procedural blanks for this study were typically $<10-15 \mathrm{pg}$ and are insignificant.

\subsubsection{MC-ICP-MS Accuracy and precision of $\mathrm{Pb}$ isotope analyses}

Internal precisions $(2 \mathrm{SE})$ of ${ }^{206} \mathrm{~Pb} /{ }^{204} \mathrm{~Pb},{ }^{207} \mathrm{~Pb} /{ }^{204} \mathrm{~Pb}$ and ${ }^{208} \mathrm{~Pb} /{ }^{204} \mathrm{~Pb}$ were $< \pm 0.0006$, \pm 0.0005 and \pm 0.0013 respectively. $\mathrm{Pb}$ isotope ratios are reported relative to ${ }^{206} \mathrm{~Pb} /{ }^{204} \mathrm{~Pb}$ $=16.9416,{ }^{207} \mathrm{~Pb} /{ }^{204} \mathrm{~Pb}=15.5000$ and ${ }^{208} \mathrm{~Pb} /{ }^{204} \mathrm{~Pb}=36.7262$ for NBS-981 (Baker et al., 2004). Repeated analysis of multiple digestions of the secondary standard JB-2 (an international rock standard from the Geological Survey of Japan) are within analytical error of the reference values from Baker et al. (2004) (Table 3.09).

Table 3.09. Accuracy of MC-ICP-MS Pb isotope analysis: repeated analysis of standard JB-2

\begin{tabular}{|lccccc|cc|}
\hline \multicolumn{1}{|c}{ Run } & A1 & A2 & B1 & B2 & C1 & Average & $\begin{array}{c}\text { Ref. } \\
\text { value }\end{array}$ \\
\hline${ }^{208} \mathrm{~Pb} / 204$ & 38.2704 & 38.2765 & 38.2677 & 38.2750 & 38.2694 & 38.2716 & 38.2784 \\
$\mathrm{~Pb}$ & \pm 47 & \pm 25 & \pm 37 & \pm 36 & \pm 27 & \pm 34 & \pm 50 \\
${ }^{207} \mathrm{~Pb} /{ }^{204}$ & 15.5598 & 15.5623 & 15.5594 & 15.5604 & 15.5604 & 15.5604 & 15.5619 \\
$\mathrm{~Pb}$ & \pm 17 & \pm 10 & \pm 14 & \pm 15 & \pm 10 & \pm 13 & \pm 16 \\
${ }^{206} \mathrm{~Pb} /{ }^{204}$ & 18.3411 & 18.3411 & 18.3416 & 18.3415 & 18.3400 & 18.3411 & 18.3435 \\
$\mathrm{~Pb}$ & \pm 16 & \pm 12 & \pm 14 & \pm 14 & \pm 11 & \pm 14 & \pm 17 \\
\hline
\end{tabular}

Reference values for JB-2 are from Baker et al. (2004). Letters represent individual digestions, numbers are repeated analysis of the same dilution.

\subsection{Mineral/glass major element analysis}

Mineral major element chemistry and crystal imaging were undertaken on a JEOL JXA 8230 SuperProbe electron probe micro-analyser (EPMA) at VUW. The JXA 8230 is equipped with 5 wavelength dispersive X-ray spectrometers (WDS), an energy dispersive X-ray spectrometer (EDS), and highly sensitive detectors for acquisition of backscattered electron (BSE) and secondary electron (SEI) images. EPMA was carried out on crystals set in $32 \mathrm{~mm}$ epoxy disks (section 3.1.2), which were coated with a ca. $25 \mathrm{~nm}$ film of carbon prior to analysis. 


\subsubsection{EPMA analysis}

All images presented in this thesis are BSE images, acquired using an accelerating voltage of $15 \mathrm{kV}$, and a current of $<6-7 \mathrm{nA}$ to avoid alkali migration. EDS analysis was only used for rapid qualitative mineral phase identification; all quantitative analyses were undertaken using WDS. In order to reduce matrix effects, the EPMA was calibrated for quantitative measurements using international mineral standards of similar composition to the material being analysed. For elements at lower abundance (e.g. $<1$ wt. \%), calibration was carried out on synthetic oxide standards. A full list of standards used for each mineral/glass calibration is shown in Table 3.10. Calibration was carried out by a $60 \mathrm{~s}$ peak-search on each element, and a $30 \mathrm{~s}$ background measurement. Measurement conditions varied depending on the material being analysed. For minerals with low alkali contents such as olivine, clinopyroxene, orthopyroxene and Fe-Ti oxides, measurements were performed using a focussed beam with a current of $20 \mathrm{nA}$ and an accelerating voltage of $15 \mathrm{kV}$. For minerals such as plagioclase and amphibole with significant levels of alkali elements, the current was reduced to $12 \mathrm{nA}$. For matrix glasses and melt inclusions, the electron beam was defocused to a diameter of $10 \mu \mathrm{m}$, and the current was reduced to $8 \mathrm{nA}$ to minimise the effects of alkali-migration during electron beam irradiation. For all materials, samples were measured for a total time of $30 \mathrm{~s}$, and background levels for a total of $15 \mathrm{~s}$. Alkali elements such as $\mathrm{Na}$ and $\mathrm{K}$ were always measured first. All major element concentrations were calculated using the ZAF correction method, which automatically

Table 3.10. List of standards used for calibration during WDS analysis

\begin{tabular}{lll}
\hline Material & Matrix-matched standards & Synthetic oxides \\
\hline Clinopyroxene & Kakanui Augite $^{1,2}(\mathrm{Si}, \mathrm{Al}, \mathrm{Mg}, \mathrm{Na}, \mathrm{Ca}, \mathrm{Fe}, \mathrm{Ti})$ & $\mathrm{MnO}, \mathrm{Cr}_{2} \mathrm{O}_{3}$ \\
Orthopyroxene & $\begin{array}{l}\text { Hypersthene }^{1}(\mathrm{Si}, \mathrm{Al}, \mathrm{Mg}, \mathrm{Na}, \mathrm{Ca}, \mathrm{Fe}) \\
\text { Kakanui Augite }^{1}(\mathrm{Na})\end{array}$ & $\mathrm{MnO}, \mathrm{Cr}_{2} \mathrm{O}_{3}, \mathrm{TiO}_{2}$ \\
Olivine & Springwater Olivine $^{1}(\mathrm{Si}, \mathrm{Mg}, \mathrm{Fe})$ & $\mathrm{MnO}, \mathrm{Cr}_{2} \mathrm{O}_{3}, \mathrm{NiO}, \mathrm{CaO}$ \\
Plagioclase & Plagioclase $^{1}(\mathrm{Si}, \mathrm{Al}, \mathrm{Mg}, \mathrm{Na}, \mathrm{Ca})$ & $\mathrm{TiO}_{2}, \mathrm{Fe}_{2} \mathrm{O}_{3}$ \\
& Orthoclase $^{3,4}(\mathrm{~K})$ & \\
Amphibole & Engels amphibole $^{3}(\mathrm{Si}, \mathrm{Al}, \mathrm{Mg}, \mathrm{Na}, \mathrm{K}, \mathrm{Ca}, \mathrm{Fe}, \mathrm{Ti})$ & $\mathrm{MnO}, \mathrm{Cr}_{2} \mathrm{O}_{3}$ \\
Fe-Ti oxides & Ilmenite $^{1}(\mathrm{Ti}, \mathrm{Fe}, \mathrm{Mn})$ & $\mathrm{Wollastonite}(\mathrm{Si}, \mathrm{Ca})$ \\
& & $\mathrm{MgO}, \mathrm{Al}_{2} \mathrm{O}_{3}, \mathrm{Cr}_{2} \mathrm{O}_{3}$ \\
Glass & VGA-99 $^{1}(\mathrm{Si}, \mathrm{Al}, \mathrm{Mg}, \mathrm{Na}, \mathrm{K}, \mathrm{Ca}, \mathrm{Fe}, \mathrm{Ti})$ & $\mathrm{MnO}$ \\
\hline
\end{tabular}

Machine calibrated to standard reference values from 1) Jaroswich et al. (1980) 2) Klügel et al. (2005) 3) Ingamells (1980) 4) Goldlich et al. (1967). 
corrects for the matrix effects of mass number $(\mathrm{Z})$, absorbance $(\mathrm{A})$ and fluorescence $(\mathrm{F})$ that lead to incorrect element concentration calculations.

\subsubsection{Mineral/glass major element precision and accuracy}

Calibrated standards were run as unknowns throughout machine runs to monitor instrumental drift and the precision and accuracy of the analyses. If the calibrated standard produced total oxide values which were more than 2 wt. \% from reference values, the analytical run was stopped and the EPMA was re-calibrated. As shown in Tables 3.11 to 3.17 , approximate $2 \sigma$ analytical precisions calculated from repeated analysis of calibration standard are generally $<5 \%$ for elements which occur in concentrations $>1$ wt. \%. For elements at lower concentrations, precisions decreases with decreasing relative concentration. The same is true for accuracy, where elements in higher concentration are generally accurate to within $<5$ wt. \%. For glass analyses 2 additional secondary standards were run to assess the precision and accuracy of glass analysis (Table 3.17), which can be susceptible to volatile losses during analysis, resulting in incorrect concentration calculations (Blundy and Cashman, 2008). The glass standards span a wide compositional range from basalt (VGA-99) to rhyolite (ATHO). Accuracy and precision for basaltic glass VGA-99 and andesite glass TR1G is $<6 \%$ (except $\mathrm{MnO}$ ). However, for rhyolite glass ATHO, slight volatile loss $(\mathrm{Na})$ has resulted in slightly lower measured concentrations than the reference values. As this discrepancy is only $10-15 \%$ of the total $\mathrm{Na}_{2} \mathrm{O}$ concentration it is considered to have minimal effects on other glasses of similar composition analysed in this study.

\subsection{Mineral trace element analysis}

Mineral trace element compositions were measured in-situ using a New Wave deep UV laser (193 nm solid state), coupled with the same Agilent ICP-MS used for solution whole rock trace element work (section 3.2). The EPMA carbon coating was removed from the epoxy mineral mounts by cleaning with methanol and Milli-Q. The $32 \mathrm{~mm}$ epoxy mounts were cut in half so they could fit in the laser with a coupled half-moon standards mount. As was the case for the whole rock solution work, the LA-ICP-MS data acquisition technique used in this study uses a minor isotope of a major element (here ${ }^{43} \mathrm{Ca}$ ), as an internal standard for secondary data normalisation. $\mathrm{CaO}$ concentrations of the minerals had previously been determined to $\pm 5 \%$ by EPMA. The 
Table 3.11. Precision and accuracy of clinopyroxene major element analysis by EPMA: Kakanui augite $(n=141)$

\begin{tabular}{rrrrrrrrrrr} 
& $\mathbf{S i O}_{2}$ & $\mathrm{TiO}_{2}$ & $\mathbf{A l}_{2} \mathbf{O}_{3}$ & $\mathbf{C r}_{2} \mathbf{O}_{3}$ & $\mathbf{F e O}$ & $\mathbf{M n O}$ & $\mathbf{M g O}$ & $\mathbf{C a O}$ & $\mathbf{N a}_{2} \mathrm{O}$ & Total \\
\hline Average & 50.64 & 0.76 & 8.80 & 0.18 & 6.38 & 0.14 & 16.66 & 15.87 & 1.30 & 100.72 \\
Max & 51.30 & 0.83 & 9.14 & 0.25 & 6.64 & 0.17 & 17.00 & 16.21 & 1.43 & 101.36 \\
Min & 49.38 & 0.71 & 8.43 & 0.14 & 6.16 & 0.10 & 16.29 & 15.46 & 1.15 & 99.85 \\
$2 \sigma$ & 0.65 & 0.05 & 0.28 & 0.06 & 0.18 & 0.03 & 0.28 & 0.26 & 0.10 & 0.68 \\
$\% 2 \sigma$ & 1.3 & 6.4 & 3.2 & 30.8 & 2.8 & 20.9 & 1.7 & 1.6 & 7.7 & 0.7 \\
ref value & 50.73 & 0.74 & 8.73 & 0.15 & 6.34 & 0.13 & 16.65 & 15.82 & 1.27 & 100.39 \\
\% offset & -0.2 & 2.4 & 0.8 & 19.4 & 0.6 & 4.3 & 0.0 & 0.3 & 2.6 & 0.3 \\
\hline Reference values from Jarosewich et al. (1980) and Klügel et al. (2005)
\end{tabular}

Table 3.12. Precision and accuracy of orthopyroxene major element analysis by EPMA: Hypersthene standard $(n=92)$

\begin{tabular}{rrrrrrrrrrr} 
& $\mathrm{SiO}_{2}$ & $\mathrm{TiO}_{2}$ & $\mathrm{Al}_{2} \mathrm{O}_{3}$ & $\mathrm{Cr}_{2} \mathrm{O}_{3}$ & $\mathbf{F e O}$ & $\mathbf{M n O}$ & $\mathbf{M g O}$ & $\mathbf{C a O}$ & $\mathrm{Na}_{2} \mathrm{O}$ & Total \\
\hline Average & 53.90 & 0.15 & 1.21 & 0.77 & 15.17 & 0.50 & 26.93 & 1.44 & 0.01 & 100.09 \\
Max & 54.79 & 0.22 & 1.32 & 0.87 & 15.57 & 0.55 & 27.60 & 1.70 & 0.03 & 100.95 \\
$\mathrm{Min}$ & 52.91 & 0.09 & 0.84 & 0.53 & 14.84 & 0.45 & 26.30 & 1.09 & 0.00 & 99.21 \\
$2 \sigma$ & 0.70 & 0.05 & 0.18 & 0.15 & 0.27 & 0.04 & 0.45 & 0.23 & 0.02 & 0.84 \\
$\% 2 \sigma$ & 1.3 & 35.4 & 15.1 & 19.3 & 1.8 & 8.2 & 1.7 & 15.8 & 151.1 & 0.8 \\
ref value & 54.09 & 0.16 & 1.23 & 0.75 & 15.22 & 0.49 & 26.79 & 1.52 & $\mathrm{n} / \mathrm{d}$ & 100.25 \\
$\%$ offset & -0.4 & -3.5 & -1.3 & 2.9 & -0.3 & 2.2 & 0.5 & -5.0 & & -0.2 \\
\hline Reference values from Jarosewich et al. (1980) & & & & & & &
\end{tabular}

Table 3.13. Precision and accuracy of plagioclase major element analysis by EPMA: Labradorite plagioclase $(\mathrm{n}=157)$

\begin{tabular}{rrrrrrrrrr} 
& $\mathbf{S i O}_{2}$ & $\mathrm{TiO}_{2}$ & $\mathbf{A l}_{\mathbf{2}} \mathbf{O}_{3}$ & $\mathbf{F e O}$ & $\mathbf{M g O}$ & $\mathbf{C a O}$ & $\mathbf{N a}_{\mathbf{2}} \mathbf{O}$ & $\mathbf{K}_{\mathbf{2}} \mathbf{O}$ & Total \\
\hline Average & 51.05 & 0.03 & 30.97 & 0.46 & 0.14 & 13.67 & 3.46 & 0.12 & 99.90 \\
Max & 52.17 & 0.05 & 31.52 & 0.57 & 0.21 & 14.04 & 3.64 & 0.15 & 101.42 \\
Min & 49.67 & 0.00 & 30.15 & 0.37 & 0.11 & 13.46 & 3.23 & 0.10 & 98.61 \\
$2 \sigma$ & 0.91 & 0.02 & 0.52 & 0.08 & 0.04 & 0.17 & 0.13 & 0.02 & 1.20 \\
$\% 2 \sigma$ & 1.8 & 73.5 & 1.7 & 17.5 & 24.7 & 1.3 & 3.7 & 14.0 & 1.2 \\
ref value & 51.25 & 0.05 & 30.91 & 0.46 & 0.14 & 13.64 & 3.45 & 0.18 & 100.08 \\
\% offset & -0.4 & -45.1 & 0.2 & -1.0 & 1.9 & 0.2 & 0.3 & -34.9 & -0.2 \\
\hline Reference values from Jarosewich et al. (1980)
\end{tabular}

Table 3.14. Precision and accuracy of olivine major element analysis by EPMA: Springwater olivine standard $(n=70)$

\begin{tabular}{rrrrrrrrr} 
& $\mathrm{SiO}_{2}$ & $\mathrm{Cr}_{2} \mathrm{O}_{3}$ & $\mathbf{F e O}$ & $\mathrm{MnO}$ & $\mathrm{MgO}$ & $\mathrm{NiO}$ & $\mathrm{CaO}$ & Total \\
\hline Average & 39.00 & 0.06 & 16.63 & 0.30 & 43.74 & 0.01 & 0.00 & 99.72 \\
Max & 39.28 & 0.11 & 17.10 & 0.36 & 44.80 & 0.04 & 0.02 & 101.16 \\
Min & 38.47 & 0.01 & 16.28 & 0.23 & 43.13 & 0.00 & 0.00 & 98.41 \\
$2 \sigma$ & 0.31 & 0.05 & 0.36 & 0.07 & 0.56 & 0.02 & 0.01 & 0.91 \\
$\% 2 \sigma$ & 0.8 & 91.5 & 2.1 & 21.8 & 1.3 & 334.3 & 334.4 & 0.9 \\
ref value & 38.95 & 0.02 & 16.62 & 0.3 & 43.58 & $\mathrm{n} / \mathrm{d}$ & $\mathrm{n} / \mathrm{d}$ & 99.47 \\
$\%$ offset & 0.1 & 189.9 & 0.0 & 0.4 & 0.4 & & & 0.2 \\
\hline Reference values from Jarosewich et al. (1980)
\end{tabular}

Table 3.15. Precision and accuracy of amphibole major element analysis by EPMA: Engels amphibole standard $(n=10)$

\begin{tabular}{rrrrrrrrrrr} 
& $\mathrm{SiO}_{2}$ & $\mathrm{TiO}_{2}$ & $\mathbf{A l}_{2} \mathrm{O}_{3}$ & $\mathbf{F e O}$ & $\mathbf{M n O}$ & $\mathbf{M g O}$ & $\mathbf{C a O}$ & $\mathbf{N a}_{2} \mathrm{O}$ & $\mathbf{K}_{2} \mathrm{O}$ & Total \\
\hline Average & 42.26 & 0.98 & 12.05 & 19.50 & 0.67 & 8.76 & 11.47 & 1.74 & 0.91 & 98.35 \\
Max & 42.53 & 1.01 & 12.25 & 19.82 & 0.71 & 8.90 & 11.51 & 1.79 & 0.96 & 98.80 \\
$\mathrm{Min}$ & 42.06 & 0.94 & 11.85 & 19.15 & 0.62 & 8.62 & 11.40 & 1.68 & 0.88 & 97.78 \\
$2 \sigma$ & 0.26 & 0.04 & 0.23 & 0.43 & 0.06 & 0.20 & 0.08 & 0.07 & 0.05 & 0.62 \\
$\% 2 \sigma$ & 0.6 & 4.3 & 1.9 & 2.2 & 9.0 & 2.3 & 0.7 & 3.8 & 5.2 & 0.6 \\
ref value & 42.14 & 0.94 & 12.09 & 19.05 & 0.63 & 8.67 & 11.56 & 1.63 & 0.91 & 97.62 \\
\% offset & 0.3 & 4.4 & -0.3 & 2.4 & 6.7 & 1.0 & -0.8 & 6.8 & 0.3 & 0.8 \\
\hline \multicolumn{2}{r}{ Reference values from Ingamells (1980) } & & & & & & &
\end{tabular}


Table 3.16. Precision and accuracy of Fe-Ti oxides major element analysis by EPMA: Ilmenite standard $(\mathrm{n}=54)$

\begin{tabular}{|c|c|c|c|c|c|c|c|c|}
\hline & $\mathrm{SiO}_{2}$ & $\mathrm{TiO}_{2}$ & $\mathrm{Al}_{2} \mathrm{O}_{3}$ & $\mathrm{FeO}$ & $\mathrm{MnO}$ & MgO & $\mathrm{CaO}$ & Total \\
\hline Average & 0.01 & 45.74 & 0.02 & 46.60 & 4.79 & 0.31 & 0.00 & 97.52 \\
\hline Max & 0.03 & 46.77 & 0.29 & 47.49 & 4.97 & 0.34 & 0.04 & 98.99 \\
\hline Min & 0.00 & 44.44 & 0.00 & 45.59 & 4.41 & 0.28 & 0.00 & 96.25 \\
\hline $2 \sigma$ & 0.02 & 0.73 & 0.08 & 0.79 & 0.20 & 0.03 & 0.02 & 1.20 \\
\hline$\% 2 \sigma$ & $\mathrm{n} / \mathrm{a}$ & 1.6 & $n / a$ & 1.7 & 4.2 & 9.6 & $n / a$ & 1.2 \\
\hline ref value & $\mathrm{n} / \mathrm{d}$ & 45.7 & $n / d$ & 46.54 & 4.77 & 0.31 & $n / d$ & 97.28 \\
\hline$\%$ offset & & 0.1 & & 0.1 & 0.4 & 0.1 & & 0.2 \\
\hline
\end{tabular}

Table 3.17. Precision and accuracy of glass major element analyses by EPMA

A) VGA-99 standard $(n=10)$

\begin{tabular}{rrrrrrrrrrr} 
& $\mathrm{SiO}_{2}$ & $\mathrm{TiO}_{2}$ & $\mathrm{Al}_{2} \mathrm{O}_{3}$ & $\mathbf{F e O}$ & $\mathbf{M n O}$ & $\mathbf{M g O}$ & $\mathrm{CaO}$ & $\mathrm{Na}_{2} \mathrm{O}$ & $\mathrm{K}_{2} \mathrm{O}$ & Total \\
\hline Average & 51.29 & 4.08 & 12.41 & 13.39 & 0.19 & 5.04 & 9.34 & 2.77 & 0.84 & 99.35 \\
Max & 51.71 & 4.11 & 12.70 & 13.76 & 0.21 & 5.20 & 9.45 & 2.88 & 0.88 & 100.01 \\
$\mathrm{Min}$ & 50.73 & 4.04 & 12.19 & 13.22 & 0.17 & 4.89 & 9.29 & 2.63 & 0.81 & 98.61 \\
$2 \sigma$ & 0.67 & 0.06 & 0.42 & 0.34 & 0.03 & 0.22 & 0.09 & 0.16 & 0.05 & 0.91 \\
$\% 2 \sigma$ & 1.3 & 1.4 & 3.4 & 2.6 & 15.1 & 4.3 & 1.0 & 5.6 & 5.5 & 0.9 \\
ref value & 51.15 & 4.11 & 12.38 & 13.35 & 0.2 & 5.07 & 9.26 & 2.68 & 0.83 & 99.02 \\
\% offset & 0.3 & -0.8 & 0.2 & 0.3 & -4.7 & -0.6 & 0.9 & 3.2 & 1.7 & 0.3 \\
\hline \multicolumn{2}{l}{ Reference values from Jarosewich et al. (1980) }
\end{tabular}

B) ATHO standard $(\mathrm{n}=10)$

\begin{tabular}{rrrrrrrrrrr} 
& $\mathbf{S i O}_{2}$ & $\mathrm{TiO}_{2}$ & $\mathbf{A l}_{2} \mathbf{O}_{3}$ & $\mathbf{F e O}$ & $\mathbf{M n O}$ & $\mathbf{M g O}$ & $\mathbf{C a O}$ & $\mathbf{N a}_{2} \mathrm{O}$ & $\mathbf{K}_{2} \mathbf{O}$ & Total \\
\hline Average & 75.27 & 0.231 & 12.12 & 3.32 & 0.105 & 0.099 & 1.76 & 3.22 & 2.67 & 98.80 \\
Max & 76.12 & 0.266 & 12.35 & 3.39 & 0.120 & 0.122 & 1.81 & 3.47 & 2.72 & 99.39 \\
$\mathrm{Min}$ & 74.64 & 0.204 & 11.99 & 3.16 & 0.088 & 0.082 & 1.72 & 2.93 & 2.60 & 98.41 \\
$2 \sigma$ & 0.86 & 0.041 & 0.23 & 0.13 & 0.02 & 0.024 & 0.08 & 0.37 & 0.07 & 0.61 \\
$\% 2 \sigma$ & 1.1 & 17.9 & 1.9 & 4.0 & 23.3 & 24.4 & 4.5 & 11.4 & 2.8 & 0.6 \\
ref value & 75.6 & 0.255 & 12.2 & 3.27 & 0.106 & 0.103 & 1.7 & 3.75 & 2.64 & 99.65 \\
\% offset & -0.4 & -9.5 & -0.6 & 1.6 & -1.0 & -4.0 & 3.8 & -14.2 & 1.3 & -0.8 \\
\hline \multicolumn{2}{l}{ Reference values from Jochum et al. (2006) } & & & & & & &
\end{tabular}

C) TR-1G standard $(n=10)$

\begin{tabular}{rrrrrrrrrrr} 
& $\mathrm{SiO}_{2}$ & $\mathrm{TiO}_{2}$ & $\mathrm{Al}_{2} \mathrm{O}_{3}$ & $\mathbf{F e O}$ & $\mathbf{M n O}$ & $\mathbf{M g O}$ & $\mathbf{C a O}$ & $\mathrm{Na}_{2} \mathrm{O}$ & $\mathbf{K}_{\mathbf{2}} \mathrm{O}$ & Total \\
\hline Average & 59.17 & 0.720 & 16.89 & 6.43 & 0.120 & 3.625 & 7.02 & 3.15 & 2.01 & 99.13 \\
$\mathrm{Max}$ & 59.56 & 0.744 & 17.12 & 6.63 & 0.137 & 3.699 & 7.12 & 3.24 & 2.05 & 99.70 \\
$\mathrm{Min}$ & 58.65 & 0.700 & 16.58 & 6.24 & 0.092 & 3.554 & 6.97 & 2.97 & 1.95 & 98.42 \\
$2 \sigma$ & 0.63 & 0.029 & 0.29 & 0.28 & 0.02 & 0.094 & 0.11 & 0.18 & 0.08 & 0.78 \\
$\% 2 \sigma$ & 1.1 & 4.0 & 1.7 & 4.3 & 20.8 & 2.6 & 1.5 & 5.9 & 4.2 & 0.8 \\
ref value & 58.6 & 0.755 & 17.1 & 6.44 & 0.127 & 3.75 & 7.1 & 3.13 & 1.96 & 99.13 \\
\% offset & 1.0 & -4.6 & -1.2 & -0.2 & -5.3 & -3.3 & -1.1 & 0.5 & 2.3 & 0.0 \\
\hline \multicolumn{2}{l}{ Reference values from Jochum et al. (2006) } & & & & & & &
\end{tabular}


exact location of the probe spot used on each mineral of interest was recorded on images taken during EPMA so that the same area could be analysed for trace element compositions and corrected to the $\mathrm{CaO}$ value.

\subsubsection{Laser ablation}

Laser ablation is a destructive analysis method which converts solid material into individual elements by firing a focused laser beam at the sample. Helium was used to transport the ablated material, which was mixed with the argon nebuliser gas flow immediately after the ablation chamber. Analysis conditions are shown in Table 3.18. The ICP-MS was tuned using two different international standards, depending on the material being analysed. For clinopyroxene and amphibole, BCR-2G was used and for plagioclase NIST 612 was used. As for solution ICP-MS, instrumental conditions such as torch position and carrier/make-up gas flow were adjusted for the analysis of both the standards and a representative sample to achieve the lowest relative standard deviation (RSD) and to optimise sensitivity. Plasma torch conditions were optimised so that the element oxide production (estimated from measured $\mathrm{ThO}+/ \mathrm{Th}+$ ratios) were $<1 \%$ (Table 3.18). Prior to analysis $\mathrm{P} / \mathrm{A}$ factors were measured for elements at high concentrations (Table 3.18). A typical analytical run consisted of a looping sequence, starting with the bracketing standard, followed by 5 samples and finishing back on the standard. Samples/standards were ablated for a total of $60 \mathrm{~s}$, followed by a $90 \mathrm{~s}$ washout of the ablation cell.

\subsubsection{Raw data processing}

Abundances of individual trace elements were calculated relative to a bracketing standard (BCR-2G or NST 612), which was analysed under identical conditions throughout the analysis sessions (Table 3.18). Background count rates were measured for $60 \mathrm{~s}$ prior to analysis of each sample and the mean background of this was subtracted from the mean count rates (CPS) measured during ablation. The backgroundcorrected CPS for each sample was then converted into a concentration based on the bracketing standard values using the following relationship:

3) Sample $C_{i}=\left(\right.$ Sample $\left._{\mathrm{CPS}} / \mathrm{STD}_{\mathrm{CPS}}\right) \times$ ref. value

4) Sample $\mathrm{C}_{\mathrm{i}}(\mathrm{Ca}$ corrected $)=$ eq. (3) $\mathrm{x}\left(\mathrm{C}_{\mathrm{ca}}\right.$ EPMA / $\mathrm{C}_{\mathrm{ca}}$ LA-ICP-MS $)$ 
Table 3.18. LA-ICP-MS istrumental and analytical conditions

\begin{tabular}{|c|c|}
\hline \multicolumn{2}{|l|}{ Laser ablation } \\
\hline System & New Wave 193 nm (deep UV) solid state laser \\
\hline Ablation mode & Static spot analysis \\
\hline Spot size & $35 \mu \mathrm{m}$ diameter \\
\hline Repetition rate & $5 \mathrm{~Hz}$ \\
\hline Laser power & $65 \%$ \\
\hline \multicolumn{2}{|l|}{ ICP-MS } \\
\hline ICP-MS system & Agilent $7500 \mathrm{CS}$ \\
\hline Aquisition mode & Peak hopping \\
\hline Detection mode & Pulse and analog (mostly pulse) \\
\hline \multicolumn{2}{|l|}{ Standards and calibration } \\
\hline Calibration/braketing standard & Clinopyroxene/Amphibole: BCR-2G \\
\hline & Plagioclase: NIST-612 \\
\hline Internal standard & ${ }^{43} \mathrm{Ca}$ (previously measured by EPMA) \\
\hline \multicolumn{2}{|l|}{ Analysis method } \\
\hline Background aquisition & $60 \mathrm{~s}$ \\
\hline Sample/standard aquisition & $60 \mathrm{~s}$ \\
\hline Total washout time & $90 \mathrm{~s}$ \\
\hline Measured isotopes and integration times: & $\begin{array}{l}\text { Clinopyroxene and amphibole } \\
10 \mathrm{~ms}:{ }^{7} \mathrm{Li},{ }^{11} \mathrm{~B},{ }^{24} \mathrm{Mg},{ }^{29} \mathrm{Si},{ }^{43} \mathrm{Ca},{ }^{45} \mathrm{Sc},{ }^{47} \mathrm{Ti},{ }^{51} \mathrm{~V}, \\
{ }^{53} \mathrm{Cr},{ }^{55} \mathrm{Mn},{ }^{60} \mathrm{Ni},{ }^{63} \mathrm{Cu},{ }^{66} \mathrm{Zn},{ }^{85} \mathrm{Rb},{ }^{88} \mathrm{Sr},{ }^{89} \mathrm{Y},{ }^{90} \mathrm{Zr} \text {, } \\
{ }^{93} \mathrm{Nb},{ }^{133} \mathrm{Cs},{ }^{137} \mathrm{Ba},{ }^{139} \mathrm{La},{ }^{140} \mathrm{Ce},{ }^{141} \mathrm{Pr},{ }^{146} \mathrm{Nd}, \\
{ }^{147} \mathrm{Sm},{ }^{153} \mathrm{Eu},{ }^{157} \mathrm{Gd},{ }^{159} \mathrm{~Tb},{ }^{163} \mathrm{Dy},{ }^{165} \mathrm{Ho},{ }^{166} \mathrm{Er}, \\
{ }^{169} \mathrm{Tm},{ }^{172} \mathrm{Yb},{ }^{173} \mathrm{Lu},{ }^{178} \mathrm{Hf},{ }^{181} \mathrm{Ta},{ }^{182} \mathrm{~W},{ }^{208} \mathrm{~Pb}, \\
{ }^{232} \mathrm{Th},{ }^{238} \mathrm{U} \\
\text { Plagioclase } \\
10 \mathrm{~ms}:{ }^{29} \mathrm{Si},{ }^{43} \mathrm{Ca},{ }^{88} \mathrm{Sr},{ }^{137} \mathrm{Ba},{ }^{138} \mathrm{Ba} \\
20 \mathrm{~ms}:{ }^{7} \mathrm{Li},{ }^{24} \mathrm{Mg},{ }^{25} \mathrm{Mg},{ }^{139} \mathrm{La},{ }^{140} \mathrm{Ce} \\
50 \mathrm{~ms}:{ }^{85} \mathrm{Rb},{ }^{89} \mathrm{Y},{ }^{133} \mathrm{Cs},{ }^{141} \mathrm{Pr},{ }^{146} \mathrm{Nd},{ }^{147} \mathrm{Sm}, \\
{ }^{153} \mathrm{Eu},{ }^{157} \mathrm{Gd},{ }^{208} \mathrm{~Pb}\end{array}$ \\
\hline \multicolumn{2}{|l|}{ Tuning } \\
\hline Tuning standards & $\begin{array}{l}\text { Clinopyroxene/Amphibole: BCR-2G } \\
\text { Plagioclase: NIST-612 }\end{array}$ \\
\hline $\begin{array}{l}\text { Ablation mode } \\
\text { Monitored isotopes }\end{array}$ & $\begin{array}{l}\text { Rastering }(2 \mu \mathrm{m} / \mathrm{sec}) \text { beneath } 50 \mu \mathrm{m} \text { spot } \\
{ }^{7} \mathrm{Li},{ }^{24} \mathrm{Mg},{ }^{29} \mathrm{Si},{ }^{43} \mathrm{Ca},{ }^{88} \mathrm{Sr},{ }^{138} \mathrm{Ba},{ }^{208} \mathrm{~Pb}(\% \mathrm{RSD} \\
\text { typically }<5 \% \text {, always }<8 \%)\end{array}$ \\
\hline Background & ${ }^{43} \mathrm{Ca}<2000 \mathrm{cps}$ \\
\hline Oxides & $\mathrm{ThO}^{+} / \mathrm{Th}^{+}$typically $<0.5 \%$, always $<1 \%$ \\
\hline Carrier gas (Ar) & $0.84-0.90 \mathrm{~L} / \mathrm{min}$ \\
\hline Optional gas & $80-90 \%$ \\
\hline RF Power & $1500 \mathrm{~W}$ \\
\hline RF matching & $1.68 \mathrm{~V}$ \\
\hline Sample depth & $3.5 \mathrm{~mm}$ \\
\hline
\end{tabular}




\subsubsection{Mineral trace element precision and accuracy}

Secondary standards were not run during the LA-ICP-MS sessions for this study. However, a recent study using similar methods on the same instrument at VUW by Allan et al. (2008) demonstrated the high level of precision and accuracy for the LAICP-MS technique. Allan et al. (2008) found that approximate $2 \sigma$ analytical precisions calculated from 91 repeated analysis of secondary standard ATHO-G were generally $<10 \%$ for most trace elements. Analysis of ATHO-G were also reproduced to an accuracy of $<5 \%$ from the recommended values of Jochum et al. (2006). Some elements that Allan et al. (2008) had difficulty measuring due to low abundances in glasses (e.g. $\mathrm{Cr}$, Ni and $\mathrm{Ti}$ ), occur in significantly higher concentration in the minerals analysed in this study. 


\section{CHAPTER 4: Results}




\subsection{Sample selection and pumice types}

Due to the contrasting physical setting of the subaerial and submarine volcanoes investigated in this study, differing sampling strategies were adopted to select a representative range of materials for chemical analysis. In the subaerial environment, sampling was controlled stratigraphically from separate eruptions as defined by the published stratigraphy of Raoul Island (Lloyd and Nathan, 1981) and Macauley Island (Brothers and Martin, 1970; Lloyd et al., 1996). In contrast, dredge sampling from the submarine environment captured a mixture of material from the top metre or so of the sea floor. In this environment the context of individual samples within the eruption record is largely unknown, and the only way to discriminate between groups of samples is by dredge location, and the physical appearance and/or chemistry of pumice clasts. Whole rock major-element chemistry was thus used as a first order method for screening samples for overall chemical diversity and for selecting representative end members for whole rock trace element, isotopic and crystal chemistry.

\subsubsection{Raoul samples}

Pumice samples were collected from five eruptive units within the stratigraphy of Raoul Island, as outlined in Lloyd and Nathan (1981) (Table 2.01). In addition, pumices were sampled from a newly discovered floated pumice unit enclosed in lake sediments below the Green Lake Pumice deposit, and from the 2006 eruption deposit (see Chapter 2 for further sampling details). Pumice clasts are generally highly vesicular (averaging 75-85 vol. \% vesicles), and partially to wholly oxidised to a pink-orange colour. Exceptions to this are the floated pumice unit and Rangitahua eruption deposits, which consist of nonoxidised pumice clasts with a wide range of vesicularities (10-80 vol. \% vesicles), including dense bread-crusted clasts interpreted to reflect interaction with lake water. The majority of pumices contain $<3-5$ vol. \% crystals with a crystal assemblage dominated by plagioclase, with lesser amounts of clinopyroxene, orthopyroxene and magnetite. Olivine is present in the Matatirohia and Fleetwood pumices, and rare quartz is present in the Oneraki, Green Lake and Rangitahua samples. Sparse $(<1-2$ vol. \%) sub-spherical, dark grey mafic blebs are found inside the Matatirohia, Oneraki and Fleetwood pumice samples, typically within open cavities (large vesicles) up to centimetres in diameter. Although these mafic blebs are generally $<5 \mathrm{~mm}$ in diameter, they can reach up to $2-3 \mathrm{~cm}$ in diameter inside large pumice clasts, and sparse larger examples occur as discrete pyroclasts. 
The Ngaio group eruptions which have been investigated in this study, produced crystal poor dacite pumice with ca. 66-70 wt. \% $\mathrm{SiO}_{2}$ (Figure 4.01). Pumice clasts analysed as part of this study plot within fields of previously published major element whole rock data from Smith et al. $(2006,2010)$, but are more well defined into tighter groups for individual eruptions (Figure 4.01). This is most evident in the Oneraki, Fleetwood and Matatirohia samples, which are also the eruptions which contain the most obvious (though sparse) mafic blebs, which were treated separately in this study. The pumice clasts generally plot along linear trends on major element variation diagrams, with Rangitahua samples being the least evolved at $66-67$ wt. \% $\mathrm{SiO}_{2}$, and the pre-Green Lake floated pumice unit the most evolved at 69-70 wt. \% $\mathrm{SiO}_{2}$ (Figure 4.01). Pumice clasts from the Matatirohia, Oneraki and Fleetwood deposits plot with subparallel trends between these two end-members. The Matatirohia samples plot off the main trend, with considerably lower $\mathrm{TiO}_{2}$ and $\mathrm{P}_{2} \mathrm{O}_{5}$ than other samples. The composition of a single pumice clast from the 2006 eruption deposits overlaps with the compositional range of the Rangitahua pumice, although its physical appearance is different, as it has very fresh glass and a blocky jointed exterior. This suggests that it could be either a recycled fragment from an unexposed part of the Rangitahua cone (and therefore not juvenile) or, more speculatively, that the clast is juvenile and thus that the major element chemistry of the 2006 magma is very similar to that of the Rangitahua eruption.

\subsubsection{Macauley samples}

Pumice clasts collected from Macauley Island are from the Sandy Bay Tephra (Brothers and Martin, 1970; Lloyd et al., 1996). They are pale to mid-grey-brown in colour and highly vesicular, averaging $\sim 80$ vol. $\%$ vesicularity. Individual pyroclasts are often coated with a hard film of adhering ash. Sandy Bay pumices contain $<1-3 \%$ vol. $\%$ crystals, dominated by large (typically $0.5-1 \mathrm{~mm}$ ) euhedral plagioclase and clinopyroxene, with smaller $(<0.5 \mathrm{~mm})$ orthopyroxene, and Fe-Ti oxides. Large olivine crystals are also present $(>0.5-1 \mathrm{~mm})$, as well as sparse discrete mafic blebs which are generally small $(<1-2 \mathrm{~mm})$ but can reach up to $2 \mathrm{~cm}$ in diameter.

Pumices dredged from around Macauley caldera vary slightly in petrography and vesicularity when compared to the Sandy Bay pumices. Pumices recovered from the northern caldera rim (stations D29, D30 and D31: Figure 2.04) are dominantly dark brown in colour, subangular/blocky in shape, crystal-poor ( $<1$ vol. \%) and less vesicular (generally 60-70 vol. \% vesicles) than Sandy Bay pumice clasts. Two large fragments of 

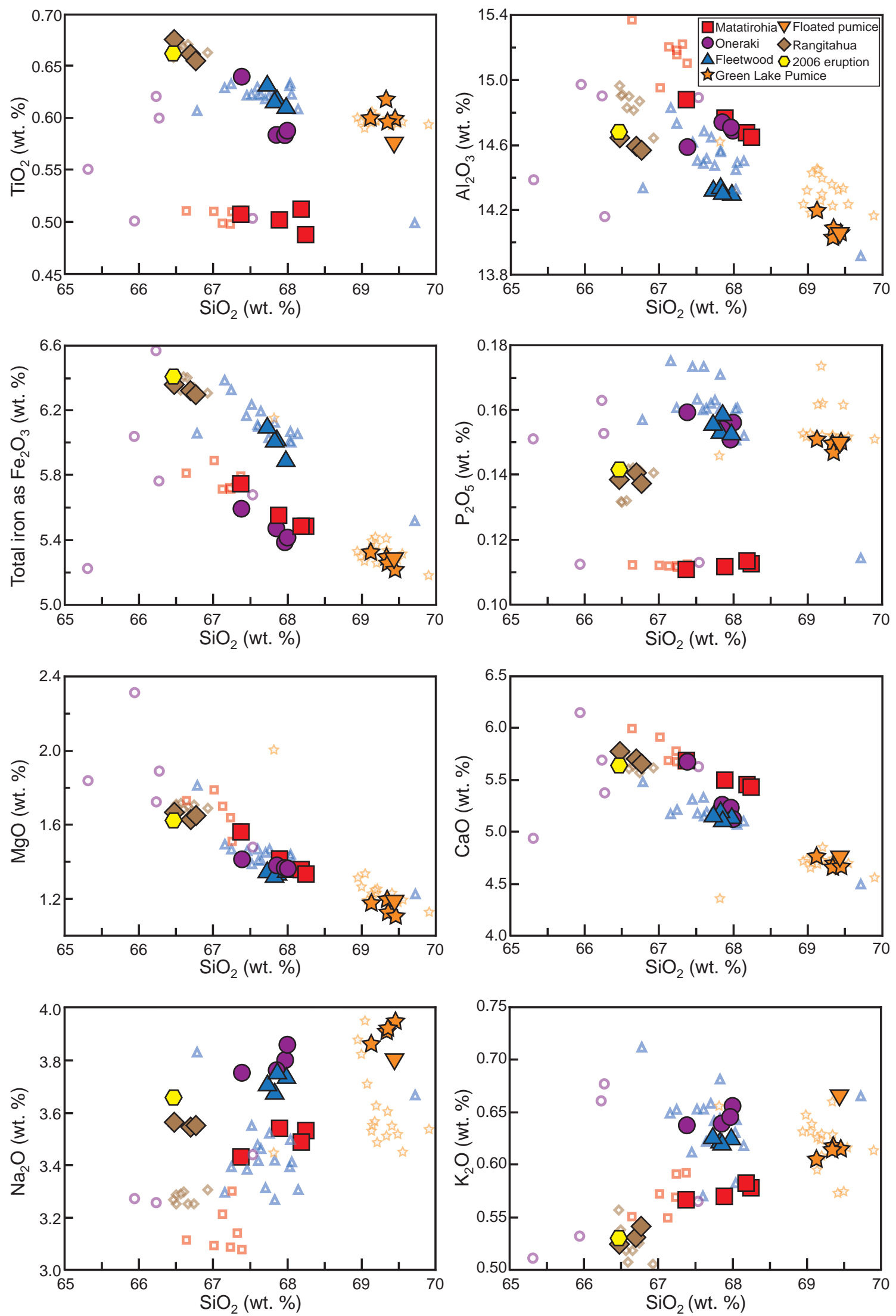

Figure 4.01. Variation diagrams of selected major oxides against $\mathrm{SiO}_{2}$ for pumices from Raoul Island eruptive units (see Figure 2.02 for sample locations). Large filled symbols denote samples analysed by XRF for this study, small open symbols denote samples analysed by Worthington (1998) and presented in Smith et al. $(2006,2010)$. All values have been normalised to $100 \%$ based on oxide totals. Raw data, original totals and LOI values are presented in Appendix B. Two standard deviation uncertanties are similar or smaller than the size of the large filled symbols (see Chapter 3). See Smith $(2006,2010)$ for the analytical uncertainties of the small open symbols. 
crystal poor light grey lava recovered in dredge haul D30 have also been included in this study for comparison. In contrast, samples from the northwestern caldera rim (D26) and from distal caldera flank dredges (stations D24, D25, D32, D33) are highly vesicular (>75-80 vol. \% vesicles) and well rounded, typically consisting of very low density, pale brown foam-like pumice fragments. Petrographic characteristics were not investigated for every pumice sample from these locations, but samples are generally crystal poor ( $<1-3$ vol. \%), with crystal assemblages dominated by plagioclase and pyroxene, often represented by round crystal clusters up to $2 \mathrm{~mm}$ in size. Large (generally $<1-2 \mathrm{~mm}$, but up to $2 \mathrm{~cm}$ ), distinctive pale green clinopyroxene crystals were also noted in some of the pumice samples from dredge D33.

Whole rock major element chemistry (Figure 4.02) shows that multiple silicic magma types have been erupted from Macauley volcano. Although prominent in the subaerial record from Macauley volcano (Lloyd et al., 1996; Smith et al., 2003a), Sandy Bay pumice compositions form only a small proportion (four of the 34 clasts analysed) of the total submarine compositional range. The Sandy Bay pumice analysed in this study plots close to the samples reported by Smith et al. (2003a), with compositions of ca. 70-71 wt \% $\mathrm{SiO}_{2}$. The most evolved compositions sampled from Macauley are the less vesicular, crystal poor blocky pumices dredged from the northern caldera rim. The two light grey lava fragments from D30 plot within the same $\mathrm{SiO}_{2}$ range of 71.75-72.5 wt $\%$. There are at least two other distinctive compositional groups within the submarine suite, with whole rock $\mathrm{SiO}_{2}$ values lower than ca. 69 wt. \% (Figure 4.02). The first population clusters as a group with notably high $\mathrm{Fe}_{2} \mathrm{O}_{3(\mathrm{~T})}$ (Figure 4.02), and is comprised mainly of pumice dredged from the southwestern caldera flank. A single pumice clast analysed by Wright et al. (2006) from the Macauley cone (Figure 2.04) plots within this high-Fe chemical population. The second population has lower Fe and $\mathrm{K}$ and higher $\mathrm{Al}_{2} \mathrm{O}_{3}$, and is comprised mainly of pumice from the northern caldera flank (D32). Several of these low-Fe type pumice samples have distinctively high $\mathrm{MgO}$ contents and have higher crystal contents (up to ca. 5 vol. \%), comprising distinctive large euhedral clinopyroxene, suggesting that whole rock variations in this sub-group may reflect variable crystal:glass proportions.

\subsubsection{Healy samples}

Material recovered from dredge hauls around Healy volcano displays a large variation in physical appearance, similar to that recorded by Wright and Gamble (1999) and 

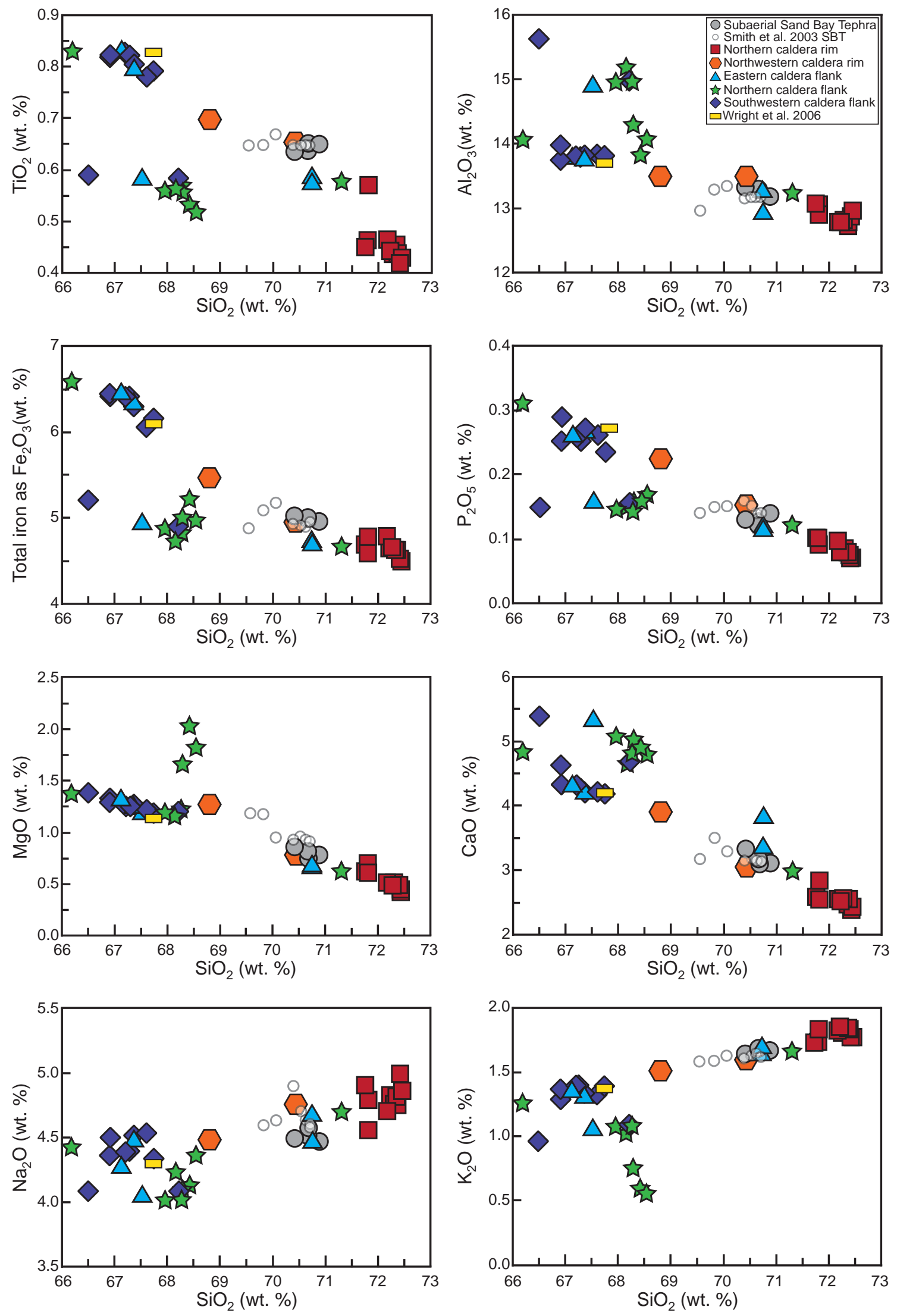

Figure 4.02. Variation diagrams of selected major oxides against $\mathrm{SiO}_{2}$ for pumice samples from Macauley volcano (see Figure 2.04 for locations). Large filled symbols denote samples analysed for this study, small open circles denote Sandy Bay Tephra samples from Smith et al. (2003a). The Wright et al. (2006) sample is from the submarine Macauley cone (Figure 2.04). Samples are grouped by dredge haul as outlined in Figure 2.04, where $\mathrm{N}$ caldera rim is D29, D30 and D31; NE caldera rim is D26; E caldera flank is D33; N caldera flank is D32; SW caldera flank is D24 and D25. All values have been recalculated based on oxide totals normalised to $100 \%$. Raw values, original totals and LOI values are presented in Appendix B. Uncertanties as in Figure 4.01. 
Wright et al. (2003). Pumices sampled here are generally highly vesicular (>75-80 vol. $\%$ vesicles). In addition, multiple large fragments of lava were recovered from the central Healy edifice and caldera floor, of which two fresh blocky dark grey lava fragments from the caldera floor were analysed. Although dominantly white, pumice clasts range in colour to dark grey, with some clasts banded with multiple shades of grey/white (the grey colour being due to microlite growth, visible in thin section). Some pumice clasts are oxidised to light pink, implying that the pumice was exposed to air during cooling (Tait et al., 1999; Moriizumi et al., 2008), and therefore the eruption plume must have breached the sea surface. The pumice crystal contents also vary considerably, with most pumice samples containing $<3-5$ wt. $\%$ crystals, but with several clasts containing up to $10-15$ wt \% crystals. Crystal rich zones are common, with thick crystal rich regions often displaying flow banding and orientation of crystals with elongated vesicles. All pumice samples contain an assemblage dominated by 1-5 $\mathrm{mm}$ euhedral plagioclase, with lesser amounts of clinopyroxene, orthopyroxene, amphibole and minor amounts of quartz. Small $(<0.1 \mathrm{~mm})$ magnetite and ilmenite crystals are also common, often visibly in higher concentrations in dark coloured and banded pumices. Large but generally sparse olivine crystals also occur in several pumice clasts. Sparse round dark grey mafic blebs (averaging $<1-2 \mathrm{~mm}$ in diameter, but reaching up to $2-3 \mathrm{~cm}$ ) are also present in many samples typically inside large open vesicles.

Although there is a large visible range of pumice types from Healy, there is little variation in the major element chemistry of the pumice samples analysed in both this study and previously documented by Wright and Gamble (1999) (Figure 4.03). There are no strong correlations between the clast type and major element chemistry with dredge location. All samples plot along linear trends on major element variation diagrams, with $\mathrm{SiO}_{2}$ varying between ca. 69.5 and 71.5 wt. \% $\mathrm{SiO}_{2}$. Most chemical variations can be attributed to variations in crystal contents, with the lowest $\mathrm{SiO}_{2}$ clasts being more crystal rich. There is one outlying clast containing $>72.5$ wt. $\% \mathrm{SiO}_{2}$ which has unusually low crystal contents $(<1-2$ wt. \%: Figure 4.03). Dark-grey coloured pumices and lava fragments have slightly higher $\mathrm{TiO}_{2}$ than white pumices, reflecting a higher abundance of Fe-Ti oxides.

\subsubsection{New volcano samples}

Samples recovered from New volcano are extremely fresh, crystal poor (1-3 vol. \%) and highly vesicular white pumice ( $>80$ vol. $\%$ vesicles). The mineral assemblage is similar 

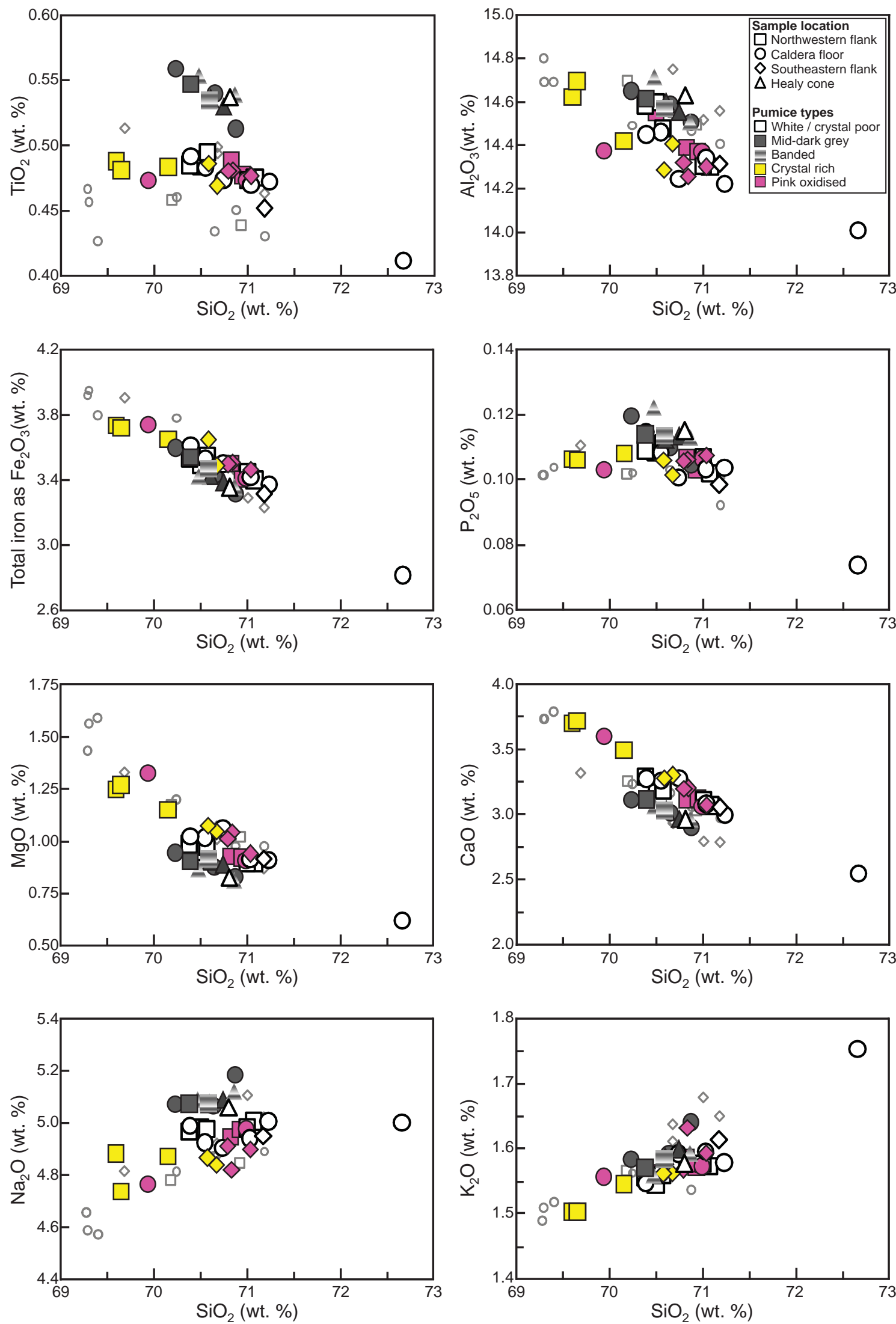

Figure 4.03. Variation diagrams of selected major oxides against $\mathrm{SiO}_{2}$ for pumice samples from Healy volcano (see Figure 2.05 for sample locations). Large symbols denote samples analysed in this study, small open symbols denote data from Wright and Gamble (1999). Samples are grouped by sample location as denoted by symbol shape, and pumice type is denoted by colour. Dredge haul locations are outlined on Figure 2.05, where NW caldera flank is D36, D37 and D38; caldera floor is D39, D40, D43; SE caldera flank is D44, D45 and D46 and the Healy edifice is D47. All values have been recalculated based on oxide totals normalised to $100 \%$. Raw values, original totals and LOI values are presented in Appendix B. Uncertainties as in Figure 4.01; see Wright and Gamble (1999) for uncertainties on the small symbols. 
to Raoul volcano, dominated by 1-5 mm euhedral plagioclase and clinopyroxene, along with smaller $(<0.5-1 \mathrm{~mm})$ orthopyroxene and Fe-Ti oxides, with minor amounts of olivine $(1-5 \mathrm{~mm})$. Sparse dark grey mafic blebs up to $2-3 \mathrm{~cm}$ in diameter are also present. There is little variation in the physical appearance and major element chemistry of the pumice, with all samples defining a narrow compositional range between ca. 73.5 and 75 wt. $\% \mathrm{SiO}_{2}$, forming a strong linear correlation on all variation diagrams (Figure 4.04). The crystal chemistries of New volcano samples have not been investigated as part of this thesis, although whole rock trace element and isotopic analyses have been carried out and are presented in section 4.5.

\subsubsection{Overall variations in major element chemistry}

Two major trends present are well defined on the $\mathrm{K}_{2} \mathrm{O}$ versus $\mathrm{SiO}_{2}$ variation diagram for the four Kemadec volcanoes studied (Figure 4.04); a low-K trend shown by samples from Raoul, New volcano and a few samples from Macauley, and a medium-K trend shown by samples from Healy and the majority of Macauley samples. Samples from New volcano lie along a colinear trend with Raoul for $\mathrm{CaO}$, but have a different trend for $\mathrm{Al}_{2} \mathrm{O}_{3}$ and $\mathrm{Fe}_{2} \mathrm{O}_{3}$, for which New volcano is colinear with Healy samples. Most of the Kermadec samples follow a low-Fe to medium-Fe trend (calc-alkaline: as defined by Miyashiro, 1974), but many samples from Macauley (especially at higher $\mathrm{SiO}_{2}$ ) follow a high-Fe (tholeiitic) trend. Macauley plots with several different trends on most variation diagrams, and the samples cover the total compositional range of Raoul and Healy combined.

Samples from Raoul represent five separate eruptions and the data plots as small clusters within a relatively confined compositional range on all variation diagrams (Figure 4.04). The number of eruptions sampled from the submarine volcanoes, however, is unknown. Macauley samples plot over a wide compositional range, with at least four separate groups, implying that the products sampled by dredging are from multiple eruptions and/or multiple magma systems. Samples from Healy and New volcano are confined to a restricted compositional spectra (despite physical differences in clast appearances at Healy), but in the absence of any constraining stratigraphy it is not possible to discern whether these are the products of single or multiple events. 

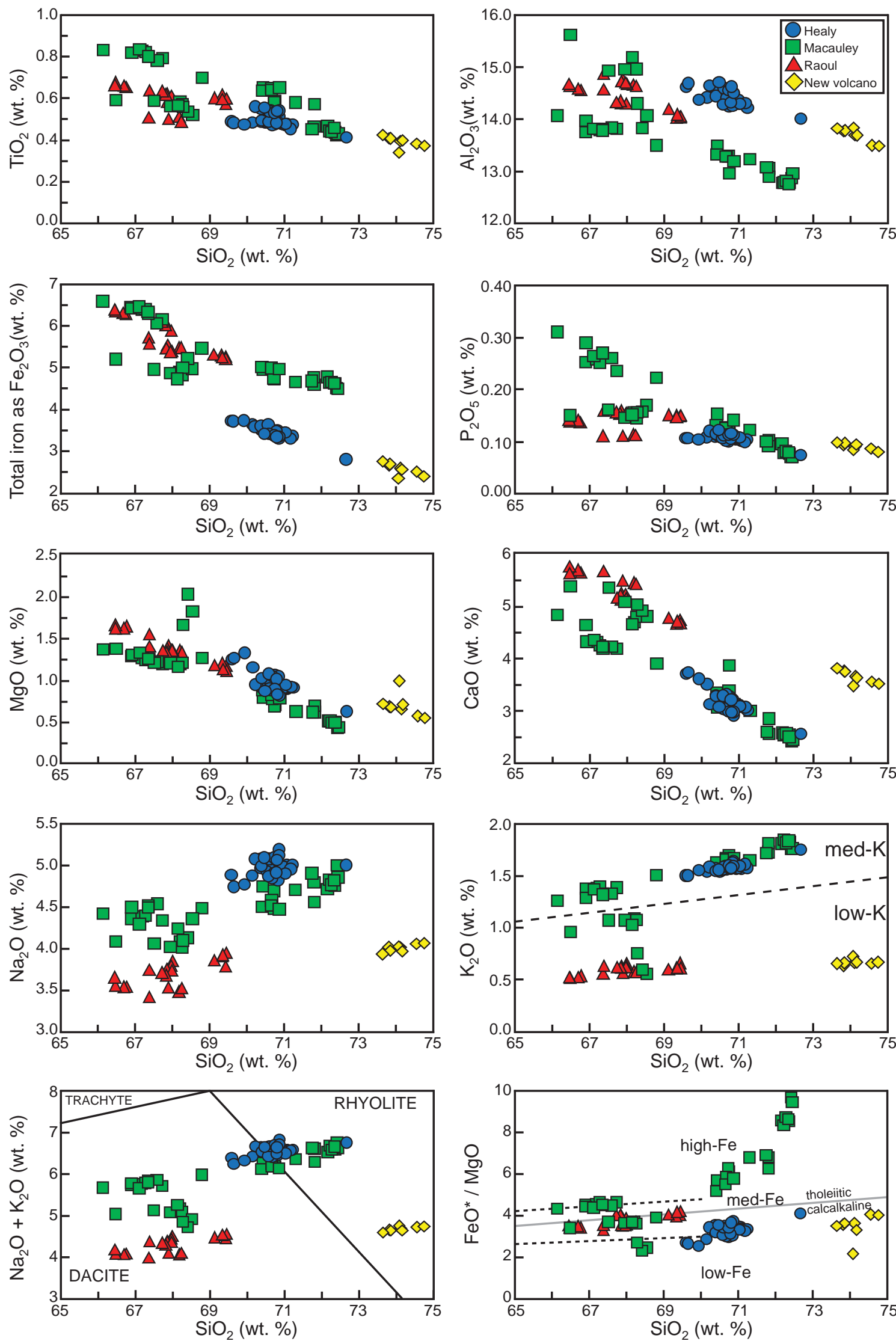

Figure 4.04. Variation diagrams for all pumice samples analysed for this study. The low and medium-K discriminant boundary is marked by a dashed line on the $\mathrm{K}_{2} \mathrm{O}$ vs. $\mathrm{SiO}_{2}$ diagram (from Gill, 1981). Compositional boundaries on total alkali $\left(\mathrm{Na}_{2} \mathrm{O}+\mathrm{K}_{2} \mathrm{O}\right)$ vs. silica (TAS) diagram are from Le Maitre et al. (1989). Low, med and high-Fe boundaries as marked by dashed lines on the $\mathrm{FeO} * / \mathrm{MgO}$ vs. $\mathrm{SiO}_{2}$ variation diagram are from Arculus (2003), and the solid grey line marks the discriminant boundary between tholeiitic and calcalkaline suites (Miyashiro, 1974). All values have been recalculated based on oxide totals normalised to $100 \%$. Raw data, original totals and LOI values are presented in Appendix B. See Figures 4.01 to 4.03 for uncertainties. 


\subsection{Mineralogy}

\subsubsection{Raoul crystal chemistry}

Representative pumice samples from the three large sheet-forming pumice fall deposits (the Matatirohia, Oneraki, Fleetwood eruptions), and the smaller Green Lake and Rangitahua eruptions were selected for detailed crystal specific work. There are significant differences in crystal varieties, sizes and compositional zoning between pumices from these individual units. However, in all samples crystals picked from glass-crystal separates (and also observed in thin section) tend to be found in one of three modes (a) individual crystals with adhering felsic glass (Figure 4.05); (b) individual or multiple crystals within a dark grey sheath of microlite rich, poorly vesiculated glass, forming round dark grey clots referred to in this study as mafic blebs (Figure 4.06A-G); or (c) round clusters of multiple crystals dominated by pyroxene and plagioclase up to $5 \mathrm{~mm}$ in diameter (Figure $4.06 \mathrm{H}$ ). A description of each observed crystal phase is given below, focussing mainly on the compositional range, zoning, and mode of occurrence for each crystal population.

\section{Clinopyroxene}

All analysed pumice contain $<1-2$ vol. $\%$ of $0.5-5 \mathrm{~mm}$ euhedral clinopyroxene belonging to one of two distinctive compositional groups. The first group is Mg-rich (15-18 wt. \% $\mathrm{MgO}$ ) and found mainly as single crystals with adhering felsic glass (Figure 4.05A,B) or as large crystals (up to $2 \mathrm{~cm}$ ) inside mafic blebs (Figure 4.06BE,G). Mg-rich clinopyroxene mostly occur in the large sheet forming eruptions, and are dominant in the Matatirohia and Fleetwood samples $(>60-70 \%$ of the total clinopyroxene analysed). Mg-rich clinopyroxene often display distinct compositional zoning, with cores that plot around the augite-diopside compositional boundary (Figure 4.07A: $\mathrm{En}_{44-50} \mathrm{Fs}_{5-15} \mathrm{Wo}_{40-47}$ ), and have sharply defined, strongly zoned rims, which have up to 5-6 wt. \% higher FeO contents. The extent of this compositional zoning is highly variable between pumices from different eruption deposits. Mg-rich clinopyroxene from the Matatirohia and Fleetwood deposits typically show only very thin $(10-20 \mu \mathrm{m})$ rims (Figure 4.05A), and many crystals lack zoning altogether. In contrast, zoned Mg-rich clinopyroxene from other Raoul deposits typically display thicker rims (30-50 $\mu \mathrm{m}$ in the Oneraki: Figure 4.06D, and up to $100 \mu \mathrm{m}$ in the Green Lake pumice: Figure 4.05B). The Oneraki and Green Lake Mg-rich clinopyroxene also 

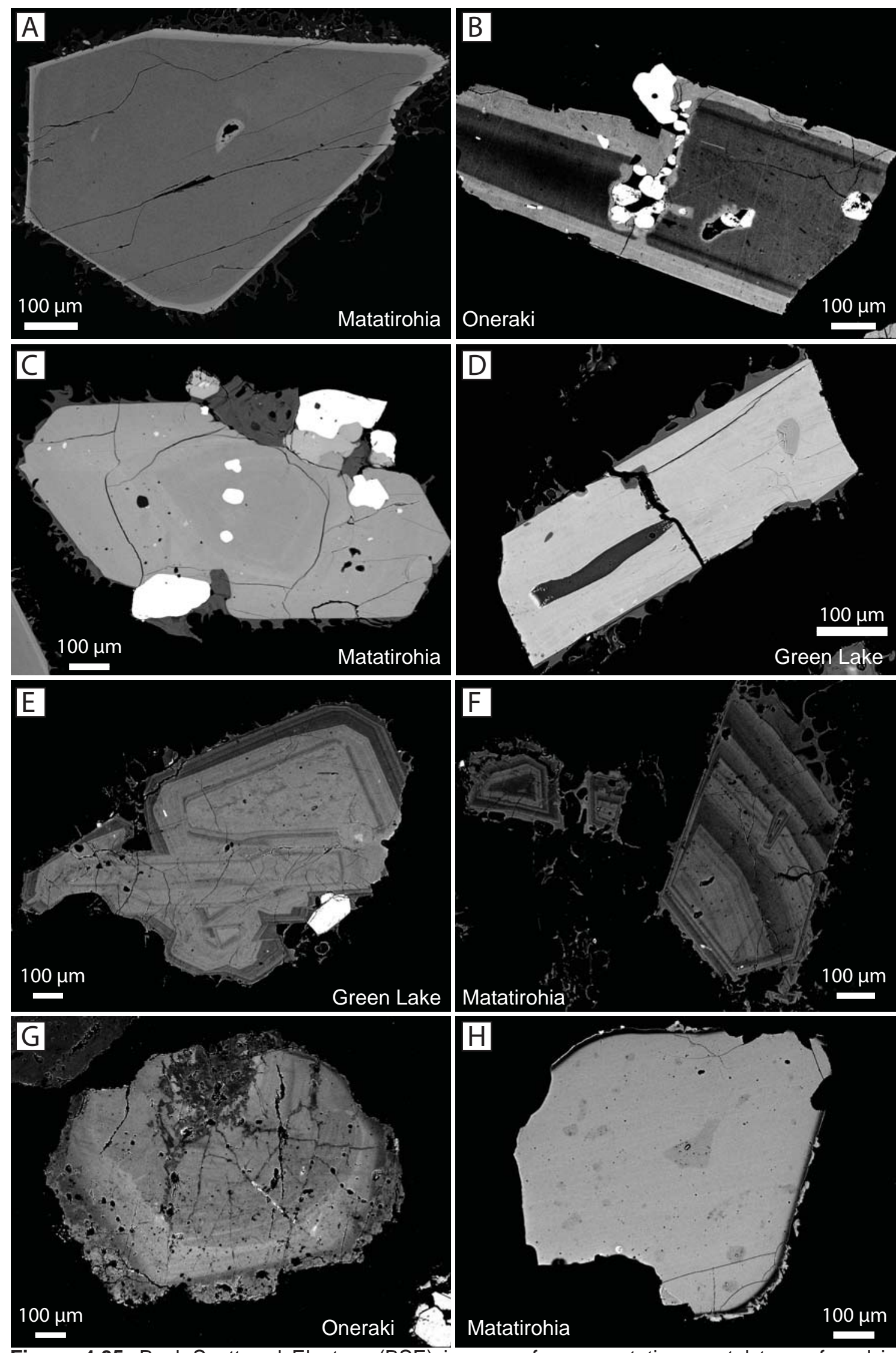

Figure 4.05. Back-Scattered Electron (BSE) images of representative crystal types found in pumices from Raoul volcano. Shading in greyscale is relative to compositional changes where lighter shades indicate higher $\mathrm{FeO}$ content in mafic minerals and higher $\mathrm{CaO}$ in plagioclase. A) Mg-rich clinopyroxene with a thin Fe-rich rim. B) Resorbed Mg-rich clinopyroxene core with a thick Fe-rich rim. C) Fe-rich clinopyroxene with inclusions of magnetite and apatite. D) Unzoned euhedral orthopyroxene. E) Plagioclase with $A n_{85}$ core and a thick $A n_{65}$ rim as thin oscillatory zoning. F) Complex oscillatory zoning in plagioclase. G) Cracked and pitted Na-rich plagioclase showing normal-type zonation. H) Olivine crystal with a thin Mg-rich (reversely zoned) rim. 

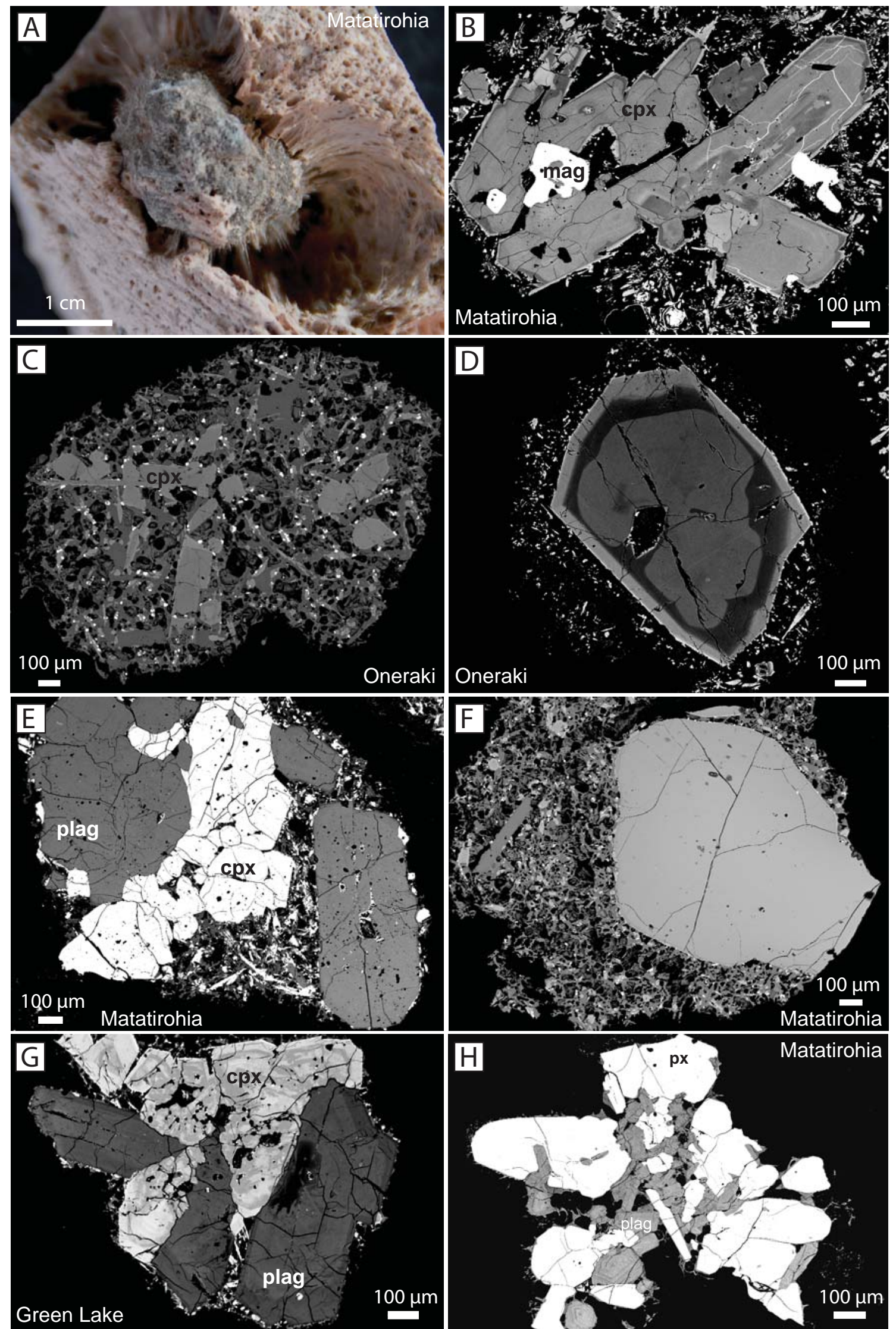

Figure 4.06. Representative images of mafic blebs and crystal clusters from Raoul pumices. A) Photograph of mafic bleb, surrounded by large open vesicles. B) BSE image of clinopyroxene inside a mafic bleb. C) Small clinopyroxene inside a sheath of microlite rich poorly vesicular glass. D) Strongly zoned Mg-rich clinopyroxene surrounded by microlite rich glass. E) Cluster of plagioclase and clinopyroxene inside a mafic bleb. F) Single completely unzoned olivine inside a vesicular mafic bleb. G) Strongly zoned cluster of plagioclase and clinopyroxene with a thin coating of microlite rich glass. H) Group of clinopyroxene, orthopyroxene and plagioclase forming a crystal cluster with adhering felsic glass. $\mathrm{px}=$ pyroxene, $\mathrm{cpx}=$ clinopyroxene, mag = magnetite, plag $=$ plagioclase, ol $=$ olivine . 

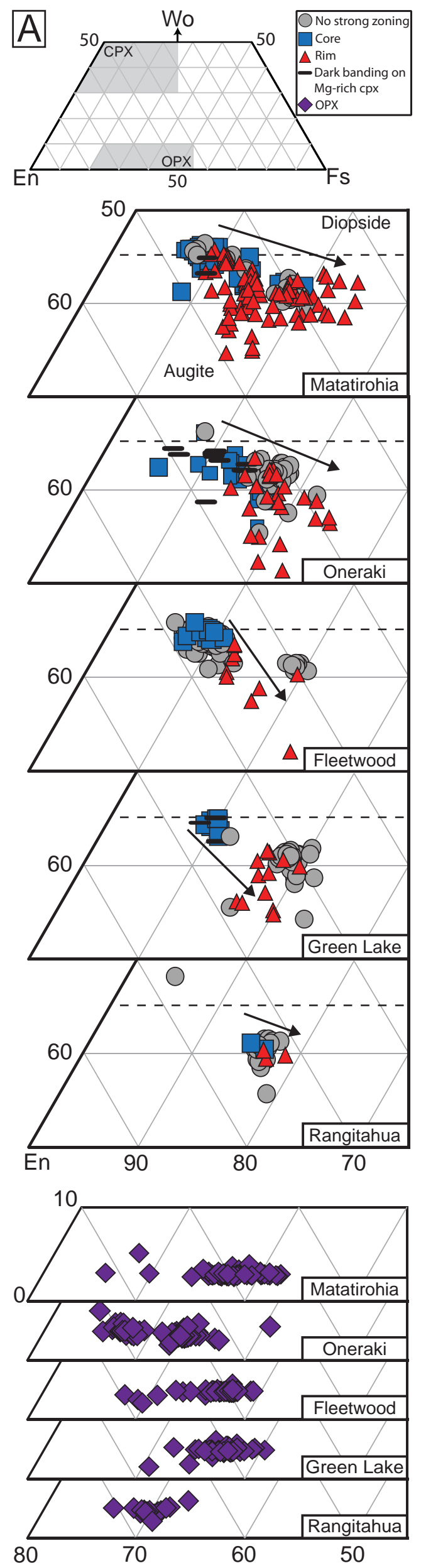
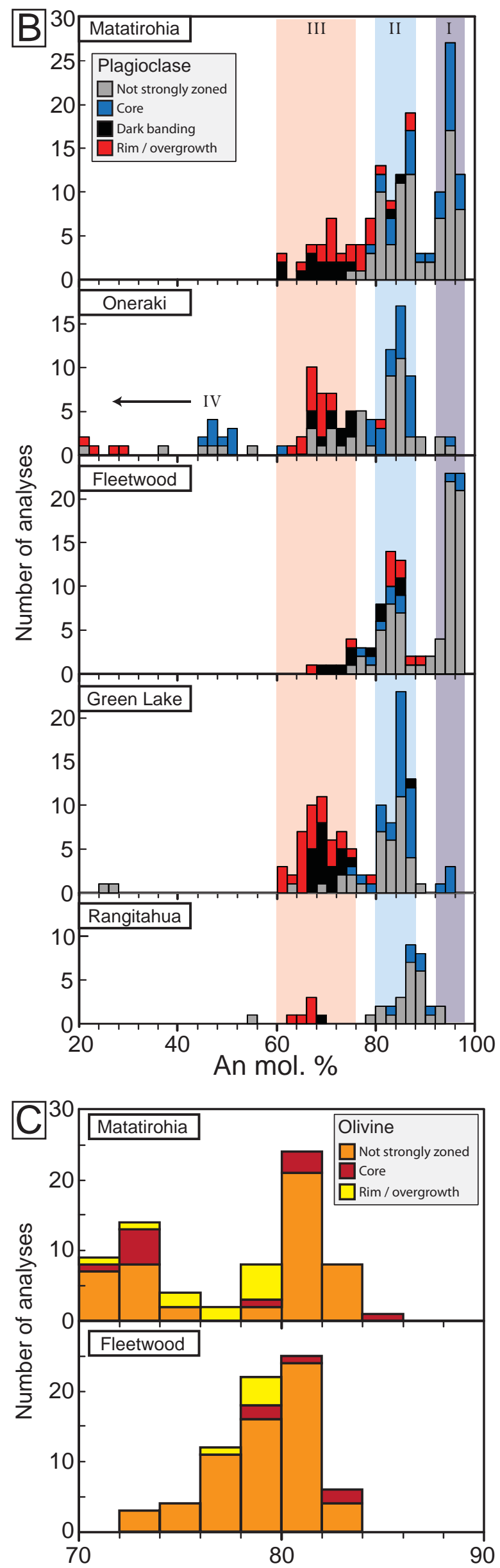

Fo mol. \% 
Figure 4.07. Composition of crystals in representative samples from five Raoul eruptive units. A) Enstatite (En)-Ferrosilite(Fs)-Wollastonite (Wo) ternary diagrams stacked by eruption. Enlarged areas are highlighted on ternary diagram at the top. Compositions calculated by En $=$ $100 \mathrm{Mg} /(\mathrm{Ca}+\mathrm{Mg}+\mathrm{Fe}), \mathrm{Fs}=100 \mathrm{Fe} /(\mathrm{Ca}+\mathrm{Mg}+\mathrm{Fe}), \mathrm{Wo}=100 \mathrm{Ca} /(\mathrm{Ca}+\mathrm{Mg}+\mathrm{Fe})$. Clinopyroxene compositions are displayed for both unzoned single crystals and for zones within individual crystals as denoted by marker type. Only zones that vary by $>3$ wt $\% \mathrm{FeO}$ are shown. Black arrows indicate the direction of core to rim compositional variation. Orthopyroxene compositions are mostly from individual unzoned crystals. Zones within orthopyroxene are not differentiated by marker type due to the generally limited compositional spectrum and the tight clustering of data. The complete compositional dataset is presented in Appendix F. B) Histograms stacked by eruption showing the variation in plagioclase anorthite content $(\mathrm{An}=100 \mathrm{Ca} /(\mathrm{Ca}+\mathrm{Na}))$ between both unzoned single crystals and zones within individual crystals. Three dominant modes are highlighted, and a fourth group of outliers is marked (see text for discussion). C) Histograms stacked by eruption showing the variation in forsterite (Fo) content (Fo $=100$ $\mathrm{Mg} /(\mathrm{Mg}+\mathrm{Fe}))$ for both unzoned single olivines and zones within individual olivines.

display resorbed cores with dark Mg-rich overgrowths (Figures 4.05B, 4.06D and 4.07A). This feature only appears in a few crystals from the Matatirohia and is generally absent from the Fleetwood and Rangitahua clinopyroxene.

The second population of clinopyroxene is Fe-rich and plot near $\operatorname{En}_{38-45} \mathrm{Fs}_{15-22}$ $\mathrm{Wo}_{37-43}$. Fe-rich type clinopyroxene is present in all samples and their compositional range overlaps to some extent with the rims of strongly zoned $\mathrm{Mg}$-rich clinopyroxene (Figure 4.07A). Fe-rich clinopyroxene are typically smaller than $\mathrm{Mg}$-rich (generally $<1$ $\mathrm{mm}$ ), and found as either individual crystals with inclusions of magnetite and apatite (Figure $4.05 \mathrm{C}$ ), or in the form of crystal clusters, combined with orthopyroxene, plagioclase and magnetite $\left(\mathrm{Mnt}_{50-80}\right)$ (Figure 4.06H). The majority of Fe-rich clinopyroxene do not display strong compositional zoning (Figure 4.06C). Zoned rims or overgrowths on weakly zoned crystals include both normal and reverse zonation, which generally only vary by $1-2$ wt $\% \mathrm{FeO}$ (therefore they are not distinguished in Figure 4.06A). Fe-rich clinopyroxene dominate in the Oneraki, Green Lake and Rangitahua samples, making up $>75 \%$ of the total clinopyroxene content.

\section{Orthopyroxene}

Orthopyroxene crystals can also be grouped into two populations based on their $\mathrm{MgO}$ contents; Mg-rich and Fe-rich (Figure 4.07A). Orthopyroxene crystals tend to be small $(<1 \mathrm{~mm})$ with an overall compositional range of $\mathrm{En}_{55-72} \mathrm{Fs}_{25-43} \mathrm{Wo}_{1-5}$ (Figure 4.07A). The majority of orthopyroxene are of the Fe-rich type and do not show strong compositional zoning, occurring either as individual crystals (Figure 4.05D) or clustered with clinopyroxene, plagioclase and magnetite (Figure 4.06H). Only sparse orthopyroxene crystals are found in mafic blebs in the Matatirohia and Fleetwood 
pumices, although they are more frequent in Oneraki mafic blebs. These crystals from mafic blebs plot as high-Mg outliers on ternary diagrams (Figure 4.07A). Several of these high-Mg orthopyroxene display compositional zoning, with Fe-rich rims on normal zoned crystals which plot in the main compositional field of unzoned orthopyroxene (Figure 4.07A, rims distinguished in Appendix F).

\section{Plagioclase}

Plagioclase is the most common crystal phase observed in pumice from Raoul volcano. Plagioclase tends to be large $(1-5 \mathrm{~mm})$ and occur as individual crystals, within crystal clusters or as crystals inside mafic blebs where they can reach up to $2 \mathrm{~cm}$ in size. Four plagioclase compositional populations are identified from single crystals, but large compositional variations exist between zones within individual crystals (I-IV on Figure 4.07B). The first population (grey field labelled ' $I$ ' in Figure 4.07B) occurs between $\mathrm{An}_{92}$ and $\mathrm{An}_{98}$ and is evident as a large peak on frequency histograms for the Matatirohia and Fleetwood pumices, and relatively minor peak for the other deposits studied (Figure 4.07B). This high-An peak represents analyses of either large unzoned crystals or the cores of zoned crystals which occur dominantly in mafic blebs (Figure 4.06E,G). A second population (II) occurs between ca. $\mathrm{An}_{80}$ and $\mathrm{An}_{88}$ and is present for all deposits studied. This peak is also dominated by unzoned crystals or the cores of zoned crystals (Figure 4.05E), although it is not restricted to crystals found inside mafic blebs. A third population (III) occurs as either a low-An peak or a long low-An tail to ca. $\mathrm{An}_{60}$ and corresponds to the analysis of either smaller unzoned groundmass crystals, rims on large strongly zoned crystals (e.g. Figure 4.05E), or zones of thin dark banding (e.g. Figure 4.05F: where dark banding in BSE image is due to higher relative $\mathrm{Na}_{2} \mathrm{O}$ ). Compositional zoning is not restricted to simple core-rim normal (decreasing An content) zonation. Some crystals have high-An cores which are overgrown by distinctive dark banding, which have compositions as low as $\mathrm{An}_{60}$, and are then mantled by a lighter coloured (lower $\mathrm{Na}_{2} \mathrm{O}$ ), higher An (reversely zoned) rim. Such complex zonation often occurs multiple times in a single crystal, forming oscillatory zoning (Figure 4.05F). A fourth population (IV) of plagioclase is found mainly in the Oneraki, but also rarely in the Green Lake Pumice samples (Figure 4.07B). This population occurs as outliers with low-An content, and consists of large mottled and cracked subhedral to anhedral crystals (Figure 4.05G). Most of these crystals display normal compositional zoning, with cores between ca. $\mathrm{An}_{44}$ and $\mathrm{An}_{52}$, and rims of $<\mathrm{An}_{30}$ (Figure 4.07B). 


\section{Olivine}

Olivine is only found in the Matatirohia and Fleetwood pumices, both as rare $(<1$ vol. $\%$ ) large individual crystals (typically 1-5 mm) and in mafic blebs. Many isolated crystals have a thin partial selvedge of dark grey, microlite rich glass, suggesting that they are derived from mafic blebs. Despite being hosted in dacite pumice, disequilibrium features are relatively uncommon in the olivines, with only a few showing very thin zoned rims $(<10-20 \mu \mathrm{m}$ : Figure $4.05 \mathrm{H})$, or reaction rims/overgrowths of small orthopyroxene crystals. Olivines from the Matatirohia have a bimodal compositional distribution, with a major peak at ca. $\mathrm{Fo}_{80}$ and a minor peak at ca. $\mathrm{Fo}_{74}$ (Figure 4.07C). In comparison, Fleetwood olivines have a single peak at ca. Fo ${ }_{80}$, but have a long tail of more Fe-rich compositions. The thin rims of zoned olivines are both normal and reversely zoned (e.g. Figure $4.05 \mathrm{H}$ ), with composition varying no more than 3-4 mol. \% Fo.

\subsubsection{Plutonic xenoliths from the Matatirohia deposits}

Previous studies have recorded plutonic clasts (mainly gabbros and tonalites) as beach boulders on the northern coast of Raoul Island (e.g. Brothers and Searle, 1970; Lloyd and Nathan, 1981; Worthington, 1998). These plutonic boulders are rarely found in situ in eruptive deposits, but since they are found on the beach directly below cliffs formed by Ngaio Group eruptive deposits, they have been suggested to be lithics derived from the young pyroclastic units (Lloyd and Nathan, 1981). Three lithologies, closely matching those previously described, were collected from within the Matatirohia deposit, and from the beach rubble directly below the Matatirohia and Oneraki coastal cliff deposits during the 2004 and 2007 Tangaroa voyages (Figure 4.08). These fragments were originally termed 'lithics' due to their strongly contrasting visual appearance and physical properties when compared to the dominant juvenile pumice component. As outlined below, however, careful study of these rock fragments suggests that they are much more intimately linked with the silicic eruption units in which they are found, and are therefore termed as 'xenoliths' in this study.

Three xenolith types have been investigated in this study. The first xenolith type is cumulate gabbros (Figure 4.08A,B), of which a single example was collected from within the Matatirohia pyroclastic flow deposits. This gabbro has large (averaging 1-2 $\mathrm{mm}$ but up to $1 \mathrm{~cm}$ ) crystals of olivine, clinopyroxene and plagioclase, interspersed with small irregular patches of dark grey, partially vesicular, microlite rich glass. Melt 

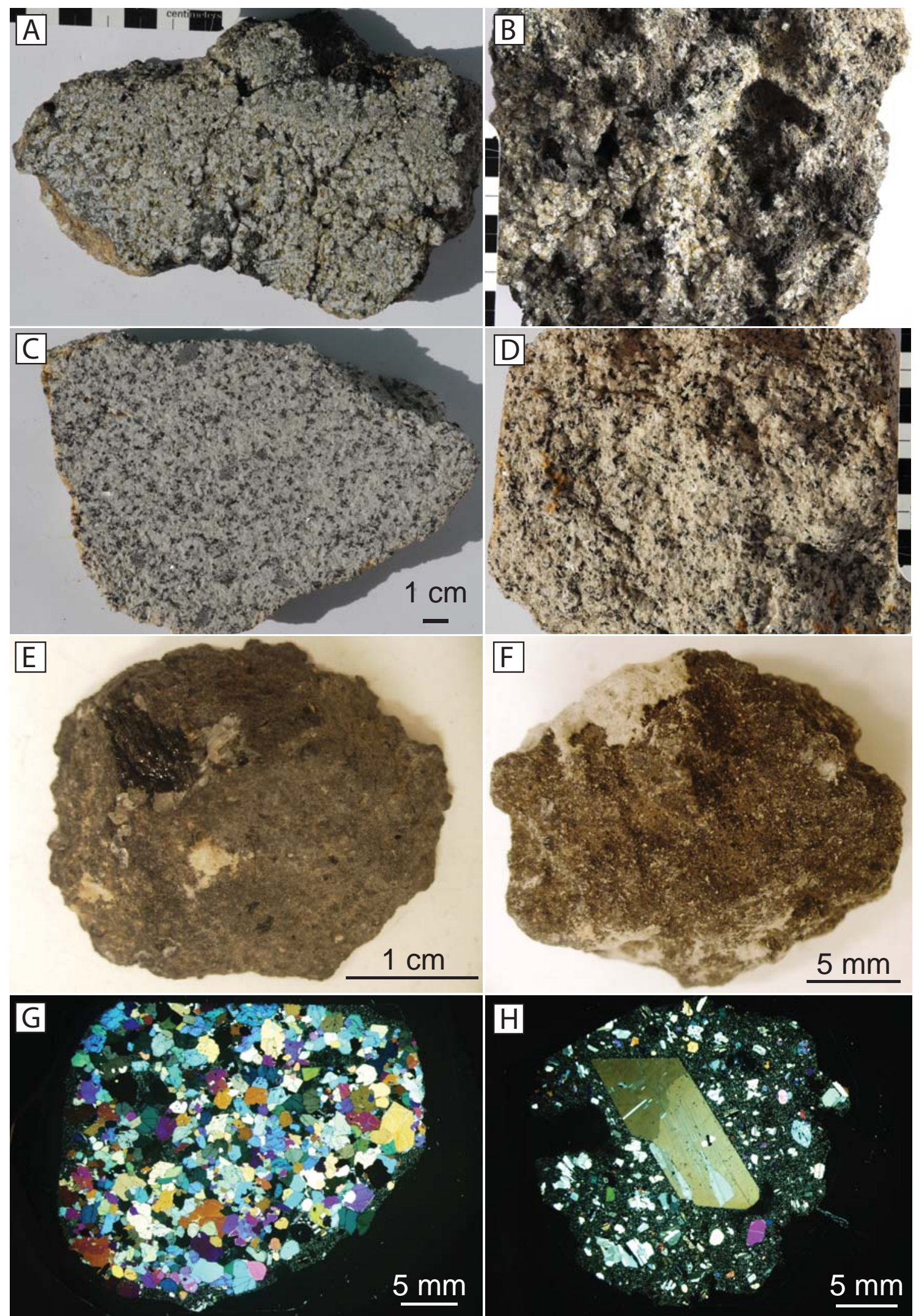

Figure 4.08. Lithic types found in the Matatirohia eruption deposit. A) Cut fresh surface of the olivine gabbro xenolith. White and black squares on scale are $1 \mathrm{~cm}$. B) Split surface of the gabbro with a crystalline granular texture and interstitial dark grey microlite rich vesiculated glass. C) Sliced section of the large tonalite xenolith. D) Exterior of the tonalite xenolith with a crystalline granular texture. E) Exterior of a large round mafic bleb with large crystals of clinopyroxene and plagioclase. F) Large mafic bleb with adhering white pumice glass. G) Thin section (crossed polarisers) of a large mafic bleb with a crystalline granular texture and a thin adhering microcrystalline glass film. Phenocrysts are dominantly plagioclase and pyroxene, with lesser amounts of olivine and magnetite. H) Thin section (crossed polarisers) of a large mafic bleb showing a single large plagioclase crystal and smaller crystals of olivine, pyroxene and plagioclase in a microcrystalline vesiculated groundmass. 
bearing films pervade the gabbro, disaggregating crystals and causing parts of the rock to be friable. The second, most common, xenolith type is represented by large boulders of intermediate to felsic plutonic composition (tonalite to quartz diorite: Worthington, 1998, Appendix A). Several subrounded tonalite xenoliths were collected from beach rubble directly below the Matatirohia and Oneraki deposits and one representative example selected for this study (Figure 4.08C,D). The clast is composed dominantly of interlocking euhedral to subhedral plagioclase and quartz with lesser amounts of hornblende, alteration minerals and/or overgrowths of actinolite (after hornblende) and epidote (after plagioclase). Small $(<0.1 \mathrm{~mm})$ crystals of spinel, ilmenite and rare zircon are also present. Although this rock appears fresh in hand specimen, the occurrence of actinolite and epidote along with the altered appearance of many crystals, indicates that it has undergone high-temperature $\left(>250^{\circ} \mathrm{C}\right)$ hydrothermal alteration.

The third xenolith type is termed 'cauliform mafic bleb' and occurs as a sparse discrete fine to coarse lapilli component in the Matatirohia fall deposit (Figure 4.08E-H; Lloyd and Nathan, 1981; Worthington, 1998). Many blebs have adhering pumice glass, suggesting they are a juvenile, dense component and not foreign lithic material. These clasts are interpreted as larger scale analogues to the smaller mafic blebs found as inclusions within individual pumice clasts (e.g. Figure 4.06A). A complete spectrum of textures is observed in loose cauliform mafic blebs collected from the Matatirohia deposit. At one extreme they have a crystalline granular texture, similar to that observed in cumulate gabbros, with only a very thin surrounding film of dark grey melt (Figure $4.08 \mathrm{G})$. At the other extreme they are dominated by dark grey microcrystalline, poorly vesiculated melt with scattered crystals of olivine, plagioclase and clinopyroxene (Figure $4.08 \mathrm{H}$ ). The incorporation of smaller mafic blebs in the dacite pumices, and their sub-spherical cauliform appearance, indicates that they were partially molten when incorporated into the dacite magma.

Compositions of major crystal phases for the three lithic types are presented in Figure 4.09. Clinopyroxene from one representative cauliform mafic bleb displays strong normal compositional zoning, with cores and resorbed dark bands that are more $\mathrm{Mg}$-rich than the rims, which have considerably higher FeO contents (up to ca. 6-8 wt. $\%$ : Figure 4.09A). A similar pattern of zonation is observed in several cumulate gabbro clinopyroxenes, although the zoning is not as strong or common (especially in regions not exposed to intruding melt). Clinopyroxene in the cauliform mafic bleb and cumulate gabbro have similar compositions and patterns of zonation to the Mg-rich population of clinopyroxene observed within dacite pumices (Figure 4.07A). Olivine crystals from 

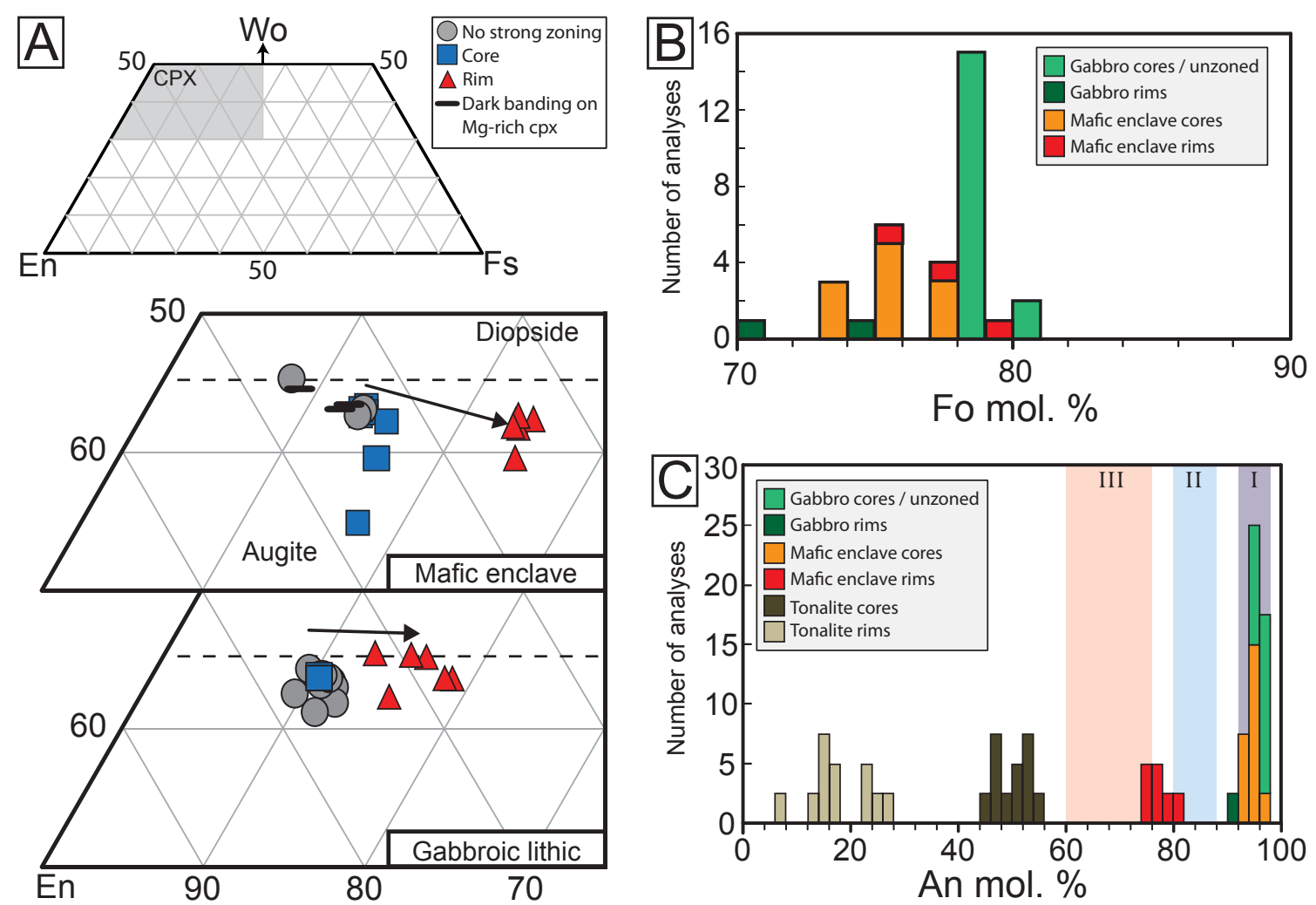

Figure 4.09. Crystal compositions in plutonic lithic fragments from the Matatirohia deposits. A) Stacked plots by lithic type showing the composition of clinopyroxene crystals on enlarged sections of an En-Fs-Wo ternary diagram (enlarged areas highlighted on ternary diagram at the top). Compositions are displayed for both unzoned single crystals and for zones from within individual crystals as denoted by marker type. Only zones that vary by more than 3 wt. \% FeO are shown. The black arrow represents the direction of core to rim compositional variation. B) Stacked histograms by lithic type showing the variation in olivine forsterite content (Fo mol. \%) for both unzoned single olivines and zones within individual olivines. C) Stacked histograms by plutonic lithic type showing the variations in plagioclase An content between both unzoned single crystals and zones within individual crystals. Highlighted areas are shown from the three dominant modes identified from crystals in Raoul pumice samples (Figure 4.07) to compare the compositions of the dominant crystal populations (see text for discussion).

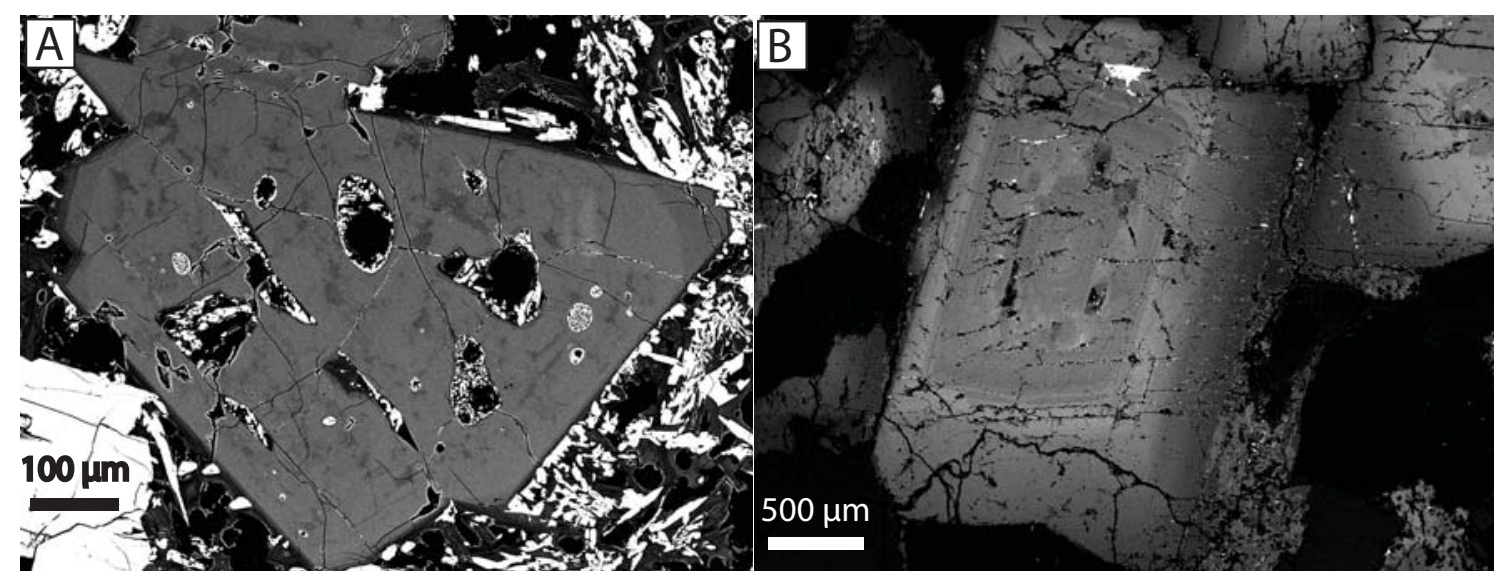

Figure 4.10. BSE images of representative plagioclase crystals in plutonic xenolith samples from Raoul volcano. A) Plagioclase crystal inside a cauliform mafic bleb, surrounded by microlites of pyroxene and plagioclase and small regions of poorly vesiculated glass. Note the large re-crystallised melt inclusions and lack of compositional zoning. Only the very outer ca. $10 \mu \mathrm{m}$ rim shows compositional zoning to lower An contents. B) Plagioclase inside a tonalite lithic showing normal zoning. The crystal has a mottled appearance with extensive cracking, similar to that observed in low-An plagioclase from Raoul pumice samples. 
these two lithic types also display a similar overall compositional range, pattern of zonation and texture to the olivines observed within the dacite pumice (Figure 4.09B).

Plagioclase was analysed from all three lithic types to compare with plagioclase populations identified from individual pumice clasts (Figure 4.09C). Unzoned crystals and cores of zoned crystals from both the cumulate gabbro and the cauliform mafic bleb have a narrow compositional range between $\mathrm{An}_{92}$ and $\mathrm{An}_{98}$ that plots directly within the high-An field seen in the dacite pumices (population I). Rims on strongly zoned plagioclase from these two lithic types have lower An values, overlapping with pumice plagioclase populations II and III (Figure 4.09C). Plagioclase in the tonalite xenoliths displays strong normal zoning with cores of $\mathrm{An}_{56}$ to $\mathrm{An}_{44}$, and rims between $\mathrm{An}_{24}$ and $\mathrm{An}_{6}$. These core-rim compositions are similar to the low-An plagioclase (population IV) outliers observed in the Oneraki and Green Lake Pumice clasts. In addition, plagioclase in the tonalite xenolith shares a similar mottled and cracked appearance and patterns of zoning on BSE images to the Oneraki and Green Lake Pumice low-An plagioclase (Figures $4.10 \mathrm{~B}$ and $4.05 \mathrm{G}$, respectively). Large anhedral crystals of quartz with a mottled and altered appearance are also observed inside the Oneraki, Green Lake Pumice and Rangitahua pumices. Although not analysed for this study the large irregular size, and altered appearance of the quartz crystals suggests they are from a tonalite source.

\subsubsection{Macauley crystal chemistry}

Representative samples from Macauley volcano were chosen for detailed crystal specific work from the geochemical groups identified by major-element composition (Section 4.1). Five pumice samples were selected from end-member chemical groups (Figures 4.02 and 4.04): (1) D29_PC02 from the most evolved rhyolite pumice group from the northern caldera rim; (2) D25_PC01 from the high-Fe/med-K dacite cluster (ca. 66-68 wt. \% $\mathrm{SiO}_{2}$ ); (3) D33_PC02 from the med-Fe/low-K dacite cluster (ca. 66-69 wt. \% $\mathrm{SiO}_{2}$ ); (4) D33_PC04 from the low-Fe/low-K, high-MgO (>1.5 wt. \%) cluster; and (5) MI07_P03 from the Sandy Bay Tephra on Macauley Island. Similar to Raoul pumices, crystals are present as individual crystals (Figure 4.11A-H) and as part of large (up to $5 \mathrm{~mm}$ ) clusters of plagioclase, pyroxene and Fe-Ti oxides (Figure 4.12A). Mafic blebs, however, are only found in the Sandy Bay Tephra (Figure 4.12B,C) and contain large $(0.5-5 \mathrm{~mm})$ crystals of olivine, plagioclase and clinopyroxene. Crystal types, size, composition and zonation vary considerably between the selected samples, consistent 


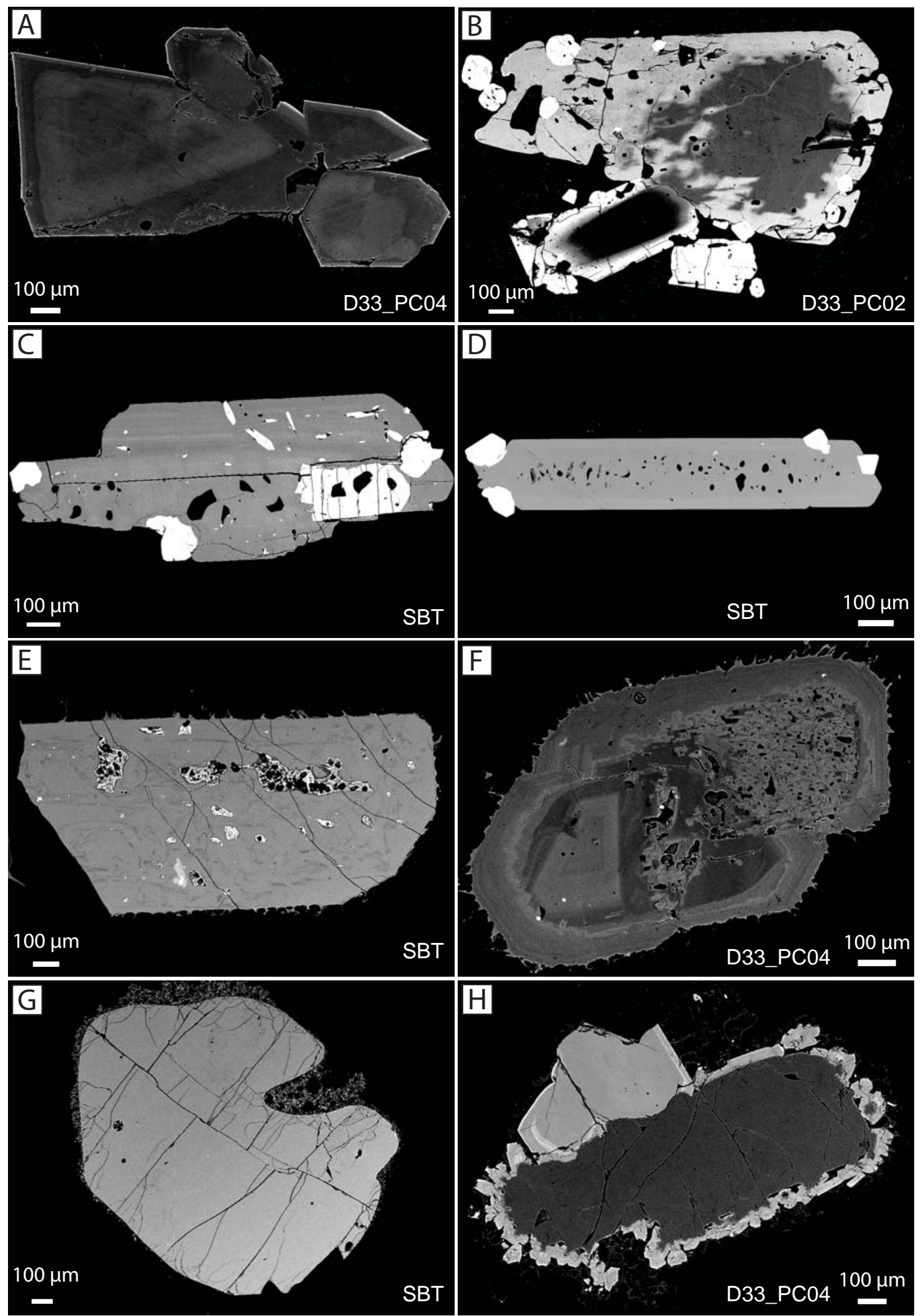

Figure 4.11. Representative BSE images of crystals found in pumices from Macauley volcano. A) Strongly zoned high-Mg clinopyroxene. B) Strongly resorbed high-Mg clinopyroxene with Fe-rich overgrowth. C) Unzoned Fe-rich clinopyroxene with inclusions of apatite and Fe-Ti oxides. D) Orthopyroxene with melt inclusions and ingrown crystals of Fe-Ti oxides. E) Unzoned An-rich plagioclase with adhering glass and large vesiculated microcrystalline melt inclusions. F) Strongly zoned $A n_{50-70}$ plagioclase with a resorbed and sieve textured core. G) Large completely unzoned olivine with adhering microlite rich glass from Sandy Bay pumice. $\mathrm{H}$ ) Olivine with a thick reaction overgrowth of orthopyroxene. 

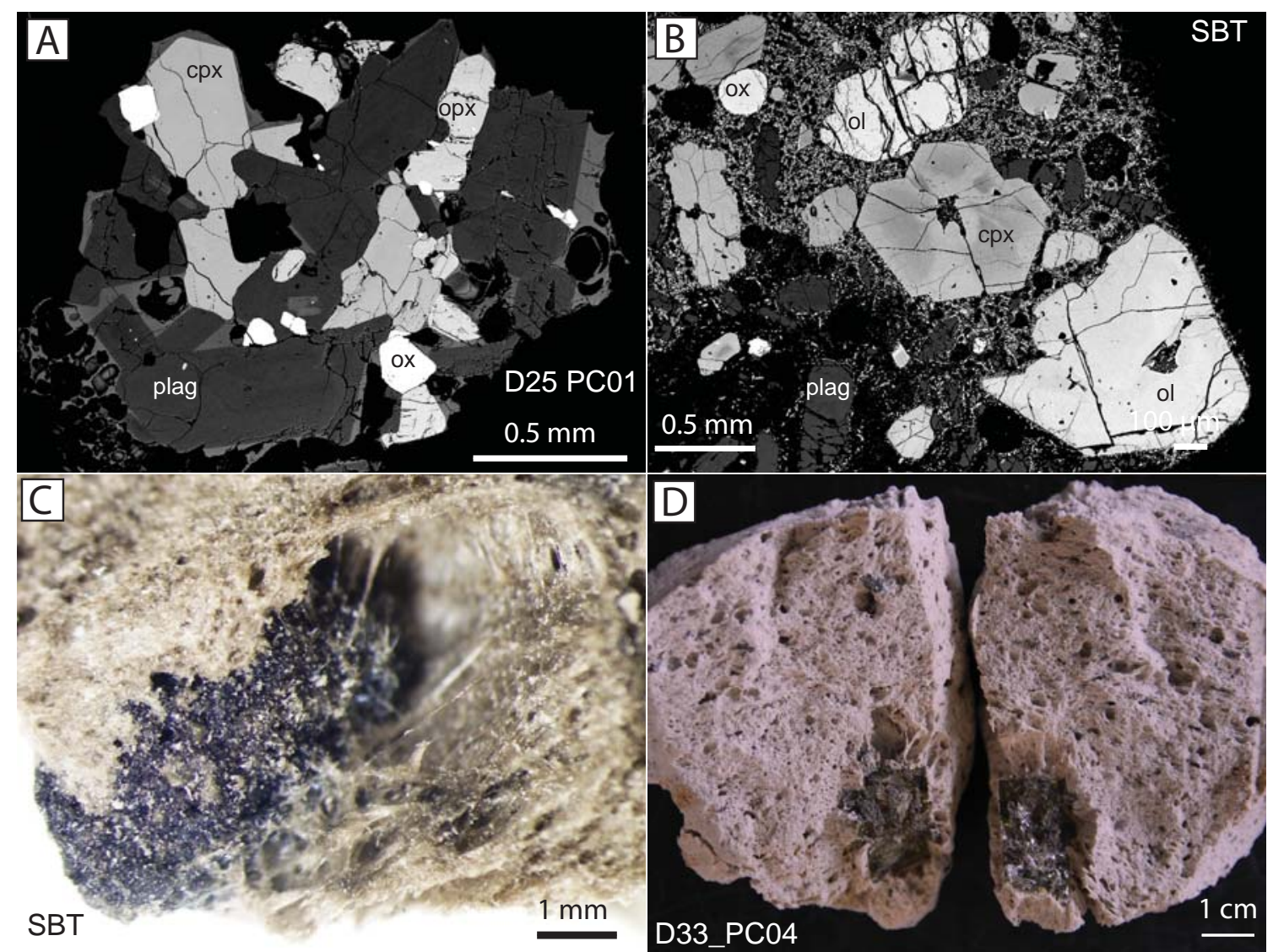

Figure 4.12. Images of representative mafic blebs and crystal clusters from Macauley pumice. A) BSE image of a large round crystal cluster with adhering felsic pumice glass. Crystals show no compositional zoning. B) BSE image of a small segment of a mafic bleb, containing high-An plagioclase, Mg-rich clinopyroxene and large olivine crystals enclosed in a microlite-rich, poorly vesiculated glass. C) Pumice hand sample showing a small mafic bleb inside a large open vesicle. D) Pumice sample D33_PC04 split in half exposing a large, pale green, euhedral clinopyroxene with interstitial regions of dark grey melt. opx= orthopyroxene, $\mathrm{cpx}=$ clinopyroxene, $\mathrm{ox}=\mathrm{Fe}-\mathrm{Ti}$ oxide, plag = plagioclase, ol = olivine.
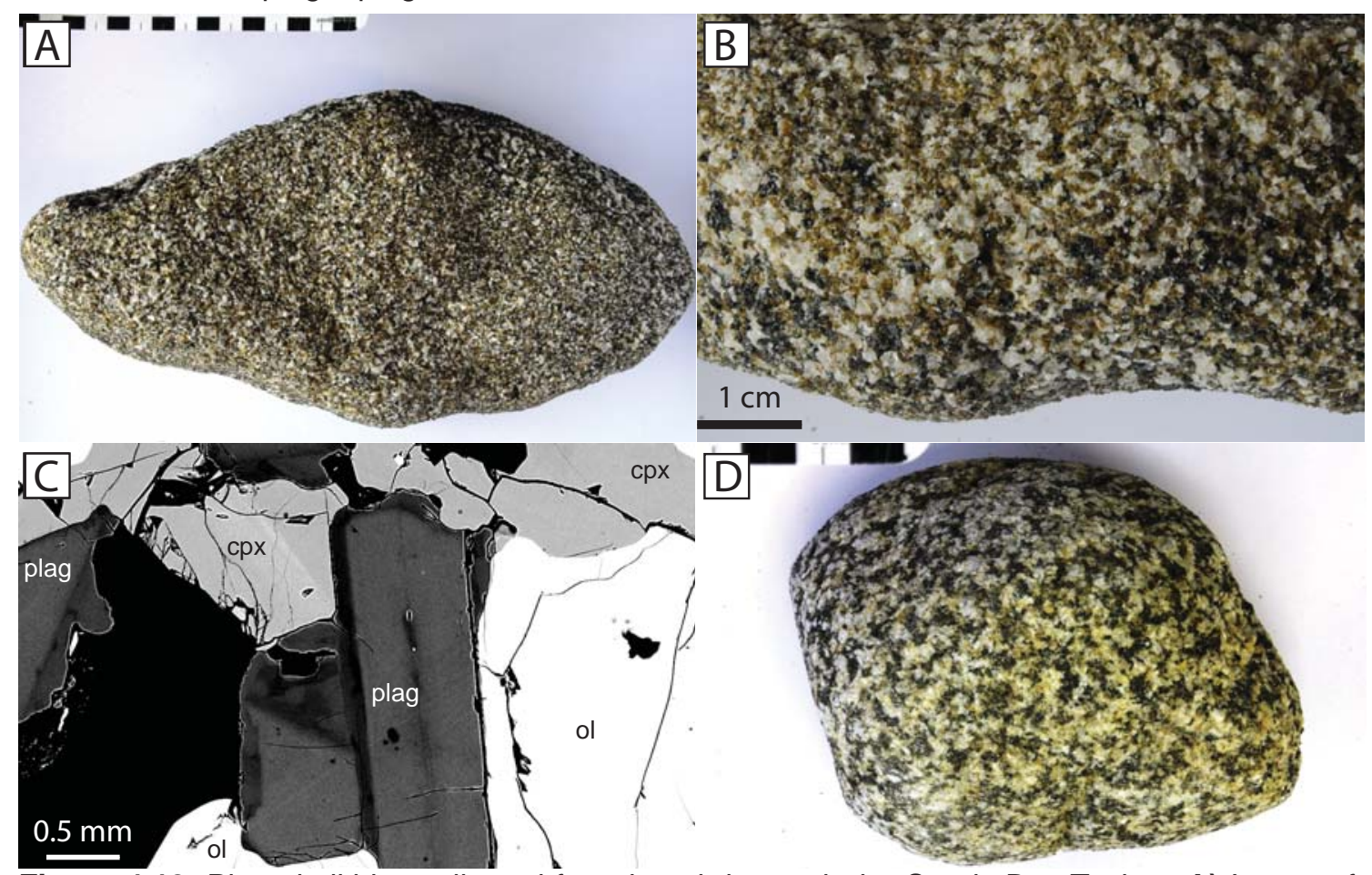

Figure 4.13. Plutonic lithics collected from beach beneath the Sandy Bay Tephra. A) Image of whole rounded gabbroic xenolith. B) Close up of gabbroic xenolith with a crystalline granular texture comprised of large (>1 mm) high-An plagioclase, Mg-rich clinopyroxene and olivine. C) BSE image of crystals within the Gabbroic xenolith showing unzoned olivine (ol), clinopyroxene $(\mathrm{cpx})$ and normal zoned plagioclase (plag). D) Rounded and strongly altered leucocratic boulder. 
with the large variations observed in whole rock major element chemistry (Section 4.1). To further investigate the origins of the crystal assemblages, a single gabbroic xenolith from the Sandy Bay Tephra has also been included for crystal work (Figure 4.13A-C).

\section{Clinopyroxene}

Clinopyroxene occurs as two compositional types, as observed at Raoul. The first type is Mg-rich, crystals of which are generally large ( $>1 \mathrm{~mm}$ : Figure 4.11A,B) with strong compositional zoning. Cores plot near the augite-diopside boundary (ca. En $44-50 \mathrm{Fs}_{5-20}$ $\mathrm{Wo}_{40-47}$ ), with strongly zoned overgrowths/rims containing considerably higher $\mathrm{FeO}$ and lower $\mathrm{CaO}$ contents (Figure 4.14A). Mg-rich clinopyroxene from D33_PC04, however, have rims that do not show a large increase in $\mathrm{FeO}$, but are significantly lower in $\mathrm{CaO}$. The Mg-rich clinopyroxene type is dominant in sample D33_PC04, common in D25_PC01 and MI07_P03, rare in D33_PC02 and absent in D29_PC02 (Figure 4.14A). Mg-rich clinopyroxene are commonly found within mafic blebs in the Sandy Bay pumice (Figure 4.12B, C), and as notably large (up to $2 \mathrm{~cm}$ : Figure 4.12D) pale green crystals in sample D33_PC04. The second type of clinopyroxene is Fe-rich, and in contrast to the Mg-rich variety, displays minimal compositional zoning (Figure 4.11C), forming tightly clustered compositional fields which often overlap with the most Fe-rich rims of Mg-rich clinopyroxene (Figure 4.14A). For sample D33_PC04, many Fe-rich clinopyroxene have reverse compositional zoning. Fe-rich clinopyroxene are also smaller $(<1 \mathrm{~mm})$, and often occur in crystal clusters with plagioclase, orthopyroxene, magnetite $\left(\mathrm{Mnt}_{50-70}\right)$ and ilmenite (Ilm85-88) (Figure 4.12A).

\section{Orthopyroxene}

Orthopyroxene is a minor crystal phase $(<1$ vol. \%) in all samples, and generally small in size ( $<0.5-1 \mathrm{~mm}$ : Figure $4.11 \mathrm{D})$. The orthopyroxene have a tightly clustered

Figure 4.14. Composition of crystals in representative pumice samples and a gabbroic xenolith from Macauley volcano. A) Stacked plots by sample showing the composition of clinopyroxene and orthopyroxene on enlarged sections from an En-Fs-Wo ternary diagram. Clinopyroxene compositions are displayed for both unzoned single crystals and for zones from within individual crystals as denoted by marker type. Only zones that vary by $>3$ wt $\% \mathrm{FeO}$ are shown. Black arrows indicate the direction of core to rim compositional variation. Dashed orange field represents the compositions of clinopyroxene analysed from the Sandy Bay gabbroic lithic. Orthopyroxene compositions are of mostly individual unzoned crystals, and zones within crystals and are not differentiated due to the limited compositional spectrum and tight clustering of data. Raw data and analysis locations are in Appendix F. B) Stacked histograms by sample showing the variation in plagioclase An content between both unzoned single crystals and zones within individual crystals. C) Stacked histograms by sample showing the variation in forsterite content (Fo mol. \%) for unzoned single olivine crystals. 

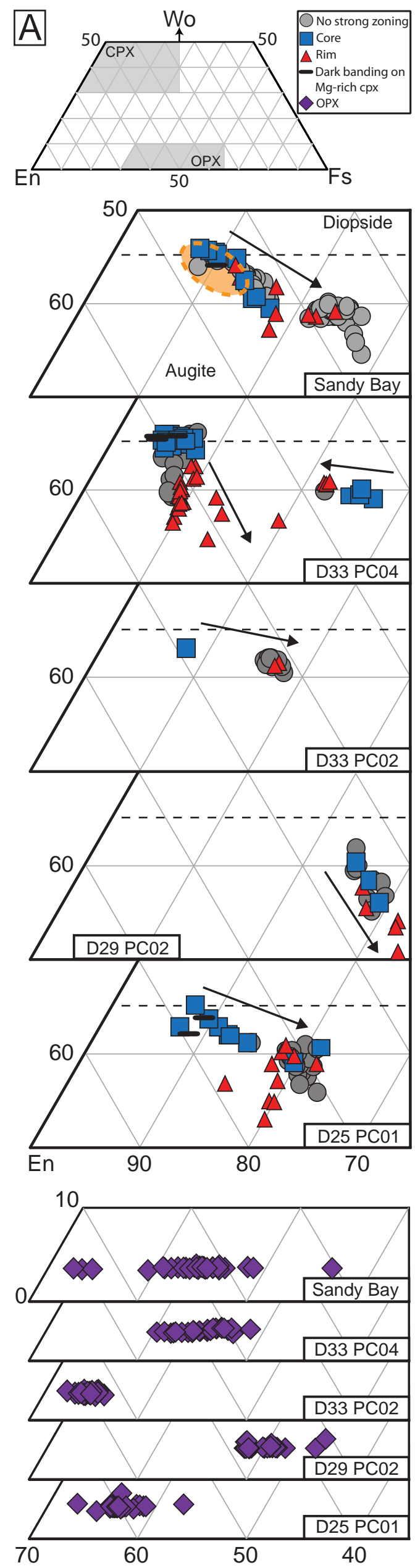
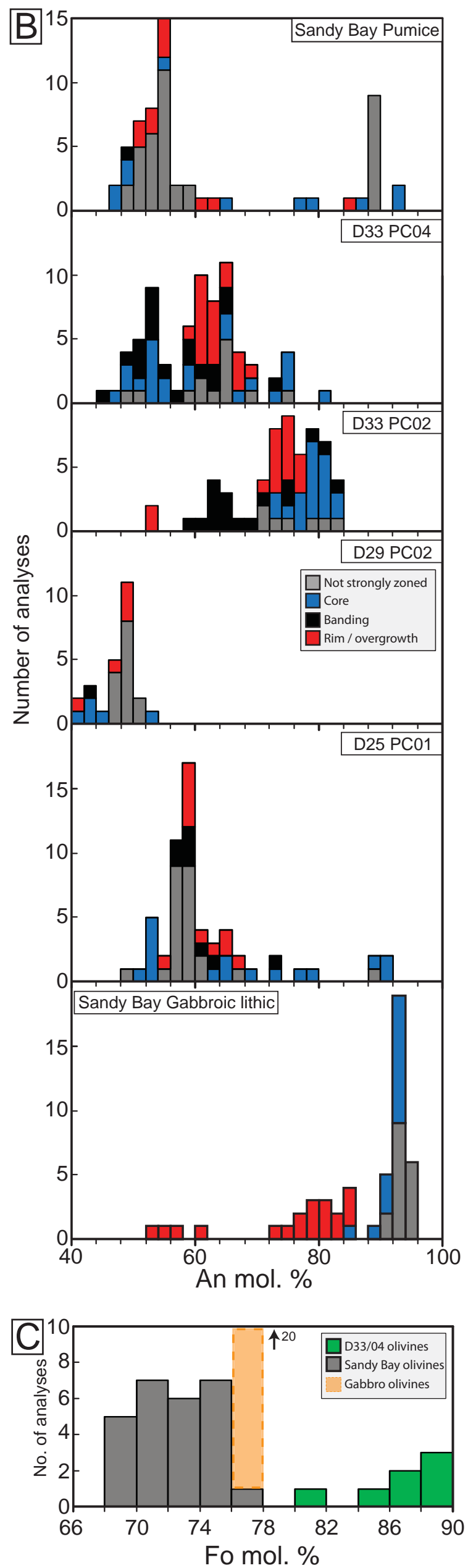
compositional range (Figure 4.14A), with only a few crystals in the Sandy Bay pumice having zoned high-Mg cores which plot as outliers (Figure 4.14A). The major element composition of orthopyroxene crystals vary consistently between samples (Figure 4.14A), with generally the highest- $\mathrm{SiO}_{2}$ hosts (from section 4.1) containing the most Ferich orthopyroxene. The range of orthopyroxene compositions also correspond well with the relative composition of clinopyroxene. D33_PC04 is an exception to this, with orthopyroxene similar in composition to the Sandy Bay pumice (with less range), even though it contains the most Mg-rich clinopyroxene.

\section{Plagioclase}

Plagioclase is the dominant crystal phase observed in Macauley pumices, and displays a wide range of textures and compositions (Figures 4.11E,F; 4.14B). Two major compositional populations are identified (Figure 4.14B). The first type is high-An plagioclase which ranges from ca. $\mathrm{An}_{88}-\mathrm{An}_{94}$. This plagioclase type can be completely unzoned (e.g. Figure 4.11E), or display strong compositional zoning with resorbed highAn cores and rims and/or overgrowths with considerably lower An values (sometimes $\left.<\mathrm{An}_{60}\right)$. The second type is low-An plagioclase, which ranges from $\mathrm{An}_{40}$ to $\mathrm{An}_{80}$. These plagioclase crystals commonly show both normal and reverse compositional zoning with some low-An plagioclase displaying complex zoning (Figure 4.11F), including sieve textures, resorbed cores and oscillatory zoning.

\section{Olivine}

Olivines are found only in the Sandy Bay Tephra, and sample D33_PC04. In the Sandy Bay Tephra, olivines are common in mafic blebs (Figure 4.12B,C) or as large $(>1 \mathrm{~mm})$ but rare $(<<1$ vol. \%) individual crystals with a thin film of adhering microlite rich, poorly vesiculated glass (Figure $4.11 \mathrm{G}$ ). These olivines are unzoned, but include a range of compositions between $\mathrm{Fo}_{68}$ and $\mathrm{Fo}_{78}$ (Figure 4.14C), with typical $\mathrm{Cr}_{2} \mathrm{O}_{3}$ and $\mathrm{NiO}$ values of $<0.02$ and 0.08 wt. \%, respectively. In sample D33_PC04, olivines are relatively sparse and commonly have reaction rims, often with overgrowths of small orthopyroxene (Figure $4.11 \mathrm{H}$ ) on cores of $\mathrm{Fo}_{80}$ to $\mathrm{Fo}_{90}$ (although few crystals were analysed due to their scarcity). These olivines also have somewhat higher $\mathrm{Cr}_{2} \mathrm{O}_{3}$ and $\mathrm{NiO}$ contents ( 0.02 to 0.04 and 0.05 to 0.15 wt. \%, respectively: Appendix F). 


\subsubsection{Plutonic xenoliths in the Sandy Bay Tephra}

Previous studies noted the presence of rare plutonic xenoliths within the Sandy Bay Tephra (Lloyd et al., 1996, Smith et al., 2003a). Samples of these plutonic xenoliths were collected during the 2007 voyage from the beach directly below the Sandy Bay Tephra on the eastern side of Macauley Island. Two main types of plutonic xenolith were collected (Figure 4.13). The first is an olivine rich cumulate gabbro, of which one large subrounded fragment was chosen for crystal-specific work. This gabbro contains large (typically 1-5 $\mathrm{mm}$, but up to $1-2 \mathrm{~cm}$ in modal layering) euhedral plagioclase, clinopyroxene and olivine, with smaller $(<0.5 \mathrm{~mm})$ magnetite (Figure $4.13 \mathrm{~A}-\mathrm{C})$. The second type is a felsic, leucocratic xenolith (Figure 4.13D). The majority of these felsic xenoliths are highly altered and weathered, with much of the original crystal assemblage replaced by hydrothermal minerals such as actinolite and epidote. As only sparse whole plagioclase and quartz remain, these xenoliths were not chosen for crystal specific work, but their presence is evidence for previously crystallised silicic plutonic bodies below Macauley volcano, similar to the tonalite observed at Raoul.

The composition of clinopyroxene, plagioclase and olivine from the Sandy Bay gabbroic xenolith are shown on Figure 4.14. Clinopyroxene has a narrow compositional range that overlaps compositions of high-Mg type clinopyroxene from the Sandy Bay pumice (ca. $\mathrm{En}_{45-48} \mathrm{Fs}_{7-12} \mathrm{Wo}_{43-45}$ : Figure 4.14A). Plagioclase, in contrast, often shows strong compositional zoning, with cores of $\mathrm{An}_{88}-\mathrm{An}_{96}$ and rims as low as $\mathrm{An}_{52}$ (Figures $4.13 \mathrm{C}, 4.14 \mathrm{~B})$. These compositions are similar to those of plagioclase from the Sandy Bay pumice, especially in the core-rim values of high-An type plagioclase. Olivine is completely unzoned and has forsterite contents between $\mathrm{Fo}_{76-78}$, overlapping with the most Mg-rich olivines found in the Sandy Bay pumice (Figure 4.14C).

\subsubsection{Healy crystal chemistry}

Four representative samples from Healy volcano were chosen for crystal specific work from differing positions along the major element compositional spectrum (Section 4.1). These are: (1) D38_PC06, a crystal rich pumice with low $\mathrm{SiO}_{2}$ (69.7 wt. \%) with the least evolved composition on the spectrum (Figures 4.03, 4.04); (2) D39_PC05, a crystal poor white pumice with high $\mathrm{SiO}_{2}$ (72.7 wt. \%); (3) D44_PC02, a pink oxidised pumice with 70.8 wt. $\% \mathrm{SiO}_{2}$; and (4) D47_PC02, a dark grey pumice with 70.7 wt. \% $\mathrm{SiO}_{2}$, but higher $\mathrm{TiO}_{2}$ than the white pumice. Crystals occur as single grains (Figure 
4.15), as parts of clusters (Figure 4.16A), and as clots forming small microcrystalline pockets within pumice clasts (Figure 4.16B,C). Crystals also can occur with a thin coating of microlite rich glass, or as part of mafic blebs which are present as sparse (1-2 wt. \%) sub-spherical inclusions in pumices from D38_PC06 and D44_PC02 (Figure 4.16D-H). Mafic blebs are commonly 1-2 mm in diameter (Figure 4.16G), but can reach $3 \mathrm{~cm}$ across (Figure 4.16F) and are generally crystal rich, consisting of 0.5 to $>1 \mathrm{~mm}$ euhedral plagioclase, clinopyroxene, olivine and smaller magnetite $(<0.5 \mathrm{~mm})$. Although the crystal contents and physical appearances of the Healy pumice types vary considerably, there is very little range in the compositions of crystals between pumice samples (Figure 4.17), consistent with the trends observed in whole rock chemistry.

\section{Clinopyroxene}

Clinopyroxene shows tonal zonation in BSE imagery (e.g. Figure 4.15 A,B), but the major element chemical variation between zones is very minimal. Zoned crystals from D38_PC06 and D44_PC02 (e.g. Figure 4.15A) have cores with between $\mathrm{En}_{43-47} \mathrm{Fs}_{8-10}$ $\mathrm{Wo}_{44-47}$, and rims with slightly higher $\mathrm{FeO}$ (up to ca. 3 wt. \%: Figure 4.17A). Resorbed cores are common and are often overgrown by a Mg-rich zone. In general, clinopyroxene in these samples are large $(0.5->1 \mathrm{~mm})$, and many have high $\mathrm{Cr}_{2} \mathrm{O}_{3}$, ranging from 0.05 to 0.5 wt. \%. Clinopyroxene in D39_PC05 and D47_PC02 are generally smaller $(<0.5-1 \mathrm{~mm})$, and often display multiple zones of resorption and growth (e.g. Figure 4.15B). Chemical differences between these zones are also very small, but overall these clinopyroxene are more Fe-rich than those from D38_PC06 and D44_PC02 (Figure 4.17A) and have $\mathrm{Cr}_{2} \mathrm{O}_{3}$ contents generally $<0.01$ wt. \% (see Appendix F).

\section{Orthopyroxene}

Orthopyroxene crystals occur as small (typically $<0.5 \mathrm{~mm}$ ) individual crystals and as part of crystal clusters and crystal clots, often with inclusions of apatite and Fe-Ti oxides (Figure 4.16A-C). Orthopyroxene are similar in composition between all pumice samples analysed, with a general compositional range of ca. $\mathrm{En}_{62-66} \mathrm{Fs}_{30-35} \mathrm{Wo}_{2-4}$ (Figure 4.17A). Only a few crystals (mostly in D47_PC02) have weak compositional zoning, with cores that have slightly higher $\mathrm{MgO}$ values (only 1-2 wt. \% higher). 


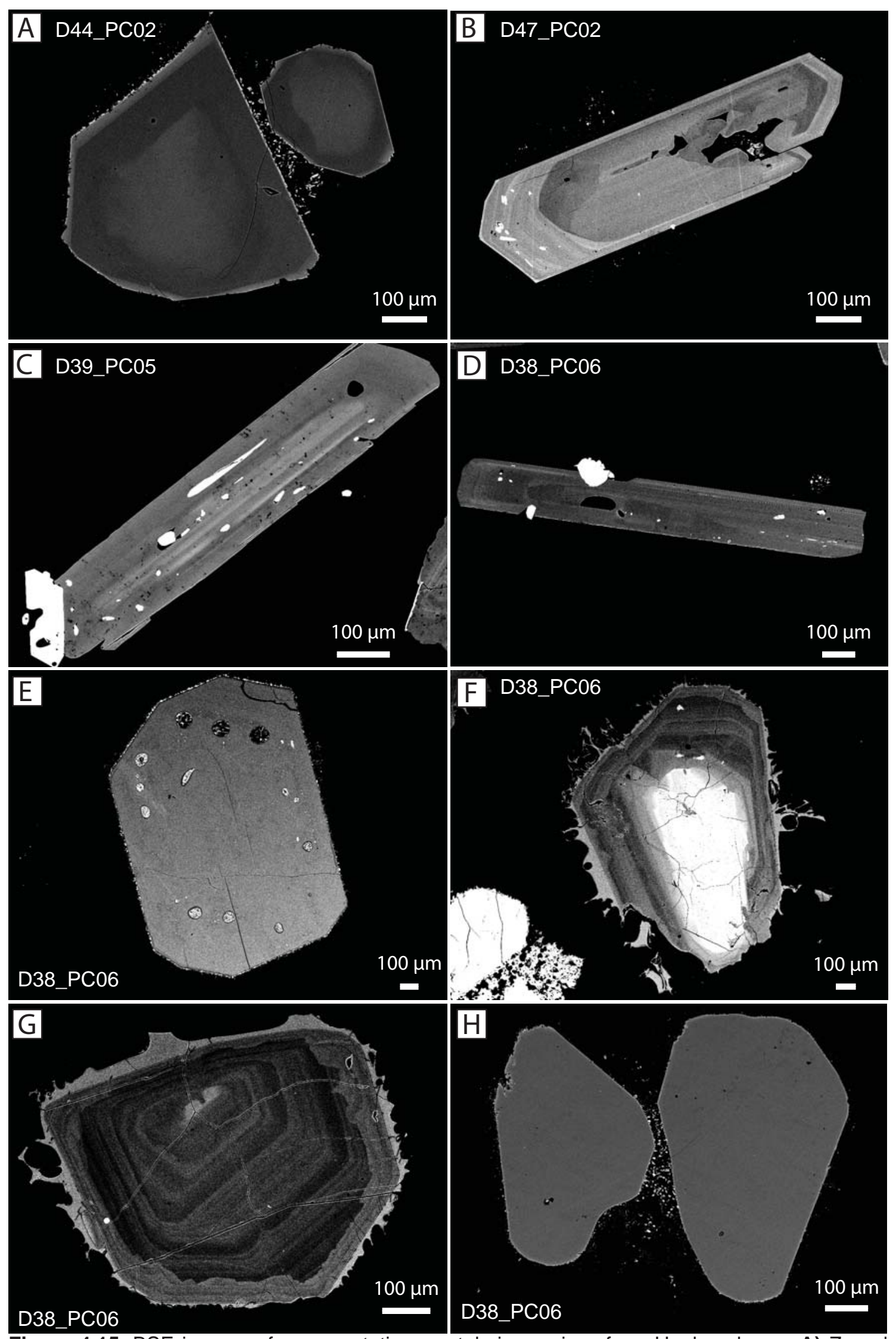

Figure 4.15. BSE images of representative crystals in pumices from Healy volcano. A) Zoned clinopyroxene with a Fe-rich rim. B) Multiply zoned clinopyroxene. C) Orthopyroxene with inclusions of Fe-Ti oxides. D) Amphibole with inclusions of Fe-Ti oxides. E) Unzoned high-An plagioclase with devitrified melt inclusions. F) Strongly zoned plagioclase with a high-An (An90) core and low-An multiply zoned overgrowth (ca. An $40-45)$. G) Plagioclase with a resorbed oscillatory zoned core with a thick rim/overgrowth. H) Two unzoned olivines, with thin reaction rims. 

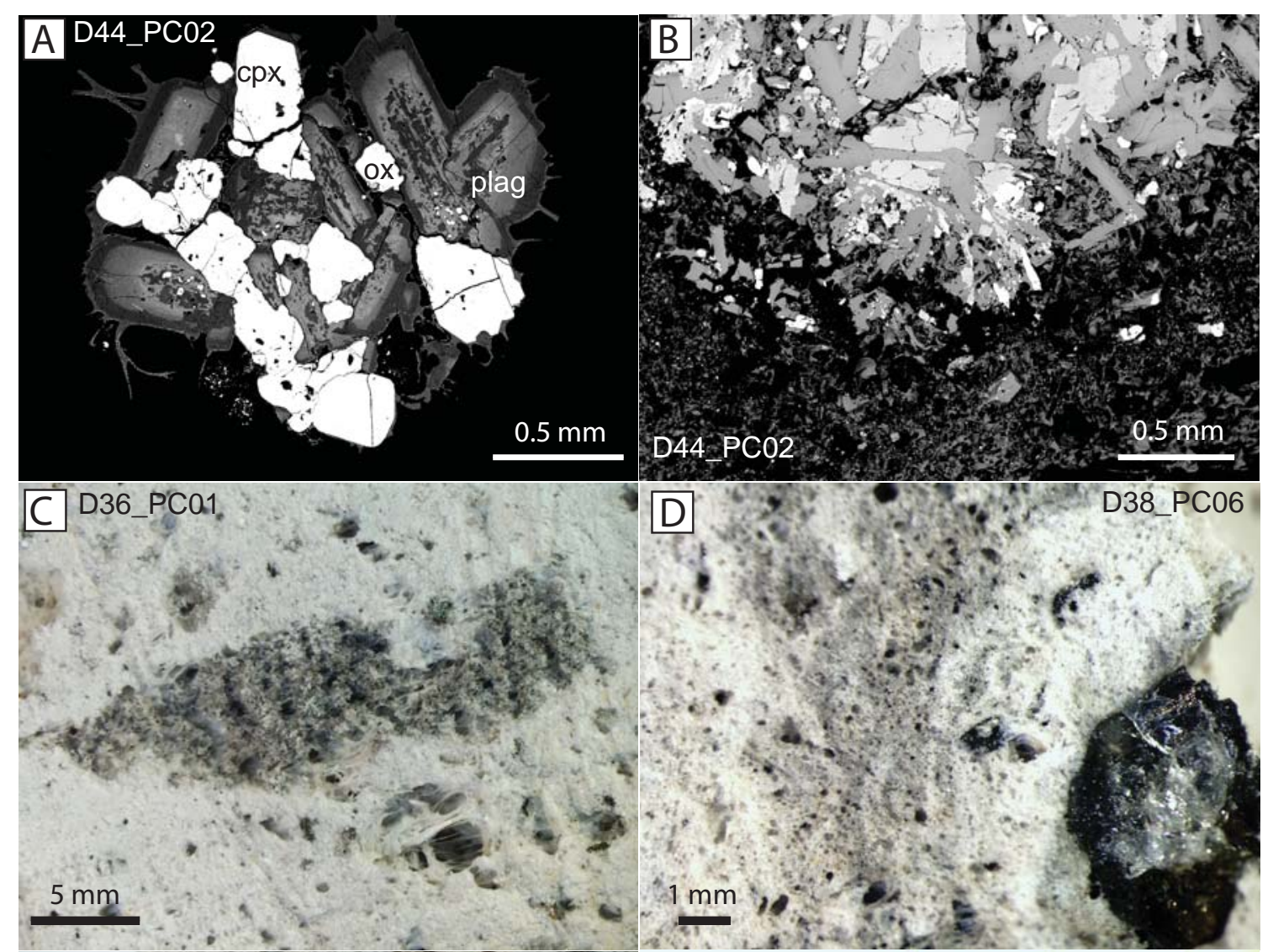

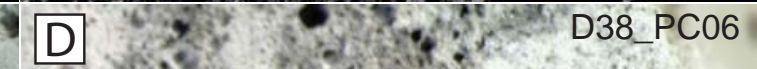
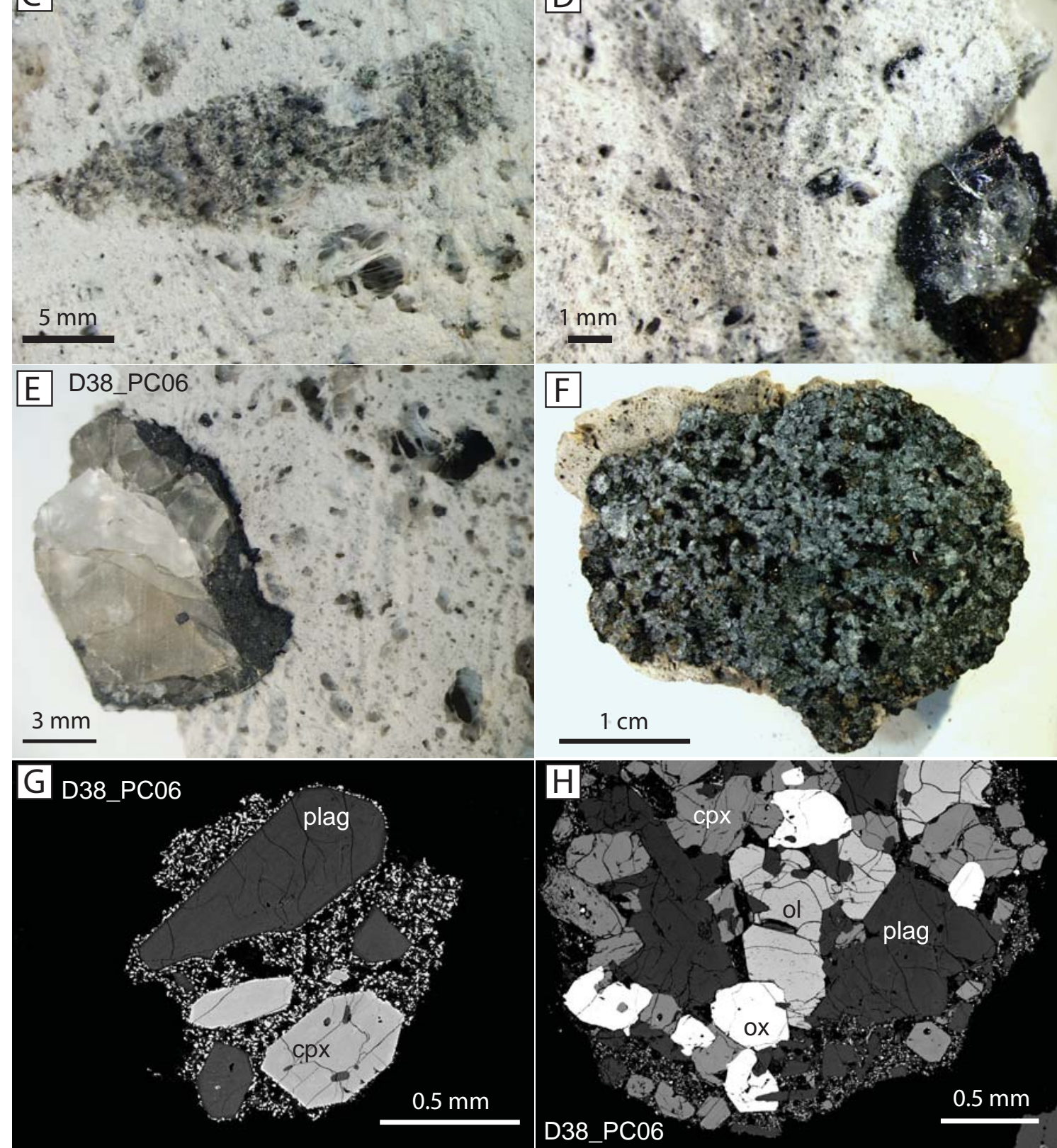

Figure 4.16. Images of representative crystal clusters, crystal clots and mafic blebs from Healy pumices. A) Crystal cluster with strongly zoned plagioclase and adhering felsic pumice glass. B) BSE image of the edge of microcrystalline crystal clot inside pumice, consisting of mainly plagioclase (dark coloured crystals) and amphibole (light coloured crystals). C) Typical crystal clot within pumice D) Large olivine and plagioclase in a mafic bleb enclosed in a grey/white banded pumice. E) Mafic bleb with a large euhedral plagioclase. F) Large mafic bleb with a crystalline granular texture, consisting mainly of plagioclase, olivine and clinopyroxene. G) BSE image of a small mafic bleb. H) BSE image of part of a large crystal rich sub-spherical mafic bleb. cpx = clinopyroxene, ox = oxides (magnetite, illmenite), plag = plagioclase, $\mathrm{ol}=$ olivine . 

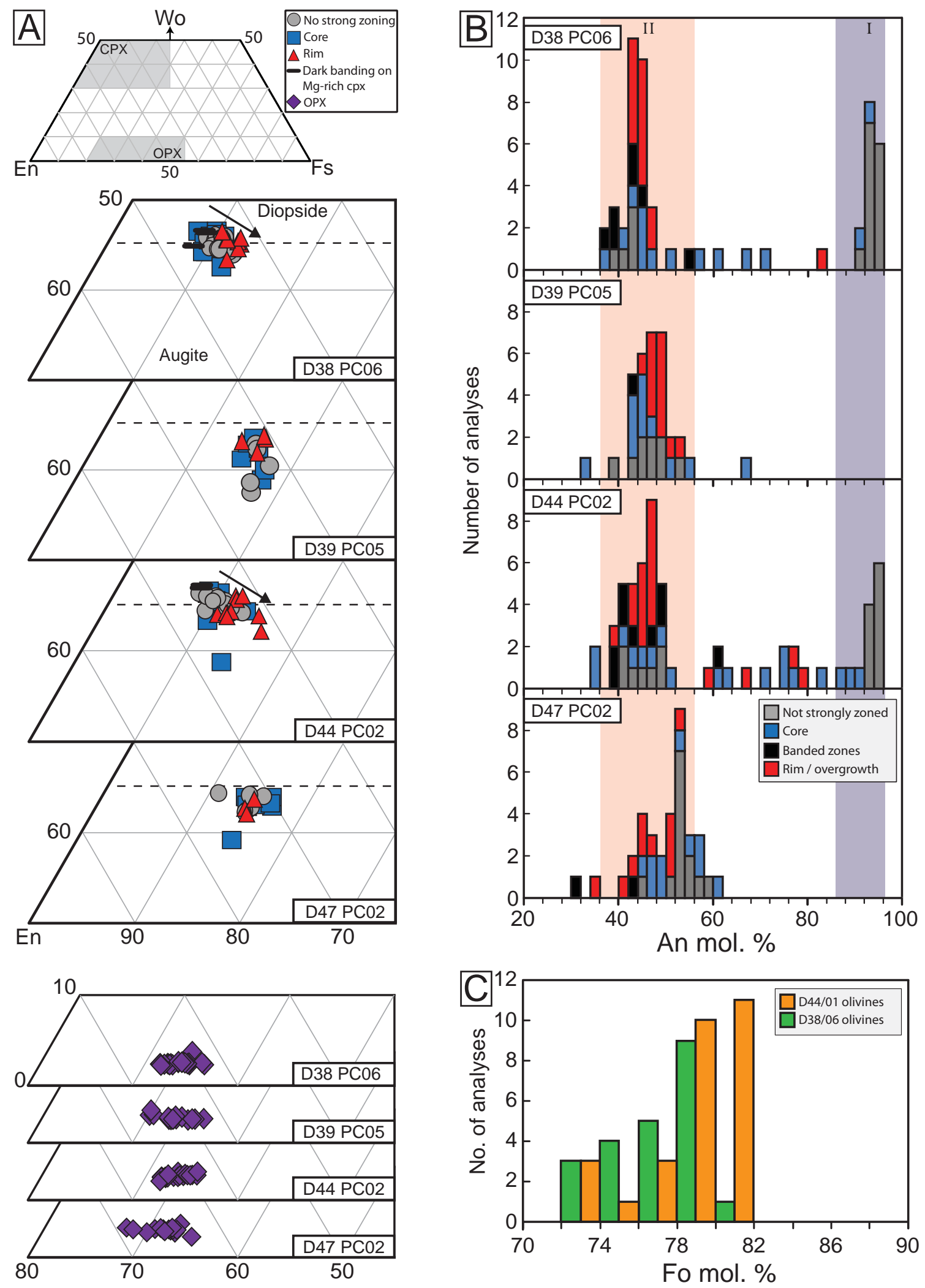

Figure 4.17. Compositions of crystals in representative pumice samples from Healy volcano. A) Stacked plots by sample showing the composition of clinopyroxene and orthopyroxene on enlarged sections from an En-Fs-Wo ternary diagram. Clinopyroxene compositions are displayed for both unzoned individual crystals and for zones within individual crystals as denoted by marker type. Only zones that vary by $>3 \mathrm{wt} \% \mathrm{FeO}$ are shown. Black arrows indicate the dominant direction of core to rim compositional variation. Orthopyroxene compositions are mostly from individual unzoned crystals, and zones within crystals and are not differentiated by marker type due to the limited compositional spectrum and tight clustering of data. All raw data and analysis locations are in Appendix F. B) Stacked histograms by sample showing variations in plagioclase An content between both unzoned individual crystals and zones within individual crystals. C) Stacked histograms by sample showing the variation in forsterite (Fo mol. \%) for unzoned single olivines. 


\section{Amphibole}

Amphibole occurs as thin acicular crystals, mostly in crystal clots (e.g. Figure 4.16B,C). The majority of amphiboles display only minor compositional zoning (e.g. Figure 4.15D), and can be classified as magnesiohornblende (Ridolfi et al., 2010). Amphibole in D47_PC02 (and a single crystal from D44_PC02), however, have higher $\mathrm{Al}_{2} \mathrm{O}_{3}$ and $\mathrm{TiO}_{2}$ and are classified as magnesiohastingsite and tschermakitic pargasite. A few of these crystals are zoned with magnesiohornblende rims which are lower in $\mathrm{Al}_{2} \mathrm{O}_{3}$ and $\mathrm{TiO}_{2}$ (Appendix F).

\section{Plagioclase}

Plagioclase shows greater chemical and textural variations when compared to other crystal phases. Plagioclase analyses from Healy pumices fall into two compositional modes on anorthite frequency histograms (Figure 4.17B). The high-An mode (grey field labelled 'I' on Figure 4.17B), represents large (1-5 mm), unzoned crystals (e.g. Figure $4.15 \mathrm{E}$ ), and the cores of strongly zoned crystals (e.g. Figure 4.15F). Plagioclase from this mode often occurs as single crystals with a thin selvedge of microlite rich glass, or as part of mafic blebs (e.g. Figure 4.15D-H), which are only found in D38_PC06 and D44_PC02. Crystal zoning is generally more pronounced in single crystals that have adhering felsic pumice glass. Rims on strongly zoned high-An plagioclase are as low as $\mathrm{An}_{60-80}$, and in some extreme cases (e.g. Figure 4.15F) plot within the mode of low-An plagioclase (red field labelled 'II': Figure 4.17B). This low-An mode is the dominant mode for all the pumice analysed, with compositions between $\mathrm{An}_{38-60}$, and a peak at ca. $\mathrm{An}_{44-48}$. Plagioclase from this mode are generally smaller in size (typically $<1 \mathrm{~mm}$ ), and often display complex zonation (Figure 4.15G). The difference in composition between cores, banded zones and rims in low-An plagioclase is small, with differences in complexly zoned plagioclase often no more than 5-10 An mol. \% (Figure 4.17B). Sample D47_PC02 plagioclase is slightly offset from population II to slightly higher An values. Several core analyses from plagioclase in large crystal clusters from samples D39_PC06 and D44_PC02 (e.g. Figure 4.16A) plot as outliers between the two major compositional modes, with a composition of $\mathrm{An}_{60-80}$. Plagioclase from these crystal clusters and also from the high-An mode often show disequilibrium features such as sieve textures and resorption (e.g. Figure 4.15, 4.16A). These features, together with the compositional differences between cores, rims and zones ( $>30$ An mol. \% in clusters, 
and up to 50 An mol. \% in high-An plagioclase: see Appendix F), indicate that they have been subjected to diverse magmatic conditions.

\section{Olivine}

Olivine occurs only in samples D38_PC06 and D44_PC02, either as single crystals with a thin selvedge of microlite rich glass, or more commonly as part of mafic blebs (e.g. Figure 4.16D,F,H). Crystals are generally $0.5-1 \mathrm{~mm}$ in size, but can reach up to $3-5 \mathrm{~mm}$ in large mafic blebs. Like olivines from the other Kermadec volcanoes, Healy olivines do not generally show strong compositional zoning (Figure $4.15 \mathrm{H}, 4.17 \mathrm{C}$ ). Very thin reaction rims $(<5 \mu \mathrm{m}$ thick) are present on only a few crystals. The overall range of forsterite content is $\mathrm{Fo}_{72}$ to $\mathrm{Fo}_{82}$, with no major differences between the two analysed pumice samples (Figure 4.17C).

\subsection{Mafic bleb whole rock chemistry}

The presence of dark grey mafic blebs and/or large crystal clots within individual pumice clasts is a widespread feature in samples collected from all four Kermadec volcanoes investigated. Sub-spherical mafic blebs are found in three of the five eruptions investigated from Raoul, the Sandy Bay Tephra from Macauley and in the majority of samples recovered from both Healy and New volcanoes. These blebs contain Mg-rich clinopyroxene and high-An plagioclase and olivine (see previous section) which also occur in felsic pumice as single large crystals with similar compositions. Mafic blebs within pumice samples vary in size and have varying crystal contents, although they are almost always found with a cauliform sub-spherical texture inside large open vesicles, indicating they were at least partially molten when mixed in with the host melt. Large mafic blebs $(\sim 3-5 \mathrm{~cm}$ in diameter) with adhering felsic pumice glass were collected as loose fragments from the Matatirohia eruption deposit for whole rock chemical analysis. Large mafic blebs were also extracted from single pumice samples from Healy volcano and New volcano. Only large mafic blebs that had the lowest proportion of large crystals were selected for whole rock chemistry. To limit the amount of contaminating felsic glass, the exterior rind of each bleb was removed prior to crushing. Major element data are presented in Table 4.01, and trace element and isotopic data are presented in Section 4.5.

Mafic blebs from the Matatirohia deposits have a basaltic whole rock composition (Table 4.01). Similar to the dacites, the mafic bleb has very low 
Table 4.01. Whole rock major element composition of mafic blebs

\begin{tabular}{lccccc}
\hline $\begin{array}{l}\text { Sample } \\
\text { Volcano }\end{array}$ & $\begin{array}{c}\text { RI06_P05_MB11 } \\
\text { Raoul }\end{array}$ & $\begin{array}{c}\text { RI06_P05_MB02 } \\
\text { Raoul }\end{array}$ & $\begin{array}{c}\text { D22_03_MB01 } \\
\text { New volcano }\end{array}$ & $\begin{array}{c}\text { D44_MB03 } \\
\text { Healy }\end{array}$ & $\begin{array}{c}\text { X594/C } \\
\text { Healy }\end{array}$ \\
\hline wt. \% & & & & & \\
$\mathrm{SiO}_{2}$ & 49.66 & 49.45 & 58.63 & 53.03 & 49.66 \\
$\mathrm{TiO}_{2}$ & 0.61 & 0.61 & 0.58 & 0.92 & 0.99 \\
$\mathrm{Al}_{2} \mathrm{O}_{3}$ & 17.55 & 18.92 & 16.41 & 16.88 & 16.66 \\
$\mathrm{Fe}_{2} \mathrm{O}_{3}$ & 11.49 & 11.30 & 8.33 & 11.24 & 12.95 \\
$\mathrm{MnO}$ & 0.19 & 0.19 & 0.18 & 0.20 & 0.19 \\
$\mathrm{MgO}$ & 6.62 & 5.44 & 4.33 & 4.62 & 5.39 \\
$\mathrm{CaO}$ & 12.05 & 12.30 & 8.98 & 9.68 & 11.56 \\
$\mathrm{Na}{ }_{2} \mathrm{O}$ & 1.63 & 1.57 & 2.26 & 2.88 & 2.11 \\
$\mathrm{~K}_{2} \mathrm{O}$ & 0.16 & 0.16 & 0.22 & 0.43 & 0.34 \\
$\mathrm{P}_{2} \mathrm{O}_{5}$ & 0.05 & 0.05 & 0.08 & 0.12 & 0.14 \\
$(\mathrm{LOI})$ & 0.21 & -0.22 & -0.34 & -0.75 & -0.19 \\
(Total) & 100.03 & 100.32 & 100.44 & 100.81 & 99.07 \\
\hline
\end{tabular}

Sample X594/C data from Wright and Gamble (1999) and shown in this table for comparison with the Healy mafic bleb. All oxide data are normalised to $100 \%$ volatile free, but the original LOI values and analytical totals are given.

concentrations of $\mathrm{K}_{2} \mathrm{O}$ and $\mathrm{TiO}_{2}$. The single mafic bleb from New volcano has a bulk composition of andesite, although this is not considered to be representative of a mafic end-member as intermingled rhyolite pumice glass could not effectively be removed prior to analysis. This composition is interpreted as a mixture of rhyolite glass and a mafic end-member that is similar to the mafic blebs from Raoul. The single mafic bleb analysed from Healy (Table 4.01) is basaltic andesite, and similar in major element chemistry to a basalt analysis in Wright and Gamble (1999). Consistent with the trends observed in the silicic samples, the Healy mafic bleb has higher total alkalies than the Raoul mafic blebs.

\subsection{Glass compositions}

As many of the Kermadec pumice samples contain mafic blebs and/or large xenocrysts (section 4.2), major element analyses were carried out on matrix glasses to assess the effects of magma mixing and xenolith/xenocryst contents on whole rock chemistry. Glass chemistry also provides a framework for calculating which crystal populations are in equilibrium with (and therefore crystallised in) the host melt (see equilibrium calculations in Chapter 5). Major element glass compositions were determined by electron microprobe analysis (EMPA). In addition, melt inclusions in pyroxene crystals from the Sandy Bay pumice were analysed where exposed on crystal probe mounts (e.g. 4.11C,D). The glass composition of a single mafic bleb from the Matatirohia deposit 
has also been analysed. Glass compositions from Raoul, Macauley and Healy samples are presented in Figures 4.18, 4.19 and 4.20 respectively. Vectors are also displayed on variation diagrams to indicate in which direction accumulation of various crystal types or mafic blebs would drive the glass compositions.

Glass from Raoul pumice generally contains $>70$ wt. $\% \mathrm{SiO}_{2}$, with a different compositional trend when compared to the chemistry of the whole pumices (Figure 4.18). The Green Lake Pumice has the most evolved whole rock chemistry, but the glass compositions overlap with those of glass from other Raoul pumices. The glass composition of Matatirohia pumice has the highest average $\mathrm{SiO}_{2}$ at ca. 71.8 wt. \% and has a contrasting trend to its whole rock chemistry. These findings are consistent with petrological observations (sections 4.1 and 4.2), where the Matatirohia, Oneraki and Fleetwood pumices were all noted to contain mafic blebs, and have slightly higher crystal contents (3-5 vol. \%) than the Green Lake pumices $(<1-2$ vol. \%). The vector which points towards the whole rock composition of a single large mafic bleb strongly parallels many of the trends on variation diagrams (Figure 4.18). For example, mixing 5\% mafic bleb composition with Green Lake whole rock composition would decrease $\mathrm{SiO}_{2}$ by 1 wt. \%, and increase $\mathrm{MgO}$ by 0.22 wt. \%.

Even though care was taken to remove visible mafic blebs during XRF sample preparation, some small mafic blebs may have been included. Therefore, the compositional difference between the most evolved whole rock samples (Green Lake Pumice) and the units with mafic blebs (Matatirohia, Oneraki and Fleetwood) can be interpreted as a function of mixing between the mafic bleb and glass compositions. Some trends observed in whole rock chemistry are, however, reflected in the glass chemistry, such as the lower $\mathrm{TiO}_{2}$ and slightly higher $\mathrm{CaO}$ values of the Matatirohia glass, as well as higher $\mathrm{K}_{2} \mathrm{O}$ content for the Oneraki and Fleetwood glasses (Figure 4.18). A feature of the glass chemistry which is not consistent is the compositional difference between the whole rock and glass chemistry of the Rangitahua pumice. The Rangitahua sample does not contain mafic blebs and has relatively low crystal contents $(<1-2$ vol. \%). The whole rock chemistry of the Rangitahua sample, however, has the lowest $\mathrm{SiO}_{2}$, with glass values that fall within the compositional field of other samples (70 and 72 wt. \% $\mathrm{SiO}_{2}$ ). A feature unique to the Rangitahua pumice is brown glass with extensive plagioclase microlite growth (Smith et al., 2006, 2010). Glass analysed from the Rangitahua sample for this study also contains microlites of plagioclase, as well as pyroxene and Fe-Ti oxide microlites. The presence of these microlites made glass analysis by EMPA difficult, with very few $10 \mu \mathrm{m}$ microlite-free areas available for 

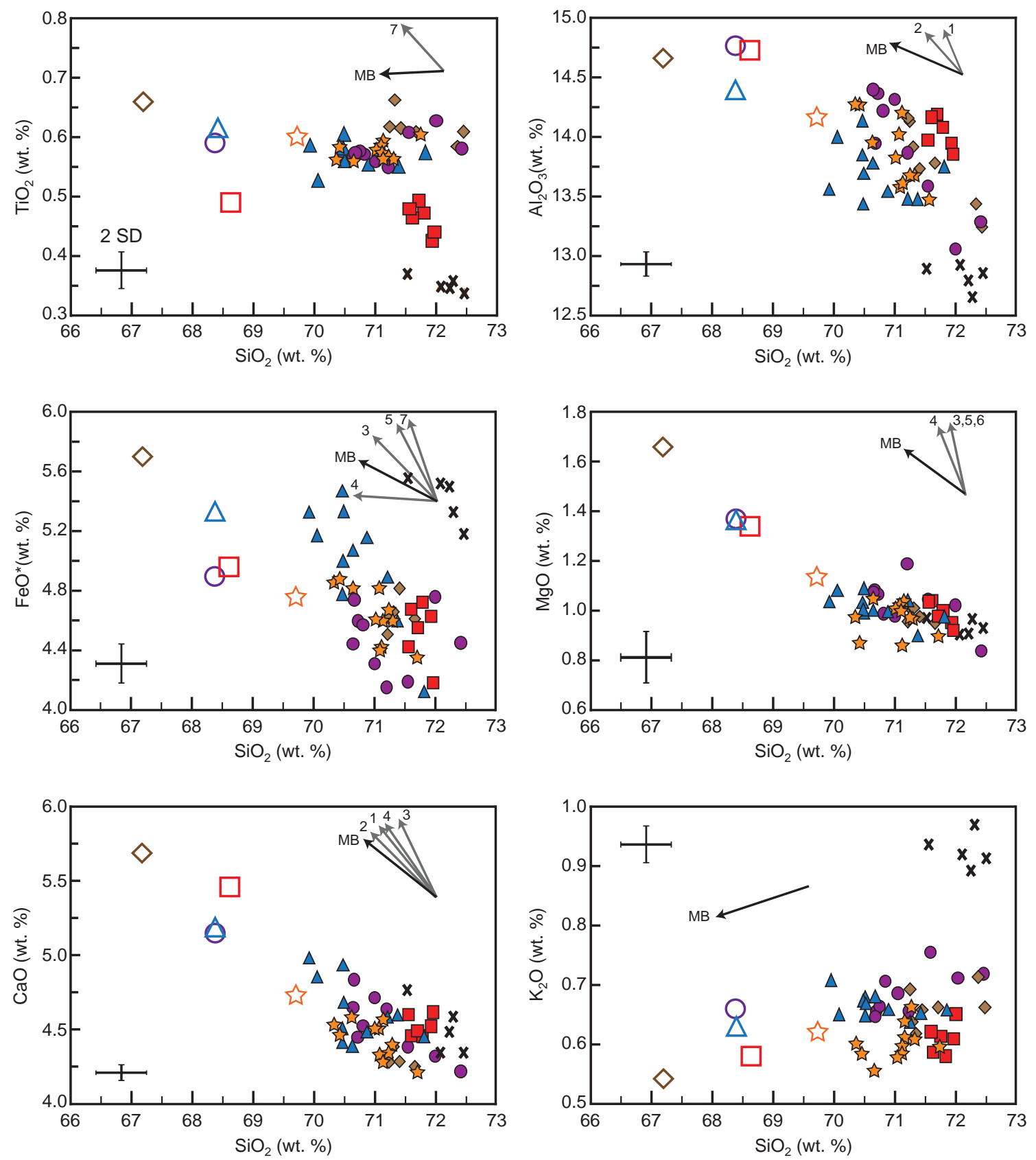

Figure 4.18. Major element glass compositions with corresponding whole rock compositions from Raoul pumice samples and a mafic bleb from the Matatirohia eruption. Small filled symbols represent single glass analyses by EMPA. Large open symbols represent the whole rock composition by XRF from the same pumice sample. All data have been normalised to $100 \%$ on a volatile free basis, and XRF values have been recalculated for total iron as FeO*. Sample denoted by symbol and colour: red squares = Matatirohia; purple circles =Oneraki; blue triangles = Fleetwood; orange stars = Green Lake; brown diamonds = Rangitahua; black crosses = glass analyses from a Matatirohia mafic bleb. Grey arrows represent vectors indicating which direction addition of various crystal types or mafic blebs would drive the glass compositions Vectors are calculated from the average composition of crystal phases found within pumice: $1=$ High-An plagioclase; 2 = Low-An plagioclase; 3 = Mg-rich clinopyroxene; 4 = Fe-rich clinopyroxene; $5=$ orthopyroxene; 6 = olivine; 7 = magnetite (see section 4.2 and Appendix $F$ for crystal compositions). Black arrows represents the vector calculated from the average whole rock composition of two mafic blebs (section 4.3). All raw glass data is presented in Appendix E. 2 SD for glass data calculated from repeated analysis of glass standard ATHO (see Chapter 3 for standard details). Uncertainties for XRF is less than the size of the large symbols. 

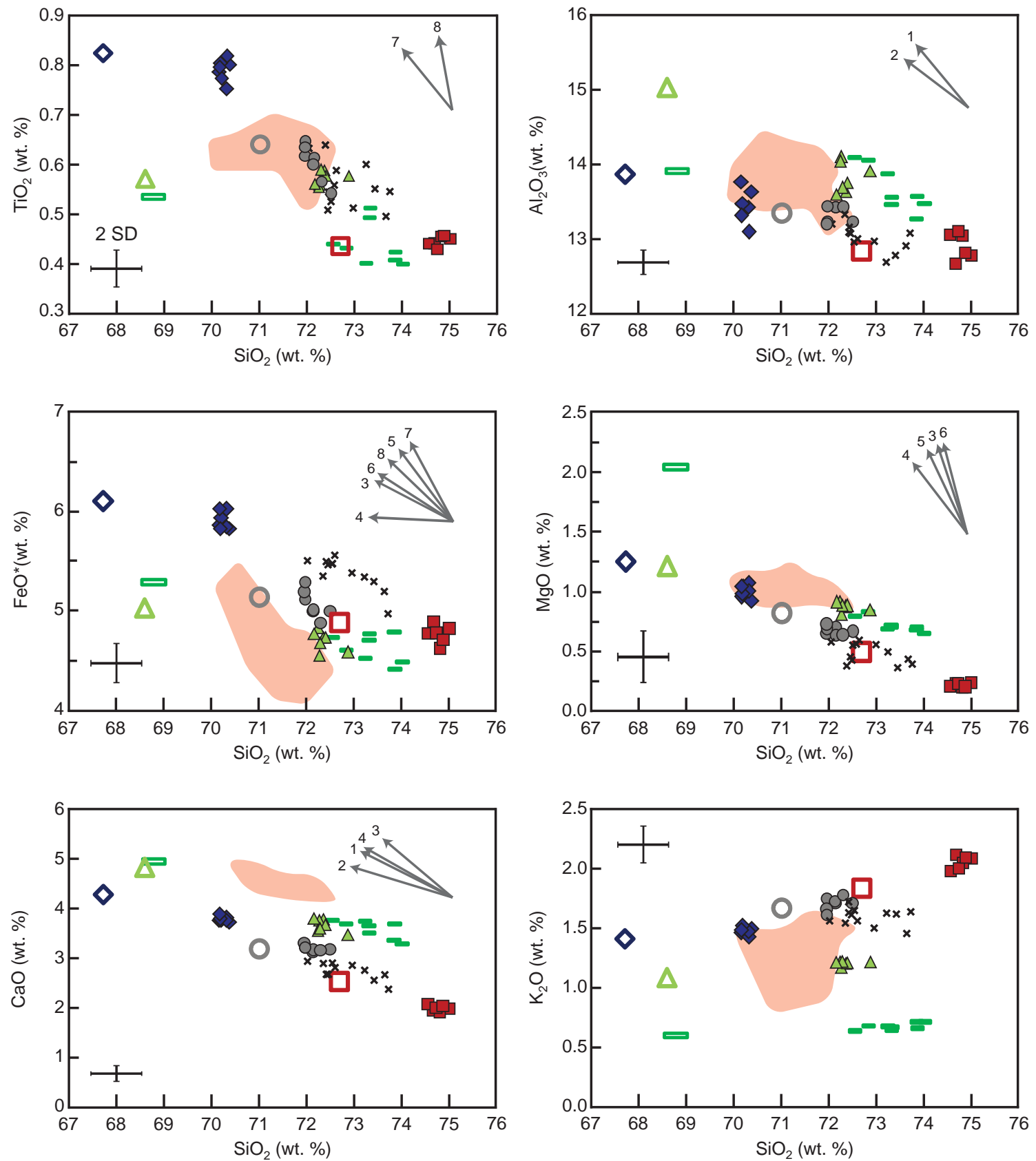

Figure 4.19. Major element compositions of pumice glasses, with corresponding whole rock data from Macauley samples. Small filled symbols represent single glass analyses by EMPA, large open symbols represent the whole rock XRF values for the same clast. Blue diamonds = D25_PC01; red squares = D29_PC02, green triangles = D33_PC02; dark green rectangles = D33 PC04; grey circles $=$ Sandy Bay pumice; black crosses $=$ melt inclusions in orthopyroxene and clinopyroxene from the Sandy Bay pumice. Grey arrows represent vectors indicating which direction addition of various crystal types or mafic blebs would drive the glass compositions. Vectors are calculated from the average composition of crystal phases found within pumice (section 4.2). 1 = High-An plagioclase; 2 = Low-An plagioclase; $3=$ Mg-rich clinopyroxene; $4=$ Fe-rich clinopyroxene; 5 = orthopyroxene; 6 = olivine; 7 = magnetite; 8 = ilmenite (see section 4.2 and Appendix $\mathrm{F}$ for crystal compositions). The highlighted pink area is the compositional field for Raoul dacite glasses (Figure 4.18). 2 SD for glass data calculated from repeated analysis of glass standard ATHO (see Chapter 3 for standard details). Uncertainties for XRF is less than the size of the large symbols. 

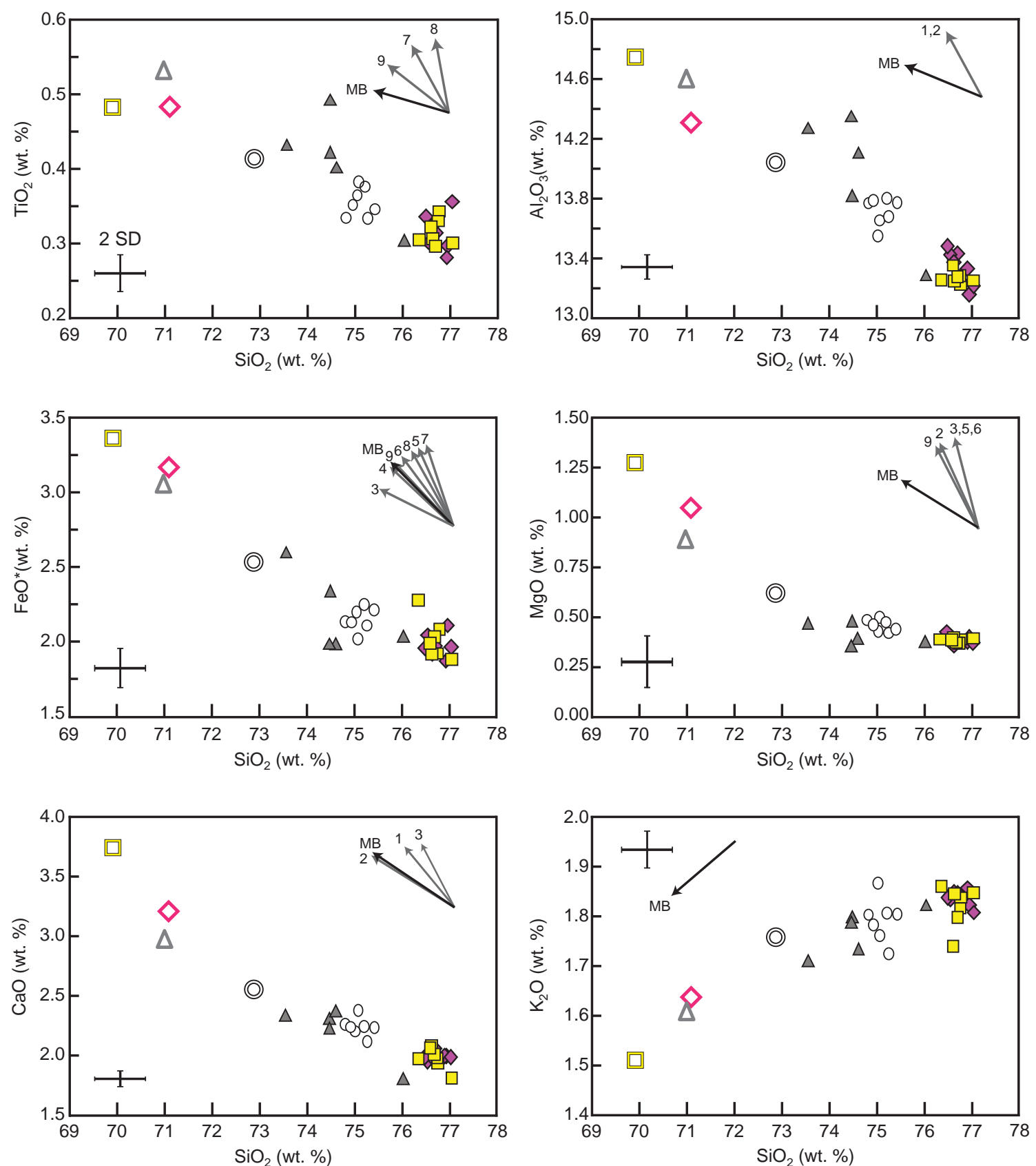

Figure 4.20. Major element compositions of pumice glasses, with corresponding whole rock data from Healy samples. Small filled symbols represent single glass analyses by EMPA, large open symbols represent the whole rock XRF values for the same clast. Yellow squares = D38_PC06; white circles = D39_PC05; pink diamonds = D44_PC02; grey triangles = D47_PC02. Grey arrows represent vectors, indicating which direction addition of various crystal types or mafic blebs would drive the glass compositions. Vectors are calculated from the average composition of crystal phases found within pumice samples (section 4.2). $1=$ High-An plagioclase; $2=$ Low-An plagioclase; 3 = Mg-rich clinopyroxene; 4 = Fe-rich clinopyroxene; 5 = orthopyroxene; 6 = olivine; 7 = magnetite; 8 = ilmenite; 9 = amphibole (see Appendix F for crystal compositions). Black arrows represents the vector calculated from the whole rock composition of a single representative mafic bleb (section 4.3). 2 SD for glass data calculated from repeated analysis of glass standard ATHO (see Chapter 3 for standard details). Uncertainties for XRF is less than the size of the large symbols. 
analysis. The few glass analyses that were determined to be of pure glass indicate that the glass composition is considerably more evolved than the whole rock compositions, even though there are very few large crystals. This inconsistency may be explained by the extensive late stage microlite formation, which could elevate the $\mathrm{SiO}_{2}$ content of the matrix glass.

In the mafic blebs there were few small areas of crystal-free interstitial glass large enough to be analysed with a $10 \mu \mathrm{m}$ microprobe beam. Even though the Matatirohia mafic blebs are basaltic (Table 4.01), the small amount of analysable interstitial glass has a composition more similar to the felsic glass of the Raoul pumice samples. The mafic bleb glass analyses were from the interior of the clast, so the analyses are not considered to be intermingled host glass. The composition of the glass also plots as a separate composition field (Figure 4.18), with lower $\mathrm{TiO}_{2}, \mathrm{Al}_{2} \mathrm{O}_{3}$, and higher $\mathrm{FeO}$ and $\mathrm{K}_{2} \mathrm{O}$ than any of the pumice glasses.

Glass compositions from selected pumice types from Macauley volcano plot as multiple compositional fields, consistent with differences observed in whole rock major element chemistry (Figure 4.19). Although the compositional fields of Raoul and Macauley glasses overlap for some oxides, no Macauley samples have compositions which consistently plot within the Raoul field. Apart from sample D25_PC01, all pumice glasses have $\mathrm{SiO}_{2}>72$ wt. \%, with the most evolved glass in sample D29_PC02, at ca. 75 wt. $\% \mathrm{SiO}_{2}$. Despite whole rock compositions of $<69$ wt. \% $\mathrm{SiO}_{2}$, glass compositions from samples D33_PC02 and D33_PC04 are between 72-74 wt. \% $\mathrm{SiO}_{2}$, with most major elements $\left(\mathrm{K}_{2} \mathrm{O}\right.$ as an exception) having similar values to the Sandy Bay pumice. Many whole rock chemistry trends can be explained through crystal addition such as the elevated whole rock $\mathrm{Al}_{2} \mathrm{O}_{3}$ and $\mathrm{CaO}$ in sample D33_PC02 which reflects plagioclase addition. High $\mathrm{MgO}$ and $\mathrm{CaO}$ in D33_PC04 can also be explained by addition of olivine and/or high-Mg clinopyroxene crystals. Melt inclusions analysed from orthopyroxene and clinopyroxene from the Sandy Bay pumice have compositions which plot within the field of Sandy Bay matrix glass, and also plot towards the most evolved D29_PC02 field at ca. 74 wt. \% $\mathrm{SiO}_{2}$.

There are significant differences between the whole rock major element chemistry and glass compositions for Healy samples (Figure 4.20), reflecting the relatively high crystal contents of some pumice samples (up to 10-15 vol. \%; sections 4.1 and 4.2). In contrast to the observed whole rock trends, the most evolved glass compositions are from samples D38_PC06 and D44_PC02 at ca. 76-77 wt. \% $\mathrm{SiO}_{2}$. Similar to pumice from Raoul volcano, these two clasts contain sparse mafic blebs 
(section 4.2). The vector representing mixing between glass and whole rock for major elements of a single mafic bleb analysed by XRF is shown on Figure 4.20. This vector parallels the trends observed in whole rock chemistry, suggesting that the linear trend with decreasing $\mathrm{SiO}_{2}$ is due to magma mixing, along with variations in crystal contents. Even though sample D39_PC05 has the most evolved whole rock composition, its glass composition has lower $\mathrm{SiO}_{2}$ than D38_PC06 and D44_PC02, at ca. 75 wt. \% $\mathrm{SiO}_{2}$. Sample D47_PC02 also has slightly lower $\mathrm{SiO}_{2}$, although there is a wide range of values from sample D47_PC02 due to extensive microlite growth of plagioclase, pyroxene and Fe-Ti oxides (evident through high $\mathrm{TiO}_{2}, \mathrm{Al}_{2} \mathrm{O}_{3}$ and $\mathrm{Fe}_{2} \mathrm{O}_{3}$ ).

\subsection{Whole rock trace element and isotopic data}

\subsubsection{Whole rock trace element variations}

The whole rock major element data presented in section 4.1 allow the identification of key chemical groups from each volcano, and highlight some important differences in overall chemical trends. On the basis of these data, a subset of ca. 50 samples was selected for trace element analysis by solution ICP-MS. Overall trends from trace element chemistry are consistent with many of the trends identified from whole rock major element chemistry and petrological observations (Figure 4.21). Compatible elements such as $\mathrm{Cr}$ and $\mathrm{Ni}$ do not show systematic variations with increasing $\mathrm{SiO}_{2}$, reflecting the diverse mineral assemblage and contamination by mafic crystals such as olivine and Mg-rich clinopyroxene that originated from a less evolved melt (sections 4.2 and 4.4). Samples with a higher proportion of xenocrysts have strongly elevated $\mathrm{Cr}$ and $\mathrm{Ni}$ values. An extreme case of this occurs in sample D33_PC04 which has Cr and Ni values of ca. 60 and $16 \mathrm{ppm}$ respectively. Other trace elements such as V and Sc show a negative linear trend with increasing $\mathrm{SiO}_{2}$, consistent with crystallisation of magnetite and also clinopyroxene (Figure 4.21). Sr shows a strong negative linear trend with increasing $\mathrm{SiO}_{2}$ for Macauley, but no strong trends for Raoul and Healy samples. Macauley trace elements separate into several discrete groups, consistent with the groups observed in major elements. A single outlier (sample D33_PC04) consistently plots with chemistry similar to the majority of Raoul pumice samples on most variation diagrams. New volcano and Raoul follow collinear trends for incompatible elements such as $\mathrm{Ba}, \mathrm{Rb}$ and $\mathrm{Zr}$. Healy and the majority of Macauley samples follow collinear trends for $\mathrm{Zr}$ and $\mathrm{Rb}$ but Healy has anomalously high $\mathrm{Ba}$, approximately double the 

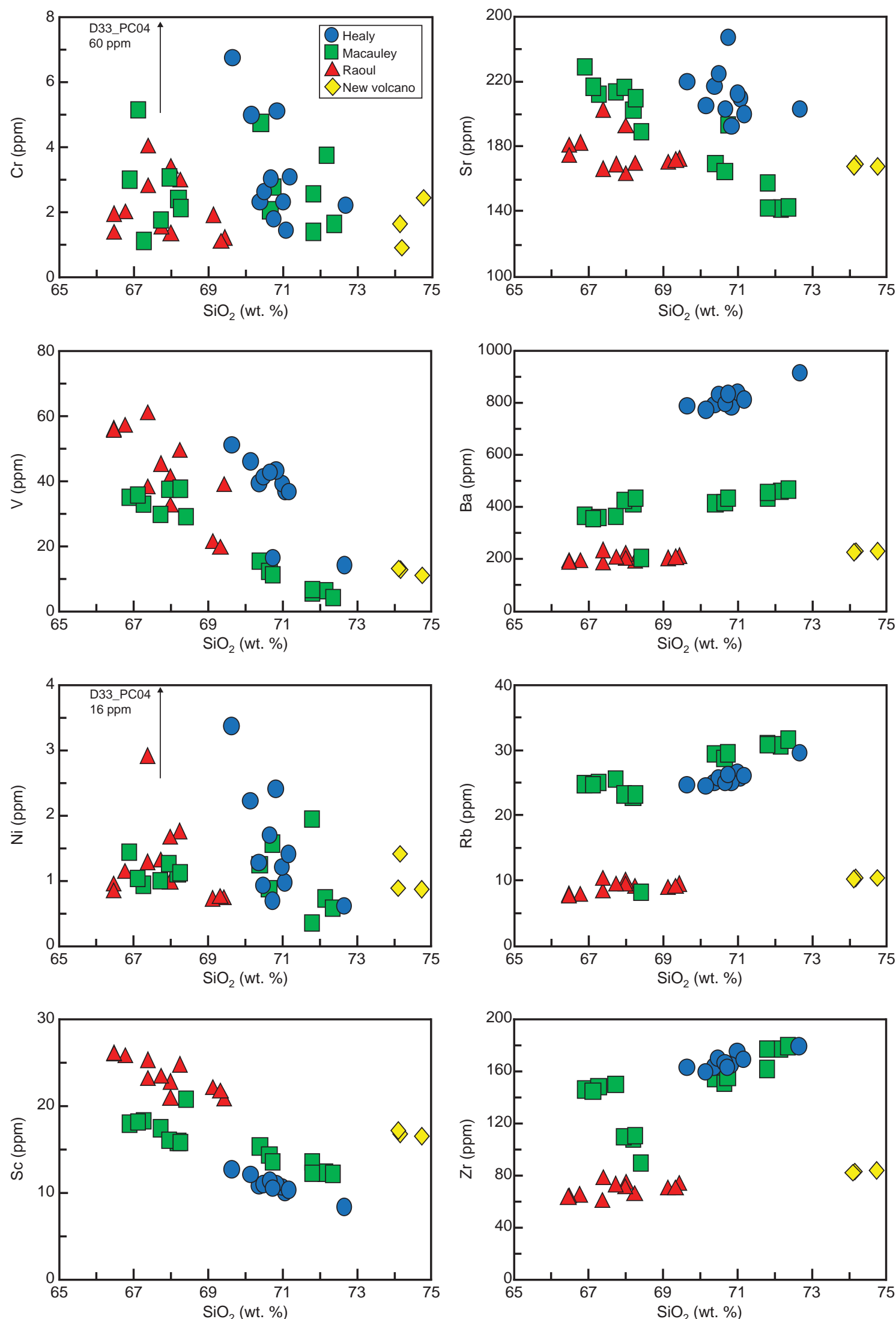

Figure 4.21. Selected whole rock trace element compositions versus $\mathrm{SiO}_{2}$ for pumice from the four volcanoes investigated in this study. Sample D33 PC04 is not shown on the Cr or Ni vs. $\mathrm{SiO}_{2}$ variation diagrams as it plots as an outlier with very high values (see text for discussion). All raw trace element data is presented in Appendix C. See Chapter 3 for analytical uncertanties. 
concentrations measured from Macauley for samples with similar $\mathrm{SiO}_{2}$ contents (Figure 4.21).

As shown on multi-element diagrams (Figures 4.22A-E), all Kermadec samples have high concentrations of fluid-mobile large ion lithophile elements (LILE: Cs, Rb, $\mathrm{Ba}, \mathrm{U}, \mathrm{K}, \mathrm{Pb}, \mathrm{Sr}$ ) and relatively low concentrations of fluid-immobile high field strength elements (HFSE: Ti, $\mathrm{Zr}, \mathrm{Hf}, \mathrm{Nb}, \mathrm{Ta}$ ) with respect to mid ocean ridge basalt (MORB), which is typical of arc magmas (Pearce and Peate, 1995). There are also significant differences in trace element concentrations between the Kermadec volcanoes (Figure 4.22E). Raoul and New volcanoes have considerably lower concentrations of HFSE, especially $\mathrm{Nb}$ and $\mathrm{Zr}$, indicating either a more depleted source or a higher degree of partial melting in their segment of the Kermadec arc. Rare Earth Element (REE) patterns (Figure 4.23A-E) also show significant differences between volcanoes, with Raoul and New volcanoes being light rare earth element (LREE) depleted (relative to MREE), and Healy and the majority of Macauley samples being LREE enriched. These differences could be caused by differences in the degree of partial melting or source enrichment/depletion or, alternatively, through differences in crystallising phases or through disequilibrium melting of a LREE-rich accessory phase in the mantle (Campbell and Gorton, 1980).

Figures 4.22 and 4.23 also highlight the variations in trace element concentrations between samples from different eruptions or locations, and compare the trace element patterns between mafic blebs, basaltic lavas and plutonic xenoliths with silicic pumices from the same volcano. Raoul pumices show only a small variation in trace elements between eruptions (Figure 4.22A, 4.23A). Dacite samples have only slightly negative $\mathrm{Eu}$ anomalies $\left(\mathrm{Eu} / \mathrm{Eu}^{*}=0.85-0.94\right)$ but large negative $\mathrm{Ti}$ anomalies. The Rangitahua samples also have anomalously high $\mathrm{Pb}$ concentrations. As the samples were collected from near lake level within the Raoul caldera, and had a thin clay coating with growth of small anhydrite crystals, this $\mathrm{Pb}$ spike is interpreted to be caused by hydrothermal clay contamination. A single tonalite xenolith shows similar trace element patterns to the dacite pumice samples analysed, with a slightly more pronounced negative $\mathrm{Eu}$ anomaly (Figure 4.23A: $\mathrm{Eu} / \mathrm{Eu}^{*}=0.65$ ). Elements such as $\mathrm{Zr}, \mathrm{U}$ and $\mathrm{Hf}$ are not shown for this xenolith as zircon is present and would not have been digested by the conventional HF digestion methods used in this study (Chapter 3). REE patterns in the tonalite may also be slightly affected by zircon crystallisation. Two mafic blebs from Raoul (section 4.3) have trace element concentrations which are considerably lower than the dacites, but strongly parallel their trace element patterns (Figures 4.22A and 

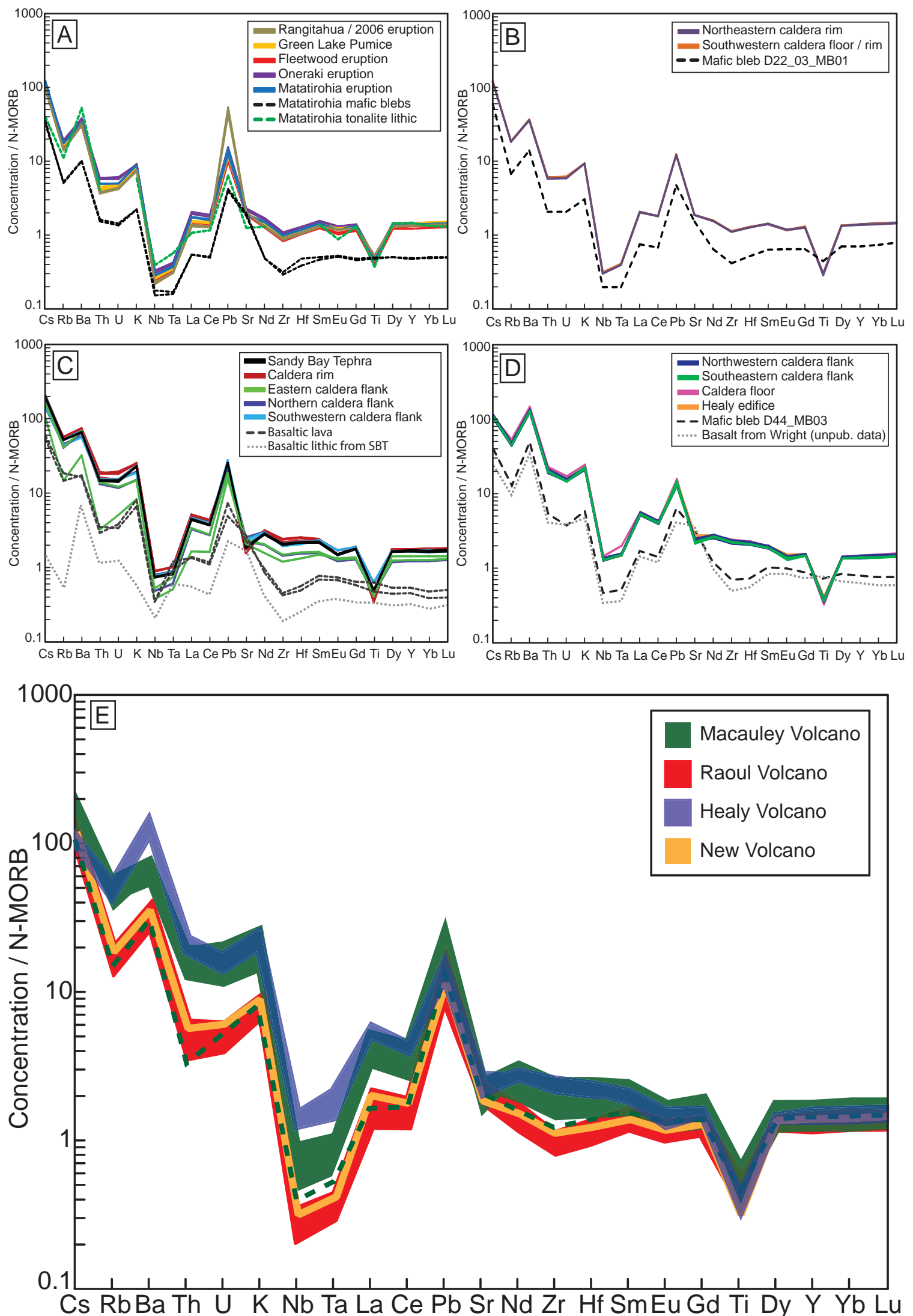

Figure 4.22. Multi-element diagrams showing incompatible trace element abundances normalised to normal-Mid Ocean Ridge Basalt (N-MORB) values of Sun and McDonough (1989). A) Raoul dacite pumices, Matatirohia mafic blebs and a tonalite xenolith. Note that $\mathrm{U}, \mathrm{Zr}$ and $\mathrm{Hf}$ are not shown for the tonalite sample (see text). B) Samples from New Volcano, including a single mafic bleb. C) Macauley pumices from this study compared with basaltic lavas and a Sandy Bay basaltic lithic from Smith et al. (2003a). D) Healy pumice samples and a single mafic bleb, plus a basaltic lava analysed by I.C. Wright (unpublished data). E) Comparison of trace element patterns from pumice from each volcano. Dashed green line represents a single outlier from Macauley (sample D33_PC04). 

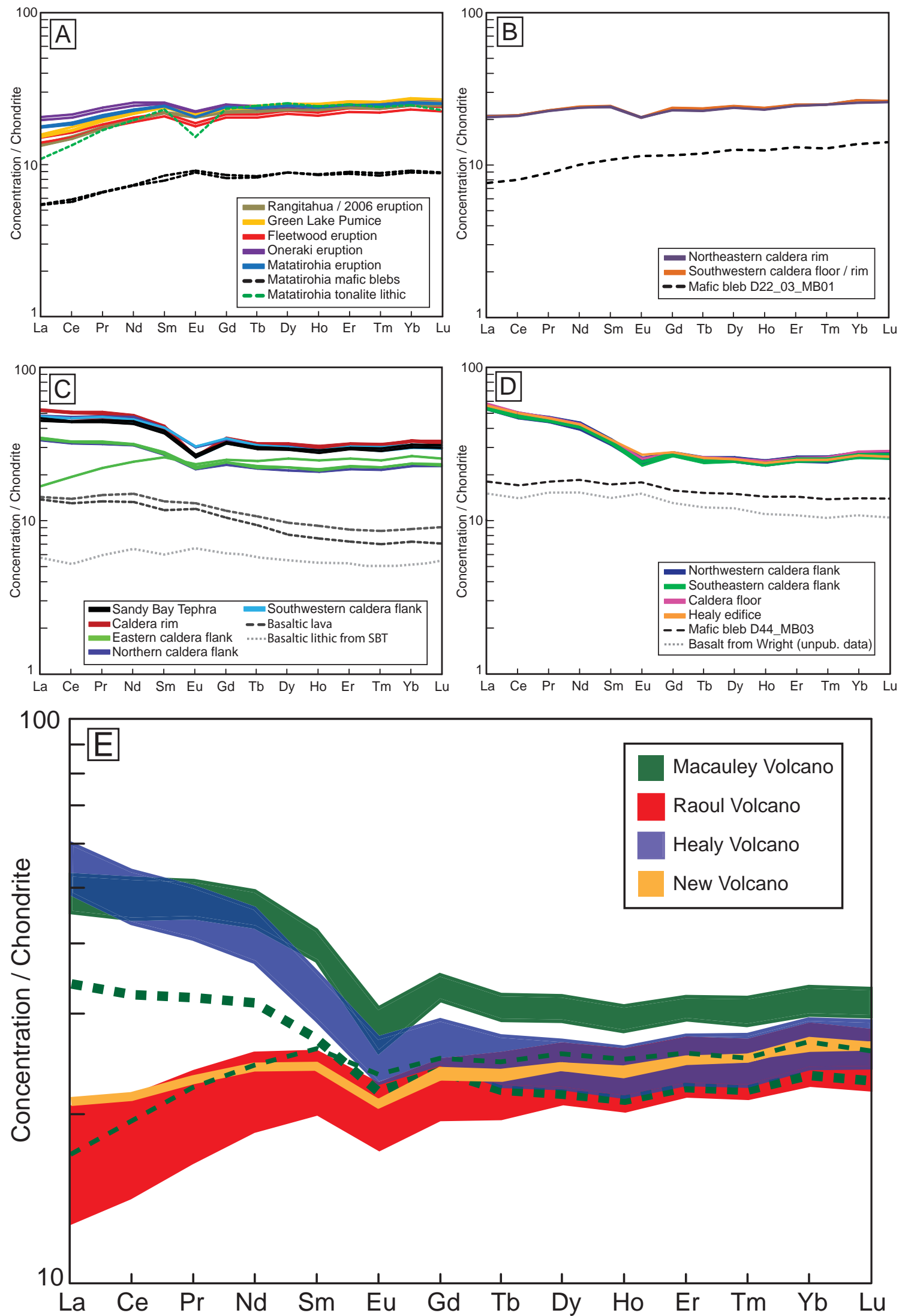

Figure 4.23. REE diagrams normalised to chondrite values (Palme and Beer, 1993). A) Raoul dacite pumices, Matatirohia mafic enclaves and a single tonalite xenolith. B) Samples from New Volcano, including a single mafic bleb. C) Macauley pumices from this study, and basaltic lavas and Sandy Bay basaltic lithic from Smith et al. (2003a). D) Healy pumice samples and the single mafic bleb, plus the basaltic lava analysed by I.C. Wright (unpublished data). E) Comparison of REE concentrations from pumice from each volcano. Thin dashed green line is a single sample from Macauley, thick dashed green line represents three samples from Macauley. 
4.23A). Mafic blebs have slightly positive Eu anomalies $\left(\mathrm{Eu} / \mathrm{Eu}^{*}=1.08-1.11\right)$ and no $\mathrm{Ti}$ anomalies, indicating that they have not undergone extensive fractionation of plagioclase or magnetite. Sr, however, does not show a large difference between the mafic blebs and the dacite samples. Similar subparallel patterns of trace element fractionation occur between pumice samples from New volcano and a single mafic bleb (Figures 4.22B and 4.23B).

Trace element patterns for Macauley samples reinforce the differences between the compositional groups previously identified by whole rock major element chemistry (section 4.2). The majority of pumice samples are LREE enriched, and plot within a narrow compositional range for most trace elements (Figures 4.22C,E and 4.23C,E). Consistent with major element chemistry, the high- $\mathrm{SiO}_{2}$ blocky pumice fragments collected from the caldera rim are the most evolved, with the highest concentration of incompatible elements and the most pronounced negative $\mathrm{Ti}$ and $\mathrm{Eu}\left(\mathrm{Eu} / \mathrm{Eu}^{*}=0.69\right.$ 0.73 ) anomalies. Three samples previously identified as low-K and low-Fe samples on whole rock major element variation diagrams plot with a similar trace element pattern to the other Macauley pumices, although at lower concentrations and with less pronounced negative $\mathrm{Eu}$ anomalies $\left(\mathrm{Eu} / \mathrm{Eu}^{*}=0.86-0.92\right)$. One sample (D33_PC04) is LREE-depleted with similar trace element patterns to samples from Raoul and New volcanoes. Although glass and mineral chemistry (sections 4.2 and 4.4, respectively) indicate that this sample has incorporated crystals which are from a melt of very different composition, these trace element patterns are significantly different to other Macauley samples and are interpreted to reflect a difference in magma source. Although no basaltic material from Macauley has been analysed in this study, trace element patterns of two basaltic samples from the Annexation and Cascade lavas and a single Sandy Bay basaltic lithic from Smith et al. (2003a) are presented in Figures 4.22C and 4.23C for comparison. Samples from the basaltic lavas are slightly LREE enriched, and have trace element patterns that strongly parallel those of the silicic pumices (Figures 4.22C and 4.23C). A single basaltic lithic from the Sandy Bay Tephra (Smith et al., 2003a) has very low LILE concentrations, especially $\mathrm{K}, \mathrm{Rb}$ and $\mathrm{Cs}$, indicating that it may have undergone secondary fluid alteration. REE patterns from this basaltic lithic however are slightly LREE depleted, similar to the single pumice sample D33_PC04. As observed at Raoul, Macauley basalts have similar Sr concentrations to silicic units, and Sr only decreases significantly for the most evolved pumice sample (Figures 4.21 and 4.22C).

At Healy, similar to the patterns observed in major element chemistry, there are little difference in trace element patterns between samples. Healy pumices are LREE 
enriched, with moderately negative $\mathrm{Eu}$ anomalies $\left(\mathrm{Eu} / \mathrm{Eu}^{*}=0.78-0.87\right)$ and large negative $\mathrm{Ti}$ anomalies (Figures 4.22D,E and 4.23D,E). Although many incompatible element concentrations are similar to those from Macauley, Healy samples have a distinctively higher Ba spike compared to other LILE, such as Th (Figure 4.22E). A single basaltic sample from I.C. Wright (unpublished data), and a single mafic bleb have trace element patterns which parallel those of the silicic pumices, but have a slightly positive $\mathrm{Eu}$ anomaly $\left(\mathrm{Eu} / \mathrm{Eu}^{*}=1.08\right)$ and slightly higher $\mathrm{Sr}$ concentrations (Figure 4.22D and 4.23D). Basaltic samples have a spike in Ba and are slightly LREE enriched, similar to the pumice samples, although LREE enrichment is significantly more pronounced in the pumice samples (Figure 4.23D).

\subsubsection{Whole rock $\mathrm{Pb}$ isotopes}

A subset of the samples analysed for trace elements were analysed for $\mathrm{Pb}$ isotopes. The results show that $\mathrm{Pb}$ isotopic compositions are relatively constant for each volcano, but each volcano has a significantly different $\mathrm{Pb}$ isotopic signature, reflecting its position along the arc (Figure 4.24). This is most evident in the Healy $\mathrm{Pb}$ isotopic compositions, which are the most radiogenic, having high ${ }^{207} \mathrm{~Pb} /{ }^{204} \mathrm{~Pb}$ and ${ }^{208} \mathrm{~Pb} /{ }^{204} \mathrm{~Pb}$ trending towards the $\mathrm{Pb}$ compositional field of Kermadec sediments (Figure 4.24; Gamble et al., 1996; Turner et al., 1997; Ewart et al., 1998). Using the model end-member compositions of altered oceanic crust fluid and sediment melt from Haase et al. (2002), Healy Pb isotopic trends suggest that the mantle below the southern Kermadec arc is influenced by sedimentary $\mathrm{Pb}$ (Figure 4.24). Similar $\mathrm{Pb}$ isotopic compositions have been identified in other southern Kermadec volcanoes (Gamble et al., 1996; Haase et al., 2002), including felsic lavas from Sonne and Brothers volcanoes (Figure 4.24). These findings are consistent with trends observed for Healy trace elements, suggesting that the $\mathrm{Ba}$ spike could be due to enrichment of the mantle wedge by Ba-rich fluids derived from altered oceanic crust and subducted oceanic sediments (Hole et al., 1984; Arculus and Powell, 1986; Wysoczanski et al., 2006).

Samples from Raoul, Macauley and New volcano show only slight differences in $\mathrm{Pb}$ isotope compositions, and are considerably less radiogenic than southern Kermadec volcanoes (Figure 4.24). Raoul samples are relatively less radiogenic than New volcano and Macauley, with lower ${ }^{207} \mathrm{~Pb} /{ }^{204} \mathrm{~Pb}$ and ${ }^{208} \mathrm{~Pb} /{ }^{204} \mathrm{~Pb}$, although a single sample (D33_PC04) and some published Macauley analyses (Smith et al., 2003a) plot within values similar to Raoul. As shown on Figure 4.24, a single Macauley outlier 

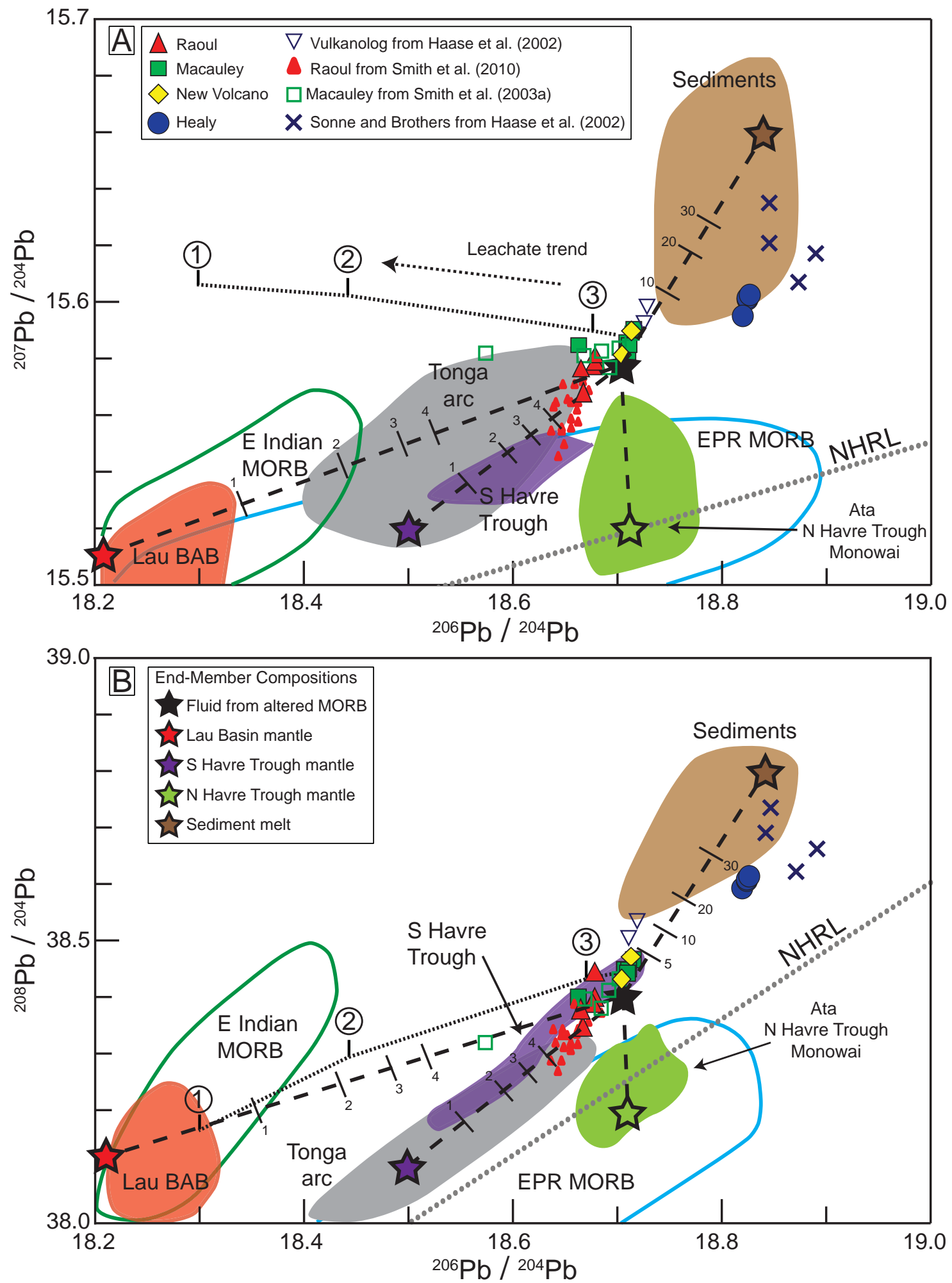

Figure 4.24. A) ${ }^{207} \mathrm{~Pb} / 204 \mathrm{~Pb}$ vs. ${ }^{206} \mathrm{~Pb} / 204 \mathrm{~Pb}$ and B) $208 \mathrm{~Pb} / 204 \mathrm{~Pb}$ vs. $206 \mathrm{~Pb} / 204 \mathrm{~Pb}$ for selected samples from the Kermadec volcanoes investigated in this study compared with previous studies of Raoul, Macauley, and other Kermadec volcanoes (cited in key). Dashed lines connect end-member compositions for mantle and sediment components (coloured stars) from Haase et al. (2002) with fluid from altered MORB (black star). Ticks on dashed lines mark the percent mixing between the two end members (mixing calculations from Haase et al. 2002). Dotted line is the leachate values for a single sample; circled numbers are leaching steps where (1) is $1 \mathrm{hr}$ in $0.1 \mathrm{M}$ cold $\mathrm{HCl}(2)$ is $1 \mathrm{hr}$ in $1 \mathrm{M}$ cold $\mathrm{HCl}$ and (3) is $1 \mathrm{hr}$ in $1 \mathrm{M}$ hot $\mathrm{HCl}$ (see Chapter 3). Shaded compositional fields represent published data from the Tonga-Kermadec region (Ewart and Hawkesworth, 1987; Loock et al., 1990; Pearce et al., 1995; Gamble et al., 1996, 1997; Regelous et al., 1997; Turner et al., 1997; Bach et al., 1998; Ewart et al., 1998; Peate et al., 2001; Haase et al., 2002). Open fields are for the East Indian MORB (Klein et al., 1988,1991), and East Pacific Rise (EPR) MORB (Cohen and O'Nions, 1982; Ito et al., 1987; White et al., 1987; Bach et al., 1994; Mahoney et al., 1994; Haase, 2002). Northern Hemisphere Reference Line (NHRL) from Hart (1984). Figure modified from Haase et al. (2002). 
from Smith et al. (2003a) has considerably lower ${ }^{206} \mathrm{~Pb} /{ }^{204} \mathrm{~Pb}$. This single outlier is considered to be contaminated with anthropogenic $\mathrm{Pb}$ as it plots closely to the leachate trend calculated from this study. Both a single tonalite and mafic bleb were analysed from Raoul, but there are no significant variations in their compositions compared to dacite pumices. When plotted with published lava compositions of Smith et al. (2006, 2010), Raoul values trend along a mixing line, slightly offset from the South Havre mantle mixing trend proposed by Haase et al. (2002) (Figure 4.24). New volcano and Macauley volcanoes continue the linear trend from Raoul along the mixing trend towards sedimentary Pb. Samples analysed by Haase et al. (2002) from Vulkanolog plot further along this mixing array, suggesting that there is a change in sediment expression over a relatively short distance from Raoul to New volcano/Macauley $(<30 \mathrm{~km}$ and ca. $100 \mathrm{~km}$, respectively), and from Macauley to Vulkanolog $(<50 \mathrm{~km})$.

\subsection{Mineral trace element data}

\subsubsection{Clinopyroxene trace elements}

Clinopyroxene from Raoul and Macauley were classified into two types based on major element chemistry (Section 4.2): 1) Mg-rich and 2) Fe-rich. Clinopyroxene from Healy did not have strongly contrasting major element chemistries, although some crystals in samples D38_PC06 and D44_PC01 had higher contents of $\mathrm{Cr}_{2} \mathrm{O}_{3}$ than other samples. The REE chemistry of clinopyroxene from all three volcanoes $(4.25 \mathrm{~A}-\mathrm{C})$ is consistent with two separate populations, with strongly bimodal REE patterns separating the two types. The Mg-rich clinopyroxene from Raoul and Macauley and Cr-rich clinopyroxene from Healy have low concentrations of REE and no Eu anomaly (Figure 4.25), indicating that they crystallised from primitive mafic magma. In contrast, Fe-rich and Cr-poor clinopyroxene have higher concentrations of REE and a negative Eu anomaly, indicating they grew in a more evolved melt which previously underwent plagioclase fractionation (Figure 4.25). In addition, there is a significant compositional gap between the REE concentrations of mafic clinopyroxene and the more evolved silicic clinopyroxene $(4.25 \mathrm{~A}-\mathrm{C})$. REE patterns are LREE depleted with $(\mathrm{La} / \mathrm{Sm})_{\mathrm{N}}$ generally 0.10-0.20 for Macauley and Healy, while Raoul samples and Macauley sample D33_PC04 have slightly more depleted values with $(\mathrm{La} / \mathrm{Sm})_{\mathrm{N}}$ generally $<0.10$.

Consistent with REE patterns, there is a large variation in other trace element concentrations between Fe-rich and Mg-rich clinopyroxene types analysed from Raoul volcano (Figure 4.26). The differences between clinopyroxene from the different 

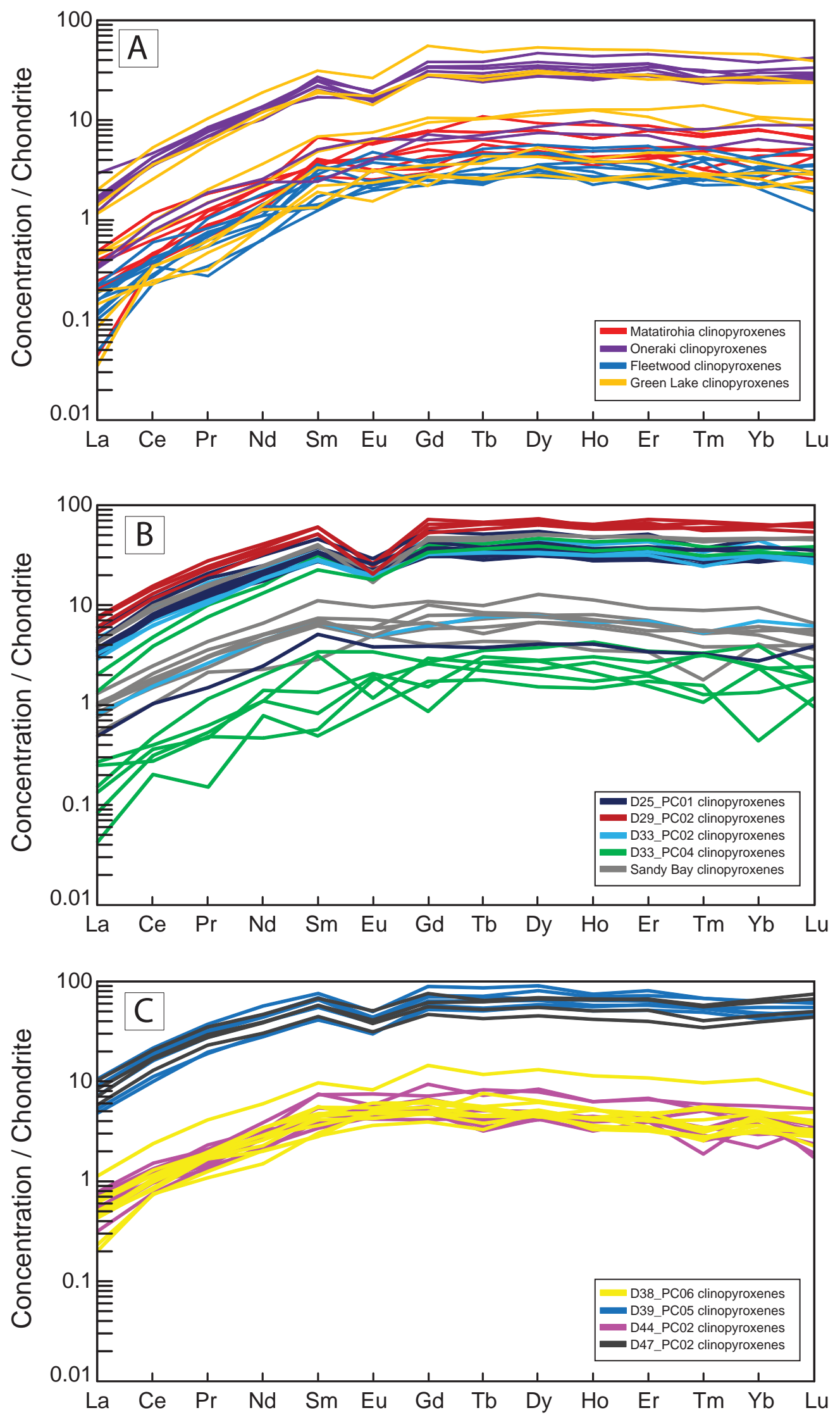

Figure 4.25. Chondrite normalised (Palme and Beer, 1993) REE patterns of clinopyroxenes analysed from: A) Raoul samples, excluding the Rangitahua pumice; B) Macauley samples; and C) Healy samples. Clinopyroxene trace element variations between different samples from Raoul are not necessarily representative of the total clinopyroxene population for each eruption (see text for discussion). Some crystals have been analysed multiple times in different zones, which are not indicated in this diagram, but zoned crystals are shown on Figures 4.26, 4.28 and 4.29. Raw data are presented in Appendix G. 

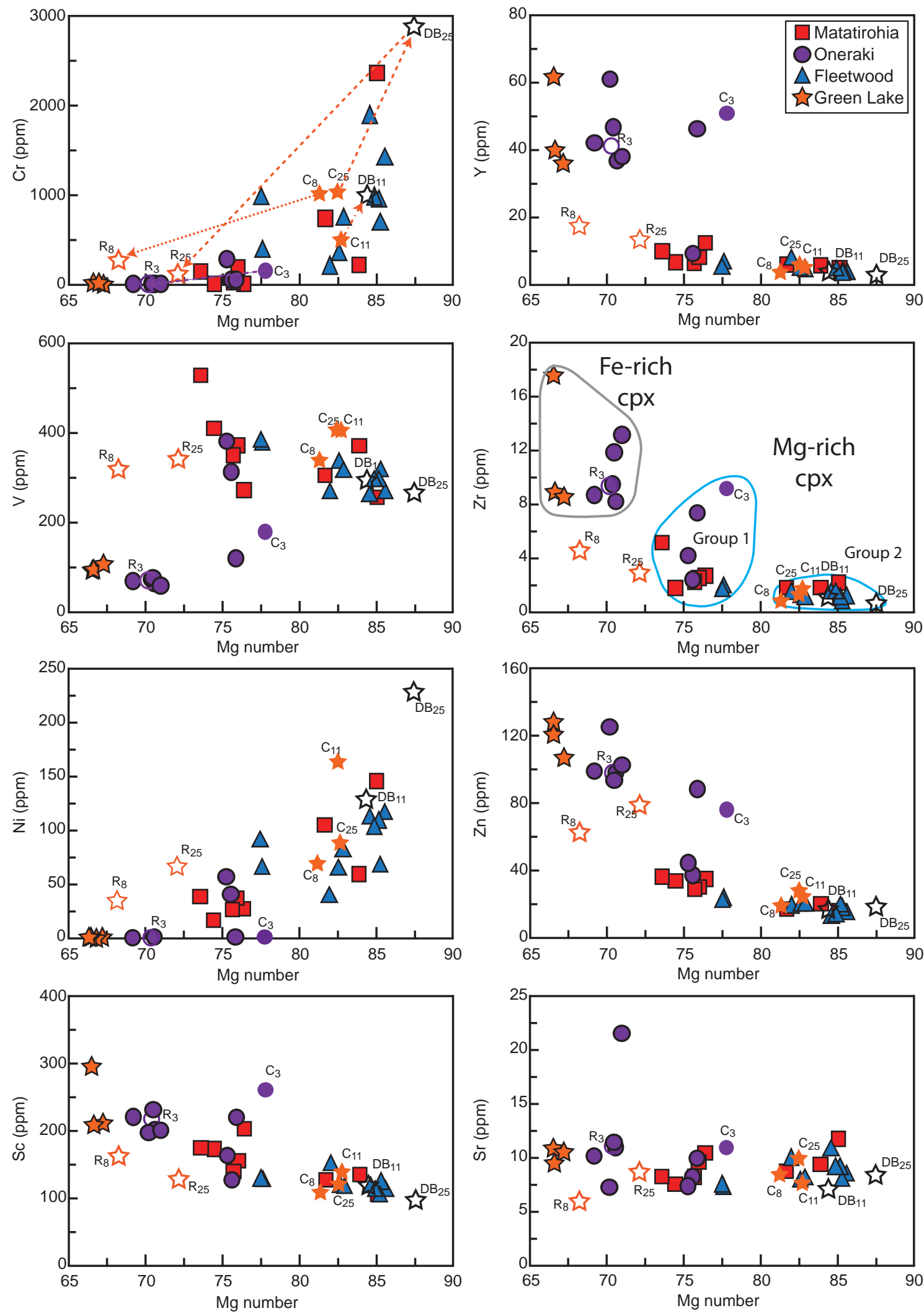

Figure 4.26. Selected trace elements as function of $\mathrm{Mg}$-number for clinopyroxene from four Raoul deposits as denoted by symbol type. Analyses are dominantly from single crystals (non-labelled data). The zones of several strongly zoned crystals were analysed and are labelled accordingly: filled symbols with no outline marked 'C' are cores, open coloured symbols marked ' $\mathrm{R}$ ' are rims, and open black symbols marked 'DB' are dark bands. Analyses from single zoned crystals are joined by dashed lines with arrows on the $\mathrm{Cr}$ variation diagram to illustrate the compositional changes between zones within single crystals. The two clinopyroxene types are highlighted on the $\mathrm{Zr}$ variation diagram, with both sub-groups shown for Mg-rich type clinopyroxenes. All raw data in Appendix G. 
eruption units from Raoul are not representative of the total clinopyroxene population as both Fe-rich (silicic) and Mg-rich (mafic) types were analysed from the Oneraki and Green lake samples, but only Mg-rich clinopyroxene from the Matatirohia and Fleetwood pumices. For the Matatirohia sample, only clinopyroxene within small (1-5 $\mathrm{mm}$ ) mafic blebs were analysed, whereas only single crystals were analysed for other samples. Fe-rich clinopyroxene typically have very low concentrations of compatible elements such as $\mathrm{Cr}$ and $\mathrm{Ni}$ (generally $<1 \mathrm{ppm}$ ). $\mathrm{Cr}$ and $\mathrm{Ni}$ concentrations in Mg-rich type clinopyroxene in contrast form a curved positive relationship with increasing $\mathrm{Mg}$ number (Figure 4.26). There are however two distinct sub-groups of Mg-rich type clinopyroxene (Figure 4.26): a) those with $\mathrm{Mg} \#<80$ which typically have lower concentrations of $\mathrm{Cr}$ and $\mathrm{Ni}$, and slightly elevated incompatible elements such as $\mathrm{Zr}, \mathrm{Y}$ and $\mathrm{Zn}$; and $\mathrm{b}$ ) those with $\mathrm{Mg} \#>80$ which have lower concentrations of incompatible elements, and considerably higher $\mathrm{Ni}$ and $\mathrm{Cr}$.

The highest values of $\mathrm{Ni}$ and $\mathrm{Cr}$ are not necessarily in the cores of Mg-rich normally zoned clinopyroxene, as would be expected from crystals growing in a melt which followed a simple fractionation path. Some strongly zoned crystals have a resorbed core overgrown by a dark (Mg-rich) band/overgrowth, with a light grey Ferich rim (Figure 4.27A). These zones were analysed for trace elements and are labelled by crystal number and zone location on Figure 4.26. Compositions from strongly zoned crystals from the Green Lake Pumice sample (Figure 4.27) show the dark bands have considerably higher $\mathrm{Cr}$ and $\mathrm{Ni}$ contents than the resorbed cores, with an increase from ca. $1000 \mathrm{ppm}$ to $3000 \mathrm{ppm}$ in Green Lake crystal 25 between core and dark band zones (Figure 4.26). This sharp increase is accompanied by a slight decrease in incompatible element contents (e.g. Zr, Zn: Figure 4.26). These changes indicate that the cores of these strongly zoned crystals were resorbed then subsequently grew in a more primitive magma with higher $\mathrm{Cr}$ and $\mathrm{Ni}$. This style of crystal zoning occurs in other samples, but the zones of dark bands were too thin to fit a $25 \mu \mathrm{m}$ LA-ICPMS laser spot for analysis. Light coloured (Fe-rich) rims on strongly zoned crystals have considerably lower concentrations of $\mathrm{Cr}$ and $\mathrm{Ni}$, and higher concentrations of incompatible elements indicating that following resorption and growth in a primitive magma, the crystals grew in a more evolved magma.

There are also significant differences in incompatible trace element concentrations between the Mg-rich and Fe-rich clinopyroxene from Raoul volcano (Figure 4.26). For example, $\mathrm{Zr}, \mathrm{Zn}$ and $\mathrm{Y}$ are negatively correlated with $\mathrm{Mg}$ number, forming a steeply curved trend as concentrations sharply increase in Fe-rich type 

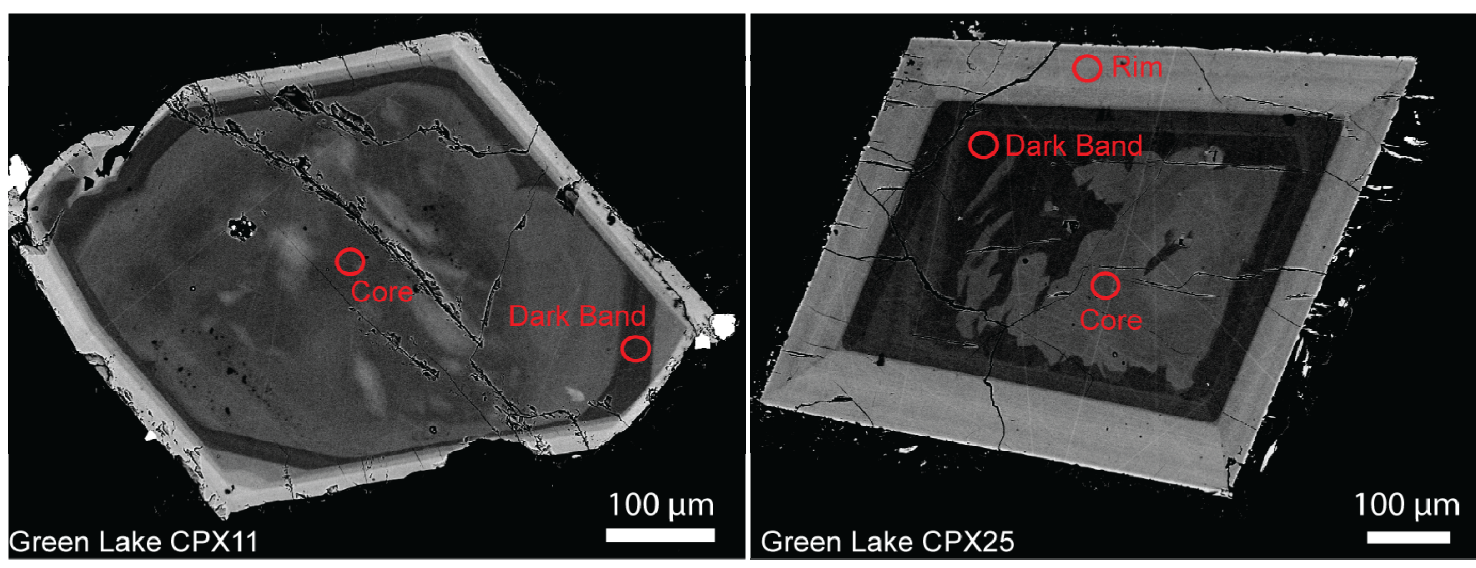

Figure 4.27. BSE images of strongly zoned clinopyroxene from Raoul showing the different regions analysed for trace element compositions. Red circles represent the LA-ICPMS analysis spots. Trace element compositions for these two crystals are shown in Figure 4.25 as labelled by sample number $\left(\mathrm{C}_{8}, \mathrm{DB}_{8}\right.$ and $\mathrm{C}_{25}, \mathrm{DB}_{25}, \mathrm{R}_{25}$ respectively).

clinopyroxene (Figure 4.26). In contrast, Sr concentrations are invariable throughout the range of clinopyroxene analysed. Similar compatible and incompatible trace element variations occur in clinopyroxene from Macauley (Figure 4.28). Mg-rich clinopyroxene with the highest concentration of compatible elements are mostly from sample D33_PC04, with a few outliers from samples D25_PC01, D33_PC02 and the Sandy Bay pumice. Outliers from the Sandy Bay pumice and sample D33_PC02 are core analyses from highly zoned crystals. The rims of these zoned crystals have lower Mgnumber and lower $\mathrm{Cr}$ and $\mathrm{Ni}$ concentrations suggesting that they subsequently grew in a less primitive melt (Figure 4.28). Fe-rich crystal types in contrast to Mg-rich crystal types have low concentrations of $\mathrm{Cr}, \mathrm{Ni}$ and relatively high concentrations of incompatible trace elements, showing a strong linear relationship with decreasing $\mathrm{Mg}$ number. The highest concentrations of incompatible elements are for the most evolved whole rock samples and glass for sample D29_PC02. Sr shows very little overall variation with crystal composition, as for Raoul, being only slightly higher for crystal compositions between Mg\# 65-75. For the Sandy Bay Tephra an intermediate subpopulation of clinopyroxene plots between the two main groups at ca. $\mathrm{Mg \#} \mathrm{75,}$ indicating there are three different populations of clinopyroxene for this sample (Figure 4.28).

REE patterns from Healy clinopyroxene are distinctly bimodal (Figure 4.25), with clinopyroxene from samples D38_PC06 and D44_PC02 having low REE concentrations and clinopyroxene from samples D39_PC05 and D47_PC02 having higher REE concentrations and negative Eu anomalies. This is consistent with the compatible trace element data (Figure 4.29), as clinopyroxene from samples D38_PC06 

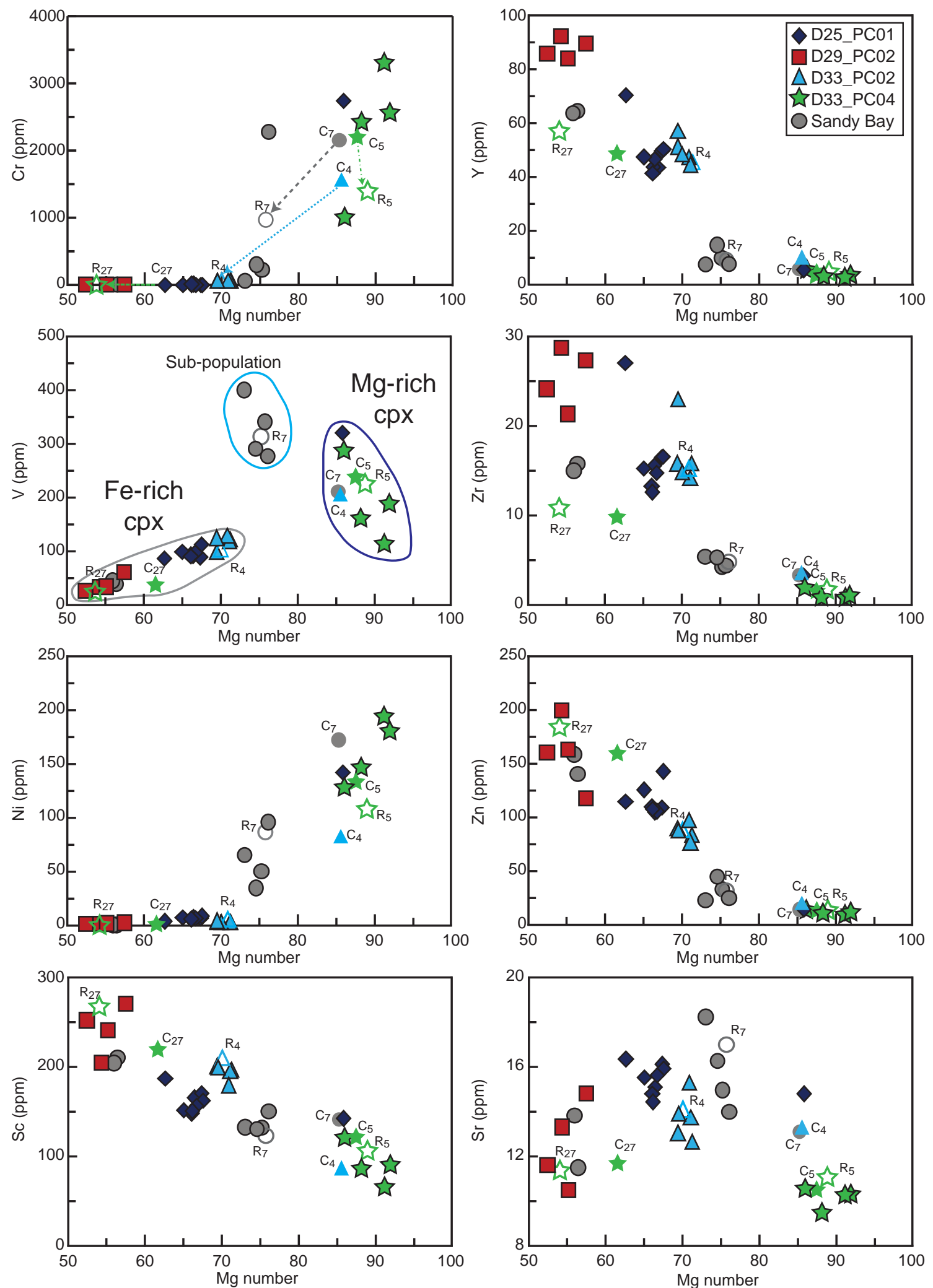

Figure 4.28. Selected trace elements vs. Mg-number for clinopyroxenes analysed from five Macauley pumice samples. Analyses are dominantly from single crystals (non-labelled data). The zones of several strongly zoned crystals were analysed and are labelled accordingly: filled symbols with no outline marked ' $C$ ' are cores, open coloured symbols marked ' $R$ ' are rims, and open black symbols marked 'DB' are dark bands. Analyses from single zoned crystals are joined by dashed lines with arrows on the $\mathrm{Cr}$ variation diagram to illustrate the compositional changes between zones within single crystals. The two clinopyroxene types are highlighted on the $\mathrm{V}$ variation diagram. All raw data is presented in Appendix G. 

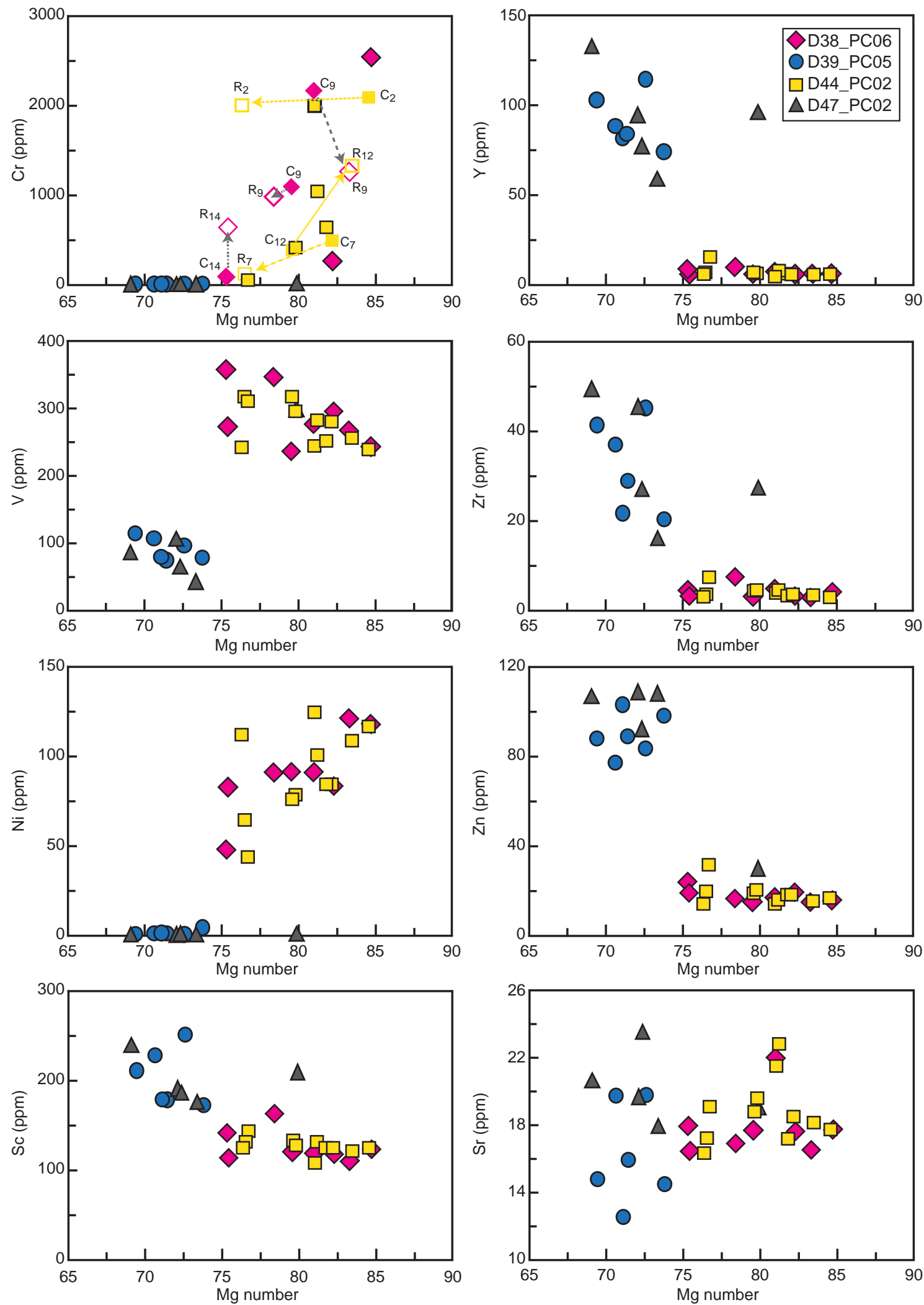

Figure 4.29. Selected trace elements as a function of Mg-number for clinopyroxene analysed from four pumices from Healy volcano. Analyses are dominantly from single crystals (non-labelled data). The zones of several strongly zoned crystals (D38 PC06 and D44 PC01) were analysed and are labelled: filled symbols with no outline markèd ' $C$ ' are cores, open coloured symbols marked ' $R$ ' are rims, and open black symbols marked 'DB' are dark bands. Analyses from single zoned crystals are joined by dashed lines with arrows to illustrate the compositional changes between zones within single crystals The differing zones for samples D39_PC06 and D47_PC02 are not plotted as there is very little variation, with generally no corrēlation with $\mathrm{Mg}$ number (see text for discussion). All raw values and analysis locations are presented in Appendix G. 
and D44_PC02 have higher concentrations of $\mathrm{Cr}$ and $\mathrm{Ni}$, indicating they are from a more primitive source. The overall variation in clinopyroxene major element chemistry is relatively small, with a boundary at $\mathrm{Mg} \# 75$ separating the two crystal populations, despite the large differences in trace element chemistry (Figures 4.25 and 4.29). Consistent with the major element chemistry, trace element zonation in clinopyroxene shows little overall variation, with no consistent trends (Figure 4.29, Appendix G). Clinopyroxene crystals with $\mathrm{Mg} \#>75$ shows no correlation between incompatible element concentrations and $\mathrm{Mg}$-number. In contrast clinopyroxene with $\mathrm{Mg} \#<75$ show a linear trend for Sc, $\mathrm{Y}$ and $\mathrm{Zr}$ with higher concentrations in crystals with lower $\mathrm{Mg}$ number (Figure 4.29). As observed at Raoul and Macauley, there is little variation in $\mathrm{Sr}$ concentrations between the two clinopyroxene populations, over their compositional ranges.

\subsubsection{Plagioclase trace elements}

Plagioclase major element compositions (Section 4.2) show that multiple populations occur in pumice samples from each volcano (Figures 4.07, 4.09, 4.14, 4.17). For Raoul samples, the main plagioclase suite spans a compositional range from ca. $\mathrm{An}_{98}$ to $<\mathrm{An}_{60}$. Trace element data from plagioclase spanning this compositional range are presented in Figure 4.30. The highest-An plagioclases from $\mathrm{An}_{90}$ to $\mathrm{An}_{98}$ have the lowest concentrations of trace elements. Trace element concentrations then show a strong negative relationship with decreasing $\mathrm{An}$ content until ca. $\mathrm{An}_{80}$, after which concentrations stay relatively constant, or decrease slightly with lower An (Figure 4.30). These variations are interpreted to be the effects of both: a) changing melt compositions and b) varying plagioclase-melt trace element partitioning with changing melt composition (Blundy and Wood, 1991).

Similar trends occur in plagioclase from Macauley (Figure 4.31), although a larger compositional range is present compared to Raoul and there are fewer crystals with $>\mathrm{An}_{80}$. Even though most Macauley pumices contain clinopyroxene (and sometimes olivines) from a mafic source, the Sandy Bay pumice is the only sample which has plagioclase with $>\mathrm{An}_{80}$ and low concentrations of trace elements (Figure 4.31). Most trace element concentrations are relatively constant from ca. $\mathrm{An}_{80}$ to $\mathrm{An}_{60}$, with only slightly lower concentration in sample D33_PC04. However, at $<\mathrm{An}_{60}$, many trace elements increase in abundance with decreasing An values. This is most pronounced for $\mathrm{Ba}$, which increases 4-5 times in concentration from $\mathrm{An}_{60}$ to $\mathrm{An}_{40}$. 

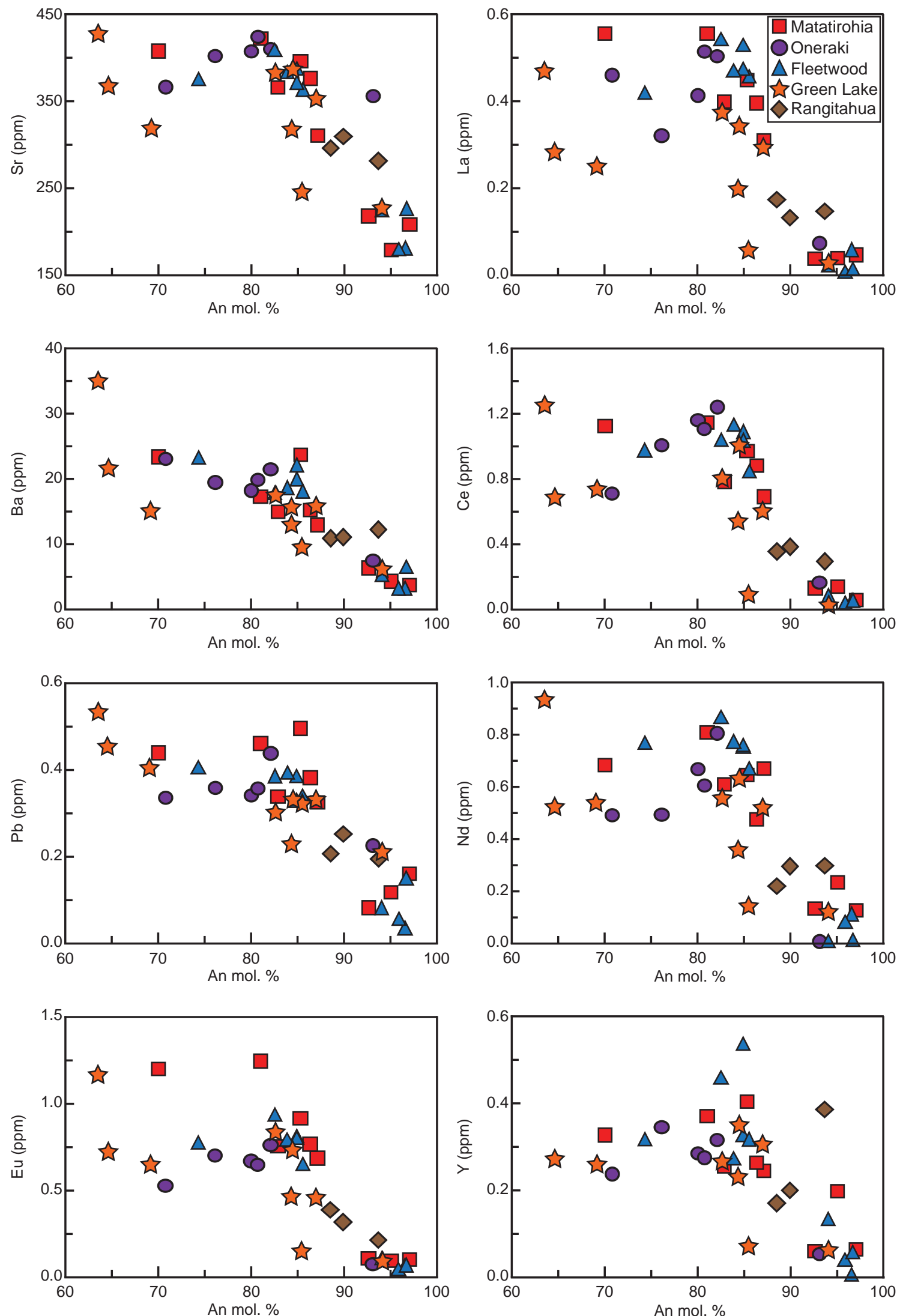

Figure 4.30. Selected trace elements variation as a function of $X_{A n}(A n=100 \mathrm{Ca} /(\mathrm{Ca}+\mathrm{Na}))$ for plagioclase analysed from five pumices from Raoul volcano. Analyses are from both single crystals and zones within individual crystals. Following the trends outlined in Figure 4.07, high-An analyses $\left(>A n_{80}\right)$ are mainly from cores and unzoned crystals, and low-An analyses are from rims. Zones are not distinguished on this diagram but all raw data with analysis location is presented in Appendix G. 

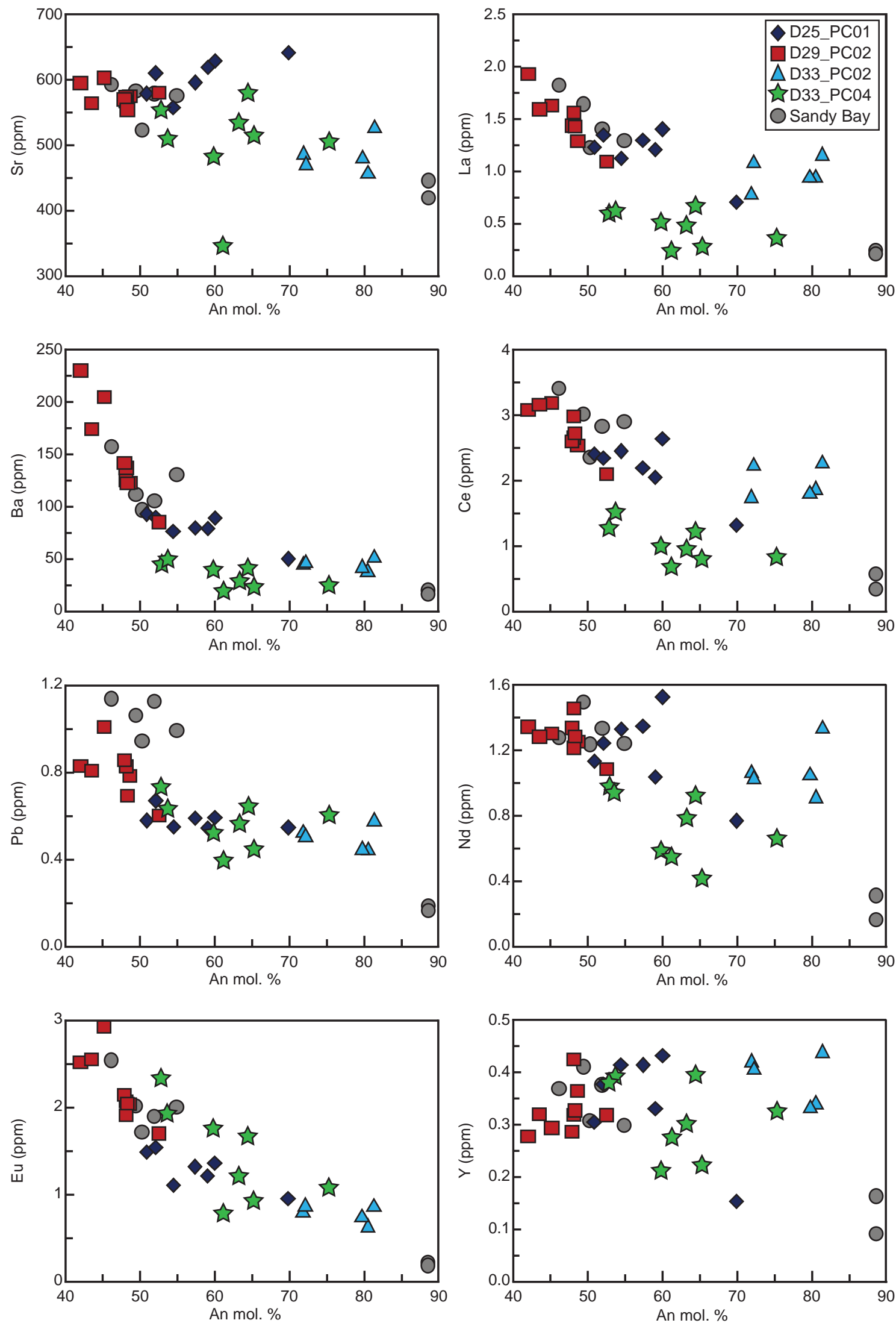

Figure 4.31. Selected trace element variation as function of $X_{A n}$ for plagioclase analysed from five pumices from Macauley volcano. Analyses are from both single crystals and zones within crystals (see Figure 4.13). Zones are not distinguished on this diagram but all raw data with analysis location is presented in Appendix G. 
Plagioclase from Healy, unlike the Macauley and Raoul examples, does not cover a wide continuous compositional range. Consistent with major element and clinopyroxene trace element chemistry, Healy plagioclase trace element compositions show a strongly bimodal distribution (Figure 4.32). High-An plagioclase from Healy is only found in samples D38_PC06 and D44_PC02 and have very low concentrations of trace elements (Figure 4.32). Similar to the trends observed at Macauley, Healy plagioclase with $<\mathrm{An}_{60}$ has trace element concentrations that generally increase with decreasing An content. (Figure 4.32), with only Sr and Y showing a slight decreasing trend. As Sr partition coefficients increase with decreasing An content (Blundy and Wood, 1991), this is interpreted to indicate that the host melt has decreasing $\mathrm{Sr}$ concentrations due to subsequent plagioclase crystallisation.

\subsubsection{Amphibole trace elements}

Amphibole has only been identified as a crystal phase in Healy samples (section 4.2). The Healy amphiboles have enriched REE patterns which are LREE depleted, and a have slight HREE-depletion (Figure 4.33A). These trends are consistent with amphibole partition coefficients which are highest for the middle-REE (Rollinson, 1993). Consistent with the two crystal populations identified through major element chemistry (section 4.2, Appendix F), Healy amphiboles also show two compositional groups based on REE content. Amphiboles from sample D47_PC02, which are magnesiohastingsite and tschermakitic pargasite, are slightly less enriched than amphiboles from other samples, which are mainly magnesiohornblende (classification from Ridolfi et al., 2010). Amphiboles from samples D38_PC06, D39_PC05 and D44_PC02 have a pronounced negative Eu anomalies $\left(\mathrm{Eu} / \mathrm{Eu}^{*}=0.50-0.57\right)$, whereas two amphiboles from sample D47_PC02 have only a slightly negative anomalies $\left(\mathrm{Eu} / \mathrm{Eu}^{*}=0.80-0.82\right)$.

The differences between the two populations are further highlighted in other trace element variation diagrams (Figure 4.33B). Amphiboles from samples D38_PC06 and D44_PC02 have higher concentrations of compatible elements such as $\mathrm{Ni}$ and $\mathrm{V}$ compared to samples D39_PC05 and D47_PC02 (<1 ppm Ni), and sample D47_PC02 has slightly higher Sr concentrations. Despite many of these differences, the enriched REE compositions of Healy amphiboles suggest that they crystallised in an evolved magma. Unlike Healy clinopyroxene and plagioclase, amphibole trace element patterns do not have a bimodal distribution and lack a contrasting 'mafic' sourced crystal population. 

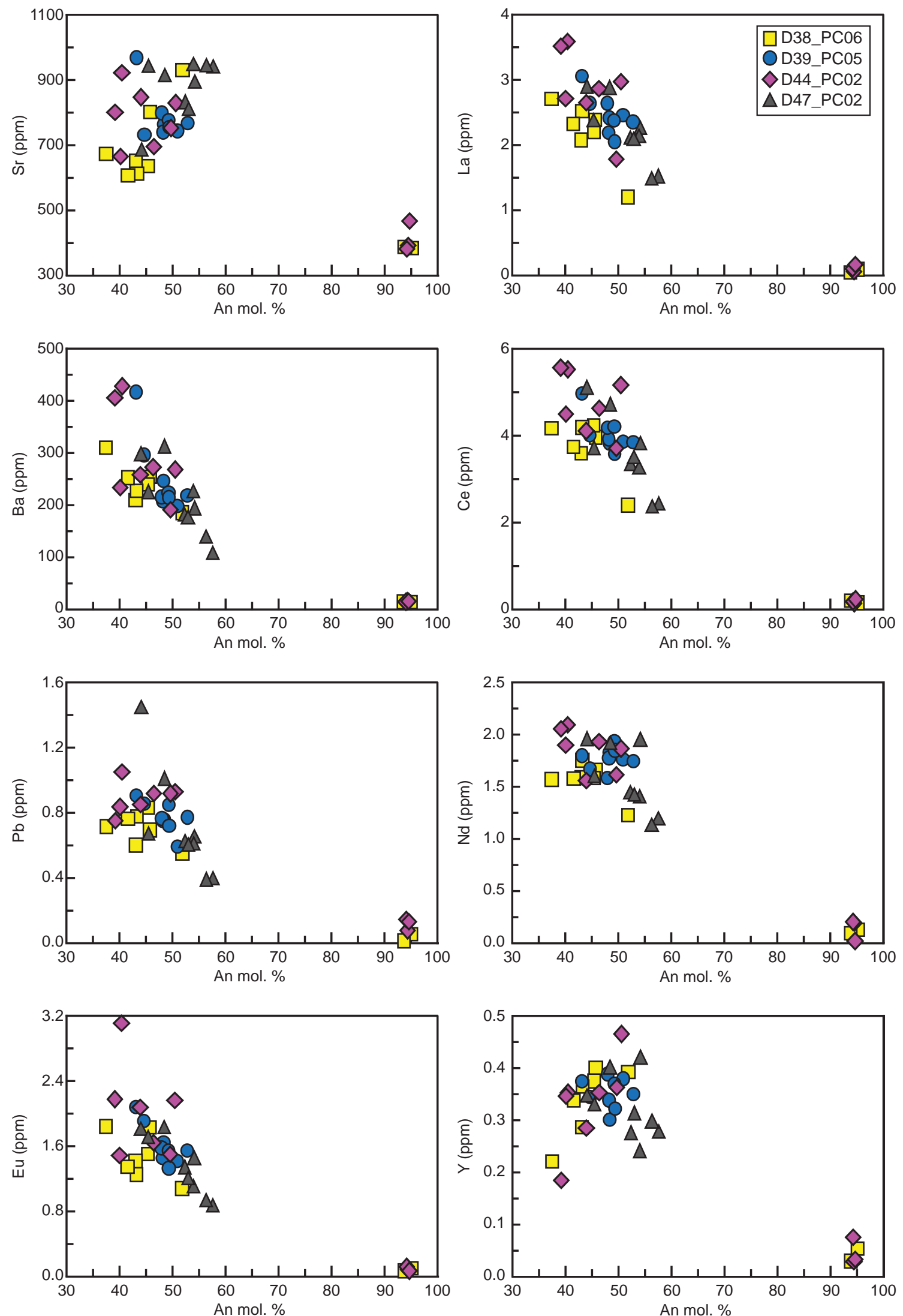

Figure 4.32. Selected trace element variation as function of $X_{\text {An }}$ for plagioclase analysed from four pumice samples from Healy volcano. Analyses are from both single crystals and zones within crystals. Zones are not distinguished on this diagram but all raw data with analysis location is presented in Appendix G. 


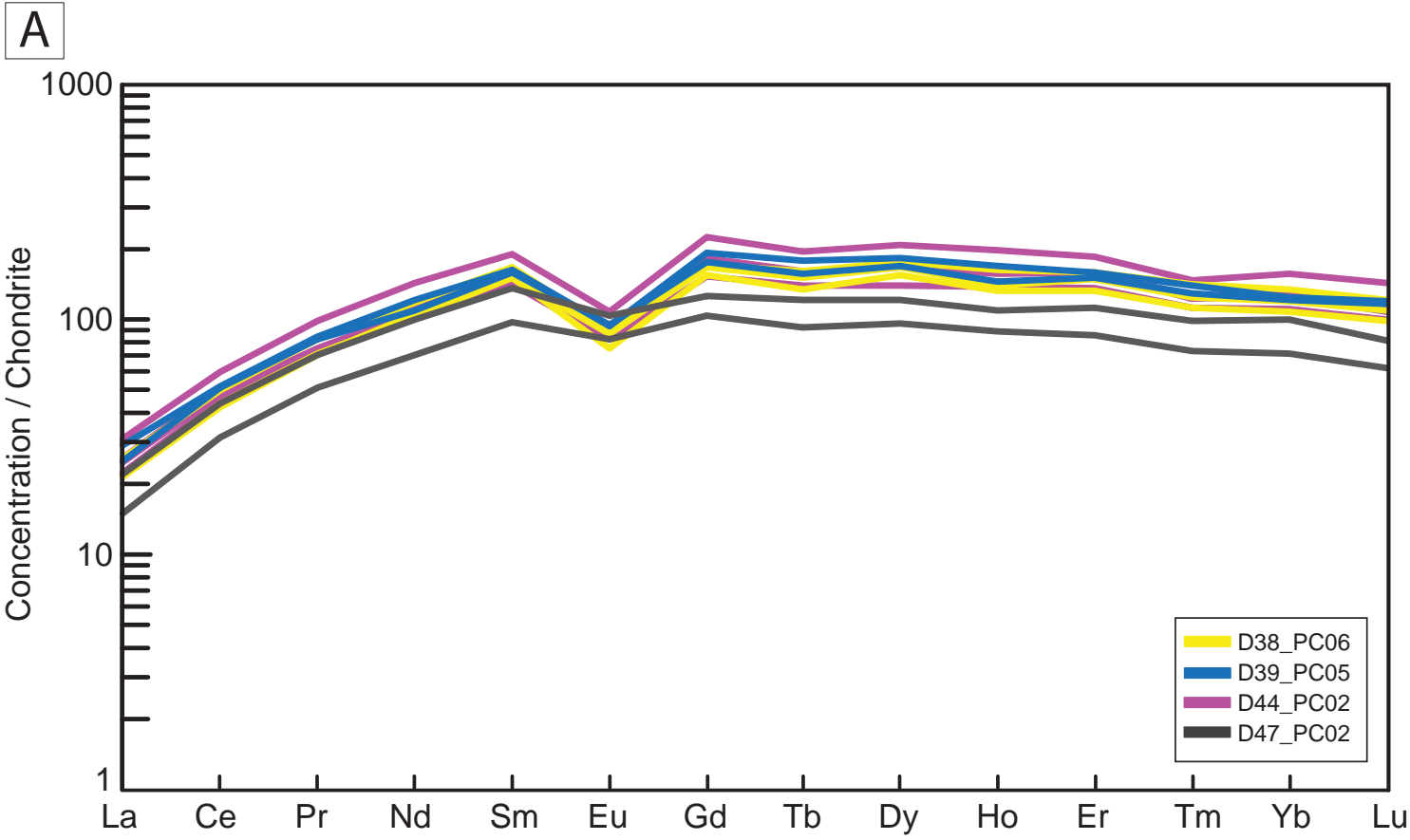

B
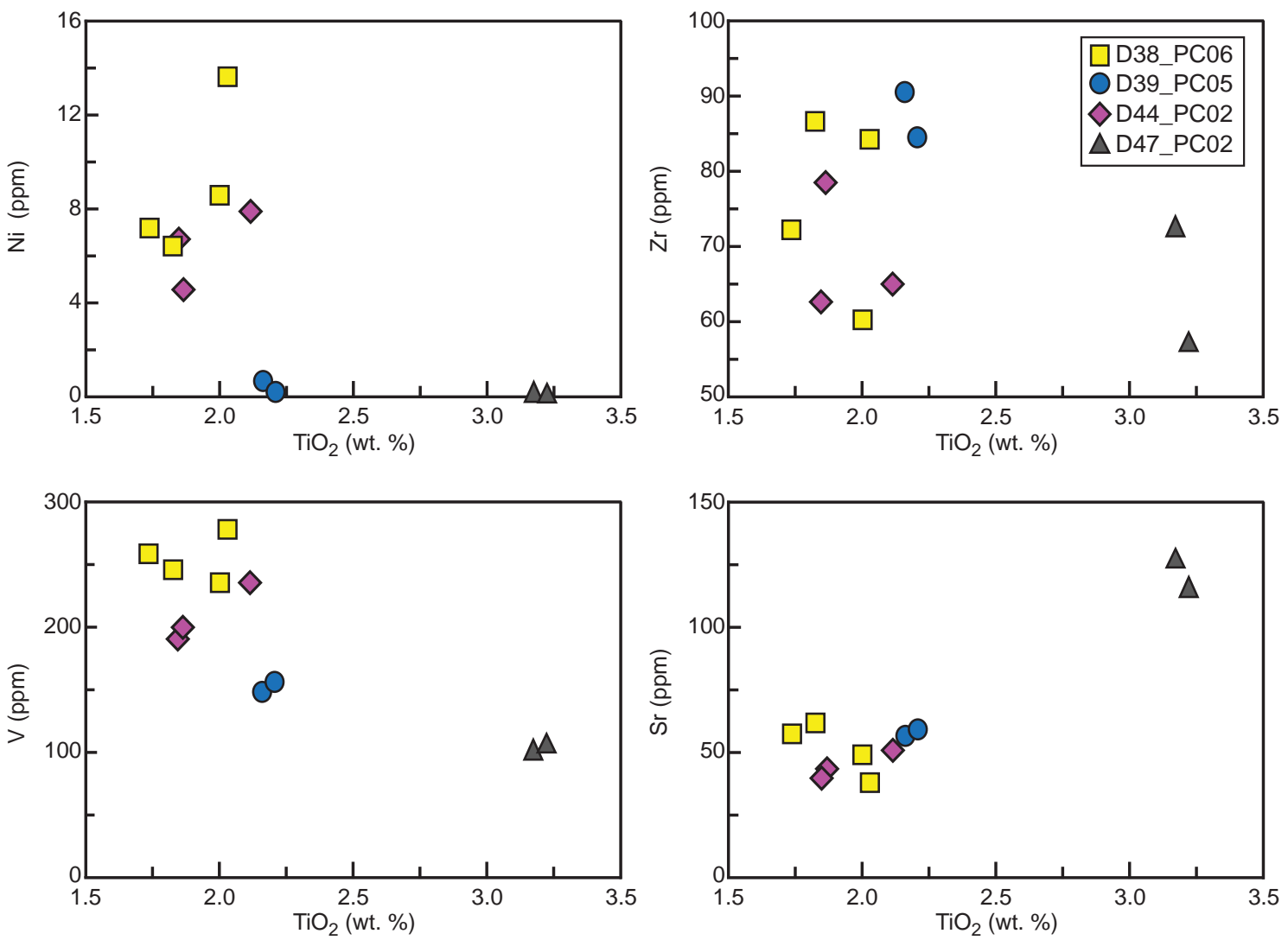

Figure 4.33. Amphibole trace element concentrations from Healy volcano. A) Chondrite normalised (Palme and Beer, 1993) REEs for crystals from four pumice samples. B) Selected trace elements as function of $\mathrm{TiO}_{2}$. All raw compositions are presented in Appendix G. 


\subsection{Intensive parameters and equilibrium calculations}

To gain insight into the pre-eruptive storage conditions of the Kermadec magmas, a range of methods have been used to determine temperature, pressure, volatile contents and oxygen fugacity of the magmas. The differing mineral assemblages of the pumice samples investigated in this study means that only a limited number of methods can be utilised for each volcano. Where possible, multiple methods were used for each sample to show a range of calculated values, and to compare and contrast the suitability of each method.

\subsubsection{Fe-Ti oxide thermo-oxybarometry}

The Fe-Ti two oxide thermo-oxybarometer of Ghiorso and Evans (2008) was used to estimate the temperature and oxygen fugacity $\left(f \mathrm{O}_{2}\right)$ of Healy samples, along with sample D33_PC04 and the Sandy Bay pumice, which were the only other samples where both magnetite and ilmenite are present. Only coexisting Fe-Ti oxide pairs (either shared a common boundary or occurred together in the same phenocryst) were used to ensure textural equilibrium (Blundy and Cashman, 2008). Fe-Ti pairs were also tested for equilibrium using the $\mathrm{Mg} / \mathrm{Mn}$ partioning test from Bacon and Hirschmann (1988). Temperature and $f_{2} \mathrm{O}_{2}$ estimates from Fe-Ti two-oxide pairs are presented in Figure 4.34A. Healy samples show two groups, with a low-temperature high- $f \mathrm{O}_{2}$ group tightly clustered between 840 to $860^{\circ} \mathrm{C}$ and $\mathrm{NNO}+1.0$ to $\mathrm{NNO}+1.1$, and a high-temperature low- $f \mathrm{O}_{2}$ group scattered between 840 to $920^{\circ} \mathrm{C}$ and $\mathrm{NNO}+0.7$ to $\mathrm{NNO}+0.95$. The high- $f \mathrm{O}_{2}$ group is comprised mainly of oxide pairs from samples D38_PC06 and D44_PC02. The low- $f \mathrm{O}_{2}$ group is mainly oxide pairs from sample D47_PC02, with a single pair from sample D39_PC05. Macauley samples plot into distinct clusters by sample, with sample D33_PC04 between 920 to $<940^{\circ} \mathrm{C}$ and NNO +0.05 to NNO +0.15 , and the Sandy Bay sample ranging from 940 to $970^{\circ} \mathrm{C}$ and NNO -0.20 to NNO +0.05 . Temperature estimates using the titanomagnetite-ilmenite thermometer of Sauerzapf et al. (2008) yields values which are on average $10-30^{\circ} \mathrm{C}$ lower than those calculated from the Ghiorso and Evans (2008) thermometer. Lower temperature estimates on the Sandy Bay Tephra of 870 to $960^{\circ} \mathrm{C}$ were also reported by Smith et al. (2003a) using the thermometer of Ghiorso and Sack (1991). The thermometer of Ghiorso and Evans (2008) has been used in this study, however, as it has been proven 

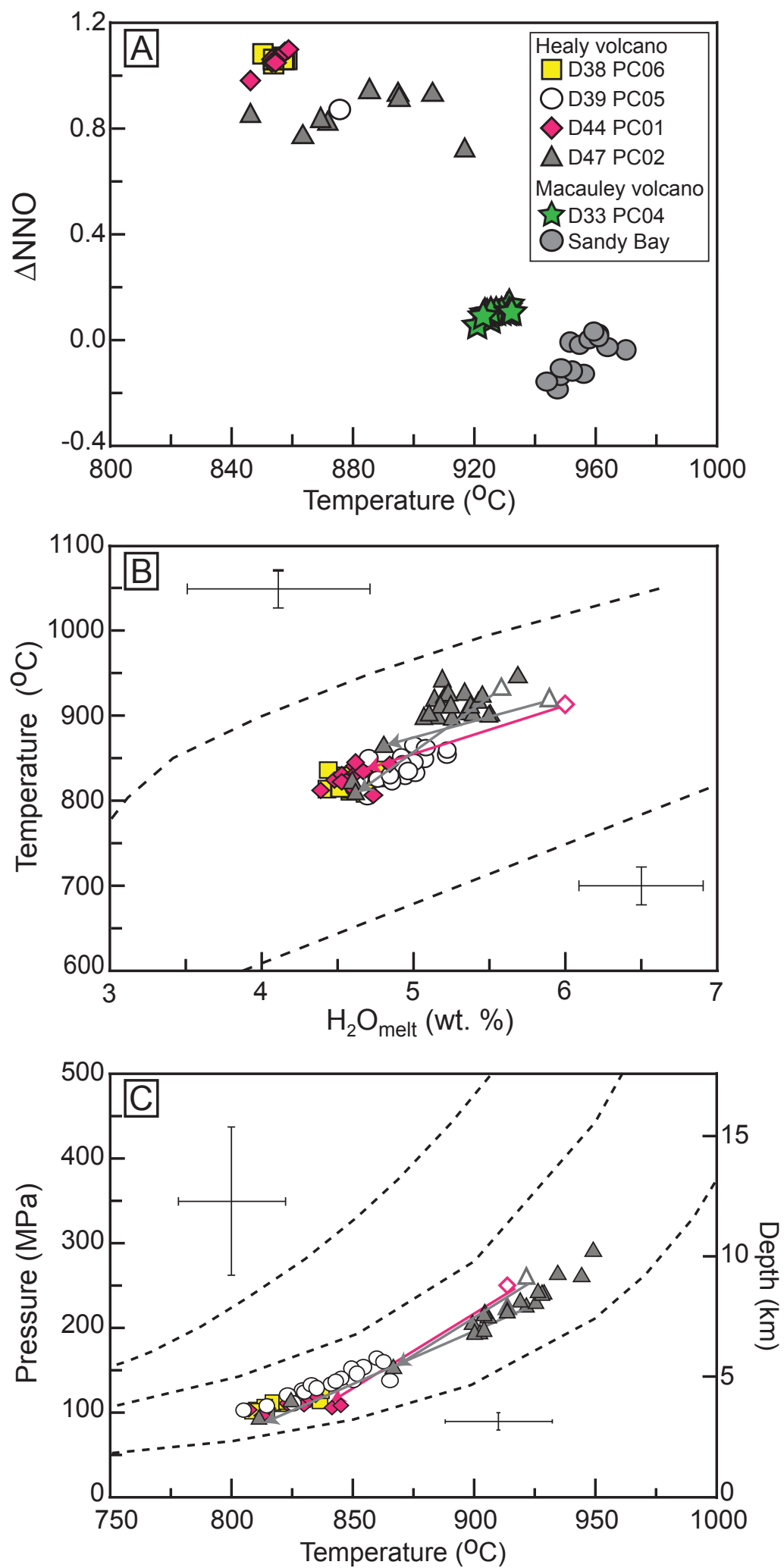

Figure 4.34. Intensive parameters calculated for selected samples from Macauley and Healy volcanoes. A) Temperature and $f \mathrm{O}_{2}$ (plotted as $\log _{10} f \mathrm{O}_{2}$ relative to the nickel-nickel oxide oxygen buffer value from O'Neill and Pownceby, 1993) estimates from Healy and two samples from Macauley, calculated from matched pairs of magnetite and ilmenite using $\mathrm{Fe}-\mathrm{Ti}$ exchange based thermometer of Ghiorso and Evans (2008). B) Temperature and water content estimates based on amphibole compositions using the thermometer/hydrometer of Ridolfi et al. (2010). Strongly zoned core-rim analyses from the same amphibole crystal are joined by tie lines with cores represented by open symbols. Error bars represent $2 \sigma$, calculated as the maximum uncertainty with changing amphibole composition as provide by Ridolfi et al. (2010). Symbols as in A. C) Temperature and pressure estimates based on amphibole compositions using the thermometer/barometer of Ridolfi et al. (2010). Relative depth is calculated for oceanic crust, assuming a density of $2890 \mathrm{~kg} / \mathrm{m}^{3}$, and not accounting for the overlying water column. Symbols, tie lines and error bars as in $\mathrm{B}$. 
by experimental comparisons with other methods (Blundy and Cashman, 2008) to produce relatively accurate estimates over a wide range of temperatures.

\subsubsection{Amphibole thermobarometry and hygrometry}

Amphibole is only present as a mineral phase in the pumice samples from Healy volcano (see section 4.2). Using the spreadsheet provided in Ridolfi et al. (2010), the composition of amphibole has been used to estimate the temperature, pressure and water content of the Healy magma(s) prior to eruption. Compared to other amphibole based barometers (e.g. Hammarstrom and Zen, 1986; Johnson and Rutherford, 1989; Anderson and Smith, 1995), which require additional mineral phases not present in the Healy samples, the formulations of Ridolfi et al. (2010) works independently, and is solely based on different compositional components in amphibole. Temperature estimates from these formulations correlate well with the temperature estimates from Fe-Ti oxide thermometry, but cover a wider range of temperatures from ca. 800 to 950 ${ }^{\circ} \mathrm{C}$ (Figure 4.34B,C). Consistent with two-oxide thermometry and the trends in crystal composition (section 4.2), amphibole data forms two distinct clusters. The first cluster is comprised of amphiboles from sample D38_PC06, D39_PC05 and D44_PC02 with a few outlier analyses from sample D47_PC02 between 800 to $870^{\circ} \mathrm{C}, 4.4$ to 5.3 wt. \% $\mathrm{H}_{2} \mathrm{O}$ and ca. 100 to $160 \mathrm{MPa}$. The second cluster is dominated by amphibole analyses from sample D47_PC02 at significantly higher values between 900 to $950{ }^{\circ} \mathrm{C}, 5$ to $6 \mathrm{wt}$. $\% \mathrm{H}_{2} 0$ and ca. 190 to $290 \mathrm{MPa}$. For the first cluster, the range of estimates for pressures and water contents using the methods of Ridolfi et al. (2010) are consistent with the range of values obtained through melt inclusion studies on Healy pumices by Saunders et al. (2010) (3-5 wt. \% $\mathrm{H}_{2} \mathrm{O}_{\mathrm{t}}$ and 2-5 km depth).

Although most of the amphibole crystals do not show strong compositional zonation (see section 4.2) and the majority of analyses used for thermometry are from the rims of unzoned crystals, a few strongly zoned crystal core-rim pairs are shown on Figures $4.34 \mathrm{~B}$ and $\mathrm{C}$. Cores analyses from these crystals correspond to higher temperature, water contents and pressures. The large difference in temperature/pressure estimates between compositional zones within individual crystals suggests that the magmatic system below Healy may be thermally and/or compositionally stratified. This is supported by the complex zonation commonly observed in plagioclase crystals from Healy (see section 4.2). 


\subsubsection{Mineral-liquid and two-pyroxene equilibrium and thermometry calculations}

The mineral assemblages of Raoul and Macauley samples do not contain amphibole, and magnetite-ilmenite pairs are present only in the Sandy Bay pumice and dredged sample D33_PC04 from Macauley. Other thermometers/barometers that are appropriate for the mineral assemblages present in these samples are based on mineral-mineral equilibrium or mineral-liquid equilibrium (Purtirka, 2008). Previous studies on the mineralogy of Raoul Island rocks have suggested that the majority of crystals in both basaltic and dacitic rocks were far from equilibrium with the host melt (Worthington, 1998; Smith et al., 2006; 2010). These studies found that only the groundmass rims of crystals were in equilibrium with the host melt. Multiple crystal populations and strong compositional zoning have been identified in all Raoul dacite pumice samples analysed in this study. Multiple crystal populations, with a wide range of compositions, have also been identified in samples from Macauley and Healy volcanoes (see section 4.2). Selected crystal and melt compositions were tested under the equilibrium criteria outlined in Putirka (2008) to assess which plagioclase, clinopyroxene and orthopyroxene crystals were in equilibrium with their host glass, and therefore suitable for mineral-liquid thermometry. Clinopyroxene and orthopyroxene pairs were also tested for equilibrium using the criteria outlined in Putirka (2008) to determine if twopyroxene thermometry could be used.

Temperature calculations from four different methods of thermometry are presented in Table 4.02. These temperature are considered to be first order estimates as the uncertainties associated with these thermometers are estimated to be at least $\pm 30^{\circ} \mathrm{C}$ (Putirka, 2008), but could be even higher considering that the thermometers are sensitive to other parameters such as pressure and water contents. All thermometry methods presented are largely pressure dependent, a parameter which has been determined for Healy magmas (Figure 4.34), but not for Raoul or Macauley volcanoes. Although many of the methods used for thermometry also serve as a barometer through numerical solution methods (where temperature and pressure are solved simultaneously), pressures calculated from these methods often have large associated errors (Putirka, 2008), and give results that are not realistic for the magmatic systems beneath Kermadec volcanoes (e.g. 1-2 GPa). Pressures were able to be calculated for Healy using amphibole barometry, therefore the average calculated pressure value of $150 \mathrm{MPa}$ has been applied for equilibrium-based thermometers. In the absence of 
Table 4.02. Calculated temperatures $\left({ }^{\circ} \mathrm{C}\right)$ for Kermadec silicic magmas using a range of thermometers

\begin{tabular}{|c|c|c|c|c|c|c|c|c|c|c|c|c|c|c|c|}
\hline \multirow[b]{2}{*}{ Thermometer } & \multicolumn{5}{|l|}{ Raoul } & \multicolumn{5}{|l|}{ Macauley } & \multicolumn{5}{|l|}{ Healy } \\
\hline & eruption & average & range & $\sigma$ & $n$ & sample & average & range & $\sigma$ & $n$ & sample & average & range & $\sigma$ & $n$ \\
\hline \multirow{5}{*}{$\begin{array}{l}2 \text { pyroxene } \\
\text { (Brey and Kohler, 1990) }\end{array}$} & Matatirohia & 922 & $886-974$ & 24 & 18 & D25 PC01 & 948 & $910-989$ & 23 & 17 & D38 PC06 & $x$ & $x$ & $x$ & $x$ \\
\hline & Oneraki & 950 & $920-984$ & 21 & 16 & D29 PC02 & 895 & $861-926$ & 26 & 5 & D39 PC05 & 962 & $957-967$ & 5 & 3 \\
\hline & Fleetwood & 931 & $899-980$ & 19 & 14 & D33 PC02 & 921 & $909-935$ & 10 & 5 & D44 PC01 & $x$ & $x$ & $x$ & $x$ \\
\hline & Green Lake & 934 & $898-977$ & 29 & 9 & D33 PC04 & 890 & $880-899$ & 7 & 5 & D47 PC02 & $x$ & $x$ & $x$ & $x$ \\
\hline & Rangitahua & 955 & 926-995 & 25 & 13 & Sandy Bay & 912 & $888-941$ & 19 & 11 & & & & & \\
\hline \multirow{5}{*}{$\begin{array}{l}2 \text { pyroxene } \\
\text { (Putirka, 2008) }\end{array}$} & Matatirohia & 934 & $905-978$ & 18 & 18 & D25 PC01 & 946 & $919-978$ & 18 & 17 & D38 PC06 & $x$ & $x$ & $x$ & $x$ \\
\hline & Oneraki & 967 & $934-1013$ & 23 & 16 & D29 PC02 & 904 & $885-919$ & 13 & 5 & D39 PC05 & 938 & $935-942$ & 5 & 3 \\
\hline & Fleetwood & 951 & $938-971$ & 10 & 14 & D33 PC02 & 927 & $921-936$ & 8 & 5 & D44 PC01 & $x$ & $x$ & $x$ & $x$ \\
\hline & Green Lake & 937 & $901-988$ & 33 & 9 & D33 PC04 & 868 & $865-872$ & 4 & 5 & D47 PC02 & $x$ & $x$ & $x$ & $x$ \\
\hline & Rangitahua & 998 & $930-1032$ & 28 & 13 & Sandy Bay & 916 & 904-933 & 11 & 11 & & & & & \\
\hline \multirow{5}{*}{$\begin{array}{l}\text { Clinopyroxene-liquid } \\
\text { (Putirka, 2003) }\end{array}$} & Matatirohia & 1016 & $1007-1029$ & 7 & 6 & D25 PC01 & 991 & $987-993$ & 2 & 7 & D38 PC06 & $x$ & $x$ & $x$ & $x$ \\
\hline & Oneraki & 1028 & $1016-1043$ & 8 & 10 & D29 PC02 & $x$ & $x$ & $x$ & $x$ & D39 PC05 & $x$ & $x$ & $x$ & $x$ \\
\hline & Fleetwood & 982 & $965-1009$ & 15 & 8 & D33 PC02 & 979 & $968-980$ & 6 & 10 & D44 PC01 & $x$ & $x$ & $x$ & $x$ \\
\hline & Green Lake & 1001 & $995-1009$ & 5 & 8 & D33 PC04 & 956 & $943-966$ & 8 & 10 & D47 PC02 & $x$ & $x$ & $x$ & $x$ \\
\hline & Rangitahua & $x$ & $x$ & $x$ & $x$ & Sandy Bay & 936 & $925-945$ & 7 & 6 & & & & & \\
\hline \multirow{5}{*}{$\begin{array}{l}\text { Orthopyroxene-liquid } \\
\text { (Putirka, 2008) }\end{array}$} & Matatirohia & 980 & $968-992$ & 7 & 30 & D25 PC01 & 1011 & $995-1018$ & 8 & 6 & D38 PC06 & $x$ & $x$ & $x$ & $x$ \\
\hline & Oneraki & 997 & $991-1004$ & 3 & 32 & D29 PC02 & $x$ & $x$ & $x$ & $x$ & D39 PC05 & 932 & $926-938$ & 4 & 6 \\
\hline & Fleetwood & 997 & $988-1000$ & 3 & 21 & D33 PC02 & 990 & 984-993 & 2 & 10 & D44 PC01 & $x$ & $x$ & $x$ & $x$ \\
\hline & Green Lake & 982 & $967-991$ & 5 & 29 & D33 PC04 & 944 & $930-960$ & 8 & 25 & D47 PC02 & 943 & $941-947$ & 3 & 5 \\
\hline & Rangitahua & $x$ & $x$ & $x$ & $x$ & Sandy Bay & 955 & $940-964$ & 7 & 17 & & & & & \\
\hline \multirow{5}{*}{$\begin{array}{l}\text { Plagioclase-liquid } \\
\text { (Putirka, 2008) }\end{array}$} & Matatirohia & 995 & $993-998$ & 2 & 15 & D25 PC01 & 968 & $963-970$ & 2 & 17 & D38 PC06 & 855 & $849-859$ & 3 & 22 \\
\hline & Oneraki & 1003 & $999-1005$ & 1 & 18 & D29 PC02 & 895 & 890-899 & 3 & 6 & D39 PC05 & 873 & $859-876$ & 4 & 15 \\
\hline & Fleetwood & 1008 & $1005-1010$ & 2 & 3 & D33 PC02 & 968 & $963-971$ & 3 & 6 & D44 PC01 & 856 & $846-861$ & 4 & 22 \\
\hline & Green Lake & 994 & $991-996$ & 2 & 10 & D33 PC04 & 956 & $951-961$ & 3 & 23 & D47 PC02 & 872 & $861-879$ & 6 & 7 \\
\hline & Rangitahua & 993 & 983-996 & 4 & 7 & Sandy Bay & 945 & $939-948$ & 3 & 23 & & & & & \\
\hline
\end{tabular}

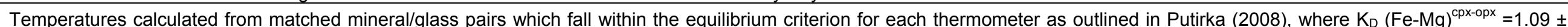

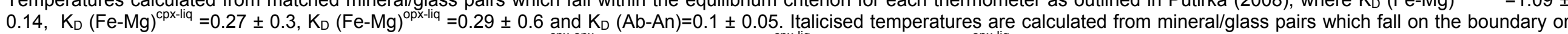

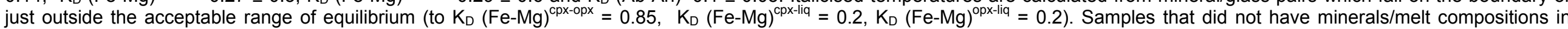

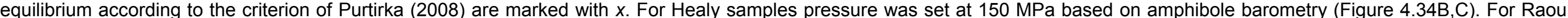

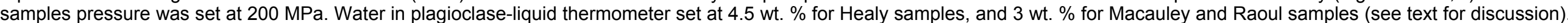
$\sigma$ is one standard deviation, $n$ is the number of mineral-mineral or mineral-glass pairs. Uncertainties from Putirka $(2003,2008)$ are estimated to be at least $\pm 30^{\circ} \mathrm{C}$. 
amphibole or melt inclusion data for Macauley and Raoul volcanoes, a conservative estimate of $200 \mathrm{MPa}$ based on the upper pressure limit calculated from Healy amphibole barometry has been used as a first order approximation. Variations in pressure input into thermometry calculations generally only vary temperature calculations by $<5-10{ }^{\circ} \mathrm{C}$ per $100 \mathrm{MPa}$ (Table 4.03), so uncertainties arising from pressure estimation is considered to be minimal when compared to the errors for each method outlined in Purtirka (2008) (minimum of $\pm 30^{\circ} \mathrm{C}$ ). Plagioclase thermometry and equilibrium calculations are also largely dependent of $\mathrm{H}_{2} \mathrm{O}$ (Putirka, 2008). Based on amphibole hygrometry carried out in this study, and melt inclusion work carried out by Saunders et al. (2010), a water content of $4.5 \mathrm{wt}$ \% \% has been used for the Healy plagioclase-liquid thermometry.

The water content of the Raoul and Macauley magmas are largely unknown without melt inclusion work. Variations in magma water contents strongly affect the temperature calculations of plagioclase-liquid thermometry (Putirka, 2008; Table 4.03). A value of 3 wt. $\% \mathrm{H}_{2} \mathrm{O}$ has been used in plagioclase-liquid calculations for Raoul and Macauley, based on water-by-difference microprobe glass totals. It must be considered that this value is only a rough estimate, and small variations in water contents (as outlined in Table 4.03) could drastically change the temperature calculations using this method. Table 4.02 also shows which mineral phases were in equilibrium, as only mineral-mineral or mineral-liquid pairs which meet the equilibrium criteria of Putirka

Table 4.03. Variations in thermometry calculations with changing pressure / water inputs

\begin{tabular}{|c|c|c|c|}
\hline Thermometer & Input & average $\left({ }^{\circ} \mathrm{C}\right)$ & range \\
\hline \multirow[t]{3}{*}{ 2-pyroxene, Brey and Kohler (1990) } & pressure: $100 \mathrm{MPa}$ & 947 & $917-981$ \\
\hline & pressure: $200 \mathrm{MPa}$ & 950 & $920-984$ \\
\hline & pressure: $500 \mathrm{MPa}$ & 960 & $930-994$ \\
\hline \multirow[t]{3}{*}{ Clinopyroxene-liquid, Putirka (2003) } & pressure: $100 \mathrm{MPa}$ & 1027 & 1016-1042 \\
\hline & pressure: $200 \mathrm{MPa}$ & 1029 & $1017-1043$ \\
\hline & pressure: $500 \mathrm{MPa}$ & 1032 & $1020-1047$ \\
\hline \multirow[t]{3}{*}{ Orthopyroxene-liquid, Putirka (2008) } & pressure: $100 \mathrm{MPa}$ & 994 & $988-1000$ \\
\hline & pressure: $200 \mathrm{MPa}$ & 997 & $992-1004$ \\
\hline & pressure: $500 \mathrm{MPa}$ & 1007 & $1001-1014$ \\
\hline \multirow[t]{6}{*}{ Plagioclase-liquid, Putirka (2008) } & pressure: $100 \mathrm{MPa}, \mathrm{H}_{2} \mathrm{O}: 3$ wt. $\%$ & 998 & $994-999$ \\
\hline & pressure: $200 \mathrm{MPa}, \mathrm{H}_{2} \mathrm{O}: 3$ wt. $\%$ & 1003 & $999-1005$ \\
\hline & pressure: $500 \mathrm{MPa}, \mathrm{H}_{2} \mathrm{O}: 3$ wt. $\%$ & 1020 & $1016-1021$ \\
\hline & pressure: $200 \mathrm{MPa}, \mathrm{H}_{2} \mathrm{O}: 2$ wt. $\%$ & 1033 & $1029-1035$ \\
\hline & pressure: $200 \mathrm{MPa}, \mathrm{H}_{2} \mathrm{O}: 4$ wt. $\%$ & 974 & $971-976$ \\
\hline & pressure: $200 \mathrm{MPa}, \mathrm{H}_{2} \mathrm{O}: 5$ wt. $\%$ & 947 & $943-948$ \\
\hline
\end{tabular}


(2008) are marked with temperature estimates. Equilibrium equations for two pyroxene and pyroxene-melt pairs are based on Fe-Mg exchange coefficients, and plagioclasemelt equilibrium is calculated by comparing An-Ab exchange (Putirka, 2008).

Consistent with previous studies on the mineralogy of Raoul dacites (Worthington, 1998; Smith et al., 2006, 2010), many of the crystals identified in Raoul pumice samples are far from equilibrium with their host glass. However, multiple crystal populations were found within pumice samples, not only large mafic crystals high $\mathrm{Mg}$ and $\mathrm{Ca}$ ) with thin strongly zoned rims (see section 4.2). Many of these crystals (not just groundmass rims) are in fact in equilibrium with the host glass according to the equilibrium criteria of Putirka (2008), and have therefore been used for thermometry (Table 4.02). In four out of five eruptive deposits, the most Fe-rich unzoned clinopyroxene and high Fe rims on strongly zoned clinopyroxene (Figure 4.07A) are in equilibrium with their host melt. The majority of orthopyroxene crystals also fall within the equilibrium criterion. Only the Rangitahua sample lacks clinopyroxene or orthopyroxene crystals in equilibrium with host glass compositions, most likely due to late stage microlite growth. In all five eruptions however, there are clinopyroxene and orthopyroxene pairs that are in equilibrium. Average temperatures calculated from twopyroxene pairs range between the five eruptions from 922 to $955^{\circ} \mathrm{C}$ using the thermometer of Brey and Kohler (1990), and 934 to $998^{\circ} \mathrm{C}$ using the thermometer of Putirka (2008). By contrast, the orthopyroxene-liquid thermometer of Putrika (2008) gives higher average temperatures ranging from $980-997^{\circ} \mathrm{C}$, and the clinopyroxeneliquid thermometer of Putirka (2003) gives even higher average temperatures from 982$1028^{\circ} \mathrm{C}$. Although the plagioclase-liquid thermometer is sensitive to input parameters which are largely unknown for Raoul, it has been used here to compare with the other thermometers and to show which eruption units have plagioclase that is in equilibrium with the host melt according to An-Ab exchange (Putirka, 2008). Consistent with the findings of Smith et al. (2010), the only plagioclase that is in equilibrium with the host glass are the rims of some strongly zoned plagioclase and small groundmass plagioclase crystals that plot at ca. $\mathrm{An}_{60}$ on compositional histograms (Figure 4.07B). Temperature estimates from plagioclase-liquid thermometry at a pressure of $200 \mathrm{MPa}$ and water content of $3 \mathrm{wt} . \%$ are similar to the relatively high estimates of clinopyroxene-liquid thermometry, although as demonstrated in Table 4.03, any variations in water content can significantly change this temperature estimate.

Mineral-glass and 2-pyroxene thermometry from the five Macauley samples yields slightly lower temperature ranges than estimated in Raoul dacites (Table 4.02). 
Only Fe-rich type clinopyroxene crystals in sample D33_PC04 and the Sandy Bay pumice are in equilibrium with their host glass. Clinopyroxene crystals in samples D25_PC01 and D33_PC02 are slightly below the recommended Fe-Mg exchange coefficient where $\mathrm{K}_{\mathrm{D}}(\mathrm{Fe}-\mathrm{Mg})^{\mathrm{cpx}-\mathrm{liq}}=0.27 \pm 0.3$ (Putirka, 2008), and clinopyroxene crystals from sample D29_PC02 are considerably below this value. The same pattern is observed in orthopyroxene-liquid equilibrium, although a few orthopyroxene crystals from sample D33_PC02 are in equilibrium with the host glass. All samples have clinopyroxene-orthopyroxene pairs that are either within the equilibrium criterion or slightly below it. Two-pyroxene thermometry gives the lowest temperature estimates, ranging from 890 to $948^{\circ} \mathrm{C}$ using the thermometer of Brey and Kohler (1990), and 868 to $946^{\circ} \mathrm{C}$ using the thermometer of Putirka (2008). As observed in Raoul samples, the clinopyroxene-liquid and orthopyroxene-liquid methods give higher temperature estimates, although the temperature calculations from sample D33_CP04 and the Sandy Bay pumice are closer to the temperatures calculated using two-oxide thermometry. Although the pressure and water content inputs into the plagioclase-liquid thermometer are not well constrained, the temperature values obtained using these conditions are in good agreement with other methods, including two-oxide thermometry.

Two-pyroxene and pyroxene-liquid thermometers could not be determined for Healy samples as clinopyroxene and orthopyroxene were not in equilibrium with oneanother or their high silica host glasses. Only a few clinopyroxene-orthopyroxene pairs and orthopyroxene-melt pairs were close to the Fe-Mg exchange coefficient, and estimated temperatures of $>930^{\circ} \mathrm{C}$. As pressure and water content could be estimated using amphibole barometry/hygrometry, plagioclase-liquid thermometry is reasonably well constrained. Temperature estimates generated from plagioclase crystals in equilibrium with the host melt range between 855 and $873^{\circ} \mathrm{C}$. These values are consistent with the temperature values estimated from both two-oxide and amphibole thermometry (Figure 4.34), suggesting that plagioclase-liquid thermometry can give good temperature estimates for the Kermadec magmas when pressure and water contents are reasonably constrained. 
CHAPTER 5:

Discussion 
The primary aim of this study has been to investigate how silicic magmas are generated, stored, and erupted from four volcanoes along the intra-oceanic Kermadec arc. Many recent studies on intra-oceanic arcs globally have tended to discount fractional crystallisation as the dominant process for generating silicic magmas in such settings, instead arguing that they are formed by crustal anatexis (e.g. Kermadec arc: Smith et al., 2003a,b, 2006, 2010. Izu Bonin arc: Tamura and Tatsumi, 2002; Shukuno et al., 2006; Tamura et al., 2009. South Sandwich arc: Leat et al., 2003, 2007). This study reassesses the dominant magmatic processes which occur to generate silicic magmas in the Kermadec arc using several approaches, each of which provides different perspectives. The discussion which follows is therefore in four sections. First, crystal specific evidence is used to demonstrate the complex range of processes which operate in Kermadec magmatic systems. Second, the potential mechanisms for generating silicic magmas in the Kermadec arc are discussed in the light of the new lines of evidence provided by this study. Third, implications of these findings for both the Kermadec volcanoes and global intra-oceanic arcs are addressed. Fourth, the large-scale variations in chemistry along the length of the Kermadec arc are examined.

\subsection{Magmatic conditions: clues from the crystals}

Mineral chemistry indicates that the majority of pumice samples analysed from Raoul, Macauley and Healy volcanoes contain multiple crystal populations, many of which show evidence for a complex growth history (Chapter 4). Crystal specific work provides important clues about several processes in the Kermadec magmatic systems that would otherwise be missed by whole rock 'bulk' chemistry.

\subsubsection{Origins of the observed crystal assemblages}

Equilibrium calculations have shown that some of the crystals observed in pumice samples are in equilibrium with their host glasses. However, most show disequilibrium, with compositions that have high $\mathrm{Mg}$ and $\mathrm{Ca}$ concentrations and less-evolved trace element chemistry. Many crystals also show strong compositional zoning, indicating that they have been in magma(s) of strongly contrasting composition. In addition, altered and mottled hydrothermally altered crystals of low-An plagioclase and quartz are found in some pumices from Raoul. It is inferred that magma mixing and/or assimilation play an important role in the Kermadec magmatic systems, physically 
evident as mafic blebs and xenocrysts which occur in many of the Kermadec pumice samples. Two major questions arise from these findings:

1) What are the sources of the different crystal populations that have been identified?

2) What is their genetic, spatial and temporal affiliation with the silicic magmas?

In order to address these questions, the different populations of crystals identified in pumice samples are compared with the co-eruptive plutonic xenoliths that were found on Raoul and Macauley Islands (see Chapters 2 and 4 for sampling details). Three main xenolith types were identified from Raoul volcano: cumulate gabbros, cauliform mafic blebs and tonalites. The chemical and textural similarities between crystals in the gabbros and blebs imply that they share a common origin (Figure 4.09). The main differences in size, crystal contents and compositional zoning between the mafic xenolith types is interpreted to reflect how disaggregated the crystals are, or how much melt each individual fragment has interacted with. This is also consistent with the textures observed in single blebs, which range from almost wholly crystalline to scattered large crystals in a dark grey, vesiculated, microcrystalline matrix (Figure 4.08E-H). Major element compositions of clinopyroxene, olivine and plagioclase from both the gabbros and the single bleb large enough to be analysed correspond closely with compositions of Mg-rich clinopyroxene, high-An plagioclase and olivine analysed from both smaller mafic blebs as well as individual crystals identified in felsic pumices (Figure 4.07 and 4.09). Plagioclase composition and zoning from the tonalite xenoliths also closely matches that of the low-An population of plagioclase found in both the Oneraki and Green Lake Pumice. Major element chemistry of crystals in the single gabbroic block from the Sandy Bay eruption deposit strongly correlates with individual mafic crystals found within the Sandy Bay pumice, also suggesting they share a common genesis (Figure 4.11).

Given the close similarities between crystal populations in the plutonic xenoliths to those within individual pumice samples, it is inferred that the former are derived from host rocks to the young felsic magma bodies below Raoul and Macauley volcanoes. The close spatial proximity of the plutonic bodies to the silicic magmas resulted in magma mixing and/or assimilation, with the plutonic bodies representing either solid country rock or partially molten cumulates. The degree of assimilation and/or mixing with the mafic source varies considerably, with some xenolithic material represented only by 
single crystals with adhering silicic pumice glass, and other xenoliths represented by large centimetre sized blebs, or loose coherent blocks of plutonic material. The large size $(1-5 \mathrm{~mm})$ and euhedral appearance of many isolated crystals within felsic pumice is further suggestive of a plutonic origin. Although plutonic fragments were not found in the Macauley or Healy submarine sample suites, their pumices also contain large mafic crystals and mafic blebs, suggesting that similar processes operated in their magmatic systems.

The amount or type of material involved in magma mixing/assimilation also varies widely between samples (although overall contents of crystals or blebs in felsic pumices are always below 3-5 vol. \%). This is expressed by the variation in crystal populations between individual pumices (Figures 4.07, 4.14 and 4.17), and also identified by the differences between glass chemistry and whole rock 'bulk' chemistry (section 4.4). For Raoul volcano, relative changes in the proportions of these crystal populations can be observed between eruptions (Figure 4.07). For the Matatirohia and Fleetwood deposits, mafic blebs are relatively common and the pumice crystal assemblage consists of large amounts of $\mathrm{Mg}$-rich clinopyroxene and high-An plagioclase, with lesser amounts of large olivine crystals (Figure 4.07). In contrast, other deposits from Raoul caldera (Oneraki, Green Lake Pumice and Rangitahua) have fewer mafic sourced crystals (and lack olivine), and the Oneraki and Green Lake Pumice samples have an additional population of low-An plagioclase and quartz (Figure 4.07B) inferred to be derived from altered tonalite. At Macauley, the amount of mixing also varies considerably. At one extreme, sample D33_PC04 contains cm-sized crystals of Mg-rich clinopyroxene and has glass compositions that are considerably higher in $\mathrm{SiO}_{2}$ than its whole rock composition. In contrast, sample D29_PC02 has no mafic crystals, and is inferred to represent an uncontaminated evolved end-member. For Healy, samples are divided into two types, where samples D38_PC06 and D44_PC02 have abundant mafic crystals and mafic blebs (Figure 4.17), and samples D39_PC05 and D47_PC02 have very few mafic crystals and no mafic blebs.

Temporal relationships between the source of the mafic crystals and the host silicic magmas are difficult to interpret, as there is no constraining stratigraphy for dredge samples, and the crystal chemistry of basaltic lavas from Macauley and Raoul Island has not been investigated in this thesis. Crystal chemistry has been reported, however, by Smith et al. (2003a, 2006) on Macauley and Raoul basalts, respectively. Although analyses by Smith et al. used EDS microprobe methods (vs. WDS analysis used in this study), plagioclase, clinopyroxene and olivine from the basaltic lavas 
generally overlap in major element composition with the composition of mafic minerals analysed in pumice samples in this study. The bulk compositions of two Matatirohia mafic blebs analysed in this study are compared with published data for these basaltic lavas (Figure 5.01). The blebs plot within the low-Fe and low-Ti porphyritic suite of basaltic samples identified by Smith et al. (2010), strongly suggesting they have a similar origin. This compositional field also includes samples from the Moumoukai lavas, erupted between 4 and $10 \mathrm{ka}$, which immediately pre-date the Ngaio Group dacites (Table 2.01). These similarities, however, are only based on broad compositional ranges, and cannot place any absolute temporal constraints on the origin of the mafic crystals. The possible genetic relationship between the older basalt units and silicic pumice samples is further considered in section 5.2.

A temporal relationship can be estimated for the tonalite source, which has been assimilated into the Oneraki and Green Lake Pumice units from Raoul volcano. A recent study by Mortimer et al. (2010) reported a U-Pb age (by LA-ICP-MS) of 1.25 $\pm 0.06 \mathrm{Ma}$ for zircons from a single tonalite fragment (P72715) collected from lithic breccias in the Matatirohia deposits, which is petrographically identical to the tonalite xenolith investigated in this study (PETLAB database: http://pet.gns.cri.nz/). If they share the same origin, this suggests that even though crystal chemistry indicates that tonalite was in close spatial proximity to the Ngaio group dacite magma chamber, it is considerably older. These findings also indicate that silicic magmatism has occurred previously on Raoul, and is therefore not necessarily confined to the recent magmatic system (cf. Smith et al., 2003b). The whole-rock REE chemistry of the tonalite analysed in this study is sub-parallel to the patterns obtained for the dacite pumice units (Figure $4.24 \mathrm{~A}$ ), but with a more pronounced Eu-anomaly, reflecting greater plagioclase fractionation. From these sub-parallel REE patterns it is suggested that the tonalite represents a wholly crystallised plutonic equivalent to an earlier episode of felsic magmatism (and volcanism?). As the tonalite has undergone high temperature (epidote, actinolite) hydrothermal alteration, the host plutonic body must be sourced from a region from within the hydrothermal envelope of Raoul Island. Assimilation of tonalite minerals into the dacite magma indicate that interaction must have occurred close to the magmatic-hydrothermal interface, which could be as shallow as $2 \mathrm{~km}$ for Raoul (Graaf, 2006). 

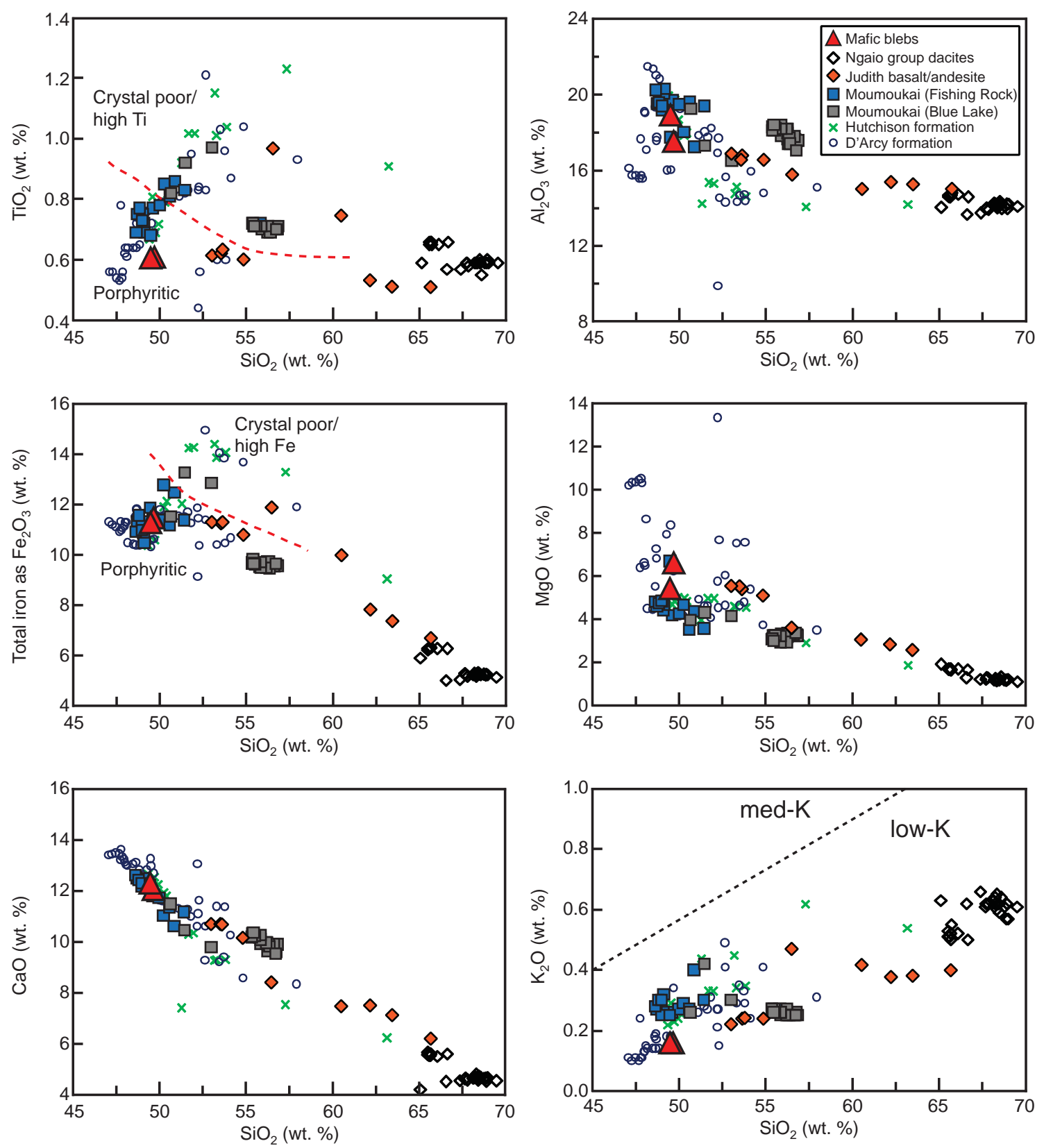

Figure 5.01. Major element composition of mafic blebs from the Matatirohia deposit analysed for this study compared to published data for Raoul (Smith et al., 2006, 2010). Filled small symbols represent the youngest basaltic/basaltic andesite material erupted from Raoul. The Moumoukai lavas have an estimated age of 4-10 ka (Lloyd and Nathan, 1981), and the Judith eruption is inferred to be part of the Ngaio group, with an estimated age of 1.85 ka (Lloyd and Nathan, 1981). Large filled triangles represent two whole mafic blebs analysed in this study. Open symbols are older basaltic and basaltic-andesite units, along with more silicic units from the Ngaio group eruptions. A complete list of inferred ages and stratigraphy is shown in Table 2.01. Low and med-K discriminant boundary on the $\mathrm{K}_{2} \mathrm{O}$ vs. $\mathrm{SiO}_{2}$ variation diagram from Gill (1981). The dashed red line separating high Fe / high Ti aphyric samples from the low Fe / low Ti porphyritic samples is from Smith et al. (2010). 


\subsubsection{Compositional zoning: diverse magmatic conditions}

Compositional zoning and disequilibrium features (e.g. sieve texture and resorption) occur in many of the crystal populations observed in the Kermadec pumices. As documented in Chapter 4, there are many types of zoning (e.g. normal, reverse, oscillatory), which vary in degree and in compositional range between crystal phases individual samples, and volcanoes. For plagioclase there are two end-member types of zoning, which record either subtle variations in local conditions (e.g. temperature/water content/pressure/ $\mathrm{fO}_{2}$ : Blundy and Wood, 1991; Bindeman et al., 1998; Bindeman and Davis, 2000; Berlo et al., 2007) or extreme variations, likely caused by large differences in melt composition (Bowen, 1913; Johannes and Holtz, 1990; Housh and Luhr, 1991; Putirka, 2005). As a case example, Healy plagioclase compositions range in total from $\mathrm{An}_{30}$ to $\mathrm{An}_{98}$ (Figure 4.17). Within this overall range, at one extreme (e.g. Figure 4.15G) the crystals show distinctive oscillatory zoning, of which there is only ca. 5-10 An mol. $\%$ variation between zones which may be caused by small variations in physical conditions within the magma chamber. At the other extreme (e.g. Figure 4.15F) the difference between zones can be as much 50 An mol. \% (Figure 4.17C). Such large variations can only be caused by a drastic change in the host melt composition, and provides further evidence for magma mixing of two strongly contrasting compositions. Variations in plagioclase compositions from Raoul and Macauley are not as extreme. Only the Sandy Bay pumice and sample D25_PC01 show significant core-to-rim variations of 20-40 An mol. \% (Figure 4.14B), although disequilibrium features such as resorbed cores and sieve textures are common. For Raoul, most normally zoned plagioclase show a decrease of 10-20 An mol. \% in their rims (Figure 4.07B). Raoul anorthite histograms are skewed with three closely spaced modes, supportive of both an evolving magma body and magma mixing from primitive melts (the latter indicated by values $>\mathrm{An}_{90}$ ). As many plagioclase also have oscillatory zoning and/or resorbed cores, it is suggested that there are diverse magmatic conditions (and possibly diverse magmas), as each crystal preserves a complex history.

In contrast to the trends observed for plagioclase, clinopyroxene from Raoul and Macauley show stronger compositional changes between zones than Healy clinopyroxene. Despite the complex tonal zoning typically shown in BSE images for Healy clinopyroxene (e.g. 4.15B), there are only small compositional difference between zones. Rims on Raoul and Macauley clinopyroxene are commonly 3-4 wt. \% (but can be up to 7-8 wt. \%) higher in $\mathrm{FeO}$ than cores, and higher in incompatible trace 
element compositions (Figures 4.26, 4.28) suggesting that the clinopyroxene subsequently crystallised in a more evolved (or evolving) magma. Several clinopyroxene from Raoul and Macauley also have resorbed cores, with high-Mg overgrowths (e.g. Figure 4.27). As these overgrowths have very high values of $\mathrm{Cr}$ and $\mathrm{Ni}$, it is interpreted that they were resorbed in a primitive magma, providing evidence for open system magma recharge events. For some samples (e.g. sample D33_PC04) there is a lack of correlation between plagioclase and clinopyroxene zonation. There is also a relatively large variation in crystal compositions between volcanoes. Such features may be caused by the timing/order of plagioclase crystallisation, which is largely controlled by water content, decompression path, degree of mineral supersaturation, and viscosity of the melt (Hammer and Rutherford, 2002; Brugger and Hammer, 2010).

As individual eruptions can be constrained within eruptive stratigraphy for Raoul volcano, comparisons can be made between zoning in crystal populations over time. One outstanding feature for Raoul samples is the relative change in zoning between different eruptions. Many clinopyroxene crystals have strong compositional zoning, with cores which are Mg-rich 'mafic' type clinopyroxene and Fe-rich rims in equilibrium with the host glass. For the Matatirohia eruption, these rims are generally thin $(<10-20 \mu \mathrm{m}$ : Figure 4.05A). In subsequent eruptions sourced from Raoul caldera (Oneraki and Green Lake Pumice), the Fe-rich rim thickens (30-50 $\mu \mathrm{m}$ in the Oneraki: Figure 4.06D, and up to $100 \mu \mathrm{m}$ in the Green Lake Pumice: Figure 4.05B and 4.28B). This pattern indicates that younger eruptions from Raoul caldera contain crystals with more pronounced evolved overgrowths.

Strongly zoned crystals provide evidence for diverse magmatic conditions in the Kermadec magmatic systems. However, in contrast to strongly zoned crystals, many crystals have compositions that are far from equilibrium with their host glass, but completely lack compositional zoning altogether. This indicates that different crystal populations have gone through different growth histories and have mixed with the silicic magmas at different times. The lack of zoning in olivine crystals is a common feature identified in pumice from Raoul, Macauley and Healy. Despite the fact that they are far from equilibrium with the host pumice glass, only a few olivines show only a thinly zoned rim (e.g. Figure $4.05 \mathrm{H}:<10 \mu \mathrm{m})$. The rest have no observed zoning or reaction rim (Figure 4.06F, 4.11G, and 4.15H). As shown by Coombs and Gardner (2004), reaction rim growth rates on olivines mixed with silicic melt are relatively rapid. For example, in experiments with conditions $\left(885{ }^{\circ} \mathrm{C}, 150 \mathrm{MPa}\right.$ and 4.2 wt. $\left.\% \mathrm{H}_{2} \mathrm{O}\right)$ 
comparable to the Healy magmatic system rim growth rates on olivines in a rhyodacite melt were found to be ca. $1 \pm 0.5 \mu \mathrm{m} / \mathrm{hr}$ (Coombs and Gardner, 2004). This indicates that in many cases in the Kermadec eruptions, magma mixing between the silicic melts and the mafic source for the olivines must have been within hours of, or during, the eruption.

\subsubsection{Calculated equilibrium liquids from mafic xenocrysts}

As demonstrated for Macauley and Raoul, the major element composition of the mafic xenocrysts in blebs strongly correlates with the compositions of crystals analysed from co-eruptive cumulate gabbros. Trace element chemistry provides further constraints on the nature of the mafic sources that have interacted with the silicic magmas beneath the Kermadec volcanoes. Mineral trace element chemistry from clinopyroxene crystals is used here to back-calculate the composition of equilibrium liquids. Knowledge of the melt compositions will help to model any genetic relationships between the mafic sources and silicic magmas (section 5.2, below).

As shown by REE diagrams (Figure 4.25), Raoul, Macauley and Healy have strongly bimodal clinopyroxene compositions, reflecting the contrasting composition of the melts that formed the two main crystal populations. The composition of the mafic liquids have been calculated using the clinopyroxene partition coefficients of McKenzie and O'Nions (1991) for REE in a basaltic liquid (Figure 5.02A-C). Also shown for reference in Figure 5.02A-C are the compositional ranges of the silicic pumices and mafic compositions used for fractional crystallisation modelling (section 5.2). To ensure that mineral compositions reflect their source compositions, only unzoned cores of large crystals have been included in these calculations. For Raoul, the equilibrium melt compositions are LREE-depleted, and generally plot close to the whole-rock composition of the mafic blebs (Figure 5.02A). The calculated REE patterns have a slightly different shape to the mafic bleb and pumice compositions, which is interpreted to reflect both errors in partition coefficients (slightly too high for the LREE) and the larger analytical uncertainties associated with low concentrations of LREE's in the mafic clinopyroxene.

A similar trend occurs in the calculated equilibrium melts from Macauley and Healy clinopyroxene (Figure 5.02B,C), where LREE's are slightly low. Equilibrium liquids for one clinopyroxene from the Sandy Bay Tephra and a single crystal from sample D25_PC01 have similar REE concentrations to the subaerial Macauley basalts 

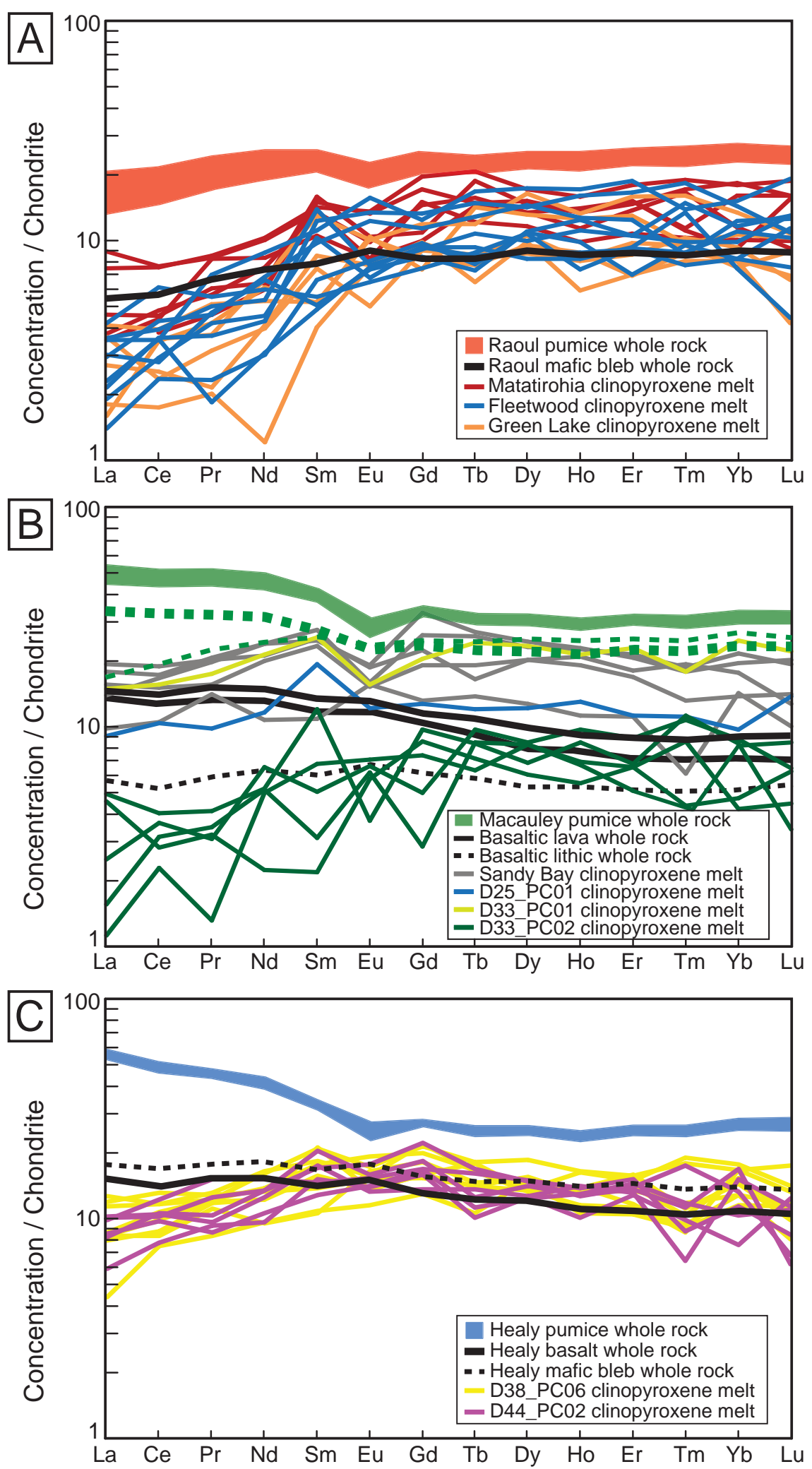

Figure 5.02. Calculated liquid REE concentrations from mafic clinopyroxene xenocrysts compared with whole rock REE compositions. A. Raoul back-calculated equilibrium liquids compared to the composition of the dacite pumices and Matatirohia mafic blebs. B. Macauley back-calculated equilibrium liquids compared to the composition of whole rock pumices and basalts. The thick dashed green line represents three whole rock pumice samples, and the thin dashed green line is a single sample. Basalts are from Smith et al. (2003a). C. Healy back-calculated equilibrium liquids compared to the composition of whole rock pumices, a single mafic bleb and a basalt from I.C. Wright (unpublished data). Clinopyroxene REE partition coefficients are from Mckenzie and O'Nions (1991). Chondrite values from Palme and Beer (1993). 
reported in Smith et al. (2003a). Other equilibrium melts from Sandy Bay and sample D33_PC02 have higher REE concentrations and slight Eu-anomalies, indicating they crystallised in a more evolved melt that has previously crystallised plagioclase (Figure 5.02B). As previously shown for Macauley (Figure 4.23), a single pumice, D33_PC04, is the only sample which is LREE depleted. Back-calculated equilibrium liquids from xenocrystic clinopyroxene in this sample also have a different REE pattern than other Macauley clinopyroxenes, as they are generally lower in REE concentration and strongly LREE depleted, being sub-parallel to the host pumice sample and similar in composition to a basaltic lithic from the Sandy Bay Tephra (Smith et al., 2003a). For Healy, the back-calculated liquids cluster into a narrower group of compositions (Figure $5.02 \mathrm{C}$ ), similar to the composition of a basalt from this volcano analysed by I.C. Wright (unpublished data). For pumice from all three volcanoes, equilibrium liquids inferred from clinopyroxene xenocrysts are closely similar to the composition of previously erupted basalts.

\subsection{Petrogenesis of silicic magma in the Kermadec arc}

The petrogenesis of evolved magmas in oceanic arc settings has received widespread attention, but still remains controversial. Studies of various oceanic arc systems either suggest an origin based on crystal fractionation from a parental magma (e.g. Sisson and Grove 1993; Devine 1995; Pearce et al., 1995; Grove et al., 2003; Sisson et al., 2005; Wade et al., 2005; Saunders et al., 2010) or anatexis of a crustal protolith (e.g. Tamura and Tatsumi, 2002; Leat et al., 2003; Smith et al., 2003a,b, 2006, 2010; Vogel et al., 2004, 2006a; Shukuno et al., 2006; Deering et al., 2007; Tamura et al., 2009). In particular, silicic magmas in the Kermadec arc have been attributed to both of these processes, with fractionation suggested for Brothers and Healy volcanoes in the southern Kermadec arc (Haase et al., 2006; Saunders et al., 2010) and lower crustal anatexis suggested for Raoul and Macauley in the northern Kermadec arc (Smith et al., 2003a,b, 2006, 2010). This section considers all lines of evidence obtained from detailed analyses of both whole rock and mineral/glass chemistry, to reassess the dominant petrogenetic processes responsible for the origin of silicic magmas in the Kermadec arc. 


\subsubsection{The dominant process: fractional crystallisation or crustal anatexis?}

In order to discriminate between fractionation and anatexis, it is important to consider what the key differences would be between the silicic magmas generated by each mechanism. Smith et al. (2003a,b, 2006, 2010) attribute the generation of silicic magmas to lower crustal dehydration melting of amphibolite. In this model, amphibolite forms in the lower oceanic crust once the crust reaches an appropriate thickness $(15 \mathrm{~km})$ and heat flow. Silicic magmas are only formed in a narrow window of time, and due to changing chemical and physical parameters the composition of the melt phase can vary significantly between magma batches (Smith et al. 2003a). If, however, silicic magmas at Raoul and Macauley were generated in this fashion, it could be expected that they would have trace element signatures that differ significantly from those of the basalts from the same volcanoes (Brophy, 2008). The silicic magma chemistry would also be expected to vary between magma batches if there were any significant changes in the degree of melting or other variables. As shown in this study, this is far from the case, as the silicic magmas generally have trace element patterns which do not show large variations between eruption or chemical groups and are sub-parallel to the trace element patterns of basalts erupted from the respective volcano (Figures 4.22 and 4.23). Isotopic compositions also show very little variation between mafic and silicic magmas (Figure 4.24; Smith et al. 2003a, 2006, 2010). On the other hand, sub-parallel trace element patterns between basalts and silicic magmas would be expected if the silicic magma was generated primarily through fractional crystallisation. Not only do previously erupted basalts show sub-parallel REE patterns with Raoul and Macauley dacites, but mafic blebs extracted from within dacite pumices also show closely similar patterns (Figures 4.23A). Furthermore, back-calculated melts from mafic crystals in pumice samples also follow a similar trend (Figure 5.02).

To further assess fractional crystallisation as a potential mechanism, and to test how much crystallisation it would take to generate the observed composition of silicic magmas at Raoul, Macauley and Healy, REE patterns have been modelled by perfect fractional crystallisation (Figure 5.03A-C). As these REE models are very dependent on a suitable starting material, selection of an appropriate parental basalt is critical. The shape of the REE pattern is also dependent on the modal proportions of crystallising phases. An approximation of the crystal proportions has been estimated based on the 

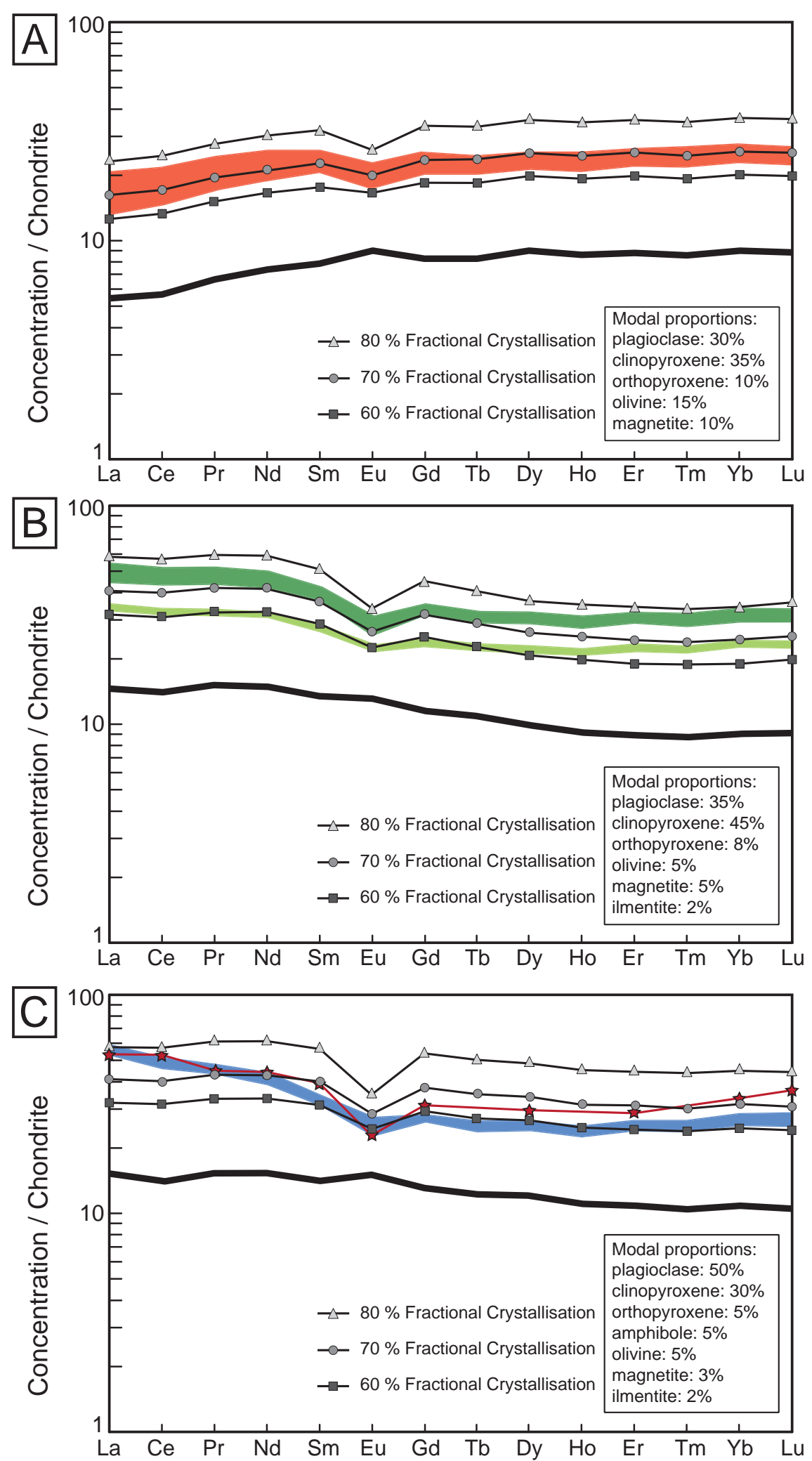

Figure 5.03. REE patterns calaculated for Kermadec magmas with varying levels of perfect fractional crystallisation from a basaltic parent. A. Raoul REE patterns with fractional crystallisation using mafic blebs from the Matatirohia eruption as a starting composition. The red compositional field represents all Raoul pumice samples analysed in this study. B. Macauley REE patterns with fractional crystallisation using basaltic lava from Smith et al. (2003a) as a starting composition. Two green compositional fields for Macauley samples analysed in this study are based on the two main compositional groups outlined in Figure 4.23. C. Healy REE patterns with fractional crystallisation using basaltic lava from I.C. Wright (unpublished data) as a starting composition. The blue compositional field represents all Healy samples analysed in this study. Also shown is the average melt inclusion REE composition (red stars) from Saunders et al. (2010). Partition coefficients are from McKenzie and O'Nions (1991) except for magnetite (Lemarchand et al., 1987) and ilmenite (Paster et al., 1974). Chondrite values from Palme and Beer (1993). Modal proportions used in fractionation calculations are shown in each diagram. 
observed mineralogy of the pumices and also the mineralogy of the co-erupted plutonic xenoliths or crystalline mafic blebs, which are interpreted to be crystal residues.

For Raoul volcano, the average composition of the whole mafic blebs was used as a parental melt. Although the mafic blebs represent a mixture of crystals and melt, their compositions are similar to both the most primitive basaltic lavas erupted from Raoul, as well as the back-calculated melt composition in equilibrium with the mafic xenocrysts in the pumice (Figure 5.02, Smith et al., 2006, 2010). As shown in Figure $5.03 \mathrm{~A}$, the composition of the observed dacites from Raoul strongly correlates with ca. $65-75 \%$ fractional crystallisation.

Although no basaltic lavas have been analysed in this study for Macauley, the composition of the silicic magmas have REE patterns that are sub-parallel to basaltic lava analysed by Smith et al. (2003a; Figure 5.03B). The composition of the Macauley pumices split into two main groups, which are consistent with $60 \%$ and $70-80 \%$ fractional crystallisation from the basaltic lavas. The only inconsistency in the modelling is the slight offset in the HREE, which is interpreted to either be the effect of an inappropriate starting composition or unsuitable partition coefficients.

For Healy volcano, 60-70\% fractionation of a basalt parent (I.C. Wright, unpublished data), forms a HREE pattern which is sub-parallel to the observed pumice compositions (Figure 5.03C). However, basic fractional crystallisation modelling cannot re-create the LREE enrichment as observed in both the pumice samples analysed in this study, and in melt inclusions analysed by Saunders et al. (2010). This LREE enrichment in the silicic magmas may be caused either by fractionation of another crystal phase not used in modelling (e.g. apatite), or late-stage amphibole crystallisation in the evolved melt, as LREE's have considerably lower partition coefficients in amphiboles than MREE's or HREE's in silicic magmas (Rollinson, 1993; Brophy, 2008). REE partioning in amphibole and clinopyroxene also changes considerably with the $\mathrm{SiO}_{2}$ content of the melt (Brophy, 2008). Amphibole is observed in crystal clots in many of the pumices, indicating that this may be the case. Further sampling of basaltic material and more sophisticated modelling is required to resolve this issue.

Although basic REE models generally support an origin of fractional crystallisation, in reality REE variations during magmatic evolution are more complex, and difficult to predict. Many variables such as changes in crystallising phases and changes in $\mathrm{D}_{\mathrm{REE}}$ with magma evolution can greatly affect the final melt composition. To address this, Brophy (2008) incorporated changes in $\mathrm{D}_{\mathrm{REE}}$ with $\mathrm{SiO}_{2}$ into mass-balanced models to discriminate between amphibolite melting and crystal fractionation processes. 
Brophy (2008) found that regardless of the type of melting (equilibrium, fractional, accumulated fractional), partial melting of either intermediate or mafic amphibolite should yield REE abundances that remain constant, and then decrease with increasing liquid- $\mathrm{SiO}_{2}$. At high $\mathrm{SiO}_{2}$ values (>63 wt. \%), LREE abundances should be slightly enriched to depleted (i.e., $\mathrm{C}_{1} / \mathrm{C}_{\mathrm{o}}$ ca. 2 to 0.2 ) while HREE abundances should be slightly depleted $\left(\mathrm{C}_{1} / \mathrm{C}_{\mathrm{o}}\right.$ ca. 1 to 0.2$)$. To test this hypothesis, La (LREE) and Yb (HREE) concentrations have been plotted against $\mathrm{SiO}_{2}$ for samples analysed from both this and previous studies on the same Kermadec volcanoes (Figure 5.04A-D).

None of the samples analysed in this study follow the conditions outlined by Brophy (2008) to indicate they formed through amphibolite melting. In contrast, they all show significant increases in REE concentrations with increasing $\mathrm{SiO}_{2}$. For Raoul and New volcano, increases in both $\mathrm{La}$ and $\mathrm{Yb}$ are relatively similar, between 2-4 times the concentration observed in the mafic blebs (Figure 5.04A and B). This is consistent with REE variations generated by upper-crustal hornblende-absent basalt fractionation (Brophy, 2008). For Macauley (excepting the one outlier sample) and Healy samples, $\mathrm{La}$ is highly enriched with high $\mathrm{SiO}_{2}\left(\mathrm{C}_{1} / \mathrm{C}_{\mathrm{o}}\right.$ ca. 3 to 4$)$, whereas $\mathrm{Yb}$ is only slightly enriched $\left(\mathrm{C}_{1} / \mathrm{C}_{\mathrm{o}}\right.$ ca. 2 to 3) (Figure 5.04C and D). According to Brophy (2008), such REE variations are consistent with mid-upper crustal hornblende-bearing basalt fractionation. Amphibole was only seen in Healy samples, although it is conceivable that amphibole could still be present in the Macauley magmatic system(s) even though it is not represented as a mineral phase in the samples included in this study. The single outlier sample from Macauley plots with lower concentrations of La, consistent with hornblende-absent fractionation (Brophy, 2008). As a single basaltic lithic analysed by Smith et al. (2003a) is the only other sample from Macauley which has similar chemical characteristics, it is further suggested that these samples may be of similar origin (Figure 5.04C).

Another feature seen in Figure 5.04, is an apparent inconsistency of the REE data presented by Smith et al. (2003a,b, 2006, 2010) with the REE data collected in this study from the same eruption units. Although exactly the same silicic units were sampled for this study, Raoul and Macauley pumices show generally 20-30\% higher concentrations than those presented by Smith et al. (op cit.). As an overall trend, however, the data presented for Raoul volcano by Smith et al. (2010) still shows an overall positive trend in REE concentration with increasing $\mathrm{SiO}_{2}$, especially for $\mathrm{Yb}$. This is not observed in the same diagrams presented by Smith et al. (2010), which in contrast show no correlation with increasing $\mathrm{SiO}_{2}$. There seems to be an inconsistency 

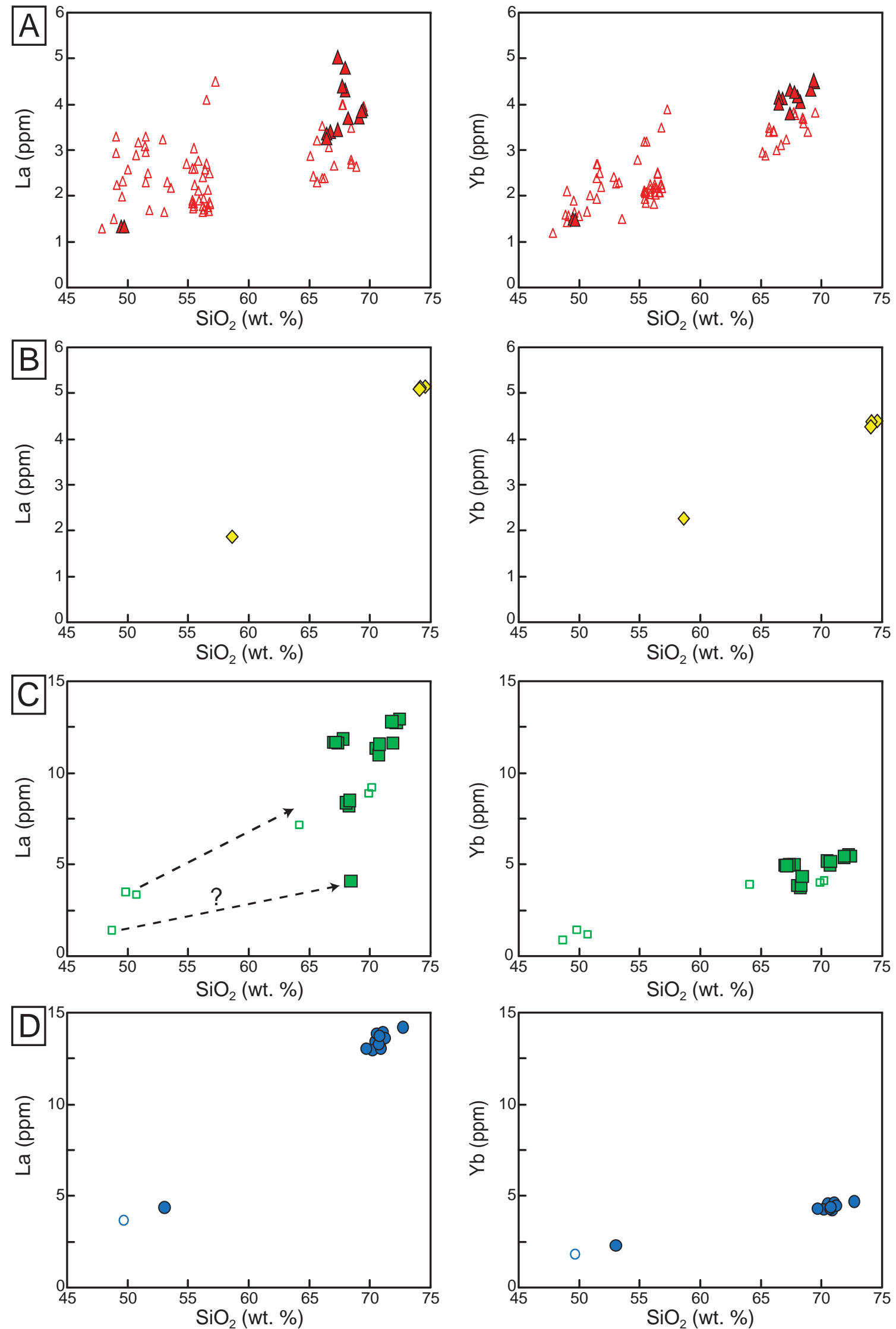

Figure 5.04. Variation diagrams showing $\mathrm{La}$ (LREE) vs. $\mathrm{SiO}_{2}$ and $\mathrm{Yb}$ (HREE) vs. $\mathrm{SiO}_{2}$ for samples from the different Kermadec volcanoes investigated in this study. A. REE variations with $\mathrm{SiO}_{2}$ for samples from Raoul volcano. Large filled symbols are samples analysed in this study, small open symbols are from Smith et al. $(2006,2010)$. B. REE variations with $\mathrm{SiO}_{2}$ for samples analysed from New volcano. C. REE variations with $\mathrm{SiO}_{2}$ for samples from Macauley volcano. Large filled symbols are samples analysed in this study, small open symbols are from Smith et al. (2003a). D. REE variations with $\mathrm{SiO}_{2}$ for samples from Macauley volcano. Large filled symbols are samples analysed in this study, small open symbols are from I.C. Wright (unpublished data). Note: variation diagrams in $C$ and $D$ have different $y$-axis scale to variation diagrams in $A$ and $B$. 
with the data presented by Smith et al. (2010), as the raw data presented in the online appendices for that publication and in their original format of Worthington (1998) do not match with the data points presented in their diagrams.

As an alternative to either amphibolite melting or crystal fractionation, partial melting of basalt could be proposed to explain the compositional patterns observed in the Kermadec volcanoes. Partial melting of differently sourced basalts has been suggested, for example, to be important in generating the range of silicic magma compositions observed in the South Sandwich arc (Leat et al., 2003, 2007). Large amounts of heat, however, are required to melt the oceanic crust and are inconsistent with the volumes of silicic eruptives. Dehydration-induced melting of amphibolite (e.g. Smith et al., 2003b) overcomes many of these energy constrains by reducing the solidus temperature, but has been shown above to be incompatible with the observed silicic magma compositions. The same silicic end-products of basalt crustal melting can be achieved by fractional crystallisation, which is thermally a more-likely process in stalled basaltic magmas which can stay partially molten and susceptible to remobilisation for long time periods (Koyaguchi and Kaneko, 1999). Partial melting processes are not ruled out, however, as newly arriving magmas could provide new heat and mass into crystallising magma bodies (Murphy et al., 2000; Bachmann et al., 2002). There is evidence for this in some clinopyroxene crystals, which have resorbed cores and high$\mathrm{Mg}$ overgrowths with extremely high concentrations of $\mathrm{Cr}$ and Ni. Overgrowths with this composition could be the result of newly arriving, primitive basalt magmas. Although it is considered that fractional crystallisation is the dominant process driving melt evolution, partial melting could still play a significant role in the Kermadec magmatic systems.

\subsubsection{Fractional crystallisation: problems and solutions}

Many studies have suggested that fractional crystallisation alone cannot explain the chemical diversity of silicic magmas in intra-oceanic arcs when compared to contemporaneous basaltic or andesitic magmas, and have therefore adopted models of lower to middle crust amphibolite melting for the genesis of silicic melts (e.g. Tamura and Tatsumi 2002; Leat et al., 2003; Smith et al., 2003a,b, 2006, 2010; Vogel et al., 2004; Shukuno et al., 2006; Tamura et al., 2009). In contrast, this study has shown that in the Kermadec arc, silicic magmas share many of the same chemical characteristics as previously erupted basalts. There are, however, still several lines of evidence proposed 
against fractional crystallisation, not only for the Kermadec arc but also the Izu-Bonin and South-Sandwich arcs:

1) Large silicic eruption volumes: The large volumes of silicic magma erupted have been proposed as a major argument against fractional crystallisation both in the Kermadec arc (Smith et al., 2003a,b) and other oceanic arc settings (e.g. Leat et al., 2003). Many of the constraints involved in these arguments have been based on assumptions that fractional crystallisation would require high degrees of crystallisation, and that such prolonged fractionation would generate small melt volumes that contain a complexly zoned phenocryst assemblage. Several studies have shown that large silicic magma volumes can be generated by fractional crystallisation, and erupted in large volumes (e.g. Baker et al., 1997, 2000; Shaw et al., 2003; Ukstins-Peate et al., 2008). Current understanding of magma crystallisation (e.g. Marsh, 1988, 1996; Vigneresse et al., 1996) and of the structure of silicic magma reservoirs (e.g. Hildreth and Wilson, 2007; Bachmann and Bergantz, 2008a) suggest that large volumes of crystal-poor magma can be rapidly and effectively extracted from crystal mush zones (Bachmann and Bergantz, 2004, 2008a; Hildreth, 2004; Glazner et al., 2004; Wilson et al., 2006; Hildreth and Wilson, 2007; Lipman, 2007; Girard and Stix, 2009; Wilson and Charlier, 2009). These models may also be applicable to the Kermadec magmatic systems, as this study along with previous work on Healy melt inclusions (Saunders et al., 2010) has shown that there is evidence for extensive fractional crystallisation in the generation of silicic magmas.

The actual volume of silicic magma that has been erupted from the Kermadec volcanoes is difficult to estimate due to limited exposure. For Raoul, the volume of silicic magma erupted over the last 4000 years could be as much as $8-16 \mathrm{~km}^{3}$ (Worthington et al., 1999; Smith et al., 2006). However, this estimate is largely based on the volume of the Fleetwood eruption, assuming that the associated Denham Bay caldera was generated in a single voluminous eruption. Similar issues are encountered with volume estimates of the Sandy Bay eruption from Macauley volcano which range from 1-100 $\mathrm{km}^{3}$ of pyroclastic material (Latter et al., 1992; Lloyd et al., 1996). Like the Fleetwood eruption, the maximum volume estimate is based on caldera reconstruction (Latter et al., 1992). This study, however, has shown that the pumice mantled around Macauley represents magmas of differing chemistry to the Sandy Bay 
Tephra, which precludes the viability of using the caldera volume to constrain the volume of a single eruption. Similar methods of caldera reconstruction have been applied to Healy volcano (Wright et al., 2003), and yield eruption estimates of 2.36 to $3.58 \mathrm{~km}^{3}$, depending on the assumed shape of the pre-caldera edifice. At New volcano, estimates of caldera volume from multibeam mapping give maxima of ca. $3-4 \mathrm{~km}^{3}$. As the chemistry of material dredged from New volcano is very uniform, as it is at Healy, it is impossible to tell how many eruptions have occurred in the absence of stratigraphy. Further stratigraphic constraints, based either on deep-sea tephra records or on submarine cliff sections, are needed to constrain the number of eruptions at each caldera, and may provide further constraints on eruption size.

Although the amount of magma released in each eruption is poorly constrained, estimates of the volume of parental melt required to generate the range of silicic eruptive volumes can be made. Modelling of fractional crystallisation indicates that the silicic magmas can be generated through 60$75 \%$ crystallisation of a parental basaltic melt (Figure 5.03A-C). The volume of parental melts required is thus 4-5 times larger than the volume of silicic magma erupted. Assuming the large eruptive bulk volume estimate of $>150 \mathrm{~km}^{3}$ (equivalent to ca. $25-30 \mathrm{~km}^{3}$ of silicic melt assuming an average vesicularity of 70-75 vol. \%) for the Sandy Bay eruption (Latter et al., 1992) a region of $>100$ $\mathrm{km}^{3}$ of crystallised parental melt is required. It is hard to envisage how such a large volume could be present in an oceanic arc setting without exceptional and unrealistic circumstances. Modest eruption sizes of $1-2 \mathrm{~km}^{3}$ would require a minimum of ca. $4-8 \mathrm{~km}^{3}$ of crystallising parental melt, a more reasonable volume given the large total volume of the Kermadec volcanoes (e.g. Raoul $>200 \mathrm{~km}^{3}$ : Smith et al., 2006) and the significant volumes of basalt erupted in recent episodes at Raoul and Macauley.

2) The aphyric nature of the pumices: The majority of Kermadec pumices are crystal-poor ( $<3-5$ vol. \% crystals), with only a few samples from Healy containing 10-15 vol. \% crystals. The eruption of aphyric pumices cannot rule out the origin of the magma via fractional crystallisation, however, as crystalmelt segregation in silicic magmas depends on many contributing processes (Bachmann and Bergantz, 2004 for review). As observed in continental volcanoes, silicic magmas erupted from mush-dominated magma reservoirs range from highly crystalline (up to 50 vol. \% crystals: e.g. Bachmann et al., 
2002; Bachmann and Bergantz, 2003), to almost aphyric (1-2 vol. \% crystals; e.g. Girard and Stix, 2009).

3) Variations in magma chemistry over time: Previous studies on Raoul volcano have proposed that each silicic eruption from Raoul tapped a distinct magma batch, and compositional variations could be accommodated by closed system fractional crystallisation (Smith et al., 2003a,b, 2006, 2010). Smith et al (op. cit.) used major element modelling to show that the silicic magma batches could not be related derived from either each other or a common parent unless the composition of the extract assemblage varied for each batch. As shown in this study, however, much of the perceived variation between these magma batches is caused by different degrees of mixing/assimilation from multiple sources. It is proposed in this study that the Raoul magmas were formed in an open magmatic system, exposed to mass and chemical exchange with not only progenitor mafic bodies, but with older and hydrothermally altered felsic plutonic material. In such an open system, it would be very difficult to relate magma batches to a common set of processes. This may also be the case for chemical groups from Macauley, which show distinctive chemical clusters, reflecting a similar set of processes which have occurred in different proportions.

4) Bimodal erupted compositions: Like other oceanic arc systems (e.g. Izu-Bonin: Tamura and Tatsumi, 2002; South-Sandwich: Leat et al., 2003) the Kermadec arc erupted compositions have a bimodal distribution, with andesitic magmas being relatively minor in volume (Figure 1.03: Smith et al., 2003a, 2006; Wright et al., 2006). This is not only highlighted by the composition of whole rock samples (Figure 5.01; Smith et al., 2006), but it is evident in the composition of minerals within the pumice samples (e.g. Figure 4.24). Similar observations, however, apply across a broad range of magmatic settings. Bimodal magma composition is a common and well documented feature of many ocean-island and arc volcanoes (e.g. Daly, 1925; Baker, 1968; Reubi and Blundy, 2009). A widespread view arising from such observations is that intermediate magmas may be primarily formed through mixing and/or mingling of melts and crystals of contrasting composition in the upper crust (Blundy and Sparks, 1992; Price et al., 2005; Reubi and Blundy, 2009). True liquids (i.e. the melt/glass component) of intermediate composition are found to be far less common than is suggested by the analysis of bulk magma (i.e. mixture of liquids and crystals) within this compositional range (see Reubi and Blundy, 2009 for a review). Such findings 
are further supported by the increasing recognition that the dominant fractionation processes that generate rhyolite magmas may be fundamentally different from those that generate less evolved melts (Eichelberger et al., 2006; Ferla and Meli, 2006). Bimodal magma compositions are therefore not a feature unique to the Kermadec volcanoes, and cannot be used to discount fractional crystallisation as the dominant differentiation process.

5) The abrupt change from basalt to dacite: At both Raoul and Macauley volcanoes, the limited record of volcanism exposed in the coastal cliffs suggests that prior to silicic volcanism, basalt and basaltic andesite were the dominant magma types erupted from each volcano (Brothers and Searle, 1970; Ewart et al., 1977; Lloyd and Nathan, 1981; Lloyd et al., 1996 Smith et al., 2003a,b, 2006). The ages of the earlier basaltic lavas are poorly constrained (Lloyd and Nathan, 1981), however, and any change from basaltic to dacitic volcanism was not necessarily 'abrupt'. In addition, the presence of tonalite clasts in the 'earliest' Matatirohia eruption deposits, together with the $1.25 \mathrm{Ma}$ age estimate from one clast (Mortimer et al., 2010) imply that silicic magmatism has occurred on previous occasions, whether or not accompanied by surviving volcanic deposits. Limited stratigraphic control from Macauley Island was used to suggest that the basalt to rhyodacite transition occurred with the Sandy Bay eruption at $6310{ }^{14} \mathrm{C}$ years ago (Lloyd et al., 1996; Smith et al., 2003a), but the presence of granitoid fragments in the Sandy Bay tephra, and the record from dredged samples show that multiple silicic eruptions must have occurred in the geologically recent past.

Compositional shifts between mafic and silicic magmas have been documented at many volcanoes (e.g. Feeley and Dungan, 1996; Leonard et al., 2002; Shukuno et al., 2006). Geist et al. (1995) showed that Volcán Alcedo in the Galápaos Islands changed from erupting basalts to erupt ca. $1 \mathrm{~km}^{3}$ of rhyolite due to a 10 -fold decrease in the mass eruption rate of the volcano. Similar to the findings of this study, Geist et al. (1995) related the previously erupted basalt and the rhyolite magmas via fractional crystallisation and recorded rounded scoriaceous basalt inclusions in the rhyolites, and two types of xenoliths (olivine bearing gabbro and medium-grained granophyres). As previously discussed, the volume of erupted magma from Raoul and Macauley is very poorly constrained, largely due to limited exposures. Therefore it is difficult to interpret changes in magma supply. However, it is possible that magma supply rate, or any other 
process which could stall the magma or induced crystallisation, could be responsible for the change in the composition of magmas erupted at Raoul and Macauley volcanoes. Any change in the thermal budget of the volcano could cause stalling in crystallisation, resulting in magmatic evolution. If this was the case for the sudden change in magma compositions at Raoul and Macauley volcanoes, it is further support for a strong relationship between mafic and silicic magmas via fractional crystallisation.

6) Sr variations with plagioclase crystallisation: Trace element variations form a sub-parallel pattern between basalt and dacite/rhyolite at each of the Kermadec volcanoes in multi-element and REE plots (Figures 4.23 and 4.24). The only trace elements which are an exception to this rule are $\mathrm{Eu}, \mathrm{Ti}$ and $\mathrm{Sr}$. As Eu and $\mathrm{Ti}$ depletions are the effects of plagioclase and magnetite fractionation respectively, these differences would be expected with magma evolution. However, the lack of a Sr-depletion in the evolved magmas has previously been used as evidence against crystal fractionation for Raoul and Macauley volcanoes, as $\mathrm{Sr}$ is compatible in plagioclase (Smith et al., 2003a, 2006). Srpartitioning into plagioclase, however, is highly dependent on the anorthitecontent of plagioclase and therefore changes in temperature, pressure, melt composition and water contents (Blundy and Wood, 1991; Bédard, 2006; Smith et al., 2009). In general, $D_{S r}$ in plagioclase increases with decreasing anorthite content (Blundy and Wood, 1991). Such changes in Sr are evident in plagioclase from the Kermadec volcanoes (Figure 4.31, 4.32 and 4.33). The lack of a Srdepletion in the silicic magmas could thus be interpreted to reflect plagioclase crystallisation acting in concert with changing $\mathrm{Sr}$ partitioning with melt composition. This results in similar $\mathrm{Sr}$ contents in the basalts and the silicic melts. A lack of Sr depletion in the silicic magmas, therefore, does not indicate that there has been a lack of plagioclase fractionation. All of the pumice analysed in this study have negative Eu-anomalies, indicating plagioclase has fractionated. In addition to this, many of the plagioclase crystals in the silicic melts are in fact xenocrysts which have been assimilated from less evolved melts, indicating the evolved magma is open to chemical and mass exchange. 


\subsection{Implications for Kermadec silicic volcanoes}

\subsubsection{Magmatic systems of the Kermadec volcanoes}

This study has demonstrated that fractional crystallisation is the dominant process for the generation of silicic magmas at four Kermadec arc volcanoes. It is envisaged that basaltic magmas stall and form partly to wholly crystalline plutonic bodies, which can then differentiate to form silicic magmas. This concept is supported by the presence of plutonic xenoliths in the eruption deposits from Raoul and Macauley Island, along with mafic-derived crystals mixed into the majority of the Kermadec pumice samples. The composition of basaltic magmas previously erupted from the volcanoes closely matches the composition of mafic blebs and the back-calculated liquid composition from the clinopyroxene, suggesting they have a close genetic affinity. Due to the strong genetic links which can be made between the mafic and silicic magmas, it is interpreted that the mafic crystals previously termed as xenocrysts might be better termed 'antecrysts' (Hildreth, 2004; Charlier et al., 2005; Jerram and Martin, 2008), as they grew in progenitor melts from which the silicic magmas fractionated.

The crystal mush model has been widely applied to continental volcanoes in order to explain the rapid generation and accumulation of large amounts of eruptible silicic magma (Bachmann and Bergantz, 2004, 2008a,b; Hildreth, 2004; Glazner et al., 2004; Wilson et al., 2006; Hildreth and Wilson, 2007; Lipman, 2007; Girard and Stix, 2009). However, its role in ocean-arc volcanoes is largely unexplored. From the results of this study, it is suggested that the crystal mush model could help explain many of the features of the Kermadec silicic magmas. The crystal mush model does not in itself favour crustal melting or fractional crystallisation as the dominant process, as the 50-60 vol. \% crystal window can be achieved by either mechanism. However, thermodynamic models of heat and mass transfer within the crust (Barboza et al., 1999; Babeyko et al., 2002; Dufek and Bergantz, 2005; Annen et al., 2006) and field observations in exposed crustal sections (Barboza and Bergantz, 2000; Greene et al., 2006; Hacker et al., 2008) suggest that fractional crystallisation occurring synchronously with some assimilation is the dominant differentiation process in most tectonic settings (Bachmann and Bergantz, 2008b).

A schematic illustration (Figure 5.05) highlights the role crystallisation of previously emplaced basaltic magmas plays in the generation of silicic magmas. This 


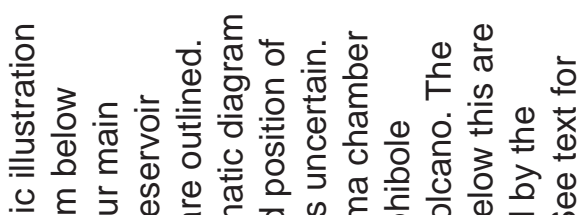

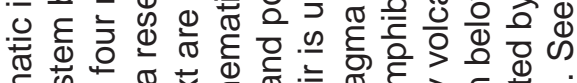

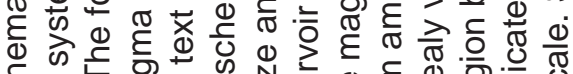

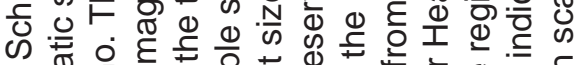

นึ Е

ก

@ $E \geq$ W

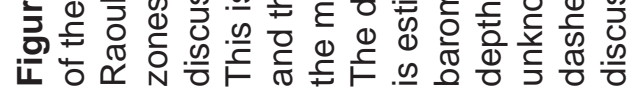

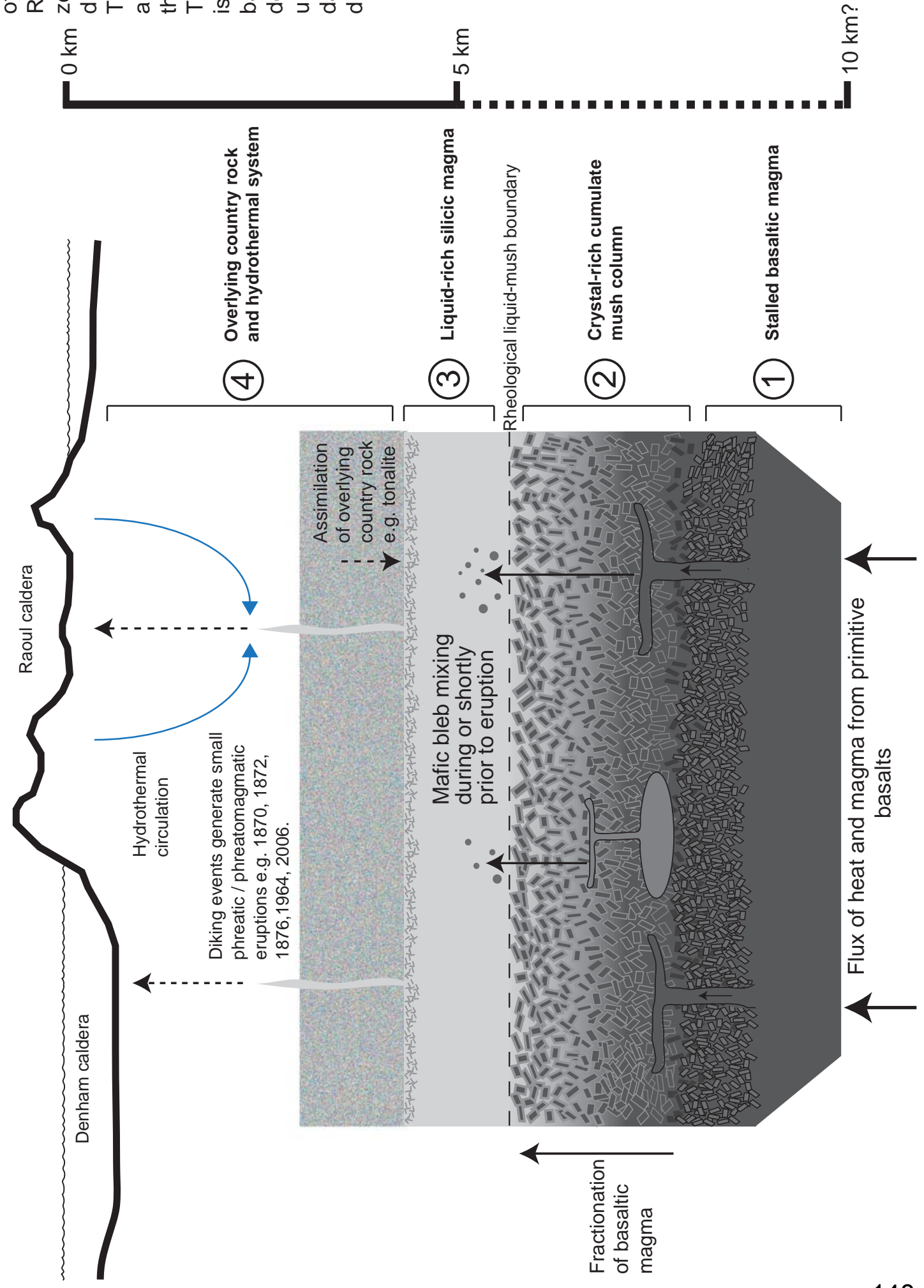


illustration is based on a simple conceptual model, and the dimensions, shape and position of the reservoir are not to scale. It is similar to the proposed structure of the magmatic plumbing system by Smith et al. (2010), but is extended to account for the formation of silicic magmas by fractional crystallisation. The magma reservoir can be defined by four main zones (Figure 5.05), each of which is described below.

Zone 1: Stalled basaltic magma. Rising mantle-derived melts stall within the mid-lower crust and crystallise, providing heat and new material to the overlying mush column (Marsh, 1988, 1996). The depth and extent of this zone is poorly constrained, and could vary significantly, possibly to as far down as the base of the crust (ca. $15 \mathrm{~km}$ ). Although there is no evidence for direct exchange of melt into the evolved silicic magmas, some high-Mg clinopyroxene antecrysts in the dacite show evidence for resorption in primitive (high $\mathrm{Cr}$ and $\mathrm{Ni}$ ) magmas (e.g. Figure 4.27). This suggests that primitive melts can make their way into the mush column and interact with more-evolved crystals. This process is considered likely given that the more primitive basalts would have a lower density than the gabbroic cumulates which make up the base of the mush column. This also suggests that newly arriving primitive magmas could induce some partial melting in some parts of the overlying cumulate mush column. These findings differ from those of Smith et al. (2010), who suggested that the crystal reservoir formed from magma more primitive than the evolved magmas that ascended into it.

Zone 2: Crystal-rich cumulate mush column. Crystallising basalts form a zone of partly to wholly crystalline crystal mush (cf. the partly molten dykes and sills extending vertically through the crust proposed by Smith et al., 2010). The mush column behaves as a rheological solid, and chunks can be disaggregated and transported by intruding magma. The crystals that make up a large part of the crystal mush column include the high-An plagioclase and also clinopyroxene and olivine with high Mg-numbers (70-85). Many of these crystals eventually erupted in the more evolved basalts and basaltic-andesites (Smith et al., 2006; 2010), as well as dacites (this study). It is inferred that the upper part of the mush column is more evolved, and largely crystalline ( $>55$ vol. \% crystals). This part of the mush column acts as a rigid sponge from which eruptible silicic melt can be readily extracted into the overlying silicic melt-dominant body. 
Zone 3: Silicic melt dominant body. As pressures/depths were not estimated for Raoul silicic magmas, estimated depths for Healy silicic melts (ca. 3-5 km: Figure 4.34) have been used in Figure 5.05. The dacite magma is hot (ca. 900$1000^{\circ} \mathrm{C}$ ) and crystal poor. As many crystals observed in the pumices are grouped into clots, crystallisation may predominantly occur on the chamber walls and/or roof (Marsh, 1988). The exact size and shape of the silicic magma chamber is unknown, although due to the sizes of the Raoul and Denham calderas versus inferred magma volumes erupted, it is likely to have had a sill-like form. Whether this is a continuous body which encompasses both calderas is uncertain. However, as activity was observed from Denham Bay during phreatic eruptions from Raoul (e.g. 1964: Lloyd and Nathan, 1981), it is inferred that they have some close connection.

Many of the Raoul pumices show evidence for magma mixing with progenitor mafic magma/crystals. Several studies have suggested that basaltic magma mixing can be a triggering mechanism for silicic eruptions (e.g. Pallister et al., 1992; Leonard et al., 2002; Wilson et al., 2006). This may be the case for the Raoul eruptions, as unzoned olivine crystals indicate that magma mixing occurred very shortly prior to eruption (section 5.1.2). As some crystals in mafic blebs have been resorbed in primitive basalts (indicated by zones with high $\mathrm{Cr}$ and $\mathrm{Ni}$ ), they may be sourced from deeper in the mush column. This also suggests that influx of new primitive magma into the deeper reservoir may disrupt the overlying crystal mush, and possibly the silicic melt dominant body. Another possibility is that the eruption of the silicic magma acted as a trigger for magma mixing, and the largely crystalline basalt at the base of the silicic magma chamber was overturned during eruption and decompression (Woods and Cowan, 2009). Regardless of mixing mechanisms, the rounded cauliform appearance of mafic blebs indicates that they were partially molten when incorporated into the dacite magma. The growth of microlites and the small amount of interstitial dacite glass in the mafic blebs supports this notion, as these features may have been caused by the cooler temperatures and quenching effect of the dacite melt. This also illustrates the major effects the formation of a silicic magma chamber has on the magmatic system. Due to a large density contrast between the basalts and the silicic melts, rising basalts are not able to penetrate through the more evolved magmas (Geist et al., 1995). This may help 
explain the change from basaltic to dacitic volcanism, and the lack of basalts erupted from Raoul during the last ca. 4000 years.

Zone 4: Overlying country rock and hydrothermal system. The region above the silicic magma chamber plays a major role in the Raoul magmatic system. This study has shown that for the Oneraki and Green Lake Pumice samples, low-An plagioclase from a tonalite source has been assimilated into the dacite magma. As the tonalite xenolith observed from Raoul has hydrothermal alteration, it must have been sourced from a region in close proximity to both the silicic magmas and the hydrothermal system at Raoul. As tonalite xenocrysts are only assimilated in younger eruptions from Raoul, it is possible that the silicic magma chamber may have shifted upwards with time even as eruption volumes have decreased. More recently, historic activity at Raoul has consisted of small phreatic/phreatomagmatic eruptions in 1870, 1872, 1876, 1964 and 2006. These explosions may be caused by the intrusion of small dikes into the hydrothermal system (Graaf, 2006).

The basic structure of the magmatic system in Figure 5.05 could also be extended to apply to both Macauley and Healy, as samples from these volcanoes share many of the features observed in Raoul pumices (e.g. mafic blebs, mafic crystals, crystal clusters). Although no crystal specific work has been carried out on samples from New volcano, its whole rock chemistry and similar crystal/mafic bleb contents indicates that it may also have a similar magmatic structure. For Healy, crystallisation may play a larger role in the silicic magma chamber, as pumices contain large clots of clustered crystals (e.g. Figure 4.16B,C). Many of the Healy crystals are not in equilibrium with their host glasses, indicating that there may be further crystal-melt segregation in the Healy silicic magma chamber.

\subsubsection{Implications for worldwide oceanic arc settings?}

Many studies have been carried out on other worldwide oceanic arc settings, but there is no consensus on which is the dominant process for generating silicic magmas. As shown in Figure 5.06, silicic magma makes up a minor compositional component in several other ocean arcs settings, in addition to the Kermadec arc. Although not considered to be fully representative of the total erupted volume, Figure 5.06 highlights the dominant basalt mode, and the relatively minor amount of silicic material at each 


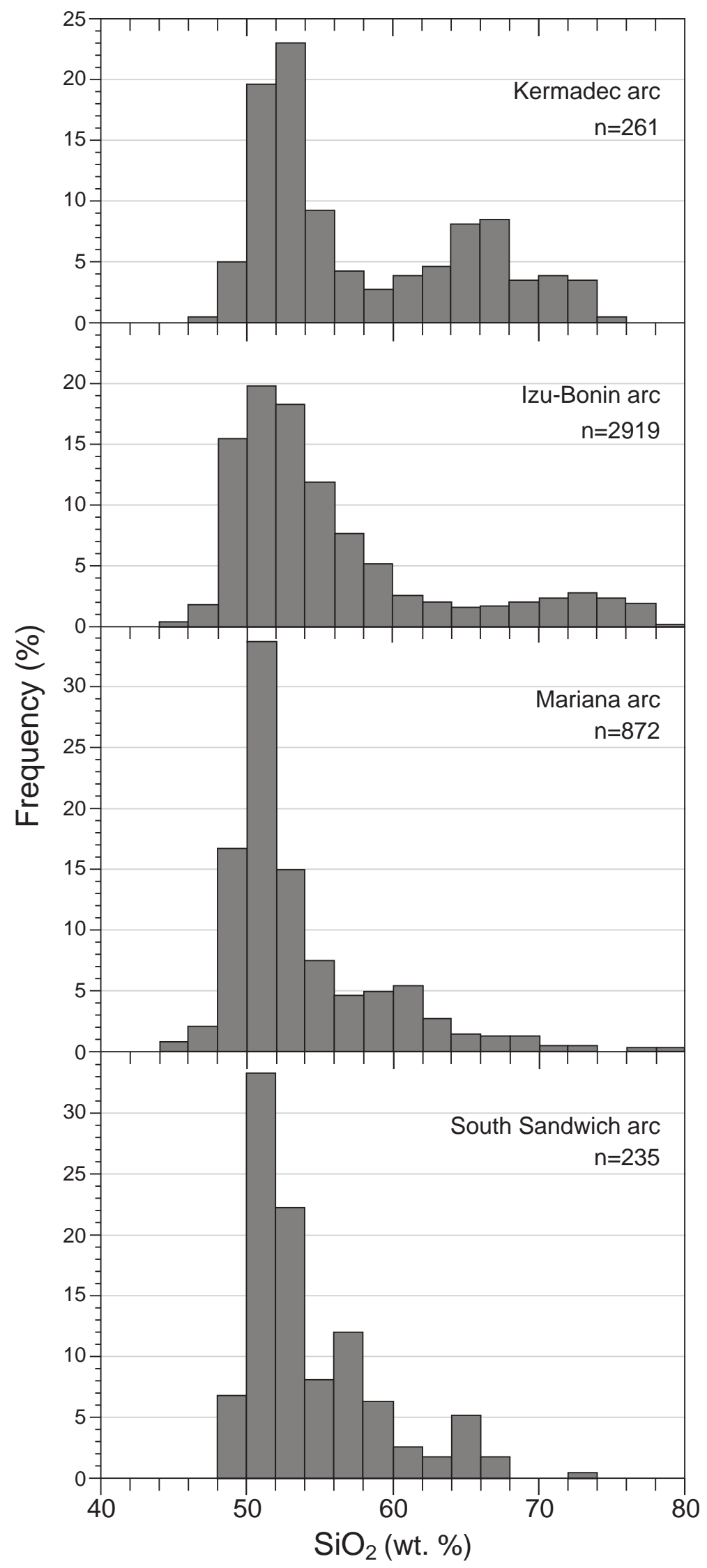

Figure 5.06. Stacked frequency histograms comparing the $\mathrm{SiO}_{2}$ variation of eruptive material from four different intra-oceanic arc settings; Kermadec arc, Izu-Bonin arc, Mariana arc and the South Sandwhich arc. All compositions presented are from the GEOROC database (http://georoc.mpch-mainz.gwdg.de/georoc/). The compositions are not considered to be representative of the total erupted volume, but the large number of analyses provides an indication of the dominant compositional modes and ranges of material sampled from each arc. 
arc. Recent work on the Izu-Bonin and South Sandwich arcs have suggested that crustal anatexis is the dominant mechanism for generating silicic magmas in ocean arc settings (e.g. Tamura and Tatsumi, 2002; Leat et al., 2003, 2007; Shukuno et al., 2006; Tamura et al., 2009). Previous studies from the Kermadec arc also supported crustal anatexis (e.g. Smith et al., 2003a,b, 2006, 2010), and the Kermadec arc has been referred to as a type example for this process. As shown by this study, however, reassessment of the Kermadec volcanoes indicates that fractional crystallisation, accompanied with open system processes (e.g. magma mixing and assimilation) is the dominant magmatic processes that contributes to the chemical variations observed in silicic magmas. This study has also shown that careful analysis of eruptive materials using several different techniques is required to gain insights into the processes that occur in ocean arc magmatic systems. The findings of this study match those of Brophy (2008), who showed that magmas generated by melting of amphibolite would produce distinctive REE patterns (see section 5.2). As these REE patterns are not observed in the Kermadec arc, or any of the arcs shown in Figure 5.06 (see Brophy, 2008), it is suggested that fractional crystallisation is likely to be the dominant process driving silicic magmatism in most ocean arc settings.

\subsection{Along-arc variations in magma chemistry}

Although the dominant processes driving silicic magma generation are similar between the volcanoes investigated in this study, there are significant variations in magma chemistry between the volcanoes. Differences in magma chemistry corresponding to distance along-arc have been identified in previous studies (e.g. Ewart and Hawkesworth, 1987; Gamble et al., 1993b; Haase et al., 2002; Smith and Price, 2006). Isotope ratios and trace element variations indicate that magma from the northern segment of the Kermadec arc are derived from less fertile and/or less slab-enriched magma sources, than those from the southern segment (Turner et al., 1997; Haase et al., 2002; Smith and Price, 2006; Wysoczanski et al., 2006). This can be recognised in this study, as Raoul, Macauley and New volcano samples are relatively depleted in comparison with Healy samples (Figure 4.23). These differences may be attributed to significant changes in the along-arc structure and morphology of the Kermadec subduction system (Wright, 1994: Figure 5.07). As shown in Figure 5.07, in the volcanoes of the northern Kermadec arc are positioned on the Kermadec ridge, and separated from the back arc basin rifting axis by $>100 \mathrm{~km}$ (see also Figure 2.01). In the 
southern Kermadec arc, the volcanoes are positioned to the west of the Kermadec ridge, and are in closer (ca. $35-45 \mathrm{~km}$ ) in proximity to the back arc rifting axis. Both the rate of subduction and the rate of back arc rifting decreases southwards (Figure 5.07 and Figure 2.01). Slower subduction rates, accompanied by larger amounts of sediment influx along the trench have contributed a greater sediment signature in the Kermadec arc lavas towards the south (Carter et al., 1996; Gamble et al., 1996; Turner et al., 1997; Haase et al., 2002; Wysoczanski et al., 2006). This is reflected in the samples analysed from Healy, which have relatively higher Ba spike than the northern volcanoes (Figure 4.22) and $\mathrm{Pb}$ isotope compositions which fall on a mixing array with sediment melt (Figure 4.24).

Another important structural feature which varies along the length of the arc, is the change in the length of the subducting slab (Figure 5.07) which may greatly affect the flow of fertile hot magma into the mantle wedge (e.g. Ewart and Hawkesworth, 1987; Gamble et al., 1993b; Wright 1994). In the northern Kermadec arc, the longer subducted slab length could possibly inhibit the inflow of fertile hot magma, and subsequent periodic melt extraction from the mantle wedge may produce a less fertile source with time (Figure 5.07, Gamble et al., 1993b). However, depletion with time is not observed at Raoul, as the oldest subaerial basalts are slightly more depleted than the youngest (Worthington, 1998). Another possibility is that the shallower dip of the subducting slab in the northern Kermadec arc (Pelletier and Dupont, 1990) may inhibit sub-arc mantle replenishment (Gamble et al., 1993b; Haase et al., 2002).

Large-scale changes in the structure of the Kermadec arc may explain the large differences between Healy, and the northern Kermadec volcanoes. It struggles, however, to explain the significant differences between Raoul plus New volcano with respect to Macauley volcano. Raoul and New volcano have a similar depleted signature to lavas in the Tonga ridge. Macauley is located only ca. $100 \mathrm{~km}$ south of Raoul/New volcanoes, yet it has less depleted $\mathrm{Nb} / \mathrm{Zr}$ and lacks the LREE/MREE depletion observed in the northern volcanoes (Figure 5.08). Although it is difficult to interpret mantle processes from evolved magmas which have been through crustal processes (especially at Healy where amphibole is present), the strong overall trend in Figure 5.07 supports a strong difference in source depletion along arc. These findings also suggest that there may be some major differences either in the composition, the degree of partial melting, or possibly the degree of source depletion in the mantle between Raoul and Macauley. 


\section{A Northern Kermadec $\left(29^{\circ} \mathrm{S}\right)$}

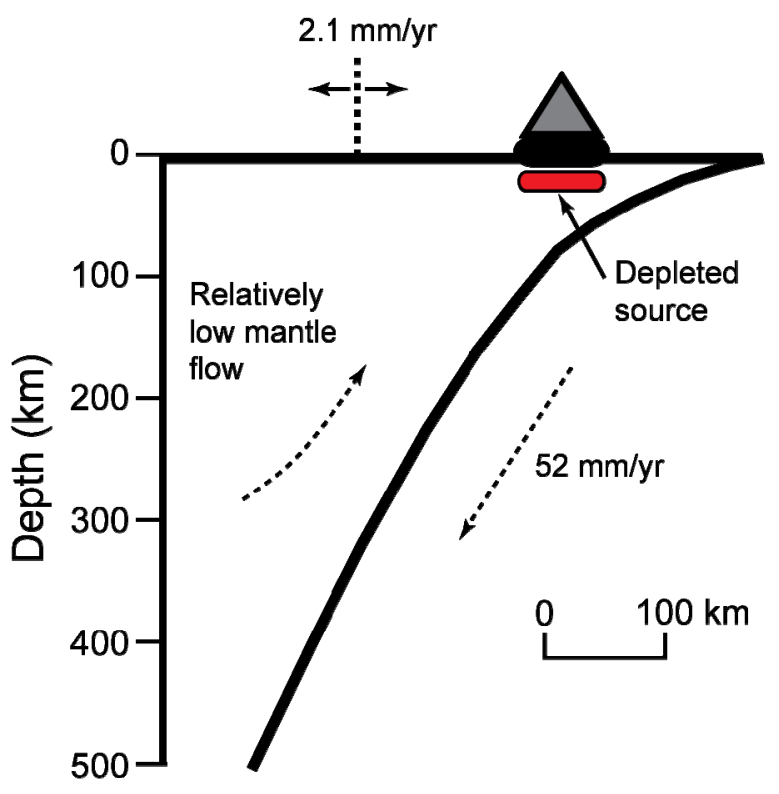

B Southern Kermadec $\left(35^{\circ} \mathrm{S}\right)$

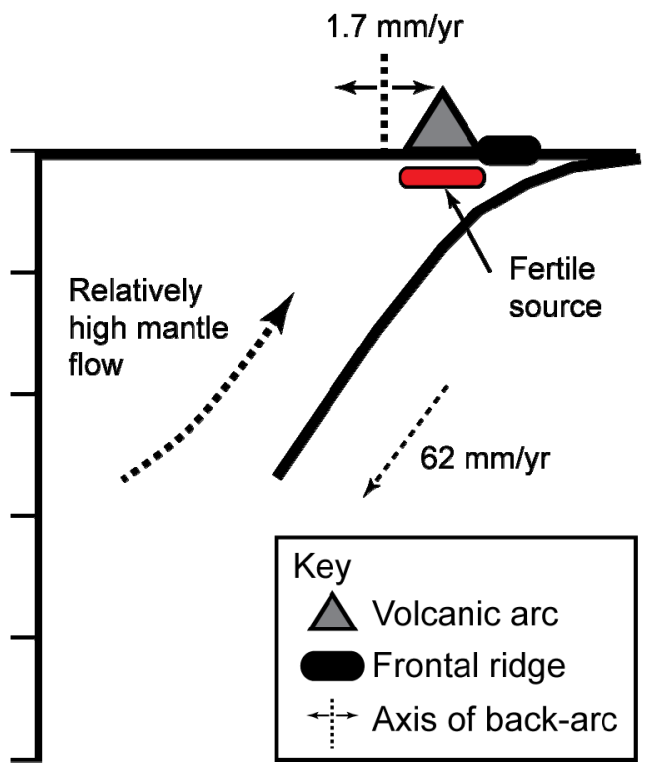

Figure 5.07. Schematic cross section of $A$ ) the northern Kermadec arc, close to the latitude of Raoul and New volcano and B) the southern Kermadec arc, close to the latitude of Healy volcano. Subduction rate is from DeMets et al. (1994) and Walace et al. (2009). Back-arc basin divergence rate is from Taylor et al. (1996). Length and dip of the subducting slab is from Isacks and Barazangi (1977) for the northern Kermadec arc, and Pelletier and Dupont (1990) for the southern Kermadec arc. Modified from Wright (1994).

Another important feature shown on Figure 5.08 is the single sample from Macauley which is more depleted than other Macauley samples and plots more closely with Raoul/New volcano compositions. This sample has previously been identified as an outlier (e.g. Figure 4.22, 4.23), but it has slightly different whole rock, glass and mineral compositions/assemblage to that of Raoul samples. Only one other sample from Macauley, a basaltic lithic analysed by Smith et al. (2003a), has similar REE patterns to this single outlier (Figure 4.23). If in fact these samples were erupted from Macauley it would suggest that magma source compositions vary significantly between individual magma batches. However, due to the many uncertainties associated with seafloor dredging as a means of sample collection, it is also possible that this outlier sample may in fact not be sourced from Macauley volcano. Pumice rafts from submarine eruptions have been documented to travel several hundred kilometres from their source (e.g. Bryan et al., 2004), highlighting the caution that must be taken when such material is used to interpret local magmatic processes. Further sampling and trace element analyses are required from Macauley samples to help resolve these issues. 


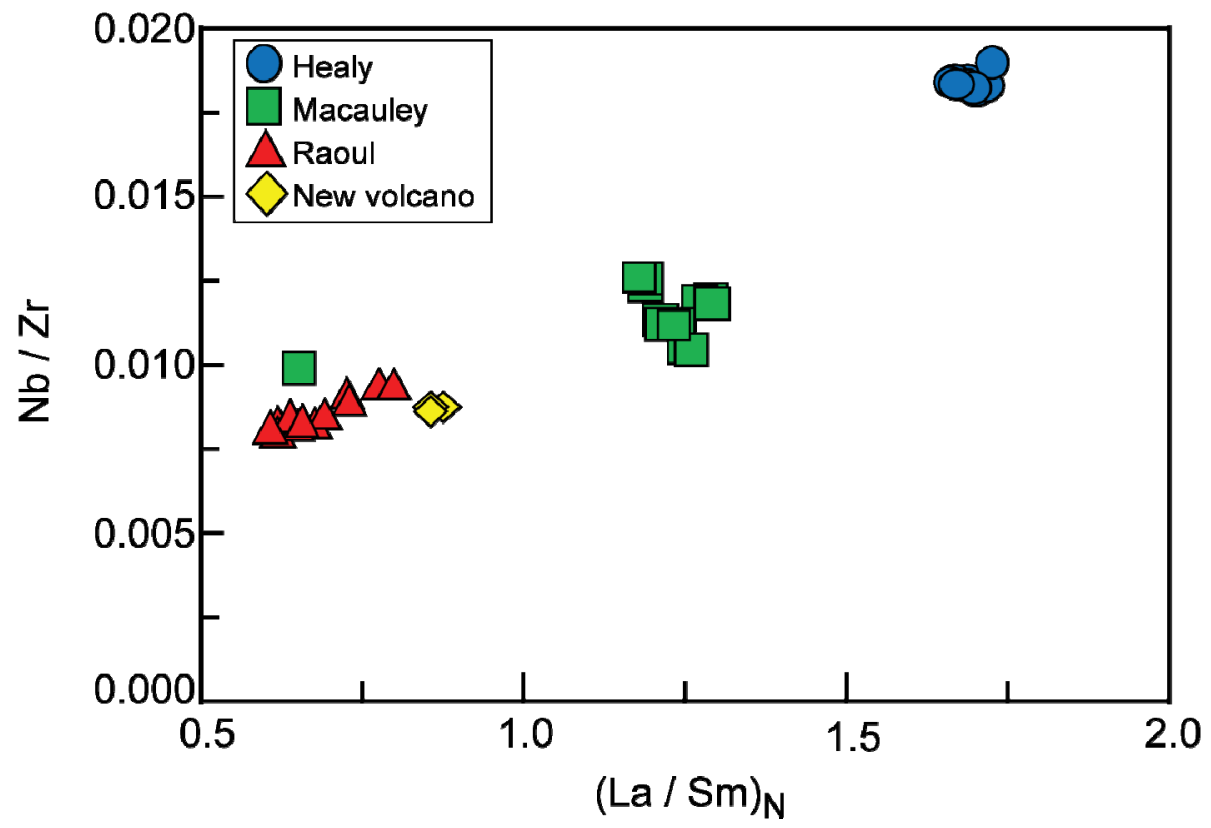

Figure 5.08. Variation diagram of $\mathrm{Nb} / \mathrm{Zr}$ versus $(\mathrm{La} / \mathrm{Sm})_{\mathrm{N}}$ highlighting the differences in depletion between the Kermadec volcanoes. La/Sm normalised to the Chondrite values of Palme and Beer (1993). 


\section{CHAPTER 6: \\ Conclusions}




\subsection{Key findings of this study}

A combination of whole rock, glass and crystal specific geochemical data obtained from the analysis of pyroclasts from four silicic volcanoes along the Kermadec arc lead to the following conclusions:

1) Magmatic diversity. Samples collected from Raoul represent at least five separate eruptions, with a relatively confined whole rock compositional range. Samples dredged from around Macauley caldera have a wide compositional range, with several different compositional groups implying that the products sampled by dredging are from multiple eruptions and/or multiple magma systems. This has major implications for the Sandy Bay Tephra as the bulk of material dredged and previously ascribed to this unit (Latter et al., 1992; Lloyd et al., 1996; Smith et al., 2003a) are clearly unrelated. This suggests a far more complex volcanic history for Macauley than realised. Samples dredged from Healy and New volcano have restricted compositions, but in the absence of any constraining stratigraphy it is not possible to discern whether these are from single or multiple events.

2) Complex magmatic histories. Pumice samples from all volcanoes have a diverse crystal assemblage with multiple populations identified, many of which show evidence for complex magmatic histories. Some crystals are in equilibrium with their host glasses, however, many are not in equilibrium, with compositions that are more consistent with a mafic source. Also, hydrothermally altered plagioclase and quartz are found in some Raoul pumice samples. Magma mixing and/or assimilation play an important role in the Kermadec magmatic systems, evident from the crystal assemblage and also from inclusions of discrete mafic blebs. Many of the whole rock compositional variations can be explained by mixing or crystal accumulation. The origin of the mixed crystals/melts at Raoul and Macauley is consistent with two sources as reflected in co-eruptive plutonic xenoliths, hydrothermally altered tonalite and cumulate olivine gabbros. The tonalite, through comparison with petrographically similar tonalites dated at ca. 1 Ma (Mortimer et al., 2010), is inferred to represent earlier silicic magmatism at Raoul. This suggests that silicic magmatism has not necessarily been confined to the past 4000 years as previously thought (cf. Smith et al., 2003b). The gabbros 
share a close genetic affinity to the silicic magmas. The bulk compositions of mafic blebs and back-calculated equilibrium melts have a similar composition to previously erupted basalts from Raoul, Macauley and Healy.

3) Fractional crystallisation the dominant process. For all four volcanoes, trace element patterns of pumice are sub-parallel to both those of erupted basalts and whole mafic blebs extracted from within pumice. The composition of the Kermadec silicic magmas can be achieved by 60 - 75\% perfect fractional crystallisation of a basaltic parent. For Raoul and Macauley, modelled REE patterns are similar to the observed pumice compositions. For Healy, the models cannot fully account for the LREE enrichment, which may be caused by late stage amphibole crystallisation. According to the model of Brophy (2008), LREE/HREE variations with $\mathrm{SiO}_{2}$ are consistent with mid-upper crustal hornblende-absent basalt fractionation for Raoul and New volcanoes, and midupper crustal hornblende-bearing basalt fractionation for Macauley and Healy volcanoes. These findings suggest that fractional crystallisation is the dominant processes for generating silicic magmas, not crustal anatexis as proposed by Smith (2003a,b, 2006, 2010). It is further suggested that this study may have implications for worldwide ocean arc settings, as the Kermadec system has been used as a type example for crustal anatexis. In agreement with Brophy (2008), fractional crystallisation is considered to be the dominant process for generating silicic magmas at most ocean arc settings.

4) Recharged mush columns. The results from this study suggest that the magmatic systems of the Kermadec volcanoes can be defined by a column of stalled crystallising basalt forming a large cumulate mush zone from which more evolved magmas form. This mush column is recharged with heat and material from newly arriving primitive melts. Due to large density contrasts, the rising basalts are not able to erupt through more evolved magmas. The silicic magma chamber is open to mixing of material from progenitor melts and the overlying country rock, as commonly recorded in the observed mineral assemblage of the pumice. The lack of zoning or reaction rims on olivine crystals suggests that mixing with the mafic source(s) occurs immediately prior to, or during eruption. 
5) Along arc variations. Large scale variations in pumice chemistry between the volcanoes can be correlated with their relative position along the Kermadec arc. In the southern Kermadec arc, Healy magmas are LREE enriched (relative to HREE). Healy samples also have a large sediment signature indicated from both a large $\mathrm{Ba}$ spike and their high ${ }^{207} \mathrm{~Pb} /{ }^{204} \mathrm{~Pb}$ and ${ }^{208} \mathrm{~Pb} /{ }^{204} \mathrm{~Pb}$ trending towards the $\mathrm{Pb}$ compositional field of Kermadec sediments. In the northern Kermadec arc the magmas are more depleted, with little or no sediment contribution. However, there is a significant difference between the chemistry of Raoul and New volcano which have a slight depletion in LREE and Macauley magmas which are LREE enriched. This suggests there are considerable differences in the chemistry of the source magmas over a relatively short distance along the arc.

\subsection{Suggestions for future work}

Many questions still remain about silicic magmatism in the Kermadec arc. Some issues that require further investigation are listed below.

1) There are few constraints on the volcanic history of the Kermadec volcanoes, in terms of timing, number of eruptions and the total eruptive volume. An eruptive history is only partially defined for the subaerial volcanoes, and as this study has shown, there are chemical groups which are unaccounted for in the partially exposed stratigraphy. In addition, several distinct chemical groups have been defined in this study for material dredged from Macauley volcano. Due to the submarine setting of many Kermadec volcanoes, defining a complete history of the Kermadec arc would be almost impossible. However, deep sea tephra records (e.g. Allan et al., 2008) may help to better define timing constraints on these chemical groups. Samples could also be collected from caldera walls and/or submarine cliff sections by remotely operated vehicle. This would place some relative timing constraints on the material collected from the seafloor, which cannot be achieved by dredging.

2) The genetic relationship between mafic and silicic magmas and source characteristics could be further investigated with Sr-Nd-Hf isotopic data. Limited Sr and Nd isotopic analyses have been published by Smith et al. (2003a, 2006), showing that there is little variation between the previously erupted basalts and silicic magmas. However, this work could also be carried out on 
mafic blebs, specific crystal phases, and on tonalites. As the tonalites have undergone hydrothermal alteration, Sr isotopes can indicate if there is sea water entrainment in the hydrothermal system. This could also be investigated by analysing anhydrite or other hydrothermal material exposed in Raoul caldera.

3) Although some dating has been done on zircons from a single tonalite xenolith (Mortimer et al., 2010), further dating could be carried out to better defined the age of the tonalite source and its relationship to the current magmatic system. As similar felsic plutonic material was found in the Sandy Bay deposit on Macauley Island, this material could also be investigated for zircons.

4) The lack of zoning or overgrowth development on olivine crystals suggests that magma mixing in the Kermadec magmatic systems occurs shortly prior to or during eruption. Diffusion modelling on the mafic crystals hosted in the pumice samples would better constrain this process (e.g. Costa and Dungan, 2005; Morgan et al., 2006).

5) A single outlier sample from the Macauley dredge suite (D33_PC04) has a composition more typical of samples from Raoul and New volcano. However, this sample has differing mineral and glass chemistry to Raoul and New volcano samples, and as well as contrasting physical appearance (brown XRF rock powder vs. New volcano which has white rock powder and Raoul which has mostly oxidised pink-orange rock powder). Analysis of further samples from this compositional group is required to resolve this issue.

6) Magmatic processes would be better constrained by the investigation of melt inclusions observed in selected crystal populations in this study. In this study, major element analysis on a small number of melt inclusions from the Sandy Bay pumice indicate that the silicic melts may change in composition prior to eruption (possibly through magma mixing). To date, the only other study of melt inclusions from the Kermadec arc silicic rocks are from Healy samples (Saunders et al., 2010). Similar studies of melt inclusions studies from Raoul, Macauley and New volcano would provide insights into magmatic conditions such as water contents, the range of silicic melt compositions and degassing histories. 


\section{References}


Allan, A. S. R., Baker, J. A., Carter, L. \& Wysoczanski, R. J. (2008). Reconstructing the Quaternary evolution of the world's most active silicic volcanic system: insights from an $\sim 1.65 \mathrm{Ma}$ deep ocean tephra record sourced from Taupo Volcanic Zone, New Zealand. Quaternary Science Reviews 27, 2341-2360.

Anderson, A. L., \& Smith, D. R. (1995). The effects of temperature and $\mathrm{f}_{\mathrm{O} 2}$ on the Alin-hornblende barometer. American Mineralogist 80, 549-559.

Annen, C., Blundy, J. D. \& Sparks, R. S. J. (2006). The genesis of intermediate and silicic magmas in deep crustal hot zones. Journal of Petrology 47, 505-539.

Arculus, R. J. (2003). Use and abuse of the terms calcalkaline and calcalkalic. Journal of Petrology 44, 929-935.

Arculus, R. J. \& Powell, R. (1986). Source component mixing in the regions of arc magma generation. Journal of Geophysical Research 91, 5913-5926.

Babeyko, A. Y., Sobolev, S. V., Trumbull, R. B., Oncken, O. \& Lavier, L. L. (2002). Numerical models of crustal scale convection and partial melting beneath the Altiplano-Puna Plateau. Earth and Planetary Science Letters 199, 373-388.

Bach, W., Hegner, E., Erzinger, J. \& Satir, M. (1994). Chemical and isotopic variations along the superfast spreading East Pacific Rise from 6 to $30^{\circ} \mathrm{S}$. Contributions to Mineralogy and Petrology 116, 365-380.

Bach, W., Hegner, E. \& Erzinger, J. (1998). Chemical fluxes in the Tonga subduction zone: Evidence from the southern Lau Basin. Geophysical Research Letters 25, 1467-1470.

Bachmann, O. \& Bergantz, G. W. (2003). Rejuvenation of the Fish Canyon magma body: A window into the evolution of large-volume silicic magma systems. Geology 31, 789-792.

Bachmann, O. \& Bergantz, G. W. (2004). On the origin of crystal-poor rhyolites: extracted from batholithic crystal mushes. Journal of Petrology 45, 1565-1582.

Bachmann, O. \& Bergantz, G. W. (2008). The magma reservoirs that feed supereruptions. Elements 4, 17-21.

Bachmann, O. \& Bergantz, G. W. (2008). Rhyolites and their source mushes across tectonic settings. Journal of Petrology 49, 2277-2285.

Bachmann, O., Dungan, M. A. \& Lipman, P. W. (2002). The Fish Canyon magma body, San Juan volcanic field, Colorado: rejuvenation and eruption of an uppercrustal batholith. Journal of Petrology 43, 1469-1503.

Bachmann, O., Miller, C. F. \& de Silva, S. L. (2007). The volcanic-plutonic connection as a stage for understanding crustal magmatism. Journal of Volcanology and Geothermal Research 167, 1-23.

Bacon, C. R. \& Hirschmann, M. M. (1988). Mg/Mn partitioning as a test for equilibrium between coexisting Fe-Ti oxides. American Mineralogist 73, 57-61.

Baker, I. (1968). Intermediate oceanic volcanic rocks and the 'Daly Gap'. Earth and Planetary Science Letters 4, 103-106.

Baker, J. A., Menzies, M. A., Thirlwall, M. F. \& MacPherson, C. G. (1997). Petrogenesis of Quaternary intraplate volcanism, Sana'a, Yemen: Implications for plume-lithosphere interaction and polybaric melt hybridization. Journal of Petrology 38, 1359-1390.

Baker, J. A., MacPherson, C. G., Menzies, M. A., Thirlwall, M. F., Al-Kadasi, M. \& Mattey, D. P. (2000). Resolving crustal and mantle contributions to continental flood volcanism, Yemen; Constraints from mineral oxygen isotope data. Journal of Petrology 41, 1805-1820.

Baker, J. A., Peate, D., Waight, T. \& Meyzen, C. (2004). Pb isotopic analysis of standards and samples using a ${ }^{207} \mathrm{~Pb}-{ }^{204} \mathrm{~Pb}$ double spike and thallium to correct for mass bias with a double focusing MC-ICPMS. Chemical Geology 211, 275303. 
Barboza, S. A. \& Bergantz, G. W. (2000). Metamorphism and anatexis in the mafic complex contact aureole, Ivrea Zone, northern Italy. Journal of Petrology 41, 1307-1327.

Barboza, S. A., Bergantz, G. W. \& Brown, M. (1999). Regional granulite facies metamorphism in the Ivrea zone: Is the Mafic Complex the smoking gun or a red herring? Geology 27, 447-450.

Bedard, J. H. (2006). Trace element partitioning in plagioclase feldspar. Geochimica et Cosmochimica Acta 70, 3717-3742.

Berlo, K., Blundy, J. D., Turner, S. P. \& Hawkesworth, C. J. (2007). Textural and chemical variation in plagioclase phenocrysts from the 1980 eruptions of Mount St. Helens, USA. Contributions to Mineralogy and Petrology 154, 291-308.

Bindeman, I. N. \& Davis, A. M. (2000). Trace element partitioning between plagioclase and melt: investigation of dopant influence on partition behavior. Geochimica et Cosmochimica Acta 64, 2863-2878.

Bindeman, I. N., Davis, A. M. \& Drake, M. J. (1998). Ion microprobe study of plagioclase-basalt partition experiments at natural concentration levels of trace elements. Geochimica et Cosmochimica Acta 62, 1175-1193.

Blundy, J. \& Cashman, K. V. (2008). Petrologic reconstruction of magmatic system variables and processes. In: Putirka, K. D. \& Tepley, F. J. (eds.) Minerals, Inclusions and Volcanic Processes. Reviews in Mineralogy and Geochemistry 69, 179-231.

Blundy, J. D. \& Sparks, R. S. J. (1992). Petrogenesis of mafic inclusions in granitoids of the Adamello Massif, Italy. Journal of Petrology 33, 1039-1104.

Blundy, J. D. \& Wood, B. J. (1991). Crystal-chemical controls on the partitioning of Sr and $\mathrm{Ba}$ between plagioclase feldspar, silicate melts, and hydrothermal solutions. Geochimica et Cosmochimica Acta 55, 193-209.

Bohrson, W. A. \& Spera, F. J. (2001). Energy-constrained open-system magmatic processes II: application of energy-constrained assimilation-fractional crystallization (EC-AFC) model to magmatic systems. Journal of Petrology 42, 1019-1041.

Bowen, N. L. (1913). The melting phenomena of the plagioclase feldspars. American Journal of Science 35, 577-599.

Bowen, N. L. (1928). The evolution of the igneous rocks: Princeton, N. J. : Princeton University Press

Brey, G. P. \& Kohler, T. (1990). Geothermobarometry in 4-phase lherzolites 2. New thermobarometers, and practical assessment of existing thermobarometers. Journal of Petrology 31, 1353-1378.

Brophy, J. G. (2008). A study of rare earth element (REE)-SiO $\mathrm{S}_{2}$ variations in felsic liquids generated by basalt fractionation and amphibole melting: a potential test for discriminating between the two different processes. Contributions to Mineralogy and Petrology 156, 337-357.

Brophy, J. G. (2009). Decompression and $\mathrm{H}_{2} \mathrm{O}$ exsolution driven crystallization and fractionation: development of a new model for low-pressure fractional crystallization in calc-alkaline magmatic systems. Contributions to Mineralogy and Petrology 157, 797-811.

Brothers, R. N. \& Martin, K. R. (1970). The geology of Macauley Island, Kermadec Group, Southwest Pacific. Bulletin Volcanologique 34, 330-346.

Brothers, R. N. \& Searle, E. J. (1970). The geology of Raoul Island, Kermadec Group, Southwest Pacific. Bulletin of Volcanology 34, 7-37.

Brugger, C. R. \& Hammer, J. E. (2010). Crystallization kinetics in continuous decompression experiments: Implications for interpreting natural magma ascent processes. Journal of Petrology 51, 1941-1965. 
Bryan, S. E., Cook, A., Evans, J. P., Colls, P. W., Wells, M. G., Lawrence, M. G., Jell, J. S., Greig, A. \& Leslie, R. (2004). Pumice rafting and faunal dispersion during 2001-2002 in the southwest Pacific: record of a dacitic submarine explosive eruption from Tonga. Earth and Planetary Science Letters 227, 135-154.

Campbell, M. E., Rowland, J. V., Wright, I. C. \& Smith, I. E. M. (2007). Oblique rifting along the central and southern Kermadec Arc from $\left(30^{\circ}-36^{\circ} \mathrm{S}\right)$, SW Pacific. Geochemistry, Geophysics, Geosystems 8, Q01007, doi:10.1029/2006GC001504.

Campbell, I. H. \& Gorton, M. P. (1980). Accessory phases and the generation of LREEenriched basalts - A test for disequilibrium melting. Contributions to Mineralogy and Petrology 72, 157-163.

Carter, R. M., Carter, L. \& McCave, I. N. (1996). Current controlled sediment deposition from the shelf to deep ocean: the Cenozoic evolution of circulation through the SW Pacific gateway. Geologische Rundschau 85, 438-451.

Cashman, K. V. \& Marsh, B. D. (1988). Crystal size distribution (CSD) in rocks and the kinetics and dynamics of crystallization II: Makaopuhi lava lake. Contributions to Mineralogy and Petrology 99, 292-305.

Castillo, P. R., Lonsdale, P. F., Morgan, C. L. \& Hawkins, J. W. (2009). Geochemistry of mid-Cretaceous Pacific crust being subducted along the Tonga-Kermadec Trench: Implications for the generation of arc lavas. Lithos 112, 87-102.

Charlier, B. L. A., Wilson, C. J. N., Lowenstern, J. B., Blake, S., van Calsteren, P. W. \& Davidson, J. P. (2005). Magma generation at a large, hyperactive silicic volcano (Taupo, New Zealand) revealed by U-Th and U-Pb systematics in zircons. Journal of Petrology 46, 3-32.

Cohen, R. S. \& O'Nions, R. K. (1982). The lead, neodymium and strontium isotopic structure of oceanic ridge basalts. Journal of Petrology 23, 299-324.

Coombs, M. L. \& Gardner, J. E. (2004). Reaction rim growth on olivine in silicic melts: implications for magma mixing. American Mineralogist 89, 748-759.

Costa, F. \& Dungan, M. (2005). Short time scales of magmatic assimilation from diffusion modeling of multiple elements in olivine. Geology 33, 837-840.

Daly, R. A. (1925). The geology of Ascension Island. Proceedings of the American Academy of Arts and Sciences 60, 1-80.

Davidson, J. P., Tepley, F. J., Palacz, Z. \& Meffan-Main, S. (2001). Magma recharge, contamination and residence times revealed by in situ laser ablation isotopic analysis of feldspar in volcanic rocks. Earth and Planetary Science Letters 184, 427-442.

Davidson, J. P., Morgan, D. J., Charlier, B. L. A., Harlou, R. \& Hora, J. M. (2007). Microsampling and isotopic analysis of igneous rocks: implications for the study of magmatic systems. Annual Review of Earth and Planetary Sciences 35, 273311 .

Deering, C. D., Vogel, T. A., Patino, L. C. \& Alvarado, G. E. (2007). Origin of distinct silicic magma types from the Guachipelím Caldera, NW Costa Rica: evidence for magma mixing and protracted subvolcanic residence. Journal of Volcanology and Geothermal Research 165, 103-126.

Delteil, J., Ruellan, E., Wright, I. \& Matsumoto, T. (2002). Structure and structural development of the Havre Trough (SW Pacific). Journal of Geophysical Research 107, 2143, doi:10.1029/2001JB000494

DeMets, C., Gordon, R. G., Argus, D. F. \& Stein, S. (1994). Effect of recent revisions to the geomagnetic reversal time scale on estimates of current plate motions. Geophysical Research Letters 21, 2191-2194.

DePaolo, D. J. (1981). Trace element and isotopic effects of combined wallrock assimilation and fractional crystallization. Earth and Planetary Science Letters 53, 189-202. 
Devine, J. D. (1995). Petrogenesis of the basalt-andesite-dacite association of the Grenada, Lesser Antilles island arc, revisited. Journal of Volcanology and Geothermal Research 69, 1-33.

Dufek, J. \& Bergantz, G. W. (2005). Transient two-dimensional dynamics in the upper conduit of a rhyolite eruption: A comparison of closure models for the granular stress. Journal of Volcanology and Geothermal Research 143, 113-132.

Eggins, S. M., Woodhead, J. D., Kinsley, L. P. J., Mortimer, G. E., Sylvester, P., McCulloch, M. T., Hergt, J. M. \& Handler, M. R. (1997). A simple method for the precise determination of $\geq 40$ trace elements in geological samples by ICPMS using enriched isotope internal standardisation. Chemical Geology 134, 311-326.

Eichelberger, J. C., Izbekov, P. E. \& Browne, B. L. (2006). Bulk chemical trends at arc volcanoes are not liquid lines of descent. Lithos 87, 135-154.

Ewart, A. \& Hawkesworth, C. J. (1987). The Pleistocene-Recent and Tonga-Kermadec arc lavas: Interpretations of new isotopic and rare earth data in terms of a depleted mantle source model. Journal of Petrology 28, 495-530.

Ewart, A., Brothers, R. N. \& Mateen, A. (1977). An outline of the geology and geochemistry, and the possible petrogenetic evolution of the volcanic rocks of the Tonga-Kermadec-New Zealand island arc. Journal of Volcanology and Geothermal Research 2, 205-250.

Ewart, A., Collerson, K. D., Regelous, M., Wendt, J. I. \& Niu, Y. (1998). Geochemical evolution within the Tonga-Kermadec-Lau arc-back-arc systems: the role of varying mantle wedge composition in space and time. Journal of Petrology 39, 331-368.

Feeley, T. C. \& Dungan, M. A. (1996). Compositional and dynamic controls on maficsilicic magma interactions at continental arc volcanoes: evidence from Cordon El Guadal, Tatara-San Pedro Complex, Chile. Journal of Petrology 37, 1547-1577.

Ferla, P. \& Meli, C. (2006). Evidence of magma mixing in the "Daly Gap" of alkaline suites; a case study from the enclaves of Pantelleria (Italy). Journal of Petrology 47, 1467-1507.

Gamble, J. A., Wright, I. C. \& Baker, J. A. (1993a). Seafloor geology and petrology in the oceanic to continental transition zone of the Kermadec-Havre-Taupo Volcanic Zone arc system, New Zealand. New Zealand Journal of Geology and Geophysics 36, 417-435.

Gamble, J. A., Smith, I. E. M., McCulloch, M. T., Graham, I. J. \& Kokelaar, B. P. (1993b). The geochemistry and petrogenesis of basalts from the Taupo Volcanic Zone and Kermadec Island Arc, S.W. Pacific. Journal of Volcanology and Geothermal Research 54, 265-290.

Gamble, J. A., Woodhead, J. D., Wright, I. C. \& Smith, I. E. M. (1996). Basalt and sediment geochemistry and magma petrogenesis in a transect from oceanic island arc to rifted continental margin arc: the Kermadec-Hikurangi margin, SW Pacific. Journal of Petrology 37, 1523-1546.

Gamble, J. A., Christie, R. H. K., Wright, I. C. \& Wysoczanski, R. J. (1997). Primitive K-rich magmas from Clark Volcano, southern Kermadec arc: A paradox in the Kdepth relationship. Canadian Mineralogist 35, 275-290.

Geist, D., Howard, K. A. \& Larson, P. (1995). The generation of oceanic rhyolites by crystal fractionation: the basalt-rhyolite association at Volcan Alcedo, Galapagos Archipelago. Journal of Petrology 36, 965-982.

Gill, J. B. (1981). Orogenic andesites and plate tectonics. Berlin: Springer.

Girard, G. \& Stix, J. (2009). Buoyant replenishment in silicic magma reservoirs: Experimental approach and implications for magma dynamics, crystal mush remobilization, and eruption. Journal of Geophysical Research 114, B08203, doi:10.1029/2008JB005791. 
Glazner, A. F., Bartley, J. M., Coleman, D. S., Gray, W. \& Taylor, R. Z. (2004). Are plutons assembled over millions of years by amalgamation from small magma chambers? GSA Today 14 (4/5), 4-11.

Goldlich, S. S., Ingamells, C. O., Suhr, N. H. \& Anderson, D. H. (1967). Analyses of silicate rock and mineral standards. Canadian Journal of Earth Sciences 4, 747755.

Ghiorso, M. S. \& Evans, B. W. (2008). Thermodynamics of rhombohedral oxide solid solutions and a revision of the Fe-Ti two-oxide geothermometer and oxygenbarometer. American Journal of Science 308, 957-1039.

Ghiorso, M. S. \& Sack, R. O. (1991). Fe-Ti oxide geothermometry: thermodynamic formulation and the estimation of intensive variables in silicic magmas. Contributions to Mineralogy and Petrology 108, 485-510.

Govindaraju, K., Potts, P. J., Webb, P. C. \& Watson, J. S. (1994). Report on Whin Sill Dolerite WS-E from England and Pitscurrie Microgabbro PM-S from Scotland: assessment by one hundred and four internal laboratories. Geostandards Newsletter 18, 211-300.

Graaf, J. H. (2006). The hydrothermal systems of Raoul Island: past and present. Unpublished M.Sc. thesis, University of Auckland, Auckland, New Zealand.

Graham, I. J., Cole, J. W., Briggs, R. M., Gamble, J. A. \& Smith, I. E. M. (1995). Petrology and petrogenesis of volcanic rocks from the Taupo Volcanic Zone: a review. Journal of Volcanology and Geothermal Research 68, 59-87.

Graham, I. J., Reyes, A. G., Wright, I. C., Peckett, K. M., Smith, I. E. M. \& Arculus, R. J. (2008). Structure and petrology of newly discovered volcanic centers in the northern Kermadec-southern Tofua arc, South Pacific Ocean. Journal of Geophysical Research 113, B08S02, doi:10.1029/2007JB005453.

Greene, A. R., DeBari, S. M., Kelemen, P. B., Blusztajn, J. \& Clift, D. (2006). A detailed geochemical study of island arc crust: the Talkeentna Arc section, southcentral Alaska. Journal of Petrology 47, 1051-1093.

Grove, T. L., Elkins-Tanton, L. E., Parman, S. W., Chatterjee, N., Muntener, O. \& Gaetani, G. A. (2003). Fractional crystallization and mantle-melting controls on calc-alkaline differentiation trends. Contributions to Mineralogy and Petrology 145, 151-533.

Haase, K. M. (2002). Geochemical constraints on magma sources and mixing processes in Easter Microplate MORB (SE Pacific): A case study of plume-ridge interaction. Chemical Geology 182, 335-355.

Haase, K. M., Worthington, T. J., Stoffers, P., Garbe-Schonberg, D. \& Wright, I. (2002). Mantle dynamics, element recycling, and magma genesis beneath the Kermadec Arc-Havre Trough. Geochemistry, Geophysics, Geosystems 3, 1071, doi:10.1029/2002GC000335.

Haase, K. M., Stroncik, N., Garbe-Schonberg, D. \& Stoffers, P. (2006). Formation of island arc dacite magmas by extreme crystal fractionation: An example from Brothers Seamount, Kermadec island arc (SW Pacific). Journal of Volcanology and Geothermal Research 152, 316-330.

Hacker, B. R., L., M., Kelemen, P. B., Rioux, M., Behn, M. D. \& Luffi, P. (2008). Reconstruction of the Talkeetna intraoceanic arc of Alaska through thermobarometry. Journal of Geophysical Research 113, B03204, doi:10.1029/2007JB005208.

Hammarstrom, J. M. \& Zen, E. A. (1986). Aluminum in hornblende - an empirical igneous geobarometer. American Mineralogist 71, 1297-1313.

Hammer, J. E. (2008). Experimental studies of the kinetics and energetics of magma crystallization. In: Putirka, K. D. \& Tepley, F. J. (eds.) Minerals, Inclusions and Volcanic Processes. Reviews in Mineralogy and Geochemistry 69, 9-52. 
Hammer, J. E. \& Rutherford, M. J. (2002). An experimental study of the kinetics of decompression-induced crystallization in silicic melt. Journal of Geophysical Research 107, doi:10.1029/2001JB000281.

Hart, S. R. (1984). A large-scale isotope anomaly in the Southern Hemisphere mantle. Nature 309, 753-757.

Hawkesworth, C. J., Blake, S., Evans, P., Hughes, R., Macdonald, R., Thomas, L. E., Turner, S. P. \& Zellmer, G. (2000). Time scales of crystal fractionation in magma chambers - integrating physical, isotopic and geochemical perspectives. Journal of Petrology 41, 991-1006.

Healy, J., Lloyd, E. F., Banwell, C. J. \& Adams, R. D. (1965). Volcanic eruption on Raoul Island, November 1964. Nature 206, 743-745.

Helz, R. T. \& Thornber, C. R. (1987). Geothermometry of Kilauea Iki lava lake, Hawaii. Bulletin of Volcanology 49, 651-668.

Hildreth, W. (1981). Gradients in silicic magma chambers: implications for lithospheric magmatism. Journal of Geophysical Research 86, 10153-10192.

Hildreth, W. (2004). Volcanological perspectives on Long Valley, Mammoth Mountain, and Mono Craters: several contiguous but discrete systems. Journal of Volcanology and Geothermal Research 136, 169-198.

Hildreth, W. \& Moorbath, S. (1988). Crustal contributions to arc magmatism in the Andes of central Chile. Contributions to Mineralogy and Petrology 98, 455-489.

Hildreth, W. \& Wilson, C. J. N. (2007). Compositional zoning of the Bishop Tuff. Journal of Petrology 48, 951-999.

Hole, M. J., Saunders, A. D., Marriner, G. F. \& Tarney, J. (1984). Subduction of pelagic sediments: implications for the origin of Ce-anomalous basalts from the Mariana Islands. Journal of the Geological Society of London 141, 453-472.

Housh, T. B. \& Luhr, J. F. (1991). Plagioclase-melt equilibria in hydrous systems. American Mineralogist 76, 477-492.

Hughes, G. R. \& Mahood, G. A. (2008). Tectonic controls on the nature of large silicic calderas in volcanic arcs. Geology 36, 627-630.

Ingamells, C. O. (1980). Analyzed minerals for electron microprobe standards. Geostandards Newsletter 2, 115.

Ito, E., White, W. M. \& Gopel, C. (1987). The O, Sr, Nd and Pb isotope geochemistry of MORB. Chemical Geology 62, 157-176.

Isacks, B. L. \& Barazangi M. (1977). Geometry of Benioff zones: lateral segmentation and downwards bending of the subducted lithosphere. In: Talwani M. \& Pitman, W. C. (eds.) Island Arcs, Deep Sea Trenches and Back-Arc Basins. M. Ewing Series I, American Geophysical Union, 99-114.

Jarosewich, E., Nelen, J. A. \& Norberg, J. A. (1980). Reference samples for electron microprobe analysis. Geostandards Newsletter 4, 43-47.

Jerram, D. A. \& Martin, V. M. (2008). Understanding crystal populations and their significance through the magma plumbing system. In: Annen, C. \& Zellmer, G. F. (eds.) Dynamics of crustal magma transfer storage and differentiation. Geological Society, London, Special Publications 304, 133-148.

Jochum, K. P., Stoll, B., Herwig, K., Willbold, M., Hofmann, A. W., Amini, M., Aarburg, S., Abouchami, W., Hellebrand, E., Mocek, B., Raczek, I., Stracke, A., Alard, O., Bouman, C., Becker, S., Ducking, M., Bratz, H., Klemd, R., de Bruin, D., Canil, D., Cornell, D., de Hoog, C. J., Dalpe, C., Danyushevsky, L., Eisenhauer, A., Gao, Y. J., Snow, J. E., Goschopf, N., Gunther, D., Latkoczy, C., Guillong, M., Hauri, E. H., Hofer, H. E., Lahaye, Y., Horz, K., Jacob, D. E., Kassemann, S. A., Kent, A. J. R., Ludwig, T., Zack, T., Mason, P. R. D., Meixner, A., Rosner, M., Misawa, K. J., Nash, B. P., Pfander, J., Premo, W. R., Sun, W. D., Tiepolo, M., Vannucci, R., Vennemann, T., Wayne, D. \& Woodhead, J. D. 
(2006). TI MPI-DING reference glasses for in situ microanalysis: New reference values for element concentrations and isotope ratios. Geochemistry, Geophysics, Geosystems 7, Q02008, doi:10.1029/2005GC001060.

Johannes, W. \& Holtz, F. (1990). Formation and composition of $\mathrm{H}_{2} \mathrm{O}$-undersaturated granitic melts. In: Ashworth, J. R. \& Brown, M. (eds.) High-Temperature Metamorphism and Crustal Anatexis, Mineralogical Society Series 2, 87-104.

Johnson, M. C. \& Rutherford, M. J. (1989). Experimental calibration of the aluminumin-hornblende geobarometer with application to Long-Valley caldera (California) volcanic rocks. Geology 17, 837-841.

Klein, E. M., Langmuir, C. H., Zindler, A., Staudigel, H. \& Hamelin, B. (1988). Isotope evidence of a mantle convection boundary at the Australian - Antarctic Discordance. Nature 333, 623-629.

Klein, E. M., Langmuir, C. H. \& Staudigel, H. (1991). Geochemistry of basalts from the Southwest Indian Ridge, $115^{\circ} \mathrm{E}-138^{\circ} \mathrm{E}$. Journal of Geophysical Research 96, 2089-2107.

Klügel, A., Hansteen, T. H. \& Galipp, K. (2005). Magma storage and underplating beneath Cumbre Vieja volcano, La Palma (Canary Islands), Earth and Planetary Science Letters 236, 211-226.

Koyaguchi, T. \& Kaneko, K. (1999). A two-stage thermal evolution model of magmas in continental crust. Journal of Petrology 40, 241-254.

Latter J.H., Lloyd E.F., Smith I.E.M., Nathan S. (1992) Volcanic Hazards in the Kermadec Islands, and at submarine volcanoes between Southern Tonga and New Zealand: Ministry of Civil Defense, 4 CD303, 44pp

Leat, P. T. \& Larter, R. D. (2003). Intra-oceanic subduction systems: introduction in Larter R.D, Leat P.T. (eds.) Intra-oceanic subduction systems: tectonic and magmatic processes. Geological Society, London, Special Publications 219, 1-17.

Leat, P. T., Smellie, J. L., Millar, I. L. \& Larter, R. D. (2003). Magmatism in the South Sandwich arc. In: Larter R. D., \& Leat P. T. (eds.) Intra-oceanic subduction systems: tectonic and magmatic processes. Geological Society, London, Special Publications 219, 285-313.

Leat, P. T., Larter, R. D. \& Millar, I. L. (2007). Silicic magmas of Protector Shoal, South Sandwich Arc: indicators of generation of primitive continental crust in an island arc. Geological Magazine 144, 179-190.

Lees, J. M. (2007). Seismic tomography of magmatic systems. Journal of Volcanology and Geothermal Research 167, 37-56.

Le Maitre, R. W., Bateman, P., Dudek, A., Keller, J., Lameyre Le Bas, M. J. Sabine, P. A., Schmid, R., Sorensen, H. Streckeisen, A., Woolley, A. R. \& Zanettin, B. (1989). A Classification of Igneous Rocks and Glossary of Terms. Oxford: Blackwell.

Lemarchand, F., Villemant, B. \& Calas, G. (1987). Trace element distribution coefficients in alkaline series. Geochimica et Cosmochimica Acta 51, 1071-1081.

Leonard, G. S., Cole, J. W., Nairn, I. A. \& Self, S. (2002). Basalt triggering of the c. AD 1305 Kaharoa rhyolite eruption, Tarawera Volcanic Complex, New Zealand. Journal of Volcanology and Geothermal Research 115, 461-486.

Lipman, P. W. (2007). Incremental assembly and prolonged consolidation of Cordilleran magma chambers: evidence from the Southern Rocky Mountain volcanic field. Geosphere 3, 42-70.

Lloyd, E. F. \& Nathan, S. (1981). Geology and tephrochronology of Raoul Island, Kermadec Group, New Zealand. New Zealand Geological Survey Bulletin 105.

Lloyd, E. F., Nathan, S., Smith, I. E. M. \& Stewart, R. B. (1996). Volcanic history of Macauley Island, Kermadec Ridge, New Zealand. New Zealand Journal of Geology and Geophysics 39, 295-308. 
Loock, G., McDonough, W. F., Goldstein, S. L. \& Hofmann, A. W. (1990). Isotopic compositions of volcanic glasses from the Lau Basin. Marine Mining 9, 235-245.

Mahoney, J. J., Sinton, J. M., Kurz, M. D., Macdougall, J. D., Spencer, K. J. \& Lugmair, G. W. (1994). Isotope and trace element characteristics of a super-fast spreading ridge: East Pacific rise, 13-23 ${ }^{\circ} \mathrm{S}$. Earth and Planetary Science Letters 121, 173-193.

Marsh, B. D. (1988). Crystal size distribution (CSD) in rocks and the kinetics and dynamics of crystallization I. Theory. Contributions to Mineralogy and Petrology 99, 277-291.

Marsh, B. D. (1996). Solidification fronts and magmatic evolution. Mineralogical Magazine 60, 5-40.

Marsh, B. D. (2004). A magmatic mush column Rosetta Stone: the McMurdo Dry Valleys of Antarctica. EOS Transactions, American Geophysical Union 85, 497502.

Martin, D. \& Nokes, R. (1988). Crystal settling in a vigorously convecting magma chamber. Nature 332, 534-536.

McFadgen, B. G. (1994). Archeology and Holocene sand dune stratigraphy on Chatham Island. Journal of the Royal Society of New Zealand 24, 17-44.

McKenzie, D. \& O'Nions, R. K. (1991). Partial melt distributions from inversion of rare earth element concentrations. Journal of Petrology 32, 1021-1091.

Miller, C. F. \& Miller, J. S. (2002). Contrasting stratified plutons exposed in tilt blocks, Eldorado Mountains, Colorado River Rift, NV, USA. Litos 61, 209-224.

Miyashiro, A. (1974). Volcanic rock series in island arcs and active continental margins. American Journal of Science 274, 321-355.

Moore, G. \& Carmichael, I. S. E. (1998). The hydrous phase equilibria (to $3 \mathrm{kbar}$ ) of an andesite and basaltic andesite from western Mexico: constraints on water content and conditions of phenocryst growth. Contributions to Mineralogy and Petrology 130, 304-319.

Morgan, D. J. \& Blake, S. (2006). Magmatic residence times of zoned phenocrysts: introduction and application of the binary element diffusion modeling (BEDM) technique. Contributions to Mineralogy and Petrology 151, 58-70.

Moriizumi, M., Nakashima, S., Okumura, S. \& Yamanoi, Y. (2008). Color-change processes of a plinian pumice and experimental constraints of color-change kinetics in air of an obsidian. Bulletin of Volcanology 71, 1-13.

Mortimer, N., Gans, P. B., Palin, J. M., Meffre, S., Herzer, R. H. \& Skinner, D. N. B. (2010). Location and migration of Miocene-Quaternary volcanic arcs in the SW Pacific region. Journal of Volcanology and Geothermal Research 190, 1-10.

Murphy, M. D., Sparks, R. S. J., Barclay, J., Carroll, M. R. \& Brewer, T. S. (2000). Remobilization of andesite magma by intrusion of mafic magma at the Soufriere Hills volcano, Montserrat, West Indies. Journal of Petrology 41, 21-42.

O’Neill, H. S. \& Pownceby, M. I. (1993). Thermodynamic data from redox reactions at high-temperatures 1. An experimental and theoretical assessment of the electrochemical method using stabilized zirconia electrolytes, with revised values for the $\mathrm{Fe}-\mathrm{FeO}, \mathrm{CO}-\mathrm{COO}, \mathrm{Ni}, \mathrm{NiO}$ and $\mathrm{Cu}-\mathrm{Cu}_{2} \mathrm{O}$ oxygen buffers, and new data for the $\mathrm{W}-\mathrm{WO}_{2}$ buffer. Contributions to Mineralogy and Petrology 114, $296-314$.

Pallister, J. S., Hoblitt, R. P. \& Reyes, A. G. (1992). A basalt trigger for the 1991 eruptions of Pinatubo volcano? Nature 356, 426-428.

Palme H. \& Beer H. (1993). Abundances of the elements in the Solar System. In: Voigt, H. H. (ed.) Astronomy and Astrophysics, Berlin: Springer 3, 196-221.

Paster, T. P., Schauwecker, D. S. \& Haskin, L. A. (1974). The behavior of some trace elements during solidification of the Skaergaard layered series. Geochimica et Cosmochimica Acta 38, 1549-1577. 
Pearce, J. A. \& Peate, D. W. (1995). Tectonic implications of the composition of volcanic arc magmas. Annual Review of Earth and Planetary Sciences 23, 251285.

Pearce, J. A., Baker, P. E., Harvey, P. K. \& Luff, I. W. (1995). Geochemical evidence for subduction fluxes, mantle melting and fractional crystallization beneath the South Sandwich Island Arc. Journal of Petrology 36, 1073-1109.

Peate, D. W., Kokfelt, T. F., Hawkesworth, C. J., van Calsteren, P., Hergt, J. M. \& Pearce, J. A. (2001). U-series isotope data on Lau Basin glasses: The role of subduction-related fluids during melt generation in back-arc basins. Journal of Petrology 42, 1449-1470.

Pelletier, B. and Dupont, J., 1990. Erosion, accretion, extension arriere-arc et longueur du plan de subduction le long de la marge active des Kermadec, Pacifique SudOuest. Comptes Rendus de l'Académie des Sciences, Paris. Serie II, 310, 1165711664.

Price, R. C., Gamble, J. A., Smith, I. E. M., Stewart, R. B., Eggins, S. M. \& Wright, I. C. (2005). An integrated model for the temporal evolution of andesites and rhyolites and crustal development in New Zealand's North Island. Journal of Volcanology and Geothermal Research 140, 1-24.

Putirka, K. D. (2005). Igneous thermometers and barometers based on plagioclase+liquid equilibria: tests of some existing models and new calibrations. American Mineralogist 90, 336-346.

Ramsey, M. H., Potts, P. J., Webb, P. C., Watkins, P., Watson, J. S. \& Coles, B. J. (1995). An objective assessment of analytical method precision: comparison of ICP-AES and XRF for the analysis of silicate rocks. Chemical Geology 124, 1-19.

Regelous, M., Collerson, K. D., Ewart, A. \& Wendt, J. I. (1997). Trace element transport rates in subduction zones: evidence from $\mathrm{Th}, \mathrm{Sr}$ and $\mathrm{Pb}$ isotope data for Tonga-Kermadec arc lavas. Earth and Planetary Science Letters 150, 291-302.

Reiners, P. W., Nelson, B. K. \& Ghiorso, M. S. (1995). Assimilation of felsic crust by basaltic magma: thermal limits and extents of crustal contamination of mantlederived magmas. Geology 23, 563-566.

Reubi, O. \& Blundy, J. (2009). A dearth of intermediate melts at subduction zone volcanoes and the petrogenesis of arc andesites. Nature 461, 1269-1273.

Reyners, M. E. (1989). New Zealand seismicity 1964-1987: an interpretation. New Zealand Journal of Geology and Geophysics 32, 307-316.

Ridolfi, F., Renzulli, A. \& Puerini, M. (2010). Stability and chemical equilibrium of amphibole in calc-alkaline magmas: an overview, new thermobarometric formulations and application to subduction-related volcanoes. Contributions to Mineralogy and Petrology 160, 45-66.

Rollinson, H. (1993). Using geochemical data: evaluation, presentation, interpretation. Harlow, England: Pearson Prentice Hall.

Ruellan, E., Delteil, J., Wright, I. \& Matsumoto, T. (2003). From rifting to active spreading in the Lau Basin - Havre Trough backarc system (SW Pacific): Locking/unlocking induced by seamount chain subduction. Geochemistry, Geophysics, Geosystems 4, 8909, doi:10.1029/2001GC000261.

Saito, T., Ishikawa, N. \& Kamata, H. (2007). Magnetic petrology of the 1991-1995 dacite lava of Unzen volcano, Japan: degree of oxidation and implication for the growth of lava domes. Journal of Volcanology and Geothermal Research 164, 268-283.

Sauerzapf, U., Lattard, D., Burchard, M. \& Engleman, R. (2008). The titanomagnetiteilmenite equilibrium: new experimental data and thermo-oxybarometric application to the crystallization of basic to intermediate rocks. Journal of Petrology 49, 1161-1185. 
Saunders, K. E., Baker, J. A. \& Wysoczanski, R. J. (2010). Microanalysis of large volume silicic magma in continental and oceanic arcs: melt inclusions in Taupo Volcanic Zone and Kermadec Arc rocks, South West Pacific. Journal of Volcanology and Geothermal Research 190, 203-218.

Schmidt, M. W. \& Poli, S. (1998). Experimentally based water budgets for dehydrating slabs and consequences for arc magma generation. Earth and Planetary Science Letters 163, 361-379.

Shane, P., Froggatt, P., Smith, I. E. M. \& Gregory, M. R. (1998). Multiple sources of the sea-rafted Loisels pumice, New Zealand. Quaternary Research 49, 271-279.

Shaw, J. E., Baker, J. A., Menzies, M. A., Thirlwall, M. F. \& Ibrahim, K. M. (2003). Petrogenesis of the largest intraplate volcanic field on the Arabian Plate (Jordan): a mixed lithosphere-asthenosphere source activated by lithospheric extension. Journal of Petrology 44, 1657-1679.

Shukuno, H., Tamura, Y., Tani, K., Chang, Q., Suzuki, T. \& Fiske, R. S. (2006). Origin of silicic magmas and the compositional gap at Sumisu submarine caldera, IzuBonin arc, Japan. Journal of Volcanology and Geothermal Research 156, 187216.

Sisson, T. W. \& Bacon, C. R. (1999). Gas-driven filter pressing in magmas. Geology 27, 613-616.

Sisson, T. W. \& Grove, T. L. (1993). Experimental investigations of the role of H2O in calc-alaline differentiation and subduction zone magmatism. Contributions to Mineralogy and Petrology 113, 143-166.

Sisson, T. W., Ratajeski, K., Hankins, W. B. \& Glazner, A. F. (2005). Voluminous granitic magmas from common basaltic sources. Contributions to Mineralogy and Petrology 148, 635-661.

Smith, I. E. M. \& Price, R. C. (2006). The Tonga-Kermadec arc and Havre-Lau backarc system: Their role in the development of tectonic and magmatic models for the western Pacific. Journal of Volcanology and Geothermal Research 156, 315331 .

Smith, I. E. M., Brothers, R. N., Muiruri, F. G. \& Browne, P. R. L. (1988). The geochemistry of rock and water from samples from Curtis Island volcano, Kermadec Group, southwest Pacific. Journal of Volcanology and Geothermal Research 34, 233-240.

Smith, I. E. M., Stewart, R. B. \& Price, R. C. (2003a). The petrology of a large intraoceanic silicic eruption: the Sandy Bay Tephra, Kermadec Arc, Southwest Pacific. Journal of Volcanology and Geothermal Research 124, 173-194.

Smith, I. E. M., Worthington, T., Stewart, R. B., Price, R. C. \& Gamble, J. A. (2003b). Felsic volcanism in the Kermadec arc, SW Pacific: crustal recycling in an oceanic setting. In: Larter, R. D. \& Leat, P. T. (eds.) Intra-Oceanic Subduction Systems: Tectonic and Magmatic Processes. London: Geological Society of London, Special Publications 219, 99-118.

Smith, I. E. M., Worthington, T. J., Price, R. C., Stewart, R. B. \& Maas, R. (2006). Petrogenesis of dacite in an oceanic subduction environment: Raoul Island, Kermadec arc. Journal of Volcanology and Geothermal Research 156, 252-265.

Smith, I. E. M., Stewart, R. B., Price, R. C. \& Worthington, T. J. (2010). Are arc-type rocks the products of magma crystallisation? Observations from a simple oceanic arc volcano: Raoul Island, Kermadec Arc, SW Pacific. Journal of Volcanology and Geothermal Research 190, 219-234.

Smith, V. C., Blundy, J. D. \& Arce, J. L. (2009). A temporal record of magma accumulation and evolution beneath Nevado de Toluca, Mexico, preserved in plagioclase phenocrysts. Journal of Petrology 50, 405-426.

Sparks, R. S. J., Sigurdsson, H. \& Wilson, L. (1977). Magma mixing: a mechanism for 
triggering acid explosive eruptions. Nature 267, 315-318.

Sun, S.-s. \& McDonough, W. F. (1989). Chemical and isotopic systematics of oceanic basalts: implications for mantle composition and process. In: Saunders, A. D. \& Norry, M. J. (eds) Magmatism in the Ocean Basins. Geological Society, London, Special Publications 42, 313-345.

Tait, S., Thomas, R., Gardner, J. \& Jaupart, C. (1998). Constraints on cooling rates and permeabilities of pumice in an explosive eruption jet from colour and magnetic mineralogy. Journal of Volcanology and Geothermal Research 86, 79-91.

Takada, A. (1994). The influence of regional stress and magmatic input on styles of monogenetic and polygenetic volcanism. Journal of Geophysical Research 99, 13563-13573.

Tamura, Y. \& Tatsumi, Y. (2002). Remelting of an andesitic crust as a possible origin for rhyolitic magma in oceanic arcs: an example from the Izu-Bonin arc. Journal of Petrology 43, 1029-1047.

Tamura, Y., Gill, J. B., Tollstrup, D., Kawabata, H., Shukuno, H., Chang, Q., Miyazaki, T., Takahashi, T., Hirahara, Y., Kodaira, S., Ishizuka, O., Suzuki, T., Kido, Y., Fiske, R. S. \& Tatsumi, Y. (2009). Silicic magmas in the Izu-Bonin oceanic arc and implications for crustal evolution. Journal of Petrology 50, 685-723.

Tani, K., Kawabata, H., Chang, Q., Sato, K. \& Tatsumi, Y. (2003). Quantitative analyses of silicate rock major and trace elements by X-ray fluorescence spectrometer: Evaluation of analytical precision and sample preparation. Frontier Research on Earth Evolution 2, Article 2-16, 8 pp.

Tani, K., Fiske, R. S., Tamura, Y., Kido, Y., Naka, J., Shukuno, H. \& Takeuchi, R. (2008). Sumisu volcano, Izu-Bonin arc, Japan: site of a silicic caldera-forming eruption from a small open-ocean island. Bulletin of Volcanology 70, 547-562.

Tatsumi, Y. \& Eggins, S. (1995). Subduction zone magmatism. Cambridge, MA: Blackwell Science.

Taylor, B., Zellmer, K. Martinez F. \& Goodliffe, A. (1996). Sea-floor spreading in the Lau back-arc basin. Earth and Planetary Science Letters 144, 35-40.

Thompson, A. B., Matile, L. \& Ulmer, P. (2002). Some thermal constraints on crustal assimilation during fractionation of hydrous, mantle-derived magmas with examples from Central Alpine batholiths. Journal of Petrology 43, 403-422.

Thompson, M., Potts, P. J., Kane, J. S. \& Webb, P. C. (1996). GeoPT1 International proficiency test for analytical geochemistry laboratories - Report on round 1. Geostandards Newsletter 20, 295-325.

Thompson, M., Potts, P. J. Kane, J. S., Webb, P. \& Watson, J. S. (2000). GeoPT4. International proficiency test for analytical geochemistry laboratories - Report on round 4. Geostandards Newsletter 24, E1-E37.

Tindle, A. G. \& Pearce, J. A. (1981). Petrogenetic modeling of in situ fractional crystallization in the zoned Loch Doon pluton, Scotland. Contributions to Mineralogy and Petrology 78, 196-207.

Todd, E., Gill, J. B., Wysoczanski, R. J., Handler, M. R., Wright, I. C. \& Gamble, J. A. (2010). Sources of constructional cross-chain volcanism in the southern Havre Trough: New insights from HFSE and REE concentration and isotope systematics. Geochemistry, Geophysics, Geosystems 11, Q04009, doi:10.1029/2009GC002888.

Turner, S., Hawkesworth, C. J., Rogers, N. W. B., Bartlett, J., Worthington, T. J., Hergt, J., Pearce, J. A. \& Smith, I. E. M. (1997). ${ }^{238} \mathrm{U}^{230}$ Th disequilibria, magma petrogenesis, and flux rates beneath the depleted Tonga-Kermadec island arc. Geochimica et Cosmochimica Acta 61, 4855-4884.

Ukstins-Peate, I., Kent, A. J. R., Baker, J. A. \& Menzies, M. A. (2008). Extreme geochemical heterogeneity in Afro-Arabian Oligocene tephras: Preserving 
fractional crystallization and mafic recharge processes in silicic magma chambers. Lithos 102, 260-278.

Vigneresse, J. L., Barbey, P. \& Cuney, M. (1996). Rheological transitions during partial melting and crystallization with application to felsic magma segregation and transfer. Journal of Petrology 37, 1579-1600.

Vogel, T. A., Patino, L. C., Alvarado, G. E. \& Gans, P. B. (2004). Silicic ignimbrites within the Costa Rican volcanic front evidence for the formation of continental crust. Earth and Planetary Science Letters 226, 149-159.

Vogel, T. A., Patino, L. C., Eaton, J. K., Valley, J. W., Rose, W. I., Alvarado, G. E. \& Viray, E. L. (2006a). Origin of silicic magmas along the Central American volcanic front: Genetic relationship to mafic melts. Journal of Volcanology and Geothermal Research 156, 217-228.

Vogel, T. A., Flood, T. P., Patino, L. C., Wilmot, M. S., Maximo, R. P. R., Arpa, C. B., Arcilla, C. A. \& Stimac, J. A. (2006b). Geochemistry of silicic magmas in the Macolod Corridor, SW Luzon, Philippines: evidence of distinct, mantle-derived, crustal sources for silicic magmas. Contributions to Mineralogy and Petrology 151, 267-281.

Wade, J. A., Plank, T., Stern, R. J., Tollstrup, D. L., Gill, J. B., O'Leary, J. C., Eiler, J. M., Moore, R. B., Woodhead, J. D., Trusdell, F., Fischer, T. P. \& Hilton, D. R. (2005). The May 2003 eruption of Anatahan volcano, Mariana Islands: Geochemical evolution of a felsic island-arc volcano. Journal of Volcanology and Geothermal Research 146, 139-170.

Wallace, L., Reyners, M., Cochran, U., Bannister, S., Barnes, P. M., Berryman, K., Downes, G., Eberhart-Phillips, D., Fagereng, A., Ellis, S., Nicol, A., McCaffrey, R., Beaven, R. J., Henrys, S., Sutherland, R., Barker, D. H. N., Litchfield, N., Townend, J., Robinson, R., Bell, R., Wilson, K. \& Power, W. (2009). Characterizing the seismogenic zone of a major plate boundary subduction thrust: Hikurangi Margin, New Zealand. Geochemistry, Geophysics, Geosystems 10, Q10006, doi:10.1029/2009GC002610.

White, W. M., Hofmann, A. W. \& Puchelt, H. (1987). Isotope geochemistry of Pacific mid-ocean ridge basalt. Journal of Geophysical Research 92, 4881-4893.

Wilson, C. J. N. \& Charlier, B. L. A. (2009). Rapid rates of magma generation at contemporaneous magma systems, Taupo volcano, New Zealand: insights from U-Th model-age spectra in zircons. Journal of Petrology 50, 875-907.

Wilson, C. J. N., Houghton, B. F., McWilliams, M. O., Lanphere, M. A., Weaver, S. D. \& Briggs, R. M. (1995). Volcanic and structural evolution of Taupo Volcanic Zone, New Zealand: a review. Journal of Volcanology and Geothermal Research 68, $1-28$.

Wilson, C. J. N., Blake, S., Charlier, B. L. A. \& Sutton, A. N. (2006). The 26.5 ka Oruanui eruption, Taupo volcano, New Zealand: development, characteristics and evacuation of a large rhyolitic magma body. Journal of Petrology 47, 35-69.

Woods, A. W. \& Cowan, A. (2009). Magma mixing triggered during volcanic eruptions. Earth and Planetary Science Letters 288, 132-137.

Worthington, T. J. (1998). Geology and petrology of Raoul volcano: magma genesis and fractionation processes beneath the Tonga-Kermadec arc. Unpublished Ph.D. thesis, University of Auckland, Auckland, New Zealand.

Worthington, T. J., Gregory, M. R. \& Bondarenko, V. (1999). The Denham Caldera on Raoul Volcano: dacite volcanism in the Tonga-Kermadec arc. Journal of Volcanology and Geothermal Research 90, 29-48.

Wright, I. C. (1993). Pre-spread rifting and heterogeneous volcanism in the southern Havre Trough back-arc basin. Marine Geology 113, 179-200.

Wright, I. C. (1994). Nature and tectonic setting of the southern Kermadec submarine 
arc volcanoes: An overview. Marine Geology 118, 217-236.

Wright, I. C. (1996). Volcaniclastic processes on modern submarine arc stratovolcanoes: sidescan and photographic evidence from the Rumble IV and V volcanoes, southern Kermadec Arc (SW Pacific). Marine Geology 136, 21-39.

Wright, I. C. (1997). Morphology and evolution of the remnant Colville and active Kermadec Arc ridges south of $33^{\circ} 30^{\prime}$ S. Marine Geophysical Researches 19, $177-$ 193.

Wright, I. C. (2001). In situ modification of modern submarine hyaloclastic/pyroclastic deposits by ocean currents: an example from the Southern Kermadec arc (SW Pacific). Marine Geology 172, 287-307.

Wright, I. C. \& Gamble, J. A. (1999). Southern Kermadec submarine caldera arc volcanoes (SW Pacific): caldera formation by effusive and pyroclastic eruption. Marine Geology 161, 207-227.

Wright, I. C., Stoffers, P., Hannington, M., de Ronde, C. E. J., Herzig, P., Smith, I., E.M. \& Browne, P. R. L. (2002). Towed-camera investigations of shallowintermediate water-depth submarine stratovolcanoes of the southern Kermadec arc, New Zealand. Marine Geology 185, 207-218.

Wright, I. C., Gamble, J. A. \& Shane, P. A. R. (2003). Submarine silicic volcanism of the Healy caldera, southern Kermadec arc (SW Pacific): I - volcanology and eruption mechanisms. Bulletin of Volcanology 65, 15-29.

Wright, I. C., Worthington, T. J. \& Gamble, J. A. (2006). New multibeam mapping and geochemistry of the $30^{\circ}-35^{\circ} \mathrm{S}$ sector, and overview of southern Kermadec arc volcanism. Journal of Volcanology and Geothermal Research 149, 263-296.

Wright, T. L. \& Okamura, R. T. (1977). Cooling and crystallization of tholeiitic basalt, 1965 Makaopuhi lava lake, Hawaii. U.S. Geological Survey Professional Paper 1004, 78 pp.

Wysoczanski, R. J., Wright, I. C., Gamble, J. A., Hauri, E. H., Luhr, J. F., Eggins, S. M. \& Handler, M. R. (2006). Volatile contents of Kermadec Arc-Havre Trough pillow glasses: fingerprinting slab-derived aqueous fluids in the mantle sources of arc and back-arc lavas. Journal of Volcanology and Geothermal Research 152, $51-73$.

Wysoczanski, R. J., Todd, E., Wright, I. C., Leybourne, M. I., Hergt, J. M., Adam, C. \& Mackay, K. (2010). Backarc rifting, constructional volcanism and nascent disorganised spreading in the southern Havre Trough backarc rifts (SW Pacific). Journal of Volcanology and Geothermal Research 190, 39-57. 


\section{Supplementary Information}

Appendix A. Sample information

Appendix B. Whole rock major element data

Appendix C. Whole rock trace element data

Appendix D. Whole rock $\mathrm{Pb}$ isotope data

Appendix E. Glass major element data

Appendix F. Mineral major element data

Appendix G. Mineral trace element data 


\section{APPENDIX A: Sample Information}

Table A.1. Sample details and descriptions 
Table A.1. Details and descriptions of all the samples analysed in this study

\begin{tabular}{|c|c|c|c|c|c|c|}
\hline Sample no. & Eruption / location & XRF & xl work & ICPMS & Isotopes & Description \\
\hline \multicolumn{7}{|c|}{ Raoul volcano: Pumice } \\
\hline RI06_PC06 & Matatirohia - mid-upper fall & $\mathbf{x}$ & & & & $\begin{array}{l}15 \mathrm{~cm} \text { long pumice fragment, oxidised pink-purple core. Many small }(<1 \mathrm{~mm}) \text { mafic blebs; total } 2-3 \text { vol. \%. 3-5 } \\
\text { vol. \% crystals; plag }<\mathrm{cpx}<\mathrm{opx}<\mathrm{mag}<<\text { ol. }\end{array}$ \\
\hline RI06_PC07 & Matatirohia - mid-upper fall & $\mathbf{x}$ & & $\mathbf{x}$ & & $\begin{array}{l}20 \mathrm{~cm} \text { long pumice fragment, oxidised core. Many mafic blebs, mostly }<1 \mathrm{~mm} \text { but one large in core }(2 \mathrm{~cm}) \text {; total } \\
5 \mathrm{vol} . \% \text {. } 3-5 \text { vol. } \% \text { crystals; plag }<\mathrm{cpx}<\mathrm{opx}<\operatorname{mag}<<\text { ol. }\end{array}$ \\
\hline RI06_PC11 & Matatirohia - mid-upper fall & $\mathbf{x}$ & & & & $\begin{array}{l}10 \mathrm{~cm} \text { long pumice broken into } 4 \text { fragments, oxidised core. A few small mafic blebs; total } 1-2 \text { vol. } \% \text {. }<3-5 \text { vol. } \% \\
\text { crystals; plag }<\mathrm{cpx}<\mathrm{opx}<\mathrm{mag}<<\text { ol. }\end{array}$ \\
\hline RI06_PC12 & Matatirohia - mid-upper fall & $\mathbf{x}$ & $\mathbf{x}$ & $\mathbf{x}$ & & $\begin{array}{l}20 \mathrm{~cm} \text { long pumice fragment, oxidised core, large vesicles. Some large mafic blebs in core }(2 \mathrm{~cm}) \text {; total } 5 \text { vol. } \% \text {. } \\
3-5 \text { vol. } \% \text { crystals; plag }<\mathrm{cpx}<\mathrm{opx}<\mathrm{mag}<<\text { ol. }\end{array}$ \\
\hline RI12_PC08 & Oneraki - mid-upper fall & $\mathbf{x}$ & $\mathbf{x}$ & $\mathbf{x}$ & $\mathbf{x}$ & $\begin{array}{l}15 \mathrm{~cm} \text { long pumice fragment, oxidised pink-purple core. A few small }(<1 \mathrm{~mm}) \text { mafic blebs; total } 1-2 \text { vol. } \% .<3-5 \\
\text { vol. \% crystals; plag }<\mathrm{cpx}<\mathrm{opx}<\mathrm{mag}<<\text { quartz. }\end{array}$ \\
\hline RI12_PC15 & Oneraki - near basal fall & $\mathbf{x}$ & & & & $\begin{array}{l}12 \mathrm{~cm} \text { long pumice fragment, oxidised pink core. Many small }(<1 \mathrm{~mm}) \text { mafic blebs; total } 1-2 \mathrm{vol} \text {. } \% \text {. Also contains } \\
1-2 \mathrm{~cm} \text { sized rounded white plutonic fragments; total } 2-3 \text { vol. } \% \text {. }<3-5 \text { vol. } \% \text { crystals; plag }<\mathrm{cpx}<\mathrm{opx}<\operatorname{mag}<< \\
\text { quartz. }\end{array}$ \\
\hline RI12_PC18 & Oneraki - near basal fall & $\mathbf{x}$ & & $\mathbf{x}$ & & $\begin{array}{l}15 \mathrm{~cm} \text { long pumice fragment, oxidised pink dark-purple highly vesicular core. No observed mafic blebs. }<1-2 \text { vol. } \\
\% \text { crystals; plag }<\mathrm{cpx}<\mathrm{opx}<\operatorname{mag} .\end{array}$ \\
\hline RI12_PC19 & Oneraki - near basal fall & $\mathbf{x}$ & & & & $\begin{array}{l}25 \mathrm{~cm} \text { long pumice fragment, oxidised pink-purple highly vesicular core. Small mafic blebs coating large vesicles; } \\
2-3 \text { vol. } \% .<1-2 \text { vol. } \% \text { crystals; plag }<\mathrm{cpx}<\mathrm{opx}<\operatorname{mag}<<\text { quartz. }\end{array}$ \\
\hline RI15_PC07 & Fleetwood - mid fall & $\mathbf{x}$ & & & & $\begin{array}{l}25 \mathrm{~cm} \text { long pumice fragment, oxidised pink purple-grey highly vesicular core. No mafic blebs observed. }<1-2 \text { vol. } \\
\% \text { crystals; plag }<\mathrm{cpx}<\mathrm{opx}<\mathrm{mag}<<\mathrm{ol} .\end{array}$ \\
\hline RI26_PC01 & Fleetwood - upper flow & $\mathbf{x}$ & $\mathbf{x}$ & $\mathbf{x}$ & $\mathbf{x}$ & $\begin{array}{l}15 \mathrm{~cm} \text { long pumice fragment, oxidised pink core. Only a few small mafic blebs; }<1-2 \text { vol. } \% \text {. }<3-5 \text { vol. } \% \text { crystals; } \\
\text { plag }<\mathrm{cpx}<\mathrm{opx}<\mathrm{mag}\end{array}$ \\
\hline RI26_PC02 & Fleetwood - upper flow & $\mathbf{x}$ & & & & $\begin{array}{l}25 \mathrm{~cm} \text { pumice broken into fragments, oxidised pink-purple core. Only a few small mafic blebs; }<3-5 \text { vol. } \% .<1-2 \\
\text { vol. \% crystals; plag }<\mathrm{cpx}<\mathrm{opx}<\text { mag }<<\text { ol. }\end{array}$ \\
\hline RI26_PC04 & Fleetwood - upper flow & $\mathbf{x}$ & & $\mathbf{x}$ & & $\begin{array}{l}15 \mathrm{~cm} \text { pumice broken into fragments, oxidised pink-purple core. Many small mafic blebs and } 1 \text { large } \mathrm{cm} \text {-sized } \\
\text { large bleb; }<3-5 \text { vol. } \% .<1-2 \text { vol. } \% \text { crystals; plag }<\mathrm{cpx}<\mathrm{opx}<\operatorname{mag}<<\text { ol. }\end{array}$ \\
\hline RI18_PC02 & Green Lake Pumice - mid fall & $\mathbf{x}$ & & & & $\begin{array}{l}25 \mathrm{~cm} \text { pumice broken into fragments, oxidised orange. Several creamy white-grey crystalline inclusions (quartz); } \\
<1-2 \text { vol. } \% .<1-2 \text { vol. } \% \text { crystals; plag }<\mathrm{cpx}<\mathrm{opx}<\mathrm{mag}<\text { quartz }\end{array}$ \\
\hline RI18_PC03 & Green Lake Pumice - mid fall & $\mathbf{x}$ & & & & $\begin{array}{l}30 \mathrm{~cm} \text { long pumice , oxidised orange. No inclusions observed. }<1-2 \text { vol. } \% \text { crystals; plag }<\mathrm{cpx}<\text { opx }<\text { mag }<< \\
\text { quartz }\end{array}$ \\
\hline RI18_PC04 & Green Lake Pumice - mid fall & $\mathbf{x}$ & & $\mathbf{x}$ & & $\begin{array}{l}25 \mathrm{~cm} \text { long pumice, oxidised orange. Several white-grey crystalline inclusions, } 1 \text { large } \mathrm{cm} \text {-sized grey inclusion; } \\
<1-2 \text { vol. } \% \text { total. }<1-2 \text { vol. } \% \text { crystals; plag }<\mathrm{cpx}<\mathrm{opx}<\mathrm{mag}<\text { quartz }\end{array}$ \\
\hline RI18_PC05 & Green Lake Pumice - mid fall & $\mathbf{x}$ & $\mathbf{x}$ & $\mathbf{x}$ & $\mathbf{x}$ & $\begin{array}{l}25 \mathrm{~cm} \text { long pumice, oxidised orange, highly vesicular core. No inclusions observed. }<1-2 \text { vol. } \% \text { crystals; plag }< \\
\mathrm{cpx}<\text { opx }<\text { mag }<<\text { quartz }\end{array}$ \\
\hline
\end{tabular}


Table A.1. Continued

\begin{tabular}{|c|c|c|c|c|c|c|}
\hline Sample no. & Eruption / location & XRF & xI work & ICPMS & Isotopes & Description \\
\hline$\overline{R I 08 \_P C 09}$ & Floated pumice unit & $\mathbf{x}$ & & $\mathbf{x}$ & & $\begin{array}{l}15 \mathrm{~cm} \text { long pumice, light grey colour, blocky and less vesicular than other samples. No inclusions observed. }<1- \\
2 \text { vol. } \% \text { crystals; plag }<\mathrm{px}<\text { mag. }\end{array}$ \\
\hline RI03_PC03 & Rangitahua - mid fall & $\mathbf{x}$ & $\mathbf{x}$ & $\mathbf{x}$ & $\mathbf{x}$ & $\begin{array}{l}10 \mathrm{~cm} \text { long pumice, mid grey colour, angular and dense. No inclusions observed. }<1-2 \text { vol. } \% \text { crystals; plag }<p x \\
<\text { mag. Distinctive light brown clay coating on exterior. }\end{array}$ \\
\hline RI03_PC09 & Rangitahua - mid fall & $\mathbf{x}$ & & & & $\begin{array}{l}10 \mathrm{~cm} \text { long pumice, mid grey-brown colour, angular and dense. No inclusions observed. }<1-2 \text { vol. } \% \text { crystals; } \\
\text { plag }<\text { px }<\text { mag. Distinctive light brown clay coating on exterior, and also in vesicles. }\end{array}$ \\
\hline RI03_PC10 & Rangitahua - mid fall & $\mathbf{x}$ & & $\mathbf{x}$ & & $\begin{array}{l}15 \mathrm{~cm} \text { pumice in fragments, mid grey-brown colour, poorly vesicular. No inclusions observed. }<1-2 \text { vol. } \% \\
\text { crystals; plag }<\text { px < mag. Distinctive light brown clay coating on exterior, and also in vesicles. }\end{array}$ \\
\hline RI19_PC01 & 2006 breccia & $\mathbf{x}$ & & $\mathbf{x}$ & & $\begin{array}{l}15 \mathrm{~cm} \text { long pumice, dark grey colour, poorly vesicular. A single } \mathrm{cm} \text {-sized dark inclusion observed. }<1-2 \text { vol. } \% \\
\text { crystals; plag }<\text { px }<\text { mag. Distinctive light brown clay coating on exterior. }\end{array}$ \\
\hline \multicolumn{7}{|c|}{ Raoul volcano: Plutonic lithics } \\
\hline RI06_R01 & Beach rubble below Ngaio & $\mathbf{x}$ & $\mathbf{x}$ & $\mathbf{x}$ & $\mathbf{x}$ & $\begin{array}{l}20 \mathrm{~cm} \text { sized leucocratic plutonic fragment. Very fresh crystalline granular texture, most crystals } 1-3 \mathrm{~mm} \text { in size. } \\
\text { Small light grey inclusions. plag }<\text { qtz }<\text { epidote }<\text { actinolite }<<\text { spinel }<<\text { ilm } \ll<<\text { zircon. }\end{array}$ \\
\hline R06_05 MB02 & Matatirohia - mid-upper fall & $\mathbf{x}$ & & $\mathbf{x}$ & $\mathbf{x}$ & $\begin{array}{l}4 \mathrm{~cm} \text { sized, dark grey cauliform mafic bleb. Adhering pink pumice glass on exterior. } 10-15 \text { vol. } \% \text { of crystals }> \\
1 \mathrm{~mm} \text {, mostly groundmass/microlites. Poorly vesiculated glass. Plag }<\mathrm{cpx}<\mathrm{ol}<\mathrm{opx}<\mathrm{mnt} .\end{array}$ \\
\hline R06_05 MB11 & Matatirohia - mid-upper fall & $\mathbf{x}$ & $\mathbf{x}$ & $\mathbf{x}$ & & $\begin{array}{l}3 \mathrm{~cm} \text { sized, dark grey cauliform mafic bleb. Adhering pink pumice glass on exterior. } 15-20 \text { vol. } \% \text { of crystals }> \\
1 \mathrm{~mm} \text {, mostly groundmass/microlites. Poorly vesiculated glass. Plag }<\mathrm{cpx}<\mathrm{ol}<\mathrm{opx}<\mathrm{mnt} .\end{array}$ \\
\hline RIRBW_01 & Beach rubble below Ngaio & & $\mathbf{x}$ & & & $\begin{array}{l}20 \mathrm{~cm} \text { sized gabbroic fragment. }>90 \% \text { crystals, mostly } 2-3 \mathrm{~mm} \text { in size (but up to } 1 \mathrm{~cm} \text { ). Some interstitial dark } \\
\text { grey vesiculated glass. Very fragile, crumbles in hand. Plag }<\mathrm{cpx}<\mathrm{ol}<\mathrm{opx}<\mathrm{mnt} \text {. }\end{array}$ \\
\hline \multicolumn{7}{|c|}{ Macauley volcano: Pumice } \\
\hline MI07_PC02 & Sandy Bay Tephra & $\mathbf{x}$ & & & & $\begin{array}{l}15 \mathrm{~cm} \text { long pumice, light grey-brown colour. Long elongated vesicles. Very few mafic blebs }<<1 \text { vol. } \% \text {. crystals } \\
<1-3 \text { vol. \%; plag }<\mathrm{cpx}<\mathrm{opx}<\mathrm{mag}<\text { ilm }<<\text { ol. }\end{array}$ \\
\hline MI07_PC03 & Sandy Bay Tephra & $\mathbf{x}$ & $\mathbf{x}$ & $\mathbf{x}$ & $\mathbf{x}$ & $\begin{array}{l}15 \mathrm{~cm} \text { long pumice, light grey-brown colour. Highly vesicular, most }<1-2 \mathrm{~mm} \text {. Small mafic blebs }<1 \text { vol. } \% \text {. } \\
\text { crystals }<1-3 \text { vol. } \% \text {; plag }<\mathrm{cpx}<\mathrm{opx}<\mathrm{mag}<\text { ilm }<<\text { ol. }\end{array}$ \\
\hline MI01_PC05 & Sandy Bay Tephra & $\mathbf{x}$ & & $\mathbf{x}$ & & $\begin{array}{l}20 \mathrm{~cm} \text { long pumice, light grey-brown colour. Vesicularity gradient with dense darker core with large }(\mathrm{cm}) \text {. Small } \\
\text { mafic blebs }<1 \text { vol. } \% \text {. crystals }<1-3 \text { vo. } \% \text {; plag }<\mathrm{cpx}<\mathrm{opx}<\mathrm{mag}<\text { ilm }<<0 \text { l. }\end{array}$ \\
\hline MI07_PC13 & Sandy Bay Tephra & $\mathbf{x}$ & & & & $\begin{array}{l}15 \mathrm{~cm} \text { long pumice, light grey-brown colour. Finely vesicular, dense crust. No mafic blebs observed. crystals }<1-3 \\
\text { vol. \%; plag }<\mathrm{cpx}<\mathrm{opx}<\mathrm{mag}<\mathrm{ilm}<<\mathrm{Ol} \text {. }\end{array}$ \\
\hline D24_PC01 & Distal SW caldera flank & $\mathbf{x}$ & & $\mathbf{x}$ & & $\begin{array}{l}8 \mathrm{~cm} \text { long pumice, white coloured core. Finely vesicular with large open vesicles. No mafic blebs observed. } \\
\text { crystals }<1-3 \text { vol. \%; plag }<\mathrm{cpx}<\mathrm{opx}<\text { mag. }\end{array}$ \\
\hline D24_PC02 & Distal SW caldera flank & $\mathbf{x}$ & & $\mathbf{x}$ & & $\begin{array}{l}8 \mathrm{~cm} \text { long pumice, light brown coloured core. Finely vesicular rim, large open vesicles in core. No mafic blebs } \\
\text { observed. crystals }<1-3 \text { vol. \%; plag }<\mathrm{cpx}<\mathrm{opx}<\text { mag. }\end{array}$ \\
\hline
\end{tabular}


Table A.1. Continued

\begin{tabular}{|c|c|c|c|c|c|c|}
\hline Sample no. & Eruption / location & XRF & xl work & ICPMS & Isotopes & Description \\
\hline D24_PC03 & Distal SW caldera flank & $\mathbf{x}$ & & & & $\begin{array}{l}12 \mathrm{~cm} \text { long pumice, light brown coloured core. Finely vesicular rim, large open vesicles in core. No mafic blebs, } \\
\text { but some large }(3-5 \mathrm{~mm}) \text { crystal clusters. crystals }<1-3 \text { vol. } \% \text {; plag }<\mathrm{cpx}<\mathrm{opx}<\text { mag. }\end{array}$ \\
\hline D24_PC04 & Distal SW caldera flank & $\mathbf{x}$ & & $\mathbf{x}$ & $\mathbf{x}$ & $\begin{array}{l}10 \mathrm{~cm} \text { long pumice, light brown coloured. Elongated vesicles, almost tube pumice. No mafic blebs, but some } \\
\text { large }(3-5 \mathrm{~mm}) \text { crystal clusters. crystals }<1-3 \text { vol. \%; plag }<\mathrm{cpx}<\mathrm{opx}<\text { mag. }\end{array}$ \\
\hline D24_PC05 & Distal SW caldera flank & $\mathbf{x}$ & & & & $\begin{array}{l}5 \mathrm{~cm} \text { long pumice, light brown colour. Highly vesicular, very low density. No mafic blebs observed. crystals }<1-3 \\
\text { vol. \%; plag }<\mathrm{cpx}<\mathrm{opx}<\mathrm{mag} \text {. }\end{array}$ \\
\hline D24_PC06 & Distal SW caldera flank & $\mathbf{x}$ & & & & $\begin{array}{l}10 \mathrm{~cm} \text { long pumice, light brown coloured. Highly vesicular core, dense crusted rim. No mafic blebs, but some } \\
\text { large }(1-3 \mathrm{~mm}) \text { crystal clusters. crystals }<1-3 \text { vol. } \% \text {; plag }<\mathrm{cpx}<\mathrm{opx}<\mathrm{mag} \text {. }\end{array}$ \\
\hline D25_PC01 & Proximal SW caldera flank & $\mathbf{x}$ & $\mathbf{x}$ & $\mathbf{x}$ & & $\begin{array}{l}15 \mathrm{~cm} \text { long pumice, light brown coloured. Some very large vesicles }(3-4 \mathrm{~cm}) \text {. No mafic blebs. crystals }<1-3 \text { vol. } \\
\% \text {; plag }<\mathrm{cpx}<\mathrm{opx}<\mathrm{mag} \text {. }\end{array}$ \\
\hline D25_PC02 & Proximal SW caldera flank & $\mathbf{x}$ & & & & $\begin{array}{l}10 \mathrm{~cm} \text { long pumice, light brown coloured. Slight vesicularity gradient, generally highly vesicular. No mafic blebs, } \\
\text { but some large }(1-3 \mathrm{~mm}) \text { crystal clusters. crystals }<1-3 \text { vol. } \% \text {; plag }<\mathrm{cpx}<\mathrm{opx}<\mathrm{mag} \text {. }\end{array}$ \\
\hline D25_PC03 & Proximal SW caldera flank & $\mathbf{x}$ & & & & $\begin{array}{l}8 \mathrm{~cm} \text { long pumice, dark brown coloured. Elongated vesicles, dense, almost tube pumice. No mafic blebs. } \\
\text { crystals }<1-3 \text { vol. } \% \text {; plag }<\mathrm{cpx}<\mathrm{opx}<\text { mag. }\end{array}$ \\
\hline D26_PC01 & W caldera rim & $\mathbf{x}$ & & & & $\begin{array}{l}7 \mathrm{~cm} \text { long pumice, light grey-brown colour. Highly vesicular, mostly }<1-2 \mathrm{~mm} \text {. no mafic blebs. crystals }<1-3 \text { vol. } \\
\% \text {; plag }<\mathrm{cpx}<\mathrm{opx}<\mathrm{mag}\end{array}$ \\
\hline D26_PC02 & W caldera rim & $\mathbf{x}$ & & & & $\begin{array}{l}6 \mathrm{~cm} \text { long pumice, light-mid brown colour. Poorly vesicular, slight gradient, some vesicles elongated. no mafic } \\
\text { blebs. crystals }<1-3 \mathrm{vol} . \% \text {; plag }<\mathrm{cpx}<\mathrm{opx}<\operatorname{mag}\end{array}$ \\
\hline D29_PC01 & $\mathrm{N}$ caldera rim & $\mathbf{x}$ & & $\mathbf{x}$ & & $\begin{array}{l}25 \mathrm{~cm} \text { long pumice, light brown coloured. Some very large vesicles }(3-4 \mathrm{~cm}) \text {. Slight gradient on one side. No } \\
\text { mafic blebs. crystals }<1-3 \text { vol. } \% \text {; plag }<\mathrm{cpx}<\mathrm{opx}<\text { mag. }\end{array}$ \\
\hline D29_PC02 & $\mathrm{N}$ caldera rim & $\mathbf{x}$ & $\mathbf{x}$ & $\mathbf{x}$ & $\mathbf{x}$ & $\begin{array}{l}30 \mathrm{~cm} \text { long pumice, light grey-brown coloured, with dark core. Dense, blocky and angular. Slight gradient in } \\
\text { vesicularity from rim to core. No mafic blebs. crystals }<1-3 \text { vol. } \% \text {; plag }<\mathrm{cpx}<\mathrm{opx}<\mathrm{mag} \text {. }\end{array}$ \\
\hline D29_PC03 & $\mathrm{N}$ caldera rim & $\mathbf{x}$ & & & & $\begin{array}{l}30 \mathrm{~cm} \text { long pumice, light grey-brown coloured, with dark core. Dense, and sub-angular. Slight gradient in } \\
\text { vesicularity from rim to core. No mafic blebs. crystals }<1-3 \text { vol. \%; plag }<\mathrm{cpx}<\mathrm{opx}<\mathrm{mag} \text {. }\end{array}$ \\
\hline D30_PC01 & $\mathrm{N}$ caldera rim & $\mathbf{x}$ & & $\mathbf{x}$ & & $\begin{array}{l}15 \mathrm{~cm} \text { long fragmented pumice, light grey-brown coloured. Dense, blocky and angular. No mafic blebs. crystals } \\
<1-3 \text { vol. \%; plag < cpx < opx < mag. }\end{array}$ \\
\hline D30_R01 & $\mathrm{N}$ caldera rim & $\mathbf{x}$ & & & & $\begin{array}{l}25 \mathrm{~cm} \text { long lava fragment, light grey colour. Dense, blocky and angular, no vesicles. No mafic blebs. crystals }<1- \\
3 \text { vol. \%; plag }<\mathrm{cpx}<\mathrm{opx}<\mathrm{mag} \text {. }\end{array}$ \\
\hline D30_R02 & $\mathrm{N}$ caldera rim & $\mathbf{x}$ & & & & $\begin{array}{l}10 \mathrm{~cm} \text { long lava fragment, slightly glassy appearance, dark grey-brown colour. Dense, blocky and angular, no } \\
\text { vesicles. No mafic blebs. crystals }<1-3 \text { vol. } \% \text {; plag }<\mathrm{cpx}<\mathrm{opx}<\mathrm{mag} \text {. }\end{array}$ \\
\hline D31_PC01 & $\mathrm{N}$ caldera rim & $\mathbf{x}$ & & & & $\begin{array}{l}30 \mathrm{~cm} \text { long pumice, light grey-brown coloured. Dense, blocky and angular. Some large vesicles on one side. No } \\
\text { mafic blebs. crystals }<1-3 \text { vol. } \% \text {; plag }<\mathrm{cpx}<\mathrm{opx}<\text { mag. }\end{array}$ \\
\hline D31_PC02 & $\mathrm{N}$ caldera rim & $\mathbf{x}$ & & $\mathbf{x}$ & & $\begin{array}{l}15 \mathrm{~cm} \text { long pumice, light grey-brown coloured. Dense, and sub-angular. Slight gradient in vesicularity from rim to } \\
\text { core, bread crusted rim. No mafic blebs. crystals }<1-3 \text { vol. \%; plag }<\mathrm{cpx}<\mathrm{opx}<\text { mag. }\end{array}$ \\
\hline
\end{tabular}


Table A.1. Continued

\begin{tabular}{|c|c|c|c|c|c|c|}
\hline Sample no. & Eruption / location & XRF & xI work & ICPMS & Isotopes & Description \\
\hline D31_PC03 & $\mathrm{N}$ caldera rim & $\mathbf{x}$ & & & & $\begin{array}{l}30 \mathrm{~cm} \text { long fragmented pumice, light grey-brown coloured, some flow banding. Dense, blocky and angular. No } \\
\text { mafic blebs. crystals }<1-3 \text { vol. \%; plag }<\mathrm{cpx}<\mathrm{opx}<\text { mag. }\end{array}$ \\
\hline D31_PC04 & $\mathrm{N}$ caldera rim & $\mathbf{x}$ & & & & $\begin{array}{l}17 \mathrm{~cm} \text { long pumice, light grey-brown coloured. Dense, and sub-angular rim, vesicular core. Bread crusted rim. No } \\
\text { mafic blebs. crystals }<1-3 \text { vol. } \% \text {; plag }<\mathrm{cpx}<\mathrm{opx}<\text { mag. }\end{array}$ \\
\hline D32_PC01 & Distal $\mathrm{N}$ caldera flank & $\mathbf{x}$ & & $\mathbf{x}$ & & $\begin{array}{l}10 \mathrm{~cm} \text { long fragmented pumice, light brown coloured. Highly vesicular, some large } \mathrm{cm} \text {-sized vesicles. No mafic } \\
\text { blebs. crystals }<1-3 \text { vol. } \% \text {; plag }<\mathrm{cpx}<\mathrm{opx}<\text { mag. }\end{array}$ \\
\hline D32_PC02 & Distal $\mathrm{N}$ caldera flank & $\mathbf{x}$ & & $\mathbf{x}$ & & $\begin{array}{l}8 \mathrm{~cm} \text { long fragmented pumice, light grey-brown coloured. Highly vesicular, some long elongated vesicles. One } \\
\text { small mm mafic bleb collected. crystals }<1-3 \text { vol. } \% \text {; plag }<\mathrm{cpx}<\mathrm{opx}<\text { mag. }\end{array}$ \\
\hline D32_PC03 & Distal $\mathrm{N}$ caldera flank & $\mathbf{x}$ & & & & $\begin{array}{l}10 \mathrm{~cm} \text { long multiclast set, light brown coloured. Highly vesicular, very rounded. crystals }<1-3 \text { vol. } \% \text {; plag }<\mathrm{cpx}< \\
\text { opx }<\text { mag. }\end{array}$ \\
\hline D32_PC04 & Distal $\mathrm{N}$ caldera flank & $\mathbf{x}$ & & & & $\begin{array}{l}7 \mathrm{~cm} \text { long pumice, light grey-brown coloured, darker core. Large vesicularity gradient. no mafic blebs observed, } \\
\text { but some large } 1-3 \mathrm{~mm} \text { crystal clusters noted. crystals }<1-3 \mathrm{vol} . \% \text {; plag }<\mathrm{cpx}<\mathrm{opx}<\text { mag. }\end{array}$ \\
\hline D32_PC05 & Distal $\mathrm{N}$ caldera flank & $\mathbf{x}$ & & & & $\begin{array}{l}8 \mathrm{~cm} \text { pumice, light grey-brown coloured. Highly vesicular. no mafic blebs. crystals }<1-3 \text { vol. } \% \text {; plag }<\mathrm{cpx}<\text { opx }< \\
\text { mag. }\end{array}$ \\
\hline D33_PC01 & Distal E caldera flank & $\mathbf{x}$ & & $\mathbf{x}$ & & $\begin{array}{l}7 \mathrm{~cm} \text { pumice, light grey-brown coloured. Highly vesicular. no mafic blebs. crystals }<1-3 \text { vol. } \% \text {; plag }<\mathrm{cpx}<\text { opx }< \\
\text { mag. }\end{array}$ \\
\hline D33_PC02 & Distal E caldera flank & $\mathbf{x}$ & $\mathbf{x}$ & $\mathbf{x}$ & & $\begin{array}{l}6 \mathrm{~cm} \text { pumice, light grey-brown coloured. Highly vesicular, very rounded. no mafic blebs. crystals }<1-3 \text { vol. \%; } \\
\text { plag }<\mathrm{cpx}<\mathrm{opx}<\text { mag. }\end{array}$ \\
\hline D33_PC03 & Distal E caldera flank & $\mathbf{x}$ & & & & $6 \mathrm{~cm}$ pumice, white coloured. Highly vesicular. no mafic blebs. crystals $<1-3$ vol. $\%$; plag $<\mathrm{cpx}<\mathrm{opx}<$ mag. \\
\hline D33_PC04 & Distal E caldera flank & $\mathbf{x}$ & $\mathbf{x}$ & $\mathbf{x}$ & $\mathbf{x}$ & $\begin{array}{l}6 \mathrm{~cm} \text { pumice, white coloured. Highly vesicular. no mafic blebs but lots of large (most } 2-3 \mathrm{~mm} \text { but up to } 2 \mathrm{~cm} \text { ) } \\
\text { dark green clinopyroxenes. crystals }>5 \text { vol. } \% ; \mathrm{cpx}<\text { plag }<\mathrm{opx}<\text { mag. }\end{array}$ \\
\hline D33_PC05 & Distal E caldera flank & $\mathbf{x}$ & & & & $\begin{array}{l}10 \mathrm{~cm} \text { long multiclast set, light grey-brown to white coloured. Highly vesicular, very rounded. crystals }<1-3 \mathrm{vol} \text {. \%; } \\
\text { plag }<\mathrm{cpx}<\mathrm{opx}<\text { mag. }\end{array}$ \\
\hline D33_PC06 & Distal E caldera flank & $\mathbf{x}$ & & & & $\begin{array}{l}5 \mathrm{~cm} \text { long pumice, light grey-brown coloured. Slight vesicularity gradient. no mafic blebs observed, but some } \\
\text { large } 1-3 \mathrm{~mm} \text { crystal clusters noted. crystals }<1-3 \text { vol. } \% \text {; plag }<\mathrm{cpx}<\mathrm{opx}<\text { mag. }\end{array}$ \\
\hline D33_PC07 & Distal E caldera flank & $\mathbf{x}$ & & & & $\begin{array}{l}5 \mathrm{~cm} \text { pumice, light grey-brown, rounded. Small vesicularity gradient, some large elongated vesicles. no mafic } \\
\text { blebs, some large } 1-3 \mathrm{~mm} \text { crystal clusters noted. crystals }<1-3 \text { vol. } \% \text {; plag }<\mathrm{cpx}<\mathrm{opx}<\mathrm{mag} \text {. }\end{array}$ \\
\hline D33_PC08 & Distal E caldera flank & $\mathbf{x}$ & & & & $\begin{array}{l}5 \mathrm{~cm} \text { pumice, light grey-brown, rounded. Large vesicularity gradient, dense and blocky on one side. no mafic } \\
\text { blebs. }<1-3 \text { vol. \%; plag }<\mathrm{cpx}<\mathrm{opx}<\mathrm{mag} \text {. }\end{array}$ \\
\hline \multicolumn{7}{|c|}{ Macauley volcano: Plutonic lithics } \\
\hline MI2007_R04 & Sandy Bay Tephra & & $\mathbf{x}$ & & & $\begin{array}{l}30 \mathrm{~cm} \text { sized gabbroic fragment. crystalline granular, crystals mostly } 2-3 \mathrm{~mm} \text { in size (but up to } 1 \mathrm{~cm} \text { ). Some } \\
\text { modal layering, by size and crystal phase. Plag }<\mathrm{cpx}<\mathrm{ol}<\mathrm{opx}<\mathrm{mnt} \text {. }\end{array}$ \\
\hline
\end{tabular}


Table A.1. Continued

\begin{tabular}{|c|c|c|c|c|c|c|}
\hline Sample no. & Eruption / location & XRF & xI work & ICPMS & Isotopes & Description \\
\hline$\overline{\text { MI2007_R01 }}$ & Sandy Bay Tephra & & & & & $\begin{array}{l}10 \mathrm{~cm} \text { sized leucocratic plutonic fragment. Highly altered, most crystals } 1-3 \mathrm{~mm} \text { in size. Small light grey } \\
\text { inclusions. Very rounded, too altered for analysis. }\end{array}$ \\
\hline \multicolumn{7}{|c|}{ Healy volcano: Pumice } \\
\hline D36_PC01 & NW caldera flank & $\mathbf{x}$ & & $\mathbf{x}$ & & $\begin{array}{l}15 \mathrm{~cm} \text { long pumice, white coloured. Highly vesicular. a few small mafic blebs observed }(<1 \text { vol. } \% \text { ), lots of crystal } \\
\text { clots, } 1 \text { big clot } 3 \mathrm{~cm} \text { in size. crystals }<3-5 \text { vol. } \% \text {; plag }<\mathrm{cpx}<\mathrm{mag}<\mathrm{hbl}<\mathrm{opx}<\mathrm{ilm}<\text { ol. }\end{array}$ \\
\hline D36_PC02 & NW caldera flank & $\mathbf{x}$ & & & & $\begin{array}{l}10 \mathrm{~cm} \text { long pumice, white coloured. Highly vesicular. no mafic blebs observed. crystals }<3-5 \text { vol. } \% \text {; plag }<\mathrm{cpx}< \\
\mathrm{mag}<\mathrm{hbl}<\mathrm{opx}<\mathrm{ilm} \text {. }\end{array}$ \\
\hline D36_PC03 & NW caldera flank & $\mathbf{x}$ & & $\mathbf{x}$ & & $\begin{array}{l}15 \mathrm{~cm} \text { long pumice, white coloured. Highly vesicular. a few small mafic blebs observed ( }<1 \text { vol. \%), lots of crystal } \\
\text { clots. crystals }<3-5 \mathrm{vol} . \% \text {; plag }<\mathrm{cpx}<\mathrm{mag}<\mathrm{hbl}<\mathrm{opx}<\mathrm{ilm}<\mathrm{ol} \text {. }\end{array}$ \\
\hline D37_PC01 & NW caldera flank & $\mathbf{x}$ & & & & $\begin{array}{l}35 \mathrm{~cm} \text { long pumice, white coloured. Highly vesicular with some large }(\mathrm{cm}) \text { open vesicles. a few small mafic blebs } \\
(<1 \text { vol. } \%) \text {, crystal clots. crystals }<3-5 \text { vol. } \% \text {; plag }<\mathrm{cpx}<\mathrm{mag}<\mathrm{hbl}<\mathrm{opx}<\mathrm{ilm}<\mathrm{ol} \text {. }\end{array}$ \\
\hline D37_PC02 & NW caldera flank & $\mathbf{x}$ & & $\mathbf{x}$ & & $\begin{array}{l}20 \mathrm{~cm} \text { long pumice, white coloured. Highly vesicular with some large }(\mathrm{cm}) \text { open vesicles. a few small mafic blebs } \\
(<1 \text { vol. } \%) \text {, crystal clots. crystals }<3-5 \text { vol. } \% \text {; plag }<\mathrm{cpx}<\mathrm{mag}<\mathrm{hbl}<\mathrm{opx}<\mathrm{ilm}<\mathrm{ol} \text {. }\end{array}$ \\
\hline D37_PC03 & NW caldera flank & $\mathbf{x}$ & & & & $\begin{array}{l}20 \mathrm{~cm} \text { long pumice, white coloured. Highly vesicular with some large }(\mathrm{cm}) \text { open vesicles. a few small mafic blebs } \\
(<1 \text { vol. } \%) \text {, crystal clots. crystals }<3-5 \text { vol. } \% \text {; plag }<\mathrm{cpx}<\mathrm{mag}<\mathrm{hbl}<\mathrm{opx}<\mathrm{ilm}\end{array}$ \\
\hline D37_PC04 & NW caldera flank & $\mathbf{x}$ & & $\mathbf{x}$ & & $\begin{array}{l}25 \mathrm{~cm} \text { long pumice, white coloured. Highly vesicular. a few small mafic blebs }(<1 \text { vol. \%), crystal clots. crystals } \\
<3-5 \text { vol. \%; plag }<\mathrm{cpx}<\mathrm{mag}<\mathrm{hbl}<\mathrm{opx}<\text { ilm }\end{array}$ \\
\hline D38_PC01 & NW caldera flank / rim & $\mathbf{x}$ & & & & $\begin{array}{l}\text { 8cm long pumice, banded grey/white. Highly vesicular. a few small mafic blebs }(<1 \text { vol. } \%) \text {, crystal clots. crystals } \\
<3-5 \text { vol. \%; plag }<\mathrm{cpx}<\mathrm{mag}<\mathrm{hbl}<\mathrm{opx}<\text { ilm }\end{array}$ \\
\hline D38_PC02 & NW caldera flank / rim & $\mathbf{x}$ & & & & $\begin{array}{l}10 \mathrm{~cm} \text { long pumice, mid grey colour. Highly vesicular. no mafic blebs. crystals }<3-5 \text { vol. } \% \text {; plag }<\mathrm{cpx}<\mathrm{mag}< \\
\mathrm{hbl}<\mathrm{opx}<\mathrm{ilm}\end{array}$ \\
\hline D38_PC03 & NW caldera flank / rim & $\mathbf{x}$ & & & & $\begin{array}{l}20 \mathrm{~cm} \text { long pumice, white coloured. Highly vesicular. a few small mafic blebs }(<1-2 \text { vol. } \%) \text {, crystal clots. crystals } \\
<5-10 \text { vol. \%; plag }<\mathrm{cpx}<\mathrm{mag}<\mathrm{hbl}<\mathrm{opx}<\text { ilm, some crystal rich bands. }\end{array}$ \\
\hline D38_PC04 & NW caldera flank / rim & $\mathbf{x}$ & & $\mathbf{x}$ & & $\begin{array}{l}25 \mathrm{~cm} \text { long pumice, white coloured. Highly vesicular. a few small mafic blebs }(<1 \text { vol. \%), crystal clots. crystals } \\
<3-5 \text { vol. \%; plag }<\mathrm{cpx}<\mathrm{mag}<\mathrm{hbl}<\mathrm{opx}<\text { ilm }\end{array}$ \\
\hline D38_PC05 & NW caldera flank / rim & $\mathbf{x}$ & & & & $\begin{array}{l}15 \mathrm{~cm} \text { long pumice, white coloured. Highly vesicular. very few small mafic blebs }(<1 \text { vol. \%), crystal clots. } \\
\text { crystals }<3-5 \text { vol. } \% \text {; plag }<\mathrm{cpx}<\mathrm{mag}<\mathrm{hbl}<\mathrm{opx}<\mathrm{ilm} \text {. }\end{array}$ \\
\hline D38_PC06 & NW caldera flank / rim & $\mathbf{x}$ & $\mathbf{x}$ & $\mathbf{x}$ & $\mathbf{x}$ & $\begin{array}{l}20 \mathrm{~cm} \text { long pumice, white coloured. Highly vesicular. a few small mafic blebs }(<1-2 \text { vol. } \%) \text {, crystal clots. crystals } \\
<10-15 \text { vol. \%; plag }<\mathrm{cpx}<\mathrm{mag}<\mathrm{hbl}<\mathrm{opx}<\text { ilm, some crystal rich bands. }\end{array}$ \\
\hline D39_PC01 & $\mathrm{N}$ caldera rim / wall & $\mathbf{x}$ & & & & $\begin{array}{l}15 \mathrm{~cm} \text { long lava fragment, mid-dark grey colour, with brown flow banding. Sparse large vesicles. some } \\
\text { hydrothermal inclusions }(<10 \text { vol. } \%) \text {. crystals }<3-5 \text { vol. } \% \text {; plag }<\mathrm{cpx}<\mathrm{mag}<\mathrm{hbl}<\mathrm{opx}\end{array}$ \\
\hline D39_PC02 & $\mathrm{N}$ caldera rim / wall & $\mathbf{x}$ & & & & $\begin{array}{l}10 \mathrm{~cm} \text { long lava fragment, mid-dark grey colour, with brown flow banding. Sparse large vesicles. some } \\
\text { hydrothermal inclusions }(<10 \text { vol. } \%) \text {. crystals }<3-5 \text { vol. } \% \text {; plag }<\mathrm{cpx}<\mathrm{mag}<\mathrm{hbl}<\mathrm{opx}\end{array}$ \\
\hline
\end{tabular}


Table A.1. Continued

\begin{tabular}{|c|c|c|c|c|c|c|}
\hline Sample no. & Eruption / location & XRF & xl work & ICPMS & Isotopes & Description \\
\hline D39_PC03 & $\mathrm{N}$ caldera rim / wall & $x$ & & & & $\begin{array}{l}15 \mathrm{~cm} \text { long lava fragment, mid-dark grey colour, flow banding. Some large vesicles on } 1 \text { side. some hydrothermal } \\
\text { inclusions ( }<2-3 \text { vol. } \%) \text {. crystals }<3-5 \text { vol. } \% \text {; plag }<\mathrm{cpx}<\mathrm{mag}<\mathrm{hbl}<\mathrm{opx}\end{array}$ \\
\hline D39_PC05 & $\mathrm{N}$ caldera rim / wall & $\mathbf{x}$ & $\mathbf{x}$ & $\mathbf{x}$ & $\mathbf{x}$ & $\begin{array}{l}10 \mathrm{~cm} \text { long pumice, white coloured, very faint light grey banding. Highly vesicular. no mafic blebs. very few } \\
\text { crystals }<1-3 \mathrm{vol} . \% \text {; plag }<\mathrm{cpx}<\mathrm{mag}<\mathrm{hbl}<\mathrm{opx}<\mathrm{ilm} \text {. }\end{array}$ \\
\hline D39_PC06 & $\mathrm{N}$ caldera rim / wall & $\mathbf{x}$ & & & & $\begin{array}{l}10 \mathrm{~cm} \text { long pumice, white coloured. Highly vesicular. no mafic blebs. very few crystals }<1-3 \mathrm{vol} \text {. } \% \text {; plag }<\mathrm{cpx}< \\
\mathrm{mag}<\mathrm{hbl}<\mathrm{opx}<\mathrm{ilm} \text {. }\end{array}$ \\
\hline D40_PC01 & Caldera floor & $\mathbf{x}$ & & & & $\begin{array}{l}15 \mathrm{~cm} \text { long pumice, white coloured, slightly pink oxidised. Highly vesicular. some small mafic blebs ( }<1-2 \mathrm{vol} . \%) \\
\text { crystal clots. crystals }<3-5 \mathrm{vol} \text {. } \% \text {; plag }<\mathrm{cpx}<\mathrm{mag}<\mathrm{hbl}<\mathrm{opx}<\mathrm{ilm} \text {. }\end{array}$ \\
\hline D40_PC02 & Caldera floor & $\mathbf{x}$ & & & & $\begin{array}{l}\text { 30cm long pumice, white coloured. Highly vesicular. some small mafic blebs }(<1-2 \text { vol. \%), crystal clots. crystals } \\
<3-5 \mathrm{vol} \text {. \%; plag }<\mathrm{cpx}<\mathrm{mag}<\mathrm{hbl}<\mathrm{opx}<\mathrm{ilm} \text {. }\end{array}$ \\
\hline D40_PC03 & Caldera floor & $\mathbf{x}$ & & & & $\begin{array}{l}\text { 20cm long pumice, white coloured. Highly vesicular. some small mafic blebs }(<1-2 \text { vol. \%), crystal clots. crystals } \\
<3-5 \mathrm{vol} \text {. \%; plag }<\mathrm{cpx}<\mathrm{mag}<\mathrm{hbl}<\mathrm{opx}<\mathrm{ilm} \text {. }\end{array}$ \\
\hline D43_PC01 & Caldera floor & $\mathbf{x}$ & & & & $\begin{array}{l}\text { 15cm long pumice, white coloured. Highly vesicular. no mafic blebs, crystal clots. crystals }<3-5 \mathrm{vol} \text {. } \% \text {; plag }<\mathrm{cpx} \\
<\mathrm{mag}<\mathrm{hbl}<\mathrm{opx}<\mathrm{ilm} \text {. }\end{array}$ \\
\hline D43_PC02 & Caldera floor & $\mathbf{x}$ & & & & $\begin{array}{l}\text { 25cm long pumice, white coloured. Highly vesicular, some large vesicles. no mafic blebs, crystal clots. crystals } \\
<3-5 \mathrm{vol} \text {. \%; plag }<\mathrm{cpx}<\mathrm{mag}<\mathrm{hbl}<\mathrm{opx}<\mathrm{ilm} \text {. }\end{array}$ \\
\hline D43_PC03 & Caldera floor & $\mathbf{x}$ & & & & $\begin{array}{l}15 \mathrm{~cm} \text { long pumice, white coloured. Highly vesicular. very few mafic blebs }(<1 \text { vol. } \%) \text {, crystal clots. crystals }<3- \\
5 \mathrm{vol} . \% \text {; plag }<\mathrm{cpx}<\operatorname{mag}<\mathrm{hbl}<\mathrm{opx}<\mathrm{ilm} \text {. }\end{array}$ \\
\hline D44_PC01 & SE caldera flank / rim & $\mathbf{x}$ & & $\mathbf{x}$ & & $\begin{array}{l}20 \mathrm{~cm} \text { long pumice, white coloured, slightly pink oxidised. Highly vesicular. some small mafic blebs }(<1-2 \mathrm{vol} . \%) \\
\text { crystal clots. crystals }<3-5 \mathrm{vol} . \% \text {; plag }<\mathrm{cpx}<\mathrm{mag}<\mathrm{hbl}<\mathrm{opx}<\mathrm{ilm}<<\text { ol. }\end{array}$ \\
\hline D44_PC02 & SE caldera flank / rim & $\mathbf{x}$ & $\mathbf{x}$ & $\mathbf{x}$ & $\mathbf{x}$ & $\begin{array}{l}15 \mathrm{~cm} \text { long pumice, white coloured. Highly vesicular. very few mafic blebs }(<1 \text { vol. } \%) \text {, crystal clots. crystals }<5- \\
10 \mathrm{vol} . \% \text {; plag }<\mathrm{cpx}<\operatorname{mag}<\mathrm{hbl}<\mathrm{opx}<\mathrm{ilm}<\mathrm{ol} \text {. }\end{array}$ \\
\hline D45_PC01 & SE caldera flank & $\mathbf{x}$ & & & & $\begin{array}{l}20 \mathrm{~cm} \text { long pumice, white coloured, pink oxidised. Highly vesicular, some large open vesicles. small mafic blebs } \\
(<1-2 \text { vol. } \%) \text {, crystal clots. crystals }<3-5 \mathrm{vol} . \% \text {; plag }<\mathrm{cpx}<\mathrm{mag}<\mathrm{hbl}<\mathrm{opx}<\mathrm{ilm}<<\text { ol. }\end{array}$ \\
\hline D45_PC02 & SE caldera flank & $\mathbf{x}$ & & $\mathbf{x}$ & & $\begin{array}{l}15 \mathrm{~cm} \text { long pumice, white coloured. less vesicular than other pumice. very few mafic blebs ( }<1 \text { vol. } \% \text { ), crystal } \\
\text { clots. crystals }<3-5 \text { vol. } \% \text {; plag }<\mathrm{cpx}<\mathrm{mag}<\mathrm{hbl}<\mathrm{opx}<\text { ilm }<\text { ol. }\end{array}$ \\
\hline D45_PC03 & SE caldera flank & $\mathbf{x}$ & & & & $\begin{array}{l}25 \mathrm{~cm} \text { long pumice, white coloured. slight light grey banding. very few mafic blebs }(<1 \text { vol. } \% \text { ), crystal clots. } \\
\text { crystals }<3-5 \mathrm{vol} . \% \text {; plag }<\mathrm{cpx}<\mathrm{mag}<\mathrm{hbl}<\mathrm{opx}<\text { ilm }<\text { ol. }\end{array}$ \\
\hline D46_PC01 & SE caldera flank & $\mathbf{x}$ & & & & $\begin{array}{l}15 \mathrm{~cm} \text { long pumice, white coloured. Highly vesicular. very few mafic blebs }(<1 \text { vol. } \%) \text {, crystal clots. crystals }<5- \\
10 \mathrm{vol} . \% \text {; plag }<\mathrm{cpx}<\mathrm{mag}<\mathrm{hbl}<\mathrm{opx}<\mathrm{ilm}<\mathrm{ol} \text {. }\end{array}$ \\
\hline D47_PC01 & SW edifice crater & $\mathbf{x}$ & & & & $\begin{array}{l}8 \mathrm{~cm} \text { long pumice, mid grey colour. Highly vesicular. a few small mafic blebs }(<1 \text { vol. \%), crystal clots. crystals }<3- \\
5 \text { vol. \%; plag }<\mathrm{cpx}<\mathrm{mag}<\mathrm{hbl}<\mathrm{opx}<\mathrm{ilm}\end{array}$ \\
\hline D47_PC02 & SW edifice crater & $\mathbf{x}$ & $\mathbf{x}$ & $\mathbf{x}$ & $\mathbf{x}$ & $\begin{array}{l}7 \mathrm{~cm} \text { long pumice, light grey colour. Highly vesicular. a few small mafic blebs }(<1 \text { vol. } \%) \text {, crystal clots. crystals } \\
<3-5 \text { vol. \%; plag }<\mathrm{cpx}<\mathrm{mag}<\mathrm{hbl}<\mathrm{opx}<\text { ilm }\end{array}$ \\
\hline
\end{tabular}


Table A.1. Continued

\begin{tabular}{|c|c|c|c|c|c|c|}
\hline Sample no. & Eruption / location & XRF & xl work & ICPMS & Isotopes & Description \\
\hline D47_PC03 & SW edifice crater & $\mathbf{x}$ & & & & $\begin{array}{l}15 \mathrm{~cm} \text { long pumice, white coloured with slight grey banding. highly vesicular. very few mafic blebs }(<1 \mathrm{vol} \text {. \%), } \\
\text { large crystal clots. crystals }<3-5 \mathrm{vol} . \% \text {; plag }<\mathrm{cpx}<\mathrm{mag}<\mathrm{hbl}<\mathrm{opx}<\mathrm{ilm}<\mathrm{ol} \text {. }\end{array}$ \\
\hline D47_PC04 & SW edifice crater & $\mathbf{x}$ & & & & $\begin{array}{l}10 \mathrm{~cm} \text { long pumice, white coloured with slight grey banding. highly vesicular. very few mafic blebs }(<1 \text { vol. } \% \text {, } \\
\text { large crystal clots. crystals }<5-10 \mathrm{vol} \text {. } \% \text {; plag }<\mathrm{cpx}<\mathrm{mag}<\mathrm{hbl}<\mathrm{opx}<\mathrm{ilm}<\mathrm{Ol} \text {. }\end{array}$ \\
\hline D47_PC05 & SW edifice crater & $\mathbf{x}$ & & & & $\begin{array}{l}\text { 8cm long pumice, white coloured. highly vesicular. very few mafic blebs ( }<1 \text { vol. } \% \text { ), large crystal clots. crystals } \\
<5-10 \text { vol. \%; plag }<\mathrm{cpx}<\mathrm{mag}<\mathrm{hbl}<\mathrm{opx}<\mathrm{ilm}\end{array}$ \\
\hline D48_PC01 & Central edifice & $\mathbf{x}$ & & & & $\begin{array}{l}25 \mathrm{~cm} \text { long lava fragment, mid-dark grey colour, with brown flow banding. Sparse large vesicles. some } \\
\text { hydrothermal inclusions }(<10 \text { vol. \%). crystals }<3-5 \text { vol. } \% \text {; plag }<\mathrm{cpx}<\mathrm{mag}<\mathrm{hbl}<\mathrm{opx}\end{array}$ \\
\hline D48_PC02 & Central edifice & $\mathbf{x}$ & & & & $\begin{array}{l}20 \mathrm{~cm} \text { long lava fragment, mid-dark grey colour, with brown flow banding. Sparse large vesicles. some } \\
\text { hydrothermal inclusions }(10-15 \text { vol. \%). crystals }<3-5 \text { vol. \%; plag }<\mathrm{cpx}<\operatorname{mag}<\mathrm{hbl}<\mathrm{opx}\end{array}$ \\
\hline \multicolumn{7}{|c|}{ Healy volcano: Plutonic lithics } \\
\hline D44_MB03 & SE caldera flank / rim & $\mathbf{x}$ & & $\mathbf{x}$ & & $\begin{array}{l}4 \mathrm{~cm} \text { sized, dark grey cauliform mafic bleb. Adhering white pumice glass on exterior. Highly crystalline, }>40 \text { vol. } \\
\% \text {, generally }>1-2 \mathrm{~mm} \text {, Poorly vesiculated dark grey groundmass. Plag }<\mathrm{cpx}<\mathrm{ol}<\mathrm{opx}<\mathrm{mnt} \text {. }\end{array}$ \\
\hline \multicolumn{7}{|c|}{ New Volcano: Pumice } \\
\hline D22_PC01 & $\mathrm{NE}$ caldera rim / wall & $\mathbf{x}$ & & & & $\begin{array}{l}25 \mathrm{~cm} \text { long pumice, white coloured. Highly vesicular. small mafic blebs ( }<1-2 \text { vol. \%), crystal clusters. crystals }<3- \\
5 \mathrm{vol} . \% \text {; plag }<\mathrm{cpx}<\mathrm{opx}<\mathrm{mag}<<\text { ol. }\end{array}$ \\
\hline D22_PC02 & NE caldera rim / wall & $\mathbf{x}$ & & $\mathbf{x}$ & $\mathbf{x}$ & $\begin{array}{l}30 \mathrm{~cm} \text { long pumice, white coloured. Highly vesicular. mafic blebs }(<1-2 \text { vol. \%), some large }(1 \mathrm{~cm}) \text {. crystal } \\
\text { clusters. crystals }<3-5 \mathrm{vol} . \% \text {; plag }<\mathrm{cpx}<\mathrm{opx}<\operatorname{mag}<<\text { ol. }\end{array}$ \\
\hline D22_PC03 & $\mathrm{NE}$ caldera rim / wall & $\mathbf{x}$ & & & & $\begin{array}{l}25 \mathrm{~cm} \text { long pumice, white coloured. Highly vesicular. mafic blebs }(<1-2 \text { vol. } \%) \text {, some large }(3-4 \mathrm{~cm}) \text {. crystal } \\
\text { clusters. crystals }<3-5 \mathrm{vol} . \% \text {; plag }<\mathrm{cpx}<\mathrm{opx}<\mathrm{mag}<<\text { ol. }\end{array}$ \\
\hline D22_PC04 & $\mathrm{NE}$ caldera rim / wall & $\mathbf{x}$ & & & & $\begin{array}{l}20 \mathrm{~cm} \text { long pumice, white coloured. Highly vesicular. small mafic blebs }(<1-2 \text { vol. \%), crystal clusters. crystals }<3- \\
5 \text { vol. \%; plag }<\mathrm{cpx}<\mathrm{opx}<\mathrm{mag}<<\text { ol. }\end{array}$ \\
\hline D22_PC05 & $\mathrm{NE}$ caldera rim / wall & $\mathbf{x}$ & & & & $\begin{array}{l}30 \mathrm{~cm} \text { long pumice, white coloured. Highly vesicular. small mafic blebs }(<1-2 \text { vol. } \%) \text {, crystal clusters. crystals }<3- \\
5 \mathrm{vol} . \% \text {; plag }<\mathrm{cpx}<\mathrm{opx}<\mathrm{mag}<<\text { ol. }\end{array}$ \\
\hline D22_PC06 & $\mathrm{NE}$ caldera rim / wall & $\mathbf{x}$ & & $\mathbf{x}$ & & $\begin{array}{l}20 \mathrm{~cm} \text { long pumice, white coloured. Highly vesicular. small mafic blebs }(<1-2 \text { vol. } \%) \text {, crystal clusters. crystals }<3- \\
5 \mathrm{vol} \text {. \%; plag }<\mathrm{cpx}<\mathrm{opx}<\mathrm{mag}<<\text { ol. }\end{array}$ \\
\hline D23_PC01 & SW caldera floor / wall & $\mathbf{x}$ & & & & $\begin{array}{l}25 \mathrm{~cm} \text { long pumice, white coloured. Highly vesicular. small mafic blebs }(<1-2 \text { vol. } \%) \text {, crystal clusters. crystals }<3- \\
5 \text { vol. \%; plag }<\mathrm{cpx}<\mathrm{opx}<\mathrm{mag}<<\text { ol. }\end{array}$ \\
\hline D23_PC02 & SW caldera floor / wall & $\mathbf{x}$ & & $\mathbf{x}$ & & $\begin{array}{l}25 \mathrm{~cm} \text { long pumice, white coloured. Highly vesicular. small mafic blebs }(<1-2 \text { vol. } \%) \text {, crystal clusters. crystals }<3- \\
5 \mathrm{vol} . \% \text {; plag }<\mathrm{cpx}<\mathrm{opx}<\mathrm{mag}<<\text { ol. }\end{array}$ \\
\hline \multicolumn{7}{|c|}{ New Volcano: Plutonic lithics } \\
\hline D22_03_MB0 & NE caldera rim / wall & $\mathbf{x}$ & & $\mathbf{x}$ & $\mathbf{x}$ & $\begin{array}{l}4 \mathrm{~cm} \text { sized, grey cauliform mafic bleb from interior of pumice. Adhering white pumice glass. no large crystals, } \\
\text { mostly smaller than } 1 \mathrm{~mm} \text {. Poorly vesiculated dark grey groundmass. Plag }<\mathrm{cpx}<\mathrm{opx}<\mathrm{mnt} \text {. }\end{array}$ \\
\hline
\end{tabular}




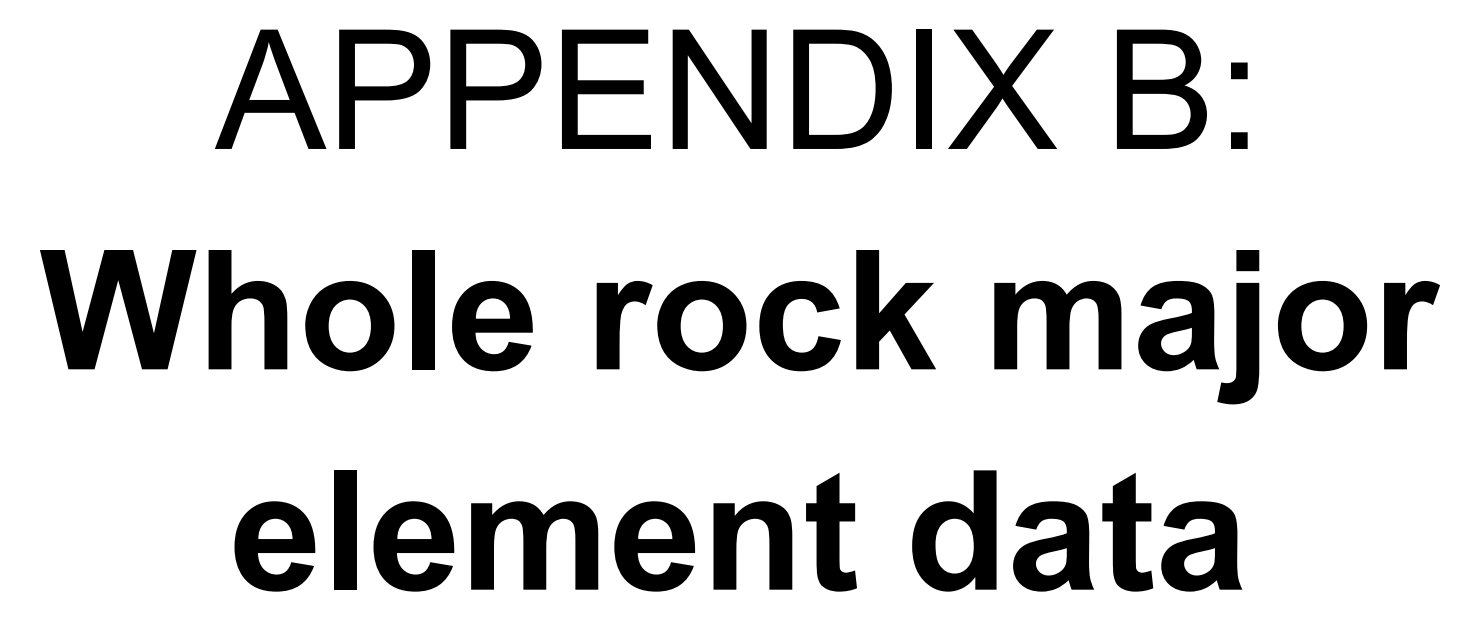

Table B.1. Whole rock major element data 
Table B.1. Major element concentrations for whole rock samples analysed by XRF.

\begin{tabular}{|c|c|c|c|c|c|c|c|c|c|c|c|}
\hline$\overline{\text { Sample }}$ & RI03_PC03 & RI03_PC09 & RI03_PC10 & RI06_PC06 & RI06_PC07 & RI06_PC11 & RI06_PC12 & RI08_PC09 & RI12_PC08 & RI12_PC15 & RI12_PC18 \\
\hline Volcano & Raoul & Raoul & Raoul & Raoul & Raoul & Raoul & Raoul & Raoul & Raoul & Raoul & Raoul \\
\hline Type & Pumice & Pumice & Pumice & Pumice & Pumice & Pumice & Pumice & Pumice & Pumice & Pumice & Pumice \\
\hline Location & Rangitahua & Rangitahua & Rangitahua & Matatirohia & Matatirohia & Matatirohia & Matatirohia & Pre-GLP & Matatirohia & Matatirohia & Matatirohia \\
\hline $\mathrm{SiO}_{2}$ & 66.77 & 66.69 & 66.47 & 67.89 & 67.37 & 68.18 & 68.24 & 69.43 & 68.00 & 67.85 & 67.38 \\
\hline $\mathrm{TiO}_{2}$ & 0.655 & 0.661 & 0.676 & 0.501 & 0.507 & 0.512 & 0.487 & 0.574 & 0.587 & 0.584 & 0.639 \\
\hline $\mathrm{Al}_{2} \mathrm{O}_{3}$ & 14.57 & 14.59 & 14.65 & 14.77 & 14.88 & 14.67 & 14.65 & 14.04 & 14.69 & 14.74 & 14.59 \\
\hline $\mathrm{Fe}_{2} \mathrm{O}_{3}$ & 6.30 & 6.32 & 6.36 & 5.55 & 5.74 & 5.48 & 5.48 & 5.28 & 5.41 & 5.47 & 5.59 \\
\hline MnO & 0.184 & 0.189 & 0.185 & 0.159 & 0.157 & 0.160 & 0.159 & 0.156 & 0.162 & 0.159 & 0.166 \\
\hline MgO & 1.650 & 1.625 & 1.665 & 1.413 & 1.559 & 1.356 & 1.333 & 1.175 & 1.361 & 1.383 & 1.411 \\
\hline $\mathrm{CaO}$ & 5.65 & 5.70 & 5.77 & 5.49 & 5.68 & 5.45 & 5.43 & 4.74 & 5.12 & 5.26 & 5.67 \\
\hline $\mathrm{Na}_{2} \mathrm{O}$ & 3.55 & 3.54 & 3.56 & 3.54 & 3.43 & 3.49 & 3.53 & 3.80 & 3.86 & 3.76 & 3.75 \\
\hline $\mathrm{K}_{2} \mathrm{O}$ & 0.541 & 0.531 & 0.525 & 0.570 & 0.566 & 0.582 & 0.578 & 0.664 & 0.656 & 0.639 & 0.637 \\
\hline $\mathrm{P}_{2} \mathrm{O}_{5}$ & 0.137 & 0.141 & 0.139 & 0.112 & 0.111 & 0.113 & 0.113 & 0.149 & 0.156 & 0.154 & 0.159 \\
\hline LOI & 1.21 & 1.14 & 1.42 & 1.30 & 1.24 & 1.25 & 1.14 & 1.89 & 1.86 & 2.18 & 1.70 \\
\hline Total & 99.79 & 100.08 & 100.05 & 100.08 & 99.90 & 100.52 & 99.15 & 99.97 & 100.43 & 99.97 & 100.37 \\
\hline Sample & RI12_PC19 & RI15_PC07 & RI26_PC01 & RI26_PC02 & RI26_PC04 & RI18_PC02 & RI18_PC03 & RI18_PC04 & RI18_PC05 & RI19_PC01 & RI06_MB11 \\
\hline Volcano & Raoul & Raoul & Raoul & Raoul & Raoul & Raoul & Raoul & Raoul & Raoul & Raoul & Raoul \\
\hline Type & Pumice & Pumice & Pumice & Pumice & Pumice & Pumice & Pumice & Pumice & Pumice & Pumice & Mafic Bleb \\
\hline Location & Matatirohia & Fleetwood & Fleetwood & Fleetwood & Fleetwood & GLP & GLP & GLP & GLP & 2006 & Matatirohia \\
\hline $\mathrm{SiO}_{2}$ & 67.97 & 67.86 & 67.98 & 67.83 & 67.73 & 69.33 & 69.45 & 69.12 & 69.34 & 66.46 & 49.67 \\
\hline $\mathrm{TiO}_{2}$ & 0.583 & 0.620 & 0.613 & 0.618 & 0.634 & 0.618 & 0.600 & 0.601 & 0.597 & 0.663 & 0.610 \\
\hline $\mathrm{Al}_{2} \mathrm{O}_{3}$ & 14.71 & 14.31 & 14.31 & 14.35 & 14.33 & 14.03 & 14.06 & 14.20 & 14.10 & 14.69 & 17.56 \\
\hline $\mathrm{Fe}_{2} \mathrm{O}_{3}$ & 5.39 & 6.03 & 5.90 & 6.02 & 6.11 & 5.30 & 5.22 & 5.33 & 5.27 & 6.40 & 11.49 \\
\hline $\mathrm{MnO}$ & 0.159 & 0.163 & 0.158 & 0.158 & 0.166 & 0.163 & 0.161 & 0.162 & 0.163 & 0.186 & 0.190 \\
\hline MgO & 1.368 & 1.346 & 1.359 & 1.335 & 1.359 & 1.202 & 1.113 & 1.182 & 1.133 & 1.626 & 6.620 \\
\hline $\mathrm{CaO}$ & 5.23 & 5.13 & 5.16 & 5.22 & 5.17 & 4.67 & 4.68 & 4.78 & 4.71 & 5.64 & 12.05 \\
\hline $\mathrm{Na}_{2} \mathrm{O}$ & 3.80 & 3.76 & 3.74 & 3.68 & 3.72 & 3.91 & 3.95 & 3.87 & 3.93 & 3.66 & 1.63 \\
\hline $\mathrm{K}_{2} \mathrm{O}$ & 0.645 & 0.622 & 0.627 & 0.624 & 0.627 & 0.616 & 0.616 & 0.606 & 0.618 & 0.531 & 0.160 \\
\hline $\mathrm{P}_{2} \mathrm{O}_{5}$ & 0.151 & 0.159 & 0.153 & 0.154 & 0.156 & 0.150 & 0.151 & 0.151 & 0.147 & 0.142 & 0.050 \\
\hline LOI & 1.60 & 1.21 & 1.60 & 1.61 & 1.90 & 1.36 & 1.50 & 1.40 & 1.40 & 0.33 & 0.21 \\
\hline Total & 100.06 & 100.23 & 100.12 & 99.86 & 100.30 & 100.45 & 99.81 & 99.57 & 99.90 & 100.14 & 100.24 \\
\hline
\end{tabular}

below detection limits. GLP is Green Lake Pumice, SBT is Sandy Bay Tephra and the Pre-GLP is the floated pumice unit (see Appendix A for sample details). 
Table B.1. Continued

\begin{tabular}{|c|c|c|c|c|c|c|c|c|c|c|c|}
\hline $\begin{array}{l}\text { Sample } \\
\text { Volcano } \\
\text { Type } \\
\text { Location } \\
\end{array}$ & $\begin{array}{r}\text { RI06_MB2 } \\
\text { Raoul } \\
\text { Mafic Bleb } \\
\text { Matatirohia } \\
\end{array}$ & $\begin{array}{r}\text { RI06_R01 } \\
\text { Raoul } \\
\text { Tonalite } \\
\text { Matatirohia } \\
\end{array}$ & $\begin{array}{r}\text { MI01_PC05 } \\
\text { Macauley } \\
\text { Pumice } \\
\text { SBT } \\
\end{array}$ & $\begin{array}{r}\text { MI07_PC02 } \\
\text { Macauley } \\
\text { Pumice } \\
\text { SBT } \\
\end{array}$ & $\begin{array}{r}\text { MI07_PC03 } \\
\text { Macauley } \\
\text { Pumice } \\
\text { SBT } \\
\end{array}$ & $\begin{array}{r}\text { MI07_PC13 } \\
\text { Macauley } \\
\text { Pumice } \\
\text { SBT } \\
\end{array}$ & $\begin{array}{r}\text { D24_PC01 } \\
\text { Macauley } \\
\text { Pumice } \\
\text { SW flank }\end{array}$ & $\begin{array}{r}\text { D24_PC02 } \\
\text { Macauley } \\
\text { Pumice } \\
\text { SW flank } \\
\end{array}$ & $\begin{array}{r}\text { D24_PC03 } \\
\text { Macauley } \\
\text { Pumice } \\
\text { SW flank }\end{array}$ & $\begin{array}{r}\text { D24_PC04 } \\
\text { Macauley } \\
\text { Pumice } \\
\text { SW flank }\end{array}$ & $\begin{array}{r}\text { D24_PC05 } \\
\text { Macauley } \\
\text { Pumice } \\
\text { SW flank } \\
\end{array}$ \\
\hline $\mathrm{SiO}_{2}$ & 49.61 & 71.09 & 70.41 & 70.67 & 70.66 & 70.88 & 68.21 & 66.90 & 67.20 & 67.73 & 66.49 \\
\hline $\mathrm{TiO}_{2}$ & 0.610 & 0.430 & 0.635 & 0.649 & 0.638 & 0.650 & 0.584 & 0.817 & 0.827 & 0.792 & 0.590 \\
\hline $\mathrm{Al}_{2} \mathrm{O}_{3}$ & 18.98 & 14.04 & 13.32 & 13.28 & 13.28 & 13.19 & 14.96 & 13.75 & 13.81 & 13.81 & 15.62 \\
\hline $\mathrm{Fe}_{2} \mathrm{O}_{3}$ & 11.34 & 4.57 & 5.02 & 4.99 & 4.99 & 4.97 & 4.90 & 6.45 & 6.39 & 6.16 & 5.21 \\
\hline MnO & 0.190 & 0.100 & 0.144 & 0.139 & 0.141 & 0.143 & 0.139 & 0.173 & 0.173 & 0.168 & 0.140 \\
\hline MgO & 5.460 & 1.110 & 0.874 & 0.769 & 0.816 & 0.774 & 1.194 & 1.286 & 1.263 & 1.193 & 1.379 \\
\hline $\mathrm{CaO}$ & 12.34 & 4.14 & 3.33 & 3.13 & 3.16 & 3.12 & 4.69 & 4.64 & 4.31 & 4.18 & 5.38 \\
\hline $\mathrm{Na}_{2} \mathrm{O}$ & 1.58 & 4.20 & 4.50 & 4.58 & 4.51 & 4.47 & 4.09 & 4.36 & 4.39 & 4.34 & 4.09 \\
\hline $\mathrm{K}_{2} \mathrm{O}$ & 0.160 & 0.420 & 1.631 & 1.669 & 1.660 & 1.672 & 1.088 & 1.375 & 1.383 & 1.388 & 0.959 \\
\hline $\mathrm{P}_{2} \mathrm{O}_{5}$ & 0.050 & 0.060 & 0.130 & 0.127 & 0.125 & 0.141 & 0.156 & 0.252 & 0.257 & 0.235 & 0.150 \\
\hline LOI & & & 0.41 & 1.68 & 2.44 & 2.35 & 0.73 & 0.52 & 0.49 & 0.54 & \\
\hline Total & 100.10 & 100.14 & 100.05 & 100.12 & 100.34 & 100.40 & 100.04 & 100.22 & 100.20 & 99.97 & 99.93 \\
\hline Sample & D24_PC06 & D25_PC01 & D25_PC02 & D25_PC03 & D26_PC01 & D26_PC02 & D29_PC01 & D29_PC02 & D29_PC03 & D30_PC01 & $\overline{\text { D30_R02 }}$ \\
\hline Volcano & Macauley & Macauley & Macauley & Macauley & Macauley & Macauley & Macauley & Macauley & Macauley & Macauley & Macauley \\
\hline Type & Pumice & Pumice & Pumice & Pumice & Pumice & Pumice & Pumice & Pumice & Pumice & Pumice & Blocky lava \\
\hline Location & SW flank & SW flank & SW flank & SW flank & E rim & E rim & $\mathrm{N}$ rim & $\mathrm{N}$ rim & $\mathrm{N}$ rim & $\mathrm{N}$ rim & $\mathrm{N}$ rim \\
\hline $\mathrm{SiO}_{2}$ & 67.60 & 67.28 & 66.91 & 67.36 & 68.80 & 70.43 & 72.17 & 72.37 & 72.22 & 71.81 & 72.42 \\
\hline $\mathrm{TiO}_{2}$ & 0.780 & 0.821 & 0.818 & 0.799 & 0.697 & 0.650 & 0.464 & 0.435 & 0.442 & 0.569 & 0.421 \\
\hline $\mathrm{Al}_{2} \mathrm{O}_{3}$ & 13.83 & 13.79 & 13.97 & 13.82 & 13.49 & 13.49 & 12.77 & 12.78 & 12.78 & 13.05 & 12.87 \\
\hline $\mathrm{Fe}_{2} \mathrm{O}_{3}$ & 6.06 & 6.41 & 6.42 & 6.29 & 5.46 & 4.95 & 4.78 & 4.62 & 4.65 & 4.60 & 4.52 \\
\hline $\mathrm{MnO}$ & 0.170 & 0.172 & 0.179 & 0.180 & 0.172 & 0.152 & 0.132 & 0.124 & 0.127 & 0.136 & 0.130 \\
\hline $\mathrm{MgO}$ & 1.219 & 1.241 & 1.306 & 1.258 & 1.262 & 0.783 & 0.504 & 0.488 & 0.503 & 0.608 & 0.421 \\
\hline $\mathrm{CaO}$ & 4.22 & 4.25 & 4.32 & 4.18 & 3.90 & 3.05 & 2.56 & 2.53 & 2.52 & 2.83 & 2.40 \\
\hline $\mathrm{Na}_{2} \mathrm{O}$ & 4.54 & 4.40 & 4.50 & 4.51 & 4.48 & 4.75 & 4.71 & 4.75 & 4.83 & 4.56 & 5.00 \\
\hline $\mathrm{K}_{2} \mathrm{O}$ & 1.329 & 1.397 & 1.286 & 1.328 & 1.505 & 1.596 & 1.812 & 1.827 & 1.850 & 1.729 & 1.762 \\
\hline $\mathrm{P}_{2} \mathrm{O}_{5}$ & 0.260 & 0.251 & 0.289 & 0.270 & 0.222 & 0.152 & 0.095 & 0.076 & 0.077 & 0.102 & 0.070 \\
\hline LOI & & 0.55 & & & 0.41 & 1.62 & 0.52 & 1.11 & 1.63 & 0.72 & 0.04 \\
\hline Total & 99.58 & 100.07 & 99.81 & 99.62 & 99.42 & 100.01 & 100.35 & 99.74 & 100.07 & 100.28 & 99.92 \\
\hline
\end{tabular}


Table B.1. Continued

\begin{tabular}{|c|c|c|c|c|c|c|c|c|c|c|c|}
\hline$\overline{\text { Sample }}$ & D30_R01 & D31_PC01 & D31_PC02 & D31_PC03 & D31_PC04 & D32_PC01 & D32_PC02 & D32_PC03 & D32_PC04 & D32_PC05 & D33_PC01 \\
\hline Volcano & Macauley & Macauley & Macauley & Macauley & Macauley & Macauley & Macauley & Macauley & Macauley & Macauley & Macauley \\
\hline Type & Blocky lava & Pumice & Pumice & Pumice & Pumice & Pumice & Pumice & Pumice & Pumice & Pumice & Pumice \\
\hline Location & $\mathrm{N}$ rim & $\mathrm{N}$ rim & $\mathrm{N}$ rim & $\mathrm{N}$ rim & $\mathrm{N}$ rim & $\mathrm{N}$ flank & $\mathrm{N}$ flank & $\mathrm{N}$ flank & $\mathrm{N}$ flank & $\mathrm{N}$ flank & E flank \\
\hline $\mathrm{SiO}_{2}$ & 72.45 & 72.28 & 71.81 & 72.35 & 71.75 & 67.12 & 70.75 & 67.52 & 67.36 & 70.74 & 67.95 \\
\hline $\mathrm{TiO}_{2}$ & 0.429 & 0.436 & 0.463 & 0.455 & 0.450 & 0.833 & 0.586 & 0.586 & 0.799 & 0.579 & 0.560 \\
\hline $\mathrm{Al}_{2} \mathrm{O}_{3}$ & 12.96 & 12.81 & 12.89 & 12.75 & 13.07 & 13.81 & 12.96 & 14.94 & 13.78 & 13.29 & 14.96 \\
\hline $\mathrm{Fe}_{2} \mathrm{O}_{3}$ & 4.50 & 4.66 & 4.78 & 4.62 & 4.68 & 6.46 & 4.73 & 4.96 & 6.33 & 4.74 & 4.87 \\
\hline $\mathrm{MnO}$ & 0.130 & 0.127 & 0.128 & 0.127 & 0.130 & 0.173 & 0.146 & 0.144 & 0.170 & 0.142 & 0.137 \\
\hline MgO & 0.429 & 0.481 & 0.689 & 0.483 & 0.610 & 1.329 & 0.697 & 1.208 & 1.258 & 0.681 & 1.204 \\
\hline $\mathrm{CaO}$ & 2.42 & 2.55 & 2.54 & 2.48 & 2.58 & 4.35 & 3.85 & 5.35 & 4.22 & 3.37 & 5.08 \\
\hline $\mathrm{Na}_{2} \mathrm{O}$ & 4.85 & 4.77 & 4.79 & 4.82 & 4.90 & 4.29 & 4.48 & 4.06 & 4.49 & 4.69 & 4.02 \\
\hline $\mathrm{K}_{2} \mathrm{O}$ & 1.764 & 1.817 & 1.813 & 1.839 & 1.721 & 1.369 & 1.695 & 1.073 & 1.318 & 1.646 & 1.072 \\
\hline $\mathrm{P}_{2} \mathrm{O}_{5}$ & 0.070 & 0.081 & 0.091 & 0.079 & 0.100 & 0.264 & 0.117 & 0.161 & 0.270 & 0.122 & 0.145 \\
\hline LOI & & 0.65 & 0.99 & 0.76 & & 0.27 & 2.42 & 1.10 & & 1.65 & 0.77 \\
\hline Total & 100.03 & 100.00 & 100.26 & 100.06 & 99.71 & 99.90 & 100.56 & 100.31 & 99.82 & 100.10 & 99.36 \\
\hline$\overline{\text { Sample }}$ & D33_PC02 & D33_PC03 & D33_PC04 & D33_PC05 & D33_PC06 & D33_PC07 & D33_PC08 & D36_PC01 & D36_PC02 & D36_PC03 & D37_PC01 \\
\hline Volcano & Macauley & Macauley & Macauley & Macauley & Macauley & Macauley & Macauley & Healy & Healy & Healy & Healy \\
\hline Type & Pumice & Pumice & Pumice & Pumice & Pumice & Pumice & Pumice & Pumice & Pumice & Pumice & Pumice \\
\hline Location & E flank & E flank & E flank & E flank & E flank & E flank & E flank & NW flank & NW flank & NW flank & NW flank \\
\hline $\mathrm{SiO}_{2}$ & 68.27 & 68.54 & 68.42 & 68.29 & 66.14 & 71.31 & 68.15 & 71.08 & 70.50 & 70.38 & 70.82 \\
\hline $\mathrm{TiO}_{2}$ & 0.570 & 0.519 & 0.533 & 0.557 & 0.830 & 0.578 & 0.564 & 0.475 & 0.484 & 0.485 & 0.489 \\
\hline $\mathrm{Al}_{2} \mathrm{O}_{3}$ & 14.96 & 14.07 & 13.83 & 14.30 & 14.07 & 13.23 & 15.19 & 14.30 & 14.60 & 14.58 & 14.39 \\
\hline $\mathrm{Fe}_{2} \mathrm{O}_{3}$ & 4.83 & 4.98 & 5.22 & 5.00 & 6.59 & 4.66 & 4.73 & 3.40 & 3.49 & 3.53 & 3.50 \\
\hline $\mathrm{MnO}$ & 0.135 & 0.180 & 0.175 & 0.161 & 0.180 & 0.142 & 0.131 & 0.116 & 0.117 & 0.117 & 0.120 \\
\hline $\mathrm{MgO}$ & 1.206 & 1.826 & 2.033 & 1.661 & 1.370 & 0.618 & 1.158 & 0.891 & 0.946 & 0.983 & 0.926 \\
\hline $\mathrm{CaO}$ & 4.79 & 4.80 & 4.91 & 5.02 & 4.83 & 2.98 & 4.65 & 3.07 & 3.23 & 3.29 & 3.11 \\
\hline $\mathrm{Na}_{2} \mathrm{O}$ & 4.02 & 4.36 & 4.13 & 4.10 & 4.42 & 4.70 & 4.24 & 5.01 & 4.98 & 4.97 & 4.95 \\
\hline $\mathrm{K}_{2} \mathrm{O}$ & 1.076 & 0.559 & 0.597 & 0.756 & 1.260 & 1.653 & 1.027 & 1.573 & 1.544 & 1.555 & 1.586 \\
\hline $\mathrm{P}_{2} \mathrm{O}_{5}$ & 0.144 & 0.170 & 0.157 & 0.156 & 0.310 & 0.122 & 0.151 & 0.102 & 0.109 & 0.109 & 0.107 \\
\hline LOI & 0.65 & & 0.62 & 0.79 & & 0.43 & 0.71 & 1.35 & 1.77 & 1.50 & 1.48 \\
\hline Total & 100.16 & 99.94 & 100.21 & 100.13 & 99.95 & 99.06 & 100.02 & 100.00 & 99.84 & 99.35 & 99.72 \\
\hline
\end{tabular}


Table B.1. Continued

\begin{tabular}{|c|c|c|c|c|c|c|c|c|c|c|c|}
\hline Sample & D37_PC02 & D37_PC03 & D37_PC04 & D38_PC01 & D38_PC02 & D38_PC03 & D38_PC04 & D38_PC05 & D38_PC06 & D39_PC01 & $\overline{\text { D39_PC02 }}$ \\
\hline Volcano & Healy & Healy & Healy & Healy & Healy & Healy & Healy & Healy & Healy & Healy & Healy \\
\hline Type & Pumice & Pumice & Pumice & Pumice & Pumice & Pumice & Pumice & Pumice & Pumice & Pumice & Pumice \\
\hline Location & NW flank & NW flank & NW flank & NW flank / rim & NW flank / rim & NW flank / rim & NW flank / rim & NW flank / rim & NW flank / rim & $\mathrm{N}$ rim / wall & $\mathrm{N}$ rim / wall \\
\hline $\mathrm{SiO}_{2}$ & 70.49 & 70.94 & 71.01 & 70.59 & 70.38 & 69.59 & 70.15 & 70.57 & 69.65 & 70.64 & 70.87 \\
\hline $\mathrm{TiO}_{2}$ & 0.489 & 0.477 & 0.473 & 0.534 & 0.547 & 0.487 & 0.483 & 0.494 & 0.481 & 0.539 & 0.512 \\
\hline $\mathrm{Al}_{2} \mathrm{O}_{3}$ & 14.55 & 14.37 & 14.30 & 14.57 & 14.62 & 14.62 & 14.42 & 14.47 & 14.69 & 14.58 & 14.51 \\
\hline $\mathrm{Fe}_{2} \mathrm{O}_{3}$ & 3.53 & 3.41 & 3.44 & 3.47 & 3.54 & 3.74 & 3.65 & 3.54 & 3.72 & 3.43 & 3.32 \\
\hline MnO & 0.120 & 0.116 & 0.116 & 0.133 & 0.137 & 0.122 & 0.118 & 0.119 & 0.117 & 0.136 & 0.133 \\
\hline MgO & 0.953 & 0.918 & 0.891 & 0.912 & 0.903 & 1.247 & 1.149 & 0.967 & 1.265 & 0.878 & 0.830 \\
\hline $\mathrm{CaO}$ & 3.22 & 3.12 & 3.10 & 3.03 & 3.11 & 3.70 & 3.50 & 3.18 & 3.72 & 3.01 & 2.90 \\
\hline $\mathrm{Na}_{2} \mathrm{O}$ & 4.97 & 4.98 & 4.98 & 5.08 & 5.07 & 4.88 & 4.88 & 4.98 & 4.74 & 5.07 & 5.19 \\
\hline $\mathrm{K}_{2} \mathrm{O}$ & 1.562 & 1.572 & 1.577 & 1.584 & 1.571 & 1.503 & 1.546 & 1.559 & 1.504 & 1.593 & 1.641 \\
\hline $\mathrm{P}_{2} \mathrm{O}_{5}$ & 0.109 & 0.103 & 0.107 & 0.113 & 0.114 & 0.106 & 0.108 & 0.111 & 0.106 & 0.110 & 0.105 \\
\hline LOI & 1.40 & 1.36 & 1.45 & 0.96 & 0.86 & 1.50 & 1.50 & 1.58 & 1.48 & 2.57 & 2.76 \\
\hline Total & 99.72 & 100.60 & 99.98 & 100.21 & 100.08 & 100.33 & 100.89 & 99.96 & 100.15 & 99.99 & 99.85 \\
\hline Sample & D39_PC03 & D39_PC05 & D39_PC06 & D40_PC01 & D40_PC02 & D40_PC03 & D43_PC01 & D43_PC02 & D43_PC03 & D44_PC01 & $\overline{\text { D44_PC02 }}$ \\
\hline Volcano & Healy & Healy & Healy & Healy & Healy & Healy & Healy & Healy & Healy & Healy & Healy \\
\hline Type & Pumice & Pumice & Pumice & Pumice & Pumice & Pumice & Pumice & Pumice & Pumice & Pumice & Pumice \\
\hline Location & $\mathrm{N} \mathrm{rim} \mathrm{/} \mathrm{wall}$ & $\mathrm{N} \mathrm{rim} \mathrm{/} \mathrm{wall}$ & $\mathrm{N} \mathrm{rim} \mathrm{/} \mathrm{wall}$ & Caldera floor & Caldera floor & Caldera floor & Caldera floor & Caldera floor & Caldera floor & SE flank / rim & SE flank / rim \\
\hline $\mathrm{SiO}_{2}$ & 70.22 & 72.67 & 70.55 & 69.93 & 71.03 & 70.74 & 70.99 & 71.23 & 70.39 & 70.84 & 71.18 \\
\hline $\mathrm{TiO}_{2}$ & 0.559 & 0.411 & 0.482 & 0.473 & 0.469 & 0.473 & 0.473 & 0.472 & 0.491 & 0.481 & 0.452 \\
\hline $\mathrm{Al}_{2} \mathrm{O}_{3}$ & 14.65 & 14.01 & 14.46 & 14.38 & 14.34 & 14.24 & 14.37 & 14.22 & 14.45 & 14.26 & 14.31 \\
\hline $\mathrm{Fe}_{2} \mathrm{O}_{3}$ & 3.59 & 2.81 & 3.53 & 3.74 & 3.41 & 3.50 & 3.41 & 3.37 & 3.61 & 3.51 & 3.31 \\
\hline MnO & 0.136 & 0.112 & 0.116 & 0.119 & 0.117 & 0.115 & 0.118 & 0.116 & 0.120 & 0.117 & 0.114 \\
\hline MgO & 0.942 & 0.618 & 1.013 & 1.326 & 0.910 & 1.059 & 0.909 & 0.906 & 1.018 & 1.041 & 0.914 \\
\hline $\mathrm{CaO}$ & 3.12 & 2.54 & 3.25 & 3.60 & 3.08 & 3.27 & 3.07 & 2.99 & 3.27 & 3.20 & 3.05 \\
\hline $\mathrm{Na}_{2} \mathrm{O}$ & 5.07 & 5.00 & 4.92 & 4.77 & 4.94 & 4.91 & 4.98 & 5.01 & 4.99 & 4.82 & 4.95 \\
\hline $\mathrm{K}_{2} \mathrm{O}$ & 1.585 & 1.754 & 1.563 & 1.557 & 1.596 & 1.592 & 1.573 & 1.579 & 1.547 & 1.632 & 1.614 \\
\hline $\mathrm{P}_{2} \mathrm{O}_{5}$ & 0.120 & 0.074 & 0.108 & 0.103 & 0.103 & 0.101 & 0.106 & 0.104 & 0.115 & 0.106 & 0.099 \\
\hline LOI & 2.72 & 1.11 & 1.76 & 1.58 & 1.64 & 1.65 & 1.58 & 1.45 & 1.59 & 1.81 & 1.68 \\
\hline Total & 99.77 & 99.70 & 100.35 & 100.82 & 100.16 & 99.85 & 100.34 & 99.91 & 101.13 & 100.28 & 99.86 \\
\hline
\end{tabular}


Table B.1. Continued

\begin{tabular}{|c|c|c|c|c|c|c|c|c|c|c|c|}
\hline Sample & D45_PC01 & D45_PC02 & D45_PC03 & D46_PC01 & D47_PC01 & D47_PC02 & D47_PC03 & D47_PC04 & D47_PC05 & D44_MB03 & D22_PC01 \\
\hline Volcano & Healy & Healy & Healy & Healy & Healy & Healy & Healy & Healy & Healy & Healy & New Volcano \\
\hline Type & Pumice & Pumice & Pumice & Pumice & Pumice & Pumice & Pumice & Pumice & Pumice & Mafic Bleb & Pumice \\
\hline Location & SE flank & SE flank & SE flank & SE flank & Edifice crater & Edifice crater & Edifice crater & Edifice crater & Edifice crater & SE flank / rim & NE rim / wall \\
\hline $\mathrm{SiO}_{2}$ & 71.03 & 70.67 & 70.58 & 70.79 & 70.60 & 70.74 & 70.47 & 70.86 & 70.81 & 53.03 & 73.82 \\
\hline $\mathrm{TiO}_{2}$ & 0.476 & 0.469 & 0.486 & 0.480 & 0.536 & 0.529 & 0.553 & 0.539 & 0.537 & 0.923 & 0.408 \\
\hline $\mathrm{Al}_{2} \mathrm{O}_{3}$ & 14.30 & 14.40 & 14.29 & 14.32 & 14.60 & 14.55 & 14.71 & 14.50 & 14.63 & 16.88 & 13.78 \\
\hline $\mathrm{Fe}_{2} \mathrm{O}_{3}$ & 3.46 & 3.48 & 3.64 & 3.49 & 3.42 & 3.39 & 3.42 & 3.36 & 3.35 & 11.24 & 2.68 \\
\hline $\mathrm{MnO}$ & 0.116 & 0.117 & 0.118 & 0.120 & 0.136 & 0.135 & 0.137 & 0.136 & 0.136 & 0.198 & 0.154 \\
\hline $\mathrm{MgO}$ & 0.937 & 1.045 & 1.073 & 1.009 & 0.900 & 0.886 & 0.866 & 0.808 & 0.824 & 4.623 & 0.675 \\
\hline $\mathrm{CaO}$ & 3.07 & 3.30 & 3.28 & 3.20 & 3.03 & 2.97 & 3.06 & 2.97 & 2.96 & 9.68 & 3.75 \\
\hline $\mathrm{Na}_{2} \mathrm{O}$ & 4.90 & 4.84 & 4.87 & 4.91 & 5.07 & 5.09 & 5.09 & 5.12 & 5.06 & 2.88 & 4.02 \\
\hline $\mathrm{K}_{2} \mathrm{O}$ & 1.594 & 1.563 & 1.562 & 1.568 & 1.589 & 1.599 & 1.559 & 1.594 & 1.578 & 0.427 & 0.635 \\
\hline $\mathrm{P}_{2} \mathrm{O}_{5}$ & 0.107 & 0.102 & 0.106 & 0.106 & 0.112 & 0.113 & 0.122 & 0.113 & 0.115 & 0.119 & 0.093 \\
\hline LOI & 1.52 & 1.61 & 1.59 & 1.60 & 0.87 & 0.85 & 0.97 & 0.87 & 0.92 & & 3.43 \\
\hline Total & 99.71 & 99.97 & 100.34 & 100.14 & 99.92 & 99.27 & 99.67 & 100.17 & 99.93 & 100.06 & 100.98 \\
\hline
\end{tabular}

\begin{tabular}{|c|c|c|c|c|c|c|c|c|c|}
\hline Sample & D22_PC02 & D22_PC03 & D22_PC04 & D22_PC05 & D22_PC06 & D23_PC01 & D23_PC02 & $\mathrm{C03}$ & $\overline{\mathrm{D} 22 \_03 \_M B 01}$ \\
\hline Volcano & New Volcano & New Volcano & New Volcano & New Volcano & New Volcano & New Volcano & New Volcano & New Volcano & New Volcano \\
\hline Type & mice & mice & umice & Pumice & Pumice & Pumice & Pumice & Pumice & Mafic Bleb \\
\hline Location & $\mathrm{NE}$ rim / wall & $\mathrm{rim} / \mathrm{wall}$ & $\mathrm{rim}$ / wall & rim / wall & $\mathrm{rim}$ / wall & oor / wall & oor / wall & oor / wall & JE rim / wall \\
\hline
\end{tabular}

Location NE rim / wall NE rim / wall NE rim / wall NE rim / wall NE rim / wall $\mathrm{SW}$ floor / wall $\mathrm{SW}$ floor / wall $\mathrm{SW}$ floor / wall $\mathrm{NE} \mathrm{rim} / \mathrm{wall}$

\begin{tabular}{|c|c|c|c|c|c|c|c|c|c|}
\hline $\mathrm{SiO}_{2}$ & 74.12 & 73.84 & 74.56 & 73.64 & 74.75 & 74.07 & 74.16 & 73.95 & 58.63 \\
\hline $\mathrm{TiO}_{2}$ & 0.395 & 0.406 & 0.381 & 0.424 & 0.371 & 0.339 & 0.399 & 0.407 & 0.577 \\
\hline $\mathrm{Al}_{2} \mathrm{O}_{3}$ & 13.70 & 13.78 & 13.50 & 13.82 & 13.49 & 13.84 & 13.69 & 13.71 & 16.41 \\
\hline $\mathrm{Fe}_{2} \mathrm{O}_{3}$ & 2.60 & 2.70 & 2.53 & 2.78 & 2.41 & 2.36 & 2.58 & 2.68 & 8.33 \\
\hline MnO & 0.119 & 0.123 & 0.119 & 0.128 & 0.117 & 0.103 & 0.121 & 0.123 & 0.179 \\
\hline MgO & 0.646 & 0.668 & 0.561 & 0.711 & 0.539 & 0.984 & 0.699 & 0.677 & 4.331 \\
\hline $\mathrm{CaO}$ & 3.64 & 3.74 & 3.54 & 3.80 & 3.50 & 3.46 & 3.62 & 3.69 & 8.98 \\
\hline $\mathrm{Na}_{2} \mathrm{O}$ & 4.02 & 3.98 & 4.06 & 3.94 & 4.07 & 4.03 & 3.97 & 4.00 & 2.26 \\
\hline $\mathrm{K}_{2} \mathrm{O}$ & 0.668 & 0.664 & 0.661 & 0.657 & 0.670 & 0.726 & 0.671 & 0.667 & 0.219 \\
\hline $\mathrm{P}_{2} \mathrm{O}_{5}$ & 0.090 & 0.096 & 0.087 & 0.099 & 0.080 & 0.084 & 0.095 & 0.098 & 0.080 \\
\hline LOI & 2.99 & 3.43 & 2.31 & 3.25 & 2.44 & 2.68 & 3.48 & 3.39 & \\
\hline Total & 99.97 & 100.16 & 100.07 & 100.35 & 99.88 & 99.88 & 101.71 & 100.46 & 100.10 \\
\hline
\end{tabular}




\section{APPENDIX C:}

\section{Whole rock trace element data}

Table C.1. Whole rock trace element data 
Table C.1. Trace element concentrations (ppm) for whole-rock samples analysed by solution-ICP-MS.

\begin{tabular}{|c|c|c|c|c|c|c|c|c|c|c|c|}
\hline Sample & RI03_PC03 & RI03_PC10 & RI06_PC07 & RI06_PC12 & RI08_PC09 & RI12_PC08 & RI12_PC18 & RI18_PC04 & RI18_PC05 & RI19_PC01 & $\overline{\mathrm{RI} 26 \_P C 01}$ \\
\hline Volcano & Raoul & Raoul & Raoul & Raoul & Raoul & Raoul & Raoul & Raoul & Raoul & Raoul & Raoul \\
\hline Type & Pumice & Pumice & Pumice & Pumice & Pumice & Pumice & Pumice & Pumice & Pumice & Pumice & Pumice \\
\hline Location & Rangitahua & Rangitahua & Matatiohia & Matatiohia & Pre-GLP & Oneraki & Oneraki & GLP & GLP & 2006 & Fleetwood \\
\hline Sc & 25.8 & 26.1 & 25.3 & 24.7 & 20.9 & 20.9 & 23.2 & 22.1 & 21.8 & 26.1 & 22.8 \\
\hline V & 57.3 & 56.2 & 61.3 & 49.8 & 39.2 & 32.9 & 38.6 & 21.7 & 19.9 & 55.8 & 41.5 \\
\hline $\mathrm{Cr}$ & 2.02 & 1.38 & 4.06 & 3.01 & 1.20 & 1.34 & 2.83 & 1.90 & 1.10 & 1.94 & 3.43 \\
\hline $\mathbf{N i}$ & 1.15 & 0.96 & 2.91 & 1.76 & 0.75 & 0.99 & 1.28 & 0.72 & 0.77 & 0.86 & 1.68 \\
\hline $\mathrm{Cu}$ & 14.28 & 16.84 & 33.62 & 24.93 & 17.40 & 10.54 & 13.12 & 10.64 & 8.60 & 9.14 & 11.05 \\
\hline $\mathrm{Zn}$ & 96.8 & 90.2 & 72.2 & 73.8 & 93.4 & 78.0 & 97.1 & 86.8 & 80.7 & 102.0 & 86.6 \\
\hline Ga & 16.8 & 16.7 & 15.7 & 16.0 & 15.5 & 16.1 & 17.1 & 15.6 & 15.5 & 16.5 & 15.6 \\
\hline $\mathbf{R b}$ & 7.96 & 7.91 & 8.50 & 9.23 & 9.49 & 10.03 & 10.53 & 9.09 & 9.21 & 7.75 & 9.62 \\
\hline $\mathrm{Sr}$ & 182 & 181 & 166 & 170 & 172 & 193 & 203 & 171 & 172 & 175 & 164 \\
\hline $\mathbf{Y}$ & 37.8 & 37.3 & 33.8 & 36.3 & 40.2 & 37.4 & 39.2 & 39.2 & 39.6 & 37.0 & 38.6 \\
\hline $\mathrm{Zr}$ & 65.0 & 64.4 & 61.0 & 66.1 & 74.0 & 75.1 & 78.6 & 70.5 & 70.9 & 63.3 & 71.6 \\
\hline $\mathrm{Nb}$ & 0.536 & 0.515 & 0.504 & 0.565 & 0.608 & 0.708 & 0.741 & 0.596 & 0.589 & 0.513 & 0.658 \\
\hline Mo & 2.50 & 2.50 & 2.31 & 2.47 & 2.54 & 2.52 & 2.142 & 2.58 & 2.53 & 1.85 & 2.02 \\
\hline Cs & 0.660 & 0.667 & 0.724 & 0.793 & 0.807 & 0.741 & 0.77 & 0.745 & 0.792 & 0.653 & 0.818 \\
\hline $\mathrm{Ba}$ & 197 & 195 & 187 & 194 & 211 & 220 & 234 & 202 & 208 & 189 & 204 \\
\hline La & 3.40 & 3.36 & 3.44 & 3.71 & 3.89 & 4.80 & 5.03 & 3.72 & 3.85 & 3.26 & 4.31 \\
\hline $\mathrm{Ce}$ & 9.76 & 9.79 & 9.67 & 10.37 & 11.27 & 13.07 & 13.67 & 10.70 & 10.81 & 9.48 & 11.76 \\
\hline $\mathrm{Pr}$ & 1.70 & 1.70 & 1.67 & 1.78 & 1.93 & 2.18 & 2.29 & 1.86 & 1.90 & 1.66 & 1.99 \\
\hline Nd & 9.42 & 9.54 & 9.05 & 9.70 & 10.70 & 11.57 & 12.12 & 10.28 & 10.46 & 9.33 & 10.70 \\
\hline Sm & 3.44 & 3.40 & 3.20 & 3.37 & 3.77 & 3.88 & 3.96 & 3.65 & 3.68 & 3.36 & 3.73 \\
\hline Eu & 1.22 & 1.20 & 1.04 & 1.09 & 1.25 & 1.27 & 1.30 & 1.21 & 1.24 & 1.19 & 1.19 \\
\hline Gd & 4.57 & 4.53 & 4.17 & 4.35 & 4.92 & 4.87 & 5.07 & 4.76 & 4.81 & 4.48 & 4.90 \\
\hline Tb & 0.855 & 0.844 & 0.767 & 0.803 & 0.919 & 0.878 & 0.905 & 0.887 & 0.912 & 0.837 & 0.885 \\
\hline Dy & 6.04 & 5.92 & 5.49 & 5.76 & 6.41 & 6.10 & 6.29 & 6.21 & 6.41 & 5.83 & 6.20 \\
\hline Ho & 1.35 & 1.32 & 1.22 & 1.27 & 1.45 & 1.34 & 1.40 & 1.37 & 1.42 & 1.32 & 1.37 \\
\hline $\mathrm{Er}$ & 4.02 & 4.03 & 3.69 & 3.90 & 4.33 & 4.10 & 4.20 & 4.20 & 4.32 & 3.94 & 4.13 \\
\hline $\mathrm{Tm}$ & 0.612 & 0.611 & 0.563 & 0.597 & 0.662 & 0.613 & 0.645 & 0.636 & 0.660 & 0.596 & 0.620 \\
\hline Yb & 4.14 & 4.14 & 3.80 & 4.05 & 4.49 & 4.17 & 4.31 & 4.32 & 4.52 & 4.02 & 4.19 \\
\hline Lu & 0.629 & 0.620 & 0.572 & 0.612 & 0.681 & 0.630 & 0.663 & 0.653 & 0.680 & 0.619 & 0.639 \\
\hline $\mathrm{Hf}$ & 2.21 & 2.15 & 2.09 & 2.21 & 2.51 & 2.49 & 2.603 & 2.37 & 2.45 & 2.11 & 2.39 \\
\hline Ta & 0.041 & 0.041 & 0.041 & 0.044 & 0.047 & 0.054 & 0.056 & 0.045 & 0.048 & 0.040 & 0.049 \\
\hline W & 0.382 & 0.173 & 0.179 & 0.259 & 0.216 & 0.200 & 0.27 & 0.194 & 0.284 & 0.183 & 0.205 \\
\hline $\mathrm{Pb}$ & 12.84 & 15.71 & 2.99 & 3.05 & 3.60 & 3.33 & 5.165 & 3.50 & 3.41 & 4.34 & 4.44 \\
\hline Th & 0.447 & 0.447 & 0.482 & 0.493 & 0.531 & 0.684 & 0.707 & 0.484 & 0.510 & 0.434 & 0.580 \\
\hline U & 0.204 & 0.201 & 0.203 & 0.209 & 0.232 & 0.267 & 0.279 & 0.214 & 0.223 & 0.196 & 0.231 \\
\hline
\end{tabular}


Table C.1. continued

\begin{tabular}{|c|c|c|c|c|c|c|c|c|c|c|c|}
\hline Sample & RI26_PC04 & RI06_MB02 & RI06_MB11 & RI06_R01 & MI01_P05 & MI07_P03 & D24_PC01 & D24_PC02 & D24_PC04 & D25_PC01 & D29_PC01 \\
\hline Volcano & Raoul & Raoul & Raoul & Raoul & Macauley & Macauley & Macauley & Macauley & Macauley & Macauley & Macauley \\
\hline Type & Pumice & Mafic bleb & Mafic bleb & Tonalite & Pumice & Pumice & Pumice & Pumice & Pumice & Pumice & Pumice \\
\hline Location & Fleetwood & Matatiohia & Matatiohia & Matatirohia & SBT & SBT & SW flank & SW flank & SW flank & SW flank & $\mathrm{N}$ rim \\
\hline$\overline{\text { Sc }}$ & 23.5 & 44.1 & 50.0 & 19.4 & 15.3 & 14.3 & 15.8 & 17.9 & 17.4 & 18.2 & 12.2 \\
\hline v & 45.3 & 356.8 & 349.9 & 78.1 & 15.3 & 12.2 & 37.5 & 34.9 & 29.7 & 32.9 & 6.2 \\
\hline $\mathrm{Cr}$ & 1.55 & 21.05 & 53.28 & 2.46 & 4.74 & 2.04 & 2.39 & 2.99 & 1.75 & 1.10 & 3.73 \\
\hline $\mathrm{Ni}$ & 1.33 & 15.81 & 32.63 & 1.85 & 1.24 & 0.87 & 1.10 & 1.43 & 0.99 & 0.93 & 0.72 \\
\hline $\mathrm{Cu}$ & 13.02 & 104.57 & 91.70 & 34.46 & 16.32 & 17.59 & 26.54 & 44.92 & 25.60 & 25.14 & 33.03 \\
\hline $\mathrm{Zn}$ & 79.4 & 73.8 & 72.7 & 52.5 & 90.4 & 90.6 & 74.4 & 106.1 & 96.6 & 96.0 & 83.1 \\
\hline Ga & 16.2 & 17.1 & 15.9 & 14.3 & 16.6 & 15.9 & 15.7 & 17.0 & 17.0 & 16.9 & 16.0 \\
\hline $\mathbf{R b}$ & 9.63 & 2.91 & 2.81 & 6.16 & 29.38 & 28.75 & 22.74 & 24.76 & 25.56 & 25.02 & 30.69 \\
\hline $\mathrm{Sr}$ & 169 & 175 & 163 & 112 & 169 & 164 & 202 & 229 & 214 & 212 & 142 \\
\hline $\mathbf{Y}$ & 38.7 & 13.1 & 13.5 & 40.8 & 47.6 & 46.1 & 34.2 & 46.3 & 47.0 & 46.7 & 49.9 \\
\hline $\mathrm{Zr}$ & 72.8 & 23.3 & 21.5 & 6.0 & 153.7 & 150.6 & 107.8 & 145.7 & 149.4 & 147.8 & 176.5 \\
\hline $\mathrm{Nb}$ & 0.653 & 0.351 & 0.409 & 0.913 & 1.740 & 1.713 & 1.131 & 1.798 & 1.877 & 1.858 & 2.108 \\
\hline Mo & 2.51 & 0.56 & 0.67 & 0.78 & 2.28 & 2.20 & 1.44 & 1.81 & 1.81 & 1.85 & 2.12 \\
\hline Cs & 0.848 & 0.222 & 0.242 & 0.275 & 1.405 & 1.348 & 1.252 & 0.988 & 1.017 & 1.008 & 1.221 \\
\hline $\mathrm{Ba}$ & 209 & 63 & 62 & 329 & 412 & 414 & 413 & 365 & 362 & 358 & 459 \\
\hline La & 4.39 & 1.34 & 1.34 & 2.67 & 11.38 & 11.00 & 8.20 & 11.71 & 11.84 & 11.66 & 12.76 \\
\hline $\mathrm{Ce}$ & 12.06 & 3.77 & 3.66 & 8.58 & 28.36 & 27.93 & 20.37 & 29.90 & 30.28 & 29.97 & 32.52 \\
\hline $\mathrm{Pr}$ & 2.05 & 0.64 & 0.64 & 1.63 & 4.35 & 4.24 & 3.04 & 4.57 & 4.62 & 4.60 & 4.81 \\
\hline Nd & 11.00 & 3.50 & 3.47 & 9.34 & 21.02 & 20.21 & 14.67 & 22.09 & 22.58 & 22.49 & 22.67 \\
\hline Sm & 3.78 & 1.31 & 1.21 & 3.57 & 5.90 & 5.70 & 4.13 & 6.18 & 6.25 & 6.20 & 6.21 \\
\hline Eu & 1.20 & 0.53 & 0.52 & 0.88 & 1.56 & 1.50 & 1.25 & 1.75 & 1.75 & 1.76 & 1.50 \\
\hline Gd & 4.88 & 1.75 & 1.67 & 4.77 & 6.62 & 6.47 & 4.73 & 6.83 & 6.92 & 6.89 & 7.00 \\
\hline Tb & 0.889 & 0.317 & 0.310 & 0.921 & 1.127 & 1.093 & 0.815 & 1.143 & 1.157 & 1.155 & 1.183 \\
\hline Dy & 6.21 & 2.26 & 2.27 & 6.47 & 7.53 & 7.35 & 5.41 & 7.56 & 7.65 & 7.69 & 7.95 \\
\hline Ho & 1.39 & 0.50 & 0.49 & 1.40 & 1.65 & 1.60 & 1.20 & 1.62 & 1.65 & 1.65 & 1.72 \\
\hline Er & 4.12 & 1.49 & 1.45 & 4.15 & 4.95 & 4.85 & 3.60 & 4.90 & 4.95 & 4.90 & 5.24 \\
\hline Tm & 0.636 & 0.225 & 0.218 & 0.615 & 0.758 & 0.729 & 0.546 & 0.735 & 0.745 & 0.751 & 0.800 \\
\hline Yb & 4.28 & 1.51 & 1.47 & 4.06 & 5.16 & 4.96 & 3.73 & 4.99 & 5.02 & 4.96 & 5.50 \\
\hline Lu & 0.646 & 0.227 & 0.224 & 0.582 & 0.787 & 0.754 & 0.574 & 0.754 & 0.761 & 0.751 & 0.825 \\
\hline $\mathrm{Hf}$ & 2.42 & 0.97 & 0.79 & 0.45 & 4.51 & 4.43 & 3.15 & 4.27 & 4.34 & 4.33 & 5.14 \\
\hline Ta & 0.050 & 0.021 & 0.022 & 0.074 & 0.111 & 0.109 & 0.080 & 0.120 & 0.118 & 0.117 & 0.134 \\
\hline W & 0.284 & 0.254 & 0.318 & 0.265 & 0.325 & 0.313 & 0.377 & 0.476 & 0.240 & 0.448 & 0.321 \\
\hline $\mathrm{Pb}$ & 3.70 & 1.24 & 1.18 & 1.89 & 7.58 & 7.64 & 6.12 & 6.54 & 5.80 & 5.57 & 6.80 \\
\hline Th & 0.594 & 0.531 & 0.182 & 0.492 & 1.783 & 1.747 & 1.576 & 1.870 & 1.888 & 1.800 & 2.212 \\
\hline $\mathbf{U}$ & 0.232 & 0.068 & 0.063 & 0.055 & 0.696 & 0.665 & 0.552 & 0.725 & 0.726 & 0.711 & 0.918 \\
\hline
\end{tabular}


Table C.1. continued

\begin{tabular}{|c|c|c|c|c|c|c|c|c|c|c|c|}
\hline $\begin{array}{l}\text { Sample } \\
\text { Volcano } \\
\text { Type } \\
\text { Location }\end{array}$ & $\begin{array}{r}\text { D29_PC02 } \\
\text { Macauley } \\
\text { Pumice } \\
\text { N rim }\end{array}$ & $\begin{array}{r}\text { D30_PC01 } \\
\text { Macauley } \\
\text { Pumice } \\
\mathrm{N} \text { rim }\end{array}$ & $\begin{array}{r}\text { D31_PC02 } \\
\text { Macauley } \\
\text { Pumice } \\
\text { N rim }\end{array}$ & $\begin{array}{r}\text { D32_PC01 } \\
\text { Macauley } \\
\text { Pumice } \\
\mathrm{N} \text { flank }\end{array}$ & $\begin{array}{r}\text { D32_PC02 } \\
\text { Macauley } \\
\text { Pumice } \\
\mathrm{N} \text { flank }\end{array}$ & $\begin{array}{r}\text { D33_PC01 } \\
\text { Macauley } \\
\text { Pumice } \\
\text { E flank }\end{array}$ & $\begin{array}{r}\text { D33_PC02 } \\
\text { Macauley } \\
\text { Pumice } \\
\text { E flank }\end{array}$ & $\begin{array}{r}\text { D33_PC04 } \\
\text { Macauley } \\
\text { Pumice } \\
\text { E flank }\end{array}$ & $\begin{array}{r}\text { D36_PC01 } \\
\text { Healy } \\
\text { Pumice } \\
\text { NW flank }\end{array}$ & $\begin{array}{r}\text { D36_PC03 } \\
\text { Healy } \\
\text { Pumice } \\
\text { NW flank }\end{array}$ & $\begin{array}{r}\text { D37_PC02 } \\
\text { Healy } \\
\text { Pumice } \\
\text { NW flank }\end{array}$ \\
\hline Sc & 12.1 & 13.5 & 12.1 & 18.1 & 13.5 & 16.0 & 15.7 & 20.7 & 10.0 & 10.8 & 11.0 \\
\hline V & 4.2 & 5.6 & 6.6 & 35.7 & 11.2 & 37.5 & 37.6 & 29.0 & 36.9 & 39.4 & 41.2 \\
\hline $\mathrm{Cr}$ & 1.63 & 1.37 & 2.56 & 5.15 & 2.76 & 3.06 & 2.11 & 61.17 & 1.44 & 2.31 & 2.62 \\
\hline $\mathrm{Ni}$ & 0.58 & 0.35 & 1.94 & 1.02 & 1.56 & 1.26 & 1.12 & 15.61 & 0.97 & 1.28 & 0.93 \\
\hline $\mathrm{Cu}$ & 25.37 & 15.18 & 30.14 & 44.33 & 25.58 & 34.63 & 42.13 & 47.61 & 15.91 & 17.25 & 20.36 \\
\hline $\mathrm{Zn}$ & 77.8 & 87.8 & 76.7 & 104.1 & 88.3 & 79.0 & 82.9 & 101.9 & 69.0 & 56.7 & 55.9 \\
\hline Ga & 16.4 & 16.1 & 16.1 & 17.0 & 15.9 & 16.1 & 16.1 & 15.9 & 16.1 & 16.4 & 16.8 \\
\hline $\mathbf{R b}$ & 31.59 & 30.97 & 30.75 & 24.64 & 29.45 & 23.19 & 23.16 & 8.16 & 25.77 & 25.00 & 25.75 \\
\hline $\mathrm{Sr}$ & 142 & 158 & 142 & 216 & 193 & 216 & 210 & 189 & 210 & 217 & 225 \\
\hline $\mathbf{Y}$ & 49.4 & 48.1 & 48.7 & 46.2 & 47.0 & 35.1 & 35.3 & 40.1 & 40.4 & 39.0 & 41.0 \\
\hline $\mathrm{Zr}$ & 178.9 & 161.5 & 176.6 & 144.2 & 154.8 & 109.4 & 110.1 & 89.3 & 169.9 & 163.2 & 169.5 \\
\hline $\mathrm{Nb}$ & 2.125 & 1.807 & 2.086 & 1.813 & 1.738 & 1.143 & 1.230 & 0.883 & 3.078 & 3.004 & 3.129 \\
\hline Mo & 2.17 & 2.34 & 2.08 & 1.76 & 2.32 & 1.49 & 0.41 & 1.93 & 1.71 & 1.25 & 1.73 \\
\hline Cs & 1.268 & 1.453 & 1.213 & 0.996 & 1.428 & 1.276 & 1.122 & 0.732 & 0.775 & 0.744 & 0.782 \\
\hline $\mathrm{Ba}$ & 466 & 433 & 455 & 352 & 433 & 424 & 432 & 202 & 820 & 792 & 830 \\
\hline La & 12.96 & 11.65 & 12.78 & 11.70 & 11.55 & 8.36 & 8.48 & 4.12 & 13.64 & 13.39 & 13.87 \\
\hline $\mathrm{Ce}$ & 32.67 & 29.51 & 32.07 & 29.56 & 28.34 & 20.62 & 20.98 & 12.30 & 31.63 & 30.36 & 31.85 \\
\hline $\operatorname{Pr}$ & 4.91 & 4.45 & 4.78 & 4.55 & 4.37 & 3.11 & 3.16 & 2.13 & 4.48 & 4.38 & 4.56 \\
\hline Nd & 23.09 & 21.28 & 22.46 & 21.67 & 20.74 & 14.86 & 14.91 & 11.50 & 20.15 & 19.27 & 20.57 \\
\hline Sm & 6.39 & 6.03 & 6.21 & 6.23 & 5.85 & 4.16 & 4.32 & 3.97 & 5.04 & 4.96 & 5.23 \\
\hline Eu & 1.53 & 1.52 & 1.51 & 1.76 & 1.51 & 1.27 & 1.30 & 1.35 & 1.46 & 1.45 & 1.48 \\
\hline Gd & 7.08 & 6.72 & 6.98 & 7.01 & 6.50 & 4.88 & 4.89 & 5.07 & 5.52 & 5.55 & 5.69 \\
\hline Tb & 1.198 & 1.159 & 1.190 & 1.158 & 1.121 & 0.828 & 0.847 & 0.919 & 0.947 & 0.931 & 0.968 \\
\hline Dy & 8.10 & 7.83 & 8.00 & 7.61 & 7.56 & 5.65 & 5.67 & 6.46 & 6.32 & 6.32 & 6.54 \\
\hline Ho & 1.76 & 1.69 & 1.72 & 1.64 & 1.65 & 1.22 & 1.25 & 1.42 & 1.39 & 1.36 & 1.42 \\
\hline Er & 5.28 & 5.15 & 5.24 & 4.88 & 5.04 & 3.72 & 3.77 & 4.23 & 4.21 & 4.16 & 4.33 \\
\hline Tm & 0.809 & 0.779 & 0.798 & 0.727 & 0.768 & 0.569 & 0.570 & 0.633 & 0.654 & 0.642 & 0.669 \\
\hline Yb & 5.47 & 5.40 & 5.48 & 4.91 & 5.18 & 3.88 & 3.88 & 4.36 & 4.49 & 4.45 & 4.61 \\
\hline Lu & 0.837 & 0.811 & 0.825 & 0.752 & 0.778 & 0.581 & 0.594 & 0.645 & 0.684 & 0.668 & 0.688 \\
\hline $\mathrm{Hf}$ & 5.24 & 4.75 & 5.12 & 4.22 & 4.55 & 3.23 & 3.30 & 2.72 & 4.53 & 4.33 & 4.54 \\
\hline Ta & 0.134 & 0.117 & 0.134 & 0.117 & 0.111 & 0.081 & 0.099 & 0.068 & 0.209 & 0.200 & 0.206 \\
\hline W & 0.264 & 0.311 & 0.256 & 0.453 & 0.389 & 0.453 & 0.604 & 0.247 & 0.348 & 0.290 & 0.263 \\
\hline $\mathrm{Pb}$ & 6.80 & 7.75 & 6.68 & 5.69 & 8.24 & 6.49 & 5.62 & 4.71 & 3.93 & 4.26 & 3.92 \\
\hline Th & 2.278 & 1.944 & 2.170 & 1.824 & 1.840 & 1.663 & 1.668 & 0.389 & 2.503 & 2.344 & 2.490 \\
\hline$\underline{U}$ & 0.854 & 0.714 & 0.850 & 0.716 & 0.710 & 0.557 & 0.570 & 0.241 & 0.724 & 0.685 & 0.729 \\
\hline
\end{tabular}


Table C.1. continued

\begin{tabular}{|c|c|c|c|c|c|c|c|c|c|c|c|}
\hline Sample & D37_PC04 & D38_PC04 & D38_PC06 & D39_PC05 & D44_PC01 & D44_PC02 & D45_PC02 & D47_PC02 & D44_MB03 & D22_PC02 & D22_PC06 \\
\hline Volcano & Healy & Healy & Healy & Healy & Healy & Healy & Healy & Healy & Healy & New Volcano & New Volcano \\
\hline Type & Pumice & Pumice & Pumice & Pumice & Pumice & Pumice & Pumice & Pumice & Mafic Bleb & Pumice & Pumice \\
\hline Location & NW flank & NW flank / rim & NW flank / rim & $\mathrm{N}$ rim / wall & SE flank / rim & SE flank / rim & SE flank & Edifice crater & SE flan / rim & NE rim / wall & NE rim / wall \\
\hline Sc & 10.7 & 12.0 & 12.6 & 8.3 & 11.0 & 10.3 & 11.3 & 10.4 & 35.3 & 17.1 & 16.5 \\
\hline V & 39.1 & 46.0 & 51.0 & 14.1 & 43.2 & 36.6 & 42.6 & 16.3 & 344.0 & 13.3 & 11.1 \\
\hline $\mathrm{Cr}$ & 2.30 & 4.98 & 6.75 & 2.20 & 5.10 & 3.08 & 3.03 & 1.78 & 15.76 & 1.62 & 2.43 \\
\hline $\mathrm{Ni}$ & 1.20 & 2.23 & 3.37 & 0.61 & 2.40 & 1.41 & 1.70 & 0.69 & 11.73 & 0.89 & 0.86 \\
\hline $\mathrm{Cu}$ & 17.89 & 16.38 & 20.16 & 7.39 & 20.71 & 14.84 & 19.64 & 7.04 & 139.03 & 6.37 & 6.94 \\
\hline $\mathrm{Zn}$ & 48.3 & 55.7 & 51.8 & 60.8 & 59.8 & 54.6 & 56.6 & 68.6 & 79.6 & 72.3 & 69.3 \\
\hline Ga & 16.3 & 15.7 & 16.5 & 15.8 & 15.6 & 15.9 & 15.9 & 16.3 & 17.3 & 14.8 & 14.7 \\
\hline $\mathbf{R b}$ & 26.55 & 24.52 & 24.65 & 29.62 & 25.05 & 26.03 & 25.05 & 26.18 & 7.01 & 10.22 & 10.49 \\
\hline $\mathrm{Sr}$ & 212 & 205 & 220 & 203 & 192 & 200 & 203 & 247 & 290 & 167 & 167 \\
\hline $\mathbf{Y}$ & 41.2 & 38.2 & 38.8 & 41.7 & 38.6 & 39.6 & 39.0 & 40.2 & 22.4 & 38.9 & 39.0 \\
\hline $\mathrm{Zr}$ & 174.7 & 159.1 & 162.5 & 178.9 & 164.3 & 168.8 & 166.1 & 162.8 & 52.2 & 81.9 & 83.5 \\
\hline Nb & 3.199 & 2.934 & 2.996 & 3.396 & 3.022 & 3.088 & 3.029 & 2.983 & 1.098 & 0.708 & 0.731 \\
\hline Mo & 1.75 & 1.28 & 1.65 & 1.09 & 1.34 & 1.38 & 1.64 & 1.35 & 1.12 & 1.87 & 1.93 \\
\hline Cs & 0.793 & 0.720 & 0.732 & 0.754 & 0.729 & 0.760 & 0.755 & 0.716 & 0.274 & 0.838 & 0.852 \\
\hline $\mathrm{Ba}$ & 838 & 772 & 788 & 915 & 782 & 811 & 795 & 833 & 300 & 225 & 228 \\
\hline La & 13.94 & 12.96 & 13.04 & 14.17 & 13.02 & 13.62 & 13.30 & 13.75 & 4.35 & 5.08 & 5.14 \\
\hline $\mathrm{Ce}$ & 32.30 & 29.57 & 29.97 & 32.34 & 30.04 & 30.92 & 30.54 & 32.06 & 10.75 & 13.49 & 13.54 \\
\hline $\mathrm{Pr}$ & 4.54 & 4.21 & 4.27 & 4.52 & 4.26 & 4.41 & 4.33 & 4.49 & 1.72 & 2.19 & 2.20 \\
\hline Nd & 20.51 & 18.59 & 18.93 & 20.26 & 19.11 & 19.63 & 19.33 & 20.13 & 8.74 & 11.27 & 11.34 \\
\hline Sm & 5.10 & 4.82 & 4.91 & 5.16 & 4.92 & 5.07 & 4.92 & 5.17 & 2.66 & 3.73 & 3.68 \\
\hline Eu & 1.48 & 1.36 & 1.44 & 1.47 & 1.32 & 1.41 & 1.40 & 1.56 & 1.03 & 1.20 & 1.18 \\
\hline Gd & 5.66 & 5.44 & 5.43 & 5.58 & 5.39 & 5.64 & 5.48 & 5.70 & 3.19 & 4.70 & 4.70 \\
\hline Tb & 0.955 & 0.906 & 0.926 & 0.968 & 0.895 & 0.947 & 0.925 & 0.961 & 0.559 & 0.857 & 0.863 \\
\hline Dy & 6.43 & 6.17 & 6.16 & 6.45 & 6.15 & 6.35 & 6.17 & 6.37 & 3.80 & 6.06 & 6.10 \\
\hline Ho & 1.42 & 1.32 & 1.32 & 1.40 & 1.32 & 1.37 & 1.35 & 1.37 & 0.81 & 1.34 & 1.36 \\
\hline Er & 4.30 & 4.02 & 4.08 & 4.24 & 4.02 & 4.21 & 4.06 & 4.15 & 2.39 & 4.06 & 4.13 \\
\hline Tm & 0.671 & 0.616 & 0.634 & 0.661 & 0.627 & 0.649 & 0.630 & 0.637 & 0.347 & 0.639 & 0.636 \\
\hline Yb & 4.59 & 4.27 & 4.32 & 4.67 & 4.24 & 4.48 & 4.31 & 4.40 & 2.31 & 4.26 & 4.40 \\
\hline Lu & 0.699 & 0.648 & 0.659 & 0.723 & 0.646 & 0.691 & 0.655 & 0.661 & 0.348 & 0.659 & 0.669 \\
\hline $\mathrm{Hf}$ & 4.61 & 4.25 & 4.34 & 4.69 & 4.28 & 4.50 & 4.34 & 4.24 & 1.50 & 2.59 & 2.63 \\
\hline Ta & 0.210 & 0.197 & 0.198 & 0.264 & 0.202 & 0.205 & 0.197 & 0.196 & 0.067 & 0.052 & 0.053 \\
\hline w & 0.246 & 0.261 & 0.253 & 0.506 & 0.268 & 0.270 & 0.247 & 0.246 & 0.385 & 0.244 & 0.255 \\
\hline $\mathrm{Pb}$ & 3.97 & 4.19 & 3.81 & 4.73 & 4.40 & 4.39 & 3.82 & 4.43 & 1.91 & 3.68 & 3.68 \\
\hline Th & 2.553 & 2.270 & 2.352 & 2.711 & 2.331 & 2.434 & 2.381 & 2.429 & 0.638 & 0.697 & 0.730 \\
\hline$\underline{U}$ & 0.738 & 0.684 & 0.692 & 0.805 & 0.682 & 0.731 & 0.694 & 0.722 & 0.175 & 0.277 & 0.278 \\
\hline
\end{tabular}




\begin{tabular}{|c|c|c|}
\hline Sample & D23_PC02 & D22_03 MB01 \\
\hline Volcano & New Volcano & New Volcano \\
\hline Type & Pumice & Mafic bleb \\
\hline Location & SW floor / wall & NE rim / wall \\
\hline Sc & 16.7 & 36.8 \\
\hline v & 12.7 & 240.1 \\
\hline $\mathrm{Cr}$ & 0.90 & 28.65 \\
\hline $\mathbf{N i}$ & 1.41 & 12.04 \\
\hline $\mathrm{Cu}$ & 8.27 & 48.21 \\
\hline $\mathrm{Zn}$ & 77.5 & 78.1 \\
\hline Ga & 14.7 & 15.3 \\
\hline $\mathbf{R b}$ & 10.39 & 3.77 \\
\hline $\mathrm{Sr}$ & 169 & 139 \\
\hline $\mathbf{Y}$ & 38.6 & 19.8 \\
\hline $\mathrm{Zr}$ & 82.9 & 31.0 \\
\hline Nb & 0.725 & 0.464 \\
\hline Mo & 1.86 & 0.82 \\
\hline Cs & 0.841 & 0.419 \\
\hline $\mathrm{Ba}$ & 231 & 88 \\
\hline La & 5.11 & 1.87 \\
\hline $\mathrm{Ce}$ & 13.59 & 5.12 \\
\hline $\operatorname{Pr}$ & 2.21 & 0.85 \\
\hline Nd & 11.46 & 4.74 \\
\hline Sm & 3.75 & 1.67 \\
\hline Eu & 1.20 & 0.66 \\
\hline Gd & 4.86 & 2.36 \\
\hline Tb & 0.878 & 0.445 \\
\hline Dy & 6.17 & 3.21 \\
\hline Ho & 1.37 & 0.72 \\
\hline Er & 4.14 & 2.17 \\
\hline $\mathrm{Tm}$ & 0.634 & 0.330 \\
\hline Yb & 4.37 & 2.26 \\
\hline Lu & 0.665 & 0.359 \\
\hline $\mathrm{Hf}$ & 2.64 & 1.07 \\
\hline Ta & 0.054 & 0.026 \\
\hline w & 0.261 & 0.334 \\
\hline $\mathbf{P b}$ & 3.72 & 1.43 \\
\hline Th & 0.722 & 0.250 \\
\hline U & 0.294 & 0.097 \\
\hline
\end{tabular}




\section{APPENDIX D: \\ Whole rock $\mathrm{Pb}$ \\ isotope data}

Table D.1. Whole rock $\mathrm{Pb}$ isotope data 
Table D.1. $\mathrm{Pb}$ isotope ratios for whole-rock samples analysed by MC-ICP-MS.

\begin{tabular}{|c|c|c|c|c|c|c|c|c|c|c|c|}
\hline Sample & RI03_PC03 & RI12_PC08 & RI18_PC05 & RI26_PC01 & RI06_MB02 & RI06_R01 & MI07_P03 & D24_PC04 & D25_PC01 & D29_PC02 & D33_PC04 \\
\hline Volcano & Raoul & Raoul & Raoul & Raoul & Raoul & Raoul & Macauley & Macauley & Macauley & Macauley & Macauley \\
\hline Type & Pumice & Pumice & Pumice & Pumice & Mafic bleb & Tonalite & Pumice & Pumice & Pumice & Pumice & Pumice \\
\hline Location & Rangitahua & Oneraki & GLP & Fleetwood & Matatiohia & Matatirohia & SBT & SW flank & SW flank & $\mathrm{N}$ rim & E flank \\
\hline${ }^{206} \mathrm{~Pb} /{ }^{204} \mathrm{~Pb}$ & 18.5362 & 18.6765 & 18.6650 & 18.6786 & 18.6669 & 18.6869 & 18.7103 & 18.7113 & 18.7158 & 18.7084 & 18.6632 \\
\hline $2 \mathrm{se}$ & 0.0016 & 0.0015 & 0.0016 & 0.0014 & 0.0017 & 0.0013 & 0.0016 & 0.0017 & 0.0016 & 0.0014 & 0.0013 \\
\hline${ }^{207} \mathrm{~Pb} /{ }^{204} \mathrm{~Pb}$ & 15.5805 & 15.5772 & 15.5765 & 15.5814 & 15.5682 & 15.5812 & 15.5824 & 15.5847 & 15.5902 & 15.5858 & 15.5848 \\
\hline $2 \mathrm{se}$ & 0.0017 & 0.0015 & 0.0017 & 0.0014 & 0.0019 & 0.0014 & 0.0016 & 0.0018 & 0.0015 & 0.0015 & 0.0012 \\
\hline$/ /^{204} \mathrm{~Pb}$ & 38.2945 & 38.3890 & 38.3769 & 38.3993 & 38.3462 & 38.4587 & 38.4408 & 38.4467 & 38.4648 & 38.4447 & 38.3980 \\
\hline $2 \mathrm{se}$ & 0.0048 & 0.0042 & 0.0050 & 0.0041 & 0.0054 & 0.0039 & 0.0045 & 0.0051 & 0.0037 & 0.0046 & 0.0034 \\
\hline${ }^{207} \mathrm{~Pb} /{ }^{206} \mathrm{~Pb}$ & 0.840163 & 0.834033 & 0.834536 & 0.834162 & 0.833995 & 0.833801 & 0.832815 & 0.832907 & 0.832965 & 0.833068 & 0.835056 \\
\hline $2 \mathrm{se}$ & 0.000025 & 0.000022 & 0.000025 & 0.000024 & 0.000032 & 0.000026 & 0.000026 & 0.000026 & 0.000018 & 0.000034 & 0.000022 \\
\hline${ }^{208} \mathrm{~Pb} /{ }^{206} \mathrm{~Pb}$ & 2.06500 & 2.05536 & 2.05614 & 2.05570 & 2.05421 & 2.05803 & 2.05455 & 2.05473 & 2.05513 & 2.05485 & 2.05742 \\
\hline $2 \mathrm{se}$ & 0.00011 & 0.00026 & 0.00010 & 0.00010 & 0.00013 & 0.00010 & 0.00010 & 0.00011 & 0.00005 & 0.00013 & 0.00008 \\
\hline Sample & D38_PC06 & D39_PC05 & D44_PC02 & D47_PC02 & D22_PC02 & D23_PC02 & D22_03 MB01 & & & & \\
\hline Volcano & Healy & Healy & Healy & Healy & New Volcano & New Volcano & New Volcano & & & & \\
\hline Type & Pumice & Pumice & Pumice & Pumice & Pumice & Pumice & Mafic bleb & & & & \\
\hline Location & NW flank / rim & $\mathrm{N}$ rim / wall & SE flank / rim & Edifice crater & NE rim / wall & SW floor / wall & NE rim / wall & & & & \\
\hline${ }^{206} \mathrm{~Pb} /{ }^{204} \mathrm{~Pb}$ & 18.8239 & 18.8242 & 18.8195 & 18.8264 & 18.7045 & 18.6994 & 18.7137 & & & & \\
\hline $2 \mathrm{se}$ & 0.0011 & 0.0010 & 0.0013 & 0.0012 & 0.0017 & 0.0012 & 0.0010 & & & & \\
\hline${ }^{4} \mathrm{~Pb}$ & 15.6012 & 15.6013 & 15.5954 & 15.6025 & 15.5816 & 15.5832 & 15.5900 & & & & \\
\hline $2 \mathrm{se}$ & 0.0011 & 0.0009 & 0.0013 & 0.0010 & 0.0018 & 0.0012 & 0.0010 & & & & \\
\hline $\mathrm{b} /{ }^{204} \mathrm{~Pb}$ & 38.6065 & 38.6073 & 38.5919 & 38.6130 & 38.4299 & 38.4304 & 38.4718 & & & & \\
\hline $2 \mathrm{se}$ & 0.0028 & 0.0022 & 0.0037 & 0.0026 & 0.0056 & 0.0037 & 0.0030 & & & & \\
\hline${ }^{207} \mathrm{~Pb} /{ }^{206} \mathrm{~Pb}$ & 0.828816 & 0.828787 & 0.828682 & 0.828762 & 0.833054 & 0.833348 & 0.833088 & & & & \\
\hline $2 \mathrm{se}$ & 0.000020 & 0.000016 & 0.000019 & 0.000015 & 0.000029 & 0.000021 & 0.000020 & & & & \\
\hline${ }^{206} \mathrm{~Pb}$ & 2.05095 & 2.05093 & 2.05056 & 2.05099 & 2.05462 & 2.05514 & 2.05584 & & & & \\
\hline $2 \mathrm{se}$ & 0.00005 & 0.00004 & 0.00007 & 0.00004 & 0.00013 & 0.00008 & 0.00007 & & & & \\
\hline
\end{tabular}

Sample values calculated relative to bracketing standard NBS-981. Reference values for NBS-981 are from Baker et al. (2004) where

${ }^{206} \mathrm{~Pb} /{ }^{204} \mathrm{~Pb}=16.9416,{ }^{207} \mathrm{~Pb} /{ }^{204} \mathrm{~Pb}=15.5000,{ }^{208} \mathrm{~Pb} /{ }^{204} \mathrm{~Pb}=36.7262,{ }^{208} \mathrm{~Pb} /{ }^{206} \mathrm{~Pb}=2.16781$ and ${ }^{207} \mathrm{~Pb} /{ }^{206} \mathrm{~Pb}=0.914905 .2$

standard error calculated from the range of values measured over 50 integrations. Abbreviations same as Table B.1 


\section{APPENDIX E: Glass major element data}

Table E.1. Glass major element data 
Table E.1. Major element concentrations for glasses analysed by EPMA

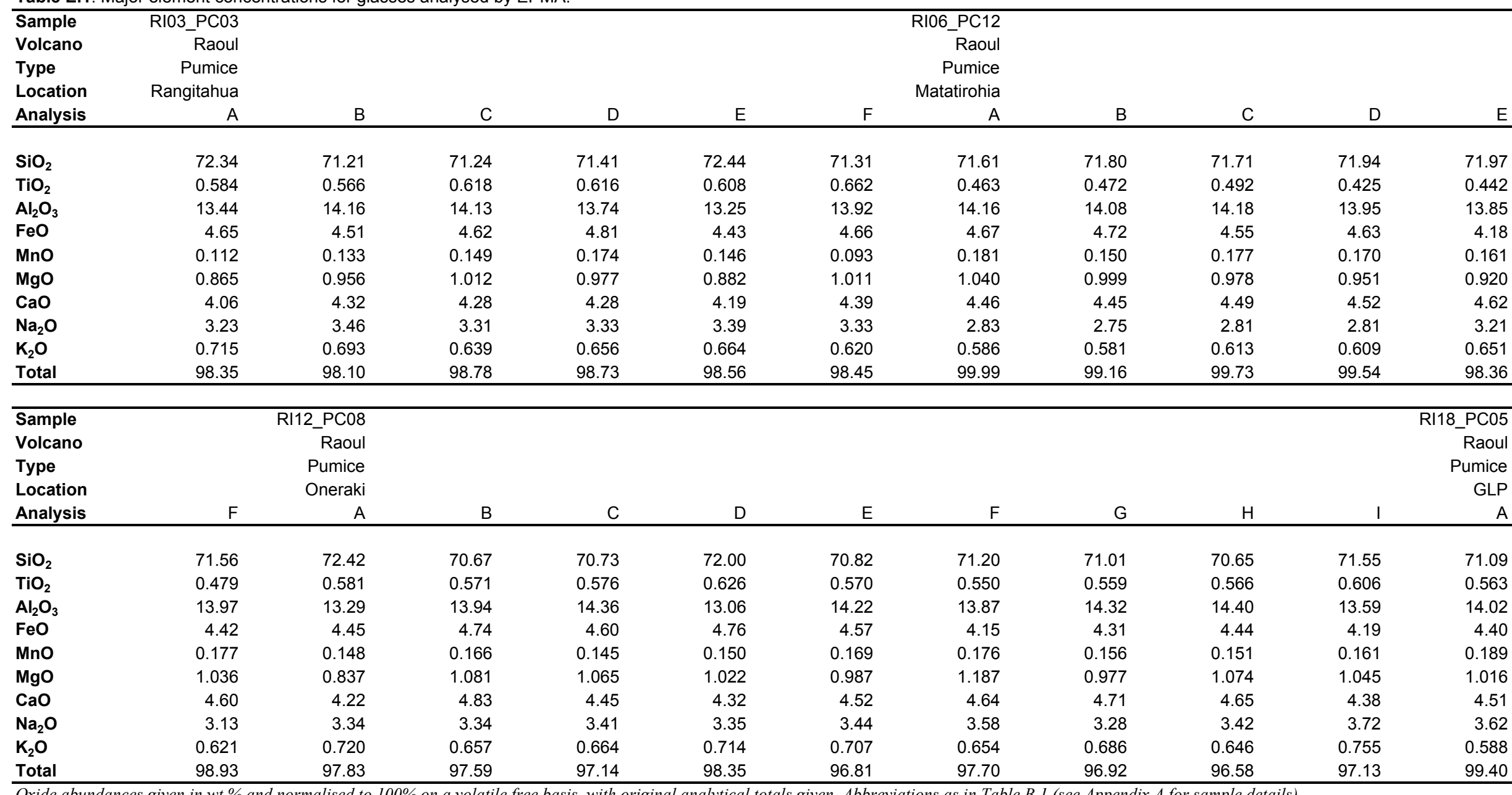


Table E.1. Continued

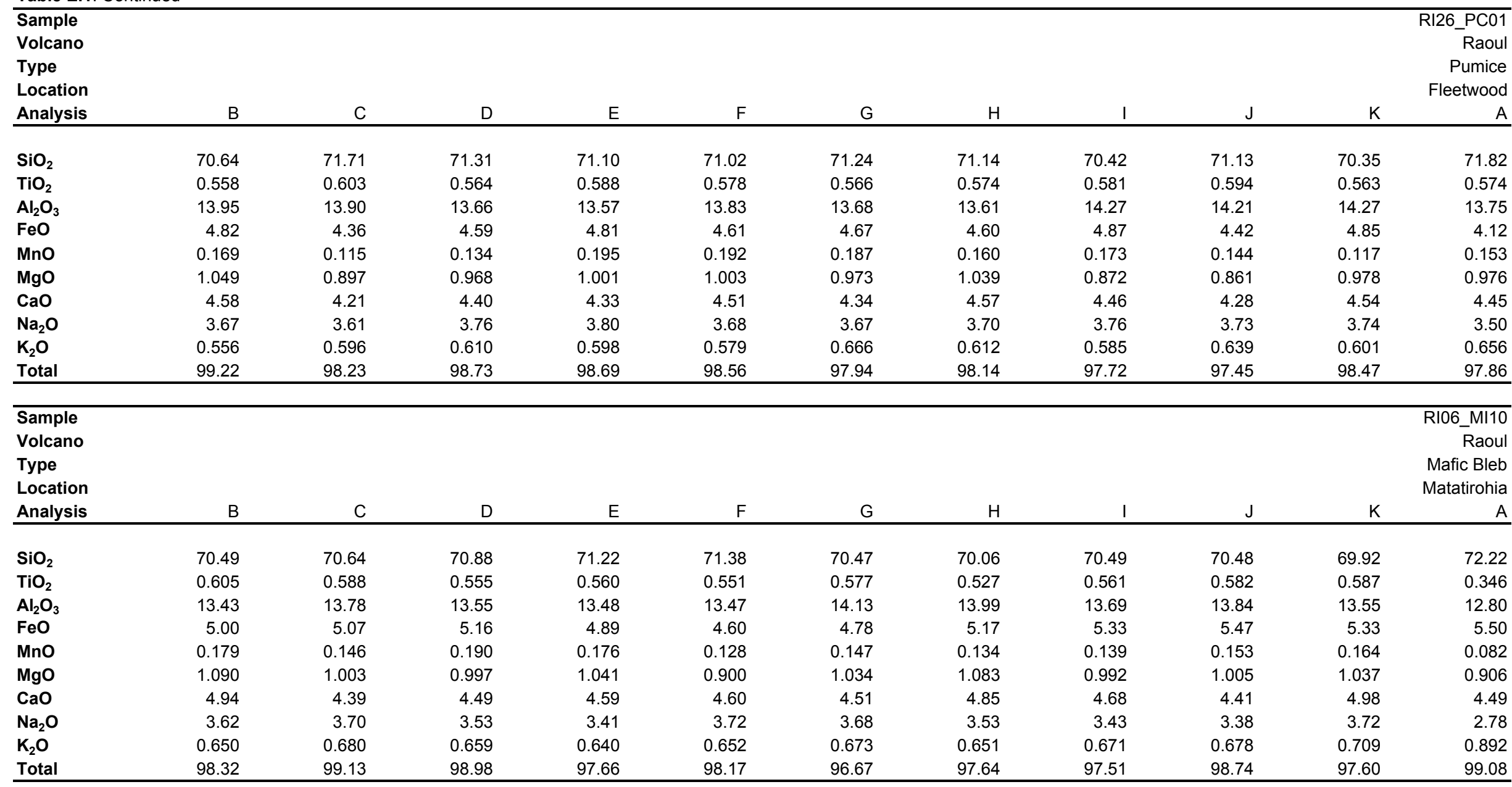


Table E.1. Continued

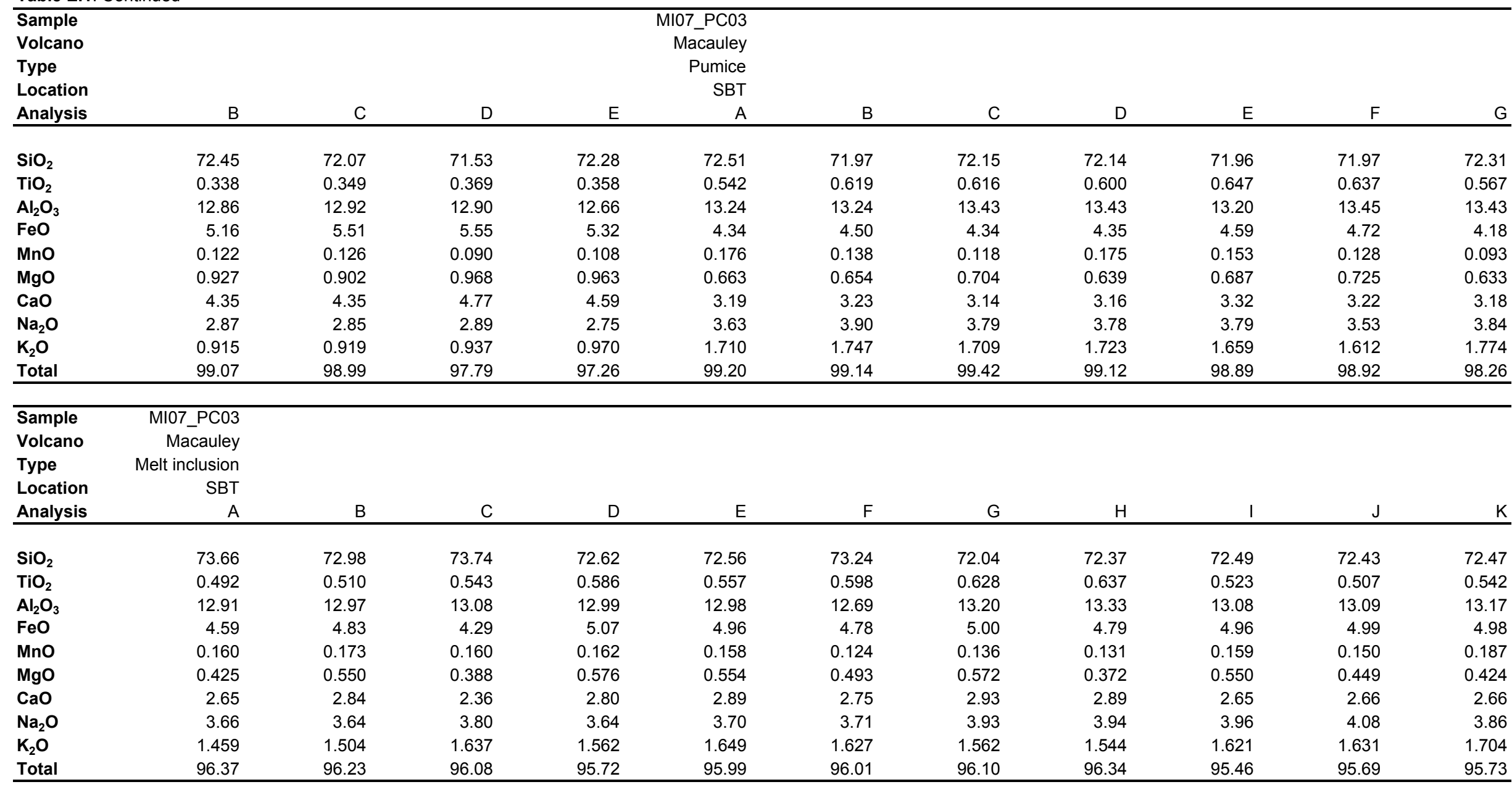


Table E.1. Continued

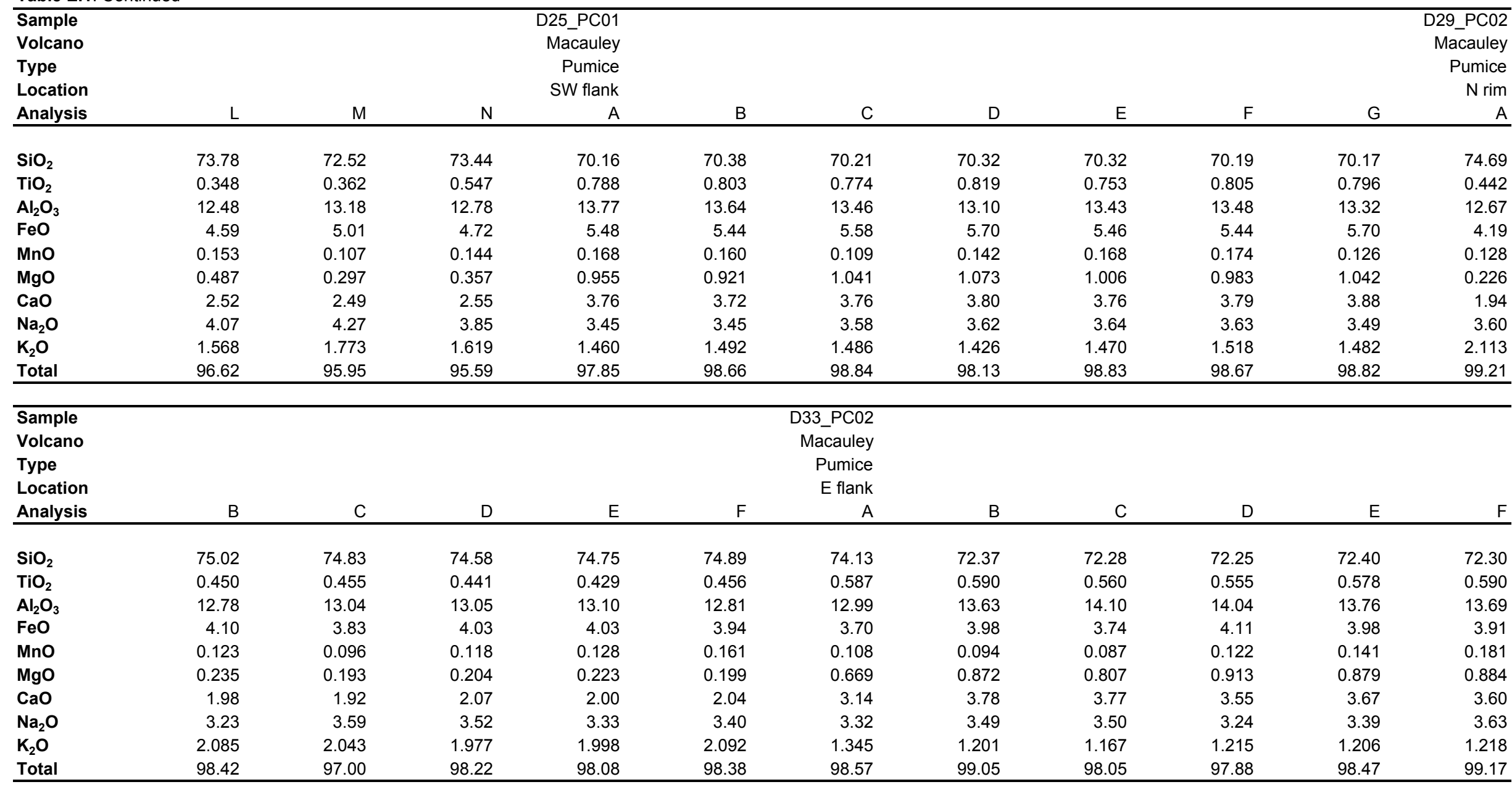


Table E.1. Continued

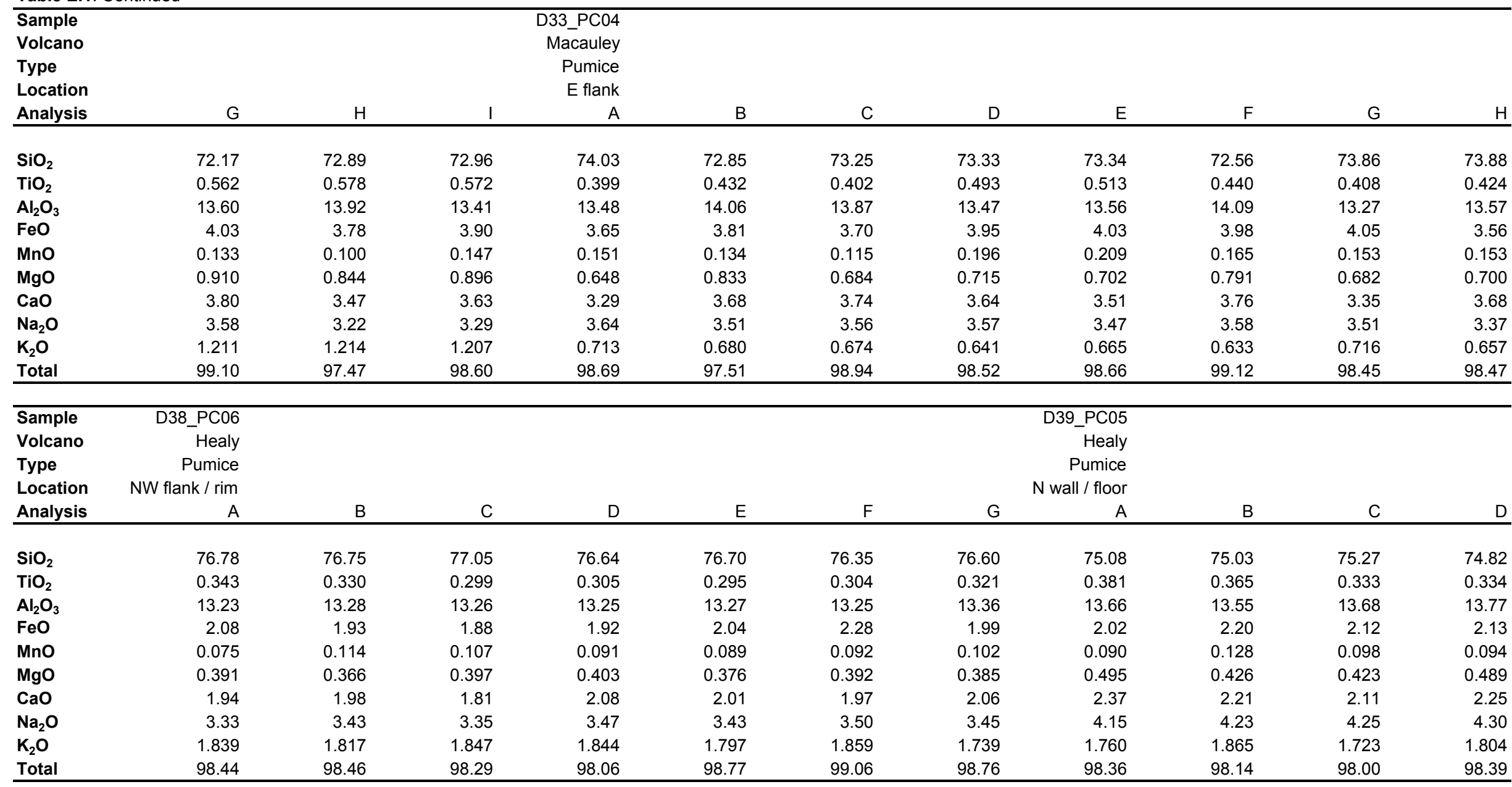


Table E.1. Continued

\begin{tabular}{|c|c|c|c|c|c|c|c|c|c|c|c|}
\hline Sample & & & & PC02 & & & & & & & $\mathrm{PC02}$ \\
\hline Volcano & & & & Healy & & & & & & & Healy \\
\hline Type & & & & Pumice & & & & & & & umice \\
\hline Location & & & & / flank & & & & & & & crater \\
\hline Analysis & $\mathrm{E}$ & $\mathrm{F}$ & G & A & B & $\mathrm{C}$ & $\mathrm{D}$ & $E$ & $\mathrm{~F}$ & G & A \\
\hline $\mathrm{SiO}_{2}$ & 74.94 & 75.42 & 75.22 & 76.70 & 76.54 & 76.63 & 76.95 & 76.91 & 77.04 & 76.49 & 73.55 \\
\hline $\mathrm{TiO}_{2}$ & 0.352 & 0.346 & 0.376 & 0.314 & 0.302 & 0.324 & 0.297 & 0.282 & 0.356 & 0.335 & 0.432 \\
\hline $\mathrm{Al}_{2} \mathrm{O}_{3}$ & 13.78 & 13.77 & 13.80 & 13.43 & 13.42 & 13.37 & 13.16 & 13.33 & 13.22 & 13.48 & 14.28 \\
\hline $\mathrm{FeO}$ & 2.14 & 2.21 & 2.25 & 1.98 & 2.05 & 1.93 & 2.12 & 1.88 & 1.97 & 1.96 & 2.60 \\
\hline MnO & 0.089 & 0.116 & 0.134 & 0.073 & 0.087 & 0.121 & 0.115 & 0.087 & 0.088 & 0.087 & 0.112 \\
\hline MgO & 0.460 & 0.439 & 0.478 & 0.390 & 0.406 & 0.360 & 0.401 & 0.377 & 0.371 & 0.429 & 0.468 \\
\hline $\mathrm{CaO}$ & 2.24 & 2.23 & 2.24 & 2.06 & 1.95 & 2.00 & 2.00 & 1.99 & 1.99 & 1.99 & 2.34 \\
\hline $\mathrm{Na}_{2} \mathrm{O}$ & 4.21 & 3.66 & 3.71 & 3.21 & 3.41 & 3.42 & 3.14 & 3.28 & 3.16 & 3.39 & 4.51 \\
\hline $\mathrm{K}_{2} \mathrm{O}$ & 1.781 & 1.803 & 1.805 & 1.847 & 1.834 & 1.849 & 1.823 & 1.858 & 1.808 & 1.838 & 1.711 \\
\hline Total & 98.99 & 98.21 & 98.34 & 98.71 & 98.79 & 99.19 & 98.32 & 98.33 & 97.72 & 99.14 & 99.53 \\
\hline
\end{tabular}

\begin{tabular}{|c|c|c|c|c|}
\hline \multicolumn{5}{|l|}{$\begin{array}{l}\text { Sample } \\
\text { Volcano } \\
\text { Type } \\
\text { Location }\end{array}$} \\
\hline Analysis & B & $\mathrm{C}$ & D & E \\
\hline $\mathrm{SiO}_{2}$ & 74.48 & 76.03 & 74.61 & 74.47 \\
\hline $\mathrm{TiO}_{2}$ & 0.492 & 0.304 & 0.402 & 0.421 \\
\hline $\mathrm{Al}_{2} \mathrm{O}_{3}$ & 13.82 & 13.29 & 14.11 & 14.35 \\
\hline $\mathrm{FeO}$ & 2.34 & 2.04 & 1.99 & 1.99 \\
\hline MnO & 0.130 & 0.117 & 0.117 & 0.115 \\
\hline MgO & 0.479 & 0.377 & 0.393 & 0.357 \\
\hline $\mathrm{CaO}$ & 2.31 & 1.81 & 2.37 & 2.23 \\
\hline $\mathrm{Na}_{2} \mathrm{O}$ & 4.14 & 4.21 & 4.27 & 4.27 \\
\hline $\mathrm{K}_{2} \mathrm{O}$ & 1.799 & 1.824 & 1.734 & 1.788 \\
\hline Total & 98.49 & 98.98 & 97.04 & 98.54 \\
\hline
\end{tabular}




\section{APPENDIX F: Mineral major element data}

Table F.1. Clinopyroxene major element data

Table F.2. Orthopyroxene major element data

Table F.3. Plagioclase major element data

Table F.4. Olivine major element data

Table F.5. Amphibole major element data

Table F.6. Magnetite major element data

Table F.7. Ilmenite major element data 


\section{$\underline{\text { List of abbreviations used in tables }}$}

$\mathbf{N V Z}=$ no visible zoning. For these crystals, the middle of the crystal was analysed.

$\mathbf{O G}=$ overgrowth. Which represents a growth zone around a resorbed core.

D band = dark band. A narrow compositional band in backscatter electron image typically indicating relatively higher $\mathrm{Mg} /$ lower Fe for clinopyroxene, orthopyroxene and olivine, and relatively higher $\mathrm{Na} /$ lower Ca for plagioclase.

$\mathbf{L}$ band = light band. A narrow compositional band in backscatter electron image typically indicating relatively lower $\mathrm{Mg} /$ higher Fe for clinopyroxene, orthopyroxene and olivine, and relatively lower $\mathrm{Na} /$ higher Ca for plagioclase.

\section{$\underline{\text { Compositional calculations }}$}

All calculations are on a molar basis.

\section{Clinopyroxene / Orthopyroxene}

Wollastonite $(\mathrm{Wn})=100 \mathrm{Ca} /(\mathrm{Ca}+\mathrm{Mg}+\mathrm{Fe})$

Enstatite $(\mathrm{En})=100 \mathrm{Mg} /(\mathrm{Ca}+\mathrm{Mg}+\mathrm{Fe})$

Fs $($ Ferrosilite $)=100 \mathrm{Fe} /(\mathrm{Ca}+\mathrm{Mg}+\mathrm{Fe})$

Magnesium number $(\mathrm{Mg} \#)=100 \mathrm{Mg} /(\mathrm{Mg}+\mathrm{Mn}+\mathrm{Fe})$

\section{Olivine}

Forsterite $(\mathrm{Fo})=100 \mathrm{Mg} /(\mathrm{Mg}+\mathrm{Fe})$

Fayalite $(\mathrm{Fa})=100 \mathrm{Fe} /(\mathrm{Fe}+\mathrm{Mg})$ 


\section{Plagioclase}

Anorthite $(\mathrm{An})=100 \mathrm{Ca} /(\mathrm{Ca}+\mathrm{Na}+\mathrm{K})$

Albite $(\mathrm{Ab})=100 \mathrm{Na} /(\mathrm{Ca}+\mathrm{Na}+\mathrm{K})$

Orthoclase $(\mathrm{An})=100 \mathrm{~K} /(\mathrm{Ca}+\mathrm{Na}+\mathrm{K})$ 
Table F.1. Major element compositions of clinopyroxene determined by EPMA

\begin{tabular}{|c|c|c|c|c|c|c|c|c|c|c|c|c|c|c|c|c|c|c|c|}
\hline Sample & RI03_PC03 & & & & & & & & & & & & & & & & & & \\
\hline Location & Rangitahua & & & & & & & & & & & & & & & & & & \\
\hline Volcano & Raoul & & & & & & & & & & & & & & & & & & \\
\hline Type & Single crystal & & & & & & & & & & & & & & & & & & \\
\hline Crystal no. & 1 & 2 & 3 & 4 & 5 & 6 & 7 & 8 & 10 & 11 & 12 & 14 & 15 & 16 & 17 & 18 & 19 & 20 & 20 \\
\hline Analysis site & NVZ & NVZ & NVZ & NVZ & NVZ & NVZ & NVZ & NVZ & NVZ & NVZ & NVZ & NVZ & NVZ & NVZ & NVZ & NVZ & NVZ & core & rim \\
\hline \multicolumn{20}{|l|}{ Oxides (wt \%) } \\
\hline $\mathrm{SiO}_{2}$ & 53.95 & 51.07 & 51.45 & 50.57 & 52.00 & 51.78 & 51.83 & 52.11 & 51.24 & 51.39 & 51.55 & 51.15 & 51.23 & 50.13 & 51.79 & 51.55 & 50.93 & 50.95 & 47.78 \\
\hline $\mathrm{TiO}_{2}$ & 0.20 & 0.39 & 0.31 & 0.37 & 0.26 & 0.27 & 0.35 & 0.26 & 0.30 & 0.28 & 0.37 & 0.31 & 0.31 & 0.51 & 0.34 & 0.30 & 0.40 & 0.35 & 0.78 \\
\hline $\mathrm{Al}_{2} \mathrm{O}_{3}$ & 0.65 & 2.32 & 1.73 & 2.26 & 1.61 & 1.43 & 2.15 & 1.51 & 1.57 & 1.45 & 1.90 & 1.80 & 1.89 & 3.02 & 1.67 & 1.84 & 2.44 & 2.07 & 6.19 \\
\hline $\mathrm{Cr}_{2} \mathrm{O}_{3}$ & 0.26 & 0.05 & 0.01 & 0.05 & 0.03 & 0.01 & 0.05 & 0.06 & 0.03 & 0.03 & 0.04 & 0.05 & 0.04 & 0.04 & 0.06 & 0.06 & 0.08 & 0.06 & 0.06 \\
\hline $\mathrm{FeO}(\mathrm{T})$ & 3.02 & 10.91 & 9.75 & 10.06 & 10.23 & 11.94 & 10.19 & 9.95 & 10.28 & 10.41 & 10.53 & 10.76 & 10.54 & 10.95 & 10.56 & 9.92 & 10.53 & 10.41 & 11.52 \\
\hline MnO & 0.07 & 0.50 & 0.43 & 0.43 & 0.47 & 0.80 & 0.43 & 0.46 & 0.58 & 0.50 & 0.52 & 0.53 & 0.49 & 0.47 & 0.61 & 0.45 & 0.43 & 0.44 & 0.34 \\
\hline MgO & 17.49 & 15.56 & 15.69 & 15.10 & 15.84 & 16.18 & 15.63 & 15.81 & 15.04 & 15.96 & 14.94 & 15.92 & 15.88 & 14.58 & 15.24 & 15.64 & 15.09 & 15.38 & 14.31 \\
\hline $\mathrm{CaO}$ & 24.82 & 19.77 & 20.47 & 20.63 & 20.16 & 17.87 & 20.58 & 20.38 & 20.68 & 19.86 & 20.61 & 19.37 & 19.70 & 20.39 & 20.40 & 20.21 & 20.56 & 20.12 & 19.18 \\
\hline $\mathrm{Na}_{2} \mathrm{O}$ & 0.19 & 0.20 & 0.17 & 0.19 & 0.20 & 0.19 & 0.19 & 0.17 & 0.20 & 0.18 & 0.22 & 0.21 & 0.20 & 0.23 & 0.22 & 0.17 & 0.22 & 0.19 & 0.21 \\
\hline Total & 100.65 & 100.76 & 100.01 & 99.65 & 100.79 & 100.47 & 101.41 & 100.71 & 99.90 & 100.06 & 100.68 & 100.09 & 100.29 & 100.32 & 100.89 & 100.13 & 100.67 & 99.96 & 100.35 \\
\hline \multicolumn{20}{|l|}{ Cations } \\
\hline $\mathbf{S i}$ & 1.96 & 1.90 & 1.92 & 1.91 & 1.93 & 1.93 & 1.91 & 1.93 & 1.93 & 1.93 & 1.92 & 1.92 & 1.92 & 1.88 & 1.93 & 1.93 & 1.90 & 1.91 & 1.80 \\
\hline $\mathrm{Ti}$ & 0.002 & 0.005 & 0.004 & 0.005 & 0.003 & 0.003 & 0.004 & 0.003 & 0.004 & 0.003 & 0.005 & 0.004 & 0.004 & 0.006 & 0.004 & 0.004 & 0.005 & 0.004 & 0.010 \\
\hline Al & 0.028 & 0.102 & 0.076 & 0.100 & 0.070 & 0.063 & 0.093 & 0.066 & 0.069 & 0.064 & 0.084 & 0.079 & 0.083 & 0.134 & 0.073 & 0.081 & 0.107 & 0.092 & 0.274 \\
\hline $\mathrm{Cr}$ & 0.008 & 0.001 & 0.000 & 0.001 & 0.001 & 0.000 & 0.002 & 0.002 & 0.001 & 0.001 & 0.001 & 0.001 & 0.001 & 0.001 & 0.002 & 0.002 & 0.002 & 0.002 & 0.002 \\
\hline Fe total & 0.087 & 0.338 & 0.303 & 0.314 & 0.316 & 0.372 & 0.312 & 0.307 & 0.321 & 0.324 & 0.326 & 0.335 & 0.328 & 0.341 & 0.327 & 0.308 & 0.326 & 0.324 & 0.357 \\
\hline $\mathrm{Fe}^{2+}$ & 0.076 & 0.314 & 0.284 & 0.291 & 0.300 & 0.355 & 0.291 & 0.291 & 0.303 & 0.307 & 0.303 & 0.316 & 0.308 & 0.308 & 0.305 & 0.289 & 0.301 & 0.303 & 0.308 \\
\hline $\mathrm{Fe}^{3+}$ & 0.012 & 0.024 & 0.019 & 0.024 & 0.016 & 0.017 & 0.021 & 0.016 & 0.019 & 0.017 & 0.023 & 0.019 & 0.019 & 0.032 & 0.021 & 0.019 & 0.025 & 0.022 & 0.049 \\
\hline Mn & 0.002 & 0.016 & 0.014 & 0.014 & 0.015 & 0.025 & 0.014 & 0.014 & 0.018 & 0.016 & 0.017 & 0.017 & 0.016 & 0.015 & 0.019 & 0.014 & 0.014 & 0.014 & 0.011 \\
\hline Mg & 0.948 & 0.865 & 0.875 & 0.848 & 0.877 & 0.901 & 0.861 & 0.875 & 0.843 & 0.892 & 0.831 & 0.890 & 0.885 & 0.816 & 0.846 & 0.871 & 0.840 & 0.861 & 0.802 \\
\hline $\mathrm{Ca}$ & 0.967 & 0.790 & 0.821 & 0.833 & 0.802 & 0.715 & 0.815 & 0.811 & 0.833 & 0.797 & 0.824 & 0.778 & 0.789 & 0.821 & 0.814 & 0.809 & 0.822 & 0.809 & 0.772 \\
\hline $\mathrm{Na}$ & 0.013 & 0.014 & 0.012 & 0.014 & 0.015 & 0.013 & 0.014 & 0.013 & 0.014 & 0.013 & 0.016 & 0.015 & 0.015 & 0.016 & 0.016 & 0.013 & 0.016 & 0.013 & 0.015 \\
\hline Total & 4.02 & 4.03 & 4.03 & 4.03 & 4.03 & 4.03 & 4.03 & 4.03 & 4.03 & 4.04 & 4.03 & 4.04 & 4.04 & 4.03 & 4.03 & 4.03 & 4.03 & 4.03 & 4.04 \\
\hline \multicolumn{20}{|l|}{ Atomic \% } \\
\hline Wo & 48.3 & 39.6 & 41.1 & 41.7 & 40.2 & 36.0 & 41.0 & 40.7 & 41.7 & 39.6 & 41.6 & 38.8 & 39.4 & 41.5 & 41.0 & 40.7 & 41.4 & 40.6 & 40.0 \\
\hline En & 47.3 & 43.4 & 43.8 & 42.5 & 44.0 & 45.3 & 43.3 & 43.9 & 42.2 & 44.3 & 41.9 & 44.4 & 44.2 & 41.3 & 42.6 & 43.8 & 42.2 & 43.2 & 41.5 \\
\hline Fs & 4.4 & 16.9 & 15.2 & 15.7 & 15.8 & 18.7 & 15.7 & 15.4 & 16.1 & 16.1 & 16.5 & 16.7 & 16.4 & 17.2 & 16.4 & 15.5 & 16.4 & 16.3 & 18.5 \\
\hline Mg\# & 91.4 & 71.0 & 73.4 & 72.1 & 72.6 & 69.4 & 72.5 & 73.1 & 71.3 & 72.4 & 70.8 & 71.6 & 72.1 & 69.6 & 71.0 & 73.0 & 71.2 & 71.8 & 68.5 \\
\hline
\end{tabular}

$\mathrm{Fe}^{2+}$ and $\mathrm{Fe}^{3+}$ calculated by charge balancing. Abbreviations as in Table B.1. 
Table F.1 Continued

\begin{tabular}{|c|c|c|c|c|c|c|c|c|c|c|c|c|c|c|c|c|c|c|c|}
\hline Sample & & & & & RI06_PC12 & & & & & & & & & & & & & & \\
\hline Location & & & & & Matatirohia & & & & & & & & & & & & & & \\
\hline Volcano & & & & & Raoul & & & & & & & & & & & & & & \\
\hline Type & & & & & Single crystal & & & & & & & & & & & & & & \\
\hline Crystal no. & 21 & 21 & 21 & 22 & 1 & 1 & 2 & 2 & 3 & 3 & 4 & 4 & 5 & 5 & 6 & 6 & 7 & 7 & 7 \\
\hline Analysis site & core & rim & rim & NVZ & core & rim & core & rim & core & rim & core & rim & core & rim & core & rim & core & rim 1 & $\operatorname{rim} 2$ \\
\hline \multicolumn{20}{|l|}{ Oxides (wt \%) } \\
\hline $\mathrm{SiO}_{2}$ & 51.40 & 49.35 & 49.81 & 51.92 & 51.36 & 48.79 & 52.78 & 49.70 & 52.20 & 50.95 & 51.72 & 52.48 & 52.04 & 52.00 & 50.78 & 50.38 & 50.43 & 52.25 & 52.28 \\
\hline $\mathrm{TiO}_{2}$ & 0.32 & 0.58 & 0.50 & 0.30 & 0.29 & 0.61 & 0.12 & 0.42 & 0.14 & 0.23 & 0.20 & 0.21 & 0.18 & 0.20 & 0.21 & 0.36 & 0.30 & 0.18 & 0.20 \\
\hline $\mathrm{Al}_{2} \mathrm{O}_{3}$ & 2.39 & 4.29 & 3.94 & 1.92 & 2.64 & 4.40 & 2.32 & 5.01 & 3.21 & 4.12 & 3.64 & 1.60 & 2.76 & 2.06 & 3.66 & 3.79 & 3.50 & 2.06 & 2.39 \\
\hline $\mathrm{Cr}_{2} \mathrm{O}_{3}$ & 0.05 & 0.05 & 0.05 & 0.05 & 0.09 & 0.03 & 0.25 & 0.11 & 0.34 & 0.12 & 0.17 & 0.06 & 0.11 & 0.10 & 0.13 & 0.10 & 0.06 & 0.07 & 0.09 \\
\hline $\mathrm{FeO}(\mathrm{T})$ & 9.61 & 10.80 & 10.39 & 9.97 & 9.04 & 12.97 & 4.38 & 7.83 & 4.65 & 6.01 & 5.14 & 9.58 & 5.44 & 8.75 & 5.61 & 8.81 & 8.50 & 10.16 & 7.26 \\
\hline MnO & 0.28 & 0.29 & 0.29 & 0.47 & 0.30 & 0.41 & 0.12 & 0.15 & 0.12 & 0.13 & 0.14 & 0.34 & 0.14 & 0.26 & 0.12 & 0.20 & 0.20 & 0.31 & 0.18 \\
\hline MgO & 15.88 & 15.38 & 15.32 & 15.64 & 15.81 & 14.02 & 17.26 & 15.22 & 16.90 & 16.01 & 16.45 & 17.22 & 16.88 & 16.63 & 16.21 & 15.36 & 15.37 & 17.69 & 17.08 \\
\hline $\mathrm{CaO}$ & 20.71 & 19.54 & 19.97 & 20.56 & 20.81 & 18.73 & 23.07 & 21.55 & 22.87 & 22.58 & 22.89 & 18.57 & 22.62 & 19.90 & 22.99 & 20.50 & 21.53 & 17.33 & 20.70 \\
\hline $\mathrm{Na}_{2} \mathrm{O}$ & 0.23 & 0.18 & 0.17 & 0.22 & 0.12 & 0.19 & 0.10 & 0.12 & 0.10 & 0.11 & 0.08 & 0.09 & 0.07 & 0.11 & 0.09 & 0.15 & 0.13 & 0.11 & 0.10 \\
\hline Total & 100.87 & 100.47 & 100.43 & 101.04 & 100.45 & 100.14 & 100.39 & 100.10 & 100.53 & 100.25 & 100.42 & 100.14 & 100.24 & 100.01 & 99.79 & 99.65 & 100.00 & 100.14 & 100.28 \\
\hline \multicolumn{20}{|l|}{ Cations } \\
\hline $\mathbf{S i}$ & 1.91 & 1.85 & 1.86 & 1.92 & 1.91 & 1.85 & 1.93 & 1.85 & 1.90 & 1.88 & 1.89 & 1.94 & 1.91 & 1.93 & 1.88 & 1.88 & 1.88 & 1.93 & 1.92 \\
\hline $\mathrm{Ti}$ & 0.004 & 0.007 & 0.006 & 0.004 & 0.004 & 0.008 & 0.001 & 0.005 & 0.002 & 0.003 & 0.002 & 0.003 & 0.002 & 0.003 & 0.003 & 0.005 & 0.004 & 0.002 & 0.003 \\
\hline Al & 0.104 & 0.189 & 0.173 & 0.084 & 0.116 & 0.196 & 0.100 & 0.219 & 0.138 & 0.179 & 0.157 & 0.070 & 0.119 & 0.090 & 0.160 & 0.167 & 0.154 & 0.090 & 0.104 \\
\hline $\mathrm{Cr}$ & 0.002 & 0.001 & 0.002 & 0.001 & 0.003 & 0.001 & 0.007 & 0.003 & 0.010 & 0.003 & 0.005 & 0.002 & 0.003 & 0.003 & 0.004 & 0.003 & 0.002 & 0.002 & 0.002 \\
\hline Fe total & 0.296 & 0.334 & 0.321 & 0.307 & 0.278 & 0.407 & 0.132 & 0.239 & 0.140 & 0.183 & 0.155 & 0.295 & 0.165 & 0.270 & 0.171 & 0.272 & 0.263 & 0.313 & 0.222 \\
\hline $\mathrm{Fe}^{2+}$ & 0.276 & 0.298 & 0.290 & 0.288 & 0.260 & 0.368 & 0.125 & 0.214 & 0.131 & 0.169 & 0.143 & 0.282 & 0.154 & 0.258 & 0.158 & 0.250 & 0.244 & 0.302 & 0.209 \\
\hline $\mathrm{Fe}^{3+}$ & 0.020 & 0.036 & 0.031 & 0.019 & 0.018 & 0.039 & 0.007 & 0.026 & 0.008 & 0.014 & 0.012 & 0.013 & 0.011 & 0.012 & 0.013 & 0.023 & 0.019 & 0.011 & 0.012 \\
\hline$M n$ & 0.009 & 0.009 & 0.009 & 0.015 & 0.009 & 0.013 & 0.004 & 0.005 & 0.004 & 0.004 & 0.004 & 0.011 & 0.004 & 0.008 & 0.004 & 0.006 & 0.006 & 0.010 & 0.006 \\
\hline $\mathrm{Mg}$ & 0.877 & 0.857 & 0.853 & 0.863 & 0.875 & 0.791 & 0.939 & 0.843 & 0.920 & 0.879 & 0.898 & 0.950 & 0.924 & 0.919 & 0.894 & 0.856 & 0.854 & 0.975 & 0.937 \\
\hline $\mathrm{Ca}$ & 0.823 & 0.783 & 0.799 & 0.816 & 0.827 & 0.759 & 0.902 & 0.858 & 0.894 & 0.891 & 0.898 & 0.737 & 0.890 & 0.791 & 0.912 & 0.821 & 0.860 & 0.686 & 0.816 \\
\hline $\mathrm{Na}$ & 0.016 & 0.013 & 0.012 & 0.016 & 0.008 & 0.014 & 0.007 & 0.009 & 0.007 & 0.008 & 0.005 & 0.006 & 0.005 & 0.008 & 0.007 & 0.011 & 0.009 & 0.008 & 0.007 \\
\hline Total & 4.04 & 4.04 & 4.04 & 4.03 & 4.03 & 4.04 & 4.02 & 4.03 & 4.02 & 4.03 & 4.02 & 4.02 & 4.02 & 4.02 & 4.03 & 4.02 & 4.03 & 4.02 & 4.02 \\
\hline \multicolumn{20}{|l|}{ Atomic \% } \\
\hline Wo & 41.2 & 39.7 & 40.5 & 41.1 & 41.8 & 38.8 & 45.7 & 44.2 & 45.8 & 45.6 & 46.0 & 37.2 & 45.0 & 39.9 & 46.1 & 42.1 & 43.5 & 34.8 & 41.3 \\
\hline En & 44.0 & 43.4 & 43.2 & 43.5 & 44.2 & 40.4 & 47.6 & 43.4 & 47.1 & 45.0 & 46.0 & 48.0 & 46.7 & 46.4 & 45.2 & 43.9 & 43.2 & 49.4 & 47.5 \\
\hline Fs & 14.8 & 16.9 & 16.3 & 15.4 & 14.0 & 20.8 & 6.7 & 12.3 & 7.2 & 9.4 & 7.9 & 14.9 & 8.3 & 13.6 & 8.7 & 14.0 & 13.3 & 15.8 & 11.2 \\
\hline Mg \# & 74.2 & 71.4 & 72.1 & 72.9 & 75.3 & 65.3 & 87.4 & 77.5 & 86.5 & 82.5 & 85.0 & 75.7 & 84.5 & 76.8 & 83.6 & 75.4 & 76.1 & 75.2 & 80.5 \\
\hline
\end{tabular}


Table F.1 Continued

\begin{tabular}{|c|c|c|c|c|c|c|c|c|c|c|c|c|c|c|c|c|c|c|c|c|}
\hline \multicolumn{21}{|l|}{ Sample } \\
\hline \multicolumn{21}{|l|}{ Location } \\
\hline \multicolumn{21}{|l|}{ Volcano } \\
\hline \multicolumn{21}{|l|}{ Type } \\
\hline Crystal no. & 8 & 8 & 9 & 9 & 10 & 10 & 12 & 12 & 12 & 12 & 12 & 11 & 11 & 11 & 11 & 13 & 13 & 13 & 13 & 14 \\
\hline Analysis site & core & rim & core & $\mathrm{rim}$ & core & rim & core 1 & core 2 & core 3 & $\operatorname{rim} 1$ & $\operatorname{rim} 2$ & core 1 & core 2 & $\operatorname{rim} 1$ & $\operatorname{rim} 2$ & core 1 & core 2 & $\operatorname{rim} 1$ & $\operatorname{rim} 2$ & core 1 \\
\hline \multicolumn{21}{|l|}{ Oxides (wt \%) } \\
\hline $\mathrm{SiO}_{2}$ & 51.03 & 51.69 & 50.58 & 50.74 & 51.99 & 51.76 & 51.52 & 50.65 & 51.84 & 49.15 & 48.46 & 52.26 & 53.49 & 50.38 & 49.04 & 51.72 & 50.75 & 50.66 & 51.21 & 50.89 \\
\hline $\mathrm{TiO}_{2}$ & 0.26 & 0.34 & 0.26 & 0.35 & 0.15 & 0.28 & 0.28 & 0.29 & 0.20 & 0.54 & 0.62 & 0.21 & 0.14 & 0.40 & 0.68 & 0.23 & 0.34 & 0.25 & 0.24 & 0.24 \\
\hline $\mathrm{Al}_{2} \mathrm{O}_{3}$ & 1.55 & 1.82 & 4.28 & 3.72 & 3.09 & 2.97 & 3.50 & 4.02 & 3.37 & 5.65 & 6.40 & 3.55 & 2.23 & 3.91 & 6.97 & 1.32 & 1.84 & 1.12 & 1.24 & 1.34 \\
\hline $\mathrm{Cr}_{2} \mathrm{O}_{3}$ & 0.04 & 0.02 & 0.15 & 0.03 & 0.28 & 0.08 & 0.06 & 0.08 & 0.05 & 0.04 & 0.05 & 0.14 & 0.07 & 0.08 & 0.04 & 0.03 & 0.05 & 0.06 & 0.04 & 0.04 \\
\hline $\mathrm{FeO}(\mathrm{T})$ & 12.13 & 11.72 & 6.12 & 11.40 & 4.72 & 9.25 & 7.96 & 8.06 & 6.20 & 11.13 & 11.45 & 6.36 & 5.94 & 9.71 & 12.50 & 11.23 & 12.12 & 12.43 & 11.61 & 11.62 \\
\hline MnO & 0.69 & 0.65 & 0.11 & 0.39 & 0.09 & 0.29 & 0.14 & 0.19 & 0.15 & 0.28 & 0.23 & 0.16 & 0.17 & 0.25 & 0.33 & 0.61 & 0.65 & 0.71 & 0.61 & 0.65 \\
\hline $\mathrm{MgO}$ & 13.49 & 13.86 & 15.75 & 16.46 & 16.98 & 15.77 & 15.44 & 15.32 & 16.44 & 13.69 & 13.33 & 16.17 & 17.23 & 15.28 & 12.74 & 14.20 & 14.01 & 13.77 & 14.22 & 14.11 \\
\hline $\mathrm{CaO}$ & 20.32 & 19.94 & 22.70 & 17.11 & 23.03 & 20.43 & 21.81 & 22.20 & 22.79 & 20.21 & 20.18 & 22.40 & 22.23 & 20.33 & 17.37 & 20.63 & 19.68 & 19.80 & 20.29 & 20.27 \\
\hline $\mathrm{Na}_{2} \mathrm{O}$ & 0.19 & 0.16 & 0.10 & 0.15 & 0.08 & 0.14 & 0.12 & 0.12 & 0.09 & 0.19 & 0.18 & 0.11 & 0.09 & 0.16 & 0.18 & 0.18 & 0.17 & 0.15 & 0.15 & 0.19 \\
\hline Total & 99.68 & 100.18 & 100.05 & 100.34 & 100.40 & 100.96 & 100.82 & 100.92 & 101.13 & 100.88 & 100.89 & 101.35 & 101.59 & 100.50 & 99.84 & 100.15 & 99.61 & 98.95 & 99.60 & 99.34 \\
\hline \multicolumn{21}{|l|}{ Cations } \\
\hline $\mathbf{S i}$ & 1.94 & 1.94 & 1.87 & 1.89 & 1.90 & 1.91 & 1.90 & 1.87 & 1.89 & 1.83 & 1.81 & 1.90 & 1.93 & 1.87 & 1.84 & 1.95 & 1.93 & 1.94 & 1.94 & 1.94 \\
\hline $\mathrm{Ti}$ & 0.003 & 0.004 & 0.003 & 0.004 & 0.002 & 0.004 & 0.003 & 0.004 & 0.002 & 0.007 & 0.008 & 0.003 & 0.002 & 0.005 & 0.009 & 0.003 & 0.004 & 0.003 & 0.003 & 0.003 \\
\hline Al & 0.069 & 0.081 & 0.186 & 0.163 & 0.133 & 0.129 & 0.152 & 0.175 & 0.145 & 0.248 & 0.282 & 0.152 & 0.095 & 0.171 & 0.308 & 0.058 & 0.082 & 0.050 & 0.055 & 0.060 \\
\hline $\mathrm{Cr}$ & 0.001 & 0.001 & 0.004 & 0.001 & 0.008 & 0.002 & 0.002 & 0.002 & 0.002 & 0.001 & 0.001 & 0.004 & 0.002 & 0.002 & 0.001 & 0.001 & 0.002 & 0.002 & 0.001 & 0.001 \\
\hline Fe total & 0.384 & 0.366 & 0.186 & 0.352 & 0.142 & 0.283 & 0.243 & 0.247 & 0.187 & 0.344 & 0.354 & 0.191 & 0.178 & 0.299 & 0.388 & 0.352 & 0.383 & 0.397 & 0.366 & 0.368 \\
\hline $\mathrm{Fe}^{2+}$ & 0.368 & 0.345 & 0.171 & 0.331 & 0.133 & 0.266 & 0.226 & 0.229 & 0.175 & 0.310 & 0.315 & 0.179 & 0.170 & 0.275 & 0.346 & 0.338 & 0.361 & 0.380 & 0.351 & 0.353 \\
\hline $\mathrm{Fe}^{3+}$ & 0.016 & 0.021 & 0.016 & 0.022 & 0.009 & 0.017 & 0.017 & 0.017 & 0.012 & 0.034 & 0.039 & 0.013 & 0.008 & 0.025 & 0.043 & 0.014 & 0.021 & 0.016 & 0.015 & 0.016 \\
\hline Mn & 0.022 & 0.021 & 0.004 & 0.012 & 0.003 & 0.009 & 0.004 & 0.006 & 0.005 & 0.009 & 0.007 & 0.005 & 0.005 & 0.008 & 0.010 & 0.019 & 0.021 & 0.023 & 0.020 & 0.021 \\
\hline Mg & 0.764 & 0.777 & 0.868 & 0.912 & 0.926 & 0.867 & 0.848 & 0.843 & 0.895 & 0.761 & 0.743 & 0.877 & 0.929 & 0.847 & 0.713 & 0.796 & 0.793 & 0.786 & 0.804 & 0.800 \\
\hline $\mathrm{Ca}$ & 0.827 & 0.803 & 0.899 & 0.681 & 0.903 & 0.807 & 0.860 & 0.878 & 0.892 & 0.808 & 0.808 & 0.873 & 0.862 & 0.810 & 0.699 & 0.832 & 0.800 & 0.813 & 0.824 & 0.826 \\
\hline $\mathrm{Na}$ & 0.014 & 0.012 & 0.007 & 0.010 & 0.006 & 0.010 & 0.008 & 0.008 & 0.007 & 0.014 & 0.013 & 0.007 & 0.006 & 0.012 & 0.013 & 0.013 & 0.013 & 0.011 & 0.011 & 0.014 \\
\hline Total & 4.02 & 4.01 & 4.03 & 4.02 & 4.02 & 4.02 & 4.02 & 4.03 & 4.03 & 4.03 & 4.03 & 4.01 & 4.01 & 4.03 & 3.98 & 4.02 & 4.02 & 4.03 & 4.03 & 4.03 \\
\hline \multicolumn{21}{|l|}{ Atomic \% } \\
\hline Wo & 41.9 & 41.3 & 46.0 & 35.0 & 45.8 & 41.2 & 44.1 & 44.6 & 45.2 & 42.2 & 42.4 & 45.0 & 43.8 & 41.4 & 38.8 & 42.0 & 40.5 & 40.7 & 41.3 & 41.4 \\
\hline En & 38.7 & 39.9 & 44.4 & 46.9 & 47.0 & 44.3 & 43.5 & 42.8 & 45.4 & 39.8 & 39.0 & 45.2 & 47.2 & 43.3 & 39.6 & 40.2 & 40.1 & 39.4 & 40.3 & 40.1 \\
\hline Fs & 19.4 & 18.8 & 9.5 & 18.1 & 7.2 & 14.5 & 12.4 & 12.5 & 9.5 & 18.0 & 18.6 & 9.9 & 9.0 & 15.3 & 21.6 & 17.8 & 19.4 & 19.9 & 18.4 & 18.5 \\
\hline Mg \# & 65.3 & 66.7 & 82.0 & 71.4 & 86.5 & 74.8 & 77.4 & 76.9 & 82.4 & 68.3 & 67.3 & 81.7 & 83.5 & 73.4 & 64.1 & 68.2 & 66.3 & 65.2 & 67.6 & 67.3 \\
\hline
\end{tabular}


Table F.1 Continued

\begin{tabular}{|c|c|c|c|c|c|c|c|c|c|c|c|c|c|c|c|c|c|c|c|c|}
\hline \multicolumn{21}{|l|}{ Sample } \\
\hline \multicolumn{21}{|l|}{ Location } \\
\hline \multicolumn{21}{|l|}{ Volcano } \\
\hline \multicolumn{21}{|l|}{ Type } \\
\hline Crystal no. & 14 & 14 & 14 & 16 & 16 & 16 & 16 & 18 & 18 & 18 & 18 & 21 & 21 & 21 & 21 & 21 & 22 & 23 & 24 & 24 \\
\hline Analysis site & core 2 & $\operatorname{rim} 1$ & $\operatorname{rim} 2$ & core 1 & core 2 & $\operatorname{rim} 1$ & $\operatorname{rim} 2$ & core 1 & core 2 & $\operatorname{rim} 1$ & $\operatorname{rim} 2$ & core 1 & core 2 & $\operatorname{rim} 1$ & $\operatorname{rim} 2$ & $\operatorname{rim} 3$ & $\mathrm{NVZ}$ & NVZ & core & rim \\
\hline \multicolumn{21}{|l|}{ Oxides (wt \%) } \\
\hline $\mathrm{SiO}_{2}$ & 50.96 & 51.77 & 51.51 & 51.64 & 51.67 & 51.04 & 51.27 & 52.04 & 51.14 & 50.59 & 50.81 & 51.55 & 50.40 & 50.72 & 49.02 & 46.98 & 52.51 & 52.29 & 52.00 & 52.38 \\
\hline $\mathrm{TiO}_{2}$ & 0.25 & 0.25 & 0.22 & 0.25 & 0.25 & 0.23 & 0.23 & 0.25 & 0.26 & 0.30 & 0.28 & 0.17 & 0.15 & 0.22 & 0.36 & 0.63 & 0.27 & 0.28 & 0.19 & 0.22 \\
\hline $\mathrm{Al}_{2} \mathrm{O}_{3}$ & 1.05 & 1.37 & 1.23 & 1.26 & 1.42 & 1.22 & 1.29 & 1.22 & 1.51 & 1.65 & 1.35 & 3.36 & 3.02 & 3.84 & 4.15 & 6.52 & 1.38 & 1.73 & 3.71 & 2.54 \\
\hline $\mathrm{Cr}_{2} \mathrm{O}_{3}$ & 0.08 & 0.00 & 0.09 & 0.02 & 0.05 & 0.04 & 0.05 & 0.04 & 0.09 & 0.07 & 0.06 & 0.23 & 0.25 & 0.16 & 0.11 & 0.03 & 0.03 & 0.04 & 0.16 & 0.09 \\
\hline $\mathrm{FeO}(\mathrm{T})$ & 11.80 & 11.39 & 11.59 & 10.95 & 11.09 & 11.40 & 11.48 & 11.00 & 10.77 & 11.94 & 11.74 & 4.95 & 4.83 & 5.93 & 8.72 & 11.30 & 11.42 & 11.73 & 5.29 & 7.99 \\
\hline MnO & 0.62 & 0.63 & 0.63 & 0.61 & 0.56 & 0.59 & 0.63 & 0.68 & 0.56 & 0.70 & 0.64 & 0.12 & 0.13 & 0.14 & 0.23 & 0.30 & 0.67 & 0.66 & 0.10 & 0.18 \\
\hline MgO & 14.40 & 14.14 & 14.41 & 14.58 & 14.47 & 14.18 & 14.05 & 14.13 & 14.33 & 13.87 & 13.92 & 16.67 & 16.79 & 16.15 & 15.04 & 13.33 & 14.29 & 14.39 & 16.70 & 16.69 \\
\hline $\mathrm{CaO}$ & 19.84 & 20.35 & 20.03 & 20.33 & 20.24 & 20.18 & 20.33 & 20.63 & 20.55 & 19.97 & 19.97 & 22.78 & 22.73 & 22.29 & 20.88 & 19.79 & 20.43 & 19.86 & 22.92 & 21.02 \\
\hline $\mathrm{Na}_{2} \mathrm{O}$ & 0.17 & 0.18 & 0.15 & 0.20 & 0.19 & 0.15 & 0.20 & 0.18 & 0.22 & 0.20 & 0.17 & 0.10 & 0.09 & 0.11 & 0.15 & 0.18 & 0.19 & 0.20 & 0.08 & 0.10 \\
\hline Total & 99.18 & 100.09 & 99.86 & 99.84 & 99.94 & 99.03 & 99.52 & 100.18 & 99.42 & 99.30 & 98.93 & 99.93 & 98.40 & 99.56 & 98.64 & 99.07 & 101.18 & 101.16 & 101.14 & 101.21 \\
\hline \multicolumn{21}{|l|}{ Cations } \\
\hline Si & 1.94 & 1.95 & 1.94 & 1.95 & 1.94 & 1.94 & 1.94 & 1.95 & 1.94 & 1.93 & 1.94 & 1.90 & 1.89 & 1.88 & 1.86 & 1.79 & 1.95 & 1.94 & 1.89 & 1.92 \\
\hline $\mathrm{Ti}$ & 0.003 & 0.003 & 0.003 & 0.003 & 0.003 & 0.003 & 0.003 & 0.003 & 0.003 & 0.004 & 0.004 & 0.002 & 0.002 & 0.003 & 0.005 & 0.008 & 0.003 & 0.004 & 0.002 & 0.003 \\
\hline Al & 0.047 & 0.061 & 0.055 & 0.056 & 0.063 & 0.055 & 0.057 & 0.054 & 0.067 & 0.074 & 0.061 & 0.146 & 0.133 & 0.168 & 0.185 & 0.293 & 0.061 & 0.076 & 0.159 & 0.110 \\
\hline $\mathrm{Cr}$ & 0.002 & 0.000 & 0.003 & 0.001 & 0.001 & 0.001 & 0.002 & 0.001 & 0.003 & 0.002 & 0.002 & 0.007 & 0.007 & 0.005 & 0.003 & 0.001 & 0.001 & 0.001 & 0.004 & 0.003 \\
\hline $\mathrm{Fe}$ total & 0.374 & 0.357 & 0.365 & 0.344 & 0.348 & 0.362 & 0.363 & 0.344 & 0.339 & 0.379 & 0.373 & 0.150 & 0.149 & 0.181 & 0.273 & 0.356 & 0.353 & 0.363 & 0.158 & 0.243 \\
\hline $\mathrm{Fe}^{2+}$ & 0.358 & 0.341 & 0.351 & 0.328 & 0.331 & 0.347 & 0.348 & 0.328 & 0.323 & 0.359 & 0.355 & 0.139 & 0.140 & 0.168 & 0.250 & 0.316 & 0.337 & 0.346 & 0.147 & 0.229 \\
\hline $\mathrm{Fe}^{3+}$ & 0.016 & 0.016 & 0.014 & 0.016 & 0.016 & 0.015 & 0.015 & 0.016 & 0.017 & 0.020 & 0.018 & 0.010 & 0.010 & 0.014 & 0.023 & 0.041 & 0.016 & 0.017 & 0.011 & 0.013 \\
\hline Mn & 0.020 & 0.020 & 0.020 & 0.019 & 0.018 & 0.019 & 0.020 & 0.022 & 0.018 & 0.023 & 0.021 & 0.004 & 0.004 & 0.004 & 0.007 & 0.010 & 0.021 & 0.021 & 0.003 & 0.005 \\
\hline Mg & 0.818 & 0.793 & 0.811 & 0.819 & 0.812 & 0.805 & 0.794 & 0.791 & 0.809 & 0.788 & 0.793 & 0.914 & 0.937 & 0.893 & 0.849 & 0.758 & 0.792 & 0.798 & 0.905 & 0.911 \\
\hline $\mathrm{Ca}$ & 0.810 & 0.820 & 0.810 & 0.821 & 0.816 & 0.824 & 0.826 & 0.830 & 0.834 & 0.815 & 0.817 & 0.898 & 0.912 & 0.885 & 0.847 & 0.808 & 0.814 & 0.791 & 0.893 & 0.824 \\
\hline $\mathrm{Na}$ & 0.013 & 0.013 & 0.011 & 0.015 & 0.013 & 0.011 & 0.015 & 0.013 & 0.016 & 0.015 & 0.012 & 0.007 & 0.006 & 0.008 & 0.011 & 0.013 & 0.014 & 0.014 & 0.005 & 0.007 \\
\hline Total & 4.03 & 4.02 & 4.02 & 4.02 & 4.02 & 4.02 & 4.02 & 4.01 & 4.03 & 4.03 & 4.02 & 4.02 & 4.04 & 4.03 & 4.04 & 4.04 & 4.01 & 4.01 & 4.02 & 4.02 \\
\hline \multicolumn{21}{|l|}{ Atomic \% } \\
\hline Wo & 40.5 & 41.6 & 40.8 & 41.4 & 41.3 & 41.4 & 41.7 & 42.2 & 42.1 & 41.1 & 41.2 & 45.8 & 45.6 & 45.2 & 43.0 & 42.0 & 41.5 & 40.5 & 45.6 & 41.7 \\
\hline En & 40.8 & 40.3 & 40.8 & 41.3 & 41.1 & 40.5 & 40.1 & 40.3 & 40.8 & 39.8 & 40.0 & 46.6 & 46.9 & 45.6 & 43.1 & 39.4 & 40.4 & 40.9 & 46.3 & 46.1 \\
\hline Fs & 18.7 & 18.1 & 18.4 & 17.3 & 17.6 & 18.2 & 18.3 & 17.5 & 17.1 & 19.1 & 18.8 & 7.6 & 7.5 & 9.3 & 13.9 & 18.5 & 18.0 & 18.6 & 8.1 & 12.3 \\
\hline Mg\# & 67.5 & 67.8 & 67.8 & 69.3 & 69.0 & 67.9 & 67.5 & 68.4 & 69.4 & 66.3 & 66.8 & 85.6 & 85.9 & 82.8 & 75.2 & 67.4 & 67.9 & 67.5 & 84.9 & 78.6 \\
\hline
\end{tabular}


Table F.1 Continued

\begin{tabular}{|c|c|c|c|c|c|c|c|c|c|c|c|c|c|c|c|c|c|c|c|c|}
\hline \multicolumn{21}{|l|}{ Sample } \\
\hline \multicolumn{21}{|l|}{ Location } \\
\hline \multicolumn{21}{|l|}{ Volcano } \\
\hline \multicolumn{21}{|l|}{ Type } \\
\hline Crystal no. & 25 & 26 & 26 & 27 & 27 & 27 & 27 & 28 & 29 & 30 & 30 & 31 & 31 & 31 & 31 & 32 & 33 & 33 & 33 & 34 \\
\hline Analysis site & NVZ & core & rim & core 1 & core 2 & rim1 & rim2 & $\mathrm{NVZ}$ & NVZ & core & rim & core1 & core2 & rim1 & rim2 & NVZ & core1 & core2 & rim1 & core \\
\hline \multicolumn{21}{|l|}{ Oxides (wt \%) } \\
\hline $\mathrm{SiO}_{2}$ & 52.00 & 51.78 & 51.53 & 52.38 & 52.08 & 50.80 & 50.98 & 52.62 & 51.80 & 52.66 & 51.40 & 52.40 & 51.76 & 52.86 & 52.21 & 51.49 & 51.75 & 51.95 & 53.23 & 52.57 \\
\hline $\mathrm{TiO}_{2}$ & 0.31 & 0.28 & 0.26 & 0.18 & 0.19 & 0.47 & 0.45 & 0.23 & 0.23 & 0.20 & 0.35 & 0.29 & 0.26 & 0.26 & 0.26 & 0.31 & 0.27 & 0.17 & 0.17 & 0.19 \\
\hline $\mathrm{Al}_{2} \mathrm{O}_{3}$ & 1.82 & 3.25 & 3.03 & 3.64 & 4.03 & 4.09 & 3.92 & 1.29 & 4.21 & 2.84 & 3.75 & 2.72 & 4.49 & 1.85 & 3.07 & 3.71 & 3.58 & 3.64 & 2.55 & 3.66 \\
\hline $\mathrm{Cr}_{2} \mathrm{O}_{3}$ & 0.03 & 0.05 & 0.06 & 0.18 & 0.19 & 0.06 & 0.06 & 0.05 & 0.23 & 0.11 & 0.07 & 0.04 & 0.17 & 0.04 & 0.04 & 0.09 & 0.24 & 0.17 & 0.14 & 0.13 \\
\hline $\mathrm{FeO}(\mathrm{T})$ & 11.38 & 8.65 & 9.10 & 5.13 & 5.10 & 9.96 & 9.83 & 11.91 & 5.31 & 6.32 & 9.65 & 9.39 & 5.90 & 11.15 & 9.65 & 8.56 & 6.16 & 5.10 & 6.31 & 5.08 \\
\hline $\mathrm{MnO}$ & 0.54 & 0.19 & 0.26 & 0.10 & 0.11 & 0.27 & 0.23 & 0.70 & 0.12 & 0.16 & 0.25 & 0.30 & 0.12 & 0.35 & 0.27 & 0.21 & 0.15 & 0.14 & 0.13 & 0.10 \\
\hline $\mathrm{MgO}$ & 14.15 & 15.47 & 15.67 & 16.57 & 16.37 & 15.03 & 15.17 & 14.22 & 16.32 & 16.60 & 15.78 & 15.64 & 15.99 & 16.58 & 16.35 & 15.33 & 16.50 & 16.66 & 17.00 & 16.69 \\
\hline $\mathrm{CaO}$ & 20.65 & 21.32 & 20.74 & 22.95 & 22.99 & 19.79 & 20.29 & 19.78 & 23.11 & 22.28 & 19.88 & 20.67 & 22.91 & 18.25 & 19.30 & 21.61 & 22.18 & 23.10 & 21.78 & 22.88 \\
\hline $\mathrm{Na}_{2} \mathrm{O}$ & 0.19 & 0.13 & 0.13 & 0.09 & 0.12 & 0.17 & 0.17 & 0.16 & 0.10 & 0.10 & 0.16 & 0.15 & 0.12 & 0.09 & 0.13 & 0.12 & 0.12 & 0.07 & 0.09 & 0.08 \\
\hline Total & 101.06 & 101.11 & 100.78 & 101.22 & 101.17 & 100.64 & 101.10 & 100.96 & 101.41 & 101.26 & 101.31 & 101.59 & 101.74 & 101.44 & 101.28 & 101.42 & 100.95 & 101.00 & 101.39 & 101.37 \\
\hline \multicolumn{21}{|l|}{ Cations } \\
\hline Si & 1.94 & 1.90 & 1.90 & 1.90 & 1.89 & 1.88 & 1.88 & 1.96 & 1.88 & 1.92 & 1.89 & 1.92 & 1.88 & 1.94 & 1.91 & 1.89 & 1.89 & 1.89 & 1.93 & 1.90 \\
\hline $\mathrm{Ti}$ & 0.004 & 0.004 & 0.003 & 0.002 & 0.002 & 0.006 & 0.006 & 0.003 & 0.003 & 0.002 & 0.004 & 0.004 & 0.003 & 0.003 & 0.003 & 0.004 & 0.003 & 0.002 & 0.002 & 0.002 \\
\hline Al & 0.080 & 0.141 & 0.132 & 0.156 & 0.172 & 0.179 & 0.170 & 0.056 & 0.180 & 0.122 & 0.163 & 0.118 & 0.192 & 0.080 & 0.132 & 0.160 & 0.154 & 0.156 & 0.109 & 0.156 \\
\hline $\mathrm{Cr}$ & 0.001 & 0.001 & 0.002 & 0.005 & 0.005 & 0.002 & 0.002 & 0.001 & 0.006 & 0.003 & 0.002 & 0.001 & 0.005 & 0.001 & 0.001 & 0.003 & 0.007 & 0.005 & 0.004 & 0.004 \\
\hline Fe total & 0.353 & 0.264 & 0.279 & 0.153 & 0.152 & 0.306 & 0.300 & 0.370 & 0.158 & 0.190 & 0.294 & 0.286 & 0.176 & 0.341 & 0.294 & 0.260 & 0.185 & 0.153 & 0.189 & 0.151 \\
\hline $\mathrm{Fe}^{2+}$ & 0.333 & 0.247 & 0.263 & 0.143 & 0.141 & 0.277 & 0.273 & 0.355 & 0.145 & 0.179 & 0.273 & 0.268 & 0.160 & 0.325 & 0.278 & 0.242 & 0.169 & 0.143 & 0.180 & 0.140 \\
\hline $\mathrm{Fe}^{3+}$ & 0.019 & 0.017 & 0.016 & 0.011 & 0.011 & 0.029 & 0.027 & 0.014 & 0.013 & 0.012 & 0.021 & 0.017 & 0.016 & 0.016 & 0.016 & 0.019 & 0.016 & 0.010 & 0.010 & 0.011 \\
\hline Mn & 0.017 & 0.006 & 0.008 & 0.003 & 0.003 & 0.008 & 0.007 & 0.022 & 0.004 & 0.005 & 0.008 & 0.009 & 0.004 & 0.011 & 0.008 & 0.006 & 0.005 & 0.004 & 0.004 & 0.003 \\
\hline Mg & 0.786 & 0.848 & 0.863 & 0.896 & 0.886 & 0.830 & 0.835 & 0.790 & 0.883 & 0.901 & 0.865 & 0.854 & 0.864 & 0.908 & 0.893 & 0.839 & 0.899 & 0.904 & 0.919 & 0.901 \\
\hline $\mathrm{Ca}$ & 0.824 & 0.840 & 0.821 & 0.892 & 0.895 & 0.786 & 0.803 & 0.790 & 0.899 & 0.869 & 0.783 & 0.812 & 0.890 & 0.718 & 0.758 & 0.850 & 0.868 & 0.901 & 0.846 & 0.887 \\
\hline $\mathrm{Na}$ & 0.014 & 0.009 & 0.009 & 0.006 & 0.008 & 0.012 & 0.012 & 0.012 & 0.007 & 0.007 & 0.012 & 0.010 & 0.008 & 0.007 & 0.009 & 0.009 & 0.009 & 0.005 & 0.006 & 0.006 \\
\hline Total & 4.02 & 4.02 & 4.02 & 4.01 & 4.02 & 4.01 & 4.02 & 4.01 & 4.02 & 4.02 & 4.02 & 4.01 & 4.02 & 4.01 & 4.01 & 4.02 & 4.02 & 4.02 & 4.01 & 4.01 \\
\hline \multicolumn{21}{|l|}{ Atomic \% } \\
\hline Wo & 42.0 & 43.0 & 41.8 & 45.9 & 46.3 & 40.9 & 41.4 & 40.5 & 46.3 & 44.3 & 40.3 & 41.6 & 46.1 & 36.5 & 39.0 & 43.6 & 44.5 & 46.0 & 43.3 & 45.8 \\
\hline En & 40.0 & 43.4 & 44.0 & 46.2 & 45.8 & 43.2 & 43.1 & 40.5 & 45.5 & 46.0 & 44.5 & 43.8 & 44.8 & 46.2 & 45.9 & 43.0 & 46.0 & 46.2 & 47.0 & 46.4 \\
\hline Fs & 18.0 & 13.5 & 14.2 & 7.9 & 7.9 & 15.9 & 15.5 & 19.0 & 8.2 & 9.7 & 15.1 & 14.6 & 9.1 & 17.3 & 15.1 & 13.4 & 9.5 & 7.8 & 9.7 & 7.8 \\
\hline Mg \# & 68.0 & 75.9 & 75.0 & 85.2 & 85.1 & 72.6 & 73.1 & 66.9 & 84.5 & 82.2 & 74.1 & 74.3 & 82.8 & 72.1 & 74.7 & 75.9 & 82.6 & 85.2 & 82.6 & 85.4 \\
\hline
\end{tabular}


Table F.1 Continued

\begin{tabular}{|c|c|c|c|c|c|c|c|c|c|c|c|c|c|c|c|c|c|c|c|c|}
\hline \multicolumn{21}{|l|}{ Sample } \\
\hline \multicolumn{21}{|l|}{ Location } \\
\hline \multicolumn{21}{|l|}{ Volcano } \\
\hline \multicolumn{21}{|l|}{ Type } \\
\hline Crystal no. & 34 & 36 & 36 & 36 & 36 & 37 & 37 & 37 & 37 & 38 & 39 & 40 & 41 & 41 & 42 & 42 & 42 & 43 & 44 & 45 \\
\hline Analysis site & $\mathrm{rim}$ & core1 & core2 & rim1 & rim2 & core 1 & core2 & rim1 & rim2 & rim & $\mathrm{NVZ}$ & NVZ & core & rim & core & rim & $\operatorname{rim} 2$ & NVZ & NVZ & core \\
\hline \multicolumn{21}{|l|}{ Oxides (wt \%) } \\
\hline $\mathrm{SiO}_{2}$ & 51.33 & 51.79 & 52.76 & 50.94 & 52.09 & 51.76 & 52.64 & 51.05 & 51.07 & 52.44 & 52.78 & 52.45 & 51.51 & 49.16 & 51.82 & 52.82 & 49.89 & 52.83 & 52.65 & 51.82 \\
\hline $\mathrm{TiO}_{2}$ & 0.43 & 0.26 & 0.17 & 0.35 & 0.31 & 0.30 & 0.18 & 0.34 & 0.43 & 0.25 & 0.16 & 0.30 & 0.31 & 0.70 & 0.20 & 0.20 & 0.54 & 0.23 & 0.31 & 0.28 \\
\hline $\mathrm{Al}_{2} \mathrm{O}_{3}$ & 4.30 & 3.77 & 3.36 & 5.15 & 2.94 & 3.37 & 3.43 & 4.82 & 4.27 & 2.63 & 3.28 & 1.56 & 3.58 & 5.90 & 3.90 & 1.74 & 4.67 & 1.38 & 1.46 & 3.05 \\
\hline $\mathrm{Cr}_{2} \mathrm{O}_{3}$ & 0.09 & 0.10 & 0.17 & 0.20 & 0.12 & 0.09 & 0.19 & 0.21 & 0.05 & 0.07 & 0.20 & 0.07 & 0.05 & 0.06 & 0.22 & 0.06 & 0.08 & 0.01 & 0.03 & 0.11 \\
\hline $\mathrm{FeO}(\mathrm{T})$ & 10.59 & 7.98 & 5.01 & 7.08 & 9.16 & 8.44 & 5.30 & 6.68 & 9.49 & 9.52 & 5.04 & 11.27 & 8.86 & 12.56 & 5.13 & 9.47 & 10.99 & 11.68 & 11.53 & 8.65 \\
\hline MnO & 0.30 & 0.18 & 0.11 & 0.15 & 0.30 & 0.19 & 0.11 & 0.14 & 0.22 & 0.29 & 0.11 & 0.73 & 0.21 & 0.31 & 0.09 & 0.29 & 0.30 & 0.62 & 0.70 & 0.19 \\
\hline MgO & 14.22 & 15.65 & 16.83 & 15.74 & 16.93 & 15.83 & 16.89 & 15.70 & 15.03 & 16.42 & 16.84 & 14.05 & 15.52 & 14.02 & 16.43 & 17.03 & 14.37 & 14.77 & 14.20 & 15.67 \\
\hline $\mathrm{CaO}$ & 19.52 & 21.78 & 23.12 & 21.90 & 19.16 & 21.18 & 22.74 & 22.25 & 20.50 & 19.79 & 22.95 & 20.97 & 21.48 & 18.50 & 22.87 & 18.93 & 19.83 & 19.88 & 20.53 & 21.15 \\
\hline $\mathrm{Na}_{2} \mathrm{O}$ & 0.18 & 0.13 & 0.09 & 0.11 & 0.16 & 0.15 & 0.08 & 0.11 & 0.18 & 0.11 & 0.09 & 0.19 & 0.15 & 0.18 & 0.11 & 0.09 & 0.19 & 0.19 & 0.20 & 0.14 \\
\hline Total & 100.95 & 101.63 & 101.62 & 101.62 & 101.17 & 101.30 & 101.57 & 101.28 & 101.24 & 101.51 & 101.46 & 101.58 & 101.66 & 101.38 & 100.77 & 100.62 & 100.85 & 101.59 & 101.60 & 101.06 \\
\hline \multicolumn{21}{|l|}{ Cations } \\
\hline $\mathbf{S i}$ & 1.90 & 1.89 & 1.91 & 1.86 & 1.91 & 1.90 & 1.90 & 1.86 & 1.88 & 1.92 & 1.91 & 1.95 & 1.89 & 1.83 & 1.89 & 1.94 & 1.86 & 1.95 & 1.95 & 1.91 \\
\hline $\mathrm{Ti}$ & 0.005 & 0.003 & 0.002 & 0.004 & 0.004 & 0.004 & 0.002 & 0.004 & 0.005 & 0.003 & 0.002 & 0.004 & 0.004 & 0.009 & 0.003 & 0.002 & 0.007 & 0.003 & 0.004 & 0.003 \\
\hline Al & 0.187 & 0.162 & 0.143 & 0.221 & 0.127 & 0.145 & 0.146 & 0.208 & 0.185 & 0.113 & 0.140 & 0.068 & 0.155 & 0.258 & 0.168 & 0.076 & 0.205 & 0.060 & 0.064 & 0.132 \\
\hline $\mathrm{Cr}$ & 0.003 & 0.003 & 0.005 & 0.006 & 0.004 & 0.003 & 0.006 & 0.006 & 0.001 & 0.002 & 0.006 & 0.002 & 0.002 & 0.002 & 0.006 & 0.002 & 0.002 & 0.000 & 0.001 & 0.003 \\
\hline $\mathrm{Fe}$ total & 0.324 & 0.242 & 0.149 & 0.212 & 0.278 & 0.256 & 0.158 & 0.200 & 0.289 & 0.290 & 0.150 & 0.348 & 0.269 & 0.386 & 0.154 & 0.290 & 0.339 & 0.360 & 0.355 & 0.264 \\
\hline $\mathrm{Fe}^{2+}$ & 0.298 & 0.226 & 0.139 & 0.192 & 0.259 & 0.238 & 0.147 & 0.180 & 0.263 & 0.275 & 0.141 & 0.329 & 0.250 & 0.343 & 0.142 & 0.278 & 0.305 & 0.346 & 0.337 & 0.247 \\
\hline $\mathrm{Fe}^{3+}$ & 0.026 & 0.015 & 0.010 & 0.021 & 0.019 & 0.018 & 0.011 & 0.020 & 0.026 & 0.015 & 0.010 & 0.019 & 0.019 & 0.043 & 0.012 & 0.012 & 0.033 & 0.014 & 0.019 & 0.017 \\
\hline Mn & 0.009 & 0.006 & 0.003 & 0.005 & 0.009 & 0.006 & 0.003 & 0.004 & 0.007 & 0.009 & 0.003 & 0.023 & 0.006 & 0.010 & 0.003 & 0.009 & 0.009 & 0.019 & 0.022 & 0.006 \\
\hline Mg & 0.784 & 0.852 & 0.906 & 0.854 & 0.925 & 0.865 & 0.911 & 0.855 & 0.825 & 0.896 & 0.908 & 0.777 & 0.848 & 0.777 & 0.893 & 0.935 & 0.798 & 0.815 & 0.784 & 0.860 \\
\hline $\mathrm{Ca}$ & 0.773 & 0.852 & 0.895 & 0.855 & 0.752 & 0.832 & 0.881 & 0.870 & 0.809 & 0.776 & 0.889 & 0.833 & 0.844 & 0.737 & 0.894 & 0.747 & 0.791 & 0.788 & 0.815 & 0.834 \\
\hline $\mathrm{Na}$ & 0.013 & 0.009 & 0.006 & 0.008 & 0.011 & 0.011 & 0.006 & 0.008 & 0.013 & 0.008 & 0.007 & 0.014 & 0.011 & 0.013 & 0.008 & 0.006 & 0.014 & 0.013 & 0.014 & 0.010 \\
\hline Total & 4.00 & 4.02 & 4.02 & 4.02 & 4.02 & 4.02 & 4.02 & 4.02 & 4.01 & 4.02 & 4.01 & 4.01 & 4.03 & 4.02 & 4.02 & 4.01 & 4.02 & 4.01 & 4.01 & 4.02 \\
\hline \multicolumn{21}{|l|}{ Atomic \% } \\
\hline Wo & 41.1 & 43.8 & 45.9 & 44.5 & 38.5 & 42.6 & 45.2 & 45.2 & 42.1 & 39.6 & 45.7 & 42.6 & 43.0 & 38.8 & 46.0 & 37.9 & 41.0 & 40.2 & 41.7 & 42.6 \\
\hline En & 41.7 & 43.8 & 46.5 & 44.5 & 47.3 & 44.3 & 46.7 & 44.4 & 42.9 & 45.7 & 46.6 & 39.7 & 43.2 & 40.9 & 46.0 & 47.4 & 41.4 & 41.5 & 40.1 & 43.9 \\
\hline Fs & 17.2 & 12.4 & 7.6 & 11.1 & 14.2 & 13.1 & 8.1 & 10.4 & 15.0 & 14.8 & 7.7 & 17.8 & 13.7 & 20.3 & 7.9 & 14.7 & 17.6 & 18.3 & 18.2 & 13.5 \\
\hline Mg \# & 70.1 & 77.5 & 85.6 & 79.7 & 76.3 & 76.7 & 85.0 & 80.7 & 73.6 & 75.0 & 85.5 & 67.7 & 75.5 & 66.2 & 85.1 & 75.8 & 69.6 & 68.2 & 67.5 & 76.1 \\
\hline
\end{tabular}


Table F.1 Continued

\begin{tabular}{|c|c|c|c|c|c|c|c|c|c|c|c|c|c|c|c|c|c|c|c|c|}
\hline \multicolumn{21}{|l|}{ Sample } \\
\hline \multicolumn{21}{|l|}{ Location } \\
\hline \multicolumn{21}{|l|}{ Volcano } \\
\hline \multicolumn{21}{|l|}{ Type } \\
\hline Crystal no. & 45 & 45 & 46 & 46 & 46 & 47 & 48 & 49 & 49 & 49 & 50 & 50 & 50 & 51 & 52 & 53 & 54 & 55 & 55 & 56 \\
\hline Analysis site & $\mathrm{d}$ band & rim & core 1 & core2 & $\mathrm{rim}$ & $\mathrm{NVZ}$ & core & core & rim1 & rim2 & core1 & rim1 & rim2 & NVZ & NVZ & $N V Z$ & $N V Z$ & core & rim & core \\
\hline \multicolumn{21}{|l|}{ Oxides (wt \%) } \\
\hline $\mathrm{SiO}_{2}$ & 52.81 & 53.01 & 50.78 & 52.93 & 51.67 & 52.29 & 52.22 & 52.35 & 50.86 & 50.72 & 52.83 & 51.55 & 50.56 & 52.85 & 52.56 & 50.96 & 51.71 & 52.70 & 53.05 & 52.37 \\
\hline $\mathrm{TiO}_{2}$ & 0.20 & 0.23 & 0.40 & 0.13 & 0.34 & 0.30 & 0.20 & 0.24 & 0.40 & 0.39 & 0.18 & 0.29 & 0.43 & 0.24 & 0.27 & 0.36 & 0.26 & 0.18 & 0.24 & 0.16 \\
\hline $\mathrm{Al}_{2} \mathrm{O}_{3}$ & 2.80 & 1.90 & 4.39 & 2.76 & 2.85 & 1.82 & 3.87 & 3.53 & 4.14 & 4.00 & 3.33 & 4.33 & 4.61 & 1.25 & 1.49 & 4.10 & 4.03 & 3.28 & 2.39 & 3.80 \\
\hline $\mathrm{Cr}_{2} \mathrm{O}_{3}$ & 0.11 & 0.06 & 0.04 & 0.31 & 0.09 & 0.05 & 0.17 & 0.58 & 0.05 & 0.08 & 0.20 & 0.20 & 0.05 & 0.05 & 0.04 & 0.06 & 0.08 & 0.19 & 0.08 & 0.13 \\
\hline $\mathrm{FeO}(\mathrm{T})$ & 6.34 & 9.03 & 8.32 & 4.54 & 9.77 & 11.65 & 5.20 & 5.23 & 9.14 & 9.29 & 4.90 & 7.04 & 11.11 & 11.98 & 11.47 & 7.31 & 7.09 & 5.17 & 8.59 & 5.06 \\
\hline MnO & 0.15 & 0.26 & 0.21 & 0.10 & 0.28 & 0.60 & 0.11 & 0.12 & 0.21 & 0.26 & 0.09 & 0.13 & 0.30 & 0.63 & 0.62 & 0.19 & 0.17 & 0.11 & 0.25 & 0.09 \\
\hline MgO & 16.94 & 16.83 & 14.90 & 17.07 & 16.33 & 14.04 & 16.56 & 16.80 & 15.36 & 15.60 & 16.86 & 15.89 & 14.92 & 14.41 & 14.35 & 15.67 & 15.88 & 16.87 & 16.38 & 16.83 \\
\hline $\mathrm{CaO}$ & 21.74 & 19.88 & 22.23 & 23.09 & 19.38 & 20.69 & 23.05 & 22.66 & 20.87 & 20.43 & 22.82 & 22.02 & 19.35 & 20.01 & 20.55 & 22.46 & 22.35 & 23.21 & 19.86 & 23.16 \\
\hline $\mathrm{Na}_{2} \mathrm{O}$ & 0.08 & 0.08 & 0.11 & 0.10 & 0.11 & 0.18 & 0.10 & 0.10 & 0.14 & 0.15 & 0.09 & 0.10 & 0.16 & 0.17 & 0.18 & 0.11 & 0.10 & 0.08 & 0.11 & 0.06 \\
\hline Total & 101.15 & 101.29 & 101.38 & 101.03 & 100.82 & 101.63 & 101.47 & 101.59 & 101.17 & 100.91 & 101.28 & 101.54 & 101.49 & 101.58 & 101.52 & 101.22 & 101.66 & 101.78 & 100.95 & 101.65 \\
\hline \multicolumn{21}{|l|}{ Cations } \\
\hline $\mathbf{S i}$ & 1.92 & 1.94 & 1.87 & 1.92 & 1.91 & 1.94 & 1.89 & 1.89 & 1.87 & 1.87 & 1.91 & 1.88 & 1.87 & 1.96 & 1.95 & 1.87 & 1.88 & 1.90 & 1.94 & 1.89 \\
\hline $\mathrm{Ti}$ & 0.002 & 0.003 & 0.005 & 0.002 & 0.004 & 0.004 & 0.003 & 0.003 & 0.005 & 0.005 & 0.002 & 0.004 & 0.005 & 0.003 & 0.003 & 0.005 & 0.003 & 0.002 & 0.003 & 0.002 \\
\hline Al & 0.120 & 0.082 & 0.190 & 0.118 & 0.124 & 0.080 & 0.165 & 0.150 & 0.180 & 0.174 & 0.142 & 0.186 & 0.200 & 0.054 & 0.065 & 0.177 & 0.173 & 0.140 & 0.103 & 0.162 \\
\hline $\mathrm{Cr}$ & 0.003 & 0.002 & 0.001 & 0.009 & 0.003 & 0.001 & 0.005 & 0.017 & 0.002 & 0.002 & 0.006 & 0.006 & 0.002 & 0.001 & 0.001 & 0.002 & 0.002 & 0.005 & 0.002 & 0.004 \\
\hline $\mathrm{Fe}$ total & 0.191 & 0.275 & 0.253 & 0.136 & 0.299 & 0.359 & 0.155 & 0.155 & 0.279 & 0.284 & 0.146 & 0.212 & 0.340 & 0.370 & 0.354 & 0.221 & 0.213 & 0.154 & 0.261 & 0.151 \\
\hline $\mathrm{Fe}^{2+}$ & 0.179 & 0.261 & 0.228 & 0.128 & 0.278 & 0.341 & 0.143 & 0.141 & 0.254 & 0.260 & 0.135 & 0.194 & 0.314 & 0.355 & 0.337 & 0.199 & 0.198 & 0.144 & 0.246 & 0.141 \\
\hline $\mathrm{Fe}^{3+}$ & 0.012 & 0.014 & 0.024 & 0.008 & 0.021 & 0.019 & 0.012 & 0.014 & 0.024 & 0.024 & 0.010 & 0.017 & 0.026 & 0.015 & 0.016 & 0.022 & 0.016 & 0.010 & 0.015 & 0.010 \\
\hline Mn & 0.005 & 0.008 & 0.006 & 0.003 & 0.009 & 0.019 & 0.003 & 0.004 & 0.007 & 0.008 & 0.003 & 0.004 & 0.009 & 0.020 & 0.019 & 0.006 & 0.005 & 0.003 & 0.008 & 0.003 \\
\hline $\mathrm{Mg}$ & 0.918 & 0.918 & 0.817 & 0.923 & 0.898 & 0.776 & 0.894 & 0.906 & 0.844 & 0.859 & 0.910 & 0.863 & 0.821 & 0.796 & 0.793 & 0.857 & 0.862 & 0.908 & 0.894 & 0.906 \\
\hline $\mathrm{Ca}$ & 0.847 & 0.779 & 0.876 & 0.897 & 0.767 & 0.822 & 0.895 & 0.879 & 0.824 & 0.809 & 0.885 & 0.859 & 0.765 & 0.794 & 0.816 & 0.883 & 0.872 & 0.898 & 0.779 & 0.897 \\
\hline $\mathrm{Na}$ & 0.006 & 0.006 & 0.008 & 0.007 & 0.008 & 0.013 & 0.007 & 0.007 & 0.010 & 0.010 & 0.006 & 0.007 & 0.012 & 0.012 & 0.013 & 0.008 & 0.007 & 0.006 & 0.008 & 0.004 \\
\hline Total & 4.01 & 4.01 & 4.02 & 4.01 & 4.02 & 4.01 & 4.02 & 4.02 & 4.02 & 4.03 & 4.01 & 4.02 & 4.02 & 4.01 & 4.01 & 4.03 & 4.02 & 4.02 & 4.00 & 4.02 \\
\hline \multicolumn{21}{|l|}{ Atomic $\%$} \\
\hline Wo & 43.3 & 39.5 & 45.0 & 45.9 & 39.0 & 42.0 & 46.0 & 45.3 & 42.3 & 41.4 & 45.6 & 44.4 & 39.7 & 40.5 & 41.6 & 45.0 & 44.8 & 45.8 & 40.3 & 45.9 \\
\hline En & 46.9 & 46.6 & 42.0 & 47.2 & 45.7 & 39.7 & 46.0 & 46.7 & 43.4 & 44.0 & 46.9 & 44.6 & 42.6 & 40.6 & 40.4 & 43.7 & 44.3 & 46.3 & 46.2 & 46.4 \\
\hline Fs & 9.8 & 13.9 & 13.0 & 6.9 & 15.2 & 18.4 & 8.0 & 8.0 & 14.3 & 14.6 & 7.5 & 11.0 & 17.7 & 18.9 & 18.0 & 11.3 & 11.0 & 7.9 & 13.5 & 7.7 \\
\hline $\mathrm{Mg} \#$ & 82.4 & 76.5 & 75.9 & 86.9 & 74.5 & 67.2 & 85.0 & 85.1 & 74.7 & 74.6 & 86.0 & 80.0 & 70.1 & 67.1 & 68.0 & 79.1 & 79.8 & 85.2 & 76.9 & 85.5 \\
\hline
\end{tabular}


Table F.1 Continued

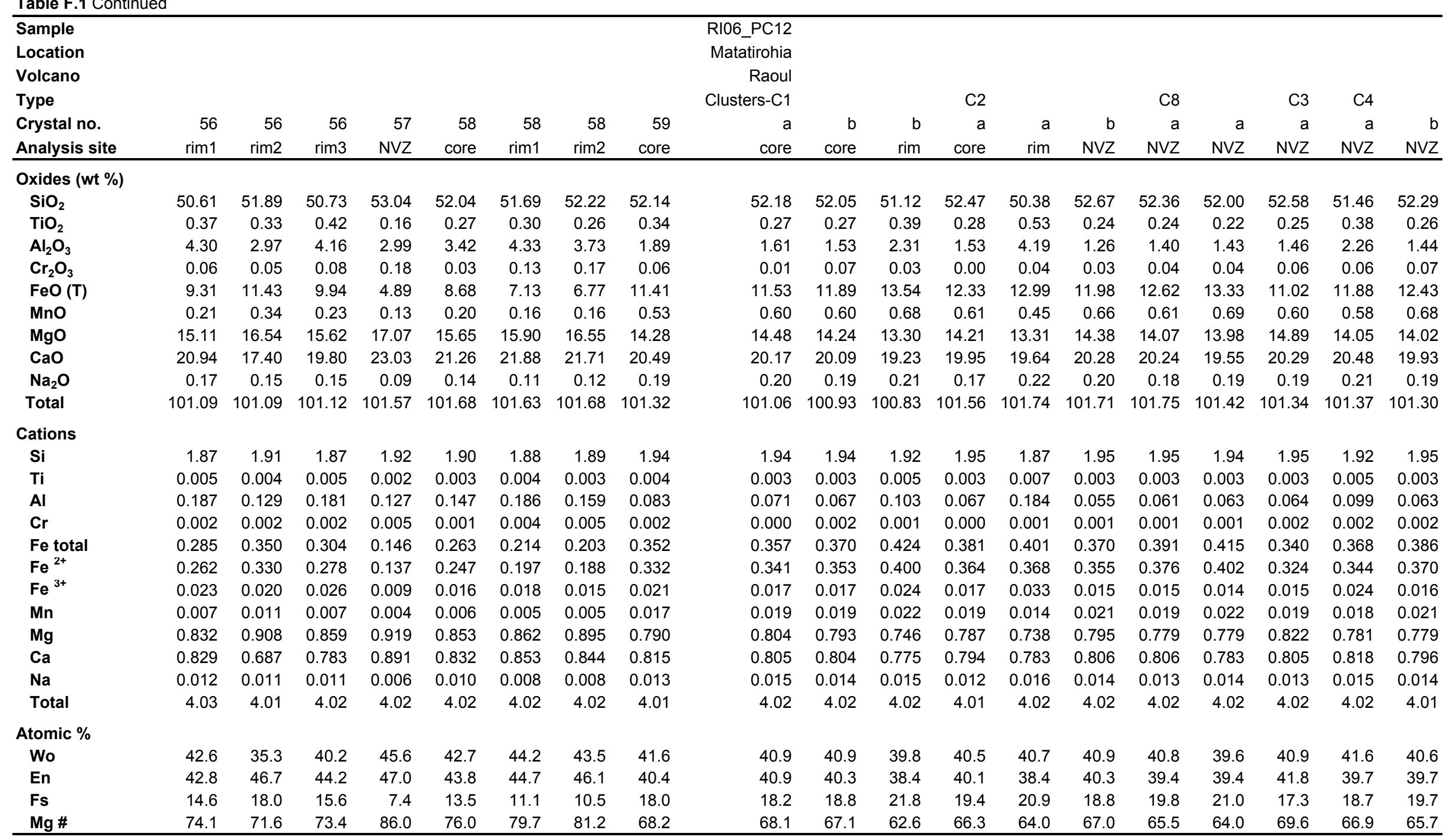


Table F.1 Continued

\begin{tabular}{|c|c|c|c|c|c|c|c|c|c|c|c|c|c|c|c|c|c|c|c|}
\hline Sample & & & & & & & & RI06_PC12 & & & & & & & & & & & \\
\hline Location & & & & & & & & Matatirohia & & & & & & & & & & & \\
\hline Volcano & & & & & & & & Raoul & & & & & & & & & & & \\
\hline Type & C5 & & & & $\mathrm{C} 6$ & $\mathrm{C} 7$ & & Mafic Bleb-1 & & & MB2 & MB3 & & & MB4 & & MB5 & & MB6 \\
\hline Crystal no. & $a$ & a & a & $a$ & $a$ & a & a & $a$ & a & a & $a$ & $a$ & a & a & $a$ & a & $a$ & a & a \\
\hline Analysis site & core & band & rim & rim & rim & core & OG & core & $\operatorname{rim} 1$ & $\operatorname{rim} 2$ & NVZ & core & $\operatorname{rim} 2$ & $\operatorname{rim} 2$ & core & rim & core & rim & core \\
\hline \multicolumn{20}{|l|}{ Oxides (wt \%) } \\
\hline $\mathrm{SiO}_{2}$ & 52.43 & 50.79 & 52.04 & 52.22 & 51.90 & 52.56 & 51.13 & 51.17 & 50.70 & 46.44 & 51.15 & 52.12 & 50.36 & 47.40 & 51.41 & 49.16 & 53.06 & 46.99 & 52.02 \\
\hline $\mathrm{TiO}_{2}$ & 0.25 & 0.49 & 0.29 & 0.24 & 0.40 & 0.23 & 0.37 & 0.25 & 0.41 & 1.01 & 0.28 & 0.21 & 0.49 & 1.00 & 0.26 & 0.55 & 0.20 & 0.99 & 0.21 \\
\hline $\mathrm{Al}_{2} \mathrm{O}_{3}$ & 1.23 & 3.03 & 1.52 & 1.22 & 2.81 & 1.41 & 3.93 & 3.17 & 4.19 & 8.41 & 3.34 & 3.56 & 4.32 & 7.83 & 3.07 & 5.51 & 2.46 & 8.50 & 2.89 \\
\hline $\mathrm{Cr}_{2} \mathrm{O}_{3}$ & 0.05 & 0.03 & 0.07 & 0.04 & 0.10 & 0.03 & 0.07 & 0.09 & 0.07 & 0.07 & 0.06 & 0.21 & 0.07 & 0.06 & 0.10 & 0.05 & 0.37 & 0.08 & 0.09 \\
\hline $\mathrm{FeO}(\mathrm{T})$ & 11.80 & 12.90 & 12.80 & 12.40 & 9.84 & 11.69 & 9.93 & 8.34 & 10.43 & 14.77 & 8.54 & 5.55 & 8.86 & 13.24 & 8.85 & 13.10 & 5.60 & 12.49 & 6.65 \\
\hline $\mathrm{MnO}$ & 0.72 & 0.62 & 0.71 & 0.64 & 0.34 & 0.61 & 0.23 & 0.18 & 0.27 & 0.32 & 0.20 & 0.12 & 0.22 & 0.32 & 0.22 & 0.31 & 0.13 & 0.24 & 0.18 \\
\hline MgO & 14.59 & 13.27 & 13.82 & 14.18 & 15.98 & 14.82 & 15.64 & 15.36 & 15.74 & 12.07 & 15.40 & 16.35 & 15.00 & 12.29 & 15.76 & 14.34 & 18.09 & 12.12 & 16.50 \\
\hline $\mathrm{CaO}$ & 20.41 & 20.19 & 19.94 & 20.00 & 19.56 & 20.09 & 20.45 & 21.63 & 19.06 & 17.67 & 21.58 & 22.86 & 20.93 & 19.28 & 20.93 & 18.42 & 20.71 & 20.07 & 22.17 \\
\hline $\mathrm{Na}_{2} \mathrm{O}$ & 0.22 & 0.25 & 0.20 & 0.68 & 0.24 & 0.19 & 0.15 & 0.14 & 0.16 & 0.19 & 0.15 & 0.12 & 0.15 & 0.23 & 0.12 & 0.13 & 0.14 & 0.21 & 0.11 \\
\hline Total & 101.71 & 101.58 & 101.37 & 101.61 & 101.17 & 101.65 & 101.90 & 100.31 & 101.01 & 100.95 & 100.69 & 101.10 & 100.40 & 101.64 & 100.73 & 101.55 & 100.74 & 101.67 & 100.82 \\
\hline \multicolumn{20}{|l|}{ Cations } \\
\hline $\mathbf{S i}$ & 1.94 & 1.90 & 1.94 & 1.94 & 1.91 & 1.95 & 1.87 & 1.90 & 1.87 & 1.75 & 1.89 & 1.90 & 1.87 & 1.77 & 1.90 & 1.83 & 1.93 & 1.75 & 1.91 \\
\hline $\mathrm{Ti}$ & 0.003 & 0.006 & 0.004 & 0.003 & 0.005 & 0.003 & 0.005 & 0.003 & 0.005 & 0.013 & 0.004 & 0.003 & 0.006 & 0.013 & 0.003 & 0.007 & 0.002 & 0.012 & 0.003 \\
\hline Al & 0.054 & 0.133 & 0.067 & 0.053 & 0.122 & 0.062 & 0.170 & 0.138 & 0.182 & 0.374 & 0.146 & 0.153 & 0.189 & 0.345 & 0.134 & 0.241 & 0.105 & 0.374 & 0.125 \\
\hline $\mathrm{Cr}$ & 0.001 & 0.001 & 0.002 & 0.001 & 0.003 & 0.001 & 0.002 & 0.003 & 0.002 & 0.002 & 0.002 & 0.006 & 0.002 & 0.002 & 0.003 & 0.001 & 0.011 & 0.002 & 0.003 \\
\hline Fe total & 0.365 & 0.400 & 0.398 & 0.385 & 0.300 & 0.361 & 0.302 & 0.257 & 0.320 & 0.461 & 0.262 & 0.167 & 0.271 & 0.408 & 0.272 & 0.405 & 0.168 & 0.384 & 0.202 \\
\hline $\mathrm{Fe}^{2+}$ & 0.349 & 0.370 & 0.380 & 0.370 & 0.276 & 0.346 & 0.280 & 0.241 & 0.295 & 0.397 & 0.245 & 0.154 & 0.241 & 0.346 & 0.256 & 0.371 & 0.156 & 0.323 & 0.189 \\
\hline $\mathrm{Fe}^{3+}$ & 0.016 & 0.031 & 0.018 & 0.015 & 0.025 & 0.014 & 0.022 & 0.015 & 0.025 & 0.064 & 0.017 & 0.013 & 0.030 & 0.062 & 0.016 & 0.034 & 0.012 & 0.061 & 0.013 \\
\hline Mn & 0.022 & 0.020 & 0.023 & 0.020 & 0.011 & 0.019 & 0.007 & 0.006 & 0.009 & 0.010 & 0.006 & 0.004 & 0.007 & 0.010 & 0.007 & 0.010 & 0.004 & 0.007 & 0.005 \\
\hline Mg & 0.807 & 0.739 & 0.769 & 0.787 & 0.877 & 0.818 & 0.855 & 0.850 & 0.867 & 0.679 & 0.849 & 0.888 & 0.830 & 0.685 & 0.868 & 0.795 & 0.979 & 0.674 & 0.902 \\
\hline $\mathrm{Ca}$ & 0.811 & 0.808 & 0.798 & 0.798 & 0.772 & 0.797 & 0.803 & 0.860 & 0.754 & 0.714 & 0.856 & 0.892 & 0.833 & 0.772 & 0.829 & 0.734 & 0.806 & 0.802 & 0.871 \\
\hline $\mathrm{Na}$ & 0.016 & 0.018 & 0.014 & 0.049 & 0.017 & 0.014 & 0.010 & 0.010 & 0.011 & 0.014 & 0.011 & 0.008 & 0.011 & 0.016 & 0.009 & 0.009 & 0.010 & 0.015 & 0.008 \\
\hline Total & 4.02 & 4.02 & 4.02 & 4.04 & 4.02 & 4.02 & 4.03 & 4.02 & 4.02 & 4.02 & 4.03 & 4.02 & 4.02 & 4.02 & 4.02 & 4.03 & 4.01 & 4.02 & 4.02 \\
\hline \multicolumn{20}{|l|}{ Atomic \% } \\
\hline Wo & 40.9 & 41.5 & 40.6 & 40.5 & 39.6 & 40.3 & 41.0 & 43.7 & 38.9 & 38.5 & 43.5 & 45.8 & 43.1 & 41.4 & 42.1 & 38.0 & 41.3 & 43.1 & 44.1 \\
\hline En & 40.7 & 38.0 & 39.2 & 40.0 & 45.0 & 41.4 & 43.6 & 43.2 & 44.7 & 36.6 & 43.2 & 45.6 & 42.9 & 36.7 & 44.1 & 41.1 & 50.1 & 36.2 & 45.7 \\
\hline Fs & 18.4 & 20.6 & 20.3 & 19.5 & 15.4 & 18.3 & 15.4 & 13.1 & 16.5 & 24.9 & 13.3 & 8.6 & 14.0 & 21.9 & 13.8 & 20.9 & 8.6 & 20.6 & 10.2 \\
\hline $\mathrm{Mg} \#$ & 67.6 & 63.8 & 64.7 & 66.0 & 73.8 & 68.3 & 73.4 & 76.4 & 72.5 & 59.0 & 76.0 & 83.9 & 74.9 & 62.1 & 75.7 & 65.7 & 85.1 & 63.3 & 81.3 \\
\hline
\end{tabular}


Table F.1 Continued

\begin{tabular}{|c|c|c|c|c|c|c|c|c|c|c|c|c|c|c|c|c|c|c|c|c|}
\hline \multicolumn{21}{|l|}{ Sample } \\
\hline \multicolumn{21}{|l|}{ Location } \\
\hline \multicolumn{21}{|l|}{ Volcano } \\
\hline Type & & MB8 & & MB9 & & MB10 & MB11 & & & MB12 & & MB13 & & & & & & & & \\
\hline $\begin{array}{l}\text { Crystal no. } \\
\text { Analysis site }\end{array}$ & $\begin{array}{r}a \\
\text { rim }\end{array}$ & $\begin{array}{r}\text { a } \\
\text { core }\end{array}$ & $\begin{array}{r}a \\
\text { rim }\end{array}$ & $\begin{array}{r}a \\
\text { core } \\
\end{array}$ & $\begin{array}{r}a \\
\text { rim }\end{array}$ & $\begin{array}{r}a \\
N V Z \\
\end{array}$ & $\begin{array}{r}a \\
\text { core } \\
\end{array}$ & $\begin{array}{r}a \\
\text { band }\end{array}$ & $\begin{array}{r}a \\
\text { rim }\end{array}$ & $\begin{array}{r}a \\
\text { band }\end{array}$ & $\begin{array}{r}a \\
\text { rim }\end{array}$ & $\begin{array}{r}a \\
\text { core } 1 \\
\end{array}$ & $\begin{array}{r}a \\
\text { core } 2 \\
\end{array}$ & $\begin{array}{r}a \\
O G\end{array}$ & $\begin{array}{r}a \\
d \text { band }\end{array}$ & $\begin{array}{r}a \\
\operatorname{rim} 1\end{array}$ & $\begin{array}{r}a \\
\operatorname{rim} 2 \\
\end{array}$ & $\begin{array}{r}a \\
\operatorname{rim} 3 \\
\end{array}$ & $\begin{array}{r}\mathrm{b} \\
\text { core }\end{array}$ & $\begin{array}{r}\mathrm{b} \\
\mathrm{rim}\end{array}$ \\
\hline \multicolumn{21}{|l|}{ Oxides (wt \%) } \\
\hline $\mathrm{SiO}_{2}$ & 51.21 & 52.40 & 50.29 & 51.94 & 53.56 & 52.13 & 52.08 & 50.96 & 44.40 & 51.29 & 45.59 & 51.19 & 51.13 & 50.93 & 51.11 & 49.46 & 49.31 & 49.66 & 49.31 & 44.88 \\
\hline $\mathrm{TiO}_{2}$ & 0.35 & 0.17 & 0.41 & 0.24 & 0.17 & 0.25 & 0.21 & 0.28 & 1.07 & 0.34 & 1.06 & 0.23 & 0.26 & 0.23 & 0.20 & 0.36 & 0.38 & 0.42 & 0.32 & 0.97 \\
\hline $\mathrm{Al}_{2} \mathrm{O}_{3}$ & 3.69 & 2.87 & 4.72 & 3.35 & 1.29 & 2.76 & 1.19 & 3.37 & 9.53 & 3.94 & 10.59 & 3.58 & 3.35 & 3.45 & 3.63 & 5.41 & 5.55 & 4.14 & 3.79 & 9.41 \\
\hline $\mathrm{Cr}_{2} \mathrm{O}_{3}$ & 0.07 & 0.26 & 0.09 & 0.15 & 0.06 & 0.05 & 0.02 & 0.05 & 0.03 & 0.06 & 0.05 & 0.19 & 0.16 & 0.15 & 0.12 & 0.18 & 0.19 & 0.06 & 0.09 & 0.01 \\
\hline $\mathrm{FeO}(\mathrm{T})$ & 9.01 & 5.22 & 8.76 & 6.39 & 9.13 & 9.32 & 11.92 & 9.70 & 14.39 & 9.92 & 14.65 & 5.83 & 6.08 & 7.05 & 5.87 & 6.84 & 6.96 & 9.30 & 8.74 & 13.35 \\
\hline $\mathrm{MnO}$ & 0.19 & 0.09 & 0.21 & 0.15 & 0.32 & 0.30 & 0.67 & 0.27 & 0.28 & 0.25 & 0.31 & 0.12 & 0.16 & 0.17 & 0.12 & 0.15 & 0.15 & 0.21 & 0.21 & 0.26 \\
\hline MgO & 15.40 & 16.70 & 14.94 & 16.18 & 17.41 & 15.66 & 14.30 & 15.69 & 11.04 & 15.80 & 11.32 & 16.35 & 16.48 & 16.08 & 16.44 & 15.39 & 15.47 & 15.34 & 15.07 & 11.58 \\
\hline $\mathrm{CaO}$ & 20.76 & 22.98 & 21.30 & 22.43 & 18.82 & 20.46 & 19.89 & 19.74 & 19.31 & 19.33 & 18.20 & 22.06 & 22.10 & 21.59 & 22.35 & 21.87 & 21.79 & 20.20 & 21.45 & 19.39 \\
\hline $\mathrm{Na}_{2} \mathrm{O}$ & 0.12 & 0.10 & 0.16 & 0.13 & 0.11 & 0.15 & 0.17 & 0.13 & 0.20 & 0.13 & 0.20 & 0.12 & 0.11 & 0.14 & 0.10 & 0.11 & 0.11 & 0.16 & 0.14 & 0.18 \\
\hline Total & 100.80 & 100.79 & 100.86 & 100.95 & 100.86 & 101.06 & 100.44 & 100.20 & 100.24 & 101.08 & 101.96 & 99.67 & 99.83 & 99.78 & 99.94 & 99.77 & 99.92 & 99.50 & 99.12 & 100.04 \\
\hline \multicolumn{21}{|l|}{ Cations } \\
\hline $\mathbf{S i}$ & 1.89 & 1.91 & 1.86 & 1.90 & 1.96 & 1.92 & 1.95 & 1.90 & 1.70 & 1.89 & 1.70 & 1.89 & 1.89 & 1.89 & 1.89 & 1.84 & 1.83 & 1.86 & 1.86 & 1.71 \\
\hline $\mathrm{Ti}$ & 0.004 & 0.002 & 0.005 & 0.003 & 0.002 & 0.003 & 0.003 & 0.004 & 0.013 & 0.004 & 0.013 & 0.003 & 0.003 & 0.003 & 0.002 & 0.005 & 0.005 & 0.005 & 0.004 & 0.012 \\
\hline Al & 0.161 & 0.123 & 0.205 & 0.144 & 0.056 & 0.120 & 0.052 & 0.148 & 0.430 & 0.171 & 0.467 & 0.156 & 0.146 & 0.151 & 0.158 & 0.237 & 0.243 & 0.183 & 0.169 & 0.423 \\
\hline $\mathrm{Cr}$ & 0.002 & 0.008 & 0.002 & 0.004 & 0.002 & 0.001 & 0.001 & 0.002 & 0.001 & 0.002 & 0.001 & 0.006 & 0.005 & 0.004 & 0.004 & 0.005 & 0.006 & 0.002 & 0.003 & 0.000 \\
\hline Fe total & 0.276 & 0.157 & 0.268 & 0.193 & 0.278 & 0.285 & 0.373 & 0.300 & 0.455 & 0.303 & 0.453 & 0.178 & 0.185 & 0.216 & 0.179 & 0.209 & 0.212 & 0.289 & 0.274 & 0.421 \\
\hline $\mathrm{Fe}^{2+}$ & 0.254 & 0.147 & 0.243 & 0.178 & 0.268 & 0.270 & 0.360 & 0.282 & 0.386 & 0.282 & 0.387 & 0.164 & 0.169 & 0.202 & 0.167 & 0.187 & 0.189 & 0.262 & 0.253 & 0.358 \\
\hline $\mathrm{Fe}^{3+}$ & 0.022 & 0.010 & 0.025 & 0.014 & 0.010 & 0.015 & 0.013 & 0.017 & 0.070 & 0.021 & 0.066 & 0.014 & 0.016 & 0.014 & 0.012 & 0.022 & 0.023 & 0.026 & 0.020 & 0.063 \\
\hline Mn & 0.006 & 0.003 & 0.007 & 0.005 & 0.010 & 0.009 & 0.021 & 0.009 & 0.009 & 0.008 & 0.010 & 0.004 & 0.005 & 0.005 & 0.004 & 0.005 & 0.005 & 0.007 & 0.007 & 0.009 \\
\hline $\mathbf{M g}$ & 0.848 & 0.909 & 0.823 & 0.882 & 0.951 & 0.859 & 0.800 & 0.870 & 0.630 & 0.867 & 0.631 & 0.901 & 0.909 & 0.890 & 0.905 & 0.852 & 0.856 & 0.858 & 0.848 & 0.658 \\
\hline $\mathrm{Ca}$ & 0.821 & 0.899 & 0.844 & 0.879 & 0.739 & 0.807 & 0.800 & 0.787 & 0.792 & 0.762 & 0.729 & 0.874 & 0.875 & 0.859 & 0.884 & 0.871 & 0.867 & 0.812 & 0.868 & 0.792 \\
\hline $\mathrm{Na}$ & 0.009 & 0.007 & 0.012 & 0.009 & 0.008 & 0.010 & 0.013 & 0.009 & 0.015 & 0.009 & 0.015 & 0.009 & 0.008 & 0.010 & 0.007 & 0.008 & 0.008 & 0.012 & 0.010 & 0.014 \\
\hline Total & 4.02 & 4.02 & 4.03 & 4.02 & 4.01 & 4.01 & 4.02 & 4.02 & 4.04 & 4.02 & 4.02 & 4.02 & 4.03 & 4.03 & 4.03 & 4.03 & 4.03 & 4.03 & 4.04 & 4.04 \\
\hline \multicolumn{21}{|l|}{ Atomic \% } \\
\hline Wo & 42.2 & 45.7 & 43.6 & 45.0 & 37.5 & 41.4 & 40.5 & 40.2 & 42.2 & 39.4 & 40.2 & 44.8 & 44.5 & 43.7 & 44.9 & 45.1 & 44.8 & 41.4 & 43.6 & 42.3 \\
\hline En & 43.6 & 46.3 & 42.6 & 45.1 & 48.3 & 44.0 & 40.6 & 44.5 & 33.6 & 44.9 & 34.8 & 46.1 & 46.1 & 45.3 & 46.0 & 44.1 & 44.2 & 43.8 & 42.6 & 35.2 \\
\hline Fs & 14.2 & 8.0 & 13.8 & 9.9 & 14.1 & 14.6 & 18.9 & 15.3 & 24.3 & 15.7 & 25.0 & 9.1 & 9.4 & 11.0 & 9.1 & 10.8 & 11.0 & 14.7 & 13.8 & 22.5 \\
\hline Mg \# & 75.1 & 85.0 & 75.0 & 81.7 & 76.7 & 74.5 & 67.0 & 73.8 & 57.6 & 73.6 & 57.7 & 83.2 & 82.7 & 80.0 & 83.2 & 80.0 & 79.8 & 74.4 & 75.2 & 60.5 \\
\hline
\end{tabular}


Table F.1 Continued

\begin{tabular}{|c|c|c|c|c|c|c|c|c|c|c|c|c|c|c|c|c|c|c|c|c|}
\hline \multicolumn{21}{|l|}{ Sample } \\
\hline \multicolumn{21}{|l|}{ Location } \\
\hline \multicolumn{21}{|l|}{ Volcano } \\
\hline \multicolumn{21}{|l|}{ Type } \\
\hline $\begin{array}{l}\text { Crystal no. } \\
\text { Analysis site }\end{array}$ & $\begin{array}{r}c \\
\text { core }\end{array}$ & $\begin{array}{r}\mathrm{C} \\
\operatorname{rim}\end{array}$ & $\begin{array}{r}d \\
N V Z\end{array}$ & $\begin{array}{r}\mathrm{e} \\
\text { core } 1\end{array}$ & $\begin{array}{r}e \\
O G\end{array}$ & $\begin{array}{r}\mathrm{e} \\
\mathrm{rim}\end{array}$ & $\begin{array}{r}f \\
\text { core }\end{array}$ & $\operatorname{rim} 1$ & $\operatorname{rim} 2$ & $\operatorname{rim} 3$ & $\begin{array}{r}g \\
\text { core }\end{array}$ & $\begin{array}{r}g \\
d \text { band }\end{array}$ & $\begin{array}{r}g \\
\operatorname{rim} 1\end{array}$ & $\begin{array}{r}g \\
\operatorname{rim} 2\end{array}$ & $\begin{array}{r}\mathrm{h} \\
\text { core }\end{array}$ & $\begin{array}{r}\mathrm{h} \\
\mathrm{rim}\end{array}$ & $\begin{array}{r}3 \\
\text { core }\end{array}$ & $\begin{array}{r}3 \\
\operatorname{rim}\end{array}$ & $\begin{array}{r}4 \\
\text { core }\end{array}$ & $\begin{array}{r}4 \\
\text { rim }\end{array}$ \\
\hline \multicolumn{21}{|l|}{ Oxides (wt \%) } \\
\hline $\mathrm{SiO}_{2}$ & 50.89 & 50.09 & 51.61 & 50.77 & 51.71 & 45.59 & 50.80 & 49.90 & 49.58 & 49.44 & 51.82 & 49.93 & 47.44 & 47.78 & 50.92 & 49.37 & 49.46 & 44.10 & 50.09 & 44.14 \\
\hline $\mathrm{TiO}_{2}$ & 0.31 & 0.41 & 0.17 & 0.29 & 0.21 & 1.18 & 0.22 & 0.37 & 0.35 & 0.32 & 0.27 & 0.37 & 0.63 & 0.68 & 0.29 & 0.50 & 0.31 & 1.00 & 0.30 & 0.98 \\
\hline $\mathrm{Al}_{2} \mathrm{O}_{3}$ & 3.58 & 5.13 & 3.60 & 3.50 & 1.25 & 9.05 & 4.08 & 4.31 & 4.15 & 3.66 & 1.59 & 4.42 & 6.28 & 6.06 & 3.34 & 4.11 & 3.77 & 8.87 & 3.33 & 8.80 \\
\hline $\mathrm{Cr}_{2} \mathrm{O}_{3}$ & 0.10 & 0.01 & 0.14 & 0.07 & 0.02 & 0.04 & 0.29 & 0.11 & 0.09 & 0.04 & 0.04 & 0.08 & 0.04 & 0.03 & 0.05 & 0.05 & 0.04 & 0.00 & 0.00 & 0.01 \\
\hline $\mathrm{FeO}(\mathrm{T})$ & 8.42 & 11.34 & 5.19 & 8.45 & 11.40 & 12.69 & 5.40 & 9.37 & 9.44 & 8.61 & 11.18 & 9.58 & 13.85 & 14.22 & 8.52 & 11.96 & 8.56 & 14.67 & 8.67 & 13.91 \\
\hline MnO & 0.18 & 0.28 & 0.11 & 0.21 & 0.63 & 0.26 & 0.11 & 0.18 & 0.27 & 0.21 & 0.60 & 0.20 & 0.33 & 0.34 & 0.19 & 0.30 & 0.19 & 0.30 & 0.20 & 0.30 \\
\hline $\mathrm{MgO}$ & 15.33 & 15.34 & 16.84 & 15.61 & 14.74 & 12.03 & 16.61 & 15.05 & 15.54 & 15.36 & 14.52 & 15.62 & 12.90 & 12.93 & 15.51 & 14.90 & 15.40 & 11.88 & 15.78 & 11.44 \\
\hline $\mathrm{CaO}$ & 21.38 & 18.68 & 22.57 & 21.31 & 19.69 & 19.82 & 22.46 & 20.27 & 19.84 & 20.82 & 20.17 & 19.90 & 18.29 & 18.34 & 21.02 & 18.71 & 21.65 & 18.33 & 21.53 & 19.62 \\
\hline $\mathrm{Na}_{2} \mathrm{O}$ & 0.13 & 0.14 & 0.09 & 0.18 & 0.20 & 0.18 & 0.11 & 0.17 & 0.17 & 0.15 & 0.22 & 0.17 & 0.22 & 0.19 & 0.14 & 0.11 & 0.14 & 0.20 & 0.15 & 0.21 \\
\hline Total & 100.32 & 101.41 & 100.31 & 100.37 & 99.84 & 100.83 & 100.08 & 99.72 & 99.41 & 98.61 & 100.40 & 100.26 & 99.99 & 100.57 & 99.99 & 100.00 & 99.51 & 99.34 & 100.05 & 99.39 \\
\hline \multicolumn{21}{|l|}{ Cations } \\
\hline $\mathbf{S i}$ & 1.89 & 1.85 & 1.89 & 1.88 & 1.95 & 1.72 & 1.87 & 1.87 & 1.86 & 1.87 & 1.94 & 1.86 & 1.80 & 1.81 & 1.89 & 1.86 & 1.86 & 1.70 & 1.87 & 1.71 \\
\hline $\mathrm{Ti}$ & 0.004 & 0.005 & 0.002 & 0.004 & 0.003 & 0.015 & 0.003 & 0.005 & 0.004 & 0.004 & 0.003 & 0.005 & 0.008 & 0.009 & 0.004 & 0.006 & 0.004 & 0.013 & 0.004 & 0.012 \\
\hline Al & 0.157 & 0.223 & 0.156 & 0.153 & 0.055 & 0.403 & 0.177 & 0.190 & 0.184 & 0.163 & 0.070 & 0.194 & 0.281 & 0.270 & 0.146 & 0.182 & 0.167 & 0.404 & 0.147 & 0.400 \\
\hline $\mathrm{Cr}$ & 0.003 & 0.000 & 0.004 & 0.002 & 0.001 & 0.001 & 0.008 & 0.003 & 0.003 & 0.001 & 0.001 & 0.002 & 0.001 & 0.001 & 0.001 & 0.001 & 0.001 & 0.000 & 0.000 & 0.000 \\
\hline Fe total & 0.259 & 0.348 & 0.157 & 0.260 & 0.358 & 0.394 & 0.163 & 0.290 & 0.294 & 0.270 & 0.349 & 0.295 & 0.437 & 0.447 & 0.263 & 0.374 & 0.267 & 0.469 & 0.268 & 0.444 \\
\hline $\mathrm{Fe}^{2+}$ & 0.240 & 0.323 & 0.147 & 0.242 & 0.344 & 0.319 & 0.150 & 0.267 & 0.272 & 0.249 & 0.331 & 0.272 & 0.397 & 0.403 & 0.245 & 0.342 & 0.247 & 0.402 & 0.250 & 0.379 \\
\hline $\mathrm{Fe}^{3+}$ & 0.019 & 0.025 & 0.010 & 0.018 & 0.013 & 0.075 & 0.014 & 0.023 & 0.022 & 0.021 & 0.017 & 0.023 & 0.040 & 0.043 & 0.018 & 0.031 & 0.020 & 0.066 & 0.019 & 0.065 \\
\hline Mn & 0.006 & 0.009 & 0.003 & 0.007 & 0.020 & 0.008 & 0.004 & 0.006 & 0.009 & 0.007 & 0.019 & 0.006 & 0.011 & 0.011 & 0.006 & 0.010 & 0.006 & 0.010 & 0.006 & 0.010 \\
\hline $\mathbf{M g}$ & 0.848 & 0.844 & 0.920 & 0.863 & 0.828 & 0.677 & 0.912 & 0.839 & 0.870 & 0.867 & 0.811 & 0.867 & 0.731 & 0.730 & 0.861 & 0.836 & 0.863 & 0.684 & 0.879 & 0.659 \\
\hline $\mathrm{Ca}$ & 0.850 & 0.739 & 0.886 & 0.847 & 0.795 & 0.801 & 0.886 & 0.813 & 0.798 & 0.844 & 0.809 & 0.793 & 0.745 & 0.744 & 0.838 & 0.755 & 0.872 & 0.759 & 0.862 & 0.812 \\
\hline $\mathrm{Na}$ & 0.009 & 0.010 & 0.006 & 0.013 & 0.015 & 0.013 & 0.008 & 0.012 & 0.012 & 0.011 & 0.016 & 0.012 & 0.016 & 0.014 & 0.010 & 0.008 & 0.010 & 0.015 & 0.011 & 0.016 \\
\hline Total & 4.02 & 4.03 & 4.02 & 4.03 & 4.02 & 4.03 & 4.03 & 4.03 & 4.04 & 4.04 & 4.02 & 4.03 & 4.04 & 4.03 & 4.02 & 4.03 & 4.05 & 4.06 & 4.05 & 4.06 \\
\hline \multicolumn{21}{|l|}{ Atomic \% } \\
\hline Wo & 43.4 & 38.3 & 45.1 & 43.0 & 40.1 & 42.8 & 45.2 & 41.8 & 40.7 & 42.6 & 41.1 & 40.6 & 38.9 & 38.7 & 42.7 & 38.4 & 43.6 & 39.7 & 42.9 & 42.4 \\
\hline En & 43.3 & 43.7 & 46.9 & 43.8 & 41.8 & 36.2 & 46.5 & 43.2 & 44.3 & 43.8 & 41.2 & 44.3 & 38.2 & 38.0 & 43.9 & 42.6 & 43.1 & 35.8 & 43.7 & 34.4 \\
\hline Fs & 13.2 & 18.0 & 8.0 & 13.2 & 18.1 & 21.0 & 8.3 & 15.0 & 15.0 & 13.6 & 17.7 & 15.1 & 22.9 & 23.3 & 13.4 & 19.0 & 13.3 & 24.5 & 13.4 & 23.2 \\
\hline Mg \# & 76.2 & 70.3 & 85.2 & 76.4 & 68.6 & 62.7 & 84.5 & 73.9 & 74.2 & 75.8 & 68.8 & 74.2 & 62.0 & 61.5 & 76.2 & 68.6 & 76.0 & 58.9 & 76.2 & 59.2 \\
\hline
\end{tabular}


Table F.1 Continued

\begin{tabular}{|c|c|c|c|c|c|c|c|c|c|c|c|c|c|c|c|c|c|c|c|}
\hline Sample & & & & & & & & & & & & & & & & RIR_BW_02 & & & \\
\hline Location & & & & & & & & & & & & & & & & Matatirohia & & & \\
\hline Volcano & & & & & & & & & & & & & & & & Raoul & & & \\
\hline Type & & & & & & & & & & & & & & & & Single crystal & & & \\
\hline Crystal no. & 5 & 5 & 6 & 6 & 6 & 7 & 7 & 8 & 8 & 8 & 9 & 10 & 12 & 12 & 12 & 1 & 2 & 4 & 6 \\
\hline Analysis site & core & rim & core & $\mathrm{d}$ band & rim & core & rim & core & $\mathrm{d}$ band & rim & NVZ & NVZ & core & OG & rim & NVZ & NVZ & NVZ & NVZ \\
\hline \multicolumn{20}{|l|}{ Oxides (wt \%) } \\
\hline $\mathrm{SiO}_{2}$ & 50.29 & 44.26 & 51.30 & 51.73 & 45.82 & 52.37 & 45.04 & 50.82 & 50.09 & 44.37 & 51.49 & 51.87 & 49.85 & 51.54 & 44.32 & 51.13 & 51.93 & 52.41 & 52.84 \\
\hline $\mathrm{TiO}_{2}$ & 0.29 & 1.05 & 0.31 & 0.23 & 1.08 & 0.20 & 1.14 & 0.31 & 0.33 & 0.94 & 0.29 & 0.28 & 0.38 & 0.18 & 1.02 & 0.21 & 0.27 & 0.18 & 0.13 \\
\hline $\mathrm{Al}_{2} \mathrm{O}_{3}$ & 3.68 & 9.38 & 3.54 & 3.38 & 8.52 & 2.09 & 9.80 & 2.58 & 4.12 & 10.02 & 3.64 & 3.47 & 4.29 & 3.63 & 9.77 & 3.09 & 3.42 & 3.05 & 2.22 \\
\hline $\mathrm{Cr}_{2} \mathrm{O}_{3}$ & 0.03 & 0.03 & 0.04 & 0.00 & 0.02 & 0.00 & 0.00 & 0.00 & 0.03 & 0.02 & 0.03 & 0.03 & 0.04 & 0.08 & 0.01 & 0.05 & 0.09 & 0.05 & 0.04 \\
\hline $\mathrm{FeO}(\mathrm{T})$ & 8.69 & 14.49 & 8.51 & 7.59 & 14.14 & 10.75 & 13.83 & 10.26 & 8.03 & 13.79 & 8.64 & 8.56 & 9.69 & 5.78 & 14.12 & 7.28 & 7.62 & 6.46 & 6.25 \\
\hline MnO & 0.20 & 0.27 & 0.19 & 0.16 & 0.26 & 0.32 & 0.25 & 0.39 & 0.16 & 0.27 & 0.23 & 0.19 & 0.21 & 0.14 & 0.25 & 0.19 & 0.16 & 0.15 & 0.17 \\
\hline MgO & 15.57 & 11.01 & 15.61 & 16.06 & 11.45 & 16.77 & 11.25 & 15.93 & 15.81 & 11.45 & 15.50 & 15.69 & 15.08 & 16.80 & 10.81 & 16.00 & 16.27 & 16.74 & 17.61 \\
\hline $\mathrm{CaO}$ & 21.57 & 19.59 & 21.64 & 21.72 & 19.35 & 17.05 & 19.65 & 19.80 & 21.79 & 19.26 & 21.61 & 21.31 & 21.01 & 22.52 & 20.19 & 21.35 & 21.44 & 22.29 & 21.76 \\
\hline $\mathrm{Na}_{2} \mathrm{O}$ & 0.13 & 0.21 & 0.15 & 0.14 & 0.20 & 0.11 & 0.20 & 0.20 & 0.13 & 0.18 & 0.14 & 0.14 & 0.15 & 0.10 & 0.19 & 0.17 & 0.12 & 0.11 & 0.08 \\
\hline Total & 100.44 & 100.28 & 101.28 & 101.01 & 100.84 & 99.67 & 101.15 & 100.29 & 100.47 & 100.30 & 101.57 & 101.53 & 100.69 & 100.77 & 100.68 & 99.46 & 101.31 & 101.44 & 101.10 \\
\hline \multicolumn{20}{|l|}{ Cations } \\
\hline $\mathbf{S i}$ & 1.87 & 1.70 & 1.89 & 1.90 & 1.74 & 1.95 & 1.70 & 1.90 & 1.86 & 1.69 & 1.89 & 1.90 & 1.85 & 1.89 & 1.69 & 1.90 & 1.90 & 1.91 & 1.92 \\
\hline $\mathrm{Ti}$ & 0.004 & 0.013 & 0.004 & 0.003 & 0.013 & 0.002 & 0.014 & 0.004 & 0.004 & 0.012 & 0.004 & 0.003 & 0.005 & 0.002 & 0.013 & 0.003 & 0.003 & 0.002 & 0.002 \\
\hline Al & 0.161 & 0.424 & 0.154 & 0.146 & 0.381 & 0.092 & 0.437 & 0.114 & 0.180 & 0.450 & 0.157 & 0.150 & 0.188 & 0.157 & 0.439 & 0.135 & 0.147 & 0.131 & 0.095 \\
\hline $\mathrm{Cr}$ & 0.001 & 0.001 & 0.001 & 0.000 & 0.000 & 0.000 & 0.000 & 0.000 & 0.001 & 0.001 & 0.001 & 0.001 & 0.001 & 0.002 & 0.000 & 0.002 & 0.002 & 0.001 & 0.001 \\
\hline Fe total & 0.268 & 0.459 & 0.259 & 0.231 & 0.443 & 0.333 & 0.431 & 0.318 & 0.246 & 0.435 & 0.263 & 0.260 & 0.299 & 0.175 & 0.445 & 0.225 & 0.230 & 0.195 & 0.189 \\
\hline $\mathrm{Fe}^{2+}$ & 0.250 & 0.390 & 0.240 & 0.217 & 0.374 & 0.321 & 0.359 & 0.299 & 0.226 & 0.374 & 0.245 & 0.243 & 0.275 & 0.164 & 0.379 & 0.212 & 0.214 & 0.184 & 0.181 \\
\hline $\mathrm{Fe}^{3+}$ & 0.018 & 0.069 & 0.019 & 0.014 & 0.069 & 0.012 & 0.072 & 0.019 & 0.020 & 0.061 & 0.017 & 0.017 & 0.024 & 0.011 & 0.066 & 0.013 & 0.016 & 0.011 & 0.008 \\
\hline Mn & 0.006 & 0.009 & 0.006 & 0.005 & 0.008 & 0.010 & 0.008 & 0.012 & 0.005 & 0.009 & 0.007 & 0.006 & 0.006 & 0.004 & 0.008 & 0.006 & 0.005 & 0.005 & 0.005 \\
\hline Mg & 0.863 & 0.629 & 0.856 & 0.878 & 0.647 & 0.930 & 0.634 & 0.887 & 0.874 & 0.651 & 0.847 & 0.856 & 0.837 & 0.916 & 0.615 & 0.888 & 0.886 & 0.908 & 0.955 \\
\hline $\mathrm{Ca}$ & 0.859 & 0.805 & 0.852 & 0.854 & 0.786 & 0.679 & 0.796 & 0.792 & 0.866 & 0.787 & 0.849 & 0.836 & 0.838 & 0.883 & 0.825 & 0.851 & 0.840 & 0.869 & 0.849 \\
\hline $\mathrm{Na}$ & 0.009 & 0.015 & 0.011 & 0.010 & 0.015 & 0.008 & 0.015 & 0.014 & 0.009 & 0.014 & 0.010 & 0.010 & 0.011 & 0.007 & 0.014 & 0.013 & 0.008 & 0.007 & 0.006 \\
\hline Total & 4.04 & 4.05 & 4.03 & 4.02 & 4.03 & 4.00 & 4.04 & 4.04 & 4.04 & 4.05 & 4.03 & 4.02 & 4.04 & 4.03 & 4.05 & 4.03 & 4.02 & 4.02 & 4.03 \\
\hline \multicolumn{20}{|l|}{ Atomic \% } \\
\hline Wo & 43.2 & 42.5 & 43.3 & 43.5 & 41.9 & 35.0 & 42.8 & 39.7 & 43.6 & 42.0 & 43.3 & 42.8 & 42.5 & 44.7 & 43.8 & 43.4 & 42.9 & 44.1 & 42.6 \\
\hline En & 43.4 & 33.2 & 43.5 & 44.8 & 34.5 & 47.9 & 34.1 & 44.4 & 44.0 & 34.8 & 43.2 & 43.9 & 42.4 & 46.4 & 32.6 & 45.2 & 45.3 & 46.1 & 47.9 \\
\hline Fs & 13.5 & 24.3 & 13.2 & 11.8 & 23.6 & 17.1 & 23.2 & 15.9 & 12.4 & 23.2 & 13.4 & 13.3 & 15.1 & 8.8 & 23.6 & 11.4 & 11.8 & 9.9 & 9.5 \\
\hline Mg \# & 75.9 & 57.4 & 76.4 & 78.9 & 58.9 & 73.0 & 59.1 & 72.8 & 77.7 & 59.5 & 75.8 & 76.3 & 73.3 & 83.7 & 57.6 & 79.4 & 79.0 & 82.0 & 83.1 \\
\hline
\end{tabular}


Table F.1 Continued

\begin{tabular}{|c|c|c|c|c|c|c|c|c|c|c|c|c|c|c|c|c|c|c|c|}
\hline Sample & & & & & & & & & & & & & & & & & RI12_PC08 & & \\
\hline Location & & & & & & & & & & & & & & & & & Oneraki & & \\
\hline Volcano & & & & & & & & & & & & & & & & & Raoul & & \\
\hline Type & & & & & & & & & & & & & & & & & Single crystal & & \\
\hline Crystal no. & 7 & 8 & 9 & 10 & 11 & 11 & 11 & 12 & 12 & 12 & 13 & 13 & 14 & 15 & 16 & 16 & 1 & 1 & 2 \\
\hline Analysis site & NVZ & NVZ & NVZ & NVZ & core & $\operatorname{rim} 1$ & $\operatorname{rim} 2$ & core & $\operatorname{rim} 1$ & rim2 & core & rim & NVZ & NVZ & core & rim & NVZ & NVZ & NVZ \\
\hline \multicolumn{20}{|l|}{ Oxides (wt \%) } \\
\hline $\mathrm{SiO}_{2}$ & 51.59 & 51.85 & 52.25 & 51.73 & 52.24 & 49.08 & 46.35 & 51.99 & 47.53 & 46.46 & 51.81 & 46.85 & 53.16 & 52.17 & 52.37 & 48.64 & 52.17 & 51.56 & 52.48 \\
\hline $\mathrm{TiO}_{2}$ & 0.19 & 0.25 & 0.20 & 0.25 & 0.19 & 0.44 & 0.86 & 0.21 & 0.72 & 0.77 & 0.21 & 0.77 & 0.15 & 0.21 & 0.20 & 0.57 & 0.33 & 0.44 & 0.30 \\
\hline $\mathrm{Al}_{2} \mathrm{O}_{3}$ & 2.99 & 3.62 & 3.03 & 3.51 & 3.08 & 6.82 & 8.70 & 3.23 & 8.28 & 9.18 & 3.30 & 8.46 & 2.07 & 3.26 & 3.18 & 7.37 & 1.75 & 2.58 & 1.61 \\
\hline $\mathrm{Cr}_{2} \mathrm{O}_{3}$ & 0.07 & 0.11 & 0.05 & 0.09 & 0.09 & 0.00 & 0.00 & 0.01 & 0.03 & 0.04 & 0.06 & 0.04 & 0.03 & 0.04 & 0.06 & 0.05 & 0.06 & 0.03 & 0.03 \\
\hline $\mathrm{FeO}(\mathrm{T})$ & 6.20 & 7.89 & 7.07 & 7.10 & 6.70 & 8.14 & 11.42 & 6.67 & 9.39 & 11.06 & 6.77 & 10.01 & 7.41 & 6.82 & 6.71 & 9.58 & 10.84 & 11.40 & 10.31 \\
\hline MnO & 0.16 & 0.20 & 0.16 & 0.17 & 0.13 & 0.17 & 0.23 & 0.15 & 0.17 & 0.21 & 0.16 & 0.15 & 0.22 & 0.16 & 0.16 & 0.18 & 0.57 & 0.60 & 0.55 \\
\hline MgO & 16.70 & 16.45 & 16.66 & 16.20 & 16.55 & 14.39 & 12.71 & 16.47 & 13.33 & 12.80 & 16.47 & 13.05 & 17.19 & 16.43 & 16.41 & 14.50 & 14.70 & 14.05 & 14.83 \\
\hline $\mathrm{CaO}$ & 22.28 & 20.90 & 21.77 & 21.69 & 22.20 & 21.97 & 20.51 & 21.98 & 21.42 & 20.42 & 21.95 & 21.36 & 20.78 & 21.97 & 21.94 & 20.21 & 20.44 & 20.34 & 20.75 \\
\hline $\mathrm{Na}_{2} \mathrm{O}$ & 0.10 & 0.13 & 0.11 & 0.10 & 0.11 & 0.13 & 0.15 & 0.12 & 0.13 & 0.17 & 0.15 & 0.13 & 0.09 & 0.12 & 0.11 & 0.13 & 0.22 & 0.24 & 0.23 \\
\hline Total & 100.28 & 101.39 & 101.31 & 100.82 & 101.27 & 101.13 & 100.93 & 100.84 & 101.01 & 101.11 & 100.88 & 100.82 & 101.08 & 101.18 & 101.14 & 101.24 & 101.08 & 101.24 & 101.08 \\
\hline \multicolumn{20}{|l|}{ Cations } \\
\hline $\mathbf{S i}$ & 1.90 & 1.89 & 1.91 & 1.90 & 1.91 & 1.81 & 1.74 & 1.90 & 1.76 & 1.73 & 1.90 & 1.75 & 1.94 & 1.90 & 1.91 & 1.79 & 1.94 & 1.92 & 1.95 \\
\hline $\mathrm{Ti}$ & 0.002 & 0.003 & 0.002 & 0.003 & 0.002 & 0.006 & 0.011 & 0.003 & 0.009 & 0.010 & 0.003 & 0.010 & 0.002 & 0.003 & 0.003 & 0.007 & 0.004 & 0.006 & 0.004 \\
\hline Al & 0.130 & 0.156 & 0.130 & 0.151 & 0.132 & 0.296 & 0.384 & 0.139 & 0.362 & 0.404 & 0.143 & 0.372 & 0.089 & 0.140 & 0.137 & 0.320 & 0.077 & 0.113 & 0.070 \\
\hline $\mathrm{Cr}$ & 0.002 & 0.003 & 0.002 & 0.003 & 0.003 & 0.000 & 0.000 & 0.000 & 0.001 & 0.001 & 0.002 & 0.001 & 0.001 & 0.001 & 0.002 & 0.002 & 0.002 & 0.001 & 0.001 \\
\hline $\mathrm{Fe}$ total & 0.189 & 0.239 & 0.214 & 0.215 & 0.202 & 0.247 & 0.353 & 0.202 & 0.286 & 0.340 & 0.205 & 0.307 & 0.225 & 0.206 & 0.203 & 0.291 & 0.335 & 0.352 & 0.318 \\
\hline $\mathrm{Fe}^{2+}$ & 0.177 & 0.224 & 0.202 & 0.201 & 0.191 & 0.220 & 0.299 & 0.190 & 0.242 & 0.292 & 0.193 & 0.260 & 0.216 & 0.194 & 0.191 & 0.257 & 0.314 & 0.325 & 0.299 \\
\hline $\mathrm{Fe}^{3+}$ & 0.012 & 0.015 & 0.012 & 0.015 & 0.011 & 0.027 & 0.054 & 0.012 & 0.044 & 0.048 & 0.013 & 0.048 & 0.009 & 0.012 & 0.012 & 0.035 & 0.020 & 0.027 & 0.018 \\
\hline Mn & 0.005 & 0.006 & 0.005 & 0.005 & 0.004 & 0.005 & 0.007 & 0.004 & 0.005 & 0.007 & 0.005 & 0.005 & 0.007 & 0.005 & 0.005 & 0.006 & 0.018 & 0.019 & 0.017 \\
\hline $\mathbf{M g}$ & 0.917 & 0.895 & 0.906 & 0.885 & 0.900 & 0.791 & 0.710 & 0.899 & 0.738 & 0.712 & 0.899 & 0.726 & 0.934 & 0.894 & 0.892 & 0.797 & 0.814 & 0.779 & 0.819 \\
\hline $\mathrm{Ca}$ & 0.879 & 0.817 & 0.851 & 0.852 & 0.867 & 0.867 & 0.824 & 0.862 & 0.852 & 0.816 & 0.861 & 0.855 & 0.812 & 0.859 & 0.857 & 0.799 & 0.814 & 0.810 & 0.824 \\
\hline $\mathrm{Na}$ & 0.007 & 0.009 & 0.008 & 0.007 & 0.007 & 0.009 & 0.011 & 0.009 & 0.009 & 0.012 & 0.011 & 0.010 & 0.006 & 0.008 & 0.008 & 0.009 & 0.016 & 0.017 & 0.017 \\
\hline Total & 4.03 & 4.02 & 4.02 & 4.02 & 4.02 & 4.03 & 4.04 & 4.02 & 4.03 & 4.04 & 4.03 & 4.04 & 4.01 & 4.02 & 4.02 & 4.03 & 4.02 & 4.01 & 4.01 \\
\hline \multicolumn{20}{|l|}{ Atomic \% } \\
\hline Wo & 44.3 & 41.9 & 43.2 & 43.6 & 44.0 & 45.5 & 43.7 & 43.9 & 45.4 & 43.7 & 43.8 & 45.3 & 41.2 & 43.8 & 43.9 & 42.3 & 41.5 & 41.7 & 42.0 \\
\hline En & 46.2 & 45.9 & 46.0 & 45.3 & 45.7 & 41.5 & 37.6 & 45.8 & 39.3 & 38.1 & 45.7 & 38.5 & 47.4 & 45.6 & 45.7 & 42.2 & 41.5 & 40.1 & 41.8 \\
\hline Fs & 9.5 & 12.2 & 10.9 & 11.0 & 10.3 & 13.0 & 18.7 & 10.3 & 15.3 & 18.2 & 10.4 & 16.3 & 11.4 & 10.5 & 10.4 & 15.4 & 17.1 & 18.1 & 16.2 \\
\hline Mg \# & 82.5 & 78.5 & 80.5 & 80.0 & 81.3 & 75.8 & 66.4 & 81.3 & 71.7 & 67.2 & 81.0 & 69.9 & 80.1 & 80.9 & 81.1 & 72.9 & 69.8 & 67.7 & 71.0 \\
\hline
\end{tabular}


Table F.1 Continued

\begin{tabular}{|c|c|c|c|c|c|c|c|c|c|c|c|c|c|c|c|c|c|c|c|c|}
\hline \multicolumn{21}{|l|}{ Sample } \\
\hline \multicolumn{21}{|l|}{ Location } \\
\hline \multicolumn{21}{|l|}{ Volcano } \\
\hline \multicolumn{21}{|l|}{ Type } \\
\hline Crystal no. & 3 & 3 & 3 & 3 & 4 & 4 & 4 & 4 & 5 & 6 & 7 & 8 & 9 & 10 & 12 & 12 & 12 & 13 & 13 & \\
\hline Analysis site & core & $\mathrm{d}$ band & $\operatorname{rim} 1$ & rim2 & core & $\mathrm{d}$ band & $\operatorname{rim} 1$ & rim2 & $N V Z$ & NVZ & NVZ & NVZ & NVZ & NVZ & core & $\mathrm{d}$ band & rim & core & $\mathrm{d}$ band & rim \\
\hline \multicolumn{21}{|l|}{ Oxides (wt \%) } \\
\hline $\mathrm{SiO}_{2}$ & 53.45 & 53.73 & 52.44 & 52.38 & 53.25 & 53.34 & 52.46 & 52.48 & 52.71 & 51.25 & 51.80 & 51.54 & 52.38 & 52.04 & 53.57 & 53.70 & 52.39 & 53.75 & 53.64 & 52.68 \\
\hline $\mathrm{TiO}_{2}$ & 0.32 & 0.31 & 0.33 & 0.33 & 0.25 & 0.33 & 0.34 & 0.32 & 0.36 & 0.50 & 0.29 & 0.38 & 0.18 & 0.45 & 0.28 & 0.28 & 0.32 & 0.25 & 0.29 & 0.33 \\
\hline $\mathrm{Al}_{2} \mathrm{O}_{3}$ & 1.50 & 1.27 & 1.87 & 1.86 & 1.20 & 1.48 & 1.85 & 1.78 & 1.60 & 3.28 & 3.04 & 2.43 & 3.79 & 2.46 & 1.30 & 1.35 & 1.82 & 1.10 & 1.30 & 1.70 \\
\hline $\mathrm{Cr}_{2} \mathrm{O}_{3}$ & 0.07 & 0.07 & 0.05 & 0.07 & 0.04 & 0.06 & 0.08 & 0.03 & 0.06 & 0.07 & 0.05 & 0.05 & 0.19 & 0.04 & 0.05 & 0.05 & 0.05 & 0.07 & 0.06 & 0.03 \\
\hline $\mathrm{FeO}(\mathrm{T})$ & 7.66 & 6.51 & 10.39 & 10.20 & 8.43 & 7.13 & 10.39 & 10.31 & 9.28 & 10.51 & 9.28 & 10.86 & 5.16 & 10.93 & 7.76 & 6.55 & 10.36 & 7.65 & 6.55 & 10.20 \\
\hline $\mathrm{MnO}$ & 0.47 & 0.46 & 0.58 & 0.53 & 0.55 & 0.48 & 0.55 & 0.59 & 0.29 & 0.33 & 0.21 & 0.52 & 0.13 & 0.53 & 0.51 & 0.49 & 0.53 & 0.51 & 0.42 & 0.54 \\
\hline MgO & 15.80 & 16.70 & 14.69 & 14.86 & 15.73 & 16.62 & 14.92 & 14.86 & $\quad 15.59$ & 14.26 & 15.86 & 14.43 & 16.52 & 14.20 & 16.23 & 16.66 & 14.90 & 16.36 & 16.75 & 14.86 \\
\hline $\mathrm{CaO}$ & 21.77 & 21.87 & 20.79 & 20.84 & 21.23 & 21.58 & 20.41 & 20.42 & 20.69 & 20.92 & 20.54 & 20.52 & 23.14 & 20.79 & 21.53 & 22.15 & 20.92 & 21.64 & 22.03 & 20.77 \\
\hline $\mathrm{Na}_{2} \mathrm{O}$ & 0.22 & 0.24 & 0.23 & 0.23 & 0.20 & 0.22 & 0.25 & 0.24 & 0.24 & 0.24 & 0.18 & 0.24 & 0.07 & 0.24 & 0.22 & 0.21 & 0.23 & 0.21 & 0.21 & 0.23 \\
\hline Total & 101.26 & 101.16 & 101.37 & 101.30 & 100.88 & 101.25 & 101.26 & 101.03 & 100.83 & 101.35 & 101.25 & 100.99 & 101.58 & 101.68 & 101.45 & 101.41 & 101.52 & 101.54 & 101.22 & 101.33 \\
\hline \multicolumn{21}{|l|}{ Cations } \\
\hline $\mathbf{S i}$ & 1.96 & 1.96 & 1.94 & 1.94 & 1.96 & 1.95 & 1.94 & 1.94 & 1.95 & 1.90 & 1.90 & 1.92 & 1.90 & 1.92 & 1.96 & 1.95 & 1.93 & 1.96 & 1.96 & 1.95 \\
\hline $\mathrm{Ti}$ & 0.004 & 0.004 & 0.004 & 0.004 & 0.003 & 0.004 & 0.004 & 0.004 & 0.005 & 0.006 & 0.004 & 0.005 & 0.002 & 0.006 & 0.003 & 0.004 & 0.004 & 0.003 & 0.004 & 0.004 \\
\hline Al & 0.065 & 0.055 & 0.081 & 0.081 & 0.052 & 0.064 & 0.081 & 0.078 & 0.070 & 0.143 & 0.132 & 0.107 & 0.162 & 0.107 & 0.056 & 0.058 & 0.079 & 0.047 & 0.056 & 0.074 \\
\hline $\mathrm{Cr}$ & 0.002 & 0.002 & 0.001 & 0.002 & 0.001 & 0.002 & 0.002 & 0.001 & 0.002 & 0.002 & 0.001 & 0.002 & 0.006 & 0.001 & 0.001 & 0.001 & 0.001 & 0.002 & 0.002 & 0.001 \\
\hline Fe tota & 0.232 & 0.195 & 0.319 & 0.313 & 0.258 & 0.215 & 0.319 & 0.317 & 0.284 & 0.322 & 0.283 & 0.336 & 0.154 & 0.335 & 0.235 & 0.197 & 0.318 & 0.231 & 0.197 & 0.313 \\
\hline $\mathrm{Fe}^{2+}$ & 0.212 & 0.177 & 0.299 & 0.293 & 0.242 & 0.195 & 0.298 & 0.298 & $\quad 0.262$ & 0.292 & 0.266 & 0.312 & 0.143 & 0.308 & 0.218 & 0.180 & 0.299 & 0.216 & 0.179 & 0.293 \\
\hline $\mathrm{Fe}^{3+}$ & 0.019 & 0.018 & 0.020 & 0.020 & 0.015 & 0.020 & 0.021 & 0.020 & 0.022 & 0.030 & 0.017 & 0.024 & 0.011 & 0.028 & 0.017 & 0.017 & 0.019 & 0.015 & 0.017 & 0.020 \\
\hline Mn & 0.014 & 0.014 & 0.018 & 0.017 & 0.017 & 0.015 & 0.017 & 0.018 & 0.009 & 0.010 & 0.007 & 0.016 & 0.004 & 0.017 & 0.016 & 0.015 & 0.017 & 0.016 & 0.013 & 0.017 \\
\hline Mg & 0.862 & 0.907 & 0.810 & 0.819 & 0.864 & 0.905 & 0.822 & 0.821 & 0.859 & 0.787 & 0.870 & 0.801 & 0.891 & 0.782 & 0.884 & 0.904 & 0.820 & 0.890 & 0.910 & 0.818 \\
\hline $\mathrm{Ca}$ & 0.854 & 0.854 & 0.824 & 0.826 & 0.838 & 0.845 & 0.808 & 0.810 & 0.819 & 0.830 & 0.809 & 0.818 & 0.897 & 0.823 & 0.843 & 0.864 & 0.828 & 0.846 & 0.860 & 0.822 \\
\hline $\mathrm{Na}$ & 0.015 & 0.017 & 0.016 & 0.016 & 0.014 & 0.016 & 0.018 & 0.017 & 0.017 & 0.017 & 0.013 & 0.018 & 0.005 & 0.017 & 0.015 & 0.015 & 0.016 & 0.015 & 0.014 & 0.016 \\
\hline Total & 4.00 & 4.01 & 4.01 & 4.02 & 4.01 & 4.01 & 4.01 & 4.01 & 4.01 & 4.02 & 4.02 & 4.02 & 4.02 & 4.01 & 4.01 & 4.01 & 4.02 & 4.01 & 4.01 & 4.01 \\
\hline \multicolumn{21}{|l|}{ Atomic \% } \\
\hline Wo & 43.8 & 43.7 & 42.2 & 42.2 & 42.8 & 43.0 & 41.5 & 41.6 & 41.7 & 42.8 & 41.2 & 41.9 & 46.2 & 42.4 & 43.0 & 44.0 & 42.1 & 43.0 & 43.7 & 42.1 \\
\hline En & 44.3 & 46.4 & 41.5 & 41.8 & 44.1 & 46.1 & 42.2 & 42.1 & 43.8 & 40.6 & 44.3 & 41.0 & 45.9 & 40.3 & 45.1 & 46.0 & 41.7 & 45.2 & 46.3 & 41.9 \\
\hline Fs & 11.9 & 10.0 & 16.3 & 16.0 & 13.2 & 10.9 & 16.4 & 16.3 & 14.5 & 16.6 & 14.4 & 17.2 & 7.9 & 17.3 & 12.0 & 10.0 & 16.2 & 11.7 & 10.0 & 16.0 \\
\hline Mg \# & 77.8 & 81.2 & 70.6 & 71.3 & 75.9 & 79.8 & 71.0 & 71.0 & 74.5 & 70.3 & 75.0 & 69.5 & 85.0 & 69.0 & 77.9 & 81.0 & 71.0 & 78.3 & 81.3 & 71.3 \\
\hline
\end{tabular}


Table F.1 Continued

\begin{tabular}{|c|c|c|c|c|c|c|c|c|c|c|c|c|c|c|c|c|c|c|c|c|}
\hline \multicolumn{21}{|l|}{ Sample } \\
\hline \multicolumn{21}{|l|}{ Location } \\
\hline \multicolumn{21}{|l|}{ Volcano } \\
\hline \multicolumn{21}{|l|}{ Type } \\
\hline Crystal no. & 14 & 15 & 16 & 17 & 18 & 20 & 21 & 22 & 23 & 24 & 25 & 26 & 27 & 28 & 29 & 30 & 31 & 31 & 31 & 32 \\
\hline Analysis site & NVZ & NVZ & NVZ & NVZ & NVZ & NVZ & NVZ & NVZ & NVZ & NVZ & NVZ & NVZ & NVZ & NVZ & $N V Z$ & NVZ & core & $\operatorname{rim} 1$ & rim2 & $\mathrm{NVZ}$ \\
\hline \multicolumn{21}{|l|}{ Oxides (wt \%) } \\
\hline $\mathrm{SiO}_{2}$ & 51.49 & 52.54 & 52.84 & 52.29 & 52.35 & 52.68 & 50.78 & 52.44 & 52.07 & 52.67 & 52.49 & 52.51 & 52.65 & 52.97 & 52.62 & 52.65 & 52.87 & 51.25 & 51.72 & 52.91 \\
\hline $\mathrm{TiO}_{2}$ & 0.51 & 0.34 & 0.30 & 0.27 & 0.36 & 0.31 & 0.57 & 0.23 & 0.40 & 0.31 & 0.33 & 0.29 & 0.29 & 0.29 & 0.32 & 0.27 & 0.19 & 0.44 & 0.39 & 0.27 \\
\hline $\mathrm{Al}_{2} \mathrm{O}_{3}$ & 2.99 & 1.82 & 1.53 & 1.50 & 1.95 & 1.63 & 3.89 & 1.25 & 2.27 & 1.70 & 1.62 & 1.63 & 1.51 & 1.46 & 1.57 & 1.42 & 1.38 & 2.98 & 2.54 & 1.47 \\
\hline $\mathrm{Cr}_{2} \mathrm{O}_{3}$ & 0.04 & 0.04 & 0.06 & 0.06 & 0.06 & 0.02 & 0.08 & 0.04 & 0.05 & 0.05 & 0.04 & 0.02 & 0.06 & 0.07 & 0.06 & 0.00 & 0.07 & 0.01 & 0.07 & 0.02 \\
\hline $\mathrm{FeO}(\mathrm{T})$ & 10.68 & 10.69 & 10.46 & 10.31 & 10.95 & 10.23 & 11.38 & 9.37 & 12.59 & 10.54 & 10.46 & 10.55 & 10.83 & 10.47 & 10.49 & 10.52 & 9.43 & 11.58 & 10.79 & 10.15 \\
\hline MnO & 0.48 & 0.52 & 0.55 & 0.57 & 0.70 & 0.55 & 0.42 & 0.46 & 0.72 & 0.55 & 0.53 & 0.58 & 0.60 & 0.60 & 0.57 & 0.55 & 0.38 & 0.54 & 0.47 & 0.58 \\
\hline MgO & 14.23 & 14.84 & 14.99 & 14.81 & 14.80 & 14.96 & 14.13 & 15.00 & 14.98 & 14.80 & 15.03 & 15.20 & 14.83 & 15.06 & 14.80 & 14.96 & 15.25 & 14.60 & 14.75 & 14.95 \\
\hline $\mathrm{CaO}$ & 21.07 & 20.66 & 20.76 & 20.90 & 20.32 & 20.93 & 20.29 & 21.46 & 18.41 & 21.01 & 20.95 & 20.74 & 20.25 & 20.68 & 20.67 & 20.95 & 21.56 & 19.80 & 20.59 & 20.78 \\
\hline $\mathrm{Na}_{2} \mathrm{O}$ & 0.25 & 0.24 & 0.21 & 0.22 & 0.23 & 0.24 & 0.23 & 0.23 & 0.21 & 0.24 & 0.23 & 0.22 & 0.21 & 0.21 & 0.24 & 0.22 & 0.26 & 0.23 & 0.21 & 0.23 \\
\hline Total & 101.73 & 101.69 & 101.70 & 100.92 & 101.71 & 101.56 & 101.75 & 100.46 & 101.70 & 101.86 & 101.67 & 101.73 & 101.22 & 101.81 & 101.33 & 101.54 & 101.38 & 101.42 & 101.52 & 101.34 \\
\hline \multicolumn{21}{|l|}{ Cations } \\
\hline Si & 1.90 & 1.94 & 1.95 & 1.94 & 1.93 & 1.94 & 1.88 & 1.95 & 1.93 & 1.94 & 1.94 & 1.94 & 1.95 & 1.95 & 1.95 & 1.95 & 1.95 & 1.90 & 1.91 & 1.95 \\
\hline $\mathrm{Ti}$ & 0.006 & 0.004 & 0.004 & 0.003 & 0.005 & 0.004 & 0.007 & 0.003 & 0.005 & 0.004 & 0.004 & 0.004 & 0.004 & 0.004 & 0.004 & 0.003 & 0.002 & 0.006 & 0.005 & 0.003 \\
\hline Al & 0.130 & 0.079 & 0.066 & 0.066 & 0.085 & 0.071 & 0.170 & 0.055 & 0.099 & 0.074 & 0.070 & 0.071 & 0.066 & 0.063 & 0.068 & 0.062 & 0.060 & 0.130 & 0.111 & 0.064 \\
\hline $\mathrm{Cr}$ & 0.001 & 0.001 & 0.002 & 0.002 & 0.002 & 0.001 & 0.002 & 0.001 & 0.002 & 0.002 & 0.001 & 0.001 & 0.002 & 0.002 & 0.002 & 0.000 & 0.002 & 0.000 & 0.002 & 0.000 \\
\hline $\mathrm{Fe}$ total & 0.327 & 0.328 & 0.320 & 0.319 & 0.336 & 0.314 & 0.349 & 0.290 & 0.388 & 0.323 & 0.321 & 0.323 & 0.334 & 0.320 & 0.322 & 0.323 & 0.289 & 0.357 & 0.331 & 0.311 \\
\hline $\mathrm{Fe}^{2+}$ & 0.295 & 0.307 & 0.302 & 0.302 & 0.314 & 0.295 & 0.314 & 0.276 & 0.363 & 0.304 & 0.301 & 0.306 & 0.316 & 0.303 & 0.303 & 0.307 & 0.278 & 0.329 & 0.307 & 0.295 \\
\hline $\mathrm{Fe}^{3+}$ & 0.031 & 0.021 & 0.018 & 0.017 & 0.022 & 0.019 & 0.035 & 0.014 & 0.024 & 0.019 & 0.020 & 0.018 & 0.018 & 0.017 & 0.020 & 0.016 & 0.012 & 0.027 & 0.024 & 0.016 \\
\hline Mn & 0.015 & 0.016 & 0.017 & 0.018 & 0.022 & 0.017 & 0.013 & 0.014 & 0.023 & 0.017 & 0.017 & 0.018 & 0.019 & 0.019 & 0.018 & 0.017 & 0.012 & 0.017 & 0.015 & 0.018 \\
\hline Mg & 0.784 & 0.816 & 0.823 & 0.820 & 0.815 & 0.823 & 0.779 & 0.832 & 0.826 & 0.813 & 0.827 & 0.836 & 0.819 & 0.826 & 0.816 & 0.824 & 0.838 & 0.808 & 0.813 & 0.823 \\
\hline $\mathrm{Ca}$ & 0.834 & 0.816 & 0.820 & 0.832 & 0.804 & 0.827 & 0.804 & 0.856 & 0.730 & 0.829 & 0.828 & 0.819 & 0.804 & 0.815 & 0.819 & 0.829 & 0.851 & 0.787 & 0.816 & 0.822 \\
\hline $\mathrm{Na}$ & 0.018 & 0.017 & 0.015 & 0.016 & 0.016 & 0.017 & 0.017 & 0.017 & 0.015 & 0.017 & 0.017 & 0.016 & 0.015 & 0.015 & 0.017 & 0.016 & 0.018 & 0.016 & 0.015 & 0.016 \\
\hline Total & 4.02 & 4.02 & 4.01 & 4.02 & 4.02 & 4.02 & 4.02 & 4.02 & 4.01 & 4.02 & 4.02 & 4.02 & 4.01 & 4.01 & 4.01 & 4.02 & 4.02 & 4.02 & 4.02 & 4.01 \\
\hline \multicolumn{21}{|l|}{ Atomic \% } \\
\hline Wo & 42.9 & 41.6 & 41.7 & 42.2 & 41.1 & 42.1 & 41.6 & 43.3 & 37.6 & 42.2 & 41.9 & 41.4 & 41.1 & 41.6 & 41.9 & 42.0 & 43.0 & 40.3 & 41.6 & 42.0 \\
\hline En & 40.3 & 41.6 & 41.9 & 41.6 & 41.7 & 41.9 & 40.3 & 42.1 & 42.5 & 41.4 & 41.8 & 42.2 & 41.9 & 42.1 & 41.7 & 41.7 & 42.3 & 41.4 & 41.5 & 42.1 \\
\hline Fs & 16.8 & 16.7 & 16.3 & 16.2 & 17.2 & 16.0 & 18.0 & 14.7 & 19.9 & 16.4 & 16.2 & 16.3 & 17.1 & 16.3 & 16.5 & 16.4 & 14.6 & 18.3 & 16.9 & 15.9 \\
\hline Mg \# & 69.6 & 70.4 & 70.9 & 70.9 & 69.5 & 71.3 & 68.3 & 73.2 & 66.8 & 70.5 & 71.0 & 71.0 & 69.9 & 70.9 & 70.6 & 70.8 & 73.6 & 68.4 & 70.2 & 71.4 \\
\hline
\end{tabular}


Table F.1 Continued

\begin{tabular}{|c|c|c|c|c|c|c|c|c|c|c|c|c|c|c|c|c|c|c|c|c|}
\hline \multicolumn{21}{|l|}{ Sample } \\
\hline \multicolumn{21}{|l|}{ Location } \\
\hline \multicolumn{21}{|l|}{ Volcano } \\
\hline \multicolumn{21}{|l|}{ Type } \\
\hline Crystal no. & 33 & 34 & 35 & 36 & 37 & 38 & 39 & 40 & 41 & 42 & 43 & 44 & 44 & 44 & 45 & 46 & 47 & 47 & 48 & 49 \\
\hline Analysis site & NVZ & NVZ & NVZ & NVZ & NVZ & $\mathrm{NVZ}$ & NVZ & NVZ & NVZ & NVZ & NVZ & core & $\mathrm{d}$ band & rim & NVZ & NVZ & core & core2 & NVZ & NVZ \\
\hline \multicolumn{21}{|l|}{ Oxides (wt \%) } \\
\hline $\mathrm{SiO}_{2}$ & 52.77 & 52.63 & 52.77 & 51.33 & 51.31 & 52.63 & 51.04 & 52.85 & 52.68 & 52.55 & 52.42 & 52.08 & 51.37 & 51.34 & 52.20 & 51.73 & 52.03 & 52.22 & 51.86 & 52.45 \\
\hline $\mathrm{TiO}_{2}$ & 0.30 & 0.34 & 0.28 & 0.47 & 0.49 & 0.29 & 0.52 & 0.25 & 0.35 & 0.31 & 0.32 & 0.37 & 0.34 & 0.34 & 0.41 & 0.41 & 0.28 & 0.26 & 0.41 & 0.29 \\
\hline $\mathrm{Al}_{2} \mathrm{O}_{3}$ & 1.64 & 1.65 & 1.51 & 2.77 & 2.91 & 1.62 & 3.35 & 1.20 & 1.80 & 2.10 & 1.76 & 2.71 & 4.17 & 3.79 & 2.13 & 2.23 & 2.82 & 2.68 & 2.71 & 1.63 \\
\hline $\mathrm{Cr}_{2} \mathrm{O}_{3}$ & 0.05 & 0.02 & 0.07 & 0.06 & 0.06 & 0.03 & 0.06 & 0.01 & 0.00 & 0.05 & 0.05 & 0.03 & 0.11 & 0.08 & 0.06 & 0.07 & 0.06 & 0.06 & 0.07 & 0.08 \\
\hline $\mathrm{FeO}(\mathrm{T})$ & 10.50 & 10.32 & 10.23 & 10.91 & 10.85 & 10.47 & 11.12 & 10.79 & 10.45 & 10.21 & 11.14 & 9.92 & 8.69 & 8.98 & 11.29 & 10.96 & 9.06 & 9.17 & 10.79 & 10.58 \\
\hline MnO & 0.56 & 0.58 & 0.54 & 0.48 & 0.48 & 0.54 & 0.43 & 0.71 & 0.54 & 0.43 & 0.59 & 0.33 & 0.22 & 0.23 & 0.65 & 0.56 & 0.23 & 0.23 & 0.48 & 0.55 \\
\hline MgO & 14.87 & 14.81 & 14.95 & 14.58 & 14.10 & 14.89 & 13.96 & 15.14 & 14.61 & 15.00 & 14.68 & 15.32 & 15.50 & 15.77 & 14.50 & 14.35 & 16.01 & 15.99 & 14.48 & 14.75 \\
\hline $\mathrm{CaO}$ & 20.80 & 20.87 & 20.93 & 20.38 & 20.63 & 20.81 & 20.74 & 20.07 & 20.73 & 21.02 & 20.26 & 20.60 & 21.01 & 20.52 & 20.06 & 20.82 & 20.56 & 20.55 & 20.41 & 20.81 \\
\hline $\mathrm{Na}_{2} \mathrm{O}$ & 0.25 & 0.20 & 0.22 & 0.24 & 0.24 & 0.21 & 0.25 & 0.24 & 0.22 & 0.23 & 0.25 & 0.21 & 0.18 & 0.16 & 0.25 & 0.24 & 0.16 & 0.18 & 0.24 & 0.20 \\
\hline Total & 101.74 & 101.41 & 101.49 & 101.21 & 101.07 & 101.49 & 101.46 & 101.25 & 101.40 & 101.89 & 101.44 & 101.56 & 101.58 & 101.20 & 101.54 & 101.36 & 101.20 & 101.33 & 101.44 & 101.34 \\
\hline \multicolumn{21}{|l|}{ Cations } \\
\hline $\mathrm{Si}$ & 1.94 & 1.94 & 1.95 & 1.91 & 1.91 & 1.94 & 1.89 & 1.96 & 1.95 & 1.93 & 1.94 & 1.92 & 1.88 & 1.89 & 1.93 & 1.92 & 1.91 & 1.92 & 1.92 & 1.94 \\
\hline $\mathrm{Ti}$ & 0.004 & 0.004 & 0.004 & 0.006 & 0.006 & 0.004 & 0.007 & 0.003 & 0.004 & 0.004 & 0.004 & 0.005 & 0.004 & 0.004 & 0.005 & 0.005 & 0.003 & 0.003 & 0.005 & 0.004 \\
\hline Al & 0.071 & 0.072 & 0.065 & 0.121 & 0.128 & 0.070 & 0.146 & 0.052 & 0.078 & 0.091 & 0.077 & 0.117 & 0.180 & 0.164 & 0.093 & 0.098 & 0.122 & 0.116 & 0.118 & 0.071 \\
\hline $\mathrm{Cr}$ & 0.002 & 0.001 & 0.002 & 0.002 & 0.002 & 0.001 & 0.002 & 0.000 & 0.000 & 0.001 & 0.001 & 0.001 & 0.003 & 0.002 & 0.002 & 0.002 & 0.002 & 0.002 & 0.002 & 0.002 \\
\hline $\mathrm{Fe}$ total & 0.322 & 0.317 & 0.314 & 0.336 & 0.334 & 0.321 & 0.342 & 0.333 & 0.321 & 0.312 & 0.343 & 0.303 & 0.263 & 0.274 & 0.347 & 0.338 & 0.276 & 0.280 & 0.331 & 0.326 \\
\hline $\mathrm{Fe}^{2+}$ & 0.303 & 0.296 & 0.297 & 0.307 & 0.304 & 0.303 & 0.310 & 0.317 & 0.299 & 0.293 & 0.324 & 0.280 & 0.243 & 0.253 & 0.321 & 0.312 & 0.260 & 0.264 & 0.306 & 0.308 \\
\hline $\mathrm{Fe}^{3+}$ & 0.018 & 0.021 & 0.017 & 0.029 & 0.030 & 0.018 & 0.032 & 0.015 & 0.021 & 0.019 & 0.019 & 0.022 & 0.021 & 0.021 & 0.025 & 0.026 & 0.017 & 0.016 & 0.025 & 0.018 \\
\hline Mn & 0.017 & 0.018 & 0.017 & 0.015 & 0.015 & 0.017 & 0.013 & 0.022 & 0.017 & 0.013 & 0.018 & 0.010 & 0.007 & 0.007 & 0.020 & 0.018 & 0.007 & 0.007 & 0.015 & 0.017 \\
\hline Mg & 0.817 & 0.815 & 0.822 & 0.807 & 0.782 & 0.820 & 0.772 & 0.836 & 0.805 & 0.822 & 0.810 & 0.840 & 0.846 & 0.864 & 0.800 & 0.794 & 0.877 & 0.875 & 0.798 & 0.814 \\
\hline $\mathrm{Ca}$ & 0.821 & 0.826 & 0.828 & 0.811 & 0.822 & 0.823 & 0.825 & 0.796 & 0.821 & 0.828 & 0.804 & 0.812 & 0.824 & 0.808 & 0.796 & 0.828 & 0.809 & 0.808 & 0.809 & 0.825 \\
\hline $\mathrm{Na}$ & 0.018 & 0.014 & 0.015 & 0.017 & 0.017 & 0.015 & 0.018 & 0.017 & 0.016 & 0.016 & 0.018 & 0.015 & 0.012 & 0.011 & 0.018 & 0.017 & 0.011 & 0.013 & 0.017 & 0.015 \\
\hline Total & 4.02 & 4.01 & 4.01 & 4.02 & 4.01 & 4.02 & 4.02 & 4.02 & 4.01 & 4.02 & 4.02 & 4.02 & 4.02 & 4.02 & 4.01 & 4.02 & 4.02 & 4.02 & 4.01 & 4.02 \\
\hline \multicolumn{21}{|l|}{ Atomic \% } \\
\hline Wo & 41.9 & 42.2 & 42.1 & 41.5 & 42.4 & 41.9 & 42.5 & 40.5 & 42.2 & 42.2 & 41.1 & 41.5 & 42.6 & 41.5 & 41.0 & 42.3 & 41.2 & 41.2 & 41.7 & 42.0 \\
\hline En & 41.7 & 41.6 & 41.9 & 41.3 & 40.3 & 41.7 & 39.8 & 42.5 & 41.4 & 41.9 & 41.4 & 43.0 & 43.8 & 44.4 & 41.2 & 40.5 & 44.7 & 44.6 & 41.2 & 41.4 \\
\hline Fs & 16.4 & 16.2 & 16.0 & 17.2 & 17.3 & 16.4 & 17.6 & 16.9 & 16.5 & 15.9 & 17.5 & 15.5 & 13.6 & 14.1 & 17.9 & 17.2 & 14.1 & 14.2 & 17.1 & 16.6 \\
\hline Mg \# & 70.7 & 70.9 & 71.3 & 69.7 & 69.1 & 70.8 & 68.5 & 70.2 & 70.5 & 71.7 & 69.2 & 72.9 & 75.8 & 75.5 & 68.5 & 69.1 & 75.6 & 75.3 & 69.8 & 70.4 \\
\hline
\end{tabular}


Table F.1 Continued

\begin{tabular}{|c|c|c|c|c|c|c|c|c|c|c|c|c|c|c|c|c|c|c|c|}
\hline Sample & & & & & & & & & RI12_PC08 & & & & & & & & & & \\
\hline Location & & & & & & & & & Oneraki & & & & & & & & & & \\
\hline Volcano & & & & & & & & & Raoul & & & & & & & & & & \\
\hline Type & & & & & & & & & Clusters-C1 & & & $\mathrm{C} 2$ & $\mathrm{C} 4$ & & & $\mathrm{C} 5$ & & & \\
\hline Crystal no. & 50 & 50 & 51 & 52 & 52 & 52 & 52 & 52 & $a$ & a & a & a & $a$ & a & $\mathrm{b}$ & a & $\mathrm{a}$ & a & . \\
\hline Analysis site & core & rim & NVZ & core & $\mathrm{d}$ band 1 & OG & $\mathrm{d}$ band2 & rim & core & $\operatorname{rim} 1$ & rim2 & NVZ & NVZ & NVZ & NVZ & core 1 & core2 & I band & $\mathrm{d}$ band \\
\hline \multicolumn{20}{|l|}{ Oxides (wt \%) } \\
\hline $\mathrm{SiO}_{2}$ & 52.79 & 53.54 & 53.20 & 52.35 & 53.39 & 53.13 & 53.16 & 52.52 & 50.52 & 47.01 & 47.01 & 52.54 & 51.86 & 52.31 & 52.64 & 50.32 & 53.14 & 50.87 & 51.72 \\
\hline $\mathrm{TiO}_{2}$ & 0.20 & 0.27 & 0.23 & 0.28 & 0.12 & 0.21 & 0.22 & 0.28 & 0.42 & 1.07 & 1.11 & 0.30 & 0.41 & 0.31 & 0.27 & 0.53 & 0.19 & 0.41 & 0.35 \\
\hline $\mathrm{Al}_{2} \mathrm{O}_{3}$ & 3.66 & 1.22 & 1.30 & 2.89 & 2.16 & 2.28 & 2.16 & 2.05 & 2.88 & 6.33 & 6.22 & 1.73 & 2.39 & 1.78 & 1.55 & 5.66 & 2.36 & 4.10 & 3.37 \\
\hline $\mathrm{Cr}_{2} \mathrm{O}_{3}$ & 0.15 & 0.23 & 0.08 & 0.09 & 0.78 & 0.16 & 0.29 & 0.07 & 0.08 & 0.02 & 0.07 & 0.02 & 0.06 & 0.04 & 0.04 & 0.12 & 0.14 & 0.08 & 0.15 \\
\hline $\mathrm{FeO}(\mathrm{T})$ & 5.16 & 9.00 & 9.15 & 8.89 & 4.41 & 8.02 & 7.73 & 11.91 & 10.69 & 14.97 & 14.68 & 10.65 & 10.59 & 10.44 & 11.04 & 8.94 & 7.03 & 9.94 & 8.73 \\
\hline $\mathrm{MnO}$ & 0.13 & 0.62 & 0.55 & 0.19 & 0.12 & 0.20 & 0.18 & 0.31 & 0.43 & 0.44 & 0.44 & 0.55 & 0.48 & 0.57 & 0.68 & 0.22 & 0.17 & 0.23 & 0.20 \\
\hline MgO & 16.64 & 15.21 & 15.27 & 16.34 & 17.91 & 17.23 & 18.06 & 16.56 & 15.21 & 13.34 & 13.20 & 14.91 & 15.03 & 15.17 & 15.71 & 15.58 & 17.44 & 15.11 & 15.84 \\
\hline $\mathrm{CaO}$ & 23.16 & 21.59 & 21.41 & 20.54 & 21.94 & 20.13 & 19.58 & 17.34 & 19.91 & 17.25 & 17.44 & 20.64 & 20.49 & 20.33 & 19.32 & 20.21 & 21.22 & 20.68 & 20.81 \\
\hline $\mathrm{Na}_{2} \mathrm{O}$ & 0.09 & 0.30 & 0.26 & 0.15 & 0.11 & 0.11 & 0.11 & 0.12 & 0.20 & 0.25 & 0.24 & 0.23 & 0.20 & 0.22 & 0.21 & 0.16 & 0.11 & 0.16 & 0.15 \\
\hline Total & 101.99 & 101.98 & 101.46 & 101.72 & 100.93 & 101.46 & 101.48 & 101.16 & 100.34 & 100.67 & 100.40 & 101.57 & 101.49 & 101.15 & 101.46 & 101.73 & 101.80 & 101.59 & 101.33 \\
\hline \multicolumn{20}{|l|}{ Cations } \\
\hline $\mathbf{S i}$ & 1.90 & 1.96 & 1.96 & 1.91 & 1.93 & 1.93 & 1.93 & 1.94 & 1.89 & 1.78 & 1.79 & 1.94 & 1.92 & 1.94 & 1.94 & 1.84 & 1.92 & 1.87 & 1.90 \\
\hline $\mathrm{Ti}$ & 0.002 & 0.003 & 0.003 & 0.003 & 0.002 & 0.003 & 0.003 & 0.004 & 0.005 & 0.013 & 0.014 & 0.004 & 0.005 & 0.004 & 0.003 & 0.007 & 0.002 & 0.005 & 0.004 \\
\hline Al & 0.155 & 0.053 & 0.056 & 0.124 & 0.092 & 0.098 & 0.092 & 0.089 & 0.127 & 0.283 & 0.278 & 0.075 & 0.104 & 0.078 & 0.067 & 0.244 & 0.101 & 0.178 & 0.146 \\
\hline $\mathrm{Cr}$ & 0.004 & 0.007 & 0.002 & 0.003 & 0.022 & 0.005 & 0.008 & 0.002 & 0.002 & 0.000 & 0.002 & 0.000 & 0.002 & 0.001 & 0.001 & 0.003 & 0.004 & 0.002 & 0.004 \\
\hline Fe tota & 0.153 & 0.273 & 0.280 & 0.269 & 0.132 & 0.242 & 0.233 & 0.366 & 0.332 & 0.470 & 0.461 & 0.327 & 0.325 & 0.321 & 0.339 & 0.269 & 0.211 & 0.303 & 0.265 \\
\hline $\mathrm{Fe}^{2+}$ & 0.141 & 0.257 & 0.266 & 0.253 & 0.124 & 0.230 & 0.220 & 0.348 & 0.306 & 0.401 & 0.390 & 0.309 & 0.300 & 0.302 & 0.323 & 0.238 & 0.200 & 0.278 & 0.244 \\
\hline $\mathrm{Fe}^{3+}$ & 0.012 & 0.016 & 0.014 & 0.017 & 0.007 & 0.012 & 0.013 & 0.017 & 0.027 & 0.068 & 0.071 & 0.018 & 0.025 & 0.019 & 0.016 & 0.032 & 0.011 & 0.025 & 0.021 \\
\hline $\mathrm{Mn}$ & 0.004 & 0.019 & 0.017 & 0.006 & 0.004 & 0.006 & 0.006 & 0.010 & 0.014 & 0.014 & 0.014 & 0.017 & 0.015 & 0.018 & 0.021 & 0.007 & 0.005 & 0.007 & 0.006 \\
\hline $\mathrm{Mg}$ & 0.893 & 0.829 & 0.837 & 0.889 & 0.967 & 0.934 & 0.977 & 0.910 & 0.849 & 0.754 & 0.748 & 0.821 & 0.828 & 0.837 & 0.864 & 0.849 & 0.941 & 0.829 & 0.866 \\
\hline $\mathrm{Ca}$ & 0.894 & 0.846 & 0.844 & 0.803 & 0.851 & 0.784 & 0.761 & 0.685 & 0.798 & 0.701 & 0.710 & 0.817 & 0.811 & 0.807 & 0.764 & 0.791 & 0.823 & 0.816 & 0.818 \\
\hline $\mathrm{Na}$ & 0.006 & 0.021 & 0.018 & 0.010 & 0.008 & 0.008 & 0.007 & 0.009 & 0.015 & 0.018 & 0.018 & 0.016 & 0.014 & 0.015 & 0.015 & 0.011 & 0.008 & 0.011 & 0.011 \\
\hline Total & 4.01 & 4.01 & 4.01 & 4.02 & 4.01 & 4.01 & 4.02 & 4.01 & 4.03 & 4.04 & 4.03 & 4.02 & 4.02 & 4.02 & 4.02 & 4.02 & 4.02 & 4.03 & 4.02 \\
\hline \multicolumn{20}{|l|}{ Atomic \% } \\
\hline Wo & 46.1 & 43.4 & 43.0 & 40.9 & 43.7 & 40.0 & 38.6 & 34.9 & 40.3 & 36.4 & 37.0 & 41.6 & 41.3 & 41.0 & 38.8 & 41.4 & 41.7 & 41.9 & 42.0 \\
\hline En & 46.0 & 42.6 & 42.7 & 45.3 & 49.6 & 47.6 & 49.6 & 46.4 & 42.9 & 39.2 & 39.0 & 41.8 & 42.2 & 42.6 & 43.9 & 44.5 & 47.6 & 42.6 & 44.4 \\
\hline Fs & 7.9 & 14.0 & 14.3 & 13.7 & 6.8 & 12.4 & 11.8 & 18.6 & 16.8 & 24.4 & 24.0 & 16.6 & 16.5 & 16.3 & 17.2 & 14.1 & 10.7 & 15.6 & 13.6 \\
\hline $\mathrm{Mg} \#$ & 85.0 & 73.9 & 73.8 & 76.4 & 87.7 & 79.0 & 80.4 & 70.8 & 71.1 & 60.9 & 61.1 & 70.5 & 70.9 & 71.2 & 70.6 & 75.5 & 81.3 & 72.7 & 76.1 \\
\hline
\end{tabular}


Table F.1 Continued

\begin{tabular}{|c|c|c|c|c|c|c|c|c|c|c|c|c|c|c|c|c|c|c|c|}
\hline Sample & & & & & & & & & & & & & & & & & 2_PC08 & & \\
\hline Location & & & & & & & & & & & & & & & & & Oneraki & & \\
\hline Volcano & & & & & & & & & & & & & & & & & Raoul & & \\
\hline Type & & & & & $\mathrm{C} 6$ & & & & $\mathrm{C} 7$ & & & & $\mathrm{Cg}$ & & & & ic Bleb-3 & & \\
\hline Crystal no. & a & $b$ & $\mathrm{~b}$ & $b$ & a & a & $b$ & $\mathrm{~b}$ & a & a & a & a & a & a & a & $\mathrm{b}$ & a & a & a \\
\hline Analysis site & $\mathrm{rim}$ & core & $\mathrm{d}$ band & rim & core & $\mathrm{rim}$ & core & rim & core & $\mathrm{d}$ band & rim1 & rim2 & core & OG & rim & NVZ & core & $O G$ & rim \\
\hline \multicolumn{20}{|l|}{ Oxides (wt \%) } \\
\hline $\mathrm{SiO}_{2}$ & 50.26 & 50.55 & 51.52 & 51.17 & 51.07 & 48.80 & 51.54 & 50.52 & 53.47 & 53.65 & 51.34 & 48.81 & 50.74 & 52.77 & 51.73 & 51.55 & 51.11 & 51.25 & 49.52 \\
\hline $\mathrm{TiO}_{2}$ & 0.48 & 0.46 & 0.34 & 0.39 & 0.36 & 0.66 & 0.38 & 0.51 & 0.14 & 0.10 & 0.37 & 0.65 & 0.43 & 0.21 & 0.33 & 0.39 & 0.35 & 0.32 & 0.50 \\
\hline $\mathrm{Al}_{2} \mathrm{O}_{3}$ & 4.65 & 4.14 & 3.66 & 3.89 & 3.63 & 4.91 & 3.48 & 3.98 & 1.96 & 2.00 & 3.42 & 5.60 & 4.20 & 2.10 & 2.07 & 3.08 & 2.87 & 2.89 & 4.75 \\
\hline $\mathrm{Cr}_{2} \mathrm{O}_{3}$ & 0.10 & 0.08 & 0.10 & 0.08 & 0.08 & 0.05 & 0.03 & 0.03 & 0.26 & 0.66 & 0.07 & 0.05 & 0.06 & 0.08 & 0.09 & 0.07 & 0.05 & 0.06 & 0.05 \\
\hline $\mathrm{FeO}(\mathrm{T})$ & 11.44 & 10.22 & 8.94 & 12.70 & 10.61 & 13.70 & 11.50 & 13.18 & 6.06 & 3.94 & 10.05 & 14.23 & 10.80 & 10.26 & 14.50 & 11.79 & 11.50 & 11.24 & 11.97 \\
\hline MnO & 0.27 & 0.24 & 0.17 & 0.36 & 0.31 & 0.33 & 0.29 & 0.44 & 0.17 & 0.07 & 0.25 & 0.41 & 0.28 & 0.26 & 0.40 & 0.35 & 0.49 & 0.30 & 0.30 \\
\hline MgO & 14.90 & 14.94 & 15.79 & 17.04 & 16.00 & 13.59 & 16.50 & 15.74 & 17.70 & 18.26 & 15.67 & 13.96 & 15.25 & 17.00 & 16.52 & 16.54 & 15.36 & 16.56 & 14.92 \\
\hline $\mathrm{CaO}$ & 19.41 & 20.69 & 20.92 & 15.96 & 19.34 & 18.70 & 17.76 & 16.64 & 21.77 & 22.56 & 20.02 & 17.79 & 19.52 & 18.64 & 15.60 & 17.63 & 19.00 & 17.91 & 18.51 \\
\hline $\mathrm{Na}_{2} \mathrm{O}$ & 0.18 & 0.19 & 0.16 & 0.14 & 0.18 & 0.22 & 0.14 & 0.18 & 0.14 & 0.09 & 0.19 & 0.20 & 0.19 & 0.17 & 0.11 & 0.17 & 0.21 & 0.16 & 0.20 \\
\hline Total & 101.68 & 101.51 & 101.60 & 101.73 & 101.57 & 100.96 & 101.61 & 101.22 & 101.65 & 101.33 & 101.37 & 101.69 & 101.48 & 101.50 & 101.34 & 101.55 & 100.92 & 100.69 & 100.71 \\
\hline \multicolumn{20}{|l|}{ Cations } \\
\hline $\mathbf{S i}$ & 1.86 & 1.87 & 1.89 & 1.88 & 1.88 & 1.84 & 1.89 & 1.87 & 1.93 & 1.93 & 1.89 & 1.82 & 1.87 & 1.93 & 1.92 & 1.90 & 1.90 & 1.90 & 1.85 \\
\hline $\mathrm{Ti}$ & 0.006 & 0.006 & 0.004 & 0.005 & 0.004 & 0.008 & 0.005 & 0.006 & 0.002 & 0.001 & 0.005 & 0.008 & 0.005 & 0.003 & 0.004 & 0.005 & 0.004 & 0.004 & 0.006 \\
\hline Al & 0.202 & 0.180 & 0.158 & 0.169 & 0.158 & 0.218 & 0.151 & 0.174 & 0.083 & 0.085 & 0.149 & 0.246 & 0.182 & 0.091 & 0.090 & 0.134 & 0.126 & 0.126 & 0.209 \\
\hline $\mathrm{Cr}$ & 0.003 & 0.002 & 0.003 & 0.002 & 0.002 & 0.001 & 0.001 & 0.001 & 0.007 & 0.019 & 0.002 & 0.002 & 0.002 & 0.002 & 0.003 & 0.002 & 0.001 & 0.002 & 0.001 \\
\hline $\mathrm{Fe}$ total & 0.350 & 0.312 & 0.271 & 0.388 & 0.324 & 0.428 & 0.351 & 0.407 & 0.182 & 0.117 & 0.307 & 0.441 & 0.330 & 0.313 & 0.449 & 0.361 & 0.356 & 0.347 & 0.371 \\
\hline $\mathrm{Fe}^{2+}$ & 0.321 & 0.284 & 0.251 & 0.364 & 0.302 & 0.386 & 0.328 & 0.375 & 0.174 & 0.112 & 0.285 & 0.400 & 0.304 & 0.300 & 0.429 & 0.337 & 0.334 & 0.327 & 0.340 \\
\hline $\mathrm{Fe}^{3+}$ & 0.029 & 0.028 & 0.021 & 0.024 & 0.022 & 0.042 & 0.023 & 0.031 & 0.008 & 0.006 & 0.023 & 0.040 & 0.026 & 0.013 & 0.020 & 0.024 & 0.021 & 0.019 & 0.031 \\
\hline Mn & 0.008 & 0.007 & 0.005 & 0.011 & 0.010 & 0.010 & 0.009 & 0.014 & 0.005 & 0.002 & 0.008 & 0.013 & 0.009 & 0.008 & 0.012 & 0.011 & 0.015 & 0.010 & 0.009 \\
\hline $\mathbf{M g}$ & 0.820 & 0.822 & 0.862 & 0.933 & 0.878 & 0.762 & 0.903 & 0.871 & 0.954 & 0.981 & 0.860 & 0.777 & 0.839 & 0.927 & 0.915 & 0.907 & 0.852 & 0.915 & 0.830 \\
\hline $\mathrm{Ca}$ & 0.768 & 0.818 & 0.821 & 0.628 & 0.763 & 0.754 & 0.699 & 0.662 & 0.843 & 0.871 & 0.790 & 0.711 & 0.772 & 0.731 & 0.621 & 0.695 & 0.757 & 0.712 & 0.740 \\
\hline $\mathrm{Na}$ & 0.013 & 0.014 & 0.012 & 0.010 & 0.013 & 0.016 & 0.010 & 0.013 & 0.010 & 0.006 & 0.013 & 0.014 & 0.014 & 0.012 & 0.008 & 0.012 & 0.015 & 0.011 & 0.014 \\
\hline Total & 4.03 & 4.03 & 4.02 & 4.02 & 4.03 & 4.03 & 4.02 & 4.02 & 4.02 & 4.01 & 4.02 & 4.03 & 4.02 & 4.02 & 4.02 & 4.02 & 4.03 & 4.03 & 4.03 \\
\hline \multicolumn{20}{|l|}{ Atomic \% } \\
\hline Wo & 39.6 & 41.9 & 42.0 & 32.2 & 38.8 & 38.8 & 35.8 & 34.1 & 42.6 & 44.2 & 40.4 & 36.9 & 39.8 & 37.1 & 31.3 & 35.4 & 38.5 & 36.1 & 38.1 \\
\hline En & 42.3 & 42.1 & 44.1 & 47.9 & 44.7 & 39.2 & 46.2 & 44.9 & 48.2 & 49.8 & 43.9 & 40.3 & 43.2 & 47.0 & 46.1 & 46.2 & 43.4 & 46.4 & 42.8 \\
\hline Fs & 18.1 & 16.0 & 13.9 & 19.9 & 16.5 & 22.0 & 18.0 & 21.0 & 9.2 & 6.0 & 15.7 & 22.9 & 17.0 & 15.9 & 22.6 & 18.4 & 18.1 & 17.6 & 19.1 \\
\hline Mg \# & 69.6 & 72.0 & 75.7 & 70.0 & 72.5 & 63.5 & 71.5 & 67.4 & 83.6 & 89.1 & 73.2 & 63.1 & 71.2 & 74.3 & 66.5 & 71.0 & 69.7 & 72.0 & 68.6 \\
\hline
\end{tabular}


Table F.1 Continued

\begin{tabular}{|c|c|c|c|c|c|c|c|c|c|c|c|c|c|c|c|c|c|c|c|}
\hline Sample & & & & & & & & & & & & & & & 3_PC05 & & & & \\
\hline Location & & & & & & & & & & & & & & & GLP & & & & \\
\hline Volcano & & & & & & & & & & & & & & & Raoul & & & & \\
\hline Type & & & & MB06 & & MB05 & & & & MB07 & & & & & crystal & & & & \\
\hline Crystal no. & a & $b$ & $\mathrm{~b}$ & $a$ & a & a & a & a & a & $a$ & a & $\mathrm{b}$ & c & c & 1 & 2 & 3 & 4 & 4 \\
\hline Analysis site & rim2 & core & rim & core & rim & core & OG & rim & rim2 & rim & core & NVZ & core & rim & $N V Z$ & NVZ & NVZ & core1 & core2 \\
\hline \multicolumn{20}{|l|}{ Oxides (wt \%) } \\
\hline $\mathrm{SiO}_{2}$ & 49.32 & 51.89 & 50.76 & 51.32 & 50.07 & 54.24 & 53.37 & 51.96 & 49.95 & 49.11 & 50.04 & 47.92 & 51.15 & 49.12 & 52.07 & 52.21 & 50.30 & 51.73 & 50.18 \\
\hline $\mathrm{TiO}_{2}$ & 0.49 & 0.24 & 0.33 & 0.23 & 0.37 & 0.05 & 0.11 & 0.24 & 0.50 & 0.58 & 0.40 & 0.72 & 0.19 & 0.54 & 0.37 & 0.31 & 0.71 & 0.31 & 0.62 \\
\hline $\mathrm{Al}_{2} \mathrm{O}_{3}$ & 4.26 & 1.80 & 2.97 & 2.80 & 3.38 & 1.00 & 1.75 & 2.49 & 4.44 & 5.57 & 3.99 & 5.97 & 1.56 & 5.53 & 1.75 & 1.34 & 3.32 & 1.32 & 3.14 \\
\hline $\mathrm{Cr}_{2} \mathrm{O}_{3}$ & 0.05 & 0.06 & 0.07 & 0.07 & 0.07 & 0.31 & 0.39 & 0.12 & 0.08 & 0.02 & 0.06 & 0.07 & 0.08 & 0.03 & 0.04 & 0.04 & 0.04 & 0.04 & 0.03 \\
\hline $\mathrm{FeO}(\mathrm{T})$ & 11.62 & 10.33 & 10.37 & 8.16 & 11.33 & 3.76 & 4.31 & 8.71 & 10.86 & 12.78 & 10.08 & 13.39 & 11.08 & 16.32 & 11.51 & 12.03 & 13.53 & 12.14 & 12.90 \\
\hline MnO & 0.32 & 0.56 & 0.31 & 0.21 & 0.33 & 0.14 & 0.12 & 0.21 & 0.23 & 0.32 & 0.26 & 0.29 & 0.34 & 0.36 & 0.56 & 0.65 & 0.64 & 0.63 & 0.61 \\
\hline MgO & 14.91 & 15.66 & 16.28 & 16.43 & 16.67 & 19.17 & 17.99 & 16.74 & 15.24 & 13.82 & 15.37 & 13.25 & 17.97 & 15.87 & 14.15 & 14.12 & 13.58 & 14.15 & 12.59 \\
\hline $\mathrm{CaO}$ & 18.74 & 19.61 & 18.78 & 20.61 & 17.24 & 21.80 & 22.31 & 20.18 & 19.11 & 18.73 & 19.98 & 18.72 & 16.39 & 12.38 & 20.10 & 19.93 & 18.75 & 19.83 & 20.43 \\
\hline $\mathrm{Na}_{2} \mathrm{O}$ & 0.18 & 0.19 & 0.15 & 0.13 & 0.15 & 0.09 & 0.10 & 0.13 & 0.16 & 0.20 & 0.18 & 0.21 & 0.12 & 0.18 & 0.20 & 0.19 & 0.23 & 0.20 & 0.25 \\
\hline Total & 99.88 & 100.34 & 100.00 & 99.96 & 99.61 & 100.56 & 100.45 & 100.78 & 100.58 & 101.11 & 100.35 & 100.53 & 98.86 & 100.32 & 100.76 & 100.81 & 101.11 & 100.34 & 100.76 \\
\hline \multicolumn{20}{|l|}{ Cations } \\
\hline $\mathbf{S i}$ & 1.86 & 1.93 & 1.89 & 1.90 & 1.88 & 1.96 & 1.94 & 1.91 & 1.86 & 1.83 & 1.87 & 1.81 & 1.93 & 1.84 & 1.94 & 1.95 & 1.89 & 1.95 & 1.89 \\
\hline $\mathrm{Ti}$ & 0.006 & 0.003 & 0.004 & 0.003 & 0.005 & 0.001 & 0.001 & 0.003 & 0.006 & 0.007 & 0.005 & 0.009 & 0.002 & 0.007 & 0.005 & 0.004 & 0.009 & 0.004 & 0.008 \\
\hline Al & 0.189 & 0.079 & 0.131 & 0.122 & 0.149 & 0.043 & 0.075 & 0.108 & 0.195 & 0.245 & 0.175 & 0.266 & 0.069 & 0.245 & 0.077 & 0.059 & 0.147 & 0.058 & 0.140 \\
\hline $\mathrm{Cr}$ & 0.001 & 0.002 & 0.002 & 0.002 & 0.002 & 0.009 & 0.011 & 0.004 & 0.002 & 0.000 & 0.002 & 0.002 & 0.002 & 0.001 & 0.001 & 0.001 & 0.001 & 0.001 & 0.001 \\
\hline Fe total & 0.363 & 0.320 & 0.322 & 0.251 & 0.353 & 0.113 & 0.129 & 0.266 & 0.335 & 0.396 & 0.312 & 0.419 & 0.347 & 0.510 & 0.357 & 0.374 & 0.421 & 0.380 & 0.404 \\
\hline $\mathrm{Fe}^{2+}$ & 0.332 & 0.305 & 0.301 & 0.238 & 0.330 & 0.110 & 0.123 & 0.252 & 0.304 & 0.360 & 0.287 & 0.373 & 0.336 & 0.476 & 0.334 & 0.355 & 0.376 & 0.361 & 0.365 \\
\hline $\mathrm{Fe}^{3+}$ & 0.031 & 0.015 & 0.020 & 0.014 & 0.023 & 0.003 & 0.006 & 0.015 & 0.031 & 0.036 & 0.025 & 0.046 & 0.012 & 0.034 & 0.023 & 0.020 & 0.045 & 0.019 & 0.039 \\
\hline Mn & 0.010 & 0.018 & 0.010 & 0.006 & 0.011 & 0.004 & 0.004 & 0.006 & 0.007 & 0.010 & 0.008 & 0.009 & 0.011 & 0.011 & 0.018 & 0.020 & 0.020 & 0.020 & 0.020 \\
\hline $\mathbf{M g}$ & 0.837 & 0.870 & 0.906 & 0.909 & 0.932 & 1.033 & 0.975 & 0.919 & 0.846 & 0.769 & 0.855 & 0.746 & 1.008 & 0.888 & 0.787 & 0.787 & 0.760 & 0.793 & 0.708 \\
\hline $\mathrm{Ca}$ & 0.756 & 0.783 & 0.751 & 0.819 & 0.693 & 0.844 & 0.870 & 0.796 & 0.762 & 0.749 & 0.798 & 0.757 & 0.661 & 0.498 & 0.804 & 0.798 & 0.754 & 0.800 & 0.826 \\
\hline $\mathrm{Na}$ & 0.013 & 0.014 & 0.011 & 0.009 & 0.011 & 0.006 & 0.007 & 0.009 & 0.012 & 0.015 & 0.013 & 0.015 & 0.008 & 0.013 & 0.015 & 0.013 & 0.017 & 0.014 & 0.019 \\
\hline Total & 4.03 & 4.02 & 4.03 & 4.03 & 4.04 & 4.01 & 4.01 & 4.03 & 4.03 & 4.03 & 4.03 & 4.03 & 4.04 & 4.02 & 4.01 & 4.01 & 4.02 & 4.02 & 4.02 \\
\hline \multicolumn{20}{|l|}{ Atomic \% } \\
\hline Wo & 38.7 & 39.7 & 38.0 & 41.4 & 35.0 & 42.4 & 44.0 & 40.2 & 39.2 & 39.1 & 40.6 & 39.4 & 32.8 & 26.3 & 41.3 & 40.7 & 39.0 & 40.5 & 42.6 \\
\hline En & 42.8 & 44.1 & 45.8 & 45.9 & 47.1 & 51.9 & 49.4 & 46.4 & 43.5 & 40.2 & 43.5 & 38.8 & 50.0 & 46.8 & 40.4 & 40.2 & 39.3 & 40.2 & 36.5 \\
\hline Fs & 18.6 & 16.2 & 16.3 & 12.7 & 17.8 & 5.7 & 6.6 & 13.4 & 17.2 & 20.7 & 15.9 & 21.8 & 17.2 & 26.9 & 18.3 & 19.1 & 21.8 & 19.3 & 20.8 \\
\hline Mg \# & 69.2 & 72.0 & 73.2 & 77.9 & 71.9 & 89.8 & 88.0 & 77.1 & 71.2 & 65.5 & 72.8 & 63.5 & 73.8 & 63.0 & 67.7 & 66.6 & 63.3 & 66.5 & 62.6 \\
\hline
\end{tabular}


Table F.1 Continued

\begin{tabular}{|c|c|c|c|c|c|c|c|c|c|c|c|c|c|c|c|c|c|c|c|c|}
\hline \multicolumn{21}{|l|}{ Sample } \\
\hline \multicolumn{21}{|l|}{ Location } \\
\hline \multicolumn{21}{|l|}{ Volcano } \\
\hline \multicolumn{21}{|l|}{ Type } \\
\hline Crystal no. & 4 & 4 & 5 & 5 & 6 & 6 & 7 & 8 & 8 & 8 & 8 & 9 & 10 & 11 & 11 & 11 & 12 & 13 & 14 & 15 \\
\hline Analysis site & $\mathrm{d}$ band & rim & core1 & core2 & core & rim & NVZ & core & rim1 & rim2 & rim3 & NVZ & NVZ & core & $\mathrm{d}$ band & rim & NVZ & NVZ & NVZ & $\mathrm{NVZ}$ \\
\hline \multicolumn{21}{|l|}{ Oxides (wt \%) } \\
\hline $\mathrm{SiO}_{2}$ & 51.60 & 50.75 & 52.15 & 51.32 & 52.15 & 50.80 & 52.53 & 51.85 & 51.37 & 51.28 & 51.34 & 51.52 & 51.89 & 52.49 & 52.84 & 49.54 & 52.09 & 52.61 & 51.93 & 52.36 \\
\hline $\mathrm{TiO}_{2}$ & 0.34 & 0.49 & 0.34 & 0.51 & 0.34 & 0.45 & 0.32 & 0.21 & 0.37 & 0.41 & 0.43 & 0.43 & 0.44 & 0.21 & 0.18 & 0.77 & 0.40 & 0.32 & 0.37 & 0.30 \\
\hline $\mathrm{Al}_{2} \mathrm{O}_{3}$ & 1.53 & 2.65 & 2.03 & 2.59 & 1.61 & 3.72 & 1.54 & 3.67 & 3.52 & 2.73 & 2.71 & 2.21 & 2.28 & 3.33 & 3.44 & 4.51 & 1.81 & 1.68 & 2.03 & 1.42 \\
\hline $\mathrm{Cr}_{2} \mathrm{O}_{3}$ & 0.04 & 0.05 & 0.07 & 0.05 & 0.03 & 0.07 & 0.06 & 0.18 & 0.12 & 0.06 & 0.04 & 0.04 & 0.06 & 0.12 & 0.17 & 0.12 & 0.04 & 0.05 & 0.06 & 0.05 \\
\hline $\mathrm{FeO}(\mathrm{T})$ & 11.30 & 12.76 & 11.83 & 12.53 & 11.45 & 10.57 & 11.17 & 6.48 & 10.62 & 12.46 & 12.69 & 11.94 & 11.97 & 6.08 & 5.55 & 11.45 & 12.20 & 11.79 & 12.67 & 11.42 \\
\hline MnO & 0.61 & 0.67 & 0.64 & 0.60 & 0.59 & 0.28 & 0.56 & 0.14 & 0.30 & 0.51 & 0.52 & 0.53 & 0.59 & 0.15 & 0.11 & 0.27 & 0.61 & 0.62 & 0.67 & 0.61 \\
\hline MgO & 13.80 & 13.18 & 14.20 & 13.27 & 14.21 & 15.57 & 14.49 & 16.03 & 16.71 & 15.64 & 15.81 & 14.27 & 14.16 & 16.47 & 16.97 & 14.38 & 14.36 & 14.61 & 14.45 & 14.43 \\
\hline $\mathrm{CaO}$ & 20.66 & 19.84 & 19.80 & 20.17 & 20.43 & 19.12 & 20.49 & 22.16 & 17.81 & 17.17 & 17.06 & 19.82 & 20.09 & 22.56 & 22.54 & 19.77 & 19.66 & 20.07 & 19.02 & 20.05 \\
\hline $\mathrm{Na}_{2} \mathrm{O}$ & 0.19 & 0.23 & 0.21 & 0.23 & 0.20 & 0.17 & 0.22 & 0.10 & 0.16 & 0.20 & 0.20 & 0.21 & 0.23 & 0.09 & 0.11 & 0.18 & 0.21 & 0.22 & 0.22 & 0.19 \\
\hline Total & 100.07 & 100.62 & 101.27 & 101.26 & 101.00 & 100.74 & 101.37 & 100.83 & 100.98 & 100.45 & 100.81 & 100.97 & 101.70 & 101.49 & 101.90 & 101.01 & 101.37 & 101.98 & 101.43 & 100.81 \\
\hline \multicolumn{21}{|l|}{ Cations } \\
\hline Si & 1.94 & 1.91 & 1.94 & 1.92 & 1.94 & 1.88 & 1.95 & 1.90 & 1.89 & 1.91 & 1.91 & 1.92 & 1.92 & 1.91 & 1.90 & 1.85 & 1.94 & 1.94 & 1.93 & 1.95 \\
\hline $\mathrm{Ti}$ & 0.004 & 0.006 & 0.004 & 0.006 & 0.004 & 0.006 & 0.004 & 0.003 & 0.005 & 0.005 & 0.005 & 0.005 & 0.005 & 0.003 & 0.002 & 0.010 & 0.005 & 0.004 & 0.005 & 0.004 \\
\hline Al & 0.068 & 0.118 & 0.089 & 0.114 & 0.071 & 0.163 & 0.067 & 0.158 & 0.153 & 0.120 & 0.119 & 0.097 & 0.100 & 0.143 & 0.146 & 0.198 & 0.079 & 0.073 & 0.089 & 0.062 \\
\hline $\mathrm{Cr}$ & 0.001 & 0.001 & 0.002 & 0.002 & 0.001 & 0.002 & 0.002 & 0.005 & 0.004 & 0.002 & 0.001 & 0.001 & 0.002 & 0.004 & 0.005 & 0.003 & 0.001 & 0.002 & 0.002 & 0.001 \\
\hline $\mathrm{Fe}$ tot & 0.354 & 0.399 & 0.366 & 0.389 & 0.355 & 0.325 & 0.344 & 0.196 & 0.325 & 0.386 & 0.393 & 0.370 & 0.369 & 0.182 & 0.165 & 0.352 & 0.377 & 0.362 & 0.392 & 0.354 \\
\hline $\mathrm{Fe}^{2+}$ & 0.332 & 0.368 & 0.345 & 0.357 & 0.334 & 0.297 & 0.325 & 0.184 & 0.302 & 0.361 & 0.366 & 0.344 & 0.342 & 0.170 & 0.154 & 0.304 & 0.352 & 0.342 & 0.369 & 0.336 \\
\hline $\mathrm{Fe}^{3+}$ & 0.022 & 0.031 & 0.021 & 0.032 & 0.021 & 0.028 & 0.019 & 0.012 & 0.023 & 0.026 & 0.027 & 0.027 & 0.027 & 0.012 & 0.011 & 0.048 & 0.025 & 0.020 & 0.023 & 0.019 \\
\hline Mn & 0.019 & 0.022 & 0.020 & 0.019 & 0.019 & 0.009 & 0.018 & 0.004 & 0.009 & 0.016 & 0.017 & 0.017 & 0.018 & 0.004 & 0.003 & 0.009 & 0.019 & 0.019 & 0.021 & 0.019 \\
\hline $\mathbf{M g}$ & 0.775 & 0.740 & 0.787 & 0.739 & 0.790 & 0.861 & 0.801 & 0.874 & 0.918 & 0.870 & 0.877 & 0.794 & 0.783 & 0.891 & 0.912 & 0.800 & 0.796 & 0.804 & 0.801 & 0.802 \\
\hline $\mathrm{Ca}$ & 0.834 & 0.801 & 0.788 & 0.808 & 0.816 & 0.760 & 0.814 & 0.869 & 0.703 & 0.687 & 0.680 & 0.793 & 0.798 & 0.878 & 0.870 & 0.790 & 0.783 & 0.793 & 0.758 & 0.801 \\
\hline $\mathrm{Na}$ & 0.014 & 0.017 & 0.015 & 0.016 & 0.014 & 0.012 & 0.016 & 0.007 & 0.011 & 0.014 & 0.014 & 0.015 & 0.016 & 0.006 & 0.008 & 0.013 & 0.015 & 0.016 & 0.016 & 0.014 \\
\hline Total & 4.01 & 4.02 & 4.01 & 4.01 & 4.01 & 4.02 & 4.01 & 4.02 & 4.02 & 4.01 & 4.02 & 4.02 & 4.01 & 4.02 & 4.02 & 4.02 & 4.01 & 4.02 & 4.02 & 4.01 \\
\hline \multicolumn{21}{|l|}{ Atomic \% } \\
\hline Wo & 42.5 & 41.3 & 40.6 & 41.7 & 41.6 & 39.1 & 41.6 & 44.8 & 36.1 & 35.3 & 34.9 & 40.5 & 40.9 & 45.0 & 44.7 & 40.7 & 40.0 & 40.5 & 38.9 & 40.9 \\
\hline En & 39.5 & 38.1 & 40.5 & 38.2 & 40.3 & 44.2 & 40.9 & 45.1 & 47.2 & 44.8 & 45.0 & 40.6 & 40.1 & 45.7 & 46.8 & 41.2 & 40.7 & 41.0 & 41.1 & 41.0 \\
\hline Fs & 18.0 & 20.6 & 18.8 & 20.1 & 18.1 & 16.7 & 17.6 & 10.1 & 16.7 & 19.9 & 20.1 & 18.9 & 18.9 & 9.3 & 8.5 & 18.1 & 19.3 & 18.5 & 20.1 & 18.1 \\
\hline Mg \# & 67.5 & 63.8 & 67.1 & 64.5 & 67.9 & 72.1 & 68.9 & 81.3 & 73.3 & 68.4 & 68.2 & 67.2 & 66.9 & 82.7 & 84.4 & 68.9 & 66.8 & 67.8 & 66.0 & 68.2 \\
\hline
\end{tabular}


Table F.1 Continued

\begin{tabular}{|c|c|c|c|c|c|c|c|c|c|c|c|c|c|c|c|c|c|c|c|c|}
\hline \multicolumn{21}{|l|}{ Sample } \\
\hline \multicolumn{21}{|l|}{ Location } \\
\hline \multicolumn{21}{|l|}{ Volcano } \\
\hline \multicolumn{21}{|l|}{ Type } \\
\hline Crystal no. & 16 & 17 & 18 & 19 & 20 & 20 & 20 & 20 & 21 & 21 & 21 & 22 & 23 & 24 & 25 & 25 & 25 & 26 & 27 & 28 \\
\hline Analysis site & $N V Z$ & NVZ & NVZ & NVZ & core1 & OG & I band & rim & core & OG & rim & NVZ & NVZ & NVZ & core & OG & rim & NVZ & NVZ & $\mathrm{NVZ}$ \\
\hline \multicolumn{21}{|l|}{ Oxides (wt \%) } \\
\hline $\mathrm{SiO}_{2}$ & 52.49 & 51.73 & 51.64 & 51.95 & 51.91 & 53.14 & 51.31 & 49.37 & 52.28 & 52.59 & 51.67 & 52.42 & 52.85 & 51.99 & 52.06 & 52.95 & 50.80 & 53.28 & 52.24 & 51.73 \\
\hline $\mathrm{TiO}_{2}$ & 0.29 & 0.31 & 0.43 & 0.40 & 0.25 & 0.14 & 0.42 & 0.63 & 0.24 & 0.16 & 0.40 & 0.36 & 0.33 & 0.35 & 0.23 & 0.14 & 0.45 & 0.22 & 0.35 & 0.35 \\
\hline $\mathrm{Al}_{2} \mathrm{O}_{3}$ & 1.39 & 3.44 & 2.38 & 1.98 & 3.50 & 2.69 & 3.94 & 5.48 & 3.18 & 3.75 & 3.40 & 1.76 & 1.65 & 1.84 & 3.77 & 2.97 & 3.72 & 1.68 & 1.87 & 1.90 \\
\hline $\mathrm{Cr}_{2} \mathrm{O}_{3}$ & 0.05 & 0.06 & 0.05 & 0.03 & 0.12 & 0.40 & 0.09 & 0.06 & 0.09 & 0.45 & 0.07 & 0.06 & 0.06 & 0.05 & 0.19 & 0.50 & 0.07 & 0.05 & 0.04 & 0.06 \\
\hline $\mathrm{FeO}(\mathrm{T})$ & 11.26 & 7.69 & 14.52 & 12.84 & 6.95 & 4.40 & 9.93 & 12.49 & 6.92 & 4.57 & 10.10 & 12.20 & 11.48 & 12.05 & 6.21 & 4.36 & 10.57 & 10.17 & 11.47 & 12.00 \\
\hline MnO & 0.52 & 0.14 & 0.78 & 0.67 & 0.17 & 0.11 & 0.23 & 0.33 & 0.15 & 0.11 & 0.29 & 0.65 & 0.57 & 0.65 & 0.14 & 0.10 & 0.28 & 0.33 & 0.57 & 0.70 \\
\hline MgO & 14.45 & 16.01 & 14.82 & 14.59 & 16.51 & 17.42 & 15.22 & 13.91 & 16.32 & 16.87 & 15.45 & 14.44 & 14.34 & 14.12 & 16.56 & 17.32 & 15.57 & 17.43 & 14.12 & 13.86 \\
\hline $\mathrm{CaO}$ & 20.61 & 21.60 & 16.80 & 18.72 & 21.66 & 22.91 & 20.35 & 19.34 & 21.98 & 22.78 & 20.02 & 19.52 & 20.23 & 20.06 & 22.21 & 22.75 & 19.12 & 17.93 & 20.30 & 20.21 \\
\hline $\mathrm{Na}_{2} \mathrm{O}$ & 0.20 & 0.12 & 0.20 & 0.23 & 0.10 & 0.08 & 0.16 & 0.22 & 0.11 & 0.09 & 0.16 & 0.21 & 0.21 & 0.22 & 0.11 & 0.08 & 0.17 & 0.11 & 0.21 & 0.20 \\
\hline Total & 101.27 & 101.10 & 101.62 & 101.42 & 101.16 & 101.28 & 101.64 & 101.82 & 101.27 & 101.35 & 101.55 & 101.62 & 101.71 & 101.33 & 101.48 & 101.17 & 100.74 & 101.19 & 101.16 & 101.00 \\
\hline \multicolumn{21}{|l|}{ Cations } \\
\hline $\mathbf{S i}$ & 1.95 & 1.90 & 1.92 & 1.93 & 1.90 & 1.92 & 1.88 & 1.83 & 1.91 & 1.90 & 1.90 & 1.94 & 1.95 & 1.94 & 1.89 & 1.91 & 1.88 & 1.95 & 1.94 & 1.93 \\
\hline $\mathrm{Ti}$ & 0.004 & 0.004 & 0.005 & 0.005 & 0.003 & 0.002 & 0.005 & 0.008 & 0.003 & 0.002 & 0.005 & 0.004 & 0.004 & 0.004 & 0.003 & 0.002 & 0.006 & 0.003 & 0.004 & 0.004 \\
\hline Al & 0.061 & 0.149 & 0.104 & 0.087 & 0.151 & 0.115 & 0.170 & 0.240 & 0.137 & 0.160 & 0.147 & 0.077 & 0.072 & 0.081 & 0.161 & 0.127 & 0.163 & 0.072 & 0.082 & 0.084 \\
\hline $\mathrm{Cr}$ & 0.002 & 0.002 & 0.001 & 0.001 & 0.003 & 0.011 & 0.003 & 0.002 & 0.002 & 0.013 & 0.002 & 0.002 & 0.002 & 0.001 & 0.006 & 0.014 & 0.002 & 0.002 & 0.001 & 0.002 \\
\hline $\mathrm{Fe}$ tot & 0.348 & 0.233 & 0.450 & 0.397 & 0.210 & 0.131 & 0.302 & 0.384 & 0.209 & 0.136 & 0.308 & 0.376 & 0.353 & 0.373 & 0.186 & 0.130 & 0.325 & 0.310 & 0.355 & 0.373 \\
\hline $\mathrm{Fe}^{2+}$ & 0.330 & 0.214 & 0.423 & 0.372 & 0.195 & 0.122 & 0.277 & 0.345 & 0.194 & 0.127 & 0.284 & 0.354 & 0.333 & 0.352 & 0.172 & 0.121 & 0.297 & 0.297 & 0.333 & 0.352 \\
\hline $\mathrm{Fe}^{3+}$ & 0.018 & 0.019 & 0.027 & 0.025 & 0.015 & 0.008 & 0.025 & 0.039 & 0.014 & 0.009 & 0.024 & 0.022 & 0.020 & 0.022 & 0.014 & 0.008 & 0.028 & 0.013 & 0.022 & 0.022 \\
\hline Mn & 0.016 & 0.004 & 0.025 & 0.021 & 0.005 & 0.003 & 0.007 & 0.010 & 0.005 & 0.003 & 0.009 & 0.020 & 0.018 & 0.020 & 0.004 & 0.003 & 0.009 & 0.010 & 0.018 & 0.022 \\
\hline $\mathbf{M g}$ & 0.800 & 0.875 & 0.822 & 0.809 & 0.899 & 0.939 & 0.833 & 0.769 & 0.887 & 0.909 & 0.846 & 0.797 & 0.790 & 0.784 & 0.897 & 0.934 & 0.861 & 0.951 & 0.783 & 0.772 \\
\hline $\mathrm{Ca}$ & 0.820 & 0.848 & 0.670 & 0.746 & 0.847 & 0.887 & 0.801 & 0.769 & 0.859 & 0.882 & 0.788 & 0.775 & 0.801 & 0.800 & 0.864 & 0.881 & 0.760 & 0.703 & 0.809 & 0.810 \\
\hline $\mathrm{Na}$ & 0.014 & 0.008 & 0.015 & 0.017 & 0.007 & 0.005 & 0.011 & 0.016 & 0.008 & 0.006 & 0.011 & 0.015 & 0.015 & 0.016 & 0.008 & 0.005 & 0.012 & 0.007 & 0.015 & 0.015 \\
\hline Total & 4.01 & 4.02 & 4.01 & 4.01 & 4.02 & 4.01 & 4.02 & 4.03 & 4.02 & 4.01 & 4.02 & 4.01 & 4.00 & 4.02 & 4.02 & 4.01 & 4.02 & 4.01 & 4.01 & 4.02 \\
\hline \multicolumn{21}{|l|}{ Atomic \% } \\
\hline Wo & 41.7 & 43.4 & 34.5 & 38.2 & 43.3 & 45.3 & 41.4 & 40.0 & 43.9 & 45.8 & 40.6 & 39.8 & 41.2 & 40.9 & 44.4 & 45.3 & 39.1 & 35.8 & 41.6 & 41.4 \\
\hline En & 40.6 & 44.7 & 42.3 & 41.4 & 45.9 & 48.0 & 43.0 & 40.0 & 45.4 & 47.2 & 43.6 & 40.9 & 40.6 & 40.0 & 46.0 & 48.0 & 44.2 & 48.4 & 40.2 & 39.5 \\
\hline Fs & 17.7 & 11.9 & 23.2 & 20.3 & 10.7 & 6.7 & 15.6 & 20.0 & 10.7 & 7.0 & 15.8 & 19.3 & 18.2 & 19.1 & 9.6 & 6.7 & 16.7 & 15.8 & 18.2 & 19.1 \\
\hline Mg \# & 68.7 & 78.7 & 63.4 & 65.9 & 80.7 & 87.5 & 72.9 & 66.1 & 80.6 & 86.7 & 72.8 & 66.8 & 68.1 & 66.6 & 82.5 & 87.5 & 72.1 & 74.8 & 67.8 & 66.2 \\
\hline
\end{tabular}


Table F.1 Continued

\begin{tabular}{|c|c|c|c|c|c|c|c|c|c|c|c|c|c|c|c|c|c|c|c|c|}
\hline \multicolumn{21}{|l|}{ Sample } \\
\hline \multicolumn{21}{|l|}{ Location } \\
\hline \multicolumn{21}{|l|}{ Volcano } \\
\hline \multicolumn{21}{|l|}{ Type } \\
\hline Crystal no. & 29 & 30 & 31 & 32 & 33 & 33 & 33 & 34 & 35 & 36 & 37 & 37 & 38 & 39 & 39 & 39 & 39 & 40 & 41 & 42 \\
\hline Analysis site & $N V Z$ & NVZ & NVZ & NVZ & core & $O G$ & rim & NVZ & NVZ & NVZ & core & rim & NVZ & core & $\mathrm{d}$ band & rim1 & rim2 & NVZ & NVZ & $\mathrm{NVZ}$ \\
\hline \multicolumn{21}{|l|}{ Oxides (wt \%) } \\
\hline $\mathrm{SiO}_{2}$ & 52.36 & 51.87 & 52.37 & 51.41 & 52.42 & 53.07 & 52.58 & 52.45 & 52.05 & 51.92 & 51.91 & 52.36 & 51.93 & 52.20 & 52.14 & 51.62 & 51.99 & 51.43 & 52.20 & 52.45 \\
\hline $\mathrm{TiO}_{2}$ & 0.31 & 0.43 & 0.33 & 0.47 & 0.22 & 0.26 & 0.32 & 0.30 & 0.34 & 0.36 & 0.46 & 0.35 & 0.45 & 0.17 & 0.26 & 0.40 & 0.41 & 0.42 & 0.33 & 0.33 \\
\hline $\mathrm{Al}_{2} \mathrm{O}_{3}$ & 1.73 & 2.29 & 1.68 & 2.52 & 3.52 & 1.74 & 1.51 & 1.51 & 1.80 & 1.75 & 2.10 & 1.66 & 2.25 & 3.57 & 3.35 & 2.90 & 2.87 & 2.29 & 1.68 & 1.63 \\
\hline $\mathrm{Cr}_{2} \mathrm{O}_{3}$ & 0.06 & 0.02 & 0.06 & 0.04 & 0.18 & 0.06 & 0.03 & 0.06 & 0.04 & 0.06 & 0.06 & 0.05 & 0.09 & 0.16 & 0.12 & 0.05 & 0.04 & 0.08 & 0.06 & 0.01 \\
\hline $\mathrm{FeO}(\mathrm{T})$ & 11.15 & 12.01 & 11.19 & 11.28 & 5.80 & 10.38 & 11.60 & 11.14 & 11.29 & 11.52 & 12.86 & 11.53 & 12.16 & 6.24 & 7.10 & 10.25 & 10.24 & 11.49 & 11.55 & 11.52 \\
\hline MnO & 0.46 & 0.58 & 0.55 & 0.52 & 0.16 & 0.31 & 0.47 & 0.52 & 0.57 & 0.58 & 0.67 & 0.60 & 0.61 & 0.12 & 0.17 & 0.35 & 0.37 & 0.56 & 0.63 & 0.60 \\
\hline MgO & 14.69 & 14.02 & 14.54 & 14.20 & 16.65 & 17.12 & 15.82 & 14.52 & 14.11 & 14.05 & 13.46 & 14.05 & 13.93 & 16.12 & 16.36 & 14.54 & 14.81 & 14.22 & 14.30 & 14.47 \\
\hline $\mathrm{CaO}$ & 20.31 & 19.75 & 20.02 & 20.23 & 22.22 & 18.15 & 18.37 & 19.95 & 20.17 & 19.86 & 19.55 & 20.33 & 19.72 & 22.39 & 21.14 & 19.98 & 20.37 & 20.24 & 20.13 & 19.99 \\
\hline $\mathrm{Na}_{2} \mathrm{O}$ & 0.21 & 0.24 & 0.21 & 0.20 & 0.10 & 0.11 & 0.16 & 0.21 & 0.22 & 0.19 & 0.22 & 0.21 & 0.22 & 0.09 & 0.11 & 0.20 & 0.20 & 0.20 & 0.20 & 0.20 \\
\hline Total & 101.28 & 101.19 & 100.94 & 100.85 & 101.26 & 101.19 & 100.84 & 100.65 & 100.57 & 100.30 & 101.28 & 101.12 & 101.34 & 101.05 & 100.73 & 100.28 & 101.29 & 100.93 & 101.08 & 101.21 \\
\hline \multicolumn{21}{|l|}{ Cations } \\
\hline $\mathbf{S i}$ & 1.94 & 1.93 & 1.95 & 1.92 & 1.90 & 1.95 & 1.95 & 1.95 & 1.95 & 1.95 & 1.94 & 1.95 & 1.93 & 1.90 & 1.91 & 1.92 & 1.92 & 1.92 & 1.94 & 1.95 \\
\hline $\mathrm{Ti}$ & 0.004 & 0.005 & 0.004 & 0.006 & 0.003 & 0.003 & 0.004 & 0.004 & 0.004 & 0.005 & 0.006 & 0.004 & 0.006 & 0.002 & 0.003 & 0.005 & 0.005 & 0.005 & 0.004 & 0.004 \\
\hline Al & 0.076 & 0.100 & 0.074 & 0.111 & 0.151 & 0.075 & 0.066 & 0.066 & 0.079 & 0.077 & 0.092 & 0.073 & 0.098 & 0.153 & 0.144 & 0.127 & 0.125 & 0.101 & 0.074 & 0.072 \\
\hline $\mathrm{Cr}$ & 0.002 & 0.001 & 0.002 & 0.001 & 0.005 & 0.002 & 0.001 & 0.002 & 0.001 & 0.002 & 0.002 & 0.001 & 0.003 & 0.004 & 0.003 & 0.001 & 0.001 & 0.002 & 0.002 & 0.000 \\
\hline $\mathrm{Fe}$ tot & 0.344 & 0.371 & 0.346 & 0.349 & 0.174 & 0.317 & 0.358 & 0.345 & 0.351 & 0.359 & 0.399 & 0.357 & 0.375 & 0.189 & 0.215 & 0.317 & 0.313 & 0.356 & 0.358 & 0.356 \\
\hline $\mathrm{Fe}^{2+}$ & 0.325 & 0.345 & 0.326 & 0.320 & 0.161 & 0.301 & 0.338 & 0.327 & 0.330 & 0.336 & 0.370 & 0.335 & 0.347 & 0.179 & 0.200 & 0.292 & 0.288 & 0.330 & 0.337 & 0.335 \\
\hline $\mathrm{Fe}^{3+}$ & 0.019 & 0.027 & 0.020 & 0.029 & 0.013 & 0.016 & 0.019 & 0.019 & 0.021 & 0.023 & 0.028 & 0.022 & 0.028 & 0.010 & 0.015 & 0.025 & 0.025 & 0.026 & 0.021 & 0.020 \\
\hline Mn & 0.015 & 0.018 & 0.017 & 0.016 & 0.005 & 0.010 & 0.015 & 0.016 & 0.018 & 0.019 & 0.021 & 0.019 & 0.019 & 0.004 & 0.005 & 0.011 & 0.012 & 0.018 & 0.020 & 0.019 \\
\hline $\mathbf{M g}$ & 0.812 & 0.778 & 0.806 & 0.790 & 0.901 & 0.936 & 0.874 & 0.806 & 0.786 & 0.785 & 0.749 & 0.779 & 0.772 & 0.876 & 0.893 & 0.807 & 0.815 & 0.791 & 0.794 & 0.801 \\
\hline $\mathrm{Ca}$ & 0.807 & 0.787 & 0.797 & 0.808 & 0.864 & 0.713 & 0.730 & 0.796 & 0.807 & 0.798 & 0.782 & 0.811 & 0.786 & 0.875 & 0.829 & 0.797 & 0.805 & 0.810 & 0.803 & 0.795 \\
\hline $\mathrm{Na}$ & 0.015 & 0.017 & 0.015 & 0.014 & 0.007 & 0.007 & 0.011 & 0.015 & 0.016 & 0.014 & 0.016 & 0.015 & 0.016 & 0.007 & 0.008 & 0.014 & 0.014 & 0.014 & 0.014 & 0.015 \\
\hline Total & 4.01 & 4.01 & 4.01 & 4.01 & 4.01 & 4.01 & 4.01 & 4.01 & 4.01 & 4.00 & 4.00 & 4.01 & 4.01 & 4.01 & 4.01 & 4.00 & 4.01 & 4.02 & 4.01 & 4.01 \\
\hline \multicolumn{21}{|l|}{ Atomic \% } \\
\hline Wo & 41.1 & 40.7 & 40.9 & 41.5 & 44.6 & 36.3 & 37.2 & 40.9 & 41.5 & 41.1 & 40.5 & 41.6 & 40.6 & 45.1 & 42.8 & 41.5 & 41.7 & 41.4 & 41.1 & 40.7 \\
\hline En & 41.4 & 40.2 & 41.3 & 40.6 & 46.5 & 47.6 & 44.6 & 41.4 & 40.4 & 40.4 & 38.8 & 40.0 & 39.9 & 45.2 & 46.1 & 42.0 & 42.1 & 40.4 & 40.6 & 41.0 \\
\hline Fs & 17.5 & 19.2 & 17.7 & 17.9 & 9.0 & 16.1 & 18.2 & 17.7 & 18.0 & 18.5 & 20.7 & 18.3 & 19.4 & 9.7 & 11.1 & 16.5 & 16.2 & 18.2 & 18.3 & 18.2 \\
\hline Mg \# & 69.4 & 66.6 & 68.9 & 68.4 & 83.5 & 74.2 & 70.1 & 69.0 & 68.1 & 67.5 & 64.1 & 67.5 & 66.2 & 82.0 & 80.2 & 71.1 & 71.5 & 67.9 & 67.8 & 68.1 \\
\hline
\end{tabular}


Table F.1 Continued

\begin{tabular}{|c|c|c|c|c|c|c|c|c|c|c|c|c|c|c|c|c|c|c|c|}
\hline Sample & & & & & & & & & & & & & & & RI18_PC05 & & & & \\
\hline Location & & & & & & & & & & & & & & & GLP & & & & \\
\hline Volcano & & & & & & & & & & & & & & & Raoul & & & & \\
\hline Type & & & & & & & & & & & & & & & Clusters-C1 & $\mathrm{C} 2$ & $\mathrm{C} 3$ & $\mathrm{C} 4$ & $\mathrm{C} 5$ \\
\hline Crystal no. & 43 & 44 & 45 & 46 & 46 & 47 & 48 & 48 & 48 & 48 & 49 & 50 & 51 & 52 & $a$ & $a$ & a & $a$ & a \\
\hline Analysis site & NVZ & NVZ & NVZ & core & rim & $\mathrm{NVZ}$ & core & $\mathrm{d}$ band & I band & rim & NVZ & NVZ & NVZ & $N V Z$ & NVZ & NVZ & NVZ & $N V Z$ & NVZ \\
\hline \multicolumn{20}{|l|}{ Oxides (wt \%) } \\
\hline $\mathrm{SiO}_{2}$ & 52.10 & 51.63 & 51.82 & 52.29 & 51.80 & 52.14 & 51.78 & 52.22 & 52.62 & 51.85 & 51.08 & 52.78 & 51.71 & 52.64 & 52.21 & 50.13 & 51.88 & 51.15 & 51.70 \\
\hline $\mathrm{TiO}_{2}$ & 0.34 & 0.43 & 0.39 & 0.33 & 0.39 & 0.29 & 0.21 & 0.19 & 0.27 & 0.39 & 0.55 & 0.28 & 0.40 & 0.27 & 0.32 & 0.50 & 0.38 & 0.36 & 0.30 \\
\hline $\mathrm{Al}_{2} \mathrm{O}_{3}$ & 1.72 & 2.43 & 1.99 & 1.54 & 2.28 & 1.59 & 3.93 & 3.85 & 2.59 & 2.26 & 3.04 & 1.28 & 2.05 & 1.40 & 1.57 & 2.69 & 1.73 & 1.71 & 1.35 \\
\hline $\mathrm{Cr}_{2} \mathrm{O}_{3}$ & 0.05 & 0.06 & 0.05 & 0.02 & 0.01 & 0.06 & 0.16 & 0.19 & 0.09 & 0.07 & 0.05 & 0.03 & 0.05 & 0.04 & 0.04 & 0.03 & 0.02 & 0.04 & 0.01 \\
\hline $\mathrm{FeO}(\mathrm{T})$ & 12.61 & 11.78 & 11.46 & 11.45 & 12.46 & 11.75 & 6.42 & 6.18 & 8.79 & 11.10 & 12.61 & 11.84 & 11.94 & 11.14 & 11.22 & 11.85 & 11.67 & 11.51 & 11.18 \\
\hline MnO & 0.69 & 0.56 & 0.54 & 0.58 & 0.59 & 0.61 & 0.16 & 0.13 & 0.22 & 0.42 & 0.59 & 0.62 & 0.58 & 0.59 & 0.56 & 0.52 & 0.58 & 0.59 & 0.58 \\
\hline MgO & 14.26 & 13.80 & 14.04 & 14.14 & 13.20 & 14.11 & 16.15 & 16.23 & 16.69 & 15.24 & 13.32 & 14.43 & 14.19 & 14.83 & 14.77 & 13.65 & 14.26 & 14.29 & 14.58 \\
\hline $\mathrm{CaO}$ & 18.98 & 20.15 & 20.52 & 20.56 & 20.36 & 20.23 & 22.59 & 22.61 & 19.74 & 19.30 & 20.01 & 20.17 & 19.87 & 19.82 & 20.36 & 20.40 & 20.34 & 20.56 & 20.37 \\
\hline $\mathrm{Na}_{2} \mathrm{O}$ & 0.21 & 0.24 & 0.23 & 0.21 & 0.21 & 0.19 & 0.09 & 0.10 & 0.11 & 0.17 & 0.26 & 0.20 & 0.20 & 0.22 & 0.20 & 0.26 & 0.22 & 0.21 & 0.18 \\
\hline Total & 100.97 & 101.08 & 101.03 & 101.12 & 101.31 & 100.98 & 101.49 & 101.69 & 101.11 & 100.80 & 101.51 & 101.62 & 100.99 & 100.95 & 101.26 & 100.02 & 101.07 & 100.43 & 100.24 \\
\hline \multicolumn{20}{|l|}{ Cations } \\
\hline Si & 1.95 & 1.93 & 1.93 & 1.95 & 1.93 & 1.95 & 1.88 & 1.89 & 1.93 & 1.93 & 1.90 & 1.96 & 1.93 & 1.96 & 1.94 & 1.90 & 1.94 & 1.92 & 1.94 \\
\hline $\mathrm{Ti}$ & 0.004 & 0.005 & 0.005 & 0.004 & 0.005 & 0.004 & 0.003 & 0.002 & 0.003 & 0.005 & 0.007 & 0.003 & 0.005 & 0.003 & 0.004 & 0.006 & 0.005 & 0.005 & 0.004 \\
\hline Al & 0.076 & 0.107 & 0.087 & 0.068 & 0.100 & 0.070 & 0.169 & 0.165 & 0.112 & 0.099 & 0.133 & 0.056 & 0.090 & 0.061 & 0.068 & 0.120 & 0.076 & 0.076 & 0.060 \\
\hline $\mathrm{Cr}$ & 0.002 & 0.002 & 0.001 & 0.001 & 0.000 & 0.002 & 0.005 & 0.005 & 0.003 & 0.002 & 0.002 & 0.001 & 0.002 & 0.001 & 0.001 & 0.001 & 0.001 & 0.001 & 0.000 \\
\hline Fe total & 0.392 & 0.365 & 0.355 & 0.355 & 0.387 & 0.365 & 0.193 & 0.186 & 0.267 & 0.342 & 0.390 & 0.365 & 0.371 & 0.344 & 0.347 & 0.372 & 0.362 & 0.360 & 0.349 \\
\hline $\mathrm{Fe}^{2+}$ & 0.371 & 0.338 & 0.331 & 0.334 & 0.362 & 0.347 & 0.181 & 0.175 & 0.251 & 0.318 & 0.356 & 0.348 & 0.346 & 0.328 & 0.327 & 0.340 & 0.338 & 0.337 & 0.331 \\
\hline $\mathrm{Fe}^{3+}$ & 0.021 & 0.027 & 0.024 & 0.020 & 0.024 & 0.018 & 0.013 & 0.011 & 0.016 & 0.024 & 0.034 & 0.017 & 0.025 & 0.016 & 0.020 & 0.032 & 0.024 & 0.023 & 0.019 \\
\hline Mn & 0.022 & 0.018 & 0.017 & 0.018 & 0.019 & 0.019 & 0.005 & 0.004 & 0.007 & 0.013 & 0.019 & 0.020 & 0.018 & 0.019 & 0.018 & 0.017 & 0.018 & 0.019 & 0.019 \\
\hline $\mathbf{M g}$ & 0.794 & 0.767 & 0.780 & 0.785 & 0.734 & 0.785 & 0.876 & 0.877 & 0.910 & 0.844 & 0.740 & 0.797 & 0.790 & 0.821 & 0.818 & 0.770 & 0.793 & 0.801 & 0.816 \\
\hline $\mathrm{Ca}$ & 0.759 & 0.805 & 0.820 & 0.820 & 0.814 & 0.809 & 0.881 & 0.879 & 0.774 & 0.768 & 0.799 & 0.801 & 0.795 & 0.789 & 0.810 & 0.827 & 0.813 & 0.829 & 0.820 \\
\hline $\mathrm{Na}$ & 0.015 & 0.017 & 0.016 & 0.015 & 0.015 & 0.014 & 0.006 & 0.007 & 0.008 & 0.012 & 0.019 & 0.014 & 0.014 & 0.016 & 0.014 & 0.019 & 0.016 & 0.015 & 0.013 \\
\hline Total & 4.01 & 4.01 & 4.01 & 4.01 & 4.01 & 4.01 & 4.02 & 4.02 & 4.01 & 4.01 & 4.01 & 4.01 & 4.01 & 4.01 & 4.02 & 4.03 & 4.02 & 4.03 & 4.02 \\
\hline \multicolumn{20}{|l|}{ Atomic \% } \\
\hline Wo & 39.0 & 41.6 & 41.9 & 41.9 & 42.1 & 41.3 & 45.2 & 45.3 & 39.7 & 39.3 & 41.4 & 40.8 & 40.6 & 40.4 & 41.0 & 42.0 & 41.3 & 41.7 & 41.3 \\
\hline En & 40.8 & 39.6 & 39.9 & 40.0 & 37.9 & 40.1 & 44.9 & 45.2 & 46.7 & 43.2 & 38.4 & 40.6 & 40.4 & 42.0 & 41.4 & 39.1 & 40.3 & 40.3 & 41.1 \\
\hline Fs & 20.1 & 18.8 & 18.2 & 18.1 & 20.0 & 18.6 & 9.9 & 9.6 & 13.7 & 17.5 & 20.2 & 18.6 & 19.0 & 17.6 & 17.6 & 18.9 & 18.4 & 18.1 & 17.6 \\
\hline Mg \# & 65.7 & 66.7 & 67.7 & 67.8 & 64.4 & 67.1 & 81.6 & 82.2 & 76.9 & 70.4 & 64.4 & 67.4 & 67.0 & 69.3 & 69.2 & 66.4 & 67.6 & 67.9 & 68.9 \\
\hline
\end{tabular}


Table F.1 Continued

\begin{tabular}{|c|c|c|c|c|c|c|c|c|c|c|c|c|c|c|c|c|c|c|c|}
\hline Sample & & & & & RI26_PC01 & & & & & & & & & & & & & & \\
\hline Location & & & & & Fleetwood & & & & & & & & & & & & & & \\
\hline Volcano & & & & & Raoul & & & & & & & & & & & & & & \\
\hline Type & $\mathrm{C} 6$ & & $\mathrm{C} 7$ & & Single crystal & & & & & & & & & & & & & & \\
\hline Crystal no. & $a$ & $\mathrm{~b}$ & a & $\mathrm{b}$ & 1 & 2 & 3 & 4 & 4 & 5 & 6 & 7 & 8 & 9 & 10 & 11 & 12 & 12 & 13 \\
\hline Analysis site & $\mathrm{NVZ}$ & NVZ & NVZ & NVZ & NVZ & NVZ & NVZ & core & rim & NVZ & NVZ & $\mathrm{NVZ}$ & NVZ & $\mathrm{NVZ}$ & NVZ & $\mathrm{NVZ}$ & core & rim & $\mathrm{NVZ}$ \\
\hline \multicolumn{20}{|l|}{ Oxides (wt \%) } \\
\hline $\mathrm{SiO}_{2}$ & 51.63 & 51.33 & 51.04 & 51.05 & 53.03 & 53.55 & 52.80 & 52.64 & 51.39 & 52.91 & 53.36 & 52.67 & 52.12 & 52.40 & 52.49 & 51.99 & 53.48 & 51.71 & 52.28 \\
\hline $\mathrm{TiO}_{2}$ & 0.33 & 0.35 & 0.41 & 0.39 & 0.19 & 0.14 & 0.18 & 0.18 & 0.29 & 0.16 & 0.19 & 0.17 & 0.18 & 0.20 & 0.19 & 0.22 & 0.11 & 0.27 & 0.21 \\
\hline $\mathrm{Al}_{2} \mathrm{O}_{3}$ & 1.55 & 1.64 & 1.99 & 1.97 & 3.13 & 2.17 & 3.28 & 3.29 & 4.00 & 3.06 & 1.71 & 3.11 & 3.06 & 2.92 & 2.89 & 3.43 & 2.27 & 3.49 & 3.29 \\
\hline $\mathrm{Cr}_{2} \mathrm{O}_{3}$ & 0.06 & 0.05 & 0.04 & 0.03 & 0.36 & 0.13 & 0.11 & 0.19 & 0.11 & 0.29 & 0.04 & 0.19 & 0.16 & 0.10 & 0.16 & 0.09 & 0.11 & 0.14 & 0.20 \\
\hline $\mathrm{FeO}(\mathrm{T})$ & 11.75 & 11.50 & 11.72 & 11.72 & 4.88 & 6.08 & 5.12 & 5.39 & 8.06 & 4.76 & 7.64 & 5.58 & 5.95 & 7.12 & 6.76 & 6.25 & 4.87 & 8.18 & 5.33 \\
\hline $\mathrm{MnO}$ & 0.64 & 0.57 & 0.60 & 0.57 & 0.10 & 0.15 & 0.10 & 0.13 & 0.20 & 0.11 & 0.27 & 0.13 & 0.13 & 0.17 & 0.17 & 0.13 & 0.10 & 0.20 & 0.12 \\
\hline MgO & 14.40 & 14.42 & 14.40 & 14.16 & 17.13 & 17.47 & 17.14 & 16.80 & 15.97 & 17.05 & 16.97 & 16.87 & 16.45 & 16.41 & 16.64 & 16.44 & 17.73 & 16.39 & 16.89 \\
\hline $\mathrm{CaO}$ & 20.37 & 20.58 & 20.30 & 20.15 & 22.70 & 21.62 & 22.28 & 22.43 & 20.77 & 22.62 & 20.93 & 22.00 & 22.18 & 21.73 & 21.59 & 22.25 & 22.22 & 20.03 & 22.30 \\
\hline $\mathrm{Na}_{2} \mathrm{O}$ & 0.23 & 0.21 & 0.23 & 0.19 & 0.10 & 0.07 & 0.10 & 0.09 & 0.12 & 0.07 & 0.13 & 0.09 & 0.19 & 0.10 & 0.11 & 0.09 & 0.07 & 0.10 & 0.07 \\
\hline Total & 100.96 & 100.65 & 100.72 & 100.23 & 101.61 & 101.37 & 101.10 & 101.13 & 100.91 & 101.03 & 101.22 & 100.82 & 100.40 & 101.15 & 100.98 & 100.90 & 100.97 & 100.50 & 100.69 \\
\hline \multicolumn{20}{|l|}{ Cations } \\
\hline $\mathrm{Si}$ & 1.93 & 1.93 & 1.91 & 1.92 & 1.91 & 1.94 & 1.91 & 1.91 & 1.89 & 1.92 & 1.95 & 1.92 & 1.91 & 1.91 & 1.92 & 1.90 & 1.94 & 1.90 & 1.91 \\
\hline $\mathrm{Ti}$ & 0.004 & 0.004 & 0.005 & 0.005 & 0.002 & 0.002 & 0.002 & 0.002 & 0.004 & 0.002 & 0.002 & 0.002 & 0.002 & 0.003 & 0.002 & 0.003 & 0.001 & 0.003 & 0.003 \\
\hline Al & 0.068 & 0.072 & 0.088 & 0.087 & 0.133 & 0.093 & 0.140 & 0.141 & 0.173 & 0.131 & 0.073 & 0.133 & 0.132 & 0.126 & 0.124 & 0.148 & 0.097 & 0.151 & 0.141 \\
\hline $\mathrm{Cr}$ & 0.002 & 0.002 & 0.001 & 0.001 & 0.010 & 0.004 & 0.003 & 0.005 & 0.003 & 0.008 & 0.001 & 0.006 & 0.005 & 0.003 & 0.005 & 0.002 & 0.003 & 0.004 & 0.006 \\
\hline $\mathrm{Fe}$ tot & 0.366 & 0.359 & 0.365 & 0.367 & 0.145 & 0.183 & 0.153 & 0.161 & 0.245 & 0.142 & 0.231 & 0.168 & 0.180 & 0.216 & 0.204 & 0.189 & 0.146 & 0.249 & 0.160 \\
\hline $\mathrm{Fe}^{2+}$ & 0.345 & 0.337 & 0.340 & 0.342 & 0.134 & 0.175 & 0.142 & 0.151 & 0.228 & 0.133 & 0.220 & 0.158 & 0.170 & 0.203 & 0.193 & 0.176 & 0.139 & 0.233 & 0.148 \\
\hline $\mathrm{Fe}^{3+}$ & 0.021 & 0.022 & 0.026 & 0.025 & 0.011 & 0.008 & 0.011 & 0.011 & 0.017 & 0.009 & 0.011 & 0.010 & 0.011 & 0.012 & 0.011 & 0.013 & 0.007 & 0.016 & 0.012 \\
\hline$M n$ & 0.020 & 0.018 & 0.019 & 0.018 & 0.003 & 0.005 & 0.003 & 0.004 & 0.006 & 0.003 & 0.008 & 0.004 & 0.004 & 0.005 & 0.005 & 0.004 & 0.003 & 0.006 & 0.004 \\
\hline $\mathbf{M g}$ & 0.803 & 0.806 & 0.805 & 0.795 & 0.921 & 0.943 & 0.926 & 0.909 & 0.874 & 0.921 & 0.923 & 0.915 & 0.899 & 0.893 & 0.906 & 0.896 & 0.957 & 0.899 & 0.918 \\
\hline $\mathrm{Ca}$ & 0.817 & 0.827 & 0.816 & 0.813 & 0.877 & 0.839 & 0.865 & 0.872 & 0.817 & 0.879 & 0.818 & 0.858 & 0.872 & 0.850 & 0.844 & 0.871 & 0.862 & 0.790 & 0.871 \\
\hline $\mathrm{Na}$ & 0.016 & 0.015 & 0.017 & 0.014 & 0.007 & 0.005 & 0.007 & 0.006 & 0.008 & 0.005 & 0.009 & 0.007 & 0.013 & 0.007 & 0.008 & 0.006 & 0.005 & 0.007 & 0.005 \\
\hline Total & 4.03 & 4.03 & 4.03 & 4.02 & 4.01 & 4.01 & 4.01 & 4.01 & 4.02 & 4.01 & 4.01 & 4.01 & 4.02 & 4.02 & 4.01 & 4.02 & 4.01 & 4.01 & 4.01 \\
\hline \multicolumn{20}{|l|}{ Atomic $\%$} \\
\hline Wo & 41.1 & 41.5 & 41.1 & 41.2 & 45.2 & 42.7 & 44.5 & 44.9 & 42.2 & 45.3 & 41.5 & 44.2 & 44.7 & 43.4 & 43.2 & 44.6 & 43.9 & 40.8 & 44.7 \\
\hline En & 40.5 & 40.5 & 40.5 & 40.3 & 47.4 & 48.0 & 47.6 & 46.8 & 45.1 & 47.4 & 46.8 & 47.2 & 46.1 & 45.6 & 46.3 & 45.8 & 48.7 & 46.4 & 47.1 \\
\hline Fs & 18.4 & 18.0 & 18.4 & 18.6 & 7.4 & 9.3 & 7.9 & 8.3 & 12.7 & 7.3 & 11.7 & 8.6 & 9.2 & 11.0 & 10.5 & 9.7 & 7.4 & 12.9 & 8.2 \\
\hline $\mathrm{Mg} \#$ & 67.5 & 68.2 & 67.7 & 67.4 & 86.2 & 83.4 & 85.6 & 84.6 & 77.7 & 86.4 & 79.4 & 84.2 & 83.0 & 80.2 & 81.2 & 82.3 & 86.5 & 77.8 & 84.9 \\
\hline
\end{tabular}


Table F.1 Continued

\begin{tabular}{|c|c|c|c|c|c|c|c|c|c|c|c|c|c|c|c|c|c|c|c|c|}
\hline \multicolumn{21}{|l|}{ Sample } \\
\hline \multicolumn{21}{|l|}{ Location } \\
\hline \multicolumn{21}{|l|}{ Volcano } \\
\hline \multicolumn{21}{|l|}{ Type } \\
\hline Crystal no. & 14 & 15 & 16 & 17 & 18 & 19 & 20 & 21 & 22 & 23 & 23 & 24 & 25 & 25 & 26 & 27 & 28 & 29 & 30 & 3 \\
\hline Analysis site & NVZ & NVZ & NVZ & NVZ & NVZ & NVZ & NVZ & $\mathrm{NVZ}$ & NVZ & core & rim & NVZ & core & rim & NVZ & NVZ & NVZ & NVZ & NVZ & $\mathrm{NVZ}$ \\
\hline \multicolumn{21}{|l|}{ Oxides (wt \%) } \\
\hline $\mathrm{SiO}_{2}$ & 52.25 & 51.78 & 52.19 & 52.42 & 52.50 & 52.04 & 52.54 & 52.44 & 53.82 & 52.69 & 52.83 & 52.25 & 52.43 & 51.02 & 52.91 & 52.77 & 53.34 & 53.06 & 52.76 & 53.16 \\
\hline $\mathrm{TiO}_{2}$ & 0.19 & 0.19 & 0.22 & 0.20 & 0.19 & 0.24 & 0.17 & 0.21 & 0.13 & 0.20 & 0.32 & 0.21 & 0.20 & 0.40 & 0.18 & 0.20 & 0.13 & 0.14 & 0.19 & 0.12 \\
\hline $\mathrm{Al}_{2} \mathrm{O}_{3}$ & 2.98 & 3.57 & 3.56 & 2.57 & 3.52 & 3.24 & 3.03 & 3.13 & 2.17 & 3.18 & 2.11 & 3.20 & 3.21 & 4.19 & 3.09 & 2.99 & 2.74 & 3.09 & 3.22 & 2.68 \\
\hline $\mathrm{Cr}_{2} \mathrm{O}_{3}$ & 0.18 & 0.23 & 0.15 & 0.06 & 0.22 & 0.08 & 0.16 & 0.19 & 0.28 & 0.17 & 0.07 & 0.13 & 0.10 & 0.12 & 0.17 & 0.14 & 0.26 & 0.08 & 0.10 & 0.52 \\
\hline $\mathrm{FeO}(\mathrm{T})$ & 6.12 & 5.29 & 6.17 & 8.16 & 5.60 & 7.78 & 6.51 & 6.46 & 5.28 & 6.08 & 13.80 & 7.10 & 6.40 & 8.09 & 5.29 & 6.21 & 4.76 & 5.24 & 5.89 & 4.63 \\
\hline $\mathrm{MnO}$ & 0.16 & 0.10 & 0.11 & 0.25 & 0.11 & 0.19 & 0.17 & 0.15 & 0.14 & 0.13 & 0.44 & 0.15 & 0.16 & 0.18 & 0.11 & 0.14 & 0.14 & 0.12 & 0.15 & 0.12 \\
\hline MgO & 16.51 & 16.52 & 16.58 & 16.12 & 16.89 & 15.98 & 16.68 & 16.62 & 17.74 & 16.71 & 15.02 & 16.22 & 16.58 & 15.84 & 17.13 & 16.81 & 17.38 & 17.24 & 16.61 & 17.62 \\
\hline $\mathrm{CaO}$ & 22.06 & 22.55 & 21.96 & 20.78 & 21.90 & 21.27 & 21.67 & 21.81 & 21.81 & 22.18 & 15.07 & 21.81 & 21.99 & 21.02 & 22.48 & 21.84 & 22.51 & 22.38 & 22.23 & 22.41 \\
\hline $\mathrm{Na}_{2} \mathrm{O}$ & 0.09 & 0.09 & 0.10 & 0.11 & 0.08 & 0.11 & 0.10 & 0.09 & 0.10 & 0.12 & 0.13 & 0.10 & 0.12 & 0.13 & 0.09 & 0.10 & 0.09 & 0.09 & 0.09 & 0.08 \\
\hline Total & 100.53 & 100.32 & 101.05 & 100.67 & 101.02 & 100.92 & 101.02 & 101.11 & 101.48 & 101.44 & 99.79 & 101.17 & 101.18 & 100.99 & 101.43 & 101.21 & 101.35 & 101.44 & 101.22 & 101.34 \\
\hline \multicolumn{21}{|l|}{ Cations } \\
\hline $\mathbf{S i}$ & 1.91 & 1.90 & 1.90 & 1.93 & 1.91 & 1.91 & 1.92 & 1.91 & 1.94 & 1.91 & 1.97 & 1.91 & 1.91 & 1.87 & 1.91 & 1.92 & 1.93 & 1.92 & 1.92 & 1.92 \\
\hline $\mathrm{Ti}$ & 0.002 & 0.002 & 0.003 & 0.003 & 0.002 & 0.003 & 0.002 & 0.003 & 0.002 & 0.003 & 0.004 & 0.003 & 0.002 & 0.005 & 0.002 & 0.002 & 0.002 & 0.002 & 0.002 & 0.002 \\
\hline Al & 0.129 & 0.154 & 0.153 & 0.111 & 0.151 & 0.140 & 0.130 & 0.134 & 0.092 & 0.136 & 0.093 & 0.138 & 0.138 & 0.181 & 0.132 & 0.128 & 0.117 & 0.131 & 0.138 & 0.114 \\
\hline $\mathrm{Cr}$ & 0.005 & 0.007 & 0.004 & 0.002 & 0.006 & 0.002 & 0.005 & 0.006 & 0.008 & 0.005 & 0.002 & 0.004 & 0.003 & 0.004 & 0.005 & 0.004 & 0.007 & 0.002 & 0.003 & 0.01 \\
\hline $\mathrm{Fe}$ total & 0.185 & 0.160 & 0.186 & 0.249 & 0.168 & 0.236 & 0.197 & 0.195 & 0.158 & 0.182 & 0.430 & 0.215 & 0.193 & 0.245 & 0.158 & 0.187 & 0.142 & 0.157 & 0.177 & 0.138 \\
\hline $\mathrm{Fe}^{2+}$ & 0.174 & 0.148 & 0.173 & 0.237 & 0.156 & 0.222 & 0.186 & 0.182 & 0.150 & 0.170 & 0.410 & 0.202 & 0.181 & 0.221 & 0.147 & 0.175 & 0.134 & 0.148 & 0.166 & 0.131 \\
\hline $\mathrm{Fe}^{3+}$ & 0.012 & 0.012 & 0.013 & 0.012 & 0.011 & 0.014 & 0.010 & 0.013 & 0.008 & 0.012 & 0.020 & 0.012 & 0.012 & 0.024 & 0.010 & 0.012 & 0.008 & 0.008 & 0.011 & 0.007 \\
\hline Mn & 0.005 & 0.003 & 0.003 & 0.008 & 0.003 & 0.006 & 0.005 & 0.005 & 0.004 & 0.004 & 0.014 & 0.005 & 0.005 & 0.006 & 0.003 & 0.004 & 0.004 & 0.004 & 0.004 & 0.004 \\
\hline Mg & 0.902 & 0.902 & 0.900 & 0.884 & 0.914 & 0.874 & 0.906 & 0.903 & 0.953 & 0.903 & 0.837 & 0.883 & 0.900 & 0.868 & 0.924 & 0.911 & 0.935 & 0.928 & 0.899 & 0.949 \\
\hline $\mathrm{Ca}$ & 0.866 & 0.885 & 0.857 & 0.819 & 0.852 & 0.836 & 0.846 & 0.852 & 0.843 & 0.862 & 0.604 & 0.854 & 0.858 & 0.828 & 0.871 & 0.851 & 0.871 & 0.866 & 0.865 & 0.867 \\
\hline $\mathrm{Na}$ & 0.007 & 0.007 & 0.007 & 0.008 & 0.005 & 0.008 & 0.007 & 0.007 & 0.007 & 0.008 & 0.010 & 0.007 & 0.009 & 0.009 & 0.006 & 0.007 & 0.006 & 0.007 & 0.007 & 0.005 \\
\hline Total & 4.01 & 4.02 & 4.01 & 4.01 & 4.01 & 4.01 & 4.01 & 4.01 & 4.01 & 4.01 & 3.97 & 4.02 & 4.02 & 4.02 & 4.01 & 4.01 & 4.01 & 4.01 & 4.01 & 4.01 \\
\hline \multicolumn{21}{|l|}{ Atomic \% } \\
\hline Wo & 44.3 & 45.5 & 44.1 & 42.0 & 44.1 & 43.0 & 43.4 & 43.7 & 43.1 & 44.3 & 32.3 & 43.7 & 44.0 & 42.6 & 44.6 & 43.7 & 44.7 & 44.4 & 44.6 & 44. \\
\hline En & 46.2 & 46.3 & 46.3 & 45.3 & 47.3 & 44.9 & 46.5 & 46.3 & 48.8 & 46.4 & 44.7 & 45.3 & 46.1 & 44.7 & 47.3 & 46.8 & 48.0 & 47.6 & 46.3 & 48.5 \\
\hline Fs & 9.5 & 8.2 & 9.6 & 12.8 & 8.7 & 12.2 & 10.1 & 10.0 & 8.1 & 9.4 & 23.0 & 11.0 & 9.9 & 12.6 & 8.1 & 9.6 & 7.3 & 8.0 & 9.1 & 7. \\
\hline Mg \# & 82.6 & 84.7 & 82.6 & 77.5 & 84.2 & 78.3 & 81.8 & 81.9 & 85.5 & 82.9 & 65.3 & 80.1 & 82.0 & 77.6 & 85.2 & 82.7 & 86.5 & 85.3 & 83.2 & 87.0 \\
\hline
\end{tabular}


Table F.1 Continued

\begin{tabular}{|c|c|c|c|c|c|c|c|c|c|c|c|c|c|c|c|c|c|c|c|c|}
\hline \multicolumn{21}{|l|}{ Sample } \\
\hline \multicolumn{21}{|l|}{ Location } \\
\hline \multicolumn{21}{|l|}{ Volcano } \\
\hline \multicolumn{21}{|l|}{ Type } \\
\hline Crystal no. & 32 & 33 & 34 & 35 & 35 & 36 & 37 & 38 & 39 & 40 & 41 & 42 & 43 & 44 & 45 & 46 & 47 & 48 & 48 & . \\
\hline Analysis site & NVZ & NVZ & NVZ & core & rim & NVZ & NVZ & NVZ & NVZ & NVZ & NVZ & NVZ & NVZ & NVZ & NVZ & NVZ & NVZ & core & rim & $\mathrm{NVZ}$ \\
\hline \multicolumn{21}{|l|}{ Oxides (wt \%) } \\
\hline $\mathrm{SiO}_{2}$ & 52.62 & 52.87 & 52.27 & 52.95 & 51.82 & 53.22 & 52.66 & 53.19 & 52.55 & 52.55 & 53.46 & 52.39 & 52.83 & 53.04 & 53.34 & 52.57 & 53.34 & 53.05 & 51.69 & 52.61 \\
\hline $\mathrm{TiO}_{2}$ & 0.16 & 0.18 & 0.22 & 0.17 & 0.38 & 0.16 & 0.21 & 0.16 & 0.21 & 0.21 & 0.17 & 0.23 & 0.16 & 0.17 & 0.15 & 0.18 & 0.14 & 0.14 & 0.33 & 0.20 \\
\hline $\mathrm{Al}_{2} \mathrm{O}_{3}$ & 3.35 & 2.92 & 3.86 & 3.36 & 3.95 & 2.94 & 3.24 & 2.89 & 3.68 & 3.40 & 2.17 & 3.19 & 3.20 & 3.12 & 2.64 & 3.22 & 2.84 & 2.94 & 4.10 & 3.25 \\
\hline $\mathrm{Cr}_{2} \mathrm{O}_{3}$ & 0.21 & 0.32 & 0.22 & 0.18 & 0.06 & 0.16 & 0.10 & 0.46 & 0.19 & 0.10 & 0.05 & 0.13 & 0.21 & 0.24 & 0.43 & 0.22 & 0.28 & 0.33 & 0.10 & 0.13 \\
\hline $\mathrm{FeO}(\mathrm{T})$ & 5.65 & 5.82 & 5.72 & 5.22 & 10.55 & 5.73 & 6.28 & 4.43 & 5.79 & 6.47 & 7.20 & 6.81 & 5.45 & 5.86 & 4.47 & 5.79 & 4.74 & 4.87 & 8.29 & 6.40 \\
\hline MnO & 0.11 & 0.14 & 0.12 & 0.11 & 0.25 & 0.12 & 0.15 & 0.11 & 0.11 & 0.15 & 0.16 & 0.14 & 0.14 & 0.13 & 0.11 & 0.10 & 0.10 & 0.11 & 0.22 & 0.14 \\
\hline MgO & 16.90 & 17.49 & 16.53 & 17.12 & 16.07 & 17.12 & 16.57 & 17.43 & 16.48 & 16.42 & 17.41 & 16.44 & 17.01 & 16.84 & 17.30 & 16.69 & 17.31 & 17.32 & 16.36 & 16.46 \\
\hline $\mathrm{CaO}$ & 22.07 & 21.49 & 22.50 & 22.63 & 18.45 & 22.46 & 22.31 & 22.62 & 22.28 & 22.16 & 20.68 & 21.93 & 22.25 & 21.96 & 22.71 & 22.63 & 22.87 & 22.40 & 19.65 & 22.04 \\
\hline $\mathrm{Na}_{2} \mathrm{O}$ & 0.11 & 0.12 & 0.11 & 0.08 & 0.15 & 0.09 & 0.10 & 0.09 & 0.10 & 0.09 & 0.10 & 0.10 & 0.09 & 0.09 & 0.09 & 0.11 & 0.06 & 0.09 & 0.13 & 0.09 \\
\hline Total & 101.18 & 101.34 & 101.54 & 101.83 & 101.67 & 101.99 & 101.61 & 101.36 & 101.38 & 101.56 & 101.41 & 101.36 & 101.35 & 101.45 & 101.24 & 101.50 & 101.67 & 101.25 & 100.86 & 101.32 \\
\hline \multicolumn{21}{|l|}{ Cations } \\
\hline $\mathbf{S i}$ & 1.91 & 1.91 & 1.89 & 1.91 & 1.89 & 1.92 & 1.91 & 1.92 & 1.90 & 1.91 & 1.94 & 1.91 & 1.91 & 1.92 & 1.93 & 1.91 & 1.92 & 1.92 & 1.89 & 1.91 \\
\hline $\mathrm{Ti}$ & 0.002 & 0.002 & 0.003 & 0.002 & 0.005 & 0.002 & 0.003 & 0.002 & 0.003 & 0.003 & 0.002 & 0.003 & 0.002 & 0.002 & 0.002 & 0.002 & 0.002 & 0.002 & 0.004 & 0.003 \\
\hline Al & 0.143 & 0.125 & 0.165 & 0.143 & 0.170 & 0.125 & 0.138 & 0.123 & 0.157 & 0.145 & 0.093 & 0.137 & 0.137 & 0.133 & 0.112 & 0.138 & 0.121 & 0.125 & 0.177 & 0.139 \\
\hline $\mathrm{Cr}$ & 0.006 & 0.009 & 0.006 & 0.005 & 0.002 & 0.005 & 0.003 & 0.013 & 0.005 & 0.003 & 0.002 & 0.004 & 0.006 & 0.007 & 0.012 & 0.006 & 0.008 & 0.009 & 0.003 & 0.004 \\
\hline $\mathrm{Fe}$ tot & 0.169 & 0.174 & 0.171 & 0.155 & 0.320 & 0.171 & 0.188 & 0.131 & 0.173 & 0.194 & 0.217 & 0.205 & 0.163 & 0.175 & 0.133 & 0.173 & 0.141 & 0.145 & 0.251 & 0.192 \\
\hline $\mathrm{Fe}^{2+}$ & 0.160 & 0.164 & 0.158 & 0.145 & 0.298 & 0.162 & 0.176 & 0.122 & 0.161 & 0.182 & 0.207 & 0.191 & 0.153 & 0.165 & 0.124 & 0.163 & 0.133 & 0.137 & 0.231 & 0.180 \\
\hline $\mathrm{Fe}^{3+}$ & 0.010 & 0.011 & 0.013 & 0.010 & 0.023 & 0.009 & 0.012 & 0.009 & 0.012 & 0.013 & 0.010 & 0.014 & 0.010 & 0.010 & 0.009 & 0.011 & 0.008 & 0.008 & 0.020 & 0.012 \\
\hline Mn & 0.003 & 0.004 & 0.004 & 0.003 & 0.008 & 0.004 & 0.005 & 0.003 & 0.003 & 0.005 & 0.005 & 0.004 & 0.004 & 0.004 & 0.003 & 0.003 & 0.003 & 0.003 & 0.007 & 0.004 \\
\hline Mg & 0.914 & 0.944 & 0.893 & 0.919 & 0.876 & 0.919 & 0.896 & 0.937 & 0.890 & 0.888 & 0.942 & 0.893 & 0.918 & 0.909 & 0.932 & 0.902 & 0.929 & 0.934 & 0.893 & 0.892 \\
\hline $\mathrm{Ca}$ & 0.858 & 0.834 & 0.873 & 0.873 & 0.723 & 0.867 & 0.867 & 0.874 & 0.865 & 0.862 & 0.804 & 0.855 & 0.863 & 0.851 & 0.879 & 0.879 & 0.882 & 0.868 & 0.771 & 0.858 \\
\hline $\mathrm{Na}$ & 0.007 & 0.009 & 0.007 & 0.005 & 0.011 & 0.006 & 0.007 & 0.006 & 0.007 & 0.007 & 0.007 & 0.007 & 0.006 & 0.006 & 0.006 & 0.007 & 0.004 & 0.006 & 0.009 & 0.006 \\
\hline Total & 4.01 & 4.02 & 4.02 & 4.01 & 4.01 & 4.01 & 4.01 & 4.01 & 4.01 & 4.01 & 4.01 & 4.02 & 4.01 & 4.01 & 4.01 & 4.02 & 4.01 & 4.01 & 4.01 & 4.01 \\
\hline \multicolumn{21}{|l|}{ Atomic \% } \\
\hline Wo & 44.2 & 42.7 & 45.1 & 44.8 & 37.7 & 44.3 & 44.4 & 45.0 & 44.9 & 44.3 & 41.0 & 43.8 & 44.4 & 44.0 & 45.2 & 45.0 & 45.2 & 44.6 & 40.3 & 44. \\
\hline En & 47.1 & 48.4 & 46.1 & 47.2 & 45.6 & 47.0 & 45.9 & 48.2 & 46.2 & 45.7 & 48.0 & 45.7 & 47.2 & 46.9 & 47.9 & 46.2 & 47.6 & 48.0 & 46.6 & 45.8 \\
\hline Fs & 8.7 & 8.9 & 8.8 & 8.0 & 16.7 & 8.7 & 9.6 & 6.8 & 9.0 & 10.0 & 11.1 & 10.5 & 8.4 & 9.1 & 6.8 & 8.9 & 7.2 & 7.5 & 13.1 & 9. \\
\hline Mg \# & 84.1 & 84.1 & 83.7 & 85.3 & 72.8 & 84.1 & 82.3 & 87.4 & 83.5 & 81.7 & 80.9 & 81.0 & 84.6 & 83.5 & 87.2 & 83.6 & 86.6 & 86.3 & 77.6 & 81.9 \\
\hline
\end{tabular}


Table F.1 Continued

\begin{tabular}{|c|c|c|c|c|c|c|c|c|c|c|c|c|c|c|c|c|c|c|c|}
\hline Sample & & & & & & & & & & & RI26_PC01 & & & & & & & & \\
\hline Location & & & & & & & & & & & Fleetwood & & & & & & & & \\
\hline Volcano & & & & & & & & & & & Raoul & & & & & & & & \\
\hline Type & & & & & & & & & & & Clusters-C1 & $\mathrm{C} 2$ & $\mathrm{C} 7$ & $\mathrm{C} 8$ & $\mathrm{C} 10$ & $\mathrm{C} 8$ & $\mathrm{C9}$ & C11 & $\mathrm{C} 12$ \\
\hline Crystal no. & 50 & 51 & 52 & 52 & 53 & 54 & 55 & 56 & 57 & 58 & $\mathrm{a}$ & a & $a$ & a & a & a & a & $a$ & a \\
\hline Analysis site & NVZ & NVZ & core & $\mathrm{rim}$ & $\mathrm{NVZ}$ & $\mathrm{NVZ}$ & NVZ & NVZ & $\mathrm{NVZ}$ & NVZ & NVZ & NVZ & NVZ & $\mathrm{NVZ}$ & NVZ & NVZ & NVZ & $\mathrm{NVZ}$ & $\mathrm{NVZ}$ \\
\hline \multicolumn{20}{|l|}{ Oxides (wt \%) } \\
\hline $\mathrm{SiO}_{2}$ & 52.50 & 52.35 & 52.59 & 51.34 & 52.05 & 52.49 & 52.64 & 52.95 & 52.42 & 52.68 & 51.14 & 51.96 & 51.46 & 51.51 & 51.23 & 51.05 & 51.00 & 50.61 & 51.38 \\
\hline $\mathrm{TiO}_{2}$ & 0.18 & 0.22 & 0.19 & 0.43 & 0.20 & 0.16 & 0.18 & 0.16 & 0.18 & 0.17 & 0.37 & 0.30 & 0.30 & 0.31 & 0.30 & 0.30 & 0.38 & 0.40 & 0.44 \\
\hline $\mathrm{Al}_{2} \mathrm{O}_{3}$ & 3.07 & 3.28 & 3.61 & 4.26 & 3.29 & 3.01 & 2.72 & 3.31 & 3.21 & 3.36 & 1.68 & 1.38 & 1.44 & 1.53 & 1.31 & 1.59 & 2.14 & 2.02 & 2.60 \\
\hline $\mathrm{Cr}_{2} \mathrm{O}_{3}$ & 0.17 & 0.15 & 0.22 & 0.06 & 0.31 & 0.21 & 0.10 & 0.21 & 0.16 & 0.23 & 0.06 & 0.04 & 0.05 & 0.06 & 0.04 & 0.01 & 0.06 & 0.04 & 0.03 \\
\hline $\mathrm{FeO}(\mathrm{T})$ & 6.42 & 6.37 & 5.42 & 10.57 & 5.50 & 6.05 & 7.27 & 5.21 & 6.15 & 5.59 & 12.08 & 11.83 & 12.07 & 12.03 & 12.03 & 12.03 & 11.87 & 12.68 & 11.31 \\
\hline $\mathrm{MnO}$ & 0.14 & 0.13 & 0.11 & 0.24 & 0.12 & 0.14 & 0.21 & 0.10 & 0.14 & 0.13 & 0.54 & 0.54 & 0.56 & 0.54 & 0.57 & 0.57 & 0.54 & 0.56 & 0.44 \\
\hline MgO & 16.72 & 16.45 & 16.74 & 15.51 & 16.74 & 16.96 & 16.48 & 17.05 & 16.58 & 16.92 & 13.94 & 14.08 & 13.92 & 14.08 & 13.92 & 13.73 & 13.88 & 13.51 & 14.08 \\
\hline $\mathrm{CaO}$ & 21.88 & 22.10 & 22.47 & 19.04 & 22.34 & 21.88 & 21.30 & 22.39 & 21.85 & 21.76 & 20.15 & 20.26 & 20.05 & 19.95 & 20.15 & 20.37 & 20.04 & 19.69 & 20.23 \\
\hline $\mathrm{Na}_{2} \mathrm{O}$ & 0.08 & 0.09 & 0.09 & 0.14 & 0.11 & 0.12 & 0.12 & 0.08 & 0.11 & 0.09 & 0.20 & 0.21 & 0.20 & 0.21 & 0.18 & 0.19 & 0.20 & 0.23 & 0.19 \\
\hline Total & 101.16 & 101.14 & 101.43 & 101.58 & 100.65 & 101.03 & 101.01 & 101.46 & 100.79 & 100.93 & 100.16 & 100.58 & 100.04 & 100.21 & 99.72 & 99.85 & 100.11 & 99.74 & 100.71 \\
\hline \multicolumn{20}{|l|}{ Cations } \\
\hline Si & 1.91 & 1.91 & 1.90 & 1.88 & 1.90 & 1.91 & 1.92 & 1.91 & 1.91 & 1.91 & 1.93 & 1.95 & 1.94 & 1.94 & 1.94 & 1.93 & 1.92 & 1.92 & 1.92 \\
\hline $\mathrm{Ti}$ & 0.002 & 0.003 & 0.002 & 0.005 & 0.002 & 0.002 & 0.002 & 0.002 & 0.002 & 0.002 & 0.005 & 0.004 & 0.004 & 0.004 & 0.004 & 0.004 & 0.005 & 0.005 & 0.006 \\
\hline Al & 0.132 & 0.141 & 0.154 & 0.184 & 0.142 & 0.129 & 0.117 & 0.141 & 0.138 & 0.144 & 0.075 & 0.061 & 0.064 & 0.068 & 0.059 & 0.071 & 0.095 & 0.090 & 0.114 \\
\hline $\mathrm{Cr}$ & 0.005 & 0.004 & 0.006 & 0.002 & 0.009 & 0.006 & 0.003 & 0.006 & 0.005 & 0.007 & 0.002 & 0.001 & 0.001 & 0.002 & 0.001 & 0.000 & 0.002 & 0.001 & 0.001 \\
\hline $\mathrm{Fe}$ total & 0.194 & 0.192 & 0.162 & 0.321 & 0.165 & 0.183 & 0.221 & 0.155 & 0.186 & 0.168 & 0.379 & 0.369 & 0.379 & 0.377 & 0.379 & 0.379 & 0.372 & 0.401 & 0.351 \\
\hline $\mathrm{Fe}^{2+}$ & 0.183 & 0.179 & 0.151 & 0.296 & 0.154 & 0.173 & 0.210 & 0.146 & 0.175 & 0.158 & 0.356 & 0.351 & 0.361 & 0.357 & 0.361 & 0.360 & 0.348 & 0.375 & 0.323 \\
\hline $\mathrm{Fe}^{3+}$ & 0.011 & 0.013 & 0.011 & 0.026 & 0.012 & 0.009 & 0.011 & 0.009 & 0.011 & 0.010 & 0.023 & 0.019 & 0.019 & 0.020 & 0.019 & 0.019 & 0.024 & 0.026 & 0.027 \\
\hline$M n$ & 0.004 & 0.004 & 0.003 & 0.008 & 0.004 & 0.004 & 0.006 & 0.003 & 0.004 & 0.004 & 0.017 & 0.017 & 0.018 & 0.017 & 0.018 & 0.018 & 0.017 & 0.018 & 0.014 \\
\hline $\mathbf{M g}$ & 0.908 & 0.894 & 0.903 & 0.848 & 0.912 & 0.921 & 0.898 & 0.918 & 0.902 & 0.916 & 0.784 & 0.787 & 0.784 & 0.790 & 0.787 & 0.775 & 0.781 & 0.765 & 0.784 \\
\hline $\mathrm{Ca}$ & 0.853 & 0.863 & 0.871 & 0.748 & 0.874 & 0.854 & 0.834 & 0.866 & 0.854 & 0.847 & 0.815 & 0.814 & 0.811 & 0.805 & 0.818 & 0.827 & 0.810 & 0.802 & 0.809 \\
\hline $\mathrm{Na}$ & 0.006 & 0.006 & 0.007 & 0.010 & 0.008 & 0.008 & 0.008 & 0.005 & 0.008 & 0.006 & 0.015 & 0.015 & 0.014 & 0.015 & 0.013 & 0.014 & 0.015 & 0.017 & 0.014 \\
\hline Total & 4.02 & 4.01 & 4.01 & 4.01 & 4.02 & 4.02 & 4.01 & 4.01 & 4.01 & 4.01 & 4.02 & 4.02 & 4.02 & 4.02 & 4.02 & 4.02 & 4.02 & 4.02 & 4.01 \\
\hline \multicolumn{20}{|l|}{ Atomic \% } \\
\hline Wo & 43.7 & 44.3 & 45.0 & 39.0 & 44.8 & 43.6 & 42.7 & 44.7 & 44.0 & 43.9 & 41.2 & 41.3 & 41.1 & 40.8 & 41.2 & 41.7 & 41.3 & 40.8 & 41.6 \\
\hline En & 46.4 & 45.9 & 46.6 & 44.2 & 46.7 & 47.1 & 46.0 & 47.3 & 46.4 & 47.4 & 39.6 & 39.9 & 39.7 & 40.1 & 39.6 & 39.1 & 39.8 & 38.9 & 40.3 \\
\hline Fs & 9.9 & 9.8 & 8.4 & 16.8 & 8.5 & 9.3 & 11.3 & 8.0 & 9.6 & 8.7 & 19.2 & 18.7 & 19.2 & 19.1 & 19.1 & 19.1 & 19.0 & 20.4 & 18.0 \\
\hline $\mathrm{Mg} \#$ & 82.1 & 82.0 & 84.5 & 72.1 & 84.3 & 83.1 & 79.8 & 85.3 & 82.6 & 84.2 & 66.4 & 67.1 & 66.3 & 66.7 & 66.4 & 66.1 & 66.7 & 64.6 & 68.3 \\
\hline
\end{tabular}


Table F.1 Continued

\begin{tabular}{|c|c|c|c|c|c|c|c|c|c|c|c|c|c|c|c|c|c|c|c|}
\hline Sample & & & & & RI26_PC01 & & & & & & & & & & & & & & \\
\hline Location & & & & & Fleetwood & & & & & & & & & & & & & & \\
\hline Volcano & & & & & Raoul & & & & & & & & & & & & & & \\
\hline Type & $\mathrm{C} 13$ & C14 & C15 & C16 & Mafic Bleb-1 & & MB02 & & & MB03 & MB04 & & MB05 & & MB06 & MB07 & & & MB08 \\
\hline Crystal no. & $a$ & $a$ & a & a & a & a & a & $\mathrm{b}$ & $\mathrm{b}$ & a & a & $a$ & a & $\mathrm{b}$ & a & $a$ & a & a & a \\
\hline Analysis site & NVZ & NVZ & NVZ & NVZ & NVZ & NVZ & core & core & rim & NVZ & NVZ & NVZ & NVZ & $\mathrm{NVZ}$ & NVZ & core & $\operatorname{rim} 1$ & $\operatorname{rim} 2$ & $\mathrm{NVZ}$ \\
\hline \multicolumn{20}{|l|}{ Oxides (wt \%) } \\
\hline $\mathrm{SiO}_{2}$ & 51.60 & 51.80 & 51.83 & 50.58 & 52.16 & 51.44 & 52.09 & 51.54 & 49.40 & 51.86 & 51.39 & 51.83 & 52.24 & 51.94 & 52.97 & 51.93 & 51.20 & 51.08 & 51.98 \\
\hline $\mathrm{TiO}_{2}$ & 0.32 & 0.31 & 0.31 & 0.41 & 0.20 & 0.23 & 0.23 & 0.25 & 0.64 & 0.20 & 0.24 & 0.23 & 0.24 & 0.26 & 0.11 & 0.20 & 0.34 & 0.35 & 0.23 \\
\hline $\mathrm{Al}_{2} \mathrm{O}_{3}$ & 1.70 & 1.57 & 1.56 & 2.85 & 3.32 & 4.14 & 3.30 & 3.33 & 7.99 & 3.41 & 3.16 & 3.31 & 3.07 & 3.17 & 2.01 & 3.13 & 4.46 & 4.50 & 3.23 \\
\hline $\mathrm{Cr}_{2} \mathrm{O}_{3}$ & 0.06 & 0.05 & 0.04 & 0.05 & 0.14 & 0.32 & 0.08 & 0.06 & 0.08 & 0.20 & 0.12 & 0.11 & 0.12 & 0.15 & 0.59 & 0.15 & 0.08 & 0.10 & 0.11 \\
\hline $\mathrm{FeO}(\mathrm{T})$ & 12.02 & 11.83 & 12.01 & 11.63 & 6.27 & 5.88 & 6.81 & 6.98 & 11.45 & 4.86 & 6.96 & 6.74 & 6.62 & 6.78 & 3.60 & 5.81 & 7.78 & 7.76 & 7.19 \\
\hline $\mathrm{MnO}$ & 0.56 & 0.56 & 0.55 & 0.43 & 0.14 & 0.11 & 0.18 & 0.17 & 0.28 & 0.12 & 0.18 & 0.15 & 0.15 & 0.17 & 0.10 & 0.12 & 0.17 & 0.14 & 0.16 \\
\hline MgO & 13.80 & 13.90 & 13.97 & 13.93 & 16.19 & 16.32 & 16.06 & 16.01 & 13.01 & 16.71 & 16.07 & 16.16 & 16.30 & 16.37 & 17.46 & 16.58 & 15.70 & 15.65 & 16.00 \\
\hline $\mathrm{CaO}$ & 20.24 & 20.27 & 20.13 & 20.12 & 22.32 & 22.49 & 22.11 & 22.03 & 18.34 & 23.00 & 22.11 & 22.22 & 21.88 & 21.62 & 23.13 & 22.86 & 21.53 & 21.54 & 22.15 \\
\hline $\mathrm{Na}_{2} \mathrm{O}$ & 0.19 & 0.21 & 0.21 & 0.19 & 0.11 & 0.09 & 0.11 & 0.12 & 0.41 & 0.10 & 0.13 & 0.11 & 0.11 & 0.12 & 0.09 & 0.09 & 0.11 & 0.11 & 0.11 \\
\hline Total & 100.49 & 100.50 & 100.61 & 100.21 & 100.85 & 101.02 & 100.97 & 100.50 & 101.60 & 100.46 & 100.36 & 100.86 & 100.73 & 100.58 & 100.05 & 100.86 & 101.36 & 101.23 & 101.15 \\
\hline \multicolumn{20}{|l|}{ Cations } \\
\hline Si & 1.94 & 1.94 & 1.94 & 1.90 & 1.91 & 1.88 & 1.91 & 1.90 & 1.82 & 1.90 & 1.90 & 1.90 & 1.91 & 1.91 & 1.93 & 1.90 & 1.87 & 1.87 & 1.90 \\
\hline $\mathrm{Ti}$ & 0.004 & 0.004 & 0.004 & 0.005 & 0.002 & 0.003 & 0.003 & 0.003 & 0.008 & 0.002 & 0.003 & 0.003 & 0.003 & 0.003 & 0.001 & 0.002 & 0.004 & 0.004 & 0.003 \\
\hline Al & 0.075 & 0.070 & 0.069 & 0.127 & 0.143 & 0.178 & 0.142 & 0.145 & 0.346 & 0.147 & 0.137 & 0.143 & 0.132 & 0.137 & 0.086 & 0.135 & 0.192 & 0.194 & 0.139 \\
\hline $\mathrm{Cr}$ & 0.002 & 0.001 & 0.001 & 0.002 & 0.004 & 0.009 & 0.002 & 0.002 & 0.002 & 0.006 & 0.003 & 0.003 & 0.003 & 0.004 & 0.017 & 0.004 & 0.002 & 0.003 & 0.003 \\
\hline Fe tot & 0.376 & 0.370 & 0.375 & 0.364 & 0.190 & 0.177 & 0.206 & 0.213 & 0.348 & 0.146 & 0.212 & 0.204 & 0.200 & 0.205 & 0.108 & 0.175 & 0.235 & 0.235 & 0.218 \\
\hline $\mathrm{Fe}^{2+}$ & 0.356 & 0.350 & 0.356 & 0.337 & 0.178 & 0.163 & 0.193 & 0.198 & 0.310 & 0.134 & 0.198 & 0.191 & 0.186 & 0.190 & 0.102 & 0.163 & 0.214 & 0.214 & 0.204 \\
\hline $\mathrm{Fe}^{3+}$ & 0.020 & 0.019 & 0.019 & 0.026 & 0.012 & 0.014 & 0.014 & 0.015 & 0.039 & 0.012 & 0.015 & 0.014 & 0.014 & 0.016 & 0.006 & 0.012 & 0.021 & 0.021 & 0.014 \\
\hline$M n$ & 0.018 & 0.018 & 0.017 & 0.014 & 0.004 & 0.003 & 0.006 & 0.005 & 0.009 & 0.004 & 0.006 & 0.005 & 0.005 & 0.005 & 0.003 & 0.004 & 0.005 & 0.004 & 0.005 \\
\hline $\mathbf{M g}$ & 0.773 & 0.778 & 0.781 & 0.782 & 0.882 & 0.888 & 0.876 & 0.879 & 0.713 & 0.911 & 0.884 & 0.883 & 0.890 & 0.896 & 0.951 & 0.904 & 0.856 & 0.855 & 0.873 \\
\hline $\mathrm{Ca}$ & 0.815 & 0.815 & 0.809 & 0.811 & 0.874 & 0.880 & 0.867 & 0.869 & 0.723 & 0.901 & 0.875 & 0.873 & 0.859 & 0.850 & 0.905 & 0.896 & 0.844 & 0.846 & 0.869 \\
\hline $\mathrm{Na}$ & 0.014 & 0.015 & 0.015 & 0.014 & 0.008 & 0.006 & 0.008 & 0.008 & 0.029 & 0.007 & 0.009 & 0.008 & 0.008 & 0.009 & 0.006 & 0.006 & 0.007 & 0.008 & 0.008 \\
\hline Total & 4.02 & 4.01 & 4.02 & 4.02 & 4.02 & 4.02 & 4.02 & 4.02 & 4.00 & 4.02 & 4.03 & 4.02 & 4.01 & 4.02 & 4.01 & 4.03 & 4.02 & 4.02 & 4.02 \\
\hline \multicolumn{20}{|l|}{ Atomic \% } \\
\hline Wo & 41.5 & 41.5 & 41.2 & 41.5 & 44.9 & 45.2 & 44.5 & 44.3 & 40.5 & 46.0 & 44.4 & 44.5 & 44.1 & 43.6 & 46.1 & 45.4 & 43.6 & 43.7 & 44.3 \\
\hline En & 39.4 & 39.6 & 39.7 & 40.0 & 45.3 & 45.7 & 45.0 & 44.8 & 40.0 & 46.5 & 44.9 & 45.0 & 45.7 & 45.9 & 48.4 & 45.8 & 44.2 & 44.2 & 44.6 \\
\hline Fs & 19.1 & 18.8 & 19.1 & 18.6 & 9.7 & 9.1 & 10.6 & 10.8 & 19.5 & 7.4 & 10.8 & 10.4 & 10.3 & 10.5 & 5.5 & 8.9 & 12.1 & 12.1 & 11.1 \\
\hline Mg \# & 66.3 & 66.8 & 66.6 & 67.4 & 82.0 & 83.1 & 80.5 & 80.1 & 66.6 & 85.9 & 80.2 & 80.9 & 81.3 & 81.0 & 89.5 & 83.5 & 78.1 & 78.1 & 79.7 \\
\hline
\end{tabular}


Table F.1 Continued

\begin{tabular}{|c|c|c|c|c|c|c|c|c|c|c|c|c|c|c|c|c|c|c|c|}
\hline Sample & & & & & & & & & & & & & & & MI07_PC03 & & & & \\
\hline Location & & & & & & & & & & & & & & & SBT & & & & \\
\hline Volcano & & & & & & & & & & & & & & & Macauley & & & & \\
\hline Type & & MB09 & MB10 & MB11 & MB12 & & & MB13 & MB14 & MB15 & & MB16 & MB17 & MB18 & Single crystal & & & & \\
\hline Crystal no. & $\mathrm{b}$ & $a$ & a & a & $a$ & $b$ & c & a & a & a & $\mathrm{b}$ & a & a & $a$ & 1 & 1 & 2 & 2 & 3 \\
\hline Analysis site & NVZ & NVZ & NVZ & NVZ & $\mathrm{NVZ}$ & $\mathrm{NVZ}$ & NVZ & NVZ & NVZ & NVZ & NVZ & $\mathrm{NVZ}$ & $\mathrm{NVZ}$ & NVZ & core & $\mathrm{rim}$ & core & $\mathrm{rim}$ & $\mathrm{NVZ}$ \\
\hline \multicolumn{20}{|l|}{ Oxides (wt \%) } \\
\hline $\mathrm{SiO}_{2}$ & 52.01 & 52.50 & 52.12 & 51.88 & 51.55 & 52.11 & 52.47 & 52.08 & 52.28 & 51.81 & 52.31 & 51.80 & 51.35 & 51.72 & 52.00 & 52.07 & 51.99 & 52.65 & 51.19 \\
\hline $\mathrm{TiO}_{2}$ & 0.19 & 0.15 & 0.18 & 0.22 & 0.22 & 0.20 & 0.21 & 0.31 & 0.22 & 0.21 & 0.21 & 0.17 & 0.23 & 0.18 & 0.36 & 0.34 & 0.33 & 0.35 & 0.32 \\
\hline $\mathrm{Al}_{2} \mathrm{O}_{3}$ & 2.81 & 3.23 & 3.31 & 3.19 & 3.50 & 3.49 & 3.40 & 2.60 & 3.53 & 3.31 & 3.28 & 3.01 & 3.06 & 3.03 & 1.20 & 1.14 & 1.12 & 1.09 & 1.06 \\
\hline $\mathrm{Cr}_{2} \mathrm{O}_{3}$ & 0.06 & 0.26 & 0.16 & 0.15 & 0.13 & 0.15 & 0.13 & 0.13 & 0.13 & 0.14 & 0.14 & 0.16 & 0.19 & 0.16 & 0.00 & 0.00 & 0.00 & 0.00 & 0.00 \\
\hline $\mathrm{FeO}(\mathrm{T})$ & 7.11 & 4.85 & 5.66 & 6.42 & 6.36 & 5.95 & 5.89 & 8.58 & 6.05 & 6.07 & 6.13 & 5.65 & 6.68 & 5.72 & 14.72 & 14.04 & 16.85 & 14.72 & 14.72 \\
\hline MnO & 0.15 & 0.12 & 0.13 & 0.14 & 0.15 & 0.13 & 0.13 & 0.22 & 0.14 & 0.14 & 0.12 & 0.13 & 0.14 & 0.17 & 0.74 & 0.68 & 0.88 & 0.72 & 0.74 \\
\hline MgO & 16.32 & 16.80 & 16.58 & 16.07 & 16.28 & 16.51 & 16.46 & 16.39 & 16.37 & 16.40 & 16.45 & 16.33 & 15.99 & 16.36 & 13.16 & 13.13 & 12.85 & 13.05 & 12.86 \\
\hline $\mathrm{CaO}$ & 21.99 & 22.76 & 22.61 & 22.38 & 22.84 & 22.94 & 22.75 & 21.03 & 22.71 & 22.80 & 22.88 & 22.70 & 22.28 & 22.66 & 19.26 & 19.75 & 17.33 & 19.13 & 19.45 \\
\hline $\mathrm{Na}_{2} \mathrm{O}$ & 0.11 & 0.10 & 0.08 & 0.12 & 0.08 & 0.11 & 0.09 & 0.16 & 0.12 & 0.10 & 0.10 & 0.08 & 0.12 & 0.09 & 0.22 & 0.23 & 0.20 & 0.21 & 0.19 \\
\hline Total & 100.75 & 100.79 & 100.83 & 100.56 & 101.10 & 101.60 & 101.53 & 101.50 & 101.55 & 101.00 & 101.63 & 100.02 & 100.02 & 100.09 & 101.66 & 101.38 & 101.55 & 101.90 & 100.52 \\
\hline \multicolumn{20}{|l|}{ Cations } \\
\hline Si & 1.91 & 1.91 & 1.90 & 1.91 & 1.89 & 1.89 & 1.90 & 1.91 & 1.90 & 1.89 & 1.90 & 1.91 & 1.90 & 1.91 & 1.95 & 1.95 & 1.96 & 1.96 & 1.95 \\
\hline $\mathrm{Ti}$ & 0.002 & 0.002 & 0.002 & 0.003 & 0.003 & 0.003 & 0.003 & 0.004 & 0.003 & 0.003 & 0.003 & 0.002 & 0.003 & 0.002 & 0.005 & 0.004 & 0.004 & 0.004 & 0.004 \\
\hline Al & 0.122 & 0.139 & 0.142 & 0.138 & 0.151 & 0.149 & 0.145 & 0.112 & 0.151 & 0.143 & 0.141 & 0.131 & 0.133 & 0.132 & 0.053 & 0.050 & 0.050 & 0.048 & 0.047 \\
\hline $\mathrm{Cr}$ & 0.002 & 0.008 & 0.005 & 0.004 & 0.004 & 0.004 & 0.004 & 0.004 & 0.004 & 0.004 & 0.004 & 0.005 & 0.006 & 0.005 & 0.000 & 0.000 & 0.000 & 0.000 & 0.000 \\
\hline $\mathrm{Fe}$ total & 0.217 & 0.146 & 0.171 & 0.195 & 0.192 & 0.179 & 0.176 & 0.260 & 0.181 & 0.183 & 0.184 & 0.172 & 0.204 & 0.174 & 0.460 & 0.439 & 0.530 & 0.458 & 0.466 \\
\hline $\mathrm{Fe}^{2+}$ & 0.205 & 0.137 & 0.160 & 0.181 & 0.179 & 0.167 & 0.164 & 0.241 & 0.168 & 0.171 & 0.171 & 0.161 & 0.191 & 0.163 & 0.437 & 0.417 & 0.509 & 0.436 & 0.446 \\
\hline $\mathrm{Fe}^{3+}$ & 0.011 & 0.009 & 0.010 & 0.013 & 0.013 & 0.012 & 0.012 & 0.019 & 0.013 & 0.013 & 0.012 & 0.011 & 0.014 & 0.011 & 0.023 & 0.022 & 0.021 & 0.021 & 0.021 \\
\hline$M n$ & 0.005 & 0.004 & 0.004 & 0.004 & 0.004 & 0.004 & 0.004 & 0.007 & 0.004 & 0.004 & 0.004 & 0.004 & 0.004 & 0.005 & 0.024 & 0.022 & 0.028 & 0.023 & 0.024 \\
\hline $\mathbf{M g}$ & 0.893 & 0.911 & 0.902 & 0.880 & 0.888 & 0.894 & 0.890 & 0.895 & 0.886 & 0.894 & 0.891 & 0.897 & 0.882 & 0.898 & 0.736 & 0.735 & 0.722 & 0.726 & 0.729 \\
\hline $\mathrm{Ca}$ & 0.865 & 0.887 & 0.885 & 0.881 & 0.896 & 0.893 & 0.884 & 0.826 & 0.883 & 0.893 & 0.890 & 0.896 & 0.883 & 0.894 & 0.774 & 0.794 & 0.700 & 0.765 & 0.792 \\
\hline $\mathrm{Na}$ & 0.008 & 0.007 & 0.006 & 0.008 & 0.006 & 0.008 & 0.006 & 0.012 & 0.009 & 0.007 & 0.007 & 0.005 & 0.009 & 0.006 & 0.016 & 0.016 & 0.015 & 0.015 & 0.014 \\
\hline Total & 4.02 & 4.01 & 4.02 & 4.02 & 4.03 & 4.03 & 4.02 & 4.03 & 4.02 & 4.03 & 4.02 & 4.02 & 4.03 & 4.02 & 4.02 & 4.01 & 4.01 & 4.00 & 4.02 \\
\hline \multicolumn{20}{|l|}{ Atomic \% } \\
\hline Wo & 43.8 & 45.6 & 45.2 & 45.0 & 45.3 & 45.4 & 45.3 & 41.7 & 45.3 & 45.3 & 45.3 & 45.6 & 44.8 & 45.5 & 39.3 & 40.4 & 35.9 & 39.2 & 39.9 \\
\hline En & 45.2 & 46.9 & 46.1 & 45.0 & 44.9 & 45.5 & 45.6 & 45.2 & 45.4 & 45.4 & 45.3 & 45.7 & 44.8 & 45.7 & 37.4 & 37.3 & 37.0 & 37.3 & 36.7 \\
\hline Fs & 11.0 & 7.5 & 8.7 & 10.0 & 9.7 & 9.1 & 9.0 & 13.1 & 9.3 & 9.3 & 9.4 & 8.7 & 10.4 & 8.8 & 23.4 & 22.3 & 27.1 & 23.5 & 23.5 \\
\hline Mg \# & 80.1 & 85.9 & 83.8 & 81.5 & 81.9 & 83.0 & 83.1 & 77.0 & 82.7 & 82.6 & 82.6 & 83.6 & 80.9 & 83.4 & 60.3 & 61.5 & 56.4 & 60.2 & 59.8 \\
\hline
\end{tabular}


Table F.1 Continued

\begin{tabular}{|c|c|c|c|c|c|c|c|c|c|c|c|c|c|c|c|c|c|c|c|c|}
\hline \multicolumn{21}{|l|}{ Sample } \\
\hline \multicolumn{21}{|l|}{ Location } \\
\hline \multicolumn{21}{|l|}{ Volcano } \\
\hline \multicolumn{21}{|l|}{ Type } \\
\hline Crystal no. & 4 & 5 & 5 & 6 & 6 & 7 & 7 & 7 & 7 & 8 & 9 & 9 & 10 & 10 & 11 & 11 & 12 & 12 & 14 & 15 \\
\hline Analysis site & NVZ & core & rim & NVZ & NVZ & core & OG & rim1 & rim2 & NVZ & NVZ & NVZ & core & rim & core & $\mathrm{d}$ band & core & rim & NVZ & core \\
\hline \multicolumn{21}{|l|}{ Oxides (wt \%) } \\
\hline $\mathrm{SiO}_{2}$ & 52.02 & 51.87 & 51.76 & 50.37 & 51.17 & 52.09 & 51.83 & 51.09 & 51.60 & 51.04 & 52.19 & 52.19 & 52.13 & 52.21 & 51.10 & 51.95 & 51.89 & 52.08 & 51.54 & 51.56 \\
\hline $\mathrm{TiO}_{2}$ & 0.35 & 0.26 & 0.37 & 0.45 & 0.33 & 0.27 & 0.42 & 0.55 & 0.45 & 0.46 & 0.38 & 0.37 & 0.34 & 0.35 & 0.42 & 0.24 & 0.40 & 0.38 & 0.43 & 0.31 \\
\hline $\mathrm{Al}_{2} \mathrm{O}_{3}$ & 2.59 & 3.66 & 3.16 & 1.54 & 1.76 & 4.15 & 2.87 & 3.44 & 2.80 & 3.39 & 1.31 & 1.25 & 1.13 & 1.14 & 4.14 & 2.47 & 2.49 & 2.87 & 3.01 & 4.19 \\
\hline $\mathrm{Cr}_{2} \mathrm{O}_{3}$ & 0.04 & 0.13 & 0.13 & 0.00 & 0.00 & 0.11 & 0.09 & 0.00 & 0.02 & 0.04 & 0.00 & 0.01 & 0.00 & 0.00 & 0.01 & 0.02 & 0.02 & 0.08 & 0.02 & 0.13 \\
\hline $\mathrm{FeO}(\mathrm{T})$ & 9.13 & 5.66 & 7.73 & 17.18 & 14.51 & 5.05 & 8.81 & 11.51 & 11.64 & 9.49 & 15.09 & 14.08 & 15.01 & 14.48 & 7.50 & 6.93 & 10.02 & 8.35 & 9.32 & 6.08 \\
\hline MnO & 0.23 & 0.11 & 0.18 & 0.89 & 0.71 & 0.14 & 0.21 & 0.30 & 0.34 & 0.23 & 0.75 & 0.67 & 0.77 & 0.72 & 0.14 & 0.18 & 0.31 & 0.22 & 0.25 & 0.13 \\
\hline MgO & 15.85 & 16.38 & 15.77 & 12.64 & 11.97 & 16.59 & 15.67 & 15.09 & 15.61 & 15.48 & 12.44 & 13.14 & 12.94 & 13.29 & 15.51 & 16.44 & 15.60 & 15.81 & 15.40 & 16.06 \\
\hline $\mathrm{CaO}$ & 20.98 & 22.93 & 22.08 & 16.40 & 18.13 & 23.03 & 21.25 & 19.14 & 18.32 & 20.76 & 19.27 & 19.56 & 18.86 & 19.29 & 22.45 & 22.30 & 20.26 & 21.36 & 21.02 & 22.64 \\
\hline $\mathrm{Na}_{2} \mathrm{O}$ & 0.23 & 0.13 & 0.19 & 0.22 & 0.19 & 0.11 & 0.23 & 0.22 & 0.21 & 0.24 & 0.21 & 0.22 & 0.22 & 0.23 & 0.14 & 0.13 & 0.23 & 0.20 & 0.22 & 0.14 \\
\hline Total & 101.41 & 101.13 & 101.36 & 99.67 & 98.77 & 101.54 & 101.38 & 101.34 & 100.99 & 101.12 & 101.64 & 101.48 & 101.41 & 101.71 & 101.41 & 100.65 & 101.22 & 101.34 & 101.20 & 101.24 \\
\hline \multicolumn{21}{|l|}{ Cations } \\
\hline $\mathbf{S i}$ & 1.91 & 1.89 & 1.90 & 1.94 & 1.97 & 1.88 & 1.90 & 1.89 & 1.91 & 1.89 & 1.96 & 1.95 & 1.96 & 1.95 & 1.87 & 1.91 & 1.92 & 1.91 & 1.90 & 1.88 \\
\hline $\mathrm{Ti}$ & 0.004 & 0.003 & 0.005 & 0.006 & 0.004 & 0.003 & 0.005 & 0.007 & 0.006 & 0.006 & 0.005 & 0.005 & 0.004 & 0.004 & 0.005 & 0.003 & 0.005 & 0.005 & 0.005 & 0.004 \\
\hline Al & 0.112 & 0.157 & 0.136 & 0.070 & 0.080 & 0.177 & 0.124 & 0.150 & 0.122 & 0.147 & 0.058 & 0.055 & 0.050 & 0.050 & 0.179 & 0.107 & 0.108 & 0.124 & 0.131 & 0.180 \\
\hline $\mathrm{Cr}$ & 0.001 & 0.004 & 0.004 & 0.000 & 0.000 & 0.003 & 0.003 & 0.000 & 0.001 & 0.001 & 0.000 & 0.000 & 0.000 & 0.000 & 0.000 & 0.001 & 0.001 & 0.002 & 0.000 & 0.004 \\
\hline $\mathrm{Fe}$ tot & 0.278 & 0.169 & 0.234 & 0.551 & 0.465 & 0.149 & 0.268 & 0.353 & 0.358 & 0.290 & 0.472 & 0.439 & 0.470 & 0.452 & 0.226 & 0.211 & 0.307 & 0.253 & 0.284 & 0.182 \\
\hline $\mathrm{Fe}^{2+}$ & 0.257 & 0.154 & 0.211 & 0.522 & 0.443 & 0.134 & 0.242 & 0.319 & 0.330 & 0.262 & 0.448 & 0.416 & 0.449 & 0.430 & 0.201 & 0.196 & 0.282 & 0.230 & 0.258 & 0.163 \\
\hline $\mathrm{Fe}^{3+}$ & 0.021 & 0.016 & 0.022 & 0.029 & 0.022 & 0.016 & 0.026 & 0.034 & 0.028 & 0.028 & 0.024 & 0.023 & 0.021 & 0.022 & 0.025 & 0.015 & 0.025 & 0.023 & 0.026 & 0.019 \\
\hline Mn & 0.007 & 0.003 & 0.006 & 0.029 & 0.023 & 0.004 & 0.007 & 0.010 & 0.011 & 0.007 & 0.024 & 0.021 & 0.025 & 0.023 & 0.004 & 0.006 & 0.010 & 0.007 & 0.008 & 0.004 \\
\hline Mg & 0.868 & 0.890 & 0.862 & 0.726 & 0.686 & 0.895 & 0.858 & 0.832 & 0.862 & 0.853 & 0.696 & 0.734 & 0.725 & 0.741 & 0.847 & 0.902 & 0.858 & 0.864 & 0.847 & 0.873 \\
\hline $\mathrm{Ca}$ & 0.826 & 0.896 & 0.867 & 0.677 & 0.747 & 0.893 & 0.837 & 0.759 & 0.727 & 0.822 & 0.775 & 0.785 & 0.759 & 0.774 & 0.881 & 0.879 & 0.801 & 0.839 & 0.831 & 0.884 \\
\hline $\mathrm{Na}$ & 0.016 & 0.009 & 0.014 & 0.016 & 0.014 & 0.008 & 0.017 & 0.016 & 0.015 & 0.017 & 0.015 & 0.016 & 0.016 & 0.016 & 0.010 & 0.009 & 0.016 & 0.014 & 0.016 & 0.010 \\
\hline Total & 4.02 & 4.02 & 4.02 & 4.01 & 3.99 & 4.02 & 4.02 & 4.02 & 4.01 & 4.03 & 4.00 & 4.01 & 4.01 & 4.01 & 4.03 & 4.03 & 4.02 & 4.02 & 4.02 & 4.02 \\
\hline \multicolumn{21}{|l|}{ Atomic \% } \\
\hline Wo & 41.9 & 45.8 & 44.2 & 34.6 & 39.4 & 46.1 & 42.6 & 39.0 & 37.3 & 41.8 & 39.9 & 40.1 & 38.8 & 39.3 & 45.1 & 44.1 & 40.8 & 42.9 & 42.3 & 45.6 \\
\hline En & 44.0 & 45.5 & 43.9 & 37.1 & 36.1 & 46.2 & 43.7 & 42.8 & 44.3 & 43.4 & 35.8 & 37.5 & 37.1 & 37.7 & 43.3 & 45.3 & 43.7 & 44.2 & 43.2 & 45.0 \\
\hline Fs & 14.1 & 8.7 & 11.9 & 28.2 & 24.5 & 7.7 & 13.6 & 18.1 & 18.4 & 14.8 & 24.3 & 22.4 & 24.1 & 23.0 & 11.6 & 10.6 & 15.6 & 12.9 & 14.5 & 9.4 \\
\hline Mg \# & 75.3 & 83.7 & 78.3 & 55.6 & 58.4 & 85.3 & 75.8 & 69.7 & 70.0 & 74.2 & 58.4 & 61.4 & 59.4 & 61.0 & 78.6 & 80.6 & 73.1 & 76.9 & 74.4 & 82.4 \\
\hline
\end{tabular}


Table F.1 Continued

\begin{tabular}{|c|c|c|c|c|c|c|c|c|c|c|c|c|c|c|c|c|c|c|c|c|}
\hline \multicolumn{21}{|l|}{ Sample } \\
\hline \multicolumn{21}{|l|}{ Location } \\
\hline \multicolumn{21}{|l|}{ Volcano } \\
\hline \multicolumn{21}{|l|}{ Type } \\
\hline Crystal no. & 15 & 15 & 16 & 16 & 17 & 17 & 17 & 18 & 19 & 19 & 20 & 20 & 21 & 22 & 23 & 23 & 24 & 25 & 26 & 27 \\
\hline Analysis site & OG & rim & core & OG & core & OG & $\mathrm{rim}$ & NVZ & core & $O G$ & NVZ & NVZ & NVZ & NVZ & core & rim & NVZ & NVZ & NVZ & $\mathrm{NVZ}$ \\
\hline \multicolumn{21}{|l|}{ Oxides (wt \%) } \\
\hline $\mathrm{SiO}_{2}$ & 51.78 & 50.29 & 51.87 & 51.35 & 51.72 & 50.38 & 50.47 & 49.33 & 51.99 & 51.20 & 52.03 & 53.17 & 49.87 & 51.92 & 51.39 & 51.67 & 51.86 & 51.46 & 51.14 & 50.60 \\
\hline $\mathrm{TiO}_{2}$ & 0.30 & 0.66 & 0.56 & 0.42 & 0.34 & 0.37 & 0.35 & 0.42 & 0.37 & 0.41 & 0.39 & 0.20 & 0.41 & 0.39 & 0.38 & 0.38 & 0.34 & 0.34 & 0.48 & 0.41 \\
\hline $\mathrm{Al}_{2} \mathrm{O}_{3}$ & 4.15 & 4.31 & 1.87 & 3.16 & 1.17 & 1.30 & 1.25 & 2.74 & 2.11 & 2.97 & 3.05 & 2.43 & 3.13 & 2.90 & 1.34 & 1.30 & 1.10 & 1.13 & 3.42 & 3.01 \\
\hline $\mathrm{Cr}_{2} \mathrm{O}_{3}$ & 0.14 & 0.03 & 0.00 & 0.06 & 0.00 & 0.00 & 0.00 & 0.04 & 0.01 & 0.01 & 0.13 & 0.08 & 0.08 & 0.13 & 0.00 & 0.01 & 0.00 & 0.01 & 0.05 & 0.03 \\
\hline $\mathrm{FeO}(\mathrm{T})$ & 6.23 & 10.64 & 10.91 & 9.23 & 14.64 & 16.49 & 15.35 & 9.91 & 10.57 & 9.08 & 8.17 & 5.54 & 8.59 & 8.60 & 14.85 & 13.75 & 15.56 & 16.40 & 9.49 & 9.20 \\
\hline MnO & 0.16 & 0.27 & 0.48 & 0.25 & 0.72 & 0.89 & 0.79 & 0.29 & 0.38 & 0.21 & 0.17 & 0.15 & 0.21 & 0.20 & 0.77 & 0.67 & 0.78 & 0.86 & 0.22 & 0.24 \\
\hline MgO & 16.13 & 14.52 & 15.19 & 15.21 & 13.14 & 12.76 & 12.47 & 14.95 & 15.33 & 15.45 & 15.63 & 17.36 & 15.56 & 15.51 & 12.87 & 13.48 & 12.49 & 12.27 & 15.55 & 15.41 \\
\hline $\mathrm{CaO}$ & 22.75 & 20.46 & 20.16 & 21.12 & 19.25 & 17.76 & 19.20 & 20.89 & 20.44 & 21.44 & 21.80 & 22.54 & 21.51 & 21.30 & 19.33 & 19.39 & 19.24 & 18.93 & 20.69 & 20.91 \\
\hline $\mathrm{Na}_{2} \mathrm{O}$ & 0.13 & 0.25 & 0.24 & 0.24 & 0.21 & 0.23 & 0.23 & 0.23 & 0.23 & 0.25 & 0.21 & 0.10 & 0.24 & 0.23 & 0.20 & 0.21 & 0.24 & 0.24 & 0.23 & 0.22 \\
\hline Total & 101.77 & 101.42 & 101.28 & 101.03 & 101.20 & 100.18 & 100.09 & 98.80 & 101.42 & 101.01 & 101.58 & 101.57 & 99.58 & 101.16 & 101.11 & 100.85 & 101.62 & 101.63 & 101.26 & 100.04 \\
\hline \multicolumn{21}{|l|}{ Cations } \\
\hline $\mathbf{S i}$ & 1.88 & 1.86 & 1.92 & 1.90 & 1.95 & 1.93 & 1.94 & 1.88 & 1.92 & 1.89 & 1.90 & 1.92 & 1.87 & 1.91 & 1.94 & 1.95 & 1.95 & 1.95 & 1.89 & $1.8 \mathrm{~s}$ \\
\hline $\mathrm{Ti}$ & 0.004 & 0.008 & 0.007 & 0.005 & 0.004 & 0.005 & 0.004 & 0.005 & 0.005 & 0.005 & 0.005 & 0.002 & 0.005 & 0.005 & 0.005 & 0.005 & 0.004 & 0.004 & 0.006 & 0.005 \\
\hline Al & 0.177 & 0.188 & 0.082 & 0.137 & 0.052 & 0.059 & 0.056 & 0.123 & 0.092 & 0.129 & 0.131 & 0.103 & 0.138 & 0.126 & 0.060 & 0.058 & 0.049 & 0.050 & 0.149 & 0.132 \\
\hline $\mathrm{Cr}$ & 0.004 & 0.001 & 0.000 & 0.002 & 0.000 & 0.000 & 0.000 & 0.001 & 0.000 & 0.000 & 0.004 & 0.002 & 0.002 & 0.004 & 0.000 & 0.000 & 0.000 & 0.000 & 0.002 & 0.00 \\
\hline $\mathrm{Fe}$ total & 0.186 & 0.325 & 0.335 & 0.282 & 0.460 & 0.527 & 0.490 & 0.313 & 0.324 & 0.278 & 0.247 & 0.165 & 0.266 & 0.261 & 0.468 & 0.431 & 0.489 & 0.517 & 0.289 & 0.284 \\
\hline $\mathrm{Fe}^{2+}$ & 0.168 & 0.284 & 0.301 & 0.256 & 0.438 & 0.503 & 0.468 & 0.286 & 0.302 & 0.253 & 0.224 & 0.154 & 0.241 & 0.238 & 0.444 & 0.407 & 0.467 & 0.496 & 0.260 & 0.259 \\
\hline $\mathrm{Fe}^{3+}$ & 0.018 & 0.041 & 0.034 & 0.026 & 0.021 & 0.024 & 0.023 & 0.027 & 0.022 & 0.025 & 0.023 & 0.012 & 0.025 & 0.024 & 0.024 & 0.024 & 0.022 & 0.021 & 0.029 & 0.026 \\
\hline Mn & 0.005 & 0.008 & 0.015 & 0.008 & 0.023 & 0.029 & 0.026 & 0.009 & 0.012 & 0.006 & 0.005 & 0.005 & 0.007 & 0.006 & 0.025 & 0.021 & 0.025 & 0.028 & 0.007 & 0.008 \\
\hline Mg & 0.873 & 0.801 & 0.840 & 0.838 & 0.738 & 0.730 & 0.713 & 0.849 & 0.844 & 0.852 & 0.853 & 0.936 & 0.871 & 0.850 & 0.725 & 0.757 & 0.701 & 0.692 & 0.855 & 0.859 \\
\hline $\mathrm{Ca}$ & 0.885 & 0.812 & 0.801 & 0.836 & 0.777 & 0.730 & 0.789 & 0.852 & 0.809 & 0.850 & 0.855 & 0.874 & 0.866 & 0.839 & 0.782 & 0.782 & 0.777 & 0.767 & 0.818 & 0.837 \\
\hline $\mathrm{Na}$ & 0.009 & 0.018 & 0.017 & 0.017 & 0.016 & 0.017 & 0.017 & 0.017 & 0.017 & 0.018 & 0.015 & 0.007 & 0.018 & 0.016 & 0.015 & 0.015 & 0.018 & 0.018 & 0.016 & 0.016 \\
\hline Total & 4.02 & 4.02 & 4.02 & 4.02 & 4.02 & 4.03 & 4.03 & 4.05 & 4.02 & 4.03 & 4.02 & 4.02 & 4.05 & 4.02 & 4.02 & 4.02 & 4.02 & 4.02 & 4.03 & 4.03 \\
\hline \multicolumn{21}{|l|}{ Atomic \% } \\
\hline Wo & 45.5 & 41.9 & 40.6 & 42.7 & 39.4 & 36.7 & 39.6 & 42.3 & 40.9 & 42.9 & 43.7 & 44.2 & 43.2 & 43.0 & 39.6 & 39.7 & 39.5 & 38.8 & 41.7 & 42. \\
\hline En & 44.9 & 41.3 & 42.5 & 42.8 & 37.4 & 36.7 & 35.8 & 42.1 & 42.7 & 43.0 & 43.6 & 47.4 & 43.5 & 43.6 & 36.7 & 38.4 & 35.7 & 35.0 & 43.6 & 43.4 \\
\hline Fs & 9.6 & 16.8 & 16.9 & 14.4 & 23.3 & 26.5 & 24.6 & 15.5 & 16.4 & 14.0 & 12.6 & 8.4 & 13.3 & 13.4 & 23.7 & 21.9 & 24.8 & 26.2 & 14.7 & 14.4 \\
\hline Mg \# & 82.1 & 70.6 & 70.6 & 74.3 & 60.5 & 56.7 & 58.0 & 72.5 & 71.5 & 75.0 & 77.2 & 84.6 & 76.1 & 76.1 & 59.6 & 62.6 & 57.7 & 55.9 & 74.3 & 74.6 \\
\hline
\end{tabular}


Table F.1 Continued

\begin{tabular}{|c|c|c|c|c|c|c|c|c|c|c|c|c|c|c|c|c|c|c|c|}
\hline Sample & & & & & & MI07_PC03 & & & & & & & & & & & & & \\
\hline Location & & & & & & SBT & & & & & & & & & & & & & \\
\hline Volcano & & & & & & Macauley & & & & & & & & & & & & & \\
\hline Type & & & & & & Clusters-C1 & & $\mathrm{C} 2$ & & & $\mathrm{C} 3$ & & & & $\mathrm{C} 4$ & & C5 & & $\mathrm{C} 6$ \\
\hline Crystal no. & 28 & 28 & 29 & 30 & 30 & a & $\mathrm{b}$ & a & $\mathrm{b}$ & c & a & $\mathrm{b}$ & c & $\mathrm{c}$ & $a$ & $a$ & a & $\mathrm{b}$ & a \\
\hline Analysis site & core & rim & $\mathrm{NVZ}$ & NVZ & $\mathrm{NVZ}$ & NVZ & NVZ & NVZ & NVZ & $\mathrm{NVZ}$ & NVZ & NVZ & core & rim & core & rim & NVZ & NVZ & core \\
\hline \multicolumn{20}{|l|}{ Oxides (wt \%) } \\
\hline $\mathrm{SiO}_{2}$ & 51.99 & 52.36 & 52.26 & 52.00 & 52.15 & 52.13 & 51.62 & 50.28 & 50.25 & 50.25 & 52.30 & 52.26 & 52.39 & 51.55 & 51.80 & 52.27 & 52.40 & 52.37 & 51.85 \\
\hline $\mathrm{TiO}_{2}$ & 0.40 & 0.33 & 0.37 & 0.35 & 0.38 & 0.39 & 0.34 & 0.41 & 0.24 & 0.35 & 0.34 & 0.32 & 0.34 & 0.31 & 0.50 & 0.36 & 0.31 & 0.36 & 0.43 \\
\hline $\mathrm{Al}_{2} \mathrm{O}_{3}$ & 1.46 & 1.14 & 1.33 & 1.12 & 1.28 & 1.30 & 1.13 & 3.85 & 2.92 & 3.26 & 1.23 & 1.17 & 1.20 & 1.06 & 2.78 & 1.24 & 1.09 & 1.23 & 2.60 \\
\hline $\mathrm{Cr}_{2} \mathrm{O}_{3}$ & 0.00 & 0.00 & 0.03 & 0.00 & 0.00 & 0.00 & 0.00 & 0.18 & 0.12 & 0.21 & 0.00 & 0.00 & 0.00 & 0.01 & 0.00 & 0.03 & 0.00 & 0.00 & 0.00 \\
\hline $\mathrm{FeO}(\mathrm{T})$ & 14.68 & 13.71 & 13.59 & 14.52 & 14.01 & 14.87 & 15.19 & 5.88 & 6.33 & 7.23 & 13.81 & 14.78 & 13.56 & 15.53 & 11.09 & 13.72 & 14.63 & 14.25 & 9.78 \\
\hline $\mathrm{MnO}$ & 0.73 & 0.73 & 0.67 & 0.75 & 0.72 & 0.68 & 0.72 & 0.16 & 0.14 & 0.14 & 0.70 & 0.74 & 0.65 & 0.74 & 0.36 & 0.74 & 0.76 & 0.71 & 0.30 \\
\hline MgO & 12.66 & 13.54 & 14.08 & 13.28 & 13.45 & 12.66 & 12.67 & 15.93 & 16.05 & 15.42 & 13.55 & 12.88 & 13.64 & 12.76 & 15.19 & 13.71 & 13.04 & 13.23 & 15.55 \\
\hline $\mathrm{CaO}$ & 19.10 & 19.12 & 18.84 & 18.78 & 18.59 & 19.01 & 18.54 & 21.99 & 22.00 & 21.66 & 18.84 & 18.78 & 19.26 & 18.30 & 19.43 & 18.81 & 18.73 & 19.01 & 19.92 \\
\hline $\mathrm{Na}_{2} \mathrm{O}$ & 0.23 & 0.21 & 0.25 & 0.23 & 0.22 & 0.23 & 0.22 & 0.15 & 0.14 & 0.21 & 0.23 & 0.21 & 0.20 & 0.21 & 0.23 & 0.23 & 0.23 & 0.22 & 0.25 \\
\hline Total & 101.24 & 101.13 & 101.41 & 101.01 & 100.80 & 101.27 & 100.42 & 98.80 & 98.19 & 98.70 & 101.00 & 101.14 & 101.24 & 100.46 & 101.38 & 101.11 & 101.18 & 101.37 & 100.67 \\
\hline \multicolumn{20}{|l|}{ Cations } \\
\hline Si & 1.95 & 1.96 & 1.95 & 1.96 & 1.96 & 1.96 & 1.96 & 1.88 & 1.89 & 1.89 & 1.96 & 1.97 & 1.96 & 1.96 & 1.91 & 1.96 & 1.97 & 1.96 & 1.92 \\
\hline $\mathrm{Ti}$ & 0.005 & 0.004 & 0.005 & 0.004 & 0.005 & 0.005 & 0.004 & 0.005 & 0.003 & 0.004 & 0.004 & 0.004 & 0.004 & 0.004 & 0.006 & 0.004 & 0.004 & 0.004 & 0.005 \\
\hline Al & 0.065 & 0.051 & 0.058 & 0.049 & 0.057 & 0.058 & 0.051 & 0.169 & 0.130 & 0.145 & 0.054 & 0.052 & 0.053 & 0.048 & 0.121 & 0.055 & 0.048 & 0.054 & 0.113 \\
\hline $\mathrm{Cr}$ & 0.000 & 0.000 & 0.001 & 0.000 & 0.000 & 0.000 & 0.000 & 0.005 & 0.004 & 0.006 & 0.000 & 0.000 & 0.000 & 0.000 & 0.000 & 0.001 & 0.000 & 0.000 & 0.000 \\
\hline $\mathrm{Fe}$ total & 0.460 & 0.428 & 0.422 & 0.456 & 0.438 & 0.466 & 0.481 & 0.179 & 0.197 & 0.224 & 0.431 & 0.463 & 0.422 & 0.492 & 0.339 & 0.428 & 0.458 & 0.445 & 0.300 \\
\hline $\mathrm{Fe}^{2+}$ & 0.435 & 0.408 & 0.400 & 0.434 & 0.414 & 0.441 & 0.459 & 0.153 & 0.182 & 0.202 & 0.410 & 0.443 & 0.401 & 0.472 & 0.309 & 0.406 & 0.438 & 0.422 & 0.274 \\
\hline $\mathrm{Fe}^{3+}$ & 0.025 & 0.020 & 0.023 & 0.022 & 0.024 & 0.024 & 0.022 & 0.025 & 0.015 & 0.022 & 0.021 & 0.020 & 0.021 & 0.020 & 0.031 & 0.022 & 0.020 & 0.022 & 0.026 \\
\hline$M n$ & 0.023 & 0.023 & 0.021 & 0.024 & 0.023 & 0.022 & 0.023 & 0.005 & 0.004 & 0.004 & 0.022 & 0.023 & 0.021 & 0.024 & 0.011 & 0.023 & 0.024 & 0.022 & 0.009 \\
\hline $\mathbf{M g}$ & 0.710 & 0.756 & 0.784 & 0.745 & 0.754 & 0.710 & 0.717 & 0.887 & 0.902 & 0.865 & 0.757 & 0.722 & 0.760 & 0.723 & 0.836 & 0.766 & 0.730 & 0.738 & 0.858 \\
\hline $\mathrm{Ca}$ & 0.770 & 0.768 & 0.753 & 0.758 & 0.749 & 0.766 & 0.754 & 0.880 & 0.889 & 0.873 & 0.757 & 0.757 & 0.772 & 0.745 & 0.769 & 0.755 & 0.754 & 0.763 & 0.790 \\
\hline $\mathrm{Na}$ & 0.017 & 0.015 & 0.018 & 0.016 & 0.016 & 0.017 & 0.016 & 0.011 & 0.010 & 0.015 & 0.016 & 0.015 & 0.015 & 0.016 & 0.016 & 0.017 & 0.017 & 0.016 & 0.018 \\
\hline Total & 4.00 & 4.01 & 4.01 & 4.01 & 4.00 & 4.00 & 4.01 & 4.02 & 4.03 & 4.03 & 4.00 & 4.00 & 4.01 & 4.01 & 4.01 & 4.01 & 4.00 & 4.00 & 4.01 \\
\hline \multicolumn{20}{|l|}{ Atomic \% } \\
\hline Wo & 39.7 & 39.3 & 38.4 & 38.7 & 38.6 & 39.4 & 38.6 & 45.2 & 44.7 & 44.5 & 38.9 & 39.0 & 39.5 & 38.0 & 39.5 & 38.7 & 38.8 & 39.2 & 40.6 \\
\hline En & 36.6 & 38.7 & 40.0 & 38.1 & 38.8 & 36.6 & 36.7 & 45.6 & 45.4 & 44.1 & 38.9 & 37.2 & 38.9 & 36.9 & 43.0 & 39.3 & 37.6 & 38.0 & 44.1 \\
\hline Fs & 23.7 & 21.9 & 21.6 & 23.3 & 22.6 & 24.0 & 24.6 & 9.2 & 9.9 & 11.4 & 22.2 & 23.9 & 21.6 & 25.1 & 17.5 & 22.0 & 23.6 & 22.9 & 15.4 \\
\hline $\mathrm{Mg} \#$ & 59.5 & 62.6 & 63.8 & 60.8 & 62.0 & 59.3 & 58.7 & 82.9 & 81.7 & 79.1 & 62.5 & 59.7 & 63.2 & 58.3 & 70.5 & 62.9 & 60.2 & 61.3 & 73.5 \\
\hline
\end{tabular}


Table F.1 Continued

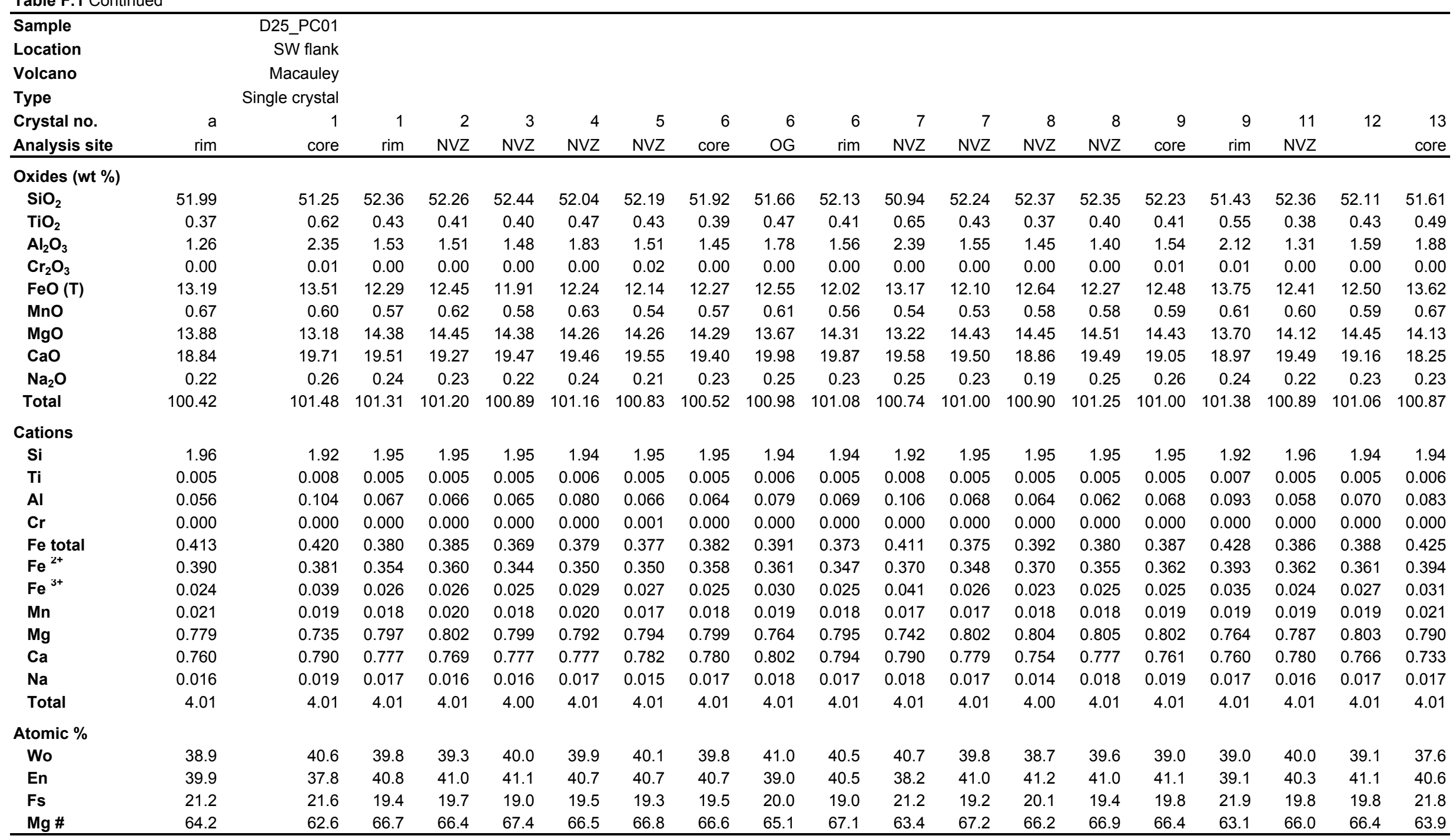


Table F.1 Continued

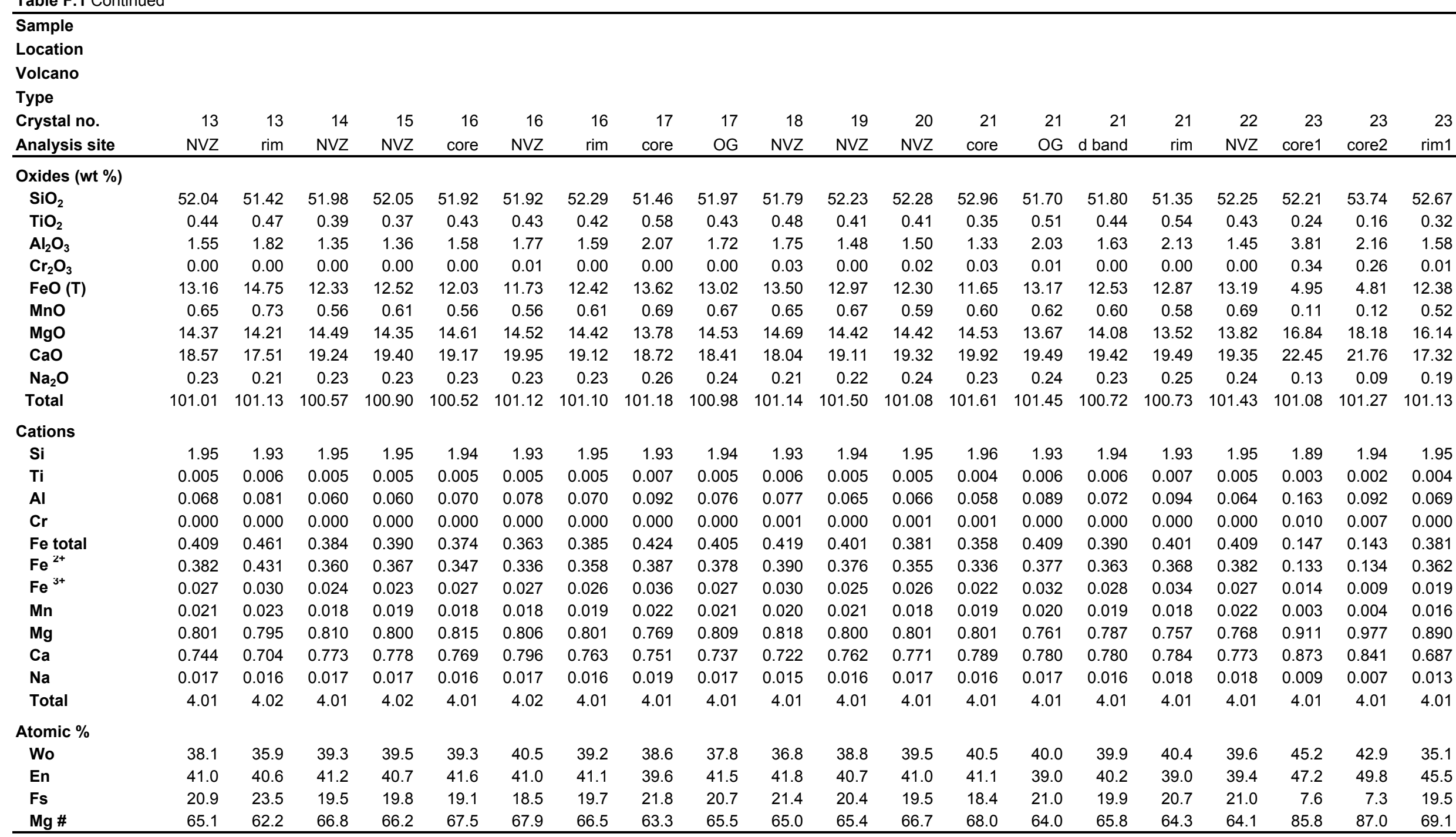


Table F.1 Continued

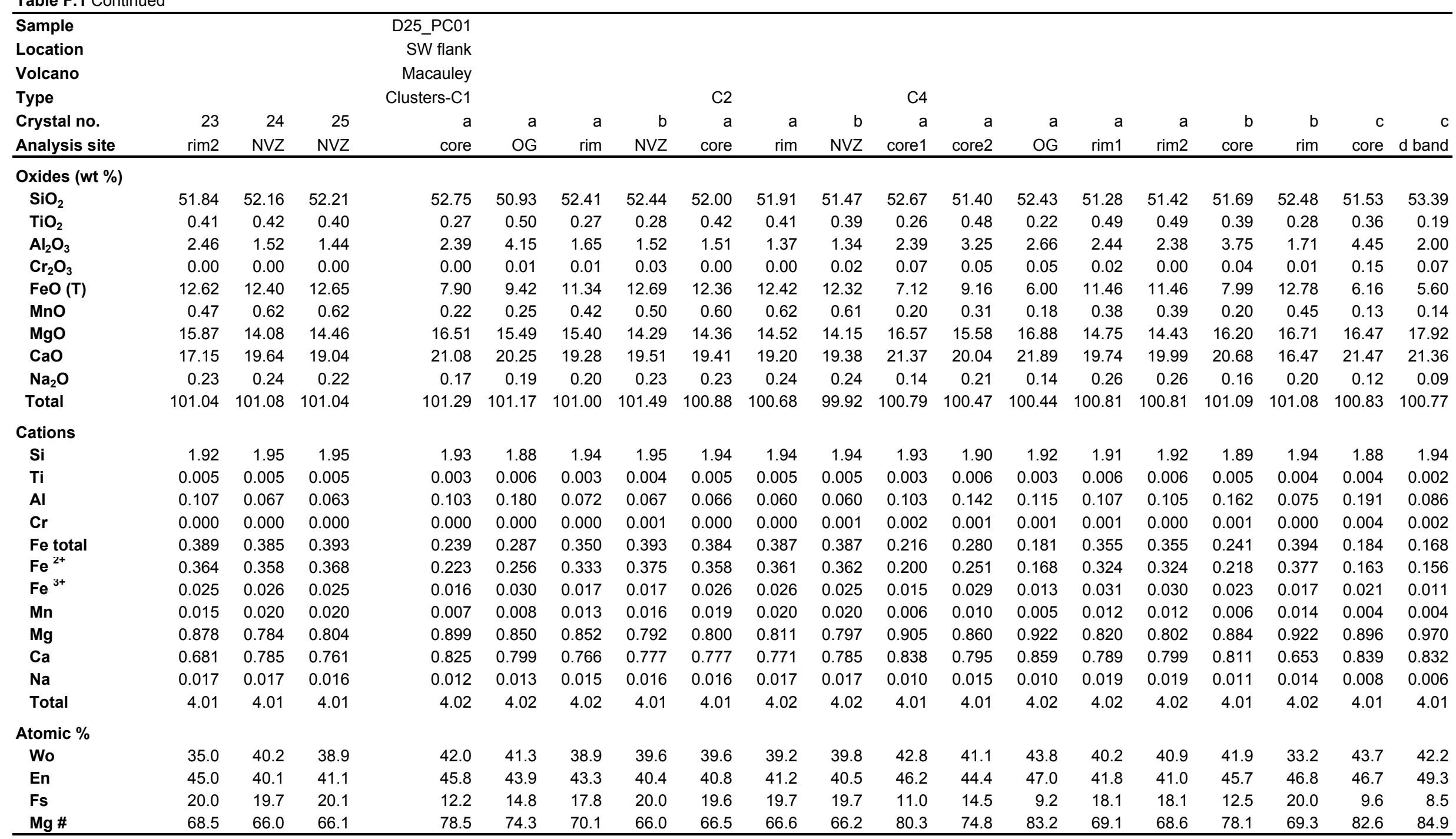


Table F.1 Continued

\begin{tabular}{|c|c|c|c|c|c|c|c|c|c|c|c|c|c|c|c|c|c|c|c|}
\hline Sample & & & & & D29_PC02 & & & & & & & & & & & & & & \\
\hline Location & & & & & $\mathrm{N}$ rim & & & & & & & & & & & & & & \\
\hline Volcano & & & & & Macauley & & & & & & & & & & & & & & \\
\hline Type & & & C5 & C6 & Single crystal & & & & & & & & & & & & & & \\
\hline Crystal no. & c & c & a & a & 1 & 1 & 2 & 2 & 3 & 4 & 4 & 4 & 5 & 6 & 6 & 7 & 8 & 8 & 9 \\
\hline Analysis site & rim1 & rim2 & NVZ & NVZ & core & OG & core & OG & $\mathrm{NVZ}$ & core & OG & rim & $\mathrm{NVZ}$ & core & $\mathrm{rim}$ & $\mathrm{NVZ}$ & core & rim & core \\
\hline \multicolumn{20}{|l|}{ Oxides (wt \%) } \\
\hline $\mathrm{SiO}_{2}$ & 52.98 & 52.08 & 52.13 & 51.82 & 51.87 & 51.98 & 51.50 & 52.06 & 51.16 & 51.51 & 51.15 & 51.48 & 51.56 & 51.76 & 51.63 & 52.07 & 52.03 & 51.76 & 51.71 \\
\hline $\mathrm{TiO}_{2}$ & 0.25 & 0.35 & 0.43 & 0.43 & 0.29 & 0.28 & 0.33 & 0.26 & 0.37 & 0.32 & 0.37 & 0.38 & 0.30 & 0.30 & 0.28 & 0.26 & 0.27 & 0.26 & 0.27 \\
\hline $\mathrm{Al}_{2} \mathrm{O}_{3}$ & 1.88 & 1.82 & 1.61 & 1.61 & 1.14 & 1.02 & 1.14 & 1.00 & 1.37 & 1.20 & 1.32 & 1.30 & 1.03 & 1.15 & 1.09 & 1.02 & 0.95 & 0.88 & 1.02 \\
\hline $\mathrm{Cr}_{2} \mathrm{O}_{3}$ & 0.00 & 0.03 & 0.02 & 0.00 & 0.00 & 0.00 & 0.00 & 0.00 & 0.00 & 0.00 & 0.00 & 0.03 & 0.00 & 0.00 & 0.02 & 0.01 & 0.02 & 0.00 & 0.00 \\
\hline $\mathrm{FeO}(\mathrm{T})$ & 9.36 & 12.13 & 12.13 & 12.85 & 15.25 & 17.47 & 16.88 & 15.69 & 17.29 & 17.82 & 19.32 & 20.27 & 18.00 & 15.61 & 15.59 & 17.12 & 16.69 & 16.56 & 17.82 \\
\hline $\mathrm{MnO}$ & 0.35 & 0.48 & 0.60 & 0.61 & 0.65 & 0.84 & 0.76 & 0.67 & 0.77 & 0.85 & 0.90 & 0.85 & 0.88 & 0.65 & 0.67 & 0.79 & 0.76 & 0.77 & 0.83 \\
\hline MgO & 17.53 & 15.38 & 14.41 & 13.77 & 12.02 & 12.57 & 11.76 & 12.36 & 11.44 & 11.90 & 11.71 & 12.09 & 11.64 & 11.97 & 12.09 & 12.31 & 12.02 & 12.28 & 12.39 \\
\hline $\mathrm{CaO}$ & 18.51 & 18.23 & 19.48 & 19.27 & 19.46 & 17.17 & 18.38 & 19.16 & 18.26 & 17.28 & 15.81 & 14.38 & 17.62 & 19.26 & 19.17 & 17.54 & 18.61 & 18.18 & 16.91 \\
\hline $\mathrm{Na}_{2} \mathrm{O}$ & 0.16 & 0.21 & 0.24 & 0.24 & 0.22 & 0.18 & 0.23 & 0.20 & 0.23 & 0.21 & 0.19 & 0.23 & 0.21 & 0.23 & 0.24 & 0.19 & 0.18 & 0.21 & 0.19 \\
\hline Total & 101.02 & 100.69 & 101.06 & 100.60 & 100.90 & 101.51 & 100.97 & 101.41 & 100.89 & 101.09 & 100.77 & 101.00 & 101.24 & 100.93 & 100.77 & 101.31 & 101.54 & 100.90 & 101.15 \\
\hline \multicolumn{20}{|l|}{ Cations } \\
\hline Si & 1.94 & 1.94 & 1.94 & 1.95 & 1.96 & 1.96 & 1.96 & 1.96 & 1.95 & 1.96 & 1.96 & 1.97 & 1.96 & 1.96 & 1.96 & 1.97 & 1.97 & 1.97 & 1.96 \\
\hline $\mathrm{Ti}$ & 0.003 & 0.004 & 0.005 & 0.005 & 0.004 & 0.003 & 0.004 & 0.003 & 0.005 & 0.004 & 0.005 & 0.005 & 0.004 & 0.004 & 0.004 & 0.003 & 0.003 & 0.003 & 0.003 \\
\hline Al & 0.081 & 0.080 & 0.071 & 0.071 & 0.051 & 0.045 & 0.051 & 0.045 & 0.062 & 0.054 & 0.059 & 0.059 & 0.046 & 0.052 & 0.049 & 0.046 & 0.042 & 0.040 & 0.046 \\
\hline $\mathrm{Cr}$ & 0.000 & 0.001 & 0.001 & 0.000 & 0.000 & 0.000 & 0.000 & 0.000 & 0.000 & 0.000 & 0.000 & 0.001 & 0.000 & 0.000 & 0.001 & 0.000 & 0.001 & 0.000 & 0.000 \\
\hline Fe total & 0.285 & 0.376 & 0.376 & 0.401 & 0.482 & 0.551 & 0.536 & 0.494 & 0.550 & 0.566 & 0.617 & 0.646 & 0.572 & 0.493 & 0.494 & 0.540 & 0.526 & 0.525 & 0.565 \\
\hline $\mathrm{Fe}^{\mathrm{z}^{+}}$ & 0.270 & 0.354 & 0.349 & 0.374 & 0.463 & 0.533 & 0.515 & 0.477 & 0.526 & 0.545 & 0.593 & 0.621 & 0.553 & 0.474 & 0.476 & 0.524 & 0.509 & 0.508 & 0.548 \\
\hline $\mathrm{Fe}^{3+}$ & 0.015 & 0.022 & 0.027 & 0.027 & 0.019 & 0.018 & 0.021 & 0.017 & 0.024 & 0.020 & 0.024 & 0.024 & 0.019 & 0.019 & 0.018 & 0.017 & 0.017 & 0.017 & 0.017 \\
\hline$M n$ & 0.011 & 0.015 & 0.019 & 0.019 & 0.021 & 0.027 & 0.024 & 0.021 & 0.025 & 0.027 & 0.029 & 0.028 & 0.028 & 0.021 & 0.021 & 0.025 & 0.024 & 0.025 & 0.027 \\
\hline $\mathbf{M g}$ & 0.957 & 0.854 & 0.801 & 0.771 & 0.679 & 0.708 & 0.667 & 0.695 & 0.651 & 0.675 & 0.668 & 0.688 & 0.661 & 0.677 & 0.684 & 0.694 & 0.677 & 0.695 & 0.701 \\
\hline $\mathrm{Ca}$ & 0.726 & 0.727 & 0.778 & 0.775 & 0.790 & 0.695 & 0.749 & 0.774 & 0.747 & 0.705 & 0.649 & 0.588 & 0.719 & 0.782 & 0.780 & 0.711 & 0.753 & 0.740 & 0.688 \\
\hline $\mathrm{Na}$ & 0.011 & 0.015 & 0.017 & 0.018 & 0.016 & 0.013 & 0.017 & 0.015 & 0.017 & 0.015 & 0.014 & 0.017 & 0.016 & 0.017 & 0.018 & 0.014 & 0.013 & 0.016 & 0.014 \\
\hline Total & 4.01 & 4.01 & 4.01 & 4.01 & 4.01 & 4.01 & 4.01 & 4.01 & 4.01 & 4.01 & 4.00 & 4.00 & 4.01 & 4.01 & 4.01 & 4.00 & 4.01 & 4.01 & 4.01 \\
\hline \multicolumn{20}{|l|}{ Atomic \% } \\
\hline Wo & 36.9 & 37.2 & 39.8 & 39.8 & 40.5 & 35.6 & 38.4 & 39.5 & 38.3 & 36.2 & 33.5 & 30.6 & 36.8 & 40.1 & 39.8 & 36.5 & 38.5 & 37.8 & 35.2 \\
\hline En & 48.6 & 43.6 & 41.0 & 39.6 & 34.8 & 36.2 & 34.2 & 35.4 & 33.4 & 34.7 & 34.6 & 35.8 & 33.9 & 34.7 & 35.0 & 35.7 & 34.6 & 35.5 & 35.9 \\
\hline Fs & 14.5 & 19.2 & 19.2 & 20.6 & 24.7 & 28.2 & 27.4 & 25.2 & 28.2 & 29.1 & 31.9 & 33.6 & 29.3 & 25.3 & 25.2 & 27.8 & 26.9 & 26.8 & 28.9 \\
\hline Mg \# & 76.4 & 68.6 & 67.0 & 64.7 & 57.5 & 55.1 & 54.3 & 57.4 & 53.1 & 53.2 & 50.8 & 50.5 & 52.4 & 56.8 & 57.0 & 55.1 & 55.1 & 55.9 & 54.2 \\
\hline
\end{tabular}


Table F.1 Continued

\begin{tabular}{|c|c|c|c|c|c|c|c|c|c|c|c|c|c|c|c|c|c|c|c|}
\hline Sample & D33_PC02 & & & & & & & & & & & & & & & & & & \\
\hline Location & E flank & & & & & & & & & & & & & & & & & & \\
\hline Volcano & Macauley & & & & & & & & & & & & & & & & & & \\
\hline Type & Single crystal & & & & & & & & & & & & & & & & & & \\
\hline Crystal no. & 1 & 1 & 2 & 3 & 4 & 4 & 5 & 6 & 7 & 7 & 9 & 9 & 10 & 11 & 12 & 13 & 14 & 15 & 16 \\
\hline Analysis site & core & rim & NVZ & NVZ & core & $\operatorname{rim}$ & NVZ & $\mathrm{NVZ}$ & NVZ & NVZ & NVZ & $\mathrm{NVZ}$ & NVZ & NVZ & NVZ & NVZ & NVZ & NVZ & NVZ \\
\hline \multicolumn{20}{|l|}{ Oxides (wt \%) } \\
\hline $\mathrm{SiO}_{2}$ & 52.32 & 51.78 & 51.78 & 52.26 & 53.41 & 52.28 & 52.39 & 52.52 & 52.26 & 52.80 & 52.23 & 52.42 & 52.65 & 52.67 & 52.63 & 52.83 & 52.79 & 52.30 & 51.65 \\
\hline $\mathrm{TiO}_{2}$ & 0.35 & 0.34 & 0.31 & 0.36 & 0.19 & 0.33 & 0.36 & 0.31 & 0.42 & 0.28 & 0.35 & 0.35 & 0.29 & 0.34 & 0.31 & 0.30 & 0.31 & 0.33 & 0.41 \\
\hline $\mathrm{Al}_{2} \mathrm{O}_{3}$ & 1.83 & 1.53 & 1.65 & 1.77 & 2.25 & 1.56 & 1.83 & 1.62 & 1.99 & 1.43 & 1.78 & 1.62 & 1.45 & 1.79 & 1.67 & 1.55 & 1.36 & 1.74 & 2.12 \\
\hline $\mathrm{Cr}_{2} \mathrm{O}_{3}$ & 0.00 & 0.03 & 0.00 & 0.02 & 0.20 & 0.00 & 0.02 & 0.00 & 0.02 & 0.00 & 0.00 & 0.00 & 0.01 & 0.00 & 0.01 & 0.00 & 0.01 & 0.00 & 0.00 \\
\hline $\mathrm{FeO}(\mathrm{T})$ & 10.27 & 10.79 & 10.32 & 10.25 & 5.23 & 10.70 & 10.37 & 10.36 & 11.05 & 10.52 & 10.59 & 10.92 & 10.63 & 10.28 & 10.49 & 10.08 & 10.62 & 10.16 & 11.45 \\
\hline $\mathrm{MnO}$ & 0.51 & 0.60 & 0.55 & 0.52 & 0.15 & 0.57 & 0.51 & 0.49 & 0.54 & 0.54 & 0.55 & 0.55 & 0.57 & 0.50 & 0.49 & 0.50 & 0.55 & 0.47 & 0.62 \\
\hline MgO & 14.88 & 14.45 & 14.51 & 14.78 & 17.73 & 14.70 & 14.78 & 14.86 & 14.69 & 15.02 & 14.69 & 14.58 & 14.84 & 14.83 & 14.90 & 15.14 & 14.93 & 14.82 & 14.53 \\
\hline $\mathrm{CaO}$ & 20.59 & 20.26 & 20.57 & 20.57 & 21.64 & 20.18 & 20.55 & 20.67 & 20.32 & 20.58 & 20.44 & 20.29 & 20.54 & 20.63 & 20.52 & 20.72 & 20.33 & 20.55 & 19.81 \\
\hline $\mathrm{Na}_{2} \mathrm{O}$ & 0.21 & 0.24 & 0.25 & 0.22 & 0.15 & 0.23 & 0.23 & 0.21 & 0.24 & 0.22 & 0.23 & 0.24 & 0.24 & 0.22 & 0.19 & 0.22 & 0.22 & 0.23 & 0.23 \\
\hline Total & 100.95 & 100.01 & 99.93 & 100.74 & 100.95 & 100.53 & 101.03 & 101.03 & 101.52 & 101.37 & 100.86 & 100.96 & 101.21 & 101.25 & 101.20 & 101.33 & 101.12 & 100.60 & 100.81 \\
\hline \multicolumn{20}{|l|}{ Cations } \\
\hline Si & 1.94 & 1.94 & 1.94 & 1.94 & 1.94 & 1.95 & 1.94 & 1.95 & 1.93 & 1.95 & 1.94 & 1.95 & 1.95 & 1.95 & 1.95 & 1.95 & 1.96 & 1.94 & 1.93 \\
\hline $\mathrm{Ti}$ & 0.004 & 0.004 & 0.004 & 0.004 & 0.002 & 0.004 & 0.004 & 0.004 & 0.005 & 0.003 & 0.004 & 0.004 & 0.004 & 0.004 & 0.004 & 0.004 & 0.004 & 0.004 & 0.005 \\
\hline Al & 0.080 & 0.068 & 0.073 & 0.078 & 0.096 & 0.068 & 0.080 & 0.071 & 0.087 & 0.062 & 0.078 & 0.071 & 0.063 & 0.078 & 0.073 & 0.067 & 0.059 & 0.076 & 0.093 \\
\hline $\mathrm{Cr}$ & 0.000 & 0.001 & 0.000 & 0.000 & 0.006 & 0.000 & 0.001 & 0.000 & 0.000 & 0.000 & 0.000 & 0.000 & 0.000 & 0.000 & 0.000 & 0.000 & 0.000 & 0.000 & 0.000 \\
\hline Fe tot & 0.316 & 0.337 & 0.322 & 0.316 & 0.156 & 0.331 & 0.319 & 0.319 & 0.339 & 0.323 & 0.327 & 0.337 & 0.327 & 0.315 & 0.323 & 0.309 & 0.327 & 0.314 & 0.355 \\
\hline $\mathrm{Fe}^{2+}$ & 0.295 & 0.316 & 0.302 & 0.294 & 0.145 & 0.311 & 0.297 & 0.300 & 0.313 & 0.306 & 0.305 & 0.315 & 0.309 & 0.295 & 0.304 & 0.291 & 0.308 & 0.293 & 0.329 \\
\hline $\mathrm{Fe}^{3+}$ & 0.021 & 0.021 & 0.020 & 0.022 & 0.011 & 0.021 & 0.022 & 0.019 & 0.026 & 0.017 & 0.021 & 0.022 & 0.018 & 0.020 & 0.019 & 0.018 & 0.019 & 0.020 & 0.025 \\
\hline Mn & 0.016 & 0.019 & 0.017 & 0.016 & 0.005 & 0.018 & 0.016 & 0.015 & 0.017 & 0.017 & 0.017 & 0.017 & 0.018 & 0.016 & 0.015 & 0.016 & 0.017 & 0.015 & 0.020 \\
\hline Mg & 0.822 & 0.809 & 0.812 & 0.819 & 0.958 & 0.817 & 0.816 & 0.821 & 0.810 & 0.828 & 0.814 & 0.808 & 0.819 & 0.817 & 0.822 & 0.833 & 0.824 & 0.822 & 0.808 \\
\hline $\mathrm{Ca}$ & 0.818 & 0.815 & 0.827 & 0.819 & 0.841 & 0.806 & 0.816 & 0.821 & 0.805 & 0.815 & 0.814 & 0.808 & 0.815 & 0.817 & 0.813 & 0.819 & 0.807 & 0.819 & 0.792 \\
\hline $\mathrm{Na}$ & 0.015 & 0.017 & 0.018 & 0.016 & 0.011 & 0.017 & 0.016 & 0.015 & 0.017 & 0.015 & 0.017 & 0.017 & 0.017 & 0.016 & 0.013 & 0.016 & 0.016 & 0.017 & 0.017 \\
\hline Total & 4.01 & 4.01 & 4.02 & 4.01 & 4.01 & 4.01 & 4.01 & 4.01 & 4.01 & 4.01 & 4.01 & 4.01 & 4.01 & 4.01 & 4.01 & 4.01 & 4.01 & 4.01 & 4.02 \\
\hline \multicolumn{20}{|l|}{ Atomic \% } \\
\hline Wo & 41.8 & 41.6 & 42.2 & 41.9 & 43.0 & 41.2 & 41.8 & 41.9 & 41.2 & 41.4 & 41.6 & 41.4 & 41.6 & 41.9 & 41.5 & 41.8 & 41.2 & 41.9 & 40.5 \\
\hline En & 42.0 & 41.3 & 41.4 & 41.9 & 49.0 & 41.8 & 41.8 & 41.9 & 41.5 & 42.1 & 41.6 & 41.4 & 41.8 & 41.9 & 42.0 & 42.5 & 42.1 & 42.0 & 41.3 \\
\hline Fs & 16.2 & 17.2 & 16.4 & 16.2 & 8.0 & 17.0 & 16.3 & 16.3 & 17.3 & 16.4 & 16.7 & 17.3 & 16.7 & 16.2 & 16.5 & 15.8 & 16.7 & 16.1 & 18.1 \\
\hline Mg \# & 71.2 & 69.4 & 70.5 & 71.1 & 85.6 & 70.0 & 70.9 & 71.1 & 69.5 & 70.9 & 70.3 & 69.5 & 70.4 & 71.1 & 70.9 & 71.9 & 70.5 & 71.4 & 68.3 \\
\hline
\end{tabular}


Table F.1 Continued

\begin{tabular}{|c|c|c|c|c|c|c|c|c|c|c|c|c|c|c|c|c|c|c|}
\hline Sample & & & D33_PC02 & & & & D33_PC04 & & & & & & & & & & & \\
\hline Location & & & E flank & & & & $\bar{E}$ flank & & & & & & & & & & & \\
\hline Volcano & & & Macauley & & & & Macauley & & & & & & & & & & & \\
\hline Type & & & Clusters-C1 & $\mathrm{C} 2$ & C5 & $\mathrm{C} 5$ & Single crystal & & & & & & & & & & & \\
\hline Crystal no. & 16 & 16 & a & a & $a$ & $\mathrm{~b}$ & 1 & 1 & 2 & 2 & 2 & 3 & 3 & 3 & 3 & 3 & 4 & 4 \\
\hline Analysis site & $N V Z$ & NVZ & $N V Z$ & NVZ & $N V Z$ & NVZ & core & rim2 & core 1 & core2 & $\mathrm{rim}$ & core1 & core 2 & band1 & band2 & $\mathrm{rim}$ & core & $\operatorname{rim} 1$ \\
\hline \multicolumn{19}{|l|}{ Oxides (wt \%) } \\
\hline $\mathrm{SiO}_{2}$ & 52.30 & 52.27 & 52.51 & 52.34 & 52.64 & 52.74 & 54.33 & 52.86 & 52.52 & 53.23 & 53.10 & 53.66 & 53.00 & 54.66 & 54.61 & 54.45 & 53.43 & 53.59 \\
\hline $\mathrm{TiO}_{2}$ & 0.32 & 0.34 & 0.31 & 0.33 & 0.25 & 0.32 & 0.08 & 0.29 & 0.21 & 0.13 & 0.19 & 0.13 & 0.18 & 0.13 & 0.11 & 0.10 & 0.10 & 0.12 \\
\hline $\mathrm{Al}_{2} \mathrm{O}_{3}$ & 1.54 & 1.64 & 1.50 & 1.61 & 1.45 & 1.62 & 1.57 & 2.61 & 3.29 & 2.35 & 2.12 & 2.23 & 2.91 & 1.10 & 1.32 & 1.08 & 2.31 & 1.53 \\
\hline $\mathrm{Cr}_{2} \mathrm{O}_{3}$ & 0.00 & 0.00 & 0.01 & 0.00 & 0.00 & 0.02 & 0.50 & 0.11 & 0.14 & 0.18 & 0.24 & 0.33 & 0.20 & 0.14 & 0.34 & 0.14 & 0.23 & 0.17 \\
\hline $\mathrm{FeO}(\mathrm{T})$ & 10.89 & 11.11 & 10.35 & 10.81 & 10.37 & 10.30 & 3.11 & 6.35 & 4.50 & 3.76 & 4.99 & 4.18 & 4.52 & 5.72 & 4.29 & 6.48 & 3.83 & 5.58 \\
\hline MnO & 0.58 & 0.57 & 0.54 & 0.53 & 0.55 & 0.48 & 0.08 & 0.22 & 0.09 & 0.10 & 0.13 & 0.11 & 0.11 & 0.22 & 0.15 & 0.27 & 0.12 & 0.20 \\
\hline MgO & 14.79 & 14.49 & 14.81 & 14.62 & 15.12 & 14.89 & 18.34 & 17.49 & 17.00 & 17.71 & 17.67 & 17.82 & 17.37 & 19.04 & 19.08 & 19.38 & 18.09 & 18.39 \\
\hline $\mathrm{CaO}$ & 20.44 & 20.09 & 20.64 & 20.61 & 20.41 & 20.68 & 23.20 & 20.70 & 23.01 & 23.26 & 21.66 & 22.82 & 22.83 & 20.07 & 21.27 & 18.89 & 22.77 & 20.70 \\
\hline $\mathrm{Na}_{2} \mathrm{O}$ & 0.22 & 0.26 & 0.23 & 0.24 & 0.23 & 0.24 & 0.09 & 0.14 & 0.10 & 0.09 & 0.14 & 0.09 & 0.06 & 0.11 & 0.07 & 0.10 & 0.08 & 0.11 \\
\hline Total & 101.08 & 100.76 & 100.90 & 101.09 & 101.02 & 101.28 & 101.30 & 100.77 & 100.85 & 100.81 & 100.24 & 101.37 & 101.16 & 101.19 & 101.23 & 100.91 & 100.96 & 100.39 \\
\hline \multicolumn{19}{|l|}{ Cations } \\
\hline Si & 1.94 & 1.95 & 1.95 & 1.94 & 1.95 & 1.95 & 1.95 & 1.93 & 1.91 & 1.93 & 1.94 & 1.93 & 1.92 & 1.97 & 1.96 & 1.97 & 1.93 & 1.95 \\
\hline $\mathrm{Ti}$ & 0.004 & 0.004 & 0.004 & 0.004 & 0.003 & 0.004 & 0.001 & 0.004 & 0.003 & 0.002 & 0.002 & 0.002 & 0.002 & 0.002 & 0.001 & 0.001 & 0.001 & 0.002 \\
\hline Al & 0.068 & 0.072 & 0.066 & 0.070 & 0.063 & 0.071 & 0.066 & 0.112 & 0.141 & 0.100 & 0.091 & 0.095 & 0.124 & 0.047 & 0.056 & 0.046 & 0.098 & 0.066 \\
\hline $\mathrm{Cr}$ & 0.000 & 0.000 & 0.000 & 0.000 & 0.000 & 0.000 & 0.014 & 0.003 & 0.004 & 0.005 & 0.007 & 0.009 & 0.006 & 0.004 & 0.010 & 0.004 & 0.007 & 0.005 \\
\hline Fe total & 0.336 & 0.344 & 0.319 & 0.334 & 0.320 & 0.316 & 0.092 & 0.190 & 0.134 & 0.112 & 0.150 & 0.124 & 0.134 & 0.171 & 0.127 & 0.195 & 0.114 & 0.168 \\
\hline $\mathrm{Fe}^{2+}$ & 0.316 & 0.323 & 0.301 & 0.313 & 0.304 & 0.296 & 0.087 & 0.173 & 0.121 & 0.104 & 0.138 & 0.116 & 0.124 & 0.163 & 0.121 & 0.189 & 0.108 & 0.161 \\
\hline $\mathrm{Fe}^{3+}$ & 0.020 & 0.021 & 0.019 & 0.020 & 0.016 & 0.020 & 0.005 & 0.017 & 0.013 & 0.007 & 0.011 & 0.008 & 0.010 & 0.008 & 0.006 & 0.006 & 0.006 & 0.007 \\
\hline Mn & 0.018 & 0.018 & 0.017 & 0.017 & 0.017 & 0.015 & 0.002 & 0.007 & 0.003 & 0.003 & 0.004 & 0.003 & 0.003 & 0.007 & 0.004 & 0.008 & 0.004 & 0.006 \\
\hline Mg & 0.819 & 0.805 & 0.820 & 0.810 & 0.835 & 0.820 & 0.982 & 0.950 & 0.921 & 0.956 & 0.961 & 0.957 & 0.937 & 1.023 & 1.021 & 1.045 & 0.974 & 0.998 \\
\hline $\mathrm{Ca}$ & 0.813 & 0.802 & 0.821 & 0.820 & 0.810 & 0.819 & 0.893 & 0.808 & 0.895 & 0.903 & 0.847 & 0.881 & 0.885 & 0.775 & 0.819 & 0.732 & 0.881 & 0.808 \\
\hline $\mathrm{Na}$ & 0.016 & 0.019 & 0.016 & 0.017 & 0.016 & 0.017 & 0.006 & 0.010 & 0.007 & 0.006 & 0.010 & 0.006 & 0.004 & 0.007 & 0.005 & 0.007 & 0.005 & 0.008 \\
\hline Total & 4.02 & 4.01 & 4.01 & 4.02 & 4.02 & 4.01 & 4.01 & 4.01 & 4.01 & 4.02 & 4.01 & 4.01 & 4.01 & 4.00 & 4.00 & 4.01 & 4.02 & 4.01 \\
\hline \multicolumn{19}{|l|}{ Atomic \% } \\
\hline Wo & 41.3 & 41.1 & 41.9 & 41.8 & 41.2 & 41.9 & 45.4 & 41.5 & 45.9 & 45.8 & 43.3 & 44.9 & 45.3 & 39.4 & 41.6 & 37.1 & 44.7 & 40.9 \\
\hline En & 41.6 & 41.3 & 41.8 & 41.2 & 42.5 & 42.0 & 49.9 & 48.8 & 47.2 & 48.5 & 49.1 & 48.8 & 47.9 & 52.0 & 51.9 & 53.0 & 49.5 & 50.6 \\
\hline Fs & 17.1 & 17.6 & 16.3 & 17.0 & 16.3 & 16.2 & 4.7 & 9.8 & 6.9 & 5.7 & 7.6 & 6.3 & 6.9 & 8.7 & 6.5 & 9.9 & 5.8 & 8.5 \\
\hline $\mathrm{Mg} \#$ & 69.8 & 69.0 & 70.9 & 69.8 & 71.3 & 71.2 & 91.3 & 82.8 & 87.1 & 89.3 & 86.2 & 88.3 & 87.2 & 85.2 & 88.6 & 83.7 & 89.2 & 85.1 \\
\hline
\end{tabular}




\begin{tabular}{|c|c|c|c|c|c|c|c|c|c|c|c|c|c|c|c|c|c|c|c|c|}
\hline \multicolumn{21}{|l|}{ Sample } \\
\hline \multicolumn{21}{|l|}{ Location } \\
\hline \multicolumn{21}{|l|}{ Volcano } \\
\hline \multicolumn{21}{|l|}{ Type } \\
\hline Crystal no. & 4 & 5 & 5 & 5 & 6 & 6 & 6 & 7 & 8 & 8 & 9 & 9 & 9 & 9 & 10 & 10 & 10 & 10 & 11 & 11 \\
\hline Analysis site & $\operatorname{rim} 2$ & core & OG & $\mathrm{rim}$ & core & $\operatorname{rim} 1$ & $\operatorname{rim} 2$ & NVZ & core & rim & core & OG & $\operatorname{rim} 1$ & $\operatorname{rim} 2$ & core & band & $\operatorname{rim} 1$ & $\operatorname{rim} 2$ & core & rim \\
\hline \multicolumn{21}{|l|}{ Oxides (wt \%) } \\
\hline $\mathrm{SiO}_{2}$ & 53.69 & 53.10 & 53.35 & 54.30 & 53.35 & 53.57 & 53.53 & 51.90 & 53.28 & 54.44 & 52.56 & 53.43 & 54.28 & 54.35 & 53.08 & 54.54 & 53.82 & 53.97 & 53.06 & 53.57 \\
\hline $\mathrm{TiO}_{2}$ & 0.15 & 0.16 & 0.14 & 0.13 & 0.15 & 0.24 & 0.19 & 0.26 & 0.24 & 0.10 & 0.22 & 0.13 & 0.13 & 0.12 & 0.17 & 0.10 & 0.14 & 0.16 & 0.11 & 0.16 \\
\hline $\mathrm{Al}_{2} \mathrm{O}_{3}$ & 1.54 & 2.86 & 2.26 & 1.06 & 2.67 & 2.37 & 2.29 & 4.59 & 3.03 & 1.67 & 3.33 & 2.30 & 1.04 & 1.08 & 2.83 & 1.18 & 0.99 & 1.15 & 2.16 & 1.51 \\
\hline $\mathrm{Cr}_{2} \mathrm{O}_{3}$ & 0.10 & 0.29 & 0.17 & 0.10 & 0.31 & 0.18 & 0.10 & 0.07 & 0.08 & 0.89 & 0.12 & 0.24 & 0.09 & 0.12 & 0.22 & 0.35 & 0.07 & 0.14 & 0.53 & 0.12 \\
\hline $\mathrm{FeO}(\mathrm{T})$ & 5.81 & 4.38 & 3.91 & 5.70 & 3.85 & 5.92 & 6.21 & 4.81 & 5.35 & 2.85 & 4.82 & 3.86 & 6.14 & 5.92 & 4.33 & 4.42 & 6.02 & 6.61 & 3.33 & 6.39 \\
\hline MnO & 0.20 & 0.11 & 0.08 & 0.23 & 0.11 & 0.18 & 0.23 & 0.09 & 0.15 & 0.09 & 0.14 & 0.10 & 0.24 & 0.23 & 0.07 & 0.15 & 0.26 & 0.28 & 0.08 & 0.25 \\
\hline MgO & 18.47 & 17.45 & 17.84 & 19.16 & 17.70 & 17.44 & 17.72 & 16.49 & 17.12 & 18.49 & 16.87 & 17.64 & 18.70 & 18.65 & 17.46 & 19.53 & 18.64 & 19.49 & 17.67 & 18.42 \\
\hline $\mathrm{CaO}$ & 20.43 & 22.70 & 23.24 & 20.19 & 22.94 & 21.41 & 20.69 & 22.88 & 22.26 & 23.21 & 22.79 & 23.16 & 19.91 & 20.28 & 22.98 & 20.51 & 19.83 & 18.52 & 23.10 & 19.35 \\
\hline $\mathrm{Na}_{2} \mathrm{O}$ & 0.14 & 0.08 & 0.09 & 0.09 & 0.07 & 0.18 & 0.13 & 0.11 & 0.11 & 0.13 & 0.10 & 0.09 & 0.09 & 0.10 & 0.10 & 0.10 & 0.09 & 0.09 & 0.08 & 0.11 \\
\hline Total & 100.52 & 101.13 & 101.08 & 100.96 & 101.15 & 101.47 & 101.09 & 101.20 & 101.61 & 101.87 & 100.96 & 100.94 & 100.61 & 100.84 & 101.25 & 100.88 & 99.86 & 100.40 & 100.12 & 99.86 \\
\hline \multicolumn{21}{|l|}{ Cations } \\
\hline $\mathbf{S i}$ & 1.95 & 1.92 & 1.93 & 1.96 & 1.92 & 1.94 & 1.94 & 1.88 & 1.92 & 1.94 & 1.91 & 1.93 & 1.97 & 1.97 & 1.92 & 1.96 & 1.97 & 1.96 & 1.93 & 1.96 \\
\hline $\mathbf{T i}$ & 0.002 & 0.002 & 0.002 & 0.002 & 0.002 & 0.003 & 0.002 & 0.003 & 0.003 & 0.001 & 0.003 & 0.002 & 0.002 & 0.002 & 0.002 & 0.001 & 0.002 & 0.002 & 0.001 & 0.002 \\
\hline Al & 0.066 & 0.122 & 0.096 & 0.045 & 0.113 & 0.101 & 0.098 & 0.196 & 0.129 & 0.070 & 0.143 & 0.098 & 0.044 & 0.046 & 0.120 & 0.050 & 0.043 & 0.049 & 0.093 & 0.065 \\
\hline $\mathrm{Cr}$ & 0.003 & 0.008 & 0.005 & 0.003 & 0.009 & 0.005 & 0.003 & 0.002 & 0.002 & 0.025 & 0.004 & 0.007 & 0.002 & 0.003 & 0.006 & 0.010 & 0.002 & 0.004 & 0.015 & 0.003 \\
\hline $\mathrm{Fe}$ total & 0.175 & 0.130 & 0.116 & 0.171 & 0.114 & 0.176 & 0.186 & 0.142 & 0.158 & 0.083 & 0.143 & 0.115 & 0.185 & 0.178 & 0.128 & 0.132 & 0.183 & 0.199 & 0.099 & 0.194 \\
\hline $\mathrm{Fe}^{2+}$ & 0.166 & 0.120 & 0.108 & 0.163 & 0.105 & 0.162 & 0.175 & 0.127 & 0.144 & 0.077 & 0.130 & 0.107 & 0.177 & 0.171 & 0.118 & 0.126 & 0.174 & 0.190 & 0.092 & 0.185 \\
\hline $\mathrm{Fe}^{3+}$ & 0.009 & 0.010 & 0.008 & 0.008 & 0.009 & 0.014 & 0.011 & 0.015 & 0.014 & 0.005 & 0.013 & 0.007 & 0.008 & 0.007 & 0.010 & 0.006 & 0.008 & 0.009 & 0.007 & 0.009 \\
\hline$M n$ & 0.006 & 0.003 & 0.003 & 0.007 & 0.003 & 0.005 & 0.007 & 0.003 & 0.004 & 0.003 & 0.004 & 0.003 & 0.007 & 0.007 & 0.002 & 0.005 & 0.008 & 0.009 & 0.002 & 0.008 \\
\hline Mg & 1.001 & 0.941 & 0.962 & 1.033 & 0.952 & 0.939 & 0.958 & 0.891 & 0.920 & 0.984 & 0.913 & 0.952 & 1.012 & 1.007 & 0.940 & 1.048 & 1.016 & 1.056 & 0.960 & 1.005 \\
\hline $\mathrm{Ca}$ & 0.796 & 0.879 & 0.900 & 0.782 & 0.887 & 0.829 & 0.803 & 0.888 & 0.860 & 0.888 & 0.887 & 0.898 & 0.774 & 0.787 & 0.890 & 0.791 & 0.777 & 0.721 & 0.902 & 0.758 \\
\hline $\mathrm{Na}$ & 0.010 & 0.005 & 0.007 & 0.006 & 0.005 & 0.013 & 0.009 & 0.008 & 0.008 & 0.009 & 0.007 & 0.006 & 0.007 & 0.007 & 0.007 & 0.007 & 0.007 & 0.006 & 0.006 & 0.008 \\
\hline Total & 4.01 & 4.01 & 4.02 & 4.01 & 4.01 & 4.01 & 4.01 & 4.01 & 4.01 & 4.01 & 4.01 & 4.01 & 4.00 & 4.01 & 4.01 & 4.01 & 4.01 & 4.01 & 4.01 & 4.00 \\
\hline \multicolumn{21}{|l|}{ Atomic \% } \\
\hline Wo & 40.4 & 45.1 & 45.5 & 39.4 & 45.4 & 42.6 & 41.3 & 46.2 & 44.4 & 45.4 & 45.6 & 45.7 & 39.3 & 39.9 & 45.4 & 40.1 & 39.3 & 36.5 & 46.0 & 38.8 \\
\hline En & 50.8 & 48.2 & 48.6 & 52.0 & 48.8 & 48.3 & 49.2 & 46.4 & 47.5 & 50.3 & 47.0 & 48.4 & 51.3 & 51.1 & 48.0 & 53.2 & 51.4 & 53.4 & 49.0 & 51.3 \\
\hline Fs & 8.9 & 6.7 & 5.9 & 8.6 & 5.8 & 9.1 & 9.6 & 7.4 & 8.2 & 4.2 & 7.4 & 5.8 & 9.4 & 9.0 & 6.5 & 6.7 & 9.2 & 10.1 & 5.1 & 9.9 \\
\hline $\mathbf{M g} \#$ & 84.7 & 87.6 & 89.0 & 85.3 & 89.1 & 83.8 & 83.2 & 86.0 & 85.0 & 92.0 & 86.1 & 89.0 & 84.0 & 84.5 & 87.8 & 88.5 & 84.2 & 83.5 & 90.4 & 83.3 \\
\hline
\end{tabular}


Table F.1 Continued

\begin{tabular}{|c|c|c|c|c|c|c|c|c|c|c|c|c|c|c|c|c|c|c|c|c|}
\hline \multicolumn{21}{|l|}{ Sample } \\
\hline \multicolumn{21}{|l|}{ Location } \\
\hline \multicolumn{21}{|l|}{ Volcano } \\
\hline \multicolumn{21}{|l|}{ Type } \\
\hline Crystal no. & 12 & 13 & 13 & 13 & 13 & 14 & 14 & 15 & 15 & 15 & 16 & 16 & 16 & 18 & 18 & 18 & 19 & 19 & 19 & 20 \\
\hline Analysis site & NVZ & core 1 & core 2 & $\operatorname{rim} 1$ & $\operatorname{rim} 2$ & core & rim & core & $\operatorname{rim} 1$ & $\operatorname{rim} 2$ & core & $\operatorname{rim} 1$ & $\operatorname{rim} 2$ & core & $\operatorname{rim} 1$ & $\operatorname{rim} 2$ & core & $\operatorname{rim} 1$ & $\operatorname{rim} 2$ & core \\
\hline \multicolumn{21}{|l|}{ Oxides (wt \%) } \\
\hline $\mathrm{SiO}_{2}$ & 53.88 & 53.13 & 54.26 & 53.57 & 53.54 & 53.18 & 53.55 & 53.80 & 53.19 & 52.88 & 53.09 & 54.26 & 54.36 & 54.06 & 54.07 & 52.91 & 53.89 & 53.33 & 54.21 & 52.92 \\
\hline $\mathrm{TiO}_{2}$ & 0.11 & 0.15 & 0.11 & 0.22 & 0.23 & 0.15 & 0.21 & 0.10 & 0.16 & 0.19 & 0.16 & 0.15 & 0.12 & 0.09 & 0.14 & 0.29 & 0.08 & 0.21 & 0.13 & 0.10 \\
\hline $\mathrm{Al}_{2} \mathrm{O}_{3}$ & 2.08 & 2.68 & 1.84 & 1.65 & 1.92 & 2.75 & 2.73 & 2.07 & 2.49 & 2.40 & 2.77 & 1.26 & 1.25 & 1.78 & 1.64 & 1.71 & 1.92 & 2.46 & 1.87 & 2.02 \\
\hline $\mathrm{Cr}_{2} \mathrm{O}_{3}$ & 0.47 & 0.44 & 0.37 & 0.05 & 0.05 & 0.53 & 0.21 & 0.35 & 0.69 & 0.64 & 0.45 & 0.19 & 0.18 & 0.40 & 0.10 & 0.07 & 0.38 & 0.18 & 0.18 & 0.54 \\
\hline $\mathrm{FeO}(\mathrm{T})$ & 3.63 & 3.99 & 3.46 & 9.11 & 8.14 & 3.99 & 6.24 & 3.66 & 4.89 & 4.65 & 4.44 & 4.97 & 5.25 & 3.49 & 5.96 & 9.40 & 3.49 & 5.66 & 6.20 & 3.30 \\
\hline MnO & 0.10 & 0.08 & 0.11 & 0.40 & 0.40 & 0.11 & 0.19 & 0.10 & 0.14 & 0.15 & 0.12 & 0.15 & 0.20 & 0.10 & 0.23 & 0.31 & 0.07 & 0.20 & 0.23 & 0.09 \\
\hline MgO & 17.77 & 17.64 & 18.25 & 17.53 & 17.23 & 17.36 & 18.61 & 18.57 & 18.56 & 18.08 & 17.29 & 18.66 & 18.99 & 18.43 & 18.52 & 18.96 & 18.17 & 17.55 & 18.58 & 17.84 \\
\hline $\mathrm{CaO}$ & 23.42 & 22.91 & 23.13 & 18.84 & 19.53 & 22.92 & 18.94 & 22.18 & 20.72 & 21.53 & 22.73 & 21.35 & 20.23 & 22.68 & 20.37 & 17.88 & 23.26 & 21.37 & 19.22 & 23.01 \\
\hline $\mathrm{Na}_{2} \mathrm{O}$ & 0.07 & 0.08 & 0.07 & 0.15 & 0.17 & 0.09 & 0.13 & 0.07 & 0.13 & 0.14 & 0.11 & 0.09 & 0.12 & 0.08 & 0.10 & 0.10 & 0.08 & 0.16 & 0.12 & 0.07 \\
\hline Total & 101.54 & 101.09 & 101.60 & 101.53 & 101.20 & 101.08 & 100.82 & 100.90 & 100.96 & 100.65 & 101.15 & 101.08 & 100.69 & 101.10 & 101.13 & 101.63 & 101.35 & 101.10 & 100.73 & 99.88 \\
\hline \multicolumn{21}{|l|}{ Cations } \\
\hline $\mathbf{S i}$ & 1.94 & 1.92 & 1.95 & 1.95 & 1.95 & 1.92 & 1.94 & 1.94 & 1.92 & 1.92 & 1.92 & 1.96 & 1.97 & 1.95 & 1.95 & 1.92 & 1.94 & 1.93 & 1.96 & 1.93 \\
\hline $\mathbf{T i}$ & 0.001 & 0.002 & 0.001 & 0.003 & 0.003 & 0.002 & 0.003 & 0.001 & 0.002 & 0.002 & 0.002 & 0.002 & 0.002 & 0.001 & 0.002 & 0.004 & 0.001 & 0.003 & 0.002 & 0.001 \\
\hline Al & 0.088 & 0.114 & 0.078 & 0.071 & 0.082 & 0.117 & 0.116 & 0.088 & 0.106 & 0.103 & 0.118 & 0.053 & 0.053 & 0.075 & 0.070 & 0.073 & 0.082 & 0.105 & 0.080 & 0.087 \\
\hline $\mathrm{Cr}$ & 0.013 & 0.013 & 0.011 & 0.001 & 0.001 & 0.015 & 0.006 & 0.010 & 0.020 & 0.018 & 0.013 & 0.006 & 0.005 & 0.011 & 0.003 & 0.002 & 0.011 & 0.005 & 0.005 & 0.016 \\
\hline $\mathrm{Fe}$ total & 0.107 & 0.118 & 0.102 & 0.276 & 0.246 & 0.118 & 0.186 & 0.109 & 0.146 & 0.139 & 0.132 & 0.148 & 0.157 & 0.104 & 0.179 & 0.284 & 0.104 & 0.169 & 0.186 & 0.099 \\
\hline $\mathrm{Fe}^{2+}$ & 0.101 & 0.109 & 0.096 & 0.262 & 0.233 & 0.109 & 0.174 & 0.103 & 0.137 & 0.127 & 0.123 & 0.140 & 0.150 & 0.098 & 0.170 & 0.267 & 0.099 & 0.157 & 0.178 & 0.093 \\
\hline $\mathrm{Fe}^{3+}$ & 0.007 & 0.009 & 0.006 & 0.013 & 0.014 & 0.009 & 0.012 & 0.006 & 0.009 & 0.011 & 0.009 & 0.008 & 0.007 & 0.005 & 0.008 & 0.017 & 0.005 & 0.012 & 0.008 & 0.006 \\
\hline Mn & 0.003 & 0.002 & 0.003 & 0.012 & 0.012 & 0.003 & 0.006 & 0.003 & 0.004 & 0.005 & 0.004 & 0.005 & 0.006 & 0.003 & 0.007 & 0.009 & 0.002 & 0.006 & 0.007 & 0.003 \\
\hline $\mathbf{M g}$ & 0.952 & 0.950 & 0.975 & 0.951 & 0.935 & 0.936 & 1.003 & 0.998 & 1.000 & 0.979 & 0.933 & 1.004 & 1.024 & 0.989 & 0.998 & 1.028 & 0.974 & 0.948 & 1.002 & 0.971 \\
\hline $\mathrm{Ca}$ & 0.902 & 0.887 & 0.889 & 0.735 & 0.762 & 0.888 & 0.734 & 0.857 & 0.803 & 0.838 & 0.881 & 0.826 & 0.784 & 0.875 & 0.789 & 0.697 & 0.897 & 0.830 & 0.745 & 0.900 \\
\hline $\mathrm{Na}$ & 0.005 & 0.006 & 0.005 & 0.011 & 0.012 & 0.006 & 0.009 & 0.005 & 0.009 & 0.010 & 0.007 & 0.006 & 0.008 & 0.005 & 0.007 & 0.007 & 0.006 & 0.011 & 0.008 & 0.005 \\
\hline Total & 4.01 & 4.01 & 4.01 & 4.01 & 4.00 & 4.01 & 4.00 & 4.01 & 4.01 & 4.02 & 4.01 & 4.01 & 4.00 & 4.01 & 4.01 & 4.03 & 4.01 & 4.01 & 4.00 & 4.01 \\
\hline \multicolumn{21}{|l|}{ Atomic \% } \\
\hline Wo & 46.0 & 45.4 & 45.2 & 37.4 & 39.2 & 45.7 & 38.2 & 43.6 & 41.2 & 42.9 & 45.3 & 41.7 & 39.9 & 44.5 & 40.1 & 34.7 & 45.4 & 42.6 & 38.5 & 45.7 \\
\hline En & 48.5 & 48.6 & 49.6 & 48.5 & 48.1 & 48.2 & 52.1 & 50.8 & 51.3 & 50.1 & 47.9 & 50.8 & 52.1 & 50.3 & 50.8 & 51.2 & 49.3 & 48.7 & 51.8 & 49.3 \\
\hline Fs & 5.5 & 6.0 & 5.2 & 14.1 & 12.7 & 6.1 & 9.7 & 5.5 & 7.5 & 7.1 & 6.8 & 7.5 & 8.0 & 5.3 & 9.1 & 14.1 & 5.2 & 8.7 & 9.6 & 5.0 \\
\hline Mg\# & 89.6 & 88.8 & 90.3 & 76.8 & 78.3 & 88.5 & 83.9 & 89.9 & 87.0 & 87.3 & 87.3 & 86.8 & 86.2 & 90.3 & 84.3 & 77.8 & 90.2 & 84.4 & 83.8 & 90.6 \\
\hline
\end{tabular}




\begin{tabular}{|c|c|c|c|c|c|c|c|c|c|c|c|c|c|c|c|c|c|c|c|c|}
\hline \multicolumn{21}{|l|}{ Sample } \\
\hline \multicolumn{21}{|l|}{ Location } \\
\hline \multicolumn{21}{|l|}{ Volcano } \\
\hline \multicolumn{21}{|l|}{ Type } \\
\hline Crystal no. & 20 & 20 & 21 & 22 & 22 & 22 & 23 & 24 & 24 & 24 & 25 & 26 & 26 & 27 & 27 & 28 & 29 & 31 & 31 & 32 \\
\hline Analysis site & band & rim & core & core & $\operatorname{rim} 1$ & $\operatorname{rim} 2$ & NVZ & core & OG & rim & NVZ & core & rim & core & rim & NVZ & NVZ & core & rim & core \\
\hline \multicolumn{21}{|l|}{ Oxides (wt \%) } \\
\hline $\mathrm{SiO}_{2}$ & 53.84 & 53.37 & 53.50 & 54.12 & 53.69 & 53.47 & 52.55 & 52.60 & 47.31 & 50.66 & 52.55 & 51.61 & 51.99 & 51.12 & 51.59 & 51.97 & 51.74 & 52.09 & 52.18 & 51.89 \\
\hline $\mathrm{TiO}_{2}$ & 0.08 & 0.14 & 0.12 & 0.10 & 0.15 & 0.16 & 0.20 & 0.20 & 0.85 & 0.63 & 0.18 & 0.28 & 0.29 & 0.23 & 0.29 & 0.30 & 0.29 & 0.24 & 0.27 & 0.26 \\
\hline $\mathrm{Al}_{2} \mathrm{O}_{3}$ & 1.10 & 1.31 & 1.79 & 1.91 & 1.10 & 1.10 & 3.10 & 3.33 & 10.11 & 3.41 & 2.59 & 1.16 & 1.35 & 1.03 & 1.30 & 1.35 & 1.17 & 0.99 & 1.20 & 1.06 \\
\hline $\mathrm{Cr}_{2} \mathrm{O}_{3}$ & 0.60 & 0.10 & 0.31 & 0.12 & 0.15 & 0.11 & 0.38 & 0.34 & 0.02 & 0.02 & 0.11 & 0.00 & 0.04 & 0.01 & 0.01 & 0.03 & 0.00 & 0.00 & 0.01 & 0.00 \\
\hline $\mathrm{FeO}(\mathrm{T})$ & 2.50 & 5.92 & 3.68 & 3.06 & 6.46 & 6.41 & 4.66 & 4.28 & 7.67 & 11.84 & 4.20 & 15.14 & 13.28 & 16.44 & 13.51 & 13.83 & 15.60 & 15.88 & 13.70 & 15.73 \\
\hline MnO & 0.06 & 0.25 & 0.09 & 0.11 & 0.28 & 0.24 & 0.11 & 0.09 & 0.15 & 0.67 & 0.11 & 0.94 & 0.79 & 1.06 & 0.87 & 0.86 & 0.98 & 1.00 & 0.81 & 0.94 \\
\hline MgO & 18.44 & 18.64 & 18.31 & 18.04 & 18.99 & 18.77 & 17.25 & 17.22 & 13.60 & 14.69 & 17.34 & 12.26 & 12.88 & 11.53 & 12.89 & 13.10 & 12.01 & 12.08 & 13.08 & 11.92 \\
\hline $\mathrm{CaO}$ & 23.05 & 19.81 & 22.94 & 23.36 & 19.27 & 19.58 & 22.68 & 22.69 & 21.41 & 17.16 & 23.00 & 18.70 & 19.48 & 18.45 & 19.48 & 19.36 & 18.91 & 19.05 & 19.82 & 19.28 \\
\hline $\mathrm{Na}_{2} \mathrm{O}$ & 0.08 & 0.10 & 0.08 & 0.08 & 0.09 & 0.09 & 0.12 & 0.11 & 0.12 & 0.25 & 0.09 & 0.21 & 0.21 & 0.21 & 0.22 & 0.20 & 0.21 & 0.20 & 0.20 & 0.21 \\
\hline Total & 99.74 & 99.63 & 100.81 & 100.90 & 100.17 & 99.93 & 101.05 & 100.85 & 101.23 & 99.32 & 100.17 & 100.31 & 100.31 & 100.07 & 100.17 & 101.00 & 100.90 & 101.52 & 101.27 & 101.30 \\
\hline \multicolumn{21}{|l|}{ Cations } \\
\hline $\mathbf{S i}$ & 1.96 & 1.96 & 1.94 & 1.95 & 1.96 & 1.96 & 1.91 & 1.91 & 1.74 & 1.91 & 1.92 & 1.96 & 1.96 & 1.96 & 1.96 & 1.95 & 1.96 & 1.97 & 1.96 & 1.96 \\
\hline $\mathrm{Ti}$ & 0.001 & 0.002 & 0.002 & 0.001 & 0.002 & 0.002 & 0.003 & 0.003 & 0.011 & 0.008 & 0.002 & 0.004 & 0.004 & 0.003 & 0.004 & 0.004 & 0.004 & 0.003 & 0.003 & 0.003 \\
\hline Al & 0.047 & 0.057 & 0.076 & 0.081 & 0.047 & 0.047 & 0.133 & 0.142 & 0.437 & 0.151 & 0.111 & 0.052 & 0.060 & 0.046 & 0.058 & 0.060 & 0.052 & 0.044 & 0.053 & 0.047 \\
\hline $\mathrm{Cr}$ & 0.017 & 0.003 & 0.009 & 0.003 & 0.004 & 0.003 & 0.011 & 0.010 & 0.001 & 0.001 & 0.003 & 0.000 & 0.001 & 0.000 & 0.000 & 0.001 & 0.000 & 0.000 & 0.000 & 0.000 \\
\hline $\mathrm{Fe}$ tot & 0.074 & 0.180 & 0.109 & 0.090 & 0.196 & 0.195 & 0.138 & 0.127 & 0.228 & 0.369 & 0.126 & 0.481 & 0.418 & 0.527 & 0.427 & 0.433 & 0.494 & 0.500 & 0.429 & 0.497 \\
\hline $\mathrm{Fe}^{2+}$ & 0.070 & 0.172 & 0.102 & 0.084 & 0.186 & 0.185 & 0.126 & 0.115 & 0.177 & 0.330 & 0.115 & 0.463 & 0.399 & 0.512 & 0.408 & 0.415 & 0.475 & 0.485 & 0.412 & 0.480 \\
\hline $\mathrm{Fe}^{3+}$ & 0.005 & 0.008 & 0.007 & 0.006 & 0.009 & 0.010 & 0.012 & 0.012 & 0.051 & 0.040 & 0.011 & 0.018 & 0.019 & 0.015 & 0.019 & 0.019 & 0.019 & 0.015 & 0.017 & 0.017 \\
\hline $\mathrm{Mn}$ & 0.002 & 0.008 & 0.003 & 0.003 & 0.009 & 0.007 & 0.003 & 0.003 & 0.005 & 0.021 & 0.003 & 0.030 & 0.025 & 0.034 & 0.028 & 0.027 & 0.032 & 0.032 & 0.026 & 0.030 \\
\hline $\mathrm{Mg}$ & 1.001 & 1.019 & 0.988 & 0.969 & 1.033 & 1.025 & 0.933 & 0.931 & 0.744 & 0.825 & 0.945 & 0.696 & 0.725 & 0.660 & 0.729 & 0.735 & 0.679 & 0.680 & 0.731 & 0.672 \\
\hline $\mathrm{Ca}$ & 0.899 & 0.778 & 0.890 & 0.902 & 0.754 & 0.768 & 0.882 & 0.882 & 0.842 & 0.693 & 0.901 & 0.763 & 0.788 & 0.760 & 0.791 & 0.780 & 0.768 & 0.770 & 0.797 & 0.782 \\
\hline $\mathrm{Na}$ & 0.005 & 0.007 & 0.005 & 0.006 & 0.006 & 0.006 & 0.008 & 0.008 & 0.009 & 0.018 & 0.006 & 0.015 & 0.015 & 0.015 & 0.016 & 0.015 & 0.016 & 0.014 & 0.015 & 0.015 \\
\hline Total & 4.01 & 4.01 & 4.02 & 4.01 & 4.01 & 4.01 & 4.02 & 4.01 & 4.01 & 4.00 & 4.02 & 4.00 & 4.00 & 4.01 & 4.01 & 4.01 & 4.01 & 4.01 & 4.01 & 4.01 \\
\hline \multicolumn{21}{|l|}{ Atomic \% } \\
\hline Wo & 45.5 & 39.4 & 44.8 & 46.0 & 38.0 & 38.7 & 45.1 & 45.5 & 46.4 & 36.7 & 45.7 & 39.3 & 40.8 & 39.0 & 40.6 & 40.0 & 39.6 & 39.5 & 40.7 & 40.1 \\
\hline En & 50.7 & 51.5 & 49.7 & 49.4 & 52.1 & 51.5 & 47.8 & 48.0 & 41.0 & 43.7 & 47.9 & 35.9 & 37.5 & 33.9 & 37.4 & 37.7 & 35.0 & 34.8 & 37.4 & 34.5 \\
\hline Fs & 3.8 & 9.1 & 5.5 & 4.6 & 9.9 & 9.8 & 7.1 & 6.5 & 12.6 & 19.6 & 6.4 & 24.8 & 21.6 & 27.1 & 21.9 & 22.2 & 25.4 & 25.6 & 21.9 & 25.5 \\
\hline $\mathrm{Mg} \#$ & 93.0 & 84.5 & 89.8 & 91.2 & 83.5 & 83.5 & 86.8 & 87.8 & 76.2 & 67.9 & 88.0 & 57.7 & 62.1 & 54.0 & 61.6 & 61.4 & 56.4 & 56.1 & 61.7 & 56.1 \\
\hline
\end{tabular}


Table F.1 Continued

\begin{tabular}{|c|c|c|c|c|c|c|c|c|c|c|c|c|c|c|c|c|c|c|c|}
\hline Sample & & MI2007_R01 & & & & & & & & & & & & & & & & & \\
\hline Location & & SBT & & & & & & & & & & & & & & & & & \\
\hline Volcano & & Macauley & & & & & & & & & & & & & & & & & \\
\hline Type & & Single crystal & & & & & & & & & & & & & & & & & \\
\hline Crystal no. & 32 & 1 & 2 & 3 & 3 & 4 & 5 & 6 & 7 & 8 & 9 & 10 & 11 & 12 & 12 & 14 & 15 & 16 & 17 \\
\hline Analysis site & $\mathrm{rim}$ & NVZ & NVZ & core & rim & NVZ & NVZ & NVZ & NVZ & NVZ & NVZ & NVZ & NVZ & core & rim & NVZ & NVZ & NVZ & $N V Z$ \\
\hline \multicolumn{20}{|l|}{ Oxides (wt \%) } \\
\hline $\mathrm{SiO}_{2}$ & 52.39 & 52.35 & 52.25 & 52.33 & 52.59 & 51.97 & 51.62 & 51.17 & 51.28 & 50.40 & 50.95 & 51.21 & 51.05 & 50.11 & 50.15 & 51.96 & 52.53 & 52.40 & 51.16 \\
\hline $\mathrm{TiO}_{2}$ & 0.27 & 0.32 & 0.31 & 0.42 & 0.27 & 0.28 & 0.23 & 0.22 & 0.26 & 0.23 & 0.25 & 0.19 & 0.21 & 0.22 & 0.33 & 0.22 & 0.42 & 0.41 & 0.25 \\
\hline $\mathrm{Al}_{2} \mathrm{O}_{3}$ & 1.20 & 3.09 & 3.27 & 2.82 & 2.92 & 3.59 & 3.27 & 3.24 & 3.12 & 3.13 & 3.84 & 3.24 & 3.26 & 3.18 & 2.72 & 3.71 & 2.69 & 2.88 & 3.94 \\
\hline $\mathrm{Cr}_{2} \mathrm{O}_{3}$ & 0.00 & 0.03 & 0.04 & 0.03 & 0.06 & 0.17 & 0.53 & 0.12 & 0.06 & 0.17 & 0.69 & 0.63 & 0.60 & 0.40 & 0.04 & 0.62 & 0.09 & 0.27 & 0.60 \\
\hline $\mathrm{FeO}(\mathrm{T})$ & 13.79 & 6.67 & 6.24 & 7.86 & 6.00 & 5.53 & 5.04 & 6.41 & 6.20 & 5.70 & 5.06 & 4.85 & 5.13 & 5.04 & 6.36 & 5.25 & 6.65 & 6.53 & 5.63 \\
\hline $\mathrm{MnO}$ & 0.84 & 0.15 & 0.13 & 0.17 & 0.14 & 0.11 & 0.12 & 0.14 & 0.15 & 0.14 & 0.11 & 0.13 & 0.12 & 0.12 & 0.18 & 0.14 & 0.17 & 0.18 & 0.12 \\
\hline MgO & 12.89 & 16.48 & 16.51 & 16.45 & 16.74 & 16.73 & 17.17 & 16.45 & 16.74 & 16.69 & 16.76 & 17.09 & 16.87 & 17.07 & 16.91 & 16.38 & 16.64 & 16.55 & 16.24 \\
\hline $\mathrm{CaO}$ & 19.88 & 21.98 & 22.33 & 21.03 & 22.48 & 22.73 & 22.63 & 22.26 & 22.29 & 22.42 & 22.55 & 22.45 & 22.56 & 22.45 & 21.84 & 22.17 & 21.33 & 21.45 & 22.23 \\
\hline $\mathrm{Na}_{2} \mathrm{O}$ & 0.18 & 0.18 & 0.17 & 0.29 & 0.15 & 0.12 & 0.13 & 0.17 & 0.13 & 0.20 & 0.17 & 0.14 & 0.17 & 0.14 & 0.18 & 0.17 & 0.20 & 0.21 & 0.20 \\
\hline Total & 101.43 & 101.26 & 101.24 & 101.39 & 101.35 & 101.23 & 100.73 & 100.17 & 100.22 & 99.07 & 100.37 & 99.93 & 99.98 & 98.73 & 98.70 & 100.61 & 100.70 & 100.87 & 100.37 \\
\hline \multicolumn{20}{|l|}{ Cations } \\
\hline $\mathbf{S i}$ & 1.96 & 1.91 & 1.90 & 1.91 & 1.91 & 1.89 & 1.89 & 1.89 & 1.89 & 1.88 & 1.87 & 1.89 & 1.88 & 1.87 & 1.88 & 1.90 & 1.92 & 1.92 & 1.88 \\
\hline $\mathrm{Ti}$ & 0.003 & 0.004 & 0.004 & 0.005 & 0.003 & 0.003 & 0.003 & 0.003 & 0.003 & 0.003 & 0.003 & 0.002 & 0.003 & 0.003 & 0.004 & 0.003 & 0.005 & 0.005 & 0.003 \\
\hline Al & 0.053 & 0.133 & 0.140 & 0.121 & 0.125 & 0.154 & 0.141 & 0.141 & 0.135 & 0.138 & 0.166 & 0.140 & 0.142 & 0.140 & 0.120 & 0.160 & 0.116 & 0.124 & 0.171 \\
\hline $\mathrm{Cr}$ & 0.000 & 0.001 & 0.001 & 0.001 & 0.002 & 0.005 & 0.015 & 0.003 & 0.002 & 0.005 & 0.020 & 0.018 & 0.018 & 0.012 & 0.001 & 0.018 & 0.002 & 0.008 & 0.017 \\
\hline Fe total & 0.430 & 0.200 & 0.187 & 0.236 & 0.180 & 0.165 & 0.151 & 0.196 & 0.188 & 0.175 & 0.152 & 0.147 & 0.155 & 0.154 & 0.196 & 0.157 & 0.199 & 0.195 & 0.170 \\
\hline $\mathrm{Fe}^{2+}$ & 0.414 & 0.181 & 0.168 & 0.211 & 0.164 & 0.148 & 0.137 & 0.183 & 0.173 & 0.161 & 0.137 & 0.135 & 0.142 & 0.141 & 0.175 & 0.144 & 0.174 & 0.171 & 0.155 \\
\hline $\mathrm{Fe}^{3+}$ & 0.017 & 0.019 & 0.018 & 0.025 & 0.016 & 0.017 & 0.014 & 0.013 & 0.016 & 0.014 & 0.015 & 0.012 & 0.013 & 0.014 & 0.021 & 0.013 & 0.025 & 0.024 & 0.015 \\
\hline$M n$ & 0.027 & 0.005 & 0.004 & 0.005 & 0.004 & 0.003 & 0.004 & 0.004 & 0.005 & 0.004 & 0.003 & 0.004 & 0.004 & 0.004 & 0.006 & 0.004 & 0.005 & 0.006 & 0.004 \\
\hline Mg & 0.720 & 0.895 & 0.897 & 0.896 & 0.907 & 0.907 & 0.935 & 0.905 & 0.920 & 0.928 & 0.918 & 0.938 & 0.928 & 0.951 & 0.946 & 0.891 & 0.907 & 0.901 & 0.889 \\
\hline $\mathrm{Ca}$ & 0.798 & 0.858 & 0.871 & 0.823 & 0.876 & 0.886 & 0.886 & 0.881 & 0.880 & 0.896 & 0.887 & 0.886 & 0.891 & 0.899 & 0.878 & 0.868 & 0.836 & 0.840 & 0.875 \\
\hline $\mathrm{Na}$ & 0.013 & 0.013 & 0.012 & 0.020 & 0.011 & 0.009 & 0.009 & 0.012 & 0.010 & 0.014 & 0.012 & 0.010 & 0.012 & 0.010 & 0.013 & 0.012 & 0.014 & 0.015 & 0.014 \\
\hline Total & 4.01 & 4.02 & 4.02 & 4.02 & 4.02 & 4.02 & 4.03 & 4.04 & 4.03 & 4.04 & 4.03 & 4.03 & 4.03 & 4.05 & 4.05 & 4.01 & 4.01 & 4.01 & 4.02 \\
\hline \multicolumn{20}{|l|}{ Atomic \% } \\
\hline Wo & 40.9 & 43.9 & 44.6 & 42.1 & 44.6 & 45.2 & 44.9 & 44.4 & 44.3 & 44.8 & 45.3 & 44.9 & 45.2 & 44.9 & 43.5 & 45.3 & 43.0 & 43.4 & 45.2 \\
\hline En & 37.0 & 45.8 & 45.9 & 45.8 & 46.2 & 46.3 & 47.4 & 45.7 & 46.3 & 46.4 & 46.9 & 47.6 & 47.0 & 47.4 & 46.8 & 46.5 & 46.7 & 46.6 & 46.0 \\
\hline Fs & 22.1 & 10.2 & 9.5 & 12.1 & 9.2 & 8.4 & 7.6 & 9.9 & 9.5 & 8.8 & 7.8 & 7.4 & 7.9 & 7.7 & 9.7 & 8.2 & 10.2 & 10.1 & 8.8 \\
\hline Mg \# & 61.2 & 81.4 & 82.5 & 78.8 & 83.1 & 84.3 & 85.8 & 81.9 & 82.6 & 83.8 & 85.5 & 86.2 & 85.4 & 85.7 & 82.4 & 84.6 & 81.6 & 81.8 & 83.7 \\
\hline
\end{tabular}


Table F.1 Continued

\begin{tabular}{|c|c|c|c|c|c|c|c|c|c|c|c|c|c|c|c|c|c|c|c|}
\hline Sample & & & D38_PC06 & & & & & & & & & & & & & & & & \\
\hline Location & & & NW flank/rim & & & & & & & & & & & & & & & & \\
\hline Volcano & & & Healy & & & & & & & & & & & & & & & & \\
\hline Type & & & Single crystal & & & & & & & & & & & & & & & & \\
\hline Crystal no. & 18 & 19 & 1 & 2 & 2 & 3 & 3 & 5 & 6 & 6 & 7 & 7 & 8 & 9 & 10 & 10 & 11 & 11 & 12 \\
\hline Analysis site & NVZ & NVZ & NVZ & core & rim & core & core & NVZ & core & rim & core & rim & NVZ & NVZ & core & rim & core & rim & core \\
\hline \multicolumn{20}{|l|}{ Oxides (wt \%) } \\
\hline $\mathrm{SiO}_{2}$ & 52.36 & 52.52 & 51.85 & 52.12 & 49.67 & 52.48 & 51.19 & 51.22 & 51.79 & 49.50 & 51.55 & 50.70 & 50.90 & 50.92 & 52.27 & 51.60 & 51.96 & 51.53 & 50.69 \\
\hline $\mathrm{TiO}_{2}$ & 0.26 & 0.25 & 0.30 & 0.27 & 0.53 & 0.26 & 0.38 & 0.38 & 0.30 & 0.56 & 0.32 & 0.43 & 0.48 & 0.44 & 0.23 & 0.30 & 0.35 & 0.30 & 0.39 \\
\hline $\mathrm{Al}_{2} \mathrm{O}_{3}$ & 2.98 & 3.04 & 3.59 & 3.64 & 5.91 & 2.67 & 3.98 & 3.59 & 3.43 & 5.72 & 3.76 & 3.89 & 3.31 & 3.52 & 2.63 & 3.38 & 2.23 & 3.38 & 4.00 \\
\hline $\mathrm{Cr}_{2} \mathrm{O}_{3}$ & 0.05 & 0.07 & 0.11 & 0.30 & 0.12 & 0.06 & 0.11 & 0.10 & 0.21 & 0.08 & 0.19 & 0.00 & 0.00 & 0.06 & 0.11 & 0.15 & 0.02 & 0.12 & 0.05 \\
\hline $\mathrm{FeO}(\mathrm{T})$ & 5.79 & 5.77 & 5.95 & 5.27 & 8.06 & 6.50 & 6.78 & 7.05 & 6.05 & 7.76 & 6.13 & 8.23 & 8.18 & 8.14 & 6.21 & 6.30 & 7.90 & 6.34 & 7.00 \\
\hline MnO & 0.14 & 0.14 & 0.15 & 0.11 & 0.17 & 0.15 & 0.13 & 0.17 & 0.11 & 0.16 & 0.13 & 0.18 & 0.24 & 0.19 & 0.15 & 0.14 & 0.26 & 0.14 & 0.15 \\
\hline MgO & 16.69 & 16.78 & 16.11 & 16.22 & 14.63 & 16.54 & 15.69 & 15.74 & 16.23 & 14.54 & 15.88 & 15.16 & 15.33 & 15.40 & 16.49 & 15.99 & 16.12 & 16.01 & 15.41 \\
\hline $\mathrm{CaO}$ & 22.36 & 22.25 & 22.86 & 23.09 & 21.77 & 22.19 & 22.66 & 22.50 & 22.37 & 21.70 & 22.81 & 22.03 & 21.85 & 21.67 & 21.94 & 22.36 & 21.18 & 22.63 & 22.79 \\
\hline $\mathrm{Na}_{2} \mathrm{O}$ & 0.14 & 0.12 & 0.17 & 0.13 & 0.21 & 0.14 & 0.16 & 0.18 & 0.12 & 0.18 & 0.13 & 0.18 & 0.21 & 0.20 & 0.13 & 0.16 & 0.20 & 0.15 & 0.16 \\
\hline Total & 100.78 & 100.94 & 101.09 & 101.13 & 101.05 & 100.97 & 101.07 & 100.92 & 100.59 & 100.19 & 100.89 & 100.80 & 100.51 & 100.55 & 100.16 & 100.37 & 100.20 & 100.60 & 100.63 \\
\hline \multicolumn{20}{|l|}{ Cations } \\
\hline $\mathbf{S i}$ & 1.91 & 1.91 & 1.89 & 1.90 & 1.83 & 1.92 & 1.88 & 1.88 & 1.90 & 1.84 & 1.89 & 1.88 & 1.89 & 1.89 & 1.92 & 1.90 & 1.92 & 1.89 & 1.87 \\
\hline $\mathrm{Ti}$ & 0.003 & 0.003 & 0.004 & 0.003 & 0.007 & 0.003 & 0.005 & 0.005 & 0.004 & 0.007 & 0.004 & 0.005 & 0.006 & 0.006 & 0.003 & 0.004 & 0.004 & 0.004 & 0.005 \\
\hline Al & 0.128 & 0.131 & 0.154 & 0.156 & 0.257 & 0.115 & 0.172 & 0.156 & 0.148 & 0.250 & 0.162 & 0.170 & 0.145 & 0.154 & 0.114 & 0.146 & 0.097 & 0.146 & 0.174 \\
\hline $\mathrm{Cr}$ & 0.002 & 0.002 & 0.003 & 0.009 & 0.003 & 0.002 & 0.003 & 0.003 & 0.006 & 0.002 & 0.005 & 0.000 & 0.000 & 0.002 & 0.003 & 0.004 & 0.000 & 0.004 & 0.001 \\
\hline Fe total & 0.174 & 0.173 & 0.178 & 0.157 & 0.244 & 0.196 & 0.204 & 0.213 & 0.182 & 0.236 & 0.184 & 0.251 & 0.250 & 0.248 & 0.188 & 0.191 & 0.242 & 0.192 & 0.212 \\
\hline $\mathrm{Fe}^{2+}$ & 0.158 & 0.158 & 0.160 & 0.141 & 0.212 & 0.180 & 0.182 & 0.190 & 0.164 & 0.202 & 0.165 & 0.225 & 0.220 & 0.221 & 0.174 & 0.172 & 0.220 & 0.173 & 0.189 \\
\hline $\mathrm{Fe}^{3+}$ & 0.016 & 0.015 & 0.018 & 0.016 & 0.032 & 0.016 & 0.023 & 0.023 & 0.018 & 0.034 & 0.019 & 0.026 & 0.030 & 0.027 & 0.014 & 0.018 & 0.021 & 0.018 & 0.024 \\
\hline$M n$ & 0.004 & 0.004 & 0.005 & 0.003 & 0.005 & 0.004 & 0.004 & 0.005 & 0.004 & 0.005 & 0.004 & 0.005 & 0.008 & 0.006 & 0.005 & 0.004 & 0.008 & 0.004 & 0.005 \\
\hline $\mathrm{Mg}$ & 0.909 & 0.911 & 0.877 & 0.880 & 0.804 & 0.901 & 0.858 & 0.863 & 0.887 & 0.804 & 0.867 & 0.836 & 0.848 & 0.850 & 0.904 & 0.877 & 0.890 & 0.878 & 0.848 \\
\hline $\mathrm{Ca}$ & 0.875 & 0.868 & 0.894 & 0.900 & 0.860 & 0.869 & 0.890 & 0.886 & 0.879 & 0.863 & 0.895 & 0.873 & 0.868 & 0.860 & 0.865 & 0.882 & 0.840 & 0.891 & 0.901 \\
\hline $\mathrm{Na}$ & 0.010 & 0.008 & 0.012 & 0.009 & 0.015 & 0.010 & 0.011 & 0.013 & 0.008 & 0.013 & 0.009 & 0.013 & 0.015 & 0.014 & 0.009 & 0.011 & 0.014 & 0.011 & 0.011 \\
\hline Total & 4.02 & 4.01 & 4.02 & 4.01 & 4.02 & 4.02 & 4.02 & 4.03 & 4.02 & 4.02 & 4.02 & 4.03 & 4.03 & 4.02 & 4.01 & 4.02 & 4.02 & 4.02 & 4.03 \\
\hline \multicolumn{20}{|l|}{ Atomic \% } \\
\hline Wo & 44.7 & 44.5 & 45.9 & 46.5 & 45.1 & 44.2 & 45.6 & 45.2 & 45.1 & 45.3 & 46.0 & 44.6 & 44.2 & 43.9 & 44.2 & 45.2 & 42.6 & 45.5 & 45.9 \\
\hline En & 46.4 & 46.7 & 45.0 & 45.4 & 42.1 & 45.8 & 43.9 & 44.0 & 45.5 & 42.3 & 44.6 & 42.6 & 43.1 & 43.4 & 46.2 & 45.0 & 45.1 & 44.8 & 43.2 \\
\hline Fs & 8.9 & 8.9 & 9.1 & 8.1 & 12.8 & 10.0 & 10.5 & 10.9 & 9.3 & 12.4 & 9.5 & 12.8 & 12.7 & 12.7 & 9.6 & 9.8 & 12.3 & 9.8 & 10.8 \\
\hline Mg \# & 83.6 & 83.7 & 82.7 & 84.6 & 76.3 & 81.8 & 80.5 & 79.8 & 82.7 & 77.0 & 82.2 & 76.5 & 76.7 & 77.0 & 82.4 & 81.8 & 78.1 & 81.8 & 79.6 \\
\hline
\end{tabular}




\begin{tabular}{|c|c|c|c|c|c|c|c|c|c|c|c|c|c|c|c|c|c|c|c|c|}
\hline \multicolumn{21}{|l|}{ Sample } \\
\hline \multicolumn{21}{|l|}{ Location } \\
\hline \multicolumn{21}{|l|}{ Volcano } \\
\hline \multicolumn{21}{|l|}{ Type } \\
\hline Crystal no. & 12 & 12 & 13 & 14 & 14 & 15 & 15 & 16 & 17 & 18 & 19 & 19 & 19 & 20 & 20 & 20 & 22 & 23 & 24 & 24 \\
\hline Analysis site & OG & rim & NVZ & core & rim & core & $\mathrm{rim}$ & NVZ & NVZ & NVZ & core & OG1 & rim & core & OG & rim & NVZ & NVZ & core & OG \\
\hline \multicolumn{21}{|l|}{ Oxides (wt \%) } \\
\hline $\mathrm{SiO}_{2}$ & 51.29 & 50.38 & 51.64 & 50.56 & 48.68 & 51.44 & 50.98 & 50.43 & 50.88 & 50.29 & 51.55 & 50.44 & 51.79 & 51.01 & 51.23 & 50.48 & 51.65 & 50.91 & 51.11 & 52.02 \\
\hline $\mathrm{TiO}_{2}$ & 0.29 & 0.45 & 0.32 & 0.38 & 0.70 & 0.34 & 0.37 & 0.50 & 0.34 & 0.36 & 0.28 & 0.40 & 0.35 & 0.40 & 0.29 & 0.42 & 0.32 & 0.35 & 0.36 & 0.27 \\
\hline $\mathrm{Al}_{2} \mathrm{O}_{3}$ & 3.88 & 4.82 & 3.36 & 4.17 & 6.27 & 3.63 & 3.75 & 4.05 & 3.80 & 3.66 & 3.35 & 3.95 & 3.63 & 3.66 & 3.70 & 3.94 & 3.50 & 3.75 & 3.99 & 2.96 \\
\hline $\mathrm{Cr}_{2} \mathrm{O}_{3}$ & 0.18 & 0.09 & 0.08 & 0.14 & 0.08 & 0.06 & 0.06 & 0.09 & 0.10 & 0.05 & 0.11 & 0.09 & 0.06 & 0.08 & 0.40 & 0.05 & 0.12 & 0.04 & 0.09 & 0.08 \\
\hline $\mathrm{FeO}(\mathrm{T})$ & 5.65 & 7.83 & 6.56 & 6.41 & 7.82 & 6.76 & 7.21 & 7.04 & 6.40 & 6.76 & 6.20 & 7.41 & 6.74 & 6.85 & 5.33 & 7.23 & 6.56 & 6.91 & 6.46 & 5.66 \\
\hline $\mathrm{MnO}$ & 0.11 & 0.17 & 0.15 & 0.12 & 0.16 & 0.17 & 0.14 & 0.16 & 0.15 & 0.13 & 0.09 & 0.13 & 0.13 & 0.16 & 0.10 & 0.14 & 0.14 & 0.12 & 0.13 & 0.11 \\
\hline MgO & 16.03 & 15.46 & 16.01 & 15.52 & 14.37 & 15.83 & 15.33 & 15.24 & 15.67 & 15.49 & 15.92 & 15.19 & 15.70 & 15.62 & 16.07 & 15.23 & 15.87 & 15.46 & 15.53 & 16.56 \\
\hline $\mathrm{CaO}$ & 23.05 & 21.01 & 22.77 & 23.00 & 21.87 & 22.35 & 22.58 & 22.46 & 22.82 & 22.47 & 22.59 & 22.06 & 22.62 & 22.30 & 22.96 & 22.36 & 22.15 & 22.57 & 22.77 & 22.47 \\
\hline $\mathrm{Na}_{2} \mathrm{O}$ & 0.14 & 0.16 & 0.17 & 0.17 & 0.17 & 0.15 & 0.17 & 0.20 & 0.14 & 0.16 & 0.15 & 0.17 & 0.16 & 0.15 & 0.13 & 0.16 & 0.14 & 0.15 & 0.16 & 0.11 \\
\hline Total & 100.61 & 100.36 & 101.07 & 100.46 & 100.13 & 100.73 & 100.58 & 100.17 & 100.29 & 99.38 & 100.24 & 99.83 & 101.19 & 100.23 & 100.21 & 100.01 & 100.46 & 100.26 & 100.60 & 100.23 \\
\hline \multicolumn{21}{|l|}{ Cations } \\
\hline Si & 1.88 & 1.86 & 1.89 & 1.87 & 1.81 & 1.89 & 1.88 & 1.87 & 1.88 & 1.88 & 1.90 & 1.88 & 1.89 & 1.89 & 1.89 & 1.88 & 1.90 & 1.88 & 1.88 & 1.91 \\
\hline $\mathrm{Ti}$ & 0.004 & 0.006 & 0.004 & 0.005 & 0.009 & 0.004 & 0.005 & 0.006 & 0.004 & 0.005 & 0.004 & 0.005 & 0.004 & 0.005 & 0.004 & 0.005 & 0.004 & 0.004 & 0.004 & 0.003 \\
\hline Al & 0.168 & 0.210 & 0.145 & 0.181 & 0.275 & 0.157 & 0.163 & 0.177 & 0.165 & 0.161 & 0.146 & 0.173 & 0.156 & 0.160 & 0.161 & 0.173 & 0.151 & 0.164 & 0.173 & 0.128 \\
\hline $\mathrm{Cr}$ & 0.005 & 0.003 & 0.002 & 0.004 & 0.002 & 0.002 & 0.002 & 0.003 & 0.003 & 0.002 & 0.003 & 0.003 & 0.002 & 0.002 & 0.012 & 0.002 & 0.004 & 0.001 & 0.003 & 0.002 \\
\hline Fe total & 0.170 & 0.238 & 0.198 & 0.194 & 0.237 & 0.204 & 0.219 & 0.213 & 0.194 & 0.208 & 0.188 & 0.227 & 0.203 & 0.208 & 0.160 & 0.220 & 0.198 & 0.210 & 0.195 & 0.171 \\
\hline $\mathrm{Fe}^{2+}$ & 0.152 & 0.211 & 0.178 & 0.170 & 0.194 & 0.183 & 0.197 & 0.182 & 0.173 & 0.185 & 0.171 & 0.202 & 0.182 & 0.183 & 0.142 & 0.195 & 0.179 & 0.189 & 0.174 & 0.155 \\
\hline $\mathrm{Fe}^{3+}$ & 0.017 & 0.027 & 0.019 & 0.023 & 0.043 & 0.021 & 0.023 & 0.031 & 0.021 & 0.023 & 0.017 & 0.025 & 0.021 & 0.024 & 0.018 & 0.026 & 0.020 & 0.021 & 0.022 & 0.016 \\
\hline Mn & 0.004 & 0.005 & 0.005 & 0.004 & 0.005 & 0.005 & 0.004 & 0.005 & 0.005 & 0.004 & 0.003 & 0.004 & 0.004 & 0.005 & 0.003 & 0.005 & 0.004 & 0.004 & 0.004 & 0.003 \\
\hline $\mathbf{M g}$ & 0.877 & 0.852 & 0.874 & 0.854 & 0.798 & 0.867 & 0.844 & 0.843 & 0.863 & 0.863 & 0.875 & 0.843 & 0.856 & 0.861 & 0.881 & 0.844 & 0.870 & 0.853 & 0.852 & 0.906 \\
\hline $\mathrm{Ca}$ & 0.906 & 0.832 & 0.894 & 0.910 & 0.873 & 0.880 & 0.893 & 0.893 & 0.903 & 0.899 & 0.892 & 0.880 & 0.886 & 0.884 & 0.905 & 0.890 & 0.873 & 0.895 & 0.898 & 0.884 \\
\hline $\mathrm{Na}$ & 0.010 & 0.012 & 0.012 & 0.012 & 0.012 & 0.011 & 0.012 & 0.015 & 0.010 & 0.011 & 0.010 & 0.012 & 0.011 & 0.011 & 0.009 & 0.012 & 0.010 & 0.010 & 0.011 & 0.008 \\
\hline Total & 4.02 & 4.02 & 4.03 & 4.03 & 4.02 & 4.02 & 4.03 & 4.03 & 4.03 & 4.03 & 4.02 & 4.02 & 4.02 & 4.02 & 4.02 & 4.03 & 4.01 & 4.02 & 4.02 & 4.02 \\
\hline \multicolumn{21}{|l|}{ Atomic \% } \\
\hline Wo & 46.4 & 43.3 & 45.5 & 46.5 & 45.7 & 45.1 & 45.7 & 45.8 & 46.1 & 45.7 & 45.6 & 45.1 & 45.6 & 45.3 & 46.5 & 45.5 & 45.0 & 45.7 & 46.2 & 45.1 \\
\hline En & 44.9 & 44.3 & 44.5 & 43.6 & 41.8 & 44.4 & 43.1 & 43.3 & 44.0 & 43.8 & 44.8 & 43.2 & 44.0 & 44.1 & 45.3 & 43.2 & 44.8 & 43.6 & 43.8 & 46.2 \\
\hline Fs & 8.7 & 12.4 & 10.1 & 9.9 & 12.4 & 10.5 & 11.2 & 10.9 & 9.9 & 10.5 & 9.6 & 11.6 & 10.4 & 10.6 & 8.2 & 11.3 & 10.2 & 10.7 & 10.0 & 8.7 \\
\hline Mg \# & 83.5 & 77.8 & 81.2 & 81.2 & 76.7 & 80.6 & 79.1 & 79.4 & 81.3 & 80.3 & 82.1 & 78.5 & 80.5 & 80.2 & 84.4 & 78.9 & 81.1 & 79.9 & 81.0 & 83.9 \\
\hline
\end{tabular}


Table F.1 Continued

\begin{tabular}{|c|c|c|c|c|c|c|c|c|c|c|c|c|c|c|c|c|c|c|}
\hline Sample & & D38_PC06 & & & & D39_PC05 & & & & & & & & & & & & \\
\hline Location & & NW flank/rim & & & & $\mathrm{N}$ wall/floor & & & & & & & & & & & & \\
\hline Volcano & & Healy & & & & Healy & & & & & & & & & & & & \\
\hline Type & & Clusters-C1 & $\mathrm{C} 2$ & & $\mathrm{C} 3$ & Single crystal & & & & & & & & & & & & \\
\hline Crystal no. & 24 & $a$ & a & $\mathrm{b}$ & $a$ & 1 & 2 & 2 & 2 & 2 & 4 & 4 & 4 & 5 & 6 & 6 & 6 & 7 \\
\hline Analysis site & rim & NVZ & NVZ & $N V Z$ & $N V Z$ & $\mathrm{NVZ}$ & core & I band & OG & rim & core & I band & rim & NVZ & core & I band & rim & core \\
\hline \multicolumn{19}{|l|}{ Oxides (wt \%) } \\
\hline $\mathrm{SiO}_{2}$ & 50.54 & 51.63 & 51.61 & 51.41 & 51.67 & 52.27 & 53.17 & 51.62 & 51.91 & 51.49 & 52.52 & 50.99 & 51.73 & 52.24 & 51.99 & 52.74 & 53.07 & 51.10 \\
\hline $\mathrm{TiO}_{2}$ & 0.49 & 0.32 & 0.29 & 0.38 & 0.31 & 0.30 & 0.24 & 0.47 & 0.34 & 0.44 & 0.23 & 0.45 & 0.29 & 0.21 & 0.40 & 0.21 & 0.22 & 0.35 \\
\hline $\mathrm{Al}_{2} \mathrm{O}_{3}$ & 4.60 & 3.33 & 3.28 & 3.17 & 3.40 & 1.53 & 1.02 & 2.52 & 1.86 & 2.32 & 1.19 & 2.28 & 1.59 & 1.03 & 2.05 & 1.16 & 1.13 & 1.99 \\
\hline $\mathrm{Cr}_{2} \mathrm{O}_{3}$ & 0.06 & 0.06 & 0.08 & 0.00 & 0.08 & 0.01 & 0.00 & 0.00 & 0.00 & 0.00 & 0.01 & 0.01 & 0.01 & 0.00 & 0.01 & 0.01 & 0.01 & 0.00 \\
\hline $\mathrm{FeO}(\mathrm{T})$ & 6.68 & 7.04 & 6.41 & 7.76 & 6.93 & 9.42 & 9.27 & 9.90 & 9.28 & 9.84 & 9.12 & 11.27 & 9.87 & 10.84 & 11.09 & 11.57 & 10.26 & 9.68 \\
\hline MnO & 0.13 & 0.17 & 0.13 & 0.20 & 0.16 & 0.74 & 0.65 & 0.67 & 0.61 & 0.66 & 0.70 & 0.83 & 0.78 & 0.91 & 0.82 & 1.00 & 0.80 & 0.70 \\
\hline MgO & 15.23 & 15.73 & 16.08 & 15.35 & 15.73 & 14.76 & 15.58 & 14.26 & 14.67 & 14.04 & 15.05 & 14.39 & 14.77 & 15.84 & 15.07 & 15.70 & 15.46 & 14.51 \\
\hline $\mathrm{CaO}$ & 22.80 & 21.95 & 22.01 & 21.77 & 21.85 & 20.87 & 20.22 & 20.81 & 21.08 & 20.88 & 21.03 & 19.16 & 20.38 & 18.23 & 18.73 & 17.71 & 19.55 & 20.41 \\
\hline $\mathrm{Na}_{2} \mathrm{O}$ & 0.17 & 0.17 & 0.19 & 0.19 & 0.17 & 0.30 & 0.23 & 0.34 & 0.33 & 0.35 & 0.25 & 0.35 & 0.31 & 0.23 & 0.32 & 0.22 & 0.26 & 0.32 \\
\hline Total & 100.71 & 100.40 & 100.07 & 100.23 & 100.28 & 100.20 & 100.37 & 100.59 & 100.07 & 100.01 & 100.09 & 99.71 & 99.73 & 99.53 & 100.47 & 100.32 & 100.76 & 99.05 \\
\hline \multicolumn{19}{|l|}{ Cations } \\
\hline $\mathbf{S i}$ & 1.86 & 1.90 & 1.90 & 1.90 & 1.90 & 1.95 & 1.97 & 1.92 & 1.94 & 1.93 & 1.96 & 1.92 & 1.94 & 1.96 & 1.94 & 1.97 & 1.97 & 1.93 \\
\hline $\mathrm{Ti}$ & 0.006 & 0.004 & 0.004 & 0.005 & 0.004 & 0.004 & 0.003 & 0.006 & 0.004 & 0.006 & 0.003 & 0.006 & 0.004 & 0.003 & 0.005 & 0.003 & 0.003 & 0.004 \\
\hline Al & 0.200 & 0.145 & 0.143 & 0.138 & 0.148 & 0.067 & 0.044 & 0.111 & 0.082 & 0.102 & 0.052 & 0.101 & 0.071 & 0.045 & 0.090 & 0.051 & 0.049 & 0.089 \\
\hline $\mathrm{Cr}$ & 0.002 & 0.002 & 0.002 & 0.000 & 0.002 & 0.000 & 0.000 & 0.000 & 0.000 & 0.000 & 0.000 & 0.000 & 0.000 & 0.000 & 0.000 & 0.000 & 0.000 & 0.000 \\
\hline Fe total & 0.201 & 0.214 & 0.195 & 0.237 & 0.210 & 0.292 & 0.286 & 0.305 & 0.287 & 0.305 & 0.283 & 0.353 & 0.308 & 0.339 & 0.343 & 0.359 & 0.316 & 0.304 \\
\hline $\mathrm{Fe}^{2+}$ & 0.171 & 0.194 & 0.177 & 0.214 & 0.192 & 0.273 & 0.271 & 0.276 & 0.266 & 0.278 & 0.268 & 0.324 & 0.289 & 0.326 & 0.318 & 0.346 & 0.303 & 0.281 \\
\hline $\mathrm{Fe}^{3+}$ & 0.030 & 0.020 & 0.018 & 0.023 & 0.019 & 0.019 & 0.015 & 0.029 & 0.021 & 0.028 & 0.014 & 0.029 & 0.018 & 0.013 & 0.025 & 0.013 & 0.014 & 0.023 \\
\hline Mn & 0.004 & 0.005 & 0.004 & 0.006 & 0.005 & 0.023 & 0.020 & 0.021 & 0.019 & 0.021 & 0.022 & 0.027 & 0.025 & 0.029 & 0.026 & 0.032 & 0.025 & 0.022 \\
\hline Mg & 0.836 & 0.864 & 0.884 & 0.848 & 0.864 & 0.821 & 0.861 & 0.792 & 0.817 & 0.785 & 0.837 & 0.809 & 0.827 & 0.887 & 0.837 & 0.873 & 0.854 & 0.818 \\
\hline $\mathrm{Ca}$ & 0.900 & 0.867 & 0.870 & 0.864 & 0.863 & 0.834 & 0.803 & 0.831 & 0.844 & 0.838 & 0.840 & 0.774 & 0.820 & 0.733 & 0.748 & 0.707 & 0.776 & 0.827 \\
\hline $\mathrm{Na}$ & 0.012 & 0.012 & 0.013 & 0.014 & 0.012 & 0.022 & 0.016 & 0.025 & 0.024 & 0.025 & 0.018 & 0.025 & 0.023 & 0.017 & 0.023 & 0.016 & 0.019 & 0.023 \\
\hline Total & 4.02 & 4.02 & 4.02 & 4.02 & 4.01 & 4.01 & 4.00 & 4.01 & 4.02 & 4.01 & 4.01 & 4.02 & 4.02 & 4.01 & 4.01 & 4.01 & 4.01 & 4.02 \\
\hline \multicolumn{19}{|l|}{ Atomic \% } \\
\hline Wo & 46.5 & 44.6 & 44.6 & 44.3 & 44.5 & 42.9 & 41.2 & 43.1 & 43.3 & 43.5 & 42.9 & 40.0 & 42.0 & 37.4 & 38.8 & 36.5 & 39.9 & 42.4 \\
\hline En & 43.2 & 44.4 & 45.4 & 43.5 & 44.6 & 42.2 & 44.2 & 41.1 & 41.9 & 40.7 & 42.7 & 41.8 & 42.3 & 45.3 & 43.4 & 45.0 & 43.9 & 42.0 \\
\hline Fs & 10.4 & 11.0 & 10.0 & 12.2 & 10.9 & 15.0 & 14.6 & 15.8 & 14.7 & 15.8 & 14.4 & 18.2 & 15.7 & 17.3 & 17.8 & 18.5 & 16.3 & 15.6 \\
\hline $\mathrm{Mg} \#$ & 80.3 & 79.8 & 81.7 & 77.7 & 80.1 & 72.3 & 73.8 & 70.8 & 72.7 & 70.6 & 73.3 & 68.1 & 71.3 & 70.7 & 69.4 & 69.1 & 71.4 & 71.5 \\
\hline
\end{tabular}


Table F.1 Continued

\begin{tabular}{|c|c|c|c|c|c|c|c|c|c|c|c|c|c|c|c|c|c|c|c|}
\hline Sample & & & & & & & & & & & D44_PC02 & & & & & & & & \\
\hline Location & & & & & & & & & & & SE rim/flank & & & & & & & & \\
\hline Volcano & & & & & & & & & & & Healy & & & & & & & & \\
\hline Type & & & & & & & & & & & Single crystal & & & & & & & & \\
\hline Crystal no. & 7 & 8 & 9 & 10 & 10 & 10 & 11 & 11 & 12 & 13 & 1 & 2 & 3 & 3 & 5 & 6 & 6 & 7 & 9 \\
\hline Analysis site & rim & NVZ & NVZ & core & I band & rim & core & rim & NVZ & NVZ & NVZ & NVZ & core & rim & NVZ & core & rim & NVZ & core \\
\hline \multicolumn{20}{|l|}{ Oxides (wt \%) } \\
\hline $\mathrm{SiO}_{2}$ & 51.11 & 51.21 & 52.74 & 51.96 & 51.86 & 52.72 & 51.47 & 51.83 & 51.54 & 51.70 & 51.58 & 52.23 & 50.95 & 50.82 & 51.50 & 51.37 & 49.89 & 51.51 & 51.35 \\
\hline $\mathrm{TiO}_{2}$ & 0.38 & 0.36 & 0.24 & 0.35 & 0.37 & 0.25 & 0.48 & 0.48 & 0.39 & 0.34 & 0.69 & 0.27 & 0.34 & 0.34 & 0.42 & 0.37 & 0.46 & 0.34 & 0.38 \\
\hline $\mathrm{Al}_{2} \mathrm{O}_{3}$ & 2.03 & 2.21 & 1.15 & 1.82 & 2.11 & 1.23 & 2.25 & 2.25 & 1.99 & 1.91 & 2.93 & 2.93 & 3.99 & 3.99 & 3.69 & 3.64 & 5.20 & 3.76 & 3.77 \\
\hline $\mathrm{Cr}_{2} \mathrm{O}_{3}$ & 0.00 & 0.00 & 0.00 & 0.00 & 0.00 & 0.00 & 0.00 & 0.00 & 0.02 & 0.00 & 0.04 & 0.09 & 0.18 & 0.16 & 0.02 & 0.15 & 0.08 & 0.09 & 0.20 \\
\hline $\mathrm{FeO}(\mathrm{T})$ & 9.63 & 10.86 & 10.64 & 9.17 & 9.72 & 8.57 & 10.86 & 9.89 & 9.69 & 11.71 & 7.48 & 6.18 & 5.87 & 7.05 & 7.09 & 5.95 & 7.44 & 6.37 & 7.14 \\
\hline MnO & 0.65 & 0.81 & 0.90 & 0.66 & 0.67 & 0.64 & 0.77 & 0.65 & 0.75 & 0.70 & 0.18 & 0.15 & 0.13 & 0.15 & 0.19 & 0.12 & 0.15 & 0.12 & 0.13 \\
\hline MgO & 14.05 & 14.39 & 15.56 & 14.49 & 14.26 & 15.12 & 14.68 & 14.41 & 14.61 & 16.75 & 15.92 & 16.37 & 16.02 & 15.96 & 15.41 & 15.95 & 14.81 & 15.75 & 15.63 \\
\hline $\mathrm{CaO}$ & 21.01 & 19.28 & 18.75 & 21.04 & 20.87 & 21.03 & 19.14 & 20.64 & 20.34 & 16.24 & 21.59 & 21.84 & 22.90 & 21.57 & 22.28 & 22.90 & 22.37 & 22.59 & 22.16 \\
\hline $\mathrm{Na}_{2} \mathrm{O}$ & 0.35 & 0.33 & 0.24 & 0.32 & 0.34 & 0.27 & 0.33 & 0.31 & 0.31 & 0.22 & 0.24 & 0.15 & 0.15 & 0.11 & 0.18 & 0.14 & 0.16 & 0.16 & 0.18 \\
\hline Total & 99.19 & 99.46 & 100.23 & 99.80 & 100.20 & 99.83 & 99.97 & 100.47 & 99.63 & 99.57 & 100.64 & 100.21 & 100.54 & 100.17 & 100.77 & 100.60 & 100.56 & 100.66 & 100.94 \\
\hline \multicolumn{20}{|l|}{ Cations } \\
\hline $\mathbf{S i}$ & 1.93 & 1.93 & 1.97 & 1.95 & 1.94 & 1.97 & 1.93 & 1.93 & 1.94 & 1.94 & 1.90 & 1.92 & 1.87 & 1.88 & 1.89 & 1.89 & 1.85 & 1.89 & 1.89 \\
\hline $\mathrm{Ti}$ & 0.005 & 0.005 & 0.003 & 0.004 & 0.005 & 0.003 & 0.006 & 0.006 & 0.005 & 0.004 & 0.009 & 0.003 & 0.004 & 0.004 & 0.005 & 0.005 & 0.006 & 0.004 & 0.005 \\
\hline Al & 0.090 & 0.098 & 0.051 & 0.080 & 0.093 & 0.054 & 0.099 & 0.099 & 0.088 & 0.084 & 0.127 & 0.127 & 0.173 & 0.174 & 0.160 & 0.158 & 0.227 & 0.163 & 0.163 \\
\hline $\mathrm{Cr}$ & 0.000 & 0.000 & 0.000 & 0.000 & 0.000 & 0.000 & 0.000 & 0.000 & 0.001 & 0.000 & 0.001 & 0.003 & 0.005 & 0.005 & 0.000 & 0.004 & 0.002 & 0.003 & 0.006 \\
\hline Fe total & 0.302 & 0.340 & 0.330 & 0.285 & 0.301 & 0.265 & 0.337 & 0.305 & 0.301 & 0.365 & 0.224 & 0.187 & 0.176 & 0.215 & 0.214 & 0.179 & 0.226 & 0.192 & 0.216 \\
\hline $\mathrm{Fe}^{2+}$ & 0.278 & 0.318 & 0.315 & 0.263 & 0.278 & 0.249 & 0.307 & 0.275 & 0.277 & 0.343 & 0.182 & 0.171 & 0.156 & 0.194 & 0.189 & 0.156 & 0.198 & 0.172 & 0.193 \\
\hline $\mathrm{Fe}^{3+}$ & 0.024 & 0.023 & 0.015 & 0.022 & 0.023 & 0.016 & 0.030 & 0.030 & 0.025 & 0.022 & 0.042 & 0.016 & 0.021 & 0.021 & 0.025 & 0.023 & 0.028 & 0.020 & 0.023 \\
\hline$M n$ & 0.021 & 0.026 & 0.028 & 0.021 & 0.021 & 0.020 & 0.024 & 0.021 & 0.024 & 0.022 & 0.006 & 0.005 & 0.004 & 0.005 & 0.006 & 0.004 & 0.005 & 0.004 & 0.004 \\
\hline Mg & 0.792 & 0.809 & 0.864 & 0.809 & 0.794 & 0.840 & 0.821 & 0.801 & 0.818 & 0.935 & 0.875 & 0.897 & 0.878 & 0.879 & 0.845 & 0.873 & 0.817 & 0.862 & 0.855 \\
\hline $\mathrm{Ca}$ & 0.851 & 0.780 & 0.749 & 0.844 & 0.836 & 0.840 & 0.769 & 0.824 & 0.818 & 0.651 & 0.853 & 0.860 & 0.902 & 0.854 & 0.878 & 0.901 & 0.886 & 0.888 & 0.872 \\
\hline $\mathrm{Na}$ & 0.026 & 0.024 & 0.018 & 0.023 & 0.024 & 0.020 & 0.024 & 0.023 & 0.022 & 0.016 & 0.017 & 0.011 & 0.011 & 0.008 & 0.013 & 0.010 & 0.012 & 0.011 & 0.013 \\
\hline Total & 4.02 & 4.01 & 4.01 & 4.01 & 4.01 & 4.01 & 4.01 & 4.01 & 4.01 & 4.01 & 4.01 & 4.01 & 4.03 & 4.02 & 4.01 & 4.02 & 4.03 & 4.02 & 4.02 \\
\hline \multicolumn{20}{|l|}{ Atomic \% } \\
\hline Wo & 43.8 & 40.4 & 38.5 & 43.6 & 43.3 & 43.2 & 39.9 & 42.7 & 42.2 & 33.4 & 43.7 & 44.2 & 46.1 & 43.8 & 45.3 & 46.1 & 45.9 & 45.7 & 44.9 \\
\hline En & 40.7 & 41.9 & 44.5 & 41.7 & 41.1 & 43.2 & 42.6 & 41.5 & 42.2 & 47.9 & 44.8 & 46.1 & 44.9 & 45.1 & 43.6 & 44.7 & 42.3 & 44.4 & 44.0 \\
\hline Fs & 15.5 & 17.6 & 17.0 & 14.7 & 15.6 & 13.6 & 17.5 & 15.8 & 15.6 & 18.7 & 11.5 & 9.6 & 9.0 & 11.0 & 11.1 & 9.1 & 11.7 & 9.9 & 11.1 \\
\hline Mg \# & 71.1 & 68.8 & 70.7 & 72.6 & 71.1 & 74.7 & 69.4 & 71.1 & 71.6 & 70.7 & 79.2 & 82.4 & 82.9 & 80.0 & 79.3 & 82.7 & 78.0 & 81.5 & 79.6 \\
\hline
\end{tabular}




\begin{tabular}{|c|c|c|c|c|c|c|c|c|c|c|c|c|c|c|c|c|c|c|c|c|}
\hline \multicolumn{21}{|l|}{ Sample } \\
\hline \multicolumn{21}{|l|}{ Location } \\
\hline \multicolumn{21}{|l|}{ Volcano } \\
\hline \multicolumn{21}{|l|}{ Type } \\
\hline Crystal no. & 9 & 9 & 10 & 12 & 12 & 13 & 13 & 14 & 14 & 14 & 15 & 16 & 17 & 18 & 19 & 20 & 21 & 22 & 22 & 23 \\
\hline Analysis site & $\mathrm{d}$ band & rim & NVZ & core & rim & core & rim & core & OG & rim & NVZ & NVZ & NVZ & $\mathrm{NVZ}$ & NVZ & NVZ & NVZ & core & rim & core \\
\hline \multicolumn{21}{|l|}{ Oxides (wt \%) } \\
\hline $\mathrm{SiO}_{2}$ & 51.40 & 50.81 & 51.59 & 50.69 & 50.73 & 51.86 & 50.45 & 50.61 & 51.45 & 50.68 & 51.12 & 51.48 & 50.55 & 53.36 & 51.06 & 50.95 & 51.26 & 51.57 & 51.49 & 50.72 \\
\hline $\mathrm{TiO}_{2}$ & 0.27 & 0.41 & 0.26 & 0.44 & 0.48 & 0.28 & 0.50 & 0.41 & 0.30 & 0.43 & 0.32 & 0.29 & 0.55 & 0.21 & 0.50 & 0.50 & 0.39 & 0.37 & 0.47 & 0.30 \\
\hline $\mathrm{Al}_{2} \mathrm{O}_{3}$ & 4.05 & 4.52 & 3.72 & 3.75 & 3.72 & 3.28 & 4.86 & 4.37 & 3.74 & 4.34 & 3.66 & 3.51 & 3.71 & 1.06 & 3.79 & 3.81 & 3.42 & 3.50 & 3.26 & 3.22 \\
\hline $\mathrm{Cr}_{2} \mathrm{O}_{3}$ & 0.15 & 0.11 & 0.46 & 0.00 & 0.01 & 0.06 & 0.03 & 0.25 & 0.19 & 0.11 & 0.06 & 0.16 & 0.00 & 0.01 & 0.01 & 0.01 & 0.01 & 0.08 & 0.01 & 0.18 \\
\hline $\mathrm{FeO}(\mathrm{T})$ & 5.58 & 7.55 & 5.20 & 8.61 & 8.60 & 6.09 & 7.58 & 6.47 & 5.75 & 7.52 & 6.33 & 5.80 & 7.97 & 8.40 & 7.60 & 7.70 & 7.21 & 6.46 & 7.81 & 6.17 \\
\hline $\mathrm{MnO}$ & 0.11 & 0.18 & 0.11 & 0.17 & 0.21 & 0.12 & 0.20 & 0.12 & 0.11 & 0.17 & 0.13 & 0.12 & 0.20 & 0.68 & 0.18 & 0.21 & 0.17 & 0.15 & 0.20 & 0.13 \\
\hline MgO & 15.96 & 15.51 & 16.22 & 14.84 & 14.96 & 15.96 & 14.78 & 15.45 & 16.10 & 15.62 & 15.76 & 16.15 & 15.10 & 15.13 & 15.22 & 15.28 & 15.51 & 15.95 & 15.50 & 15.95 \\
\hline $\mathrm{CaO}$ & 23.19 & 21.58 & 22.81 & 21.59 & 21.59 & 22.61 & 22.04 & 22.89 & 23.02 & 21.64 & 22.68 & 22.81 & 21.85 & 21.81 & 21.94 & 21.80 & 22.16 & 22.66 & 21.80 & 22.30 \\
\hline $\mathrm{Na}_{2} \mathrm{O}$ & 0.11 & 0.16 & 0.14 & 0.23 & 0.20 & 0.12 & 0.16 & 0.16 & 0.13 & 0.15 & 0.14 & 0.12 & 0.19 & 0.30 & 0.23 & 0.22 & 0.17 & 0.20 & 0.23 & 0.19 \\
\hline Total & 100.83 & 100.82 & 100.50 & 100.32 & 100.50 & 100.38 & 100.60 & 100.73 & 100.78 & 100.66 & 100.19 & 100.44 & 100.12 & 100.96 & 100.53 & 100.49 & 100.31 & 100.93 & 100.76 & 99.15 \\
\hline \multicolumn{21}{|l|}{ Cations } \\
\hline Si & 1.88 & 1.87 & 1.89 & 1.88 & 1.88 & 1.91 & 1.86 & 1.86 & 1.88 & 1.87 & 1.89 & 1.89 & 1.88 & 1.97 & 1.89 & 1.88 & 1.90 & 1.89 & 1.90 & 1.89 \\
\hline $\mathrm{Ti}$ & 0.003 & 0.005 & 0.003 & 0.006 & 0.006 & 0.003 & 0.006 & 0.005 & 0.004 & 0.005 & 0.004 & 0.004 & 0.007 & 0.003 & 0.006 & 0.006 & 0.005 & 0.005 & 0.006 & 0.004 \\
\hline Al & 0.175 & 0.196 & 0.161 & 0.164 & 0.163 & 0.142 & 0.212 & 0.190 & 0.161 & 0.188 & 0.159 & 0.152 & 0.163 & 0.046 & 0.165 & 0.166 & 0.149 & 0.151 & 0.142 & 0.142 \\
\hline $\mathrm{Cr}$ & 0.004 & 0.003 & 0.013 & 0.000 & 0.000 & 0.002 & 0.001 & 0.007 & 0.006 & 0.003 & 0.002 & 0.005 & 0.000 & 0.000 & 0.000 & 0.000 & 0.000 & 0.002 & 0.000 & 0.005 \\
\hline $\mathrm{Fe}$ total & 0.167 & 0.228 & 0.156 & 0.264 & 0.263 & 0.184 & 0.230 & 0.195 & 0.173 & 0.228 & 0.192 & 0.175 & 0.243 & 0.257 & 0.230 & 0.234 & 0.219 & 0.194 & 0.237 & 0.189 \\
\hline $\mathrm{Fe}^{2+}$ & 0.151 & 0.204 & 0.141 & 0.237 & 0.233 & 0.168 & 0.199 & 0.170 & 0.155 & 0.202 & 0.173 & 0.157 & 0.209 & 0.244 & 0.200 & 0.203 & 0.196 & 0.172 & 0.208 & 0.170 \\
\hline $\mathrm{Fe}^{3+}$ & 0.016 & 0.025 & 0.015 & 0.027 & 0.030 & 0.017 & 0.031 & 0.025 & 0.018 & 0.026 & 0.019 & 0.017 & 0.034 & 0.013 & 0.031 & 0.031 & 0.024 & 0.022 & 0.028 & 0.019 \\
\hline Mn & 0.003 & 0.006 & 0.003 & 0.005 & 0.007 & 0.004 & 0.006 & 0.004 & 0.003 & 0.005 & 0.004 & 0.004 & 0.006 & 0.021 & 0.006 & 0.007 & 0.005 & 0.005 & 0.006 & 0.004 \\
\hline $\mathbf{M g}$ & 0.871 & 0.851 & 0.886 & 0.822 & 0.828 & 0.874 & 0.814 & 0.848 & 0.879 & 0.859 & 0.868 & 0.885 & 0.838 & 0.832 & 0.839 & 0.842 & 0.855 & 0.872 & 0.852 & 0.887 \\
\hline $\mathrm{Ca}$ & 0.909 & 0.850 & 0.895 & 0.860 & 0.858 & 0.890 & 0.872 & 0.903 & 0.904 & 0.855 & 0.897 & 0.898 & 0.871 & 0.862 & 0.868 & 0.864 & 0.878 & 0.890 & 0.861 & 0.891 \\
\hline $\mathrm{Na}$ & 0.008 & 0.011 & 0.010 & 0.017 & 0.014 & 0.009 & 0.012 & 0.011 & 0.009 & 0.011 & 0.010 & 0.008 & 0.013 & 0.021 & 0.016 & 0.015 & 0.012 & 0.014 & 0.017 & 0.014 \\
\hline Total & 4.02 & 4.02 & 4.02 & 4.02 & 4.02 & 4.01 & 4.01 & 4.03 & 4.02 & 4.02 & 4.02 & 4.02 & 4.02 & 4.01 & 4.02 & 4.02 & 4.02 & 4.02 & 4.02 & 4.03 \\
\hline \multicolumn{21}{|l|}{ Atomic \% } \\
\hline Wo & 46.7 & 44.1 & 46.2 & 44.2 & 44.0 & 45.7 & 45.5 & 46.4 & 46.2 & 44.0 & 45.9 & 45.9 & 44.6 & 44.2 & 44.8 & 44.5 & 45.0 & 45.5 & 44.2 & 45.3 \\
\hline En & 44.7 & 44.1 & 45.7 & 42.3 & 42.5 & 44.9 & 42.5 & 43.6 & 45.0 & 44.2 & 44.3 & 45.2 & 42.9 & 42.6 & 43.3 & 43.4 & 43.8 & 44.6 & 43.7 & 45.1 \\
\hline Fs & 8.6 & 11.8 & 8.1 & 13.6 & 13.5 & 9.4 & 12.0 & 10.0 & 8.8 & 11.7 & 9.8 & 8.9 & 12.5 & 13.2 & 11.9 & 12.0 & 11.2 & 9.9 & 12.1 & 9.6 \\
\hline $\mathrm{Mg} \#$ & 83.6 & 78.4 & 84.8 & 75.3 & 75.4 & 82.3 & 77.5 & 81.0 & 83.3 & 78.6 & 81.6 & 83.2 & 77.0 & 74.9 & 78.0 & 77.8 & 79.2 & 81.4 & 77.8 & 82.1 \\
\hline
\end{tabular}


Table F.1 Continued

\begin{tabular}{|c|c|c|c|c|c|c|c|c|c|c|c|c|c|c|c|c|c|c|}
\hline Sample & & & & & & D44_PC02 & & & & D47_PC02 & & & & & & & & \\
\hline Location & & & & & & SE rim/flank & & & & Edifice crater & & & & & & & & \\
\hline Volcano & & & & & & Healy & & & & Healy & & & & & & & & \\
\hline Type & & & & & & Clusters $-\mathrm{C} 1$ & $\mathrm{C} 1$ & C5 & C5 & Single crystal & & & & & & & & \\
\hline Crystal no. & 23 & 24 & 24 & 25 & 26 & a & a & a & $a$ & 1 & 2 & 3 & 3 & 4 & 5 & 5 & 6 & 6 \\
\hline Analysis site & rim & core & rim & NVZ & $N V Z$ & core & OG & core & OG & $\mathrm{NVZ}$ & $N V Z$ & core & rim & NVZ & core & rim & core & OG \\
\hline \multicolumn{19}{|l|}{ Oxides (wt \%) } \\
\hline $\mathrm{SiO}_{2}$ & 49.35 & 51.20 & 50.65 & 51.34 & 52.07 & 52.43 & 49.32 & 52.14 & 49.08 & 51.87 & 52.51 & 50.64 & 52.20 & 51.12 & 51.63 & 51.34 & 51.05 & 51.60 \\
\hline $\mathrm{TiO}_{2}$ & 0.43 & 0.30 & 0.44 & 0.35 & 0.33 & 0.27 & 0.61 & 0.28 & 0.61 & 0.26 & 0.27 & 0.48 & 0.23 & 0.42 & 0.15 & 0.20 & 0.28 & 0.21 \\
\hline $\mathrm{Al}_{2} \mathrm{O}_{3}$ & 4.40 & 4.14 & 4.77 & 3.84 & 3.58 & 2.36 & 5.52 & 2.97 & 6.40 & 1.27 & 1.05 & 2.69 & 1.19 & 1.86 & 0.71 & 1.07 & 1.41 & 1.02 \\
\hline $\mathrm{Cr}_{2} \mathrm{O}_{3}$ & 0.05 & 0.14 & 0.12 & 0.14 & 0.14 & 0.00 & 0.01 & 0.09 & 0.03 & 0.01 & 0.00 & 0.01 & 0.00 & 0.00 & 0.01 & 0.00 & 0.01 & 0.00 \\
\hline $\mathrm{FeO}(\mathrm{T})$ & 7.78 & 5.73 & 7.68 & 6.55 & 6.30 & 8.97 & 9.99 & 6.78 & 9.34 & 9.11 & 6.96 & 10.33 & 9.06 & 9.25 & 8.71 & 9.04 & 9.00 & 8.93 \\
\hline MnO & 0.17 & 0.14 & 0.16 & 0.14 & 0.12 & 0.27 & 0.24 & 0.16 & 0.19 & 0.68 & 0.23 & 0.75 & 0.75 & 0.69 & 0.40 & 0.33 & 0.69 & 0.76 \\
\hline MgO & 14.47 & 15.86 & 15.59 & 15.75 & 16.00 & 16.87 & 14.40 & 16.65 & 14.18 & 14.56 & 15.86 & 13.77 & 15.08 & 14.64 & 14.94 & 14.85 & 14.80 & 15.04 \\
\hline $\mathrm{CaO}$ & 22.17 & 23.00 & 21.32 & 22.64 & 22.52 & 19.12 & 20.03 & 21.54 & 20.88 & 20.96 & 21.78 & 20.23 & 20.89 & 20.47 & 21.45 & 20.93 & 20.64 & 20.37 \\
\hline $\mathrm{Na}_{2} \mathrm{O}$ & 0.17 & 0.14 & 0.14 & 0.15 & 0.15 & 0.17 & 0.24 & 0.14 & 0.19 & 0.28 & 0.29 & 0.35 & 0.30 & 0.32 & 0.33 & 0.34 & 0.29 & 0.26 \\
\hline Total & 98.97 & 100.66 & 100.87 & 100.90 & 101.20 & 100.45 & 100.36 & 100.75 & 100.90 & 98.99 & 98.94 & 99.25 & 99.70 & 98.77 & 98.33 & 98.10 & 98.16 & 98.18 \\
\hline \multicolumn{19}{|l|}{ Cations } \\
\hline Si & 1.86 & 1.88 & 1.86 & 1.88 & 1.90 & 1.93 & 1.84 & 1.91 & 1.82 & 1.96 & 1.96 & 1.92 & 1.96 & 1.94 & 1.96 & 1.95 & 1.94 & 1.96 \\
\hline $\mathrm{Ti}$ & 0.005 & 0.004 & 0.006 & 0.004 & 0.004 & 0.003 & 0.008 & 0.003 & 0.008 & 0.003 & 0.003 & 0.006 & 0.003 & 0.005 & 0.002 & 0.002 & 0.004 & 0.003 \\
\hline Al & 0.195 & 0.179 & 0.206 & 0.166 & 0.154 & 0.102 & 0.242 & 0.128 & 0.279 & 0.056 & 0.046 & 0.120 & 0.052 & 0.083 & 0.032 & 0.048 & 0.063 & 0.046 \\
\hline $\mathrm{Cr}$ & 0.001 & 0.004 & 0.003 & 0.004 & 0.004 & 0.000 & 0.000 & 0.003 & 0.001 & 0.000 & 0.000 & 0.000 & 0.000 & 0.000 & 0.000 & 0.000 & 0.000 & 0.000 \\
\hline Fe total & 0.241 & 0.172 & 0.232 & 0.197 & 0.188 & 0.274 & 0.307 & 0.205 & 0.285 & 0.285 & 0.215 & 0.324 & 0.282 & 0.290 & 0.275 & 0.286 & 0.284 & 0.282 \\
\hline $\mathrm{Fe}^{2+}$ & 0.214 & 0.154 & 0.205 & 0.176 & 0.169 & 0.258 & 0.269 & 0.188 & 0.248 & 0.269 & 0.198 & 0.293 & 0.268 & 0.263 & 0.266 & 0.274 & 0.266 & 0.269 \\
\hline $\mathrm{Fe}^{3+}$ & 0.027 & 0.018 & 0.027 & 0.021 & 0.020 & 0.016 & 0.038 & 0.017 & 0.037 & 0.017 & 0.017 & 0.030 & 0.014 & 0.027 & 0.010 & 0.013 & 0.018 & 0.013 \\
\hline Mn & 0.005 & 0.004 & 0.005 & 0.004 & 0.004 & 0.008 & 0.008 & 0.005 & 0.006 & 0.022 & 0.007 & 0.024 & 0.024 & 0.022 & 0.013 & 0.011 & 0.022 & 0.024 \\
\hline Mg & 0.813 & 0.867 & 0.855 & 0.862 & 0.870 & 0.926 & 0.800 & 0.909 & 0.783 & 0.819 & 0.884 & 0.777 & 0.842 & 0.826 & 0.846 & 0.843 & 0.840 & 0.852 \\
\hline $\mathrm{Ca}$ & 0.895 & 0.904 & 0.840 & 0.890 & 0.880 & 0.755 & 0.800 & 0.845 & 0.829 & 0.848 & 0.872 & 0.821 & 0.838 & 0.830 & 0.873 & 0.854 & 0.842 & 0.830 \\
\hline $\mathrm{Na}$ & 0.012 & 0.010 & 0.010 & 0.011 & 0.011 & 0.012 & 0.017 & 0.010 & 0.014 & 0.020 & 0.021 & 0.026 & 0.022 & 0.023 & 0.024 & 0.025 & 0.021 & 0.019 \\
\hline Total & 4.03 & 4.02 & 4.02 & 4.02 & 4.01 & 4.01 & 4.02 & 4.02 & 4.02 & 4.01 & 4.01 & 4.01 & 4.02 & 4.02 & 4.03 & 4.02 & 4.02 & 4.02 \\
\hline \multicolumn{19}{|l|}{ Atomic \% } \\
\hline Wo & 45.9 & 46.5 & 43.6 & 45.7 & 45.4 & 38.6 & 41.9 & 43.1 & 43.7 & 43.4 & 44.2 & 42.7 & 42.7 & 42.7 & 43.8 & 43.1 & 42.8 & 42.2 \\
\hline En & 41.7 & 44.6 & 44.4 & 44.2 & 44.9 & 47.4 & 42.0 & 46.4 & 41.3 & 42.0 & 44.8 & 40.4 & 42.9 & 42.5 & 42.4 & 42.5 & 42.7 & 43.4 \\
\hline Fs & 12.4 & 8.9 & 12.0 & 10.1 & 9.7 & 14.0 & 16.1 & 10.5 & 15.0 & 14.6 & 10.9 & 16.9 & 14.4 & 14.9 & 13.8 & 14.4 & 14.5 & 14.4 \\
\hline $\mathrm{Mg} \#$ & 76.7 & 83.1 & 78.3 & 81.0 & 81.9 & 76.6 & 71.8 & 81.2 & 72.9 & 72.7 & 79.9 & 69.1 & 73.4 & 72.6 & 74.6 & 74.0 & 73.3 & 73.5 \\
\hline
\end{tabular}




\begin{tabular}{|c|c|c|c|c|c|c|c|c|c|c|c|c|c|}
\hline \multicolumn{14}{|l|}{ Sample } \\
\hline \multicolumn{14}{|l|}{ Location } \\
\hline \multicolumn{14}{|l|}{ Volcano } \\
\hline \multicolumn{14}{|l|}{ Type } \\
\hline Crystal no. & 6 & 7 & 8 & 9 & 10 & 10 & 11 & 12 & 12 & 13 & 13 & 14 & 14 \\
\hline Analysis site & rim & NVZ & NVZ & NVZ & core & rim & NVZ & core & rim & NVZ & NVZ & core & rim \\
\hline \multicolumn{14}{|l|}{ Oxides (wt \%) } \\
\hline $\mathrm{SiO}_{2}$ & 50.23 & 51.66 & 52.45 & 51.50 & 50.78 & 51.56 & 52.58 & 50.89 & 52.38 & 52.53 & 51.08 & 50.58 & 51.06 \\
\hline $\mathrm{TiO}_{2}$ & 0.43 & 0.38 & 0.22 & 0.27 & 0.43 & 0.35 & 0.24 & 0.52 & 0.23 & 0.35 & 0.68 & 0.56 & 0.61 \\
\hline $\mathrm{Al}_{2} \mathrm{O}_{3}$ & 2.25 & 2.07 & 0.99 & 1.39 & 2.20 & 1.63 & 1.10 & 2.78 & 1.04 & 1.34 & 2.99 & 3.02 & 3.06 \\
\hline $\mathrm{Cr}_{2} \mathrm{O}_{3}$ & 0.02 & 0.00 & 0.00 & 0.00 & 0.02 & 0.00 & 0.01 & 0.01 & 0.00 & 0.00 & 0.00 & 0.00 & 0.01 \\
\hline $\mathrm{FeO}(\mathrm{T})$ & 9.56 & 9.60 & 9.09 & 8.86 & 9.36 & 9.39 & 9.07 & 10.11 & 8.95 & 9.36 & 9.33 & 10.18 & 9.15 \\
\hline $\mathrm{MnO}$ & 0.67 & 0.68 & 0.80 & 0.69 & 0.68 & 0.72 & 0.79 & 0.68 & 0.79 & 0.66 & 0.60 & 0.69 & 0.63 \\
\hline $\mathrm{MgO}$ & 14.15 & 13.97 & 15.03 & 14.58 & 14.41 & 14.72 & 15.18 & 13.65 & 15.02 & 16.23 & 15.05 & 13.74 & 14.35 \\
\hline $\mathrm{CaO}$ & 20.73 & 21.01 & 20.56 & 21.15 & 20.55 & 20.68 & 20.48 & 20.83 & 20.69 & 19.15 & 20.37 & 20.34 & 20.88 \\
\hline $\mathrm{Na}_{2} \mathrm{O}$ & 0.33 & 0.37 & 0.27 & 0.30 & 0.29 & 0.29 & 0.29 & 0.36 & 0.24 & 0.22 & 0.30 & 0.37 & 0.36 \\
\hline Total & 98.36 & 99.74 & 99.40 & 98.73 & 98.71 & 99.34 & 99.73 & 99.82 & 99.33 & 99.83 & 100.39 & 99.47 & 100.10 \\
\hline \multicolumn{14}{|l|}{ Cations } \\
\hline $\mathbf{S i}$ & 1.92 & 1.94 & 1.97 & 1.95 & 1.93 & 1.94 & 1.97 & 1.92 & 1.97 & 1.96 & 1.90 & 1.91 & 1.91 \\
\hline $\mathrm{Ti}$ & 0.005 & 0.005 & 0.003 & 0.003 & 0.005 & 0.004 & 0.003 & 0.006 & 0.003 & 0.004 & 0.008 & 0.007 & 0.008 \\
\hline Al & 0.101 & 0.091 & 0.044 & 0.062 & 0.098 & 0.072 & 0.048 & 0.123 & 0.046 & 0.059 & 0.131 & 0.134 & 0.135 \\
\hline $\mathrm{Cr}$ & 0.000 & 0.000 & 0.000 & 0.000 & 0.000 & 0.000 & 0.000 & 0.000 & 0.000 & 0.000 & 0.000 & 0.000 & 0.000 \\
\hline Fe total & 0.302 & 0.299 & 0.284 & 0.278 & 0.294 & 0.293 & 0.282 & 0.315 & 0.279 & 0.289 & 0.285 & 0.317 & 0.281 \\
\hline $\mathrm{Fe}^{2+}$ & 0.274 & 0.275 & 0.270 & 0.261 & 0.266 & 0.271 & 0.266 & 0.282 & 0.265 & 0.267 & 0.244 & 0.282 & 0.243 \\
\hline $\mathrm{Fe}^{3+}$ & 0.028 & 0.024 & 0.014 & 0.017 & 0.027 & 0.022 & 0.015 & 0.033 & 0.014 & 0.022 & 0.042 & 0.036 & 0.038 \\
\hline Mn & 0.021 & 0.022 & 0.025 & 0.022 & 0.022 & 0.023 & 0.025 & 0.022 & 0.025 & 0.021 & 0.019 & 0.022 & 0.020 \\
\hline $\mathbf{M g}$ & 0.805 & 0.782 & 0.841 & 0.823 & 0.815 & 0.826 & 0.846 & 0.766 & 0.840 & 0.901 & 0.835 & 0.773 & 0.799 \\
\hline $\mathrm{Ca}$ & 0.848 & 0.845 & 0.827 & 0.858 & 0.835 & 0.835 & 0.820 & 0.840 & 0.832 & 0.764 & 0.812 & 0.822 & 0.836 \\
\hline $\mathrm{Na}$ & 0.025 & 0.027 & 0.019 & 0.022 & 0.021 & 0.021 & 0.021 & 0.026 & 0.018 & 0.016 & 0.022 & 0.027 & 0.026 \\
\hline Total & 4.03 & 4.01 & 4.01 & 4.02 & 4.02 & 4.02 & 4.01 & 4.01 & 4.01 & 4.01 & 4.01 & 4.01 & 4.01 \\
\hline \multicolumn{14}{|l|}{ Atomic \% } \\
\hline Wo & 43.4 & 43.9 & 42.4 & 43.8 & 43.0 & 42.7 & 42.1 & 43.7 & 42.6 & 39.1 & 42.0 & 43.0 & 43.6 \\
\hline En & 41.2 & 40.6 & 43.1 & 42.0 & 41.9 & 42.3 & 43.4 & 39.9 & 43.1 & 46.1 & 43.2 & 40.4 & 41.7 \\
\hline Fs & 15.4 & 15.5 & 14.5 & 14.2 & 15.1 & 15.0 & 14.5 & 16.4 & 14.3 & 14.8 & 14.8 & 16.6 & 14.7 \\
\hline Mg \# & 71.3 & 70.9 & 73.1 & 73.3 & 72.1 & 72.3 & 73.4 & 69.5 & 73.4 & 74.4 & 73.3 & 69.5 & 72.6 \\
\hline
\end{tabular}


Table F.2. Major element compositions of orthopyroxene determined by EPMA

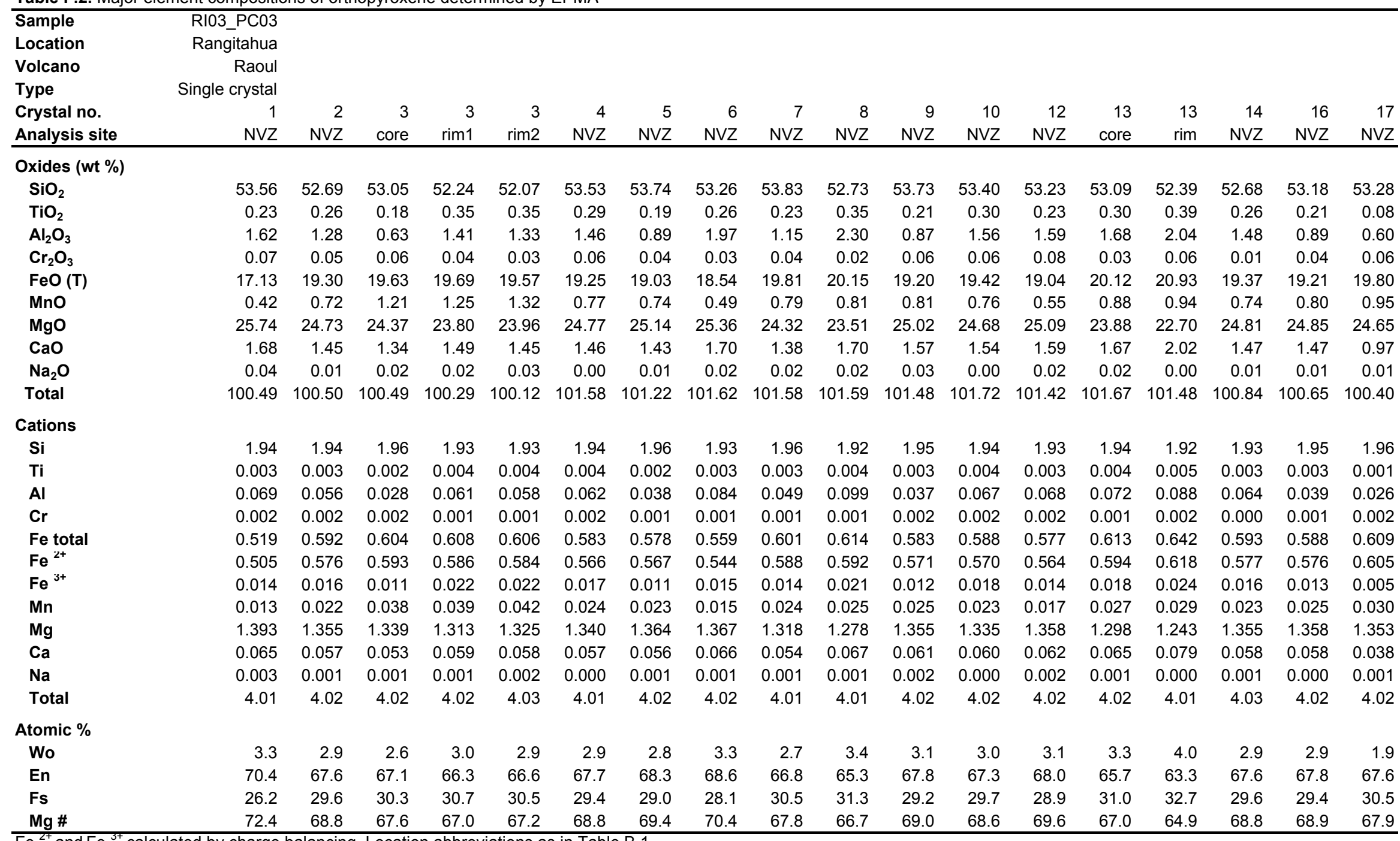

$\mathrm{Fe}^{{ }^{+}}$and $\mathrm{Fe}^{3+}$ calculated by charge balancing. Location abbreviations as in Table B.1. 
Table F.2. Continued

\begin{tabular}{|c|c|c|c|c|c|c|c|c|c|c|c|c|c|c|c|c|c|c|c|}
\hline Sample & RI06_PC12 & & & & & & & & & & & & & & & & & & \\
\hline Location & Matatirohia & & & & & & & & & & & & & & & & & & \\
\hline Volcano & Raoul & & & & & & & & & & & & & & & & & & \\
\hline Type & Single crystal & & & & & & & & & & & & & & & & & & \\
\hline Crystal no. & 1 & 2 & 3 & 4 & 5 & 6 & 7 & 8 & 9 & 11 & 11 & 12 & 13 & 15 & 16 & 18 & 21 & 23 & 28 \\
\hline Analysis site & NVZ & NVZ & NVZ & $N V Z$ & $N V Z$ & NVZ & NVZ & $N V Z$ & $N V Z$ & NVZ & NVZ & NVZ & NVZ & NVZ & NVZ & NVZ & NVZ & NVZ & NVZ \\
\hline \multicolumn{20}{|l|}{ Oxides (wt \%) } \\
\hline $\mathrm{SiO}_{2}$ & 52.48 & 52.92 & 51.86 & 52.04 & 52.57 & 53.04 & 52.87 & 52.62 & 52.35 & 53.34 & 53.37 & 52.90 & 53.04 & 52.86 & 52.83 & 52.79 & 52.98 & 52.85 & 52.48 \\
\hline $\mathrm{TiO}_{2}$ & 0.24 & 0.25 & 0.22 & 0.21 & 0.22 & 0.23 & 0.24 & 0.27 & 0.24 & 0.20 & 0.20 & 0.22 & 0.19 & 0.24 & 0.24 & 0.24 & 0.25 & 0.24 & 0.28 \\
\hline $\mathrm{Al}_{2} \mathrm{O}_{3}$ & 0.96 & 0.89 & 0.83 & 0.85 & 0.93 & 0.73 & 0.93 & 1.14 & 0.77 & 0.85 & 0.86 & 1.02 & 0.79 & 0.82 & 0.92 & 0.90 & 0.86 & 0.76 & 1.39 \\
\hline $\mathrm{Cr}_{2} \mathrm{O}_{3}$ & 0.05 & 0.06 & 0.06 & 0.05 & 0.04 & 0.05 & 0.06 & 0.02 & 0.03 & 0.05 & 0.06 & 0.04 & 0.03 & 0.04 & 0.04 & 0.02 & 0.04 & 0.07 & 0.04 \\
\hline $\mathrm{FeO}(\mathrm{T})$ & 22.79 & 23.35 & 22.56 & 22.76 & 24.70 & 23.10 & 23.80 & 23.30 & 24.12 & 22.85 & 22.81 & 23.20 & 23.45 & 23.97 & 23.46 & 23.99 & 23.65 & 23.64 & 23.53 \\
\hline MnO & 1.01 & 1.23 & 1.14 & 1.02 & 1.14 & 1.15 & 1.09 & 1.20 & 1.26 & 1.02 & 1.09 & 1.06 & 1.08 & 1.23 & 1.15 & 1.06 & 1.07 & 1.17 & 1.19 \\
\hline MgO & 22.28 & 21.77 & 22.17 & 22.07 & 20.85 & 21.78 & 21.37 & 21.84 & 21.13 & 22.08 & 22.08 & 21.81 & 21.70 & 21.27 & 21.62 & 21.30 & 21.55 & 21.51 & 21.11 \\
\hline $\mathrm{CaO}$ & 1.42 & 1.32 & 1.35 & 1.41 & 1.39 & 1.37 & 1.40 & 1.36 & 1.38 & 1.38 & 1.39 & 1.39 & 1.43 & 1.28 & 1.40 & 1.44 & 1.43 & 1.37 & 1.86 \\
\hline $\mathrm{Na}_{2} \mathrm{O}$ & 0.01 & 0.02 & 0.02 & 0.02 & 0.01 & 0.03 & 0.03 & 0.01 & 0.02 & 0.01 & 0.03 & 0.01 & 0.03 & 0.02 & 0.02 & 0.00 & 0.02 & 0.00 & 0.03 \\
\hline Total & 101.24 & 101.81 & 100.21 & 100.42 & 101.84 & 101.47 & 101.79 & 101.75 & 101.30 & 101.78 & 101.88 & 101.67 & 101.72 & 101.70 & 101.69 & 101.75 & 101.85 & 101.60 & 101.91 \\
\hline \multicolumn{20}{|l|}{ Cations } \\
\hline $\mathbf{S i}$ & 1.95 & 1.96 & 1.95 & 1.95 & 1.96 & 1.96 & 1.96 & 1.95 & 1.95 & 1.96 & 1.96 & 1.96 & 1.96 & 1.96 & 1.96 & 1.96 & 1.96 & 1.96 & 1.94 \\
\hline $\mathrm{Ti}$ & 0.003 & 0.003 & 0.003 & 0.003 & 0.003 & 0.003 & 0.003 & 0.003 & 0.003 & 0.003 & 0.003 & 0.003 & 0.002 & 0.003 & 0.003 & 0.003 & 0.003 & 0.003 & 0.003 \\
\hline Al & 0.042 & 0.039 & 0.037 & 0.037 & 0.041 & 0.032 & 0.040 & 0.050 & 0.034 & 0.037 & 0.037 & 0.044 & 0.034 & 0.036 & 0.040 & 0.039 & 0.037 & 0.033 & 0.061 \\
\hline $\mathrm{Cr}$ & 0.001 & 0.002 & 0.002 & 0.001 & 0.001 & 0.002 & 0.002 & 0.001 & 0.001 & 0.001 & 0.002 & 0.001 & 0.001 & 0.001 & 0.001 & 0.001 & 0.001 & 0.002 & 0.001 \\
\hline Fe total & 0.706 & 0.721 & 0.707 & 0.712 & 0.768 & 0.715 & 0.737 & 0.720 & 0.753 & 0.703 & 0.701 & 0.717 & 0.725 & 0.743 & 0.726 & 0.743 & 0.731 & 0.733 & 0.728 \\
\hline $\mathrm{Fe}^{2+}$ & 0.691 & 0.706 & 0.693 & 0.699 & 0.754 & 0.701 & 0.722 & 0.704 & 0.738 & 0.691 & 0.689 & 0.703 & 0.713 & 0.728 & 0.711 & 0.728 & 0.715 & 0.718 & 0.711 \\
\hline $\mathrm{Fe}^{3+}$ & 0.015 & 0.015 & 0.014 & 0.013 & 0.013 & 0.014 & 0.015 & 0.016 & 0.015 & 0.012 & 0.012 & 0.014 & 0.012 & 0.015 & 0.015 & 0.015 & 0.015 & 0.015 & 0.017 \\
\hline$M n$ & 0.032 & 0.038 & 0.036 & 0.032 & 0.036 & 0.036 & 0.034 & 0.038 & 0.040 & 0.032 & 0.034 & 0.033 & 0.034 & 0.039 & 0.036 & 0.033 & 0.034 & 0.037 & 0.037 \\
\hline $\mathbf{M g}$ & 1.233 & 1.200 & 1.240 & 1.232 & 1.156 & 1.203 & 1.180 & 1.205 & 1.176 & 1.212 & 1.211 & 1.202 & 1.197 & 1.176 & 1.193 & 1.177 & 1.188 & 1.189 & 1.165 \\
\hline $\mathrm{Ca}$ & 0.056 & 0.052 & 0.054 & 0.057 & 0.055 & 0.054 & 0.056 & 0.054 & 0.055 & 0.054 & 0.055 & 0.055 & 0.057 & 0.051 & 0.056 & 0.057 & 0.057 & 0.054 & 0.074 \\
\hline $\mathrm{Na}$ & 0.001 & 0.001 & 0.001 & 0.001 & 0.000 & 0.002 & 0.002 & 0.000 & 0.002 & 0.001 & 0.002 & 0.001 & 0.002 & 0.001 & 0.001 & 0.000 & 0.001 & 0.000 & 0.002 \\
\hline Total & 4.02 & 4.01 & 4.03 & 4.02 & 4.01 & 4.01 & 4.01 & 4.02 & 4.02 & 4.01 & 4.01 & 4.01 & 4.01 & 4.01 & 4.01 & 4.01 & 4.01 & 4.01 & 4.01 \\
\hline \multicolumn{20}{|l|}{ Atomic \% } \\
\hline Wo & 2.8 & 2.7 & 2.7 & 2.8 & 2.8 & 2.8 & 2.8 & 2.7 & 2.8 & 2.8 & 2.8 & 2.8 & 2.9 & 2.6 & 2.8 & 2.9 & 2.9 & 2.8 & 3.8 \\
\hline En & 61.8 & 60.8 & 62.0 & 61.6 & 58.4 & 61.0 & 59.8 & 60.9 & 59.3 & 61.5 & 61.6 & 60.9 & 60.5 & 59.7 & 60.4 & 59.5 & 60.1 & 60.2 & 59.2 \\
\hline Fs & 35.4 & 36.5 & 35.3 & 35.6 & 38.8 & 36.2 & 37.3 & 36.4 & 37.9 & 35.7 & 35.7 & 36.3 & 36.6 & 37.7 & 36.8 & 37.6 & 37.0 & 37.1 & 37.0 \\
\hline Mg \# & 62.5 & 61.2 & 62.5 & 62.3 & 59.0 & 61.6 & 60.5 & 61.4 & 59.8 & 62.2 & 62.2 & 61.6 & 61.2 & 60.1 & 61.0 & 60.3 & 60.9 & 60.7 & 60.4 \\
\hline
\end{tabular}


Table F.2. Continued

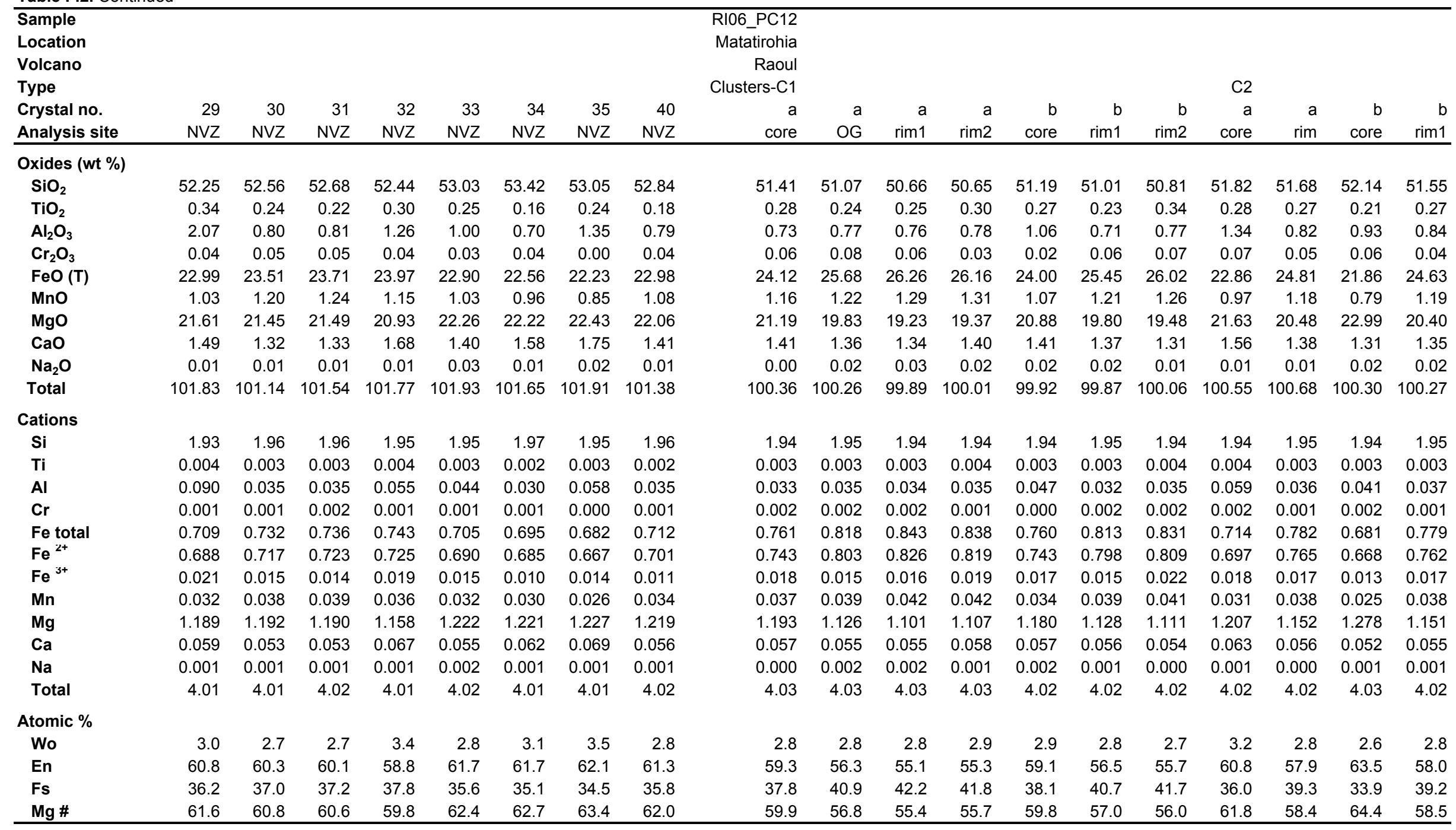


Table F.2. Continued

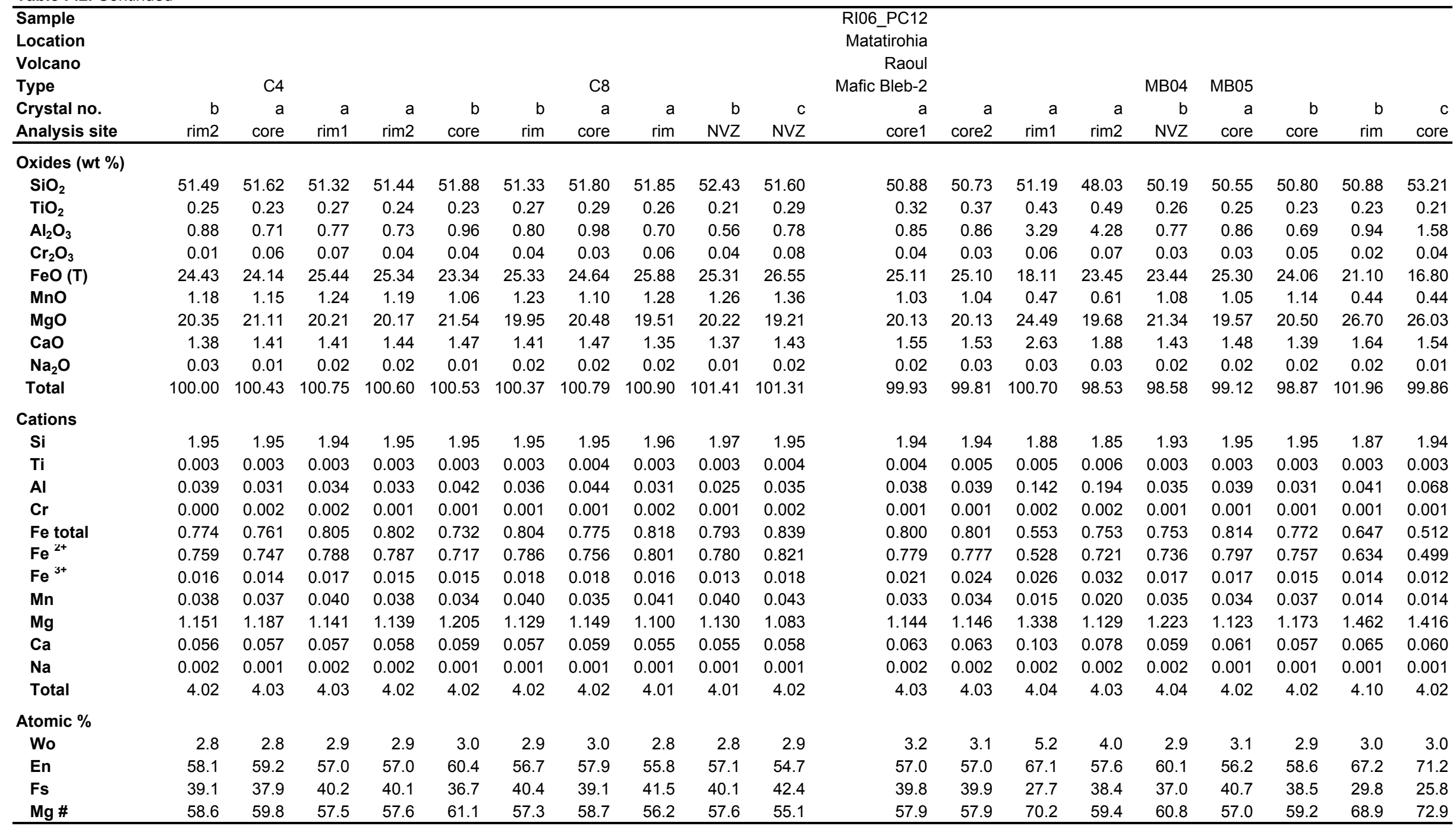


Table F.2. Continued

\begin{tabular}{|c|c|c|c|c|c|c|c|c|c|c|c|c|c|c|c|c|c|c|c|}
\hline $\begin{array}{l}\text { Sample } \\
\text { Location } \\
\text { Volcano } \\
\text { Type }\end{array}$ & MB07 & & & & $\begin{array}{r}\text { RI12_PC08 } \\
\text { Oneraki } \\
\text { Raoul } \\
\text { Single crystal }\end{array}$ & & & & & & & & & & & & & & \\
\hline Crystal no. & a & b & c & d & 1 & 2 & 3 & 4 & 6 & 7 & 8 & 9 & 11 & 12 & 13 & 14 & 16 & 17 & 18 \\
\hline Analysis site & NVZ & NVZ & NVZ & NVZ & NVZ & NVZ & NVZ & NVZ & $N V Z$ & NVZ & NVZ & NVZ & NVZ & NVZ & NVZ & NVZ & core & NVZ & NVZ \\
\hline \multicolumn{20}{|l|}{ Oxides (wt \%) } \\
\hline $\mathrm{SiO}_{2}$ & 52.07 & 51.35 & 51.19 & 51.39 & 53.23 & 53.46 & 51.98 & 52.49 & 53.18 & 52.81 & 52.94 & 52.48 & 53.54 & 53.24 & 53.09 & 52.71 & 54.18 & 52.54 & 52.61 \\
\hline $\mathrm{TiO}_{2}$ & 0.27 & 0.21 & 0.24 & 0.18 & 0.19 & 0.28 & 0.35 & 0.36 & 0.18 & 0.31 & 0.25 & 0.28 & 0.24 & 0.22 & 0.28 & 0.31 & 0.25 & 0.35 & 0.34 \\
\hline $\mathrm{Al}_{2} \mathrm{O}_{3}$ & 0.85 & 0.72 & 0.58 & 0.54 & 0.70 & 1.01 & 2.24 & 2.12 & 0.55 & 1.80 & 0.98 & 1.09 & 1.01 & 0.77 & 1.67 & 1.10 & 1.70 & 1.33 & 1.86 \\
\hline $\mathrm{Cr}_{2} \mathrm{O}_{3}$ & 0.03 & 0.08 & 0.04 & 0.06 & 0.06 & 0.05 & 0.00 & 0.06 & 0.06 & 0.04 & 0.05 & 0.04 & 0.03 & 0.06 & 0.04 & 0.03 & 0.05 & 0.03 & 0.04 \\
\hline $\mathrm{FeO}(\mathrm{T})$ & 23.16 & 23.93 & 24.12 & 23.75 & 20.97 & 21.63 & 20.65 & 21.80 & 23.16 & 20.73 & 21.51 & 21.23 & 21.17 & 21.46 & 20.51 & 21.51 & 18.16 & 21.90 & 21.05 \\
\hline MnO & 1.28 & 1.27 & 1.35 & 1.27 & 0.95 & 1.03 & 0.81 & 0.87 & 1.28 & 0.87 & 1.04 & 0.98 & 1.00 & 1.04 & 0.85 & 0.99 & 0.51 & 1.10 & 0.95 \\
\hline MgO & 21.47 & 19.81 & 21.13 & 21.15 & 23.84 & 23.13 & 23.25 & 22.57 & 22.16 & 23.52 & 23.33 & 23.24 & 23.18 & 23.21 & 23.34 & 22.38 & 25.54 & 22.54 & 23.07 \\
\hline $\mathrm{CaO}$ & 1.46 & 1.31 & 1.34 & 1.34 & 1.34 & 1.36 & 1.63 & 1.43 & 1.26 & 1.56 & 1.31 & 1.44 & 1.31 & 1.48 & 1.42 & 1.49 & 1.49 & 1.59 & 1.81 \\
\hline $\mathrm{Na}_{2} \mathrm{O}$ & 0.03 & 0.02 & 0.01 & 0.00 & 0.01 & 0.02 & 0.03 & 0.02 & 0.02 & 0.01 & 0.02 & 0.04 & 0.01 & 0.01 & 0.02 & 0.05 & 0.02 & 0.01 & 0.02 \\
\hline Total & 100.63 & 98.70 & 99.99 & 99.67 & 101.29 & 101.96 & 100.93 & 101.74 & 101.84 & 101.66 & 101.42 & 100.81 & 101.48 & 101.48 & 101.21 & 100.57 & 101.90 & 101.38 & 101.74 \\
\hline \multicolumn{20}{|l|}{ Cations } \\
\hline $\mathbf{S i}$ & 1.95 & 1.97 & 1.94 & 1.95 & 1.95 & 1.95 & 1.92 & 1.93 & 1.96 & 1.93 & 1.95 & 1.94 & 1.96 & 1.96 & 1.95 & 1.96 & 1.95 & 1.94 & 1.93 \\
\hline $\mathrm{Ti}$ & 0.003 & 0.003 & 0.003 & 0.002 & 0.002 & 0.003 & 0.004 & 0.005 & 0.002 & 0.004 & 0.003 & 0.003 & 0.003 & 0.003 & 0.003 & 0.004 & 0.003 & 0.004 & 0.004 \\
\hline Al & 0.038 & 0.033 & 0.026 & 0.024 & 0.030 & 0.043 & 0.097 & 0.092 & 0.024 & 0.078 & 0.042 & 0.048 & 0.043 & 0.033 & 0.072 & 0.048 & 0.072 & 0.058 & 0.080 \\
\hline $\mathrm{Cr}$ & 0.001 & 0.002 & 0.001 & 0.002 & 0.002 & 0.002 & 0.000 & 0.002 & 0.002 & 0.001 & 0.001 & 0.001 & 0.001 & 0.002 & 0.001 & 0.001 & 0.002 & 0.001 & 0.001 \\
\hline Fe total & 0.725 & 0.767 & 0.765 & 0.754 & 0.644 & 0.661 & 0.635 & 0.668 & 0.715 & 0.633 & 0.661 & 0.656 & 0.648 & 0.659 & 0.627 & 0.667 & 0.545 & 0.675 & 0.644 \\
\hline $\mathrm{Fe}^{2+}$ & 0.708 & 0.753 & 0.750 & 0.742 & 0.632 & 0.644 & 0.614 & 0.646 & 0.704 & 0.614 & 0.646 & 0.639 & 0.634 & 0.646 & 0.611 & 0.648 & 0.530 & 0.654 & 0.624 \\
\hline $\mathrm{Fe}^{3+}$ & 0.017 & 0.014 & 0.015 & 0.012 & 0.011 & 0.017 & 0.021 & 0.022 & 0.011 & 0.019 & 0.015 & 0.017 & 0.014 & 0.013 & 0.017 & 0.019 & 0.014 & 0.021 & 0.020 \\
\hline Mn & 0.041 & 0.041 & 0.043 & 0.041 & 0.030 & 0.032 & 0.025 & 0.027 & 0.040 & 0.027 & 0.032 & 0.031 & 0.031 & 0.032 & 0.026 & 0.031 & 0.015 & 0.034 & 0.029 \\
\hline $\mathbf{M g}$ & 1.199 & 1.133 & 1.196 & 1.198 & 1.305 & 1.261 & 1.277 & 1.235 & 1.219 & 1.282 & 1.279 & 1.282 & 1.266 & 1.272 & 1.274 & 1.238 & 1.367 & 1.241 & 1.260 \\
\hline $\mathrm{Ca}$ & 0.059 & 0.054 & 0.054 & 0.054 & 0.053 & 0.053 & 0.064 & 0.056 & 0.050 & 0.061 & 0.052 & 0.057 & 0.051 & 0.058 & 0.056 & 0.059 & 0.057 & 0.063 & 0.071 \\
\hline $\mathrm{Na}$ & 0.002 & 0.002 & 0.001 & 0.000 & 0.001 & 0.001 & 0.002 & 0.001 & 0.001 & 0.001 & 0.001 & 0.003 & 0.001 & 0.001 & 0.001 & 0.004 & 0.001 & 0.001 & 0.001 \\
\hline Total & 4.02 & 4.00 & 4.03 & 4.03 & 4.02 & 4.01 & 4.02 & 4.01 & 4.02 & 4.02 & 4.02 & 4.02 & 4.01 & 4.02 & 4.01 & 4.01 & 4.01 & 4.02 & 4.02 \\
\hline \multicolumn{20}{|l|}{ Atomic \% } \\
\hline Wo & 3.0 & 2.8 & 2.7 & 2.7 & 2.6 & 2.7 & 3.2 & 2.9 & 2.5 & 3.1 & 2.6 & 2.9 & 2.6 & 2.9 & 2.8 & 3.0 & 2.9 & 3.2 & 3.6 \\
\hline En & 60.5 & 58.0 & 59.3 & 59.7 & 65.2 & 63.8 & 64.6 & 63.0 & 61.5 & 64.9 & 64.2 & 64.3 & 64.4 & 63.9 & 65.1 & 63.0 & 69.4 & 62.7 & 63.8 \\
\hline Fs & 36.6 & 39.3 & 38.0 & 37.6 & 32.2 & 33.5 & 32.1 & 34.1 & 36.0 & 32.0 & 33.2 & 32.9 & 33.0 & 33.1 & 32.1 & 33.9 & 27.7 & 34.1 & 32.6 \\
\hline Mg \# & 61.0 & 58.4 & 59.7 & 60.1 & 66.0 & 64.5 & 65.9 & 64.0 & 61.8 & 66.0 & 64.8 & 65.1 & 65.1 & 64.8 & 66.1 & 64.0 & 70.9 & 63.6 & 65.2 \\
\hline
\end{tabular}




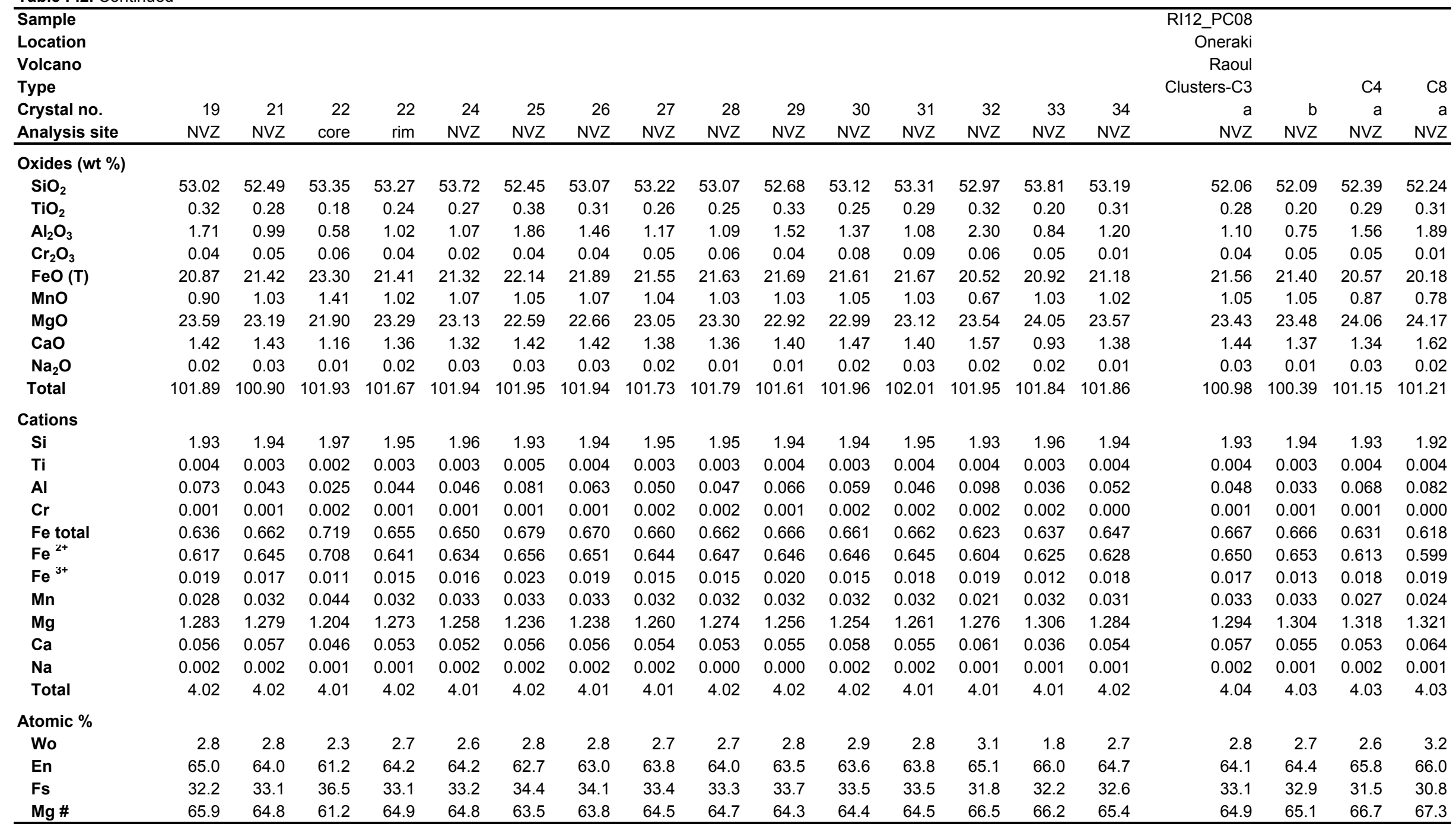


Table F.2. Continued

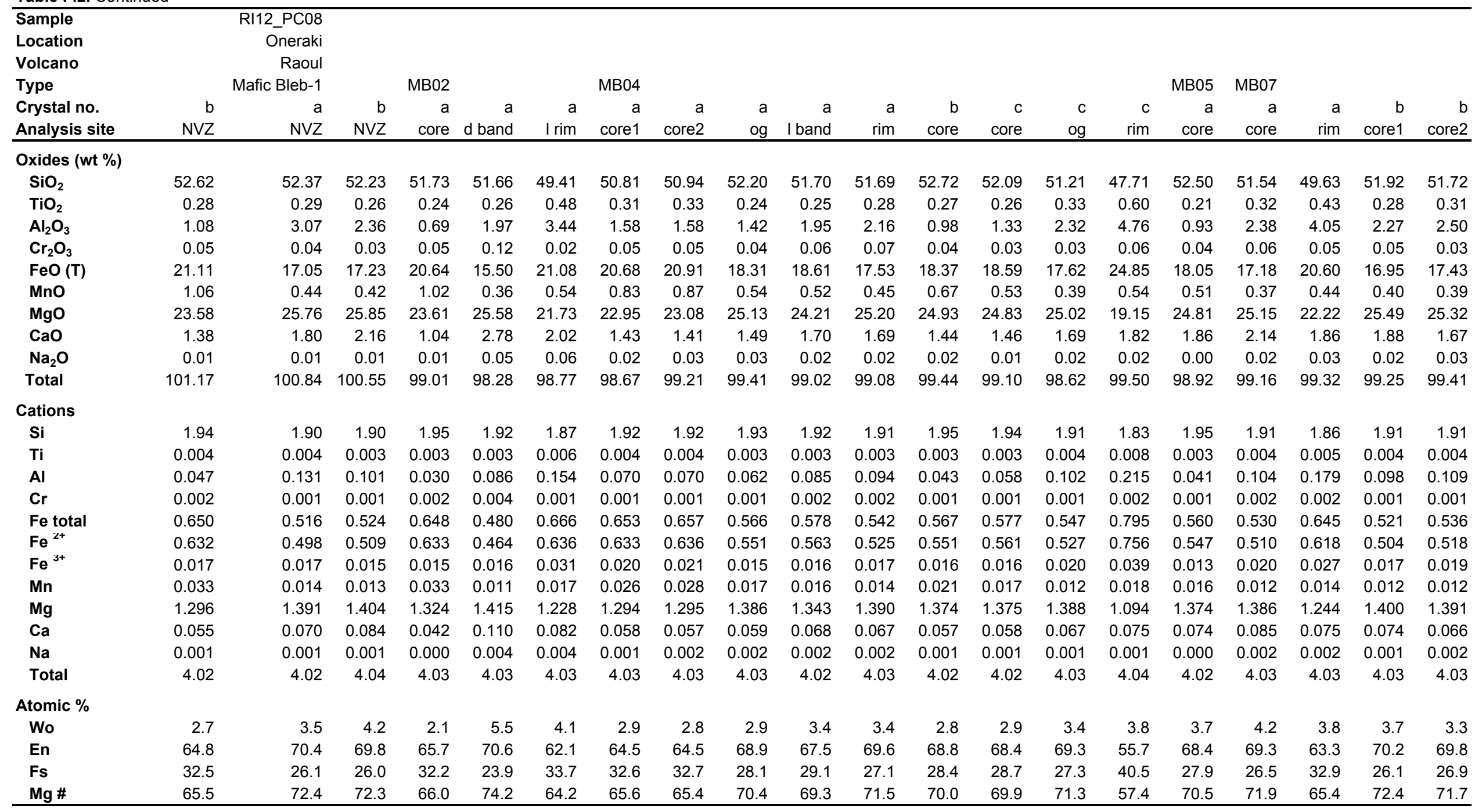


Table F.2. Continued

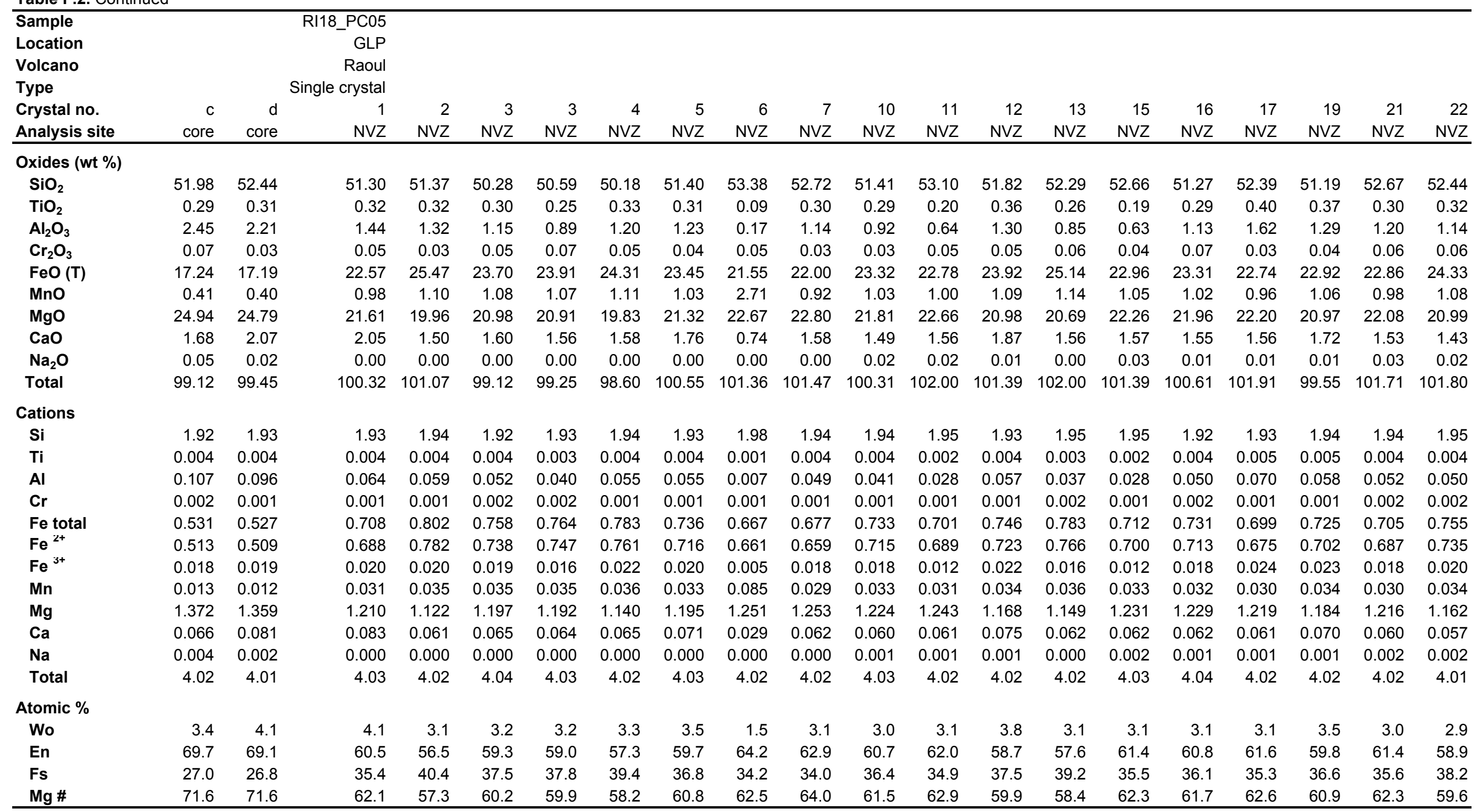


Table F.2. Continued

\begin{tabular}{|c|c|c|c|c|c|c|c|c|c|c|c|c|c|c|c|c|c|c|c|c|}
\hline Sample & & & & & & & & & & & & & & & & & & RI18_PC05 & & \\
\hline Location & & & & & & & & & & & & & & & & & & GLP & & \\
\hline Volcano & & & & & & & & & & & & & & & & & & Raoul & & \\
\hline Type & & & & & & & & & & & & & & & & & & Clusters-C1 & $\mathrm{C} 2$ & C6 \\
\hline Crystal no. & 23 & 23 & 24 & 25 & 26 & 27 & 27 & 28 & 29 & 30 & 31 & 32 & 33 & 36 & 37 & 38 & 38 & a & a & a \\
\hline Analysis site & core1 & core2 & NVZ & NVZ & NVZ & core & rim & NVZ & NVZ & NVZ & NVZ & NVZ & NVZ & NVZ & NVZ & NVZ & NVZ & NVZ & NVZ & NVZ \\
\hline \multicolumn{21}{|l|}{ Oxides (wt \%) } \\
\hline $\mathrm{SiO}_{2}$ & 53.09 & 54.16 & 51.41 & 52.78 & 52.65 & 52.87 & 52.49 & 52.54 & 52.85 & 52.08 & 52.55 & 52.44 & 52.23 & 50.88 & 52.90 & 52.42 & 53.07 & 51.55 & 51.59 & 51.64 \\
\hline $\mathrm{TiO}_{2}$ & 0.32 & 0.15 & 0.41 & 0.31 & 0.22 & 0.28 & 0.24 & 0.30 & 0.30 & 0.33 & 0.26 & 0.30 & 0.27 & 0.42 & 0.25 & 0.30 & 0.28 & 0.20 & 0.27 & 0.29 \\
\hline $\mathrm{Al}_{2} \mathrm{O}_{3}$ & 0.50 & 0.79 & 2.13 & 1.07 & 0.66 & 1.74 & 0.87 & 1.04 & 0.96 & 1.42 & 0.84 & 1.11 & 0.91 & 2.06 & 0.83 & 0.97 & 0.91 & 0.61 & 0.95 & 0.98 \\
\hline $\mathrm{Cr}_{2} \mathrm{O}_{3}$ & 0.04 & 0.05 & 0.05 & 0.05 & 0.06 & 0.06 & 0.03 & 0.05 & 0.05 & 0.07 & 0.07 & 0.03 & 0.06 & 0.04 & 0.04 & 0.05 & 0.06 & 0.03 & 0.05 & 0.04 \\
\hline $\mathrm{FeO}(\mathrm{T})$ & 23.09 & 19.80 & 23.39 & 23.57 & 23.19 & 20.78 & 23.08 & 24.46 & 23.74 & 23.85 & 23.78 & 23.46 & 23.97 & 23.93 & 24.01 & 23.54 & 22.84 & 21.72 & 22.11 & 23.13 \\
\hline MnO & 1.01 & 0.96 & 1.02 & 1.06 & 1.09 & 0.64 & 0.95 & 1.15 & 1.11 & 1.06 & 1.16 & 1.03 & 1.10 & 1.10 & 1.15 & 1.08 & 1.01 & 0.94 & 0.99 & 1.03 \\
\hline MgO & 22.20 & 25.11 & 21.11 & 21.69 & 21.86 & 23.64 & 21.75 & 20.78 & 21.35 & 21.26 & 21.29 & 21.65 & 21.32 & 20.93 & 21.30 & 21.69 & 22.06 & 22.21 & 22.02 & 21.60 \\
\hline $\mathrm{CaO}$ & 1.15 & 0.66 & 1.68 & 1.38 & 1.51 & 1.70 & 1.46 & 1.46 & 1.42 & 1.53 & 1.39 & 1.41 & 1.43 & 1.63 & 1.46 & 1.46 & 1.46 & 1.57 & 1.45 & 1.41 \\
\hline $\mathrm{Na}_{2} \mathrm{O}$ & 0.01 & 0.01 & 0.04 & 0.03 & 0.03 & 0.00 & 0.03 & 0.01 & 0.02 & 0.02 & 0.01 & 0.00 & 0.01 & 0.02 & 0.02 & 0.01 & 0.02 & 0.02 & 0.03 & 0.01 \\
\hline Total & 101.42 & 101.67 & 101.24 & 101.93 & 101.27 & 101.72 & 100.89 & 101.80 & 101.78 & 101.61 & 101.33 & 101.43 & 101.30 & 101.00 & 101.97 & 101.52 & 101.71 & 98.85 & 99.47 & 100.13 \\
\hline \multicolumn{21}{|l|}{ Cations } \\
\hline $\mathbf{S i}$ & 1.97 & 1.96 & 1.92 & 1.95 & 1.96 & 1.93 & 1.96 & 1.95 & 1.96 & 1.94 & 1.96 & 1.95 & 1.95 & 1.91 & 1.96 & 1.95 & 1.96 & 1.95 & 1.95 & 1.94 \\
\hline $\mathrm{Ti}$ & 0.004 & 0.002 & 0.005 & 0.004 & 0.003 & 0.004 & 0.003 & 0.004 & 0.004 & 0.004 & 0.003 & 0.004 & 0.003 & 0.005 & 0.003 & 0.004 & 0.003 & 0.003 & 0.003 & 0.004 \\
\hline Al & 0.022 & 0.034 & 0.094 & 0.046 & 0.029 & 0.075 & 0.038 & 0.046 & 0.042 & 0.062 & 0.037 & 0.049 & 0.040 & 0.091 & 0.036 & 0.042 & 0.040 & 0.027 & 0.042 & 0.043 \\
\hline $\mathrm{Cr}$ & 0.001 & 0.001 & 0.001 & 0.002 & 0.002 & 0.002 & 0.001 & 0.001 & 0.001 & 0.002 & 0.002 & 0.001 & 0.002 & 0.001 & 0.001 & 0.001 & 0.002 & 0.001 & 0.001 & 0.001 \\
\hline Fe total & 0.714 & 0.600 & 0.728 & 0.727 & 0.720 & 0.634 & 0.719 & 0.760 & 0.734 & 0.740 & 0.740 & 0.728 & 0.747 & 0.749 & 0.743 & 0.730 & 0.704 & 0.688 & 0.697 & 0.727 \\
\hline $\mathrm{Fe}^{2+}$ & 0.694 & 0.591 & 0.702 & 0.709 & 0.707 & 0.617 & 0.704 & 0.741 & 0.716 & 0.720 & 0.724 & 0.709 & 0.731 & 0.723 & 0.727 & 0.712 & 0.687 & 0.675 & 0.679 & 0.709 \\
\hline $\mathrm{Fe}^{3+}$ & 0.020 & 0.009 & 0.026 & 0.019 & 0.014 & 0.017 & 0.015 & 0.019 & 0.018 & 0.021 & 0.016 & 0.019 & 0.017 & 0.026 & 0.015 & 0.019 & 0.017 & 0.013 & 0.017 & 0.018 \\
\hline Mn & 0.032 & 0.029 & 0.032 & 0.033 & 0.034 & 0.020 & 0.030 & 0.036 & 0.035 & 0.033 & 0.037 & 0.032 & 0.035 & 0.035 & 0.036 & 0.034 & 0.031 & 0.030 & 0.032 & 0.033 \\
\hline Mg & 1.225 & 1.357 & 1.173 & 1.195 & 1.211 & 1.287 & 1.208 & 1.151 & 1.179 & 1.178 & 1.182 & 1.198 & 1.186 & 1.170 & 1.176 & 1.201 & 1.213 & 1.255 & 1.238 & 1.212 \\
\hline $\mathrm{Ca}$ & 0.046 & 0.025 & 0.067 & 0.054 & 0.060 & 0.067 & 0.058 & 0.058 & 0.056 & 0.061 & 0.055 & 0.056 & 0.057 & 0.066 & 0.058 & 0.058 & 0.058 & 0.064 & 0.059 & 0.057 \\
\hline $\mathrm{Na}$ & 0.001 & 0.000 & 0.003 & 0.002 & 0.002 & 0.000 & 0.002 & 0.001 & 0.001 & 0.002 & 0.001 & 0.000 & 0.001 & 0.002 & 0.001 & 0.001 & 0.002 & 0.001 & 0.002 & 0.001 \\
\hline Total & 4.01 & 4.01 & 4.02 & 4.01 & 4.02 & 4.02 & 4.02 & 4.01 & 4.01 & 4.02 & 4.01 & 4.01 & 4.02 & 4.03 & 4.01 & 4.02 & 4.01 & 4.02 & 4.02 & 4.02 \\
\hline \multicolumn{21}{|l|}{ Atomic \% } \\
\hline Wo & 2.3 & 1.3 & 3.4 & 2.8 & 3.0 & 3.4 & 2.9 & 2.9 & 2.9 & 3.1 & 2.8 & 2.8 & 2.9 & 3.3 & 2.9 & 2.9 & 2.9 & 3.2 & 2.9 & 2.9 \\
\hline En & 61.7 & 68.5 & 59.6 & 60.4 & 60.8 & 64.8 & 60.9 & 58.5 & 59.9 & 59.5 & 59.8 & 60.5 & 59.6 & 58.9 & 59.5 & 60.4 & 61.4 & 62.5 & 62.1 & 60.7 \\
\hline Fs & 36.0 & 30.3 & 37.0 & 36.8 & 36.2 & 31.9 & 36.2 & 38.6 & 37.3 & 37.4 & 37.4 & 36.7 & 37.5 & 37.7 & 37.6 & 36.7 & 35.6 & 34.3 & 34.9 & 36.4 \\
\hline Mg \# & 62.2 & 68.3 & 60.7 & 61.1 & 61.6 & 66.3 & 61.7 & 59.1 & 60.5 & 60.4 & 60.4 & 61.2 & 60.3 & 59.9 & 60.2 & 61.1 & 62.3 & 63.6 & 63.0 & 61.5 \\
\hline
\end{tabular}


Table F.2. Continued

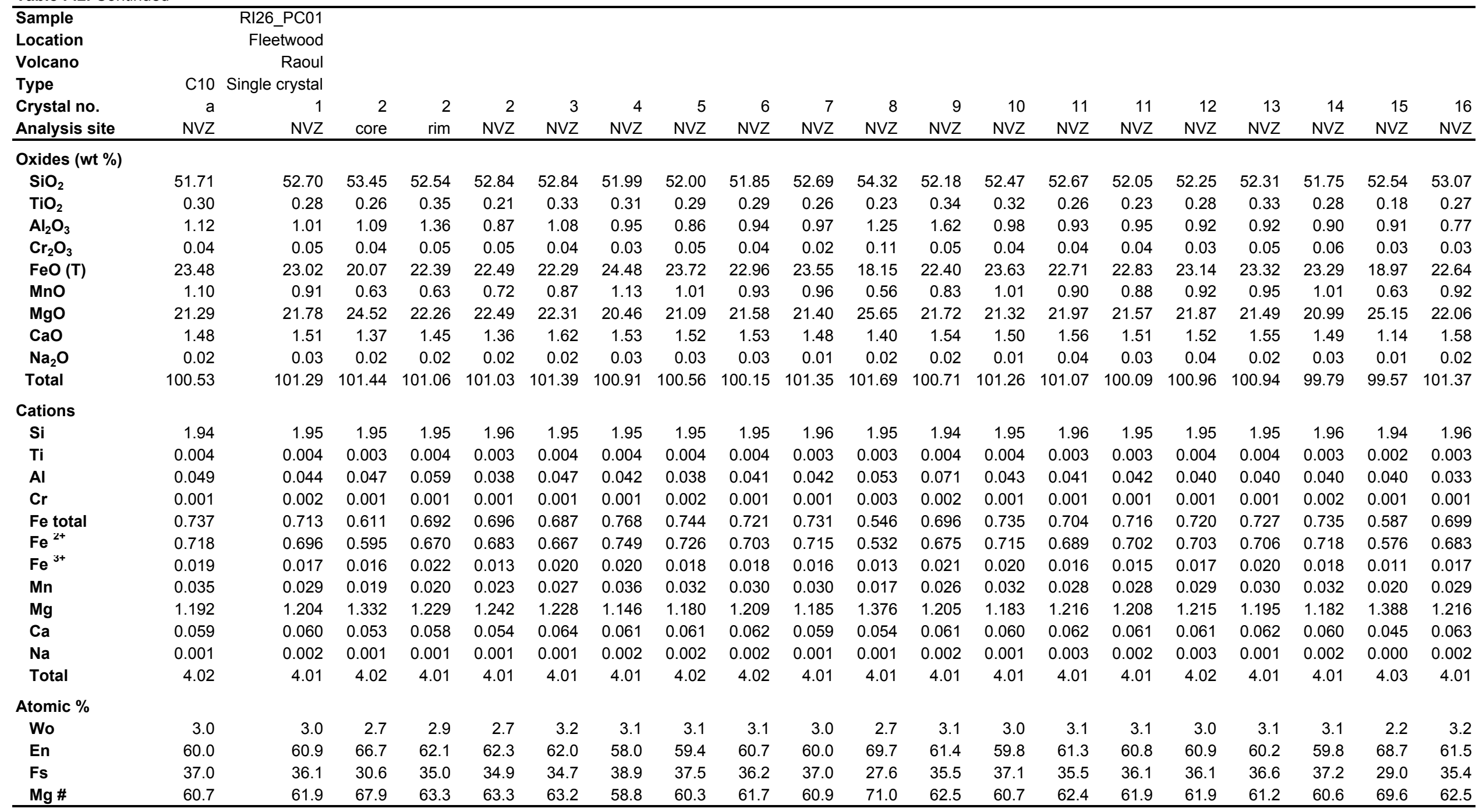


Table F.2. Continued

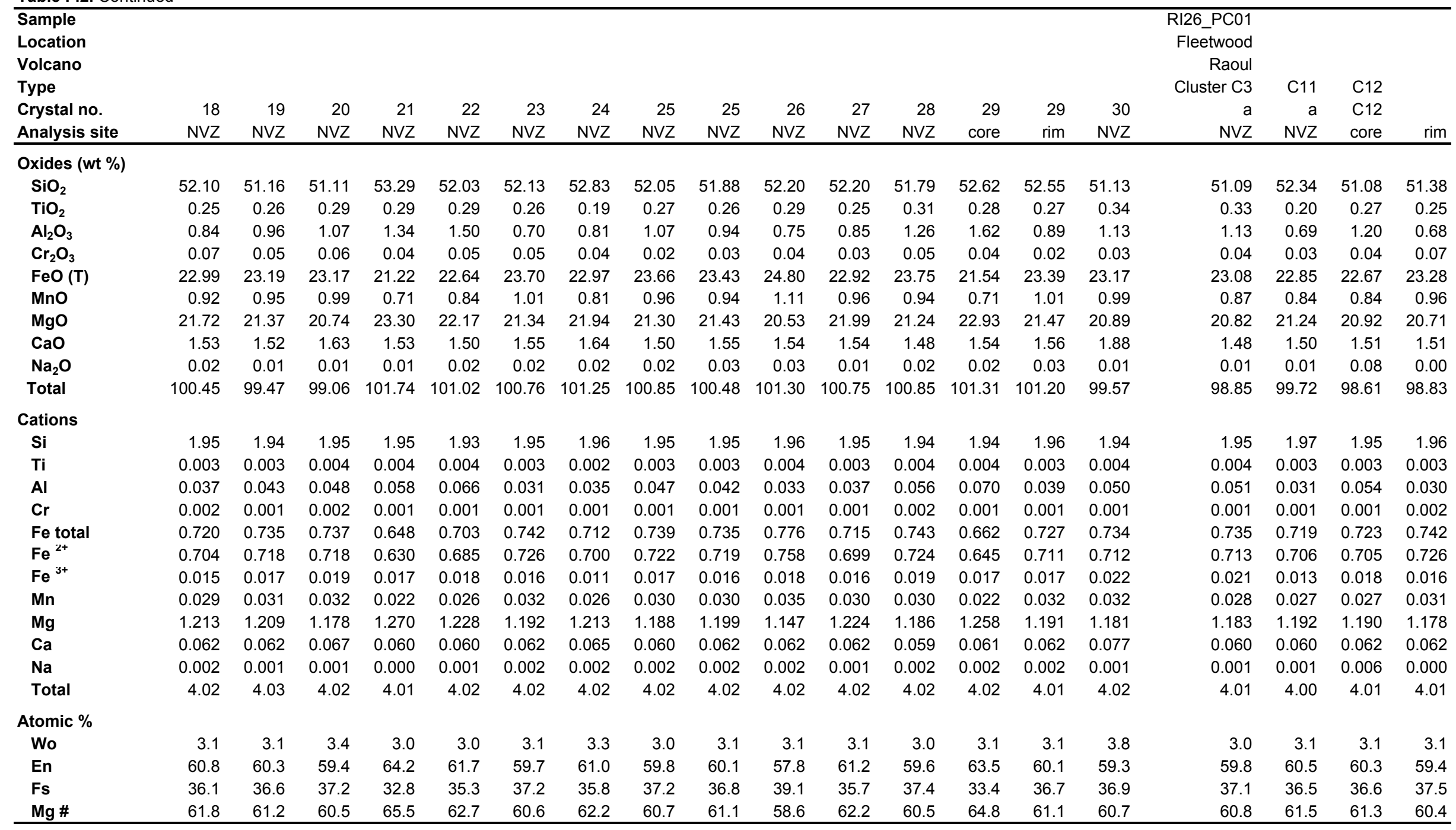


Table F.2. Continued

\begin{tabular}{|c|c|c|c|c|c|c|c|c|c|c|c|c|c|c|c|c|c|c|c|}
\hline Sample & & & & & & & & RI26_PC01 & & & MI07_PC03 & & & & & & & & \\
\hline Location & & & & & & & & Fleetwood & & & SBT & & & & & & & & \\
\hline Volcano & & & & & & & & Raoul & & & Macauley & & & & & & & & \\
\hline Type & & $\mathrm{C} 13$ & & $\mathrm{C} 14$ & $\mathrm{C} 15$ & & $\mathrm{C} 16$ & Mafic bleb-1 & MB02 & MB07 & Single crystal & & & & & & & & \\
\hline Crystal no. & b & $a$ & b & $a$ & $a$ & b & $a$ & $a$ & $a$ & a & 1 & 1 & 2 & 3 & 4 & 5 & 7 & 9 & 9 \\
\hline Analysis site & NVZ & NVZ & NVZ & NVZ & NVZ & NVZ & NVZ & NVZ & NVZ & $N V Z$ & core & rim & NVZ & NVZ & $N V Z$ & $\mathrm{NVZ}$ & NVZ & core & rim \\
\hline \multicolumn{20}{|l|}{ Oxides (wt \%) } \\
\hline $\mathrm{SiO}_{2}$ & 51.96 & 51.91 & 52.11 & 52.08 & 51.86 & 51.90 & 51.69 & 51.48 & 53.43 & 51.29 & 51.26 & 50.66 & 50.82 & 50.87 & 50.87 & 50.21 & 50.78 & 52.38 & 50.08 \\
\hline $\mathrm{TiO}_{2}$ & 0.27 & 0.27 & 0.30 & 0.28 & 0.30 & 0.26 & 0.23 & 0.24 & 0.13 & 0.30 & 0.51 & 0.44 & 0.42 & 0.53 & 0.43 & 0.43 & 0.38 & 0.63 & 0.31 \\
\hline $\mathrm{Al}_{2} \mathrm{O}_{3}$ & 0.81 & 0.67 & 0.80 & 0.82 & 0.87 & 0.70 & 0.65 & 1.39 & 0.70 & 0.70 & 0.77 & 0.64 & 0.58 & 0.78 & 0.53 & 0.61 & 0.43 & 1.20 & 0.39 \\
\hline $\mathrm{Cr}_{2} \mathrm{O}_{3}$ & 0.03 & 0.05 & 0.03 & 0.05 & 0.05 & 0.02 & 0.05 & 0.04 & 0.04 & 0.05 & 0.00 & 0.00 & 0.00 & 0.01 & 0.00 & 0.01 & 0.00 & 0.01 & 0.02 \\
\hline $\mathrm{FeO}(\mathrm{T})$ & 23.39 & 23.28 & 23.28 & 23.18 & 23.21 & 23.51 & 23.18 & 20.28 & 19.30 & 23.22 & 25.58 & 26.89 & 27.85 & 26.44 & 28.31 & 29.36 & 29.44 & 21.09 & 33.07 \\
\hline $\mathrm{MnO}$ & 0.94 & 0.96 & 0.95 & 0.94 & 0.98 & 1.01 & 0.95 & 0.67 & 0.52 & 1.00 & 1.07 & 1.13 & 1.25 & 1.12 & 1.27 & 1.34 & 1.34 & 0.83 & 1.60 \\
\hline $\mathrm{MgO}$ & 20.64 & 20.87 & 20.99 & 21.07 & 20.85 & 20.68 & 20.84 & 22.98 & 25.01 & 20.45 & 19.59 & 18.22 & 17.76 & 18.66 & 17.22 & 16.38 & 16.08 & 22.46 & 13.37 \\
\hline $\mathrm{CaO}$ & 1.50 & 1.49 & 1.52 & 1.54 & 1.50 & 1.52 & 1.61 & 1.58 & 0.95 & 1.51 & 1.71 & 1.70 & 1.72 & 1.70 & 1.68 & 1.72 & 1.66 & 1.67 & 1.61 \\
\hline $\mathrm{Na}_{2} \mathrm{O}$ & 0.01 & 0.03 & 0.02 & 0.02 & 0.02 & 0.03 & 0.02 & 0.03 & 0.02 & 0.02 & 0.03 & 0.03 & 0.02 & 0.02 & 0.01 & 0.02 & 0.02 & 0.03 & 0.02 \\
\hline Total & 99.54 & 99.52 & 100.00 & 99.96 & 99.63 & 99.63 & 99.21 & 98.65 & 100.11 & 98.53 & 100.52 & 99.71 & 100.43 & 100.13 & 100.32 & 100.08 & 100.14 & 100.29 & 100.46 \\
\hline \multicolumn{20}{|l|}{ Cations } \\
\hline $\mathbf{S i}$ & 1.97 & 1.97 & 1.96 & 1.96 & 1.96 & 1.97 & 1.96 & 1.94 & 1.96 & 1.96 & 1.95 & 1.95 & 1.96 & 1.95 & 1.96 & 1.96 & 1.97 & 1.95 & 1.98 \\
\hline $\mathrm{Ti}$ & 0.003 & 0.003 & 0.004 & 0.003 & 0.004 & 0.003 & 0.003 & 0.003 & 0.002 & 0.004 & 0.006 & 0.005 & 0.005 & 0.007 & 0.005 & 0.005 & 0.005 & 0.008 & 0.004 \\
\hline Al & 0.036 & 0.030 & 0.035 & 0.036 & 0.039 & 0.031 & 0.029 & 0.062 & 0.030 & 0.032 & 0.034 & 0.029 & 0.026 & 0.035 & 0.024 & 0.028 & 0.020 & 0.052 & 0.018 \\
\hline $\mathrm{Cr}$ & 0.001 & 0.001 & 0.001 & 0.001 & 0.002 & 0.001 & 0.001 & 0.001 & 0.001 & 0.002 & 0.000 & 0.000 & 0.000 & 0.000 & 0.000 & 0.000 & 0.000 & 0.000 & 0.001 \\
\hline Fe total & 0.739 & 0.736 & 0.732 & 0.729 & 0.733 & 0.744 & 0.736 & 0.638 & 0.593 & 0.743 & 0.811 & 0.866 & 0.895 & 0.846 & 0.912 & 0.955 & 0.956 & 0.654 & 1.091 \\
\hline $\mathrm{Fe}^{2+}$ & 0.722 & 0.719 & 0.714 & 0.712 & 0.714 & 0.727 & 0.721 & 0.623 & 0.585 & 0.723 & 0.778 & 0.838 & 0.867 & 0.812 & 0.884 & 0.926 & 0.930 & 0.615 & 1.070 \\
\hline $\mathrm{Fe}^{\mathrm{st}}$ & 0.017 & 0.017 & 0.019 & 0.018 & 0.019 & 0.017 & 0.015 & 0.015 & 0.008 & 0.019 & 0.033 & 0.029 & 0.028 & 0.034 & 0.028 & 0.029 & 0.025 & 0.039 & 0.021 \\
\hline Mn & 0.030 & 0.031 & 0.030 & 0.030 & 0.032 & 0.032 & 0.031 & 0.021 & 0.016 & 0.032 & 0.035 & 0.037 & 0.041 & 0.036 & 0.041 & 0.044 & 0.044 & 0.026 & 0.053 \\
\hline $\mathrm{Mg}$ & 1.164 & 1.178 & 1.178 & 1.183 & 1.175 & 1.168 & 1.180 & 1.290 & 1.371 & 1.167 & 1.109 & 1.048 & 1.019 & 1.066 & 0.990 & 0.951 & 0.932 & 1.245 & 0.787 \\
\hline $\mathrm{Ca}$ & 0.061 & 0.060 & 0.061 & 0.062 & 0.061 & 0.062 & 0.066 & 0.064 & 0.037 & 0.062 & 0.070 & 0.070 & 0.071 & 0.070 & 0.069 & 0.072 & 0.069 & 0.067 & 0.068 \\
\hline $\mathrm{Na}$ & 0.001 & 0.002 & 0.001 & 0.002 & 0.001 & 0.002 & 0.002 & 0.002 & 0.001 & 0.001 & 0.002 & 0.002 & 0.002 & 0.001 & 0.001 & 0.002 & 0.002 & 0.002 & 0.002 \\
\hline Total & 4.00 & 4.01 & 4.01 & 4.01 & 4.01 & 4.01 & 4.01 & 4.02 & 4.02 & 4.01 & 4.01 & 4.01 & 4.01 & 4.01 & 4.01 & 4.01 & 4.00 & 4.00 & 4.00 \\
\hline \multicolumn{20}{|l|}{ Atomic \% } \\
\hline Wo & 3.1 & 3.1 & 3.1 & 3.1 & 3.1 & 3.1 & 3.3 & 3.2 & 1.9 & 3.2 & 3.5 & 3.5 & 3.6 & 3.5 & 3.5 & 3.6 & 3.5 & 3.4 & 3.5 \\
\hline En & 59.3 & 59.6 & 59.7 & 59.9 & 59.7 & 59.2 & 59.6 & 64.8 & 68.5 & 59.2 & 55.7 & 52.8 & 51.3 & 53.8 & 50.2 & 48.1 & 47.6 & 63.3 & 40.4 \\
\hline Fs & 37.6 & 37.3 & 37.1 & 36.9 & 37.2 & 37.7 & 37.1 & 32.0 & 29.6 & 37.7 & 40.8 & 43.7 & 45.1 & 42.7 & 46.3 & 48.3 & 48.9 & 33.3 & 56.1 \\
\hline $\mathrm{Mg} \#$ & 60.2 & 60.6 & 60.7 & 60.9 & 60.6 & 60.1 & 60.6 & 66.2 & 69.2 & 60.1 & 56.7 & 53.7 & 52.1 & 54.7 & 50.9 & 48.8 & 48.2 & 64.7 & 40.7 \\
\hline
\end{tabular}


Table F.2. Continued

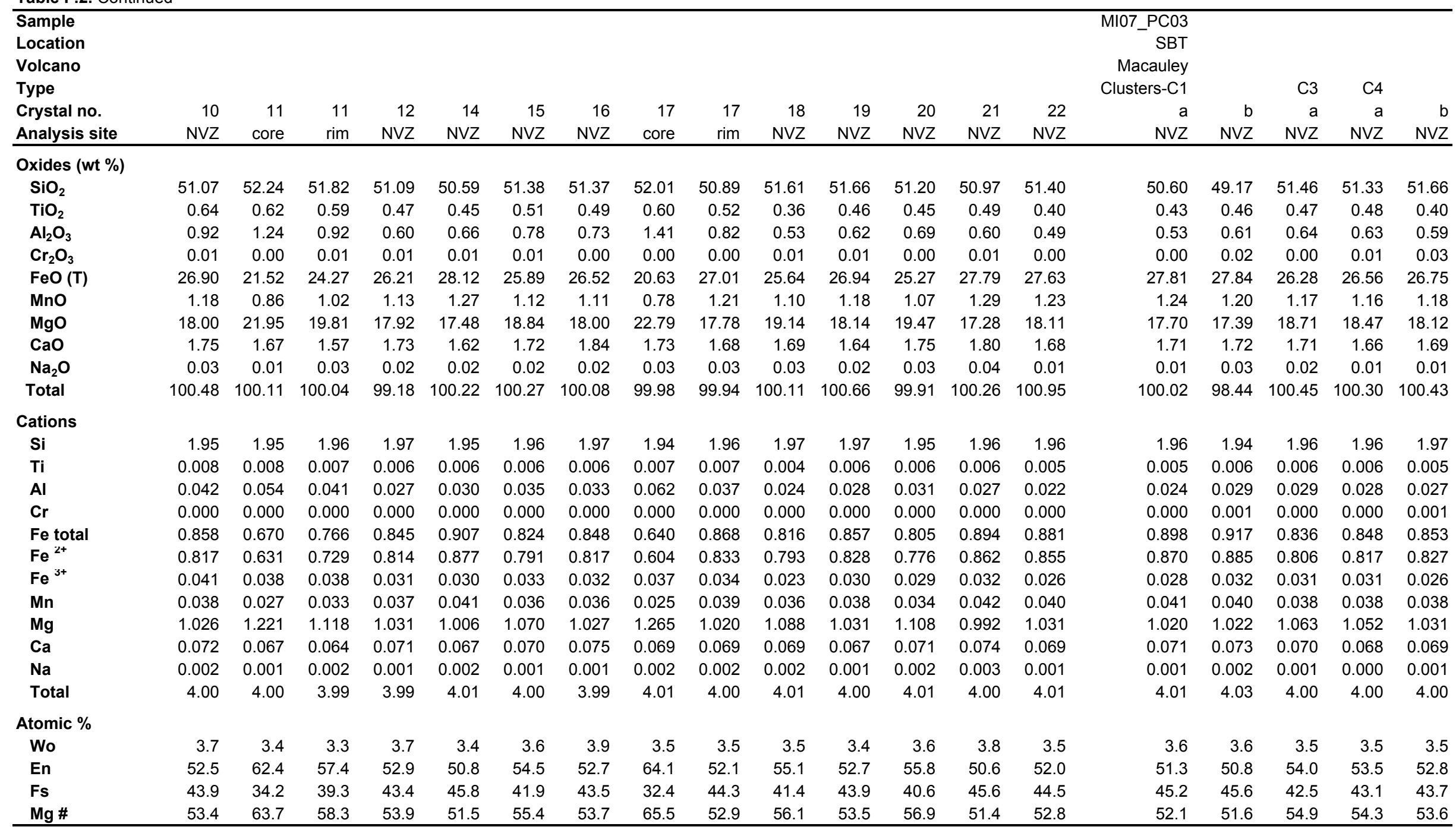


Table F.2. Continued

\begin{tabular}{|c|c|c|c|c|c|c|c|c|c|c|c|c|c|c|c|c|c|c|c|}
\hline $\begin{array}{l}\text { Sample } \\
\text { Location } \\
\text { Volcano } \\
\text { Type }\end{array}$ & C5 & & $\begin{array}{r}\text { D25_PC01 } \\
\text { SW flank } \\
\text { Macauley } \\
\text { Single crystal }\end{array}$ & & & & & & & & & & & & & & & & \\
\hline $\begin{array}{l}\text { Crystal no. } \\
\text { Analysis site }\end{array}$ & $\begin{array}{r}a \\
N V Z \\
\end{array}$ & $\begin{array}{r}b \\
N V Z \\
\end{array}$ & $\begin{array}{r}1 \\
N V Z \\
\end{array}$ & $\begin{array}{r}2 \\
\text { core }\end{array}$ & $\begin{array}{r}2 \\
\text { rim }\end{array}$ & $\begin{array}{r}3 \\
\text { core } \\
\end{array}$ & $\begin{array}{r}3 \\
\text { rim }\end{array}$ & $\begin{array}{r}4 \\
N V Z \\
\end{array}$ & $\begin{array}{r}5 \\
N V Z \\
\end{array}$ & $\begin{array}{r}6 \\
\text { core } \\
\end{array}$ & $\begin{array}{r}6 \\
\text { rim }\end{array}$ & $\begin{array}{r}7 \\
\text { core } \\
\end{array}$ & $\begin{array}{r}7 \\
\mathrm{~d} \text { band } \\
\end{array}$ & $\begin{array}{r}7 \\
\text { rim }\end{array}$ & $\begin{array}{r}8 \\
\text { core } \\
\end{array}$ & $\begin{array}{r}8 \\
\text { rim }\end{array}$ & $\begin{array}{r}9 \\
N V Z \\
\end{array}$ & $\begin{array}{r}10 \\
\text { core }\end{array}$ & $\begin{array}{r}10 \\
O G\end{array}$ \\
\hline \multicolumn{20}{|l|}{ Oxides (wt \%) } \\
\hline $\mathrm{SiO}_{2}$ & 50.60 & 50.64 & 52.32 & 51.78 & 52.36 & 52.28 & 52.24 & 52.96 & 53.00 & 52.83 & 52.87 & 52.91 & 53.21 & 53.08 & 52.00 & 52.71 & 52.29 & 53.39 & 52.19 \\
\hline $\mathrm{TiO}_{2}$ & 0.46 & 0.39 & 0.40 & 0.42 & 0.41 & 0.37 & 0.32 & 0.37 & 0.36 & 0.42 & 0.40 & 0.33 & 0.40 & 0.37 & 0.47 & 0.35 & 0.39 & 0.28 & 0.44 \\
\hline $\mathrm{Al}_{2} \mathrm{O}_{3}$ & 0.62 & 0.53 & 0.78 & 1.05 & 0.88 & 0.75 & 0.72 & 0.75 & 0.73 & 0.92 & 0.86 & 0.86 & 1.33 & 1.06 & 1.15 & 0.77 & 0.87 & 0.77 & 1.35 \\
\hline $\mathrm{Cr}_{2} \mathrm{O}_{3}$ & 0.00 & 0.02 & 0.01 & 0.00 & 0.00 & 0.01 & 0.00 & 0.00 & 0.01 & 0.01 & 0.00 & 0.00 & 0.00 & 0.01 & 0.00 & 0.02 & 0.00 & 0.00 & 0.00 \\
\hline $\mathrm{FeO}(\mathrm{T})$ & 27.27 & 27.44 & 23.06 & 24.10 & 22.88 & 24.49 & 23.10 & 23.51 & 23.29 & 23.62 & 23.05 & 23.09 & 21.02 & 22.80 & 24.22 & 22.98 & 23.29 & 22.33 & 23.85 \\
\hline MnO & 1.24 & 1.25 & 0.95 & 1.08 & 0.98 & 1.02 & 1.00 & 1.04 & 1.01 & 0.97 & 0.95 & 1.00 & 0.82 & 0.93 & 1.09 & 0.99 & 1.01 & 0.96 & 1.02 \\
\hline MgO & 18.10 & 17.86 & 21.50 & 20.61 & 21.55 & 20.35 & 21.58 & 21.40 & 21.67 & 21.18 & 21.74 & 21.63 & 22.94 & 21.68 & 20.45 & 21.67 & 21.23 & 22.39 & 20.60 \\
\hline $\mathrm{CaO}$ & 1.75 & 1.68 & 1.71 & 1.78 & 1.68 & 1.70 & 1.67 & 1.71 & 1.69 & 1.73 & 1.77 & 1.67 & 1.87 & 1.64 & 1.74 & 1.70 & 1.72 & 1.48 & 1.57 \\
\hline $\mathrm{Na}_{2} \mathrm{O}$ & 0.02 & 0.02 & 0.02 & 0.03 & 0.01 & 0.01 & 0.01 & 0.02 & 0.03 & 0.02 & 0.02 & 0.04 & 0.02 & 0.00 & 0.03 & 0.02 & 0.02 & 0.03 & 0.03 \\
\hline Total & 100.05 & 99.82 & 100.77 & 100.84 & 100.75 & 100.97 & 100.63 & 101.74 & 101.78 & 101.69 & 101.65 & 101.52 & 101.62 & 101.56 & 101.15 & 101.20 & 100.82 & 101.63 & 101.07 \\
\hline \multicolumn{20}{|l|}{ Cations } \\
\hline Si & 1.95 & 1.96 & 1.95 & 1.94 & 1.95 & 1.96 & 1.95 & 1.96 & 1.96 & 1.96 & 1.96 & 1.96 & 1.95 & 1.96 & 1.95 & 1.96 & 1.95 & 1.97 & 1.95 \\
\hline $\mathrm{Ti}$ & 0.006 & 0.005 & 0.005 & 0.005 & 0.005 & 0.005 & 0.004 & 0.005 & 0.004 & 0.005 & 0.005 & 0.004 & 0.005 & 0.005 & 0.006 & 0.004 & 0.005 & 0.003 & 0.006 \\
\hline Al & 0.028 & 0.024 & 0.034 & 0.046 & 0.039 & 0.033 & 0.032 & 0.033 & 0.032 & 0.040 & 0.037 & 0.037 & 0.057 & 0.046 & 0.051 & 0.034 & 0.038 & 0.033 & 0.060 \\
\hline $\mathrm{Cr}$ & 0.000 & 0.001 & 0.000 & 0.000 & 0.000 & 0.000 & 0.000 & 0.000 & 0.000 & 0.000 & 0.000 & 0.000 & 0.000 & 0.000 & 0.000 & 0.001 & 0.000 & 0.000 & 0.000 \\
\hline Fe total & 0.878 & 0.886 & 0.719 & 0.756 & 0.713 & 0.767 & 0.722 & 0.727 & 0.719 & 0.731 & 0.712 & 0.714 & 0.642 & 0.703 & 0.757 & 0.713 & 0.727 & 0.687 & 0.744 \\
\hline $\mathrm{Fe}^{2+}$ & 0.847 & 0.860 & 0.694 & 0.729 & 0.688 & 0.744 & 0.702 & 0.704 & 0.698 & 0.705 & 0.688 & 0.694 & 0.618 & 0.680 & 0.728 & 0.691 & 0.703 & 0.670 & 0.716 \\
\hline $\mathrm{Fe}^{3+}$ & 0.030 & 0.026 & 0.025 & 0.027 & 0.025 & 0.023 & 0.020 & 0.023 & 0.022 & 0.026 & 0.024 & 0.020 & 0.024 & 0.022 & 0.029 & 0.022 & 0.024 & 0.017 & 0.028 \\
\hline Mn & 0.040 & 0.041 & 0.030 & 0.034 & 0.031 & 0.033 & 0.032 & 0.033 & 0.032 & 0.030 & 0.030 & 0.031 & 0.025 & 0.029 & 0.035 & 0.031 & 0.032 & 0.030 & 0.032 \\
\hline Mg & 1.040 & 1.029 & 1.197 & 1.154 & 1.199 & 1.138 & 1.204 & 1.181 & 1.194 & 1.170 & 1.199 & 1.194 & 1.252 & 1.193 & 1.141 & 1.200 & 1.183 & 1.229 & 1.147 \\
\hline $\mathrm{Ca}$ & 0.072 & 0.070 & 0.068 & 0.072 & 0.067 & 0.068 & 0.067 & 0.068 & 0.067 & 0.068 & 0.070 & 0.066 & 0.074 & 0.065 & 0.070 & 0.068 & 0.069 & 0.058 & 0.063 \\
\hline $\mathrm{Na}$ & 0.002 & 0.001 & 0.002 & 0.002 & 0.001 & 0.001 & 0.001 & 0.002 & 0.002 & 0.001 & 0.002 & 0.003 & 0.001 & 0.000 & 0.002 & 0.001 & 0.001 & 0.002 & 0.002 \\
\hline Total & 4.02 & 4.01 & 4.01 & 4.01 & 4.01 & 4.01 & 4.02 & 4.01 & 4.01 & 4.00 & 4.01 & 4.01 & 4.01 & 4.00 & 4.01 & 4.01 & 4.01 & 4.01 & 4.00 \\
\hline \multicolumn{20}{|l|}{ Atomic \% } \\
\hline Wo & 3.6 & 3.5 & 3.4 & 3.6 & 3.4 & 3.5 & 3.4 & 3.4 & 3.4 & 3.5 & 3.5 & 3.4 & 3.7 & 3.3 & 3.5 & 3.4 & 3.5 & 2.9 & 3.2 \\
\hline En & 52.3 & 51.9 & 60.3 & 58.2 & 60.6 & 57.7 & 60.4 & 59.8 & 60.3 & 59.4 & 60.5 & 60.5 & 63.6 & 60.8 & 58.0 & 60.6 & 59.8 & 62.3 & 58.7 \\
\hline Fs & 44.1 & 44.6 & 36.2 & 38.1 & 36.0 & 38.9 & 36.2 & 36.8 & 36.3 & 37.1 & 35.9 & 36.2 & 32.6 & 35.8 & 38.5 & 36.0 & 36.7 & 34.8 & 38.1 \\
\hline Mg \# & 53.1 & 52.6 & 61.5 & 59.4 & 61.7 & 58.7 & 61.5 & 60.9 & 61.4 & 60.6 & 61.8 & 61.6 & 65.2 & 62.0 & 59.0 & 61.7 & 60.9 & 63.2 & 59.6 \\
\hline
\end{tabular}


Table F.2. Continued

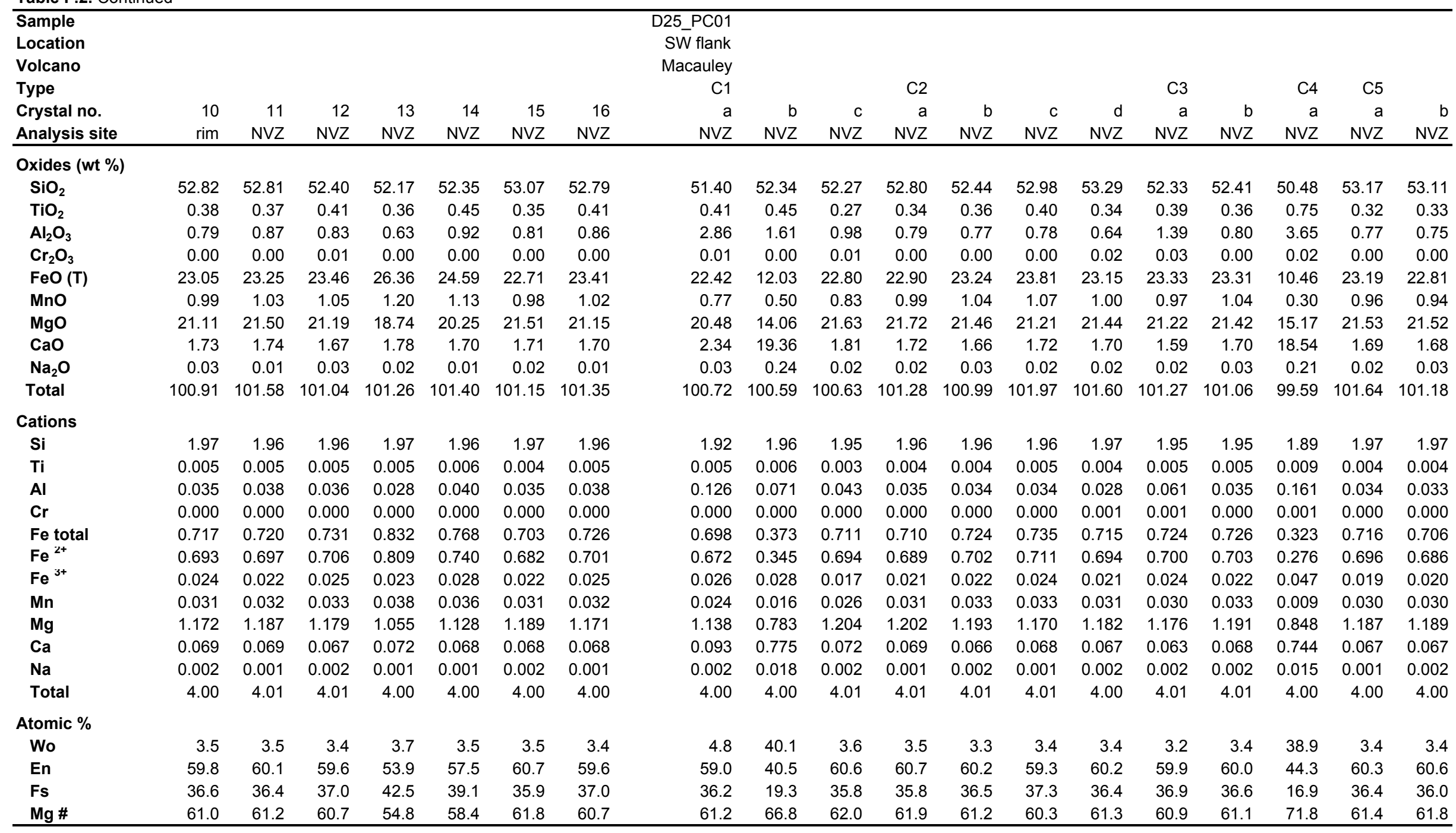


Table F.2. Continued

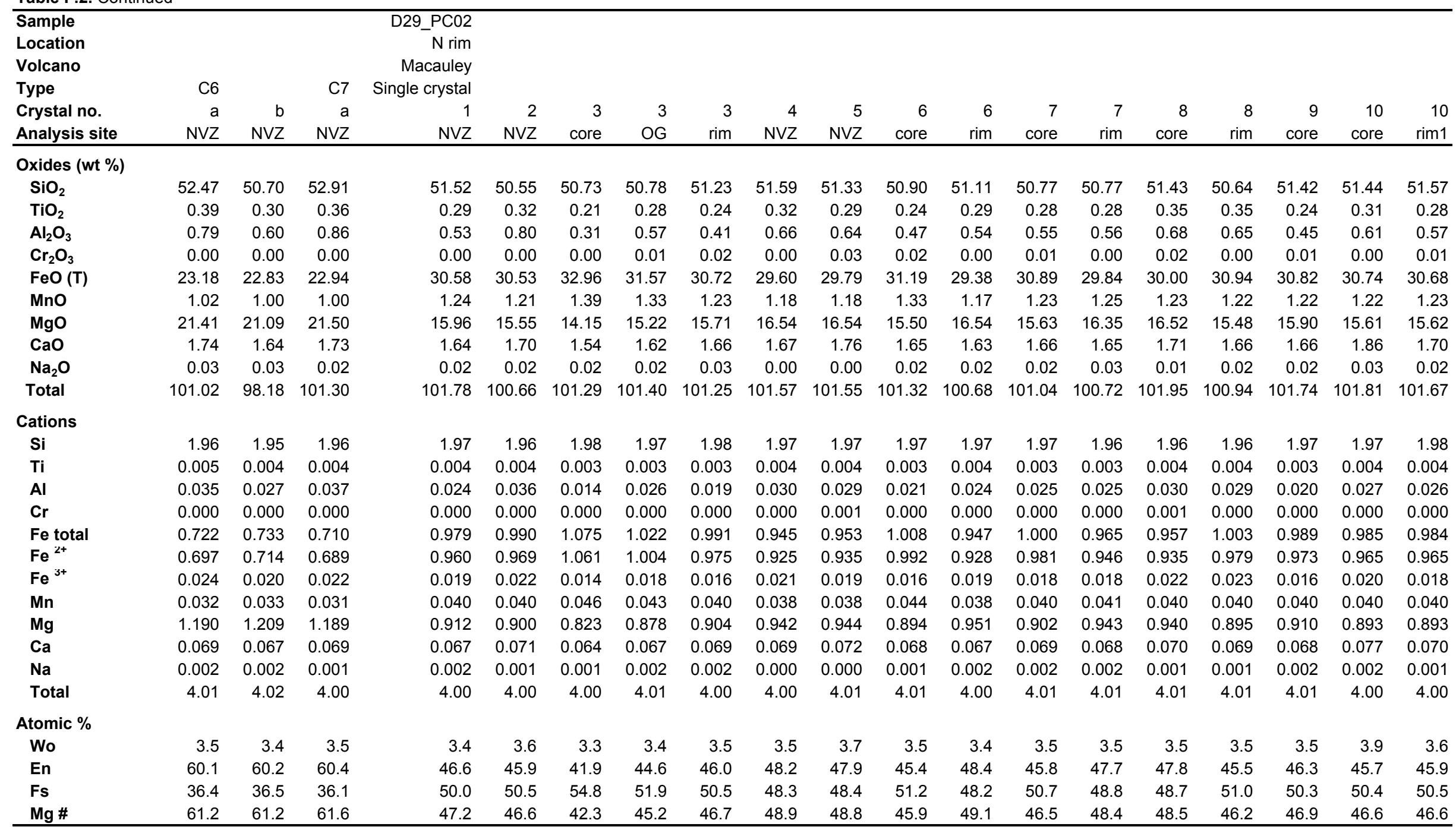


Table F.2. Continued

\begin{tabular}{|c|c|c|c|c|c|c|c|c|c|c|c|c|c|c|c|c|c|c|c|}
\hline $\begin{array}{l}\text { Sample } \\
\text { Location } \\
\text { Volcano } \\
\text { Type }\end{array}$ & & & & & & & & & $\begin{array}{r}\text { D33_PC02 } \\
\text { E flank } \\
\text { Macauley } \\
\text { Single crystal }\end{array}$ & & & & & & & & & & \\
\hline $\begin{array}{l}\text { Crystal no. } \\
\text { Analysis site }\end{array}$ & $\begin{array}{r}10 \\
\text { rim2 }\end{array}$ & $\begin{array}{r}11 \\
N V Z\end{array}$ & $\begin{array}{c}12 \\
\text { core }\end{array}$ & $\begin{array}{r}12 \\
\text { rim }\end{array}$ & $\begin{array}{r}13 \\
N V Z\end{array}$ & $\begin{array}{r}14 \\
N V Z\end{array}$ & $\begin{array}{r}15 \\
N V Z\end{array}$ & $\begin{array}{r}16 \\
N V Z\end{array}$ & $\begin{array}{r}1 \\
N V Z\end{array}$ & $\begin{array}{r}2 \\
N V Z\end{array}$ & $\begin{array}{r}3 \\
N V Z\end{array}$ & $\begin{array}{r}4 \\
N V Z\end{array}$ & $\begin{array}{r}5 \\
N V Z\end{array}$ & $\begin{array}{r}6 \\
\text { core } \\
\end{array}$ & $\begin{array}{r}6 \\
\text { rim } \\
\end{array}$ & $\begin{array}{r}7 \\
\text { core } \\
\end{array}$ & $\begin{array}{r}7 \\
\text { rim } \\
\end{array}$ & $\begin{array}{r}8 \\
N V Z \\
\end{array}$ & $\begin{array}{r}9 \\
N V Z \\
\end{array}$ \\
\hline \multicolumn{20}{|l|}{ Oxides (wt \%) } \\
\hline $\mathrm{SiO}_{2}$ & 51.98 & 51.65 & 50.63 & 50.95 & 51.51 & 51.66 & 51.13 & 51.03 & 52.69 & 52.82 & 52.58 & 53.28 & 53.26 & 53.18 & 53.03 & 51.51 & 52.83 & 53.28 & 53.29 \\
\hline $\mathrm{TiO}_{2}$ & 0.27 & 0.25 & 0.28 & 0.26 & 0.29 & 0.30 & 0.30 & 0.30 & 0.26 & 0.29 & 0.29 & 0.31 & 0.28 & 0.28 & 0.28 & 0.51 & 0.27 & 0.26 & 0.29 \\
\hline $\mathrm{Al}_{2} \mathrm{O}_{3}$ & 0.53 & 0.49 & 0.60 & 0.56 & 0.64 & 0.60 & 0.70 & 0.68 & 0.94 & 0.85 & 0.97 & 1.24 & 0.88 & 1.03 & 0.87 & 1.70 & 0.88 & 1.09 & 1.01 \\
\hline $\mathrm{Cr}_{2} \mathrm{O}_{3}$ & 0.00 & 0.03 & 0.00 & 0.00 & 0.00 & 0.00 & 0.00 & 0.01 & 0.00 & 0.00 & 0.00 & 0.01 & 0.00 & 0.00 & 0.00 & 0.00 & 0.00 & 0.00 & 0.01 \\
\hline $\mathrm{FeO}(\mathrm{T})$ & 30.30 & 29.76 & 33.00 & 30.29 & 29.34 & 29.72 & 29.28 & 29.86 & 21.89 & 22.81 & 22.18 & 21.54 & 21.95 & 21.10 & 21.96 & 10.94 & 22.02 & 22.20 & 22.01 \\
\hline MnO & 1.26 & 1.20 & 1.42 & 1.24 & 1.19 & 1.17 & 1.17 & 1.21 & 0.98 & 1.16 & 1.00 & 0.99 & 1.01 & 0.93 & 1.04 & 0.53 & 1.01 & 1.03 & 0.98 \\
\hline MgO & 15.90 & 16.65 & 13.57 & 15.44 & 16.44 & 16.40 & 16.32 & 16.54 & 22.71 & 22.13 & 22.36 & 22.74 & 22.61 & 23.09 & 22.64 & 14.31 & 22.61 & 22.31 & 22.51 \\
\hline $\mathrm{CaO}$ & 1.67 & 1.64 & 2.07 & 1.69 & 1.95 & 1.62 & 2.00 & 1.65 & 1.42 & 1.30 & 1.38 & 1.34 & 1.44 & 1.39 & 1.39 & 19.89 & 1.36 & 1.26 & 1.39 \\
\hline $\mathrm{Na}_{2} \mathrm{O}$ & 0.03 & 0.03 & 0.02 & 0.02 & 0.04 & 0.01 & 0.02 & 0.03 & 0.00 & 0.02 & 0.02 & 0.02 & 0.02 & 0.01 & 0.01 & 0.21 & 0.03 & 0.03 & 0.01 \\
\hline Total & 101.94 & 101.70 & 101.59 & 100.46 & 101.40 & 101.49 & 100.91 & 101.30 & 100.89 & 101.36 & 100.78 & 101.46 & 101.45 & 101.00 & 101.21 & 99.61 & 101.01 & 101.46 & 101.49 \\
\hline \multicolumn{20}{|l|}{ Cations } \\
\hline Si & 1.98 & 1.97 & 1.97 & 1.98 & 1.97 & 1.98 & 1.97 & 1.96 & 1.95 & 1.96 & 1.95 & 1.96 & 1.96 & 1.96 & 1.96 & 1.94 & 1.96 & 1.96 & 1.96 \\
\hline $\mathrm{Ti}$ & 0.003 & 0.003 & 0.004 & 0.003 & 0.004 & 0.004 & 0.004 & 0.004 & 0.003 & 0.004 & 0.004 & 0.004 & 0.004 & 0.004 & 0.003 & 0.006 & 0.003 & 0.003 & 0.004 \\
\hline Al & 0.024 & 0.022 & 0.028 & 0.026 & 0.029 & 0.027 & 0.032 & 0.031 & 0.041 & 0.037 & 0.042 & 0.054 & 0.038 & 0.045 & 0.038 & 0.076 & 0.039 & 0.047 & 0.044 \\
\hline $\mathrm{Cr}$ & 0.000 & 0.001 & 0.000 & 0.000 & 0.000 & 0.000 & 0.000 & 0.000 & 0.000 & 0.000 & 0.000 & 0.000 & 0.000 & 0.000 & 0.000 & 0.000 & 0.000 & 0.000 & 0.000 \\
\hline Fe total & 0.967 & 0.950 & 1.075 & 0.983 & 0.939 & 0.950 & 0.942 & 0.959 & 0.678 & 0.706 & 0.688 & 0.660 & 0.675 & 0.649 & 0.677 & 0.342 & 0.681 & 0.683 & 0.676 \\
\hline $\mathrm{Fe}^{2+}$ & 0.949 & 0.934 & 1.055 & 0.966 & 0.920 & 0.930 & 0.922 & 0.939 & 0.662 & 0.688 & 0.670 & 0.642 & 0.658 & 0.632 & 0.661 & 0.309 & 0.664 & 0.667 & 0.659 \\
\hline $\mathrm{Fe}^{3+}$ & 0.018 & 0.016 & 0.019 & 0.017 & 0.019 & 0.020 & 0.019 & 0.019 & 0.016 & 0.018 & 0.018 & 0.019 & 0.017 & 0.017 & 0.017 & 0.033 & 0.017 & 0.016 & 0.018 \\
\hline Mn & 0.041 & 0.039 & 0.047 & 0.041 & 0.039 & 0.038 & 0.038 & 0.039 & 0.031 & 0.036 & 0.031 & 0.031 & 0.032 & 0.029 & 0.033 & 0.017 & 0.032 & 0.032 & 0.030 \\
\hline Mg & 0.905 & 0.948 & 0.788 & 0.894 & 0.938 & 0.935 & 0.936 & 0.948 & 1.254 & 1.222 & 1.238 & 1.245 & 1.241 & 1.268 & 1.246 & 0.804 & 1.248 & 1.225 & 1.235 \\
\hline $\mathrm{Ca}$ & 0.068 & 0.067 & 0.086 & 0.070 & 0.080 & 0.066 & 0.082 & 0.068 & 0.056 & 0.051 & 0.055 & 0.053 & 0.057 & 0.055 & 0.055 & 0.803 & 0.054 & 0.050 & 0.055 \\
\hline $\mathrm{Na}$ & 0.002 & 0.002 & 0.002 & 0.002 & 0.003 & 0.001 & 0.002 & 0.002 & 0.000 & 0.001 & 0.001 & 0.002 & 0.001 & 0.001 & 0.001 & 0.015 & 0.002 & 0.002 & 0.001 \\
\hline Total & 3.99 & 4.01 & 4.00 & 4.00 & 4.00 & 4.00 & 4.00 & 4.01 & 4.02 & 4.01 & 4.01 & 4.00 & 4.01 & 4.01 & 4.01 & 4.01 & 4.01 & 4.00 & 4.01 \\
\hline \multicolumn{20}{|l|}{ Atomic \% } \\
\hline Wo & 3.5 & 3.4 & 4.4 & 3.6 & 4.1 & 3.4 & 4.2 & 3.4 & 2.8 & 2.6 & 2.8 & 2.7 & 2.9 & 2.8 & 2.8 & 41.2 & 2.7 & 2.5 & 2.8 \\
\hline En & 46.6 & 48.2 & 40.4 & 45.9 & 47.9 & 47.9 & 47.8 & 48.0 & 63.1 & 61.7 & 62.5 & 63.6 & 62.9 & 64.3 & 63.0 & 41.3 & 62.9 & 62.6 & 62.8 \\
\hline Fs & 49.8 & 48.3 & 55.1 & 50.5 & 48.0 & 48.7 & 48.0 & 48.6 & 34.1 & 35.7 & 34.7 & 33.7 & 34.2 & 32.9 & 34.2 & 17.5 & 34.3 & 34.9 & 34.4 \\
\hline Mg \# & 47.3 & 48.9 & 41.3 & 46.6 & 49.0 & 48.6 & 48.9 & 48.7 & 63.9 & 62.2 & 63.3 & 64.3 & 63.7 & 65.2 & 63.7 & 69.2 & 63.7 & 63.1 & 63.6 \\
\hline
\end{tabular}


Table F.2. Continued

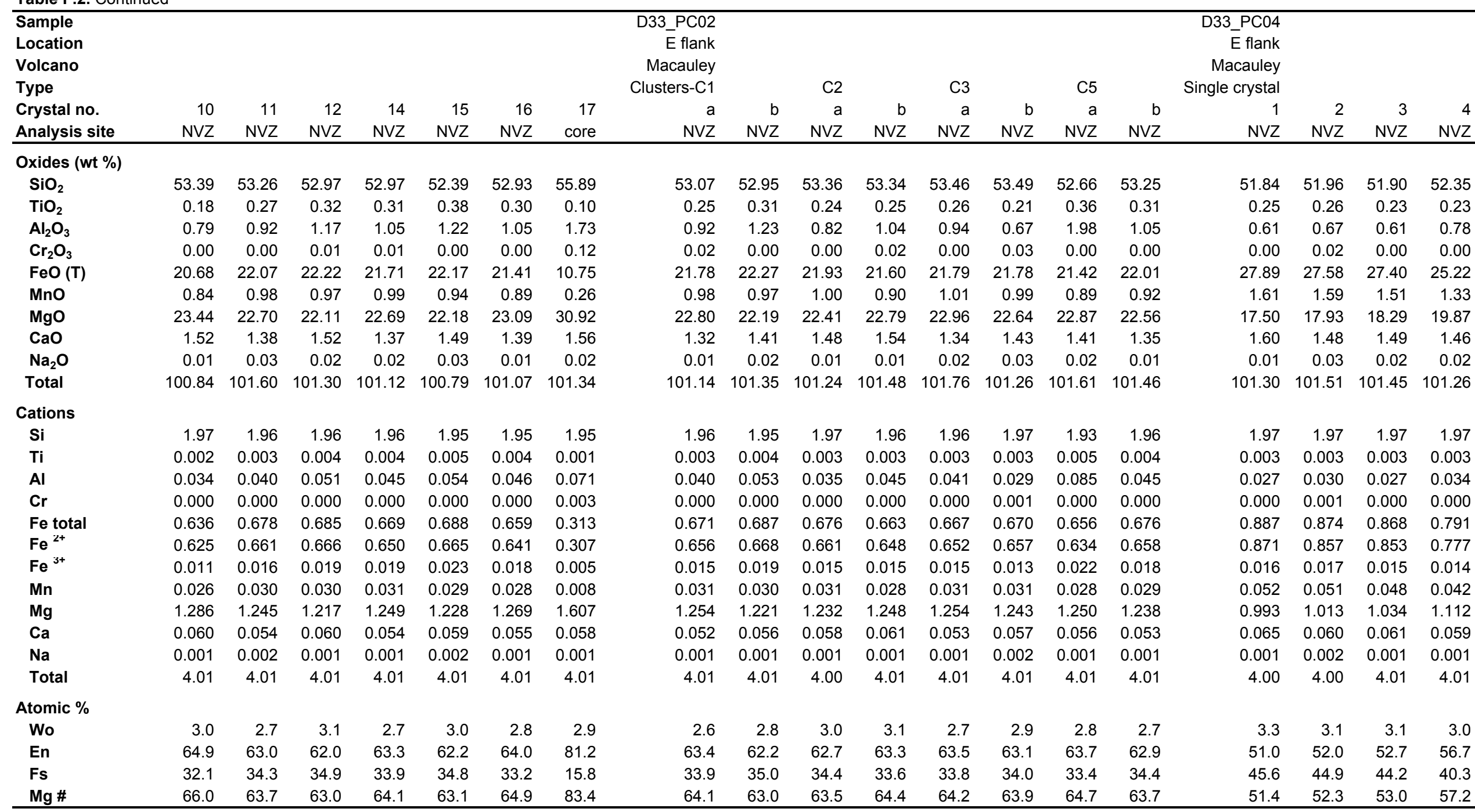


Table F.2. Continued

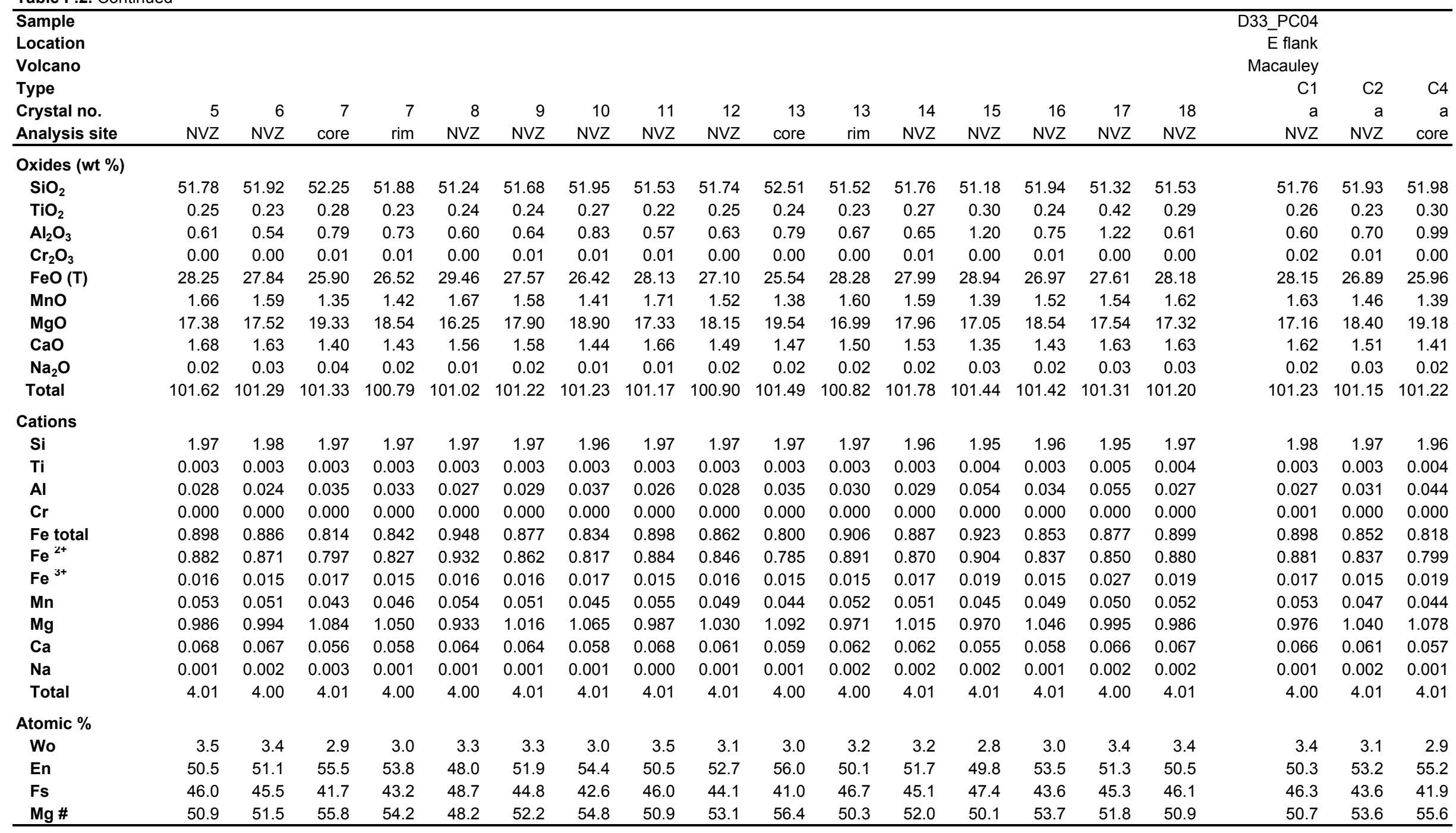


Table F.2. Continued

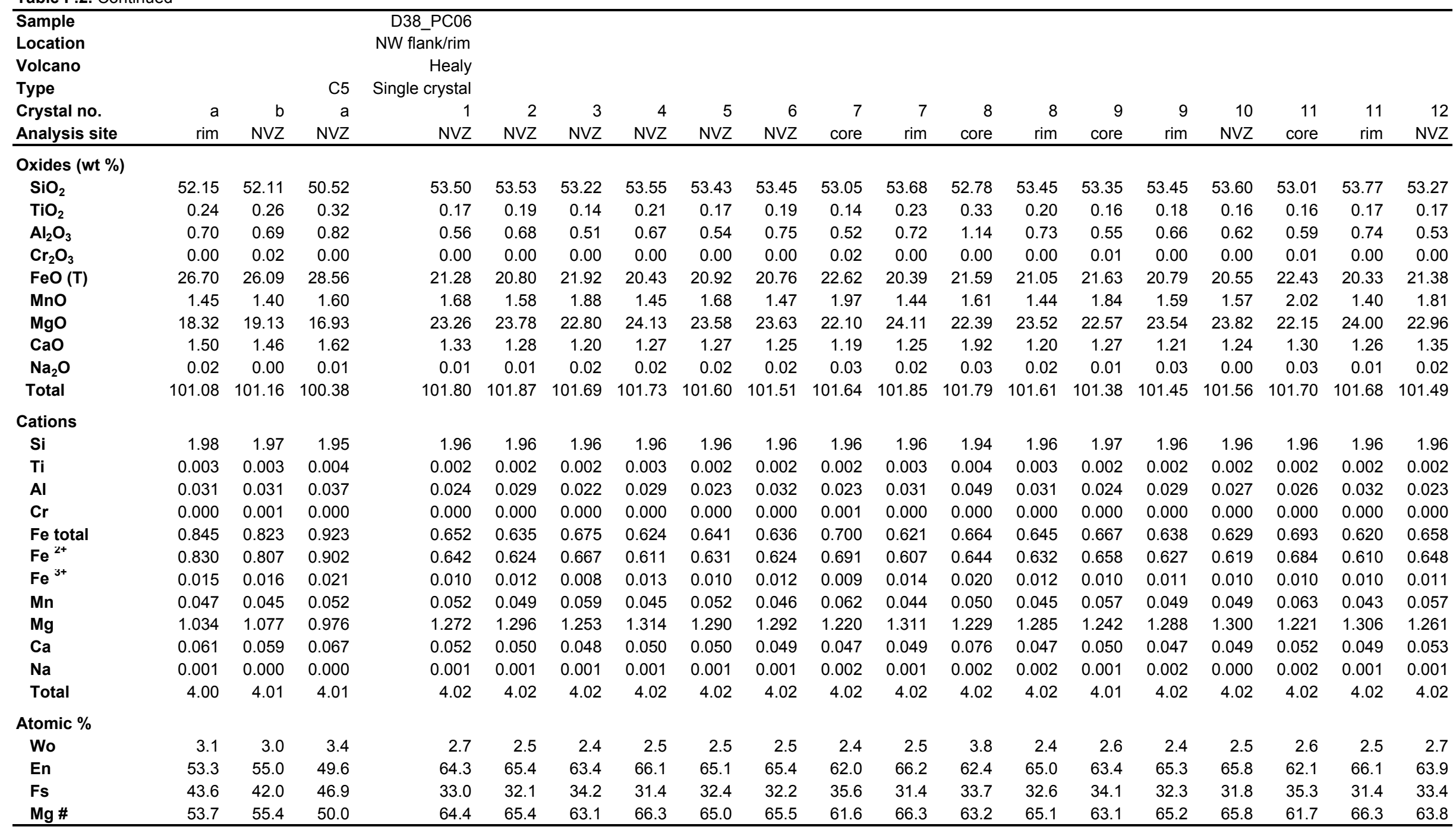


Table F.2. Continued

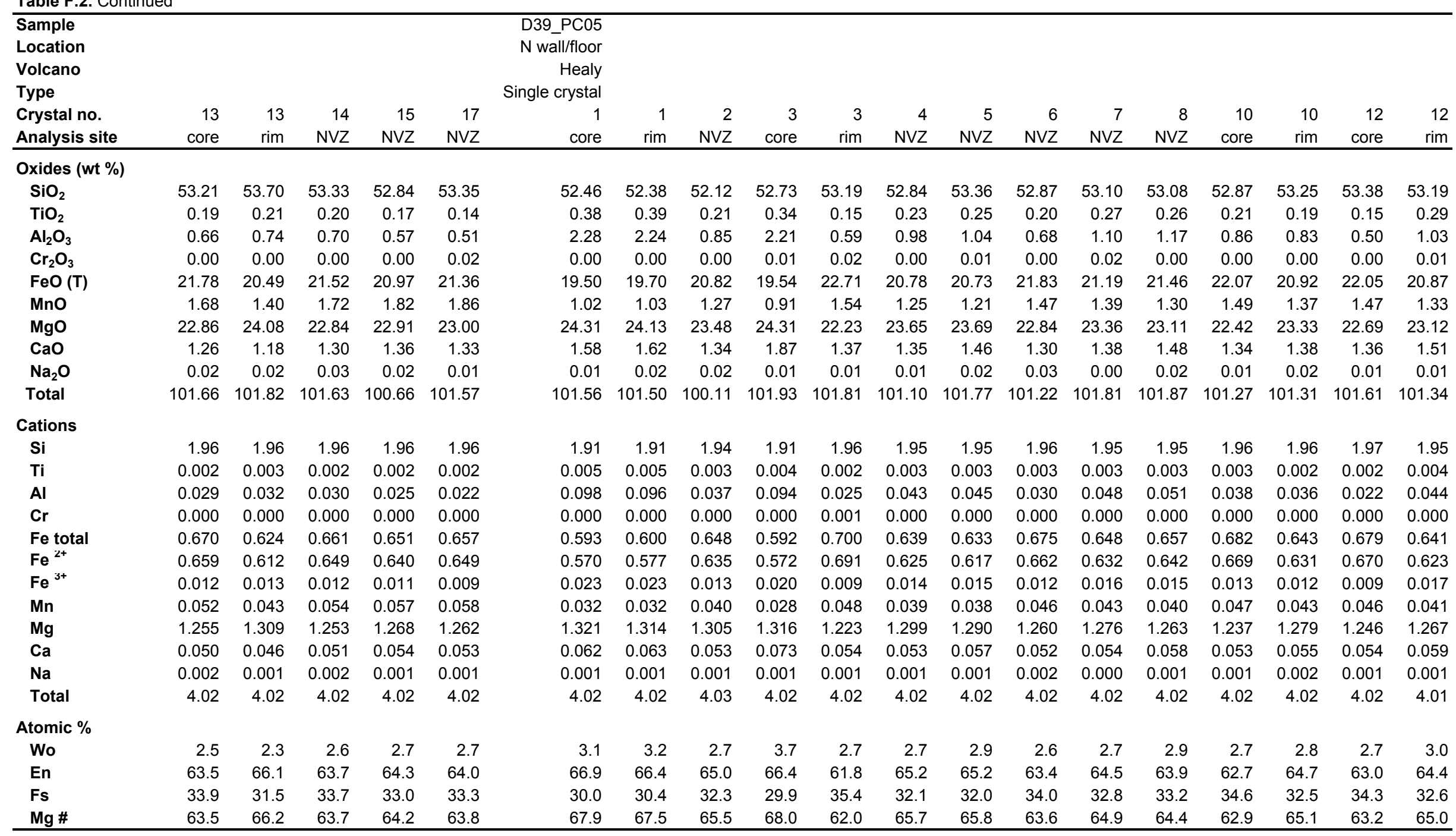


Table F.2. Continued

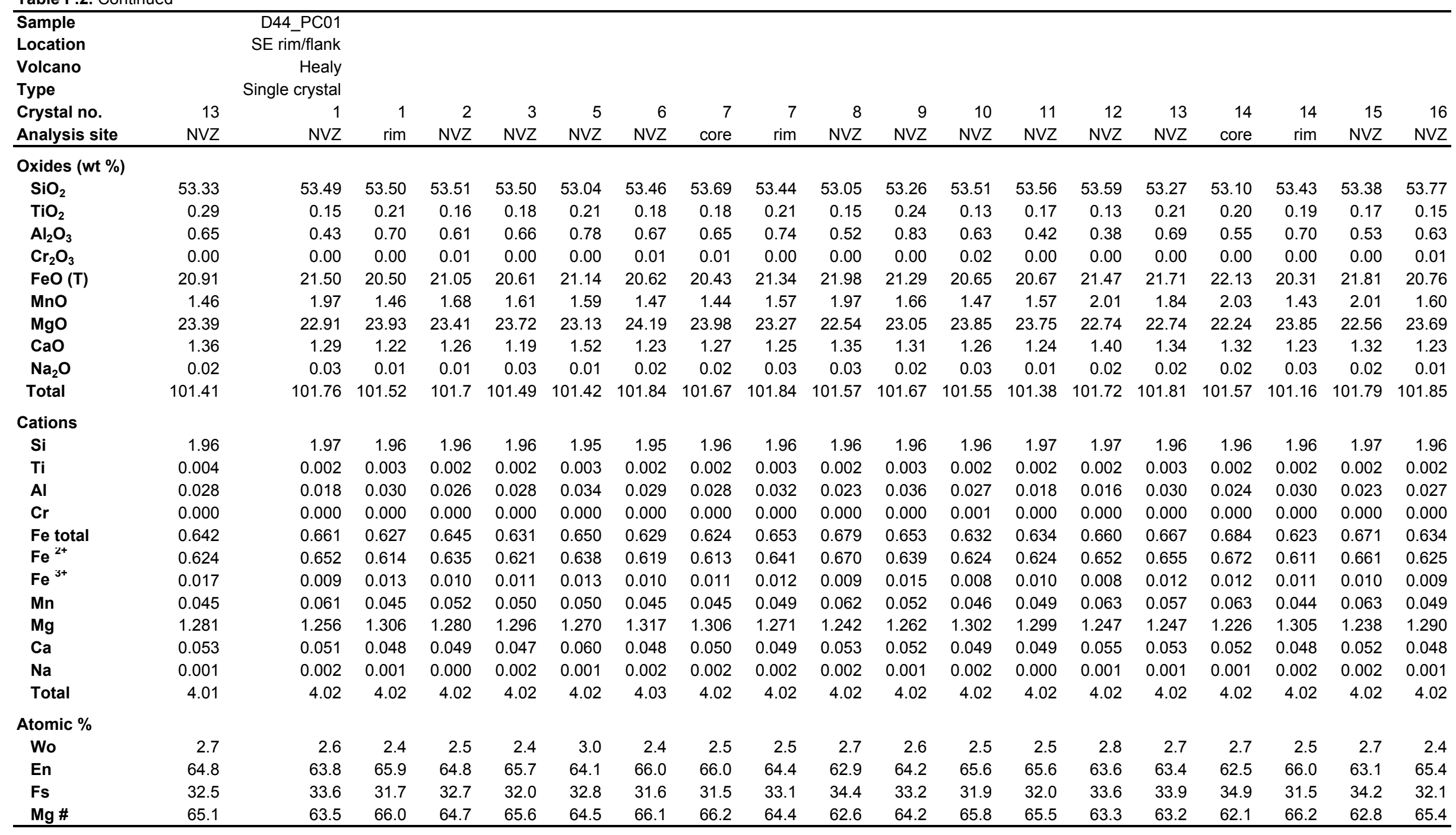


Table F.2. Continued

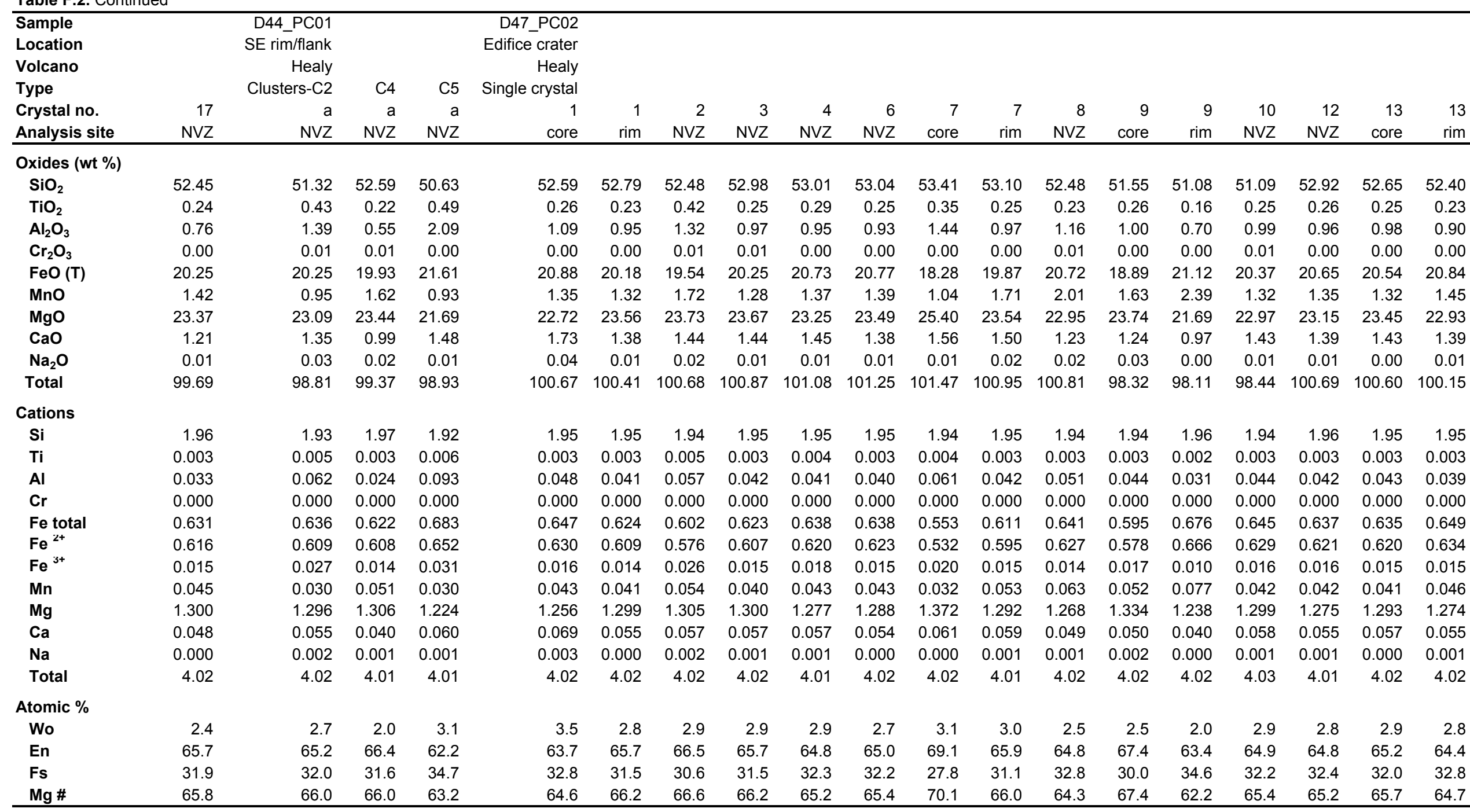


Table F.2. Continued

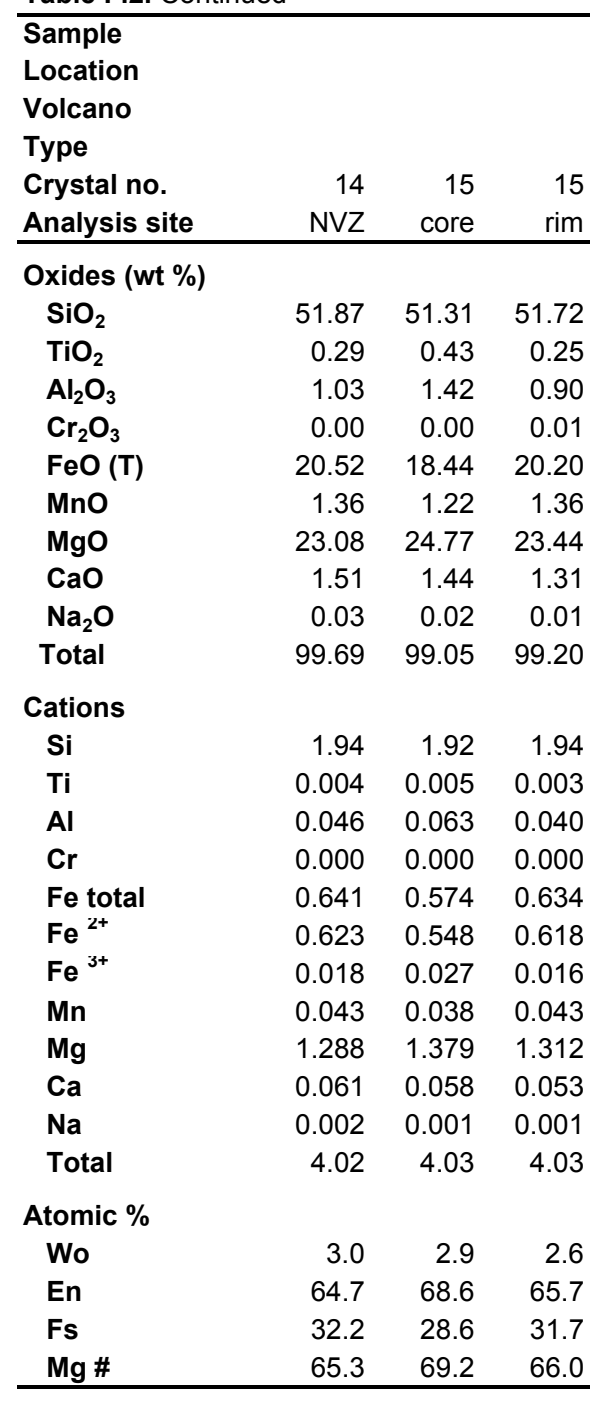


Table F.3. Major element compositions of plagioclase determined by EPMA

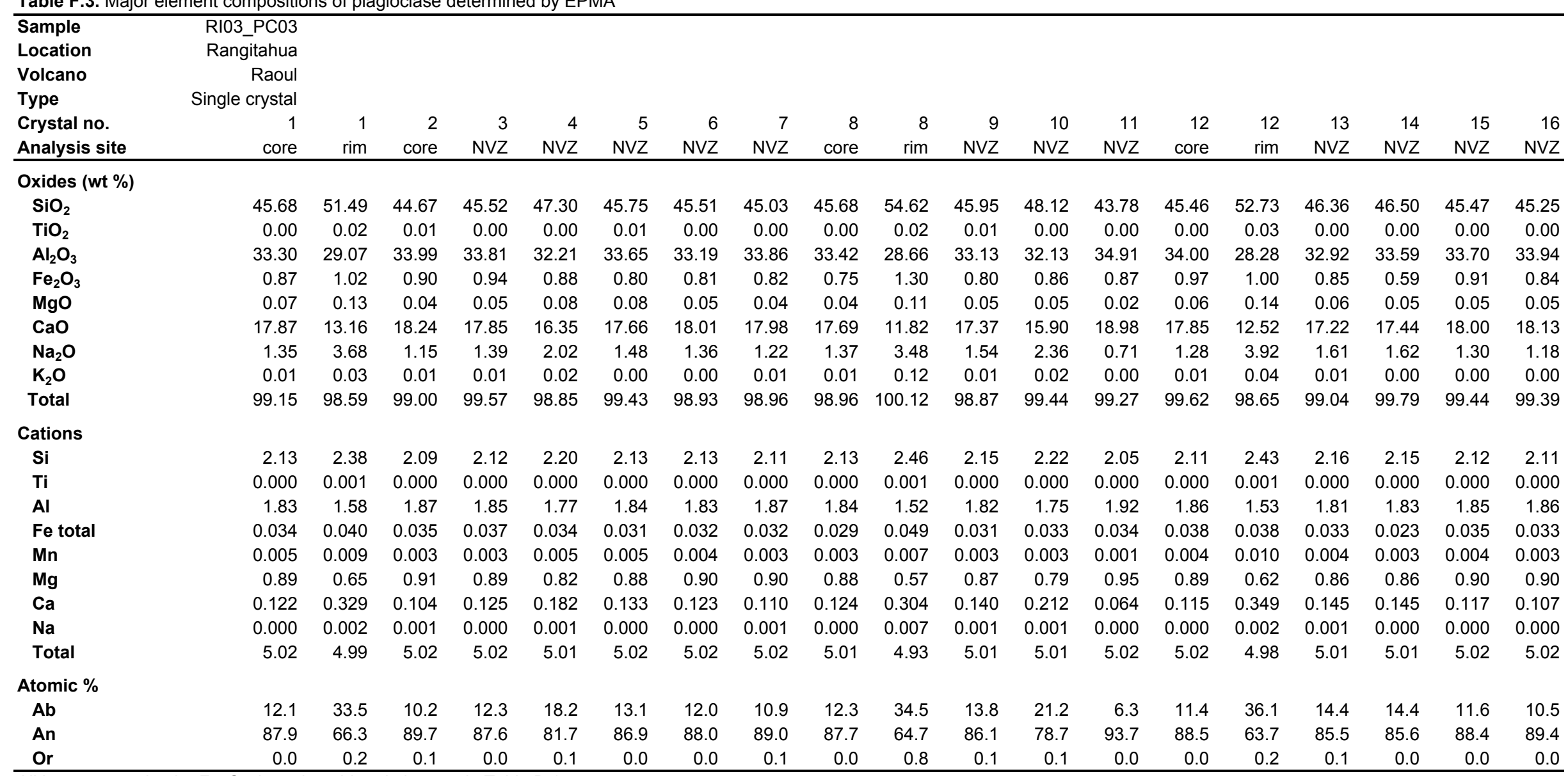


Table F.3. Continued

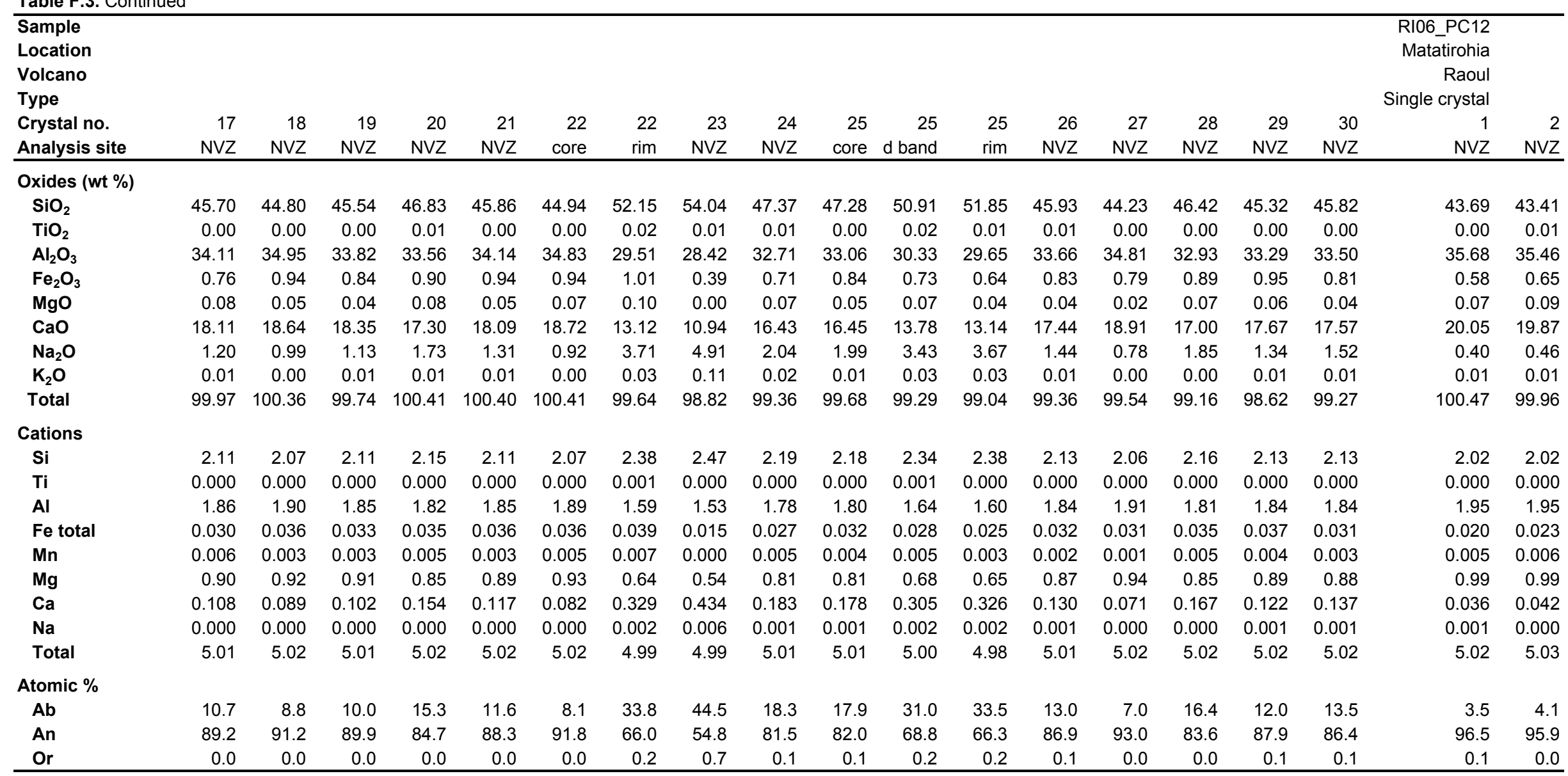


Table F.3. Continued

\begin{tabular}{|c|c|c|c|c|c|c|c|c|c|c|c|c|c|c|c|c|c|c|c|c|}
\hline $\begin{array}{l}\text { Sample } \\
\text { Location } \\
\text { Volcano } \\
\text { Type }\end{array}$ & & & & & & & & & & & & & & & & & & & & \\
\hline $\begin{array}{l}\text { Crystal no. } \\
\text { Analysis site }\end{array}$ & $\begin{array}{r}3 \\
\text { core } \\
\end{array}$ & $\begin{array}{r}3 \\
\text { rim } \\
\end{array}$ & $\begin{array}{r}4 \\
\text { core1 } \\
\end{array}$ & $\begin{array}{r}4 \\
\text { core2 } \\
\end{array}$ & $\begin{array}{r}4 \\
\mathrm{~d} \text { band } \\
\end{array}$ & $\begin{array}{r}4 \\
\text { rim } \\
\end{array}$ & $\begin{array}{r}5 \\
\text { core } \\
\end{array}$ & $\begin{array}{r}5 \\
\text { rim } \\
\end{array}$ & $\begin{array}{r}6 \\
\text { core1 } \\
\end{array}$ & $\begin{array}{r}6 \\
\text { core2 } \\
\end{array}$ & $\begin{array}{r}6 \\
\text { rim } \\
\end{array}$ & $\begin{array}{r}7 \\
\text { core } \\
\end{array}$ & $\begin{array}{r}7 \\
O G \\
\end{array}$ & $\begin{array}{r}8 \\
N V Z \\
\end{array}$ & $\begin{array}{r}9 \\
\text { I band } \\
\end{array}$ & $\begin{array}{r}9 \\
\mathrm{~d} \text { band } \\
\end{array}$ & $\begin{array}{r}10 \\
\text { core } \\
\end{array}$ & $\begin{array}{r}10 \\
O G \\
\end{array}$ & $\begin{array}{r}10 \\
\text { rim } \\
\end{array}$ & $\begin{array}{r}11 \\
\text { core } \\
\end{array}$ \\
\hline \multicolumn{21}{|l|}{ Oxides (wt \%) } \\
\hline $\mathrm{SiO}_{2}$ & 44.56 & 46.84 & 46.19 & 46.08 & 50.60 & 46.80 & 44.11 & 45.90 & 46.84 & 45.82 & 50.37 & 44.78 & 46.07 & 43.45 & 46.01 & 46.94 & 46.81 & 46.39 & 48.18 & 46.68 \\
\hline $\mathrm{TiO}_{2}$ & 0.01 & 0.00 & 0.00 & 0.00 & 0.01 & 0.00 & 0.00 & 0.00 & 0.00 & 0.00 & 0.02 & 0.00 & 0.00 & 0.00 & 0.00 & 0.00 & 0.00 & 0.00 & 0.00 & 0.01 \\
\hline $\mathrm{Al}_{2} \mathrm{O}_{3}$ & 35.03 & 33.49 & 33.79 & 33.90 & 30.70 & 33.83 & 35.65 & 34.02 & 32.89 & 34.08 & 30.89 & 35.22 & 33.82 & 35.60 & 33.44 & 32.54 & 33.07 & 33.89 & 33.25 & 33.86 \\
\hline $\mathrm{Fe}_{2} \mathrm{O}_{3}$ & 0.95 & 0.71 & 0.71 & 0.77 & 0.57 & 0.63 & 0.76 & 0.75 & 0.69 & 0.74 & 0.69 & 0.83 & 0.69 & 0.68 & 0.67 & 0.60 & 0.70 & 0.75 & 0.63 & 0.74 \\
\hline MgO & 0.05 & 0.05 & 0.11 & 0.04 & 0.04 & 0.04 & 0.03 & 0.04 & 0.03 & 0.05 & 0.05 & 0.04 & 0.03 & 0.11 & 0.03 & 0.06 & 0.02 & 0.05 & 0.05 & 0.03 \\
\hline $\mathrm{CaO}$ & 19.07 & 16.94 & 17.63 & 17.88 & 14.24 & 17.47 & 19.63 & 17.91 & 17.13 & 17.91 & 14.48 & 19.08 & 17.68 & 19.74 & 17.23 & 16.32 & 17.24 & 17.69 & 16.29 & 17.54 \\
\hline $\mathrm{Na}_{2} \mathrm{O}$ & 0.83 & 1.92 & 1.54 & 1.44 & 3.22 & 1.65 & 0.56 & 1.46 & 1.80 & 1.46 & 3.12 & 0.81 & 1.50 & 0.48 & 1.72 & 2.18 & 1.73 & 1.57 & 2.17 & 1.58 \\
\hline $\mathrm{K}_{2} \mathrm{O}$ & 0.00 & 0.02 & 0.00 & 0.02 & 0.02 & 0.01 & 0.00 & 0.01 & 0.02 & 0.02 & 0.02 & 0.02 & 0.02 & 0.00 & 0.02 & 0.02 & 0.01 & 0.01 & 0.02 & 0.00 \\
\hline Total & 100.50 & 99.97 & 99.98 & 100.12 & 99.39 & 100.43 & 100.74 & 100.08 & 99.40 & 100.06 & 99.64 & 100.76 & 99.81 & 100.06 & 99.12 & 98.65 & 99.58 & 100.35 & 100.59 & 100.43 \\
\hline \multicolumn{21}{|l|}{ Cations } \\
\hline Si & 2.06 & 2.16 & 2.13 & 2.13 & 2.32 & 2.15 & 2.03 & 2.12 & 2.17 & 2.12 & 2.31 & 2.06 & 2.13 & 2.02 & 2.14 & 2.19 & 2.17 & 2.14 & 2.20 & 2.14 \\
\hline $\mathrm{Ti}$ & 0.000 & 0.000 & 0.000 & 0.000 & 0.000 & 0.000 & 0.000 & 0.000 & 0.000 & 0.000 & 0.001 & 0.000 & 0.000 & 0.000 & 0.000 & 0.000 & 0.000 & 0.000 & 0.000 & 0.000 \\
\hline Al & 1.91 & 1.82 & 1.84 & 1.84 & 1.66 & 1.83 & 1.94 & 1.85 & 1.80 & 1.86 & 1.67 & 1.91 & 1.84 & 1.95 & 1.83 & 1.79 & 1.80 & 1.84 & 1.79 & 1.83 \\
\hline Fe total & 0.033 & 0.025 & 0.025 & 0.027 & 0.020 & 0.022 & 0.026 & 0.026 & 0.024 & 0.026 & 0.024 & 0.029 & 0.024 & 0.024 & 0.024 & 0.021 & 0.024 & 0.026 & 0.022 & 0.026 \\
\hline Mn & 0.003 & 0.003 & 0.008 & 0.003 & 0.002 & 0.003 & 0.002 & 0.002 & 0.002 & 0.003 & 0.003 & 0.002 & 0.002 & 0.008 & 0.002 & 0.004 & 0.002 & 0.004 & 0.004 & 0.002 \\
\hline Mg & 0.94 & 0.84 & 0.87 & 0.88 & 0.70 & 0.86 & 0.97 & 0.89 & 0.85 & 0.89 & 0.71 & 0.94 & 0.88 & 0.98 & 0.86 & 0.82 & 0.86 & 0.87 & 0.80 & 0.86 \\
\hline $\mathrm{Ca}$ & 0.075 & 0.172 & 0.138 & 0.128 & 0.287 & 0.147 & 0.050 & 0.130 & 0.162 & 0.130 & 0.277 & 0.072 & 0.135 & 0.043 & 0.155 & 0.197 & 0.155 & 0.140 & 0.192 & 0.140 \\
\hline $\mathrm{Na}$ & 0.000 & 0.001 & 0.000 & 0.001 & 0.001 & 0.001 & 0.000 & 0.000 & 0.001 & 0.001 & 0.001 & 0.001 & 0.001 & 0.000 & 0.001 & 0.001 & 0.001 & 0.001 & 0.001 & 0.000 \\
\hline Total & 5.02 & 5.02 & 5.02 & 5.02 & 4.99 & 5.01 & 5.02 & 5.02 & 5.01 & 5.02 & 5.00 & 5.02 & 5.01 & 5.03 & 5.02 & 5.02 & 5.01 & 5.02 & 5.00 & 5.01 \\
\hline \multicolumn{21}{|l|}{ Atomic \% } \\
\hline$A b$ & 7.3 & 17.0 & 13.6 & 12.7 & 29.0 & 14.6 & 4.9 & 12.8 & 16.0 & 12.8 & 28.0 & 7.1 & 13.3 & 4.2 & 15.3 & 19.5 & 15.4 & 13.9 & 19.4 & 14.0 \\
\hline An & 92.7 & 82.9 & 86.4 & 87.2 & 70.8 & 85.3 & 95.1 & 87.1 & 83.9 & 87.1 & 71.9 & 92.8 & 86.6 & 95.8 & 84.6 & 80.4 & 84.6 & 86.1 & 80.5 & 86.0 \\
\hline Or & 0.0 & 0.1 & 0.0 & 0.1 & 0.1 & 0.1 & 0.0 & 0.0 & 0.1 & 0.1 & 0.1 & 0.1 & 0.1 & 0.0 & 0.1 & 0.1 & 0.1 & 0.1 & 0.1 & 0.0 \\
\hline
\end{tabular}




\begin{tabular}{|c|c|c|c|c|c|c|c|c|c|c|c|c|c|c|c|c|c|c|c|c|}
\hline $\begin{array}{l}\text { Sample } \\
\text { Location } \\
\text { Volcano } \\
\text { Type }\end{array}$ & & & & & & & & & & & & & & & & & & & & \\
\hline $\begin{array}{l}\text { Crystal no. } \\
\text { Analysis site }\end{array}$ & $\begin{array}{r}11 \\
\text { rim }\end{array}$ & $\begin{array}{r}12 \\
N V Z \\
\end{array}$ & $\begin{array}{r}13 \\
\text { core } \\
\end{array}$ & $\begin{array}{r}13 \\
\mathrm{~d} \text { band } \\
\end{array}$ & $\begin{array}{r}14 \\
N V Z \\
\end{array}$ & $\begin{array}{r}15 \\
\text { core } \\
\end{array}$ & $\begin{array}{r}15 \\
\mathrm{~d} \text { band } \\
\end{array}$ & $\begin{array}{r}15 \\
\text { rim } \\
\end{array}$ & $\begin{array}{r}16 \\
\text { core } \\
\end{array}$ & $\begin{array}{r}16 \\
\mathrm{~d} \text { band } \\
\end{array}$ & $\begin{array}{r}16 \\
\mathrm{~d} \text { band } \\
\end{array}$ & $\begin{array}{r}16 \\
\mathrm{~d} \text { band } \\
\end{array}$ & $\begin{array}{r}16 \\
\text { rim } \\
\end{array}$ & $\begin{array}{r}17 \\
\text { core } \\
\end{array}$ & $\begin{array}{r}17 \\
\mathrm{~d} \text { band } \\
\end{array}$ & $\begin{array}{r}17 \\
\text { rim } \\
\end{array}$ & $\begin{array}{r}18 \\
\text { core } \\
\end{array}$ & $\begin{array}{r}18 \\
\text { rim } \\
\end{array}$ & $\begin{array}{r}19 \\
\text { core } \\
\end{array}$ & $\begin{array}{r}19 \\
\mathrm{~d} \text { band } \\
\end{array}$ \\
\hline \multicolumn{21}{|l|}{ Oxides (wt \%) } \\
\hline $\mathrm{SiO}_{2}$ & 50.67 & 43.37 & 45.96 & 49.10 & 44.56 & 47.18 & 50.36 & 47.78 & 47.57 & 50.94 & 51.26 & 51.66 & 47.60 & 46.85 & 46.99 & 47.18 & 46.37 & 47.58 & 46.87 & 51.92 \\
\hline $\mathrm{TiO}_{2}$ & 0.00 & 0.01 & 0.00 & 0.00 & 0.00 & 0.00 & 0.01 & 0.01 & 0.00 & 0.00 & 0.00 & 0.01 & 0.00 & 0.00 & 0.00 & 0.01 & 0.00 & 0.01 & 0.01 & 0.00 \\
\hline $\mathrm{Al}_{2} \mathrm{O}_{3}$ & 31.12 & 36.03 & 33.30 & 31.05 & 34.94 & 33.17 & 31.11 & 32.99 & 32.97 & 30.69 & 30.58 & 30.47 & 33.10 & 33.57 & 32.80 & 33.17 & 33.67 & 32.67 & 33.21 & 30.07 \\
\hline $\mathrm{Fe}_{2} \mathrm{O}_{3}$ & 0.65 & 0.54 & 0.69 & 0.70 & 0.92 & 0.74 & 0.67 & 0.62 & 0.58 & 0.63 & 0.62 & 0.56 & 0.65 & 0.60 & 0.75 & 0.67 & 0.69 & 0.57 & 0.65 & 0.59 \\
\hline MgO & 0.04 & 0.09 & 0.02 & 0.04 & 0.08 & 0.04 & 0.03 & 0.05 & 0.03 & 0.03 & 0.03 & 0.03 & 0.06 & 0.04 & 0.03 & 0.04 & 0.05 & 0.04 & 0.05 & 0.03 \\
\hline $\mathrm{CaO}$ & 14.48 & 20.25 & 17.65 & 15.20 & 19.23 & 17.12 & 14.54 & 16.46 & 16.51 & 14.06 & 13.92 & 13.61 & 16.69 & 17.30 & 16.79 & 16.65 & 17.43 & 16.54 & 17.17 & 13.30 \\
\hline $\mathrm{Na}_{2} \mathrm{O}$ & 3.18 & 0.32 & 1.57 & 2.74 & 0.85 & 1.88 & 3.10 & 2.17 & 2.13 & 3.31 & 3.37 & 3.58 & 1.99 & 1.78 & 2.07 & 2.05 & 1.68 & 2.02 & 1.84 & 3.72 \\
\hline $\mathrm{K}_{2} \mathrm{O}$ & 0.03 & 0.00 & 0.00 & 0.02 & 0.00 & 0.02 & 0.03 & 0.02 & 0.01 & 0.02 & 0.04 & 0.03 & 0.01 & 0.00 & 0.01 & 0.01 & 0.01 & 0.02 & 0.01 & 0.02 \\
\hline Total & 100.17 & 100.59 & 99.20 & 98.85 & 100.59 & 100.15 & 99.87 & 100.09 & 99.79 & 99.68 & 99.82 & 99.94 & 100.10 & 100.14 & 99.44 & 99.77 & 99.90 & 99.44 & 99.81 & 99.66 \\
\hline \multicolumn{21}{|l|}{ Cations } \\
\hline Si & 2.31 & 2.01 & 2.14 & 2.28 & 2.06 & 2.17 & 2.30 & 2.19 & 2.19 & 2.33 & 2.34 & 2.35 & 2.19 & 2.16 & 2.18 & 2.18 & 2.14 & 2.20 & 2.16 & 2.37 \\
\hline $\mathrm{Ti}$ & 0.000 & 0.000 & 0.000 & 0.000 & 0.000 & 0.000 & 0.000 & 0.000 & 0.000 & 0.000 & 0.000 & 0.000 & 0.000 & 0.000 & 0.000 & 0.000 & 0.000 & 0.000 & 0.000 & 0.000 \\
\hline Al & 1.67 & 1.96 & 1.83 & 1.70 & 1.90 & 1.80 & 1.68 & 1.79 & 1.79 & 1.65 & 1.64 & 1.63 & 1.79 & 1.82 & 1.79 & 1.80 & 1.83 & 1.78 & 1.81 & 1.62 \\
\hline Fe total & 0.022 & 0.019 & 0.024 & 0.024 & 0.032 & 0.026 & 0.023 & 0.021 & 0.020 & 0.022 & 0.021 & 0.019 & 0.023 & 0.021 & 0.026 & 0.023 & 0.024 & 0.020 & 0.022 & 0.020 \\
\hline Mn & 0.003 & 0.006 & 0.002 & 0.003 & 0.006 & 0.003 & 0.002 & 0.004 & 0.002 & 0.002 & 0.002 & 0.002 & 0.004 & 0.002 & 0.002 & 0.003 & 0.003 & 0.003 & 0.003 & 0.002 \\
\hline Mg & 0.71 & 1.00 & 0.88 & 0.75 & 0.95 & 0.84 & 0.71 & 0.81 & 0.81 & 0.69 & 0.68 & 0.66 & 0.82 & 0.85 & 0.83 & 0.82 & 0.86 & 0.82 & 0.85 & 0.65 \\
\hline $\mathrm{Ca}$ & 0.281 & 0.029 & 0.142 & 0.246 & 0.077 & 0.168 & 0.275 & 0.193 & 0.190 & 0.293 & 0.298 & 0.316 & 0.177 & 0.159 & 0.186 & 0.183 & 0.150 & 0.181 & 0.165 & 0.329 \\
\hline $\mathrm{Na}$ & 0.001 & 0.000 & 0.000 & 0.001 & 0.000 & 0.001 & 0.002 & 0.001 & 0.001 & 0.001 & 0.002 & 0.002 & 0.001 & 0.000 & 0.001 & 0.001 & 0.001 & 0.001 & 0.001 & 0.001 \\
\hline Total & 5.00 & 5.03 & 5.02 & 5.00 & 5.03 & 5.01 & 5.00 & 5.01 & 5.01 & 4.99 & 4.99 & 4.99 & 5.01 & 5.01 & 5.02 & 5.01 & 5.02 & 5.00 & 5.01 & 4.99 \\
\hline \multicolumn{21}{|l|}{ Atomic \% } \\
\hline$A b$ & 28.4 & 2.8 & 13.9 & 24.6 & 7.4 & 16.6 & 27.8 & 19.3 & 18.9 & 29.8 & 30.4 & 32.2 & 17.7 & 15.7 & 18.2 & 18.2 & 14.8 & 18.1 & 16.2 & 33.5 \\
\hline An & 71.4 & 97.2 & 86.1 & 75.3 & 92.6 & 83.4 & 72.0 & 80.6 & 81.0 & 70.0 & 69.4 & 67.6 & 82.2 & 84.3 & 81.7 & 81.8 & 85.1 & 81.8 & 83.7 & 66.3 \\
\hline Or & 0.1 & 0.0 & 0.0 & 0.1 & 0.0 & 0.1 & 0.2 & 0.1 & 0.1 & 0.1 & 0.2 & 0.2 & 0.1 & 0.0 & 0.1 & 0.1 & 0.1 & 0.1 & 0.1 & 0.1 \\
\hline
\end{tabular}




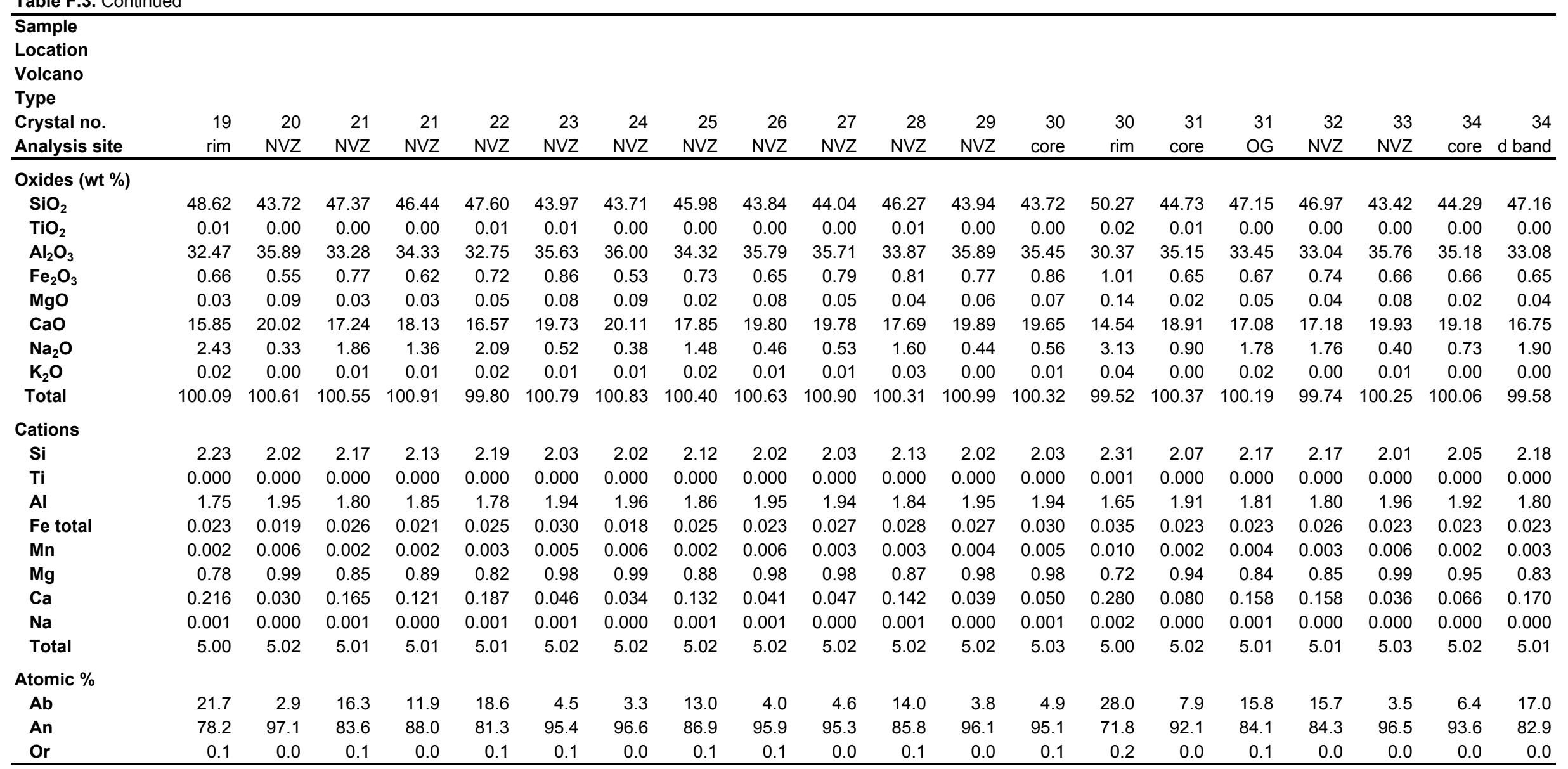


Table F.3. Continued

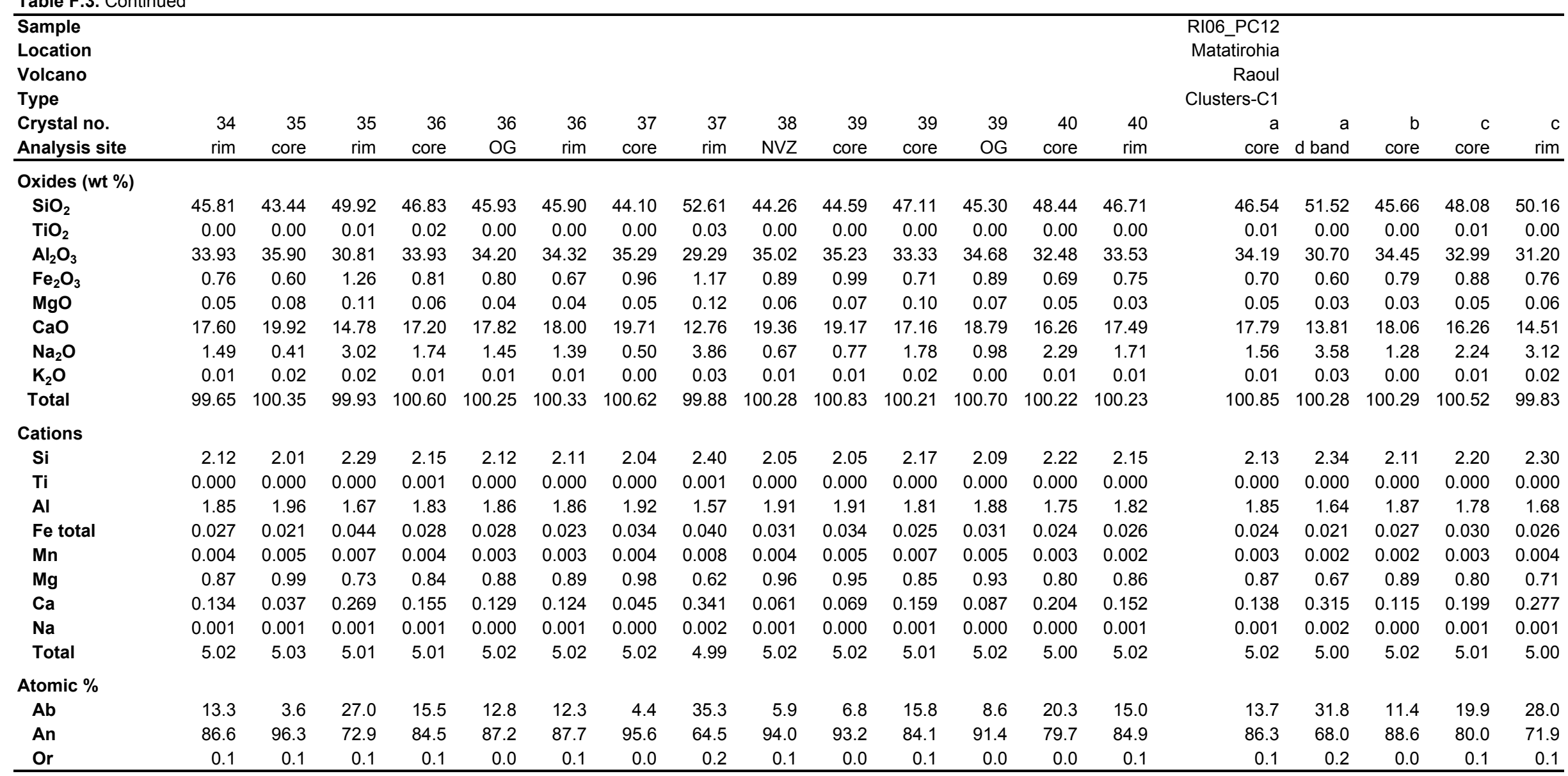


Table F.3. Continued

\begin{tabular}{|c|c|c|c|c|c|c|c|c|c|c|c|c|c|c|c|c|c|c|c|c|}
\hline \multicolumn{21}{|l|}{$\begin{array}{l}\text { Sample } \\
\text { Location }\end{array}$} \\
\hline \multicolumn{21}{|l|}{ Volcano } \\
\hline Type & $\mathrm{C} 2$ & & & C3 & & & $\mathrm{C} 4$ & & $\mathrm{C} 5$ & & $\mathrm{C} 6$ & & & $\mathrm{C} 7$ & & & $\mathrm{C} 8$ & & & \\
\hline $\begin{array}{l}\text { Crystal no. } \\
\text { Analysis site }\end{array}$ & $\begin{array}{r}a \\
\text { core } \\
\end{array}$ & $\begin{array}{r}a \\
\text { core }\end{array}$ & $\begin{array}{r}b \\
\text { core }\end{array}$ & $\begin{array}{r}a \\
N V Z \\
\end{array}$ & $\begin{array}{r}b \\
N V Z\end{array}$ & $\begin{array}{r}c \\
N V Z \\
\end{array}$ & $\begin{array}{r}a \\
N V Z \\
\end{array}$ & $\begin{array}{r}b \\
N V Z \\
\end{array}$ & $\begin{array}{r}a \\
N V Z \\
\end{array}$ & $\begin{array}{r}a \\
N V Z \\
\end{array}$ & $\begin{array}{r}a \\
\text { core }\end{array}$ & $\begin{array}{r}a \\
\operatorname{rim} 1\end{array}$ & $\begin{array}{r}a \\
\operatorname{rim} 2 \\
\end{array}$ & $\begin{array}{r}a \\
\text { core }\end{array}$ & $\begin{array}{r}a \\
\mathrm{~d} \text { band }\end{array}$ & $\begin{array}{r}a \\
\text { rim }\end{array}$ & $\begin{array}{r}a \\
\text { core } \\
\end{array}$ & $\begin{array}{r}a \\
\mathrm{~d} \text { band }\end{array}$ & $\begin{array}{r}a \\
\mathrm{~d} \text { band }\end{array}$ & $\begin{array}{r}a \\
\mathrm{rim}\end{array}$ \\
\hline \multicolumn{21}{|l|}{ Oxides (wt \%) } \\
\hline $\mathrm{SiO}_{2}$ & 46.02 & 46.41 & 46.01 & 49.00 & 46.77 & 47.36 & 46.20 & 48.04 & 47.77 & 47.52 & 44.84 & 49.76 & 51.53 & 48.01 & 52.55 & 46.08 & 47.60 & 50.68 & 50.95 & 48.75 \\
\hline $\mathrm{TiO}_{2}$ & 0.03 & 0.00 & 0.00 & 0.01 & 0.01 & 0.00 & 0.00 & 0.00 & 0.01 & 0.01 & 0.00 & 0.00 & 0.01 & 0.00 & 0.01 & 0.00 & 0.00 & 0.01 & 0.01 & 0.00 \\
\hline $\mathrm{Al}_{2} \mathrm{O}_{3}$ & 34.36 & 34.12 & 34.23 & 32.08 & 33.72 & 33.45 & 34.32 & 32.56 & 33.06 & 33.20 & 34.90 & 31.29 & 30.25 & 33.52 & 30.49 & 34.29 & 33.34 & 31.87 & 31.10 & 33.09 \\
\hline $\mathrm{Fe}_{2} \mathrm{O}_{3}$ & 1.58 & 0.80 & 0.84 & 0.74 & 0.75 & 0.73 & 0.69 & 0.87 & 0.68 & 0.65 & 0.83 & 1.14 & 1.32 & 0.62 & 0.64 & 1.16 & 0.91 & 0.78 & 0.69 & 0.76 \\
\hline $\mathrm{MgO}$ & 0.05 & 0.04 & 0.05 & 0.06 & 0.05 & 0.03 & 0.04 & 0.03 & 0.06 & 0.04 & 0.14 & 0.14 & 0.11 & 0.04 & 0.04 & 0.11 & 0.09 & 0.03 & 0.05 & 0.05 \\
\hline $\mathrm{CaO}$ & 18.04 & 17.77 & 17.79 & 15.33 & 17.26 & 16.82 & 17.87 & 16.72 & 16.60 & 16.63 & 18.98 & 15.01 & 13.76 & 16.77 & 13.11 & 18.09 & 16.97 & 14.64 & 14.06 & 16.08 \\
\hline $\mathrm{Na}_{2} \mathrm{O}$ & 1.39 & 1.50 & 1.47 & 2.69 & 1.83 & 2.05 & 1.50 & 2.17 & 2.04 & 2.13 & 0.95 & 2.80 & 3.55 & 2.17 & 3.93 & 1.39 & 1.93 & 3.13 & 3.38 & 2.32 \\
\hline $\mathrm{K}_{2} \mathrm{O}$ & 0.00 & 0.01 & 0.02 & 0.03 & 0.01 & 0.02 & 0.01 & 0.01 & 0.01 & 0.02 & 0.01 & 0.03 & 0.04 & 0.00 & 0.02 & 0.03 & 0.01 & 0.02 & 0.03 & 0.02 \\
\hline Total & 101.49 & 100.64 & 100.40 & 99.94 & 100.39 & 100.46 & 100.64 & 100.40 & 100.23 & 100.20 & 100.64 & 100.16 & 100.57 & 101.14 & 100.80 & 101.14 & 100.84 & 101.15 & 100.26 & 101.09 \\
\hline \multicolumn{21}{|l|}{ Cations } \\
\hline Si & 2.11 & 2.13 & 2.12 & 2.25 & 2.15 & 2.17 & 2.12 & 2.20 & 2.19 & 2.18 & 2.07 & 2.28 & 2.34 & 2.18 & 2.37 & 2.11 & 2.18 & 2.29 & 2.32 & 2.21 \\
\hline $\mathrm{Ti}$ & 0.001 & 0.000 & 0.000 & 0.000 & 0.000 & 0.000 & 0.000 & 0.000 & 0.000 & 0.000 & 0.000 & 0.000 & 0.000 & 0.000 & 0.000 & 0.000 & 0.000 & 0.000 & 0.000 & 0.000 \\
\hline Al & 1.85 & 1.85 & 1.86 & 1.73 & 1.83 & 1.81 & 1.86 & 1.76 & 1.79 & 1.80 & 1.90 & 1.69 & 1.62 & 1.80 & 1.62 & 1.85 & 1.80 & 1.70 & 1.67 & 1.77 \\
\hline Fe total & 0.054 & 0.028 & 0.029 & 0.026 & 0.026 & 0.025 & 0.024 & 0.030 & 0.023 & 0.023 & 0.029 & 0.039 & 0.045 & 0.021 & 0.022 & 0.040 & 0.031 & 0.026 & 0.024 & 0.026 \\
\hline Mn & 0.004 & 0.002 & 0.003 & 0.004 & 0.003 & 0.002 & 0.003 & 0.002 & 0.004 & 0.003 & 0.010 & 0.009 & 0.008 & 0.003 & 0.002 & 0.008 & 0.006 & 0.002 & 0.003 & 0.004 \\
\hline $\mathrm{Mg}$ & 0.88 & 0.87 & 0.88 & 0.75 & 0.85 & 0.83 & 0.88 & 0.82 & 0.82 & 0.82 & 0.94 & 0.74 & 0.67 & 0.82 & 0.63 & 0.89 & 0.83 & 0.71 & 0.69 & 0.78 \\
\hline $\mathrm{Ca}$ & 0.124 & 0.133 & 0.131 & 0.239 & 0.163 & 0.182 & 0.134 & 0.193 & 0.181 & 0.189 & 0.085 & 0.249 & 0.313 & 0.191 & 0.344 & 0.124 & 0.171 & 0.274 & 0.298 & 0.204 \\
\hline $\mathrm{Na}$ & 0.000 & 0.001 & 0.001 & 0.002 & 0.000 & 0.001 & 0.001 & 0.001 & 0.001 & 0.001 & 0.001 & 0.001 & 0.002 & 0.000 & 0.001 & 0.002 & 0.001 & 0.001 & 0.002 & 0.001 \\
\hline Total & 5.03 & 5.01 & 5.02 & 5.01 & 5.02 & 5.02 & 5.02 & 5.01 & 5.01 & 5.01 & 5.03 & 5.00 & 5.00 & 5.01 & 4.99 & 5.02 & 5.01 & 5.00 & 5.00 & 5.00 \\
\hline \multicolumn{21}{|l|}{ Atomic \% } \\
\hline$A b$ & 12.3 & 13.2 & 13.0 & 24.1 & 16.1 & 18.1 & 13.2 & 19.0 & 18.2 & 18.8 & 8.3 & 25.2 & 31.8 & 19.0 & 35.1 & 12.2 & 17.0 & 27.9 & 30.3 & 20.7 \\
\hline An & 87.7 & 86.7 & 86.9 & 75.8 & 83.9 & 81.8 & 86.8 & 80.9 & 81.7 & 81.1 & 91.6 & 74.6 & 68.0 & 81.0 & 64.7 & 87.7 & 82.9 & 72.0 & 69.6 & 79.2 \\
\hline Or & 0.0 & 0.1 & 0.1 & 0.2 & 0.0 & 0.1 & 0.1 & 0.1 & 0.1 & 0.1 & 0.1 & 0.1 & 0.2 & 0.0 & 0.1 & 0.2 & 0.1 & 0.1 & 0.2 & 0.1 \\
\hline
\end{tabular}


Table F.3. Continued

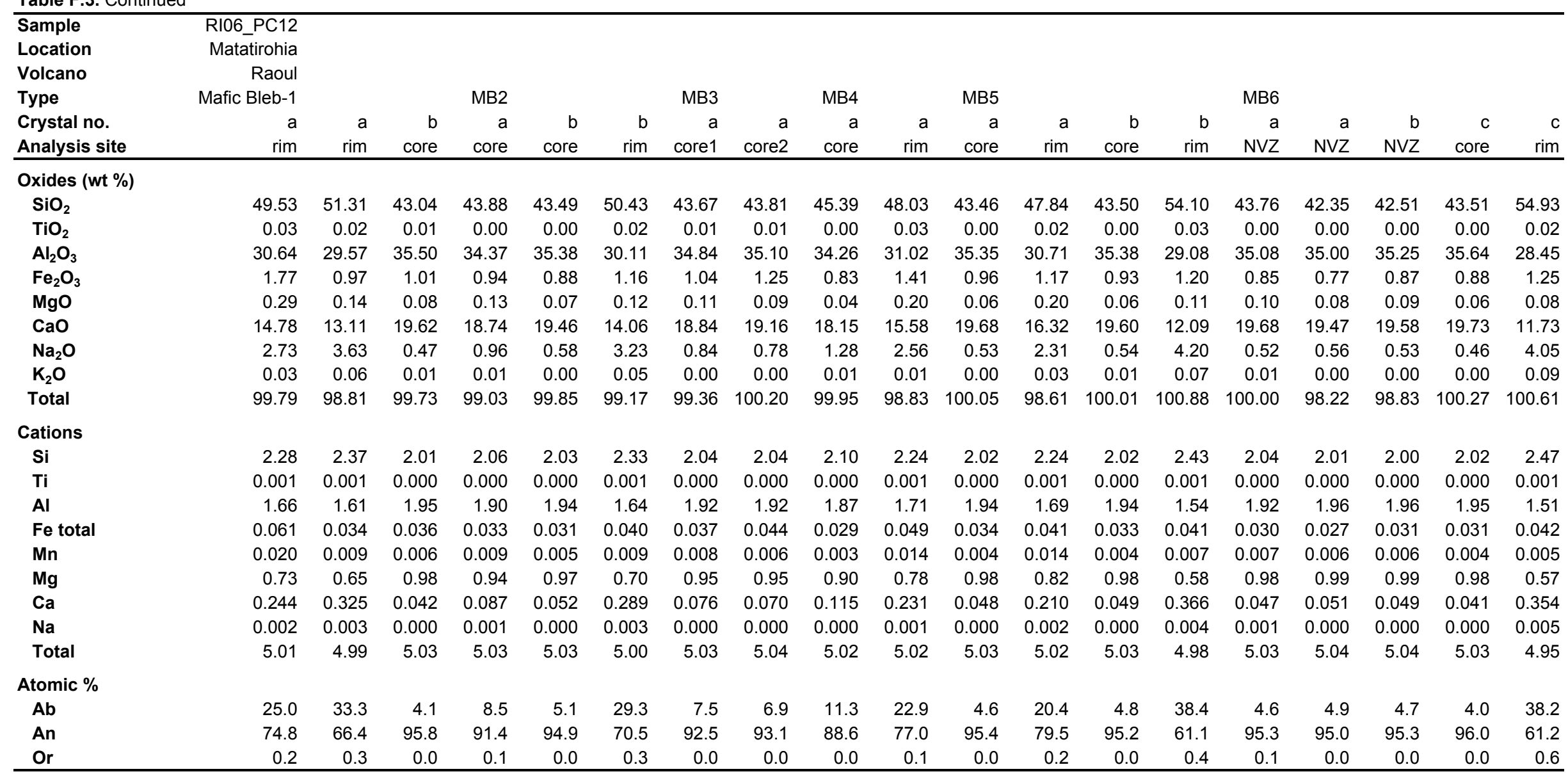


Table F.3. Continued

\begin{tabular}{|c|c|c|c|c|c|c|c|c|c|c|c|c|c|c|c|c|c|c|c|c|}
\hline \multicolumn{21}{|l|}{$\begin{array}{l}\text { Sample } \\
\text { Location } \\
\text { Volcano }\end{array}$} \\
\hline Type & & MB7 & MB8 & & & & MB9 & MB10 & & MB11 & & & MB12 & & MB13 & & & & & \\
\hline $\begin{array}{l}\text { Crystal no. } \\
\text { Analysis site } \\
\end{array}$ & $\begin{array}{r}d \\
N V Z \\
\end{array}$ & $\begin{array}{r}a \\
\text { core } \\
\end{array}$ & $\begin{array}{r}a \\
N V Z \\
\end{array}$ & $\begin{array}{r}\text { a } \\
\text { rim } \\
\end{array}$ & $\begin{array}{r}a \\
N V Z \\
\end{array}$ & $\begin{array}{r}\mathrm{b} \\
\mathrm{NVZ} \\
\end{array}$ & $\begin{array}{r}a \\
N V Z \\
\end{array}$ & $\begin{array}{r}a \\
N V Z \\
\end{array}$ & $\begin{array}{r}a \\
\text { rim } \\
\end{array}$ & $\begin{array}{r}a \\
N V Z \\
\end{array}$ & $\begin{array}{r}b \\
N V Z \\
\end{array}$ & $\begin{array}{r}c \\
N V Z \\
\end{array}$ & $\begin{array}{r}a \\
N V Z \\
\end{array}$ & $\begin{array}{r}a \\
N V Z \\
\end{array}$ & $\begin{array}{r}a \\
N V Z \\
\end{array}$ & $\begin{array}{r}\mathrm{b} \\
\mathrm{NVZ} \\
\end{array}$ & $\begin{array}{r}c \\
\text { core } \\
\end{array}$ & $\begin{array}{r}\mathrm{c} \\
\mathrm{rim} \\
\end{array}$ & $\begin{array}{r}\mathrm{c} \\
\operatorname{rim} 2 \\
\end{array}$ & $\begin{array}{r}c \\
\operatorname{rim} 3 \\
\end{array}$ \\
\hline \multicolumn{21}{|l|}{ Oxides (wt \%) } \\
\hline $\mathrm{SiO}_{2}$ & 54.33 & 43.46 & 43.87 & 44.21 & 43.96 & 45.68 & 43.40 & 43.66 & 51.17 & 43.93 & 43.57 & 49.26 & 43.67 & 43.46 & 43.91 & 46.07 & 43.88 & 48.78 & 48.63 & 49.10 \\
\hline $\mathrm{TiO}_{2}$ & 0.03 & 0.01 & 0.01 & 0.00 & 0.00 & 0.00 & 0.00 & 0.00 & 0.04 & 0.01 & 0.00 & 0.00 & 0.00 & 0.00 & 0.00 & 0.00 & 0.00 & 0.00 & 0.01 & 0.02 \\
\hline $\mathrm{Al}_{2} \mathrm{O}_{3}$ & 28.03 & 35.92 & 35.06 & 33.85 & 35.21 & 33.47 & 34.81 & 34.88 & 30.03 & 35.04 & 35.07 & 30.70 & 35.50 & 35.39 & 35.25 & 33.70 & 35.10 & 31.45 & 31.37 & 31.59 \\
\hline $\mathrm{Fe}_{2} \mathrm{O}_{3}$ & 1.23 & 0.69 & 0.89 & 0.92 & 0.87 & 1.09 & 0.82 & 1.03 & 1.22 & 1.03 & 1.21 & 2.02 & 0.74 & 0.73 & 0.81 & 0.68 & 0.98 & 1.73 & 1.63 & 1.13 \\
\hline MgO & 0.10 & 0.07 & 0.09 & 0.13 & 0.06 & 0.12 & 0.06 & 0.07 & 0.13 & 0.08 & 0.09 & 0.23 & 0.09 & 0.07 & 0.07 & 0.02 & 0.06 & 0.19 & 0.16 & 0.14 \\
\hline $\mathrm{CaO}$ & 11.53 & 20.06 & 19.18 & 19.37 & 19.36 & 17.92 & 19.43 & 19.42 & 13.84 & 19.43 & 19.40 & 15.46 & 19.74 & 19.75 & 19.40 & 17.46 & 19.15 & 15.59 & 15.54 & 15.17 \\
\hline $\mathrm{Na}_{2} \mathrm{O}$ & 4.47 & 0.37 & 0.63 & 0.69 & 0.57 & 1.45 & 0.50 & 0.53 & 3.36 & 0.59 & 0.52 & 2.49 & 0.46 & 0.42 & 0.55 & 1.63 & 0.64 & 2.47 & 2.39 & 2.56 \\
\hline $\mathrm{K}_{2} \mathrm{O}$ & 0.07 & 0.00 & 0.00 & 0.01 & 0.01 & 0.01 & 0.00 & 0.01 & 0.06 & 0.00 & 0.01 & 0.05 & 0.01 & 0.00 & 0.00 & 0.00 & 0.01 & 0.04 & 0.03 & 0.05 \\
\hline Total & 99.79 & 100.57 & 99.73 & 99.18 & 100.03 & 99.73 & 99.03 & 99.59 & 99.85 & 100.10 & 99.87 & 100.21 & 100.19 & 99.82 & 100.00 & 99.56 & 99.81 & 100.25 & 99.77 & 99.76 \\
\hline \multicolumn{21}{|l|}{ Cations } \\
\hline $\mathrm{Si}$ & 2.47 & 2.01 & 2.04 & 2.07 & 2.04 & 2.12 & 2.04 & 2.04 & 2.34 & 2.04 & 2.03 & 2.27 & 2.03 & 2.02 & 2.04 & 2.14 & 2.04 & 2.24 & 2.25 & 2.26 \\
\hline $\mathrm{Ti}$ & 0.001 & 0.000 & 0.000 & 0.000 & 0.000 & 0.000 & 0.000 & 0.000 & 0.001 & 0.000 & 0.000 & 0.000 & 0.000 & 0.000 & 0.000 & 0.000 & 0.000 & 0.000 & 0.000 & 0.001 \\
\hline Al & 1.50 & 1.96 & 1.93 & 1.87 & 1.93 & 1.83 & 1.93 & 1.92 & 1.62 & 1.92 & 1.93 & 1.67 & 1.94 & 1.94 & 1.93 & 1.84 & 1.93 & 1.71 & 1.71 & 1.71 \\
\hline Fe total & 0.042 & 0.024 & 0.031 & 0.032 & 0.030 & 0.038 & 0.029 & 0.036 & 0.042 & 0.036 & 0.042 & 0.070 & 0.026 & 0.026 & 0.028 & 0.024 & 0.034 & 0.060 & 0.057 & 0.039 \\
\hline Mn & 0.007 & 0.005 & 0.006 & 0.009 & 0.004 & 0.009 & 0.004 & 0.005 & 0.009 & 0.005 & 0.006 & 0.016 & 0.006 & 0.005 & 0.005 & 0.001 & 0.004 & 0.013 & 0.011 & 0.010 \\
\hline Mg & 0.56 & 0.99 & 0.96 & 0.97 & 0.96 & 0.89 & 0.98 & 0.97 & 0.68 & 0.97 & 0.97 & 0.76 & 0.98 & 0.99 & 0.97 & 0.87 & 0.96 & 0.77 & 0.77 & 0.75 \\
\hline $\mathrm{Ca}$ & 0.394 & 0.033 & 0.057 & 0.063 & 0.052 & 0.130 & 0.046 & 0.048 & 0.298 & 0.053 & 0.047 & 0.222 & 0.041 & 0.038 & 0.050 & 0.146 & 0.058 & 0.220 & 0.214 & 0.228 \\
\hline $\mathrm{Na}$ & 0.004 & 0.000 & 0.000 & 0.001 & 0.000 & 0.001 & 0.000 & 0.001 & 0.003 & 0.000 & 0.000 & 0.003 & 0.000 & 0.000 & 0.000 & 0.000 & 0.000 & 0.002 & 0.002 & 0.003 \\
\hline Total & 4.98 & 5.03 & 5.02 & 5.02 & 5.02 & 5.03 & 5.02 & 5.02 & 5.00 & 5.02 & 5.03 & 5.01 & 5.02 & 5.02 & 5.02 & 5.02 & 5.02 & 5.01 & 5.01 & 5.00 \\
\hline \multicolumn{21}{|l|}{ Atomic \% } \\
\hline$A b$ & 41.1 & 3.2 & 5.6 & 6.0 & 5.1 & 12.7 & 4.5 & 4.7 & 30.4 & 5.2 & 4.6 & 22.5 & 4.0 & 3.7 & 4.9 & 14.4 & 5.7 & 22.2 & 21.7 & 23.3 \\
\hline An & 58.5 & 96.8 & 94.4 & 93.9 & 94.9 & 87.2 & 95.5 & 95.3 & 69.2 & 94.8 & 95.4 & 77.2 & 95.9 & 96.3 & 95.1 & 85.5 & 94.3 & 77.5 & 78.1 & 76.4 \\
\hline Or & 0.4 & 0.0 & 0.0 & 0.1 & 0.0 & 0.1 & 0.0 & 0.1 & 0.3 & 0.0 & 0.0 & 0.3 & 0.0 & 0.0 & 0.0 & 0.0 & 0.0 & 0.2 & 0.2 & 0.3 \\
\hline
\end{tabular}


Table F.3. Continued

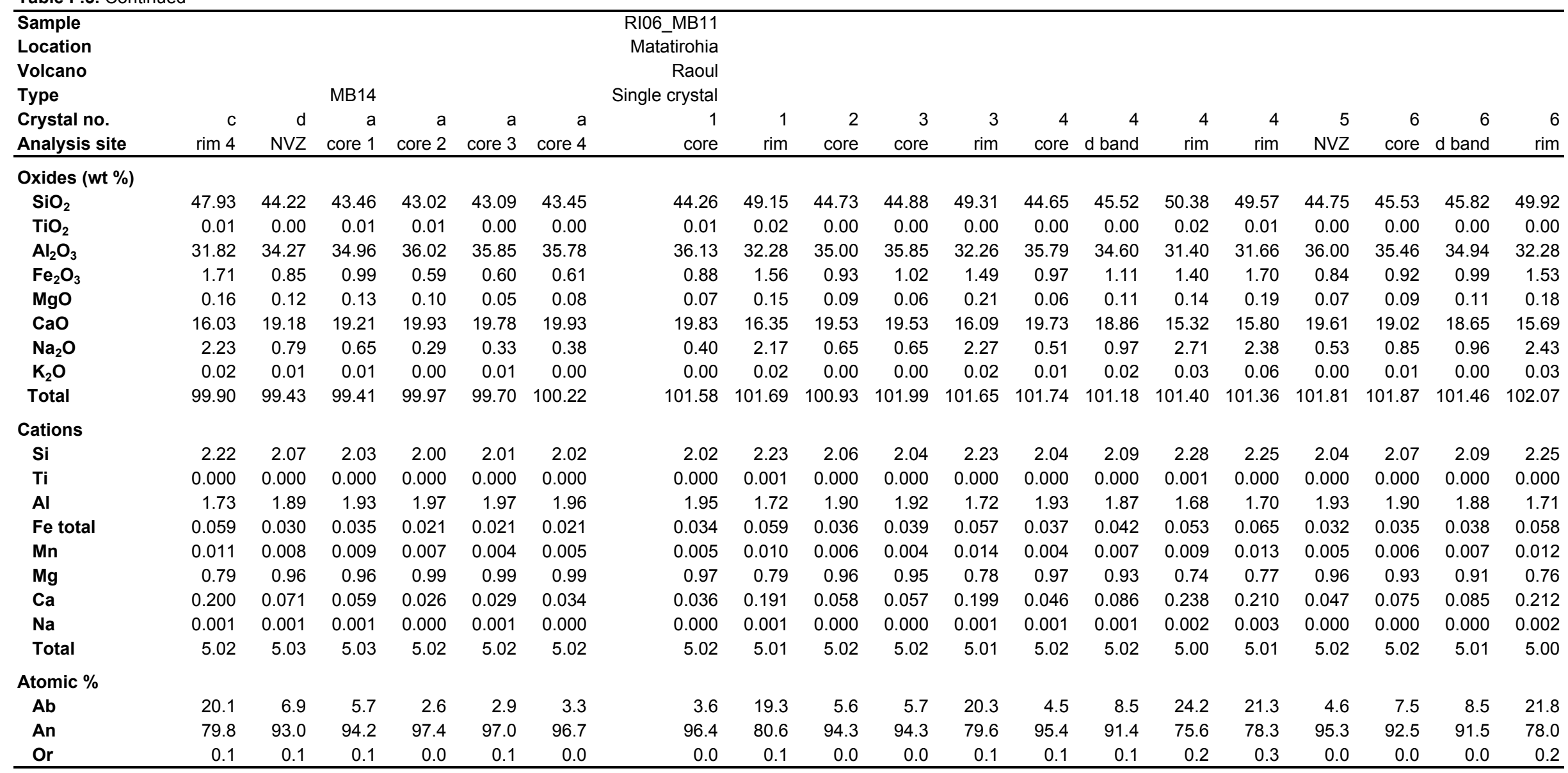


Table F.3. Continued

\begin{tabular}{|c|c|c|c|c|c|c|c|c|c|c|c|c|c|c|c|c|c|c|c|}
\hline $\begin{array}{l}\text { Sample } \\
\text { Location } \\
\text { Volcano } \\
\text { Type }\end{array}$ & & & & & & & & $\begin{array}{r}\text { RI06_R01 } \\
\text { Matatirohia } \\
\text { Raoul } \\
\text { Single crystal }\end{array}$ & & & & & & & & & & & \\
\hline $\begin{array}{l}\text { Crystal no. } \\
\text { Analysis site }\end{array}$ & $\begin{array}{r}7 \\
\text { core } \\
\end{array}$ & $\begin{array}{r}7 \\
\mathrm{~d} \text { band } \\
\end{array}$ & $\begin{array}{r}7 \\
\text { rim } \\
\end{array}$ & $\begin{array}{r}8 \\
N V Z \\
\end{array}$ & $\begin{array}{r}9 \\
\text { core } \\
\end{array}$ & $\begin{array}{r}9 \\
\text { rim } \\
\end{array}$ & $\begin{array}{r}10 \\
N V Z \\
\end{array}$ & $\begin{array}{r}1 \\
\text { core } \\
\end{array}$ & $\begin{array}{r}1 \\
\text { rim } \\
\end{array}$ & $\begin{array}{r}2 \\
\text { core } \\
\end{array}$ & $\begin{array}{r}2 \\
\mathrm{rim} \\
\end{array}$ & $\begin{array}{r}3 \\
\text { core } \\
\end{array}$ & $\begin{array}{r}3 \\
\mathrm{~d} \text { band } \\
\end{array}$ & $\begin{array}{r}3 \\
\text { I band } \\
\end{array}$ & $\begin{array}{r}3 \\
\text { rim } \\
\end{array}$ & $\begin{array}{r}4 \\
\text { core } \\
\end{array}$ & $\begin{array}{r}4 \\
\text { rim } \\
\end{array}$ & $\begin{array}{r}5 \\
\text { core } \\
\end{array}$ & $\begin{array}{r}5 \\
\mathrm{~d} \text { band } \\
\end{array}$ \\
\hline \multicolumn{20}{|l|}{ Oxides (wt \%) } \\
\hline $\mathrm{SiO}_{2}$ & 45.03 & 45.76 & 50.99 & 44.44 & 43.53 & 49.13 & 45.22 & 55.66 & 63.37 & 57.68 & 64.28 & 57.43 & 57.34 & 61.83 & 63.70 & 55.55 & 65.12 & 55.83 & 55.61 \\
\hline $\mathrm{TiO}_{2}$ & 0.01 & 0.00 & 0.02 & 0.00 & 0.00 & 0.01 & 0.00 & 0.01 & 0.00 & 0.00 & 0.02 & 0.03 & 0.01 & 0.00 & 0.00 & 0.00 & 0.00 & 0.00 & 0.01 \\
\hline $\mathrm{Al}_{2} \mathrm{O}_{3}$ & 35.69 & 35.29 & 31.36 & 36.33 & 36.29 & 31.72 & 35.54 & 28.64 & 23.73 & 27.32 & 22.17 & 27.56 & 27.92 & 25.17 & 25.00 & 28.98 & 22.59 & 28.54 & 28.46 \\
\hline $\mathrm{Fe}_{2} \mathrm{O}_{3}$ & 0.91 & 1.06 & 1.58 & 0.83 & 0.90 & 1.56 & 0.96 & 0.45 & 0.19 & 0.49 & 0.32 & 0.44 & 0.47 & 0.30 & 0.06 & 0.46 & 0.27 & 0.54 & 0.40 \\
\hline MgO & 0.09 & 0.11 & 0.20 & 0.07 & 0.07 & 0.18 & 0.08 & 0.01 & 0.05 & 0.01 & 0.00 & 0.00 & 0.00 & 0.02 & 0.00 & 0.00 & 0.01 & 0.04 & 0.03 \\
\hline $\mathrm{CaO}$ & 19.14 & 18.78 & 14.96 & 19.65 & 19.45 & 15.31 & 19.16 & 10.67 & 4.49 & 9.14 & 3.00 & 9.24 & 9.56 & 5.80 & 4.64 & 10.70 & 2.97 & 10.48 & 10.48 \\
\hline $\mathrm{Na}_{2} \mathrm{O}$ & 0.72 & 0.94 & 2.80 & 0.51 & 0.45 & 2.43 & 0.78 & 4.97 & 7.90 & 5.86 & 8.69 & 5.68 & 5.71 & 7.53 & 8.15 & 4.97 & 8.88 & 5.29 & 5.13 \\
\hline $\mathrm{K}_{2} \mathrm{O}$ & 0.01 & 0.01 & 0.04 & 0.00 & 0.01 & 0.04 & 0.00 & 0.13 & 0.38 & 0.10 & 0.68 & 0.10 & 0.10 & 0.31 & 0.52 & 0.11 & 0.55 & 0.13 & 0.08 \\
\hline Total & 101.61 & 101.94 & 101.96 & 101.83 & 100.71 & 100.39 & 101.74 & 100.53 & 100.11 & 100.59 & 99.16 & 100.49 & 101.10 & 100.96 & 102.06 & 100.76 & 100.39 & 100.85 & 100.19 \\
\hline \multicolumn{20}{|l|}{ Cations } \\
\hline Si & 2.06 & 2.08 & 2.29 & 2.03 & 2.01 & 2.25 & 2.06 & 2.49 & 2.79 & 2.57 & 2.85 & 2.56 & 2.54 & 2.72 & 2.76 & 2.48 & 2.85 & 2.49 & 2.50 \\
\hline $\mathrm{Ti}$ & 0.000 & 0.000 & 0.001 & 0.000 & 0.000 & 0.000 & 0.000 & 0.000 & 0.000 & 0.000 & 0.001 & 0.001 & 0.000 & 0.000 & 0.000 & 0.000 & 0.000 & 0.000 & 0.000 \\
\hline Al & 1.92 & 1.89 & 1.66 & 1.95 & 1.97 & 1.71 & 1.91 & 1.51 & 1.23 & 1.43 & 1.16 & 1.45 & 1.46 & 1.30 & 1.28 & 1.53 & 1.17 & 1.50 & 1.51 \\
\hline Fe total & 0.035 & 0.040 & 0.060 & 0.032 & 0.035 & 0.060 & 0.037 & 0.017 & 0.007 & 0.018 & 0.012 & 0.016 & 0.017 & 0.011 & 0.002 & 0.017 & 0.010 & 0.020 & 0.015 \\
\hline Mn & 0.006 & 0.007 & 0.013 & 0.005 & 0.005 & 0.012 & 0.005 & 0.001 & 0.003 & 0.000 & 0.000 & 0.000 & 0.000 & 0.001 & 0.000 & 0.000 & 0.001 & 0.002 & 0.002 \\
\hline Mg & 0.94 & 0.91 & 0.72 & 0.96 & 0.96 & 0.75 & 0.94 & 0.51 & 0.21 & 0.44 & 0.14 & 0.44 & 0.45 & 0.27 & 0.22 & 0.51 & 0.14 & 0.50 & 0.50 \\
\hline $\mathrm{Ca}$ & 0.064 & 0.082 & 0.244 & 0.045 & 0.040 & 0.216 & 0.069 & 0.432 & 0.675 & 0.506 & 0.749 & 0.491 & 0.491 & 0.641 & 0.684 & 0.431 & 0.754 & 0.458 & 0.446 \\
\hline $\mathrm{Na}$ & 0.001 & 0.000 & 0.003 & 0.000 & 0.001 & 0.002 & 0.000 & 0.007 & 0.021 & 0.006 & 0.039 & 0.006 & 0.005 & 0.017 & 0.029 & 0.006 & 0.031 & 0.007 & 0.004 \\
\hline Total & 5.02 & 5.02 & 5.00 & 5.02 & 5.03 & 5.00 & 5.02 & 4.97 & 4.94 & 4.97 & 4.96 & 4.96 & 4.97 & 4.96 & 4.96 & 4.97 & 4.96 & 4.99 & 4.97 \\
\hline \multicolumn{20}{|l|}{ Atomic \% } \\
\hline $\mathbf{A b}$ & 6.4 & 8.3 & 25.2 & 4.5 & 4.0 & 22.3 & 6.8 & 45.4 & 74.3 & 53.4 & 80.5 & 52.3 & 51.6 & 68.9 & 73.7 & 45.4 & 81.6 & 47.4 & 46.7 \\
\hline An & 93.6 & 91.7 & 74.5 & 95.5 & 95.9 & 77.5 & 93.1 & 53.8 & 23.3 & 46.0 & 15.3 & 47.1 & 47.8 & 29.3 & 23.2 & 54.0 & 15.1 & 51.9 & 52.8 \\
\hline Or & 0.1 & 0.0 & 0.3 & 0.0 & 0.1 & 0.2 & 0.0 & 0.8 & 2.3 & 0.6 & 4.2 & 0.6 & 0.6 & 1.8 & 3.1 & 0.6 & 3.3 & 0.8 & 0.5 \\
\hline
\end{tabular}


Table F.3. Continued

\begin{tabular}{|c|c|c|c|c|c|c|c|c|c|c|c|c|c|c|c|c|c|c|c|c|}
\hline $\begin{array}{l}\text { Sample } \\
\text { Location } \\
\text { Volcano } \\
\text { Type }\end{array}$ & & & & & & & & & & & & & & & & & & & & \\
\hline $\begin{array}{l}\text { Crystal no. } \\
\text { Analysis site }\end{array}$ & $\begin{array}{r}5 \\
\operatorname{rim} 1 \\
\end{array}$ & $\begin{array}{r}5 \\
\text { rim2 } \\
\end{array}$ & $\begin{array}{r}6 \\
\text { core } \\
\end{array}$ & $\begin{array}{r}6 \\
\text { rim1 } \\
\end{array}$ & $\begin{array}{r}6 \\
\text { rim2 } \\
\end{array}$ & $\begin{array}{r}9 \\
\text { core } \\
\end{array}$ & $\begin{array}{r}9 \\
\mathrm{~d} \text { band } \\
\end{array}$ & $\begin{array}{r}9 \\
\text { rim } \\
\end{array}$ & $\begin{array}{r}11 \\
\text { core } \\
\end{array}$ & $\begin{array}{r}11 \\
\mathrm{~d} \text { band } \\
\end{array}$ & $\begin{array}{r}11 \\
\text { I band } \\
\end{array}$ & $\begin{array}{r}11 \\
\text { rim } \\
\end{array}$ & $\begin{array}{r}12 \\
\text { core } \\
\end{array}$ & $\begin{array}{r}12 \\
\text { I band } \\
\end{array}$ & $\begin{array}{r}13 \\
\text { rim } \\
\end{array}$ & $\begin{array}{r}14 \\
\text { core } \\
\end{array}$ & $\begin{array}{r}14 \\
\text { I band } \\
\end{array}$ & $\begin{array}{r}14 \\
\text { rim }\end{array}$ & $\begin{array}{r}15 \\
\text { core } \\
\end{array}$ & $\begin{array}{r}15 \\
\text { rim } \\
\end{array}$ \\
\hline \multicolumn{21}{|l|}{ Oxides (wt \%) } \\
\hline $\mathrm{SiO}_{2}$ & 62.22 & 62.44 & 55.82 & 64.71 & 65.23 & 58.00 & 56.49 & 65.14 & 56.94 & 56.14 & 62.28 & 67.42 & 55.06 & 60.69 & 65.05 & 56.68 & 58.15 & 61.51 & 55.43 & 64.07 \\
\hline $\mathrm{TiO}_{2}$ & 0.01 & 0.00 & 0.00 & 0.00 & 0.00 & 0.00 & 0.01 & 0.01 & 0.01 & 0.00 & 0.00 & 0.00 & 0.02 & 0.01 & 0.00 & 0.02 & 0.00 & 0.00 & 0.01 & 0.00 \\
\hline $\mathrm{Al}_{2} \mathrm{O}_{3}$ & 23.91 & 24.34 & 29.30 & 22.85 & 22.57 & 27.43 & 28.27 & 22.19 & 28.06 & 28.77 & 25.04 & 21.78 & 29.38 & 25.52 & 23.41 & 27.27 & 27.65 & 24.04 & 28.56 & 22.47 \\
\hline $\mathrm{Fe}_{2} \mathrm{O}_{3}$ & 0.27 & 0.21 & 0.44 & 0.21 & 0.19 & 0.50 & 0.44 & 0.18 & 0.48 & 0.43 & 0.32 & 0.16 & 0.56 & 0.22 & 0.21 & 0.47 & 0.40 & 0.12 & 0.51 & 0.18 \\
\hline $\mathrm{MgO}$ & 0.00 & 0.00 & 0.00 & 0.00 & 0.02 & 0.02 & 0.01 & 0.01 & 0.00 & 0.00 & 0.00 & 0.00 & 0.00 & 0.05 & 0.00 & 0.06 & 0.06 & 0.00 & 0.03 & 0.00 \\
\hline $\mathrm{CaO}$ & 4.83 & 4.83 & 10.77 & 3.38 & 3.09 & 9.16 & 10.05 & 2.57 & 9.87 & 10.55 & 5.92 & 1.30 & 11.30 & 6.66 & 3.36 & 9.46 & 8.55 & 5.32 & 10.48 & 3.19 \\
\hline $\mathrm{Na}_{2} \mathrm{O}$ & 8.05 & 7.51 & 5.01 & 8.72 & 8.83 & 5.99 & 5.60 & 9.04 & 5.68 & 5.24 & 7.65 & 9.93 & 4.86 & 7.17 & 8.60 & 5.72 & 6.41 & 7.80 & 5.35 & 8.78 \\
\hline $\mathrm{K}_{2} \mathrm{O}$ & 0.44 & 0.45 & 0.19 & 0.62 & 0.57 & 0.12 & 0.14 & 0.93 & 0.12 & 0.13 & 0.30 & 0.67 & 0.09 & 0.27 & 0.68 & 0.10 & 0.17 & 0.46 & 0.10 & 0.73 \\
\hline Total & 99.73 & 99.78 & 101.53 & 100.47 & 100.49 & 101.23 & 101.02 & 100.05 & 101.16 & 101.25 & 101.51 & 101.27 & 101.27 & 100.58 & 101.30 & 99.77 & 101.39 & 99.25 & 100.48 & 99.41 \\
\hline \multicolumn{21}{|l|}{ Cations } \\
\hline Si & 2.76 & 2.76 & 2.48 & 2.84 & 2.85 & 2.57 & 2.52 & 2.87 & 2.53 & 2.50 & 2.72 & 2.92 & 2.45 & 2.68 & 2.83 & 2.55 & 2.57 & 2.75 & 2.49 & 2.84 \\
\hline $\mathrm{Ti}$ & 0.000 & 0.000 & 0.000 & 0.000 & 0.000 & 0.000 & 0.000 & 0.000 & 0.000 & 0.000 & 0.000 & 0.000 & 0.001 & 0.000 & 0.000 & 0.001 & 0.000 & 0.000 & 0.000 & 0.000 \\
\hline Al & 1.25 & 1.27 & 1.53 & 1.18 & 1.16 & 1.43 & 1.48 & 1.15 & 1.47 & 1.51 & 1.29 & 1.11 & 1.54 & 1.33 & 1.20 & 1.45 & 1.44 & 1.26 & 1.51 & 1.17 \\
\hline Fe total & 0.010 & 0.008 & 0.016 & 0.008 & 0.007 & 0.019 & 0.016 & 0.007 & 0.018 & 0.016 & 0.012 & 0.006 & 0.021 & 0.008 & 0.008 & 0.018 & 0.015 & 0.005 & 0.019 & 0.007 \\
\hline Mn & 0.000 & 0.000 & 0.000 & 0.000 & 0.001 & 0.001 & 0.001 & 0.000 & 0.000 & 0.000 & 0.000 & 0.000 & 0.000 & 0.003 & 0.000 & 0.004 & 0.004 & 0.000 & 0.002 & 0.000 \\
\hline Mg & 0.23 & 0.23 & 0.51 & 0.16 & 0.14 & 0.43 & 0.48 & 0.12 & 0.47 & 0.50 & 0.28 & 0.06 & 0.54 & 0.32 & 0.16 & 0.46 & 0.40 & 0.25 & 0.50 & 0.15 \\
\hline $\mathrm{Ca}$ & 0.693 & 0.644 & 0.431 & 0.741 & 0.749 & 0.514 & 0.484 & 0.771 & 0.490 & 0.452 & 0.648 & 0.833 & 0.420 & 0.614 & 0.724 & 0.499 & 0.549 & 0.675 & 0.465 & 0.755 \\
\hline $\mathrm{Na}$ & 0.025 & 0.026 & 0.011 & 0.034 & 0.032 & 0.007 & 0.008 & 0.052 & 0.007 & 0.007 & 0.017 & 0.037 & 0.005 & 0.015 & 0.038 & 0.006 & 0.009 & 0.026 & 0.005 & 0.041 \\
\hline Total & 4.97 & 4.94 & 4.98 & 4.96 & 4.95 & 4.98 & 4.99 & 4.97 & 4.98 & 4.98 & 4.97 & 4.96 & 4.99 & 4.97 & 4.95 & 4.98 & 4.99 & 4.97 & 4.99 & 4.97 \\
\hline \multicolumn{21}{|l|}{ Atomic \% } \\
\hline$A b$ & 73.1 & 71.7 & 45.2 & 79.3 & 80.9 & 53.8 & 49.8 & 81.7 & 50.7 & 47.0 & 68.8 & 89.6 & 43.5 & 65.0 & 78.9 & 51.9 & 57.0 & 70.6 & 47.7 & 79.7 \\
\hline An & 24.2 & 25.5 & 53.7 & 17.0 & 15.7 & 45.5 & 49.4 & 12.8 & 48.6 & 52.2 & 29.4 & 6.5 & 55.9 & 33.4 & 17.0 & 47.5 & 42.0 & 26.6 & 51.7 & 16.0 \\
\hline Or & 2.6 & 2.9 & 1.1 & 3.7 & 3.4 & 0.7 & 0.8 & 5.5 & 0.7 & 0.8 & 1.8 & 4.0 & 0.6 & 1.6 & 4.1 & 0.6 & 1.0 & 2.7 & 0.6 & 4.3 \\
\hline
\end{tabular}


Table F.3. Continued

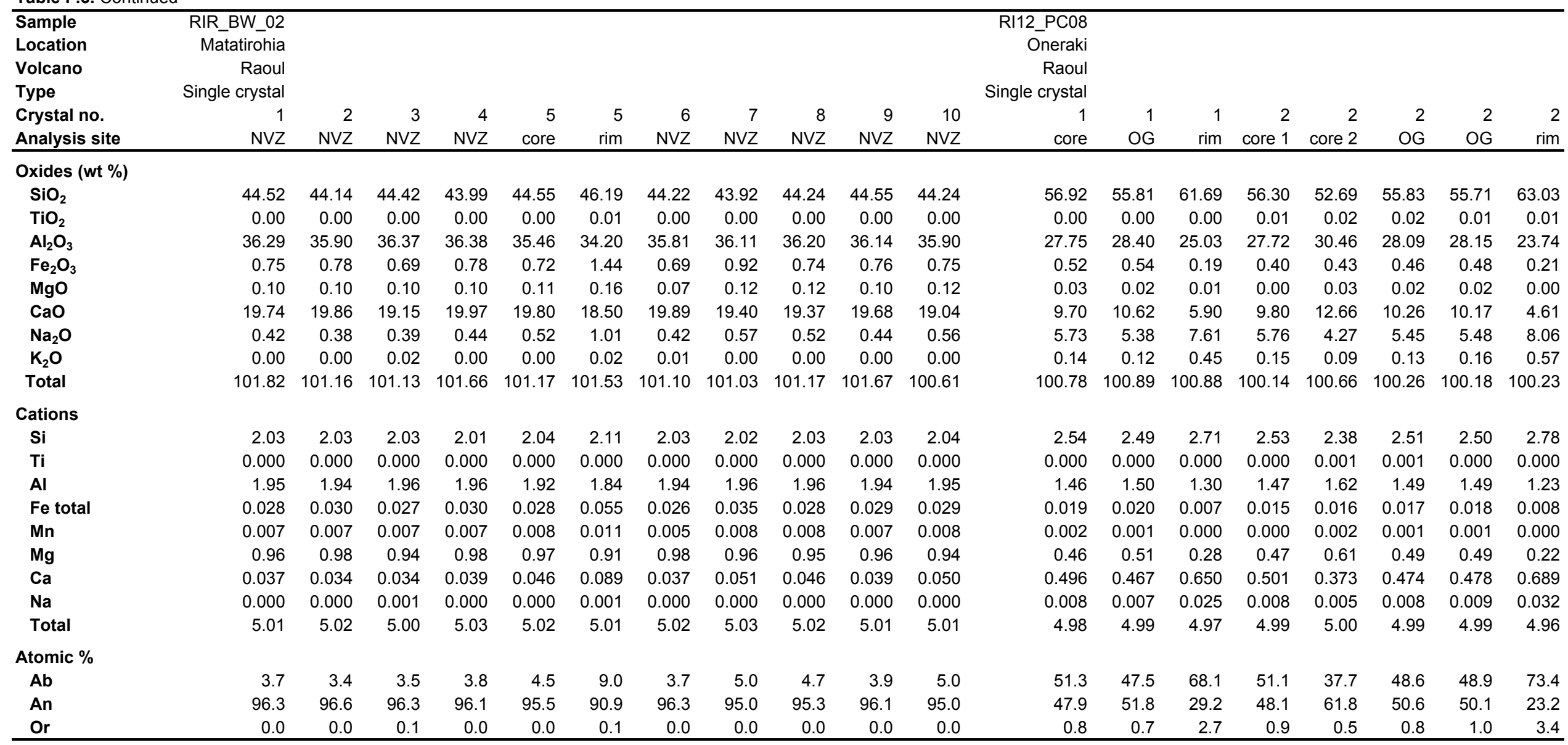




\begin{tabular}{|c|c|c|c|c|c|c|c|c|c|c|c|c|c|c|c|c|c|c|c|c|}
\hline $\begin{array}{l}\text { Sample } \\
\text { Location } \\
\text { Volcano } \\
\text { Type }\end{array}$ & & & & & & & & & & & & & & & & & & & & \\
\hline $\begin{array}{l}\text { Crystal no. } \\
\text { Analysis site }\end{array}$ & $\begin{array}{r}3 \\
N V Z \\
\end{array}$ & $\begin{array}{r}3 \\
N V Z \\
\end{array}$ & $\begin{array}{r}4 \\
\text { core } \\
\end{array}$ & $\begin{array}{r}4 \\
\text { I band } \\
\end{array}$ & $\begin{array}{r}4 \\
\text { I band } \\
\end{array}$ & $\begin{array}{r}4 \\
\mathrm{~d} \text { band } \\
\end{array}$ & $\begin{array}{r}5 \\
\text { core } \\
\end{array}$ & $\begin{array}{r}5 \\
\mathrm{~d} \text { band } \\
\end{array}$ & $\begin{array}{r}5 \\
\mathrm{~d} \text { band } \\
\end{array}$ & $\begin{array}{r}5 \\
\text { rim } \\
\end{array}$ & $\begin{array}{r}6 \\
\text { core } \\
\end{array}$ & $\begin{array}{r}6 \\
\mathrm{~d} \text { band } \\
\end{array}$ & $\begin{array}{r}6 \\
\mathrm{rim} \\
\end{array}$ & $\begin{array}{r}7 \\
N V Z \\
\end{array}$ & $\begin{array}{r}8 \\
\text { core } \\
\end{array}$ & $\begin{array}{r}8 \\
\text { rim } \\
\end{array}$ & $\begin{array}{r}9 \\
\text { core } \\
\end{array}$ & $\begin{array}{r}9 \\
\mathrm{rim} \\
\end{array}$ & $\begin{array}{r}10 \\
\text { core } \\
\end{array}$ & $\begin{array}{r}10 \\
\text { rim } \\
\end{array}$ \\
\hline \multicolumn{21}{|l|}{ Oxides (wt \%) } \\
\hline $\mathrm{SiO}_{2}$ & 54.95 & 56.52 & 50.02 & 47.69 & 47.85 & 50.25 & 46.67 & 51.83 & 50.67 & 48.38 & 47.46 & 51.05 & 47.28 & 46.39 & 47.56 & 51.60 & 47.30 & 52.52 & 46.83 & 52.00 \\
\hline $\mathrm{TiO}_{2}$ & 0.03 & 0.01 & 0.01 & 0.01 & 0.00 & 0.01 & 0.00 & 0.02 & 0.00 & 0.00 & 0.01 & 0.01 & 0.01 & 0.00 & 0.01 & 0.00 & 0.01 & 0.02 & 0.00 & 0.01 \\
\hline $\mathrm{Al}_{2} \mathrm{O}_{3}$ & 28.97 & 27.57 & 32.21 & 33.86 & 33.84 & 32.12 & 34.55 & 31.38 & 31.68 & 33.58 & 34.08 & 31.51 & 34.19 & 34.10 & 34.00 & 30.84 & 33.92 & 30.78 & 34.62 & 30.85 \\
\hline $\mathrm{Fe}_{2} \mathrm{O}_{3}$ & 0.36 & 0.48 & 0.82 & 0.78 & 0.78 & 0.84 & 0.82 & 0.79 & 0.79 & 0.74 & 0.86 & 0.64 & 0.76 & 1.00 & 0.72 & 0.80 & 0.70 & 0.76 & 0.81 & 0.77 \\
\hline MgO & 0.03 & 0.00 & 0.05 & 0.05 & 0.05 & 0.06 & 0.04 & 0.06 & 0.06 & 0.06 & 0.06 & 0.05 & 0.05 & 0.02 & 0.05 & 0.09 & 0.04 & 0.09 & 0.04 & 0.09 \\
\hline $\mathrm{CaO}$ & 11.26 & 9.79 & 15.57 & 17.48 & 17.26 & 15.38 & 17.99 & 14.38 & 14.90 & 16.55 & 17.36 & 14.74 & 17.57 & 17.90 & 17.42 & 14.51 & 17.39 & 13.70 & 18.12 & 14.04 \\
\hline $\mathrm{Na}_{2} \mathrm{O}$ & 4.97 & 5.72 & 2.68 & 1.78 & 1.92 & 2.82 & 1.47 & 3.29 & 3.05 & 2.27 & 1.79 & 3.15 & 1.69 & 1.47 & 1.76 & 3.45 & 1.76 & 3.68 & 1.49 & 3.53 \\
\hline $\mathrm{K}_{2} \mathrm{O}$ & 0.14 & 0.15 & 0.02 & 0.01 & 0.01 & 0.01 & 0.01 & 0.03 & 0.02 & 0.02 & 0.01 & 0.02 & 0.01 & 0.01 & 0.02 & 0.03 & 0.01 & 0.03 & 0.00 & 0.04 \\
\hline Total & 100.70 & 100.25 & 101.39 & 101.64 & 101.71 & 101.49 & 101.55 & 101.76 & 101.17 & 101.61 & 101.62 & 101.17 & 101.56 & 100.89 & 101.54 & 101.32 & 101.12 & 101.58 & 101.91 & 101.33 \\
\hline \multicolumn{21}{|l|}{ Cations } \\
\hline Si & 2.46 & 2.54 & 2.26 & 2.16 & 2.17 & 2.27 & 2.12 & 2.32 & 2.29 & 2.19 & 2.15 & 2.30 & 2.15 & 2.13 & 2.16 & 2.33 & 2.16 & 2.35 & 2.12 & 2.34 \\
\hline $\mathrm{Ti}$ & 0.001 & 0.000 & 0.000 & 0.000 & 0.000 & 0.000 & 0.000 & 0.001 & 0.000 & 0.000 & 0.000 & 0.000 & 0.000 & 0.000 & 0.000 & 0.000 & 0.000 & 0.001 & 0.000 & 0.000 \\
\hline Al & 1.53 & 1.46 & 1.72 & 1.81 & 1.81 & 1.71 & 1.85 & 1.66 & 1.69 & 1.79 & 1.82 & 1.68 & 1.83 & 1.84 & 1.82 & 1.64 & 1.82 & 1.63 & 1.85 & 1.64 \\
\hline $\mathrm{Fe}$ total & 0.013 & 0.018 & 0.031 & 0.029 & 0.030 & 0.032 & 0.031 & 0.030 & 0.030 & 0.028 & 0.033 & 0.024 & 0.029 & 0.038 & 0.027 & 0.030 & 0.027 & 0.028 & 0.031 & 0.029 \\
\hline Mn & 0.002 & 0.000 & 0.004 & 0.003 & 0.004 & 0.004 & 0.003 & 0.004 & 0.004 & 0.004 & 0.004 & 0.003 & 0.003 & 0.002 & 0.003 & 0.006 & 0.002 & 0.006 & 0.003 & 0.006 \\
\hline Mg & 0.54 & 0.47 & 0.75 & 0.85 & 0.84 & 0.74 & 0.88 & 0.69 & 0.72 & 0.80 & 0.84 & 0.71 & 0.85 & 0.88 & 0.85 & 0.70 & 0.85 & 0.66 & 0.88 & 0.68 \\
\hline $\mathrm{Ca}$ & 0.432 & 0.497 & 0.235 & 0.156 & 0.168 & 0.247 & 0.130 & 0.285 & 0.267 & 0.199 & 0.157 & 0.276 & 0.149 & 0.130 & 0.155 & 0.301 & 0.155 & 0.320 & 0.131 & 0.308 \\
\hline $\mathrm{Na}$ & 0.008 & 0.009 & 0.001 & 0.001 & 0.001 & 0.001 & 0.000 & 0.002 & 0.001 & 0.001 & 0.001 & 0.001 & 0.000 & 0.001 & 0.001 & 0.002 & 0.000 & 0.002 & 0.000 & 0.002 \\
\hline Total & 4.99 & 4.99 & 5.00 & 5.01 & 5.01 & 5.00 & 5.02 & 4.99 & 5.00 & 5.02 & 5.01 & 5.00 & 5.01 & 5.02 & 5.01 & 5.01 & 5.01 & 4.99 & 5.02 & 5.00 \\
\hline \multicolumn{21}{|l|}{ Atomic \% } \\
\hline$A b$ & 44.0 & 50.9 & 23.7 & 15.5 & 16.7 & 24.9 & 12.9 & 29.2 & 27.0 & 19.9 & 15.7 & 27.8 & 14.9 & 12.9 & 15.5 & 30.0 & 15.5 & 32.7 & 12.9 & 31.2 \\
\hline An & 55.2 & 48.2 & 76.1 & 84.4 & 83.2 & 75.1 & 87.1 & 70.6 & 72.9 & 80.0 & 84.2 & 72.0 & 85.1 & 87.0 & 84.5 & 69.8 & 84.5 & 67.2 & 87.1 & 68.6 \\
\hline Or & 0.8 & 0.9 & 0.1 & 0.1 & 0.1 & 0.1 & 0.0 & 0.2 & 0.1 & 0.1 & 0.1 & 0.1 & 0.0 & 0.1 & 0.1 & 0.2 & 0.0 & 0.2 & 0.0 & 0.2 \\
\hline
\end{tabular}




\begin{tabular}{|c|c|c|c|c|c|c|c|c|c|c|c|c|c|c|c|c|c|c|c|c|}
\hline $\begin{array}{l}\text { Sample } \\
\text { Location } \\
\text { Volcano } \\
\text { Type }\end{array}$ & & & & & & & & & & & & & & & & & & & & \\
\hline $\begin{array}{l}\text { Crystal no. } \\
\text { Analysis site }\end{array}$ & $\begin{array}{r}11 \\
N V Z \\
\end{array}$ & $\begin{array}{r}12 \\
\text { core } \\
\end{array}$ & $\begin{array}{r}12 \\
\text { rim } \\
\end{array}$ & $\begin{array}{r}13 \\
N V Z \\
\end{array}$ & $\begin{array}{r}14 \\
N V Z \\
\end{array}$ & $\begin{array}{r}15 \\
N V Z \\
\end{array}$ & $\begin{array}{r}16 \\
N V Z \\
\end{array}$ & $\begin{array}{r}17 \\
N V Z \\
\end{array}$ & $\begin{array}{r}18 \\
\text { core } \\
\end{array}$ & $\begin{array}{r}18 \\
\mathrm{~d} \text { band } \\
\end{array}$ & $\begin{array}{r}18 \\
\text { I band } \\
\end{array}$ & $\begin{array}{r}18 \\
\text { rim } \\
\end{array}$ & $\begin{array}{r}19 \\
\text { core } \\
\end{array}$ & $\begin{array}{r}19 \\
\text { rim } \\
\end{array}$ & $\begin{array}{r}20 \\
\text { core } 1 \\
\end{array}$ & $\begin{array}{r}20 \\
\text { core } 2 \\
\end{array}$ & $\begin{array}{r}20 \\
O G \\
\end{array}$ & $\begin{array}{r}20 \\
\mathrm{rim} \\
\end{array}$ & $\begin{array}{r}22 \\
N V Z \\
\end{array}$ & $\begin{array}{r}23 \\
N V Z \\
\end{array}$ \\
\hline \multicolumn{21}{|l|}{ Oxides (wt \%) } \\
\hline $\mathrm{SiO}_{2}$ & 56.83 & 47.99 & 53.18 & 47.61 & 47.70 & 47.58 & 63.48 & 47.22 & 48.19 & 50.23 & 47.81 & 51.49 & 48.16 & 51.30 & 48.45 & 48.75 & 46.95 & 51.31 & 50.04 & 46.57 \\
\hline $\mathrm{TiO}_{2}$ & 0.01 & 0.01 & 0.03 & 0.00 & 0.00 & 0.00 & 0.02 & 0.00 & 0.00 & 0.01 & 0.00 & 0.01 & 0.00 & 0.02 & 0.01 & 0.00 & 0.00 & 0.03 & 0.00 & 0.01 \\
\hline $\mathrm{Al}_{2} \mathrm{O}_{3}$ & 27.73 & 33.29 & 30.78 & 33.79 & 33.88 & 33.32 & 23.04 & 34.17 & 33.43 & 31.48 & 33.67 & 30.74 & 33.54 & 31.14 & 33.00 & 32.89 & 34.34 & 31.48 & 32.18 & 34.13 \\
\hline $\mathrm{Fe}_{2} \mathrm{O}_{3}$ & 0.46 & 0.70 & 0.80 & 0.89 & 0.71 & 0.68 & 0.15 & 0.84 & 0.75 & 0.71 & 0.80 & 0.82 & 0.78 & 0.67 & 0.75 & 0.85 & 0.73 & 0.75 & 1.17 & 0.74 \\
\hline MgO & 0.02 & 0.06 & 0.09 & 0.04 & 0.06 & 0.06 & 0.00 & 0.04 & 0.06 & 0.05 & 0.05 & 0.06 & 0.04 & 0.05 & 0.06 & 0.06 & 0.06 & 0.07 & 0.17 & 0.05 \\
\hline $\mathrm{CaO}$ & 9.72 & 16.84 & 13.30 & 17.34 & 17.22 & 17.11 & 4.26 & 17.57 & 16.92 & 15.36 & 17.29 & 14.39 & 17.06 & 14.45 & 16.37 & 16.51 & 17.70 & 14.69 & 15.22 & 17.35 \\
\hline $\mathrm{Na}_{2} \mathrm{O}$ & 5.77 & 2.02 & 3.76 & 1.85 & 1.93 & 1.94 & 8.20 & 1.71 & 2.11 & 2.90 & 1.97 & 3.50 & 2.05 & 3.29 & 2.30 & 2.32 & 1.58 & 3.16 & 2.84 & 1.82 \\
\hline $\mathrm{K}_{2} \mathrm{O}$ & 0.12 & 0.01 & 0.05 & 0.02 & 0.01 & 0.02 & 0.65 & 0.02 & 0.02 & 0.02 & 0.01 & 0.03 & 0.02 & 0.03 & 0.01 & 0.02 & 0.01 & 0.03 & 0.03 & 0.00 \\
\hline Total & 100.66 & 100.92 & 101.98 & 101.55 & 101.51 & 100.70 & 99.81 & 101.57 & 101.46 & 100.74 & 101.60 & 101.05 & 101.66 & 100.94 & 100.95 & 101.38 & 101.36 & 101.51 & 101.64 & 100.66 \\
\hline \multicolumn{21}{|l|}{ Cations } \\
\hline Si & 2.54 & 2.19 & 2.37 & 2.16 & 2.16 & 2.18 & 2.81 & 2.15 & 2.19 & 2.28 & 2.17 & 2.33 & 2.18 & 2.32 & 2.21 & 2.21 & 2.14 & 2.31 & 2.26 & 2.13 \\
\hline $\mathrm{Ti}$ & 0.000 & 0.000 & 0.001 & 0.000 & 0.000 & 0.000 & 0.001 & 0.000 & 0.000 & 0.000 & 0.000 & 0.000 & 0.000 & 0.001 & 0.000 & 0.000 & 0.000 & 0.001 & 0.000 & 0.000 \\
\hline Al & 1.46 & 1.79 & 1.62 & 1.81 & 1.81 & 1.80 & 1.20 & 1.83 & 1.79 & 1.69 & 1.80 & 1.64 & 1.79 & 1.66 & 1.77 & 1.76 & 1.84 & 1.67 & 1.71 & 1.84 \\
\hline $\mathrm{Fe}$ total & 0.017 & 0.027 & 0.030 & 0.034 & 0.027 & 0.026 & 0.006 & 0.032 & 0.028 & 0.027 & 0.030 & 0.031 & 0.030 & 0.025 & 0.028 & 0.032 & 0.028 & 0.028 & 0.044 & 0.029 \\
\hline Mn & 0.001 & 0.004 & 0.006 & 0.003 & 0.004 & 0.004 & 0.000 & 0.003 & 0.004 & 0.004 & 0.003 & 0.004 & 0.003 & 0.003 & 0.004 & 0.004 & 0.004 & 0.004 & 0.011 & 0.003 \\
\hline Mg & 0.46 & 0.82 & 0.63 & 0.84 & 0.84 & 0.84 & 0.20 & 0.86 & 0.82 & 0.75 & 0.84 & 0.70 & 0.83 & 0.70 & 0.80 & 0.80 & 0.86 & 0.71 & 0.74 & 0.85 \\
\hline $\mathrm{Ca}$ & 0.499 & 0.179 & 0.325 & 0.163 & 0.170 & 0.172 & 0.703 & 0.151 & 0.185 & 0.255 & 0.173 & 0.307 & 0.180 & 0.288 & 0.203 & 0.204 & 0.139 & 0.275 & 0.249 & 0.161 \\
\hline $\mathrm{Na}$ & 0.007 & 0.000 & 0.003 & 0.001 & 0.001 & 0.001 & 0.037 & 0.001 & 0.001 & 0.001 & 0.001 & 0.002 & 0.001 & 0.002 & 0.001 & 0.001 & 0.000 & 0.002 & 0.001 & 0.000 \\
\hline Total & 4.99 & 5.01 & 4.99 & 5.02 & 5.01 & 5.01 & 4.96 & 5.02 & 5.01 & 5.00 & 5.02 & 5.01 & 5.01 & 5.00 & 5.01 & 5.01 & 5.01 & 5.00 & 5.01 & 5.02 \\
\hline \multicolumn{21}{|l|}{ Atomic \% } \\
\hline$A b$ & 51.4 & 17.8 & 33.8 & 16.2 & 16.8 & 17.0 & 74.7 & 15.0 & 18.4 & 25.4 & 17.1 & 30.5 & 17.8 & 29.1 & 20.2 & 20.3 & 13.9 & 27.9 & 25.2 & 15.9 \\
\hline An & 47.9 & 82.1 & 65.9 & 83.7 & 83.1 & 82.9 & 21.5 & 84.9 & 81.5 & 74.5 & 82.8 & 69.3 & 82.0 & 70.7 & 79.7 & 79.7 & 86.1 & 71.9 & 74.6 & 84.1 \\
\hline Or & 0.7 & 0.0 & 0.3 & 0.1 & 0.1 & 0.1 & 3.9 & 0.1 & 0.1 & 0.1 & 0.1 & 0.2 & 0.1 & 0.2 & 0.1 & 0.1 & 0.0 & 0.2 & 0.1 & 0.0 \\
\hline
\end{tabular}




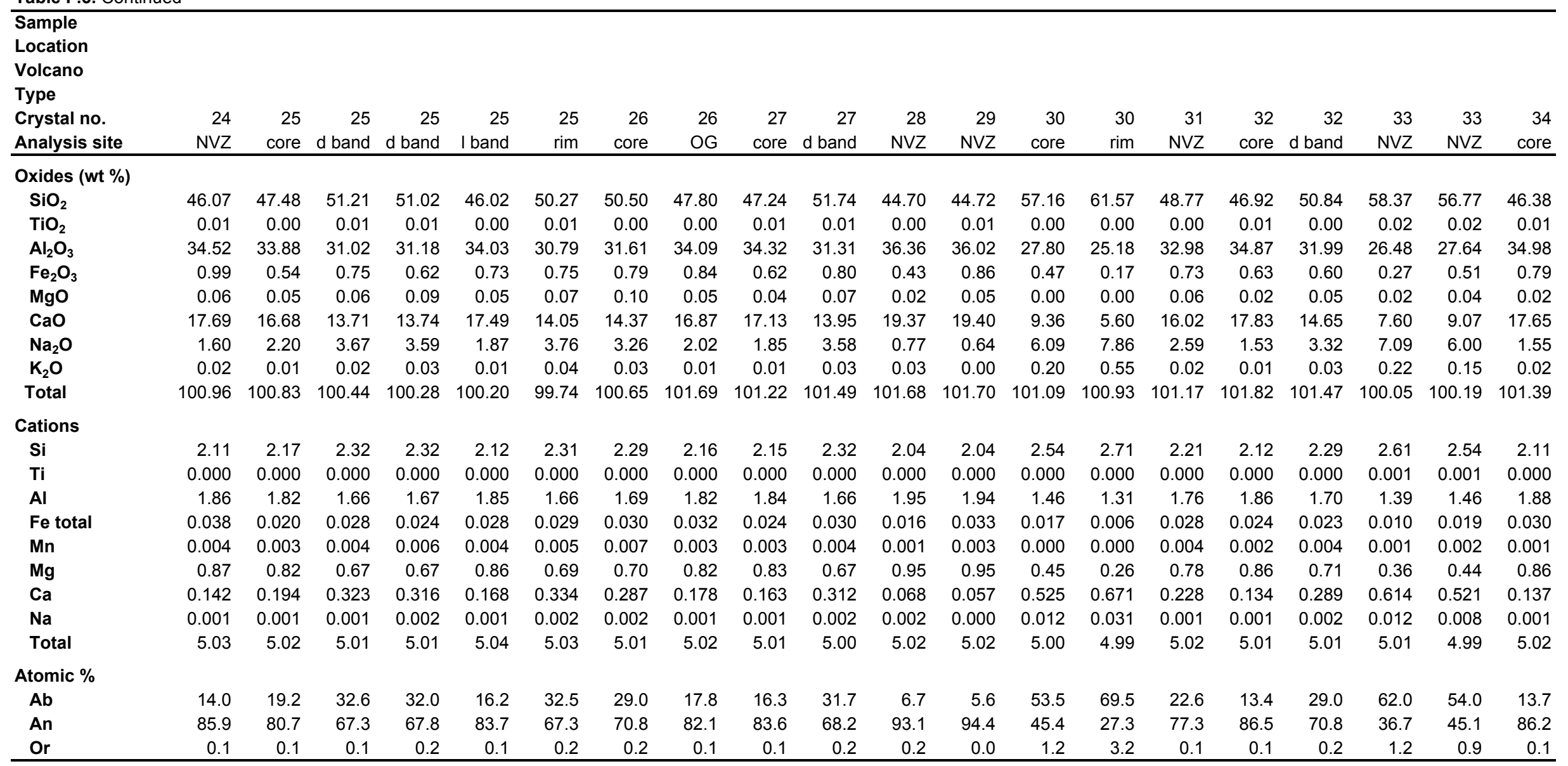


Table F.3. Continued

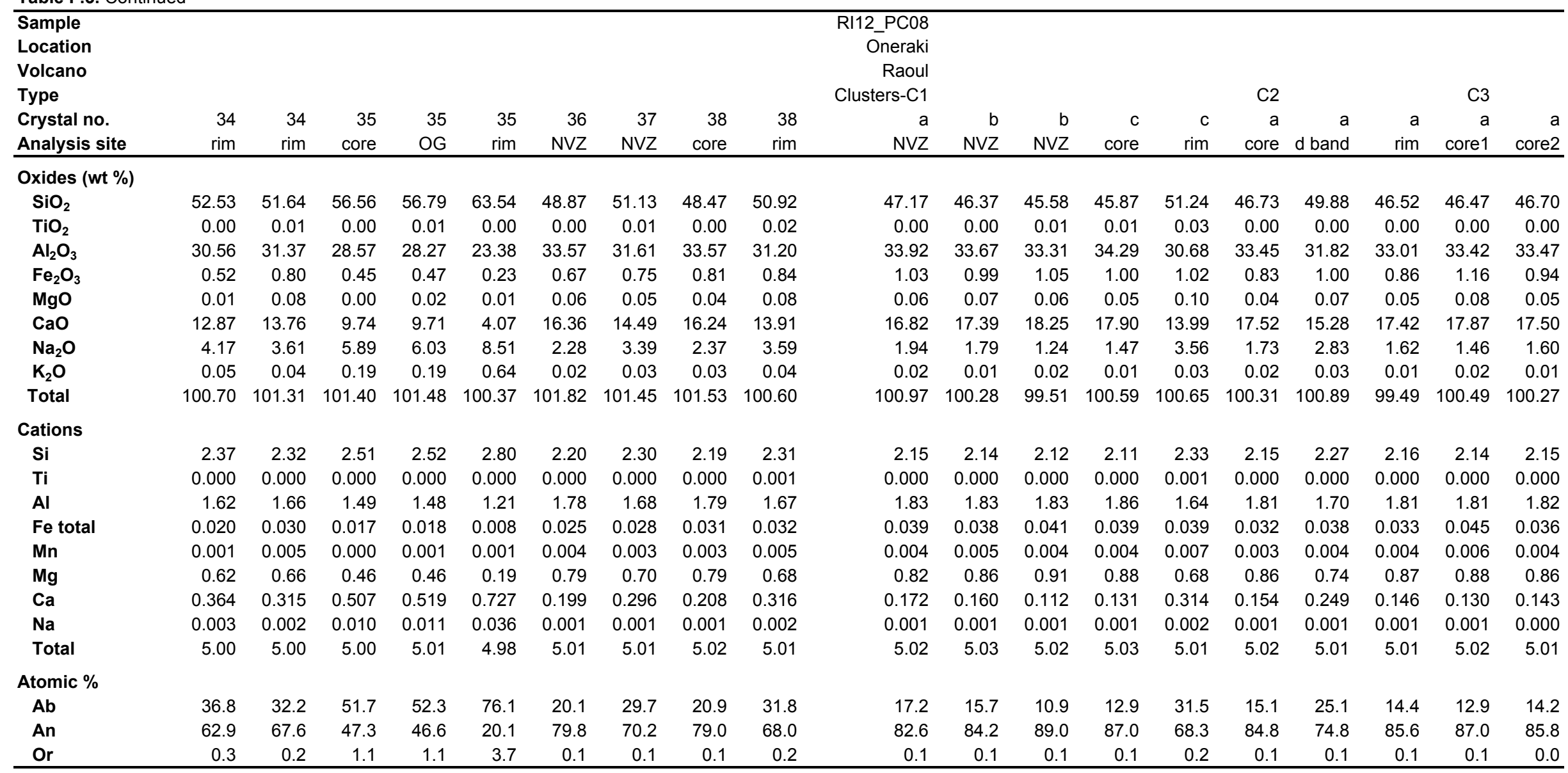


Table F.3. Continued

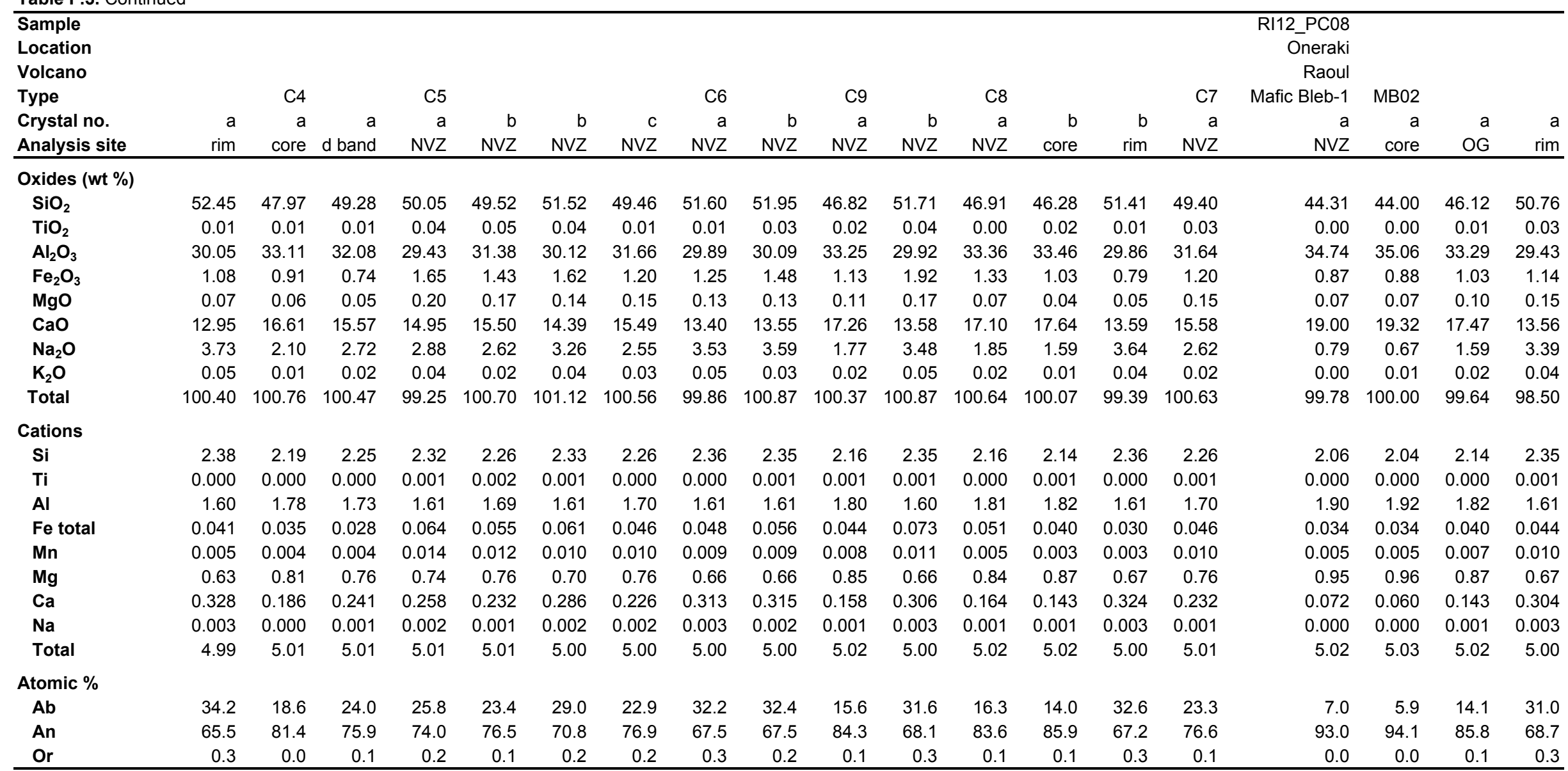


Table F.3. Continued

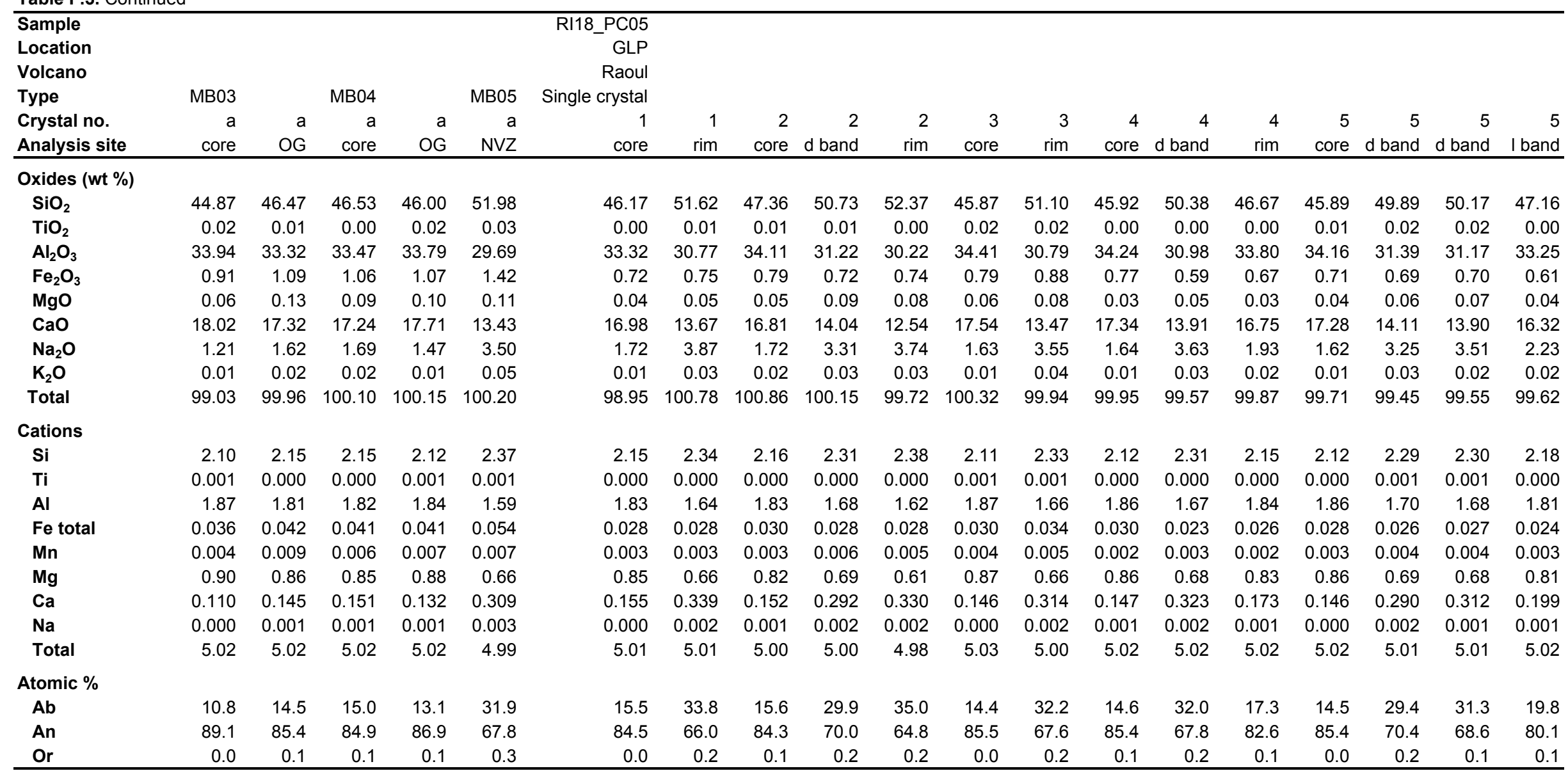


Table F.3. Continued

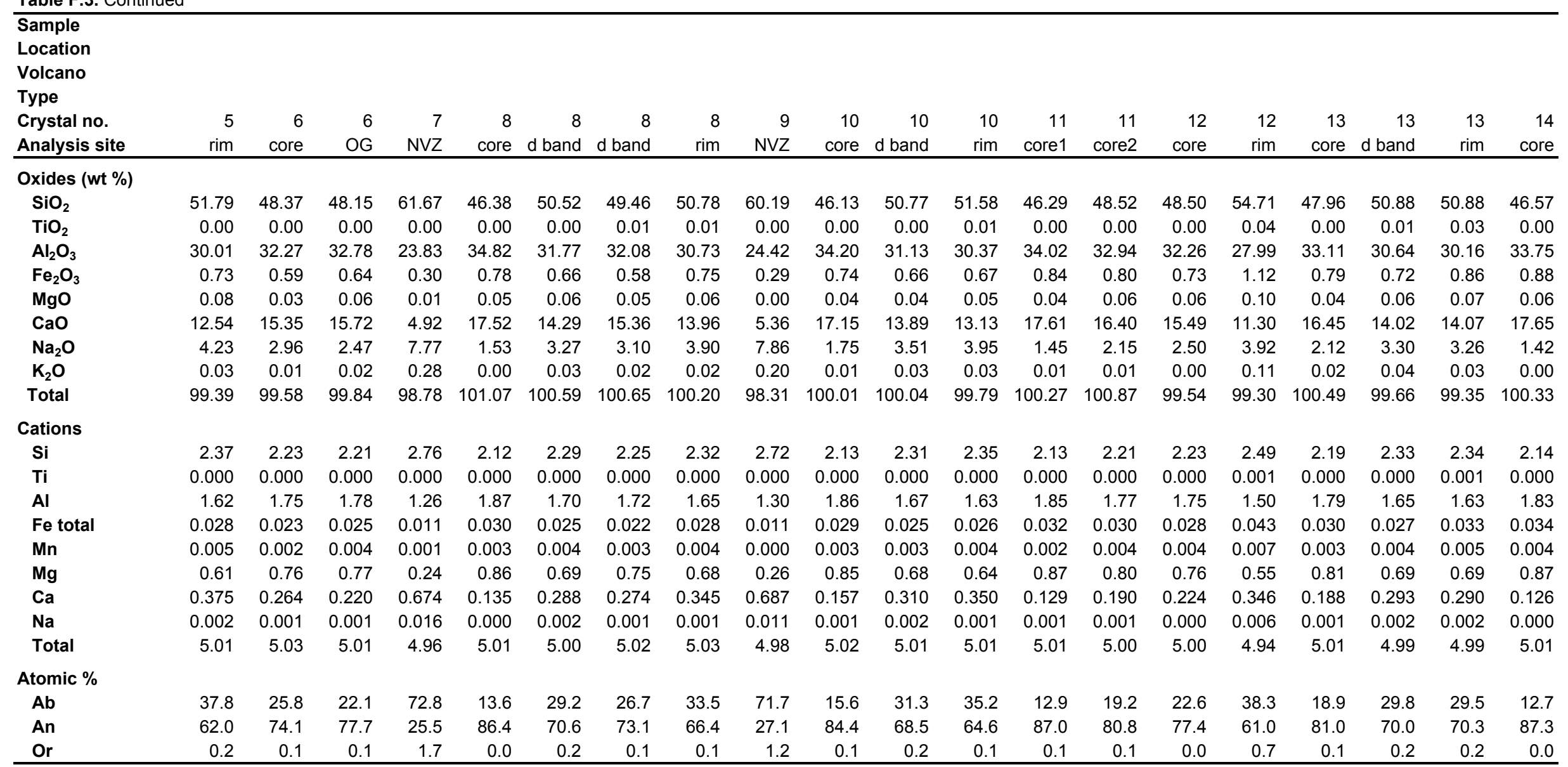




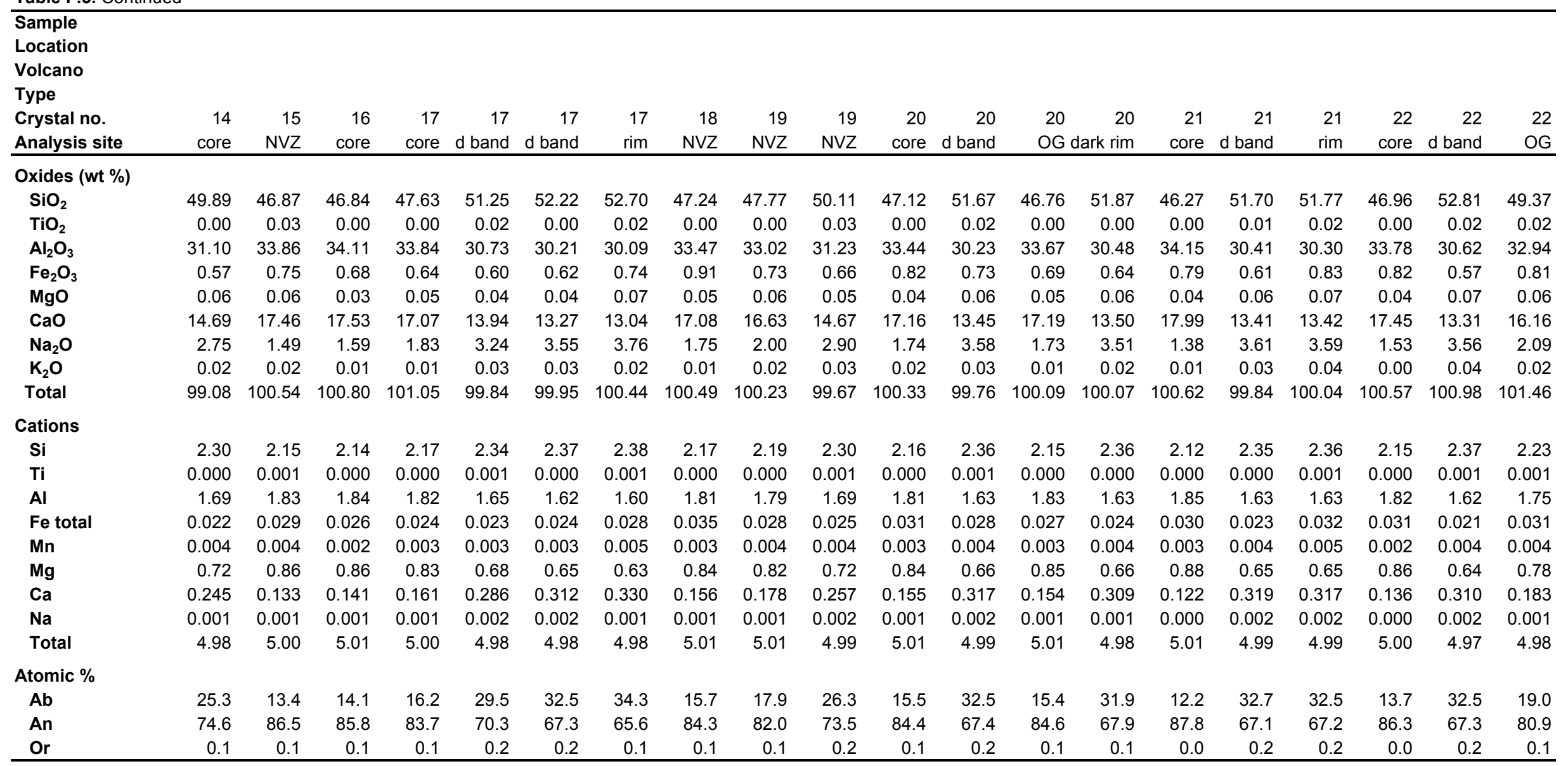




\begin{tabular}{|c|c|c|c|c|c|c|c|c|c|c|c|c|c|c|c|c|c|c|c|c|}
\hline $\begin{array}{l}\text { Sample } \\
\text { Location } \\
\text { Volcano } \\
\text { Type }\end{array}$ & & & & & & & & & & & & & & & & & & & & \\
\hline $\begin{array}{l}\text { Crystal no. } \\
\text { Analysis site }\end{array}$ & $\begin{array}{r}23 \\
\text { core } \\
\end{array}$ & $\begin{array}{r}23 \\
O G \\
\end{array}$ & $\begin{array}{r}23 \\
\text { rim }\end{array}$ & $\begin{array}{r}24 \\
\text { core } \\
\end{array}$ & $\begin{array}{r}24 \\
\text { rim1 } \\
\end{array}$ & $\begin{array}{r}24 \\
\text { rim2 } \\
\end{array}$ & $\begin{array}{r}25 \\
\text { core } \\
\end{array}$ & $\begin{array}{r}25 \\
\mathrm{~d} \text { band } \\
\end{array}$ & $\begin{array}{r}25 \\
\mathrm{OG} \\
\end{array}$ & $\begin{array}{r}26 \\
\text { core } \\
\end{array}$ & $\begin{array}{r}26 \\
\text { rim } \\
\end{array}$ & $\begin{array}{r}28 \\
\text { core } \\
\end{array}$ & $\begin{array}{r}28 \\
\mathrm{~d} \text { band } \\
\end{array}$ & $\begin{array}{r}28 \\
O G \\
\end{array}$ & $\begin{array}{r}28 \\
\text { rim } \\
\end{array}$ & $\begin{array}{r}29 \\
\text { core } \\
\end{array}$ & $\begin{array}{r}29 \\
\mathrm{~d} \text { band } \\
\end{array}$ & $\begin{array}{r}30 \\
\text { core } \\
\end{array}$ & $\begin{array}{r}31 \\
N V Z \\
\end{array}$ & $\begin{array}{r}32 \\
\text { core } \\
\end{array}$ \\
\hline \multicolumn{21}{|l|}{ Oxides (wt \%) } \\
\hline $\mathrm{SiO}_{2}$ & 52.65 & 46.95 & 51.05 & 44.75 & 47.30 & 54.24 & 46.81 & 51.72 & 47.61 & 46.81 & 54.85 & 47.43 & 50.12 & 46.67 & 51.03 & 46.56 & 50.75 & 47.55 & 45.80 & 46.85 \\
\hline $\mathrm{TiO}_{2}$ & 0.00 & 0.00 & 0.00 & 0.00 & 0.02 & 0.05 & 0.00 & 0.00 & 0.00 & 0.00 & 0.02 & 0.01 & 0.01 & 0.00 & 0.01 & 0.00 & 0.01 & 0.01 & 0.00 & 0.00 \\
\hline $\mathrm{Al}_{2} \mathrm{O}_{3}$ & 29.81 & 33.04 & 30.54 & 35.27 & 33.47 & 29.62 & 33.71 & 30.18 & 33.28 & 33.98 & 29.41 & 33.37 & 31.20 & 33.62 & 30.58 & 33.32 & 30.98 & 33.02 & 34.09 & 33.99 \\
\hline $\mathrm{Fe}_{2} \mathrm{O}_{3}$ & 0.45 & 0.61 & 0.85 & 0.99 & 1.04 & 1.39 & 0.79 & 0.68 & 0.80 & 0.71 & 0.96 & 0.81 & 0.76 & 0.65 & 0.69 & 0.62 & 0.74 & 0.77 & 0.76 & 0.75 \\
\hline MgO & 0.04 & 0.03 & 0.06 & 0.09 & 0.12 & 0.15 & 0.04 & 0.05 & 0.04 & 0.04 & 0.07 & 0.04 & 0.07 & 0.05 & 0.08 & 0.06 & 0.07 & 0.06 & 0.04 & 0.05 \\
\hline $\mathrm{CaO}$ & 12.56 & 16.64 & 13.77 & 19.09 & 17.22 & 12.87 & 17.39 & 13.59 & 16.78 & 17.45 & 11.61 & 16.98 & 14.69 & 17.28 & 14.04 & 16.87 & 14.24 & 16.62 & 17.68 & 17.32 \\
\hline $\mathrm{Na}_{2} \mathrm{O}$ & 3.97 & 1.95 & 3.38 & 0.65 & 1.60 & 3.30 & 1.55 & 3.40 & 1.92 & 1.57 & 4.02 & 1.79 & 2.89 & 1.60 & 3.38 & 1.75 & 3.04 & 2.06 & 1.47 & 1.68 \\
\hline $\mathrm{K}_{2} \mathrm{O}$ & 0.02 & 0.01 & 0.02 & 0.01 & 0.02 & 0.07 & 0.01 & 0.03 & 0.02 & 0.01 & 0.07 & 0.01 & 0.03 & 0.01 & 0.03 & 0.01 & 0.03 & 0.01 & 0.01 & 0.00 \\
\hline Total & 99.49 & 99.23 & 99.66 & 100.84 & 100.79 & 101.68 & 100.30 & 99.65 & 100.45 & 100.55 & 101.01 & 100.44 & 99.78 & 99.87 & 99.84 & 99.19 & 99.85 & 100.08 & 99.84 & 100.65 \\
\hline \multicolumn{21}{|l|}{ Cations } \\
\hline Si & 2.40 & 2.18 & 2.33 & 2.06 & 2.16 & 2.42 & 2.15 & 2.36 & 2.18 & 2.15 & 2.45 & 2.17 & 2.29 & 2.15 & 2.33 & 2.16 & 2.32 & 2.19 & 2.12 & 2.15 \\
\hline $\mathrm{Ti}$ & 0.000 & 0.000 & 0.000 & 0.000 & 0.001 & 0.002 & 0.000 & 0.000 & 0.000 & 0.000 & 0.001 & 0.000 & 0.000 & 0.000 & 0.000 & 0.000 & 0.000 & 0.000 & 0.000 & 0.000 \\
\hline Al & 1.60 & 1.81 & 1.65 & 1.91 & 1.80 & 1.56 & 1.83 & 1.62 & 1.80 & 1.84 & 1.55 & 1.80 & 1.68 & 1.83 & 1.65 & 1.82 & 1.67 & 1.79 & 1.86 & 1.83 \\
\hline $\mathrm{Fe}$ total & 0.017 & 0.024 & 0.032 & 0.038 & 0.040 & 0.052 & 0.030 & 0.026 & 0.031 & 0.027 & 0.036 & 0.031 & 0.029 & 0.025 & 0.026 & 0.024 & 0.028 & 0.030 & 0.029 & 0.029 \\
\hline Mn & 0.003 & 0.002 & 0.004 & 0.006 & 0.008 & 0.010 & 0.003 & 0.004 & 0.003 & 0.002 & 0.005 & 0.003 & 0.005 & 0.003 & 0.006 & 0.004 & 0.005 & 0.004 & 0.003 & 0.003 \\
\hline Mg & 0.61 & 0.83 & 0.67 & 0.94 & 0.84 & 0.62 & 0.86 & 0.66 & 0.82 & 0.86 & 0.56 & 0.83 & 0.72 & 0.85 & 0.69 & 0.84 & 0.70 & 0.82 & 0.88 & 0.85 \\
\hline $\mathrm{Ca}$ & 0.350 & 0.175 & 0.300 & 0.058 & 0.142 & 0.285 & 0.138 & 0.301 & 0.171 & 0.140 & 0.348 & 0.159 & 0.256 & 0.143 & 0.299 & 0.158 & 0.269 & 0.183 & 0.131 & 0.149 \\
\hline $\mathrm{Na}$ & 0.001 & 0.000 & 0.001 & 0.001 & 0.001 & 0.004 & 0.001 & 0.002 & 0.001 & 0.001 & 0.004 & 0.001 & 0.002 & 0.001 & 0.001 & 0.000 & 0.001 & 0.000 & 0.000 & 0.000 \\
\hline Total & 4.98 & 5.01 & 4.99 & 5.01 & 5.00 & 4.94 & 5.01 & 4.98 & 5.01 & 5.01 & 4.95 & 5.00 & 4.99 & 5.01 & 5.00 & 5.01 & 4.98 & 5.01 & 5.02 & 5.01 \\
\hline \multicolumn{21}{|l|}{ Atomic \% } \\
\hline$A b$ & 36.4 & 17.5 & 30.7 & 5.8 & 14.4 & 31.5 & 13.9 & 31.1 & 17.2 & 14.0 & 38.4 & 16.0 & 26.2 & 14.4 & 30.3 & 15.8 & 27.8 & 18.3 & 13.0 & 14.9 \\
\hline An & 63.5 & 82.5 & 69.2 & 94.1 & 85.5 & 68.1 & 86.0 & 68.7 & 82.7 & 86.0 & 61.2 & 83.9 & 73.6 & 85.6 & 69.6 & 84.1 & 72.0 & 81.7 & 86.9 & 85.1 \\
\hline Or & 0.1 & 0.0 & 0.1 & 0.1 & 0.1 & 0.4 & 0.1 & 0.2 & 0.1 & 0.1 & 0.4 & 0.1 & 0.2 & 0.1 & 0.1 & 0.0 & 0.2 & 0.0 & 0.0 & 0.0 \\
\hline
\end{tabular}




\begin{tabular}{|c|c|c|c|c|c|c|c|c|c|c|c|c|c|c|c|c|c|c|c|c|}
\hline $\begin{array}{l}\text { Sample } \\
\text { Location } \\
\text { Volcano } \\
\text { Type }\end{array}$ & & & & & & & & & & & & & & & & & & & & \\
\hline $\begin{array}{l}\text { Crystal no. } \\
\text { Analysis site }\end{array}$ & $\begin{array}{r}33 \\
\text { core } \\
\end{array}$ & $\begin{array}{r}33 \\
\text { rim1 } \\
\end{array}$ & $\begin{array}{r}33 \\
\text { rim2 } \\
\end{array}$ & $\begin{array}{r}34 \\
\text { core } \\
\end{array}$ & $\begin{array}{r}34 \\
\text { rim } \\
\end{array}$ & $\begin{array}{r}35 \\
\text { core } \\
\end{array}$ & $\begin{array}{r}35 \\
\text { I band } \\
\end{array}$ & $\begin{array}{r}35 \\
\text { rim } \\
\end{array}$ & $\begin{array}{r}36 \\
\text { core } \\
\end{array}$ & $\begin{array}{r}36 \\
\mathrm{~d} \text { band } \\
\end{array}$ & $\begin{array}{r}36 \\
\mathrm{OG} \\
\end{array}$ & $\begin{array}{r}37 \\
\text { core } \\
\end{array}$ & $\begin{array}{r}38 \\
N V Z \\
\end{array}$ & $\begin{array}{r}39 \\
\text { core } \\
\end{array}$ & $\begin{array}{r}39 \\
\text { OG1 } \\
\end{array}$ & $\begin{array}{r}39 \\
\text { OG2 } \\
\end{array}$ & $\begin{array}{r}39 \\
\text { rim } \\
\end{array}$ & $\begin{array}{r}40 \\
\text { core } \\
\end{array}$ & $\begin{array}{r}40 \\
\mathrm{~d} \text { band } \\
\end{array}$ & $\begin{array}{r}40 \\
\text { rim } \\
\end{array}$ \\
\hline \multicolumn{21}{|l|}{ Oxides (wt \%) } \\
\hline $\mathrm{SiO}_{2}$ & 44.90 & 47.25 & 51.03 & 44.23 & 52.33 & 50.80 & 46.98 & 52.22 & 47.22 & 51.71 & 47.05 & 48.27 & 46.05 & 46.50 & 47.35 & 48.50 & 48.51 & 46.62 & 49.54 & 47.05 \\
\hline $\mathrm{TiO}_{2}$ & 0.00 & 0.00 & 0.02 & 0.00 & 0.02 & 0.00 & 0.01 & 0.02 & 0.00 & 0.00 & 0.00 & 0.00 & 0.01 & 0.00 & 0.01 & 0.02 & 0.00 & 0.02 & 0.00 & 0.00 \\
\hline $\mathrm{Al}_{2} \mathrm{O}_{3}$ & 34.95 & 33.50 & 29.71 & 35.20 & 29.51 & 32.15 & 33.25 & 29.27 & 33.96 & 30.78 & 33.48 & 32.95 & 34.28 & 33.98 & 33.60 & 33.42 & 32.12 & 34.05 & 31.47 & 33.66 \\
\hline $\mathrm{Fe}_{2} \mathrm{O}_{3}$ & 0.86 & 1.01 & 1.20 & 0.83 & 0.73 & 1.78 & 0.70 & 0.75 & 0.78 & 0.67 & 0.58 & 0.67 & 0.72 & 0.79 & 0.68 & 0.76 & 0.71 & 0.80 & 0.66 & 0.64 \\
\hline MgO & 0.10 & 0.13 & 0.17 & 0.09 & 0.06 & 0.08 & 0.04 & 0.06 & 0.05 & 0.05 & 0.04 & 0.04 & 0.03 & 0.06 & 0.04 & 0.05 & 0.04 & 0.05 & 0.07 & 0.03 \\
\hline $\mathrm{CaO}$ & 19.00 & 17.23 & 14.22 & 19.20 & 12.99 & 14.87 & 16.88 & 12.66 & 17.27 & 13.86 & 17.13 & 16.36 & 18.02 & 17.56 & 16.92 & 16.15 & 16.11 & 17.63 & 15.37 & 17.27 \\
\hline $\mathrm{Na}_{2} \mathrm{O}$ & 0.78 & 1.65 & 3.19 & 0.63 & 3.75 & 2.11 & 1.83 & 3.69 & 1.64 & 3.28 & 1.67 & 2.07 & 1.29 & 1.47 & 1.74 & 2.13 & 2.33 & 1.43 & 2.69 & 1.62 \\
\hline $\mathrm{K}_{2} \mathrm{O}$ & 0.00 & 0.01 & 0.04 & 0.00 & 0.04 & 0.08 & 0.01 & 0.03 & 0.01 & 0.02 & 0.01 & 0.01 & 0.01 & 0.00 & 0.01 & 0.03 & 0.02 & 0.01 & 0.02 & 0.01 \\
\hline Total & 100.60 & 100.78 & 99.57 & 100.17 & 99.41 & 101.88 & 99.69 & 98.71 & 100.92 & 100.37 & 99.96 & 100.38 & 100.40 & 100.35 & 100.35 & 101.06 & 99.83 & 100.61 & 99.81 & 100.28 \\
\hline \multicolumn{21}{|l|}{ Cations } \\
\hline Si & 2.07 & 2.16 & 2.34 & 2.05 & 2.39 & 2.28 & 2.17 & 2.40 & 2.15 & 2.34 & 2.17 & 2.21 & 2.12 & 2.14 & 2.17 & 2.20 & 2.23 & 2.14 & 2.27 & 2.16 \\
\hline $\mathrm{Ti}$ & 0.000 & 0.000 & 0.001 & 0.000 & 0.001 & 0.000 & 0.000 & 0.001 & 0.000 & 0.000 & 0.000 & 0.000 & 0.000 & 0.000 & 0.000 & 0.001 & 0.000 & 0.001 & 0.000 & 0.000 \\
\hline Al & 1.90 & 1.81 & 1.61 & 1.92 & 1.59 & 1.70 & 1.81 & 1.59 & 1.83 & 1.64 & 1.82 & 1.78 & 1.86 & 1.84 & 1.81 & 1.79 & 1.74 & 1.84 & 1.70 & 1.82 \\
\hline Fe total & 0.033 & 0.038 & 0.046 & 0.032 & 0.028 & 0.067 & 0.027 & 0.029 & 0.030 & 0.025 & 0.022 & 0.026 & 0.028 & 0.030 & 0.026 & 0.029 & 0.027 & 0.031 & 0.025 & 0.025 \\
\hline Mn & 0.007 & 0.009 & 0.012 & 0.006 & 0.004 & 0.005 & 0.003 & 0.004 & 0.003 & 0.003 & 0.003 & 0.003 & 0.002 & 0.004 & 0.003 & 0.003 & 0.003 & 0.003 & 0.004 & 0.002 \\
\hline Mg & 0.94 & 0.84 & 0.70 & 0.95 & 0.64 & 0.72 & 0.84 & 0.62 & 0.84 & 0.67 & 0.84 & 0.80 & 0.89 & 0.86 & 0.83 & 0.79 & 0.79 & 0.87 & 0.76 & 0.85 \\
\hline $\mathrm{Ca}$ & 0.070 & 0.147 & 0.284 & 0.056 & 0.332 & 0.184 & 0.163 & 0.329 & 0.145 & 0.288 & 0.149 & 0.184 & 0.115 & 0.131 & 0.155 & 0.188 & 0.207 & 0.127 & 0.239 & 0.144 \\
\hline $\mathrm{Na}$ & 0.000 & 0.001 & 0.002 & 0.000 & 0.002 & 0.004 & 0.001 & 0.002 & 0.001 & 0.001 & 0.001 & 0.001 & 0.000 & 0.000 & 0.001 & 0.002 & 0.001 & 0.001 & 0.001 & 0.000 \\
\hline Total & 5.02 & 5.01 & 5.00 & 5.02 & 4.98 & 4.96 & 5.01 & 4.97 & 5.00 & 4.98 & 5.00 & 5.00 & 5.01 & 5.01 & 5.00 & 5.00 & 5.00 & 5.01 & 5.00 & 5.00 \\
\hline \multicolumn{21}{|l|}{ Atomic \% } \\
\hline $\mathbf{A b}$ & 6.9 & 14.8 & 28.8 & 5.6 & 34.2 & 20.3 & 16.4 & 34.5 & 14.6 & 30.0 & 15.0 & 18.6 & 11.4 & 13.2 & 15.7 & 19.3 & 20.7 & 12.8 & 24.0 & 14.5 \\
\hline An & 93.1 & 85.1 & 71.0 & 94.4 & 65.5 & 79.2 & 83.6 & 65.3 & 85.3 & 69.9 & 85.0 & 81.3 & 88.5 & 86.8 & 84.2 & 80.6 & 79.2 & 87.1 & 75.9 & 85.5 \\
\hline Or & 0.0 & 0.1 & 0.2 & 0.0 & 0.2 & 0.5 & 0.1 & 0.2 & 0.1 & 0.1 & 0.1 & 0.1 & 0.0 & 0.0 & 0.1 & 0.2 & 0.1 & 0.1 & 0.1 & 0.0 \\
\hline
\end{tabular}


Table F.3. Continued

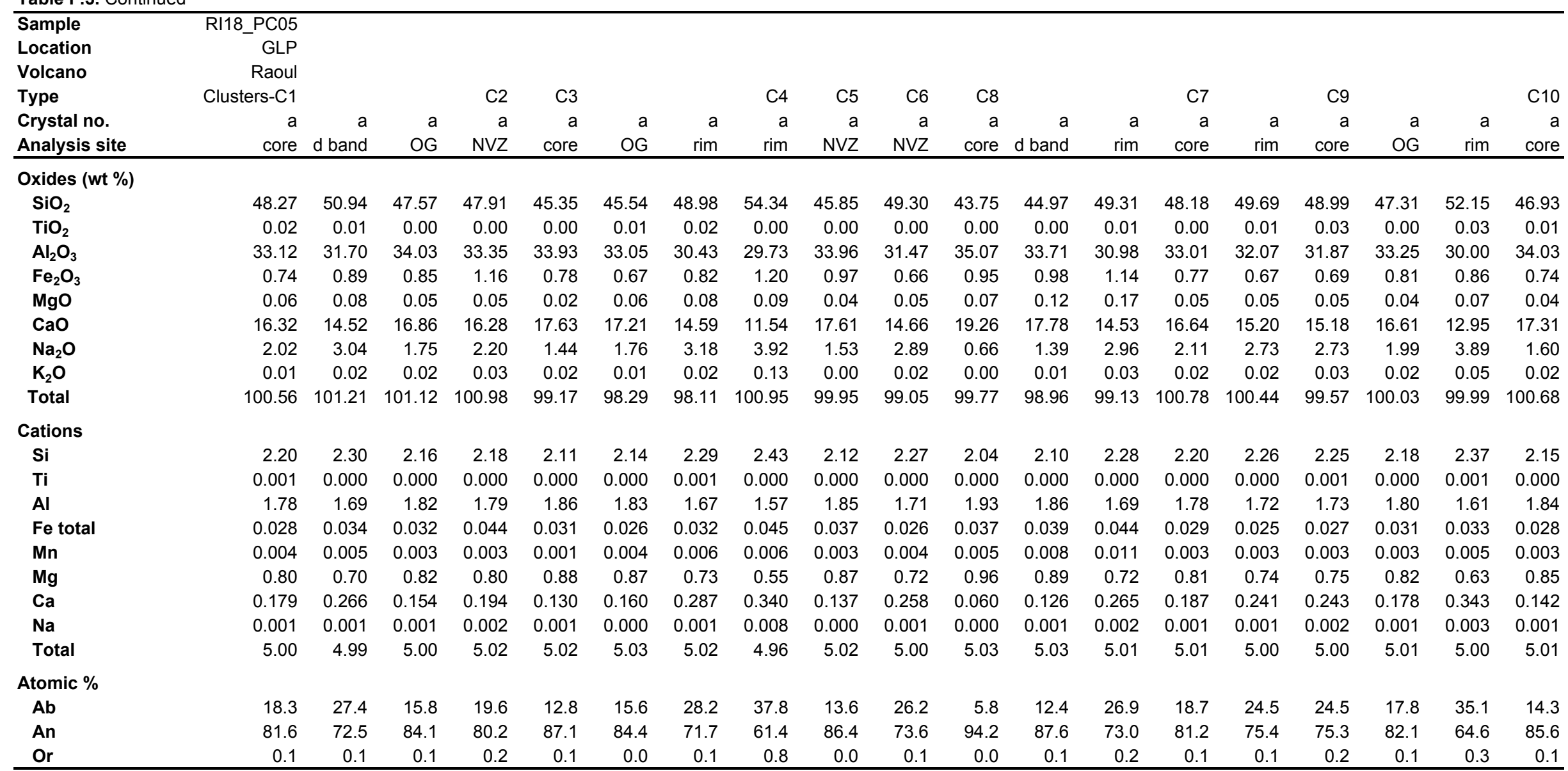


Table F.3. Continued

\begin{tabular}{|c|c|c|c|c|c|c|c|c|c|c|c|c|c|c|c|c|c|c|c|}
\hline $\begin{array}{l}\text { Sample } \\
\text { Location } \\
\text { Volcano } \\
\text { Type }\end{array}$ & & & & $\begin{array}{r}\text { RI26_PC01 } \\
\text { Fleetwood } \\
\text { Raoul } \\
\text { Single crystal }\end{array}$ & & & & & & & & & & & & & & & \\
\hline $\begin{array}{l}\text { Crystal no. } \\
\text { Analysis site }\end{array}$ & $\begin{array}{r}a \\
\mathrm{~d} \text { band } \\
\end{array}$ & $\begin{array}{r}a \\
O G \\
\end{array}$ & $\begin{array}{r}\text { a } \\
\text { rim }\end{array}$ & $\begin{array}{r}1 \\
N V Z \\
\end{array}$ & $\begin{array}{r}2 \\
N V Z \\
\end{array}$ & $\begin{array}{r}3 \\
\text { core } \\
\end{array}$ & $\begin{array}{r}3 \\
\text { rim } \\
\end{array}$ & $\begin{array}{r}4 \\
N V Z \\
\end{array}$ & $\begin{array}{r}5 \\
N V Z \\
\end{array}$ & $\begin{array}{r}6 \\
N V Z \\
\end{array}$ & $\begin{array}{r}7 \\
\text { NVZ } \\
\end{array}$ & $\begin{array}{r}8 \\
N V Z \\
\end{array}$ & $\begin{array}{r}9 \\
N V Z \\
\end{array}$ & $\begin{array}{r}9 \\
\text { rim } \\
\end{array}$ & $\begin{array}{r}10 \\
N V Z \\
\end{array}$ & $\begin{array}{r}11 \\
\text { core } \\
\end{array}$ & $\begin{array}{r}11 \\
\text { core } \\
\end{array}$ & $\begin{array}{r}11 \\
\text { rim }\end{array}$ & $\begin{array}{r}11 \\
\text { rim } \\
\end{array}$ \\
\hline \multicolumn{20}{|l|}{ Oxides (wt \%) } \\
\hline $\mathrm{SiO}_{2}$ & 51.63 & 51.45 & 52.47 & 43.66 & 43.43 & 43.51 & 46.47 & 43.57 & 43.67 & 43.96 & 43.96 & 43.98 & 43.43 & 46.13 & 44.20 & 49.81 & 50.06 & 47.92 & 46.99 \\
\hline $\mathrm{TiO}_{2}$ & 0.01 & 0.00 & 0.03 & 0.00 & 0.00 & 0.00 & 0.00 & 0.00 & 0.00 & 0.00 & 0.00 & 0.00 & 0.00 & 0.00 & 0.00 & 0.02 & 0.00 & 0.01 & 0.01 \\
\hline $\mathrm{Al}_{2} \mathrm{O}_{3}$ & 30.39 & 32.29 & 30.18 & 35.53 & 35.77 & 35.54 & 33.30 & 35.45 & 35.62 & 35.60 & 35.77 & 35.85 & 36.20 & 33.78 & 35.48 & 31.68 & 31.27 & 32.88 & 33.70 \\
\hline $\mathrm{Fe}_{2} \mathrm{O}_{3}$ & 0.72 & 0.75 & 0.87 & 0.68 & 0.57 & 0.78 & 0.90 & 0.82 & 0.67 & 0.81 & 0.79 & 0.57 & 0.57 & 0.93 & 0.73 & 0.74 & 0.70 & 0.79 & 0.83 \\
\hline MgO & 0.08 & 0.04 & 0.08 & 0.11 & 0.09 & 0.09 & 0.18 & 0.07 & 0.08 & 0.11 & 0.08 & 0.09 & 0.08 & 0.17 & 0.09 & 0.06 & 0.07 & 0.05 & 0.06 \\
\hline $\mathrm{CaO}$ & 13.77 & 13.90 & 12.94 & 19.98 & 19.87 & 19.89 & 17.74 & 19.94 & 19.88 & 19.86 & 19.84 & 19.85 & 20.29 & 18.35 & 19.61 & 15.28 & 15.07 & 16.53 & 17.54 \\
\hline $\mathrm{Na}_{2} \mathrm{O}$ & 3.42 & 3.40 & 3.80 & 0.41 & 0.39 & 0.44 & 1.51 & 0.42 & 0.44 & 0.50 & 0.52 & 0.47 & 0.33 & 1.29 & 0.63 & 2.77 & 2.86 & 2.17 & 1.72 \\
\hline $\mathrm{K}_{2} \mathrm{O}$ & 0.03 & 0.04 & 0.04 & 0.01 & 0.00 & 0.00 & 0.02 & 0.00 & 0.01 & 0.00 & 0.01 & 0.00 & 0.01 & 0.01 & 0.02 & 0.02 & 0.03 & 0.02 & 0.01 \\
\hline Total & 100.04 & 101.86 & 100.40 & 100.39 & 100.12 & 100.24 & 100.11 & 100.27 & 100.38 & 100.83 & 100.97 & 100.82 & 100.90 & 100.65 & 100.76 & 100.39 & 100.05 & 100.37 & 100.85 \\
\hline \multicolumn{20}{|l|}{ Cations } \\
\hline Si & 2.35 & 2.30 & 2.37 & 2.02 & 2.02 & 2.02 & 2.15 & 2.02 & 2.02 & 2.03 & 2.03 & 2.03 & 2.00 & 2.12 & 2.04 & 2.27 & 2.29 & 2.20 & 2.15 \\
\hline $\mathrm{Ti}$ & 0.000 & 0.000 & 0.001 & 0.000 & 0.000 & 0.000 & 0.000 & 0.000 & 0.000 & 0.000 & 0.000 & 0.000 & 0.000 & 0.000 & 0.000 & 0.001 & 0.000 & 0.000 & 0.000 \\
\hline Al & 1.63 & 1.70 & 1.61 & 1.94 & 1.96 & 1.94 & 1.81 & 1.94 & 1.95 & 1.94 & 1.94 & 1.95 & 1.97 & 1.83 & 1.93 & 1.70 & 1.68 & 1.78 & 1.82 \\
\hline Fe total & 0.028 & 0.028 & 0.033 & 0.024 & 0.020 & 0.027 & 0.031 & 0.029 & 0.023 & 0.028 & 0.027 & 0.020 & 0.020 & 0.032 & 0.025 & 0.026 & 0.024 & 0.027 & 0.028 \\
\hline Mn & 0.005 & 0.003 & 0.006 & 0.008 & 0.006 & 0.006 & 0.012 & 0.005 & 0.006 & 0.007 & 0.006 & 0.006 & 0.006 & 0.011 & 0.006 & 0.004 & 0.005 & 0.003 & 0.004 \\
\hline Mg & 0.67 & 0.67 & 0.63 & 0.99 & 0.99 & 0.99 & 0.88 & 0.99 & 0.99 & 0.98 & 0.98 & 0.98 & 1.00 & 0.90 & 0.97 & 0.75 & 0.74 & 0.81 & 0.86 \\
\hline $\mathrm{Ca}$ & 0.301 & 0.295 & 0.334 & 0.037 & 0.035 & 0.040 & 0.135 & 0.038 & 0.040 & 0.044 & 0.046 & 0.042 & 0.029 & 0.115 & 0.056 & 0.245 & 0.253 & 0.193 & 0.152 \\
\hline $\mathrm{Na}$ & 0.002 & 0.002 & 0.002 & 0.001 & 0.000 & 0.000 & 0.001 & 0.000 & 0.000 & 0.000 & 0.000 & 0.000 & 0.001 & 0.001 & 0.001 & 0.001 & 0.002 & 0.001 & 0.001 \\
\hline Total & 4.99 & 5.00 & 4.99 & 5.02 & 5.02 & 5.03 & 5.02 & 5.03 & 5.02 & 5.03 & 5.03 & 5.02 & 5.03 & 5.02 & 5.03 & 5.00 & 5.00 & 5.01 & 5.02 \\
\hline \multicolumn{20}{|l|}{ Atomic \% } \\
\hline $\mathbf{A b}$ & 30.9 & 30.6 & 34.6 & 3.6 & 3.4 & 3.8 & 13.4 & 3.7 & 3.9 & 4.3 & 4.5 & 4.1 & 2.8 & 11.3 & 5.5 & 24.7 & 25.5 & 19.2 & 15.0 \\
\hline An & 68.9 & 69.2 & 65.2 & 96.4 & 96.6 & 96.1 & 86.6 & 96.3 & 96.1 & 95.7 & 95.5 & 95.9 & 97.1 & 88.7 & 94.4 & 75.2 & 74.3 & 80.7 & 84.9 \\
\hline Or & 0.2 & 0.2 & 0.2 & 0.1 & 0.0 & 0.0 & 0.1 & 0.0 & 0.0 & 0.0 & 0.0 & 0.0 & 0.1 & 0.1 & 0.1 & 0.1 & 0.2 & 0.1 & 0.1 \\
\hline
\end{tabular}




\begin{tabular}{|c|c|c|c|c|c|c|c|c|c|c|c|c|c|c|c|c|c|c|c|c|}
\hline $\begin{array}{l}\text { Sample } \\
\text { Location } \\
\text { Volcano } \\
\text { Type }\end{array}$ & & & & & & & & & & & & & & & & & & & & \\
\hline $\begin{array}{l}\text { Crystal no. } \\
\text { Analysis site }\end{array}$ & $\begin{array}{r}12 \\
N V Z \\
\end{array}$ & $\begin{array}{r}13 \\
\text { core } \\
\end{array}$ & $\begin{array}{r}13 \\
\text { rim } \\
\end{array}$ & $\begin{array}{r}14 \\
N V Z \\
\end{array}$ & $\begin{array}{r}15 \\
N V Z \\
\end{array}$ & $\begin{array}{r}16 \\
N V Z \\
\end{array}$ & $\begin{array}{r}17 \\
N V Z \\
\end{array}$ & $\begin{array}{r}18 \\
N V Z \\
\end{array}$ & $\begin{array}{r}19 \\
\text { core } \\
\end{array}$ & $\begin{array}{r}19 \\
\text { rim } \\
\end{array}$ & $\begin{array}{r}20 \\
N V Z \\
\end{array}$ & $\begin{array}{r}21 \\
N V Z \\
\end{array}$ & $\begin{array}{r}22 \\
\text { core } \\
\end{array}$ & $\begin{array}{r}22 \\
\text { rim } \\
\end{array}$ & $\begin{array}{r}23 \\
N V Z \\
\end{array}$ & $\begin{array}{r}24 \\
\text { core } \\
\end{array}$ & $\begin{array}{r}24 \\
\text { I band1 } \\
\end{array}$ & $\begin{array}{r}24 \\
\text { I band2 } \\
\end{array}$ & $\begin{array}{r}24 \\
\text { rim } \\
\end{array}$ & $\begin{array}{r}25 \\
N V Z \\
\end{array}$ \\
\hline \multicolumn{21}{|l|}{ Oxides (wt \%) } \\
\hline $\mathrm{SiO}_{2}$ & 43.84 & 43.51 & 46.72 & 44.11 & 47.57 & 43.56 & 45.27 & 43.51 & 47.25 & 49.84 & 43.65 & 43.88 & 44.34 & 46.75 & 47.46 & 46.97 & 48.57 & 51.09 & 47.39 & 44.38 \\
\hline $\mathrm{TiO}_{2}$ & 0.01 & 0.01 & 0.01 & 0.00 & 0.02 & 0.01 & 0.00 & 0.00 & 0.01 & 0.00 & 0.00 & 0.00 & 0.00 & 0.00 & 0.00 & 0.00 & 0.00 & 0.00 & 0.00 & 0.02 \\
\hline $\mathrm{Al}_{2} \mathrm{O}_{3}$ & 35.58 & 36.01 & 33.74 & 36.03 & 33.08 & 35.93 & 34.57 & 35.98 & 33.53 & 31.31 & 36.39 & 36.14 & 35.48 & 33.89 & 32.99 & 33.77 & 32.76 & 30.93 & 33.25 & 35.98 \\
\hline $\mathrm{Fe}_{2} \mathrm{O}_{3}$ & 0.71 & 0.71 & 0.87 & 0.62 & 0.69 & 0.60 & 0.90 & 0.68 & 0.70 & 0.82 & 0.63 & 0.59 & 0.91 & 0.77 & 0.83 & 0.77 & 0.76 & 0.68 & 0.76 & 0.66 \\
\hline MgO & 0.12 & 0.03 & 0.02 & 0.11 & 0.04 & 0.08 & 0.07 & 0.10 & 0.04 & 0.09 & 0.08 & 0.07 & 0.01 & 0.06 & 0.04 & 0.05 & 0.07 & 0.07 & 0.05 & 0.12 \\
\hline $\mathrm{CaO}$ & 19.93 & 20.03 & 17.53 & 19.92 & 16.82 & 20.28 & 18.57 & 20.06 & 17.27 & 15.60 & 20.12 & 20.09 & 19.48 & 17.49 & 17.11 & 17.43 & 16.33 & 14.30 & 17.07 & 19.92 \\
\hline $\mathrm{Na}_{2} \mathrm{O}$ & 0.48 & 0.39 & 1.63 & 0.48 & 1.96 & 0.32 & 1.10 & 0.36 & 1.82 & 2.95 & 0.38 & 0.39 & 0.68 & 1.72 & 1.93 & 1.74 & 2.34 & 3.36 & 1.93 & 0.49 \\
\hline $\mathrm{K}_{2} \mathrm{O}$ & 0.00 & 0.01 & 0.01 & 0.01 & 0.01 & 0.01 & 0.01 & 0.00 & 0.02 & 0.03 & 0.00 & 0.01 & 0.01 & 0.01 & 0.03 & 0.00 & 0.03 & 0.04 & 0.01 & 0.00 \\
\hline Total & 100.67 & 100.70 & 100.55 & 101.28 & 100.18 & 100.79 & 100.49 & 100.67 & 100.64 & 100.63 & 101.24 & 101.18 & 100.91 & 100.69 & 100.38 & 100.73 & 100.86 & 100.47 & 100.48 & 101.55 \\
\hline \multicolumn{21}{|l|}{ Cations } \\
\hline Si & 2.03 & 2.01 & 2.15 & 2.02 & 2.19 & 2.01 & 2.09 & 2.01 & 2.16 & 2.27 & 2.01 & 2.02 & 2.04 & 2.14 & 2.18 & 2.15 & 2.21 & 2.32 & 2.17 & 2.03 \\
\hline $\mathrm{Ti}$ & 0.000 & 0.000 & 0.000 & 0.000 & 0.001 & 0.000 & 0.000 & 0.000 & 0.000 & 0.000 & 0.000 & 0.000 & 0.000 & 0.000 & 0.000 & 0.000 & 0.000 & 0.000 & 0.000 & 0.001 \\
\hline Al & 1.94 & 1.96 & 1.83 & 1.95 & 1.79 & 1.96 & 1.88 & 1.96 & 1.81 & 1.68 & 1.97 & 1.96 & 1.93 & 1.83 & 1.79 & 1.82 & 1.76 & 1.66 & 1.80 & 1.94 \\
\hline $\mathrm{Fe}$ total & 0.025 & 0.025 & 0.030 & 0.022 & 0.024 & 0.021 & 0.031 & 0.024 & 0.024 & 0.028 & 0.022 & 0.021 & 0.032 & 0.026 & 0.029 & 0.026 & 0.026 & 0.023 & 0.026 & 0.023 \\
\hline Mn & 0.008 & 0.002 & 0.002 & 0.008 & 0.002 & 0.006 & 0.005 & 0.007 & 0.003 & 0.006 & 0.005 & 0.005 & 0.001 & 0.004 & 0.003 & 0.004 & 0.005 & 0.005 & 0.004 & 0.008 \\
\hline Mg & 0.99 & 0.99 & 0.86 & 0.98 & 0.83 & 1.00 & 0.92 & 0.99 & 0.85 & 0.76 & 0.99 & 0.99 & 0.96 & 0.86 & 0.84 & 0.86 & 0.80 & 0.70 & 0.84 & 0.98 \\
\hline $\mathrm{Ca}$ & 0.043 & 0.035 & 0.145 & 0.043 & 0.175 & 0.028 & 0.098 & 0.032 & 0.162 & 0.261 & 0.034 & 0.035 & 0.061 & 0.153 & 0.172 & 0.155 & 0.207 & 0.296 & 0.171 & 0.043 \\
\hline $\mathrm{Na}$ & 0.000 & 0.000 & 0.001 & 0.001 & 0.001 & 0.000 & 0.001 & 0.000 & 0.001 & 0.002 & 0.000 & 0.000 & 0.000 & 0.001 & 0.002 & 0.000 & 0.002 & 0.002 & 0.001 & 0.000 \\
\hline Total & 5.03 & 5.03 & 5.01 & 5.02 & 5.01 & 5.03 & 5.02 & 5.03 & 5.01 & 5.02 & 5.03 & 5.02 & 5.02 & 5.02 & 5.01 & 5.01 & 5.01 & 5.00 & 5.01 & 5.02 \\
\hline \multicolumn{21}{|l|}{ Atomic \% } \\
\hline$A b$ & 4.2 & 3.4 & 14.4 & 4.2 & 17.4 & 2.8 & 9.7 & 3.1 & 16.0 & 25.4 & 3.3 & 3.4 & 5.9 & 15.1 & 17.0 & 15.3 & 20.5 & 29.8 & 16.9 & 4.2 \\
\hline An & 95.8 & 96.5 & 85.5 & 95.8 & 82.5 & 97.2 & 90.3 & 96.9 & 83.9 & 74.4 & 96.7 & 96.6 & 94.0 & 84.9 & 82.9 & 84.7 & 79.3 & 70.0 & 83.0 & 95.8 \\
\hline Or & 0.0 & 0.0 & 0.1 & 0.1 & 0.1 & 0.0 & 0.1 & 0.0 & 0.1 & 0.2 & 0.0 & 0.0 & 0.0 & 0.1 & 0.1 & 0.0 & 0.2 & 0.2 & 0.1 & 0.0 \\
\hline
\end{tabular}


Table F.3. Continued

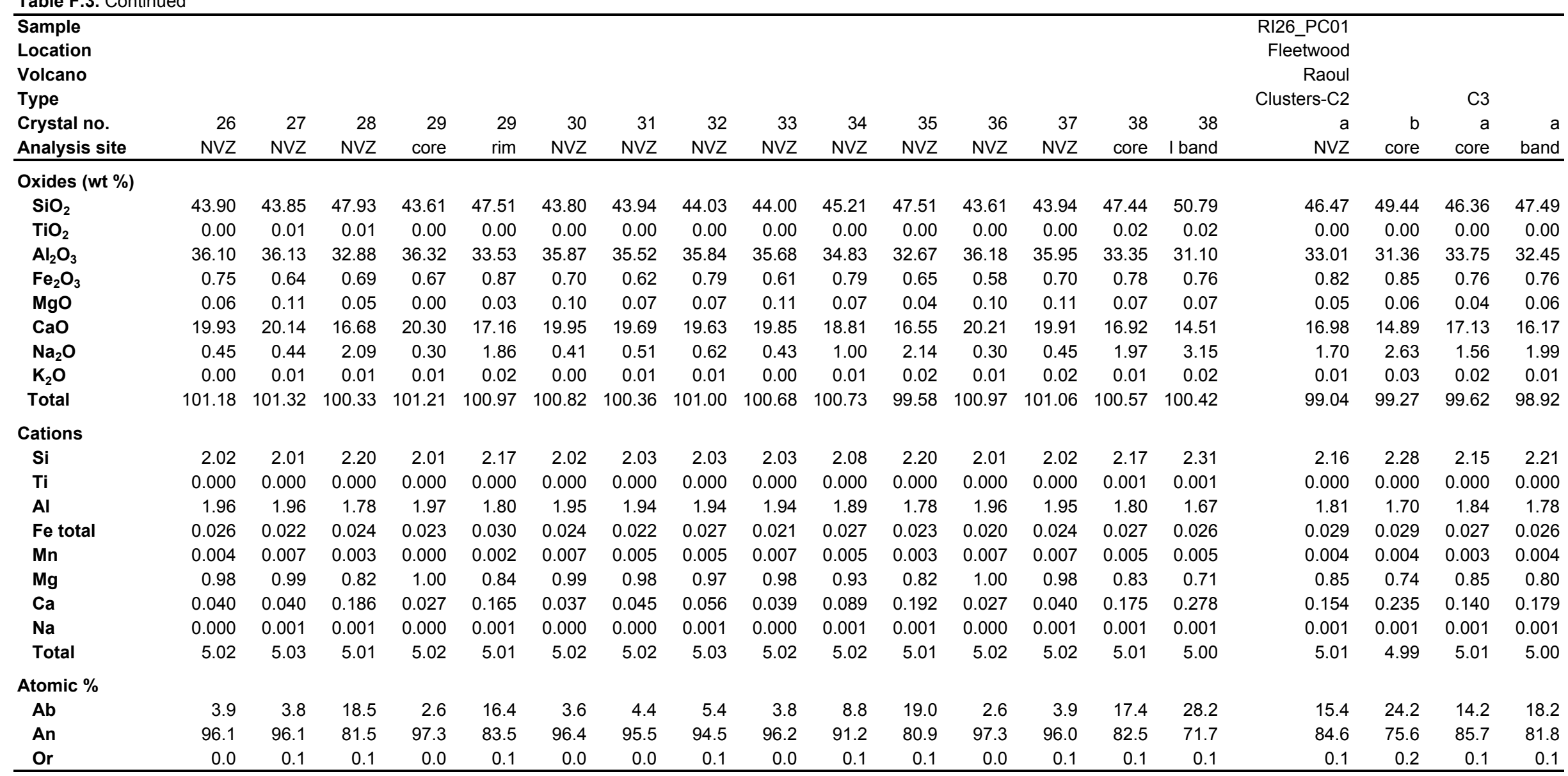


Table F.3. Continued

\begin{tabular}{|c|c|c|c|c|c|c|c|c|c|c|c|c|c|c|c|c|c|c|c|c|}
\hline \multicolumn{21}{|l|}{$\begin{array}{l}\text { Sample } \\
\text { Location }\end{array}$} \\
\hline Type & \multicolumn{3}{|c|}{ C4 } & $\mathrm{C} 5$ & $\mathrm{C} 6$ & $\mathrm{C} 7$ & \multicolumn{3}{|c|}{$\mathrm{C9}$} & \multicolumn{3}{|c|}{ C11 } & \multicolumn{5}{|c|}{ C12 } & \multicolumn{3}{|c|}{ C13 } \\
\hline $\begin{array}{l}\text { Crystal no. } \\
\text { Analysis site }\end{array}$ & $\begin{array}{r}\mathrm{a} \\
\mathrm{rim} \\
\end{array}$ & $\begin{array}{r}a \\
\text { core } \\
\end{array}$ & $\begin{array}{r}a \\
O G \\
\end{array}$ & $\begin{array}{r}a \\
N V Z \\
\end{array}$ & $\begin{array}{r}a \\
N V Z \\
\end{array}$ & $\begin{array}{r}\text { a } \\
\text { core } \\
\end{array}$ & $\begin{array}{r}a \\
d \text { band } \\
\end{array}$ & $\begin{array}{r}a \\
N V Z \\
\end{array}$ & $\begin{array}{r}a \\
N V Z \\
\end{array}$ & $\begin{array}{r}a \\
d \text { band } \\
\end{array}$ & $\begin{array}{r}a \\
N V Z \\
\end{array}$ & $\begin{array}{r}b \\
N V Z \\
\end{array}$ & $\begin{array}{r}\mathrm{C} \\
\text { core } \\
\end{array}$ & $\begin{array}{r}\mathrm{c} \\
\mathrm{rim} \\
\end{array}$ & $\begin{array}{r}a \\
\text { core } \\
\end{array}$ & $\begin{array}{r}a \\
\text { band } \\
\end{array}$ & $\begin{array}{r}\mathrm{a} \\
\mathrm{rim} \\
\end{array}$ & $\begin{array}{r}b \\
N V Z \\
\end{array}$ & $\begin{array}{r}a \\
N V Z \\
\end{array}$ & $\begin{array}{r}b \\
N V Z \\
\end{array}$ \\
\hline \multicolumn{21}{|l|}{ Oxides (wt \%) } \\
\hline $\mathrm{SiO}_{2}$ & 47.34 & 48.91 & 46.47 & 47.21 & 47.17 & 47.19 & 46.93 & 46.91 & 47.03 & 46.81 & 46.93 & 50.90 & 47.37 & 51.63 & 48.02 & 49.75 & 47.13 & 48.74 & 47.57 & 47.30 \\
\hline $\mathrm{TiO}_{2}$ & 0.00 & 0.01 & 0.00 & 0.00 & 0.01 & 0.00 & 0.02 & 0.00 & 0.00 & 0.01 & 0.00 & 0.04 & 0.00 & 0.02 & 0.00 & 0.02 & 0.00 & 0.00 & 0.03 & 0.01 \\
\hline $\mathrm{Al}_{2} \mathrm{O}_{3}$ & 33.11 & 31.85 & 33.44 & 33.20 & 33.84 & 32.64 & 32.39 & 33.24 & 33.56 & 33.16 & 32.44 & 31.36 & 32.78 & 29.73 & 31.97 & 31.25 & 33.07 & 31.96 & 32.70 & 33.15 \\
\hline $\mathrm{Fe}_{2} \mathrm{O}_{3}$ & 0.75 & 0.79 & 0.81 & 0.83 & 0.94 & 0.90 & 1.02 & 0.69 & 0.69 & 0.72 & 0.88 & 2.59 & 0.91 & 0.81 & 0.88 & 0.85 & 0.88 & 0.93 & 0.95 & 1.02 \\
\hline MgO & 0.06 & 0.06 & 0.05 & 0.06 & 0.03 & 0.05 & 0.05 & 0.04 & 0.04 & 0.05 & 0.05 & 0.05 & 0.04 & 0.06 & 0.08 & 0.07 & 0.04 & 0.07 & 0.07 & 0.03 \\
\hline $\mathrm{CaO}$ & 16.54 & 15.34 & 17.10 & 16.70 & 16.77 & 16.09 & 16.52 & 16.91 & 16.72 & 16.86 & 16.56 & 12.02 & 16.29 & 12.96 & 15.59 & 14.67 & 16.40 & 15.37 & 16.49 & 16.54 \\
\hline $\mathrm{Na}_{2} \mathrm{O}$ & 1.87 & 2.54 & 1.62 & 1.84 & 1.61 & 1.96 & 1.89 & 1.75 & 1.81 & 1.72 & 1.88 & 1.88 & 2.06 & 3.61 & 2.37 & 2.89 & 1.94 & 2.48 & 1.68 & 1.89 \\
\hline $\mathrm{K}_{2} \mathrm{O}$ & 0.02 & 0.02 & 0.01 & 0.02 & 0.03 & 0.01 & 0.02 & 0.02 & 0.01 & 0.01 & 0.02 & 0.19 & 0.02 & 0.04 & 0.01 & 0.03 & 0.02 & 0.03 & 0.03 & 0.01 \\
\hline Total & 99.70 & 99.53 & 99.50 & 99.86 & 100.40 & 98.83 & 98.84 & 99.55 & 99.88 & 99.34 & 98.76 & 99.03 & 99.45 & 98.86 & 98.92 & 99.53 & 99.49 & 99.58 & 99.52 & 99.96 \\
\hline \multicolumn{21}{|l|}{ Cations } \\
\hline $\mathrm{Si}$ & 2.18 & 2.25 & 2.15 & 2.18 & 2.16 & 2.20 & 2.19 & 2.17 & 2.17 & 2.17 & 2.19 & 2.34 & 2.19 & 2.37 & 2.23 & 2.29 & 2.18 & 2.25 & 2.20 & 2.18 \\
\hline $\mathrm{Ti}$ & 0.000 & 0.000 & 0.000 & 0.000 & 0.000 & 0.000 & 0.001 & 0.000 & 0.000 & 0.000 & 0.000 & 0.001 & 0.000 & 0.001 & 0.000 & 0.001 & 0.000 & 0.000 & 0.001 & 0.000 \\
\hline Al & 1.80 & 1.73 & 1.83 & 1.80 & 1.83 & 1.79 & 1.78 & 1.81 & 1.82 & 1.81 & 1.78 & 1.70 & 1.79 & 1.61 & 1.75 & 1.69 & 1.80 & 1.73 & 1.78 & 1.80 \\
\hline $\mathrm{Fe}$ total & 0.026 & 0.027 & 0.028 & 0.029 & 0.032 & 0.031 & 0.036 & 0.024 & 0.024 & 0.025 & 0.031 & 0.090 & 0.032 & 0.028 & 0.031 & 0.030 & 0.031 & 0.032 & 0.033 & 0.035 \\
\hline Mn & 0.004 & 0.004 & 0.004 & 0.004 & 0.002 & 0.003 & 0.004 & 0.003 & 0.003 & 0.004 & 0.003 & 0.003 & 0.002 & 0.004 & 0.006 & 0.004 & 0.003 & 0.005 & 0.005 & 0.002 \\
\hline Mg & 0.82 & 0.76 & 0.85 & 0.82 & 0.82 & 0.80 & 0.83 & 0.84 & 0.83 & 0.84 & 0.83 & 0.59 & 0.81 & 0.64 & 0.78 & 0.72 & 0.81 & 0.76 & 0.82 & 0.82 \\
\hline $\mathrm{Ca}$ & 0.167 & 0.227 & 0.146 & 0.164 & 0.143 & 0.177 & 0.171 & 0.157 & 0.162 & 0.154 & 0.170 & 0.168 & 0.185 & 0.322 & 0.214 & 0.257 & 0.174 & 0.222 & 0.151 & 0.169 \\
\hline $\mathrm{Na}$ & 0.001 & 0.001 & 0.000 & 0.001 & 0.002 & 0.001 & 0.001 & 0.001 & 0.001 & 0.001 & 0.001 & 0.011 & 0.001 & 0.002 & 0.001 & 0.002 & 0.001 & 0.002 & 0.002 & 0.001 \\
\hline Total & 5.00 & 5.00 & 5.01 & 5.00 & 5.00 & 5.00 & 5.01 & 5.00 & 5.00 & 5.00 & 5.00 & 4.90 & 5.01 & 4.98 & 5.00 & 5.00 & 5.01 & 5.00 & 4.99 & 5.00 \\
\hline \multicolumn{21}{|l|}{ Atomic \% } \\
\hline$A b$ & 17.0 & 23.0 & 14.6 & 16.6 & 14.8 & 18.0 & 17.1 & 15.7 & 16.4 & 15.5 & 17.0 & 21.8 & 18.6 & 33.5 & 21.6 & 26.2 & 17.6 & 22.6 & 15.5 & 17.2 \\
\hline An & 82.9 & 76.8 & 85.3 & 83.3 & 85.0 & 81.9 & 82.8 & 84.2 & 83.6 & 84.4 & 82.9 & 76.8 & 81.3 & 66.3 & 78.4 & 73.6 & 82.3 & 77.3 & 84.3 & 82.8 \\
\hline Or & 0.1 & 0.1 & 0.0 & 0.1 & 0.2 & 0.1 & 0.1 & 0.1 & 0.1 & 0.1 & 0.1 & 1.4 & 0.1 & 0.2 & 0.1 & 0.2 & 0.1 & 0.2 & 0.2 & 0.1 \\
\hline
\end{tabular}


Table F.3. Continued

\begin{tabular}{|c|c|c|c|c|c|c|c|c|c|c|c|c|c|c|c|c|c|c|c|}
\hline $\begin{array}{l}\text { Sample } \\
\text { Location } \\
\text { Volcano }\end{array}$ & & & & & & & $\begin{array}{r}\text { RI26_PC01 } \\
\text { Fleetwood } \\
\text { Raoul }\end{array}$ & & & & & & & & & & & & \\
\hline Type & C14 & & C15 & & & $\mathrm{C} 16$ & Mafic Bleb-1 & MB02 & MB03 & & MB04 & & MB05 & IB06 & & MB07 & B08 & 9 & B10 \\
\hline Crystal no. & a & $b$ & $a$ & a & b & $a$ & a I & plag2 & a & $\mathrm{b}$ & a & $\mathrm{b}$ & $a$ & a & $\mathrm{b}$ & $a$ & a & & $a$ \\
\hline Analysis site & NVZ & NVZ & NVZ & NVZ & NVZ & NVZ & NVZ & $\mathrm{NVZ}$ & NVZ & NVZ & NVZ & NVZ & NVZ & NVZ & NVZ & NVZ & NVZ & NVZ & NVZ \\
\hline \multicolumn{20}{|l|}{ Oxides (wt \%) } \\
\hline $\mathrm{SiO}_{2}$ & 46.36 & 48.58 & 47.43 & 46.89 & 46.62 & 48.30 & 43.44 & 44.04 & 43.29 & 43.65 & 43.89 & 43.46 & 43.86 & 43.83 & 43.60 & 43.88 & 44.07 & 43.93 & 43.46 \\
\hline $\mathrm{TiO}_{2}$ & 0.01 & 0.01 & 0.00 & 0.01 & 0.00 & 0.01 & 0.00 & 0.00 & 0.00 & 0.00 & 0.00 & 0.00 & 0.00 & 0.00 & 0.01 & 0.00 & 0.00 & 0.00 & 0.00 \\
\hline $\mathrm{Al}_{2} \mathrm{O}_{3}$ & 33.77 & 32.36 & 32.86 & 33.25 & 33.51 & 32.34 & 35.72 & 34.97 & 35.68 & 35.59 & 34.77 & 35.50 & 35.45 & 35.52 & 35.19 & 35.79 & 35.40 & 35.67 & 36.09 \\
\hline $\mathrm{Fe}_{2} \mathrm{O}_{3}$ & 0.82 & 0.95 & 0.77 & 0.83 & 0.80 & 1.26 & 0.72 & 0.84 & 0.77 & 0.72 & 0.78 & 0.70 & 0.79 & 0.69 & 0.66 & 0.80 & 0.93 & 0.58 & 0.69 \\
\hline MgO & 0.03 & 0.05 & 0.06 & 0.04 & 0.05 & 0.05 & 0.07 & 0.08 & 0.07 & 0.12 & 0.08 & 0.09 & 0.08 & 0.09 & 0.10 & 0.09 & 0.07 & 0.08 & 0.08 \\
\hline $\mathrm{CaO}$ & 17.26 & 15.78 & 16.20 & 16.66 & 16.98 & 15.96 & 19.66 & 19.36 & 19.81 & 19.68 & 19.51 & 19.82 & 19.73 & 19.48 & 19.54 & 19.84 & 19.24 & 19.78 & 20.17 \\
\hline $\mathrm{Na}_{2} \mathrm{O}$ & 1.58 & 2.25 & 1.99 & 1.80 & 1.69 & 2.15 & 0.39 & 0.62 & 0.38 & 0.46 & 0.56 & 0.45 & 0.56 & 0.52 & 0.56 & 0.47 & 0.72 & 0.49 & 0.32 \\
\hline $\mathrm{K}_{2} \mathrm{O}$ & 0.01 & 0.02 & 0.02 & 0.01 & 0.01 & 0.02 & 0.01 & 0.00 & 0.00 & 0.00 & 0.01 & 0.02 & 0.01 & 0.01 & 0.00 & 0.00 & 0.00 & 0.00 & 0.00 \\
\hline Total & 99.84 & 99.99 & 99.32 & 99.50 & 99.66 & 100.10 & 100.01 & 99.92 & 100.00 & 100.21 & 99.61 & 100.03 & 100.48 & 100.15 & 99.65 & 100.87 & 100.43 & 100.52 & 100.81 \\
\hline \multicolumn{20}{|l|}{ Cations } \\
\hline Si & 2.14 & 2.23 & 2.19 & 2.17 & 2.16 & 2.22 & 2.02 & 2.05 & 2.01 & 2.02 & 2.05 & 2.02 & 2.03 & 2.03 & 2.03 & 2.02 & 2.04 & 2.03 & 2.01 \\
\hline $\mathrm{Ti}$ & 0.000 & 0.000 & 0.000 & 0.000 & 0.000 & 0.000 & 0.000 & 0.000 & 0.000 & 0.000 & 0.000 & 0.000 & 0.000 & 0.000 & 0.000 & 0.000 & 0.000 & 0.000 & 0.000 \\
\hline Al & 1.84 & 1.75 & 1.79 & 1.81 & 1.83 & 1.75 & 1.96 & 1.92 & 1.96 & 1.95 & 1.91 & 1.95 & 1.93 & 1.94 & 1.93 & 1.95 & 1.93 & 1.94 & 1.96 \\
\hline Fe total & 0.029 & 0.033 & 0.027 & 0.029 & 0.028 & 0.044 & 0.025 & 0.030 & 0.027 & 0.025 & 0.028 & 0.024 & 0.028 & 0.024 & 0.023 & 0.028 & 0.032 & 0.020 & 0.024 \\
\hline Mn & 0.002 & 0.003 & 0.004 & 0.002 & 0.003 & 0.004 & 0.005 & 0.006 & 0.005 & 0.008 & 0.006 & 0.006 & 0.005 & 0.006 & 0.007 & 0.006 & 0.005 & 0.005 & 0.006 \\
\hline Mg & 0.85 & 0.78 & 0.80 & 0.83 & 0.84 & 0.79 & 0.98 & 0.96 & 0.99 & 0.98 & 0.98 & 0.99 & 0.98 & 0.97 & 0.98 & 0.98 & 0.95 & 0.98 & 1.00 \\
\hline $\mathrm{Ca}$ & 0.142 & 0.200 & 0.178 & 0.162 & 0.152 & 0.192 & 0.035 & 0.056 & 0.034 & 0.041 & 0.050 & 0.041 & 0.050 & 0.047 & 0.051 & 0.042 & 0.064 & 0.044 & 0.028 \\
\hline $\mathrm{Na}$ & 0.000 & 0.001 & 0.001 & 0.000 & 0.001 & 0.001 & 0.001 & 0.000 & 0.000 & 0.000 & 0.001 & 0.001 & 0.000 & 0.001 & 0.000 & 0.000 & 0.000 & 0.000 & 0.000 \\
\hline Total & 5.01 & 5.00 & 5.00 & 5.00 & 5.01 & 5.00 & 5.02 & 5.02 & 5.02 & 5.02 & 5.02 & 5.03 & 5.03 & 5.02 & 5.02 & 5.03 & 5.03 & 5.02 & 5.03 \\
\hline \multicolumn{20}{|l|}{ Atomic \% } \\
\hline$A b$ & 14.2 & 20.5 & 18.1 & 16.4 & 15.3 & 19.6 & 3.5 & 5.5 & 3.4 & 4.1 & 4.9 & 3.9 & 4.9 & 4.6 & 5.0 & 4.1 & 6.3 & 4.3 & 2.8 \\
\hline An & 85.7 & 79.4 & 81.8 & 83.6 & 84.7 & 80.3 & 96.5 & 94.5 & 96.6 & 95.9 & 95.0 & 95.9 & 95.1 & 95.3 & 95.0 & 95.9 & 93.7 & 95.7 & 97.2 \\
\hline Or & 0.0 & 0.1 & 0.1 & 0.0 & 0.1 & 0.1 & 0.1 & 0.0 & 0.0 & 0.0 & 0.1 & 0.1 & 0.0 & 0.1 & 0.0 & 0.0 & 0.0 & 0.0 & 0.0 \\
\hline
\end{tabular}


Table F.3. Continued

\begin{tabular}{|c|c|c|c|c|c|c|c|c|c|c|c|c|c|c|c|c|c|c|c|}
\hline Sample & & & & & & & & & & & & MI07_PC03 & & & & & & & \\
\hline Location & & & & & & & & & & & & $\mathrm{SBT}$ & & & & & & & \\
\hline Volcano & & & & & & & & & & & & Macauley & & & & & & & \\
\hline Type & & MB11 & MB12 & MB13 & MB14 & MB15 & MB16 & MB17 & MB18 & MB19 & MB20 & Single crystal & & & & & & & \\
\hline Crystal no. & b & a & $\mathrm{a}$ & a & a & a & a & $\mathrm{a}$ & a & a & a & 1 & 2 & 3 & 4 & 5 & 5 & 6 & 7 \\
\hline Analysis site & NVZ & NVZ & NVZ & NVZ & NVZ & NVZ & NVZ & NVZ & NVZ & NVZ & NVZ & NVZ & NVZ & NVZ & $\mathrm{NVZ}$ & core & rim & NVZ & core \\
\hline \multicolumn{20}{|l|}{ Oxides (wt \%) } \\
\hline $\mathrm{SiO}_{2}$ & 43.62 & 43.90 & 44.04 & 45.62 & 44.46 & 43.81 & 46.23 & 43.72 & 43.82 & 43.70 & 43.69 & 45.95 & 46.65 & 45.14 & 56.06 & 54.62 & 54.63 & 54.57 & 55.08 \\
\hline $\mathrm{TiO}_{2}$ & 0.00 & 0.00 & 0.00 & 0.02 & 0.00 & 0.00 & 0.01 & 0.00 & 0.00 & 0.00 & 0.00 & 0.00 & 0.00 & 0.00 & 0.02 & 0.02 & 0.02 & 0.02 & 0.03 \\
\hline $\mathrm{Al}_{2} \mathrm{O}_{3}$ & 35.59 & 35.54 & 34.87 & 34.27 & 34.50 & 35.35 & 34.06 & 35.65 & 34.89 & 35.80 & 35.63 & 33.32 & 33.84 & 33.77 & 27.27 & 28.08 & 27.58 & 28.29 & 27.84 \\
\hline $\mathrm{Fe}_{2} \mathrm{O}_{3}$ & 0.60 & 0.82 & 0.68 & 0.61 & 0.99 & 0.75 & 0.79 & 0.65 & 0.83 & 0.67 & 0.69 & 0.99 & 0.97 & 1.00 & 0.64 & 0.60 & 0.60 & 0.66 & 0.69 \\
\hline $\mathrm{MgO}$ & 0.06 & 0.11 & 0.10 & 0.03 & 0.08 & 0.09 & 0.04 & 0.08 & 0.11 & 0.09 & 0.08 & 0.09 & 0.09 & 0.06 & 0.02 & 0.04 & 0.03 & 0.04 & 0.06 \\
\hline $\mathrm{CaO}$ & 19.96 & 19.74 & 19.05 & 17.92 & 18.79 & 19.44 & 17.52 & 19.70 & 18.89 & 19.50 & 19.55 & 17.54 & 17.85 & 17.92 & 9.94 & 10.69 & 10.63 & 11.03 & 10.84 \\
\hline $\mathrm{Na}_{2} \mathrm{O}$ & 0.39 & 0.57 & 0.70 & 1.23 & 0.85 & 0.57 & 1.41 & 0.37 & 0.72 & 0.47 & 0.46 & 1.30 & 1.25 & 1.27 & 5.17 & 4.60 & 4.89 & 4.76 & 4.69 \\
\hline $\mathrm{K}_{2} \mathrm{O}$ & 0.01 & 0.01 & 0.00 & 0.01 & 0.01 & 0.00 & 0.01 & 0.01 & 0.01 & 0.01 & 0.00 & 0.03 & 0.02 & 0.02 & 0.12 & 0.11 & 0.12 & 0.10 & 0.13 \\
\hline Total & 100.21 & 100.69 & 99.43 & 99.71 & 99.67 & 100.02 & 100.07 & 100.17 & 99.27 & 100.24 & 100.11 & 99.21 & 100.67 & 99.19 & 99.24 & 98.75 & 98.49 & 99.47 & 99.34 \\
\hline \multicolumn{20}{|l|}{ Cations } \\
\hline Si & 2.02 & 2.03 & 2.05 & 2.11 & 2.07 & 2.04 & 2.13 & 2.03 & 2.05 & 2.02 & 2.03 & 2.14 & 2.14 & 2.11 & 2.54 & 2.49 & 2.50 & 2.48 & 2.50 \\
\hline $\mathrm{Ti}$ & 0.000 & 0.000 & 0.000 & 0.001 & 0.000 & 0.000 & 0.000 & 0.000 & 0.000 & 0.000 & 0.000 & 0.000 & 0.000 & 0.000 & 0.001 & 0.001 & 0.001 & 0.001 & 0.001 \\
\hline Al & 1.95 & 1.94 & 1.92 & 1.87 & 1.89 & 1.94 & 1.85 & 1.95 & 1.92 & 1.95 & 1.95 & 1.83 & 1.83 & 1.86 & 1.46 & 1.51 & 1.49 & 1.51 & 1.49 \\
\hline Fe total & 0.021 & 0.029 & 0.024 & 0.021 & 0.035 & 0.026 & 0.027 & 0.023 & 0.029 & 0.024 & 0.024 & 0.038 & 0.037 & 0.039 & 0.024 & 0.023 & 0.023 & 0.025 & 0.026 \\
\hline Mn & 0.004 & 0.008 & 0.007 & 0.002 & 0.005 & 0.006 & 0.003 & 0.005 & 0.008 & 0.006 & 0.005 & 0.006 & 0.006 & 0.004 & 0.001 & 0.002 & 0.002 & 0.003 & 0.004 \\
\hline Mg & 0.99 & 0.98 & 0.95 & 0.89 & 0.94 & 0.97 & 0.87 & 0.98 & 0.95 & 0.97 & 0.97 & 0.87 & 0.88 & 0.90 & 0.48 & 0.52 & 0.52 & 0.54 & 0.53 \\
\hline $\mathrm{Ca}$ & 0.035 & 0.051 & 0.064 & 0.110 & 0.077 & 0.051 & 0.126 & 0.033 & 0.066 & 0.042 & 0.042 & 0.118 & 0.111 & 0.115 & 0.454 & 0.407 & 0.434 & 0.419 & 0.412 \\
\hline $\mathrm{Na}$ & 0.000 & 0.001 & 0.000 & 0.001 & 0.000 & 0.000 & 0.001 & 0.000 & 0.000 & 0.001 & 0.000 & 0.001 & 0.001 & 0.001 & 0.007 & 0.006 & 0.007 & 0.006 & 0.007 \\
\hline Total & 5.02 & 5.03 & 5.02 & 5.01 & 5.02 & 5.02 & 5.01 & 5.02 & 5.02 & 5.02 & 5.02 & 5.01 & 5.00 & 5.02 & 4.96 & 4.96 & 4.98 & 4.98 & 4.97 \\
\hline \multicolumn{20}{|l|}{ Atomic \% } \\
\hline$A b$ & 3.4 & 5.0 & 6.3 & 11.0 & 7.5 & 5.0 & 12.7 & 3.3 & 6.5 & 4.1 & 4.1 & 11.8 & 11.2 & 11.3 & 48.2 & 43.5 & 45.1 & 43.6 & 43.6 \\
\hline An & 96.6 & 94.9 & 93.7 & 88.9 & 92.4 & 95.0 & 87.2 & 96.7 & 93.5 & 95.8 & 95.9 & 88.0 & 88.6 & 88.5 & 51.1 & 55.9 & 54.2 & 55.8 & 55.7 \\
\hline Or & 0.0 & 0.1 & 0.0 & 0.1 & 0.0 & 0.0 & 0.1 & 0.0 & 0.0 & 0.1 & 0.0 & 0.1 & 0.1 & 0.1 & 0.7 & 0.7 & 0.7 & 0.6 & 0.8 \\
\hline
\end{tabular}




\begin{tabular}{|c|c|c|c|c|c|c|c|c|c|c|c|c|c|c|c|c|c|c|c|c|}
\hline $\begin{array}{l}\text { Sample } \\
\text { Location } \\
\text { Volcano } \\
\text { Type }\end{array}$ & & & & & & & & & & & & & & & & & & & & \\
\hline $\begin{array}{l}\text { Crystal no. } \\
\text { Analysis site }\end{array}$ & $\begin{array}{r}7 \\
\mathrm{~d} \text { band } \\
\end{array}$ & $\begin{array}{r}7 \\
\text { OG } \\
\end{array}$ & $\begin{array}{r}8 \\
N V Z \\
\end{array}$ & $\begin{array}{r}9 \\
N V Z \\
\end{array}$ & $\begin{array}{r}11 \\
N V Z \\
\end{array}$ & $\begin{array}{r}12 \\
N V Z \\
\end{array}$ & $\begin{array}{r}13 \\
N V Z \\
\end{array}$ & $\begin{array}{r}14 \\
N V Z \\
\end{array}$ & $\begin{array}{r}15 \\
N V Z \\
\end{array}$ & $\begin{array}{r}16 \\
\text { core } \\
\end{array}$ & $\begin{array}{r}16 \\
\mathrm{~d} \text { band } \\
\end{array}$ & $\begin{array}{r}17 \\
\text { NVZ } \\
\end{array}$ & $\begin{array}{r}17 \\
\text { NVZ } \\
\end{array}$ & $\begin{array}{r}18 \\
N V Z \\
\end{array}$ & $\begin{array}{r}19 \\
N V Z \\
\end{array}$ & $\begin{array}{r}20 \\
N V Z \\
\end{array}$ & $\begin{array}{r}21 \\
N V Z \\
\end{array}$ & $\begin{array}{r}22 \\
N V Z \\
\end{array}$ & $\begin{array}{r}22 \\
N V Z \\
\end{array}$ & $\begin{array}{r}23 \\
N V Z \\
\end{array}$ \\
\hline \multicolumn{21}{|l|}{ Oxides (wt \%) } \\
\hline $\mathrm{SiO}_{2}$ & 55.98 & 55.05 & 45.12 & 54.92 & 54.70 & 55.22 & 55.96 & 55.79 & 45.66 & 54.91 & 57.45 & 54.76 & 56.71 & 45.46 & 45.74 & 55.00 & 54.09 & 45.25 & 45.92 & 55.53 \\
\hline $\mathrm{TiO}_{2}$ & 0.03 & 0.02 & 0.01 & 0.00 & 0.04 & 0.00 & 0.01 & 0.03 & 0.01 & 0.03 & 0.01 & 0.01 & 0.01 & 0.01 & 0.03 & 0.01 & 0.01 & 0.02 & 0.02 & 0.02 \\
\hline $\mathrm{Al}_{2} \mathrm{O}_{3}$ & 27.87 & 27.95 & 33.44 & 28.71 & 28.63 & 28.11 & 26.90 & 28.95 & 33.97 & 27.50 & 27.19 & 27.90 & 27.75 & 34.55 & 34.63 & 28.62 & 28.10 & 35.01 & 34.07 & 27.97 \\
\hline $\mathrm{Fe}_{2} \mathrm{O}_{3}$ & 0.60 & 0.54 & 0.90 & 0.55 & 0.63 & 0.53 & 0.62 & 0.65 & 0.86 & 0.63 & 0.56 & 0.55 & 0.60 & 0.85 & 0.87 & 0.63 & 0.66 & 0.86 & 0.88 & 0.61 \\
\hline MgO & 0.07 & 0.05 & 0.08 & 0.05 & 0.06 & 0.04 & 0.04 & 0.06 & 0.10 & 0.05 & 0.05 & 0.06 & 0.04 & 0.09 & 0.11 & 0.05 & 0.06 & 0.10 & 0.11 & 0.06 \\
\hline $\mathrm{CaO}$ & 10.42 & 10.92 & 17.92 & 10.91 & 11.15 & 10.80 & 9.81 & 11.15 & 17.85 & 10.66 & 9.57 & 10.71 & 9.74 & 18.24 & 18.14 & 11.02 & 11.21 & 18.20 & 17.94 & 10.94 \\
\hline $\mathrm{Na}_{2} \mathrm{O}$ & 4.86 & 4.80 & 1.31 & 4.81 & 4.86 & 4.78 & 5.27 & 4.26 & 1.15 & 4.76 & 5.32 & 4.77 & 5.34 & 1.29 & 1.22 & 4.88 & 4.48 & 1.18 & 1.32 & 4.67 \\
\hline $\mathrm{K}_{2} \mathrm{O}$ & 0.11 & 0.12 & 0.02 & 0.11 & 0.10 & 0.12 & 0.15 & 0.10 & 0.02 & 0.12 & 0.14 & 0.10 & 0.13 & 0.02 & 0.02 & 0.10 & 0.10 & 0.02 & 0.02 & 0.12 \\
\hline Total & 99.93 & 99.45 & 98.80 & 100.06 & 100.17 & 99.60 & 98.75 & 100.99 & 99.63 & 98.67 & 100.27 & 98.86 & 100.32 & 100.49 & 100.75 & 100.31 & 98.71 & 100.63 & 100.28 & 99.91 \\
\hline \multicolumn{21}{|l|}{ Cations } \\
\hline Si & 2.52 & 2.50 & 2.11 & 2.47 & 2.47 & 2.50 & 2.55 & 2.49 & 2.12 & 2.51 & 2.57 & 2.50 & 2.54 & 2.09 & 2.10 & 2.47 & 2.47 & 2.08 & 2.12 & 2.50 \\
\hline $\mathrm{Ti}$ & 0.001 & 0.001 & 0.000 & 0.000 & 0.001 & 0.000 & 0.000 & 0.001 & 0.000 & 0.001 & 0.000 & 0.000 & 0.000 & 0.000 & 0.001 & 0.000 & 0.000 & 0.001 & 0.001 & 0.001 \\
\hline Al & 1.48 & 1.49 & 1.85 & 1.52 & 1.52 & 1.50 & 1.44 & 1.52 & 1.86 & 1.48 & 1.43 & 1.50 & 1.46 & 1.88 & 1.87 & 1.52 & 1.51 & 1.90 & 1.85 & 1.49 \\
\hline Fe total & 0.023 & 0.021 & 0.035 & 0.021 & 0.024 & 0.020 & 0.024 & 0.024 & 0.033 & 0.024 & 0.021 & 0.021 & 0.023 & 0.033 & 0.034 & 0.024 & 0.025 & 0.033 & 0.034 & 0.023 \\
\hline Mn & 0.004 & 0.003 & 0.006 & 0.003 & 0.004 & 0.003 & 0.003 & 0.004 & 0.007 & 0.004 & 0.003 & 0.004 & 0.002 & 0.006 & 0.007 & 0.003 & 0.004 & 0.007 & 0.007 & 0.004 \\
\hline Mg & 0.50 & 0.53 & 0.90 & 0.53 & 0.54 & 0.52 & 0.48 & 0.53 & 0.89 & 0.52 & 0.46 & 0.52 & 0.47 & 0.90 & 0.89 & 0.53 & 0.55 & 0.90 & 0.89 & 0.53 \\
\hline $\mathrm{Ca}$ & 0.424 & 0.421 & 0.119 & 0.420 & 0.425 & 0.419 & 0.465 & 0.368 & 0.104 & 0.421 & 0.461 & 0.422 & 0.463 & 0.115 & 0.109 & 0.425 & 0.397 & 0.105 & 0.118 & 0.408 \\
\hline $\mathrm{Na}$ & 0.006 & 0.007 & 0.001 & 0.006 & 0.006 & 0.007 & 0.009 & 0.006 & 0.001 & 0.007 & 0.008 & 0.006 & 0.008 & 0.001 & 0.001 & 0.006 & 0.006 & 0.001 & 0.001 & 0.007 \\
\hline Total & 4.96 & 4.97 & 5.02 & 4.98 & 4.99 & 4.97 & 4.97 & 4.94 & 5.01 & 4.97 & 4.95 & 4.97 & 4.97 & 5.03 & 5.02 & 4.98 & 4.97 & 5.02 & 5.02 & 4.96 \\
\hline \multicolumn{21}{|l|}{ Atomic $\%$} \\
\hline$A b$ & 45.5 & 44.0 & 11.6 & 44.1 & 43.8 & 44.2 & 48.8 & 40.6 & 10.4 & 44.4 & 49.7 & 44.4 & 49.4 & 11.3 & 10.8 & 44.2 & 41.7 & 10.5 & 11.8 & 43.3 \\
\hline An & 53.9 & 55.3 & 88.2 & 55.3 & 55.6 & 55.1 & 50.3 & 58.7 & 89.4 & 54.9 & 49.4 & 55.0 & 49.8 & 88.6 & 89.1 & 55.2 & 57.7 & 89.4 & 88.1 & 56.0 \\
\hline Or & 0.7 & 0.7 & 0.1 & 0.7 & 0.6 & 0.7 & 0.9 & 0.6 & 0.1 & 0.7 & 0.9 & 0.6 & 0.8 & 0.1 & 0.1 & 0.6 & 0.6 & 0.1 & 0.1 & 0.7 \\
\hline
\end{tabular}


Table F.3. Continued

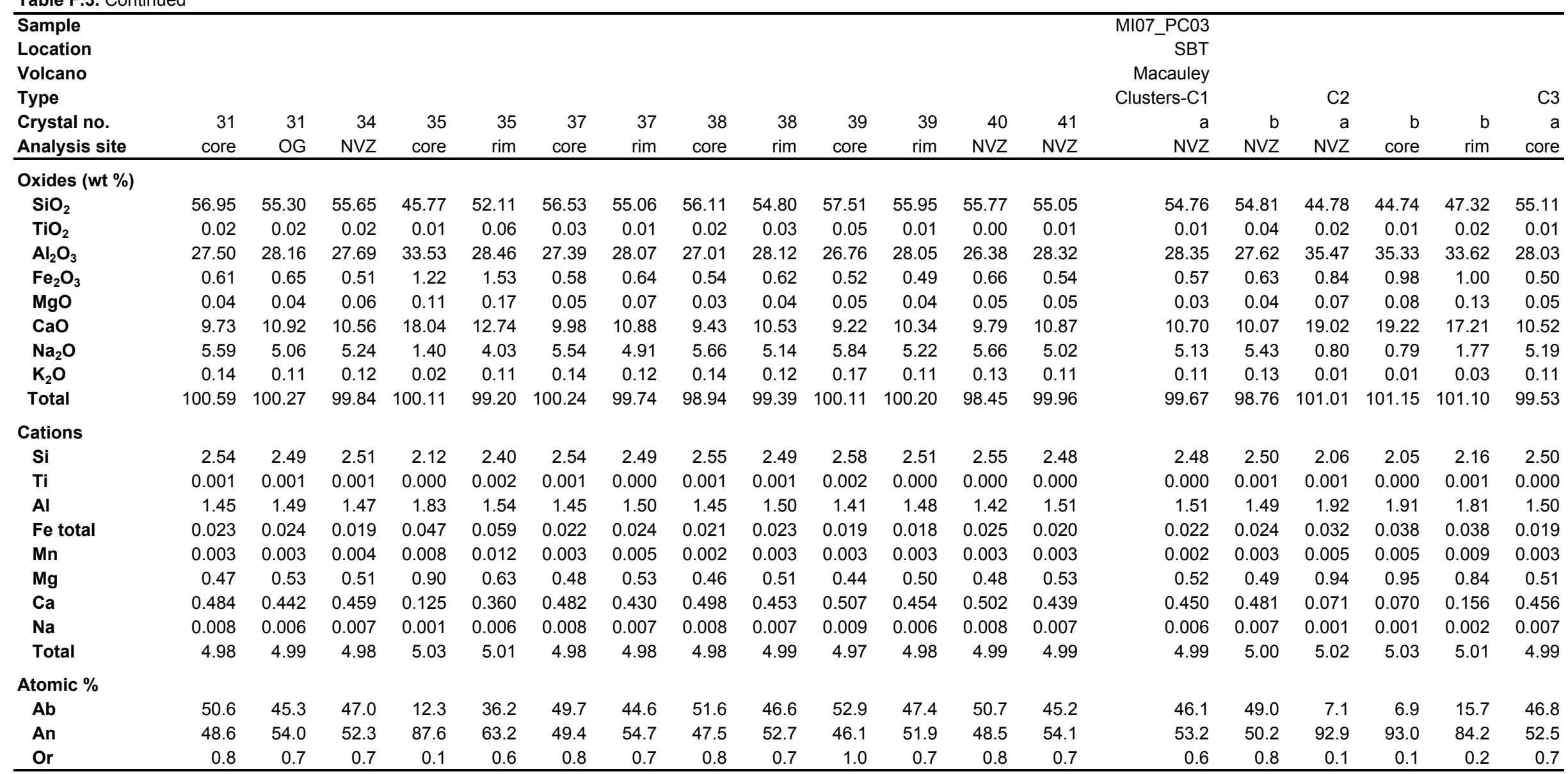


Table F.3. Continued

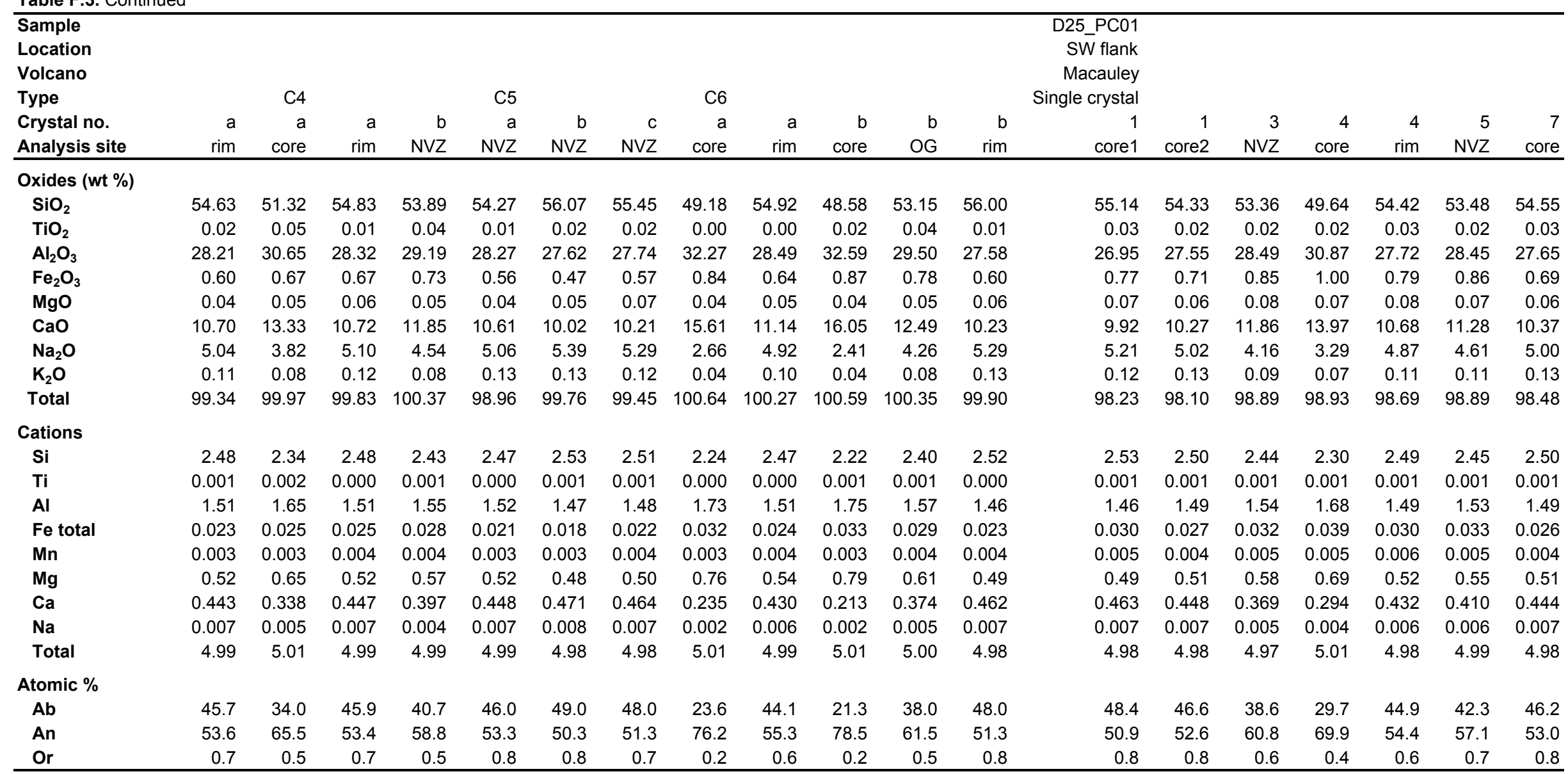


Table F.3. Continued

\begin{tabular}{|c|c|c|c|c|c|c|c|c|c|c|c|c|c|c|c|c|c|c|c|c|}
\hline $\begin{array}{l}\text { Sample } \\
\text { Location } \\
\text { Volcano } \\
\text { Type }\end{array}$ & & & & & & & & & & & & & & & & & & & & \\
\hline $\begin{array}{l}\text { Crystal no. } \\
\text { Analysis site }\end{array}$ & $\begin{array}{r}7 \\
\text { rim } \\
\end{array}$ & $\begin{array}{r}8 \\
\text { core } \\
\end{array}$ & $\begin{array}{r}8 \\
\text { I band } \\
\end{array}$ & $\begin{array}{r}8 \\
\mathrm{~d} \text { band } \\
\end{array}$ & $\begin{array}{r}8 \\
\text { rim } \\
\end{array}$ & $\begin{array}{r}9 \\
N V Z \\
\end{array}$ & $\begin{array}{r}10 \\
N V Z \\
\end{array}$ & $\begin{array}{r}11 \\
N V Z \\
\end{array}$ & $\begin{array}{r}12 \\
N V Z \\
\end{array}$ & $\begin{array}{r}13 \\
\text { core } \\
\end{array}$ & $\begin{array}{r}13 \\
\text { I band } \\
\end{array}$ & $\begin{array}{r}13 \\
\mathrm{rim} \\
\end{array}$ & $\begin{array}{r}14 \\
\text { core } \\
\end{array}$ & $\begin{array}{r}14 \\
\mathrm{~d} \text { band } \\
\end{array}$ & $\begin{array}{r}14 \\
\text { rim } \\
\end{array}$ & $\begin{array}{r}15 \\
N V Z \\
\end{array}$ & $\begin{array}{r}16 \\
N V Z \\
\end{array}$ & $\begin{array}{r}17 \\
\text { core } \\
\end{array}$ & $\begin{array}{r}17 \\
\text { rim } \\
\end{array}$ & $\begin{array}{r}18 \\
N V Z \\
\end{array}$ \\
\hline \multicolumn{21}{|l|}{ Oxides (wt \%) } \\
\hline $\mathrm{SiO}_{2}$ & 53.06 & 51.76 & 49.17 & 52.85 & 52.20 & 53.96 & 52.79 & 52.63 & 53.04 & 55.22 & 52.20 & 52.95 & 51.54 & 53.00 & 52.99 & 52.95 & 53.47 & 54.17 & 52.57 & 52.38 \\
\hline $\mathrm{TiO}_{2}$ & 0.03 & 0.03 & 0.02 & 0.02 & 0.03 & 0.01 & 0.03 & 0.02 & 0.02 & 0.04 & 0.02 & 0.03 & 0.04 & 0.03 & 0.02 & 0.04 & 0.02 & 0.02 & 0.03 & 0.03 \\
\hline $\mathrm{Al}_{2} \mathrm{O}_{3}$ & 28.74 & 29.33 & 31.11 & 28.54 & 29.26 & 28.49 & 28.47 & 28.80 & 28.60 & 27.67 & 29.24 & 28.53 & 29.84 & 28.56 & 28.67 & 28.42 & 28.66 & 27.75 & 29.19 & 28.67 \\
\hline $\mathrm{Fe}_{2} \mathrm{O}_{3}$ & 0.85 & 0.84 & 0.90 & 0.82 & 0.85 & 0.90 & 0.74 & 0.81 & 0.75 & 0.66 & 0.86 & 0.88 & 0.91 & 0.68 & 0.71 & 0.71 & 0.68 & 0.97 & 0.79 & 0.74 \\
\hline MgO & 0.09 & 0.08 & 0.08 & 0.07 & 0.08 & 0.08 & 0.07 & 0.07 & 0.08 & 0.07 & 0.08 & 0.09 & 0.09 & 0.08 & 0.07 & 0.04 & 0.09 & 0.06 & 0.08 & 0.09 \\
\hline $\mathrm{CaO}$ & 11.73 & 12.34 & 14.54 & 11.69 & 12.11 & 11.32 & 11.57 & 11.76 & 11.40 & 10.33 & 12.42 & 11.75 & 12.96 & 11.32 & 11.43 & 11.29 & 11.42 & 10.52 & 11.80 & 11.73 \\
\hline $\mathrm{Na}_{2} \mathrm{O}$ & 4.37 & 4.08 & 3.01 & 4.52 & 4.24 & 4.58 & 4.47 & 4.40 & 4.59 & 5.17 & 4.11 & 4.44 & 3.83 & 4.59 & 4.46 & 4.55 & 4.61 & 4.90 & 4.39 & 4.39 \\
\hline $\mathrm{K}_{2} \mathrm{O}$ & 0.10 & 0.08 & 0.06 & 0.09 & 0.09 & 0.11 & 0.10 & 0.09 & 0.09 & 0.13 & 0.08 & 0.10 & 0.06 & 0.09 & 0.10 & 0.10 & 0.10 & 0.12 & 0.09 & 0.10 \\
\hline Total & 98.96 & 98.52 & 98.89 & 98.61 & 98.86 & 99.45 & 98.24 & 98.58 & 98.56 & 99.29 & 99.02 & 98.76 & 99.25 & 98.37 & 98.46 & 98.10 & 99.05 & 98.53 & 98.94 & 98.12 \\
\hline \multicolumn{21}{|l|}{ Cations } \\
\hline Si & 2.43 & 2.39 & 2.28 & 2.43 & 2.40 & 2.46 & 2.43 & 2.42 & 2.44 & 2.51 & 2.40 & 2.43 & 2.36 & 2.44 & 2.44 & 2.44 & 2.44 & 2.48 & 2.41 & 2.42 \\
\hline $\mathrm{Ti}$ & 0.001 & 0.001 & 0.001 & 0.001 & 0.001 & 0.000 & 0.001 & 0.001 & 0.001 & 0.001 & 0.001 & 0.001 & 0.001 & 0.001 & 0.001 & 0.001 & 0.001 & 0.001 & 0.001 & 0.001 \\
\hline Al & 1.55 & 1.59 & 1.70 & 1.55 & 1.58 & 1.53 & 1.55 & 1.56 & 1.55 & 1.48 & 1.58 & 1.54 & 1.61 & 1.55 & 1.55 & 1.54 & 1.54 & 1.50 & 1.58 & 1.56 \\
\hline $\mathrm{Fe}$ total & 0.033 & 0.032 & 0.035 & 0.032 & 0.033 & 0.034 & 0.028 & 0.031 & 0.029 & 0.025 & 0.033 & 0.034 & 0.035 & 0.026 & 0.027 & 0.027 & 0.026 & 0.037 & 0.030 & 0.029 \\
\hline Mn & 0.006 & 0.005 & 0.006 & 0.005 & 0.005 & 0.005 & 0.005 & 0.005 & 0.005 & 0.004 & 0.006 & 0.006 & 0.006 & 0.005 & 0.005 & 0.003 & 0.006 & 0.004 & 0.006 & 0.006 \\
\hline Mg & 0.58 & 0.61 & 0.72 & 0.58 & 0.60 & 0.55 & 0.57 & 0.58 & 0.56 & 0.50 & 0.61 & 0.58 & 0.64 & 0.56 & 0.56 & 0.56 & 0.56 & 0.52 & 0.58 & 0.58 \\
\hline $\mathrm{Ca}$ & 0.388 & 0.365 & 0.270 & 0.403 & 0.378 & 0.404 & 0.400 & 0.392 & 0.409 & 0.455 & 0.365 & 0.395 & 0.340 & 0.410 & 0.398 & 0.407 & 0.409 & 0.436 & 0.390 & 0.393 \\
\hline $\mathrm{Na}$ & 0.006 & 0.004 & 0.004 & 0.005 & 0.005 & 0.006 & 0.006 & 0.005 & 0.005 & 0.008 & 0.005 & 0.006 & 0.004 & 0.006 & 0.006 & 0.006 & 0.006 & 0.007 & 0.005 & 0.006 \\
\hline Total & 4.99 & 5.00 & 5.01 & 5.00 & 5.00 & 4.99 & 4.99 & 5.00 & 5.00 & 4.98 & 5.00 & 5.00 & 5.00 & 4.99 & 4.99 & 4.99 & 4.99 & 4.99 & 5.00 & 5.00 \\
\hline \multicolumn{21}{|l|}{ Atomic \% } \\
\hline$A b$ & 40.0 & 37.3 & 27.1 & 40.9 & 38.6 & 42.0 & 40.9 & 40.1 & 41.9 & 47.1 & 37.3 & 40.4 & 34.7 & 42.1 & 41.2 & 41.9 & 42.0 & 45.4 & 40.0 & 40.1 \\
\hline An & 59.4 & 62.3 & 72.5 & 58.5 & 60.9 & 57.4 & 58.5 & 59.3 & 57.6 & 52.1 & 62.2 & 59.0 & 64.9 & 57.3 & 58.2 & 57.5 & 57.4 & 53.9 & 59.4 & 59.3 \\
\hline Or & 0.6 & 0.5 & 0.4 & 0.5 & 0.5 & 0.7 & 0.6 & 0.5 & 0.5 & 0.8 & 0.5 & 0.6 & 0.4 & 0.6 & 0.6 & 0.6 & 0.6 & 0.7 & 0.6 & 0.6 \\
\hline
\end{tabular}


Table F.3. Continued

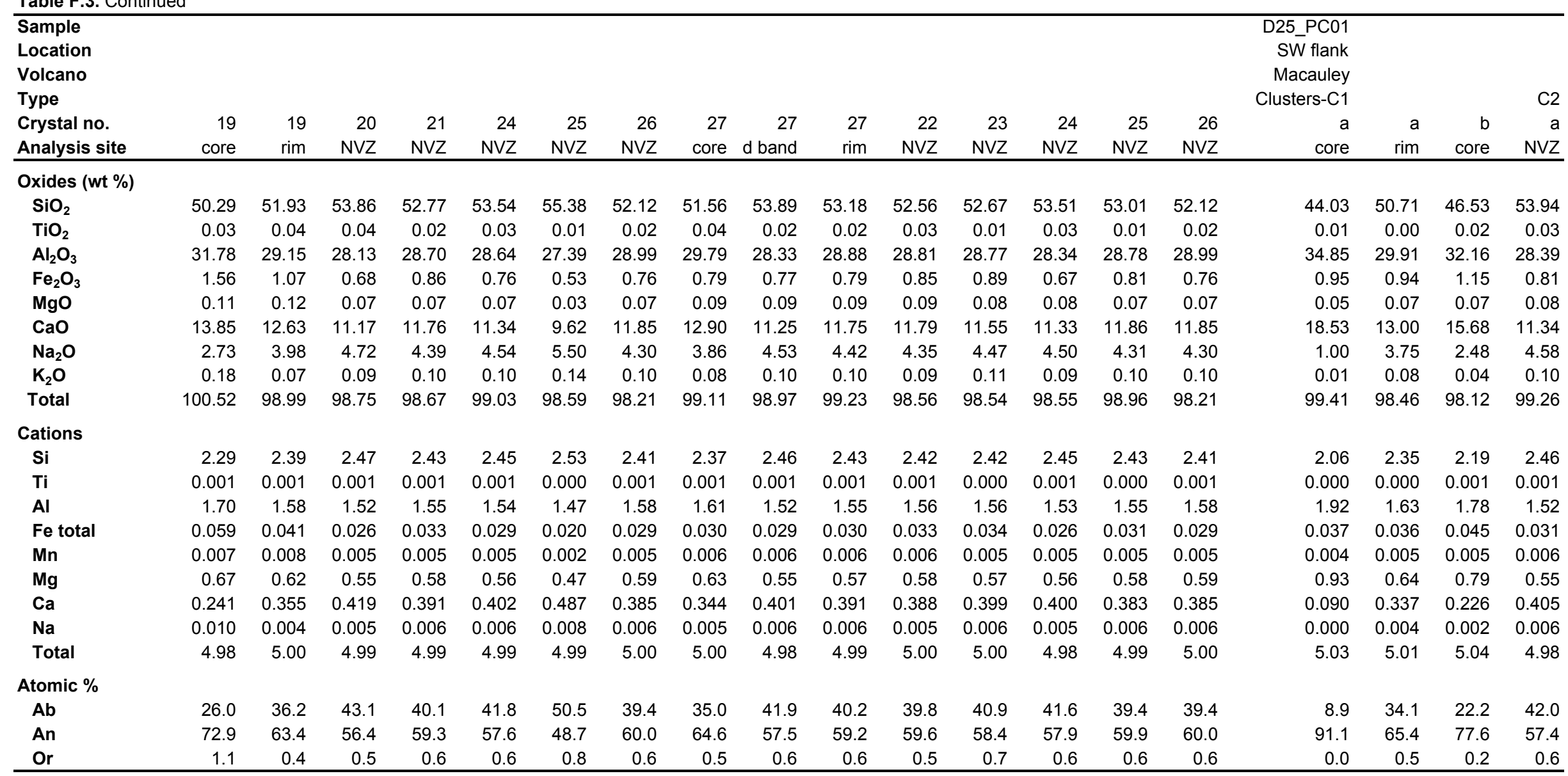


Table F.3. Continued

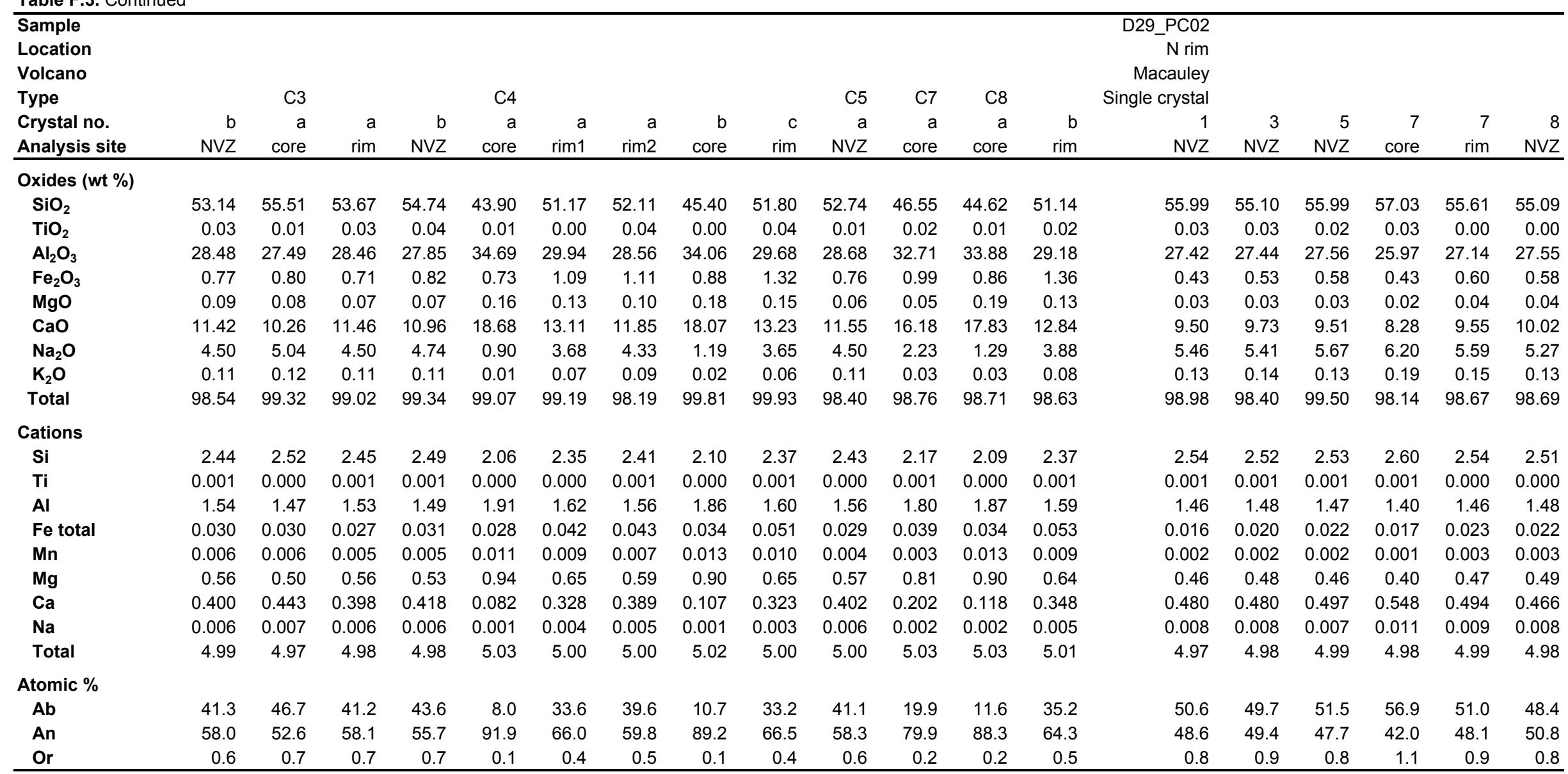


Table F.3. Continued

\begin{tabular}{|c|c|c|c|c|c|c|c|c|c|c|c|c|c|c|c|c|c|c|c|}
\hline $\begin{array}{l}\text { Sample } \\
\text { Location } \\
\text { Volcano } \\
\text { Type }\end{array}$ & & & & & & & & & & & & & & & & & & & \\
\hline $\begin{array}{l}\text { Crystal no. } \\
\text { Analysis site }\end{array}$ & $\begin{array}{r}9 \\
\text { core } \\
\end{array}$ & $\begin{array}{r}9 \\
\text { rim } \\
\end{array}$ & $\begin{array}{r}10 \\
N V Z \\
\end{array}$ & $\begin{array}{r}11 \\
N V Z \\
\end{array}$ & $\begin{array}{r}12 \\
N V Z \\
\end{array}$ & $\begin{array}{r}13 \\
N V Z \\
\end{array}$ & $\begin{array}{r}14 \\
N V Z \\
\end{array}$ & $\begin{array}{r}15 \\
\text { core } \\
\end{array}$ & $\begin{array}{r}15 \\
\text { rim } \\
\end{array}$ & $\begin{array}{r}16 \\
N V Z \\
\end{array}$ & $\begin{array}{r}17 \\
N V Z \\
\end{array}$ & $\begin{array}{r}18 \\
\text { core } \\
\end{array}$ & $\begin{array}{r}18 \\
O G \\
\end{array}$ & $\begin{array}{r}18 \\
\text { rim } \\
\end{array}$ & $\begin{array}{r}19 \\
N V Z \\
\end{array}$ & $\begin{array}{r}21 \\
\text { core } \\
\end{array}$ & $\begin{array}{r}21 \\
\text { rim } \\
\end{array}$ & $\begin{array}{r}22 \\
N V Z \\
\end{array}$ & $\begin{array}{r}23 \\
N V Z \\
\end{array}$ \\
\hline \multicolumn{20}{|l|}{ Oxides (wt \%) } \\
\hline $\mathrm{SiO}_{2}$ & 56.69 & 57.32 & 55.28 & 55.93 & 56.19 & 55.43 & 55.77 & 56.63 & 54.98 & 55.23 & 56.09 & 54.65 & 56.56 & 55.98 & 54.72 & 58.19 & 55.45 & 55.57 & 55.19 \\
\hline $\mathrm{TiO}_{2}$ & 0.02 & 0.01 & 0.00 & 0.02 & 0.01 & 0.01 & 0.01 & 0.00 & 0.02 & 0.01 & 0.01 & 0.03 & 0.02 & 0.02 & 0.03 & 0.02 & 0.01 & 0.02 & 0.00 \\
\hline $\mathrm{Al}_{2} \mathrm{O}_{3}$ & 26.50 & 25.89 & 27.13 & 27.16 & 26.93 & 27.21 & 26.93 & 26.30 & 27.34 & 27.31 & 27.15 & 27.64 & 26.32 & 27.25 & 27.55 & 25.43 & 27.18 & 27.49 & 27.28 \\
\hline $\mathrm{Fe}_{2} \mathrm{O}_{3}$ & 0.37 & 0.38 & 0.54 & 0.51 & 0.53 & 0.58 & 0.54 & 0.43 & 0.49 & 0.59 & 0.53 & 0.62 & 0.46 & 0.54 & 0.39 & 0.37 & 0.57 & 0.62 & 0.49 \\
\hline MgO & 0.03 & 0.04 & 0.04 & 0.05 & 0.04 & 0.05 & 0.05 & 0.03 & 0.04 & 0.05 & 0.05 & 0.04 & 0.03 & 0.04 & 0.04 & 0.02 & 0.02 & 0.04 & 0.04 \\
\hline $\mathrm{CaO}$ & 8.79 & 7.83 & 9.44 & 9.49 & 9.43 & 9.59 & 9.46 & 8.64 & 9.69 & 9.80 & 9.42 & 10.38 & 8.60 & 9.56 & 9.78 & 7.54 & 9.42 & 9.98 & 9.67 \\
\hline $\mathrm{Na}_{2} \mathrm{O}$ & 5.80 & 6.43 & 5.64 & 5.65 & 5.52 & 5.54 & 5.47 & 6.12 & 5.44 & 5.40 & 5.57 & 5.11 & 6.07 & 5.57 & 5.42 & 6.54 & 5.66 & 5.36 & 5.36 \\
\hline $\mathrm{K}_{2} \mathrm{O}$ & 0.15 & 0.20 & 0.15 & 0.14 & 0.15 & 0.14 & 0.14 & 0.16 & 0.14 & 0.13 & 0.14 & 0.12 & 0.16 & 0.14 & 0.15 & 0.20 & 0.15 & 0.13 & 0.15 \\
\hline Total & 98.35 & 98.10 & 98.21 & 98.94 & 98.80 & 98.56 & 98.37 & 98.30 & 98.15 & 98.51 & 98.96 & 98.59 & 98.21 & 99.08 & 98.07 & 98.31 & 98.45 & 99.22 & 98.19 \\
\hline \multicolumn{20}{|l|}{ Cations } \\
\hline Si & 2.58 & 2.61 & 2.53 & 2.54 & 2.55 & 2.53 & 2.55 & 2.58 & 2.52 & 2.52 & 2.55 & 2.50 & 2.58 & 2.54 & 2.51 & 2.64 & 2.53 & 2.52 & 2.53 \\
\hline $\mathrm{Ti}$ & 0.001 & 0.000 & 0.000 & 0.001 & 0.000 & 0.000 & 0.000 & 0.000 & 0.001 & 0.000 & 0.000 & 0.001 & 0.001 & 0.001 & 0.001 & 0.001 & 0.000 & 0.001 & 0.000 \\
\hline Al & 1.42 & 1.39 & 1.46 & 1.45 & 1.44 & 1.46 & 1.45 & 1.41 & 1.48 & 1.47 & 1.45 & 1.49 & 1.42 & 1.46 & 1.49 & 1.36 & 1.46 & 1.47 & 1.47 \\
\hline Fe total & 0.014 & 0.014 & 0.021 & 0.019 & 0.020 & 0.022 & 0.021 & 0.016 & 0.019 & 0.022 & 0.020 & 0.024 & 0.018 & 0.020 & 0.015 & 0.014 & 0.022 & 0.024 & 0.019 \\
\hline Mn & 0.002 & 0.002 & 0.003 & 0.003 & 0.003 & 0.004 & 0.003 & 0.002 & 0.003 & 0.003 & 0.003 & 0.003 & 0.002 & 0.002 & 0.002 & 0.001 & 0.002 & 0.003 & 0.003 \\
\hline Mg & 0.43 & 0.38 & 0.46 & 0.46 & 0.46 & 0.47 & 0.46 & 0.42 & 0.48 & 0.48 & 0.46 & 0.51 & 0.42 & 0.46 & 0.48 & 0.37 & 0.46 & 0.49 & 0.47 \\
\hline $\mathrm{Ca}$ & 0.512 & 0.568 & 0.500 & 0.497 & 0.486 & 0.490 & 0.484 & 0.541 & 0.483 & 0.478 & 0.490 & 0.453 & 0.537 & 0.490 & 0.482 & 0.576 & 0.501 & 0.471 & 0.476 \\
\hline $\mathrm{Na}$ & 0.008 & 0.011 & 0.009 & 0.008 & 0.009 & 0.008 & 0.008 & 0.010 & 0.008 & 0.008 & 0.008 & 0.007 & 0.009 & 0.008 & 0.008 & 0.011 & 0.009 & 0.008 & 0.009 \\
\hline Total & 4.97 & 4.98 & 4.99 & 4.98 & 4.97 & 4.99 & 4.97 & 4.99 & 4.99 & 4.98 & 4.98 & 4.98 & 4.98 & 4.98 & 4.99 & 4.97 & 4.99 & 4.98 & 4.98 \\
\hline \multicolumn{20}{|l|}{ Atomic \% } \\
\hline $\mathbf{A b}$ & 53.9 & 59.1 & 51.5 & 51.4 & 51.0 & 50.7 & 50.7 & 55.6 & 49.9 & 49.5 & 51.2 & 46.8 & 55.6 & 50.9 & 49.6 & 60.4 & 51.6 & 48.9 & 49.6 \\
\hline An & 45.2 & 39.7 & 47.6 & 47.7 & 48.1 & 48.5 & 48.4 & 43.4 & 49.2 & 49.7 & 47.9 & 52.5 & 43.5 & 48.3 & 49.5 & 38.4 & 47.5 & 50.3 & 49.5 \\
\hline Or & 0.9 & 1.2 & 0.9 & 0.9 & 0.9 & 0.8 & 0.9 & 1.0 & 0.9 & 0.8 & 0.9 & 0.7 & 0.9 & 0.8 & 0.9 & 1.2 & 0.9 & 0.8 & 0.9 \\
\hline
\end{tabular}


Table F.3. Continued

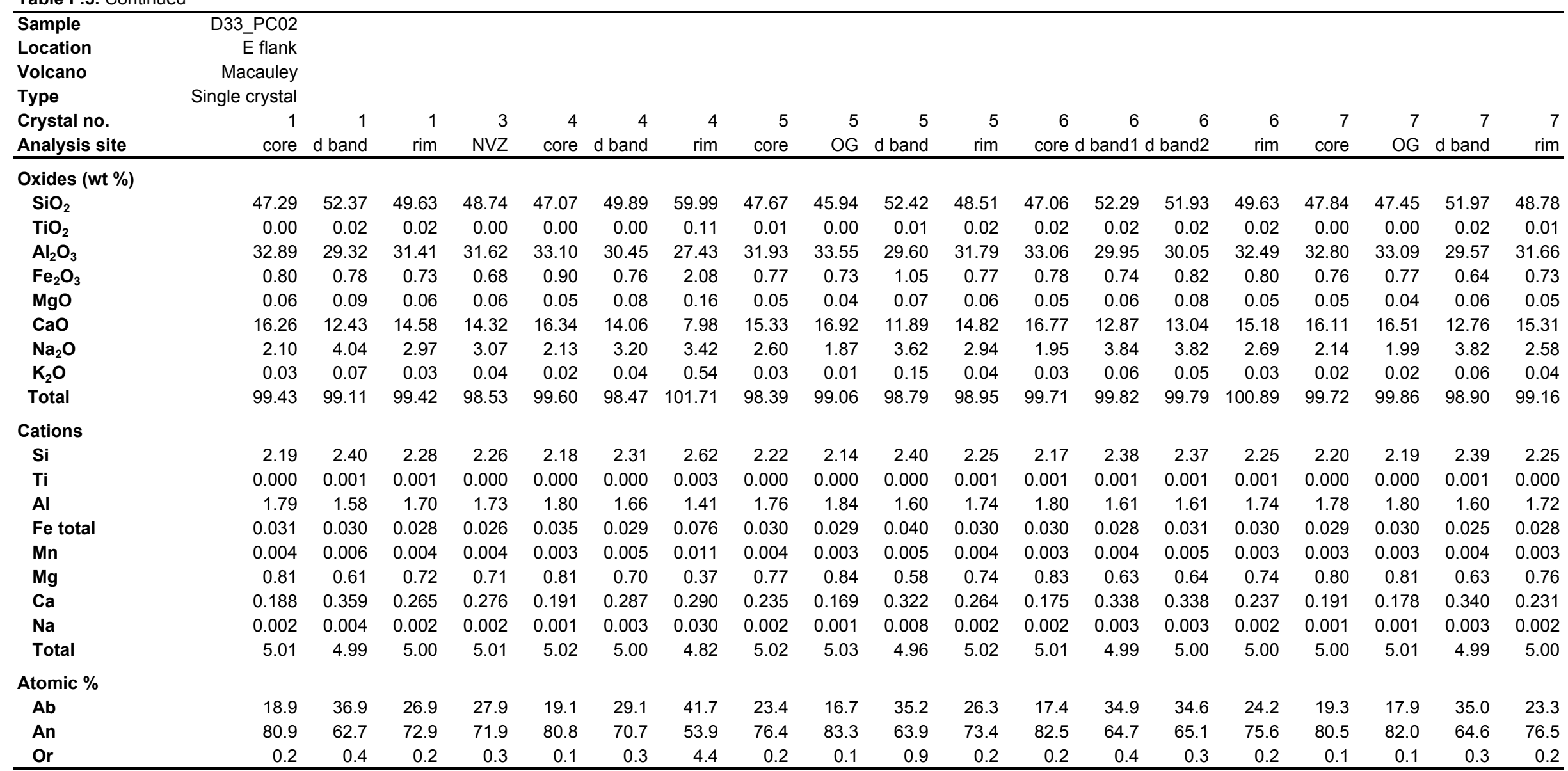


Table F.3. Continued

\begin{tabular}{|c|c|c|c|c|c|c|c|c|c|c|c|c|c|c|c|c|c|c|c|c|}
\hline $\begin{array}{l}\text { Sample } \\
\text { Location } \\
\text { Volcano } \\
\text { Type }\end{array}$ & & & & & & & & & & & & & & & & & & & & \\
\hline $\begin{array}{l}\text { Crystal no. } \\
\text { Analysis site }\end{array}$ & $\begin{array}{r}8 \\
\text { core } \\
\end{array}$ & $\begin{array}{r}8 \\
\text { rim } \\
\end{array}$ & $\begin{array}{r}9 \\
\text { core } \\
\end{array}$ & $\begin{array}{r}10 \\
\text { core } \\
\end{array}$ & $\begin{array}{r}10 \\
\mathrm{~d} \text { band } \\
\end{array}$ & $\begin{array}{r}10 \\
\text { rim } \\
\end{array}$ & $\begin{array}{r}11 \\
\text { core } \\
\end{array}$ & $\begin{array}{r}11 \\
\mathrm{~d} \text { band } \\
\end{array}$ & $\begin{array}{r}11 \\
\mathrm{~d} \text { band } \\
\end{array}$ & $\begin{array}{r}13 \\
N V Z \\
\end{array}$ & $\begin{array}{r}14 \\
N V Z \\
\end{array}$ & $\begin{array}{r}15 \\
\text { core } \\
\end{array}$ & $\begin{array}{r}15 \\
\mathrm{~d} \text { band } \\
\end{array}$ & $\begin{array}{r}15 \\
\text { rim } \\
\end{array}$ & $\begin{array}{r}16 \\
\text { core } \\
\end{array}$ & $\begin{array}{r}16 \\
\text { rim } \\
\end{array}$ & $\begin{array}{r}17 \\
\text { NVZ } \\
\end{array}$ & $\begin{array}{r}18 \\
\text { core } \\
\end{array}$ & $\begin{array}{r}18 \\
\text { rim } \\
\end{array}$ & $\begin{array}{r}19 \\
\text { core } \\
\end{array}$ \\
\hline \multicolumn{21}{|l|}{ Oxides (wt \%) } \\
\hline $\mathrm{SiO}_{2}$ & 47.75 & 48.23 & 47.16 & 48.35 & 49.85 & 57.53 & 48.71 & 48.36 & 48.09 & 46.39 & 48.45 & 47.36 & 51.88 & 47.78 & 46.69 & 48.78 & 48.78 & 47.35 & 49.19 & 48.75 \\
\hline $\mathrm{TiO}_{2}$ & 0.01 & 0.00 & 0.01 & 0.01 & 0.02 & 0.03 & 0.02 & 0.02 & 0.02 & 0.00 & 0.00 & 0.01 & 0.01 & 0.01 & 0.01 & 0.01 & 0.02 & 0.00 & 0.00 & 0.01 \\
\hline $\mathrm{Al}_{2} \mathrm{O}_{3}$ & 33.11 & 32.17 & 33.41 & 31.89 & 30.72 & 28.59 & 31.58 & 31.81 & 31.82 & 33.08 & 31.79 & 32.69 & 29.76 & 32.18 & 32.67 & 31.77 & 31.68 & 33.06 & 32.00 & 31.27 \\
\hline $\mathrm{Fe}_{2} \mathrm{O}_{3}$ & 0.81 & 0.76 & 0.77 & 0.76 & 0.73 & 1.26 & 0.76 & 0.76 & 0.83 & 0.85 & 0.75 & 0.85 & 0.68 & 0.84 & 0.80 & 0.68 & 0.84 & 0.66 & 0.85 & 0.74 \\
\hline $\mathrm{MgO}$ & 0.03 & 0.04 & 0.06 & 0.07 & 0.05 & 0.08 & 0.06 & 0.04 & 0.06 & 0.04 & 0.05 & 0.06 & 0.07 & 0.05 & 0.05 & 0.06 & 0.05 & 0.06 & 0.06 & 0.06 \\
\hline $\mathrm{CaO}$ & 16.50 & 15.38 & 16.75 & 15.05 & 13.81 & 9.50 & 14.80 & 14.94 & 14.98 & 16.40 & 15.01 & 15.97 & 12.63 & 15.42 & 16.07 & 14.66 & 14.87 & 16.31 & 14.78 & 14.51 \\
\hline $\mathrm{Na}_{2} \mathrm{O}$ & 2.07 & 2.64 & 1.97 & 2.76 & 3.36 & 4.28 & 2.87 & 2.82 & 2.75 & 2.06 & 2.79 & 2.32 & 3.93 & 2.53 & 2.23 & 3.04 & 2.91 & 2.13 & 2.91 & 3.06 \\
\hline $\mathrm{K}_{2} \mathrm{O}$ & 0.02 & 0.04 & 0.03 & 0.04 & 0.05 & 0.31 & 0.04 & 0.03 & 0.03 & 0.02 & 0.03 & 0.03 & 0.07 & 0.02 & 0.02 & 0.03 & 0.04 & 0.02 & 0.04 & 0.04 \\
\hline Total & 100.31 & 99.26 & 100.15 & 98.94 & 98.59 & 101.58 & 98.84 & 98.80 & 98.59 & 98.86 & 98.87 & 99.29 & 99.02 & 98.84 & 98.54 & 99.03 & 99.17 & 99.60 & 99.83 & 98.45 \\
\hline \multicolumn{21}{|l|}{ Cations } \\
\hline Si & 2.19 & 2.23 & 2.17 & 2.24 & 2.31 & 2.54 & 2.26 & 2.24 & 2.24 & 2.16 & 2.25 & 2.19 & 2.38 & 2.22 & 2.18 & 2.25 & 2.25 & 2.19 & 2.26 & 2.27 \\
\hline $\mathrm{Ti}$ & 0.000 & 0.000 & 0.000 & 0.000 & 0.001 & 0.001 & 0.001 & 0.001 & 0.001 & 0.000 & 0.000 & 0.000 & 0.000 & 0.000 & 0.000 & 0.000 & 0.001 & 0.000 & 0.000 & 0.000 \\
\hline Al & 1.79 & 1.75 & 1.81 & 1.74 & 1.68 & 1.49 & 1.72 & 1.74 & 1.74 & 1.82 & 1.74 & 1.78 & 1.61 & 1.76 & 1.80 & 1.73 & 1.73 & 1.80 & 1.73 & 1.71 \\
\hline Fe total & 0.031 & 0.030 & 0.029 & 0.029 & 0.028 & 0.047 & 0.029 & 0.030 & 0.032 & 0.033 & 0.029 & 0.033 & 0.026 & 0.033 & 0.031 & 0.026 & 0.032 & 0.026 & 0.032 & 0.029 \\
\hline$M n$ & 0.002 & 0.003 & 0.004 & 0.005 & 0.004 & 0.005 & 0.004 & 0.003 & 0.004 & 0.003 & 0.004 & 0.004 & 0.005 & 0.004 & 0.004 & 0.004 & 0.003 & 0.004 & 0.004 & 0.004 \\
\hline $\mathbf{M g}$ & 0.81 & 0.76 & 0.82 & 0.75 & 0.68 & 0.45 & 0.73 & 0.74 & 0.75 & 0.82 & 0.75 & 0.79 & 0.62 & 0.77 & 0.80 & 0.73 & 0.74 & 0.81 & 0.73 & 0.72 \\
\hline $\mathrm{Ca}$ & 0.184 & 0.236 & 0.175 & 0.248 & 0.302 & 0.366 & 0.258 & 0.253 & 0.248 & 0.186 & 0.251 & 0.208 & 0.349 & 0.228 & 0.202 & 0.272 & 0.260 & 0.190 & 0.259 & 0.276 \\
\hline $\mathrm{Na}$ & 0.001 & 0.002 & 0.002 & 0.002 & 0.003 & 0.017 & 0.003 & 0.002 & 0.002 & 0.001 & 0.002 & 0.002 & 0.004 & 0.001 & 0.001 & 0.002 & 0.003 & 0.001 & 0.002 & 0.002 \\
\hline Total & 5.01 & 5.01 & 5.01 & 5.01 & 5.01 & 4.91 & 5.01 & 5.01 & 5.02 & 5.02 & 5.01 & 5.02 & 4.99 & 5.01 & 5.02 & 5.02 & 5.01 & 5.01 & 5.01 & 5.02 \\
\hline \multicolumn{21}{|l|}{ Atomic $\%$} \\
\hline$A b$ & 18.5 & 23.6 & 17.5 & 24.8 & 30.5 & 44.0 & 25.9 & 25.4 & 24.9 & 18.5 & 25.1 & 20.8 & 35.9 & 22.9 & 20.1 & 27.2 & 26.1 & 19.1 & 26.2 & 27.6 \\
\hline An & 81.4 & 76.2 & 82.3 & 74.9 & 69.2 & 53.9 & 73.8 & 74.4 & 74.9 & 81.4 & 74.7 & 79.1 & 63.7 & 77.0 & 79.8 & 72.6 & 73.7 & 80.8 & 73.5 & 72.2 \\
\hline Or & 0.1 & 0.2 & 0.2 & 0.2 & 0.3 & 2.1 & 0.3 & 0.2 & 0.2 & 0.1 & 0.2 & 0.2 & 0.4 & 0.1 & 0.1 & 0.2 & 0.3 & 0.1 & 0.2 & 0.2 \\
\hline
\end{tabular}


Table F.3. Continued

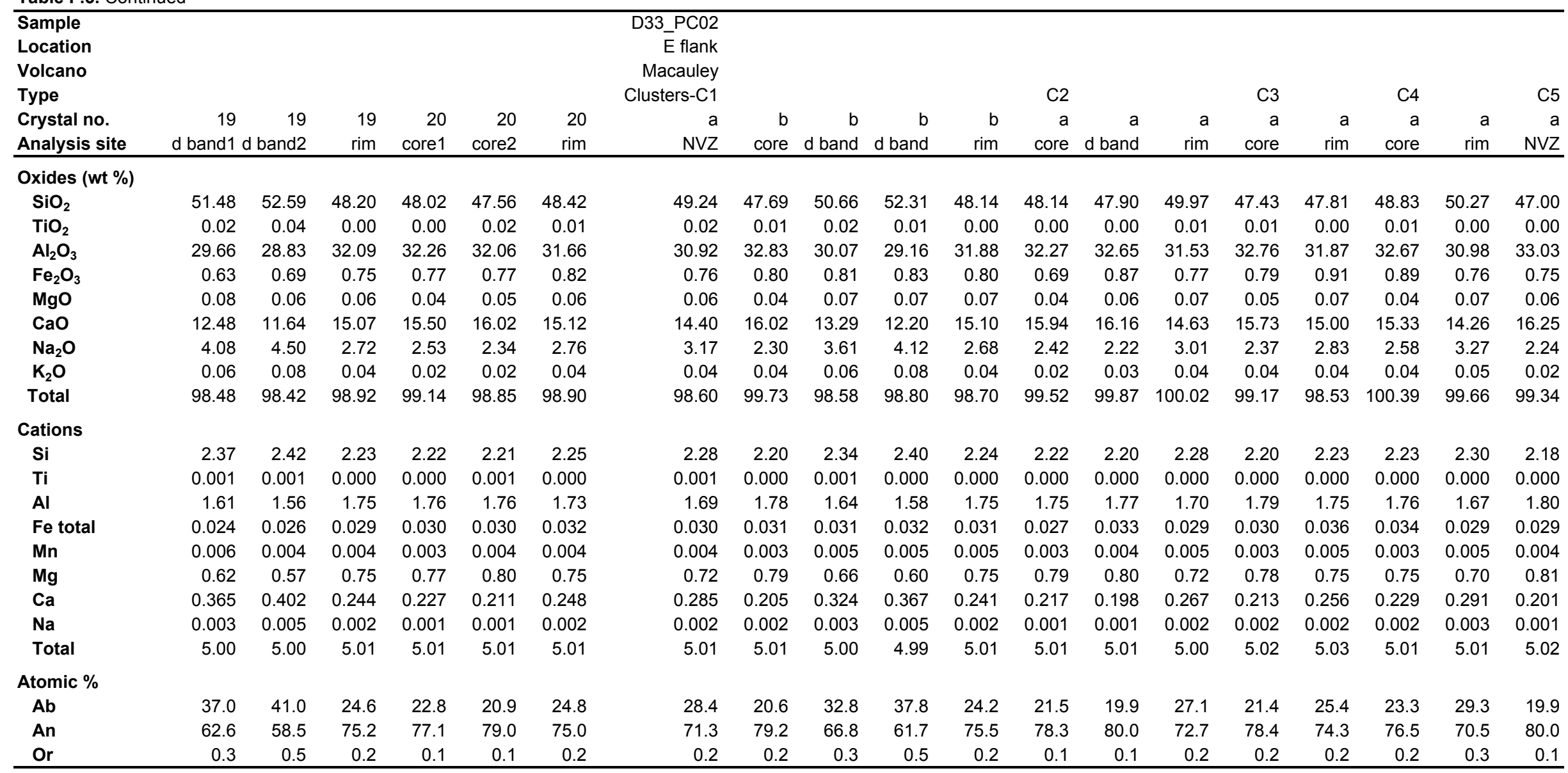


Table F.3. Continued

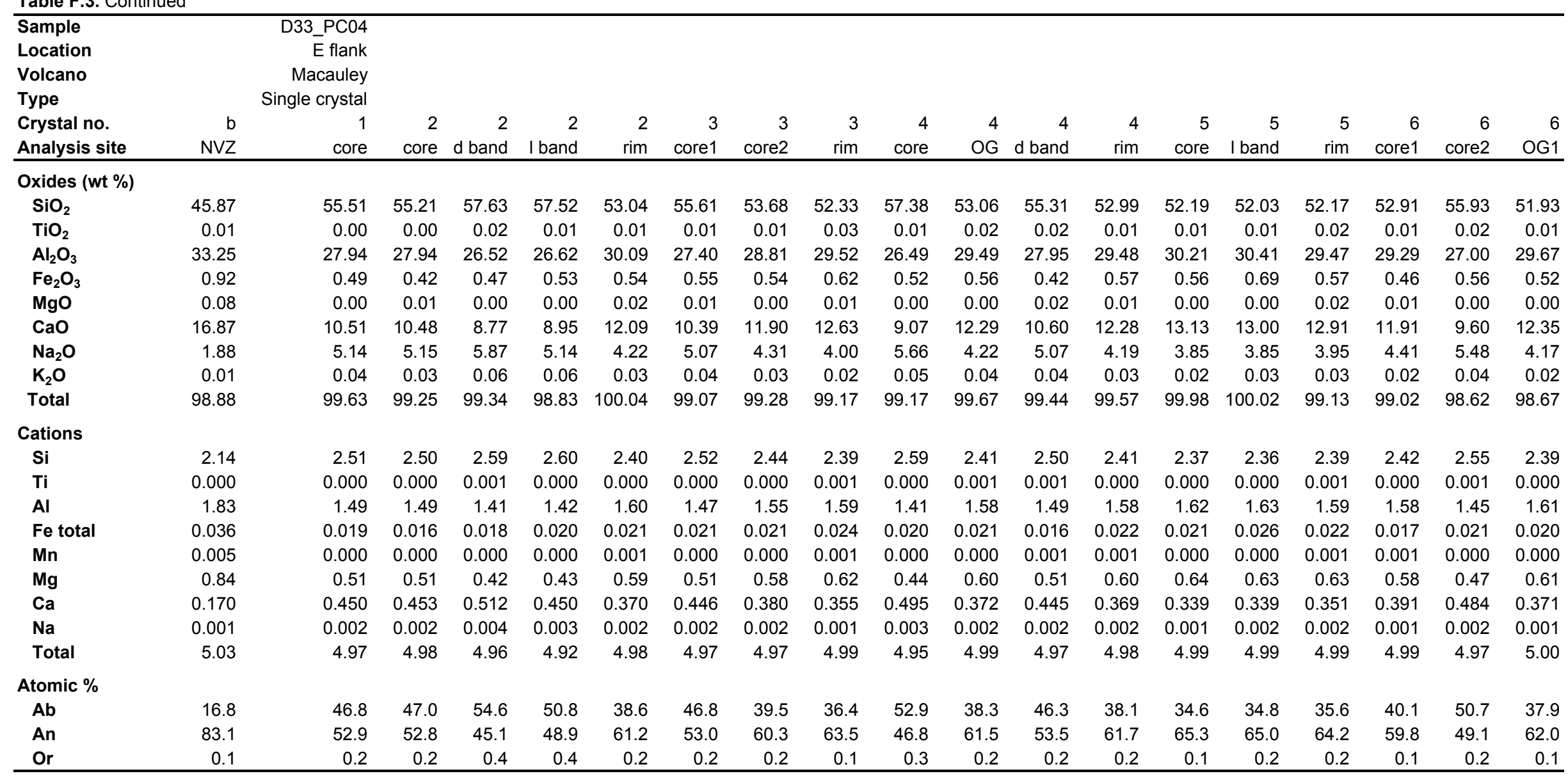


Table F.3. Continued

\begin{tabular}{|c|c|c|c|c|c|c|c|c|c|c|c|c|c|c|c|c|c|c|c|c|}
\hline $\begin{array}{l}\text { Sample } \\
\text { Location } \\
\text { Volcano } \\
\text { Type }\end{array}$ & & & & & & & & & & & & & & & & & & & & \\
\hline $\begin{array}{l}\text { Crystal no. } \\
\text { Analysis site }\end{array}$ & $\begin{array}{r}6 \\
\text { OG2 } \\
\end{array}$ & $\begin{array}{r}6 \\
\text { rim } \\
\end{array}$ & $\begin{array}{r}7 \\
\text { core } \\
\end{array}$ & $\begin{array}{r}7 \\
O G \\
\end{array}$ & $\begin{array}{r}7 \\
\text { rim } \\
\end{array}$ & $\begin{array}{r}8 \\
\text { core } \\
\end{array}$ & $\begin{array}{r}8 \\
O G \\
\end{array}$ & $\begin{array}{r}8 \\
\text { rim } \\
\end{array}$ & $\begin{array}{r}9 \\
\text { core } \\
\end{array}$ & $\begin{array}{r}9 \\
O G \\
\end{array}$ & $\begin{array}{r}9 \\
\text { rim } \\
\end{array}$ & $\begin{array}{r}10 \\
\text { core } \\
\end{array}$ & $\begin{array}{r}10 \\
O G \\
\end{array}$ & $\begin{array}{r}10 \\
\text { rim } \\
\end{array}$ & $\begin{array}{r}11 \\
\text { core } \\
\end{array}$ & $\begin{array}{r}11 \\
\mathrm{~d} \text { band } \\
\end{array}$ & $\begin{array}{r}11 \\
\text { rim } \\
\end{array}$ & $\begin{array}{r}12 \\
\mathrm{~d} \text { band } \\
\end{array}$ & $\begin{array}{r}12 \\
\text { I band } \\
\end{array}$ & $\begin{array}{r}13 \\
\text { core } \\
\end{array}$ \\
\hline \multicolumn{21}{|l|}{ Oxides (wt \%) } \\
\hline $\mathrm{SiO}_{2}$ & 54.92 & 51.16 & 55.67 & 52.27 & 51.36 & 49.52 & 52.57 & 52.38 & 51.52 & 56.02 & 51.81 & 54.87 & 50.02 & 53.53 & 54.75 & 55.25 & 51.53 & 54.07 & 51.14 & 48.94 \\
\hline $\mathrm{TiO}_{2}$ & 0.00 & 0.00 & 0.00 & 0.01 & 0.03 & 0.01 & 0.02 & 0.00 & 0.03 & 0.00 & 0.00 & 0.01 & 0.00 & 0.00 & 0.01 & 0.00 & 0.02 & 0.00 & 0.00 & 0.00 \\
\hline $\mathrm{Al}_{2} \mathrm{O}_{3}$ & 27.67 & 29.87 & 27.72 & 30.15 & 30.06 & 31.43 & 29.78 & 29.61 & 30.51 & 27.59 & 30.71 & 28.24 & 32.01 & 29.59 & 27.79 & 27.65 & 29.51 & 28.07 & 29.72 & 33.20 \\
\hline $\mathrm{Fe}_{2} \mathrm{O}_{3}$ & 0.45 & 0.57 & 0.51 & 0.60 & 0.53 & 0.59 & 0.56 & 0.56 & 0.68 & 0.53 & 0.50 & 0.56 & 0.52 & 0.57 & 0.56 & 0.48 & 0.54 & 0.56 & 0.60 & 0.65 \\
\hline MgO & 0.00 & 0.00 & 0.00 & 0.00 & 0.00 & 0.00 & 0.00 & 0.00 & 0.00 & 0.01 & 0.00 & 0.00 & 0.00 & 0.00 & 0.00 & 0.01 & 0.01 & 0.00 & 0.01 & 0.01 \\
\hline $\mathrm{CaO}$ & 10.12 & 12.86 & 10.23 & 13.05 & 13.20 & 14.70 & 12.59 & 12.74 & 13.46 & 10.11 & 13.45 & 10.71 & 14.80 & 12.29 & 10.60 & 10.22 & 12.38 & 10.58 & 12.71 & 16.14 \\
\hline $\mathrm{Na}_{2} \mathrm{O}$ & 5.27 & 3.90 & 5.23 & 3.85 & 3.73 & 3.01 & 4.03 & 4.06 & 3.69 & 5.25 & 3.71 & 4.99 & 2.97 & 4.28 & 5.12 & 5.27 & 4.17 & 4.98 & 3.93 & 2.18 \\
\hline $\mathrm{K}_{2} \mathrm{O}$ & 0.04 & 0.04 & 0.04 & 0.03 & 0.02 & 0.02 & 0.03 & 0.03 & 0.03 & 0.04 & 0.03 & 0.04 & 0.02 & 0.02 & 0.03 & 0.06 & 0.03 & 0.05 & 0.02 & 0.00 \\
\hline Total & 98.47 & 98.40 & 99.39 & 99.96 & 98.94 & 99.28 & 99.58 & 99.39 & 99.93 & 99.54 & 100.20 & 99.42 & 100.34 & 100.28 & 98.85 & 98.94 & 98.19 & 98.30 & 98.14 & 101.10 \\
\hline \multicolumn{21}{|l|}{ Cations } \\
\hline Si & 2.51 & 2.36 & 2.52 & 2.37 & 2.36 & 2.28 & 2.39 & 2.39 & 2.35 & 2.53 & 2.35 & 2.49 & 2.28 & 2.42 & 2.50 & 2.51 & 2.38 & 2.48 & 2.37 & 2.22 \\
\hline $\mathrm{Ti}$ & 0.000 & 0.000 & 0.000 & 0.000 & 0.001 & 0.000 & 0.001 & 0.000 & 0.001 & 0.000 & 0.000 & 0.000 & 0.000 & 0.000 & 0.000 & 0.000 & 0.001 & 0.000 & 0.000 & 0.000 \\
\hline Al & 1.49 & 1.63 & 1.48 & 1.61 & 1.63 & 1.71 & 1.60 & 1.59 & 1.64 & 1.47 & 1.64 & 1.51 & 1.72 & 1.57 & 1.49 & 1.48 & 1.61 & 1.52 & 1.62 & 1.77 \\
\hline $\mathrm{Fe}$ total & 0.017 & 0.022 & 0.019 & 0.023 & 0.020 & 0.023 & 0.021 & 0.021 & 0.026 & 0.020 & 0.019 & 0.021 & 0.020 & 0.021 & 0.021 & 0.018 & 0.021 & 0.022 & 0.023 & 0.024 \\
\hline Mn & 0.000 & 0.000 & 0.000 & 0.000 & 0.000 & 0.000 & 0.000 & 0.000 & 0.000 & 0.000 & 0.000 & 0.000 & 0.000 & 0.000 & 0.000 & 0.000 & 0.001 & 0.000 & 0.001 & 0.001 \\
\hline Mg & 0.50 & 0.64 & 0.50 & 0.64 & 0.65 & 0.73 & 0.61 & 0.62 & 0.66 & 0.49 & 0.65 & 0.52 & 0.72 & 0.59 & 0.52 & 0.50 & 0.61 & 0.52 & 0.63 & 0.78 \\
\hline $\mathrm{Ca}$ & 0.467 & 0.349 & 0.459 & 0.339 & 0.332 & 0.269 & 0.356 & 0.359 & 0.326 & 0.460 & 0.326 & 0.438 & 0.262 & 0.375 & 0.453 & 0.465 & 0.374 & 0.443 & 0.353 & 0.191 \\
\hline $\mathrm{Na}$ & 0.002 & 0.002 & 0.002 & 0.002 & 0.001 & 0.001 & 0.002 & 0.002 & 0.002 & 0.002 & 0.001 & 0.002 & 0.001 & 0.001 & 0.002 & 0.003 & 0.002 & 0.003 & 0.001 & 0.000 \\
\hline Total & 4.98 & 5.00 & 4.97 & 4.99 & 4.99 & 5.00 & 4.99 & 4.99 & 5.00 & 4.97 & 4.99 & 4.98 & 5.00 & 4.98 & 4.98 & 4.98 & 5.00 & 4.98 & 5.00 & 4.99 \\
\hline \multicolumn{21}{|l|}{ Atomic $\%$} \\
\hline$A b$ & 48.4 & 35.3 & 48.0 & 34.8 & 33.8 & 27.0 & 36.6 & 36.5 & 33.1 & 48.3 & 33.2 & 45.6 & 26.6 & 38.6 & 46.6 & 48.1 & 37.8 & 45.9 & 35.8 & 19.6 \\
\hline An & 51.4 & 64.5 & 51.8 & 65.1 & 66.1 & 72.9 & 63.2 & 63.3 & 66.7 & 51.4 & 66.6 & 54.2 & 73.3 & 61.2 & 53.2 & 51.5 & 62.0 & 53.8 & 64.0 & 80.4 \\
\hline Or & 0.2 & 0.2 & 0.3 & 0.2 & 0.1 & 0.1 & 0.2 & 0.2 & 0.2 & 0.2 & 0.1 & 0.2 & 0.1 & 0.1 & 0.2 & 0.4 & 0.2 & 0.3 & 0.1 & 0.0 \\
\hline
\end{tabular}


Table F.3. Continued

\begin{tabular}{|c|c|c|c|c|c|c|c|c|c|c|c|c|c|c|c|c|c|c|c|c|}
\hline $\begin{array}{l}\text { Sample } \\
\text { Location } \\
\text { Volcano } \\
\text { Type }\end{array}$ & & & & & & & & & & & & & & & & & & & & \\
\hline $\begin{array}{l}\text { Crystal no. } \\
\text { Analysis site }\end{array}$ & $\begin{array}{r}13 \\
\text { rim } \\
\end{array}$ & $\begin{array}{r}14 \\
N V Z \\
\end{array}$ & $\begin{array}{r}15 \\
\text { core } \\
\end{array}$ & $\begin{array}{r}16 \\
\text { core } \\
\end{array}$ & $\begin{array}{r}16 \\
O G \\
\end{array}$ & $\begin{array}{r}16 \\
\text { rim } \\
\end{array}$ & $\begin{array}{r}17 \\
N V Z \\
\end{array}$ & $\begin{array}{r}18 \\
\text { core } \\
\end{array}$ & $\begin{array}{r}18 \\
\text { rim } \\
\end{array}$ & $\begin{array}{r}19 \\
N V Z \\
\end{array}$ & $\begin{array}{r}20 \\
N V Z \\
\end{array}$ & $\begin{array}{r}21 \\
N V Z \\
\end{array}$ & $\begin{array}{r}22 \\
\text { core } \\
\end{array}$ & $\begin{array}{r}22 \\
\mathrm{OG} \\
\end{array}$ & $\begin{array}{r}22 \\
\text { rim } \\
\end{array}$ & $\begin{array}{r}23 \\
\text { core } \\
\end{array}$ & $\begin{array}{l}23 \\
O G \\
\end{array}$ & $\begin{array}{r}23 \\
\text { rim } \\
\end{array}$ & $\begin{array}{r}24 \\
\text { core } \\
\end{array}$ & $\begin{array}{r}25 \\
\text { core } \\
\end{array}$ \\
\hline \multicolumn{21}{|l|}{ Oxides (wt \%) } \\
\hline $\mathrm{SiO}_{2}$ & 51.85 & 51.12 & 51.14 & 51.73 & 54.53 & 50.60 & 53.07 & 54.95 & 52.94 & 55.96 & 48.61 & 54.82 & 50.50 & 54.14 & 53.23 & 48.69 & 54.15 & 51.19 & 52.53 & 54.47 \\
\hline $\mathrm{TiO}_{2}$ & 0.00 & 0.00 & 0.03 & 0.01 & 0.01 & 0.00 & 0.02 & 0.00 & 0.02 & 0.00 & 0.00 & 0.00 & 0.00 & 0.00 & 0.01 & 0.01 & 0.00 & 0.00 & 0.03 & 0.00 \\
\hline $\mathrm{Al}_{2} \mathrm{O}_{3}$ & 30.23 & 30.89 & 30.32 & 30.07 & 27.98 & 30.69 & 29.56 & 28.05 & 28.89 & 28.48 & 31.83 & 27.42 & 30.93 & 28.58 & 29.44 & 32.13 & 28.10 & 29.80 & 30.89 & 28.16 \\
\hline $\mathrm{Fe}_{2} \mathrm{O}_{3}$ & 0.54 & 0.57 & 0.60 & 0.67 & 0.50 & 0.55 & 0.50 & 0.57 & 0.62 & 0.43 & 0.56 & 0.51 & 0.60 & 0.58 & 0.56 & 0.57 & 0.54 & 0.54 & 0.66 & 0.48 \\
\hline $\mathrm{MgO}$ & 0.01 & 0.01 & 0.01 & 0.01 & 0.02 & 0.00 & 0.00 & 0.01 & 0.01 & 0.01 & 0.01 & 0.01 & 0.00 & 0.00 & 0.00 & 0.00 & 0.00 & 0.02 & 0.00 & 0.00 \\
\hline $\mathrm{CaO}$ & 13.23 & 13.88 & 13.14 & 13.05 & 10.70 & 13.64 & 12.31 & 10.49 & 11.75 & 10.37 & 15.07 & 9.85 & 13.90 & 11.30 & 12.09 & 15.18 & 10.54 & 12.71 & 13.12 & 10.68 \\
\hline $\mathrm{Na}_{2} \mathrm{O}$ & 3.86 & 3.42 & 3.78 & 3.90 & 4.94 & 3.47 & 4.30 & 4.99 & 4.52 & 5.28 & 2.82 & 5.55 & 3.37 & 4.77 & 4.40 & 2.73 & 4.99 & 4.09 & 3.86 & 5.07 \\
\hline $\mathrm{K}_{2} \mathrm{O}$ & 0.04 & 0.02 & 0.02 & 0.03 & 0.04 & 0.02 & 0.03 & 0.05 & 0.03 & 0.05 & 0.02 & 0.05 & 0.02 & 0.03 & 0.03 & 0.02 & 0.04 & 0.03 & 0.03 & 0.04 \\
\hline Total & 99.77 & 99.90 & 99.01 & 99.46 & 98.71 & 98.95 & 99.79 & 99.11 & 98.77 & 100.57 & 98.91 & 98.22 & 99.32 & 99.39 & 99.75 & 99.33 & 98.37 & 98.37 & 101.11 & 98.90 \\
\hline \multicolumn{21}{|l|}{ Cations } \\
\hline $\mathbf{S i}$ & 2.36 & 2.33 & 2.35 & 2.37 & 2.49 & 2.33 & 2.41 & 2.50 & 2.43 & 2.50 & 2.25 & 2.51 & 2.32 & 2.46 & 2.42 & 2.24 & 2.48 & 2.37 & 2.36 & 2.48 \\
\hline $\mathrm{Ti}$ & 0.000 & 0.000 & 0.001 & 0.000 & 0.000 & 0.000 & 0.001 & 0.000 & 0.001 & 0.000 & 0.000 & 0.000 & 0.000 & 0.000 & 0.000 & 0.000 & 0.000 & 0.000 & 0.001 & 0.000 \\
\hline Al & 1.62 & 1.66 & 1.64 & 1.62 & 1.51 & 1.66 & 1.58 & 1.50 & 1.56 & 1.50 & 1.74 & 1.48 & 1.67 & 1.53 & 1.58 & 1.75 & 1.52 & 1.62 & 1.64 & 1.51 \\
\hline Fe total & 0.020 & 0.022 & 0.023 & 0.026 & 0.019 & 0.021 & 0.019 & 0.021 & 0.024 & 0.016 & 0.022 & 0.020 & 0.023 & 0.022 & 0.021 & 0.022 & 0.021 & 0.021 & 0.025 & 0.018 \\
\hline Mn & 0.001 & 0.000 & 0.000 & 0.000 & 0.001 & 0.000 & 0.000 & 0.001 & 0.000 & 0.001 & 0.001 & 0.001 & 0.000 & 0.000 & 0.000 & 0.000 & 0.000 & 0.001 & 0.000 & 0.000 \\
\hline Mg & 0.65 & 0.68 & 0.65 & 0.64 & 0.52 & 0.67 & 0.60 & 0.51 & 0.58 & 0.50 & 0.75 & 0.48 & 0.68 & 0.55 & 0.59 & 0.75 & 0.52 & 0.63 & 0.63 & 0.52 \\
\hline $\mathrm{Ca}$ & 0.341 & 0.302 & 0.336 & 0.346 & 0.437 & 0.309 & 0.378 & 0.439 & 0.402 & 0.458 & 0.253 & 0.493 & 0.300 & 0.420 & 0.388 & 0.244 & 0.444 & 0.367 & 0.336 & 0.448 \\
\hline $\mathrm{Na}$ & 0.002 & 0.001 & 0.001 & 0.002 & 0.002 & 0.001 & 0.002 & 0.003 & 0.002 & 0.003 & 0.001 & 0.003 & 0.001 & 0.002 & 0.002 & 0.001 & 0.003 & 0.001 & 0.002 & 0.002 \\
\hline Total & 5.00 & 4.99 & 5.00 & 5.00 & 4.98 & 5.00 & 4.99 & 4.97 & 4.99 & 4.98 & 5.01 & 4.99 & 5.00 & 4.99 & 4.99 & 5.01 & 4.98 & 5.01 & 4.99 & 4.99 \\
\hline \multicolumn{21}{|l|}{ Atomic \% } \\
\hline$A b$ & 34.5 & 30.8 & 34.2 & 35.0 & 45.4 & 31.5 & 38.7 & 46.1 & 41.0 & 47.8 & 25.2 & 50.3 & 30.4 & 43.2 & 39.7 & 24.5 & 46.0 & 36.8 & 34.7 & 46.1 \\
\hline An & 65.3 & 69.1 & 65.7 & 64.8 & 54.4 & 68.4 & 61.1 & 53.6 & 58.9 & 51.9 & 74.6 & 49.4 & 69.4 & 56.6 & 60.2 & 75.4 & 53.7 & 63.1 & 65.2 & 53.7 \\
\hline Or & 0.2 & 0.1 & 0.1 & 0.2 & 0.2 & 0.1 & 0.2 & 0.3 & 0.2 & 0.3 & 0.1 & 0.3 & 0.1 & 0.2 & 0.2 & 0.1 & 0.3 & 0.1 & 0.2 & 0.2 \\
\hline
\end{tabular}


Table F.3. Continued

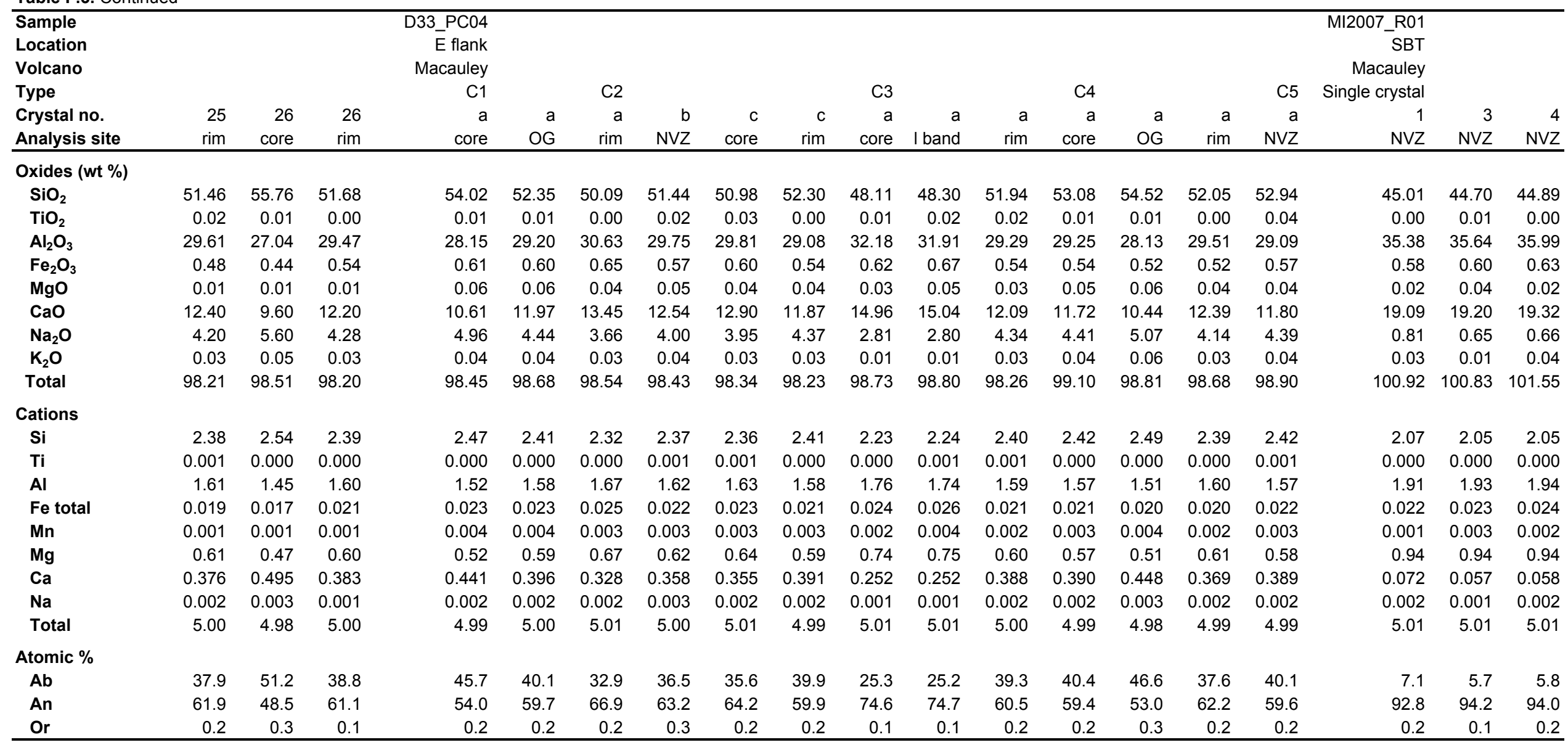


Table F.3. Continued

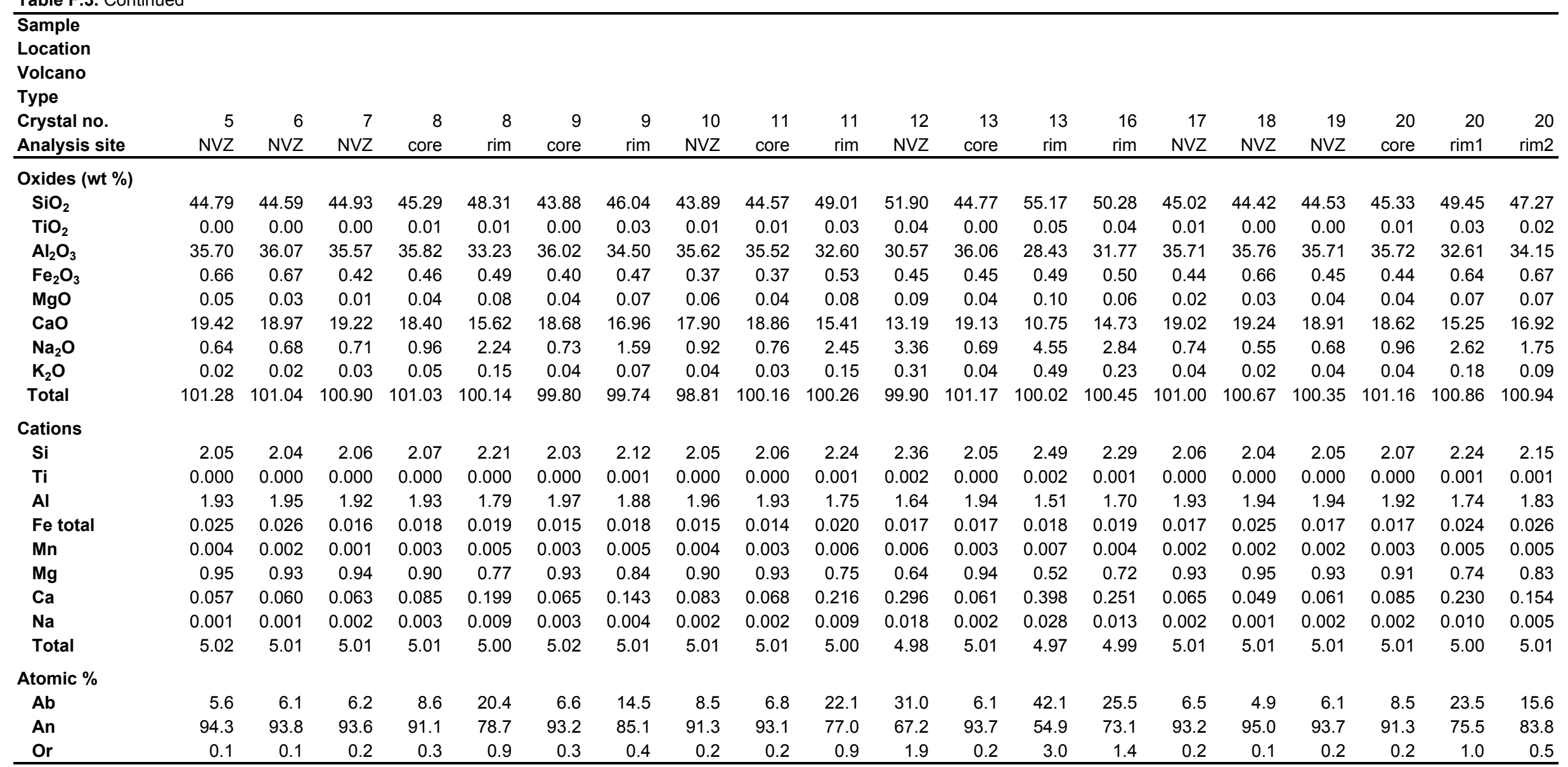


Table F.3. Continued

\begin{tabular}{|c|c|c|c|c|c|c|c|c|c|c|c|c|c|c|c|c|c|c|c|c|}
\hline $\begin{array}{l}\text { Sample } \\
\text { Location } \\
\text { Volcano } \\
\text { Type }\end{array}$ & & & & & & & & & & & & & & & & & & & & \\
\hline $\begin{array}{l}\text { Crystal no. } \\
\text { Analysis site }\end{array}$ & $\begin{array}{r}21 \\
\text { core } \\
\end{array}$ & $\begin{array}{r}21 \\
\mathrm{rim} \\
\end{array}$ & $\begin{array}{r}22 \\
\text { core } \\
\end{array}$ & $\begin{array}{r}22 \\
\text { rim } \\
\end{array}$ & $\begin{array}{r}23 \\
\text { core } \\
\end{array}$ & $\begin{array}{r}23 \\
\text { rim } \\
\end{array}$ & $\begin{array}{r}24 \\
\text { core } \\
\end{array}$ & $\begin{array}{r}24 \\
\text { rim } \\
\end{array}$ & $\begin{array}{r}25 \\
N V Z \\
\end{array}$ & $\begin{array}{r}26 \\
\text { core } \\
\end{array}$ & $\begin{array}{r}26 \\
\mathrm{rim} \\
\end{array}$ & $\begin{array}{r}28 \\
\text { core } \\
\end{array}$ & $\begin{array}{r}28 \\
\mathrm{rim} \\
\end{array}$ & $\begin{array}{r}29 \\
\text { core } \\
\end{array}$ & $\begin{array}{r}29 \\
\mathrm{rim} \\
\end{array}$ & $\begin{array}{r}30 \\
N V Z \\
\end{array}$ & $\begin{array}{r}31 \\
N V Z \\
\end{array}$ & $\begin{array}{r}32 \\
\text { core } \\
\end{array}$ & $\begin{array}{r}32 \\
\text { rim } \\
\end{array}$ & $\begin{array}{r}33 \\
\text { core } \\
\end{array}$ \\
\hline \multicolumn{21}{|l|}{ Oxides (wt \%) } \\
\hline $\mathrm{SiO}_{2}$ & 44.79 & 48.30 & 44.16 & 48.50 & 45.64 & 54.13 & 45.47 & 48.45 & 44.88 & 44.76 & 55.30 & 45.03 & 46.82 & 44.46 & 47.26 & 43.97 & 42.76 & 44.91 & 47.82 & 45.18 \\
\hline $\mathrm{TiO}_{2}$ & 0.00 & 0.01 & 0.00 & 0.03 & 0.01 & 0.06 & 0.00 & 0.02 & 0.00 & 0.00 & 0.07 & 0.00 & 0.02 & 0.00 & 0.03 & 0.01 & 0.00 & 0.00 & 0.02 & 0.00 \\
\hline $\mathrm{Al}_{2} \mathrm{O}_{3}$ & 36.03 & 33.40 & 35.75 & 32.62 & 35.08 & 28.68 & 35.67 & 33.01 & 36.08 & 35.65 & 28.24 & 35.64 & 33.93 & 35.96 & 33.82 & 35.96 & 35.67 & 35.90 & 33.04 & 35.76 \\
\hline $\mathrm{Fe}_{2} \mathrm{O}_{3}$ & 0.41 & 0.42 & 0.44 & 0.63 & 0.50 & 0.41 & 0.45 & 0.46 & 0.45 & 0.39 & 0.53 & 0.59 & 0.53 & 0.41 & 0.49 & 0.46 & 0.44 & 0.46 & 0.45 & 0.52 \\
\hline MgO & 0.05 & 0.08 & 0.02 & 0.07 & 0.05 & 0.10 & 0.05 & 0.07 & 0.02 & 0.02 & 0.12 & 0.05 & 0.06 & 0.03 & 0.06 & 0.05 & 0.04 & 0.04 & 0.05 & 0.04 \\
\hline $\mathrm{CaO}$ & 19.06 & 16.21 & 19.16 & 15.46 & 18.24 & 11.11 & 18.83 & 15.96 & 19.10 & 18.88 & 10.60 & 18.88 & 17.09 & 19.27 & 16.84 & 19.21 & 19.48 & 19.04 & 16.44 & 18.95 \\
\hline $\mathrm{Na}_{2} \mathrm{O}$ & 0.80 & 2.19 & 0.77 & 2.55 & 1.15 & 4.39 & 0.81 & 2.19 & 0.68 & 0.77 & 4.72 & 0.96 & 1.88 & 0.77 & 1.99 & 0.78 & 0.62 & 0.76 & 2.18 & 0.79 \\
\hline $\mathrm{K}_{2} \mathrm{O}$ & 0.04 & 0.13 & 0.03 & 0.16 & 0.08 & 0.62 & 0.04 & 0.14 & 0.03 & 0.03 & 0.45 & 0.03 & 0.08 & 0.03 & 0.10 & 0.03 & 0.02 & 0.03 & 0.11 & 0.04 \\
\hline Total & 101.18 & 100.75 & 100.33 & 100.03 & 100.73 & 99.48 & 101.31 & 100.29 & 101.23 & 100.49 & 100.02 & 101.18 & 100.39 & 100.93 & 100.58 & 100.46 & 99.03 & 101.14 & 100.11 & 101.28 \\
\hline \multicolumn{21}{|l|}{ Cations } \\
\hline $\mathbf{S i}$ & 2.05 & 2.20 & 2.04 & 2.22 & 2.09 & 2.46 & 2.07 & 2.21 & 2.05 & 2.06 & 2.49 & 2.06 & 2.15 & 2.04 & 2.16 & 2.03 & 2.01 & 2.05 & 2.19 & 2.06 \\
\hline $\mathrm{Ti}$ & 0.000 & 0.000 & 0.000 & 0.001 & 0.000 & 0.002 & 0.000 & 0.001 & 0.000 & 0.000 & 0.002 & 0.000 & 0.001 & 0.000 & 0.001 & 0.000 & 0.000 & 0.000 & 0.001 & 0.000 \\
\hline Al & 1.94 & 1.79 & 1.95 & 1.76 & 1.90 & 1.54 & 1.92 & 1.78 & 1.94 & 1.93 & 1.50 & 1.92 & 1.83 & 1.95 & 1.82 & 1.96 & 1.97 & 1.94 & 1.79 & 1.92 \\
\hline $\mathrm{Fe}$ total & 0.016 & 0.016 & 0.017 & 0.024 & 0.019 & 0.015 & 0.017 & 0.017 & 0.017 & 0.015 & 0.020 & 0.023 & 0.020 & 0.016 & 0.019 & 0.018 & 0.017 & 0.017 & 0.017 & 0.020 \\
\hline$M n$ & 0.003 & 0.006 & 0.001 & 0.005 & 0.003 & 0.007 & 0.003 & 0.005 & 0.001 & 0.001 & 0.008 & 0.003 & 0.004 & 0.002 & 0.004 & 0.003 & 0.003 & 0.003 & 0.004 & 0.003 \\
\hline $\mathbf{M g}$ & 0.93 & 0.79 & 0.95 & 0.76 & 0.90 & 0.54 & 0.92 & 0.78 & 0.93 & 0.93 & 0.51 & 0.93 & 0.84 & 0.95 & 0.83 & 0.95 & 0.98 & 0.93 & 0.81 & 0.93 \\
\hline $\mathrm{Ca}$ & 0.071 & 0.193 & 0.069 & 0.227 & 0.102 & 0.386 & 0.071 & 0.194 & 0.060 & 0.068 & 0.412 & 0.085 & 0.167 & 0.068 & 0.177 & 0.070 & 0.056 & 0.067 & 0.194 & 0.070 \\
\hline $\mathrm{Na}$ & 0.002 & 0.008 & 0.002 & 0.009 & 0.004 & 0.036 & 0.002 & 0.008 & 0.002 & 0.002 & 0.026 & 0.002 & 0.005 & 0.002 & 0.006 & 0.001 & 0.001 & 0.002 & 0.006 & 0.002 \\
\hline Total & 5.02 & 5.00 & 5.02 & 5.01 & 5.01 & 4.98 & 5.00 & 5.00 & 5.01 & 5.01 & 4.97 & 5.02 & 5.02 & 5.02 & 5.02 & 5.03 & 5.04 & 5.01 & 5.01 & 5.01 \\
\hline \multicolumn{21}{|l|}{ Atomic $\%$} \\
\hline$A b$ & 7.0 & 19.5 & 6.8 & 22.8 & 10.2 & 40.1 & 7.2 & 19.7 & 6.0 & 6.8 & 43.4 & 8.4 & 16.5 & 6.7 & 17.5 & 6.9 & 5.4 & 6.7 & 19.2 & 7.0 \\
\hline An & 92.8 & 79.7 & 93.0 & 76.3 & 89.3 & 56.1 & 92.6 & 79.5 & 93.8 & 93.0 & 53.9 & 91.4 & 83.0 & 93.1 & 81.9 & 93.0 & 94.5 & 93.1 & 80.1 & 92.8 \\
\hline Or & 0.2 & 0.8 & 0.2 & 0.9 & 0.4 & 3.7 & 0.2 & 0.8 & 0.2 & 0.2 & 2.7 & 0.2 & 0.5 & 0.2 & 0.6 & 0.1 & 0.1 & 0.2 & 0.6 & 0.2 \\
\hline
\end{tabular}


Table F.3. Continued

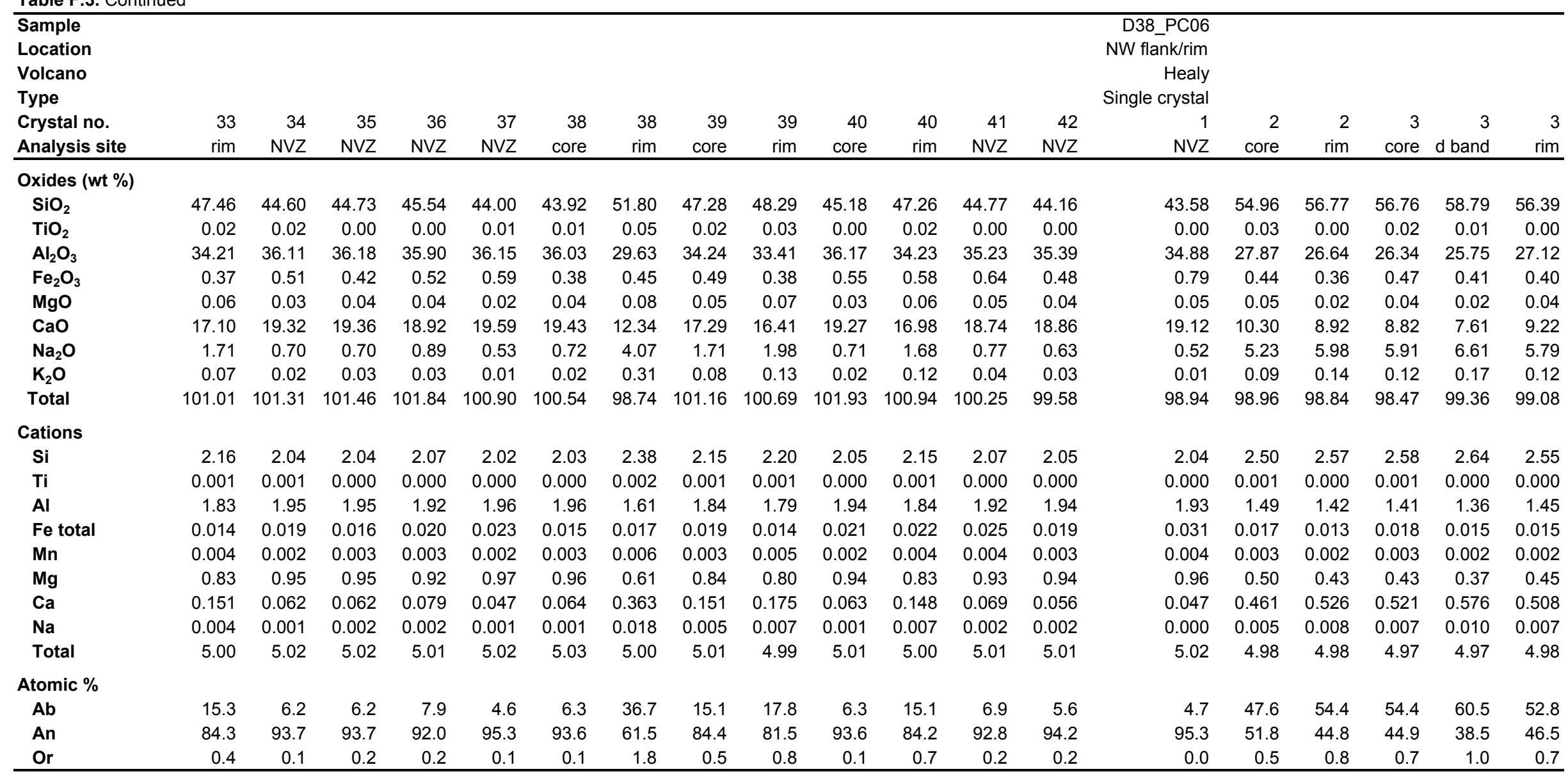


Table F.3. Continued

\begin{tabular}{|c|c|c|c|c|c|c|c|c|c|c|c|c|c|c|c|c|c|c|c|c|}
\hline $\begin{array}{l}\text { Sample } \\
\text { Location } \\
\text { Volcano } \\
\text { Type }\end{array}$ & & & & & & & & & & & & & & & & & & & & \\
\hline $\begin{array}{l}\text { Crystal no. } \\
\text { Analysis site }\end{array}$ & $\begin{array}{r}4 \\
\text { core } \\
\end{array}$ & $\begin{array}{r}4 \\
\text { rim } \\
\end{array}$ & $\begin{array}{r}5 \\
\text { core } \\
\end{array}$ & $\begin{array}{r}5 \\
\mathrm{~d} \text { band } \\
\end{array}$ & $\begin{array}{r}5 \\
\text { rim } \\
\end{array}$ & $\begin{array}{r}6 \\
\text { NVZ } \\
\end{array}$ & $\begin{array}{r}7 \\
\text { core } \\
\end{array}$ & $\begin{array}{r}7 \\
\mathrm{~d} \text { band } \\
\end{array}$ & $\begin{array}{r}7 \\
\text { rim } \\
\end{array}$ & $\begin{array}{r}8 \\
N V Z \\
\end{array}$ & $\begin{array}{r}9 \\
\text { core } \\
\end{array}$ & $\begin{array}{r}9 \\
\text { rim } \\
\end{array}$ & $\begin{array}{r}10 \\
\text { core } \\
\end{array}$ & $\begin{array}{r}10 \\
\mathrm{~d} \text { band } \\
\end{array}$ & $\begin{array}{r}11 \\
\text { core } \\
\end{array}$ & $\begin{array}{r}11 \\
\text { rim } \\
\end{array}$ & $\begin{array}{r}12 \\
\text { I band } \\
\end{array}$ & $\begin{array}{r}12 \\
\mathrm{~d} \text { band } \\
\end{array}$ & $\begin{array}{r}12 \\
\text { rim2 } \\
\end{array}$ & $\begin{array}{r}13 \\
N V Z \\
\end{array}$ \\
\hline \multicolumn{21}{|l|}{ Oxides (wt \%) } \\
\hline $\mathrm{SiO}_{2}$ & 58.53 & 57.23 & 56.74 & 59.00 & 57.08 & 44.00 & 44.90 & 57.24 & 57.10 & 44.59 & 56.86 & 56.44 & 52.15 & 56.50 & 56.27 & 57.24 & 53.31 & 56.78 & 56.46 & 43.92 \\
\hline $\mathrm{TiO}_{2}$ & 0.01 & 0.01 & 0.03 & 0.00 & 0.00 & 0.00 & 0.00 & 0.00 & 0.01 & 0.00 & 0.02 & 0.01 & 0.02 & 0.01 & 0.01 & 0.00 & 0.02 & 0.02 & 0.00 & 0.00 \\
\hline $\mathrm{Al}_{2} \mathrm{O}_{3}$ & 25.59 & 26.48 & 26.55 & 25.01 & 26.76 & 35.72 & 34.65 & 26.06 & 26.26 & 34.37 & 26.40 & 26.51 & 28.96 & 26.81 & 26.93 & 26.01 & 28.57 & 26.58 & 26.83 & 34.47 \\
\hline $\mathrm{Fe}_{2} \mathrm{O}_{3}$ & 0.39 & 0.36 & 0.41 & 0.37 & 0.50 & 0.67 & 0.76 & 0.35 & 0.47 & 0.80 & 0.38 & 0.47 & 0.55 & 0.46 & 0.40 & 0.44 & 0.52 & 0.33 & 0.37 & 0.68 \\
\hline MgO & 0.02 & 0.02 & 0.05 & 0.04 & 0.03 & 0.09 & 0.04 & 0.01 & 0.03 & 0.13 & 0.05 & 0.03 & 0.05 & 0.02 & 0.07 & 0.05 & 0.04 & 0.02 & 0.04 & 0.07 \\
\hline $\mathrm{CaO}$ & 7.47 & 8.67 & 8.95 & 7.21 & 8.95 & 19.48 & 18.39 & 8.38 & 8.40 & 18.77 & 8.89 & 8.96 & 12.08 & 9.04 & 9.38 & 8.33 & 10.80 & 8.52 & 8.38 & 18.93 \\
\hline $\mathrm{Na}_{2} \mathrm{O}$ & 6.86 & 6.09 & 5.79 & 6.54 & 5.87 & 0.55 & 1.12 & 6.16 & 6.05 & 0.81 & 5.86 & 5.74 & 4.15 & 5.96 & 5.65 & 6.04 & 4.98 & 6.13 & 5.99 & 0.63 \\
\hline $\mathrm{K}_{2} \mathrm{O}$ & 0.15 & 0.13 & 0.12 & 0.17 & 0.12 & 0.01 & 0.00 & 0.14 & 0.14 & 0.00 & 0.13 & 0.13 & 0.07 & 0.13 & 0.12 & 0.13 & 0.09 & 0.14 & 0.14 & 0.00 \\
\hline Total & 99.03 & 99.00 & 98.64 & 98.34 & 99.31 & 100.53 & 99.85 & 98.35 & 98.47 & 99.46 & 98.57 & 98.29 & 98.03 & 98.92 & 98.82 & 98.26 & 98.33 & 98.51 & 98.21 & 98.70 \\
\hline \multicolumn{21}{|l|}{ Cations } \\
\hline Si & 2.64 & 2.59 & 2.58 & 2.67 & 2.58 & 2.03 & 2.08 & 2.60 & 2.59 & 2.08 & 2.58 & 2.57 & 2.41 & 2.56 & 2.55 & 2.60 & 2.45 & 2.58 & 2.57 & 2.06 \\
\hline $\mathrm{Ti}$ & 0.000 & 0.000 & 0.001 & 0.000 & 0.000 & 0.000 & 0.000 & 0.000 & 0.000 & 0.000 & 0.001 & 0.000 & 0.001 & 0.000 & 0.000 & 0.000 & 0.001 & 0.001 & 0.000 & 0.000 \\
\hline Al & 1.36 & 1.41 & 1.42 & 1.33 & 1.42 & 1.94 & 1.89 & 1.40 & 1.41 & 1.89 & 1.41 & 1.42 & 1.58 & 1.43 & 1.44 & 1.40 & 1.55 & 1.42 & 1.44 & 1.91 \\
\hline $\mathrm{Fe}$ total & 0.015 & 0.014 & 0.016 & 0.014 & 0.019 & 0.026 & 0.030 & 0.013 & 0.018 & 0.031 & 0.014 & 0.018 & 0.021 & 0.018 & 0.015 & 0.017 & 0.020 & 0.013 & 0.014 & 0.027 \\
\hline Mn & 0.001 & 0.001 & 0.004 & 0.003 & 0.002 & 0.006 & 0.003 & 0.001 & 0.002 & 0.009 & 0.003 & 0.002 & 0.003 & 0.001 & 0.004 & 0.004 & 0.003 & 0.001 & 0.003 & 0.005 \\
\hline Mg & 0.36 & 0.42 & 0.44 & 0.35 & 0.43 & 0.96 & 0.91 & 0.41 & 0.41 & 0.94 & 0.43 & 0.44 & 0.60 & 0.44 & 0.46 & 0.41 & 0.53 & 0.41 & 0.41 & 0.95 \\
\hline $\mathrm{Ca}$ & 0.600 & 0.534 & 0.510 & 0.574 & 0.513 & 0.049 & 0.101 & 0.544 & 0.533 & 0.073 & 0.516 & 0.507 & 0.372 & 0.524 & 0.497 & 0.533 & 0.443 & 0.540 & 0.529 & 0.058 \\
\hline $\mathrm{Na}$ & 0.008 & 0.008 & 0.007 & 0.010 & 0.007 & 0.000 & 0.000 & 0.008 & 0.008 & 0.000 & 0.007 & 0.007 & 0.004 & 0.007 & 0.007 & 0.008 & 0.005 & 0.008 & 0.008 & 0.000 \\
\hline Total & 4.98 & 4.98 & 4.97 & 4.95 & 4.97 & 5.02 & 5.02 & 4.97 & 4.97 & 5.02 & 4.97 & 4.97 & 4.99 & 4.99 & 4.98 & 4.97 & 5.00 & 4.98 & 4.98 & 5.01 \\
\hline \multicolumn{21}{|l|}{ Atomic $\%$} \\
\hline$A b$ & 61.9 & 55.5 & 53.5 & 61.5 & 53.9 & 4.9 & 10.0 & 56.6 & 56.1 & 7.3 & 54.0 & 53.3 & 38.2 & 54.0 & 51.8 & 56.3 & 45.2 & 56.1 & 55.9 & 5.7 \\
\hline An & 37.3 & 43.7 & 45.7 & 37.4 & 45.4 & 95.1 & 90.0 & 42.5 & 43.0 & 92.7 & 45.3 & 45.9 & 61.4 & 45.3 & 47.5 & 42.9 & 54.2 & 43.1 & 43.2 & 94.3 \\
\hline Or & 0.9 & 0.8 & 0.7 & 1.1 & 0.7 & 0.0 & 0.0 & 0.9 & 0.8 & 0.0 & 0.8 & 0.8 & 0.4 & 0.8 & 0.7 & 0.8 & 0.5 & 0.8 & 0.8 & 0.0 \\
\hline
\end{tabular}


Table F.3. Continued

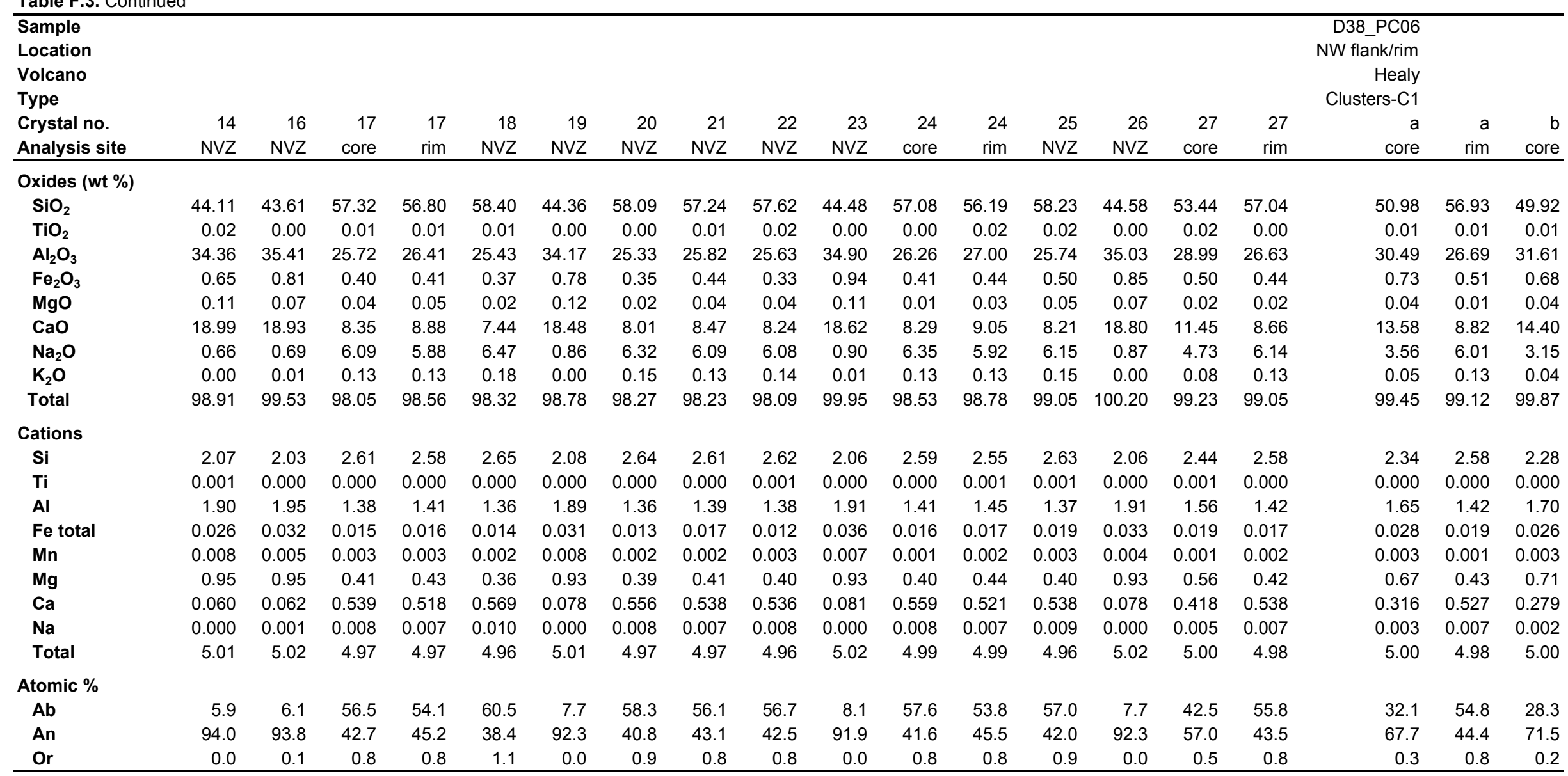


Table F.3. Continued

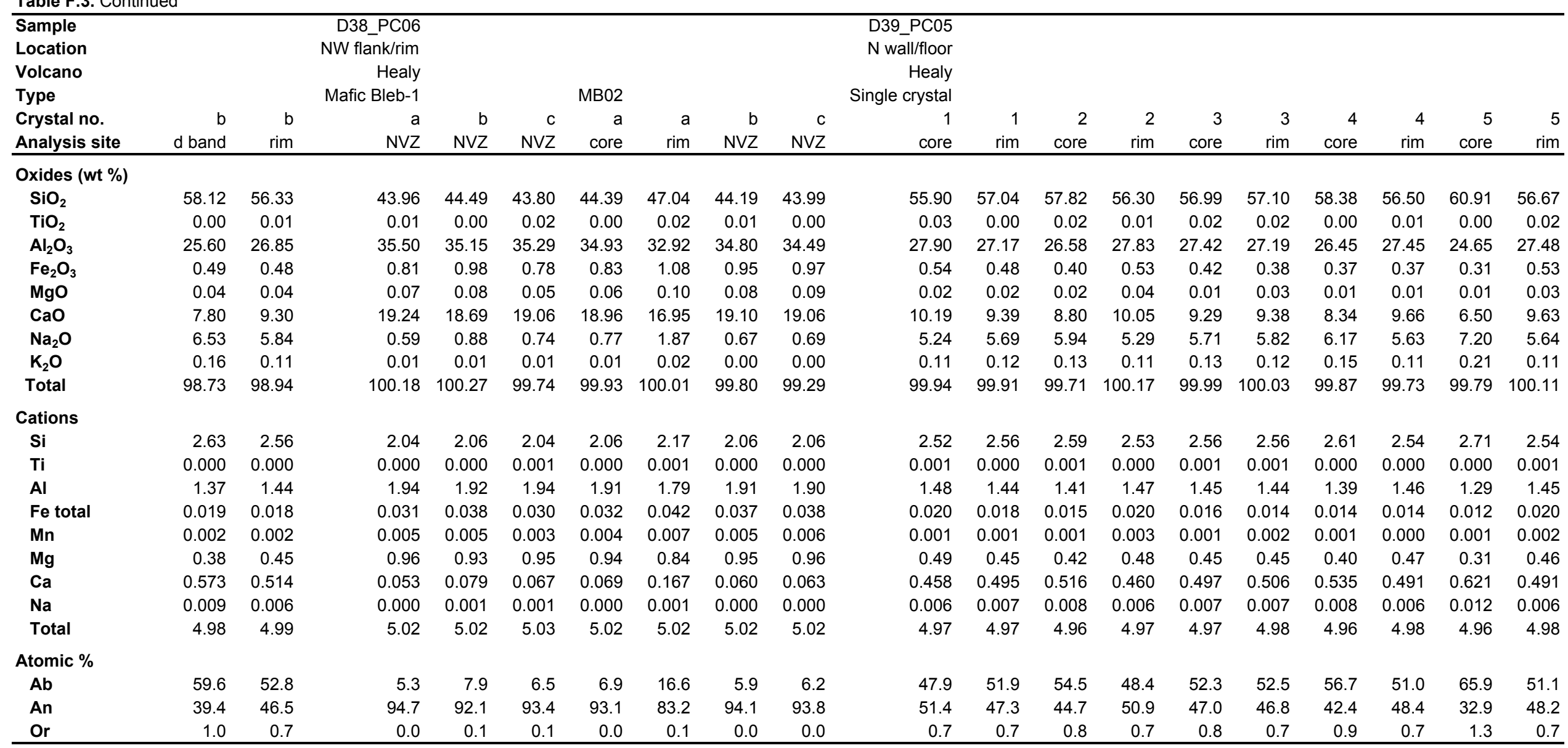


Table F.3. Continued

\begin{tabular}{|c|c|c|c|c|c|c|c|c|c|c|c|c|c|c|c|c|c|c|c|c|}
\hline $\begin{array}{l}\text { Sample } \\
\text { Location } \\
\text { Volcano } \\
\text { Type }\end{array}$ & & & & & & & & & & & & & & & & & & & & \\
\hline $\begin{array}{l}\text { Crystal no. } \\
\text { Analysis site }\end{array}$ & $\begin{array}{r}6 \\
\text { core } \\
\end{array}$ & $\begin{array}{r}6 \\
\text { rim } \\
\end{array}$ & $\begin{array}{r}7 \\
N V Z \\
\end{array}$ & $\begin{array}{r}8 \\
N V Z \\
\end{array}$ & $\begin{array}{r}9 \\
N V Z \\
\end{array}$ & $\begin{array}{r}10 \\
\text { core } \\
\end{array}$ & $\begin{array}{r}10 \\
\text { rim } \\
\end{array}$ & $\begin{array}{r}11 \\
\text { core } \\
\end{array}$ & $\begin{array}{r}11 \\
\text { rim } \\
\end{array}$ & $\begin{array}{r}12 \\
\text { core } \\
\end{array}$ & $\begin{array}{r}12 \\
\text { rim } \\
\end{array}$ & $\begin{array}{r}13 \\
N V Z \\
\end{array}$ & $\begin{array}{r}15 \\
N V Z \\
\end{array}$ & $\begin{array}{r}16 \\
N V Z \\
\end{array}$ & $\begin{array}{r}17 \\
N V Z \\
\end{array}$ & $\begin{array}{r}18 \\
N V Z \\
\end{array}$ & $\begin{array}{r}18 \\
\mathrm{rim} \\
\end{array}$ & $\begin{array}{r}19 \\
\text { core } \\
\end{array}$ & $\begin{array}{r}19 \\
\text { rim } \\
\end{array}$ & $\begin{array}{r}20 \\
\text { core } \\
\end{array}$ \\
\hline \multicolumn{21}{|l|}{ Oxides (wt \%) } \\
\hline $\mathrm{SiO}_{2}$ & 58.28 & 56.59 & 55.43 & 56.84 & 56.74 & 58.08 & 55.38 & 57.93 & 56.44 & 55.03 & 56.59 & 57.55 & 58.57 & 56.15 & 57.56 & 56.27 & 55.51 & 57.17 & 56.81 & 51.74 \\
\hline $\mathrm{TiO}_{2}$ & 0.01 & 0.01 & 0.00 & 0.02 & 0.00 & 0.02 & 0.00 & 0.00 & 0.01 & 0.03 & 0.01 & 0.01 & 0.02 & 0.01 & 0.01 & 0.03 & 0.01 & 0.00 & 0.03 & 0.03 \\
\hline $\mathrm{Al}_{2} \mathrm{O}_{3}$ & 26.54 & 27.32 & 28.30 & 27.38 & 27.57 & 26.79 & 28.23 & 26.46 & 27.59 & 28.57 & 27.06 & 27.06 & 26.00 & 27.82 & 26.74 & 26.87 & 27.40 & 26.84 & 27.01 & 30.68 \\
\hline $\mathrm{Fe}_{2} \mathrm{O}_{3}$ & 0.48 & 0.40 & 0.42 & 0.43 & 0.49 & 0.34 & 0.46 & 0.31 & 0.47 & 0.49 & 0.45 & 0.51 & 0.40 & 0.46 & 0.41 & 0.45 & 0.50 & 0.41 & 0.47 & 0.79 \\
\hline MgO & 0.00 & 0.02 & 0.05 & 0.03 & 0.04 & 0.03 & 0.02 & 0.02 & 0.04 & 0.03 & 0.02 & 0.01 & 0.02 & 0.02 & 0.03 & 0.02 & 0.01 & 0.01 & 0.00 & 0.04 \\
\hline $\mathrm{CaO}$ & 8.40 & 9.54 & 10.47 & 9.52 & 9.72 & 8.91 & 10.61 & 8.54 & 9.76 & 10.85 & 9.24 & 8.99 & 7.90 & 9.84 & 8.69 & 9.01 & 9.59 & 9.04 & 9.34 & 13.42 \\
\hline $\mathrm{Na}_{2} \mathrm{O}$ & 6.23 & 5.59 & 5.11 & 5.64 & 5.44 & 6.09 & 5.07 & 6.13 & 5.48 & 4.95 & 5.88 & 5.90 & 6.52 & 5.39 & 6.04 & 5.82 & 5.48 & 5.83 & 5.61 & 3.71 \\
\hline $\mathrm{K}_{2} \mathrm{O}$ & 0.15 & 0.12 & 0.10 & 0.11 & 0.11 & 0.14 & 0.10 & 0.14 & 0.11 & 0.09 & 0.12 & 0.14 & 0.16 & 0.10 & 0.14 & 0.13 & 0.11 & 0.13 & 0.12 & 0.05 \\
\hline Total & 100.09 & 99.59 & 99.87 & 99.96 & 100.10 & 100.40 & 99.87 & 99.52 & 99.89 & 100.03 & 99.36 & 100.17 & 99.58 & 99.78 & 99.61 & 98.59 & 98.62 & 99.43 & 99.39 & 100.44 \\
\hline \multicolumn{21}{|l|}{ Cations } \\
\hline Si & 2.60 & 2.55 & 2.50 & 2.55 & 2.54 & 2.59 & 2.50 & 2.60 & 2.54 & 2.48 & 2.56 & 2.57 & 2.63 & 2.53 & 2.59 & 2.56 & 2.53 & 2.58 & 2.56 & 2.35 \\
\hline $\mathrm{Ti}$ & 0.000 & 0.000 & 0.000 & 0.001 & 0.000 & 0.001 & 0.000 & 0.000 & 0.000 & 0.001 & 0.000 & 0.000 & 0.001 & 0.000 & 0.000 & 0.001 & 0.000 & 0.000 & 0.001 & 0.001 \\
\hline Al & 1.40 & 1.45 & 1.50 & 1.45 & 1.46 & 1.41 & 1.50 & 1.40 & 1.46 & 1.52 & 1.44 & 1.43 & 1.37 & 1.48 & 1.42 & 1.44 & 1.47 & 1.43 & 1.44 & 1.64 \\
\hline Fe total & 0.018 & 0.015 & 0.016 & 0.016 & 0.019 & 0.013 & 0.017 & 0.012 & 0.018 & 0.018 & 0.017 & 0.019 & 0.015 & 0.017 & 0.015 & 0.017 & 0.019 & 0.015 & 0.018 & 0.030 \\
\hline Mn & 0.000 & 0.001 & 0.003 & 0.002 & 0.002 & 0.002 & 0.002 & 0.001 & 0.002 & 0.002 & 0.001 & 0.001 & 0.001 & 0.002 & 0.002 & 0.001 & 0.001 & 0.001 & 0.000 & 0.003 \\
\hline Mg & 0.40 & 0.46 & 0.51 & 0.46 & 0.47 & 0.43 & 0.51 & 0.41 & 0.47 & 0.52 & 0.45 & 0.43 & 0.38 & 0.47 & 0.42 & 0.44 & 0.47 & 0.44 & 0.45 & 0.65 \\
\hline $\mathrm{Ca}$ & 0.540 & 0.489 & 0.446 & 0.491 & 0.473 & 0.526 & 0.443 & 0.534 & 0.478 & 0.432 & 0.515 & 0.511 & 0.567 & 0.470 & 0.526 & 0.514 & 0.484 & 0.509 & 0.490 & 0.326 \\
\hline $\mathrm{Na}$ & 0.008 & 0.007 & 0.006 & 0.006 & 0.006 & 0.008 & 0.006 & 0.008 & 0.006 & 0.005 & 0.007 & 0.008 & 0.009 & 0.006 & 0.008 & 0.008 & 0.006 & 0.008 & 0.007 & 0.003 \\
\hline Total & 4.97 & 4.97 & 4.98 & 4.97 & 4.97 & 4.97 & 4.98 & 4.97 & 4.97 & 4.98 & 4.98 & 4.97 & 4.97 & 4.97 & 4.97 & 4.98 & 4.98 & 4.97 & 4.97 & 5.00 \\
\hline \multicolumn{21}{|l|}{ Atomic $\%$} \\
\hline$A b$ & 56.8 & 51.1 & 46.6 & 51.4 & 50.0 & 54.8 & 46.1 & 56.1 & 50.1 & 45.0 & 53.1 & 53.8 & 59.3 & 49.5 & 55.2 & 53.5 & 50.5 & 53.4 & 51.7 & 33.2 \\
\hline An & 42.3 & 48.2 & 52.8 & 48.0 & 49.4 & 44.3 & 53.3 & 43.1 & 49.3 & 54.5 & 46.1 & 45.3 & 39.7 & 49.9 & 43.9 & 45.7 & 48.8 & 45.8 & 47.6 & 66.5 \\
\hline Or & 0.9 & 0.7 & 0.6 & 0.6 & 0.7 & 0.8 & 0.6 & 0.8 & 0.7 & 0.5 & 0.7 & 0.8 & 1.0 & 0.6 & 0.9 & 0.8 & 0.7 & 0.8 & 0.7 & 0.3 \\
\hline
\end{tabular}


Table F.3. Continued

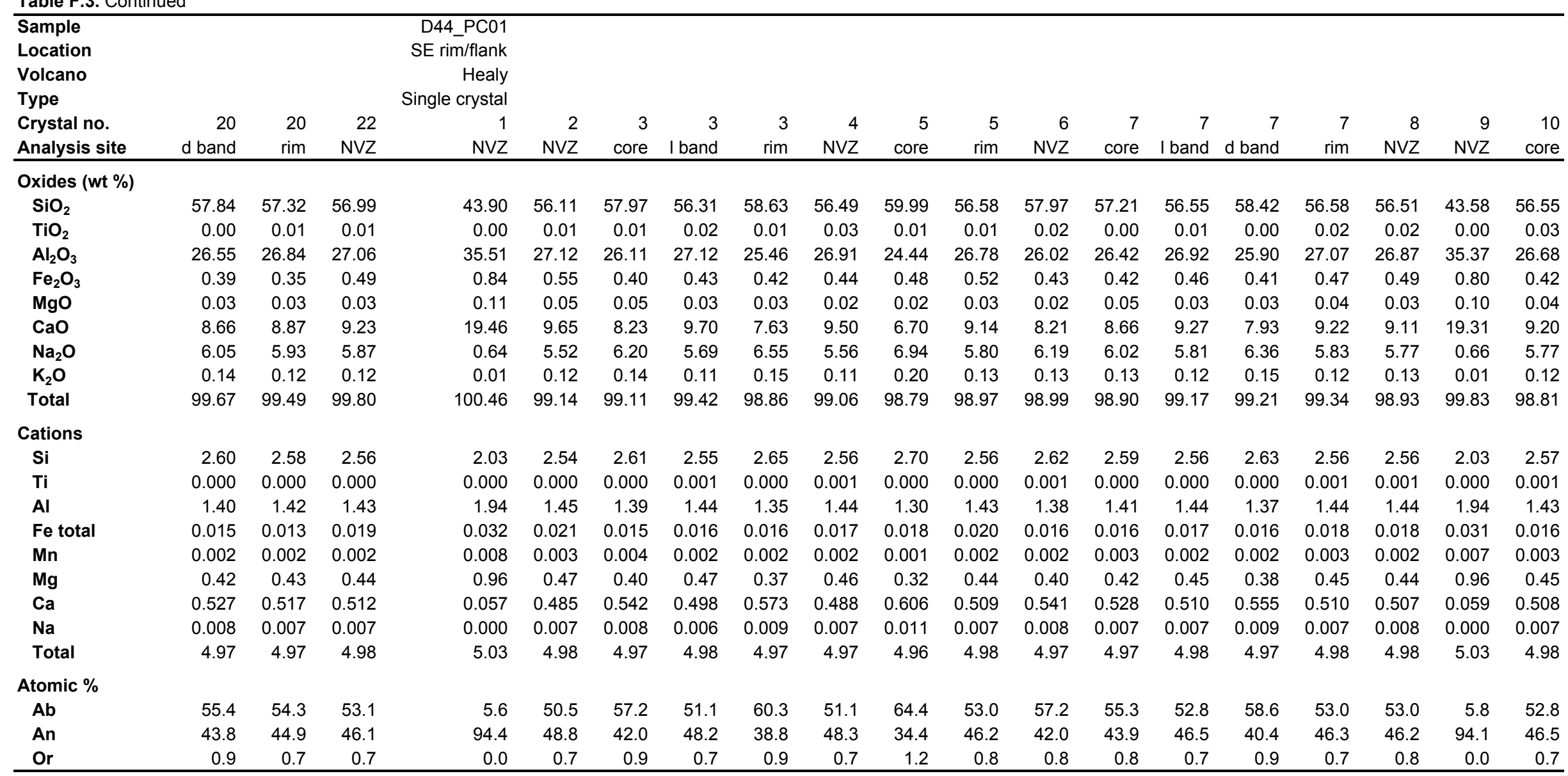


Table F.3. Continued

\begin{tabular}{|c|c|c|c|c|c|c|c|c|c|c|c|c|c|c|c|c|c|c|c|c|}
\hline $\begin{array}{l}\text { Sample } \\
\text { Location } \\
\text { Volcano } \\
\text { Type }\end{array}$ & & & & & & & & & & & & & & & & & & & & \\
\hline $\begin{array}{l}\text { Crystal no. } \\
\text { Analysis site }\end{array}$ & $\begin{array}{r}10 \\
\text { rim } \\
\end{array}$ & $\begin{array}{r}11 \\
N V Z \\
\end{array}$ & $\begin{array}{r}12 \\
N V Z \\
\end{array}$ & $\begin{array}{r}13 \\
\text { core } \\
\end{array}$ & $\begin{array}{r}13 \\
\mathrm{~d} \text { band } \\
\end{array}$ & $\begin{array}{r}13 \\
\text { rim } \\
\end{array}$ & $\begin{array}{r}14 \\
\text { core } \\
\end{array}$ & $\begin{array}{r}14 \\
\text { rim } \\
\end{array}$ & $\begin{array}{r}15 \\
\text { core } \\
\end{array}$ & $\begin{array}{r}15 \\
\mathrm{~d} \text { band } \\
\end{array}$ & $\begin{array}{r}15 \\
\text { I band } \\
\end{array}$ & $\begin{array}{r}15 \\
\text { rim } \\
\end{array}$ & $\begin{array}{r}16 \\
N V Z \\
\end{array}$ & $\begin{array}{r}17 \\
\text { core } \\
\end{array}$ & $\begin{array}{r}17 \\
\mathrm{~d} \text { band } \\
\end{array}$ & $\begin{array}{r}17 \\
\mathrm{~d} \text { band } \\
\end{array}$ & $\begin{array}{r}17 \\
\text { rim }\end{array}$ & $\begin{array}{r}18 \\
N V Z \\
\end{array}$ & $\begin{array}{r}19 \\
N V Z \\
\end{array}$ & $\begin{array}{r}20 \\
N V Z \\
\end{array}$ \\
\hline \multicolumn{21}{|l|}{ Oxides (wt \%) } \\
\hline $\mathrm{SiO}_{2}$ & 57.06 & 58.24 & 44.67 & 55.61 & 58.48 & 56.57 & 56.11 & 55.32 & 59.67 & 57.57 & 55.49 & 57.17 & 57.47 & 55.22 & 57.66 & 58.08 & 56.06 & 44.15 & 44.31 & 44.51 \\
\hline $\mathrm{TiO}_{2}$ & 0.00 & 0.01 & 0.00 & 0.03 & 0.00 & 0.00 & 0.01 & 0.00 & 0.01 & 0.00 & 0.02 & 0.01 & 0.00 & 0.01 & 0.01 & 0.02 & 0.01 & 0.00 & 0.00 & 0.00 \\
\hline $\mathrm{Al}_{2} \mathrm{O}_{3}$ & 26.81 & 25.83 & 34.92 & 27.44 & 25.42 & 26.70 & 26.84 & 27.17 & 24.52 & 26.21 & 27.44 & 26.21 & 25.68 & 28.39 & 26.15 & 25.92 & 27.42 & 34.64 & 35.24 & 34.67 \\
\hline $\mathrm{Fe}_{2} \mathrm{O}_{3}$ & 0.45 & 0.38 & 0.78 & 0.46 & 0.55 & 0.52 & 0.43 & 0.42 & 0.37 & 0.53 & 0.41 & 0.45 & 0.36 & 0.42 & 0.33 & 0.33 & 0.44 & 0.63 & 0.71 & 0.92 \\
\hline MgO & 0.03 & 0.03 & 0.10 & 0.05 & 0.02 & 0.04 & 0.01 & 0.04 & 0.04 & 0.03 & 0.04 & 0.04 & 0.02 & 0.02 & 0.03 & 0.02 & 0.02 & 0.14 & 0.06 & 0.14 \\
\hline $\mathrm{CaO}$ & 8.86 & 7.95 & 18.88 & 9.77 & 7.67 & 9.12 & 9.06 & 9.44 & 6.78 & 8.35 & 9.91 & 8.64 & 8.39 & 10.02 & 7.95 & 7.69 & 9.12 & 19.17 & 19.04 & 18.93 \\
\hline $\mathrm{Na}_{2} \mathrm{O}$ & 5.95 & 6.31 & 0.89 & 5.42 & 6.49 & 5.74 & 5.86 & 5.67 & 6.83 & 6.18 & 5.43 & 5.93 & 6.20 & 5.36 & 6.47 & 6.46 & 5.82 & 0.60 & 0.65 & 0.77 \\
\hline $\mathrm{K}_{2} \mathrm{O}$ & 0.14 & 0.14 & 0.01 & 0.11 & 0.16 & 0.14 & 0.12 & 0.11 & 0.17 & 0.14 & 0.12 & 0.15 & 0.14 & 0.11 & 0.15 & 0.15 & 0.12 & 0.00 & 0.01 & 0.00 \\
\hline Total & 99.30 & 98.89 & 100.25 & 98.88 & 98.79 & 98.83 & 98.44 & 98.17 & 98.39 & 99.02 & 98.85 & 98.59 & 98.26 & 99.55 & 98.75 & 98.66 & 99.00 & 99.34 & 100.03 & 99.93 \\
\hline \multicolumn{21}{|l|}{ Cations } \\
\hline $\mathrm{Si}$ & 2.57 & 2.63 & 2.07 & 2.53 & 2.64 & 2.57 & 2.56 & 2.53 & 2.70 & 2.60 & 2.52 & 2.60 & 2.62 & 2.50 & 2.61 & 2.63 & 2.54 & 2.06 & 2.05 & 2.07 \\
\hline $\mathrm{Ti}$ & 0.000 & 0.000 & 0.000 & 0.001 & 0.000 & 0.000 & 0.000 & 0.000 & 0.000 & 0.000 & 0.001 & 0.000 & 0.000 & 0.000 & 0.000 & 0.001 & 0.000 & 0.000 & 0.000 & 0.000 \\
\hline Al & 1.43 & 1.37 & 1.90 & 1.47 & 1.35 & 1.43 & 1.44 & 1.47 & 1.31 & 1.40 & 1.47 & 1.40 & 1.38 & 1.51 & 1.39 & 1.38 & 1.46 & 1.91 & 1.92 & 1.90 \\
\hline Fe total & 0.017 & 0.014 & 0.030 & 0.017 & 0.021 & 0.020 & 0.017 & 0.016 & 0.014 & 0.020 & 0.016 & 0.017 & 0.014 & 0.016 & 0.012 & 0.013 & 0.017 & 0.025 & 0.028 & 0.036 \\
\hline Mn & 0.002 & 0.002 & 0.007 & 0.003 & 0.001 & 0.003 & 0.001 & 0.003 & 0.003 & 0.002 & 0.003 & 0.003 & 0.002 & 0.001 & 0.002 & 0.001 & 0.001 & 0.009 & 0.004 & 0.009 \\
\hline Mg & 0.43 & 0.38 & 0.94 & 0.48 & 0.37 & 0.44 & 0.44 & 0.46 & 0.33 & 0.40 & 0.48 & 0.42 & 0.41 & 0.49 & 0.39 & 0.37 & 0.44 & 0.96 & 0.95 & 0.94 \\
\hline $\mathrm{Ca}$ & 0.520 & 0.552 & 0.080 & 0.477 & 0.568 & 0.505 & 0.518 & 0.503 & 0.598 & 0.542 & 0.479 & 0.522 & 0.547 & 0.470 & 0.568 & 0.567 & 0.511 & 0.054 & 0.058 & 0.069 \\
\hline $\mathrm{Na}$ & 0.008 & 0.008 & 0.000 & 0.006 & 0.009 & 0.008 & 0.007 & 0.006 & 0.010 & 0.008 & 0.007 & 0.009 & 0.008 & 0.006 & 0.009 & 0.009 & 0.007 & 0.000 & 0.001 & 0.000 \\
\hline Total & 4.98 & 4.96 & 5.02 & 4.98 & 4.97 & 4.97 & 4.98 & 4.99 & 4.95 & 4.97 & 4.98 & 4.97 & 4.97 & 4.99 & 4.98 & 4.97 & 4.99 & 5.01 & 5.01 & 5.02 \\
\hline \multicolumn{21}{|l|}{ Atomic \% } \\
\hline$A b$ & 54.4 & 58.5 & 7.8 & 49.8 & 59.9 & 52.8 & 53.5 & 51.7 & 63.9 & 56.8 & 49.4 & 54.9 & 56.7 & 48.9 & 59.0 & 59.8 & 53.2 & 5.4 & 5.8 & 6.8 \\
\hline An & 44.8 & 40.7 & 92.1 & 49.6 & 39.1 & 46.4 & 45.7 & 47.6 & 35.1 & 42.4 & 49.9 & 44.2 & 42.4 & 50.5 & 40.1 & 39.3 & 46.1 & 94.6 & 94.2 & 93.2 \\
\hline Or & 0.8 & 0.9 & 0.0 & 0.7 & 1.0 & 0.8 & 0.7 & 0.7 & 1.0 & 0.9 & 0.7 & 0.9 & 0.9 & 0.6 & 0.9 & 0.9 & 0.7 & 0.0 & 0.1 & 0.0 \\
\hline
\end{tabular}


Table F.3. Continued

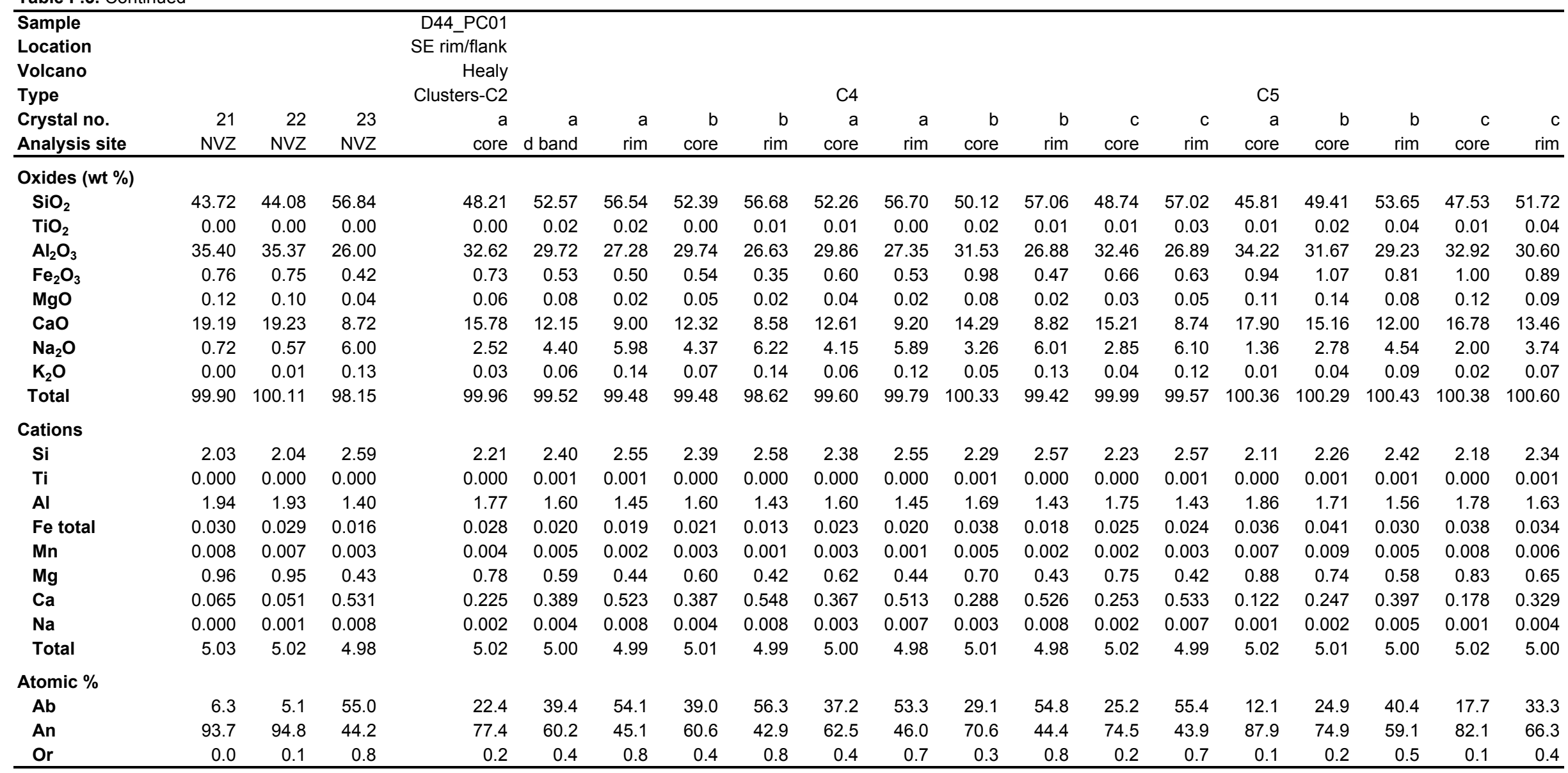


Table F.3. Continued

\begin{tabular}{|c|c|c|c|c|c|c|c|c|c|c|c|c|c|c|c|c|c|c|c|}
\hline Sample & D44_PC01 & & & & & & D47_PC02 & & & & & & & & & & & & \\
\hline Location & SE rim/flank & & & & & & Edifice crater & & & & & & & & & & & & \\
\hline Volcano & Healy & & & & & & Healy & & & & & & & & & & & & \\
\hline Type & Mafic Bleb-1 & & & & MB02 & & Single crystal & & & & & & & & & & & & \\
\hline Crystal no. & a & a & $\mathrm{b}$ & $\mathrm{b}$ & $a$ & $\mathrm{~b}$ & 1 & 1 & 2 & 3 & 3 & 4 & 5 & 5 & 5 & 7 & 8 & 9 & 10 \\
\hline Analysis site & core & rim & core & rim & NVZ & NVZ & core & rim & NVZ & core & rim & NVZ & core & $\mathrm{d}$ band & rim & NVZ & NVZ & NVZ & core \\
\hline \multicolumn{20}{|l|}{ Oxides (wt \%) } \\
\hline $\mathrm{SiO}_{2}$ & 44.77 & 48.39 & 45.38 & 48.61 & 43.93 & 44.36 & 57.45 & 55.72 & 55.23 & 53.74 & 57.99 & 54.05 & 56.79 & 61.26 & 59.91 & 53.50 & 55.23 & 55.02 & 54.11 \\
\hline $\mathrm{TiO}_{2}$ & 0.00 & 0.03 & 0.00 & 0.02 & 0.00 & 0.00 & 0.00 & 0.00 & 0.02 & 0.03 & 0.03 & 0.03 & 0.01 & 0.02 & 0.02 & 0.02 & 0.00 & 0.01 & 0.01 \\
\hline $\mathrm{Al}_{2} \mathrm{O}_{3}$ & 34.95 & 32.37 & 34.50 & 32.11 & 35.65 & 35.53 & 26.56 & 27.93 & 27.94 & 29.15 & 26.32 & 28.88 & 27.24 & 24.43 & 25.08 & 29.23 & 27.88 & 28.50 & 27.74 \\
\hline $\mathrm{Fe}_{2} \mathrm{O}_{3}$ & 0.87 & 1.17 & 1.13 & 1.16 & 0.83 & 0.86 & 0.42 & 0.49 & 0.51 & 0.60 & 0.39 & 0.58 & 0.49 & 0.23 & 0.45 & 0.58 & 0.41 & 0.57 & 0.55 \\
\hline MgO & 0.07 & 0.14 & 0.09 & 0.12 & 0.08 & 0.08 & 0.03 & 0.03 & 0.04 & 0.04 & 0.01 & 0.02 & 0.01 & 0.01 & 0.03 & 0.05 & 0.04 & 0.02 & 0.05 \\
\hline $\mathrm{CaO}$ & 18.33 & 15.77 & 18.00 & 15.38 & 19.27 & 19.14 & 8.65 & 10.11 & 10.33 & 11.55 & 8.36 & 11.46 & 9.34 & 6.06 & 7.00 & 11.77 & 10.24 & 10.77 & 10.59 \\
\hline $\mathrm{Na}_{2} \mathrm{O}$ & 1.01 & 2.40 & 1.22 & 2.55 & 0.62 & 0.72 & 5.97 & 5.32 & 5.15 & 4.66 & 6.18 & 4.64 & 5.55 & 7.28 & 6.91 & 4.54 & 5.15 & 4.98 & 4.93 \\
\hline $\mathrm{K}_{2} \mathrm{O}$ & 0.00 & 0.04 & 0.01 & 0.03 & 0.01 & 0.01 & 0.15 & 0.10 & 0.09 & 0.07 & 0.12 & 0.08 & 0.24 & 0.24 & 0.18 & 0.06 & 0.11 & 0.11 & 0.09 \\
\hline Total & 100.00 & 100.30 & 100.34 & 99.98 & 100.38 & 100.71 & 99.22 & 99.70 & 99.31 & 99.83 & 99.39 & 99.74 & 99.67 & 99.52 & 99.57 & 99.75 & 99.07 & 99.98 & 98.07 \\
\hline \multicolumn{20}{|l|}{ Cations } \\
\hline $\mathbf{S i}$ & 2.07 & 2.22 & 2.09 & 2.23 & 2.03 & 2.04 & 2.59 & 2.51 & 2.50 & 2.44 & 2.61 & 2.45 & 2.56 & 2.73 & 2.68 & 2.43 & 2.51 & 2.48 & 2.49 \\
\hline $\mathrm{Ti}$ & 0.000 & 0.001 & 0.000 & 0.001 & 0.000 & 0.000 & 0.000 & 0.000 & 0.001 & 0.001 & 0.001 & 0.001 & 0.000 & 0.001 & 0.001 & 0.001 & 0.000 & 0.000 & 0.000 \\
\hline Al & 1.91 & 1.75 & 1.88 & 1.74 & 1.94 & 1.93 & 1.41 & 1.49 & 1.49 & 1.56 & 1.39 & 1.54 & 1.45 & 1.28 & 1.32 & 1.56 & 1.49 & 1.51 & 1.50 \\
\hline Fe total & 0.034 & 0.045 & 0.044 & 0.045 & 0.032 & 0.033 & 0.016 & 0.019 & 0.019 & 0.023 & 0.015 & 0.022 & 0.018 & 0.008 & 0.017 & 0.022 & 0.016 & 0.021 & 0.021 \\
\hline Mn & 0.005 & 0.009 & 0.006 & 0.008 & 0.006 & 0.006 & 0.002 & 0.002 & 0.003 & 0.003 & 0.001 & 0.002 & 0.001 & 0.001 & 0.002 & 0.003 & 0.003 & 0.001 & 0.003 \\
\hline $\mathbf{M g}$ & 0.91 & 0.77 & 0.89 & 0.76 & 0.96 & 0.95 & 0.42 & 0.49 & 0.50 & 0.56 & 0.40 & 0.56 & 0.45 & 0.29 & 0.34 & 0.57 & 0.50 & 0.52 & 0.52 \\
\hline $\mathrm{Ca}$ & 0.091 & 0.213 & 0.109 & 0.227 & 0.055 & 0.064 & 0.522 & 0.465 & 0.453 & 0.410 & 0.539 & 0.408 & 0.484 & 0.628 & 0.599 & 0.400 & 0.454 & 0.435 & 0.439 \\
\hline $\mathrm{Na}$ & 0.000 & 0.002 & 0.001 & 0.002 & 0.000 & 0.001 & 0.008 & 0.006 & 0.005 & 0.004 & 0.007 & 0.004 & 0.014 & 0.014 & 0.010 & 0.004 & 0.007 & 0.006 & 0.005 \\
\hline Total & 5.02 & 5.01 & 5.02 & 5.01 & 5.02 & 5.02 & 4.97 & 4.98 & 4.98 & 4.99 & 4.97 & 4.98 & 4.97 & 4.95 & 4.96 & 4.99 & 4.98 & 4.98 & 4.98 \\
\hline \multicolumn{20}{|l|}{ Atomic \% } \\
\hline $\mathbf{A b}$ & 9.1 & 21.5 & 10.9 & 23.0 & 5.5 & 6.4 & 55.1 & 48.5 & 47.2 & 42.0 & 56.8 & 42.1 & 51.1 & 67.5 & 63.4 & 41.0 & 47.3 & 45.2 & 45.5 \\
\hline An & 90.9 & 78.2 & 89.0 & 76.8 & 94.5 & 93.6 & 44.1 & 50.9 & 52.3 & 57.6 & 42.5 & 57.4 & 47.5 & 31.0 & 35.5 & 58.7 & 52.0 & 54.1 & 54.0 \\
\hline Or & 0.0 & 0.2 & 0.1 & 0.2 & 0.0 & 0.1 & 0.9 & 0.6 & 0.6 & 0.4 & 0.7 & 0.4 & 1.4 & 1.5 & 1.1 & 0.4 & 0.7 & 0.6 & 0.6 \\
\hline
\end{tabular}


Table F.3. Continued

\begin{tabular}{|c|c|c|c|c|c|c|c|c|c|c|c|c|c|c|c|c|c|c|c|c|}
\hline $\begin{array}{l}\text { Sample } \\
\text { Location } \\
\text { Volcano } \\
\text { Type }\end{array}$ & & & & & & & & & & & & & & & & & & & & \\
\hline $\begin{array}{l}\text { Crystal no. } \\
\text { Analysis site }\end{array}$ & $\begin{array}{r}10 \\
\text { rim } \\
\end{array}$ & $\begin{array}{r}12 \\
\text { core } \\
\end{array}$ & $\begin{array}{r}12 \\
\text { rim } \\
\end{array}$ & $\begin{array}{r}13 \\
\text { core } \\
\end{array}$ & $\begin{array}{r}13 \\
\mathrm{~d} \text { band } \\
\end{array}$ & $\begin{array}{r}13 \\
\text { rim } \\
\end{array}$ & $\begin{array}{r}14 \\
N V Z \\
\end{array}$ & $\begin{array}{r}15 \\
\text { core } \\
\end{array}$ & $\begin{array}{r}15 \\
\text { rim } \\
\end{array}$ & $\begin{array}{r}16 \\
N V Z \\
\end{array}$ & $\begin{array}{r}17 \\
N V Z \\
\end{array}$ & $\begin{array}{r}18 \\
\text { core } \\
\end{array}$ & $\begin{array}{r}18 \\
\mathrm{rim} \\
\end{array}$ & $\begin{array}{r}19 \\
N V Z \\
\end{array}$ & $\begin{array}{r}20 \\
N V Z \\
\end{array}$ & $\begin{array}{r}21 \\
N V Z \\
\end{array}$ & $\begin{array}{r}22 \\
\text { core } \\
\end{array}$ & $\begin{array}{r}22 \\
\mathrm{rim} \\
\end{array}$ & $\begin{array}{r}23 \\
\text { core } \\
\end{array}$ & $\begin{array}{r}23 \\
\mathrm{rim} \\
\end{array}$ \\
\hline \multicolumn{21}{|l|}{ Oxides (wt \%) } \\
\hline $\mathrm{SiO}_{2}$ & 56.09 & 54.47 & 57.47 & 56.27 & 57.31 & 55.36 & 55.50 & 54.34 & 56.94 & 54.89 & 54.51 & 52.96 & 56.94 & 55.16 & 57.49 & 55.05 & 56.58 & 55.67 & 55.52 & 53.83 \\
\hline $\mathrm{TiO}_{2}$ & 0.01 & 0.02 & 0.01 & 0.02 & 0.01 & 0.01 & 0.01 & 0.02 & 0.03 & 0.01 & 0.02 & 0.04 & 0.01 & 0.01 & 0.00 & 0.02 & 0.00 & 0.00 & 0.03 & 0.02 \\
\hline $\mathrm{Al}_{2} \mathrm{O}_{3}$ & 26.50 & 27.92 & 25.83 & 27.14 & 26.24 & 27.69 & 28.10 & 28.41 & 26.69 & 28.11 & 28.14 & 29.55 & 27.14 & 28.10 & 26.71 & 28.18 & 27.26 & 28.20 & 27.22 & 28.19 \\
\hline $\mathrm{Fe}_{2} \mathrm{O}_{3}$ & 0.48 & 0.45 & 0.35 & 0.44 & 0.47 & 0.48 & 0.50 & 0.57 & 0.42 & 0.56 & 0.51 & 0.64 & 0.40 & 0.50 & 0.43 & 0.44 & 0.44 & 0.52 & 0.50 & 0.52 \\
\hline MgO & 0.04 & 0.04 & 0.02 & 0.01 & 0.02 & 0.03 & 0.04 & 0.06 & 0.01 & 0.03 & 0.03 & 0.06 & 0.02 & 0.04 & 0.04 & 0.03 & 0.04 & 0.02 & 0.02 & 0.03 \\
\hline $\mathrm{CaO}$ & 9.09 & 10.97 & 8.10 & 9.40 & 8.43 & 9.96 & 10.48 & 11.05 & 8.99 & 10.90 & 10.77 & 12.21 & 9.22 & 10.50 & 9.03 & 10.48 & 9.54 & 10.27 & 9.57 & 10.62 \\
\hline $\mathrm{Na}_{2} \mathrm{O}$ & 5.82 & 5.02 & 6.28 & 5.72 & 6.20 & 5.30 & 5.09 & 4.69 & 5.91 & 4.95 & 5.04 & 4.29 & 5.76 & 5.09 & 6.03 & 5.19 & 5.54 & 5.29 & 5.49 & 4.96 \\
\hline $\mathrm{K}_{2} \mathrm{O}$ & 0.13 & 0.08 & 0.14 & 0.13 & 0.14 & 0.10 & 0.10 & 0.07 & 0.11 & 0.09 & 0.07 & 0.06 & 0.10 & 0.11 & 0.14 & 0.09 & 0.12 & 0.10 & 0.11 & 0.09 \\
\hline Total & 98.17 & 98.97 & 98.19 & 99.13 & 98.82 & 98.92 & 99.83 & 99.20 & 99.10 & 99.53 & 99.07 & 99.80 & 99.60 & 99.49 & 99.86 & 99.48 & 99.51 & 100.08 & 98.45 & 98.25 \\
\hline \multicolumn{21}{|l|}{ Cations } \\
\hline Si & 2.56 & 2.48 & 2.62 & 2.55 & 2.60 & 2.52 & 2.50 & 2.47 & 2.57 & 2.49 & 2.48 & 2.41 & 2.56 & 2.50 & 2.58 & 2.49 & 2.55 & 2.50 & 2.53 & 2.47 \\
\hline $\mathrm{Ti}$ & 0.000 & 0.001 & 0.000 & 0.001 & 0.000 & 0.000 & 0.000 & 0.001 & 0.001 & 0.000 & 0.001 & 0.001 & 0.000 & 0.000 & 0.000 & 0.001 & 0.000 & 0.000 & 0.001 & 0.001 \\
\hline Al & 1.43 & 1.50 & 1.39 & 1.45 & 1.40 & 1.48 & 1.49 & 1.52 & 1.42 & 1.50 & 1.51 & 1.58 & 1.44 & 1.50 & 1.41 & 1.50 & 1.45 & 1.50 & 1.46 & 1.53 \\
\hline Fe total & 0.018 & 0.017 & 0.013 & 0.017 & 0.018 & 0.018 & 0.019 & 0.022 & 0.016 & 0.021 & 0.019 & 0.024 & 0.015 & 0.019 & 0.016 & 0.017 & 0.016 & 0.020 & 0.019 & 0.020 \\
\hline Mn & 0.002 & 0.003 & 0.002 & 0.001 & 0.001 & 0.002 & 0.002 & 0.004 & 0.001 & 0.002 & 0.002 & 0.004 & 0.002 & 0.002 & 0.002 & 0.002 & 0.002 & 0.002 & 0.002 & 0.002 \\
\hline Mg & 0.45 & 0.54 & 0.39 & 0.46 & 0.41 & 0.48 & 0.51 & 0.54 & 0.44 & 0.53 & 0.53 & 0.59 & 0.44 & 0.51 & 0.43 & 0.51 & 0.46 & 0.49 & 0.47 & 0.52 \\
\hline $\mathrm{Ca}$ & 0.516 & 0.444 & 0.554 & 0.502 & 0.545 & 0.467 & 0.445 & 0.414 & 0.518 & 0.435 & 0.445 & 0.378 & 0.502 & 0.447 & 0.525 & 0.455 & 0.484 & 0.462 & 0.486 & 0.441 \\
\hline $\mathrm{Na}$ & 0.008 & 0.005 & 0.008 & 0.008 & 0.008 & 0.006 & 0.006 & 0.004 & 0.006 & 0.005 & 0.004 & 0.004 & 0.006 & 0.006 & 0.008 & 0.005 & 0.007 & 0.006 & 0.007 & 0.005 \\
\hline Total & 4.98 & 4.99 & 4.97 & 4.98 & 4.98 & 4.98 & 4.98 & 4.98 & 4.98 & 4.98 & 4.99 & 4.99 & 4.97 & 4.98 & 4.98 & 4.99 & 4.97 & 4.98 & 4.98 & 4.99 \\
\hline \multicolumn{21}{|l|}{ Atomic \% } \\
\hline$A b$ & 53.2 & 45.1 & 57.9 & 52.0 & 56.6 & 48.7 & 46.5 & 43.3 & 54.0 & 44.9 & 45.6 & 38.7 & 52.7 & 46.4 & 54.3 & 47.0 & 50.9 & 48.0 & 50.6 & 45.5 \\
\hline An & 45.9 & 54.5 & 41.3 & 47.2 & 42.5 & 50.6 & 52.9 & 56.3 & 45.4 & 54.6 & 53.9 & 60.9 & 46.7 & 52.9 & 44.9 & 52.5 & 48.4 & 51.4 & 48.7 & 53.9 \\
\hline Or & 0.8 & 0.5 & 0.8 & 0.8 & 0.8 & 0.6 & 0.6 & 0.4 & 0.7 & 0.5 & 0.4 & 0.4 & 0.6 & 0.6 & 0.8 & 0.6 & 0.7 & 0.6 & 0.7 & 0.6 \\
\hline
\end{tabular}


Table F.3. Continued

\section{Sample}

Location

Volcano

Type

Crystal no.

Analysis site

$24 \quad 25$

Oxides (wt \%)

$\mathrm{SiO}_{2}$

$\mathrm{TiO}_{2}$

$\mathrm{Al}_{2} \mathrm{O}_{3}$

$55.08 \quad 55.19$

$\mathrm{Fe}_{2} \mathrm{O}_{3} \quad 0.50 \quad 0.51$

$\begin{array}{lll}\text { MgO } & 0.03 & 0.06\end{array}$

$\begin{array}{lll}\mathrm{CaO} & 10.69 & 10.26\end{array}$

$\begin{array}{lll}\mathrm{Na}_{2} \mathrm{O} & 5.03 & 5.17\end{array}$

$\begin{array}{rrr}\mathrm{K}_{2} \mathrm{O} & 0.10 & 0.10 \\ \text { Total } & 99.73 & 99.04\end{array}$

Cations

$\begin{array}{lll}\text { Si } & 2.49 & 2.51\end{array}$

$\begin{array}{lll}\mathrm{Ti} & 0.000 & 0.001\end{array}$

Al $\quad 1.51 \quad 1.49$

\begin{tabular}{lll} 
Fe total & 0.019 & 0.019 \\
\hline$n$ & 0.002 & 0.004
\end{tabular}

$\begin{array}{lll}\text { Mn } & 0.002 & 0.004\end{array}$

Mg $\quad 0.52 \quad 0.50$

$\begin{array}{lll}\mathrm{Ca} & 0.441 & 0.455\end{array}$

$\begin{array}{lll}\mathrm{Na} & 0.006 & 0.006\end{array}$

$\begin{array}{lll}\text { Total } & 4.98 & 4.98\end{array}$

Atomic \%

Ab $\quad 45.7$

\begin{tabular}{lrr} 
An & 53.7 & 52.0 \\
\hline
\end{tabular}

\begin{tabular}{lrr} 
Or & 0.6 & 0.6 \\
\hline
\end{tabular}


Table F.4. Major element compositions of olivine determined by EPMA

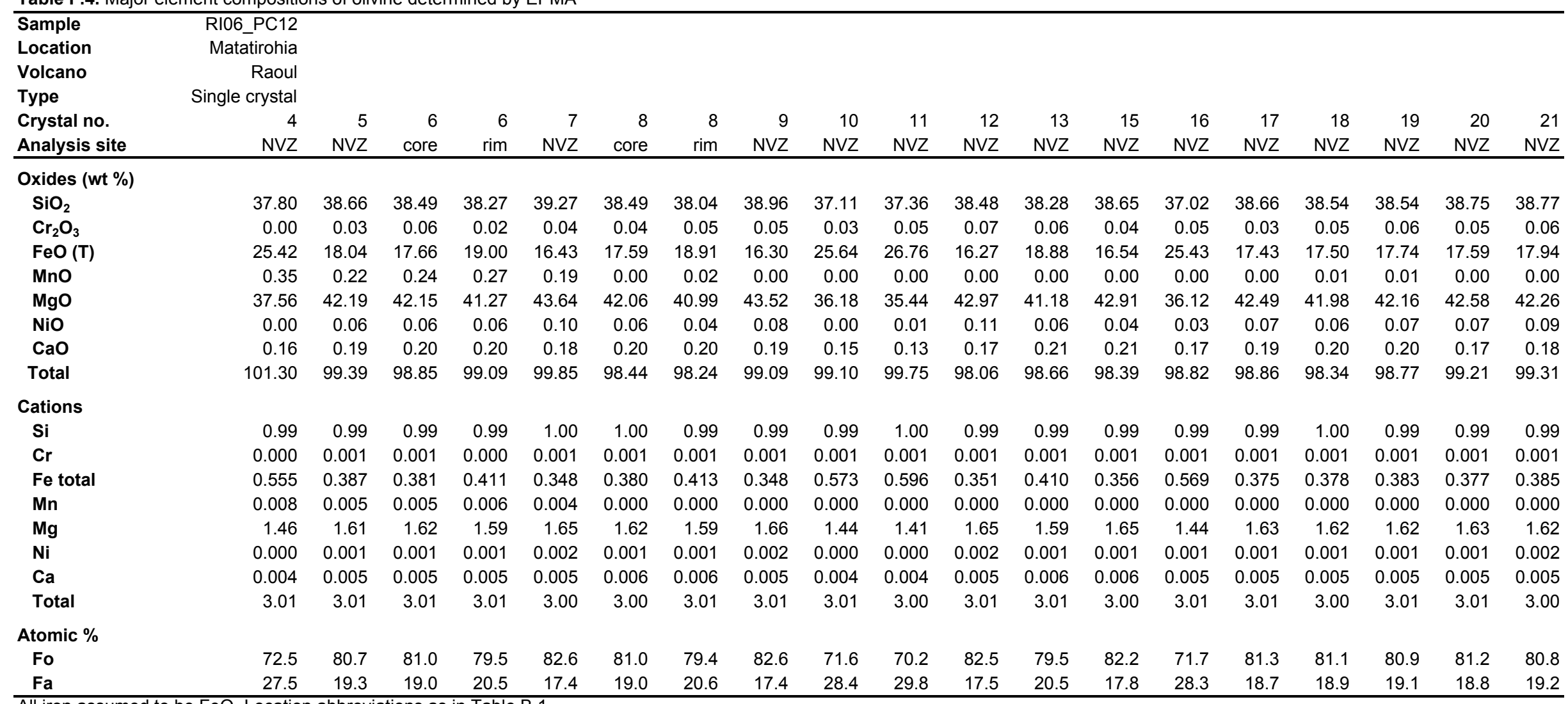

All iron assumed to be FeO. Location abbreviations as in Table B.1. 
Table F.4. Continued

\begin{tabular}{|c|c|c|c|c|c|c|c|c|c|c|c|c|c|c|c|c|c|c|c|c|}
\hline $\begin{array}{l}\text { Sample } \\
\text { Location } \\
\text { Volcano } \\
\text { Type }\end{array}$ & & & & & & & & & & & & & & & & & & & & \\
\hline Crystal no. & 22 & 23 & 24 & 25 & 26 & 27 & 29 & 30 & 32 & 33 & 34 & 35 & 36 & 37 & 37 & 38 & 39 & 40 & 40 & 41 \\
\hline Analysis site & NVZ & NVZ & NVZ & NVZ & NVZ & $\mathrm{NVZ}$ & NVZ & NVZ & NVZ & NVZ & NVZ & NVZ & NVZ & core & rim & $\mathrm{NVZ}$ & NVZ & core & rim & core \\
\hline \multicolumn{21}{|l|}{ Oxides (wt \%) } \\
\hline $\mathrm{SiO}_{2}$ & 38.70 & 38.69 & 37.76 & 38.83 & 38.94 & 38.80 & 38.66 & 39.02 & 38.57 & 38.63 & 37.09 & 38.54 & 38.88 & 37.57 & 38.68 & 38.73 & 38.66 & 37.62 & 37.94 & 37.70 \\
\hline $\mathrm{Cr}_{2} \mathrm{O}_{3}$ & 0.04 & 0.06 & 0.07 & 0.03 & 0.05 & 0.03 & 0.26 & 0.26 & 0.28 & 0.31 & 0.45 & 0.30 & 0.27 & 0.36 & 0.29 & 0.29 & 0.33 & 0.39 & 0.38 & 0.40 \\
\hline $\mathrm{FeO}(\mathrm{T})$ & 17.80 & 16.20 & 22.75 & 18.19 & 16.58 & 16.67 & 17.69 & 16.89 & 18.00 & 17.74 & 26.83 & 18.16 & 18.22 & 25.16 & 18.93 & 18.13 & 17.91 & 25.13 & 23.21 & 25.54 \\
\hline $\mathrm{MnO}$ & 0.00 & 0.00 & 0.01 & 0.00 & 0.00 & 0.02 & 0.04 & 0.04 & 0.08 & 0.03 & 0.05 & 0.06 & 0.04 & 0.05 & 0.06 & 0.03 & 0.04 & 0.03 & 0.04 & 0.04 \\
\hline MgO & 42.07 & 43.22 & 38.03 & 42.35 & 42.97 & 43.28 & 42.46 & 42.96 & 42.27 & 42.31 & 35.52 & 42.73 & 42.44 & 36.53 & 41.48 & 41.93 & 42.20 & 36.71 & 38.38 & 36.73 \\
\hline $\mathrm{NiO}$ & 0.07 & 0.08 & 0.00 & 0.08 & 0.03 & 0.06 & 0.07 & 0.08 & 0.06 & 0.04 & 0.02 & 0.06 & 0.04 & 0.01 & 0.06 & 0.06 & 0.07 & 0.04 & 0.05 & 0.02 \\
\hline $\mathrm{CaO}$ & 0.20 & 0.18 & 0.16 & 0.19 & 0.20 & 0.20 & 0.19 & 0.29 & 0.19 & 0.20 & 0.14 & 0.20 & 0.20 & 0.15 & 0.23 & 0.19 & 0.19 & 0.17 & 0.19 & 0.15 \\
\hline Total & 98.87 & 98.43 & 98.77 & 99.67 & 98.77 & 99.05 & 99.39 & 99.53 & 99.44 & 99.26 & 100.10 & 100.05 & 100.09 & 99.84 & 99.72 & 99.35 & 99.39 & 100.09 & 100.19 & 100.58 \\
\hline \multicolumn{21}{|l|}{ Cations } \\
\hline $\mathbf{S i}$ & 1.00 & 0.99 & 1.00 & 0.99 & 1.00 & 0.99 & 0.99 & 0.99 & 0.99 & 0.99 & 0.99 & 0.98 & 0.99 & 0.99 & 0.99 & 0.99 & 0.99 & 0.99 & 0.99 & 0.99 \\
\hline $\mathrm{Cr}$ & 0.001 & 0.001 & 0.001 & 0.001 & 0.001 & 0.001 & 0.005 & 0.005 & 0.006 & 0.006 & 0.009 & 0.006 & 0.005 & 0.007 & 0.006 & 0.006 & 0.007 & 0.008 & 0.008 & 0.008 \\
\hline Fe total & 0.383 & 0.348 & 0.502 & 0.389 & 0.355 & 0.357 & 0.379 & 0.360 & 0.386 & 0.381 & 0.597 & 0.388 & 0.389 & 0.556 & 0.407 & 0.389 & 0.384 & 0.554 & 0.507 & 0.561 \\
\hline Mn & 0.000 & 0.000 & 0.000 & 0.000 & 0.000 & 0.000 & 0.001 & 0.001 & 0.002 & 0.001 & 0.001 & 0.001 & 0.001 & 0.001 & 0.001 & 0.001 & 0.001 & 0.001 & 0.001 & 0.001 \\
\hline $\mathrm{Mg}$ & 1.62 & 1.66 & 1.50 & 1.62 & 1.64 & 1.65 & 1.62 & 1.63 & 1.62 & 1.62 & 1.41 & 1.63 & 1.61 & 1.44 & 1.59 & 1.61 & 1.61 & 1.44 & 1.49 & 1.44 \\
\hline $\mathrm{Ni}$ & 0.001 & 0.002 & 0.000 & 0.002 & 0.001 & 0.001 & 0.001 & 0.002 & 0.001 & 0.001 & 0.000 & 0.001 & 0.001 & 0.000 & 0.001 & 0.001 & 0.001 & 0.001 & 0.001 & 0.000 \\
\hline $\mathrm{Ca}$ & 0.006 & 0.005 & 0.004 & 0.005 & 0.005 & 0.005 & 0.005 & 0.008 & 0.005 & 0.006 & 0.004 & 0.005 & 0.005 & 0.004 & 0.006 & 0.005 & 0.005 & 0.005 & 0.005 & 0.004 \\
\hline Total & 3.00 & 3.01 & 3.00 & 3.01 & 3.00 & 3.01 & 3.01 & 3.00 & 3.01 & 3.01 & 3.01 & 3.01 & 3.01 & 3.00 & 3.00 & 3.00 & 3.00 & 3.00 & 3.01 & 3.01 \\
\hline \multicolumn{21}{|l|}{ Atomic \% } \\
\hline Fo & 80.8 & 82.6 & 74.9 & 80.6 & 82.2 & 82.2 & 81.1 & 81.9 & 80.7 & 81.0 & 70.2 & 80.8 & 80.6 & 72.1 & 79.6 & 80.5 & 80.8 & 72.3 & 74.7 & 71.9 \\
\hline $\mathrm{Fa}$ & 19.2 & 17.4 & 25.1 & 19.4 & 17.8 & 17.8 & 18.9 & 18.1 & 19.3 & 19.0 & 29.8 & 19.2 & 19.4 & 27.9 & 20.4 & 19.5 & 19.2 & 27.7 & 25.3 & 28.1 \\
\hline
\end{tabular}


Table F.4. Continued

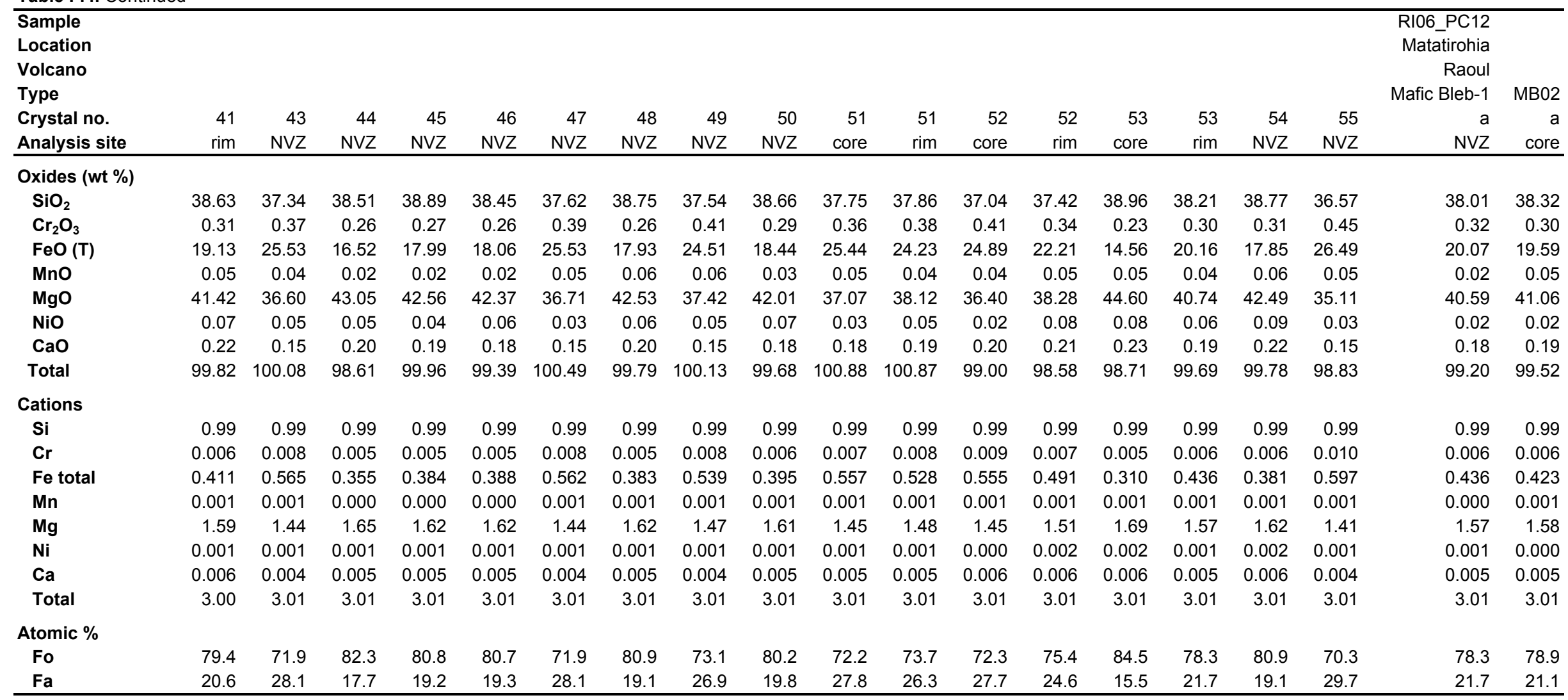


Table F.4. Continued

\begin{tabular}{|c|c|c|c|c|c|c|c|c|c|c|c|c|c|c|c|c|c|c|c|}
\hline $\begin{array}{l}\text { Sample } \\
\text { Location }\end{array}$ & & & & & & & & & & & & & $\begin{array}{l}\text { RI06_MB11 } \\
\text { Matatirohia }\end{array}$ & & & & & & \\
\hline Volcano & & & & & & & & & & & & & Raoul & & & & & & \\
\hline Type & & MB03 & MB04 & MB05 & MB06 & MB08 & & MB09 & MB10 & MB11 & & MB13 & Single crystal & & & & & & \\
\hline Crystal no. & $a$ & $a$ & a & a & a & a & a & $a$ & a & a & a & a & 1 & 1 & 2 & 2 & 2 & 3 & 3 \\
\hline Analysis site & rim & NVZ & NVZ & NVZ & NVZ & core & rim & NVZ & NVZ & core & rim & NVZ & NVZ & NVZ & core1 & core2 & rim & NVZ & NVZ \\
\hline \multicolumn{20}{|l|}{ Oxides (wt \%) } \\
\hline $\mathrm{SiO}_{2}$ & 37.89 & 37.35 & 37.19 & 37.21 & 37.35 & 38.62 & 37.99 & 37.82 & 37.36 & 38.02 & 37.44 & 38.01 & 37.74 & 37.62 & 37.12 & 37.22 & 37.27 & 37.45 & 37.54 \\
\hline $\mathrm{Cr}_{2} \mathrm{O}_{3}$ & 0.35 & 0.39 & 0.38 & 0.39 & 0.41 & 0.27 & 0.33 & 0.03 & 0.04 & 0.03 & 0.02 & 0.03 & 0.00 & 0.00 & 0.00 & 0.00 & 0.00 & 0.00 & 0.01 \\
\hline $\mathrm{FeO}(\mathrm{T})$ & 21.51 & 25.11 & 25.12 & 24.85 & 25.25 & 17.63 & 20.63 & 24.76 & 24.95 & 24.96 & 26.50 & 23.04 & 21.77 & 22.38 & 24.39 & 24.82 & 23.28 & 25.36 & 25.35 \\
\hline $\mathrm{MnO}$ & 0.06 & 0.08 & 0.04 & 0.05 & 0.06 & 0.03 & 0.05 & 0.05 & 0.05 & 0.03 & 0.02 & 0.03 & 0.36 & 0.34 & 0.37 & 0.38 & 0.36 & 0.35 & 0.39 \\
\hline MgO & 39.04 & 36.79 & 36.57 & 36.52 & 36.67 & 42.54 & 39.53 & 37.32 & 37.04 & 37.18 & 35.27 & 38.43 & 39.25 & 38.75 & 37.95 & 37.95 & 38.79 & 37.09 & 37.22 \\
\hline $\mathrm{NiO}$ & 0.02 & 0.03 & 0.03 & 0.01 & 0.00 & 0.04 & 0.05 & 0.37 & 0.36 & 0.40 & 0.44 & 0.34 & 0.02 & 0.06 & 0.03 & 0.01 & 0.04 & 0.01 & 0.03 \\
\hline $\mathrm{CaO}$ & 0.20 & 0.16 & 0.17 & 0.16 & 0.17 & 0.19 & 0.21 & 0.15 & 0.16 & 0.17 & 0.21 & 0.15 & 0.16 & 0.17 & 0.16 & 0.15 & 0.20 & 0.17 & 0.15 \\
\hline Total & 99.07 & 99.90 & 99.48 & 99.18 & 99.91 & 99.32 & 98.78 & 100.49 & 99.96 & 100.78 & 99.90 & 100.01 & 99.30 & 99.31 & 100.02 & 100.52 & 99.94 & 100.42 & 100.68 \\
\hline \multicolumn{20}{|l|}{ Cations } \\
\hline $\mathrm{Si}$ & 0.99 & 0.99 & 0.99 & 0.99 & 0.99 & 0.99 & 0.99 & 0.99 & 0.99 & 0.99 & 1.00 & 0.99 & 0.99 & 0.99 & 0.98 & 0.98 & 0.98 & 0.99 & 0.99 \\
\hline $\mathrm{Cr}$ & 0.007 & 0.008 & 0.008 & 0.008 & 0.008 & 0.005 & 0.007 & 0.001 & 0.001 & 0.001 & 0.000 & 0.001 & 0.000 & 0.000 & 0.000 & 0.000 & 0.000 & 0.000 & 0.000 \\
\hline Fe total & 0.471 & 0.555 & 0.558 & 0.553 & 0.559 & 0.378 & 0.451 & 0.543 & 0.552 & 0.546 & 0.590 & 0.504 & 0.477 & 0.492 & 0.538 & 0.545 & 0.511 & 0.559 & 0.557 \\
\hline $\mathrm{Mn}$ & 0.001 & 0.002 & 0.001 & 0.001 & 0.001 & 0.001 & 0.001 & 0.001 & 0.001 & 0.001 & 0.000 & 0.001 & 0.008 & 0.008 & 0.008 & 0.008 & 0.008 & 0.008 & 0.009 \\
\hline Mg & 1.52 & 1.45 & 1.45 & 1.45 & 1.45 & 1.63 & 1.54 & 1.46 & 1.46 & 1.45 & 1.40 & 1.50 & 1.53 & 1.52 & 1.49 & 1.49 & 1.52 & 1.46 & 1.46 \\
\hline $\mathrm{Ni}$ & 0.000 & 0.001 & 0.001 & 0.000 & 0.000 & 0.001 & 0.001 & 0.008 & 0.008 & 0.008 & 0.009 & 0.007 & 0.001 & 0.001 & 0.001 & 0.000 & 0.001 & 0.000 & 0.001 \\
\hline $\mathrm{Ca}$ & 0.005 & 0.004 & 0.005 & 0.004 & 0.005 & 0.005 & 0.006 & 0.004 & 0.004 & 0.005 & 0.006 & 0.004 & 0.005 & 0.005 & 0.005 & 0.004 & 0.006 & 0.005 & 0.004 \\
\hline Total & 3.00 & 3.01 & 3.01 & 3.01 & 3.01 & 3.01 & 3.00 & 3.01 & 3.01 & 3.00 & 3.00 & 3.01 & 3.01 & 3.01 & 3.02 & 3.02 & 3.02 & 3.01 & 3.01 \\
\hline \multicolumn{20}{|l|}{ Atomic \% } \\
\hline Fo & 76.4 & 72.3 & 72.2 & 72.4 & 72.1 & 81.1 & 77.4 & 72.9 & 72.6 & 72.6 & 70.3 & 74.8 & 76.3 & 75.5 & 73.5 & 73.2 & 74.8 & 72.3 & 72.4 \\
\hline $\mathrm{Fa}$ & 23.6 & 27.7 & 27.8 & 27.6 & 27.9 & 18.9 & 22.6 & 27.1 & 27.4 & 27.4 & 29.7 & 25.2 & 23.7 & 24.5 & 26.5 & 26.8 & 25.2 & 27.7 & 27.6 \\
\hline
\end{tabular}


Table F.4. Continued

\begin{tabular}{|c|c|c|c|c|c|c|c|c|c|c|c|c|c|c|c|c|c|c|c|}
\hline $\begin{array}{l}\text { Sample } \\
\text { Location } \\
\text { Volcano } \\
\text { Type }\end{array}$ & & & & & & & & $\begin{array}{r}\text { RIR_BW_02 } \\
\text { Matatirohia } \\
\text { Raoul } \\
\text { Single crystal }\end{array}$ & & & & & & & & & & & \\
\hline $\begin{array}{l}\text { Crystal no. } \\
\text { Analysis site }\end{array}$ & $\begin{array}{r}4 \\
\text { core1 } \\
\end{array}$ & $\begin{array}{r}4 \\
\text { core2 } \\
\end{array}$ & $\begin{array}{r}4 \\
\operatorname{rim} 1 \\
\end{array}$ & $\begin{array}{r}4 \\
\text { rim2 } \\
\end{array}$ & $\begin{array}{r}5 \\
N V Z \\
\end{array}$ & $\begin{array}{r}5 \\
N V Z \\
\end{array}$ & $\begin{array}{r}6 \\
N V Z \\
\end{array}$ & $\begin{array}{r}1 \\
N V Z \\
\end{array}$ & $\begin{array}{r}1 \\
N V Z \\
\end{array}$ & $\begin{array}{r}2 \\
\text { core } \\
\end{array}$ & $\begin{array}{r}2 \\
\mathrm{rim} \\
\end{array}$ & $\begin{array}{r}3 \\
\text { core } \\
\end{array}$ & $\begin{array}{r}3 \\
\text { rim } \\
\end{array}$ & $\begin{array}{r}4 \\
N V Z \\
\end{array}$ & $\begin{array}{r}5 \\
N V Z \\
\end{array}$ & $\begin{array}{r}13 \\
N V Z \\
\end{array}$ & $\begin{array}{r}14 \\
N V Z \\
\end{array}$ & $\begin{array}{r}15 \\
N V Z \\
\end{array}$ & $\begin{array}{r}17 \\
N V Z \\
\end{array}$ \\
\hline \multicolumn{20}{|l|}{ Oxides (wt \%) } \\
\hline $\mathrm{SiO}_{2}$ & 37.14 & 37.17 & 37.72 & 37.86 & 37.40 & 37.11 & 37.42 & 37.63 & 37.74 & 38.14 & 37.31 & 37.14 & 35.49 & 38.02 & 37.02 & 38.04 & 37.89 & 37.16 & 38.24 \\
\hline $\mathrm{Cr}_{2} \mathrm{O}_{3}$ & 0.00 & 0.00 & 0.00 & 0.02 & 0.00 & 0.00 & 0.00 & 0.01 & 0.00 & 0.00 & 0.02 & 0.00 & 0.00 & 0.00 & 0.00 & 0.01 & 0.00 & 0.00 & 0.00 \\
\hline $\mathrm{FeO}(\mathrm{T})$ & 26.74 & 26.57 & 22.63 & 22.07 & 24.81 & 25.98 & 25.06 & 20.92 & 20.87 & 20.94 & 25.44 & 21.17 & 30.16 & 21.07 & 20.91 & 20.96 & 20.81 & 19.21 & 20.32 \\
\hline MnO & 0.45 & 0.40 & 0.36 & 0.33 & 0.42 & 0.43 & 0.39 & 0.32 & 0.35 & 0.33 & 0.38 & 0.33 & 0.51 & 0.34 & 0.32 & 0.32 & 0.33 & 0.31 & 0.33 \\
\hline MgO & 35.73 & 35.80 & 39.18 & 39.17 & 37.40 & 36.47 & 37.73 & 40.63 & 40.37 & 40.59 & 37.17 & 40.62 & 33.07 & 40.43 & 40.31 & 40.36 & 40.87 & 41.71 & 40.70 \\
\hline $\mathrm{NiO}$ & 0.02 & 0.00 & 0.05 & 0.05 & 0.00 & 0.00 & 0.02 & 0.05 & 0.01 & 0.04 & 0.02 & 0.02 & 0.03 & 0.03 & 0.03 & 0.03 & 0.05 & 0.04 & 0.03 \\
\hline $\mathrm{CaO}$ & 0.15 & 0.15 & 0.22 & 0.20 & 0.19 & 0.14 & 0.18 & 0.17 & 0.17 & 0.19 & 0.19 & 0.16 & 0.21 & 0.19 & 0.18 & 0.18 & 0.21 & 0.18 & 0.20 \\
\hline Total & 100.22 & 100.08 & 100.17 & 99.70 & 100.23 & 100.13 & 100.80 & 99.73 & 99.49 & 100.21 & 100.53 & 99.44 & 99.46 & 100.07 & 98.77 & 99.92 & 100.16 & 98.61 & 99.80 \\
\hline \multicolumn{20}{|l|}{ Cations } \\
\hline Si & 0.99 & 0.99 & 0.98 & 0.99 & 0.99 & 0.98 & 0.98 & 0.98 & 0.98 & 0.99 & 0.98 & 0.97 & 0.97 & 0.98 & 0.97 & 0.99 & 0.98 & 0.97 & 0.99 \\
\hline $\mathrm{Cr}$ & 0.000 & 0.000 & 0.000 & 0.000 & 0.000 & 0.000 & 0.000 & 0.000 & 0.000 & 0.000 & 0.000 & 0.000 & 0.000 & 0.000 & 0.000 & 0.000 & 0.000 & 0.000 & 0.000 \\
\hline Fe total & 0.595 & 0.591 & 0.494 & 0.482 & 0.547 & 0.576 & 0.549 & 0.455 & 0.454 & 0.452 & 0.560 & 0.463 & 0.690 & 0.456 & 0.460 & 0.454 & 0.450 & 0.420 & 0.439 \\
\hline Mn & 0.010 & 0.009 & 0.008 & 0.007 & 0.009 & 0.010 & 0.009 & 0.007 & 0.008 & 0.007 & 0.008 & 0.007 & 0.012 & 0.007 & 0.007 & 0.007 & 0.007 & 0.007 & 0.007 \\
\hline Mg & 1.42 & 1.42 & 1.52 & 1.53 & 1.47 & 1.44 & 1.47 & 1.57 & 1.57 & 1.56 & 1.46 & 1.58 & 1.35 & 1.56 & 1.58 & 1.56 & 1.58 & 1.63 & 1.57 \\
\hline $\mathrm{Ni}$ & 0.000 & 0.000 & 0.001 & 0.001 & 0.000 & 0.000 & 0.000 & 0.001 & 0.000 & 0.001 & 0.000 & 0.000 & 0.001 & 0.001 & 0.001 & 0.001 & 0.001 & 0.001 & 0.001 \\
\hline $\mathrm{Ca}$ & 0.004 & 0.004 & 0.006 & 0.006 & 0.005 & 0.004 & 0.005 & 0.005 & 0.005 & 0.005 & 0.005 & 0.005 & 0.006 & 0.005 & 0.005 & 0.005 & 0.006 & 0.005 & 0.005 \\
\hline Total & 3.01 & 3.01 & 3.02 & 3.01 & 3.01 & 3.02 & 3.02 & 3.02 & 3.02 & 3.01 & 3.02 & 3.03 & 3.03 & 3.02 & 3.03 & 3.01 & 3.02 & 3.03 & 3.01 \\
\hline \multicolumn{20}{|l|}{ Atomic \% } \\
\hline Fo & 70.4 & 70.6 & 75.5 & 76.0 & 72.9 & 71.4 & 72.9 & 77.6 & 77.5 & 77.6 & 72.3 & 77.4 & 66.2 & 77.4 & 77.5 & 77.4 & 77.8 & 79.5 & 78.1 \\
\hline $\mathrm{Fa}$ & 29.6 & 29.4 & 24.5 & 24.0 & 27.1 & 28.6 & 27.1 & 22.4 & 22.5 & 22.4 & 27.7 & 22.6 & 33.8 & 22.6 & 22.5 & 22.6 & 22.2 & 20.5 & 21.9 \\
\hline
\end{tabular}


Table F.4. Continued

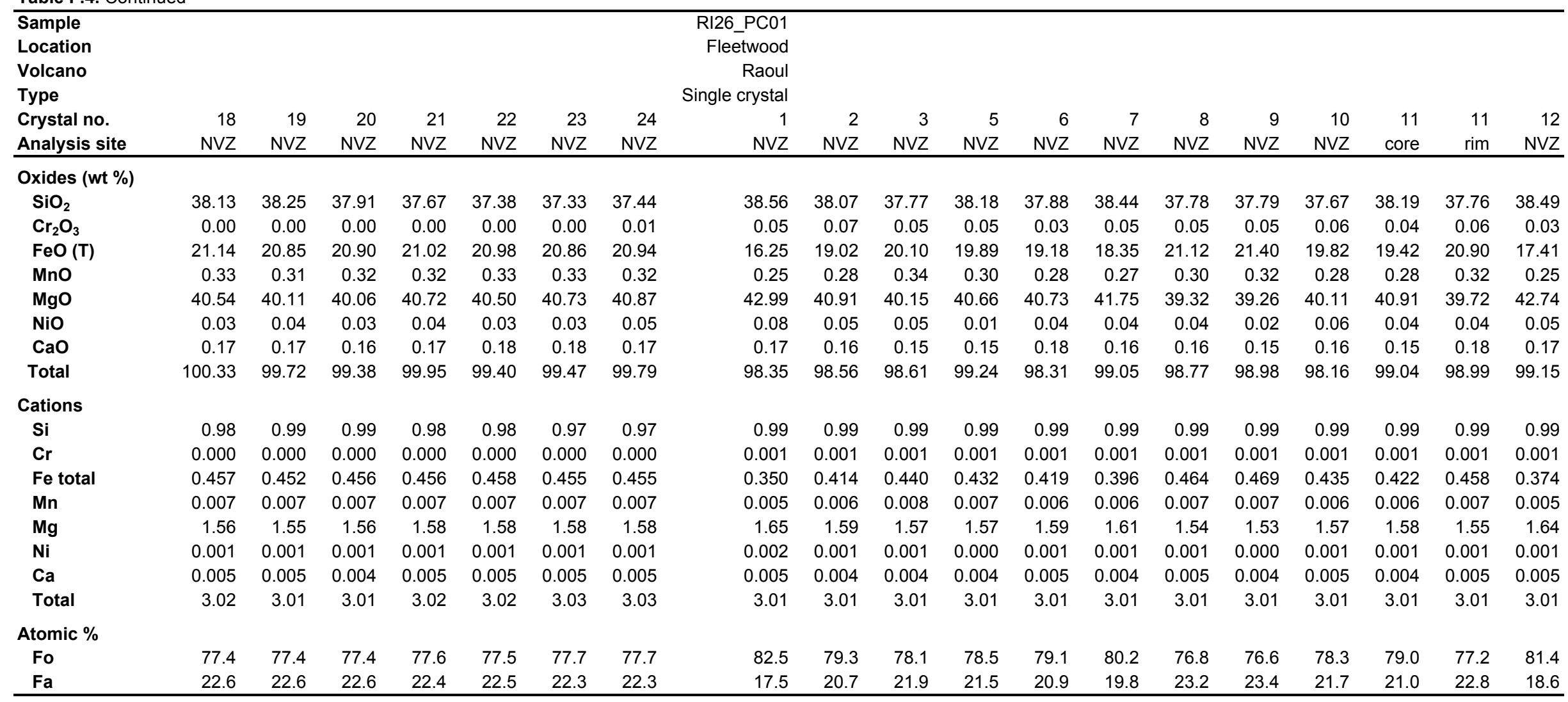


Table F.4. Continued

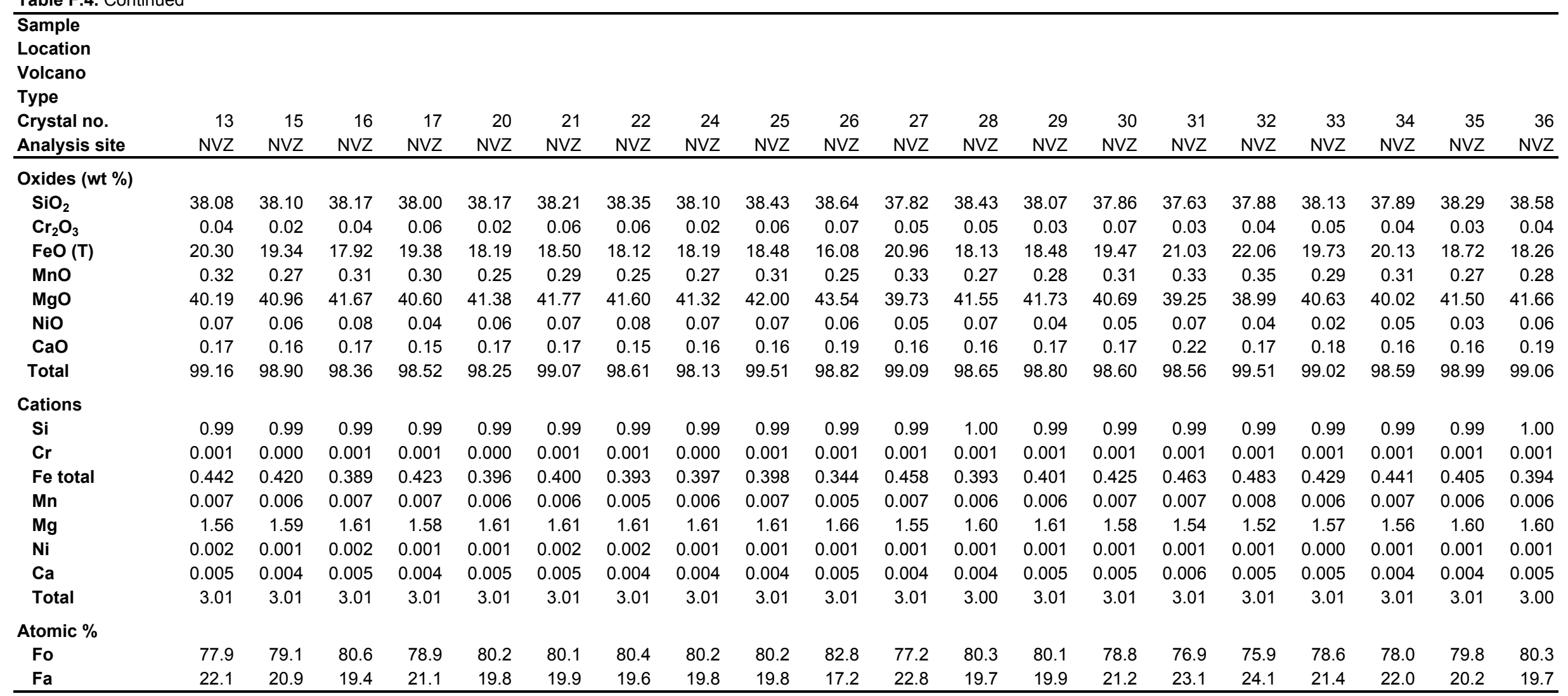


Table F.4. Continued

\begin{tabular}{|c|c|c|c|c|c|c|c|c|c|c|c|c|c|c|c|c|c|c|c|c|}
\hline $\begin{array}{l}\text { Sample } \\
\text { Location } \\
\text { Volcano } \\
\text { Type }\end{array}$ & & & & & & & & & & & & & & & & & & & & \\
\hline $\begin{array}{l}\text { Crystal no. } \\
\text { Analysis site } \\
\end{array}$ & $\begin{array}{r}37 \\
N V Z \\
\end{array}$ & $\begin{array}{r}38 \\
N V Z \\
\end{array}$ & $\begin{array}{r}39 \\
N V Z \\
\end{array}$ & $\begin{array}{r}40 \\
N V Z \\
\end{array}$ & $\begin{array}{r}41 \\
N V Z \\
\end{array}$ & $\begin{array}{r}42 \\
N V Z \\
\end{array}$ & $\begin{array}{r}43 \\
N V Z \\
\end{array}$ & $\begin{array}{r}44 \\
\mathrm{NVZ} \\
\end{array}$ & $\begin{array}{r}45 \\
N V Z \\
\end{array}$ & $\begin{array}{r}46 \\
\text { core } \\
\end{array}$ & $\begin{array}{r}46 \\
\text { rim } \\
\end{array}$ & $\begin{array}{r}47 \\
\text { core } \\
\end{array}$ & $\begin{array}{r}47 \\
\text { rim } \\
\end{array}$ & $\begin{array}{r}48 \\
N V Z \\
\end{array}$ & $\begin{array}{r}49 \\
N V Z \\
\end{array}$ & $\begin{array}{r}50 \\
N V Z \\
\end{array}$ & $\begin{array}{r}51 \\
\text { core } \\
\end{array}$ & $\begin{array}{r}51 \\
\text { rim } \\
\end{array}$ & $\begin{array}{r}52 \\
\text { core } \\
\end{array}$ & $\begin{array}{r}52 \\
\text { rim } \\
\end{array}$ \\
\hline \multicolumn{21}{|l|}{ Oxides (wt \%) } \\
\hline $\mathrm{SiO}_{2}$ & 37.95 & 38.49 & 38.44 & 37.85 & 38.07 & 38.62 & 38.60 & 38.35 & 37.86 & 38.26 & 38.32 & 38.59 & 38.86 & 38.08 & 37.50 & 37.99 & 38.01 & 38.34 & 38.62 & 38.30 \\
\hline $\mathrm{Cr}_{2} \mathrm{O}_{3}$ & 0.04 & 0.05 & 0.03 & 0.03 & 0.05 & 0.06 & 0.03 & 0.04 & 0.05 & 0.03 & 0.06 & 0.06 & 0.06 & 0.04 & 0.04 & 0.05 & 0.04 & 0.04 & 0.05 & 0.05 \\
\hline $\mathrm{FeO}(\mathrm{T})$ & 20.38 & 18.39 & 16.52 & 20.74 & 20.83 & 16.40 & 17.05 & 16.96 & 20.20 & 18.33 & 19.10 & 16.33 & 18.52 & 19.26 & 22.69 & 19.93 & 20.21 & 18.99 & 16.11 & 18.63 \\
\hline MnO & 0.32 & 0.29 & 0.25 & 0.31 & 0.31 & 0.27 & 0.28 & 0.25 & 0.31 & 0.28 & 0.26 & 0.20 & 0.26 & 0.29 & 0.34 & 0.30 & 0.33 & 0.28 & 0.24 & 0.24 \\
\hline MgO & 40.26 & 41.89 & 43.28 & 39.64 & 39.65 & 42.64 & 42.84 & 42.43 & 40.10 & 41.85 & 40.85 & 43.15 & 40.88 & 41.11 & 37.75 & 40.25 & 40.28 & 40.93 & 43.27 & 41.22 \\
\hline $\mathrm{NiO}$ & 0.04 & 0.06 & 0.07 & 0.07 & 0.04 & 0.08 & 0.09 & 0.08 & 0.05 & 0.05 & 0.08 & 0.05 & 0.06 & 0.06 & 0.03 & 0.06 & 0.05 & 0.07 & 0.03 & 0.08 \\
\hline $\mathrm{CaO}$ & 0.16 & 0.16 & 0.18 & 0.18 & 0.18 & 0.18 & 0.18 & 0.18 & 0.15 & 0.15 & 0.19 & 0.18 & 0.18 & 0.16 & 0.29 & 0.15 & 0.16 & 0.18 & 0.18 & 0.22 \\
\hline Total & 99.15 & 99.33 & 98.77 & 98.82 & 99.12 & 98.25 & 99.06 & 98.28 & 98.73 & 98.96 & 98.88 & 98.57 & 98.83 & 98.98 & 98.64 & 98.74 & 99.08 & 98.83 & 98.50 & 98.74 \\
\hline \multicolumn{21}{|l|}{ Cations } \\
\hline Si & 0.99 & 0.99 & 0.99 & 0.99 & 0.99 & 1.00 & 0.99 & 0.99 & 0.99 & 0.99 & 0.99 & 0.99 & 1.00 & 0.99 & 0.99 & 0.99 & 0.99 & 1.00 & 0.99 & 0.99 \\
\hline $\mathrm{Cr}$ & 0.001 & 0.001 & 0.001 & 0.001 & 0.001 & 0.001 & 0.001 & 0.001 & 0.001 & 0.001 & 0.001 & 0.001 & 0.001 & 0.001 & 0.001 & 0.001 & 0.001 & 0.001 & 0.001 & 0.001 \\
\hline Fe total & 0.444 & 0.396 & 0.355 & 0.454 & 0.455 & 0.354 & 0.366 & 0.367 & 0.442 & 0.396 & 0.415 & 0.351 & 0.401 & 0.418 & 0.503 & 0.435 & 0.440 & 0.412 & 0.346 & 0.404 \\
\hline$M n$ & 0.007 & 0.006 & 0.005 & 0.007 & 0.007 & 0.006 & 0.006 & 0.005 & 0.007 & 0.006 & 0.006 & 0.004 & 0.006 & 0.006 & 0.008 & 0.007 & 0.007 & 0.006 & 0.005 & 0.005 \\
\hline $\mathbf{M g}$ & 1.56 & 1.61 & 1.66 & 1.55 & 1.54 & 1.64 & 1.64 & 1.64 & 1.56 & 1.61 & 1.58 & 1.65 & 1.58 & 1.59 & 1.49 & 1.57 & 1.56 & 1.58 & 1.66 & 1.59 \\
\hline $\mathrm{Ni}$ & 0.001 & 0.001 & 0.001 & 0.001 & 0.001 & 0.002 & 0.002 & 0.002 & 0.001 & 0.001 & 0.002 & 0.001 & 0.001 & 0.001 & 0.001 & 0.001 & 0.001 & 0.001 & 0.001 & 0.002 \\
\hline $\mathrm{Ca}$ & 0.005 & 0.004 & 0.005 & 0.005 & 0.005 & 0.005 & 0.005 & 0.005 & 0.004 & 0.004 & 0.005 & 0.005 & 0.005 & 0.004 & 0.008 & 0.004 & 0.004 & 0.005 & 0.005 & 0.006 \\
\hline Total & 3.01 & 3.01 & 3.01 & 3.01 & 3.01 & 3.00 & 3.01 & 3.01 & 3.01 & 3.01 & 3.00 & 3.01 & 2.99 & 3.01 & 3.01 & 3.01 & 3.01 & 3.00 & 3.01 & 3.01 \\
\hline \multicolumn{21}{|l|}{ Atomic \% } \\
\hline Fo & 77.9 & 80.2 & 82.4 & 77.3 & 77.2 & 82.2 & 81.7 & 81.7 & 78.0 & 80.3 & 79.2 & 82.5 & 79.7 & 79.2 & 74.8 & 78.3 & 78.0 & 79.4 & 82.7 & 79.8 \\
\hline $\mathbf{F a}$ & 22.1 & 19.8 & 17.6 & 22.7 & 22.8 & 17.8 & 18.3 & 18.3 & 22.0 & 19.7 & 20.8 & 17.5 & 20.3 & 20.8 & 25.2 & 21.7 & 22.0 & 20.6 & 17.3 & 20.2 \\
\hline
\end{tabular}


Table F.4. Continued

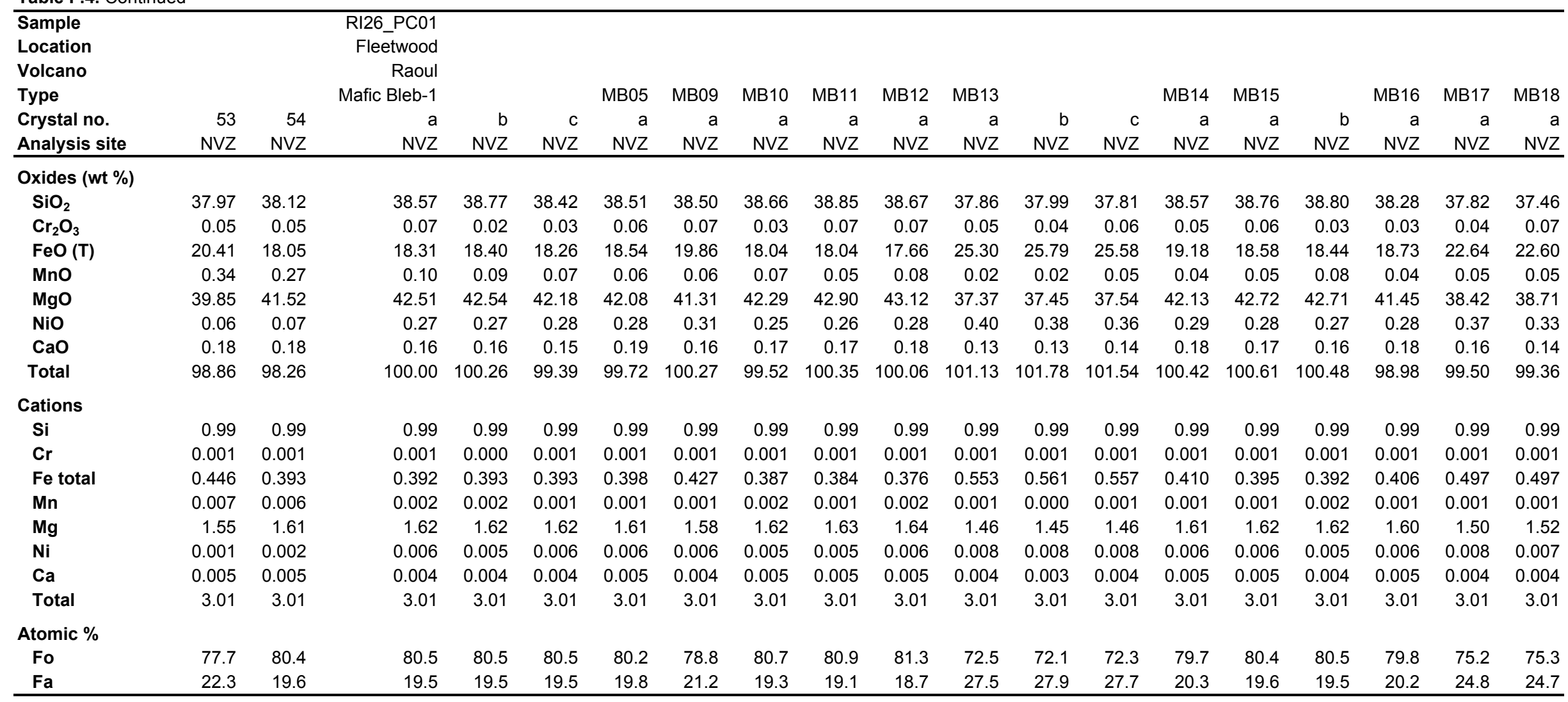


Table F.4. Continued

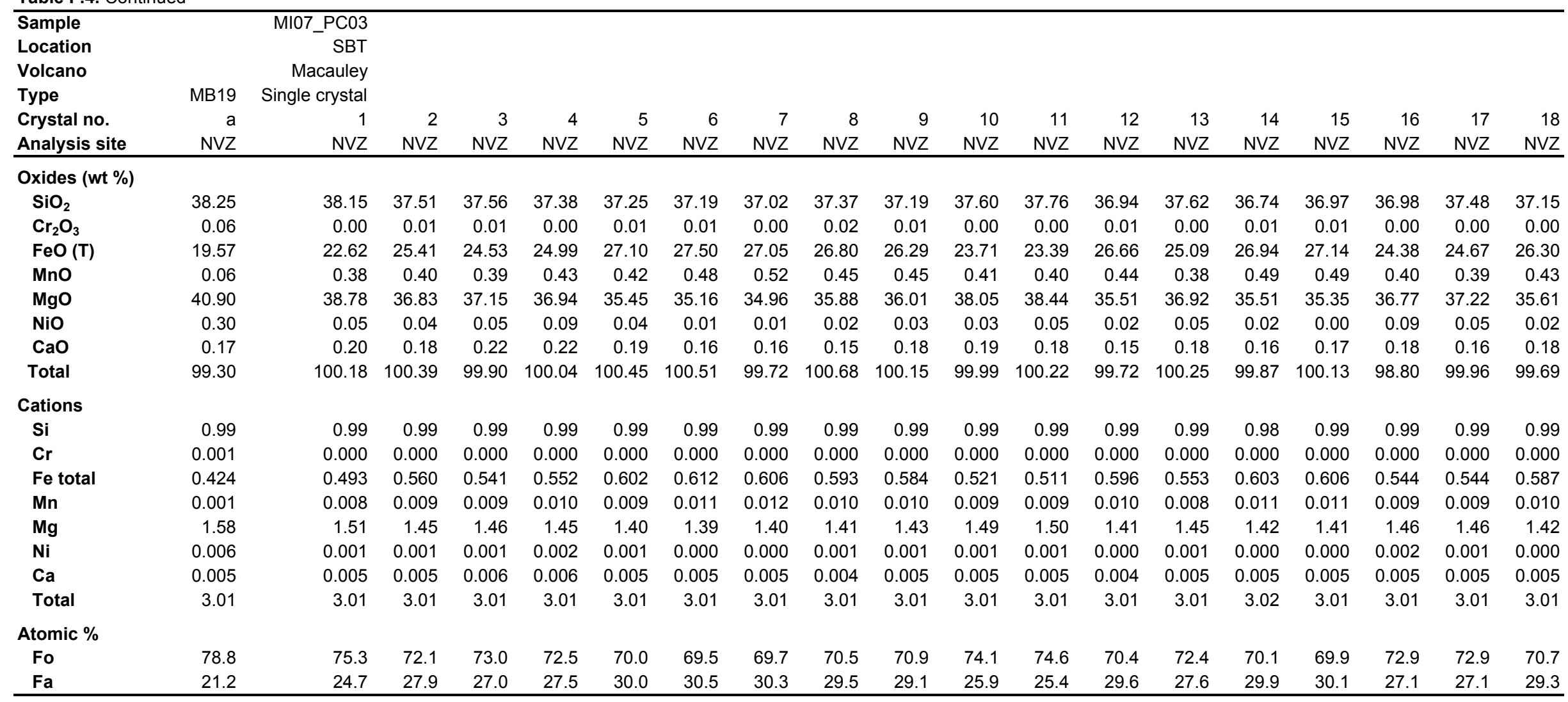


Table F.4. Continued

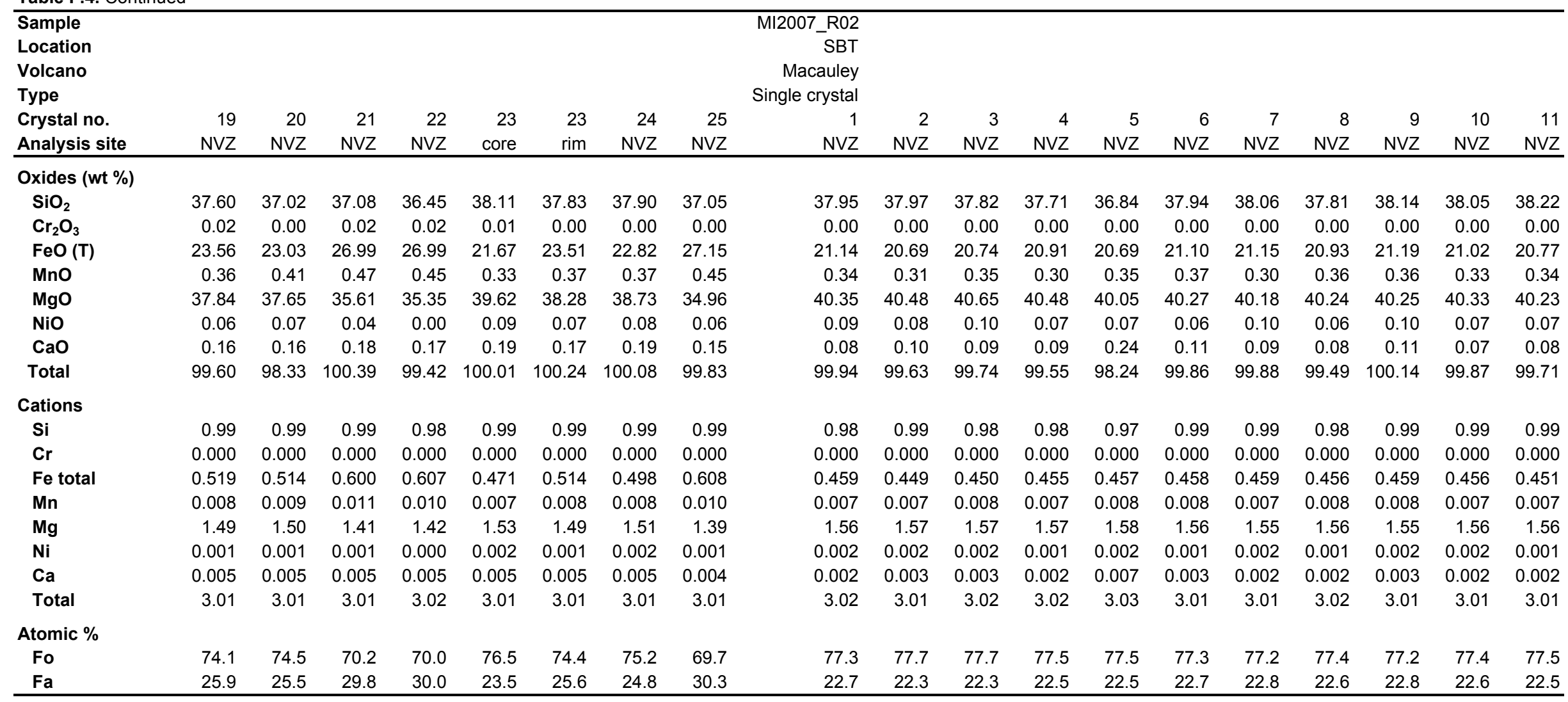


Table F.4. Continued

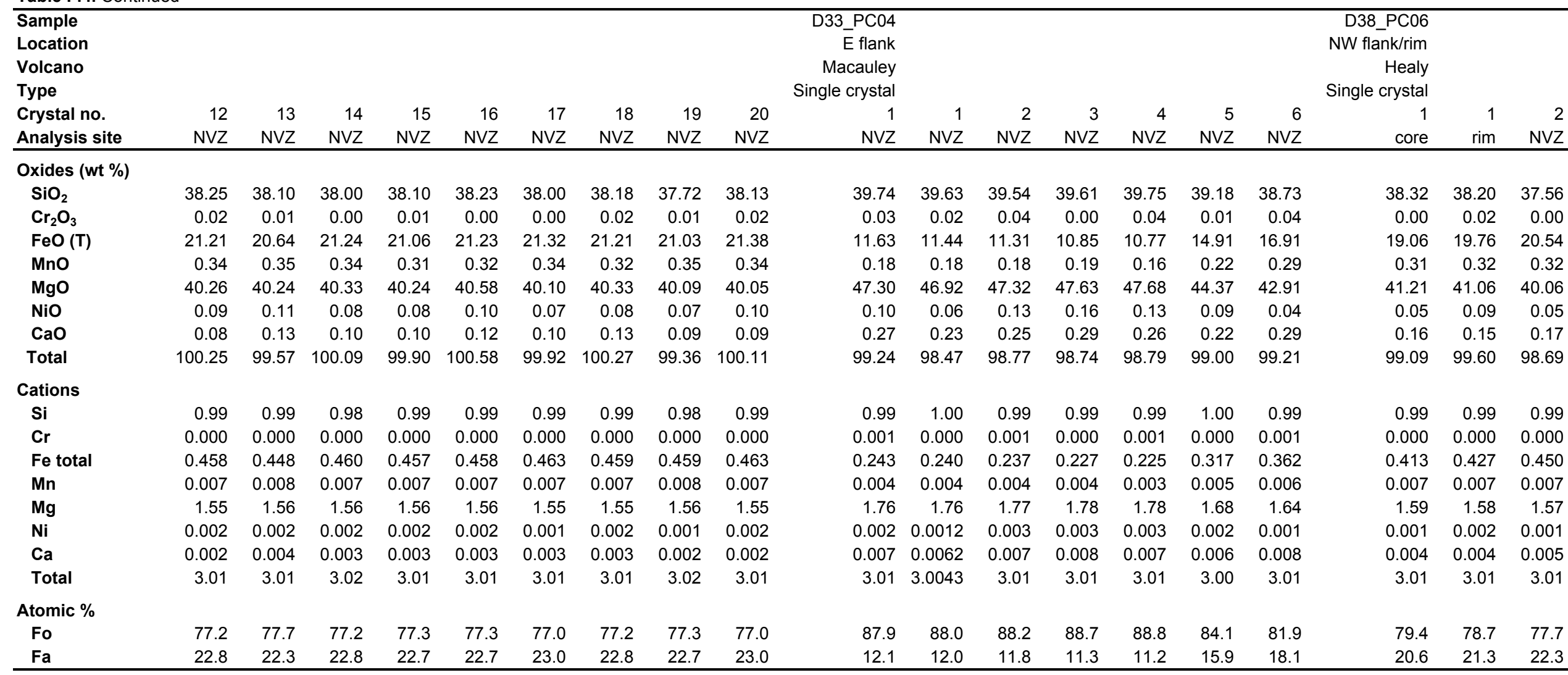


Table F.4. Continued

\begin{tabular}{|c|c|c|c|c|c|c|c|c|c|c|c|c|c|c|c|c|c|c|c|}
\hline $\begin{array}{l}\text { Sample } \\
\text { Location } \\
\text { Volcano } \\
\text { Type }\end{array}$ & & & & & & & & & & & & & & & & & & & \\
\hline Crystal no. & 3 & 4 & 5 & 6 & 11 & 12 & 13 & 14 & 15 & 16 & 17 & 18 & 19 & 20 & 21 & 22 & 23 & 24 & 25 \\
\hline Analysis site & NVZ & NVZ & NVZ & NVZ & NVZ & NVZ & NVZ & NVZ & NVZ & NVZ & NVZ & NVZ & NVZ & NVZ & NVZ & NVZ & NVZ & NVZ & NVZ \\
\hline \multicolumn{20}{|l|}{ Oxides (wt \%) } \\
\hline $\mathrm{SiO}_{2}$ & 37.50 & 38.12 & 37.25 & 36.70 & 36.55 & 38.65 & 37.77 & 38.74 & 38.41 & 38.35 & 38.31 & 38.25 & 38.28 & 37.74 & 38.15 & 38.03 & 38.24 & 37.96 & 37.06 \\
\hline $\mathrm{Cr}_{2} \mathrm{O}_{3}$ & 0.00 & 0.00 & 0.00 & 0.00 & 0.00 & 0.00 & 0.00 & 0.01 & 0.00 & 0.02 & 0.00 & 0.00 & 0.00 & 0.00 & 0.01 & 0.00 & 0.00 & 0.00 & 0.00 \\
\hline $\mathrm{FeO}(\mathrm{T})$ & 22.64 & 19.56 & 22.41 & 24.46 & 23.65 & 18.93 & 23.70 & 17.95 & 19.52 & 19.95 & 19.53 & 20.30 & 20.05 & 23.62 & 20.16 & 21.12 & 20.54 & 21.14 & 24.29 \\
\hline $\mathrm{MnO}$ & 0.32 & 0.31 & 0.39 & 0.42 & 0.42 & 0.34 & 0.41 & 0.29 & 0.30 & 0.33 & 0.32 & 0.35 & 0.33 & 0.38 & 0.33 & 0.35 & 0.32 & 0.32 & 0.44 \\
\hline MgO & 38.43 & 40.79 & 38.50 & 36.79 & 37.25 & 41.36 & 38.00 & 42.41 & 40.96 & 40.53 & 41.05 & 40.31 & 40.96 & 37.94 & 40.40 & 39.70 & 40.18 & 39.70 & 36.98 \\
\hline $\mathrm{NiO}$ & 0.04 & 0.07 & 0.06 & 0.02 & 0.06 & 0.06 & 0.03 & 0.04 & 0.04 & 0.04 & 0.07 & 0.03 & 0.04 & 0.04 & 0.07 & 0.07 & 0.05 & 0.04 & 0.03 \\
\hline $\mathrm{CaO}$ & 0.16 & 0.19 & 0.18 & 0.15 & 0.12 & 0.18 & 0.15 & 0.18 & 0.18 & 0.18 & 0.17 & 0.16 & 0.17 & 0.18 & 0.17 & 0.17 & 0.17 & 0.17 & 0.15 \\
\hline Total & 99.08 & 99.03 & 98.80 & 98.53 & 98.05 & 99.53 & 100.06 & 99.61 & 99.41 & 99.39 & 99.43 & 99.39 & 99.81 & 99.89 & 99.28 & 99.45 & 99.51 & 99.33 & 98.95 \\
\hline \multicolumn{20}{|l|}{ Cations } \\
\hline $\mathbf{S i}$ & 0.99 & 0.99 & 0.99 & 0.98 & 0.98 & 1.00 & 0.99 & 0.99 & 0.99 & 0.99 & 0.99 & 0.99 & 0.99 & 0.99 & 0.99 & 0.99 & 0.99 & 0.99 & 0.99 \\
\hline $\mathrm{Cr}$ & 0.000 & 0.000 & 0.000 & 0.000 & 0.000 & 0.000 & 0.000 & 0.000 & 0.000 & 0.000 & 0.000 & 0.000 & 0.000 & 0.000 & 0.000 & 0.000 & 0.000 & 0.000 & 0.000 \\
\hline Fe total & 0.499 & 0.425 & 0.496 & 0.548 & 0.531 & 0.408 & 0.520 & 0.384 & 0.422 & 0.433 & 0.422 & 0.441 & 0.433 & 0.519 & 0.438 & 0.461 & 0.446 & 0.461 & 0.541 \\
\hline $\mathbf{M n}$ & 0.007 & 0.007 & 0.009 & 0.009 & 0.010 & 0.007 & 0.009 & 0.006 & 0.007 & 0.007 & 0.007 & 0.008 & 0.007 & 0.008 & 0.007 & 0.008 & 0.007 & 0.007 & 0.010 \\
\hline $\mathbf{M g}$ & 1.51 & 1.58 & 1.52 & 1.47 & 1.49 & 1.59 & 1.49 & 1.62 & 1.58 & 1.57 & 1.58 & 1.56 & 1.58 & 1.49 & 1.57 & 1.54 & 1.56 & 1.54 & 1.47 \\
\hline $\mathrm{Ni}$ & 0.001 & 0.001 & 0.001 & 0.000 & 0.001 & 0.001 & 0.001 & 0.001 & 0.001 & 0.001 & 0.001 & 0.001 & 0.001 & 0.001 & 0.001 & 0.001 & 0.001 & 0.001 & 0.001 \\
\hline $\mathrm{Ca}$ & 0.005 & 0.005 & 0.005 & 0.004 & 0.004 & 0.005 & 0.004 & 0.005 & 0.005 & 0.005 & 0.005 & 0.004 & 0.005 & 0.005 & 0.005 & 0.005 & 0.005 & 0.005 & 0.004 \\
\hline Total & 3.01 & 3.01 & 3.01 & 3.02 & 3.02 & 3.00 & 3.01 & 3.01 & 3.01 & 3.01 & 3.01 & 3.01 & 3.01 & 3.01 & 3.01 & 3.01 & 3.01 & 3.01 & 3.01 \\
\hline \multicolumn{20}{|l|}{ Atomic \% } \\
\hline Fo & 75.2 & 78.8 & 75.4 & 72.8 & 73.7 & 79.6 & 74.1 & 80.8 & 78.9 & 78.4 & 78.9 & 78.0 & 78.5 & 74.1 & 78.1 & 77.0 & 77.7 & 77.0 & 73.1 \\
\hline $\mathrm{Fa}$ & 24.8 & 21.2 & 24.6 & 27.2 & 26.3 & 20.4 & 25.9 & 19.2 & 21.1 & 21.6 & 21.1 & 22.0 & 21.5 & 25.9 & 21.9 & 23.0 & 22.3 & 23.0 & 26.9 \\
\hline
\end{tabular}


Table F.4. Continued

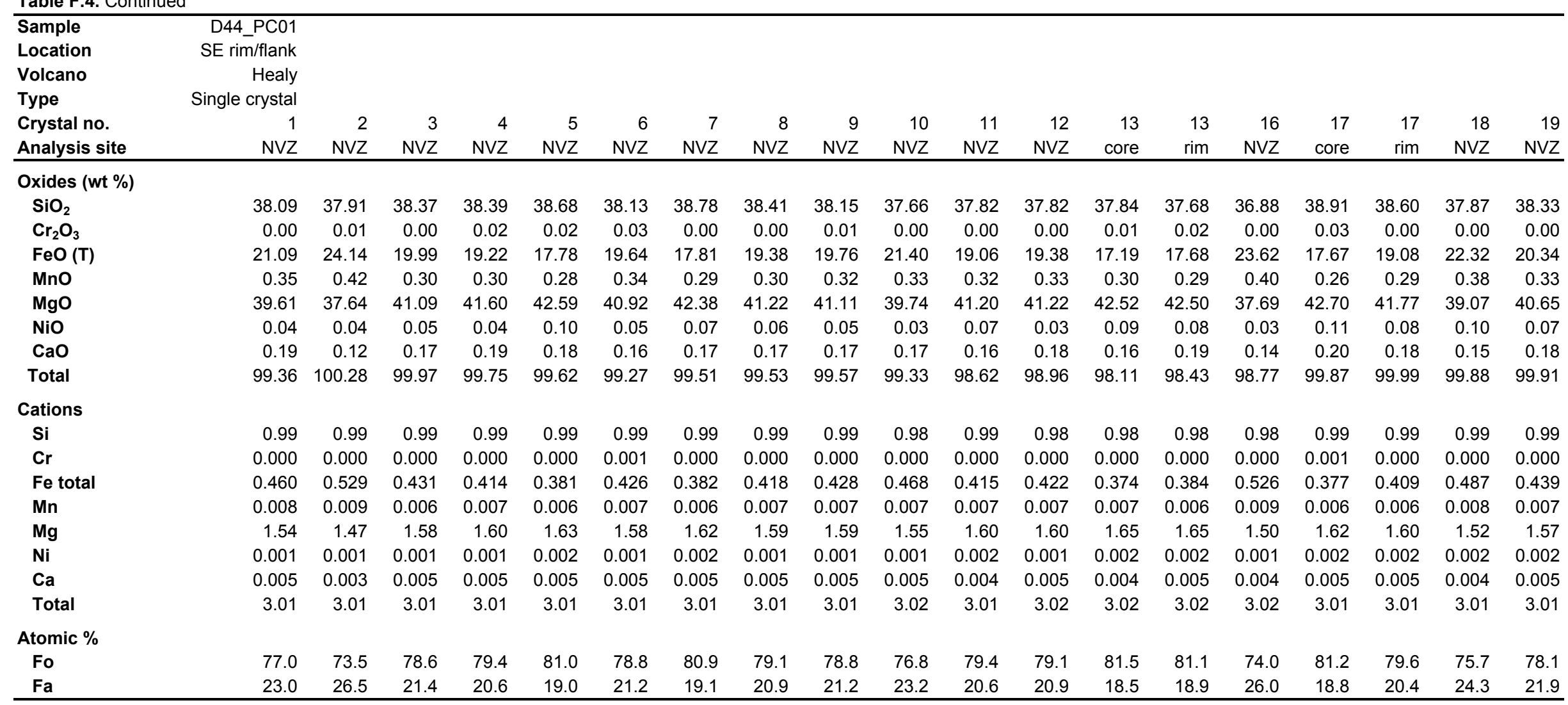




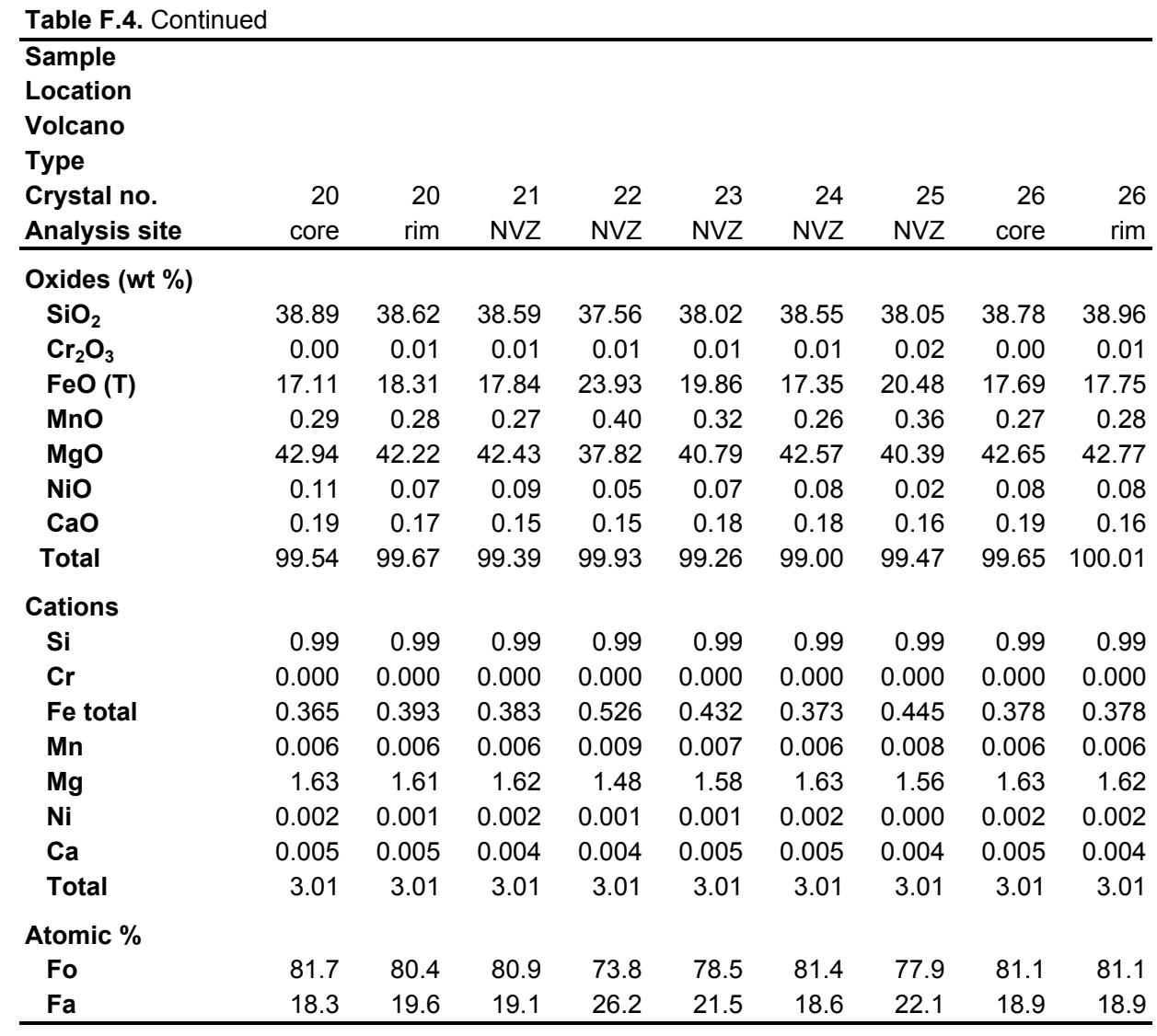


Table F.5. Major element compositions of amphibole determined by EPMA

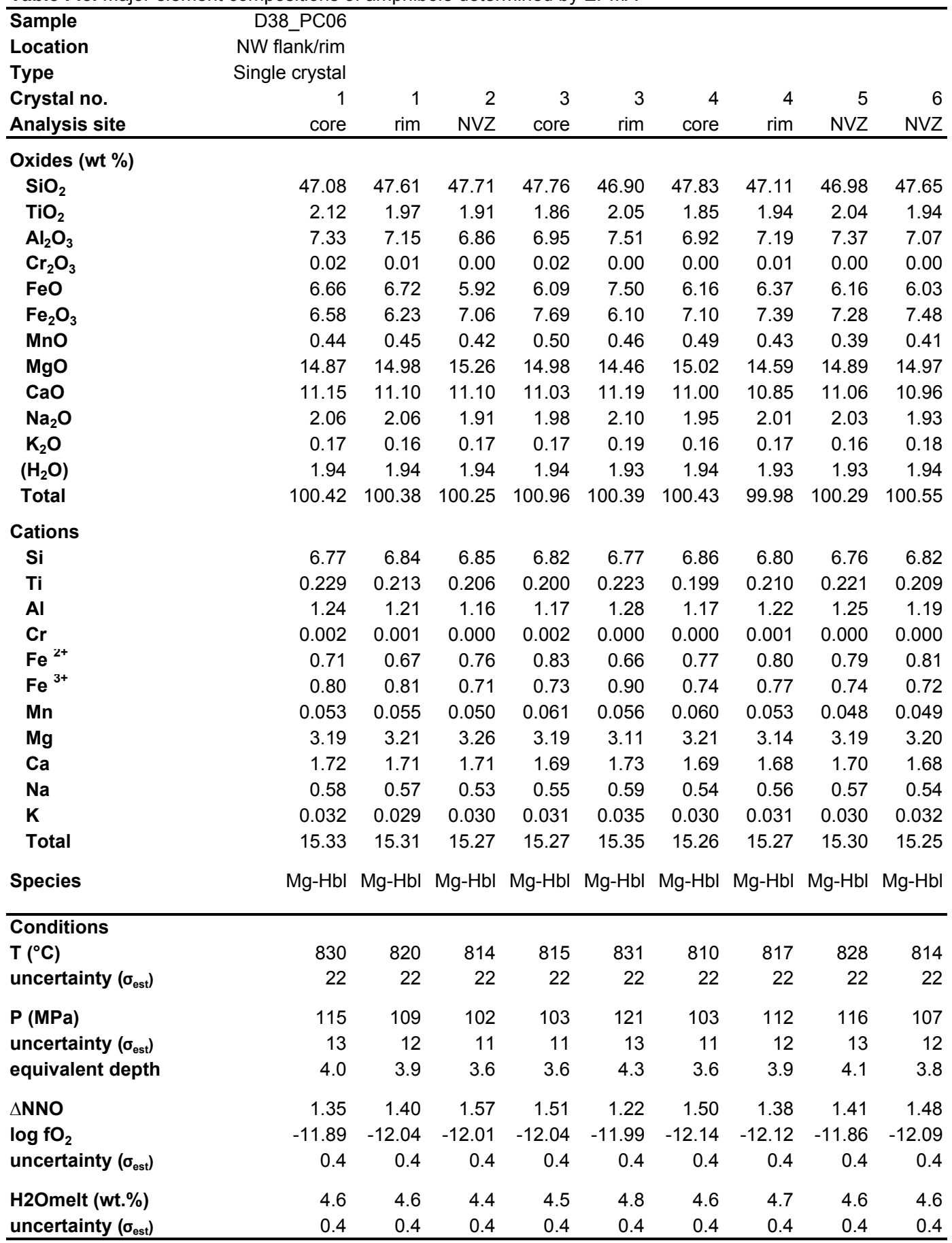

Compositions calculated on the basis of 13 cations using the formulae of Leake et al. (1997). Species and intensive parameters calculated using the spreadsheet of Ridolfi et al. (2009). 


\begin{tabular}{|c|c|c|c|c|c|c|c|c|c|}
\hline $\begin{array}{l}\text { Sample } \\
\text { Location } \\
\text { Type }\end{array}$ & & & & & & & & & \\
\hline Crystal no. & 7 & 8 & 9 & 9 & 10 & 11 & 12 & 13 & 14 \\
\hline Analysis site & NVZ & NVZ & core & core & NVZ & $\mathrm{NVZ}$ & NVZ & NVZ & $\mathrm{NVZ}$ \\
\hline \multicolumn{10}{|l|}{ Oxides (wt \%) } \\
\hline $\mathrm{SiO}_{2}$ & 47.78 & 46.97 & 46.70 & 46.91 & 47.35 & 47.32 & 46.76 & 46.53 & 47.56 \\
\hline $\mathrm{TiO}_{2}$ & 1.90 & 2.03 & 2.03 & 1.99 & 2.00 & 2.03 & 2.11 & 2.06 & 1.86 \\
\hline $\mathrm{Al}_{2} \mathrm{O}_{3}$ & 6.86 & 7.35 & 7.22 & 7.40 & 7.39 & 7.24 & 7.49 & 7.68 & 6.82 \\
\hline $\mathrm{Cr}_{2} \mathrm{O}_{3}$ & 0.00 & 0.02 & 0.00 & 0.00 & 0.00 & 0.02 & 0.00 & 0.01 & 0.02 \\
\hline $\mathrm{FeO}$ & 5.67 & 6.95 & 6.85 & 6.53 & 6.08 & 6.32 & 6.77 & 6.46 & 6.32 \\
\hline $\mathrm{Fe}_{2} \mathrm{O}_{3}$ & 7.74 & 6.41 & 6.65 & 7.34 & 7.83 & 7.18 & 6.86 & 7.87 & 7.92 \\
\hline MnO & 0.45 & 0.47 & 0.45 & 0.49 & 0.48 & 0.47 & 0.43 & 0.53 & 0.53 \\
\hline $\mathrm{MgO}$ & 15.19 & 14.72 & 14.78 & 14.56 & 14.83 & 14.87 & 14.52 & 14.40 & 14.59 \\
\hline $\mathrm{CaO}$ & 11.03 & 11.18 & 11.19 & 11.05 & 11.05 & 11.08 & 11.06 & 11.04 & 10.93 \\
\hline $\mathrm{Na}_{2} \mathrm{O}$ & 1.88 & 2.06 & 2.12 & 2.00 & 2.01 & 1.98 & 1.99 & 2.07 & 1.85 \\
\hline $\mathrm{K}_{2} \mathrm{O}$ & 0.16 & 0.19 & 0.18 & 0.18 & 0.17 & 0.18 & 0.19 & 0.18 & 0.17 \\
\hline$\left(\mathrm{H}_{2} \mathrm{O}\right)$ & 1.94 & 1.93 & 1.93 & 1.93 & 1.95 & 1.94 & 1.93 & 1.93 & 1.93 \\
\hline Total & 100.60 & 100.28 & 100.10 & 100.38 & 101.14 & 100.62 & 100.10 & 100.76 & 100.50 \\
\hline \multicolumn{10}{|l|}{ Cations } \\
\hline $\mathrm{Si}$ & 6.83 & 6.77 & 6.75 & 6.76 & 6.76 & 6.79 & 6.75 & 6.69 & 6.84 \\
\hline $\mathrm{Ti}$ & 0.204 & 0.220 & 0.221 & 0.216 & 0.215 & 0.219 & 0.229 & 0.223 & 0.201 \\
\hline Al & 1.16 & 1.25 & 1.23 & 1.26 & 1.24 & 1.22 & 1.27 & 1.30 & 1.16 \\
\hline $\mathrm{Cr}$ & 0.000 & 0.003 & 0.000 & 0.000 & 0.000 & 0.002 & 0.000 & 0.001 & 0.002 \\
\hline $\mathrm{Fe}^{2+}$ & 0.83 & 0.70 & 0.72 & 0.80 & 0.84 & 0.77 & 0.75 & 0.85 & 0.86 \\
\hline $\mathrm{Fe}^{3+}$ & 0.68 & 0.84 & 0.83 & 0.79 & 0.73 & 0.76 & 0.82 & 0.78 & 0.76 \\
\hline Mn & 0.055 & 0.058 & 0.056 & 0.060 & 0.059 & 0.056 & 0.052 & 0.065 & 0.064 \\
\hline $\mathbf{M g}$ & 3.24 & 3.16 & 3.19 & 3.13 & 3.16 & 3.18 & 3.13 & 3.09 & 3.13 \\
\hline $\mathrm{Ca}$ & 1.69 & 1.73 & 1.73 & 1.70 & 1.69 & 1.70 & 1.71 & 1.70 & 1.68 \\
\hline $\mathrm{Na}$ & 0.52 & 0.58 & 0.60 & 0.56 & 0.56 & 0.55 & 0.56 & 0.58 & 0.52 \\
\hline $\mathrm{K}$ & 0.029 & 0.035 & 0.033 & 0.033 & 0.031 & 0.033 & 0.034 & 0.033 & 0.031 \\
\hline Total & 15.24 & 15.34 & 15.36 & 15.30 & 15.28 & 15.28 & 15.30 & 15.31 & 15.23 \\
\hline Species & $\mathrm{Mg}-\mathrm{Hbl}$ & $\mathrm{Mg}-\mathrm{Hbl}$ & $\mathrm{Mg}-\mathrm{Hbl}$ & $\mathrm{Mg}-\mathrm{Hbl}$ & $\mathrm{Mg}-\mathrm{Hbl}$ & $\mathrm{Mg}-\mathrm{Hbl}$ & $\mathrm{Mg}-\mathrm{Hbl}$ & $\mathrm{Mg}-\mathrm{Hbl}$ & $\mathrm{Mg}-\mathrm{Hbl}$ \\
\hline \multicolumn{10}{|l|}{ Conditions } \\
\hline $\mathrm{T}\left({ }^{\circ} \mathrm{C}\right)$ & 814 & 829 & 836 & 826 & 824 & 823 & 830 & 837 & 809 \\
\hline uncertainty $\left(\sigma_{\text {est }}\right)$ & 22 & 22 & 22 & 22 & 22 & 22 & 22 & 22 & 22 \\
\hline $\mathrm{P}(\mathrm{MPa})$ & 101 & 116 & 113 & 117 & 115 & 112 & 120 & 125 & 101 \\
\hline uncertainty $\left(\sigma_{\mathrm{est}}\right)$ & 11 & 13 & 12 & 13 & 13 & 12 & 13 & 14 & 11 \\
\hline equivalent depth & 3.6 & 4.1 & 4.0 & 4.1 & 4.1 & 3.9 & 4.2 & 4.4 & 3.6 \\
\hline$\Delta$ NNO & 1.59 & 1.32 & 1.39 & 1.33 & 1.40 & 1.40 & 1.28 & 1.27 & 1.46 \\
\hline $\log \mathrm{fO}_{2}$ & -11.98 & -11.92 & -11.72 & -11.97 & -11.95 & -11.98 & -11.95 & -11.81 & -12.22 \\
\hline uncertainty $\left(\sigma_{\text {est }}\right)$ & 0.4 & 0.4 & 0.4 & 0.4 & 0.4 & 0.4 & 0.4 & 0.4 & 0.4 \\
\hline H2Omelt (wt.\%) & 4.5 & 4.6 & 4.4 & 4.8 & 4.7 & 4.6 & 4.8 & 4.8 & 4.7 \\
\hline uncertainty $\left(\sigma_{\text {est }}\right)$ & 0.4 & 0.4 & 0.4 & 0.4 & 0.4 & 0.4 & 0.4 & 0.4 & 0.4 \\
\hline
\end{tabular}


Table F.5. Continued

\begin{tabular}{|c|c|c|c|c|c|c|c|c|c|}
\hline Sample & D39_PC05 & & & & & & & & \\
\hline Location & $\mathrm{N}$ wall/floor & & & & & & & & \\
\hline Type & Single crystal & & & & & & & & \\
\hline Crystal no. & 1 & 2 & 3 & 4 & 5 & 6 & 6 & 7 & 8 \\
\hline Analysis site & NVZ & NVZ & NVZ & NVZ & NVZ & core & rim & NVZ & $\mathrm{NVZ}$ \\
\hline \multicolumn{10}{|l|}{ Oxides (wt \%) } \\
\hline $\mathrm{SiO}_{2}$ & 46.94 & 46.23 & 45.42 & 47.31 & 46.30 & 45.78 & 46.80 & 46.37 & 44.93 \\
\hline $\mathrm{TiO}_{2}$ & 2.02 & 2.26 & 2.38 & 1.94 & 2.01 & 2.28 & 2.02 & 2.14 & 2.16 \\
\hline $\mathrm{Al}_{2} \mathrm{O}_{3}$ & 7.43 & 8.09 & 8.40 & 7.05 & 7.66 & 8.50 & 7.51 & 7.93 & 7.93 \\
\hline $\mathrm{Cr}_{2} \mathrm{O}_{3}$ & 0.01 & 0.01 & 0.01 & 0.00 & 0.02 & 0.00 & 0.00 & 0.02 & 0.02 \\
\hline $\mathrm{FeO}$ & 7.02 & 7.29 & 8.17 & 6.63 & 6.43 & 6.13 & 6.73 & 7.04 & 5.77 \\
\hline $\mathrm{Fe}_{2} \mathrm{O}_{3}$ & 7.44 & 7.04 & 6.21 & 7.20 & 7.97 & 9.27 & 7.65 & 7.15 & 8.85 \\
\hline $\mathrm{MnO}$ & 0.51 & 0.45 & 0.43 & 0.54 & 0.45 & 0.44 & 0.47 & 0.45 & 0.43 \\
\hline $\mathrm{MgO}$ & 14.32 & 14.28 & 13.51 & 14.57 & 14.12 & 13.84 & 14.19 & 14.24 & 14.07 \\
\hline $\mathrm{CaO}$ & 11.05 & 11.14 & 10.99 & 10.91 & 10.80 & 10.66 & 10.81 & 11.02 & 10.79 \\
\hline $\mathrm{Na}_{2} \mathrm{O}$ & 2.06 & 2.31 & 2.22 & 2.05 & 2.01 & 2.24 & 2.04 & 2.18 & 2.09 \\
\hline $\mathrm{K}_{2} \mathrm{O}$ & 0.17 & 0.20 & 0.22 & 0.16 & 0.19 & 0.20 & 0.19 & 0.20 & 0.18 \\
\hline$\left(\mathrm{H}_{2} \mathrm{O}\right)$ & 1.93 & 1.94 & 1.91 & 1.93 & 1.91 & 1.93 & 1.93 & 1.93 & 1.89 \\
\hline Total & 100.89 & 101.24 & 99.86 & 100.29 & 99.86 & 101.27 & 100.35 & 100.66 & 99.11 \\
\hline \multicolumn{10}{|l|}{ Cations } \\
\hline Si & 6.75 & 6.64 & 6.62 & 6.82 & 6.71 & 6.57 & 6.75 & 6.68 & 6.58 \\
\hline $\mathrm{Ti}$ & 0.218 & 0.244 & 0.261 & 0.210 & 0.219 & 0.246 & 0.220 & 0.232 & 0.238 \\
\hline Al & 1.26 & 1.37 & 1.44 & 1.20 & 1.31 & 1.44 & 1.28 & 1.35 & 1.37 \\
\hline $\mathrm{Cr}$ & 0.001 & 0.001 & 0.001 & 0.000 & 0.002 & 0.000 & 0.000 & 0.002 & 0.002 \\
\hline $\mathrm{Fe}^{2+}$ & 0.80 & 0.76 & 0.68 & 0.78 & 0.87 & 1.00 & 0.83 & 0.78 & 0.98 \\
\hline $\mathrm{Fe}^{3+}$ & 0.84 & 0.88 & 1.00 & 0.80 & 0.78 & 0.74 & 0.81 & 0.85 & 0.71 \\
\hline Mn & 0.062 & 0.055 & 0.053 & 0.066 & 0.055 & 0.054 & 0.058 & 0.055 & 0.054 \\
\hline Mg & 3.07 & 3.06 & 2.94 & 3.13 & 3.05 & 2.96 & 3.05 & 3.06 & 3.07 \\
\hline $\mathrm{Ca}$ & 1.70 & 1.71 & 1.72 & 1.68 & 1.68 & 1.64 & 1.67 & 1.70 & 1.69 \\
\hline $\mathrm{Na}$ & 0.57 & 0.64 & 0.63 & 0.57 & 0.57 & 0.62 & 0.57 & 0.61 & 0.59 \\
\hline $\mathbf{K}$ & 0.032 & 0.036 & 0.041 & 0.030 & 0.035 & 0.036 & 0.035 & 0.036 & 0.033 \\
\hline Total & 15.31 & 15.39 & 15.38 & 15.29 & 15.28 & 15.30 & 15.28 & 15.35 & 15.32 \\
\hline Species & $\mathrm{Mg}-\mathrm{Hbl}$ & $\mathrm{Mg}-\mathrm{Hbl}$ & $\mathrm{Mg}-\mathrm{Hbl}$ & $\mathrm{Mg}-\mathrm{Hbl}$ & $\mathrm{Mg}-\mathrm{Hbl}$ & $\mathrm{Mg}-\mathrm{Hbl}$ & $\mathrm{Mg}-\mathrm{Hbl}$ & $\mathrm{Mg}-\mathrm{Hbl}$ & $\mathrm{Mg}-\mathrm{Hbl}$ \\
\hline \multicolumn{10}{|l|}{ Conditions } \\
\hline $\mathrm{T}\left({ }^{\circ} \mathrm{C}\right)$ & 826 & 850 & 854 & 815 & 829 & 849 & 823 & 841 & 865 \\
\hline uncertainty $\left(\sigma_{\text {est }}\right)$ & 22 & 22 & 22 & 22 & 22 & 22 & 22 & 22 & 22 \\
\hline P (MPa) & 117 & 138 & 153 & 107 & 126 & 152 & 120 & 133 & 137 \\
\hline uncertainty ( $\left.\sigma_{\text {est }}\right)$ & 13 & 15 & 17 & 12 & 14 & 17 & 13 & 15 & 15 \\
\hline equivalent depth & 4.1 & 4.9 & 5.4 & 3.8 & 4.5 & 5.4 & 4.2 & 4.7 & 4.8 \\
\hline$\triangle$ NNO & 1.24 & 1.10 & 0.86 & 1.36 & 1.25 & 1.07 & 1.24 & 1.15 & 1.34 \\
\hline $\log \mathrm{fO}_{2}$ & -12.08 & -11.73 & -11.88 & -12.19 & -12.00 & -11.77 & -12.13 & -11.85 & -11.20 \\
\hline uncertainty $\left(\sigma_{\text {est }}\right)$ & 0.4 & 0.4 & 0.4 & 0.4 & 0.4 & 0.4 & 0.4 & 0.4 & 0.4 \\
\hline H2Omelt (wt.\%) & 4.8 & 4.7 & 5.2 & 4.6 & 4.9 & 5.1 & 4.9 & 4.9 & 5.0 \\
\hline uncertainty $\left(\sigma_{\text {est }}\right)$ & 0.4 & 0.4 & 0.4 & 0.4 & 0.4 & 0.4 & 0.4 & 0.4 & 0.4 \\
\hline
\end{tabular}




\begin{tabular}{|c|c|c|c|c|c|c|c|c|c|c|}
\hline $\begin{array}{l}\text { Sample } \\
\text { Location } \\
\text { Type }\end{array}$ & & & & & & & & & & \\
\hline Crystal no. & 9 & 9 & 10 & 11 & 12 & 13 & 14 & 15 & 15 & 16 \\
\hline Analysis site & core & rim & NVZ & NVZ & NVZ & NVZ & NVZ & core & rim & NVZ \\
\hline Oxides (wt \%) & & & & & & & & & & \\
\hline $\mathrm{SiO}_{2}$ & 45.27 & 46.05 & 47.53 & 47.41 & 44.85 & 46.68 & 46.62 & 45.85 & 46.23 & 46.42 \\
\hline $\mathrm{TiO}_{2}$ & 2.45 & 2.38 & 1.97 & 1.85 & 2.51 & 2.21 & 2.08 & 2.34 & 2.19 & 2.14 \\
\hline $\mathrm{Al}_{2} \mathrm{O}_{3}$ & 8.72 & 8.29 & 7.26 & 6.85 & 8.57 & 7.65 & 7.95 & 8.08 & 8.04 & 7.75 \\
\hline $\mathrm{Cr}_{2} \mathrm{O}_{3}$ & 0.00 & 0.01 & 0.02 & 0.00 & 0.00 & 0.00 & 0.00 & 0.00 & 0.03 & 0.00 \\
\hline $\mathrm{FeO}$ & 8.25 & 7.36 & 5.95 & 6.65 & 7.33 & 7.53 & 6.08 & 7.36 & 6.68 & 6.99 \\
\hline $\mathrm{Fe}_{2} \mathrm{O}_{3}$ & 6.72 & 6.69 & 8.41 & 7.67 & 7.52 & 7.21 & 8.55 & 7.11 & 7.66 & 6.95 \\
\hline MnO & 0.39 & 0.41 & 0.47 & 0.48 & 0.42 & 0.52 & 0.45 & 0.43 & 0.44 & 0.45 \\
\hline MgO & 13.31 & 14.11 & 14.82 & 14.41 & 13.51 & 13.97 & 14.24 & 13.85 & 14.21 & 14.22 \\
\hline $\mathrm{CaO}$ & 10.84 & 11.01 & 10.95 & 10.86 & 10.83 & 10.96 & 10.75 & 10.92 & 10.96 & 11.00 \\
\hline $\mathrm{Na}_{2} \mathrm{O}$ & 2.40 & 2.26 & 2.05 & 1.91 & 2.29 & 2.14 & 2.11 & 2.17 & 2.15 & 2.04 \\
\hline $\mathrm{K}_{2} \mathrm{O}$ & 0.22 & 0.22 & 0.17 & 0.16 & 0.20 & 0.19 & 0.17 & 0.19 & 0.19 & 0.19 \\
\hline$\left(\mathrm{H}_{2} \mathrm{O}\right)$ & 1.92 & 1.93 & 1.95 & 1.93 & 1.91 & 1.93 & 1.93 & 1.92 & 1.93 & 1.92 \\
\hline Total & 100.50 & 100.72 & 101.55 & 100.17 & 99.93 & 100.98 & 100.93 & 100.21 & 100.70 & 100.06 \\
\hline Cations & & & & & & & & & & \\
\hline $\mathbf{S i}$ & 6.57 & 6.64 & 6.76 & 6.84 & 6.54 & 6.72 & 6.68 & 6.65 & 6.66 & 6.72 \\
\hline $\mathrm{Ti}$ & 0.268 & 0.258 & 0.211 & 0.200 & 0.276 & 0.239 & 0.224 & 0.255 & 0.237 & 0.233 \\
\hline Al & 1.49 & 1.41 & 1.22 & 1.16 & 1.47 & 1.30 & 1.34 & 1.38 & 1.36 & 1.32 \\
\hline $\mathrm{Cr}$ & 0.000 & 0.002 & 0.002 & 0.000 & 0.000 & 0.000 & 0.000 & 0.000 & 0.003 & 0.000 \\
\hline $\mathrm{Fe}^{2+}$ & 0.73 & 0.73 & 0.90 & 0.83 & 0.83 & 0.78 & 0.92 & 0.78 & 0.83 & 0.76 \\
\hline $\mathrm{Fe}^{3+}$ & 1.00 & 0.89 & 0.71 & 0.80 & 0.89 & 0.91 & 0.73 & 0.89 & 0.80 & 0.85 \\
\hline $\mathrm{Mn}$ & 0.048 & 0.050 & 0.057 & 0.059 & 0.052 & 0.063 & 0.054 & 0.053 & 0.054 & 0.055 \\
\hline Mg & 2.88 & 3.03 & 3.14 & 3.10 & 2.94 & 3.00 & 3.04 & 2.99 & 3.05 & 3.07 \\
\hline $\mathrm{Ca}$ & 1.69 & 1.70 & 1.67 & 1.68 & 1.69 & 1.69 & 1.65 & 1.70 & 1.69 & 1.71 \\
\hline $\mathrm{Na}$ & 0.68 & 0.63 & 0.56 & 0.53 & 0.65 & 0.60 & 0.59 & 0.61 & 0.60 & 0.57 \\
\hline K & 0.040 & 0.040 & 0.031 & 0.029 & 0.036 & 0.035 & 0.032 & 0.035 & 0.035 & 0.035 \\
\hline Total & 15.40 & 15.37 & 15.27 & 15.24 & 15.37 & 15.32 & 15.27 & 15.34 & 15.32 & 15.31 \\
\hline Species & $\mathrm{Mg}-\mathrm{Hbl}$ & $\mathrm{Mg}-\mathrm{Hbl}$ & $\mathrm{Mg}-\mathrm{Hbl}$ & $\mathrm{Mg}-\mathrm{Hbl}$ & $\mathrm{Mg}-\mathrm{Hbl}$ & $\mathrm{Mg}-\mathrm{Hbl}$ & $\mathrm{Mg}-\mathrm{Hbl}$ & $\mathrm{Mg}-\mathrm{Hbl}$ & $\mathrm{Mg}-\mathrm{Hbl}$ & $\mathrm{Mg}-\mathrm{Hbl}$ \\
\hline comati & & & & & & & & & & \\
\hline $\mathrm{T}\left({ }^{\circ} \mathrm{C}\right)$ & 860 & 852 & 826 & 805 & 863 & 830 & 833 & 845 & 843 & 835 \\
\hline uncertainty $\left(\sigma_{\text {est }}\right)$ & 22 & 22 & 22 & 22 & 22 & 22 & 22 & 22 & 22 & 22 \\
\hline $\mathrm{P}(\mathrm{MPa})$ & 164 & 146 & 111 & 102 & 160 & 124 & 133 & 140 & 137 & 129 \\
\hline uncertainty ( $\left.\sigma_{\text {est }}\right)$ & 18 & 16 & 12 & 11 & 18 & 14 & 15 & 15 & 15 & 14 \\
\hline equivalent depth & 5.8 & 5.1 & 3.9 & 3.6 & 5.6 & 4.4 & 4.7 & 4.9 & 4.8 & 4.5 \\
\hline$\triangle$ NNO & 0.77 & 1.02 & 1.46 & 1.39 & 0.88 & 1.08 & 1.24 & 1.02 & 1.16 & 1.18 \\
\hline $\log \mathrm{fO}_{2}$ & -11.87 & -11.77 & -11.86 & -12.36 & -11.71 & -12.15 & -11.93 & -11.91 & -11.81 & -11.94 \\
\hline uncertainty $\left(\sigma_{\text {est }}\right)$ & 0.4 & 0.4 & 0.4 & 0.4 & 0.4 & 0.4 & 0.4 & 0.4 & 0.4 & 0.4 \\
\hline H2Omelt (wt.\%) & 5.2 & 4.9 & 4.7 & 4.7 & 5.1 & 4.8 & 5.0 & 5.0 & 4.9 & 5.0 \\
\hline uncertainty $\left(\sigma_{\text {est }}\right)$ & 0.4 & 0.4 & 0.4 & 0.4 & 0.4 & 0.4 & 0.4 & 0.4 & 0.4 & 0.4 \\
\hline
\end{tabular}


Table F.5. Continued

\begin{tabular}{|c|c|c|c|c|c|c|c|c|c|}
\hline Sample & D44_PC01 & & & & & & & & \\
\hline Location & SE rim/flank & & & & & & & & \\
\hline Type & Single crystal & & & & & & & & \\
\hline Crystal no. & 1 & 2 & 3 & 3 & 4 & 5 & 6 & 6 & 7 \\
\hline Analysis site & NVZ & NVZ & core & OG & NVZ & NVZ & core & rim & $\mathrm{NVZ}$ \\
\hline \multicolumn{10}{|l|}{ Oxides (wt \%) } \\
\hline $\mathrm{SiO}_{2}$ & 47.36 & 47.72 & 43.54 & 46.65 & 46.61 & 47.99 & 47.49 & 46.57 & 46.25 \\
\hline $\mathrm{TiO}_{2}$ & 2.03 & 1.83 & 2.72 & 1.96 & 1.87 & 1.87 & 1.74 & 2.04 & 1.98 \\
\hline $\mathrm{Al}_{2} \mathrm{O}_{3}$ & 7.21 & 7.01 & 10.42 & 6.96 & 7.08 & 6.68 & 6.88 & 7.39 & 7.01 \\
\hline $\mathrm{Cr}_{2} \mathrm{O}_{3}$ & 0.00 & 0.00 & 0.03 & 0.01 & 0.00 & 0.02 & 0.00 & 0.00 & 0.00 \\
\hline $\mathrm{FeO}$ & 6.43 & 5.97 & 8.12 & 5.60 & 5.74 & 5.86 & 6.33 & 6.13 & 5.54 \\
\hline $\mathrm{Fe}_{2} \mathrm{O}_{3}$ & 6.91 & 7.56 & 6.73 & 8.09 & 7.89 & 7.49 & 7.34 & 7.31 & 8.04 \\
\hline $\mathrm{MnO}$ & 0.47 & 0.47 & 0.39 & 0.50 & 0.44 & 0.48 & 0.45 & 0.44 & 0.48 \\
\hline MgO & 15.00 & 15.09 & 13.04 & 14.93 & 14.82 & 15.25 & 14.71 & 14.76 & 14.86 \\
\hline $\mathrm{CaO}$ & 11.13 & 11.13 & 11.14 & 10.99 & 10.93 & 11.05 & 10.96 & 10.98 & 10.93 \\
\hline $\mathrm{Na}_{2} \mathrm{O}$ & 2.08 & 1.90 & 2.63 & 1.98 & 1.99 & 1.93 & 1.86 & 2.07 & 1.99 \\
\hline $\mathrm{K}_{2} \mathrm{O}$ & 0.17 & 0.16 & 0.17 & 0.16 & 0.16 & 0.17 & 0.16 & 0.18 & 0.16 \\
\hline$\left(\mathrm{H}_{2} \mathrm{O}\right)$ & 1.94 & 1.94 & 1.92 & 1.92 & 1.91 & 1.94 & 1.93 & 1.92 & 1.90 \\
\hline Total & 100.71 & 100.77 & 100.84 & 99.75 & 99.42 & 100.72 & 99.84 & 99.80 & 99.14 \\
\hline \multicolumn{10}{|l|}{ Cations } \\
\hline Si & 6.79 & 6.82 & 6.32 & 6.75 & 6.77 & 6.86 & 6.86 & 6.74 & 6.74 \\
\hline $\mathrm{Ti}$ & 0.219 & 0.196 & 0.297 & 0.213 & 0.204 & 0.201 & 0.189 & 0.222 & 0.217 \\
\hline Al & 1.22 & 1.18 & 1.78 & 1.19 & 1.21 & 1.12 & 1.17 & 1.26 & 1.20 \\
\hline $\mathrm{Cr}$ & 0.000 & 0.000 & 0.003 & 0.001 & 0.000 & 0.003 & 0.000 & 0.000 & 0.000 \\
\hline $\mathrm{Fe}^{2+}$ & 0.74 & 0.81 & 0.74 & 0.88 & 0.86 & 0.81 & 0.80 & 0.80 & 0.88 \\
\hline $\mathrm{Fe}^{3+}$ & 0.77 & 0.71 & 0.99 & 0.68 & 0.70 & 0.70 & 0.76 & 0.74 & 0.67 \\
\hline Mn & 0.056 & 0.057 & 0.048 & 0.061 & 0.054 & 0.058 & 0.054 & 0.054 & 0.059 \\
\hline Mg & 3.20 & 3.22 & 2.82 & 3.22 & 3.21 & 3.25 & 3.17 & 3.18 & 3.23 \\
\hline $\mathrm{Ca}$ & 1.71 & 1.71 & 1.73 & 1.70 & 1.70 & 1.69 & 1.70 & 1.70 & 1.71 \\
\hline $\mathrm{Na}$ & 0.58 & 0.53 & 0.74 & 0.56 & 0.56 & 0.53 & 0.52 & 0.58 & 0.56 \\
\hline $\mathbf{K}$ & 0.030 & 0.028 & 0.032 & 0.030 & 0.029 & 0.031 & 0.030 & 0.034 & 0.029 \\
\hline Total & 15.32 & 15.26 & 15.50 & 15.29 & 15.29 & 15.26 & 15.24 & 15.32 & 15.30 \\
\hline Species & Mg-Hbl & $\mathrm{Mg}-\mathrm{Hbl}$ & Mg-Hst & $\mathrm{Mg}-\mathrm{Hbl}$ & $\mathrm{Mg}-\mathrm{Hbl}$ & $\mathrm{Mg}-\mathrm{Hbl}$ & Mg-Hbl & $\mathrm{Mg}-\mathrm{Hbl}$ & $\mathrm{Mg}-\mathrm{Hbl}$ \\
\hline \multicolumn{10}{|l|}{ Conditions } \\
\hline $\mathrm{T}\left({ }^{\circ} \mathrm{C}\right)$ & 825 & 815 & 914 & 841 & 830 & 813 & 807 & 831 & 845 \\
\hline uncertainty $\left(\sigma_{\text {est }}\right)$ & 22 & 22 & 22 & 22 & 22 & 22 & 22 & 22 & 22 \\
\hline P (MPa) & 111 & 105 & 250 & 106 & 110 & 97 & 103 & 118 & 108 \\
\hline uncertainty ( $\left.\sigma_{\text {est }}\right)$ & 12 & 12 & 27 & 12 & 12 & 11 & 11 & 13 & 12 \\
\hline equivalent depth & 3.9 & 3.7 & 8.8 & 3.7 & 3.9 & 3.4 & 3.6 & 4.2 & 3.8 \\
\hline$\triangle$ NNO & 1.41 & 1.53 & 0.50 & 1.63 & 1.55 & 1.61 & 1.49 & 1.39 & 1.62 \\
\hline $\log \mathrm{fO}_{2}$ & -11.93 & -12.01 & -11.12 & -11.38 & -11.69 & -11.98 & -12.22 & -11.82 & -11.32 \\
\hline uncertainty $\left(\sigma_{\text {est }}\right)$ & 0.4 & 0.4 & 0.4 & 0.4 & 0.4 & 0.4 & 0.4 & 0.4 & 0.4 \\
\hline H2Omelt (wt.\%) & 4.5 & 4.6 & 6.0 & 4.6 & 4.6 & 4.4 & 4.7 & 4.5 & 4.6 \\
\hline uncertainty $\left(\sigma_{\text {est }}\right)$ & 0.4 & 0.4 & 0.9 & 0.4 & 0.4 & 0.4 & 0.4 & 0.4 & 0.4 \\
\hline
\end{tabular}


Table F.5. Continued

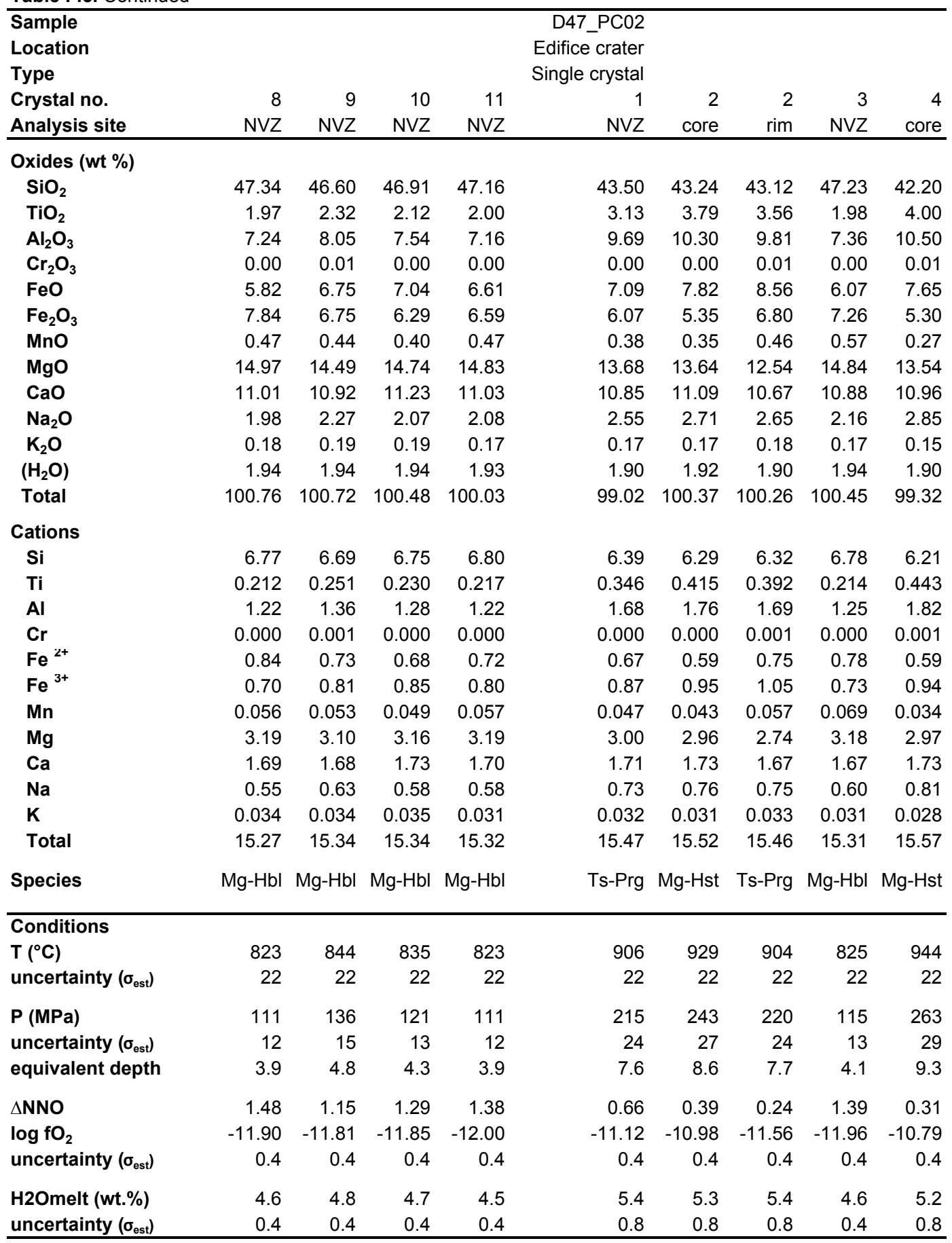


Table F.5. Continued

\begin{tabular}{|c|c|c|c|c|c|c|c|c|c|c|}
\hline $\begin{array}{l}\text { Sample } \\
\text { Location } \\
\text { Type }\end{array}$ & & & & & & & & & & \\
\hline Crystal no. & 4 & 5 & 5 & 6 & 6 & 7 & $\begin{array}{r}7 \\
\text { rim }\end{array}$ & $\begin{array}{r}8 \\
\text { NyV }\end{array}$ & $\begin{array}{r}9 \\
N V / 7\end{array}$ & 10 \\
\hline Oxides (wt \%) & $\mathrm{nIm}$ & core & $1 \mathrm{~mm}$ & core & $\mathrm{nIm}$ & core & & 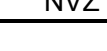 & & \\
\hline $\begin{array}{l}\text { Uxides (Wt \%) } \\
\mathrm{SiO}_{2}\end{array}$ & 42.83 & 43.05 & 43.04 & 44.17 & 43.94 & 43.00 & 47.78 & 43.07 & 43.30 & 42.63 \\
\hline $\mathrm{TiO}_{2}$ & 3.62 & 3.71 & 3.61 & 3.30 & 3.23 & 3.44 & 1.72 & 3.62 & 3.57 & 3.70 \\
\hline $\mathrm{Al}_{2} \mathrm{O}_{3}$ & 9.95 & 10.04 & 9.89 & 9.43 & 9.84 & 10.03 & 6.59 & 10.24 & 9.89 & 10.61 \\
\hline $\mathrm{Cr}_{2} \mathrm{O}_{3}$ & 0.03 & 0.00 & 0.02 & 0.00 & 0.01 & 0.00 & 0.02 & 0.03 & 0.03 & 0.00 \\
\hline $\mathrm{FeO}$ & 7.75 & 7.50 & 7.74 & 7.05 & 7.52 & 8.17 & 4.79 & 7.18 & 6.98 & 6.97 \\
\hline $\mathrm{Fe}_{2} \mathrm{O}_{3}$ & 6.50 & 5.68 & 6.19 & 5.94 & 6.28 & 5.63 & 9.29 & 5.99 & 6.83 & 6.42 \\
\hline $\mathrm{MnO}$ & 0.45 & 0.38 & 0.50 & 0.44 & 0.54 & 0.35 & 0.74 & 0.30 & 0.37 & 0.32 \\
\hline MgO & 13.19 & 13.68 & 13.13 & 14.03 & 13.44 & 13.23 & 14.92 & 13.77 & 13.58 & 13.49 \\
\hline $\mathrm{CaO}$ & 10.78 & 11.07 & 10.78 & 11.05 & 10.90 & 11.03 & 10.60 & 10.97 & 10.82 & 10.84 \\
\hline $\mathrm{Na}_{2} \mathrm{O}$ & 2.81 & 2.63 & 2.63 & 2.47 & 2.59 & 2.61 & 1.93 & 2.74 & 2.60 & 2.72 \\
\hline $\mathrm{K}_{2} \mathrm{O}$ & 0.15 & 0.17 & 0.16 & 0.16 & 0.17 & 0.18 & 0.16 & 0.16 & 0.17 & 0.14 \\
\hline$\left(\mathrm{H}_{2} \mathrm{O}\right)$ & 1.90 & 1.91 & 1.90 & 1.92 & 1.92 & 1.90 & 1.93 & 1.91 & 1.91 & 1.91 \\
\hline Total & 99.97 & 99.80 & 99.58 & 99.94 & 100.39 & 99.56 & 100.46 & 99.97 & 100.02 & 99.75 \\
\hline Cations & & & & & & & & & & \\
\hline $\mathbf{S i}$ & 6.28 & 6.29 & 6.32 & 6.42 & 6.38 & 6.32 & 6.85 & 6.28 & 6.31 & 6.23 \\
\hline $\mathrm{Ti}$ & 0.399 & 0.407 & 0.398 & 0.361 & 0.353 & 0.379 & 0.185 & 0.397 & 0.391 & 0.407 \\
\hline Al & 1.72 & 1.73 & 1.71 & 1.62 & 1.69 & 1.74 & 1.11 & 1.76 & 1.70 & 1.83 \\
\hline $\mathrm{Cr}$ & 0.003 & 0.000 & 0.002 & 0.000 & 0.001 & 0.000 & 0.003 & 0.004 & 0.003 & 0.000 \\
\hline $\mathrm{Fe}^{2+}$ & 0.72 & 0.62 & 0.68 & 0.65 & 0.69 & 0.62 & 1.00 & 0.66 & 0.75 & 0.71 \\
\hline $\mathrm{Fe}^{3+}$ & 0.95 & 0.92 & 0.95 & 0.86 & 0.91 & 1.00 & 0.57 & 0.88 & 0.85 & 0.85 \\
\hline Mn & 0.056 & 0.047 & 0.062 & 0.054 & 0.067 & 0.043 & 0.089 & 0.037 & 0.045 & 0.039 \\
\hline $\mathbf{M g}$ & 2.88 & 2.98 & 2.87 & 3.04 & 2.91 & 2.90 & 3.19 & 2.99 & 2.95 & 2.94 \\
\hline $\mathrm{Ca}$ & 1.69 & 1.73 & 1.70 & 1.72 & 1.70 & 1.74 & 1.63 & 1.71 & 1.69 & 1.70 \\
\hline $\mathrm{Na}$ & 0.80 & 0.74 & 0.75 & 0.70 & 0.73 & 0.74 & 0.54 & 0.77 & 0.73 & 0.77 \\
\hline $\mathbf{K}$ & 0.028 & 0.031 & 0.030 & 0.030 & 0.032 & 0.034 & 0.029 & 0.030 & 0.032 & 0.027 \\
\hline Total & 15.52 & 15.51 & 15.47 & 15.45 & 15.46 & 15.51 & 15.19 & 15.52 & 15.46 & 15.49 \\
\hline Species & Mg-Hst & Mg-Hst & Ts-Prg & Ts-Prg & Ts-Prg & Mg-Hst & $\mathrm{Mg}-\mathrm{Hbl}$ & Mg-Hst & Ts-Prg & Ts-Prg \\
\hline Conditions & & & & & & & & & & \\
\hline $\mathrm{T}\left({ }^{\circ} \mathrm{C}\right)$ & 921 & 925 & 914 & 901 & 904 & 919 & 811 & 928 & 914 & 935 \\
\hline uncertainty $\left(\sigma_{\text {est }}\right)$ & 22 & 22 & 22 & 22 & 22 & 22 & 22 & 22 & 22 & 22 \\
\hline P (MPa) & 227 & 231 & 225 & 196 & 217 & 233 & 95 & 241 & 221 & 266 \\
\hline uncertainty $\left(\sigma_{\text {est }}\right)$ & 25 & 25 & 25 & 22 & 24 & 26 & 10 & 27 & 24 & 29 \\
\hline equivalent depth & 8.0 & 8.2 & 7.9 & 6.9 & 7.7 & 8.2 & 3.4 & 8.5 & 7.8 & 9.4 \\
\hline$\triangle N N O$ & 0.38 & 0.46 & 0.37 & 0.70 & 0.53 & 0.41 & 1.70 & 0.50 & 0.53 & 0.42 \\
\hline $\log \mathrm{fO}_{2}$ & -11.12 & -10.97 & -11.26 & -11.17 & -11.28 & -11.13 & -11.93 & -10.89 & -11.10 & -10.85 \\
\hline uncertainty $\left(\sigma_{\text {est }}\right)$ & 0.4 & 0.4 & 0.4 & 0.4 & 0.4 & 0.4 & 0.4 & 0.4 & 0.4 & 0.4 \\
\hline H2Omelt (wt.\%) & 5.1 & 5.2 & 5.4 & 5.2 & 5.5 & 5.4 & 4.6 & 5.2 & 5.2 & 5.6 \\
\hline uncertainty $\left(\sigma_{\text {est }}\right)$ & 0.8 & 0.8 & 0.8 & 0.8 & 0.8 & 0.8 & 0.4 & 0.8 & 0.8 & 0.8 \\
\hline
\end{tabular}




\begin{tabular}{|c|c|c|c|c|c|c|c|c|c|}
\hline $\begin{array}{l}\text { Sample } \\
\text { Location } \\
\text { Type }\end{array}$ & & & & & & & & & \\
\hline $\begin{array}{l}\text { Crystal no. } \\
\text { Analysis site }\end{array}$ & $\begin{array}{r}10 \\
\text { rim }\end{array}$ & $\begin{array}{r}11 \\
N V Z\end{array}$ & $\begin{array}{r}12 \\
\text { core }\end{array}$ & $\begin{array}{r}12 \\
\text { rim }\end{array}$ & $\begin{array}{r}13 \\
\text { core }\end{array}$ & $\begin{array}{r}13 \\
\text { I band }\end{array}$ & $\begin{array}{r}13 \\
\text { rim }\end{array}$ & $\begin{array}{r}14 \\
N V Z\end{array}$ & $\begin{array}{r}15 \\
N V Z\end{array}$ \\
\hline \multicolumn{10}{|l|}{ Oxides (wt \%) } \\
\hline $\mathrm{SiO}_{2}$ & 43.40 & 41.82 & 43.98 & 43.61 & 44.10 & 42.52 & 45.17 & 43.83 & 43.99 \\
\hline $\mathrm{TiO}_{2}$ & 3.72 & 4.03 & 3.04 & 3.15 & 3.22 & 3.17 & 2.81 & 3.38 & 3.25 \\
\hline $\mathrm{Al}_{2} \mathrm{O}_{3}$ & 10.35 & 10.94 & 9.66 & 9.44 & 9.41 & 10.49 & 8.49 & 9.96 & 9.46 \\
\hline $\mathrm{Cr}_{2} \mathrm{O}_{3}$ & 0.00 & 0.00 & 0.00 & 0.01 & 0.00 & 0.00 & 0.00 & 0.00 & 0.01 \\
\hline $\mathrm{FeO}$ & 7.13 & 8.36 & 6.86 & 6.05 & 6.99 & 9.00 & 7.06 & 7.47 & 7.49 \\
\hline $\mathrm{Fe}_{2} \mathrm{O}_{3}$ & 5.82 & 5.86 & 7.22 & 10.05 & 6.29 & 6.89 & 6.76 & 6.21 & 5.55 \\
\hline $\mathrm{MnO}$ & 0.34 & 0.32 & 0.41 & 0.56 & 0.44 & 0.50 & 0.55 & 0.37 & 0.41 \\
\hline MgO & 13.82 & 12.78 & 13.69 & 12.98 & 13.98 & 12.20 & 13.98 & 13.76 & 13.95 \\
\hline $\mathrm{CaO}$ & 10.99 & 10.99 & 10.83 & 10.26 & 11.01 & 10.97 & 10.87 & 11.09 & 11.14 \\
\hline $\mathrm{Na}_{2} \mathrm{O}$ & 2.67 & 2.77 & 2.59 & 2.55 & 2.51 & 2.66 & 2.37 & 2.63 & 2.51 \\
\hline $\mathrm{K}_{2} \mathrm{O}$ & 0.15 & 0.16 & 0.17 & 0.15 & 0.17 & 0.21 & 0.19 & 0.18 & 0.18 \\
\hline$\left(\mathrm{H}_{2} \mathrm{O}\right)$ & 1.92 & 1.90 & 1.92 & 1.90 & 1.92 & 1.90 & 1.92 & 1.93 & 1.92 \\
\hline Total & 100.30 & 99.94 & 100.36 & 100.71 & 100.05 & 100.51 & 100.17 & 100.81 & 99.86 \\
\hline \multicolumn{10}{|l|}{ Cations } \\
\hline Si & 6.30 & 6.14 & 6.38 & 6.33 & 6.41 & 6.24 & 6.56 & 6.34 & 6.41 \\
\hline $\mathrm{Ti}$ & 0.405 & 0.446 & 0.332 & 0.344 & 0.352 & 0.350 & 0.307 & 0.367 & 0.357 \\
\hline Al & 1.77 & 1.89 & 1.65 & 1.61 & 1.61 & 1.81 & 1.45 & 1.70 & 1.62 \\
\hline $\mathrm{Cr}$ & 0.000 & 0.000 & 0.000 & 0.001 & 0.000 & 0.000 & 0.000 & 0.000 & 0.001 \\
\hline $\mathrm{Fe}^{2+}$ & 0.64 & 0.65 & 0.79 & 1.10 & 0.69 & 0.76 & 0.74 & 0.68 & 0.61 \\
\hline $\mathrm{Fe}^{3+}$ & 0.86 & 1.03 & 0.83 & 0.73 & 0.85 & 1.10 & 0.86 & 0.90 & 0.91 \\
\hline Mn & 0.042 & 0.040 & 0.050 & 0.069 & 0.054 & 0.062 & 0.068 & 0.046 & 0.050 \\
\hline $\mathbf{M g}$ & 2.99 & 2.80 & 2.96 & 2.81 & 3.03 & 2.67 & 3.02 & 2.97 & 3.03 \\
\hline $\mathrm{Ca}$ & 1.71 & 1.73 & 1.68 & 1.60 & 1.71 & 1.73 & 1.69 & 1.72 & 1.74 \\
\hline $\mathrm{Na}$ & 0.75 & 0.79 & 0.73 & 0.72 & 0.71 & 0.76 & 0.67 & 0.74 & 0.71 \\
\hline $\mathrm{K}$ & 0.028 & 0.031 & 0.031 & 0.028 & 0.032 & 0.039 & 0.036 & 0.033 & 0.033 \\
\hline Total & 15.49 & 15.55 & 15.45 & 15.34 & 15.45 & 15.52 & 15.39 & 15.49 & 15.48 \\
\hline Species & Ts-Prg & Mg-Hst & Ts-Prg & Ts-Prg & Ts-Prg & Mg-Hst & $\mathrm{Mg}-\mathrm{Hbl}$ & Ts-Prg & Ts-Prg \\
\hline \multicolumn{10}{|l|}{ Conditions } \\
\hline $\mathrm{T}\left({ }^{\circ} \mathrm{C}\right)$ & 926 & 949 & 899 & 902 & 900 & 922 & 867 & 914 & 904 \\
\hline uncertainty $\left(\sigma_{\text {est }}\right)$ & 22 & 22 & 22 & 22 & 22 & 22 & 22 & 22 & 22 \\
\hline $\mathrm{P}(\mathrm{MPa})$ & 244 & 293 & 207 & 196 & 195 & 261 & 155 & 221 & 199 \\
\hline uncertainty $\left(\sigma_{\text {est }}\right)$ & 27 & 32 & 23 & 22 & 21 & 29 & 17 & 24 & 22 \\
\hline equivalent depth & 8.6 & 10.3 & 7.3 & 6.9 & 6.9 & 9.2 & 5.5 & 7.8 & 7.0 \\
\hline$\triangle N N O$ & 0.48 & 0.09 & 0.69 & 0.73 & 0.72 & 0.18 & 0.89 & 0.56 & 0.67 \\
\hline $\log \mathrm{fO}_{2}$ & -10.93 & -10.92 & -11.20 & -11.11 & -11.16 & -11.30 & -11.62 & -11.07 & -11.14 \\
\hline uncertainty $\left(\sigma_{\text {est }}\right)$ & 0.4 & 0.4 & 0.4 & 0.4 & 0.4 & 0.4 & 0.4 & 0.4 & 0.4 \\
\hline H2Omelt (wt.\%) & 5.5 & 5.7 & 5.3 & 5.5 & 5.1 & 5.9 & 4.8 & 5.2 & 5.1 \\
\hline uncertainty $\left(\sigma_{\text {est }}\right)$ & 0.8 & 0.9 & 0.8 & 0.8 & 0.8 & 0.9 & 0.4 & 0.8 & 0.8 \\
\hline
\end{tabular}


Table F.6. Major element compositions of magnetite determined by EPMA

\begin{tabular}{|c|c|c|c|c|c|c|c|c|c|c|c|c|c|c|c|c|c|c|c|}
\hline Sample & RI03_PC03 & & & & & & & & & & & & & & & & & & \\
\hline Location & Rangitahua & & & & & & & & & & & & & & & & & & \\
\hline Volcano & Raoul & & & & & & & & & & & & & & & & & & \\
\hline Type & Single crystal & & & & & & & & & & & & & & & & & & \\
\hline Crystal no. & 1 & 2 & 3 & 4 & 5 & 6 & 7 & 8 & 9 & 10 & 11 & 12 & 13 & 14 & 15 & 16 & 17 & 18 & 19 \\
\hline Analysis site & NVZ & NVZ & NVZ & NVZ & NVZ & NVZ & NVZ & NVZ & NVZ & NVZ & NVZ & NVZ & NVZ & NVZ & NVZ & NVZ & NVZ & NVZ & NVZ \\
\hline \multicolumn{20}{|l|}{ Oxides (wt \%) } \\
\hline $\mathrm{SiO}_{2}$ & 0.25 & 0.24 & 0.21 & 0.44 & 0.38 & 0.30 & 0.26 & 0.28 & 0.08 & 0.51 & 0.34 & 0.23 & 0.27 & 0.06 & 0.52 & 0.17 & 0.20 & 2.09 & 0.08 \\
\hline $\mathrm{TiO}_{2}$ & 11.19 & 7.88 & 7.87 & 7.72 & 7.70 & 7.91 & 7.98 & 8.05 & 8.80 & 7.75 & 7.85 & 7.97 & 11.09 & 8.66 & 8.00 & 7.93 & 7.93 & 7.74 & 7.99 \\
\hline $\mathrm{Al}_{2} \mathrm{O}_{3}$ & 2.40 & 3.30 & 3.31 & 3.33 & 3.20 & 3.19 & 3.27 & 3.28 & 2.44 & 3.13 & 3.33 & 3.35 & 2.45 & 2.27 & 3.32 & 3.36 & 3.31 & 2.87 & 3.19 \\
\hline $\mathrm{Cr}_{2} \mathrm{O}_{3}$ & 0.12 & 0.09 & 0.13 & 0.17 & 0.12 & 0.11 & 0.11 & 0.12 & 0.12 & 0.12 & 0.11 & 0.12 & 0.08 & 0.14 & 0.10 & 0.08 & 0.12 & 0.11 & 0.11 \\
\hline $\mathrm{FeO}$ & 44.56 & 49.72 & 49.79 & 49.74 & 49.07 & 49.65 & 49.92 & 49.92 & 50.10 & 48.57 & 49.59 & 49.82 & 44.95 & 50.21 & 48.63 & 49.98 & 49.97 & 45.83 & 50.20 \\
\hline $\mathrm{Fe}_{2} \mathrm{O}_{3}$ & 39.93 & 36.21 & 36.09 & 36.40 & 35.84 & 36.33 & 36.46 & 36.61 & 36.98 & 36.37 & 36.24 & 36.36 & 39.87 & 36.63 & 36.53 & 36.25 & 36.33 & 38.47 & 36.21 \\
\hline MnO & 1.40 & 2.41 & 2.46 & 2.52 & 2.48 & 2.46 & 2.46 & 2.55 & 2.19 & 2.05 & 2.49 & 2.50 & 1.53 & 2.12 & 2.45 & 2.51 & 2.38 & 2.17 & 2.45 \\
\hline MgO & 0.65 & 0.47 & 0.50 & 0.44 & 0.45 & 0.43 & 0.46 & 0.44 & 0.64 & 0.46 & 0.49 & 0.47 & 0.65 & 0.68 & 0.47 & 0.44 & 0.49 & 0.53 & 0.43 \\
\hline $\mathrm{CaO}$ & 0.00 & 0.00 & 0.00 & 0.00 & 0.00 & 0.00 & 0.00 & 0.00 & 0.00 & 0.00 & 0.00 & 0.00 & 0.00 & 0.00 & 0.03 & 0.00 & 0.00 & 0.00 & 0.00 \\
\hline Total & 100.50 & 100.32 & 100.35 & 100.75 & 99.25 & 100.38 & 100.93 & 101.25 & 101.35 & 98.95 & 100.42 & 100.80 & 100.89 & 100.76 & 100.05 & 100.71 & 100.73 & 99.80 & 100.65 \\
\hline \multicolumn{20}{|l|}{ Cations } \\
\hline $\mathbf{S i}$ & 0.01 & 0.01 & 0.01 & 0.02 & 0.01 & 0.01 & 0.01 & 0.01 & 0.00 & 0.02 & 0.01 & 0.01 & 0.01 & 0.00 & 0.02 & 0.01 & 0.01 & 0.08 & 0.00 \\
\hline $\mathrm{Ti}$ & 0.313 & 0.221 & 0.220 & 0.215 & 0.218 & 0.222 & 0.222 & 0.223 & 0.245 & 0.220 & 0.220 & 0.222 & 0.309 & 0.243 & 0.224 & 0.221 & 0.221 & 0.217 & 0.223 \\
\hline Al & 0.105 & 0.145 & 0.145 & 0.145 & 0.142 & 0.140 & 0.143 & 0.143 & 0.106 & 0.139 & 0.146 & 0.146 & 0.107 & 0.099 & 0.146 & 0.147 & 0.145 & 0.126 & 0.140 \\
\hline $\mathrm{Cr}$ & 0.004 & 0.003 & 0.004 & 0.005 & 0.004 & 0.003 & 0.003 & 0.004 & 0.004 & 0.003 & 0.003 & 0.004 & 0.002 & 0.004 & 0.003 & 0.002 & 0.004 & 0.003 & 0.003 \\
\hline $\mathrm{Fe}^{2+}$ & 1.242 & 1.128 & 1.123 & 1.128 & 1.128 & 1.132 & 1.129 & 1.130 & 1.144 & 1.148 & 1.127 & 1.127 & 1.235 & 1.140 & 1.139 & 1.125 & 1.127 & 1.196 & 1.126 \\
\hline $\mathrm{Fe}^{3+}$ & 1.247 & 1.393 & 1.394 & 1.387 & 1.390 & 1.391 & 1.391 & 1.386 & 1.395 & 1.379 & 1.387 & 1.389 & 1.253 & 1.407 & 1.364 & 1.395 & 1.394 & 1.283 & 1.404 \\
\hline$M n$ & 0.044 & 0.076 & 0.077 & 0.079 & 0.079 & 0.077 & 0.077 & 0.080 & 0.069 & 0.065 & 0.078 & 0.078 & 0.048 & 0.067 & 0.077 & 0.079 & 0.075 & 0.068 & 0.077 \\
\hline Mg & 0.036 & 0.026 & 0.028 & 0.024 & 0.025 & 0.024 & 0.026 & 0.024 & 0.035 & 0.026 & 0.027 & 0.026 & 0.036 & 0.038 & 0.026 & 0.024 & 0.027 & 0.029 & 0.024 \\
\hline $\mathrm{Ca}$ & 0.000 & 0.000 & 0.000 & 0.000 & 0.000 & 0.000 & 0.000 & 0.000 & 0.000 & 0.000 & 0.000 & 0.000 & 0.000 & 0.000 & 0.001 & 0.000 & 0.000 & 0.000 & 0.000 \\
\hline Total & 3.000 & 3.000 & 3.000 & 3.000 & 3.000 & 3.000 & 3.000 & 3.000 & 3.000 & 3.000 & 3.000 & 3.000 & 3.000 & 3.000 & 3.000 & 3.000 & 3.000 & 3.000 & 3.000 \\
\hline \multicolumn{20}{|l|}{ Atomic \% } \\
\hline Usp & 33.4 & 24.1 & 24.0 & 23.7 & 23.9 & 24.2 & 24.2 & 24.4 & 26.0 & 24.2 & 24.0 & 24.2 & 33.0 & 25.6 & 24.7 & 24.1 & 24.1 & 25.2 & 24.1 \\
\hline Mnt & 66.6 & 75.9 & 76.0 & 76.3 & 76.1 & 75.8 & 75.8 & 75.6 & 74.0 & 75.8 & 76.0 & 75.8 & 67.0 & 74.4 & 75.3 & 75.9 & 75.9 & 74.8 & 75.9 \\
\hline
\end{tabular}

Oxide formulae recalculated using the methods of Lepage (2003). Molecular proportions calculated using the formulae of Sauerzapf et al. (2008). Location abbreviations as in Table B.1. 


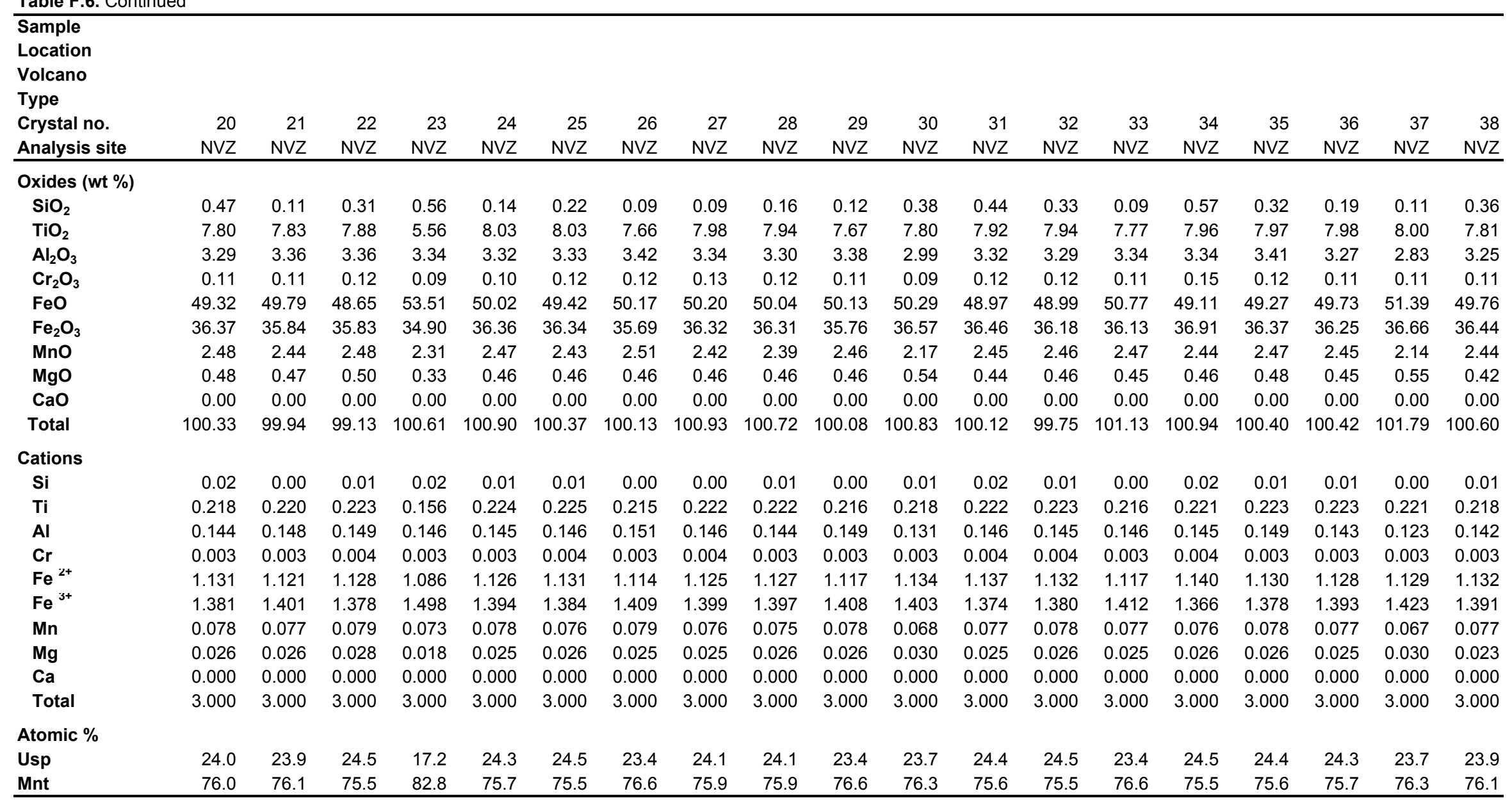


Table F.6. Continued

\begin{tabular}{|c|c|c|c|c|c|c|c|c|c|c|c|c|c|c|c|c|c|c|}
\hline Sample & RI06_PC12 & & & & & & & & RI06_PC12 & & RI06_PC12 & & & & & & & \\
\hline Location & Matatirohia & & & & & & & & Matatirohia & & Matatirohia & & & & & & & \\
\hline Volcano & Raoul & & & & & & & & Raoul & & Raoul & & & & & & & \\
\hline Type & Single crystal & & & & & & & & Clusters-C3 & $\mathrm{C} 8$ & Mafic Bleb-1 & & & MB02 & & MB03 & & MB05 \\
\hline Crystal no. & 9 & 10 & 15 & 22 & 26 & 27 & 32 & 33 & a & a & a & $b$ & c & a & $\mathrm{b}$ & a & b & a \\
\hline Analysis site & NVZ & NVZ & NVZ & NVZ & NVZ & NVZ & NVZ & NVZ & NVZ & NVZ & NVZ & NVZ & NVZ & NVZ & NVZ & NVZ & NVZ & NVZ \\
\hline \multicolumn{19}{|l|}{ Oxides (wt \%) } \\
\hline $\mathrm{SiO}_{2}$ & 0.08 & 0.06 & 0.07 & 0.09 & 0.09 & 0.09 & 0.05 & 0.07 & 0.10 & 0.09 & 0.08 & 0.11 & 0.08 & 0.07 & 0.09 & 0.08 & 0.09 & 0.08 \\
\hline $\mathrm{TiO}_{2}$ & 11.47 & 11.29 & 11.61 & 8.83 & 11.39 & 10.27 & 10.67 & 10.44 & 11.89 & 10.43 & 8.78 & 8.16 & 8.61 & 8.18 & 8.70 & 12.63 & 12.45 & 4.34 \\
\hline $\mathrm{Al}_{2} \mathrm{O}_{3}$ & 2.38 & 2.38 & 2.41 & 2.93 & 2.43 & 2.57 & 2.47 & 2.44 & 2.42 & 2.69 & 2.96 & 3.61 & 3.00 & 3.17 & 2.93 & 2.42 & 2.40 & 6.83 \\
\hline $\mathrm{Cr}_{2} \mathrm{O}_{3}$ & 0.11 & 0.15 & 0.07 & 0.10 & 0.08 & 0.11 & 0.10 & 0.11 & 0.10 & 0.11 & 0.14 & 0.12 & 0.13 & 0.13 & 0.10 & 0.10 & 0.11 & 0.30 \\
\hline $\mathrm{FeO}$ & 45.79 & 46.18 & 45.55 & 50.13 & 46.00 & 47.89 & 47.20 & 47.02 & 44.97 & 47.52 & 50.13 & 50.36 & 50.57 & 51.63 & 49.71 & 42.81 & 43.58 & 55.00 \\
\hline $\mathrm{Fe}_{2} \mathrm{O}_{3}$ & 39.78 & 39.86 & 39.98 & 37.42 & 39.76 & 38.60 & 39.00 & 38.51 & 40.30 & 38.77 & 36.44 & 35.43 & 35.53 & 35.17 & 35.99 & 40.09 & 40.23 & 30.43 \\
\hline MnO & 0.66 & 0.65 & 0.67 & 0.50 & 0.68 & 0.61 & 0.63 & 0.59 & 0.69 & 0.60 & 0.51 & 0.42 & 0.46 & 0.46 & 0.58 & 0.58 & 0.62 & 0.26 \\
\hline MgO & 1.52 & 1.38 & 1.46 & 1.59 & 1.51 & 1.61 & 1.51 & 1.55 & 1.46 & 1.64 & 2.10 & 2.41 & 2.59 & 2.69 & 2.12 & 1.83 & 1.74 & 3.93 \\
\hline $\mathrm{CaO}$ & 0.00 & 0.00 & 0.00 & 0.00 & 0.00 & 0.00 & 0.00 & 0.00 & 0.00 & 0.00 & 0.00 & 0.03 & 0.00 & 0.00 & 0.00 & 0.00 & 0.00 & 0.00 \\
\hline Total & 101.80 & 101.96 & 101.80 & 101.59 & 101.93 & 101.74 & 101.63 & 100.73 & 101.92 & 101.85 & 101.14 & 100.65 & 100.95 & 101.50 & 100.23 & 100.56 & 101.22 & 101.18 \\
\hline \multicolumn{19}{|l|}{ Cations } \\
\hline $\mathbf{S i}$ & 0.00 & 0.00 & 0.00 & 0.00 & 0.00 & 0.00 & 0.00 & 0.00 & 0.00 & 0.00 & 0.00 & 0.00 & 0.00 & 0.00 & 0.00 & 0.00 & 0.00 & 0.00 \\
\hline $\mathrm{Ti}$ & 0.315 & 0.310 & 0.319 & 0.243 & 0.312 & 0.282 & 0.294 & 0.290 & 0.326 & 0.286 & 0.242 & 0.224 & 0.236 & 0.223 & 0.241 & 0.350 & 0.343 & 0.116 \\
\hline Al & 0.103 & 0.102 & 0.104 & 0.126 & 0.104 & 0.110 & 0.106 & 0.106 & 0.104 & 0.116 & 0.127 & 0.156 & 0.129 & 0.136 & 0.127 & 0.105 & 0.104 & 0.286 \\
\hline $\mathrm{Cr}$ & 0.003 & 0.004 & 0.002 & 0.003 & 0.002 & 0.003 & 0.003 & 0.003 & 0.003 & 0.003 & 0.004 & 0.004 & 0.004 & 0.004 & 0.003 & 0.003 & 0.003 & 0.008 \\
\hline $\mathrm{Fe}^{2+}$ & 1.215 & 1.217 & 1.221 & 1.144 & 1.213 & 1.179 & 1.194 & 1.189 & 1.229 & 1.182 & 1.114 & 1.083 & 1.084 & 1.067 & 1.110 & 1.234 & 1.232 & 0.903 \\
\hline $\mathrm{Fe}^{3+}$ & 1.258 & 1.268 & 1.252 & 1.379 & 1.262 & 1.316 & 1.300 & 1.306 & 1.234 & 1.303 & 1.380 & 1.384 & 1.389 & 1.409 & 1.380 & 1.186 & 1.201 & 1.468 \\
\hline$M n$ & 0.020 & 0.020 & 0.021 & 0.015 & 0.021 & 0.019 & 0.020 & 0.018 & 0.021 & 0.018 & 0.016 & 0.013 & 0.014 & 0.014 & 0.018 & 0.018 & 0.019 & 0.008 \\
\hline Mg & 0.083 & 0.075 & 0.079 & 0.087 & 0.082 & 0.088 & 0.083 & 0.085 & 0.080 & 0.089 & 0.114 & 0.131 & 0.141 & 0.145 & 0.116 & 0.100 & 0.095 & 0.208 \\
\hline $\mathrm{Ca}$ & 0.000 & 0.000 & 0.000 & 0.000 & 0.000 & 0.000 & 0.000 & 0.000 & 0.000 & 0.000 & 0.000 & 0.001 & 0.000 & 0.000 & 0.000 & 0.000 & 0.000 & 0.000 \\
\hline Total & 3.000 & 3.000 & 3.000 & 3.000 & 3.000 & 3.000 & 3.000 & 3.000 & 3.000 & 3.000 & 3.000 & 3.000 & 3.000 & 3.000 & 3.000 & 3.000 & 3.000 & 3.000 \\
\hline \multicolumn{19}{|l|}{ Atomic \% } \\
\hline Usp & 33.4 & 32.8 & 33.8 & 26.0 & 33.1 & 30.0 & 31.1 & 30.7 & 34.6 & 30.5 & 25.9 & 24.5 & 25.4 & 24.1 & 25.9 & 37.1 & 36.4 & 13.6 \\
\hline Mnt & 66.6 & 67.2 & 66.2 & 74.0 & 66.9 & 70.0 & 68.9 & 69.3 & 65.4 & 69.5 & 74.1 & 75.5 & 74.6 & 75.9 & 74.1 & 62.9 & 63.6 & 86.4 \\
\hline
\end{tabular}


Table F.6. Continued

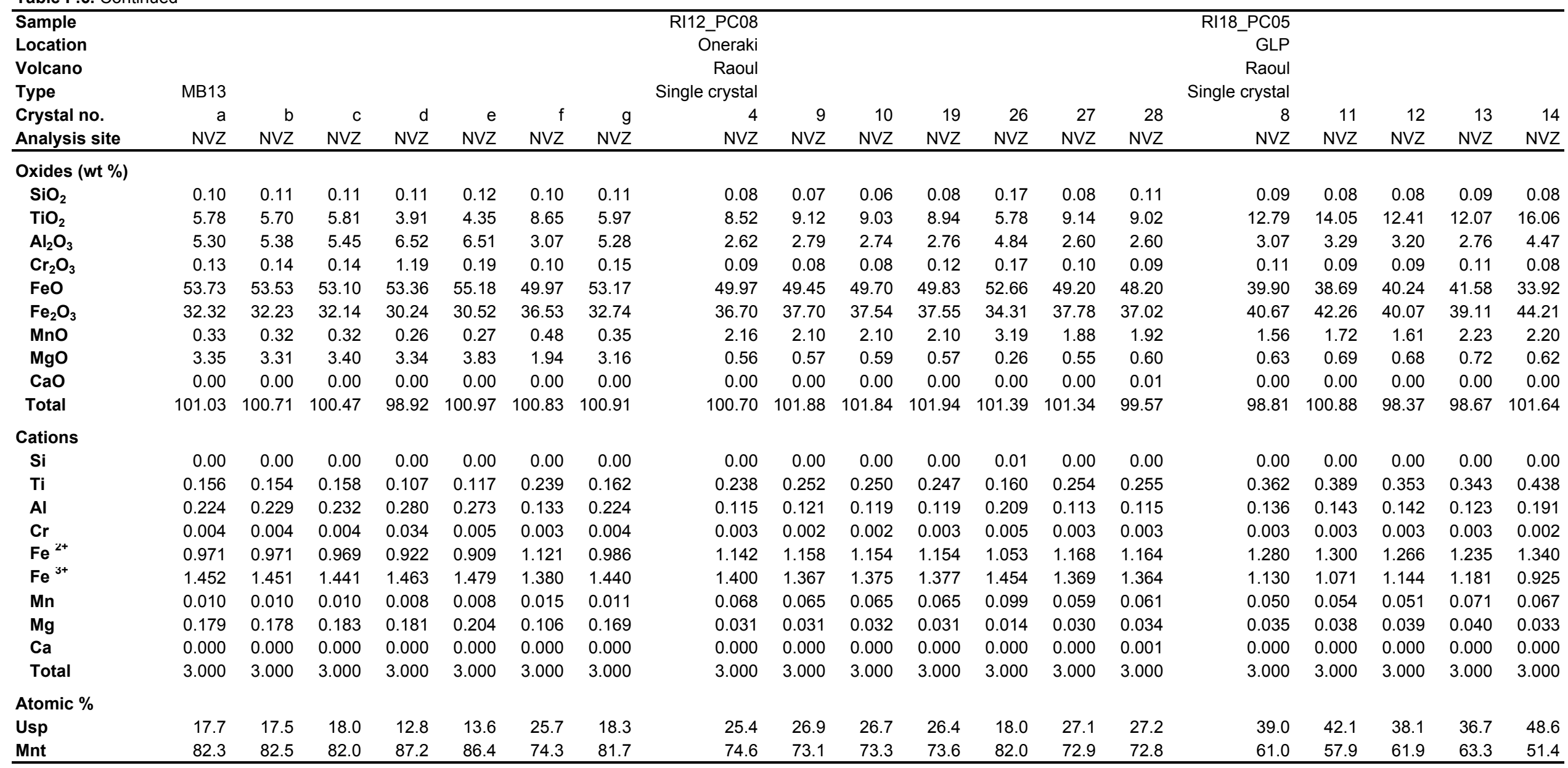


Table F.6. Continued

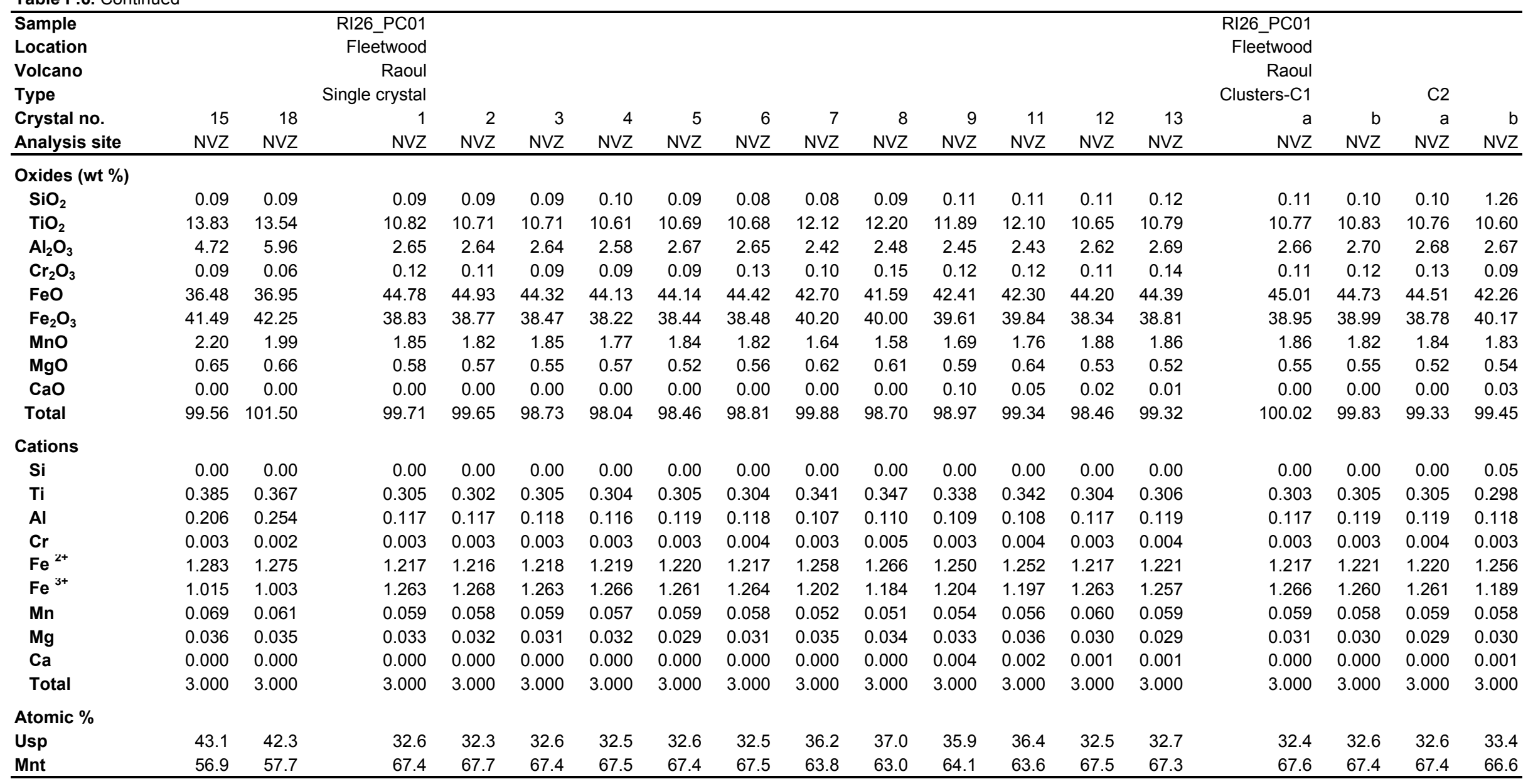


Table F.6. Continued

\begin{tabular}{|c|c|c|c|c|c|c|c|c|c|c|c|c|c|c|c|c|c|c|c|}
\hline Sample & RI26_PC01 & & & & & & & & MI07_PC03 & & & & & & & & & & \\
\hline Location & Fleetwood & & & & & & & & SBT & & & & & & & & & & \\
\hline Volcano & Raoul & & & & & & & & Macauley & & & & & & & & & & \\
\hline Type & Mafic Bleb-1 & & & MB02 & MB12 & & & MB14 & Single crystal & & & & & & & & & & \\
\hline Crystal no. & a & $\mathrm{b}$ & c & $\mathrm{a}$ & $a$ & $b$ & c & a & 1 & 2 & 3 & 4 & 5 & 6 & 7 & 8 & 9 & 10 & 11 \\
\hline Analysis site & NVZ & NVZ & NVZ & NVZ & NVZ & NVZ & NVZ & $\mathrm{NVZ}$ & NVZ & NVZ & $\mathrm{NVZ}$ & NVZ & NVZ & NVZ & NVZ & NVZ & NVZ & NVZ & NVZ \\
\hline \multicolumn{20}{|l|}{ Oxides (wt \%) } \\
\hline $\mathrm{SiO}_{2}$ & 0.10 & 0.21 & 0.67 & 0.11 & 0.08 & 0.11 & 0.09 & 0.07 & 0.09 & 0.09 & 0.08 & 0.09 & 0.08 & 0.10 & 0.07 & 0.07 & 0.09 & 0.07 & 0.09 \\
\hline $\mathrm{TiO}_{2}$ & 8.66 & 5.06 & 6.49 & 10.12 & 7.51 & 7.55 & 7.51 & 6.67 & 16.13 & 16.12 & 17.02 & 16.88 & 16.96 & 16.24 & 16.86 & 16.92 & 16.78 & 16.17 & 16.33 \\
\hline $\mathrm{Al}_{2} \mathrm{O}_{3}$ & 2.67 & 6.66 & 3.72 & 2.77 & 3.50 & 3.44 & 3.45 & 3.93 & 2.17 & 2.13 & 2.07 & 2.09 & 2.10 & 2.20 & 2.06 & 2.03 & 2.08 & 2.22 & 2.26 \\
\hline $\mathrm{Cr}_{2} \mathrm{O}_{3}$ & 0.12 & 4.02 & 0.18 & 0.15 & 0.21 & 0.20 & 0.20 & 0.15 & 0.00 & 0.01 & 0.01 & 0.01 & 0.02 & 0.01 & 0.02 & 0.01 & 0.02 & 0.01 & 0.00 \\
\hline $\mathrm{FeO}$ & 49.38 & 47.03 & 51.08 & 45.95 & 49.46 & 49.30 & 49.39 & 51.16 & 43.13 & 43.21 & 44.53 & 44.46 & 44.25 & 43.46 & 44.57 & 44.36 & 44.00 & 43.31 & 43.47 \\
\hline $\mathrm{Fe}_{2} \mathrm{O}_{3}$ & 36.66 & 32.59 & 35.15 & 38.35 & 35.47 & 35.44 & 35.45 & 34.56 & 36.11 & 36.14 & 35.28 & 35.96 & 35.28 & 36.30 & 35.92 & 35.89 & 35.76 & 36.53 & 36.22 \\
\hline MnO & 2.68 & 4.18 & 3.13 & 1.85 & 2.49 & 2.51 & 2.46 & 2.81 & 0.74 & 0.73 & 0.69 & 0.74 & 0.71 & 0.71 & 0.50 & 0.75 & 0.78 & 0.72 & 0.74 \\
\hline MgO & 0.33 & 0.30 & 0.36 & 0.54 & 0.30 & 0.32 & 0.30 & 0.35 & 1.75 & 1.70 & 1.64 & 1.70 & 1.73 & 1.78 & 1.72 & 1.72 & 1.78 & 1.81 & 1.82 \\
\hline $\mathrm{CaO}$ & 0.01 & 0.00 & 0.00 & 0.00 & 0.00 & 0.00 & 0.00 & 0.00 & 0.00 & 0.00 & 0.00 & 0.00 & 0.00 & 0.00 & 0.00 & 0.00 & 0.00 & 0.00 & 0.00 \\
\hline Total & 100.60 & 100.03 & 100.78 & 99.84 & 99.01 & 98.88 & 98.84 & 99.70 & 100.11 & 100.13 & 101.32 & 101.92 & 101.13 & 100.79 & 101.72 & 101.75 & 101.29 & 100.84 & 100.92 \\
\hline \multicolumn{20}{|l|}{ Cations } \\
\hline $\mathrm{Si}$ & 0.00 & 0.01 & 0.02 & 0.00 & 0.00 & 0.00 & 0.00 & 0.00 & 0.00 & 0.00 & 0.00 & 0.00 & 0.00 & 0.00 & 0.00 & 0.00 & 0.00 & 0.00 & 0.00 \\
\hline $\mathrm{Ti}$ & 0.243 & 0.140 & 0.181 & 0.285 & 0.213 & 0.215 & 0.214 & 0.188 & 0.448 & 0.448 & 0.468 & 0.461 & 0.466 & 0.448 & 0.461 & 0.463 & 0.461 & 0.446 & 0.449 \\
\hline Al & 0.117 & 0.288 & 0.162 & 0.122 & 0.156 & 0.153 & 0.154 & 0.174 & 0.094 & 0.093 & 0.089 & 0.089 & 0.090 & 0.095 & 0.088 & 0.087 & 0.089 & 0.096 & 0.098 \\
\hline $\mathrm{Cr}$ & 0.004 & 0.117 & 0.005 & 0.004 & 0.006 & 0.006 & 0.006 & 0.005 & 0.000 & 0.000 & 0.000 & 0.000 & 0.001 & 0.000 & 0.001 & 0.000 & 0.000 & 0.000 & 0.000 \\
\hline $\mathrm{Fe}^{2+}$ & 1.143 & 1.001 & 1.087 & 1.201 & 1.120 & 1.120 & 1.122 & 1.082 & 1.332 & 1.335 & 1.360 & 1.350 & 1.353 & 1.333 & 1.356 & 1.349 & 1.343 & 1.327 & 1.330 \\
\hline $\mathrm{Fe}^{3+}$ & 1.386 & 1.300 & 1.422 & 1.295 & 1.405 & 1.403 & 1.406 & 1.441 & 1.003 & 1.005 & 0.969 & 0.982 & 0.970 & 1.001 & 0.983 & 0.982 & 0.982 & 1.007 & 0.997 \\
\hline Mn & 0.085 & 0.130 & 0.098 & 0.059 & 0.080 & 0.080 & 0.079 & 0.089 & 0.023 & 0.023 & 0.021 & 0.023 & 0.022 & 0.022 & 0.015 & 0.023 & 0.024 & 0.022 & 0.023 \\
\hline Mg & 0.018 & 0.016 & 0.020 & 0.030 & 0.017 & 0.018 & 0.017 & 0.020 & 0.096 & 0.094 & 0.089 & 0.092 & 0.094 & 0.097 & 0.093 & 0.093 & 0.097 & 0.099 & 0.099 \\
\hline $\mathrm{Ca}$ & 0.000 & 0.000 & 0.000 & 0.000 & 0.000 & 0.000 & 0.000 & 0.000 & 0.000 & 0.000 & 0.000 & 0.000 & 0.000 & 0.000 & 0.000 & 0.000 & 0.000 & 0.000 & 0.000 \\
\hline Total & 3.000 & 3.000 & 3.000 & 3.000 & 3.000 & 3.000 & 3.000 & 3.000 & 3.000 & 3.000 & 3.000 & 3.000 & 3.000 & 3.000 & 3.000 & 3.000 & 3.000 & 3.000 & 3.000 \\
\hline \multicolumn{20}{|l|}{ Atomic \% } \\
\hline Usp & 26.0 & 17.7 & 20.3 & 30.6 & 23.3 & 23.5 & 23.3 & 20.7 & 47.2 & 47.1 & 49.1 & 48.4 & 49.0 & 47.2 & 48.4 & 48.5 & 48.4 & 46.9 & 47.4 \\
\hline Mnt & 74.0 & 82.3 & 79.7 & 69.4 & 76.7 & 76.5 & 76.7 & 79.3 & 52.8 & 52.9 & 50.9 & 51.6 & 51.0 & 52.8 & 51.6 & 51.5 & 51.6 & 53.1 & 52.6 \\
\hline
\end{tabular}


Table F.6. Continued

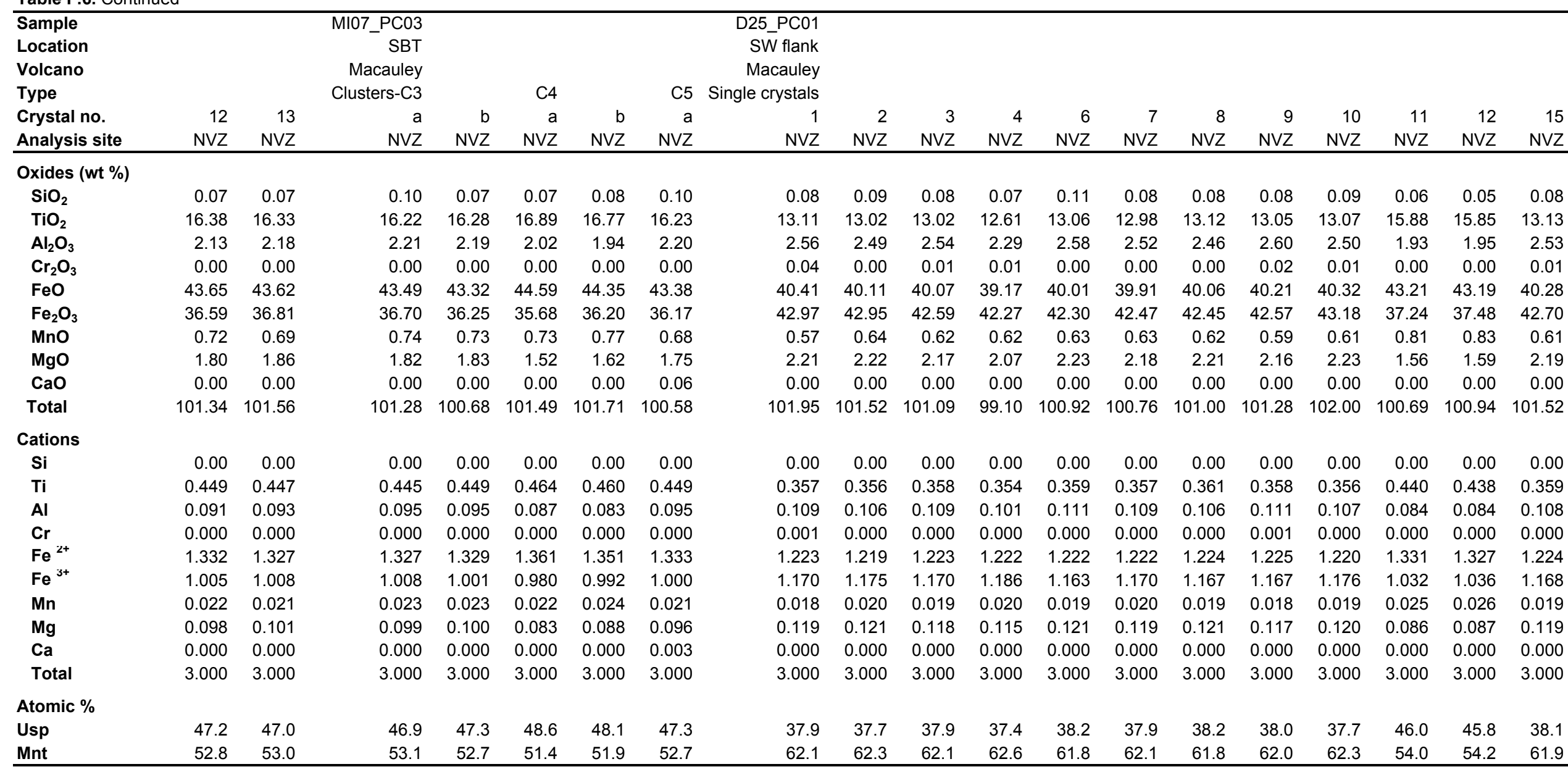


Table F.6. Continued

\begin{tabular}{|c|c|c|c|c|c|c|c|c|c|c|c|c|c|c|c|c|c|c|}
\hline Sample & D25_PC01 & & & & & D29_PC02 & & & & & & & & & & & & \\
\hline Location & SW flank & & & & & $\mathrm{N}$ rim & & & & & & & & & & & & \\
\hline Volcano & Macauley & & & & & Macauley & & & & & & & & & & & & \\
\hline Type & Clusters-C2 & & & $\mathrm{C} 4$ & C5 & Single crystal & & & & & & & & & & & & \\
\hline Crystal no. & a & $\mathrm{b}$ & c & a & a & 1 & 2 & 3 & 5 & 6 & 7 & 9 & 10 & 11 & 12 & 13 & 14 & 15 \\
\hline Analysis site & NVZ & NVZ & NVZ & NVZ & NVZ & NVZ & NVZ & NVZ & NVZ & NVZ & NVZ & NVZ & NVZ & $\mathrm{NVZ}$ & $\mathrm{NVZ}$ & $\mathrm{NVZ}$ & NVZ & $\mathrm{NVZ}$ \\
\hline \multicolumn{19}{|l|}{ Oxides (wt \%) } \\
\hline $\mathrm{SiO}_{2}$ & 0.11 & 0.09 & 0.09 & 0.10 & 0.08 & 0.09 & 0.10 & 0.10 & 0.09 & 0.08 & 0.09 & 0.10 & 0.08 & 0.10 & 0.09 & 0.09 & 0.07 & 0.08 \\
\hline $\mathrm{TiO}_{2}$ & 13.21 & 12.95 & 13.14 & 8.21 & 12.98 & 16.29 & 16.22 & 16.38 & 16.37 & 16.33 & 16.38 & 16.26 & 16.22 & 16.28 & 16.29 & 15.94 & 16.24 & 16.40 \\
\hline $\mathrm{Al}_{2} \mathrm{O}_{3}$ & 2.57 & 2.51 & 2.50 & 2.59 & 2.57 & 1.89 & 1.92 & 1.98 & 1.93 & 1.93 & 1.93 & 1.97 & 1.93 & 1.94 & 1.92 & 1.92 & 1.92 & 1.92 \\
\hline $\mathrm{Cr}_{2} \mathrm{O}_{3}$ & 0.02 & 0.01 & 0.03 & 0.02 & 0.00 & 0.01 & 0.00 & 0.00 & 0.02 & 0.00 & 0.02 & 0.01 & 0.00 & 0.00 & 0.01 & 0.01 & 0.01 & 0.01 \\
\hline $\mathrm{FeO}$ & 40.42 & 39.92 & 40.16 & 35.30 & 40.17 & 44.46 & 44.37 & 44.71 & 44.63 & 44.54 & 44.66 & 44.44 & 44.35 & 44.35 & 44.61 & 44.31 & 44.25 & 44.70 \\
\hline $\mathrm{Fe}_{2} \mathrm{O}_{3}$ & 42.59 & 42.64 & 42.29 & 51.69 & 43.26 & 36.60 & 36.75 & 36.55 & 36.53 & 36.69 & 36.44 & 36.49 & 36.51 & 36.15 & 36.56 & 37.34 & 36.27 & 36.64 \\
\hline $\mathrm{MnO}$ & 0.61 & 0.66 & 0.63 & 0.54 & 0.62 & 0.69 & 0.68 & 0.71 & 0.69 & 0.66 & 0.62 & 0.68 & 0.68 & 0.65 & 0.67 & 0.64 & 0.67 & 0.66 \\
\hline MgO & 2.23 & 2.18 & 2.17 & 2.38 & 2.25 & 1.22 & 1.26 & 1.19 & 1.21 & 1.25 & 1.22 & 1.22 & 1.19 & 1.21 & 1.15 & 1.17 & 1.20 & 1.21 \\
\hline $\mathrm{CaO}$ & 0.00 & 0.00 & 0.00 & 0.00 & 0.00 & 0.00 & 0.00 & 0.00 & 0.00 & 0.00 & 0.00 & 0.00 & 0.00 & 0.00 & 0.00 & 0.00 & 0.00 & 0.00 \\
\hline Total & 101.77 & 100.95 & 101.02 & 100.82 & 101.92 & 101.26 & 101.30 & 101.64 & 101.48 & 101.47 & 101.35 & 101.17 & 100.95 & 100.68 & 101.30 & 101.40 & 100.63 & 101.62 \\
\hline \multicolumn{19}{|l|}{ Cations } \\
\hline Si & 0.00 & 0.00 & 0.00 & 0.00 & 0.00 & 0.00 & 0.00 & 0.00 & 0.00 & 0.00 & 0.00 & 0.00 & 0.00 & 0.00 & 0.00 & 0.00 & 0.00 & 0.00 \\
\hline $\mathrm{Ti}$ & 0.360 & 0.356 & 0.361 & 0.227 & 0.353 & 0.450 & 0.448 & 0.451 & 0.451 & 0.450 & 0.452 & 0.449 & 0.449 & 0.452 & 0.450 & 0.440 & 0.451 & 0.451 \\
\hline Al & 0.110 & 0.108 & 0.108 & 0.112 & 0.109 & 0.082 & 0.083 & 0.085 & 0.083 & 0.083 & 0.083 & 0.085 & 0.084 & 0.084 & 0.083 & 0.083 & 0.084 & 0.083 \\
\hline $\mathrm{Cr}$ & 0.001 & 0.000 & 0.001 & 0.001 & 0.000 & 0.000 & 0.000 & 0.000 & 0.001 & 0.000 & 0.001 & 0.000 & 0.000 & 0.000 & 0.000 & 0.000 & 0.000 & 0.000 \\
\hline $\mathrm{Fe}^{2+}$ & 1.225 & 1.220 & 1.227 & 1.083 & 1.216 & 1.365 & 1.361 & 1.367 & 1.367 & 1.364 & 1.370 & 1.365 & 1.366 & 1.369 & 1.370 & 1.359 & 1.367 & 1.368 \\
\hline $\mathrm{Fe}^{3+}$ & 1.161 & 1.173 & 1.162 & 1.427 & 1.178 & 1.011 & 1.015 & 1.006 & 1.007 & 1.011 & 1.006 & 1.009 & 1.012 & 1.004 & 1.010 & 1.031 & 1.008 & 1.009 \\
\hline$M n$ & 0.019 & 0.020 & 0.019 & 0.017 & 0.019 & 0.022 & 0.021 & 0.022 & 0.021 & 0.021 & 0.019 & 0.021 & 0.021 & 0.020 & 0.021 & 0.020 & 0.021 & 0.020 \\
\hline $\mathrm{Mg}$ & 0.120 & 0.119 & 0.118 & 0.130 & 0.122 & 0.067 & 0.069 & 0.065 & 0.066 & 0.068 & 0.067 & 0.067 & 0.065 & 0.066 & 0.063 & 0.064 & 0.066 & 0.066 \\
\hline $\mathrm{Ca}$ & 0.000 & 0.000 & 0.000 & 0.000 & 0.000 & 0.000 & 0.000 & 0.000 & 0.000 & 0.000 & 0.000 & 0.000 & 0.000 & 0.000 & 0.000 & 0.000 & 0.000 & 0.000 \\
\hline Total & 3.000 & 3.000 & 3.000 & 3.000 & 3.000 & 3.000 & 3.000 & 3.000 & 3.000 & 3.000 & 3.000 & 3.000 & 3.000 & 3.000 & 3.000 & 3.000 & 3.000 & 3.000 \\
\hline \multicolumn{19}{|l|}{ Atomic $\%$} \\
\hline Usp & 38.3 & 37.8 & 38.3 & 24.1 & 37.5 & 47.1 & 46.9 & 47.3 & 47.3 & 47.1 & 47.3 & 47.1 & 47.0 & 47.4 & 47.1 & 46.0 & 47.2 & 47.2 \\
\hline Mnt & 61.7 & 62.2 & 61.7 & 75.9 & 62.5 & 52.9 & 53.1 & 52.7 & 52.7 & 52.9 & 52.7 & 52.9 & 53.0 & 52.6 & 52.9 & 54.0 & 52.8 & 52.8 \\
\hline
\end{tabular}


Table F.6. Continued

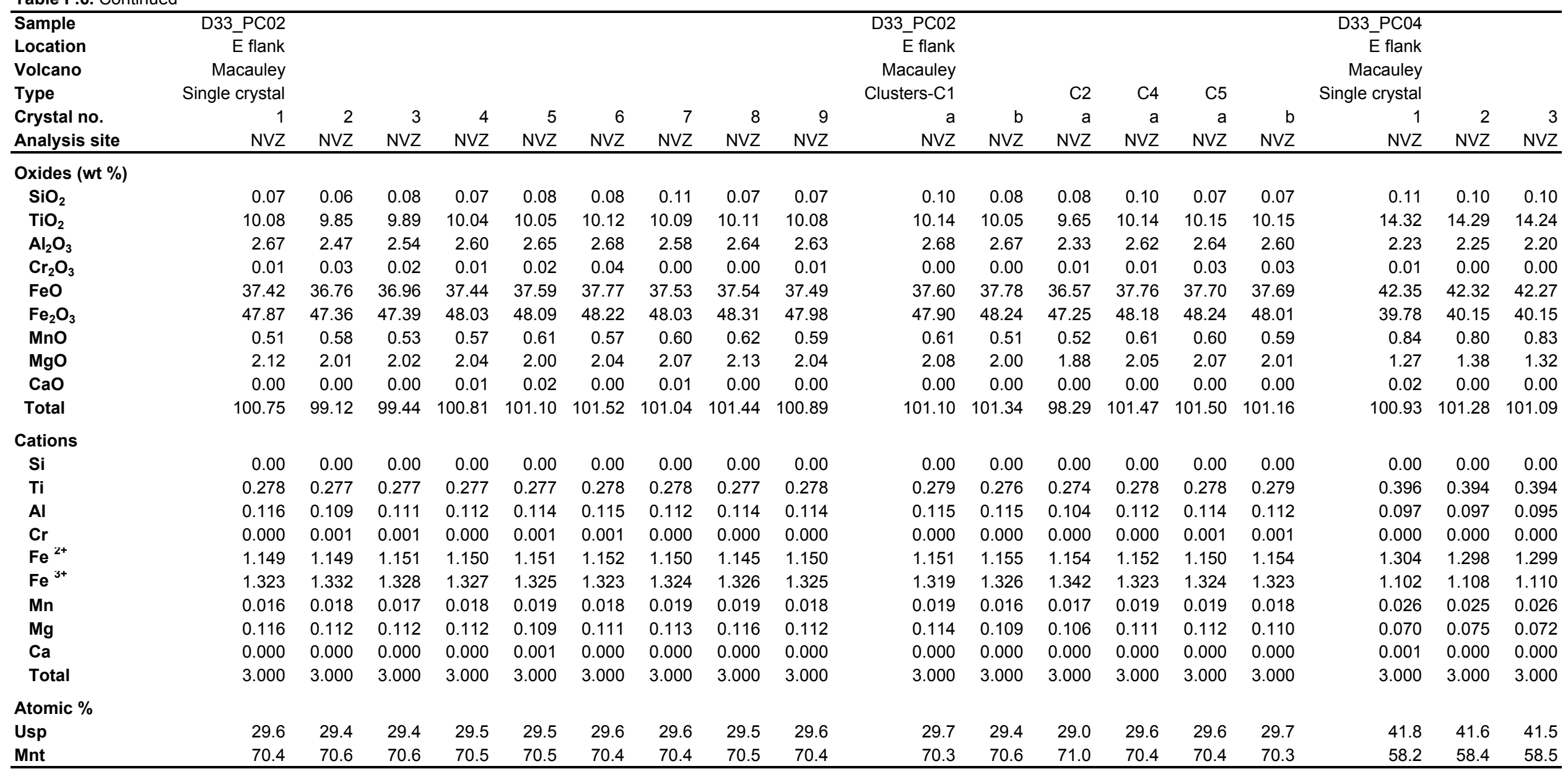


Table F.6. Continued

\begin{tabular}{|c|c|c|c|c|c|c|c|c|c|c|c|c|c|c|c|c|c|c|c|}
\hline Sample & & & & & & & & & D33_PC04 & & & & & D38_PC06 & & & & & \\
\hline Location & & & & & & & & & E flank & & & & & NW flank/rim & & & & & \\
\hline Volcano & & & & & & & & & Macauley & & & & & Healy & & & & & \\
\hline Type & & & & & & & & & Clusters-C1 & $\mathrm{C} 2$ & $\mathrm{C} 4$ & $\mathrm{C} 5$ & & Single crystal & & & & & \\
\hline Crystal no. & 4 & 5 & 6 & 7 & 8 & 9 & 10 & 11 & a & a & $\mathrm{a}$ & $\mathrm{a}$ & $\mathrm{b}$ & 1 & 2 & 3 & 4 & 5 & 6 \\
\hline Analysis site & NVZ & $\mathrm{NVZ}$ & NVZ & NVZ & NVZ & NVZ & NVZ & NVZ & NVZ & NVZ & $\mathrm{NVZ}$ & NVZ & NVZ & NVZ & $\mathrm{NVZ}$ & NVZ & $\mathrm{NVZ}$ & $\mathrm{NVZ}$ & $\mathrm{NVZ}$ \\
\hline \multicolumn{20}{|l|}{ Oxides (wt \%) } \\
\hline $\mathrm{SiO}_{2}$ & 0.10 & 0.10 & 0.09 & 0.08 & 0.10 & 0.09 & 0.09 & 0.09 & 0.08 & 0.07 & 0.08 & 0.09 & 0.08 & 0.10 & 0.11 & 0.05 & 0.05 & 0.10 & 0.07 \\
\hline $\mathrm{TiO}_{2}$ & 14.33 & 14.32 & 14.41 & 14.28 & 14.42 & 14.19 & 14.41 & 14.38 & 14.29 & 14.24 & 14.38 & 14.40 & 14.43 & 5.48 & 5.81 & 8.17 & 8.23 & 6.32 & 8.01 \\
\hline $\mathrm{Al}_{2} \mathrm{O}_{3}$ & 2.29 & 2.28 & 2.23 & 2.28 & 2.30 & 2.31 & 2.27 & 2.27 & 2.21 & 2.26 & 2.28 & 2.29 & 2.24 & 6.78 & 5.63 & 1.87 & 1.85 & 5.72 & 1.88 \\
\hline $\mathrm{Cr}_{2} \mathrm{O}_{3}$ & 0.01 & 0.02 & 0.03 & 0.03 & 0.00 & 0.00 & 0.02 & 0.01 & 0.00 & 0.00 & 0.02 & 0.00 & 0.00 & 0.45 & 0.26 & 0.02 & 0.00 & 0.17 & 0.03 \\
\hline $\mathrm{FeO}$ & 42.38 & 42.37 & 42.35 & 42.24 & 42.37 & 42.12 & 42.59 & 42.39 & 42.12 & 42.29 & 42.21 & 42.38 & 42.45 & 30.76 & 31.21 & 35.71 & 35.85 & 31.50 & 35.73 \\
\hline $\mathrm{Fe}_{2} \mathrm{O}_{3}$ & 40.25 & 40.19 & 39.87 & 39.88 & 39.62 & 40.16 & 40.31 & 39.90 & 39.95 & 40.27 & 39.58 & 39.79 & 40.09 & 52.20 & 52.78 & 51.89 & 51.96 & 51.65 & 52.38 \\
\hline $\mathrm{MnO}$ & 0.84 & 0.84 & 0.85 & 0.85 & 0.82 & 0.87 & 0.85 & 0.86 & 0.88 & 0.83 & 0.83 & 0.85 & 0.83 & 0.30 & 0.27 & 0.81 & 0.78 & 0.28 & 0.79 \\
\hline MgO & 1.41 & 1.39 & 1.37 & 1.33 & 1.37 & 1.37 & 1.36 & 1.34 & 1.36 & 1.32 & 1.36 & 1.34 & 1.39 & 4.21 & 3.96 & 1.67 & 1.66 & 4.02 & 1.62 \\
\hline $\mathrm{CaO}$ & 0.00 & 0.00 & 0.00 & 0.00 & 0.00 & 0.00 & 0.00 & 0.00 & 0.00 & 0.00 & 0.00 & 0.00 & 0.00 & 0.00 & 0.00 & 0.00 & 0.00 & 0.00 & 0.05 \\
\hline Total & 101.60 & 101.51 & 101.19 & 100.97 & 101.00 & 101.12 & 101.89 & 101.23 & 100.89 & 101.28 & 100.72 & 101.14 & 101.50 & 100.28 & 100.02 & 100.18 & 100.37 & 99.76 & 100.55 \\
\hline \multicolumn{20}{|l|}{ Cations } \\
\hline $\mathbf{S i}$ & 0.00 & 0.00 & 0.00 & 0.00 & 0.00 & 0.00 & 0.00 & 0.00 & 0.00 & 0.00 & 0.00 & 0.00 & 0.00 & 0.00 & 0.00 & 0.00 & 0.00 & 0.00 & 0.00 \\
\hline $\mathrm{Ti}$ & 0.394 & 0.394 & 0.398 & 0.395 & 0.399 & 0.392 & 0.395 & 0.397 & 0.396 & 0.393 & 0.399 & 0.398 & 0.397 & 0.147 & 0.157 & 0.229 & 0.230 & 0.171 & 0.224 \\
\hline Al & 0.099 & 0.098 & 0.096 & 0.099 & 0.100 & 0.100 & 0.098 & 0.098 & 0.096 & 0.098 & 0.099 & 0.099 & 0.096 & 0.285 & 0.239 & 0.082 & 0.081 & 0.243 & 0.082 \\
\hline $\mathrm{Cr}$ & 0.000 & 0.001 & 0.001 & 0.001 & 0.000 & 0.000 & 0.001 & 0.000 & 0.000 & 0.000 & 0.000 & 0.000 & 0.000 & 0.013 & 0.007 & 0.001 & 0.000 & 0.005 & 0.001 \\
\hline $\mathrm{Fe}^{2+}$ & 1.295 & 1.296 & 1.300 & 1.299 & 1.302 & 1.293 & 1.298 & 1.300 & 1.297 & 1.297 & 1.301 & 1.301 & 1.299 & 0.918 & 0.940 & 1.113 & 1.116 & 0.950 & 1.110 \\
\hline $\mathrm{Fe}^{3+}$ & 1.106 & 1.106 & 1.101 & 1.104 & 1.096 & 1.110 & 1.105 & 1.101 & 1.107 & 1.111 & 1.098 & 1.099 & 1.104 & 1.401 & 1.431 & 1.455 & 1.455 & 1.402 & 1.464 \\
\hline $\mathrm{Mn}$ & 0.026 & 0.026 & 0.027 & 0.026 & 0.026 & 0.027 & 0.026 & 0.027 & 0.027 & 0.026 & 0.026 & 0.027 & 0.026 & 0.009 & 0.008 & 0.025 & 0.025 & 0.009 & 0.025 \\
\hline $\mathbf{M g}$ & 0.077 & 0.076 & 0.075 & 0.073 & 0.075 & 0.075 & 0.074 & 0.073 & 0.075 & 0.072 & 0.075 & 0.073 & 0.076 & 0.224 & 0.213 & 0.093 & 0.092 & 0.216 & 0.090 \\
\hline $\mathrm{Ca}$ & 0.000 & 0.000 & 0.000 & 0.000 & 0.000 & 0.000 & 0.000 & 0.000 & 0.000 & 0.000 & 0.000 & 0.000 & 0.000 & 0.000 & 0.000 & 0.000 & 0.000 & 0.000 & 0.002 \\
\hline Total & 3.000 & 3.000 & 3.000 & 3.000 & 3.000 & 3.000 & 3.000 & 3.000 & 3.000 & 3.000 & 3.000 & 3.000 & 3.000 & 3.000 & 3.000 & 3.000 & 3.000 & 3.000 & 3.000 \\
\hline \multicolumn{20}{|l|}{ Atomic \% } \\
\hline Usp & 41.6 & 41.6 & 41.9 & 41.7 & 42.1 & 41.4 & 41.7 & 41.9 & 41.7 & 41.4 & 42.1 & 42.0 & 41.9 & 17.4 & 18.0 & 24.0 & 24.0 & 19.7 & 23.4 \\
\hline Mnt & 58.4 & 58.4 & 58.1 & 58.3 & 57.9 & 58.6 & 58.3 & 58.1 & 58.3 & 58.6 & 57.9 & 58.0 & 58.1 & 82.6 & 82.0 & 76.0 & 76.0 & 80.3 & 76.6 \\
\hline
\end{tabular}


Table F.6. Continued

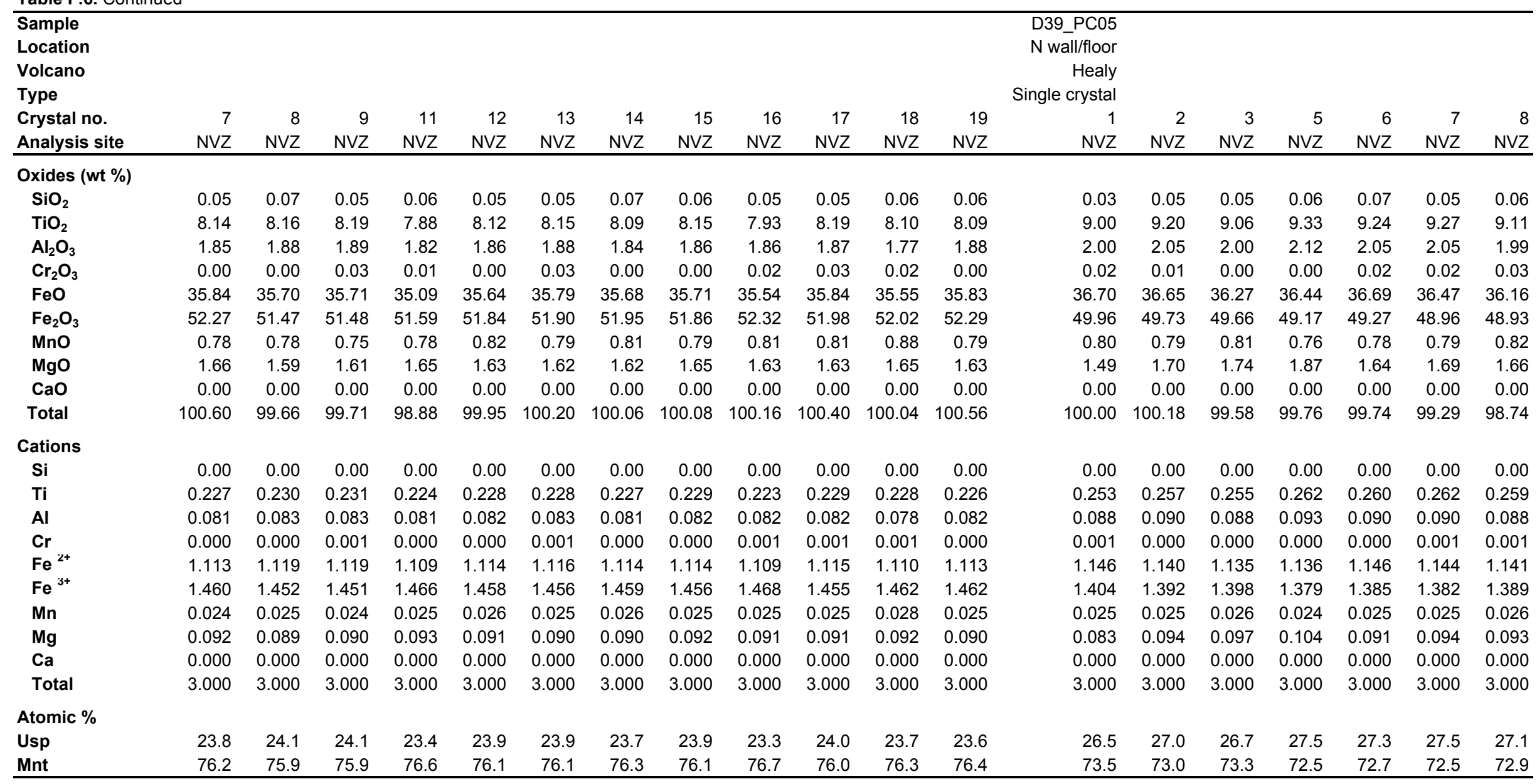


Table F.6. Continued

\begin{tabular}{|c|c|c|c|c|c|c|c|c|c|c|c|c|c|c|c|c|c|c|c|}
\hline \multirow{6}{*}{$\begin{array}{l}\text { Sample } \\
\text { Location } \\
\text { Volcano } \\
\text { Type } \\
\text { Crystal no. } \\
\text { Analysis site } \\
\end{array}$} & \multicolumn{19}{|c|}{ D44_PC01 } \\
\hline & \multicolumn{19}{|c|}{ SE rim/flank } \\
\hline & \multicolumn{19}{|c|}{ Healy } \\
\hline & & & & & & & & & & Single crystal & & & & & & & & & \\
\hline & 9 & 10 & 11 & 13 & 14 & 15 & 17 & 18 & 19 & 1 & 2 & 3 & 4 & 5 & 6 & 7 & 8 & 9 & 10 \\
\hline & NVZ & NVZ & NVZ & NVZ & NVZ & NVZ & NVZ & NVZ & NVZ & NVZ & NVZ & NVZ & NVZ & NVZ & NVZ & NVZ & NVZ & NVZ & NVZ \\
\hline \multicolumn{20}{|l|}{ Oxides (wt \%) } \\
\hline $\mathrm{SiO}_{2}$ & 0.06 & 0.06 & 0.06 & 0.05 & 0.07 & 0.05 & 0.07 & 0.04 & 0.08 & 0.05 & 0.06 & 0.05 & 0.03 & 0.05 & 0.05 & 0.08 & 0.06 & 0.05 & 0.06 \\
\hline $\mathrm{TiO}_{2}$ & 9.28 & 9.33 & 9.02 & 9.21 & 9.29 & 9.24 & 9.10 & 9.08 & 9.24 & 8.16 & 8.25 & 8.18 & 8.21 & 8.19 & 8.10 & 8.17 & 8.18 & 8.17 & 8.08 \\
\hline $\mathrm{Al}_{2} \mathrm{O}_{3}$ & 1.97 & 2.14 & 2.02 & 2.21 & 2.07 & 2.10 & 2.02 & 2.00 & 2.01 & 1.87 & 1.91 & 1.90 & 1.87 & 1.83 & 1.76 & 1.90 & 1.88 & 1.87 & 1.84 \\
\hline $\mathrm{Cr}_{2} \mathrm{O}_{3}$ & 0.00 & 0.01 & 0.03 & 0.00 & 0.00 & 0.00 & 0.00 & 0.02 & 0.00 & 0.03 & 0.01 & 0.04 & 0.00 & 0.02 & 0.01 & 0.02 & 0.00 & 0.00 & 0.01 \\
\hline $\mathrm{FeO}$ & 36.32 & 36.28 & 36.28 & 36.47 & 36.40 & 36.44 & 36.34 & 36.47 & 36.81 & 35.88 & 36.17 & 36.04 & 35.80 & 35.43 & 35.31 & 35.93 & 35.98 & 36.02 & 35.68 \\
\hline $\mathrm{Fe}_{2} \mathrm{O}_{3}$ & 48.54 & 48.62 & 49.31 & 49.64 & 48.98 & 48.94 & 49.56 & 49.66 & 49.77 & 52.28 & 52.41 & 52.40 & 51.85 & 51.12 & 51.20 & 51.84 & 52.51 & 52.38 & 52.05 \\
\hline MnO & 0.85 & 0.78 & 0.80 & 0.70 & 0.80 & 0.78 & 0.80 & 0.81 & 0.82 & 0.84 & 0.78 & 0.82 & 0.80 & 0.83 & 0.82 & 0.77 & 0.80 & 0.77 & 0.79 \\
\hline MgO & 1.62 & 1.81 & 1.62 & 1.90 & 1.78 & 1.69 & 1.74 & 1.63 & 1.68 & 1.63 & 1.66 & 1.63 & 1.62 & 1.63 & 1.59 & 1.61 & 1.70 & 1.62 & 1.63 \\
\hline $\mathrm{CaO}$ & 0.00 & 0.00 & 0.00 & 0.00 & 0.00 & 0.00 & 0.00 & 0.00 & 0.00 & 0.00 & 0.00 & 0.00 & 0.00 & 0.00 & 0.00 & 0.00 & 0.00 & 0.00 & 0.00 \\
\hline Total & 98.64 & 99.03 & 99.15 & 100.16 & 99.38 & 99.24 & 99.62 & 99.70 & 100.39 & 100.74 & 101.24 & 101.06 & 100.19 & 99.09 & 98.84 & 100.32 & 101.11 & 100.87 & 100.13 \\
\hline \multicolumn{20}{|l|}{ Cations } \\
\hline $\mathrm{Si}$ & 0.00 & 0.00 & 0.00 & 0.00 & 0.00 & 0.00 & 0.00 & 0.00 & 0.00 & 0.00 & 0.00 & 0.00 & 0.00 & 0.00 & 0.00 & 0.00 & 0.00 & 0.00 & 0.00 \\
\hline $\mathrm{Ti}$ & 0.264 & 0.263 & 0.255 & 0.257 & 0.262 & 0.261 & 0.256 & 0.255 & 0.258 & 0.228 & 0.229 & 0.227 & 0.230 & 0.232 & 0.230 & 0.229 & 0.227 & 0.227 & 0.227 \\
\hline Al & 0.088 & 0.095 & 0.090 & 0.097 & 0.091 & 0.093 & 0.089 & 0.088 & 0.088 & 0.082 & 0.083 & 0.083 & 0.082 & 0.081 & 0.078 & 0.083 & 0.082 & 0.082 & 0.081 \\
\hline $\mathrm{Cr}$ & 0.000 & 0.000 & 0.001 & 0.000 & 0.000 & 0.000 & 0.000 & 0.001 & 0.000 & 0.001 & 0.000 & 0.001 & 0.000 & 0.001 & 0.000 & 0.001 & 0.000 & 0.000 & 0.000 \\
\hline $\mathrm{Fe}^{2+}$ & 1.148 & 1.139 & 1.141 & 1.132 & 1.140 & 1.143 & 1.136 & 1.141 & 1.143 & 1.113 & 1.116 & 1.114 & 1.116 & 1.117 & 1.117 & 1.118 & 1.111 & 1.116 & 1.113 \\
\hline $\mathrm{Fe}^{3+}$ & 1.380 & 1.374 & 1.395 & 1.386 & 1.380 & 1.382 & 1.394 & 1.397 & 1.390 & 1.459 & 1.455 & 1.457 & 1.455 & 1.450 & 1.457 & 1.452 & 1.459 & 1.460 & 1.461 \\
\hline Mn & 0.027 & 0.025 & 0.026 & 0.022 & 0.025 & 0.025 & 0.025 & 0.026 & 0.026 & 0.026 & 0.024 & 0.026 & 0.025 & 0.026 & 0.026 & 0.024 & 0.025 & 0.024 & 0.025 \\
\hline Mg & 0.091 & 0.102 & 0.091 & 0.105 & 0.099 & 0.094 & 0.097 & 0.091 & 0.093 & 0.090 & 0.091 & 0.090 & 0.090 & 0.091 & 0.090 & 0.089 & 0.093 & 0.090 & 0.091 \\
\hline $\mathrm{Ca}$ & 0.000 & 0.000 & 0.000 & 0.000 & 0.000 & 0.000 & 0.000 & 0.000 & 0.000 & 0.000 & 0.000 & 0.000 & 0.000 & 0.000 & 0.000 & 0.000 & 0.000 & 0.000 & 0.000 \\
\hline Total & 3.000 & 3.000 & 3.000 & 3.000 & 3.000 & 3.000 & 3.000 & 3.000 & 3.000 & 3.000 & 3.000 & 3.000 & 3.000 & 3.000 & 3.000 & 3.000 & 3.000 & 3.000 & 3.000 \\
\hline \multicolumn{20}{|l|}{ Atomic \% } \\
\hline Usp & 27.7 & 27.7 & 26.8 & 27.1 & 27.5 & 27.4 & 26.8 & 26.8 & 27.1 & 23.8 & 23.9 & 23.8 & 24.0 & 24.3 & 24.0 & 24.0 & 23.8 & 23.8 & 23.7 \\
\hline Mnt & 72.3 & 72.3 & 73.2 & 72.9 & 72.5 & 72.6 & 73.2 & 73.2 & 72.9 & 76.2 & 76.1 & 76.2 & 76.0 & 75.7 & 76.0 & 76.0 & 76.2 & 76.2 & 76.3 \\
\hline
\end{tabular}


Table F.6. Continued

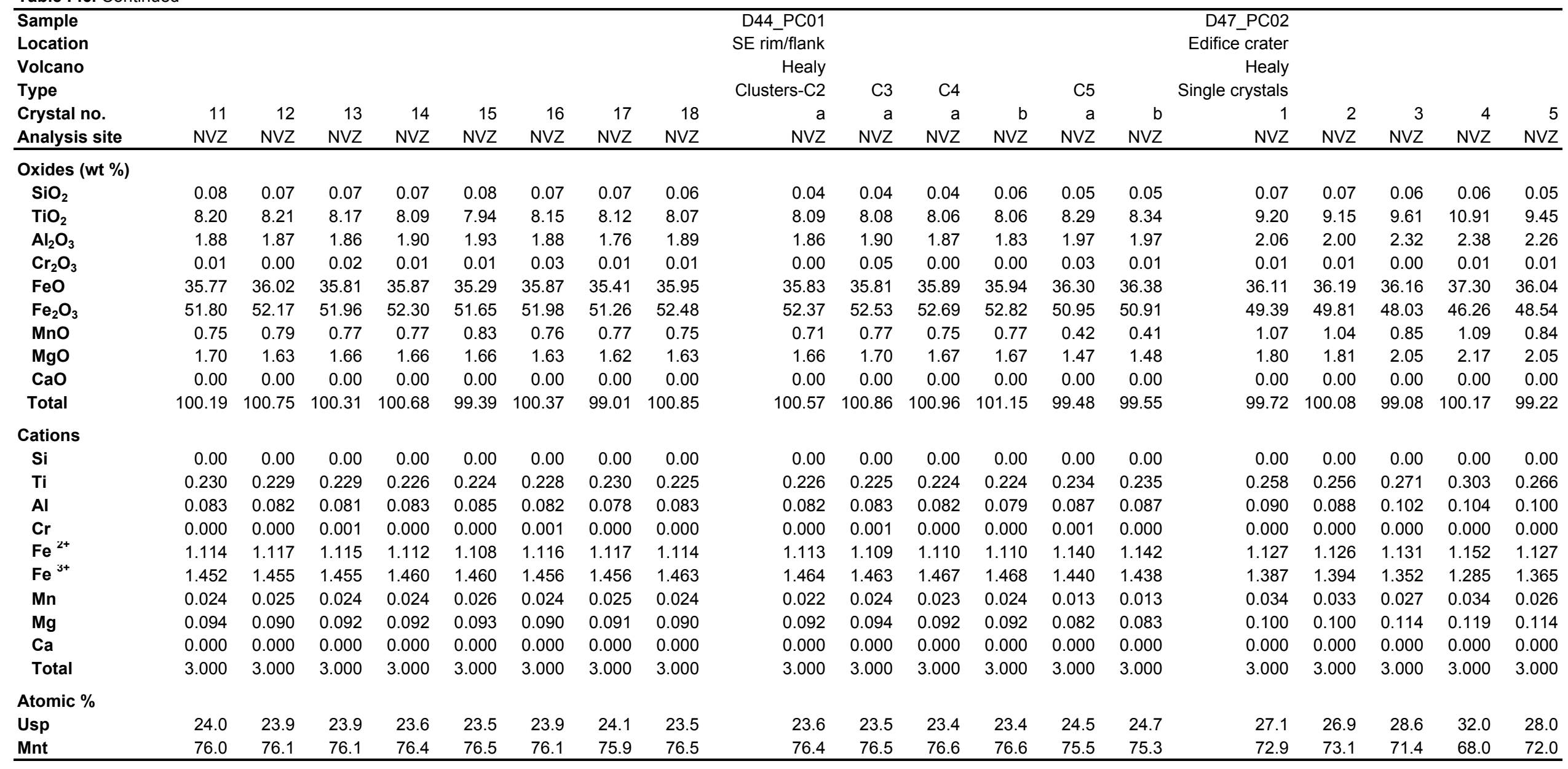


Table F.6. Continued

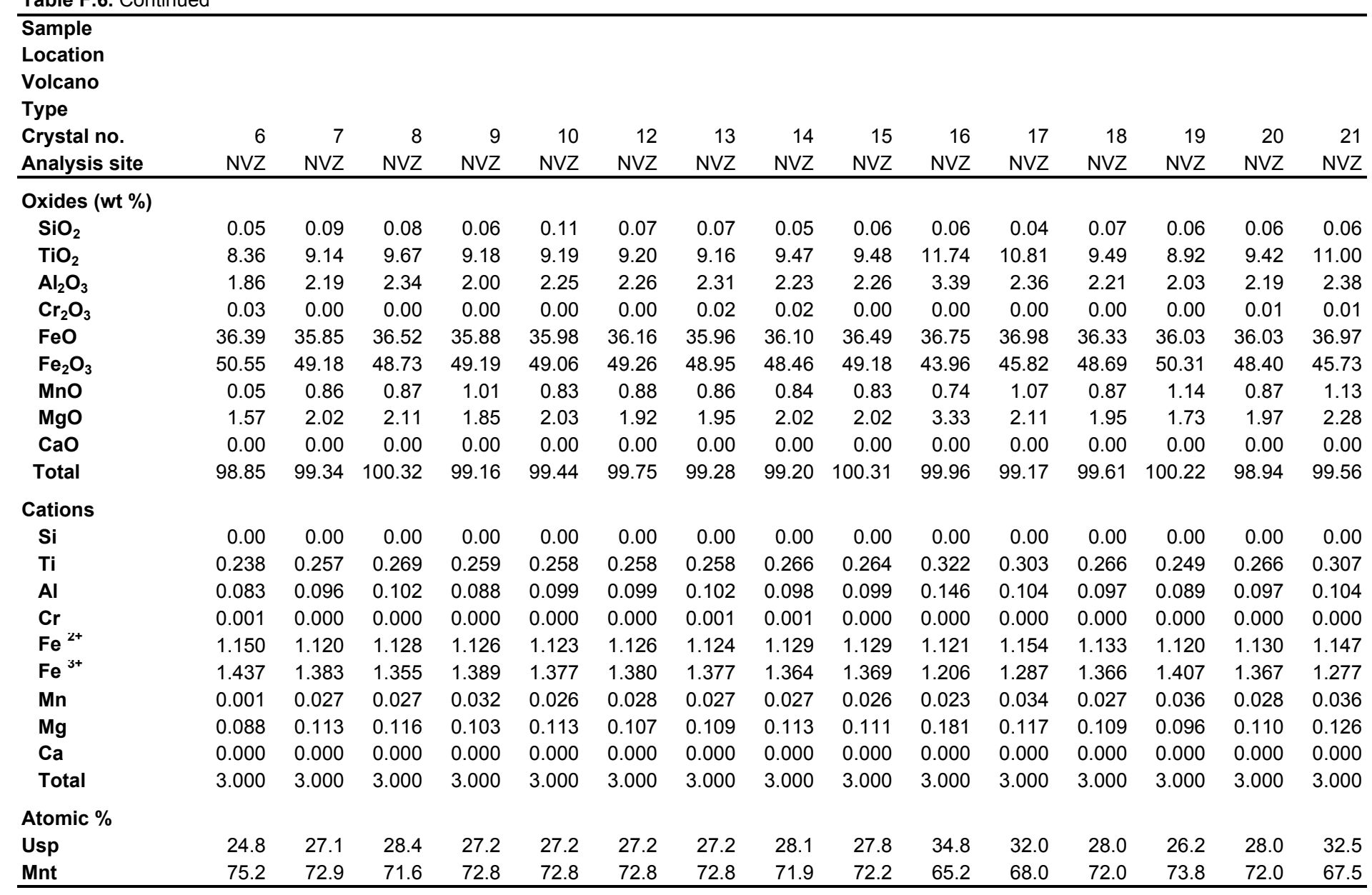


Table F.7. Major element compositions of IImentite determined by EPMA

\begin{tabular}{|c|c|c|c|c|c|c|c|c|c|c|c|c|c|c|c|c|c|c|}
\hline Sample & MI07_PC03 & & & & & & & & & & MI07_PC03 & & D33_PC04 & & & & & \\
\hline Location & SBT & & & & & & & & & & SBT & & $\bar{E}$ flank & & & & & \\
\hline Volcano & Macauley & & & & & & & & & & Macauley & & Macauley & & & & & \\
\hline Type & Single crystal & & & & & & & & & & Clusters-C4 & C5 & Single crystal & & & & & \\
\hline Crystal no. & 1 & 2 & 3 & 4 & 5 & 6 & 7 & 8 & 9 & 12 & a & a & 1 & 2 & 3 & 4 & 5 & 6 \\
\hline Analysis site & NVZ & NVZ & NVZ & NVZ & NVZ & NVZ & NVZ & NVZ & NVZ & NVZ & NVZ & NVZ & NVZ & NVZ & NVZ & NVZ & NVZ & NVZ \\
\hline \multicolumn{19}{|l|}{ Oxides (wt \%) } \\
\hline $\mathrm{SiO}_{2}$ & 0.00 & 0.00 & 0.03 & 0.01 & 0.02 & 0.00 & 0.01 & 0.00 & 0.02 & 0.00 & 0.02 & 0.00 & 0.02 & 0.02 & 0.01 & 0.00 & 0.02 & 0.02 \\
\hline $\mathrm{TiO}_{2}$ & 46.70 & 47.74 & 47.48 & 47.20 & 47.31 & 46.35 & 47.44 & 47.44 & 47.12 & 46.79 & 47.10 & 47.32 & 45.96 & 46.08 & 46.47 & 46.39 & 46.43 & 46.15 \\
\hline $\mathrm{Al}_{2} \mathrm{O}_{3}$ & 0.20 & 0.15 & 0.18 & 0.18 & 0.19 & 0.23 & 0.20 & 0.18 & 0.16 & 0.22 & 0.19 & 0.20 & 0.19 & 0.18 & 0.18 & 0.20 & 0.19 & 0.19 \\
\hline $\mathrm{Cr}_{2} \mathrm{O}_{3}$ & 0.00 & 0.00 & 0.00 & 0.01 & 0.01 & 0.00 & 0.00 & 0.00 & 0.02 & 0.01 & 0.01 & 0.00 & 0.02 & 0.00 & 0.00 & 0.02 & 0.02 & 0.00 \\
\hline $\mathrm{FeO}$ & 13.22 & 11.78 & 12.04 & 12.92 & 12.18 & 13.84 & 12.25 & 11.86 & 12.48 & 13.27 & 13.10 & 13.13 & 13.73 & 13.43 & 13.27 & 13.11 & 13.81 & 13.91 \\
\hline $\mathrm{Fe}_{2} \mathrm{O}_{3}$ & 36.41 & 37.40 & 37.16 & 36.81 & 36.93 & 36.07 & 37.12 & 37.06 & 37.01 & 36.53 & 37.00 & 36.95 & 36.11 & 36.40 & 36.81 & 36.59 & 36.26 & 36.53 \\
\hline MnO & 0.85 & 0.91 & 0.89 & 0.86 & 0.87 & 0.85 & 0.90 & 0.86 & 0.86 & 0.81 & 0.87 & 0.85 & 1.05 & 1.08 & 1.07 & 1.08 & 1.13 & 1.06 \\
\hline MgO & 2.66 & 2.60 & 2.63 & 2.68 & 2.67 & 2.67 & 2.62 & 2.66 & 2.54 & 2.66 & 2.53 & 2.67 & 2.23 & 2.20 & 2.20 & 2.27 & 2.42 & 2.21 \\
\hline $\mathrm{CaO}$ & 0.00 & 0.00 & 0.00 & 0.00 & 0.00 & 0.00 & 0.00 & 0.00 & 0.00 & 0.00 & 0.00 & 0.01 & 0.17 & 0.03 & 0.00 & 0.00 & 0.06 & 0.00 \\
\hline Total & 100.04 & 100.57 & 100.40 & 100.66 & 100.18 & 100.01 & 100.53 & 100.07 & 100.20 & 100.29 & 100.82 & 101.13 & 99.48 & 99.42 & 100.00 & 99.67 & 100.34 & 100.06 \\
\hline \multicolumn{19}{|l|}{ Cations } \\
\hline Si & 0.00 & 0.00 & 0.00 & 0.00 & 0.00 & 0.00 & 0.00 & 0.00 & 0.00 & 0.00 & 0.00 & 0.00 & 0.00 & 0.00 & 0.00 & 0.00 & 0.00 & 0.00 \\
\hline $\mathrm{Ti}$ & 0.873 & 0.888 & 0.885 & 0.877 & 0.883 & 0.867 & 0.883 & 0.887 & 0.880 & 0.873 & 0.875 & 0.875 & 0.867 & 0.870 & 0.873 & 0.873 & 0.868 & 0.866 \\
\hline Al & 0.006 & 0.004 & 0.005 & 0.005 & 0.005 & 0.007 & 0.006 & 0.005 & 0.005 & 0.007 & 0.005 & 0.006 & 0.006 & 0.005 & 0.005 & 0.006 & 0.006 & 0.005 \\
\hline $\mathrm{Cr}$ & 0.000 & 0.000 & 0.000 & 0.000 & 0.000 & 0.000 & 0.000 & 0.000 & 0.000 & 0.000 & 0.000 & 0.000 & 0.000 & 0.000 & 0.000 & 0.000 & 0.000 & 0.000 \\
\hline $\mathrm{Fe}^{2+}$ & 0.757 & 0.774 & 0.770 & 0.760 & 0.766 & 0.750 & 0.768 & 0.770 & 0.769 & 0.757 & 0.764 & 0.760 & 0.757 & 0.764 & 0.768 & 0.766 & 0.753 & 0.762 \\
\hline $\mathrm{Fe}^{3+}$ & 0.247 & 0.219 & 0.224 & 0.240 & 0.227 & 0.259 & 0.228 & 0.222 & 0.233 & 0.248 & 0.243 & 0.243 & 0.259 & 0.254 & 0.249 & 0.247 & 0.258 & 0.261 \\
\hline Mn & 0.018 & 0.019 & 0.019 & 0.018 & 0.018 & 0.018 & 0.019 & 0.018 & 0.018 & 0.017 & 0.018 & 0.018 & 0.022 & 0.023 & 0.023 & 0.023 & 0.024 & 0.022 \\
\hline Mg & 0.099 & 0.096 & 0.097 & 0.099 & 0.099 & 0.099 & 0.096 & 0.099 & 0.094 & 0.098 & 0.093 & 0.098 & 0.083 & 0.082 & 0.082 & 0.085 & 0.089 & 0.082 \\
\hline $\mathrm{Ca}$ & 0.000 & 0.000 & 0.000 & 0.000 & 0.000 & 0.000 & 0.000 & 0.000 & 0.000 & 0.000 & 0.000 & 0.000 & 0.005 & 0.001 & 0.000 & 0.000 & 0.002 & 0.000 \\
\hline Total & 2.000 & 2.000 & 2.000 & 2.000 & 2.000 & 2.000 & 2.000 & 2.000 & 2.000 & 2.000 & 2.000 & 2.000 & 2.000 & 2.000 & 2.000 & 2.000 & 2.000 & 2.000 \\
\hline \multicolumn{19}{|l|}{ Atomic \% } \\
\hline Usp & 86.0 & 87.6 & 87.3 & 86.4 & 87.1 & 85.3 & 87.1 & 87.4 & 86.8 & 86.0 & 86.3 & 86.2 & 85.4 & 85.8 & 86.0 & 86.1 & 85.4 & 85.4 \\
\hline Mnt & 14.0 & 12.4 & 12.7 & 13.6 & 12.9 & 14.7 & 12.9 & 12.6 & 13.2 & 14.0 & 13.7 & 13.8 & 14.6 & 14.2 & 14.0 & 13.9 & 14.6 & 14.6 \\
\hline
\end{tabular}

Oxide formulae recalculated using the methods of Lepage (2003). Molecular proportions calculated using the formulae of Sauerzapf et al. (2008). Location abbreviations as in Table B.1. 
Table F.7. Continued

\begin{tabular}{|c|c|c|c|c|c|c|c|c|c|c|c|c|c|c|c|c|c|c|}
\hline Sample & & & & PC06 & & & & & & & & & & & & PC05 & & $\begin{array}{r}\text { D44_PC01 } \\
\text { SE rim/flank }\end{array}$ \\
\hline Location & & & & ank/rim & & & & & & & & & & & & all/floor & & SE rim/flank \\
\hline Volcano & & & & Healy & & & & & & & & & & & & Healy & & Healy \\
\hline Type & & & & crystal & & & & & & & & & & & & crystal & & Single crystal \\
\hline Crystal no. & 7 & 8 & 9 & 1 & 2 & 3 & 4 & 5 & 6 & 7 & 8 & 9 & 10 & 11 & 12 & 1 & 2 & 1 \\
\hline Analysis site & NVZ & NVZ & NVZ & NVZ & NVZ & NVZ & $\mathrm{NVZ}$ & NVZ & NVZ & NVZ & NVZ & NVZ & NVZ & NVZ & NVZ & $\mathrm{NVZ}$ & NVZ & $\mathrm{NVZ}$ \\
\hline \multicolumn{19}{|l|}{ Oxides (wt \%) } \\
\hline $\mathrm{SiO}_{2}$ & 0.02 & 0.01 & 0.01 & 0.00 & 0.02 & 0.01 & 0.01 & 0.00 & 0.01 & 0.01 & 0.04 & 0.01 & 0.01 & 0.01 & 0.01 & 0.01 & 0.02 & 0.00 \\
\hline $\mathrm{TiO}_{2}$ & 46.14 & 46.44 & 46.38 & 41.28 & 40.94 & 41.20 & 41.05 & 41.05 & 40.58 & 40.99 & 40.74 & 41.05 & 40.78 & 41.17 & 40.93 & 40.80 & 42.08 & 41.58 \\
\hline $\mathrm{Al}_{2} \mathrm{O}_{3}$ & 0.18 & 0.18 & 0.19 & 0.22 & 0.20 & 0.24 & 0.21 & 0.23 & 0.21 & 0.22 & 0.21 & 0.22 & 0.21 & 0.21 & 0.20 & 0.20 & 0.22 & 0.21 \\
\hline $\mathrm{Cr}_{2} \mathrm{O}_{3}$ & 0.00 & 0.00 & 0.00 & 0.00 & 0.02 & 0.00 & 0.03 & 0.00 & 0.01 & 0.00 & 0.00 & 0.03 & 0.03 & 0.00 & 0.00 & 0.00 & 0.01 & 0.02 \\
\hline $\mathrm{FeO}$ & 13.91 & 13.83 & 13.73 & 23.19 & 23.77 & 23.75 & 23.63 & 23.52 & 23.54 & 23.73 & 23.97 & 23.84 & 23.83 & 23.84 & 23.91 & 24.16 & 20.92 & 24.14 \\
\hline $\mathrm{Fe}_{2} \mathrm{O}_{3}$ & 36.44 & 36.74 & 36.40 & 31.41 & 31.18 & 31.30 & 31.23 & 31.39 & 30.81 & 31.29 & 30.95 & 31.20 & 31.02 & 31.41 & 30.98 & 31.10 & 31.74 & 31.64 \\
\hline MnO & 1.10 & 1.03 & 1.07 & 0.94 & 0.97 & 0.95 & 0.93 & 0.89 & 0.95 & 0.96 & 0.95 & 0.93 & 0.94 & 0.94 & 0.96 & 0.95 & 1.01 & 0.91 \\
\hline MgO & 2.22 & 2.25 & 2.38 & 2.68 & 2.64 & 2.70 & 2.68 & 2.61 & 2.66 & 2.59 & 2.68 & 2.69 & 2.65 & 2.63 & 2.66 & 2.61 & 2.81 & 2.71 \\
\hline $\mathrm{CaO}$ & 0.00 & 0.00 & 0.00 & 0.00 & 0.00 & 0.00 & 0.00 & 0.00 & 0.00 & 0.00 & 0.00 & 0.00 & 0.00 & 0.00 & 0.11 & 0.00 & 0.08 & 0.00 \\
\hline Total & 100.01 & 100.48 & 100.15 & 99.72 & 99.74 & 100.14 & 99.76 & 99.69 & 98.77 & 99.80 & 99.54 & 99.97 & 99.48 & 100.21 & 99.76 & 99.83 & 98.88 & 101.22 \\
\hline \multicolumn{19}{|l|}{ Cations } \\
\hline $\mathbf{S i}$ & 0.00 & 0.00 & 0.00 & 0.00 & 0.00 & 0.00 & 0.00 & 0.00 & 0.00 & 0.00 & 0.00 & 0.00 & 0.00 & 0.00 & 0.00 & 0.00 & 0.00 & 0.00 \\
\hline $\mathrm{Ti}$ & 0.866 & 0.868 & 0.868 & 0.778 & 0.772 & 0.773 & 0.774 & 0.775 & 0.772 & 0.773 & 0.770 & 0.772 & 0.771 & 0.773 & 0.771 & 0.769 & 0.798 & 0.772 \\
\hline Al & 0.005 & 0.005 & 0.006 & 0.006 & 0.006 & 0.007 & 0.006 & 0.007 & 0.006 & 0.007 & 0.006 & 0.007 & 0.006 & 0.006 & 0.006 & 0.006 & 0.007 & 0.006 \\
\hline $\mathrm{Cr}$ & 0.000 & 0.000 & 0.000 & 0.000 & 0.000 & 0.000 & 0.001 & 0.000 & 0.000 & 0.000 & 0.000 & 0.001 & 0.001 & 0.000 & 0.000 & 0.000 & 0.000 & 0.000 \\
\hline $\mathrm{Fe}^{2+}$ & 0.761 & 0.763 & 0.758 & 0.658 & 0.654 & 0.653 & 0.654 & 0.658 & 0.652 & 0.656 & 0.650 & 0.652 & 0.652 & 0.655 & 0.649 & 0.652 & 0.669 & 0.653 \\
\hline $\mathrm{Fe}^{3+}$ & 0.261 & 0.259 & 0.257 & 0.437 & 0.448 & 0.446 & 0.445 & 0.444 & 0.448 & 0.448 & 0.453 & 0.448 & 0.451 & 0.448 & 0.451 & 0.456 & 0.397 & 0.449 \\
\hline Mn & 0.023 & 0.022 & 0.023 & 0.020 & 0.021 & 0.020 & 0.020 & 0.019 & 0.020 & 0.020 & 0.020 & 0.020 & 0.020 & 0.020 & 0.020 & 0.020 & 0.022 & 0.019 \\
\hline $\mathbf{M g}$ & 0.083 & 0.083 & 0.088 & 0.100 & 0.098 & 0.100 & 0.100 & 0.097 & 0.100 & 0.097 & 0.100 & 0.100 & 0.099 & 0.098 & 0.099 & 0.097 & 0.106 & 0.100 \\
\hline $\mathrm{Ca}$ & 0.000 & 0.000 & 0.000 & 0.000 & 0.000 & 0.000 & 0.000 & 0.000 & 0.000 & 0.000 & 0.000 & 0.000 & 0.000 & 0.000 & 0.003 & 0.000 & 0.002 & 0.000 \\
\hline Total & 2.000 & 2.000 & 2.000 & 2.000 & 2.000 & 2.000 & 2.000 & 2.000 & 2.000 & 2.000 & 2.000 & 2.000 & 2.000 & 2.000 & 2.000 & 2.000 & 2.000 & 2.000 \\
\hline \multicolumn{19}{|l|}{ Atomic \% } \\
\hline Usp & 85.3 & 85.5 & 85.5 & 75.1 & 74.5 & 74.5 & 74.6 & 74.8 & 74.4 & 74.6 & 74.2 & 74.4 & 74.3 & 74.5 & 74.2 & 74.1 & 77.1 & 74.4 \\
\hline Mnt & 14.7 & 14.5 & 14.5 & 24.9 & 25.5 & 25.5 & 25.4 & 25.2 & 25.6 & 25.4 & 25.8 & 25.6 & 25.7 & 25.5 & 25.8 & 25.9 & 22.9 & 25.6 \\
\hline
\end{tabular}


Table F.7. Continued

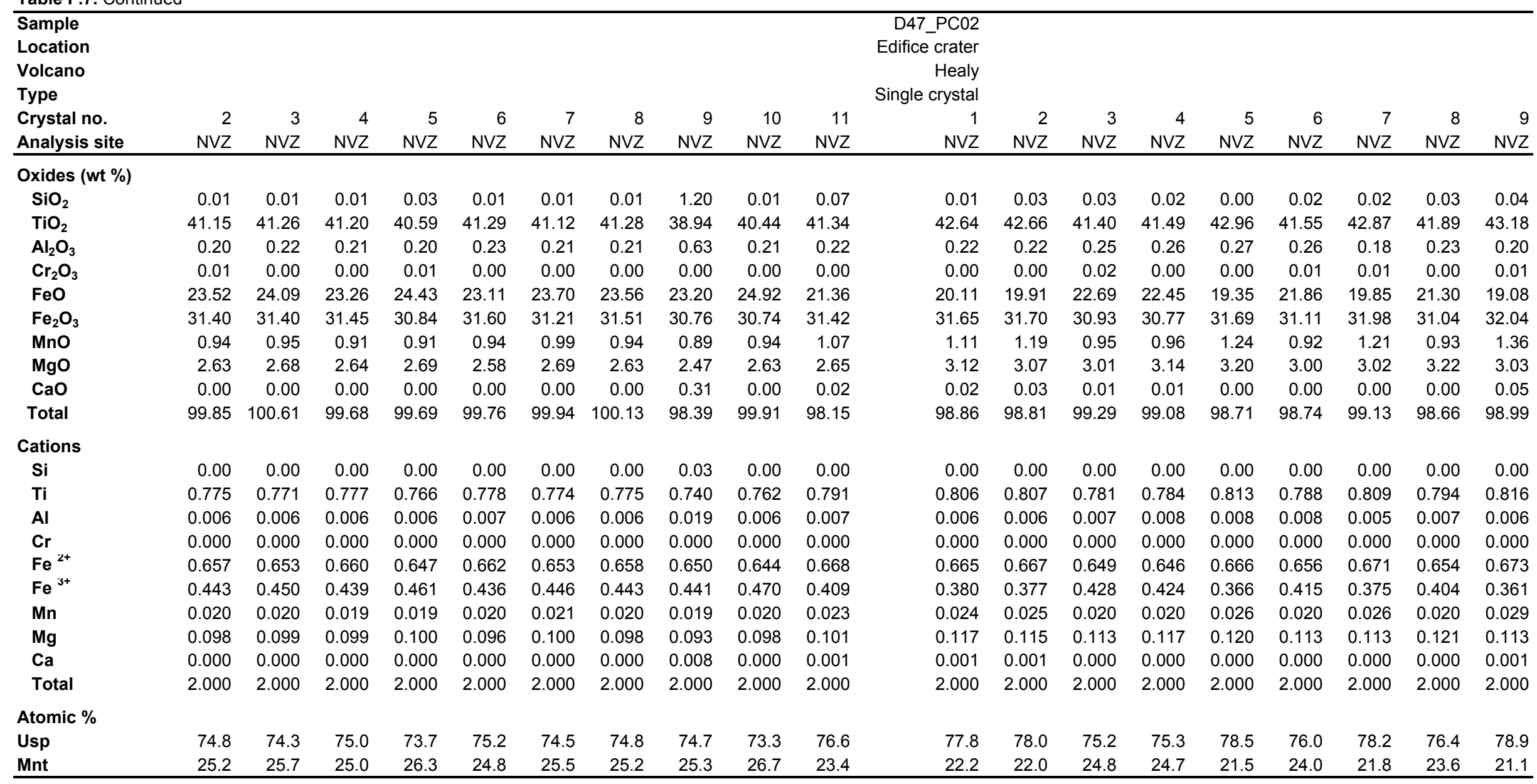


Table F.7. Continued

\begin{tabular}{|c|c|c|c|}
\hline $\begin{array}{l}\text { Sample } \\
\text { Location } \\
\text { Volcano } \\
\text { Type }\end{array}$ & & & \\
\hline $\begin{array}{l}\text { Crystal no. } \\
\text { Analysis site } \\
\end{array}$ & $\begin{array}{r}10 \\
N V Z \\
\end{array}$ & $\begin{array}{r}11 \\
N V Z \\
\end{array}$ & $\begin{array}{r}12 \\
\mathrm{NVZ} \\
\end{array}$ \\
\hline \multicolumn{4}{|l|}{ Oxides (wt \%) } \\
\hline $\mathrm{SiO}_{2}$ & 0.05 & 0.01 & 0.03 \\
\hline $\mathrm{TiO}_{2}$ & 41.54 & 41.54 & 41.80 \\
\hline $\mathrm{Al}_{2} \mathrm{O}_{3}$ & 0.27 & 0.27 & 0.25 \\
\hline $\mathrm{Cr}_{2} \mathrm{O}_{3}$ & 0.02 & 0.00 & 0.01 \\
\hline $\mathrm{FeO}$ & 21.66 & 21.48 & 21.81 \\
\hline $\mathrm{Fe}_{2} \mathrm{O}_{3}$ & 31.14 & 30.97 & 31.23 \\
\hline MnO & 0.88 & 0.97 & 0.96 \\
\hline MgO & 3.02 & 3.04 & 3.05 \\
\hline $\mathrm{CaO}$ & 0.01 & 0.01 & 0.00 \\
\hline Total & 98.59 & 98.28 & 99.14 \\
\hline \multicolumn{4}{|l|}{ Cations } \\
\hline $\mathbf{S i}$ & 0.00 & 0.00 & 0.00 \\
\hline $\mathrm{Ti}$ & 0.789 & 0.791 & 0.790 \\
\hline Al & 0.008 & 0.008 & 0.007 \\
\hline $\mathrm{Cr}$ & 0.000 & 0.000 & 0.000 \\
\hline $\mathrm{Fe}^{2+}$ & 0.657 & 0.656 & 0.656 \\
\hline $\mathrm{Fe}^{3+}$ & 0.411 & 0.409 & 0.412 \\
\hline $\mathrm{Mn}$ & 0.019 & 0.021 & 0.020 \\
\hline Mg & 0.114 & 0.115 & 0.114 \\
\hline $\mathrm{Ca}$ & 0.000 & 0.000 & 0.000 \\
\hline Total & 2.000 & 2.000 & 2.000 \\
\hline \multicolumn{4}{|l|}{ Atomic \% } \\
\hline Usp & 76.2 & 76.2 & 76.1 \\
\hline Mnt & 23.8 & 23.8 & 23.9 \\
\hline
\end{tabular}




\section{APPENDIX G: Mineral trace element data}

Table G.1. Clinopyroxene trace element data

Table G.2. Plagioclase trace element data

Table G.3. Amphibole trace element data 
Table G.1. Trace element concentrations in clinopyroxenes analysed by LA-ICP-MS

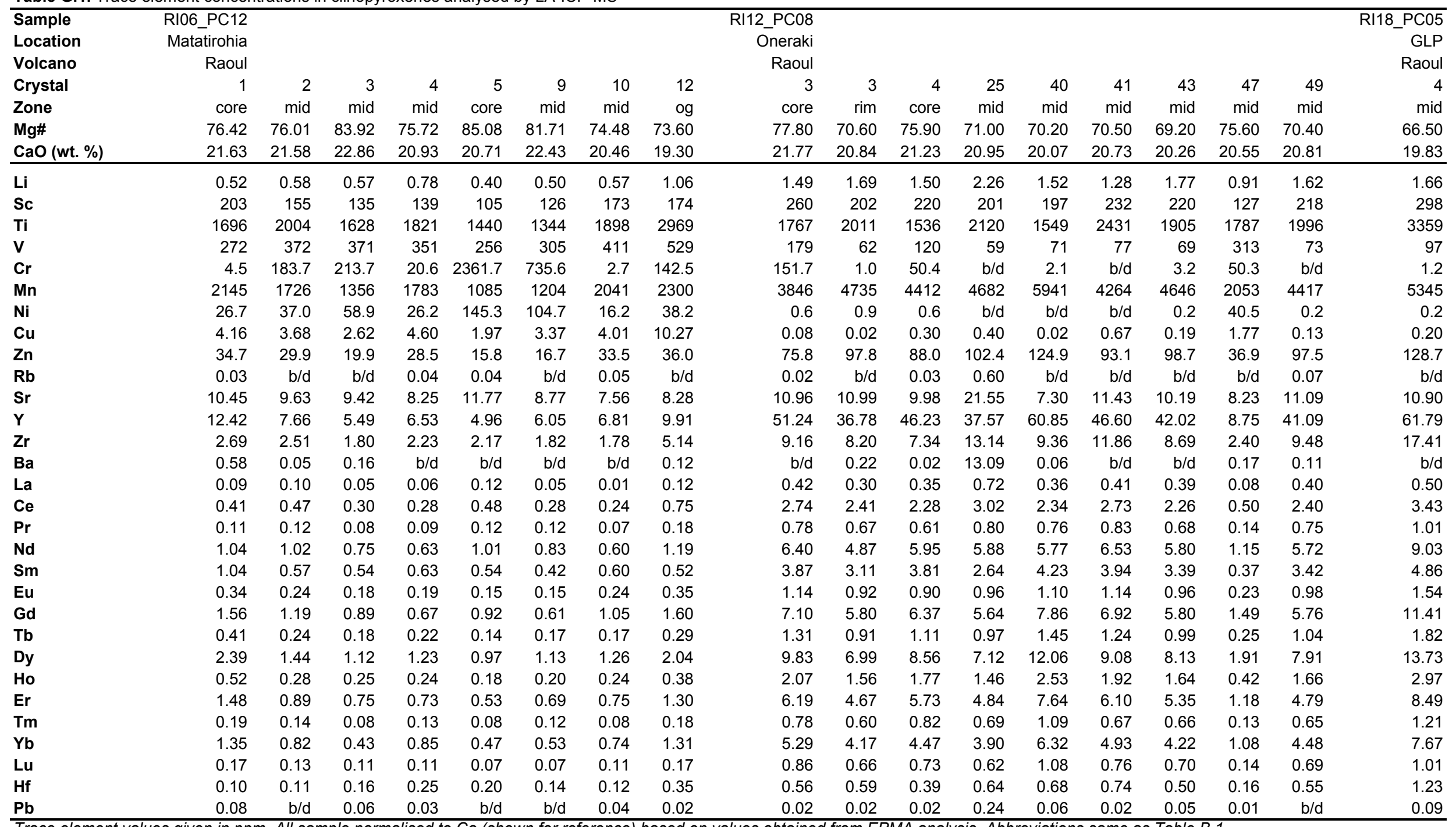


Table G.1. Continued

\begin{tabular}{|c|c|c|c|c|c|c|c|c|c|c|c|c|c|c|c|c|c|c|c|}
\hline Sample & & & & & & & & & & 6_PC01 & & & & & & & & & \\
\hline Location & & & & & & & & & & eetwood & & & & & & & & & \\
\hline Volcano & & & & & & & & & & Raoul & & & & & & & & & \\
\hline Crystal & 8 & 8 & 9 & 11 & 11 & 25 & 25 & 25 & 30 & 3 & 4 & 13 & 14 & 17 & 23 & 25 & 25 & 26 & 29 \\
\hline Zone & core & rim & mid & core & $\mathrm{d}$ band & core & $\mathrm{d}$ band & rim & mid & mid & mid & mid & mid & mid & mid & core & rim & mid & mid \\
\hline Mg\# & 81.30 & 68.20 & 67.20 & 82.70 & 84.40 & 82.50 & 87.50 & 72.10 & 66.60 & 85.60 & 84.60 & 84.90 & 82.60 & 77.50 & 82.90 & 82.00 & 77.60 & 85.20 & 85.30 \\
\hline $\mathrm{CaO}$ (wt. \%) & 22.16 & 17.81 & 19.82 & 22.56 & 22.54 & 22.21 & 22.75 & 19.12 & 19.75 & 22.28 & 22.43 & 22.30 & 22.06 & 20.78 & 22.18 & 21.99 & 21.02 & 22.48 & 22.38 \\
\hline Li & 0.28 & 0.89 & 1.47 & 0.45 & 0.36 & 0.54 & 0.49 & 1.38 & 1.79 & 0.39 & 0.27 & 0.38 & 0.53 & 0.41 & 0.52 & 0.52 & 0.44 & 0.37 & 0.66 \\
\hline Sc & 111 & 163 & 211 & 141 & 119 & 123 & 99 & 131 & 208 & 115 & 120 & 114 & 121 & 130 & 119 & 153 & 129 & 106 & 125 \\
\hline $\mathrm{Ti}$ & 1286 & 2566 & 2373 & 1794 & 1235 & 1488 & 888 & 1650 & 2495 & 1138 & 1206 & 1326 & 1479 & 1638 & 1353 & 1464 & 1542 & 1161 & 1295 \\
\hline $\mathbf{v}$ & 342 & 320 & 103 & 410 & 296 & 408 & 267 & 346 & 96 & 272 & 265 & 299 & 340 & 387 & 319 & 272 & 380 & 299 & 320 \\
\hline $\mathrm{Cr}$ & 1030.9 & 269.7 & 0.5 & 515.8 & 1009.0 & 1057.7 & 2879.6 & 121.7 & 1.5 & 1430.2 & 1895.5 & 982.8 & 360.7 & 988.6 & 757.7 & 208.3 & 401.3 & 957.4 & 700.8 \\
\hline Mn & 1175 & 3170 & 4574 & 1536 & 1180 & 1520 & 1336 & 3806 & 5221 & 960 & 981 & 1016 & 1246 & 1269 & 1166 & 1403 & 1374 & 1053 & 1201 \\
\hline $\mathrm{Ni}$ & 70.6 & 35.8 & 0.1 & 88.5 & 129.8 & 164.0 & 226.1 & 67.4 & 0.5 & 117.3 & 112.9 & 103.4 & 65.6 & 91.8 & 82.7 & 40.5 & 66.7 & 109.2 & 68.5 \\
\hline $\mathrm{Cu}$ & 0.36 & 1.51 & 0.02 & 2.14 & 2.37 & 2.71 & 3.13 & 3.24 & 0.31 & 1.88 & 1.75 & 1.34 & 2.26 & 1.91 & 2.75 & 2.95 & 3.01 & 1.20 & 1.74 \\
\hline $\mathrm{Zn}$ & 18.8 & 63.0 & 107.5 & 25.2 & 17.1 & 28.4 & 18.5 & 79.7 & 120.4 & 15.4 & 13.1 & 14.1 & 20.4 & 22.6 & 20.3 & 19.3 & 23.8 & 20.1 & 17.9 \\
\hline $\mathbf{R b}$ & $\mathrm{b} / \mathrm{d}$ & $\mathrm{b} / \mathrm{d}$ & $\mathrm{b} / \mathrm{d}$ & $\mathrm{b} / \mathrm{d}$ & $\mathrm{b} / \mathrm{d}$ & $\mathrm{b} / \mathrm{d}$ & $\mathrm{b} / \mathrm{d}$ & $\mathrm{b} / \mathrm{d}$ & $\mathrm{b} / \mathrm{d}$ & $\mathrm{b} / \mathrm{d}$ & $\mathrm{b} / \mathrm{d}$ & $\mathrm{b} / \mathrm{d}$ & 0.04 & $\mathrm{~b} / \mathrm{d}$ & $\mathrm{b} / \mathrm{d}$ & $\mathrm{b} / \mathrm{d}$ & $\mathrm{b} / \mathrm{d}$ & 0.02 & $\mathrm{~b} / \mathrm{d}$ \\
\hline $\mathrm{Sr}$ & 8.48 & 5.98 & 10.65 & 7.82 & 7.23 & 9.96 & 8.54 & 8.56 & 9.67 & 8.62 & 10.97 & 9.22 & 8.05 & 7.60 & 8.29 & 10.07 & 7.38 & 9.22 & 8.13 \\
\hline $\mathbf{Y}$ & 3.85 & 17.23 & 36.44 & 5.90 & 3.96 & 5.84 & 2.96 & 13.83 & 39.95 & 3.35 & 4.24 & 4.51 & 4.75 & 5.69 & 4.18 & 7.24 & 6.39 & 3.48 & 3.99 \\
\hline $\mathrm{Zr}$ & 0.94 & 4.66 & 8.60 & 1.85 & 1.13 & 1.35 & 0.68 & 2.89 & 9.01 & 1.22 & 1.60 & 1.57 & 1.32 & 1.76 & 1.16 & 1.55 & 2.06 & 1.16 & 0.85 \\
\hline $\mathrm{Ba}$ & $\mathrm{b} / \mathrm{d}$ & $\mathrm{b} / \mathrm{d}$ & $\mathrm{b} / \mathrm{d}$ & $\mathrm{b} / \mathrm{d}$ & 0.06 & $\mathrm{~b} / \mathrm{d}$ & 0.05 & 0.12 & 0.02 & 0.03 & $\mathrm{~b} / \mathrm{d}$ & 0.11 & 0.10 & 0.07 & $\mathrm{~b} / \mathrm{d}$ & 0.50 & $\mathrm{~b} / \mathrm{d}$ & $\mathrm{b} / \mathrm{d}$ & 0.11 \\
\hline La & 0.04 & 0.11 & 0.29 & 0.01 & 0.05 & 0.02 & 0.02 & 0.11 & 0.35 & 0.05 & 0.06 & 0.05 & 0.04 & 0.04 & 0.01 & 0.05 & 0.03 & 0.03 & 0.03 \\
\hline $\mathrm{Ce}$ & 0.16 & 0.63 & 1.66 & 0.22 & 0.15 & 0.22 & 0.11 & 0.47 & 2.33 & 0.25 & 0.38 & 0.25 & 0.17 & 0.27 & 0.15 & 0.22 & 0.23 & 0.18 & 0.22 \\
\hline $\mathrm{Pr}$ & 0.03 & 0.20 & 0.55 & 0.05 & 0.05 & 0.06 & 0.03 & 0.15 & 0.60 & 0.07 & 0.08 & 0.07 & 0.07 & 0.07 & 0.03 & 0.10 & 0.05 & 0.06 & 0.03 \\
\hline Nd & 0.41 & 1.75 & 5.10 & 0.66 & 0.39 & 0.61 & 0.12 & 1.09 & 5.73 & 0.53 & 0.59 & 0.53 & 0.66 & 0.68 & 0.30 & 0.87 & 0.43 & 0.45 & 0.31 \\
\hline $\mathrm{Sm}$ & 0.34 & 1.07 & 3.10 & 0.52 & 0.30 & 0.21 & 0.16 & 0.75 & 2.92 & 0.21 & 0.22 & 0.56 & 0.20 & 0.39 & 0.27 & 0.45 & 0.49 & 0.41 & 0.19 \\
\hline Eu & 0.14 & 0.44 & 0.84 & 0.18 & 0.09 & 0.19 & 0.14 & 0.37 & 1.02 & 0.18 & 0.12 & 0.14 & 0.13 & 0.22 & 0.15 & 0.28 & 0.24 & 0.12 & 0.14 \\
\hline Gd & 0.59 & 2.18 & 5.88 & 0.73 & 0.55 & 0.45 & 0.60 & 1.94 & 5.87 & 0.51 & 0.46 & 0.56 & 0.52 & 0.69 & 0.59 & 0.76 & 0.81 & 0.57 & 0.57 \\
\hline Tb & 0.10 & 0.39 & 0.96 & 0.14 & 0.10 & 0.16 & 0.08 & 0.39 & 1.04 & 0.09 & 0.10 & 0.12 & 0.09 & 0.15 & 0.09 & 0.19 & 0.17 & 0.11 & 0.10 \\
\hline Dy & 0.73 & 3.14 & 7.51 & 1.37 & 0.88 & 1.10 & 0.82 & 2.87 & 7.98 & 0.80 & 0.91 & 0.84 & 0.92 & 1.21 & 0.91 & 1.45 & 1.18 & 0.69 & 0.74 \\
\hline Ho & 0.14 & 0.74 & 1.65 & 0.24 & 0.15 & 0.22 & 0.11 & 0.73 & 1.63 & 0.16 & 0.13 & 0.20 & 0.22 & 0.23 & 0.18 & 0.31 & 0.29 & 0.15 & 0.16 \\
\hline $\mathrm{Er}$ & 0.43 & 2.13 & 4.75 & 0.79 & 0.49 & 0.65 & 0.35 & 1.80 & 4.30 & 0.35 & 0.46 & 0.52 & 0.52 & 0.62 & 0.35 & 0.93 & 0.83 & 0.47 & 0.45 \\
\hline Tm & 0.08 & 0.36 & 0.63 & 0.12 & 0.07 & 0.07 & 0.06 & 0.20 & 0.67 & 0.07 & 0.07 & 0.07 & 0.11 & 0.06 & 0.07 & 0.10 & 0.13 & 0.10 & 0.06 \\
\hline $\mathrm{Yb}$ & 0.43 & 1.79 & 3.92 & 0.62 & 0.35 & 0.49 & 0.37 & 1.73 & 4.53 & 0.38 & 0.51 & 0.46 & 0.53 & 0.57 & 0.38 & 0.70 & 0.67 & 0.35 & 0.38 \\
\hline Lu & 0.05 & 0.26 & 0.61 & 0.08 & 0.06 & 0.07 & 0.03 & 0.21 & 0.61 & 0.05 & 0.07 & 0.09 & 0.09 & 0.09 & 0.08 & 0.14 & 0.08 & 0.03 & 0.05 \\
\hline Hf & 0.04 & 0.28 & 0.58 & 0.17 & 0.09 & 0.19 & 0.13 & 0.21 & 0.73 & $\mathrm{~b} / \mathrm{d}$ & 0.15 & 0.12 & 0.06 & 0.28 & 0.13 & 0.09 & 0.18 & 0.10 & 0.08 \\
\hline $\mathrm{Pb}$ & $\mathrm{b} / \mathrm{d}$ & 0.02 & $\mathrm{~b} / \mathrm{d}$ & $\mathrm{b} / \mathrm{d}$ & $\mathrm{b} / \mathrm{d}$ & $\mathrm{b} / \mathrm{d}$ & 0.05 & $\mathrm{~b} / \mathrm{d}$ & 0.03 & 0.06 & $\mathrm{~b} / \mathrm{d}$ & 0.13 & 0.11 & 0.09 & 0.08 & $\mathrm{~b} / \mathrm{d}$ & $\mathrm{b} / \mathrm{d}$ & $\mathrm{b} / \mathrm{d}$ & 0.04 \\
\hline
\end{tabular}


Table G.1. Continued

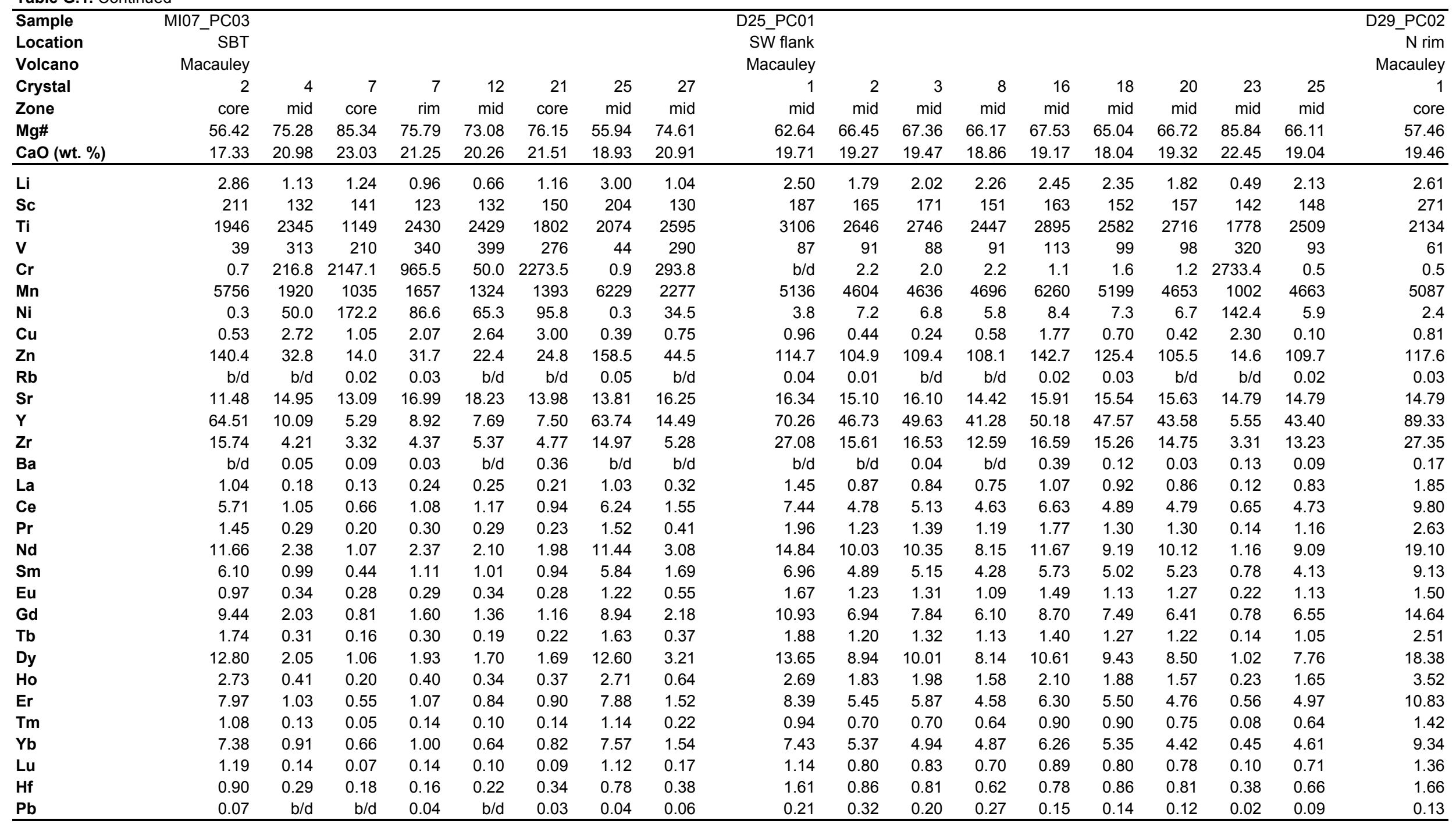


Table G.1. Continued

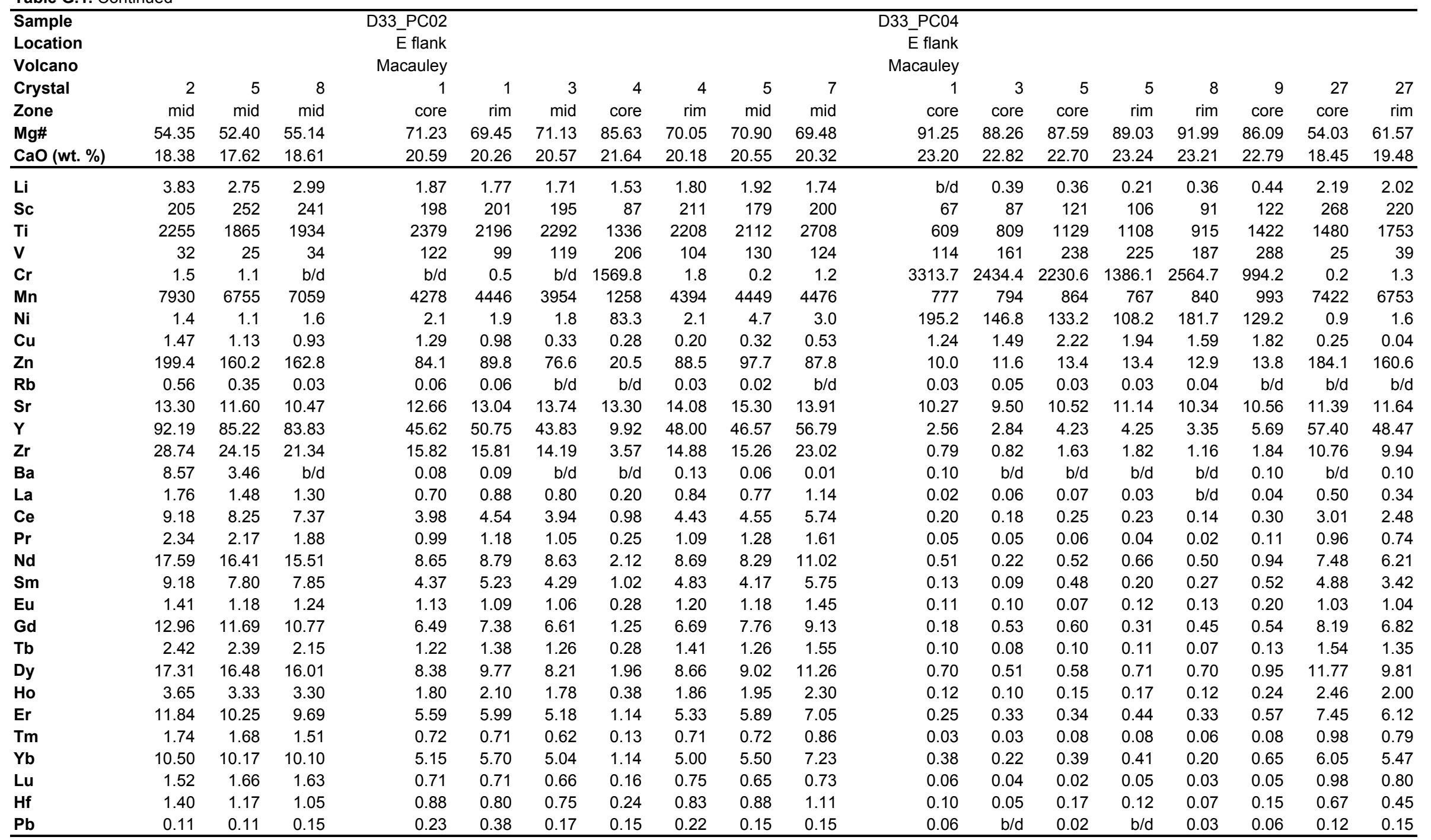


Table G.1. Continued

\begin{tabular}{|c|c|c|c|c|c|c|c|c|c|c|c|c|c|c|c|c|c|c|}
\hline Sample & D38_PC06 & & & & & & & & & & & 9_PC05 & & & & & & D44_PC01 \\
\hline Location & NW flank/rim & & & & & & & & & & & all/floor & & & & & & SE rim/flank \\
\hline Volcano & Healy & & & & & & & & & & & Healy & & & & & & Healy \\
\hline Crystal & 2 & 2 & 3 & 5 & 7 & 7 & 8 & 12 & 12 & 14 & 24 & 2 & 2 & 6 & 6 & 10 & 11 & 9 \\
\hline Zone & core & rim & mid & mid & mid & I band & rim & core & rim & core & core & core & rim & core & rim & core & rim & core \\
\hline Mg\# & 84.58 & 76.34 & 81.81 & 79.81 & 82.17 & 76.53 & 76.72 & 79.61 & 83.49 & 81.23 & 81.05 & 73.79 & 70.63 & 69.42 & 71.43 & 72.60 & 71.10 & 79.56 \\
\hline $\mathrm{CaO}$ (wt. \%) & 23.09 & 21.77 & 22.19 & 22.50 & 22.81 & 22.03 & 21.85 & 22.79 & 23.05 & 23.00 & 22.77 & 20.22 & 20.88 & 18.73 & 19.55 & 21.04 & 20.64 & 22.16 \\
\hline Li & 0.44 & 0.35 & 0.35 & 0.31 & 0.50 & 0.38 & 0.80 & 0.27 & 0.41 & 0.42 & 0.46 & 2.95 & 2.59 & 3.17 & 2.92 & 2.74 & 2.75 & 0.52 \\
\hline Sc & 124 & 125 & 125 & 128 & 125 & 132 & 144 & 134 & 121 & 132 & 109 & 173 & 228 & 211 & 178 & 251 & 179 & 120 \\
\hline $\mathrm{Ti}$ & 1862 & 1796 & 1870 & 2268 & 2232 & 2529 & 2599 & 2459 & 1937 & 2596 & 2066 & 1569 & 2254 & 2681 & 1785 & 2206 & 1605 & 1931 \\
\hline v & 239 & 243 & 252 & 295 & 281 & 318 & 311 & 317 & 256 & 283 & 244 & 79 & 107 & 115 & 75 & 96 & 80 & 236 \\
\hline $\mathrm{Cr}$ & 2096.0 & 1961.8 & 653.2 & 425.3 & 498.8 & 132.6 & 55.7 & 401.4 & 1331.2 & 1047.5 & 1996.7 & 2.3 & $b / d$ & 0.6 & $b / d$ & 0.9 & $b / d$ & 1097.6 \\
\hline Mn & 949 & 935 & 1207 & 1257 & 1109 & 1220 & 1964 & 1179 & 981 & 1074 & 911 & 6103 & 4690 & 5883 & 5518 & 5339 & 6948 & 993 \\
\hline $\mathrm{Ni}$ & 116.6 & 111.8 & 84.5 & 78.5 & 84.4 & 64.8 & 44.1 & 76.3 & 108.8 & 100.7 & 124.5 & 4.8 & 0.5 & 0.2 & 0.5 & $\mathrm{~b} / \mathrm{d}$ & 0.7 & 91.2 \\
\hline $\mathrm{Cu}$ & 1.94 & 1.78 & 2.38 & 2.95 & 2.13 & 2.02 & 2.46 & 2.12 & 2.03 & 2.17 & 2.63 & 428.46 & 0.77 & 0.74 & $b / d$ & 0.13 & $\mathrm{~b} / \mathrm{d}$ & 2.11 \\
\hline Zn & 16.8 & 14.5 & 18.4 & 20.8 & 19.0 & 19.9 & 31.9 & 19.1 & 15.8 & 15.9 & 14.3 & 98.1 & 77.2 & 88.1 & 88.9 & 83.5 & 103.1 & 15.2 \\
\hline $\mathbf{R b}$ & 0.02 & $b / d$ & 0.03 & $b / d$ & $b / d$ & $\mathrm{~b} / \mathrm{d}$ & $b / d$ & $\mathrm{~b} / \mathrm{d}$ & $b / d$ & $b / d$ & $b / d$ & 0.05 & $b / d$ & 0.02 & 0.04 & $\mathrm{~b} / \mathrm{d}$ & 0.05 & $b / d$ \\
\hline $\mathrm{Sr}$ & 17.74 & 16.35 & 17.21 & 19.62 & 18.51 & 17.24 & 19.10 & 18.80 & 18.14 & 22.81 & 21.51 & 14.51 & 19.73 & 14.79 & 15.95 & 19.79 & 12.56 & 17.69 \\
\hline $\mathbf{Y}$ & 5.98 & 6.14 & 6.03 & 6.46 & 5.67 & 6.75 & 15.48 & 7.26 & 6.05 & 7.12 & 4.88 & 74.07 & 88.33 & 102.67 & 83.84 & 114.11 & 82.56 & 5.64 \\
\hline $\mathrm{Zr}$ & 3.00 & 3.12 & 3.37 & 4.37 & 3.64 & 3.72 & 7.49 & 4.37 & 3.40 & 4.52 & 4.16 & 20.32 & 36.98 & 41.37 & 28.93 & 45.16 & 21.71 & 3.13 \\
\hline $\mathrm{Ba}$ & $\mathrm{b} / \mathrm{d}$ & 0.12 & $\mathrm{~b} / \mathrm{d}$ & $b / d$ & 0.13 & $\mathrm{~b} / \mathrm{d}$ & $b / d$ & $\mathrm{~b} / \mathrm{d}$ & 0.25 & $b / d$ & $b / d$ & $b / d$ & 0.40 & 0.09 & $b / d$ & 0.24 & $\mathrm{~b} / \mathrm{d}$ & $b / d$ \\
\hline La & 0.06 & 0.05 & 0.11 & 0.17 & 0.11 & 0.13 & 0.28 & 0.11 & 0.11 & 0.15 & 0.16 & 1.30 & 2.20 & 2.19 & 1.75 & 2.58 & 1.19 & 0.14 \\
\hline $\mathrm{Ce}$ & 0.47 & 0.48 & 0.55 & 0.73 & 0.62 & 0.62 & 1.52 & 0.67 & 0.52 & 0.73 & 0.82 & 7.10 & 11.25 & 12.12 & 10.12 & 13.60 & 6.38 & 0.65 \\
\hline $\mathrm{Pr}$ & 0.12 & 0.10 & 0.17 & 0.19 & 0.17 & 0.17 & 0.40 & 0.18 & 0.16 & 0.18 & 0.19 & 1.81 & 2.94 & 3.05 & 2.62 & 3.55 & 1.86 & 0.14 \\
\hline Nd & 0.96 & 0.70 & 1.21 & 1.64 & 1.22 & 1.07 & 2.80 & 1.37 & 0.95 & 1.61 & 1.33 & 13.87 & 20.60 & 21.30 & 18.25 & 26.38 & 12.98 & 1.25 \\
\hline Sm & 0.43 & 0.46 & 0.63 & 0.73 & 0.85 & 0.68 & 1.49 & 0.71 & 0.42 & 0.84 & 0.55 & 6.27 & 10.04 & 10.37 & 8.33 & 11.47 & 6.38 & 0.71 \\
\hline Eu & 0.21 & 0.28 & 0.25 & 0.28 & 0.24 & 0.28 & 0.47 & 0.35 & 0.30 & 0.31 & 0.27 & 1.75 & 2.31 & 2.50 & 2.19 & 2.85 & 1.71 & 0.24 \\
\hline Gd & 0.79 & 0.96 & 0.97 & 1.34 & 0.97 & 0.99 & 2.93 & 1.22 & 1.11 & 1.31 & 0.94 & 10.59 & 14.08 & 14.43 & 12.79 & 17.66 & 11.53 & 0.83 \\
\hline Tb & 0.12 & 0.14 & 0.21 & 0.19 & 0.16 & 0.28 & 0.44 & 0.19 & 0.17 & 0.21 & 0.16 & 1.87 & 2.58 & 2.60 & 2.32 & 3.16 & 2.00 & 0.16 \\
\hline Dy & 1.25 & 1.15 & 1.13 & 1.12 & 1.30 & 1.59 & 3.28 & 1.14 & 1.24 & 1.55 & 1.12 & 14.01 & 16.73 & 20.10 & 16.06 & 22.47 & 14.61 & 1.06 \\
\hline Ho & 0.23 & 0.21 & 0.25 & 0.25 & 0.23 & 0.31 & 0.65 & 0.29 & 0.19 & 0.29 & 0.20 & 2.88 & 3.64 & 3.96 & 3.28 & 4.24 & 3.16 & 0.25 \\
\hline Er & 0.67 & 0.54 & 0.79 & 0.58 & 0.70 & 0.66 & 1.78 & 0.75 & 0.52 & 0.78 & 0.56 & 8.46 & 10.44 & 11.76 & 9.45 & 13.19 & 9.53 & 0.66 \\
\hline Tm & 0.09 & 0.07 & 0.08 & 0.06 & 0.08 & 0.10 & 0.25 & 0.14 & 0.07 & 0.13 & 0.07 & 1.23 & 1.37 & 1.71 & 1.34 & 1.70 & 1.35 & 0.05 \\
\hline Yb & 0.59 & 0.50 & 0.66 & 0.77 & 0.71 & 0.78 & 1.71 & 0.82 & 0.53 & 0.77 & 0.60 & 6.89 & 7.83 & 10.32 & 7.56 & 10.12 & 8.86 & 0.70 \\
\hline Lu & 0.06 & 0.07 & 0.07 & 0.12 & 0.08 & 0.10 & 0.19 & 0.10 & 0.08 & 0.09 & 0.08 & 1.12 & 1.15 & 1.50 & 1.24 & 1.60 & 1.37 & 0.08 \\
\hline $\mathrm{Hf}$ & 0.17 & 0.10 & 0.22 & 0.27 & 0.25 & 0.28 & 0.37 & 0.34 & 0.22 & 0.32 & 0.38 & 1.30 & 1.97 & 2.21 & 1.52 & 2.00 & 1.16 & 0.17 \\
\hline $\mathrm{Pb}$ & 0.09 & 0.02 & 0.11 & $\mathrm{~b} / \mathrm{d}$ & 0.13 & 0.03 & $\mathrm{~b} / \mathrm{d}$ & 0.03 & 0.04 & 0.03 & 0.02 & 0.13 & 0.14 & 0.32 & 0.02 & 0.08 & 0.18 & 0.10 \\
\hline
\end{tabular}


Table G.1. Continued

\begin{tabular}{|c|c|c|c|c|c|c|c|c|c|c|c|c|}
\hline Sample & & & & & & & & PC02 & & & & \\
\hline Location & & & & & & & & crater & & & & \\
\hline Volcano & & & & & & & & Healy & & & & \\
\hline Crystal & 9 & 10 & 12 & 12 & 13 & 14 & 14 & 2 & 3 & 3 & 10 & 10 \\
\hline Zone & rim & mid & core & rim & mid & core & rim & rim & core & rim & core & rim \\
\hline Mg\# & 78.41 & 84.75 & 75.32 & 75.44 & 82.32 & 81.03 & 83.33 & 79.91 & 69.08 & 73.36 & 72.09 & 72.34 \\
\hline $\mathrm{CaO}$ (wt. \%) & 21.58 & 22.81 & 21.59 & 21.59 & 22.61 & 22.89 & 23.02 & 21.78 & 20.23 & 20.89 & 20.55 & 20.68 \\
\hline Li & 0.46 & 0.49 & 0.70 & 0.39 & 0.29 & 0.31 & 0.63 & 2.47 & 2.72 & 2.63 & 2.67 & 2.22 \\
\hline Sc & 163 & 123 & 141 & 114 & 118 & 119 & 110 & 209 & 240 & 176 & 191 & 187 \\
\hline $\mathrm{Ti}$ & 2950 & 1975 & 2876 & 2085 & 2322 & 2610 & 1937 & 1844 & 2760 & 1365 & 3291 & 2069 \\
\hline v & 346 & 243 & 357 & 273 & 295 & 276 & 267 & 299 & 87 & 43 & 107 & 66 \\
\hline $\mathrm{Cr}$ & 986.2 & 2540.6 & 95.4 & 645.3 & 253.9 & 2168.1 & 1265.9 & 11.4 & $b / d$ & $b / d$ & 2.2 & 1.2 \\
\hline Mn & 1129 & 919 & 1476 & 1137 & 1194 & 1053 & 1005 & 2115 & 6450 & 6048 & 6112 & 5606 \\
\hline $\mathrm{Ni}$ & 90.9 & 117.8 & 48.2 & 82.8 & 83.4 & 91.1 & 121.2 & 0.4 & 0.1 & 0.2 & $b / d$ & 0.4 \\
\hline $\mathrm{Cu}$ & 2.37 & 1.56 & 2.96 & 2.48 & 1.67 & 1.41 & 1.35 & 0.20 & 0.57 & 0.40 & 0.19 & 0.64 \\
\hline Zn & 16.7 & 15.8 & 24.1 & 19.1 & 19.5 & 17.1 & 15.1 & 30.1 & 107.0 & 108.1 & 108.8 & 92.3 \\
\hline $\mathbf{R b}$ & $b / d$ & $b / d$ & 0.01 & $b / d$ & $b / d$ & 0.03 & $b / d$ & $\mathrm{~b} / \mathrm{d}$ & 0.07 & 0.02 & 0.09 & 0.36 \\
\hline $\mathrm{Sr}$ & 16.91 & 17.74 & 17.95 & 16.47 & 17.62 & 21.98 & 16.53 & 19.06 & 20.67 & 17.98 & 19.67 & 23.53 \\
\hline $\mathbf{Y}$ & 9.95 & 5.58 & 8.83 & 5.84 & 5.90 & 6.20 & 5.30 & 95.77 & 131.83 & 58.64 & 94.53 & 76.97 \\
\hline $\mathrm{Zr}$ & 7.56 & 4.24 & 4.57 & 3.26 & 3.26 & 4.84 & 2.88 & 27.50 & 49.43 & 16.26 & 45.51 & 27.20 \\
\hline $\mathrm{Ba}$ & 0.13 & 0.12 & 0.22 & $b / d$ & $b / d$ & 0.08 & 0.11 & 0.19 & 3.17 & 0.13 & 2.46 & 13.83 \\
\hline La & 0.18 & 0.11 & 0.19 & 0.11 & 0.13 & 0.13 & 0.08 & 1.73 & 3.12 & 1.42 & 2.51 & 2.05 \\
\hline $\mathrm{Ce}$ & 0.86 & 0.66 & 0.97 & 0.61 & 0.64 & 0.76 & 0.49 & 10.63 & 17.47 & 8.16 & 13.06 & 10.80 \\
\hline $\mathrm{Pr}$ & 0.20 & 0.15 & 0.20 & 0.13 & 0.18 & 0.22 & 0.13 & 2.62 & 4.58 & 2.19 & 3.35 & 2.80 \\
\hline Nd & 1.49 & 1.35 & 1.84 & 1.05 & 1.34 & 1.52 & 0.97 & 18.18 & 31.91 & 14.19 & 21.79 & 18.36 \\
\hline Sm & 1.14 & 0.82 & 1.13 & 0.52 & 0.69 & 0.59 & 0.61 & 8.74 & 14.75 & 6.68 & 10.17 & 8.77 \\
\hline Eu & 0.34 & 0.29 & 0.43 & 0.25 & 0.32 & 0.28 & 0.25 & 2.35 & 3.67 & 1.78 & 2.89 & 2.18 \\
\hline Gd & 1.91 & 1.12 & 1.46 & 1.02 & 1.36 & 1.04 & 0.98 & 12.37 & 21.93 & 9.36 & 15.10 & 11.24 \\
\hline Tb & 0.27 & 0.15 & 0.31 & 0.13 & 0.20 & 0.19 & 0.12 & 2.30 & 3.65 & 1.57 & 2.37 & 1.95 \\
\hline Dy & 2.13 & 1.19 & 1.99 & 1.03 & 1.24 & 1.26 & 1.06 & 16.62 & 24.10 & 11.35 & 17.22 & 13.81 \\
\hline Ho & 0.36 & 0.23 & 0.36 & 0.23 & 0.23 & 0.25 & 0.18 & 3.73 & 5.12 & 2.36 & 3.76 & 2.87 \\
\hline $\mathrm{Er}$ & 1.08 & 0.68 & 1.13 & 0.72 & 0.70 & 0.76 & 0.64 & 10.94 & 14.59 & 6.50 & 10.69 & 8.38 \\
\hline Tm & 0.15 & 0.08 & 0.13 & 0.09 & 0.13 & 0.06 & 0.07 & 1.46 & 2.03 & 0.87 & 1.40 & 1.02 \\
\hline Yb & 0.93 & 0.78 & 0.75 & 0.48 & 0.61 & 0.53 & 0.35 & 10.61 & 12.56 & 6.31 & 9.98 & 7.40 \\
\hline Lu & 0.14 & 0.04 & 0.09 & 0.08 & 0.05 & 0.06 & 0.09 & 1.87 & 2.19 & 1.09 & 1.67 & 1.25 \\
\hline $\mathrm{Hf}$ & 0.52 & 0.28 & 0.32 & 0.25 & 0.19 & 0.34 & 0.16 & 1.51 & 2.58 & 0.72 & 2.60 & 1.47 \\
\hline $\mathrm{Pb}$ & 0.17 & 0.18 & 0.06 & 0.05 & 0.10 & 0.16 & 0.01 & 0.01 & 0.06 & 0.13 & 0.20 & 0.26 \\
\hline
\end{tabular}


Table G.2. Trace element concentrations in plagioclase analysed by LA-ICP-MS

\begin{tabular}{|c|c|c|c|c|c|c|c|c|c|c|c|c|c|c|c|c|c|c|}
\hline Sample & RI06_PC12 & & & & & & & & & 2_PC08 & & & & & & & & RI18_PC05 \\
\hline Location & Matatirohia & & & & & & & & & Oneraki & & & & & & & & GLP \\
\hline Volcano & Raoul & & & & & & & & & Raoul & & & & & & & & Raoul \\
\hline Crystal & 3 & 3 & 4 & 4 & 5 & 5 & 16 & 16 & 20 & 2 & 2 & 4 & 5 & 25 & 26 & 26 & 28 & 1 \\
\hline Zone & core & rim & core & rim & core & rim & core & $\mathrm{d}$ band & mid & core & rim & core & rim & mid & core & rim & mid & mid \\
\hline $\mathrm{CaO}$ (wt. \%) & 19.07 & 16.94 & 17.63 & 17.47 & 19.63 & 17.91 & 16.51 & 14.06 & 20.02 & 12.66 & 4.61 & 15.57 & 16.55 & 16.68 & 14.37 & 16.87 & 19.37 & 16.98 \\
\hline Anorthite & 92.65 & 82.89 & 86.36 & 85.32 & 95.06 & 87.14 & 81.03 & 70.05 & 97.06 & 61.79 & 23.22 & 76.14 & 80.03 & 80.72 & 70.80 & 82.11 & 93.11 & 84.47 \\
\hline $\mathrm{Li}$ & 1.93 & 1.89 & 1.57 & 2.91 & 0.56 & 1.55 & 3.46 & 5.21 & 0.81 & 2.36 & 1.01 & 2.12 & 2.18 & 3.25 & 2.65 & 2.06 & 0.74 & 9.60 \\
\hline Mg & 345 & 347 & 358 & 403 & 161 & 267 & 292 & 324 & 699 & 176 & 52 & 443 & 413 & 376 & 576 & 384 & 248 & 348 \\
\hline $\mathbf{R b}$ & 0.03 & 0.02 & 0.01 & 0.08 & 0.03 & $\mathrm{~b} / \mathrm{d}$ & 0.07 & 0.03 & $\mathrm{~b} / \mathrm{d}$ & 0.19 & 0.46 & 0.03 & $\mathrm{~b} / \mathrm{d}$ & $\mathrm{b} / \mathrm{d}$ & 0.02 & 0.03 & 0.01 & 0.04 \\
\hline $\mathrm{Sr}$ & 218 & 366 & 376 & 396 & 179 & 310 & 422 & 408 & 209 & 402 & 184 & 402 & 407 & 424 & 366 & 410 & 356 & 386 \\
\hline $\mathbf{Y}$ & 0.06 & 0.26 & 0.26 & 0.40 & 0.20 & 0.24 & 0.37 & 0.33 & 0.07 & 0.58 & 0.40 & 0.35 & 0.29 & 0.27 & 0.24 & 0.32 & 0.05 & 0.35 \\
\hline Cs & $b / d$ & $b / d$ & $\mathrm{~b} / \mathrm{d}$ & $\mathrm{b} / \mathrm{d}$ & 0.02 & $\mathrm{~b} / \mathrm{d}$ & $b / d$ & 0.02 & 0.03 & 0.02 & $\mathrm{~b} / \mathrm{d}$ & $\mathrm{b} / \mathrm{d}$ & $\mathrm{b} / \mathrm{d}$ & 0.01 & $\mathrm{~b} / \mathrm{d}$ & $b / d$ & $b / d$ & $\mathrm{~b} / \mathrm{d}$ \\
\hline $\mathrm{Ba}$ & 5.5 & 14.8 & 15.7 & 22.6 & 4.8 & 13.1 & 20.1 & 23.5 & 3.8 & 104.7 & 232.8 & 17.9 & 17.0 & 18.5 & 20.2 & 21.1 & 6.8 & 16.1 \\
\hline La & 0.04 & 0.40 & 0.40 & 0.45 & 0.04 & 0.31 & 0.55 & 0.56 & 0.05 & 1.01 & 1.02 & 0.32 & 0.41 & 0.51 & 0.46 & 0.50 & 0.07 & 0.34 \\
\hline $\mathrm{Ce}$ & 0.13 & 0.78 & 0.88 & 0.97 & 0.14 & 0.69 & 1.14 & 1.12 & 0.06 & 2.33 & 2.55 & 1.01 & 1.16 & 1.11 & 0.71 & 1.24 & 0.17 & 1.00 \\
\hline $\operatorname{Pr}$ & 0.03 & 0.11 & 0.13 & 0.10 & 0.01 & 0.12 & 0.15 & 0.12 & 0.02 & 0.25 & 0.28 & 0.11 & 0.14 & 0.14 & 0.09 & 0.16 & 0.02 & 0.10 \\
\hline Nd & 0.13 & 0.61 & 0.47 & 0.64 & 0.23 & 0.67 & 0.81 & 0.68 & 0.13 & 1.43 & 1.34 & 0.49 & 0.67 & 0.60 & 0.49 & 0.80 & $b / d$ & 0.63 \\
\hline Sm & 0.01 & 0.07 & 0.13 & 0.25 & 0.05 & $\mathrm{~b} / \mathrm{d}$ & 0.09 & 0.03 & 0.04 & 0.28 & 0.32 & 0.22 & 0.09 & 0.21 & 0.03 & 0.22 & 0.16 & 0.21 \\
\hline Eu & 0.11 & 0.76 & 0.77 & 0.92 & 0.09 & 0.69 & 1.24 & 1.20 & 0.10 & 1.94 & 1.76 & 0.70 & 0.67 & 0.65 & 0.53 & 0.76 & 0.08 & 0.73 \\
\hline Gd & 0.06 & 0.18 & 0.06 & 0.03 & 0.07 & 0.05 & 0.07 & 0.26 & 0.08 & 0.41 & 0.08 & 0.05 & 0.15 & 0.19 & 0.08 & 0.01 & 0.01 & 0.17 \\
\hline $\mathrm{Pb}$ & 0.08 & 0.34 & 0.38 & 0.50 & 0.12 & 0.33 & 0.46 & 0.44 & 0.16 & 1.33 & 1.46 & 0.36 & 0.34 & 0.36 & 0.34 & 0.44 & 0.23 & 0.33 \\
\hline
\end{tabular}

Trace element values given in ppm. All sample normalised to Ca (shown for reference) based on values obtained from EPMA analysis. Abbreviations same as Table B.1. 
Table G.2. Continued

\begin{tabular}{|c|c|c|c|c|c|c|c|c|c|c|c|c|c|c|c|c|c|c|c|}
\hline $\begin{array}{l}\text { Sample } \\
\text { Location }\end{array}$ & & & & & & & & & $\begin{array}{l}\text { PC01 } \\
\text { d }\end{array}$ & & & & & & & & & & $\begin{array}{l}\mathrm{PC} 03 \\
\text { ua }\end{array}$ \\
\hline Volcano & & & & & & & & & Raoul & & & & & & & & & & Raoul \\
\hline Crystal & 4 & 10 & 10 & 11 & 23 & 23 & 24 & 24 & 2 & 8 & 11 & 11 & 13 & 15 & 19 & 20 & 22 & 22 & 11 \\
\hline Zone & rim & core & rim & mid & core & rim & core & rim & mid & mid & core & rim & rim & rim & core & core & core & rim & mid \\
\hline $\mathrm{CaO}$ (wt. \%) & 16.75 & 17.15 & 13.13 & 17.61 & 12.56 & 13.77 & 19.09 & 17.22 & 19.87 & 19.85 & 15.07 & 17.54 & 17.53 & 16.82 & 17.27 & 20.12 & 19.48 & 17.49 & 18.98 \\
\hline Anorthite & 82.64 & 84.35 & 64.64 & 86.99 & 63.54 & 69.17 & 94.11 & 85.49 & 96.55 & 95.86 & 74.31 & 84.90 & 85.53 & 82.52 & 83.87 & 96.68 & 94.04 & 84.88 & 93.68 \\
\hline $\mathbf{L i}$ & 14.62 & 8.48 & 14.88 & 6.22 & 3.19 & 9.88 & 3.74 & 12.28 & 0.74 & 1.84 & 2.28 & 3.24 & 8.11 & 2.28 & 4.76 & 0.45 & 1.08 & 7.23 & 1.82 \\
\hline Mg & 405 & 370 & 442 & 423 & 395 & 318 & 771 & 1054 & 696 & 677 & 472 & 369 & 422 & 383 & 423 & 1053 & 263 & 460 & 736 \\
\hline $\mathbf{R b}$ & $\mathrm{b} / \mathrm{d}$ & 0.01 & 0.02 & 0.03 & $\mathrm{~b} / \mathrm{d}$ & $b / d$ & $b / d$ & 0.08 & $b / d$ & $b / d$ & 0.08 & $b / d$ & 0.05 & $b / d$ & $b / d$ & 0.02 & 0.08 & 0.07 & 0.12 \\
\hline $\mathrm{Sr}$ & 382 & 317 & 366 & 351 & 427 & 317 & 226 & 245 & 181 & 180 & 376 & 388 & 364 & 409 & 384 & 227 & 225 & 372 & 282 \\
\hline $\mathbf{Y}$ & 0.27 & 0.23 & 0.27 & 0.30 & 1.10 & 0.26 & 0.06 & 0.07 & $\mathrm{~b} / \mathrm{d}$ & 0.04 & 0.32 & 0.33 & 0.32 & 0.46 & 0.27 & 0.06 & 0.14 & 0.54 & 0.39 \\
\hline Cs & $\mathrm{b} / \mathrm{d}$ & $\mathrm{b} / \mathrm{d}$ & $\mathrm{b} / \mathrm{d}$ & $\mathrm{b} / \mathrm{d}$ & $\mathrm{b} / \mathrm{d}$ & $\mathrm{b} / \mathrm{d}$ & $\mathrm{b} / \mathrm{d}$ & $\mathrm{b} / \mathrm{d}$ & $\mathrm{b} / \mathrm{d}$ & $\mathrm{b} / \mathrm{d}$ & 0.03 & $\mathrm{~b} / \mathrm{d}$ & $\mathrm{b} / \mathrm{d}$ & $\mathrm{b} / \mathrm{d}$ & $\mathrm{b} / \mathrm{d}$ & 0.02 & 0.01 & $\mathrm{~b} / \mathrm{d}$ & 0.03 \\
\hline $\mathrm{Ba}$ & 16.7 & 12.8 & 22.7 & 15.3 & 33.5 & 14.5 & 6.4 & 8.8 & 3.6 & 4.1 & 24.2 & 19.6 & 18.6 & 20.0 & 18.6 & 4.0 & 5.6 & 21.3 & 11.6 \\
\hline La & 0.37 & 0.20 & 0.28 & 0.29 & 0.47 & 0.25 & 0.02 & 0.06 & 0.06 & 0.01 & 0.42 & 0.53 & 0.46 & 0.54 & 0.47 & 0.02 & 0.02 & 0.48 & 0.15 \\
\hline $\mathrm{Ce}$ & 0.81 & 0.53 & 0.68 & 0.61 & 1.24 & 0.73 & 0.03 & 0.08 & 0.06 & 0.05 & 0.98 & 1.09 & 0.85 & 1.04 & 1.13 & 0.06 & 0.09 & 1.04 & 0.30 \\
\hline $\operatorname{Pr}$ & 0.13 & 0.08 & 0.13 & 0.10 & 0.19 & 0.09 & $\mathrm{~b} / \mathrm{d}$ & 0.03 & $b / d$ & $\mathrm{~b} / \mathrm{d}$ & 0.14 & 0.14 & 0.13 & 0.19 & 0.16 & $\mathrm{~b} / \mathrm{d}$ & 0.03 & 0.13 & 0.03 \\
\hline Nd & 0.56 & 0.36 & 0.52 & 0.52 & 0.93 & 0.54 & 0.12 & 0.14 & 0.11 & 0.08 & 0.77 & 0.75 & 0.67 & 0.87 & 0.77 & 0.02 & 0.01 & 0.76 & 0.30 \\
\hline Sm & 0.09 & 0.03 & 0.25 & 0.20 & 0.31 & 0.08 & 0.05 & 0.04 & 0.13 & 0.04 & 0.29 & 0.22 & 0.03 & 0.37 & 0.21 & 0.05 & 0.15 & 0.24 & 0.04 \\
\hline Eu & 0.84 & 0.47 & 0.72 & 0.46 & 1.17 & 0.65 & 0.09 & 0.15 & 0.07 & 0.05 & 0.78 & 0.81 & 0.65 & 0.94 & 0.79 & 0.07 & 0.11 & 0.80 & 0.22 \\
\hline Gd & 0.11 & 0.16 & 0.35 & 0.01 & 0.48 & 0.17 & 0.04 & 0.14 & 0.05 & 0.26 & 0.23 & 0.29 & 0.04 & 0.36 & 0.28 & 0.10 & 0.10 & 0.39 & 0.23 \\
\hline $\mathrm{Pb}$ & 0.30 & 0.23 & 0.45 & 0.33 & 0.54 & 0.40 & 0.21 & 0.32 & 0.04 & 0.06 & 0.41 & 0.33 & 0.34 & 0.39 & 0.39 & 0.15 & 0.08 & 0.39 & 0.20 \\
\hline
\end{tabular}


Table G.2. Continued

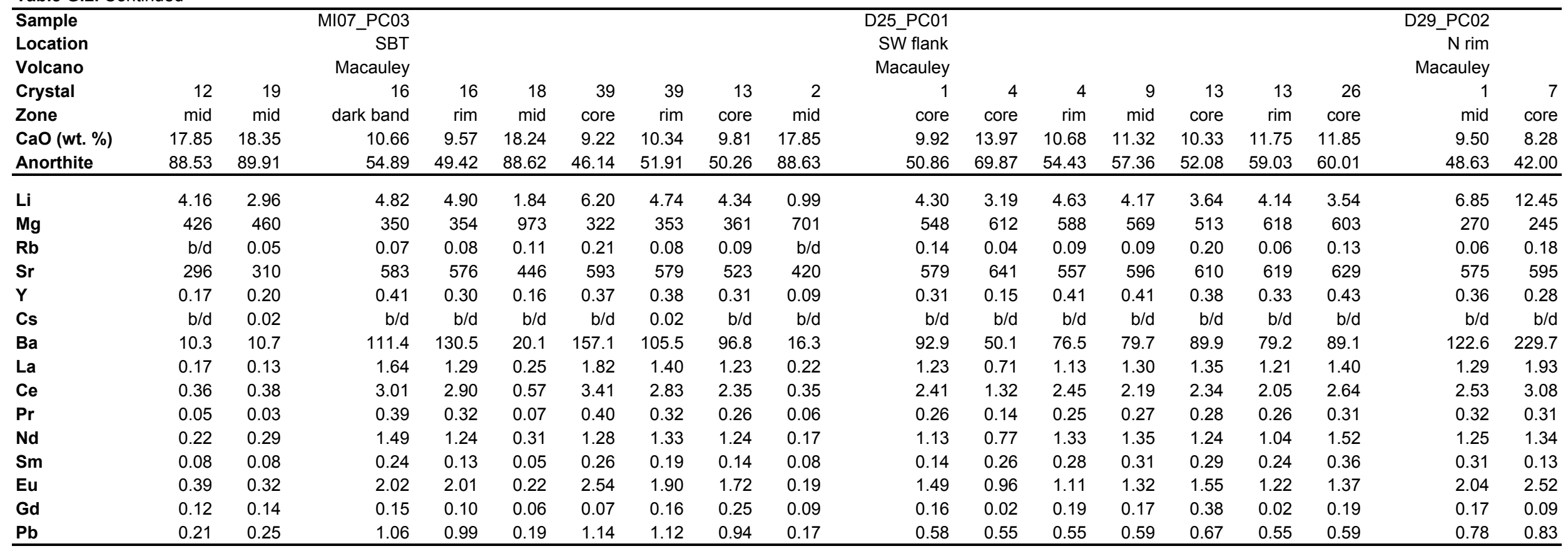


Table G.2. Continued

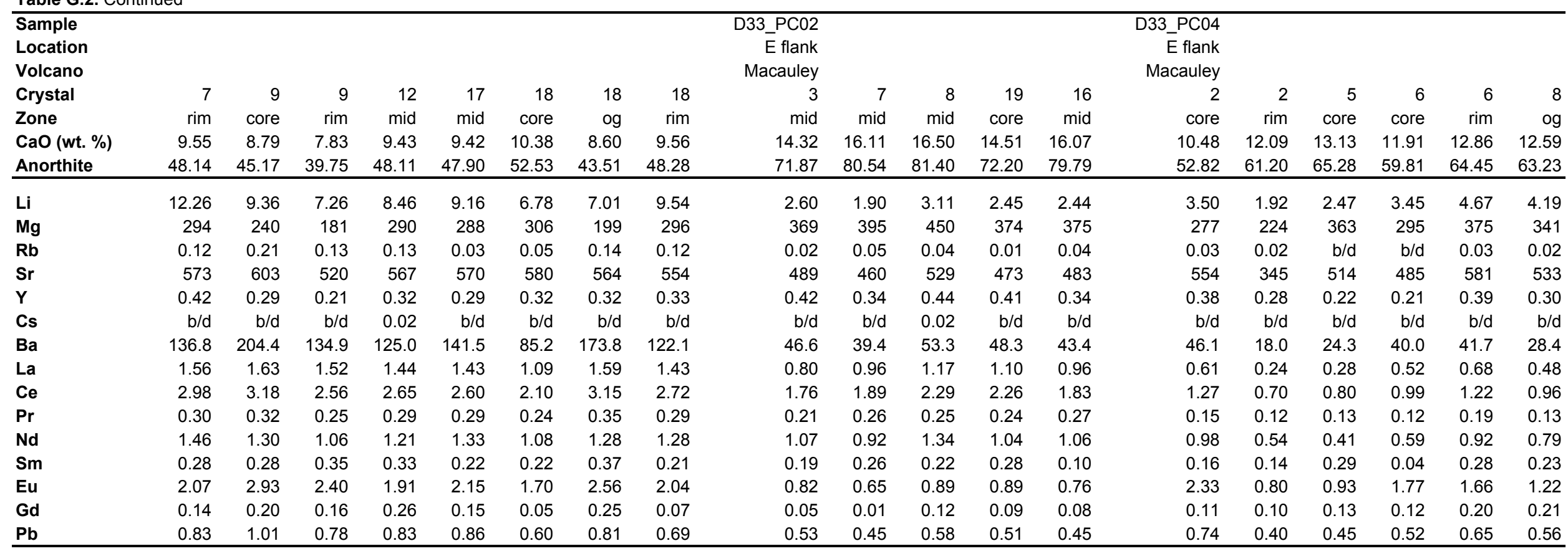


Table G.2. Continued

\begin{tabular}{|c|c|c|c|c|c|c|c|c|c|c|c|c|c|c|c|c|c|c|c|}
\hline Sample & & & PC06 & & & & & & & & & _PC05 & & & & & & & \\
\hline Location & & & nk/rim & & & & & & & & & all/floor & & & & & & & \\
\hline Volcano & & & Healy & & & & & & & & & Healy & & & & & & & \\
\hline Crystal & 23 & 23 & 2 & 5 & 5 & 5 & 6 & 16 & 12 & 12 & 24 & 2 & 2 & 4 & 5 & 7 & 8 & 9 & 11 \\
\hline Zone & core & rim & core & core & $\mathrm{d}$ band & rim & mid & mid & core & rim & core & core & rim & og & og & mid & mid & mid & core \\
\hline $\mathrm{CaO}$ (wt. \%) & 15.18 & 10.54 & 10.30 & 8.95 & 7.21 & 8.95 & 19.48 & 18.93 & 8.52 & 8.38 & 8.29 & 8.80 & 10.05 & 9.66 & 9.63 & 10.47 & 9.52 & 9.72 & 8.54 \\
\hline Anorthite & 75.35 & 53.70 & 51.84 & 45.72 & 37.44 & 45.40 & 95.09 & 93.78 & 43.07 & 43.23 & 41.57 & 44.67 & 50.89 & 48.35 & 48.23 & 52.82 & 47.96 & 49.35 & 43.13 \\
\hline $\mathbf{L i}$ & 2.75 & 5.32 & 3.94 & 3.75 & 5.00 & 11.27 & 0.71 & 7.40 & 4.12 & 12.62 & 7.83 & 4.39 & 4.96 & 7.02 & 3.99 & 4.05 & 5.92 & 4.01 & 5.49 \\
\hline Mg & 300 & 306 & 209 & 205 & 186 & 225 & 590 & 579 & 204 & 226 & 214 & 208 & 258 & 233 & 263 & 334 & 261 & 264 & 225 \\
\hline $\mathbf{R b}$ & $\mathrm{b} / \mathrm{d}$ & $\mathrm{b} / \mathrm{d}$ & 0.01 & 0.05 & 0.10 & 0.08 & 0.03 & 0.04 & 0.07 & 0.14 & 0.09 & 0.11 & 0.06 & 0.06 & 0.07 & 0.14 & 0.10 & 0.09 & 0.19 \\
\hline $\mathrm{Sr}$ & 507 & 512 & 929 & 801 & 673 & 636 & 384 & 388 & 650 & 612 & 608 & 732 & 744 & 764 & 740 & 767 & 799 & 754 & 968 \\
\hline$Y$ & 0.33 & 0.39 & 0.39 & 0.40 & 0.22 & 0.38 & 0.05 & 0.03 & 0.29 & 0.36 & 0.34 & 0.34 & 0.38 & 0.30 & 0.34 & 0.35 & 0.39 & 0.32 & 0.37 \\
\hline Cs & $\mathrm{b} / \mathrm{d}$ & 0.02 & $\mathrm{~b} / \mathrm{d}$ & $\mathrm{b} / \mathrm{d}$ & $\mathrm{b} / \mathrm{d}$ & $\mathrm{b} / \mathrm{d}$ & $\mathrm{b} / \mathrm{d}$ & $\mathrm{b} / \mathrm{d}$ & $\mathrm{b} / \mathrm{d}$ & $\mathrm{b} / \mathrm{d}$ & $\mathrm{b} / \mathrm{d}$ & $\mathrm{b} / \mathrm{d}$ & $\mathrm{b} / \mathrm{d}$ & $\mathrm{b} / \mathrm{d}$ & $\mathrm{b} / \mathrm{d}$ & $\mathrm{b} / \mathrm{d}$ & $\mathrm{b} / \mathrm{d}$ & $\mathrm{b} / \mathrm{d}$ & $\mathrm{b} / \mathrm{d}$ \\
\hline $\mathrm{Ba}$ & 26.0 & 50.8 & 183.9 & 237.9 & 303.0 & 239.6 & 14.8 & 16.6 & 212.3 & 238.2 & 257.5 & 293.8 & 195.1 & 249.3 & 208.9 & 220.7 & 224.6 & 219.0 & 424.8 \\
\hline La & 0.38 & 0.62 & 1.20 & 2.38 & 2.70 & 2.20 & 0.10 & 0.05 & 2.07 & 2.51 & 2.32 & 2.64 & 2.45 & 2.41 & 2.19 & 2.35 & 2.64 & 2.05 & 3.05 \\
\hline $\mathrm{Ce}$ & 0.84 & 1.53 & 2.40 & 3.96 & 4.17 & 4.24 & 0.16 & 0.20 & 3.60 & 4.19 & 3.75 & 4.01 & 3.87 & 3.83 & 3.93 & 3.85 & 4.19 & 3.59 & 4.97 \\
\hline $\mathrm{Pr}$ & 0.12 & 0.18 & 0.27 & 0.44 & 0.40 & 0.40 & 0.01 & $\mathrm{~b} / \mathrm{d}$ & 0.43 & 0.39 & 0.39 & 0.47 & 0.44 & 0.48 & 0.44 & 0.36 & 0.49 & 0.41 & 0.53 \\
\hline Nd & 0.67 & 0.95 & 1.23 & 1.66 & 1.57 & 1.58 & 0.13 & 0.10 & 1.59 & 1.75 & 1.58 & 1.67 & 1.76 & 1.83 & 1.77 & 1.75 & 1.58 & 1.85 & 1.80 \\
\hline Sm & 0.12 & 0.24 & 0.29 & 0.14 & 0.11 & 0.27 & 0.08 & 0.05 & 0.25 & 0.14 & 0.23 & 0.33 & 0.27 & 0.24 & 0.23 & 0.24 & 0.13 & 0.14 & 0.28 \\
\hline Eu & 1.10 & 1.93 & 1.08 & 1.83 & 1.84 & 1.50 & 0.10 & 0.07 & 1.42 & 1.25 & 1.35 & 1.91 & 1.42 & 1.65 & 1.46 & 1.55 & 1.58 & 1.33 & 2.08 \\
\hline Gd & 0.09 & 0.04 & 0.14 & 0.12 & 0.14 & 0.13 & 0.06 & 0.13 & $\mathrm{~b} / \mathrm{d}$ & 0.28 & 0.04 & 0.23 & 0.18 & 0.36 & 0.10 & 0.10 & 0.19 & 0.22 & 0.17 \\
\hline $\mathrm{Pb}$ & 0.61 & 0.64 & 0.55 & 0.69 & 0.72 & 0.83 & 0.05 & 0.01 & 0.60 & 0.78 & 0.76 & 0.86 & 0.59 & 0.76 & 0.75 & 0.77 & 0.77 & 0.72 & 0.91 \\
\hline
\end{tabular}


Table G.2. Continued

\begin{tabular}{|c|c|c|c|c|c|c|c|c|c|c|c|c|c|c|c|c|c|c|c|c|}
\hline Sample & & PC02 & & & & & & & & & & $\mathrm{PC} 02$ & & & & & & & & \\
\hline Location & & n/flank & & & & & & & & & & crater & & & & & & & & \\
\hline Volcano & & Healy & & & & & & & & & & Healy & & & & & & & & \\
\hline Crystal & 11 & 1 & 7 & 7 & 9 & 13 & 13 & 13 & 17 & 17 & 18 & 1 & 2 & 3 & 9 & 15 & 15 & 17 & 19 & 22 \\
\hline Zone & rim & mid & core & $\mathrm{d}$ band & mid & core & $\mathrm{d}$ band & rim & core & rim & mid & core & core & mid & mid & core & rim & mid & mid & mid \\
\hline $\mathrm{CaO}$ (wt. \%) & 9.76 & 19.46 & 8.66 & 7.93 & 19.31 & 9.77 & 7.67 & 9.12 & 10.02 & 7.95 & 19.17 & 8.65 & 10.33 & 11.55 & 10.77 & 11.05 & 8.99 & 10.77 & 10.50 & 9.54 \\
\hline Anorthite & 49.25 & 94.38 & 43.95 & 40.42 & 94.15 & 49.57 & 39.13 & 46.37 & 50.48 & 40.07 & 94.61 & 44.06 & 52.27 & 57.55 & 54.12 & 56.30 & 45.37 & 53.91 & 52.93 & 48.41 \\
\hline $\mathbf{L i}$ & 6.66 & 2.47 & 4.62 & 5.98 & 0.39 & 4.35 & 6.89 & 4.77 & 4.84 & 4.34 & 0.64 & 4.26 & 3.95 & 3.38 & 4.80 & 3.01 & 7.96 & 3.65 & 3.61 & 4.37 \\
\hline Mg & 306 & 718 & 227 & 257 & 699 & 238 & 247 & 236 & 242 & 223 & 659 & 231 & 336 & 423 & 308 & 433 & 201 & 373 & 297 & 327 \\
\hline $\mathbf{R b}$ & 0.08 & 0.04 & 0.04 & 0.20 & 0.01 & 0.02 & 0.32 & $\mathrm{~b} / \mathrm{d}$ & 0.12 & 0.04 & 0.01 & 0.30 & 0.09 & 0.06 & 0.04 & 0.06 & 0.06 & $\mathrm{~b} / \mathrm{d}$ & 0.01 & 0.10 \\
\hline $\mathrm{Sr}$ & 776 & 394 & 847 & 922 & 382 & 752 & 801 & 696 & 829 & 666 & 468 & 688 & 832 & 942 & 896 & 945 & 944 & 949 & 812 & 915 \\
\hline $\mathbf{Y}$ & 0.37 & 0.03 & 0.29 & 0.35 & 0.08 & 0.36 & 0.19 & 0.35 & 0.47 & 0.35 & 0.03 & 0.35 & 0.28 & 0.28 & 0.42 & 0.30 & 0.33 & 0.24 & 0.31 & 0.40 \\
\hline Cs & $b / d$ & $\mathrm{~b} / \mathrm{d}$ & $\mathrm{b} / \mathrm{d}$ & $\mathrm{b} / \mathrm{d}$ & $b / d$ & $\mathrm{~b} / \mathrm{d}$ & $\mathrm{b} / \mathrm{d}$ & $\mathrm{b} / \mathrm{d}$ & $\mathrm{b} / \mathrm{d}$ & $\mathrm{b} / \mathrm{d}$ & $b / d$ & 0.03 & 0.02 & 0.01 & $\mathrm{~b} / \mathrm{d}$ & $\mathrm{b} / \mathrm{d}$ & 0.02 & $\mathrm{~b} / \mathrm{d}$ & 0.01 & 0.02 \\
\hline $\mathrm{Ba}$ & 230.8 & 17.2 & 263.7 & 412.5 & 17.1 & 195.2 & 410.7 & 278.3 & 257.9 & 236.4 & 17.0 & 299.8 & 183.8 & 114.0 & 196.1 & 140.3 & 222.4 & 229.1 & 174.2 & 315.0 \\
\hline La & 2.37 & 0.07 & 2.65 & 3.58 & 0.11 & 1.78 & 3.51 & 2.86 & 2.97 & 2.71 & 0.18 & 2.89 & 2.11 & 1.52 & 2.27 & 1.49 & 2.38 & 2.14 & 2.10 & 2.88 \\
\hline $\mathrm{Ce}$ & 4.21 & 0.15 & 4.11 & 5.53 & 0.19 & 3.72 & 5.57 & 4.64 & 5.17 & 4.51 & 0.24 & 5.11 & 3.36 & 2.45 & 3.84 & 2.39 & 3.72 & 3.28 & 3.52 & 4.73 \\
\hline $\mathrm{Pr}$ & 0.44 & $\mathrm{~b} / \mathrm{d}$ & 0.44 & 0.66 & 0.02 & 0.34 & 0.50 & 0.44 & 0.48 & 0.41 & 0.04 & 0.54 & 0.32 & 0.28 & 0.42 & 0.28 & 0.45 & 0.37 & 0.37 & 0.53 \\
\hline Nd & 1.93 & 0.20 & 1.56 & 2.09 & 0.21 & 1.62 & 2.06 & 1.93 & 1.86 & 1.90 & 0.02 & 1.96 & 1.45 & 1.20 & 1.95 & 1.14 & 1.60 & 1.41 & 1.43 & 1.92 \\
\hline Sm & 0.32 & 0.04 & 0.19 & 0.28 & 0.17 & 0.04 & 0.30 & 0.09 & 0.11 & 0.26 & 0.03 & 0.46 & 0.27 & 0.32 & 0.24 & 0.13 & 0.22 & 0.31 & 0.14 & 0.34 \\
\hline Eu & 1.55 & 0.09 & 2.08 & 3.11 & 0.12 & 1.51 & 2.18 & 1.65 & 2.17 & 1.49 & 0.07 & 1.82 & 1.35 & 0.88 & 1.46 & 0.94 & 1.72 & 1.12 & 1.21 & 1.84 \\
\hline Gd & 0.20 & 0.06 & 0.10 & 0.27 & 0.11 & 0.25 & 0.24 & 0.37 & 0.03 & 0.14 & 0.18 & 0.23 & 0.20 & 0.17 & 0.16 & 0.24 & 0.12 & 0.02 & 0.18 & 0.14 \\
\hline $\mathrm{Pb}$ & 0.85 & 0.08 & 0.85 & 1.05 & 0.15 & 0.92 & 0.75 & 0.92 & 0.93 & 0.84 & 0.13 & 1.45 & 0.63 & 0.40 & 0.66 & 0.39 & 0.68 & 0.61 & 0.61 & 1.01 \\
\hline
\end{tabular}


Table G.3. Trace element concentrations in amphiboles from Healy analysed by LA-ICP-MS

\begin{tabular}{|c|c|c|c|c|c|c|c|c|c|c|c|}
\hline Sample & \multirow{2}{*}{\multicolumn{2}{|c|}{$\begin{array}{l}\text { D38_PC06 } \\
\text { NW flank/rim }\end{array}$}} & \multirow{2}{*}{\multicolumn{3}{|c|}{$\begin{array}{l}\text { D39_PC05 } \\
\text { N wall/floor }\end{array}$}} & \multicolumn{3}{|c|}{ D44_PC02 } & \multicolumn{3}{|c|}{ D47_PC02 } \\
\hline Location & & & & & & $\mathrm{SE} \mathrm{rim} / \mathrm{fl}$ & & & & Edifice c & ater \\
\hline Crystal & 1 & 3 & 4 & 8 & 13 & 1 & 2 & 6 & 11 & 11 & 13 \\
\hline Zone & mid & mid & mid & core & mid & core & rim & mid & mid & mid & core \\
\hline $\mathrm{CaO}$ (wt. \%) & 11.15 & 11.03 & 11.00 & 10.79 & 10.96 & 11.13 & 11.13 & 10.96 & 11.03 & 10.97 & 11.01 \\
\hline Li & 2.23 & 2.12 & 2.08 & 1.82 & 2.39 & 2.15 & 2.46 & 2.12 & 2.26 & 2.09 & 1.76 \\
\hline Sc & 235 & 192 & 182 & 224 & 218 & 185 & 258 & 234 & 222 & 149 & 194 \\
\hline $\mathrm{Ti}$ & 11549 & 11068 & 10107 & 12226 & 12737 & 10566 & 13004 & 12101 & 11645 & 19590 & 18174 \\
\hline V & 234 & 200 & 190 & 147 & 156 & 277 & 245 & 258 & 235 & 103 & 106 \\
\hline $\mathrm{Cr}$ & 0.40 & 1.42 & 1.88 & 1.11 & 2.14 & 0.51 & 2.04 & 1.44 & 0.85 & 0.40 & 0.82 \\
\hline Mn & 3540 & 3875 & 3924 & 3980 & 4031 & 3692 & 3825 & 3126 & 3519 & 4314 & 3612 \\
\hline $\mathrm{Ni}$ & 7.91 & 4.56 & 6.73 & 0.60 & 0.14 & 13.64 & 6.35 & 7.21 & 8.55 & 0.10 & 0.10 \\
\hline $\mathrm{Cu}$ & 1.08 & 1.42 & 0.58 & 0.88 & 0.82 & 1.24 & 1.18 & 1.30 & 0.60 & 1.23 & 0.73 \\
\hline $\mathrm{Zn}$ & 143 & 146 & 136 & 139 & 148 & 147 & 143 & 127 & 134 & 175 & 134 \\
\hline Rb & 0.27 & 0.23 & 0.19 & 0.27 & 0.21 & 0.27 & 0.33 & 0.26 & 0.23 & 0.30 & 0.25 \\
\hline $\mathrm{Sr}$ & 50.9 & 43.2 & 39.7 & 56.4 & 58.7 & 37.9 & 61.5 & 57.4 & 48.9 & 127.4 & 116.0 \\
\hline $\mathbf{Y}$ & 216 & 232 & 203 & 252 & 221 & 235 & 275 & 219 & 197 & 172 & 131 \\
\hline $\mathrm{Zr}$ & 65.1 & 78.4 & 62.6 & 90.4 & 84.4 & 84.2 & 86.5 & 72.1 & 60.1 & 72.6 & 57.3 \\
\hline $\mathrm{Nb}$ & 3.61 & 3.94 & 3.66 & 3.99 & 3.95 & 4.28 & 4.35 & 4.07 & 3.79 & 3.56 & 2.25 \\
\hline $\mathrm{Ba}$ & 70.1 & 63.2 & 56.3 & 75.1 & 74.6 & 58.7 & 91.3 & 91.1 & 69.6 & 116.0 & 87.2 \\
\hline La & 5.29 & 6.30 & 5.33 & 7.20 & 6.17 & 6.08 & 7.63 & 6.38 & 5.47 & 5.45 & 3.70 \\
\hline $\mathrm{Ce}$ & 27.3 & 31.9 & 28.1 & 33.4 & 32.7 & 31.0 & 38.3 & 32.9 & 29.1 & 28.1 & 20.2 \\
\hline Pr & 6.83 & 7.97 & 6.90 & 8.18 & 8.03 & 7.34 & 9.45 & 7.94 & 7.22 & 6.82 & 4.95 \\
\hline Nd & 50.1 & 56.2 & 48.5 & 58.0 & 52.3 & 51.6 & 68.0 & 54.4 & 49.7 & 47.0 & 33.7 \\
\hline Sm & 23.3 & 25.8 & 22.9 & 25.2 & 24.5 & 23.0 & 29.2 & 24.0 & 21.6 & 20.9 & 15.2 \\
\hline Eu & 5.03 & 5.15 & 4.36 & 5.46 & 5.51 & 4.90 & 6.22 & 5.17 & 4.79 & 6.03 & 4.82 \\
\hline Gd & 34.2 & 35.0 & 31.2 & 39.4 & 36.0 & 35.9 & 45.7 & 37.4 & 31.0 & 25.7 & 21.3 \\
\hline Tb & 5.69 & 6.05 & 4.98 & 6.72 & 5.89 & 5.74 & 7.28 & 6.05 & 5.19 & 4.55 & 3.47 \\
\hline Dy & 42.7 & 44.7 & 39.1 & 46.6 & 43.3 & 42.3 & 52.7 & 43.1 & 35.4 & 30.9 & 24.8 \\
\hline Ho & 8.12 & 9.39 & 7.61 & 9.73 & 8.34 & 9.03 & 11.39 & 9.16 & 7.94 & 6.27 & 5.16 \\
\hline Er & 24.9 & 26.5 & 21.9 & 26.6 & 25.0 & 26.5 & 30.8 & 26.1 & 22.5 & 18.5 & 14.3 \\
\hline Tm & 3.21 & 3.64 & 2.87 & 3.61 & 3.31 & 3.24 & 3.78 & 3.10 & 2.85 & 2.52 & 1.90 \\
\hline$Y b$ & 19.9 & 22.1 & 17.8 & 20.7 & 20.1 & 21.5 & 25.9 & 20.7 & 18.2 & 16.4 & 11.8 \\
\hline Lu & 2.81 & 3.07 & 2.50 & 3.04 & 2.97 & 2.92 & 3.62 & 2.72 & 2.54 & 2.06 & 1.60 \\
\hline Hf & 3.14 & 3.60 & 3.09 & 4.66 & 4.56 & 4.05 & 4.12 & 3.78 & 2.89 & 2.99 & 2.52 \\
\hline $\mathrm{Ta}$ & 0.10 & 0.12 & 0.12 & 0.11 & 0.11 & 0.15 & 0.17 & 0.14 & 0.13 & 0.10 & 0.10 \\
\hline $\mathrm{Pb}$ & 0.24 & 0.23 & 0.25 & 0.25 & 0.21 & 0.32 & 0.17 & 0.14 & 0.24 & 0.18 & 0.12 \\
\hline Th & 0.02 & 0.03 & 0.03 & 0.06 & 0.04 & 0.03 & 0.02 & 0.04 & 0.01 & 0.03 & 0.03 \\
\hline
\end{tabular}

Trace element values given in ppm. All sample normalised to Ca (shown for reference) based on values obtained from EPMA analysis. 